
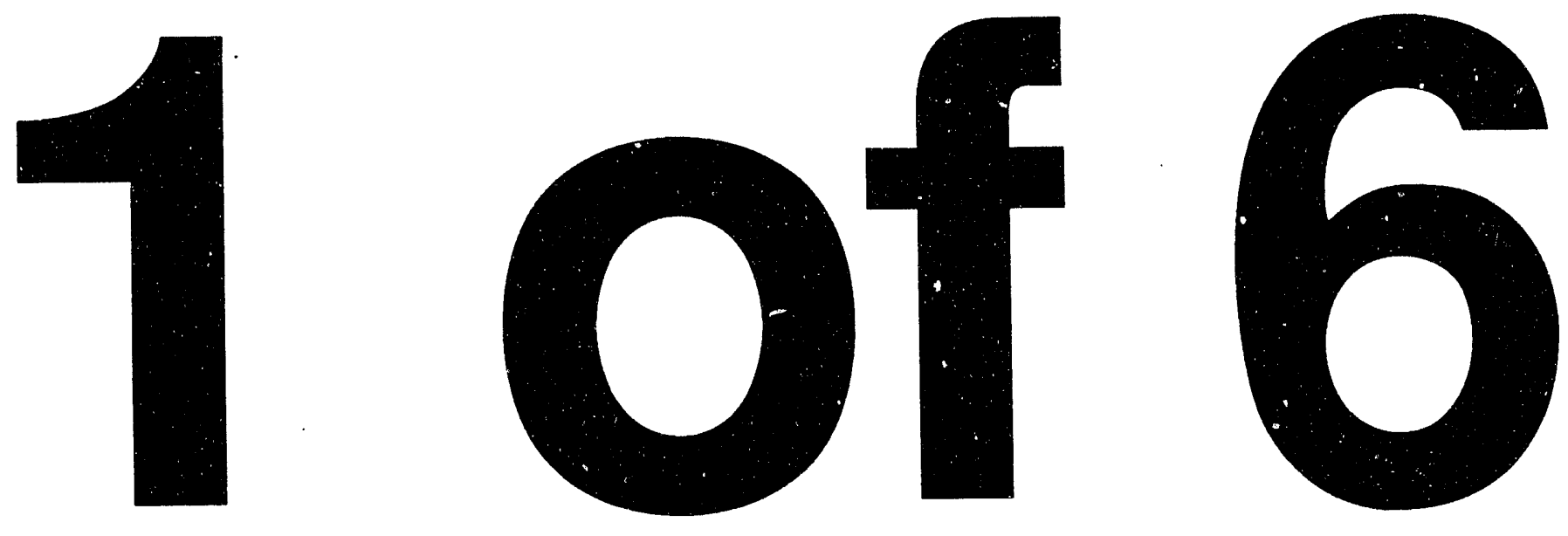


\section{MIXED WASTE MANAGEMENT FACILITY GROUNDWATER MONITORING REDPORT (U)}

FIRST QUARTER 1994

Publication Date: June 1994

Authorized Derivative Classifier:

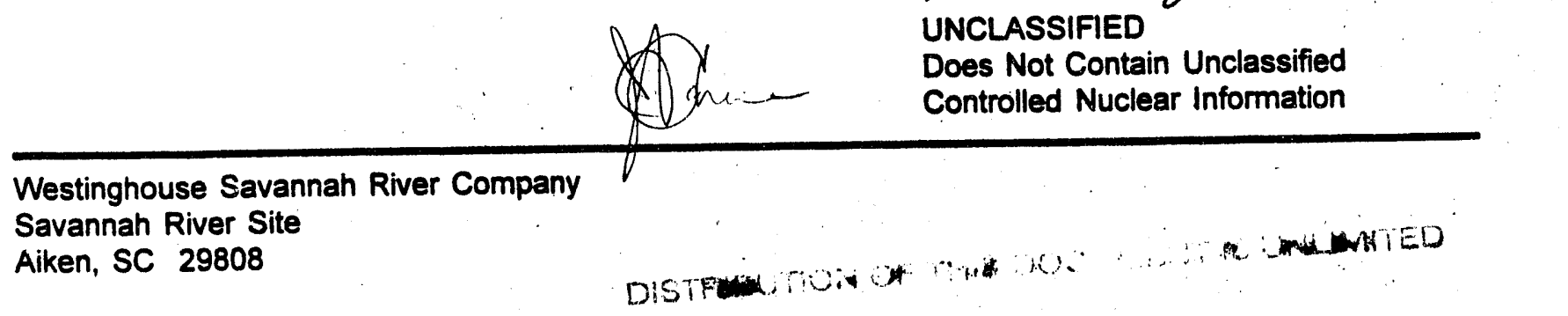

Prepared for the U.S. Department of Energy under Control Contract No. DE-AC09-89SR18035 
WSRC-TR-94-0240

Unclassified

\section{MIXED WASTE MANAGEMENT FACILITY GROUNDWATER MONITORING REPORT (U)}

FIRST QUARTER 1994

Publication Date: June 1994

Authorized Derivative Classifier:

UNCLASSIFIED

Does Not Contain Uriclassified

Controlled Nuclear Information

Westinghouse Savannah River Company

Savannah River Site

Aiken, SC 29808

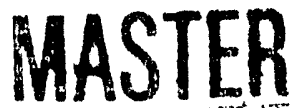




\section{DISCLAIMER}

This report was prepared by Westinghouse Savannah River Company (WSRC) for the United States Department of Energy under Contract No. DE-AC09-89SR18035 and is an account of work performed under that contract. Neither the United States Department of Energy, nor WSRC, nor any of their employees makes any warranty, expressed or implied, or assumes any legal liability or responsibility for the accuracy, completeness, or usefulness of any information, apparatus, product, or process disclosed herein or represents that its use will not infringe on privately owned rights. Reference herein to any specific commercial product, process, or service by trademark, name, manufacturer, or otherwise does not necessarily constitute or imply endorsement, recommendation, or favoring of same by WSRC or by the United States Government or any agency thereof. The views and opinions of the authors expressed herein do not necessarily state or reflect those of the United States Government or any agency thereof. 
WSRC-TR-94-0240

Unclassified

\title{
MIXED WASTE MANAGEMENT FACILITY GROUNDWATER MONITORING REPORT (U)
}

FIRST QUARTER 1994

Publication Date: June 1994

\author{
Key Words \\ aluminum \\ BGO wells \\ FSS wells \\ tetrachloroethylene \\ tritium
}

Westinghouse Sayannah River Company

Savannah River Site

Aiken, SC 29808 
WSRC-TR-94-0240

Unclassified

THIS PAGE LEFT BLANK INTENTIONALLY 


\section{Abstract}

During first quarter 1994, nine constituents exceeded final Primary Drinking Water Standards in groundwater samples from downgradient monitoring wells at the Mixed Waste Management Facility, the Old Burial Ground, the E-Area Vaults, the proposed Hazardous Waste/Mixed Waste Disposal Vaults, and the F-Area Sewage Sludge Application Site.

As in previous quarters, tritium and trichloroethylene were the most widespread elevated constituents. Chloroethene (vinyl chloride), copper, 1,1-dichloroethylene, lead, mercury, nonvolatile beta, or tetrachloroethylene also exceeded standards in one or more wells. Elevated constituents were found in numerous Aquifer Zone $\| \mathrm{B}_{2}$ (Water Table) and Aquifer Zone IIB, (Barnwell/ McBean) wells and in one Aquifer Unit IIA (Congaree) well.

The groundwater flow directions and rates in the three hydrostratigraphic units were similar to those of previous quarters. 
WSRC-TR-94-0240

Unclassified

THIS PAGE LEFT BLANK INTENTIONALLY 


\section{Contents}

Page

Abstract $\ldots \ldots \ldots \ldots \ldots \ldots \ldots \ldots \ldots \ldots \ldots \ldots \ldots \ldots \ldots \ldots$

List of Figures $\ldots \ldots \ldots \ldots \ldots \ldots \ldots \ldots \ldots \ldots \ldots \ldots$

List of Tables $\ldots \ldots \ldots \ldots \ldots \ldots \ldots \ldots \ldots \ldots \ldots \ldots \ldots$

Executive Summary $\ldots \ldots \ldots \ldots \ldots \ldots \ldots \ldots \ldots \ldots$

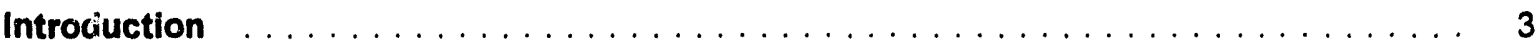

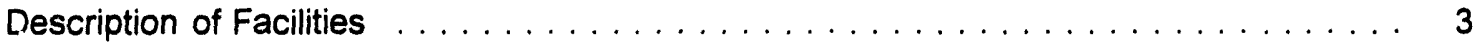

Hydrostratigraphic Units $\ldots \ldots \ldots \ldots \ldots \ldots \ldots \ldots \ldots \ldots$

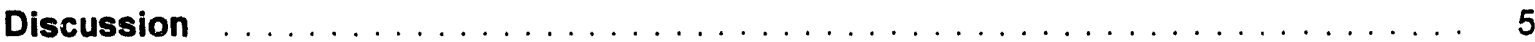

Groundwater Monitoring Data $\ldots \ldots \ldots \ldots \ldots \ldots \ldots \ldots \ldots \ldots$

Integrity of the Monitoring Well Network $\ldots \ldots \ldots \ldots \ldots \ldots$

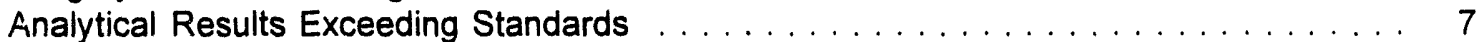

Trichlorcethylene and Tritium Time-Trend Data . . . . . . . . . . . . . . . . 9

Water Levels . . . . . . . . . . . . . . . . . . . . . . . . . . . . . . . . . . . . . . . . . . . . . . . 10

Groundwater Flow Rates and Directions . . . . . . . . . . . . . . . . . . . . . . . . . . . . 11

Upgradient Versus Downgradient Results . . . . . . . . . . . . . . . . . . . . . . . . 13

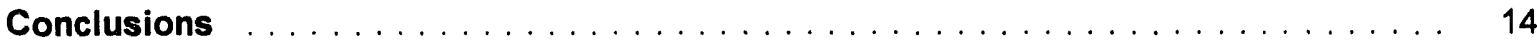

References Cited . . . . . . . . . . . . . . . . . . . . . . . . 15

Errata $\ldots \ldots \ldots \ldots \ldots \ldots \ldots \ldots \ldots \ldots \ldots \ldots \ldots$

Appendix A-Final Primary Drinking Water Standards . . . . . . . . . . . . . . . . . A-1

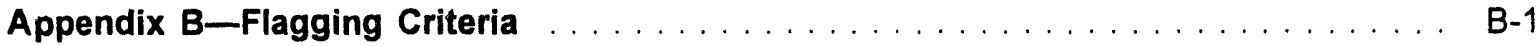

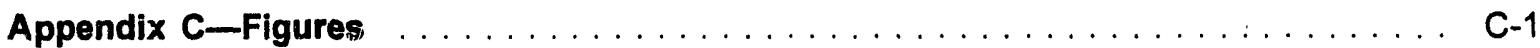

Appendix D-Groundwater Monitoring Results Tables . . . . . . . . . . . . . . D

Appendix E-Data Quality/Useability Assessment . . . . . . . . . . . . . . . . . E-1

Appendix F-Time Series Plots $\ldots \ldots \ldots \ldots \ldots \ldots \ldots \ldots$

Appendix G-Hydrographs $\ldots \ldots \ldots \ldots \ldots \ldots \ldots \ldots$ 


\section{List of Figures}

Page

1. Location of the Mixed Waste Management Facility at the Savannah River Site . . . C C-2

2. Location of the Groundwater Monitoring Wells at the Mixed Waste Management Facility, the Old Burial Ground, the E-Area Vaults, and the Hazardous Waste/ Mixed Waste Disposal Vaults (the Burial Ground Complex), and the F-Area Sewage Sludge Application Site $\ldots \ldots \ldots \ldots \ldots \ldots \ldots \ldots \ldots$ C-3

3. Hydrostratigraphic Nomenclature $\ldots \ldots \ldots \ldots \ldots \ldots \ldots \ldots \ldots \ldots \ldots \ldots \ldots$

4. Regional Correlation of Hydrostratigraphic and Lithostratigraphic Nomenclature . . . . C-5

5. Location of Aquifer Zone $\| B_{2}$ (Water Table) Wells at the Burial Ground Complex . . . C-6

6. Location of Aquifer Zone IIB, (Barnwell/McBean) Wells at the Burial Ground Complex ........................... C-7

7. Location of Aquifer Unit IIA (Congaree) Wells at the Burial Ground Complex . . . . . . C-8

8. Lead Concentrations in Aquifer Zone $\|_{2}$ (Water Table) at the Burial Ground Complex, First Quarter 1994

9. Lead Concentrations in Aquifer Zone $\| \mathrm{B}_{1}$ (Barnwell/McBean) at the Burial Ground Complex, First Quarter 1994

10. Lead Concentrations in Aquifer Unit IIA (Congaree) at the Burial Ground Complex, First Quarter 1994

11. pH Values in Aquifer Zone $\| \mathrm{B}_{2}$ (Water Table) at the Burial Ground Complex, First Quarter 1994

12. $\mathrm{pH}$ Values in Aquifer Zone $\|_{1}$ (Barnwell/McBean) at the Burial Ground Complex, First Quarter $1994 \ldots \ldots \ldots \ldots \ldots \ldots$. . . . . . . . . . . . . . . . . . . . . . . .

13. pH Values in Aquifer Unit IIA (Congaree) at the Burial Ground Complex, First Quarter 1994

14. Specific Conductance in Aquifer Zone $\| \mathrm{B}_{2}$ (Water Table) at the Burial Ground Complex, First Quarter 1994

15. Specific Conductance in Aquifer Zone $\| \mathrm{B}_{1}$ (Barnwell/McBean) at the Burial Ground Complex, First Quarter 1994

16. Specific Conductance in Aquifer Unit IIA (Congaree) at the Burial Ground Complex, First Quarter 1994 
17. Trichloroethylene Concentrations in Aquifer Zone $\|_{2}$ (Water Table) at the Burial Ground Complex, First Quarter $1994 \ldots \ldots \ldots \ldots$. . . . . . . . . . . C-18

18. Trichloroethylene Concentrations in Aquifer Zone $\| B_{1}$ (Barnwell/McBean) at the Burial Ground Complex, First Quarter $1994 \ldots \ldots$. . . . . . . . . . . . . . . . . . . . . . . . C-19

19. Trichloroethylene Concentrations in Aquifer Unit IIA (Congaree) at the Burial Ground

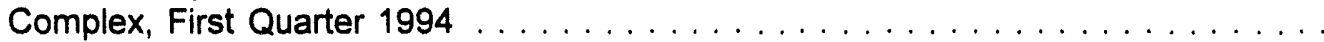

20. Tritium Activities in Aquifer Zone ${\| B_{2}}_{2}$ (Water Table) at the Burial Ground Complex, First Quarter 1994

21. Tritium Activities in Aquifer Zone IIB, (Barnwell/McBean) at the Burial Ground Complex, First Quarter 1994

22. Tritium Activities in Aquifer Unit IIA (Congaree) at the Burial Ground Complex, First Quarter 1994

23. Piezometric Surface Map of Aquifer Zone $\| B_{2}$ (Water Table) at the Burial Ground Complex

24. Potentiometric Surface Map of Aquifer Zone IIB, (Barnwell/McBean) at the Burial Ground Complex

25. Potentiometric Surface Map of Aquifer Unit IIA (Congaree) at the Burial Ground Complex

\section{List of Tables}

1. Maximum Levels of Constituents Exceeding the Final Primary Drinking Water Standards

2. Maximum Levels of Constituents Exceeding Other Flag 2 Criteria

D-11

3. Groundwater Monitoring Results for Individual Wells 
WSRC-TR-94-0240

Unclassified

THIS PAGE LEFT BLANK INTENTIONALLY. 


\section{Executive Summary}

Currently, 125 wells monitor groundwater quality in the uppermost aquifer beneath the Mixed Waste Management Facility (MWMF) at the Savannah River Site as required by the South Carolina Hazardous Waste Management Regulations and settlement agreements 87-52-SW and 91-51-SW. Samples from the welis are analyzed for selected heavy metals, indicator parameters, radionuclides, volatile organic compounds, and other constituents.

During first quarter 1994, chloroethene (vinyl chloride), copper, 1,1-dichloroethylene, lead, mercury, nonvolatile beta, tetrachloroethylene, trichloroethylene, or tritium exceeded final Primary Drinking Water Standards (PDWS) in approximately half of the downgradient wells at the MWMF. Elevated copper was found only in well FSS 1D at the F-Area Sewage Sludge Application Site; MWMF wells do not have a history of elevated copper occurrences. Consistent with historical trends, elevated constituent levels were found primarily in Aquifer Zone $\| B_{2}$ (Water Table) and Aquifer Zone IIB, (Barnwell/McBean). Elevated constituents also occurred in one Aquifer Unit IIA (Congaree) well.

As in previous quarters, tritium and trichloroethylene were the most widespread elevated constituents during first quarter 1994 . Forty-nine $(39 \%)$ of the 125 monitoring wells contained elevated tritium activities. Trichloroethylene concentrations exceeded the final PDWS in $22(18 \%)$ wells. Chloroethene, 1,1-dichloroethylene, lead, mercury, and tetrachloroethylene, elevated in one or more wells during first quarter 1994, also occurred in elevated levels during fourth quarter 1993. These constituents generally were elevated in the same wells during both quarters.

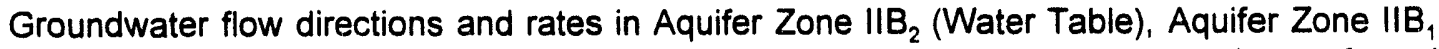
(Barnwell/McBean), and Aquifer Unit IIA (Congaree) were generally similar to those of previous quarters. 
THIS PAGE LEFT BLANK INTLNTIONALLY. 


\section{Introduction}

\section{Description of Facilities}

The Mixed Waste Management Facility (MWMF) is part of the Burial Ground Complex, which also includes the Old Burial Ground, the Low-Level Radioactive Waste Disposal Facility (LLRWDF), the E-Area Vaults, and the proposed Hazardous Waste/Mixed Waste Disposal Vaults (HWMWDV). The Burial Ground Complex is located within the General Separations Area at the Savannah River Site (SRS) (Figures 1 and 2, Appendix C). The following description outlines important events in the history of the MWMF:

- In 1972, the NWMF began receiving various radioactive and nonradioactive wastes (Heffner and Exploration Resources, 1991).

- A closure plan for the MWMF was filed November 23, 1985, with the South Carolina Department of Health and Environmental Control (SCDHEC) (Jaegge et al., 1987). The closure plan included placing a low permeability cap and final vegetative cover over the facility.

- The MWMF became inactive in 1986 (WSRC, 1993b).

- A consent decree between the U.S. Department of Energy and the Natural Resources Defense Council et al. (Civil Action 1:85-2583-6, U.S. District Court, District of South Carolina, Aiken Division), signed May 26, 1988, and effective June 1, 1988, identified the MWMF as subject to the requirements of Subtitle $C$ of the Resource Conservation and Recovery Act (RCRA).

- SCDHEC approved an interim status closure plan for the MWMF in December 1990 and accepted the closure certification in April 1991 in accordance with South Carolina Hazardous Waste Management Regulations (SCHWMR), Subpart G (SCDHEC, 1993).

- A RCRA Part B post-closure care permit application renewal was submitted to SCDHEC in Novernber 1992 (WSRC, 1992). This permit application includes the 58-acre MWMF and the 13-acre Solvent Rag Portions of the LLRWDF as agreed upon by SRS and SCDHEC in settlement agreements 87-52-SW (May 10, 1991) and 91-51-SW (August 26, 1991).

- A closure plan for the Solvent Rag Portions was submitted to SCDHEC in August 1993 (WSRC, 1993b).

- A revised RCRA Part B post-closure care permit application renewal, containing a groundwater corrective action plan, was submitted to SCDHEC on November 30, 1993 (WSRC, 1993c). 
- A final field investigation plan (FIP) for the Burial Ground Complex (WSRC, 1993a) has been approved by SCDHEC. The FIP will address data uncertainties that were identified during the preparation of the MWMF RCRA Part B post-closure care permit application renewal.

- Phase 1 of the FIP field work has been divided in the following subphases: $1 A$-installation of 12 groundwater monitoring wells; $1 \mathrm{~B}$-exploratory work in the southwest corner of the Burial Ground Complex using direct push technology and exploratory borings; $1 \mathrm{C}$-exploratory work in the northeast corner of the Burial Ground Complex using direct push technology and exploratory borings; $1 \mathrm{D}$-soil gas survey. Subphases $1 \mathrm{~B}$ and $1 \mathrm{C}$ will determine the horizontal and vertical extent of groundwater contamination away from the Burial Ground Complex. Phase 1A well drilling bega, May 3, 1994.

- Beginning first quarter 1994, welis FSS 1D, 2D, 3D, and 4D, located at the F-Area Sewage Sludge Application Site, were added to the MWMF monitoring well network. As a conditional requirement for the closure of the F-Area Sewage Sludge Application Site, the FSS monitoring wells are to be monitored for radionuclides related to the Burial Ground Complex.

Currently, the Environmental Protection Department/Environmental Monitoring Section (EPD/ EMS) conducts quarterly sampling of the 125 wells monitoring the groundwater beneath the MWMF as part of the SRS Groundwater Monitoring Program. The Environmental Restoration Department provides a quarterly report to SCDHEC describing the monitoring results to meet the requirements of SCHWMR (SCDHEC, 1993).

\section{Hydrostratigraphic Units}

Historically, groundwater quality assessment reports for the MWMF have used the lithostratigraphic nomenclature Water Table, Barnwell, McBean, and Congaree to identify hydrologic units. However, an interim alphanumeric system developed by Aadland and Bledsoe (1990) (Figure 3, Appendix $C$ ) defines the aquifer and aquitard units at SRS using hydrostratigraphic designations. Figure 4 (Appendix $C$ ) shows a correlation of these designations. This report uses both nomenclatures. The November 1992 MWMF RCRA Part B post-closure care permit application renewal includes an in-depth explanation of this nomenclature and a detailed description of the geologic and hydrogeologic systems at the Burial Ground Complex (WSRC, 1992).

The MWMF well network monitors three distinct hydrostratigraphic units in the uppermost aquifer beneath the facility: Aquifer Zone $\| \mathrm{B}_{2}$ (Water Table), which is underlain by Confining Zone $\left\|\mathrm{B}_{1}-\right\|_{1} \mathrm{~B}_{2}$ (Tan Clay); the semi-confined Aquifer Zone IIB, (Barnwell/McBean); and the semiconfined Aquifer Unit IIA (Congaree), which is separated from the overlying Aquifer Zone IIB, by Confining Unit IIA-IIB (Green Clay). The boundary between the uppermost aquifer and the principal confining unit is the uppermost confining bed of Confining System I-II (Ellenton Formation), which lies approximately $300 \mathrm{ft}$ below the surface of the Burial Ground Complex. 


\section{Discussion}

\section{Groundwater Monitoring Data}

The EPD/EMS sampling procedure (EPD/EMS, 1992) requires evacuation of a minimum of two well volumes and stabilization of $\mathrm{pH}$, specific conductance, and turbidity prior to sample collection. Stability is established when a minimum of three successive measurements, taken within a given time period, are within a specified tolerance range. If a well pumps dry before two well volumes are purged or before stabilization is achieved, it must be revisited within 24 hours for the data to be considered from a single sampling event. On the second visit within 24 hours, samples are taken without purging or stability measurements; thus, these samples may not be representative of groundwater quality.

All of the wells in the BGO, BGX, FSS, and HMD series and in cluster HSB 85 have single-speed centrifugal downhole pumps.

During first quarter 1994, groundwater samples from the MWMF were analyzed for selected indicator parameters, heavy metals, radionuclides, and other constituents. This report describes the results that equaled o: exceeded the Safe Drinking Water Act final Primary Drinking Water Standards (PDWS) or drinking water screening levels, as established by the U.S. Environmental Protection Agency (EPA) (Appendix A); the South Carolina final PDWS for lead (Appendix A); or SRS flagging criteria based on PDWS, Secondary Drinking Water Standards, or method detection limits (Appendix B). For simplicity, results that equaled or exceeded standards are described as exceeding or above standards or as elevated.

The final PDWS for individual analytes provided in Appendix A may not always match the SRS flagging criteria provided in Appendix B. The final PDWS are used as guidelines in this compliance report to meet regulatory requirements; the flagging criteria are used by EPD/EMS to identify relative levels of constituents in the groundwater and as guides for scheduling groundwater sampling.

\section{Integrity of the Monitoring Well Network}

The current groundwater monitoring well network at the MWMF (Figure 2, Appendix C) is composed of the following:

- 55 Aquifer Zone $\|_{2}$ (Water Table) wells (Figure 5, Appendix C):

BGO 1D, 2D, 3D, 4D, 5D, 6D, 7D, 8D, 9D, 10DR, 11D, 12D, 14DR, 15D, 16D, 17DR, 18D, 19D, 20D, 21D, 22DR, 23D, 24D, 26D, 27D, 28D, 29D, 30D, 31D, 32D, 33D, 34D, 35D, 36D, 37D, 38D, 39D, 40D, 44D, 45D, 46D, 47D, 48D, 49D, 50D; BGX 1D, 9D, 10D, 11D, 12D; FSS 1D, 2D, 3D, 4D; HSB 85C 
- 46 Aquifer Zone IIB, (Barnwell/McBean) wells (Figure 6, Appendix C):

BG0 5C, 6B, 6C, 8C, 10B, 10C, 12CR, 13DR, 14CR, 16B, 27C, 29C, 30C, 31C, 33C, 35C, 37C, 42C, 43CR, 43D, 44B, 44C, 45B, 45C, 46B, 46C, 47C, 48C, 49C, 50C; BGX 1C, 2B, 2D, 3D, 4C, 4D, 5D, 6D, 7D, 8DR, 12C; HMD 1D, 2D, 3D, 4D; HSB 85B

- 24 Aquifer Unit IIA (Congaree) wells (Figure 7, Appendix C):

BGo 6A, 8AR, 9AA, 10AA, 10AR, 12AR, 14AR, 16AR, 18A, 25A, 26A, 29A, 41A, 43A, 43AA, 44A, 44AA, 45A, 47A, 49A, 50A; BGX 1A, 4A; HSB 85A

SRS has a program in place to rehabilitate and replace wells that do not produce representative samples from the units being monitored. A complete record of well installations, replacements, and abandonments at the MWMF is found in the EPD/EMS well inventory (EPD/EMS, 1993).

The designated background wells for Aquifer Zone $\| B_{2}$ (Water Table) are $B G O 1 D$ and $2 \mathrm{D}$, and HSB 85C; HSB 85B is the background well for Aquifer Zone $\|_{1}$ (Barnwell/McBean); and HSB $85 \mathrm{~A}$ is the background well for Aquifer Unit IIA (Congaree).

Table 3 (Appendix D) lists the number if well volumes purged from each of the BGO, BGX, FSS, and HMD series wells and the HSB 85 well cluster during first quarter 1994 and provides statements that describe incomplete or unsuccessful sampling events. Incomplete or unsuccessful sampling events occurred as follows.

- Wells that went dry during purging:

BGo 1D, 3D, 5C, 5D, 6B, 6D, 9AA, 10B, 10C, 10DR, 12CR, 12D, 13DR, 14CR, 16B, 16D, 17DR, 20D, 21D, 22DR, 24D, 25A, 26D, 27D, 28D, 29A, 29C, 29D, 30C, 30D, 31C, 31D, 32D, 33D, 34D, 35D, 36D, 37D, 38D, 39D, 40D, 42C, 43CR, 44B, 44C, 45B, 45C, 46C, 49D, $50 A, 50 C$; BGX 1C, 1D, 2B, 2D, 10D, 11D, 12D; FSS 2D, 3D, 4D; HMD 1D, 4D; HSB 85B

- Wells that could not be sampled because they were inaccessible to the samplers:

BGO 4D

- Wells that could not be sampled because they had mechanical problems:

None

- Wells that had no water-elevation measurements because they had no water in the standpipe:

BGO 49A

- Wells that could not be sampled because they are in the Purge Water Containment (PWC) Program. The PWC program was instituted at SRS in 1991 to contain and dispose of groundwater purged from wells during sampling that exhibits parameters 100 times their standards. Currently, MWMF does not have a method for containing and disposing of the purged water; thus, these wells have only water-level measurements taken during sampling. 
Wells in the Purge Water Containment Program

\begin{tabular}{|lllll|}
\hline Well & $\begin{array}{l}\text { Quarter Last } \\
\text { Sampled }\end{array}$ & $\begin{array}{l}\text { Constituent } \\
\text { Exceeding Limit }\end{array}$ & $\begin{array}{l}\text { Level at } \\
\text { Last Sample }\end{array}$ & $\begin{array}{l}\text { Completion Date } \\
\text { of Next Evaluation }\end{array}$ \\
\hline BGO 26A & $3 Q 91$ & $\mathrm{pH}$ & $11.6 \mathrm{pH}$ units $^{\mathrm{a}}$ & June 30,1994 \\
BGO 37C & $1 Q 91$ & trichloroethylene & $690 \mu \mathrm{g} /$ & June 30,1994 \\
BGO 41A & $2 \mathrm{Q} 93$ & $\mathrm{pH}$ & $12.3 \mathrm{pH}$ units & June 30,1994 \\
BGO 43A & $2 \mathrm{Q} 93$ & $\mathrm{pH}$ & $12.6 \mathrm{pH}$ units & June 30,1994 \\
BGX 1A & $1 Q 93$ & $\mathrm{pH}$ & $12.4 \mathrm{pH}$ units & June 30,1994 \\
\hline
\end{tabular}

a Field measurements.

\section{Analytical Results Exceeding Standards}

Results for analytes that exceeded the final PDWS during first quarter 1994 are summarized in Table 1 (Appendix D) and described below. In the text description, the maximum level for each constituent is indicated in parentheses following the well in which it was detected.

Aquifer Zone $\| B_{2}$ (Water Table): 38 of the 55 wells contained elevated constituents during first quarter 1994.

- Tritium was elevated in 32 wells: BGO 2D, 3D, 5D, 6D, 7D, 9D, 10DR, 11D, 12D, 15D, 16D, 19D, 20D, 21D, 22DR, 23D, 27D, 28D (maximum activity at $1.2 \mathrm{E}+05 \mathrm{pCi} / \mathrm{mL}$ ), 30D, 31D, 32D, 33D, 34D, 35D, 36D, 37D, 38D, 39D, 45D, and 49D; and FSS 2D and 3D.

- Trichloroethylene was elevated in 13 wells: BGO 6D, 7D, 12D, 14DR, 15D, 16D, 28D (maximum concentration at $190 \mu \mathrm{g} / \mathrm{L}$ ), 30D, 32D, 46D, 47D, 48D, and 50D.

- Tetrachloroethylene was elevated in 4 wells: BGO 7D, 32D, 46D, and 48D (maximum concentration at $68 \mu \mathrm{g} / \mathrm{L})$.

- Chloroetherie (vinyl chloride) was elevated in 2 wells: BGO 28D (maximum concentration at $140 \mu \mathrm{g} / \mathrm{L})$ and $30 \mathrm{D}$.

- Copper was elevated in well FSS 1D at 1,400 $\mu \mathrm{g} / \mathrm{L}$. Historically, copper has not exceeded standards in wells at the MWMF.

- 1,1-Dichloroethylene was elevated in well BGO 30D at $19 \mu \mathrm{g} / \mathrm{L}$.

- Lead was elevated in well FSS $1 \mathrm{D}$ at $119 \mu \mathrm{g} / \mathrm{L}$. 
Aquifer Zone IIB (Barnwell/McBean): 22 of the 46 wells contained elevated constituents during first quarter 1994.

- Tritium was elevated in 17 wells: BGO 5C, 6B, 6C, 10B, 10C, 14CR, 27C, 29C, 30C, $31 \mathrm{C}, 33 \mathrm{C}$ (maximum activity at $8.2 \mathrm{E}+03 \mathrm{pCi} / \mathrm{mL}$ ), 45C, and $49 \mathrm{C} ; \mathrm{BGX} 1 \mathrm{C}, 3 \mathrm{D}$, and 5D; and HMD $1 D$.

- Trichloroethylene was elevated in 9 wells: BGO $12 \mathrm{CR}$ (maximum conceritration at $79 \mu \mathrm{g} / \mathrm{L}), 14 \mathrm{CR}, 27 \mathrm{C}, 30 \mathrm{C}, 33 \mathrm{C}, 42 \mathrm{C}$, and $46 \mathrm{C}$; and BGX 2D and 3D.

- Lead was elevated in well BGO 44B at $55 \mu \mathrm{g} / \mathrm{L}$.

- Mercury was elevated in well BGO $33 \mathrm{C}$ at $2.8 \mu \mathrm{g} / \mathrm{L}$.

- Nonvolatile beta was elevated in well BGX 5D at 1.5E+02 pCi/L.

- Tetrachloroethylene was elevated in well BGO 33C at $5.1 \mu \mathrm{g} / \mathrm{L}$.

Aquifer Unit IIA (Congaree): 1 of the 24 wells contained elevated constituents during first quarter 1994.

- Nonvolatile beta was elevated in well BGO 9AA at 7.8E+01 pCi/L.

Results for analytes that exceeded other SRS flagging criteria during first quarter 1994 are summarized in Table 2 (Appendix D).

Table 3 (Appendix D) shows the results for all of the constituents and indicates the analytical laboratories that conducted the analyses, the dilution factors used in the analyses, and the analyses that received modifiers (which help identify laboratory accuracy ar d precision) or that exceeded the EPA-approved holding times during first quarter 1994. Constituent results in Table 3 that appear to equal the final PDWS but are not marked in the $D$ column (exceeded final PDWS or screening level) are below the final PDWS in the database. Database results, the results that are compared to the final PDWS, are entered with more significant digits than the results given in this report. Apparent discrepancies are the result of the rounding of reported results.

In addition to the results tables, Appendix $D$ provides definitions of the abbreviations and the modifiers used in the results tables as well as descriptions of holding times, data rounding, and data qualification practices. Appendix $E$ provides a general assessment of the quality and useability of the data.

Isoconcentration maps of lead, $\mathrm{pH}$, specific conductance, trichloroethylene, and tritium in Aquifer Zone $\| B_{2}$ (Water Table), Aquifer Zone IIB (Barnwell/McBean), and Aquifer Unit IIA (Congaree) wells during first quarter 1994 appear in Figures 8 through 22 (Appendix C). 


\section{Trichloroethylene and Tritium Time-Trend Data}

Time series plots from first quarter 1990 through first quarter 1994 for wells containing trichloroethylene and tritium are presented in Appendix F. Statistical analyses of these data have not been conducted; thus, statements concerning changes in constituent concentrations or activities over time are not included in this report. Statement concerning relative concentrations or activities of the constituents are provided below.

Trichloroethylene concentrations have exhibited the following trends since first quarter 1992:

- Trichloroethylene concentrations in wells BGo 6A, 6C, 8AR, 8C, 27D, 29D, 31D, 32D, 33D, 41A, 44A, 44AA, 44B, 44D, 47A, and 50A have been consistently below or near detection limits.

- Trichloroethylene concentrations in wells BGo 8D, 13DR, 14AR, 29A, 29C, 31C, 40D, $44 C, 46 B, 47 C$, and $48 C$ and $B G X 2 B$ have been consistently near or below the final PDWS.

- Wells BGo 6D, 7D, 12CR, 12D, 14CR, 14DR, 15D, 16D, 27C, 28D, 30C, 30D, 33C, 42C, 46C, 46D,47D, 48D, and 50D and BGX 2D have exhibited concentrations of trichloroethylene that consistently exceeded the final PDWS.

- Well BGO 28D, screened in Aquifer Zone $\|_{1} B_{2}$ (Water Table), has consistently exhibited the highest trichloroethylene concentrations, usually ranging from approximately $190 \mu \mathrm{g} / \mathrm{L}$ to $340 \mu \mathrm{g} / \mathrm{L}$.

- Other wells have exhibited somewhat erratic activities, ranging from relatively high above the final PDWS to below the final PDWS (e.g., wells BGO 50C and BGX 3D). Data are insufficient to determine trends for other wells. However, trichloroethylene concentrations in wells BGO 6B, 16AR, and 16B have not exceeded the final PDWS since sampling began several quarters ago.

Tritium activities have exhibited the following trends since first quarter 1992:

- Tritium activities in wells BGo 6A, 8AR, 8C, 10AR, 12AR, 12CR, 18A, 25A, 26A, 41A, 43A, 43AA, 44A, 44AA, 45A, 47A, 49A, and 50A; BGX 4A and 12C; FSS 1D; and HSB $85 C$ have been consistently near or below detection limits.

- Tritium a ivities have not exceeded the final PDWS in upgradient wells BGO 1D, HSB 85A, and HSB 85B.

- Tritium activities in wells BGO 2D, 5C, 5D, 8D, 12D, 14AR, 18D, 20D, 24D, 26D, 29A, 29D, 33D, 35C, 40D, 42C, 43CR, 43D, and 45B; BGX 2B, 4C, 6D, 9D, 10D, 11D, and 12D; FSS 4D; and HMD 2D, 3D, and 4D have been consistently near or below the final PDWS.

- Wells BGO 3D, 6C, 6D, 7D, 10DR, 11D, 13DR, 14CR, 15D, 16D, 21D, 23D, 27C, 27D, 28D, 29C, 30C, 30D, 31C, 31D, 32D, 33C, 34D, 35D, 36D, 37D, 38D, 39D, 44B, 44C, 
44D, 45C, 45D, 46C, 46D, 47C, 47D, 48C, 48D, 49D, 50C, and 50D; BGX 1C, 1D, 2D, $3 \mathrm{D}$, and $8 \mathrm{DR}$; and FSS $2 \mathrm{D}$ and $3 \mathrm{D}$ have exhibited tritium levels that have consistently exceeded the final PDWS.

- Well BGO 28D, located in Aquifer Zone $\| B_{2}$ (Water Table) at the west edge of the Old Burial Ground, has consistently exhibited the highest tritium activities, exceeding 1.0E+05 $\mathrm{pCi} / \mathrm{mL}$ during most quarters.

- Some wells have exhibited erratic activities, ranging from relatively high above the final PDWS to below the final PDWS (e.g., wells BGO $10 \mathrm{C}$ and 46B and BGX 7D). Data are still insufficient to determine trends for other wells. However, tritium activities in wells BGO 9AA, 10AA, 16AR, and 17DR have been consistently below the final PDWS since sampling began several quarters ago.

Tritium activities in wells BGO 12D, 14AR, 26D, 29A, 34D, 35C, 36D, 37D, 38D, and 39D appear to have been anomalously high during fourth quarter 1991 as compared to preceding and more recent quarters.

Time series plots of $\mathrm{pH}$ for selected wells also are provided in Appendix $\mathrm{F}$.

\section{Water Levels}

Hydrographs for selected wells and well clusters at the MWMF are provided in Appendix $G$. Average water elevations for all of the wells in each of the three hydrostratigraphic units beneath the MWMF for the past four quarters are shown in the following table.

Average Water Elevations (ft msl) in the Hydrostratigraphic Units beneath the MWMF

\begin{tabular}{|lllll|}
\hline Unit & $2 \mathrm{Q} 93$ & $3 \mathrm{Q} 93$ & $4 \mathrm{Q} 93$ & $1 \mathrm{Q} 94$ \\
\hline Aquifer Zone $\|_{\mathrm{B}}$ (Water Table) & 233.89 & 233.07 & 231.13 & $230.70^{\mathrm{a}}$ \\
Aquifer Zone $\mathrm{IB}_{1}$ (Barnwell/McBean) & 221.54 & 220.34 & 219.14 & 218.15 \\
Aquifer Unit IIA (Congaree) & 163.31 & 160.60 & 160.29 & 159.45 \\
\hline
\end{tabular}

a Average includes water elevations for wells FSS 1D, 2D, and 3D for the first time.

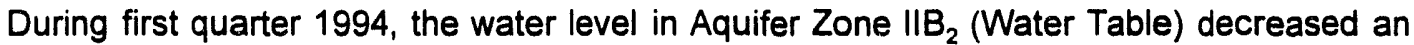
average of $0.43 \mathrm{ft}$ compared to fourth quarter 1993, the water level in Aquifer Zone IIB, (Barnwell/McBean) decreased an average of $0.99 \mathrm{ft}$, and the water level in Aquifer Unit IIA (Congaree) fell an average of $0.84 \mathrm{ft}$.

A consistent vertical head relationship exists among the hydrostratigraphic units monitored at the MWMF. Flow potential is downward from Aquifer Zone $\| \mathrm{B}_{2}$ (Water Table) to Aquifer Zone $\|_{1}$ (Barnwell/McBean) and downward from Aquifer Zone IIB, (Barnwell/McBean) to Aquifer Unit IIA (Congaree). This relationship, which was first noted in 1988, exists at all BGO well clusters. 


\section{Groundwater Flow Rates and Directions}

The groundwater in Aquifer Zone $\|_{2} B_{2}$ (Water Table) and Aquifer Zone IIB, (Barnwell/McBean) diverges beneath the Burial Ground Complex. Historically the groundwater in Aquifer Zone $\| B_{2}$ (Water Table) has discharged either to the north toward Upper Three Runs Creek or to the southwest toward Fourmile Branch (using universal transverse Mercator coordinates [UTM]); the groundwater in Aquifer Zone $\| B_{1}$ (Barnwell/McBean) has discharged either to the northwest or to the southwest. Near Upper Three Runs Creek, the upper portion of the saturated zone lies beneath Confining Zone IIB,-IIB (Tan Clay) in Aquifer Zone IIB, (Barnwell/McBean). The historical horizontal groundwater flow direction in Aquifer Unit IIA (Congaree) has been consistently northwest toward Upper Three Runs Creek.

Using universal transverse Mercator coordinates, the first quarter 1994 flow directions in Aquifer Zone $\| B_{2}$ (Water Table) were to the southwest (flow path $A$ ) and north (flow path B). Flow directions in Zone $\| B_{1}$ (Barnwell/McBean) were to the southwest (flow path $A$ ) and northwest (flow path $B$ ), and the flow direction in Aquifer Unit IIA (Congaree) was to the northwest (Figures 23, 24, and 25, Appendix C). Horizontal flow rate estimates for the three hydrostratigraphic units during the past four quarters are provided in the following table.

\section{Estimated Horizontal Groundwater Flow Rates (ftyr) in the Hydrostratigraphic Units beneath the MWMF}

\begin{tabular}{|lllll|}
\hline Unit & 2093 & 3093 & $4 Q 93$ & $1 Q 94$ \\
\hline Aquifer Zone $\|_{2}$ (Water Table) & $19-33$ & $27-51$ & $17-35$ & $20-31$ \\
Aquifer Zone IIB, (Barnwell/McBean) & $4.0-16$ & $5.1-15$ & $8.8-16$ & $8.8-16$ \\
Aquifer Unit IIA (Congaree) & 200 & 190 & 180 & 150 \\
\hline
\end{tabular}

Horizontal flow rate calculations provide estimates of the transport rate of constituents originating from the MWMF. Flow rates in Aquifer Zone $\| B_{2}$ (Water Table) and Aquifer Zone IIB (Barnwell/ McBean) are calculated along two flow paths (designated flow paths $A$ and $B$ ) to characterize the divergent groundwater flows toward Upper Three. Runs Creek and Fourmile Branch. The flow rate for Aquifer Unit IIA (Congaree) is calculated along a single flow path because flow directions within this unit are generally more uniform than in the overlying units. Flow rates are estimated using the following equation:

$$
\text { Flow }(\mathrm{ft} / \mathrm{day})=\frac{\text { Hydraulic Conductivity }(\mathrm{ft} / \text { day })}{\text { Porosity (unitless) }} \times \frac{d h(\mathrm{ft})}{d l(\mathrm{ft})}
$$

Hydraulic conductivity constants of $3.03 \mathrm{ft} /$ day, $1.50 \mathrm{ft} /$ day, and $45 \mathrm{ft}$ day are used for Aquifer

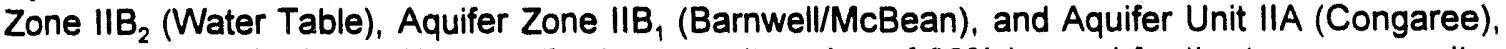
respectively (WSRC, 1992). An effective porosity value of $20 \%$ is used for the two upper units, and an effective porosity value of $25 \%$ is used for Aquifer Unit IIA (Congaree) (WSRC, 1992). The value $d h$ is the difference in head, and $d l$ is the length of the flow path.

Flow path lengths are calculated to the nearest $50 \mathrm{ft}$. Flow rate per day is calculated to two significant figures, then multiplied by 365 and rounded to two significant figures for the flow rate per year. Flow rate estimates vary depending on the vertical gradient between wells, the size of the area under consideration, the number of data points, and the length and location of the flow path. Because these are based on inferred or estimated parameters, flow rate estimates should be considered accurate to an order of magnitude only. 
The flow rate estimates for groundwater in Aquifer Zone $\mathrm{IIB}_{2}$ (Water Table) beneath the MWMF during first quarter 1994 are as follows (Figure 23, Appendix $C$ ):

Flow path $\mathrm{A}$ (toward Fourmile Branch)

$$
\begin{aligned}
& \frac{3.03}{0.20} \times \frac{8}{2.150} \approx 0.056 \mathrm{ft} / \text { day } \\
& 0.056 \mathrm{ft} / \text { day } \times 365 \text { days } \approx 20 \mathrm{ft} / \mathrm{yr}
\end{aligned}
$$

Flow path B (toward Upper Three Runs Creek)

$$
\begin{aligned}
& \frac{3.03}{0.20} \times \frac{12}{2.150} \approx 0.085 \mathrm{ft} / \text { day } \\
& 0.085 \mathrm{ft} / \text { day } \times 365 \text { days } \approx 31 \mathrm{ft} / \mathrm{yr}
\end{aligned}
$$

The flow rate estimates for groundwater in Aquifer Zone $\| B_{1}$ (Barnwell/McBean) beneath the MWMF are as follows (Figure 24, Appendix C):

Flow path $A$ (toward Fourmile Branch)

$$
\begin{aligned}
& \frac{1.50}{0.20} \times \frac{8}{2,450} \approx 0.024 \mathrm{ft} / \text { day } \\
& 0.024 \mathrm{ft} / \text { day } \times 365 \text { days } \approx 8.8 \mathrm{ft} / \mathrm{yr}
\end{aligned}
$$

Flow path B (toward Upper Three Runs Creek)

$$
\begin{aligned}
& \frac{1.50}{0.20} \times \frac{12}{2,100} \approx 0.043 \mathrm{ft} / \text { day } \\
& 0.043 \mathrm{ft} / \text { day } \times 365 \text { days } \approx 16 \mathrm{ft} / \mathrm{yr}
\end{aligned}
$$

The flow rate estimate for groundwater in Aquifer Unit IIA (Congaree) beneath the MWMF is as follows (Figure 25, Appendix C):

$$
\begin{aligned}
& \frac{45}{0.25} \times \frac{5}{2,250} \approx 0.40 \mathrm{ft} / \text { day } \\
& 0.40 \mathrm{ft} / \text { day } \times 365 \text { days } \approx 150 \mathrm{ft} / \mathrm{yr}
\end{aligned}
$$




\section{Upgradient Versus Downgradient Results}

Wells $B G O 1 D, 2 D$, and HSB $85 C$ are upgradient wells in Aquifer Zone $\| B_{2}$ (Water Table); wells HSB $85 \mathrm{~A}$ and $85 \mathrm{~B}$ are upgradient wells in Aquifer Unit IIA (Congaree) and Aquifer Zone IIB, (Barnwell/McBean), respectively. The remaining wells in these hydrostratigraphic units monitor downgradient water quality.

Upgradient well BGO 2D contained tritium activity that exceeded the final PDWS during first quarter 1994. No elevated constituents were detected in the remaining upgradient wells. Downgradient wells in the three hydrostratigraphic units contained elevated levels of chloroethene, copper, 1,1-dichloroethylene, lead, mercury, nonvolatile beta, tetrachloroethylene, trichloroethylene, or tritium. 


\section{Conclusions}

The groundwater at the MWMF contains elevated levels of heavy metals, radionuclides, volatile organic compounds, and other constituents resulting from 40 years of operations at the Burial Ground Complex. During first quarter 1994, chloroethene, copper, 1,1-dichloroethylene, lead, mercury, nonvolatile beta, tetrachloroethylene, trichloroethylene, and tritium exceeded their final PDWS in one or more wells at the MWMF. All of these constituents, except copper and nonvolatile beta, also occurred in elevated levels during fourth quarter 1993. Elevated copper occurred only in well FSS 1D at the F-Area Sewage Sludge Application Site; historically, copper has not been elevated in BGO, BGX, or HMD wells or in well cluster HSB 85 . Nonvolatile beta was elevated sporadically in two wells at the MWMF during 1993 and three wells during 1992 . Elevated lead occurred in only in well FSS $1 D$ during the quarter; nearby BGO wells do not have a history of elevated lead concentrations.

As in previsus quarters, tritium and trichloroethylene were the most widespread constituents. Forty-nine $(39 \%)$ of the 125 monitoring w'alls contained elevated tritium activities, with maximum activity $\left(1.2 \mathrm{E}+05 \mathrm{pCi} / \mathrm{mL}\right.$ ) occurring in well BGO 28D in Aquifer Zone $\| \mathrm{B}_{2}$ (Water Table). Trichloroethylene concentrations exceeded the final PDWS in $22(18 \%)$ of the wells, with the maximum concentration found at $190 \mu \mathrm{g} / \mathrm{L}$ in well BGO 28D in Aquifer Zone $\|_{2} B_{2}$ (Water Table).

Elevated constituent levels were found primarily in Aquifer Zone $\| \mathrm{B}_{2}$ (Water Table) and Aquifer Zone IIB, (Barnwell/McBean), consistent with historical data. Elevated constituents also occurred in one well in Aquifer Unit IIA (Congaree), indicating that vertical pathways into this deeper water-bearing unit exist. A current groundwater flow model for the General Separations Area indicates that the vertical component beneath this area is important (GeoTrans, Inc., 1992).

Constituents exceeding the final PDWS were found in upgradient well BGO 2D and in numerous downgradient wells. Generally, elevated levels of constituents found in downgradient wells but not in upgradient wells at a waste management unit are considered products of the waste management unit.

Groundwater in Aquifer Zone $\| B_{2}$ (Water Table) and Aquifer Zone IIB ${ }_{1}$ (Barnwell/McBean) diverges beneath the Burial Ground Complex and discharges toward Upper Three Runs Creek or toward Fourmile Branch. During first quarter 1994, flow in these units was to the north-northwest toward Upper Three Runs Creek or to the southwest toward Fourmile Branch (UTM coordinates). The groundwater flow direction in Aquifer Unit IIA (Congaree) is consistently northwest toward Upper Three Runs Creek.

Groundwater flow rate estimates were in the same order of magnitude as previous quarters. Estimates ranged from $20 \mathrm{ft} / \mathrm{yr}$ to $31 \mathrm{ft} / \mathrm{yr}$ in Aquifer Zone $\mathrm{IB}_{2}$ (Water Table) and from $8.8 \mathrm{ft} / \mathrm{yr}$ to $16 \mathrm{ft} / \mathrm{yr}$ in Aquifer Zone $\| \mathrm{B}_{1}$ (Barnwell/McBean); the flow rate estimate in Aquifer Unit IIA (Congaree) was $150 \mathrm{ft} / \mathrm{yr}$. 
WSRC-TR-94-0240

Unclassified

\section{References Cited}

Aatlland, R. K., and H. W. Bledsoe, 1990. Classification of Hydrostratigraphic Units at the Savannah River Site, South Carolina, WSRC-RP-90-987. Westinghouse Savannah River Company, Savannah River Site, Aiken, SC.

EPD/EMS (Environmental Protection Department, Environmental Monitoring Section), 1992. Hydrogeologic Data Collection Procedures and Specifications: Sampling Groundwater Monitoring Wells, Manual 3Q5, Chapter 15, Revision 0. Westinghouse Savannah River Company, Savannah River Site, Aiken, SC.

EPD/EMS (Environmental Protection Department/Environmental Monitoring Section), 1993. Environmental Protection Department's Well Inventory (through the second quarter of 1993), ESH-EMS-930261. Westinghouse Savannah River Company, Savannah River Site, Aiken, SC.

GeoTrans, Inc., 1992. Groundwater Flow Model for the General Separations Area, Savannah River Site. Prepared for Westinghouse Savannah River Company, Environmental Restoration Department, Savannah River Site, Aiken, SC.

Heffner, J. D., and Exploration Resources, Inc., 1991. Technical Summary of Groundwater Quality Protection Program at the Savannah River Site (1952-1986), Volume I-Site Geohydrology and Waste Sites, DPSP-88-1002. Westinghouse Savannah River Company, Aiken, SC.

Jaegge, W. J., N. L. Kolb, B. B. Looney, I. W. Marine, O. A. Towler, and J. R. Cook, 1987. Environmental Information Document: Radioactive Waste Burial Grounds, DPST-85-694. Savannah River Laboratory, E. I. du Pont de Nemours \& Company, Aiken, SC.

SCDHEC (South Carolina Department of Health and Environmental Control), 1993. South Carolina Hazardous Waste Management Regulations; R.61-79.124, 260 through .266, .268, and .270. Columbia, SC.

WSRC (Westinghouse Savannah River Company), 1992. 1992 RCRA Part B Permit Renewal Application. Mixed Waste Management Facility (MWMF) Post-Closure, Volume VII, Revision 0, November 1992, WSRC-IM-91-53. Savannah River Site, Aiken, SC.

WSRC (Westinghouse Savannah River Company), 1993a. A Field Investigation Plan for the Burial Ground Complex. September 1993, WSRC-RP-93-848. Savannah River Site, Aiken, SC.

WSRC (Westinghouse Savannah River Company), 1993b. Mixed Waste Management Facility Closure Plan (LLRWDF), Volume II, August 1993, Q-CLP-E-00001. Savannah River Site, Aiken, SC.

WSRC (Westinghouse Savannah River Company), 1993c. 1992 RCRA Part B Permit Application, Mixed Waste Management Facility Postclosure, Volume VII, Revision 2, November 1993, WSRC-IM-91-53. Savannah River Site, Aiken, SC. 


\section{Errata}

In tables with four quarters of data, some values for earlier quarters may differ from values for those same quarters presented in earlier reports because some reanalyses may have been performed by the laboratories after the reports were printed.

First Quarter 1993:

- Page 10, footnote to table: The date the effective porosity value for Aquifer Unit IIA (Congaree) was changed should read "between second and third quarters 1992."

- Page D-9, Table 2: Dichloromethane should be italicized.

- Page D-132, Table 3: Well BGO 31C went dry after 29 gallons of water ( 0.9 well volumes) were evacuated.

Second Quarter 1993:

- No errata have been reported.

Third Quarter 1993:

- Page D-5, Table 1: The correct result for trichloroethylene in well BGO 12D during second quarter is $83 \mu \mathrm{g} / \mathrm{L}$.

- Page F-14, Trichloroethylene concentrations, well cluster BGO 6: The symbols were incorrect. The open triangle should be a black square; the black square should be an open triangle.

Fourth Quarter 1993:

- No errata have been reported. 
WSRC-TR-94-0240

Unclassified

\section{Appendix A}

Final Primary Drinking Water Standards 
WSRC-TR-94-0240

Unclassified

THIS PAGE LEFT BLANK INTENTIONALLY. 
Final Primary Drinking Water Standards

\begin{tabular}{|c|c|c|c|c|}
\hline Analyte & Unit & Level & $\underline{\text { Status }}$ & Source \\
\hline Alachlor & $\mu g / L$ & 2 & Final & EPA, 1993 \\
\hline Aldicarb $^{a}$ & $\mu g / L$ & 3 & Final & EPA, 1993 \\
\hline Aldicarb sulfone ${ }^{a}$ & $\mu g / L$ & 2 & Final & EPA, 1993 \\
\hline Aldicarb sulfoxide ${ }^{a}$ & $\mu g / L$ & 4 & Final & EPA, 1993 \\
\hline Antimony & $\mu g / L$ & 6 & Final & EPA, 1993 \\
\hline Antimony, dissolved & $\mu g / L$ & 6 & Final & EPA, 1993 \\
\hline Antimony, total recoverable & $\mu g / L$ & 6 & Final & EPA, 1993 \\
\hline Arsenic & $\mu g / L$ & 50 & Final & EPA, 1993 \\
\hline Arsenic, dissolved & $\mu g / L$ & 50 & Final & EPA, 1993 \\
\hline Arsenic, total recoverable & $\mu g / L$ & 50 & Final & EPA, 1993 \\
\hline Asbestos & Fibers/L & $7,000,000$ & Final & EPA, 1993 \\
\hline Atrazine & $\mu g / L$ & 3 & Final & EPA, 1993 \\
\hline Barium & $\mu g / L$ & 2,000 & Final & EPA, 1993 \\
\hline Barium, dissolved & $\mu g / L$ & 2,000 & Final & EPA, 1993 \\
\hline Barium, total recoverable & $\mu g / L$ & 2,000 & Final & EPA, 1993 \\
\hline Benzene & $\mu g / L$ & 5 & Final & EPA, 1993 \\
\hline Benzo[a]pyrene & $\mu g / L$ & 0.2 & Final & EPA, 1993 \\
\hline Beryllium & $\mu g / L$ & 4 & Final & EPA, 1993 \\
\hline Beryllium, dissolved & $\mu g / L$ & 4 & Final & EPA, 1993 \\
\hline Beryllium, total recoverable & $\mu g / L$ & 4 & Final & EPA, 1993 \\
\hline Bis(2-ethylhexyl) phthalate & $\mu g / L$ & 6 & Final & EPA, 1993 \\
\hline Bromodichloromethane & $\mu g / L$ & 100 & Final & EPA, 1993 \\
\hline Bromoform & $\mu g / L$ & 100 & Final & EPA, 1993 \\
\hline 2-sec-Butyl-4,6-dinitrophenol & $\mu g / L$ & 7 & Final & EPA, 1993 \\
\hline Cadmium & $\mu g / L$ & 5 & Final & EPA, 1993 \\
\hline Cadmium, dissolved & $\mu g / L$ & 5 & Final & EPA, 1993 \\
\hline Cadmium, total recoverable & $\mu g / L$ & 5 & Final & EPA, 1993 \\
\hline Carbofuran & $\mu g / L$ & 40 & Final & EPA, 1993 \\
\hline Carbon tetrachloride & $\mu g / L$ & 5 & Final & EPA, 1993 \\
\hline Chlordane & $\mu g / L$ & 2 & Final & EPA, 1993 \\
\hline Chlorobenzene & $\mu \mathrm{g} / \mathrm{L}$ & 100 & Final & EPA, 1993 \\
\hline Chloroethene (Vinyl chloride) & $\mu g / L$ & 2 & Final & EPA, 1993 \\
\hline Chloroform & $\mu \mathrm{g} / \mathrm{L}$ & 100 & Final & EPA, 1993 \\
\hline Chromium & $\mu g / L$ & 100 & Final & EPA, 1993 \\
\hline Chromium, dissolved & $\mu \mathrm{g} / \mathrm{L}$ & 100 & Final & EPA, 1993 \\
\hline Chromium, total recoverable & $\mu g / L$ & 100 & Final & EPA, 1993 \\
\hline Copper & $\mu g / L$ & 1,300 & Final & EPA, 1993 \\
\hline Copper, dissolved & $\mu \mathrm{g} / \mathrm{L}$ & 1,300 & Final & EPA, 1993 \\
\hline Copper, total recoverable & $\mu g / L$ & 1,300 & Final & EPA, 1993 \\
\hline Cyanide & $\mu g / L$ & 200 & Final & EPA, 1993 \\
\hline Dalapon ${ }^{a}$ & $\mu g / L$ & 200 & Final & EPA, 1993 \\
\hline Dibromochloromethane & $\mu g / L$ & 100 & Final & EPA, 1993 \\
\hline 1,2-Dibromo-3-chloropropane & $\mu g / L$ & 0.2 & Final & EPA, 1993 \\
\hline 1,2-Dibromoethane & $\mu g / L$ & 0.05 & Final & EPA, 1993 \\
\hline 1,2-Dichlorobenzene & $\mu g / L$ & 600 & Final & EPA, 1993 \\
\hline 1,4-Dichlorobenzene & $\mu g / L$ & 75 & Final & EPA, 1993 \\
\hline 1,2-Dichloroethane & $\mu g / L$ & 5 & Final & EPA, 1993 \\
\hline 1,1-Dichloroethylene & $\mu g / L$ & 7 & Final & EPA, 1993 \\
\hline 1,2-Dichloroethylene & $\mu g / L$ & 50 & Final & EPA, 1993 \\
\hline cis-1,2-Dichloroethylene & $\mu g / L$ & 70 & Final & EPA, 1993 \\
\hline trans-1,2-Dichloroethylene & $\mu g / L$ & 100 & Final & EPA, 1993 \\
\hline Dichloromethane (Methylene chloride) & $\mu \mathrm{g} / \mathrm{L}$ & 5 & Final & EPA, 1993 \\
\hline 2,4-Dichlorophenoxyacetic acid & $\mu g / L$ & 70 & Final & EPA, 1993 \\
\hline
\end{tabular}


Analyte

1,2-Dichloropropane

Di(2-ethylhexyl) adipate ${ }^{a}$

Diquat dibromide ${ }^{a}$

Endothall ${ }^{a}$

Endrin

Ethylbenzene

Fluoride

Glyphosate $^{a}$

Gross alphab

Heptachlor

Heptachlor epoxide

Hexachlorobenzene

Hexachlorocyclopentadiene

Lead

Lead, dissolved

Lead, total recoverable

Lindane

Mercury

Mercury, dissolved

Mercury, total recoverable

Methoxychlor

Nickel

Nickel, dissolved

Nickel, total recoverable

Nitrate as nitrogen

Nitrate-nitrite as nitrogen

Nitrite as nitrogen

Nonvolatile beta

Oxamyl

PCB 1016

PCB 1221

PCB 1232

PCB 1242

PCB 1248

PCB 1254

PCB 1260

PCB 1262

Pentachlorophenol

Picloram ${ }^{\mathrm{a}}$

Selenium

Selenium, dissolved

Selenium, total recoverable

Simazine ${ }^{a}$

Strontium-89/90 ${ }^{c}$

Strontium-90

Styrene

2,3,7,8-TCDD

Tetrachloroethylene

Thallium

Thallium, dissolved

Thallium, total recoverable

Toluene

Toxaphene

2,4,5-TP (Silvex)

1,2,4-Trichlorobenzene

\begin{tabular}{|c|c|c|}
\hline Unit & Level & Status \\
\hline$\mu g / L$ & 5 & Final \\
\hline$\mu g / L$ & 400 & Final \\
\hline$\mu g / L$ & 20 & Final \\
\hline$\mu g / L$ & 100 & Final \\
\hline$\mu g / L$ & 2 & Final \\
\hline$\mu \mathrm{g} / \mathrm{L}$ & 700 & Final \\
\hline$\mu g / L$ & 4,000 & Final \\
\hline$\mu g / L$ & 700 & Final \\
\hline $\mathrm{pCi} / \mathrm{L}$ & $1.5 E+01$ & Final \\
\hline$\mu g / L$ & 0.4 & Final \\
\hline$\mu g / L$ & 0.2 & Final \\
\hline$\mu g / L$ & 1 & Final \\
\hline$\mu g / L$ & 50 & Final \\
\hline$\mu \mathrm{g} / \mathrm{L}$ & 50 & Final \\
\hline$\mu g / L$ & 50 & Final \\
\hline$\mu \mathrm{g} / \mathrm{L}$ & 50 & Final \\
\hline$\mu g / L$ & 0.2 & Final \\
\hline$\mu g / L$ & 2 & Final \\
\hline$\mu g / L$ & 2 & Final \\
\hline$\mu g / L$ & 2 & Final \\
\hline$\mu g / L$ & 40 & Final \\
\hline$\mu g / L$ & 100 & Final \\
\hline$\mu g / L$ & 100 & Final \\
\hline$\mu g / L$ & 100 & Final \\
\hline$\mu \mathrm{g} / \mathrm{L}$ & 10,000 & Final \\
\hline$\mu g / L$ & 10,000 & Final \\
\hline$\mu g / L$ & 1,000 & Final \\
\hline $\mathrm{pCi} / \mathrm{L}$ & $5 E+01$ & Interim Final \\
\hline$\mu g / L$ & 200 & Final \\
\hline$\mu g / L$ & 0.5 & Final \\
\hline$\mu g / L$ & 0.5 & Final \\
\hline$\mu g / L$ & 0.5 & Final \\
\hline$\mu g / L$ & 0.5 & Final \\
\hline$\mu \mathrm{g} / \mathrm{L}$ & 0.5 & Final \\
\hline$\mu \mathrm{g} / \mathrm{L}$ & 0.5 & Final \\
\hline$\mu g / L$ & 0.5 & Final \\
\hline$\mu g / L$ & 0.5 & Final \\
\hline$\mu g / L$ & 1 & Final \\
\hline$\mu g / L$ & 500 & Final \\
\hline$\mu g / L$ & 50 & Final \\
\hline$\mu g / L$ & 50 & Final \\
\hline$\mu g / L$ & 50 & Final \\
\hline$\mu g / L$ & 4 & Final \\
\hline$p C i / L$ & $8 E+00$ & Final \\
\hline$p C i / L$ & $8 E+00$ & Final \\
\hline$\mu g / L$ & 100 & Final \\
\hline$\mu g / L$ & 0.00003 & Final \\
\hline$\mu g / L$ & 5 & Final \\
\hline$\mu g / L$ & 2 & Final \\
\hline$\mu \mathrm{g} / \mathrm{L}$ & 2 & Final \\
\hline$\mu \mathrm{g} / \mathrm{L}$ & 2 & Final \\
\hline$\mu \mathrm{g} / \mathrm{L}$ & 1,000 & Final \\
\hline$\mu \mathrm{g} / \mathrm{L}$ & 3 & Final \\
\hline$\mu g / L$ & 50 & Final \\
\hline$g / L$ & 70 & Final \\
\hline
\end{tabular}

Source

EPA, 1993

EPA, 1993

EPA, 1993

EPA, 1993

EPA, 1993

EPA, 1993

EPA, 1993

EPA, 1993

EPA, 1993

EPA, 1993

EPA, 1993

EPA, 1993

EPA, 1993

SCDHEC, 1981

SCDHEC, 1981

SCDHEC, 1981

EPA, 1993

EPA, 1993

EPA, 1993

EPA, 1993

EPA, 1993

EPA, 1993

EPA, 1993

EPA, 1993

EPA, 1993

EPA, 1993

EPA, 1993

EPA, 1977

EPA, 1993

EPA, 1993

EPA, 1993

EPA, 1993

EPA, 1993

EPA, 1993

EPA, 1993

EPA, 1993

EPA, 1993

EPA, 1993

EPA, 1993

EPA, 1993

EPA, 1993

EPA, 1993

EPA, 1993

EPA, 1993

EPA, 1993

EPA, 1993

EPA, 1993

EPA, 1993

EPA, 1993

EPA, 1993

EPA, 1993

EPA, 1993

EPA, 1993

EPA, 1993

EPA, 1993 
Analyte

1,1,1-Trichloroethane

1,1,2-Trichloroethane

Trichloroethylene

Tritium

Xylenes

$\begin{array}{lll}\text { Unit } & & \text { Level } \\ \mu \mathrm{g} / \mathrm{L} & 200 \\ \mu \mathrm{g} / \mathrm{L} & 5 \\ \mu \mathrm{g} / \mathrm{L} & 5 \\ \mathrm{pCi} / \mathrm{mL} & 2 \mathrm{E}+01 \\ \mu \mathrm{g} / \mathrm{L} & 10,000\end{array}$

Status

Final

Final

Final

Final

Final
Source

EPA, 1993

EPA, 1993

EPA, 1993

EPA, 1993

EPA, 1993

a At present, EMS does not perform this analysis because the constituent is not in the current contract.

b The standard given is for gross alpha including radium-226 but excluding radon and uranium.

c For double radionuclide analyses where each separate radionuclide has its own standard, the more stringent standard is used.

\section{References}

EPA (U.S. Environmental Protection Agency), 1977. National Interim Primary Drinking Water Regulations, EPA-570/9-76-003. Washington, DC.

EPA (U.S. Environmental Protection Agency), 1993. National Primary Drinking Water Regulations. Code of Federal Regulations, Section 40, Part 141, pp. 592-732. Washington, DC.

SCDHEC (South Carolina Department of Health and Environmental Control), 1981. State Primary Drinking Water Regulations, R.61-58.5. Columbia, SC. 
THIS PAGE LEFT BLANK INTENTIONALLY. 
WSRC-TR-94-0240

Unclassified

\section{Appendix B}

\section{Flagging Criteria}


WSRC-TR-94-0240

Unclassified

THIS PAGE LEFT BLANK INTENTIONALLY. 


\section{Flagging Criteria}

The Savannah River Site Environmental Protection Department/Environmental Monitoring Section (EPD/EMS) flagging criteria are as follows:

- Flag 2 criteria for constituents equal the Safe Drinking Water Act (SDWA) final Primary Drinking Water Standard (PDWS), the SDWA proposed PDWS, or the SDWA Secondary Drinking Water Standard (SDWS). If a constituent does not have a drinking water standard, the Flag 2 criterion equals 10 times the method detection limit (MDL) calculated as the 90th percentile detection limit obtained recently by one of the primary analytical laboratories.

- Flag 1 criteria for constituents equal one-half of the final PDWS, one-half the proposed PDWS, or one-half the SDWS. If a constituent does not have a drinking water standard, the Flag 1 criterion equals 5 times the MDL calculated as the 90th percentile detection limit obtained recently by one of the primary analytical laboratories.

- Flag 0 criteria are assigned to constituent levels below Flag 1 criteria, constituent levels below the sample detection limits, or constituents having no flagging criteria.

The following parameters are exceptions to the flagging rules:

- EPD/EMS sets flagging criteria for specific conductance and $\mathrm{pH}$. No flags are set for alkalinity, calcium, carbonate, magnesium, potassium, silica, sodium, total dissr/ved solids, total phosphates (as P), and total phosphorus. Analyses for these parameters are conducted as part of the biennial comprehensive analyses or by special request.

- Aesthetic parameters such as color, corrosivity, Eh, odor, surfactants, and turbidity are not assigned flagging criteria but are analyzed by special request.

- Common laboratory contaminants and cleaners such as dichloromethane (methylene chloride), ketones, phthalates, and toluene are not assigned flagging criteria unless they have primary drinking water standards. These constituents are analyzed by special request.

Analyte

Acenaphthene

Acenaphthylene

Acetone

Acetonitrile (Methyl cyanide)

Acetophenone

2-Acetylaminofluorene

Acrolein

Acrylonitrile

Actinium-228

Alachlor

Aldicarb ${ }^{b}$

Aldicarb sulfone $e^{b}$

Aldicarb sulfoxide

Aldrin

Alkalinity (as $\mathrm{CaCO}_{3}$ )

Allyl chloride

\begin{tabular}{llll} 
Unit & Flag 1 & Flag 2 \\
\cline { 3 - 3 }$\mu \mathrm{g} / \mathrm{L}$ & 50 & 100 \\
$\mu \mathrm{g} / \mathrm{L}$ & 50 & 100 \\
$\mu \mathrm{g} / \mathrm{L}$ & 500 & 1,000 \\
$\mu \mathrm{g} / \mathrm{L}$ & 500 & 1,000 \\
$\mu \mathrm{g} / \mathrm{L}$ & 50 & 100 \\
$\mu \mathrm{g} / \mathrm{L}$ & 50 & 100 \\
$\mu \mathrm{g} / \mathrm{L}$ & 100 & 200 \\
$\mu \mathrm{g} / \mathrm{L}$ & 100 & 200 \\
$\mathrm{pCi} / \mathrm{L}$ & $1.64 \mathrm{E}+03$ & $3.27 \mathrm{E}+03$ \\
$\mu \mathrm{g} / \mathrm{L}$ & 1 & 2 \\
$\mu \mathrm{g} / \mathrm{L}$ & 1.5 & 3 \\
$\mu \mathrm{g} / \mathrm{L}$ & 1 & 2 \\
$\mu \mathrm{g} / \mathrm{L}$ & 2 & 4 \\
$\mu \mathrm{g} / \mathrm{L}$ & 0.25 & 0.5 \\
& No flag & No flag \\
$\mu \mathrm{g} / \mathrm{L}$ & 250 & 500 \\
& &
\end{tabular}

Source $^{\mathrm{a}}$

EPA Method 8270

EPA Method 8270

EPA Method 8240

EPA Method 8240

EPA Method 8270

EPA Method 8270

EPA Method 8240

EPA Method 8240

Proposed PDWS (EPA, 1991)

Final PDWS (EPA, 1993a)

Final PDWS (EPA, 1993a)

Final PDWS (EPA, 1993a)

Final PDWS (EPA, 1993a)

EPA Method 8080

Set by EPD/EMS

EPA Method 8240 
Analyte

Aluminum

Aluminum, dissolved

Aluminum, total recoverable

Americium-241

Americium-243

4-Aminobiphenyl

Ammonia

Ammonia nitrogen

Aniline

Anthracene

Antimony

Antimony, dissolved

Antimony, total recoverable

Antimony-125

Aramite

Arsenic

Arsenic, dissolved

Arsenic, total recoverable

Asbestos

Atrazine

Azobenzene

Barium

Barium, dissolved

Barium, total recoverable

Barium-140

Benzene

alpha-Benzene hexachloride

beta-Benzene hexachloride

delta-Benzene hexachloride

Benzidine

Benzolalanthracene

Benzol $b$ lfluoranthene

Benzolk]tiuoranthene

Benzoic acid

Benzo[g,h,i]perylene

Benzolalpyrene

1,4-Benzoquinone

Benzyl alcohol

Beryllium

Beryllium, dissolved

Beryllium, total recoverable

Beryllium-7

Bis(2-chloroethoxy) methane

Bis (2-chloroethyl) ether

Bis (2-chloroisopropyl) ether

Bis(chloromethyl) ether

Bis(2-ethylhexyl) phthalate

Bismuth-214

Boron

Boron, dissolved

Boron, total recoverable

Bromide

Bromodichloromethane

Bromoform

Bromomethane (Methyl bromide)

\begin{tabular}{llll} 
Unit & Flag 1 & Flag 2 \\
\cline { 1 - 2 } & & \\
$\mu \mathrm{g} / \mathrm{L}$ & 25 & 50 \\
$\mu \mathrm{g} / \mathrm{L}$ & 25 & 50 \\
$\mu \mathrm{g} / \mathrm{L}$ & 25 & 50 \\
$\mathrm{pCi} / \mathrm{L}$ & $3.17 \mathrm{E}+00$ & $6.34 \mathrm{E}+00$ \\
$\mathrm{pCi} / \mathrm{L}$ & $3.19 \mathrm{E}+00$ & $6.37 \mathrm{E}+00$ \\
$\mu \mathrm{g} / \mathrm{L}$ & 50 & 100 \\
$\mu \mathrm{g} / \mathrm{L}$ & 500 & 1,000 \\
$\mu \mathrm{g} / \mathrm{L}$ & 500 & 1,000 \\
$\mu \mathrm{g} / \mathrm{L}$ & 50 & 100 \\
$\mu \mathrm{g} / \mathrm{L}$ & 50 & 100 \\
$\mu \mathrm{g} / \mathrm{L}$ & 3 & 6 \\
$\mu \mathrm{g} / \mathrm{L}$ & 3 & 6 \\
$\mu \mathrm{g} / \mathrm{L}$ & 3 & 6 \\
$\mathrm{pCi} / \mathrm{L}$ & $1.5 \mathrm{E}+02$ & $3 \mathrm{E}+02$ \\
$\mu \mathrm{g} / \mathrm{L}$ & 50 & 100 \\
$\mu \mathrm{g} / \mathrm{L}$ & 25 & 50 \\
$\mu \mathrm{g} / \mathrm{L}$ & 25 & 50 \\
$\mu \mathrm{g} / \mathrm{L}$ & 25 & 50
\end{tabular}

Fibers/L 3,500,000 7,000,000

$\mu \mathrm{g} / \mathrm{L} \quad 1.5 \quad 3$

$\mu \mathrm{g} / \mathrm{L} \quad 50 \quad 100$

$\mu \mathrm{g} / \mathrm{L} \quad 1,000 \quad 2,000$

$\mu g / L \quad 1,000 \quad 2,000$

$\mu \mathrm{g} / \mathrm{L} \quad 1,000 \quad 2,000$

$\mathrm{pCi} / \mathrm{L} \quad 4.5 \mathrm{E}+01 \quad 9 \mathrm{E}+01$

$\mu \mathrm{g} / \mathrm{L} \quad 2.5 \quad 5$

$\mu \mathrm{g} / \mathrm{L} \quad 0.25 \quad 0.5$

$\mu \mathrm{g} / \mathrm{L} \quad 0.25 \quad 0.5$

$\mu \mathrm{g} / \mathrm{L} \quad 0.25 \quad 0.5$

$\mu g / L \quad 250 \quad 500$

$\mu \mathrm{g} / \mathrm{L} \quad 0.05 \quad 0.1$

$\mu \mathrm{g} / \mathrm{L} \quad 0.1 \quad 0.2$

$\mu \mathrm{g} / \mathrm{L} \quad 0.1 \quad 0.2$

$\mu \mathrm{g} / \mathrm{L} \quad 250 \quad 500$

$\mu \mathrm{g} / \mathrm{L} \quad 50 \quad 100$

$\mu g / L \quad 0.1 \quad 0.2$

$\mu \mathrm{g} / \mathrm{L} \quad 50 \quad 100$

$\mu g / L \quad 50 \quad 100$

$\mu \mathrm{g} / \mathrm{L} \quad 2 \quad 4$

$\mu \mathrm{g} / \mathrm{L} \quad 2 \quad 4$

$\mu \mathrm{g} / \mathrm{L} \quad 2 \quad 4$

$\mathrm{pCi} / \mathrm{L} \quad 3 \mathrm{E}+03 \quad 6 \mathrm{E}+03$

$\mu \mathrm{g} / \mathrm{L} \quad 50 \quad 100$

$\mu g / L \quad 50 \quad 100$

$\mu \mathrm{g} / \mathrm{L} \quad 50 \quad 100$

$\mu \mathrm{g} / \mathrm{L} \quad 50 \quad 100$

$\mu \mathrm{g} / \mathrm{L} \quad 3 \quad 6$

$\mathrm{pCi} / \mathrm{L} \quad 9.4 \mathrm{E}+03 \quad 1.89 \mathrm{E}+04$

$\mu \mathrm{g} / \mathrm{L} \quad 150 \quad 300$

$\mu \mathrm{g} / \mathrm{L} \quad 150 \quad 300$

$\mu \mathrm{g} / \mathrm{L} \quad 150 \quad 300$

$\mu \mathrm{g} / \mathrm{L} \quad 5,000 \quad 10,000$

$\mu \mathrm{g} / \mathrm{L} \quad 50 \quad 100$

$\mu \mathrm{g} / \mathrm{L} \quad 50 \quad 100$

$\mu \mathrm{g} / \mathrm{L} \quad 5 \quad 10$
Source $^{a}$

SDWS (EPA, 1993b)

SDWS (EPA, 1993b)

SDWS (EPA, 1993b)

Proposed PDWS (EPA, 1991)

Proposed PDWS (EPA, 1991)

EPA Method 8270

APHA Method 417B

EPA Method 350.1

EPA Method 8270

EPA Method 8270

Final PDWS (EPA, 1993a)

Final PDWS (EPA, 1993a)

Final PDWS (EPA, 1993a)

Interim Final PDWS (EPA, 1977)

EPA Method 8270

Final PDWS (EPA, 1993a)

Final PDWS (EPA, 1993a)

Final PDWS (EPA, 1993a)

Final PDWS (EPA, 1993a)

Final PDWS (EPA, 1993a)

EPA Method 625

Final PDWS (EPA, 1993a)

Final PDWS (EPA, 1993a)

Final PDWS (EPA, 1993a)

Interin Final PDWS (EPA, 1977)

Final PDWS (EPA, 1993a)

EPA Method 8080

EPA Method 8080

EPA Method 8080

EPA Method 8270

Proposed PDWS (EPA, 1990)

Proposed PDWS (EPA, 1990)

Proposed PDWS (EPA, 1990)

EPA Method 8270

EPA Method 8270

Final PDWS (EPA, 1993a)

EPA Method 8270

EPA Method 8270

Final PDWS (EPA, 1993a)

Final PDWS (EPA, 1993a)

Final PDWS (EPA, 1993a)

Interim Final PDWS (EPA, 1977)

EPA Method 8270

EPA Method 8270

EPA Method 8270

EPA Method 8270

Final PDWS (EPA, 1993a)

Proposed PDWS (EPA, 1991)

EPA Method 6010

EPA Method 6010

EPA Method 6010

EPA Method 300.0

Final PDWS (EPA, 1993a)

Final PDWS (EPA, 1993a)

EPA Method 8240 
Analyte

4-Bromophenyl phenyl ether 2-sec-Butyl-4,6-dinitrophenol Butylbenzyl phthalate Cadmium

Cadmium, dissolved

Cadmium, total recoverable

Calcium

Calcium, dissolved

Calcium, total recoverable

Carbon disulfide

Carbofuran

Carbon tetrachloride

Carbon-14

Carbonate

Cerium-141 $\mathrm{C}$

Cerium-144

Cesium-134

Cesium-137

Chlordane

Chloride

4-Chloroaniline

Chlorobenzene

Chlorobenzilate

Chloroethane

Chloroethene (Vinyl chloride)

Chloroethyl vinyl ether

2-Chloroethyl vinyl ether

Chloroform

4-Chloro-m-cresol

Chloromethane (Methyl chloride)

2-Chloronaphthalene

2-Chlorophenol

4-Chlorophenyl phenyl ether

Chloroprene

Chromium

Chromium, dissolved

Chromium, total recoverable

Chromium $-51^{\mathrm{C}}$

Chrysene

Cobalt

Cobalt, dissolved

Cobalt, total recoverable

Cobalt -57

Cobalt-58

Cobalt -60

Color

Copper

Copper, dissolved

Copper, total recoverable

Corrosivity

m-Cresol (3-Methylphenol)

o-Cresol (2-Methylphenol)

p-Cresol (4-Methyiphenol)

Curium-242

Curium-243

\begin{tabular}{|c|c|c|c|}
\hline Unit & Flag 1 & Flag 2 & Source $^{a}$ \\
\hline$\mu \mathrm{g} / \mathrm{L}$ & 50 & 100 & EPA Method 8270 \\
\hline$\mu \mathrm{g} / \mathrm{L}$ & 3.5 & & Final PDWS (EPA, 1993a) \\
\hline & No flag & No flag & Set by EPD/EMS \\
\hline$\mu g / L$ & 2.5 & 5 & Final PDWS (EPA, 1993a) \\
\hline$\mu g / L$ & 2.5 & 5 & Final PDWS (EPA, 1993a) \\
\hline$\mu \mathrm{g} / \mathrm{L}$ & 2.5 & 5 & Final PDWS (EPA, 1993a) \\
\hline & No flag & No flag & Set by EPD/EMS \\
\hline & No flag & No flag & Set by EPD/EMS \\
\hline & No flag & No flag & Set by EPD/EMS \\
\hline$\mu g / L$ & 5 & 10 & EPA Method 8240 \\
\hline$\mu \mathrm{g} / \mathrm{L}$ & 20 & 40 & Final PDWS (EPA, 1993a) \\
\hline$\mu g / L$ & 2.5 & 5 & Final PDWS (EPA, 1993a) \\
\hline $\mathrm{pCi} / \mathrm{L}$ & $\begin{array}{l}1 E+03 \\
\text { No flag }\end{array}$ & $\begin{array}{l}2 E+03 \\
\text { No flag }\end{array}$ & $\begin{array}{l}\text { Interim Final PDWS (EPA, 1977) } \\
\text { Set by EPD/EMS }\end{array}$ \\
\hline $\mathrm{pCi} / \mathrm{L}$ & $1.5 E+02$ & $3 E+02$ & Interim Final PDWS (EPA, 1977) \\
\hline $\mathrm{pCi} / \mathrm{L}$ & $1.31 E+02$ & $2.61 E+02$ & Proposed PDWS (EPA, 1991) \\
\hline $\mathrm{pCi} / \mathrm{L}$ & $4.07 E+01$ & $8.13 E+01$ & Proposed PDWS (EPA, 1991) \\
\hline $\mathrm{pCi} / \mathrm{L}$ & $1 E+02$ & $2 E+02$ & Interim Final PDWS (EPA, 1977) \\
\hline$\mu g / L$ & 1 & 2 & Final PDWS (EPA, 1993a) \\
\hline$\mu \mathrm{g} / \mathrm{L}$ & 125,000 & 250,000 & SDWS (EPA, 1993b) \\
\hline$\mu \mathrm{g} / \mathrm{L}$ & 50 & 100 & EPA Method 8270 \\
\hline$\mu g / L$ & 50 & 100 & Final PDWS (EPA, 1993a) \\
\hline$\mu \mathrm{g} / \mathrm{L}$ & 50 & 100 & EPA Method 8270 \\
\hline$\mu g / L$ & 5 & 10 & EPA Methiod 8240 \\
\hline$\mu \mathrm{g} / \mathrm{L}$ & 1 & 2 & Final PDWS (EPA, 1993a) \\
\hline$\mu \mathrm{g} / \mathrm{L}$ & 5 & 10 & EPA Method 8240 \\
\hline$\mu \mathrm{g} / \mathrm{L}$ & 5 & 10 & EPA Method 8240 \\
\hline$\mu \mathrm{g} / \mathrm{L}$ & 50 & 100 & Final PDWS (EPA, 1993a) \\
\hline$\mu \mathrm{g} / \mathrm{L}$ & 50 & 100 & EPA Method 8270 \\
\hline$\mu g / L$ & 5 & 10 & EPA Method 8240 \\
\hline$\mu g / L$ & 50 & 100 & EPA Method 8240 \\
\hline$\mu \mathrm{g} / \mathrm{L}$ & 50 & 100 & EPA Method 8270 \\
\hline$\mu \mathrm{g} / \mathrm{L}$ & 50 & 100 & EPA Method 8270 \\
\hline$\mu \mathrm{g} / \mathrm{L}$ & 1,000 & 2,000 & EPA Method 8240 \\
\hline$\mu \mathrm{g} / \mathrm{L}$ & 50 & 100 & Final PDWS (EPA, 1993a) \\
\hline$\mu \mathrm{g} / \mathrm{L}$ & 50 & 100 & Final PDWS (EPA, 1993a) \\
\hline$\mu \mathrm{g} / \mathrm{L}$ & 50 & 100 & Final PDWS (EPA, 1993a) \\
\hline $\mathrm{pCi} / \mathrm{L}$ & $3 E+03$ & $6 E+03$ & Interim Final PDWS (EPA, 1977) \\
\hline$\mu \mathrm{g} / \mathrm{L}$ & 0.1 & 0.2 & Proposed PDWS (EPA, 1990) \\
\hline$\mu \mathrm{g} / \mathrm{L}$ & 20 & 40 & EPA Method 6010 \\
\hline$\mu \mathrm{g} / \mathrm{L}$ & 20 & 40 & EPA Method 6010 \\
\hline$\mu g / L$ & 20 & 40 & EPA Method 6010 \\
\hline $\mathrm{pCi} / \mathrm{L}$ & $5 E+02$ & $1 E+03$ & Interim Final PDWS (EPA, 1977) \\
\hline $\mathrm{pCi} / \mathrm{L}$ & $4.5 E+03$ & $9 E+03$ & Interim Final PDWS (EPA, 1977) \\
\hline $\mathrm{pCi} / \mathrm{L}$ & $5 E+01$ & $1 E+02$ & Interim Final PDWS (EPA, 1977 ) \\
\hline & No flag & No flag & Set by EPD/EMS \\
\hline$\mu \mathrm{g} / \mathrm{L}$ & 500 & 1,000 & Final PDWS (SCDHEC, 1981) \\
\hline$\mu \mathrm{g} / \mathrm{L}$ & 500 & 1.000 & Final PDWS (SCDHEC, 1981) \\
\hline$\mu \mathrm{g} / \mathrm{L}$ & 500 & 1,000 & Final PDWS (SCDHEC, 1981 ) \\
\hline & No flag & No flag & Set by EPD/EMS \\
\hline$\mu \mathrm{g} / \mathrm{L}$ & 50 & 100 & EPA Method 8270 \\
\hline$\mu \mathrm{g} / \mathrm{L}$ & 50 & 100 & EPA Method 8270 \\
\hline$\mu \mathrm{g} / \mathrm{L}$ & 50 & 100 & EPA Method 8270 \\
\hline $\mathrm{pCi} / \mathrm{L}$ & $6.65 E+01$ & $1.33 E+02$ & Proposed PDWS (EPA, 1991 ) \\
\hline $\mathrm{pCi} / \mathrm{L}$ & $4.15 E+00$ & $8.3 E+00$ & Proposed PDWS (EPA, 1991) \\
\hline
\end{tabular}




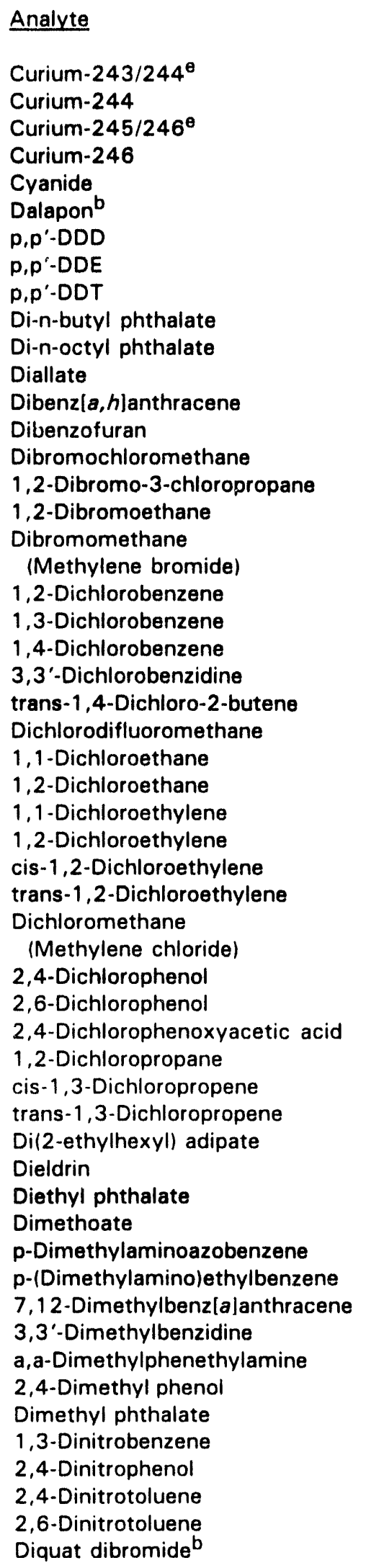

\begin{tabular}{|c|c|c|c|}
\hline$\underline{\text { Unit }}$ & Flag 1 & Flag 2 & Source $^{a}$ \\
\hline $\mathrm{pCi} / \mathrm{L}$ & $4.15 E+00$ & $8.3 E+00$ & Proposed PDWS (EPA, 1991) \\
\hline $\mathrm{pCi} / \mathrm{L}$ & $4.92 E+00$ & $9.84 E+00$ & Proposed PDWS (EPA, 1991) \\
\hline $\mathrm{pCi} / \mathrm{L}$ & $3.12 E+00$ & $6.23 E+00$ & Proposed PDWS (EPA, 1991) \\
\hline $\mathrm{pCi} / \mathrm{L}$ & $3.14 E+00$ & $6.27 E+00$ & Proposed PDWS (EPA, 1991) \\
\hline$\mu g / L$ & 100 & 200 & Final PDWS (EPA, 1993a) \\
\hline$\mu \mathrm{g} / \mathrm{L}$ & 100 & 200 & Final PDWS (EPA, 1993a) \\
\hline$\mu \mathrm{g} / \mathrm{L}$ & 0.5 & 1 & EPA Method 8080 \\
\hline$\mu \mathrm{g} / \mathrm{L}$ & 0.5 & 1 & EPA Method 8080 \\
\hline$\mu \mathrm{g} / \mathrm{L}$ & 0.5 & 1 & EPA Method 8080 \\
\hline & No flag & No flag & Set by EPD/EMS \\
\hline & No flag & No flag & Set by EPD/EMS \\
\hline$\mu g / L$ & 50 & 100 & EPA Method 8270 \\
\hline$\mu \mathrm{g} / \mathrm{L}$ & 0.15 & 0.3 & Proposed PDWS (EPA, 1990 \\
\hline$\mu \mathrm{g} / \mathrm{L}$ & 50 & 100 & EPA Method 8270 \\
\hline$\mu g / L$ & 50 & 100 & Final PDWS (EPA, 1993a) \\
\hline$\mu g / L$ & 0.1 & 0.2 & Final PDWS (EPA, 1993a) \\
\hline$\mu g / L$ & 0.025 & 0.05 & Final PDWS (EPA, 1993a) \\
\hline$\mu \mathrm{g} / \mathrm{L}$ & 5 & 10 & EPA Method 8240 \\
\hline$\mu \mathrm{g} / \mathrm{L}$ & 300 & 600 & Final PDWS (EPA, 1993a) \\
\hline$\mu \mathrm{g} / \mathrm{L}$ & 50 & 100 & EPA Method 8270 \\
\hline$\mu g / L$ & 37.5 & 75 & Final PDWS (EPA, 1993a) \\
\hline$\mu g / L$ & 50 & 100 & EPA Method 8270 \\
\hline$\mu g / L$ & 150 & 300 & EPA Method 8240 \\
\hline$\mu \mathrm{g} / \mathrm{L}$ & 5 & 10 & EPA Method 8240 \\
\hline$\mu \mathrm{g} / \mathrm{L}$ & 5 & 10 & EPA Method 8240 \\
\hline$\mu \mathrm{g} / \mathrm{L}$ & 2.5 & 5 & Final PDWS (EPA, 1993a) \\
\hline$\mu \mathrm{g} / \mathrm{L}$ & 3.5 & 7 & Final PDWS (EPA, 1993a) \\
\hline$\mu \mathrm{g} / \mathrm{L}$ & 25 & 50 & Final PDWS (EPA, 1993a) \\
\hline$\mu \mathrm{g} / \mathrm{L}$ & 35 & 70 & Final PDWS (EPA, 1993a) \\
\hline$\mu \mathrm{g} / \mathrm{L}$ & 50 & 100 & Final PDWS (EPA, 1993a) \\
\hline$\mu \mathrm{g} / \mathrm{L}$ & 2.5 & 5 & Final PDWS (EPA, 1993a) \\
\hline$\mu \mathrm{g} / \mathrm{L}$ & 50 & 100 & EPA Method 8270 \\
\hline$\mu \mathrm{g} / \mathrm{L}$ & 50 & 100 & EPA Method 8270 \\
\hline$\mu \mathrm{g} / \mathrm{L}$ & 35 & 70 & Final PDWS (EPA, 1993a) \\
\hline$\mu \mathrm{g} / \mathrm{L}$ & 2.5 & 5 & Final PDWS (EPA, 1993a) \\
\hline$\mu \mathrm{g} / \mathrm{L}$ & 5 & 10 & EPA Method 8240 \\
\hline$\mu \mathrm{g} / \mathrm{L}$ & 5 & 10 & EPA Method 8240 \\
\hline$\mu \mathrm{g} / \mathrm{L}$ & 200 & 400 & Final PDWS (EPA, 1993a) \\
\hline$\mu \mathrm{g} / \mathrm{L}$ & 2.5 & 5 & EPA Method 8080 \\
\hline & No flag & No flag & Set by EPD/EMS \\
\hline$\mu g / L$ & 50 & 100 & EPA Method 8270 \\
\hline$\mu g / L$ & 50 & 100 & EPA Method 8270 \\
\hline$\mu \mathrm{g} / \mathrm{L}$ & 50 & 100 & EPA Method 8270 \\
\hline$\mu \mathrm{g} / \mathrm{L}$ & 50 & 100 & EPA Method 8270 \\
\hline$\mu \mathrm{g} / \mathrm{L}$ & 50 & 100 & EPA Method 8270 \\
\hline$\mu g / L$ & 50 & 100 & EPA Method 8270 \\
\hline$\mu \mathrm{g} / \mathrm{L}$ & 50 & 100 & EPA Method 8270 \\
\hline & No flag & No flag & Set by EPD/EMS \\
\hline$\mu \mathrm{g} / \mathrm{L}$ & 50 & 100 & EPA Method 8270 \\
\hline$\mu \mathrm{g} / \mathrm{L}$ & 250 & 500 & EPA Method 8270 \\
\hline$\mu \mathrm{g} / \mathrm{L}$ & 50 & 100 & EPA Method 8270 \\
\hline$\mu \mathrm{g} / \mathrm{L}$ & 50 & 100 & EPA Method 8270 \\
\hline$\mu \mathrm{g} / \mathrm{L}$ & 10 & 20 & Final PDWS (EPA, 1993a) \\
\hline
\end{tabular}


Analyte

1,4-Dioxane

Diphenylamine

1,2-Diphenylhydrazine

Dissolved organic carbon

Disulfoton

Eh

Endosulfan 1

Endosulfan II

Endosulfan sulfate

Endothall $^{b}$

Endrin

Endrin aldehyde

Endrin ketone

Ethylbenzene

Ethyl methacrylate

Ethyl methanesulfonate

Europium-152

Europium-154

Europium-155

Famphur

Fluoranthene

Fluorene

Fluoride

Glyphosate $^{b}$

Gross alpha

Heptachlor

Heptachlor epoxide

Heptachlorodibenzo-p-dioxin isomers

$1,2,3,4,6,7,8$-HPCDD

Heptachlorodibenzo-p-furan isomers

$1,2,3,4,6,7,8 \cdot H P C D F$

Hexachlorobenzene

Hexachlorobutadiene

Hexachlorocyclopentadiene

Hexachlorodibenzo-p-dioxin isomers

$1,2,3,4,7,8-H \times C D D$

Hexachlorodibenzo-p-furan isomers

$1,2,3,4,7,8-H \times C D F$

Hexachloroethane

Hexachlorophene

Hexachloropropene

2-Hexanone

Indeno $[1,2,3-c, d]$ pyrene

lodine

lodine-129

lodine-131 $\mathrm{C}$

lodomethane (Methyl iodide)

Iron

Iron, dissolved

Iron, total recoverable

Iron-55

\begin{tabular}{|c|c|c|c|}
\hline Unit & Flag 1 & Flag 2 & $\underline{\text { Source }}^{a}$ \\
\hline$\mu \mathrm{g} / \mathrm{L}$ & 50 & 100 & EPA Method 8270 \\
\hline$\mu g / L$ & 50 & 100 & EPA Method 8270 \\
\hline$\mu g / L$ & 50 & 100 & EPA Method 8270 \\
\hline$\mu \mathrm{g} / \mathrm{L}$ & 5,000 & 10,000 & EPA Method 9060 \\
\hline$\mu g / L$ & 50 & 100 & EPA Method 8270 \\
\hline & No flag & No flag & Set by EPD/EMS \\
\hline$\mu g / L$ & 0.5 & 1 & EPA Method 8080 \\
\hline$\mu \mathrm{g} / \mathrm{L}$ & 0.5 & 1 & EPA Method 8080 \\
\hline$\mu \mathrm{g} / \mathrm{L}$ & 0.5 & 1 & EPA Method 8080 \\
\hline$\mu \mathrm{g} / \mathrm{L}$ & 50 & 100 & Final PDWS (EPA, 1993a) \\
\hline$\mu g / L$ & 1 & 2 & Final PDWS (EPA, 1993a) \\
\hline$\mu g / L$ & 0.5 & 1 & EPA Method 8080 \\
\hline & No flag & No flag & Set by EPD/EMS \\
\hline$\mu g / L$ & 350 & 700 & Final PDWS (EPA, 1993a) \\
\hline$\mu \mathrm{g} / \mathrm{L}$ & 50 & 100 & EPA Method 8270 \\
\hline$\mu \mathrm{g} / \mathrm{L}$ & 50 & 100 & EPA Method 8270 \\
\hline $\mathrm{pCi} / \mathrm{L}$ & $3 E+01$ & $6 E+01$ & Interim Final PDWS (EPA, 1977) \\
\hline $\mathrm{pCi} / \mathrm{L}$ & $1 E+02$ & $2 E+02$ & Interim Final PDWS (EPA, 1977 ) \\
\hline $\mathrm{pCi} / \mathrm{L}$ & $3 E+02$ & $6 \mathrm{E}+02$ & Interim Final PDWS (EPA, 1977) \\
\hline$\mu \mathrm{g} / \mathrm{L}$ & 50 & 100 & EPA Method 8270 \\
\hline$\mu \mathrm{g} / \mathrm{L}$ & 50 & 100 & EPA Method 8270 \\
\hline$\mu \mathrm{g} / \mathrm{L}$ & 50 & 100 & EPA Method 8270 \\
\hline$\mu g / L$ & 2,000 & 4,000 & Final PDWS (EPA, 1993a) \\
\hline$\mu \mathrm{g} / \mathrm{L}$ & 350 & 700 & Final PDWS (EPA, 1993a) \\
\hline $\mathrm{pCi} / \mathrm{L}$ & $7.5 E+00$ & $1.5 E+01$ & Final PDWS (EPA, 1993a) \\
\hline$\mu \mathrm{g} / \mathrm{L}$ & 0.2 & 0.4 & Final PDWS (EPA, 1993a) \\
\hline$\mu \mathrm{g} / \mathrm{L}$ & 0.1 & 0.2 & Final PDWS (EPA, 1993a) \\
\hline$\mu \mathrm{g} / \mathrm{L}$ & 0.00325 & 0.0065 & EPA Method 8280 \\
\hline$\mu g / L$ & 0.00325 & 0.0065 & EPA Method 8280 \\
\hline$\mu \mathrm{g} / \mathrm{L}$ & 0.00225 & 0.0045 & EPA Method 8280 \\
\hline$\mu \mathrm{g} / \mathrm{L}$ & 0.00225 & 0.0045 & EPA Method 8280 \\
\hline$\mu \mathrm{g} / \mathrm{L}$ & 0.5 & 1 & Final PDWS (EPA, 1993a) \\
\hline$\mu \mathrm{g} / \mathrm{L}$ & 50 & 100 & EPA Method 8270 \\
\hline$\mu \mathrm{g} / \mathrm{L}$ & 25 & 50 & Final PDWS (EPA, 1993a) \\
\hline$\mu \mathrm{g} / \mathrm{L}$ & 0.00225 & 0.0045 & EPA Method 8280 \\
\hline$\mu \mathrm{g} / \mathrm{L}$ & 0.00225 & 0.0045 & EPA Method 8280 \\
\hline$\mu \mathrm{g} / \mathrm{L}$ & 0.002 & 0.004 & EPA Method 8280 \\
\hline$\mu g / L$ & 0.002 & 0.004 & EPA Method 8280 \\
\hline$\mu \mathrm{g} / \mathrm{L}$ & 50 & 100 & EPA Method 8270 \\
\hline$\mu g / L$ & 250 & 500 & EPA Method 8270 \\
\hline$\mu \mathrm{g} / \mathrm{L}$ & 50 & 100 & EPA Method 8270 \\
\hline$\mu \mathrm{g} / \mathrm{L}$ & 50 & 100 & EPA Method 8240 \\
\hline$\mu \mathrm{g} / \mathrm{L}$ & 50 & 100 & EPA Method 8270 \\
\hline$\mu \mathrm{g} / \mathrm{L}$ & 250 & 500 & APHA Method $415 \mathrm{~A}$ \\
\hline $\mathrm{pCi} / \mathrm{L}$ & $5 E-01$ & $1 E+00$ & Interim Final PDWS (EPA, 1977) \\
\hline $\mathrm{pCi} / \mathrm{L}$ & $1.5 E+00$ & $3 E+00$ & Interim Final PDWS (EPA, 1977) \\
\hline$\mu \mathrm{g} / \mathrm{L}$ & 75 & 150 & EPA Method 8240 \\
\hline$\mu \mathrm{g} / \mathrm{L}$ & 150 & 300 & SDWS (EPA, 1993b) \\
\hline$\mu \mathrm{g} / \mathrm{L}$ & 150 & 300 & SDWS (EPA 1993b) \\
\hline$\mu \mathrm{g} / \mathrm{L}$ & 150 & 300 & SDWS (EPA, 1993b) \\
\hline $\mathrm{pCi} / \mathrm{L}$ & $1 E+03$ & $2 E+03$ & Interim Final PDWS (EPA, 1977) \\
\hline
\end{tabular}




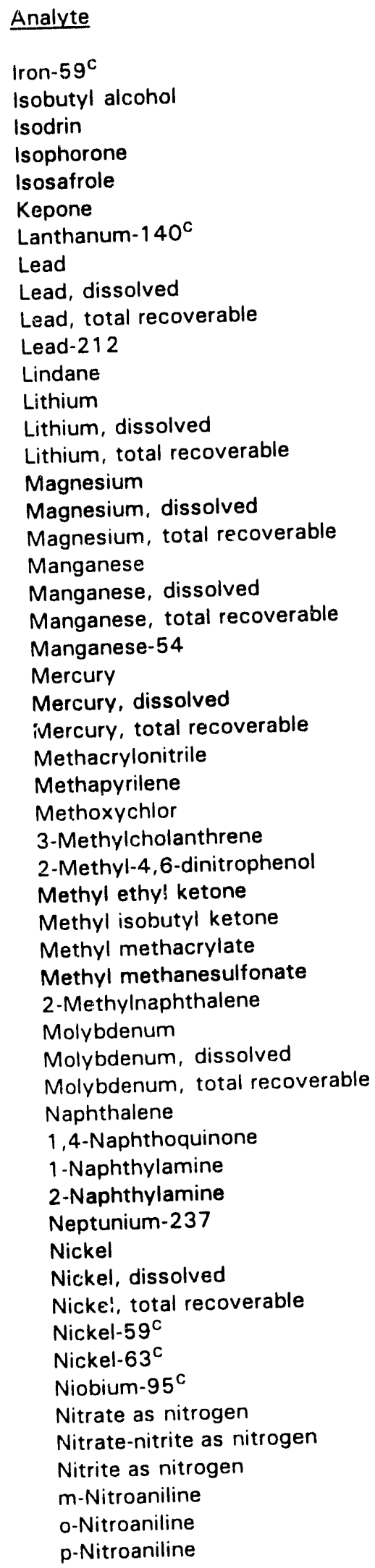

\begin{tabular}{|c|c|c|}
\hline Unit & Flag 1 & Flag 2 \\
\hline $\mathrm{pCi} / \mathrm{L}$ & $1 E+02$ & $2 E+02$ \\
\hline$\mu g / L$ & 500 & 1,000 \\
\hline$\mu \mathrm{g} / \mathrm{L}$ & 50 & 100 \\
\hline$\mu g / L$ & 50 & 100 \\
\hline$\mu g / L$ & 50 & 100 \\
\hline$\mu \mathrm{g} / \mathrm{L}$ & 50 & 100 \\
\hline $\mathrm{pCi} / \mathrm{L}$ & $3 E+01$ & $6 E+01$ \\
\hline$\mu g / L$ & 25 & 50 \\
\hline$\mu \mathrm{g} / \mathrm{L}$ & 25 & 50 \\
\hline$\mu \mathrm{g} / \mathrm{L}$ & 25 & 50 \\
\hline $\mathrm{pCi} / \mathrm{L}$ & $6.2 E+01$ & $1.23 E+02$ \\
\hline$\mu g / L$ & 0.1 & 0.2 \\
\hline$\mu \mathrm{g} / \mathrm{L}$ & 25 & 50 \\
\hline$\mu \mathrm{g} / \mathrm{L}$ & 25 & 50 \\
\hline$\mu \mathrm{g} / \mathrm{L}$ & 25 & 50 \\
\hline & No fiag & No flag \\
\hline & No flag & No flag \\
\hline & No flag & No flag \\
\hline$\mu \mathrm{g} / \mathrm{L}$ & 25 & 50 \\
\hline$\mu \mathrm{g} / \mathrm{L}$ & 25 & 50 \\
\hline$\mu g / L$ & 25 & 50 \\
\hline $\mathrm{pCi} / \mathrm{L}$ & $1.5 E+02$ & $3 E+02$ \\
\hline$\mu \mathrm{g} / \mathrm{L}$ & 1 & 2 \\
\hline$\mu g / L$ & 1 & 2 \\
\hline$\mu \mathbf{g} / L$ & 1 & 2 \\
\hline$\mu \mathrm{g} / \mathrm{L}$ & 250 & 500 \\
\hline$\mu \mathrm{g} / \mathrm{L}$ & 50 & 100 \\
\hline$\mu \mathrm{g} / \mathrm{L}$ & 20 & 40 \\
\hline$\mu \mathrm{g} / \mathrm{L}$ & 50 & 100 \\
\hline$\mu \mathrm{g} / \mathrm{L}$ & 250 & 500 \\
\hline & $\begin{array}{l}\text { No flag } \\
\text { No flag }\end{array}$ & $\begin{array}{l}\text { No flag } \\
\text { No flag }\end{array}$ \\
\hline$\mu \mathrm{g} / \mathrm{L}$ & 50 & 100 \\
\hline$\mu \mathrm{g} / \mathrm{L}$ & 50 & 100 \\
\hline$\mu \mathrm{g} / \mathrm{L}$ & 50 & 100 \\
\hline$\mu \mathrm{g} / \mathrm{L}$ & 250 & 500 \\
\hline$\mu \mathrm{g} / \mathrm{L}$ & 250 & 500 \\
\hline$\mu \mathrm{g} / \mathrm{L}$ & 250 & 500 \\
\hline$\mu \mathrm{g} / \mathrm{L}$ & 50 & 100 \\
\hline$\mu \mathrm{g} / \mathrm{L}$ & 50 & 100 \\
\hline$\mu \mathrm{g} / \mathrm{L}$ & 50 & 100 \\
\hline$\mu \mathrm{g} / \mathrm{L}$ & 50 & 100 \\
\hline $\mathrm{pCi} / \mathrm{L}$ & $3.53 E+00$ & $7.06 E+00$ \\
\hline$\mu \mathrm{g} / \mathrm{L}$ & 50 & 100 \\
\hline$\mu \mathrm{g} / \mathrm{L}$ & 50 & 100 \\
\hline$\mu \mathrm{g} / \mathrm{L}$ & 50 & 100 \\
\hline $\mathrm{pCi} / \mathrm{L}$ & $1.5 E+02$ & $3 E+02$ \\
\hline $\mathrm{pCi} / \mathrm{L}$ & $2.5 E+01$ & $5 E+01$ \\
\hline $\mathrm{pCi} / \mathrm{L}$ & $1.5 E+02$ & 3.E +02 \\
\hline$\mu \mathrm{g} / \mathrm{L}$ & 5,000 & 10,000 \\
\hline$\mu \mathrm{g} / \mathrm{L}$ & 5,000 & 10,000 \\
\hline$\mu \mathrm{g} / \mathrm{L}$ & 500 & 1,000 \\
\hline$\mu \mathrm{g} / \mathrm{L}$ & 50 & 100 \\
\hline$\mu \mathrm{g} / \mathrm{L}$ & 50 & 100 \\
\hline$\mu \mathrm{g} / \mathrm{L}$ & 50 & 100 \\
\hline
\end{tabular}

\section{Source $^{a}$}

Interim Final PDWS (EPA, 1977)

EPA Method 8240

EPA Method 8270

EPA Method 8270

EPA Method 8270

EPA Method 8270

Interim Final PDWS (EPA, 1977)

Final PDWS (SCDHEC, 1981)

Final PDWS (SCDHEC, 1981)

Final PDWS (SCDHEC, 1981)

Proposed PDWS (EPA, 1991)

Final PDWS (EPA, 1993a)

EPA Method 6010

EPA Method 6010

EPA Method 6010

Set by EPD/EMS

Set by EPD/EMS

Set by EPD/EMS

SDWS (EPA, 1993b)

SDWS (EPA, 1993b)

SDWS (EPA, 1993b)

Interim Final PDWS (EPA, 1977)

Final PDWS (EPA, 1993a)

Final PDWS (EPA, 1993a)

Final PDWS (EPA, 1993a)

EPA Method 8240

EPA Method 8270

Final PDWS (EPA, 1993a)

EPA Method 8270

EPA Method 8270

Set by EPD/EMS

Set by EPD/EMS

EPA Method 8270

EPA Method 8270

EPA Method 8270

EPA Method 6010

EPA Method 6010

EPA Method 6010

EPA Method 8270

EPA Method 8270

EPA Method 8270

EPA Method 8270

Proposed PDWS (EPA, 1991)

Final PDWS (EPA, 1993a)

Final PDWS (EPA, 1993a)

Final PDWS (EPA, 1993a)

Interim Final PDWS (EPA, 1977)

Interim Final PDWS (EPA, 1977)

Interim Final PDWS (EPA, 1977)

Final PDWS (EPA, 1993a)

Final PDWS (EPA, 1993a)

Final PDWS (EPA, 1993a)

EPA Method 8270

EPA Method 8270

EPA Method 8270 


Analyte
Nitrobenzene
Nitrogen by Kjeldahl method
2-Nitrophenol
4-Nitrophenol
4-Nitroquinoline-1-oxide
N-Nitrosodi-n-butylamine
N-Nitrosodiethylamine
N-Nitrosodimethylamine
N-Nitrosodiphenylamine
N-Nitrosodipropylamine
N-Nitrosomethylethylamine
N-Nitrosomorpholine
N-Nitrosopiperidine
N-Nitrosopyrrolidine
5-Nitro-0-toluidine
Nonvolatile beta
Octachlorodibenzo-p-dioxin
isomers
Octachlorodibenzo-p-furan
isomers
Odor
Oil \& Grease
Oxamyl
Parathion
Parathion methyl
PCB 1016
PCB 1221
PCB 1232
PCB 1242
PCB 1248
PCB 1254
PCB 1260
PCB 1262
Pentachlorobenzene
Pentachlorodibenzo-p-dioxin
isomers
1,2,3,7,8-PCDD
Pentachlorodibenzo-p-furan
isomers
1,2,3,7,8-PCDF
Pentachloroethane
Pentachloronitrobenzene
Pentachlorophenol
pH
pH
Phenacetin
Phenanthrenylenediamine
Phenol
Plutonium-239

\begin{tabular}{|c|c|c|c|}
\hline$\underline{\text { Unit }}$ & Flag 1 & Flag 2 & Source $^{a}$ \\
\hline$\mu \mathrm{g} / \mathrm{L}$ & 50 & 100 & EPA Method 8270 \\
\hline$\mu \mathrm{g} / \mathrm{L}$ & 500 & 1,000 & EPA Method 351.2 \\
\hline$\mu \mathrm{g} / \mathrm{L}$ & 50 & 100 & EPA Method 8270 \\
\hline$\mu \mathrm{g} / \mathrm{L}$ & 50 & 100 & EPA Method 8270 \\
\hline$\mu \mathrm{g} / \mathrm{L}$ & 50 & 100 & EPA Method 8270 \\
\hline$\mu \mathrm{g} / \mathrm{L}$ & 50 & 100 & EPA Method 8270 \\
\hline$\mu \mathrm{g} / \mathrm{L}$ & 50 & 100 & EPA Method 8270 \\
\hline$\mu \mathrm{g} / \mathrm{L}$ & 50 & 100 & EPA Method 8270 \\
\hline$\mu g / L$ & 50 & 100 & EPA Method 8270 \\
\hline$\mu g / L$ & 50 & 100 & EPA Method 8270 \\
\hline$\mu \mathrm{g} / \mathrm{L}$ & 50 & 100 & EPA Method 8270 \\
\hline$\mu \mathrm{g} / \mathrm{L}$ & 50 & 100 & EPA Method 8270 \\
\hline$\mu \mathrm{g} / \mathrm{L}$ & 50 & 100 & EPA Method 8270 \\
\hline$\mu \mathrm{g} / \mathrm{L}$ & 50 & 100 & EPA Method 8270 \\
\hline$\mu g / L$ & 50 & 100 & EPA Method 8270 \\
\hline $\mathrm{pCi} / \mathrm{L}$ & $2.5 E+01$ & $5 E+01$ & Interim Final PDWS (EPA, 1977) \\
\hline$\mu \mathrm{g} / \mathrm{L}$ & 0.005 & 0.01 & EPA Method 8280 \\
\hline$\mu g / L$ & 0.005 & 0.01 & EPA Method 8280 \\
\hline & No flag & No flag & Set by EPD/EMS \\
\hline$\mu g / L$ & 5,000 & 10,000 & EPA Method 413.1 \\
\hline$\mu g / L$ & 100 & 200 & Final PDWS (EPA, 1993a) \\
\hline$\mu \mathrm{g} / \mathrm{L}$ & 0.25 & 0.5 & EPA Method 8080 \\
\hline$\mu \mathrm{g} / \mathrm{L}$ & 0.25 & 0.5 & EPA Method 8080 \\
\hline$\mu \mathrm{g} / \mathrm{L}$ & 0.25 & 0.5 & Final PDWS (EPA, 1993a) \\
\hline$\mu \mathrm{g} / \mathrm{L}$ & 0.25 & 0.5 & Final PDWS (EPA, 1993a) \\
\hline$\mu \mathrm{g} / \mathrm{L}$ & 0.25 & 0.5 & Final PDWS (EPA, 1993a) \\
\hline$\mu \mathrm{g} / \mathrm{L}$ & 0.25 & 0.5 & Final PDWS (EPA, 1993a) \\
\hline$\mu \mathrm{g} / \mathrm{L}$ & 0.25 & 0.5 & Final PDWS (EPA, 1993a) \\
\hline$\mu \mathrm{g} / \mathrm{L}$ & 0.25 & 0.5 & Final PDWS (EPA, 1993a) \\
\hline$\mu \mathrm{g} / \mathrm{L}$ & 0.25 & 0.5 & Final PDWS (EPA, 1993a) \\
\hline$\mu \mathrm{g} / \mathrm{L}$ & 0.25 & 0.5 & Final PDWS (EPA, 1993a) \\
\hline$\mu \mathrm{g} / \mathrm{L}$ & 50 & 100 & EPA Method $827 C$ \\
\hline$\mu \mathrm{g} / \mathrm{L}$ & 0.00275 & 0.0055 & EPA Method 8280 \\
\hline$\mu \mathrm{g} / \mathrm{L}$ & 0.00275 & 0.0055 & EPA Method 8280 \\
\hline$\mu \mathrm{g} / \mathrm{L}$ & 0.00275 & 0.0055 & EPA Method 8280 \\
\hline$\mu \mathrm{g} / \mathrm{L}$ & 0.00275 & 0.0055 & EPA Method 8280 \\
\hline$\mu \mathrm{g} / \mathrm{L}$ & 50 & 100 & EPA Method 8270 \\
\hline$\mu \mathrm{g} / \mathrm{L}$ & 50 & 100 & EPA Method 8270 \\
\hline$\mu \mathrm{g} / \mathrm{L}$ & 0.5 & 1 & Final PDWS (EPA, 1993a) \\
\hline $\mathrm{pH}$ & 8 & 10 & Set by EPD/EMS \\
\hline $\mathrm{pH}$ & 4 & 3 & Set by EPD/EMS \\
\hline$\mu g / L$ & 50 & 100 & EPA Method 8270 \\
\hline$\mu \mathrm{g} / \mathrm{L}$ & 50 & 100 & EPA Method 8270 \\
\hline$\mu \mathrm{g} / \mathrm{L}$ & 50 & 100 & EPA Method 8270 \\
\hline$\mu \mathrm{g} / \mathrm{L}$ & 25 & 50 & EPA Method 420.1 \\
\hline$\mu \mathrm{g} / \mathrm{L}$ & 50 & 100 & EPA Method 8270 \\
\hline$\mu \mathrm{g} / \mathrm{L}$ & 0.5 & 1 & EPA Method 8080 \\
\hline$\mu \mathrm{g} / \mathrm{L}$ & 250 & 500 & Final PDWS (EPA, 1993a) \\
\hline$\mu \mathrm{g} / \mathrm{L}$ & 50 & 100 & EPA Method 8270 \\
\hline $\mathrm{pCi} / \mathrm{L}$ & $3.51 E+00$ & $7.02 E+00$ & Proposed PDWS (EPA, 1991) \\
\hline $\mathrm{pCi} / \mathrm{L}$ & $3.11 E+01$ & $6.21 E+01$ & Proposed PDWS (EPA, 1991) \\
\hline
\end{tabular}


Analyte

Plutonium-239/240

Plutonium-240

Plutonium-241 $\mathrm{C}$

Plutonium-242 ${ }^{\mathrm{C}}$

Potassium

Potassium, dissolved

Potassium, total recoverable

Potassium-40

Promethium-144

Promethium-146

Promethium-147

Pronamid

Propionitrile

Pyrene

Pyridine

Radium (alpha-emitting)

Radium-226

Radium-228

Radon-222

Ruthenium-103c

Ruthenium-106

Safrole

Selenium

Selenium, dissolved

Selenium, total recoverable

Silica

Silica, dissolved

Silica, total recoverable

Silver

Silver, dissolved

Silver, total recoverable

Simazine ${ }^{b}$

Sodium

Sodium, dissolved

Sodium, total recoverable

Sodium-22

Specific conductance

Strontium-89

Strontium-89/90

Strontium-90

Styrene

Sulfate

Sulfide

Sulfotepp

Surfactants

2,3,7,8-TCDD

$2,3,7,8$-TCDF

Technetium-99

1,2,4,5-Tetrachlorobenzene

Tetrachlorodibenzo-p-dioxin isomers

Tetrachlorodibenzo-p-furan isomers

1,1,1,2-Tetrachloroethane

$1,1,2,2$-Tetrachloroethane

\begin{tabular}{|c|c|c|c|}
\hline Unit & Flag 1 & Flag 2 & Source $^{a}$ \\
\hline $\mathrm{pCi} / \mathrm{L}$ & $3.11 E+01$ & $6.21 E+01$ & Proposed PDWS (EPA, 1991) \\
\hline $\mathrm{pCi} / \mathrm{L}$ & $3.11 E+01$ & $6.22 E+01$ & Proposed PDWS (EPA, 1991) \\
\hline $\mathrm{pCi} / \mathrm{L}$ & $3.13 E+01$ & $6.26 E+01$ & Proposed PDWS (EPA, 1991) \\
\hline $\mathrm{pCi} / \mathrm{L}$ & $3.27 E+01$ & $6.54 E+01$ & Proposed PDWS (EPA, 1991) \\
\hline & No flag & No flag & Set by EPD/EMS \\
\hline & No flag & No flag & Set by EPD/EMS \\
\hline & No flag & No flag & Set by EPD/EMS \\
\hline $\begin{array}{l}\text { ii/L } \\
\text { ai/L }\end{array}$ & $1.5 E+02$ & $3 E+02$ & Proposed PDWS (EPA, 1986) \\
\hline $\begin{array}{l}\mathrm{pCi} / \mathrm{L} \\
\mathrm{pCi} / \mathrm{L}\end{array}$ & $5 \mathrm{E}+01$ & $1 E+02$ & EPA Method 901.1 \\
\hline $\mathrm{pCi} / \mathrm{L}$ & $5 E+01$ & $1 E+02$ & EPA Method 901.1 \\
\hline $\mathrm{pCi} / \mathrm{L}$ & $5.24 E+03$ & $5.24 E+03$ & Pro,osed PDWS (EPA, 1991) \\
\hline$\mu \mathrm{g} / \mathrm{L}$ & 50 & 100 & EPA Method 8270 \\
\hline$\mu g / L$ & 1,000 & 2,000 & EPA Method 8240 \\
\hline$\mu g / L$ & 50 & 100 & EPA Method 8270 \\
\hline$\mu g / L$ & 50 & 100 & EPA Method 8270 \\
\hline $\mathrm{pCi} / \mathrm{L}$ & $1 E+01$ & $2 E+01$ & Proposed PDWS (EPA, 1991) \\
\hline $\mathrm{pCi} / \mathrm{L}$ & $1 E+01$ & $2 E+01$ & Proposed PDWS (EPA, 1991) \\
\hline $\mathrm{pCi} / \mathrm{L}$ & $1 E+01$ & $2 E+01$ & Proposed PDWS (EPA, 1991) \\
\hline $\mathrm{pCi} / \mathrm{L}$ & $1.5 E+02$ & $3 E+02$ & Proposed PDWS (EPA, 1991) \\
\hline $\mathrm{pCi} / \mathrm{L}$ & $1 E+02$ & $2 E+02$ & Iriterim Final PDWS (EPA, 1977) \\
\hline $\mathrm{pCi} / \mathrm{L}$ & $1.5 E+01$ & $3 E+01$ & Interim Final PDWS (EPA, 1977) \\
\hline$\mu \mathrm{g} / \mathrm{L}$ & 50 & 100 & EPA Method 8270 \\
\hline$\mu g / L$ & 25 & 50 & Final PDWS (EPA, 1993a) \\
\hline$\mu g / L$ & 25 & 50 & Final PDWS (EPA, 1993a) \\
\hline$\mu \mathrm{g} / \mathrm{L}$ & 25 & 50 & Final PDWS (EPA, 1993a) \\
\hline & No flag & No flag & Set by EPD/EMS \\
\hline & No flag & No flag & Set by EPD/EMS \\
\hline & No flag & No flag & Set by EPD/EMS \\
\hline$\mu \mathrm{g} / \mathrm{L}$ & 50 & 100 & SDWS (EPA, 1993b) \\
\hline$\mu g / L$ & 50 & 100 & SDWS (EPA, 1993b) \\
\hline$\mu g / L$ & 50 & 100 & SDWS (EPA, 1993b) \\
\hline$\mu \mathrm{g} / \mathrm{L}$ & 2 & 4 & Final PDWS (EPA, 1993a) \\
\hline & No flag & No flag & Set by EPD/EMS \\
\hline & No flag & No flag & Set by EPD/EMS \\
\hline & No flag & No flag & Set by EPD/EMS \\
\hline$p C i / L$ & $2.33 E+02$ & $4.66 E+02$ & Proposed PDWS (EPA, 1991) \\
\hline$\mu \mathrm{S} / \mathrm{cm}$ & 250 & 500 & Set by EPD/EMS \\
\hline $\mathrm{pCi} / \mathrm{L}$ & $1 E+01$ & $2 E+01$ & Interim Final PDWS (EPA, 1977) \\
\hline $\mathrm{pCi} / \mathrm{L}$ & $4 E+00$ & $8 E+00$ & Final PDWS (EPA, 1993a) \\
\hline $\mathrm{pCi} / \mathrm{L}$ & $4 E+00$ & $8 E+00$ & Final PDWS (EPA, 1993a) \\
\hline$\mu \mathrm{g} / \mathrm{L}$ & 50 & 100 & Final PDWS (EPA, 1993a) \\
\hline$\mu g / L$ & 200,000 & 400,000 & Proposed PDWS (EPA, 1990$)$ \\
\hline$\mu g / L$ & 5,000 & 10,000 & EPA Method 9030 \\
\hline$\mu g / L$ & 50 & 100 & EPA Method 8270 \\
\hline & No flag & No flag & Set by EPD/EMS \\
\hline$\mu g / L$ & 0.000015 & 0.00003 & Final PDWS (EPA, 1993a) \\
\hline$\mu g / L$ & 0.002 & 0.004 & EPA Method 8280 \\
\hline $\mathrm{pCi} / \mathrm{L}$ & $4.5 E+02$ & $9 E+02$ & Interim Final PDWS (EPA, 1977) \\
\hline$\mu \mathrm{g} / \mathrm{L}$ & 50 & 100 & EPA Method 8270 \\
\hline$\mu g / L$ & 0.00225 & 0.0045 & EPA Method 8280 \\
\hline$\mu g / L$ & 0.002 & 0.004 & EPA Method 8280 \\
\hline 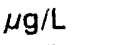 & 5 & 10 & EPA Method 8240 \\
\hline $\mathrm{g} / \mathrm{L}$ & 5 & 10 & EPA Method 8240 \\
\hline
\end{tabular}




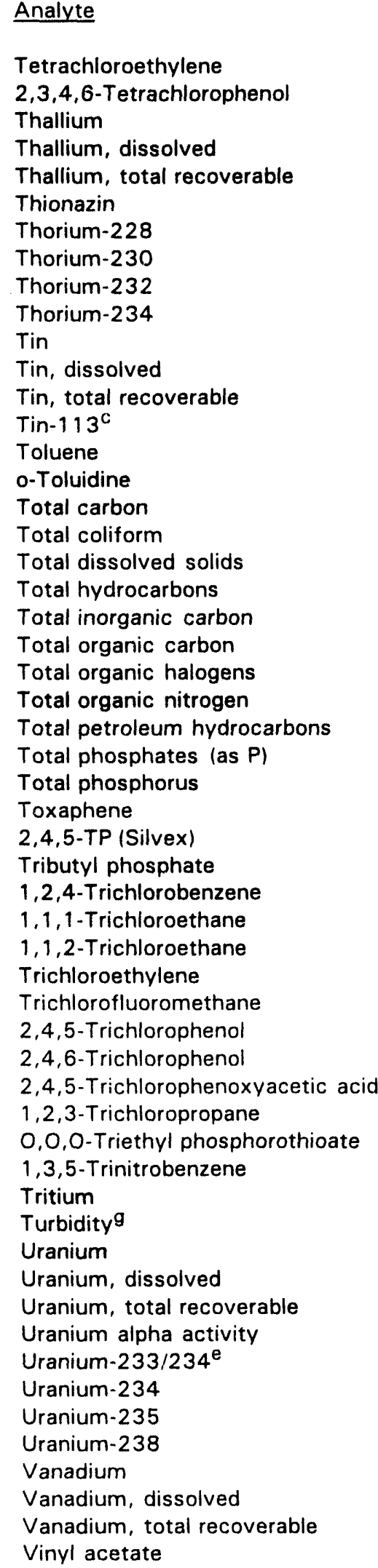

\begin{tabular}{|c|c|c|c|}
\hline Unit & Flag 1 & Flag 2 & Source $^{a}$ \\
\hline$\mu g / L$ & 2.5 & 5 & Final PDWS (EPA, 1993a) \\
\hline$\mu g / L$ & 50 & 100 & EPA Method 8270 \\
\hline$\mu \mathrm{g} / \mathrm{L}$ & 1 & 2 & Final PDWS (EPA, 1993a) \\
\hline$\mu g / L$ & 1 & 2 & Final PDWS (EPA, 1993a) \\
\hline$\mu \mathrm{g} / \mathrm{L}$ & 1 & 2 & Final PDWS (EPA, 1993a) \\
\hline$\mu g / L$ & 50 & 100 & EPA Method 8270 \\
\hline $\mathrm{pCi} / \mathrm{L}$ & $6.25 E+01$ & $1.25 E+02$ & Proposed PDWS (EPA, 1991) \\
\hline $\mathrm{pCi} / \mathrm{L}$ & $3.96 \mathrm{E}+01$ & $7.92 E+01$ & Proposed PDWS (EPA, 1991) \\
\hline $\mathrm{pCi} / \mathrm{L}$ & $4.4 E+01$ & $8.8 E+01$ & Proposed PDWS (EPA, 1991) \\
\hline $\mathrm{pCi} / \mathrm{L}$ & $2 E+02$ & $4.01 E+02$ & Proposed PDWS (EPA, 1991) \\
\hline$\mu \mathrm{g} / \mathrm{L}$ & 10 & 20 & EPA Method 282.2 \\
\hline$\mu \mathrm{g} / \mathrm{L}$ & 10 & 20 & EPA Method 282.2 \\
\hline$\mu \mathrm{g} / \mathrm{L}$ & 10 & 20 & EPA Method 282.2 \\
\hline $\mathrm{pCi} / \mathrm{L}$ & $1.5 E+02$ & $3 E+02$ & Interim Final PDWS (EPA, 1977) \\
\hline$\mu \mathrm{g} / \mathrm{L}$ & 500 & 1,000 & Final PDWS (EPA, 1993a) \\
\hline$\mu g / L$ & 50 & 100 & EPA Method 8270 \\
\hline$\mu g / L$ & 5,000 & 10,000 & EPA Method 9060 \\
\hline & 0 & 0 & Final PDWS (EPA, 1993a) \\
\hline & No flag & No flag & Set by EPD/EMS \\
\hline$\mu \mathrm{g} / \mathrm{L}$ & 5,000 & 10,000 & EPA Method 418.1 \\
\hline$\mu \mathrm{g} / \mathrm{L}$ & 5,000 & 10,000 & EPA Method 9060 \\
\hline$\mu g / L$ & 5,000 & 10,000 & EPA Method 9060 \\
\hline$\mu \mathrm{g} / \mathrm{L}$ & 25 & 50 & EPA Method 9020 \\
\hline$\mu g / L$ & 500 & 1,000 & APHA Method 420 \\
\hline$\mu \mathrm{g} / \mathrm{L}$ & 5,000 & 10,000 & EPA Method 418.1 \\
\hline & No flag & No flag & Set by EPD/EMS \\
\hline & No flag & No flag & Set by EPD/EMS \\
\hline$\mu \mathrm{g} / \mathrm{L}$ & 1.5 & 3 & Final PDWS (EPA, 1993a) \\
\hline$\mu \mathrm{g} / \mathrm{L}$ & 25 & 50 & Final PDWS (EPA, 1993a) \\
\hline$\mu \mathrm{g} / \mathrm{L}$ & 50 & 100 & EPA Method 8270 \\
\hline$\mu \mathrm{g} / \mathrm{L}$ & 35 & 70 & Final PDWS (EPA, 1993a) \\
\hline$\mu g / L$ & 100 & 200 & Final PDWS (EPA, 1993a) \\
\hline$\mu \mathrm{g} / \mathrm{L}$ & 2.5 & 5 & Final PDWS (EPA, 1993a) \\
\hline$\mu \mathrm{g} / \mathrm{L}$ & 2.5 & 5 & Final PDWS (EPA, 1993a) \\
\hline$\mu \mathrm{g} / \mathrm{L}$ & 5 & 10 & EPA Method 8240 \\
\hline$\mu \mathrm{g} / \mathrm{L}$ & 50 & 100 & EPA Method 8270 \\
\hline$\mu \mathrm{g} / \mathrm{L}$ & 50 & 100 & EPA Method 8270 \\
\hline$\mu \mathrm{g} / \mathrm{L}$ & 2.5 & 5 & EPA Method 8150 \\
\hline$\mu \mathrm{g} / \mathrm{L}$ & 5 & 10 & EPA Method 8240 \\
\hline$\mu \mathrm{g} / \mathrm{L}$ & 50 & 100 & EPA Method 8270 \\
\hline$\mu \mathrm{g} / \mathrm{L}$ & 50 & 100 & EPA Method 8270 \\
\hline $\mathrm{pCi} / \mathrm{mL}$ & $1 E+01$ & $2 E+01$ & Final PDWS (EPA, 1993a) \\
\hline & No flag & No flag & Set by EPD/EMS \\
\hline$\mu g / L$ & 10 & 20 & Proposed PDWS (EPA, 1991) \\
\hline$\mu \mathrm{g} / \mathrm{L}$ & 10 & 20 & Proposed PDWS (EPA, 1991) \\
\hline$\mu g / L$ & 10 & 20 & Proposed PDWS (EPA, 1991) \\
\hline $\mathrm{pCi} / \mathrm{L}$ & $1.5 E+01$ & $3 E+01$ & Proposed PDWS (EPA, 1991) \\
\hline $\mathrm{pCi} / \mathrm{L}$ & $6.9 \mathrm{E}+00$ & $1.38 E+01$ & Proposed PDWS (EPA, 1991) \\
\hline $\mathrm{pCi} / \mathrm{L}$ & $6.95 E+00$ & $1.39 E+01$ & Proposed PDWS (EPA, 1991) \\
\hline $\mathrm{pCi} / \mathrm{L}$ & $7.25 E+00$ & $1.45 E+01$ & Proposed PDWS (EPA, 1991) \\
\hline $\mathrm{pCi} / \mathrm{L}$ & $7.3 E+00$ & $1.46 E+01$ & Proposed PDWS (EPA, 1991) \\
\hline$\mu \mathrm{g} / \mathrm{L}$ & 40 & 80 & EPA Method 6010 \\
\hline$\mu \mathrm{g} / \mathrm{L}$ & 40 & 80 & EPA Method 6010 \\
\hline$\mu \mathrm{g} / \mathrm{L}$ & 40 & 80 & EPA Method 6010 \\
\hline$\mu g / L$ & 5 & 10 & EPA Method 8240 \\
\hline
\end{tabular}




\begin{tabular}{|c|c|c|c|c|}
\hline Analyte & $\underline{\text { Unit }}$ & Flag 1 & Flag 2 & Source $^{a}$ \\
\hline Xylenes & $\mu \mathrm{g} / \mathrm{L}$ & 5,000 & 10,000 & Final PDWS (EPA, 1993a) \\
\hline Yttrium-88 & $\mathrm{pCi} / \mathrm{L}$ & $5 E+01$ & $1 E+02$ & EPA Method 901.1 \\
\hline Zinc & $\mu \mathrm{g} / \mathrm{L}$ & 2,500 & 5,000 & SDWS (EPA, 1993b) \\
\hline Zinc, dissolved & $\mu g / L$ & 2,500 & 5,000 & SDWS (EPA, 1993b) \\
\hline Zinc, total recoverable & $\mu \sigma / L$ & 2,500 & 5,000 & SDWS (EPA, 1993b) \\
\hline Zinc-65 & $\mathrm{pCi} / \mathrm{L}$ & $1.5 E+02$ & $3 E+02$ & Interim Final PDWS (EPA, 1977) \\
\hline Zirconium-95 & $\mathrm{pCi} / \mathrm{L}$ & $1 E+02$ & $2 E+02$ & Interim Final PDWS (EPA, 1977) \\
\hline Zirconium/Niobium-95 & $\mathrm{pCi} / \mathrm{L}$ & $1 E+02$ & $2 E+02$ & Interim Final PDWS (EPA, 1977) \\
\hline
\end{tabular}

a References for methods are found in Appendix E; references for dated sources are at the end of this appendix.

b EMS is currently unable to perform this analysis.

c EMS discontinued monitoring this radionuclide because it is inappropriate for the SRS groundwater monitoring program.

d EPD/EMS set this flagging criterion using the 1991 proposed PDWS because the final PDWS in 1977 may have been in error.

e For double radionuclide analyses where each separate radionuclide has its own standard, the more stringent standard is used.

$f$ The applied standard is for radium-226.

$\mathrm{g}$ The primary maximum contaminant level range for turbidity is $1-5 \mathrm{TU}$, which is inappropriate for the SRS groundwater monitoring program.

\section{References}

EPA (U.S. Environmental Protection Agency), 1977. National Interim Primary Drinking Water Regulations, EPA-570/9-76-003. Washington, DC.

EPA (U.S. Environmental Protection Agency), 1986. Water Pollution Control; National Primary Drinking Water Regulations, Radionuclides (Proposed). Federal Register, September 30, 1986, pp. 34835-34862. Washington, DC.

EPA (U.S. Environmental Protection Agency), 1990. National Primary and Secondary Drinking Water Regulations; Synthetic Organic Chemicals and Inorganic Chemicals (Proposed Rule). Federal Register, July 25, 1990, pp. 30369-30448. Washington, DC.

EPA (U.S. Environmental Protection Agency), 1991. National Primary Drinking Water Regulations; Radionuclides; Proposed Rule. Federal Register, July 18, 1991, pp. 33052-33127. Washington, DC.

EPA (U.S. Environmental Protection Agency), 1993a. National Primary Drinking Water Regulations, Code of Federal Regulations, Section 40, Part 141, pp. 592-732. Washington, DC.

EPA (U.S. Environmental Protection Agency), 1993b. National Secondary Drinking Water Regulations, Code of Federal Regulations, Section 40, Part 143, pp. 774-777. Washington, DC.

SCDHEC (South Carolina Department of Health and Environmental Control), 1981. State Primary Drinking Water Regulations, R.61-58.5. Columbia, SC. 
WSRC-TR-94-0240

Unclassified

\section{Appendix C}

Figures 


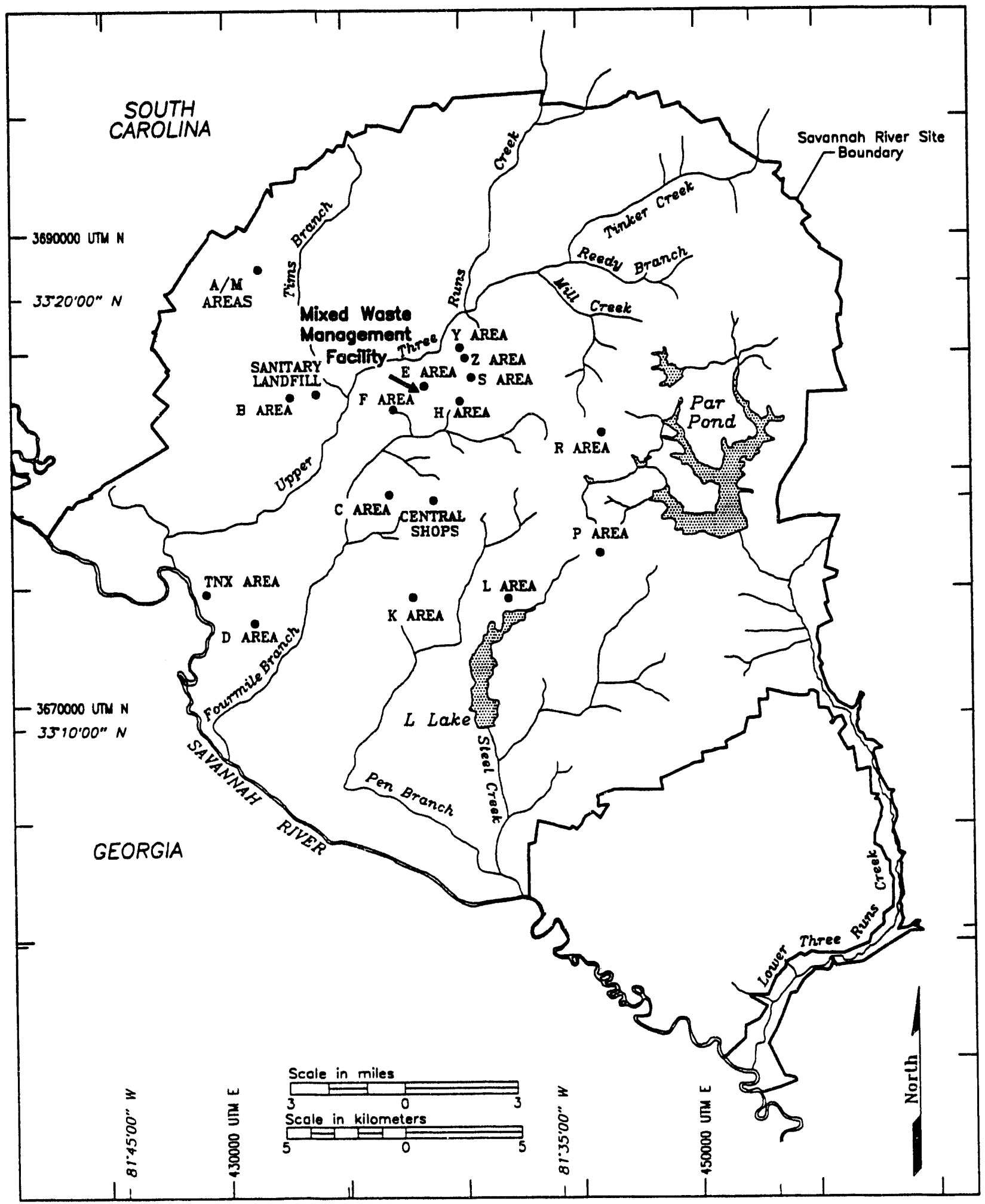

Figure 1. Location of the Mixed Waste Management Facility at the Savannah River Site 


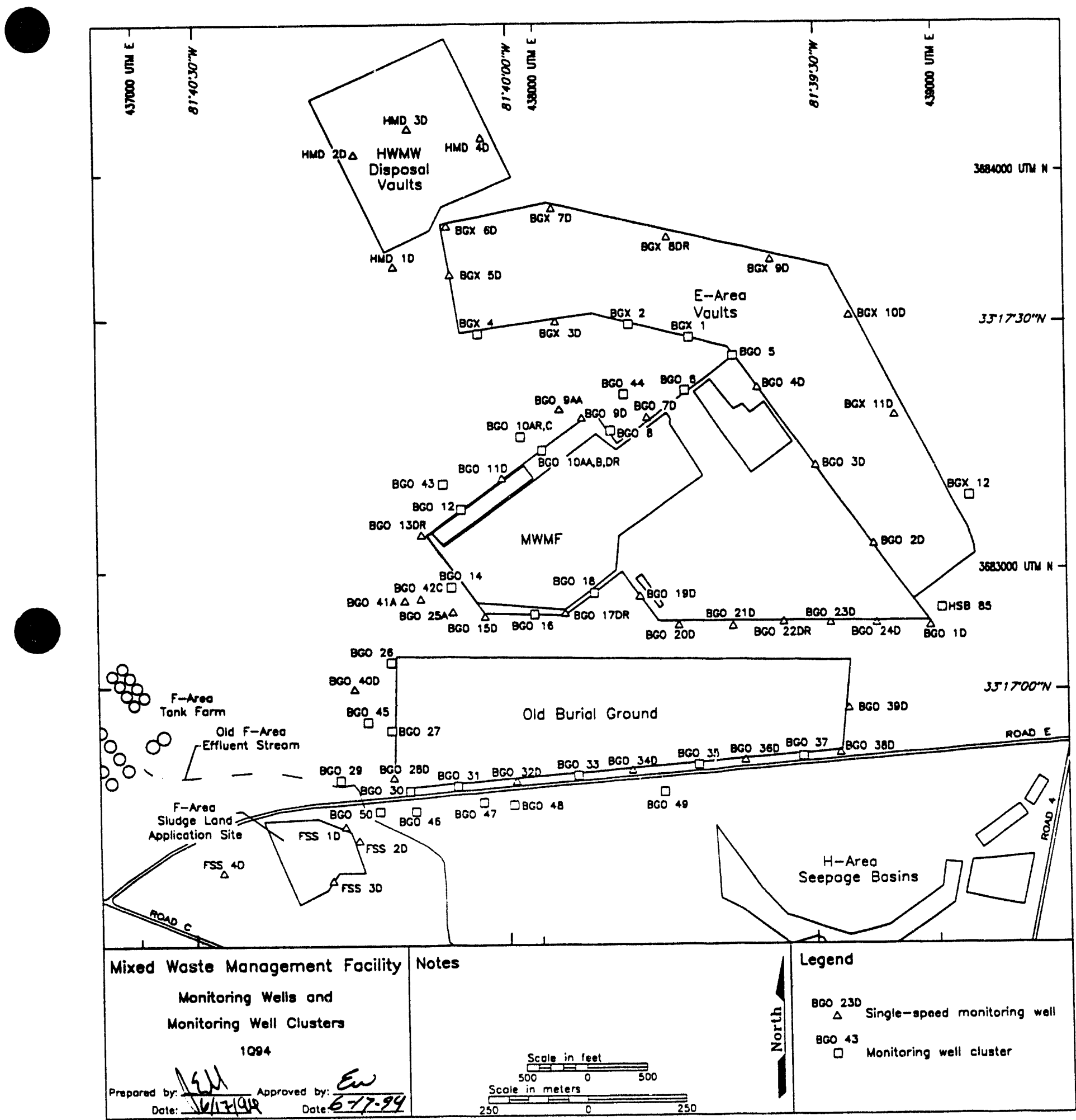

Figure 2. Location of the Groundwater Monitoring Wells at the Mixed Waste Management Facility, the Old Burial Ground, the E-Area Vaults, the Hazardous Waste/Mixed Waste Disposal Vaults (the Burial Ground Complex), and the F-Area Sewage Sludge Application Site 


\begin{tabular}{|c|c|c|c|c|c|c|}
\hline$\frac{0}{\frac{0}{\circ}}$ & \multicolumn{3}{|c|}{$\begin{array}{c}\text { Lithostratigraphic } \\
\text { Units }\end{array}$} & \multicolumn{3}{|c|}{$\begin{array}{c}\text { Hydrostratigraphic } \\
\text { Units }\end{array}$} \\
\hline \multirow{9}{*}{ 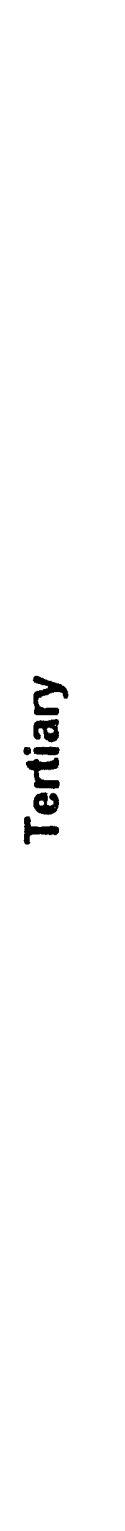 } & \multicolumn{2}{|c|}{ "Upland Unit" } & \multirow{7}{*}{ 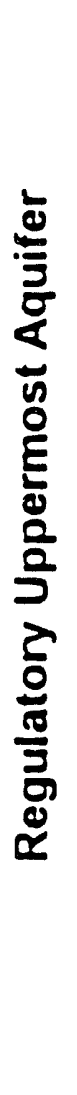 } & \multirow{5}{*}{ 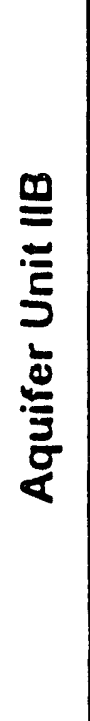 } & \multirow{2}{*}{$\begin{array}{l}\text { Aquifer } \\
\text { Zone } \| B_{2}\end{array}$} & \multirow{9}{*}{ 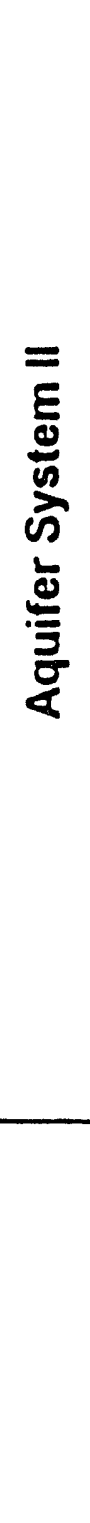 } \\
\hline & \multirow{3}{*}{ 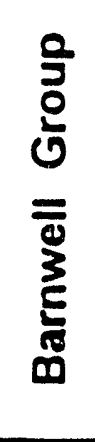 } & $\begin{array}{c}\text { Tobacco Rd } \\
\text { Formation }\end{array}$ & & & & \\
\hline & & $\begin{array}{l}\text { Dry Branch } \\
\text { Formation }\end{array}$ & & & $\begin{array}{c}\text { Confining } \\
\text { Zone }\left\|B_{1}-\right\| B_{2}\end{array}$ & \\
\hline & & Formation & & & \multirow{2}{*}{$\begin{array}{l}\text { Aquifer } \\
\text { Zone IIB, }\end{array}$} & \\
\hline & \multicolumn{2}{|c|}{$\begin{array}{c}\text { Santee Limestone } \\
\text { Formation }\end{array}$} & & & & \\
\hline & \multicolumn{2}{|c|}{$\begin{array}{l}\text { Warley Hill } \\
\text { Formation }\end{array}$} & & \multicolumn{2}{|c|}{$\begin{array}{l}\text { Confining Unit } \\
\text { IA-\|B }\end{array}$} & \\
\hline & \multicolumn{2}{|c|}{$\begin{array}{l}\text { Congareel } \\
\text { Fishburne } \\
\text { Formations }\end{array}$} & & \multicolumn{2}{|c|}{ Aquifer Unit IIA } & \\
\hline & \multicolumn{3}{|c|}{$\begin{array}{l}\text { Williamsburg } \\
\text { Formation }\end{array}$} & \multirow{2}{*}{\multicolumn{2}{|c|}{$\begin{array}{l}\text { Confining } \\
\text { System I-II }\end{array}$}} & \\
\hline & \multicolumn{3}{|c|}{$\begin{array}{l}\text { Ellenton } \\
\text { Formation }\end{array}$} & & & \\
\hline
\end{tabular}

Figure 3. Hydrostratigraphic Nomenclature 


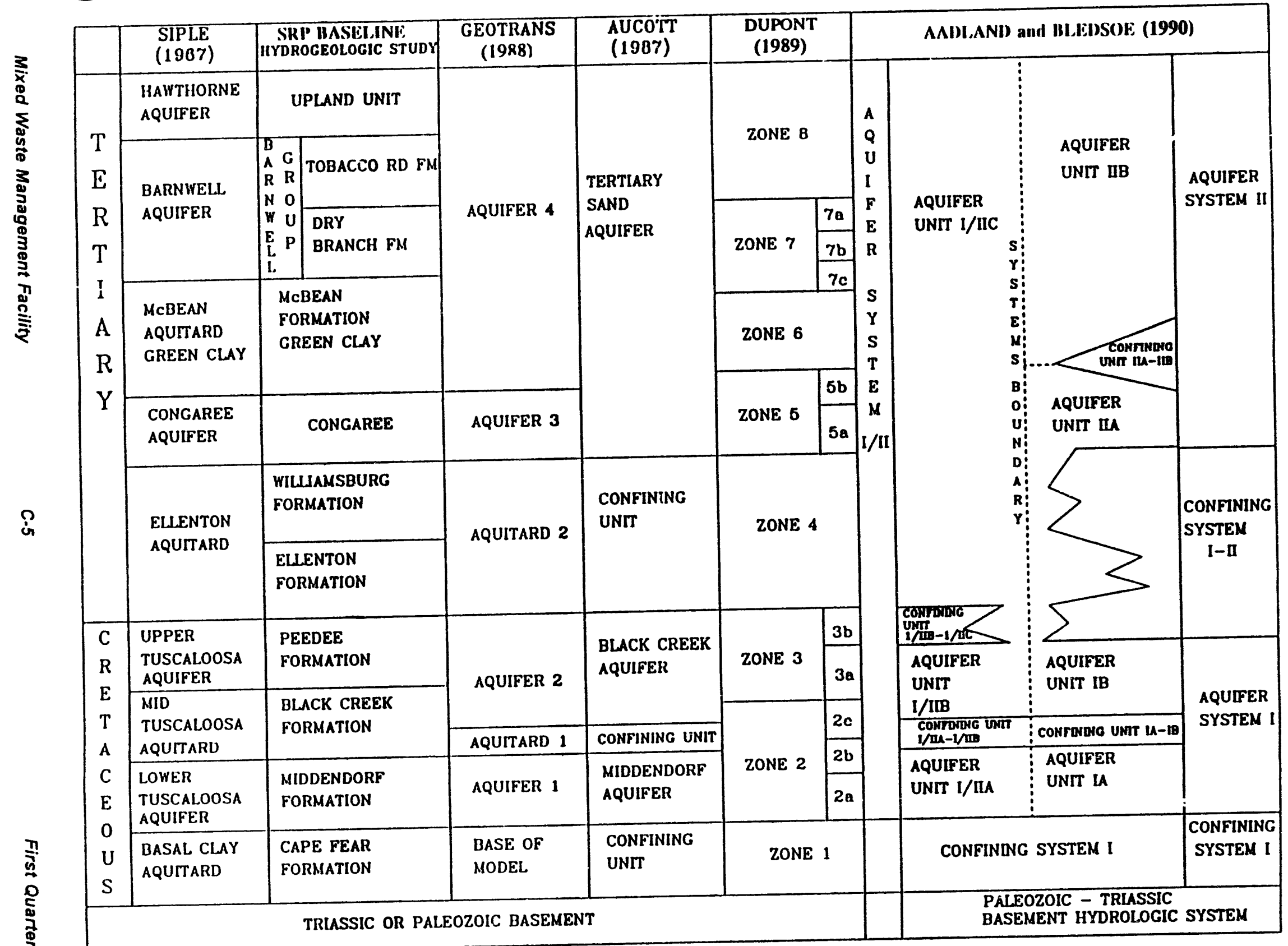

Figure 4. Regional Correlation of Hydrostratigraphic and Lithostratigraphic Nomenclature 


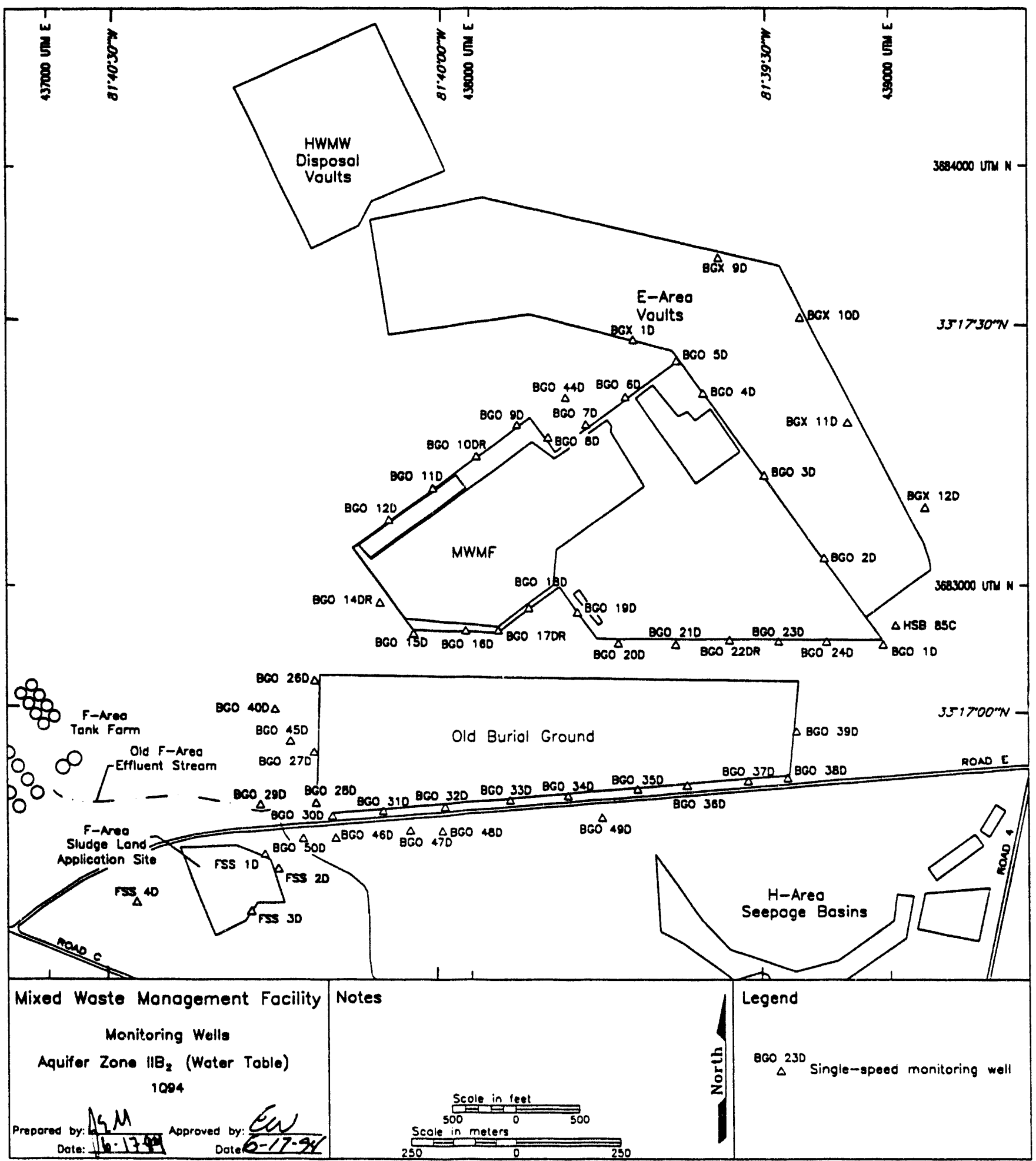

Figure 5. Location of Aquifer Zone $\|_{2}$ (Water Table) Wells at the Burial Ground Complex 


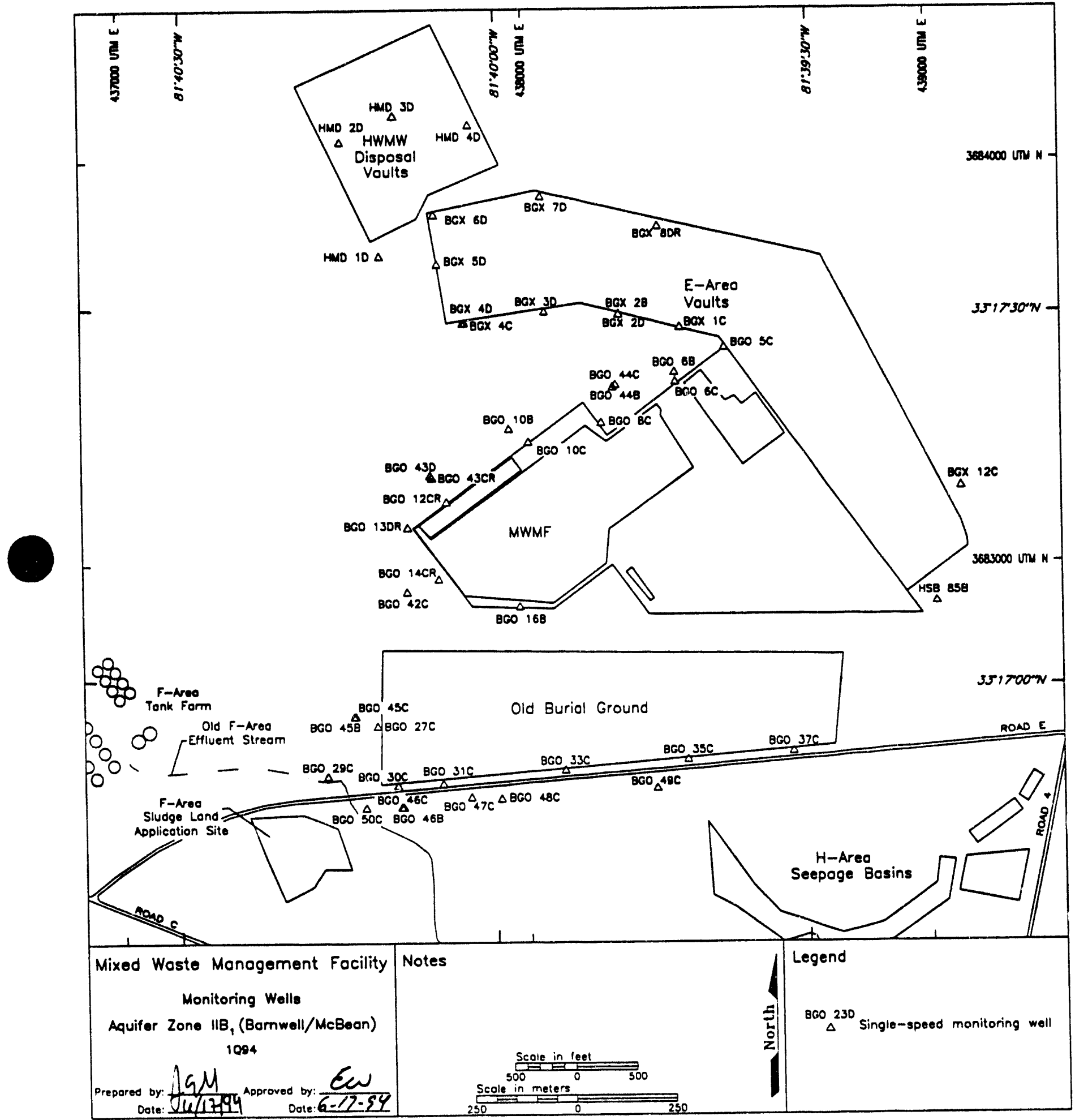

Figure 6. Location of Aquifer Zone $\| B_{1}$ (Barnwell/McBean) Wells at ihe Burial Ground Complex 


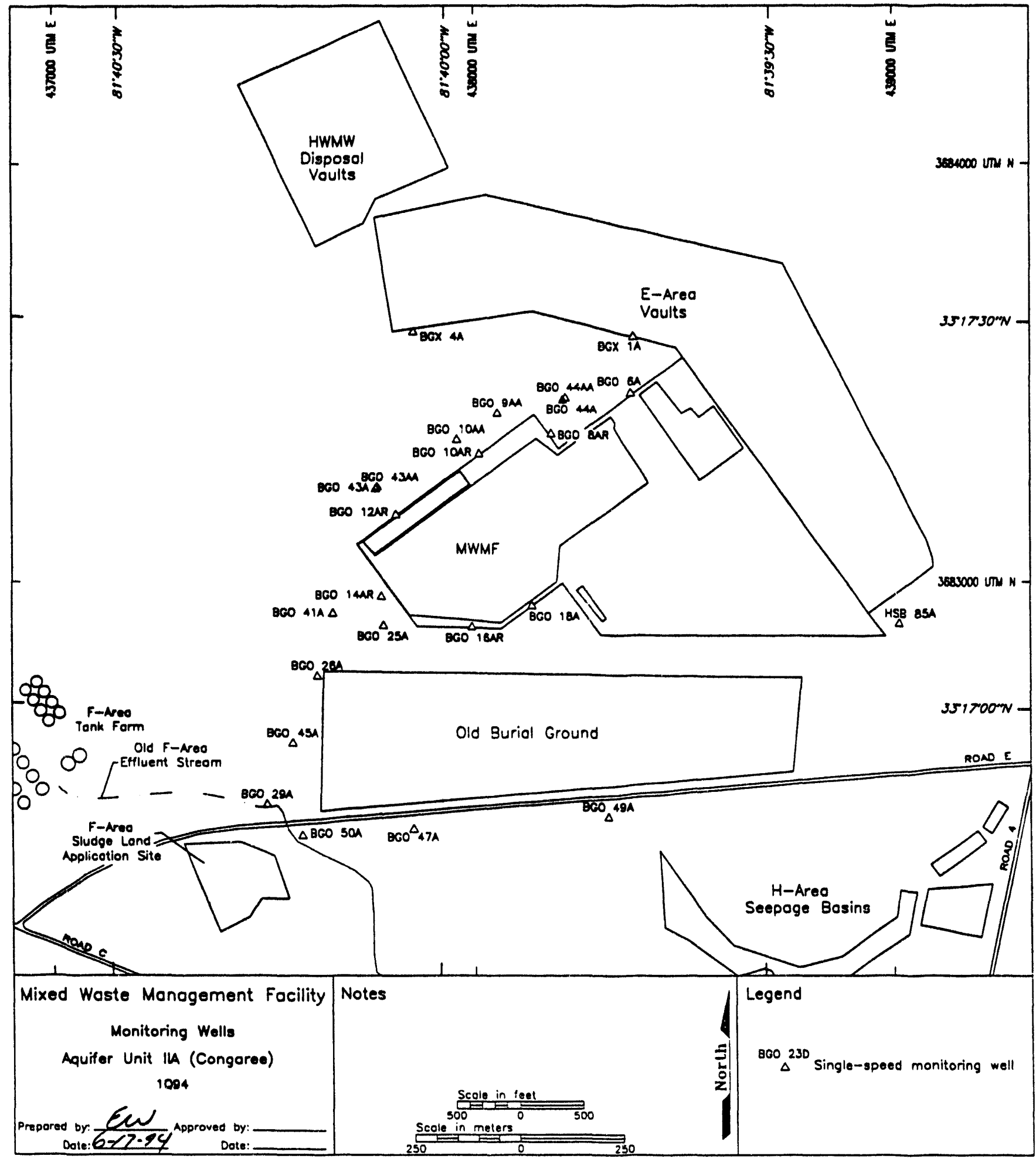

Figure 7. Location of Aquifer Unit IIA (Congaree) Wells at the Burial Ground Complex 


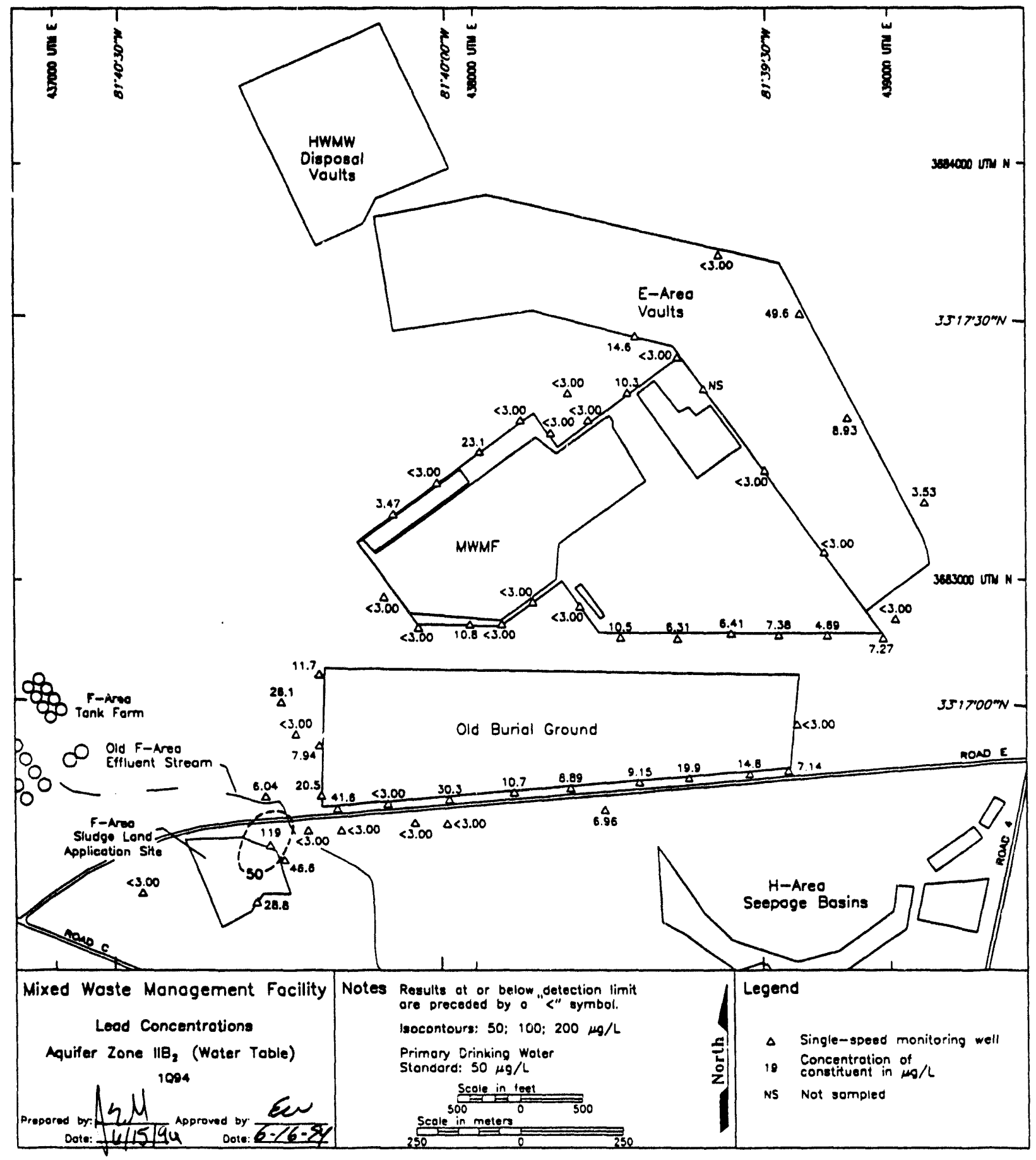

Figure 8. Lead Concentrations in Aquifer Zone $\|_{2}$ (Water Table) at the Burial Ground Complex, First Quarter 1994 


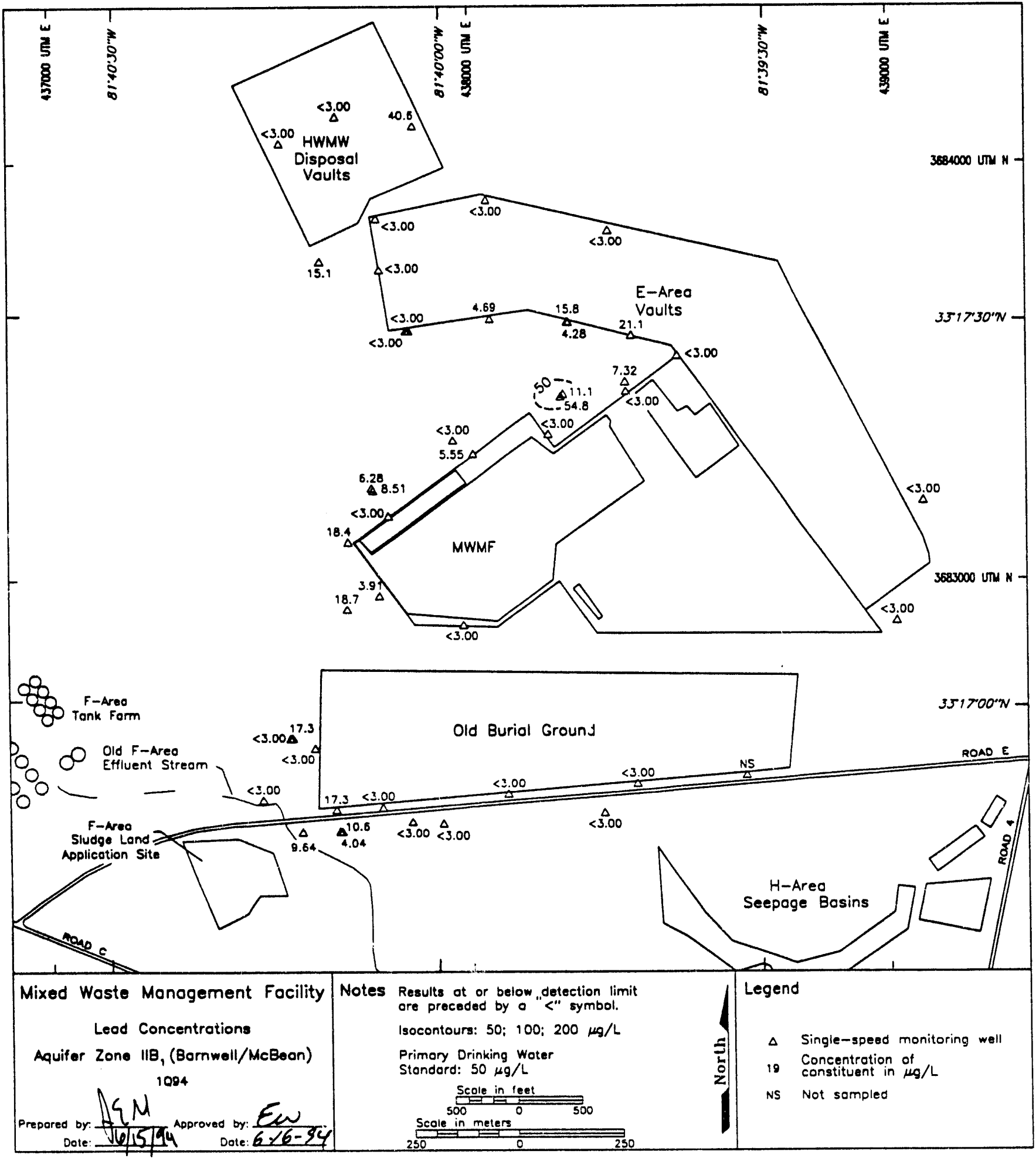

Figure 9. Lead Concentrations in Aquifer Zone IIB, (Barnwell/McBean) at the Burial Ground Complex, First Quarter 1994 


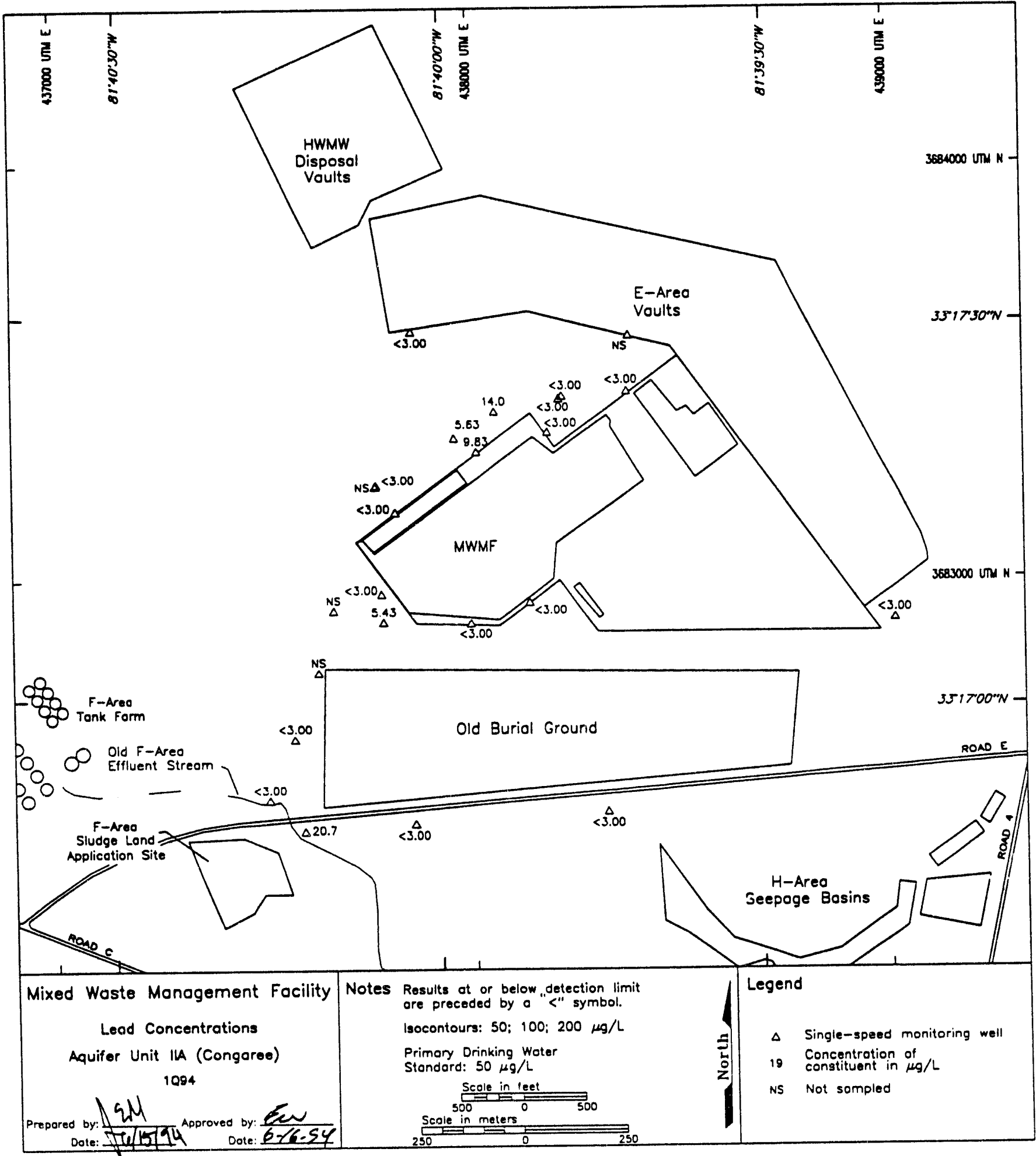

Figure 10. Lead Concentrations in Aquifer Unit IIA (Congaree) at the Burial Ground Complex, First Quarter 1994 


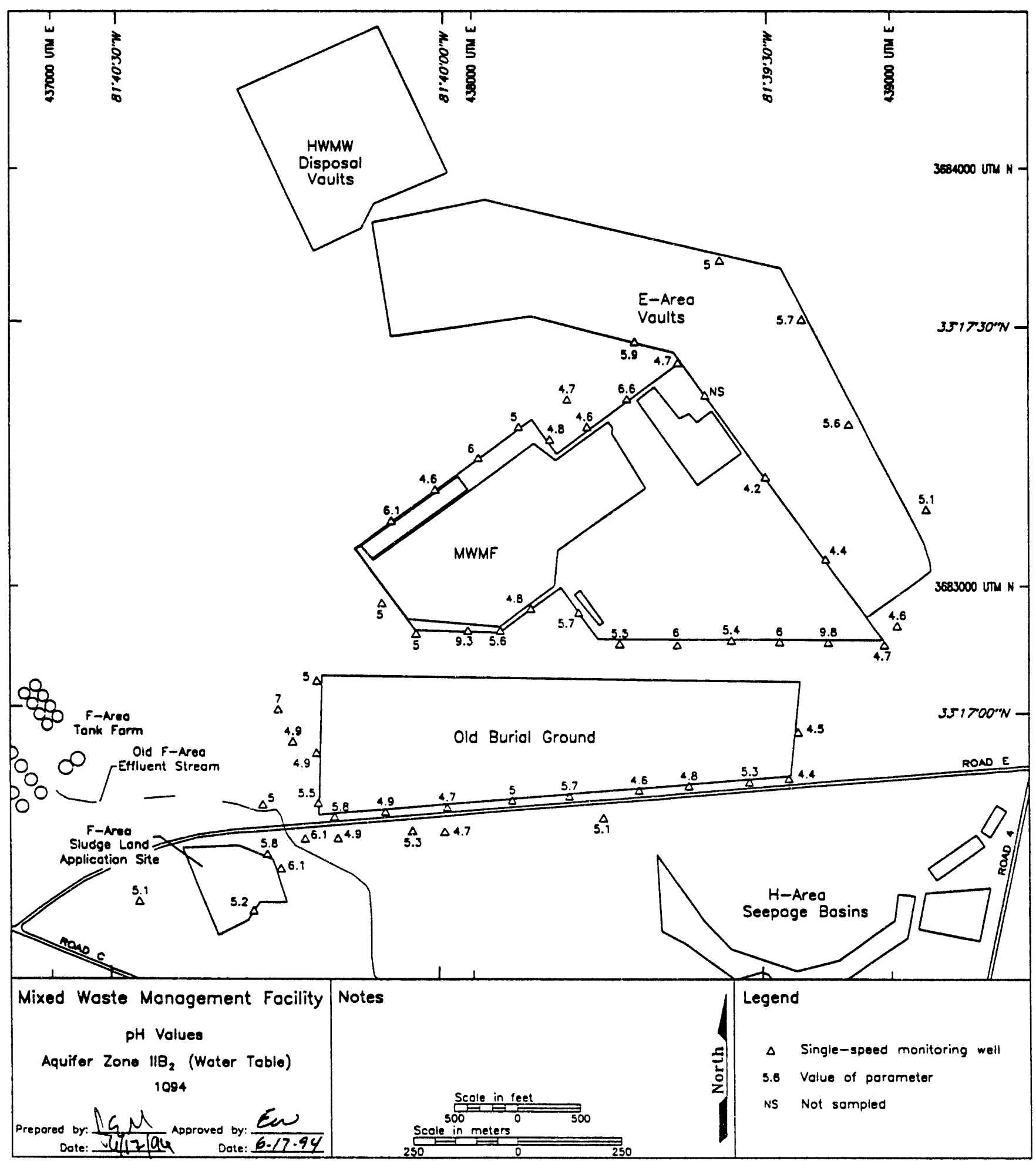

Figure 11. $\mathrm{pH}$ Values in Aquifer Zone $\|_{2} \mathrm{~B}_{2}$ (Water Table) at the Burial Ground Complex, First Quarter 1994 


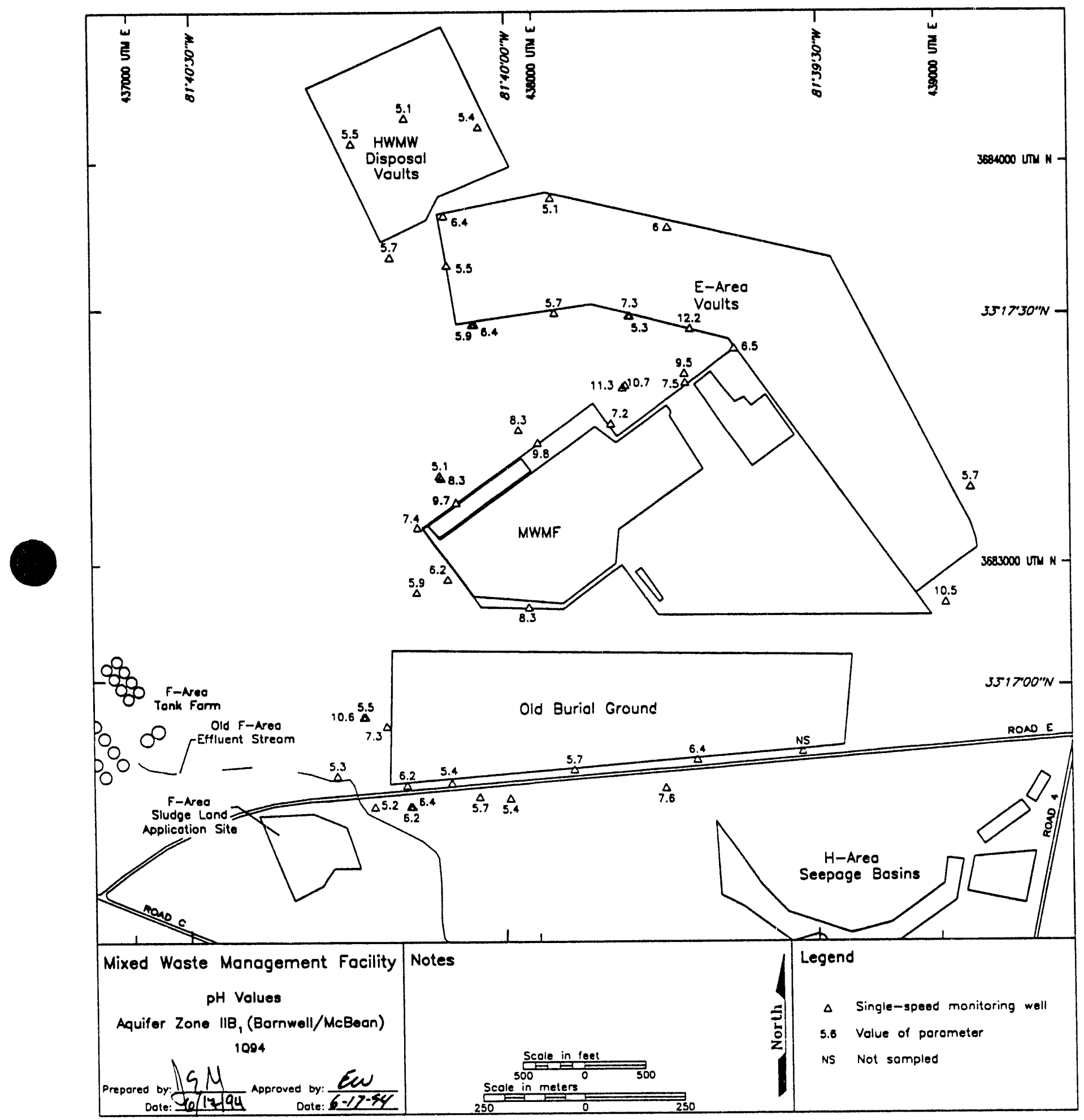

Figure 12. $\mathrm{pH}$ Values in Aquifer Zone $\| \mathrm{B}_{1}$ (Barnwell/McBean) at the Burial Ground Complex, First Quarter 1994 


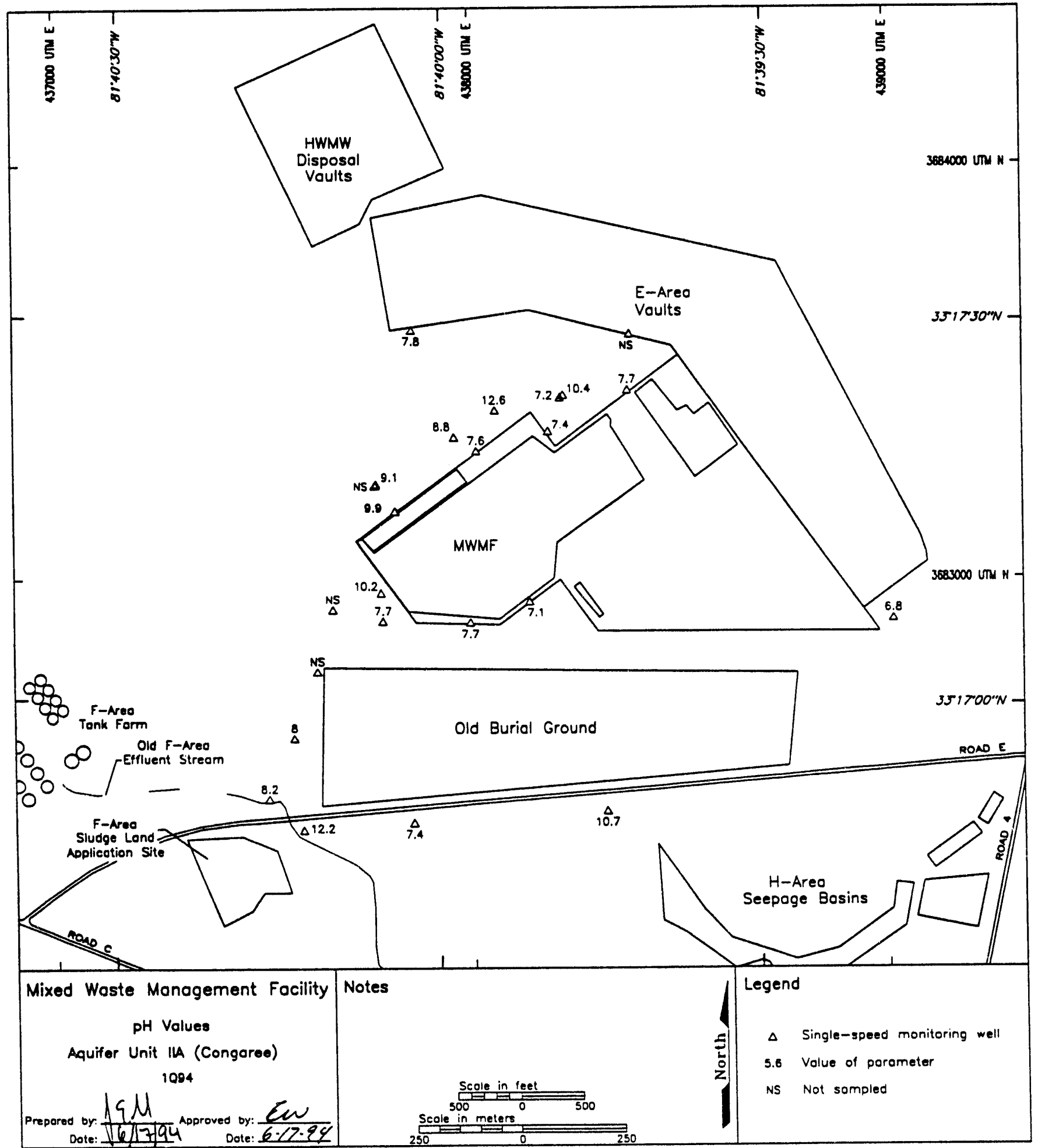

Figure 13. pH Values in Aquifer Zone IIA (Congaree) at the Burial Ground Complex, First Quarter 1994 


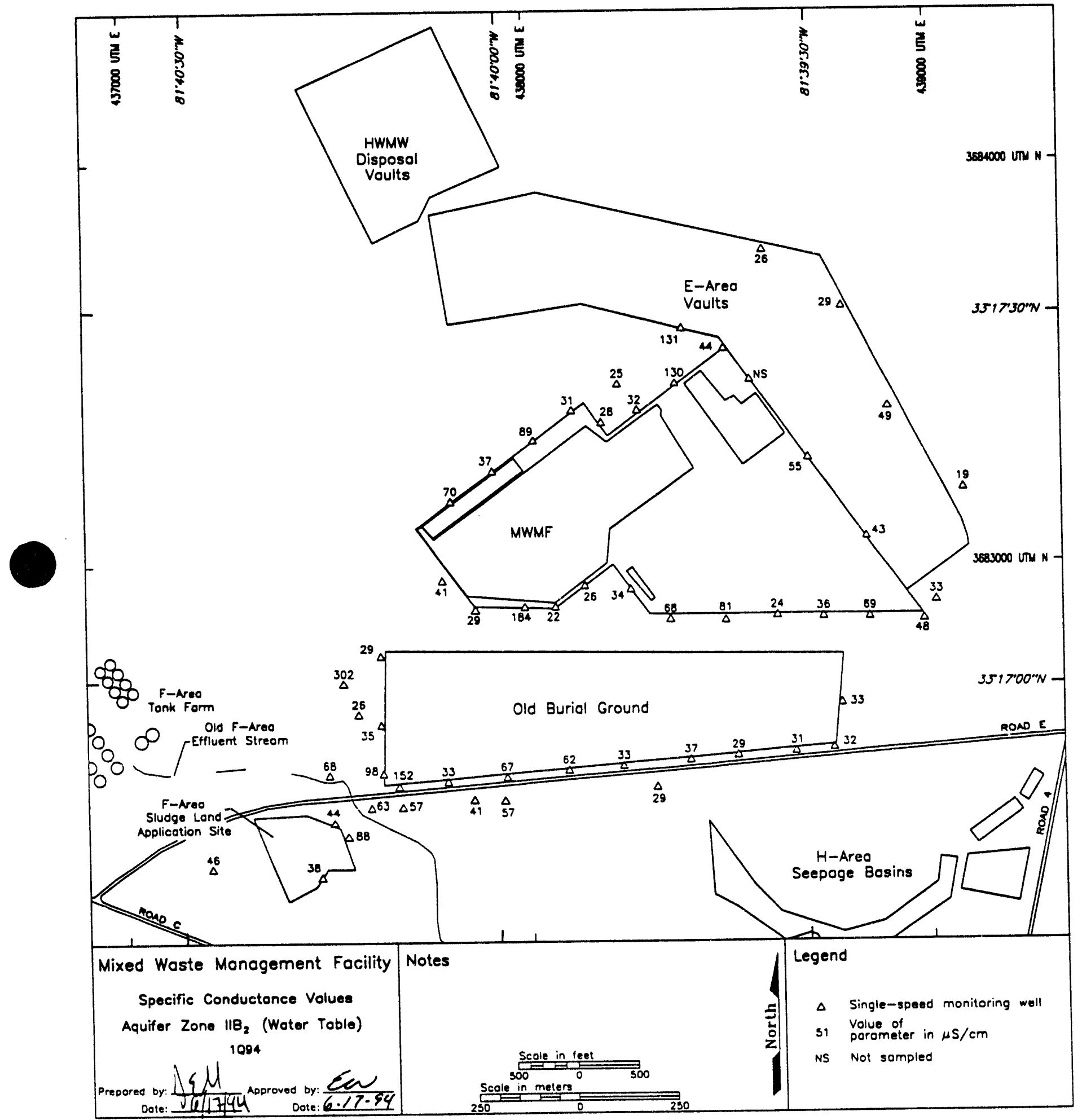

Figure 14. Specific Conductance in Aquifer Zone $\| B_{2}$ (Water Table) at the Burial Ground Complex, First Quarter 1994 


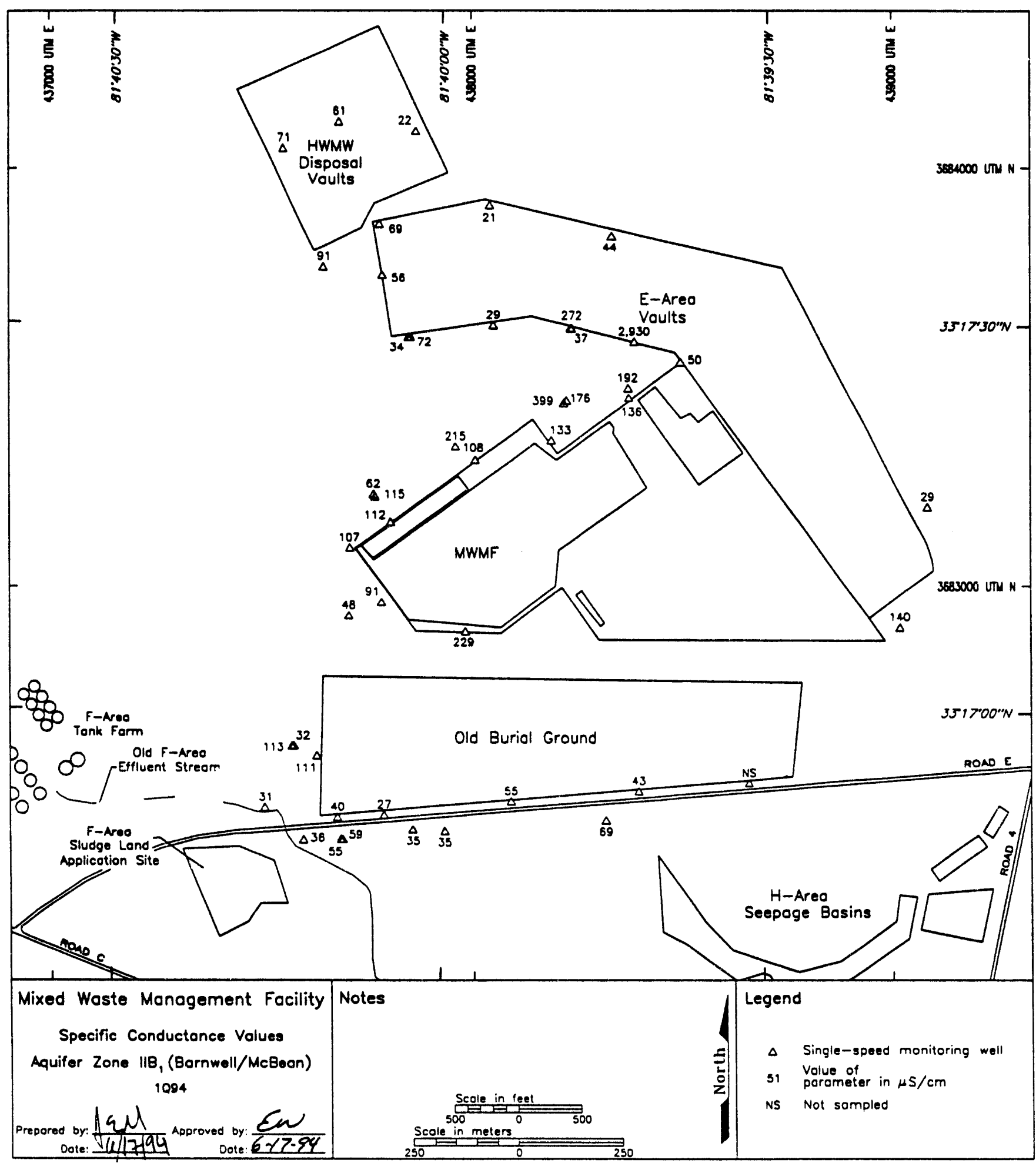

Figure 15. Specific Conductance in Aquifer Zone IIB, (Barnwell/McBean) at the Burial Ground Complex, First Quarter 1994 


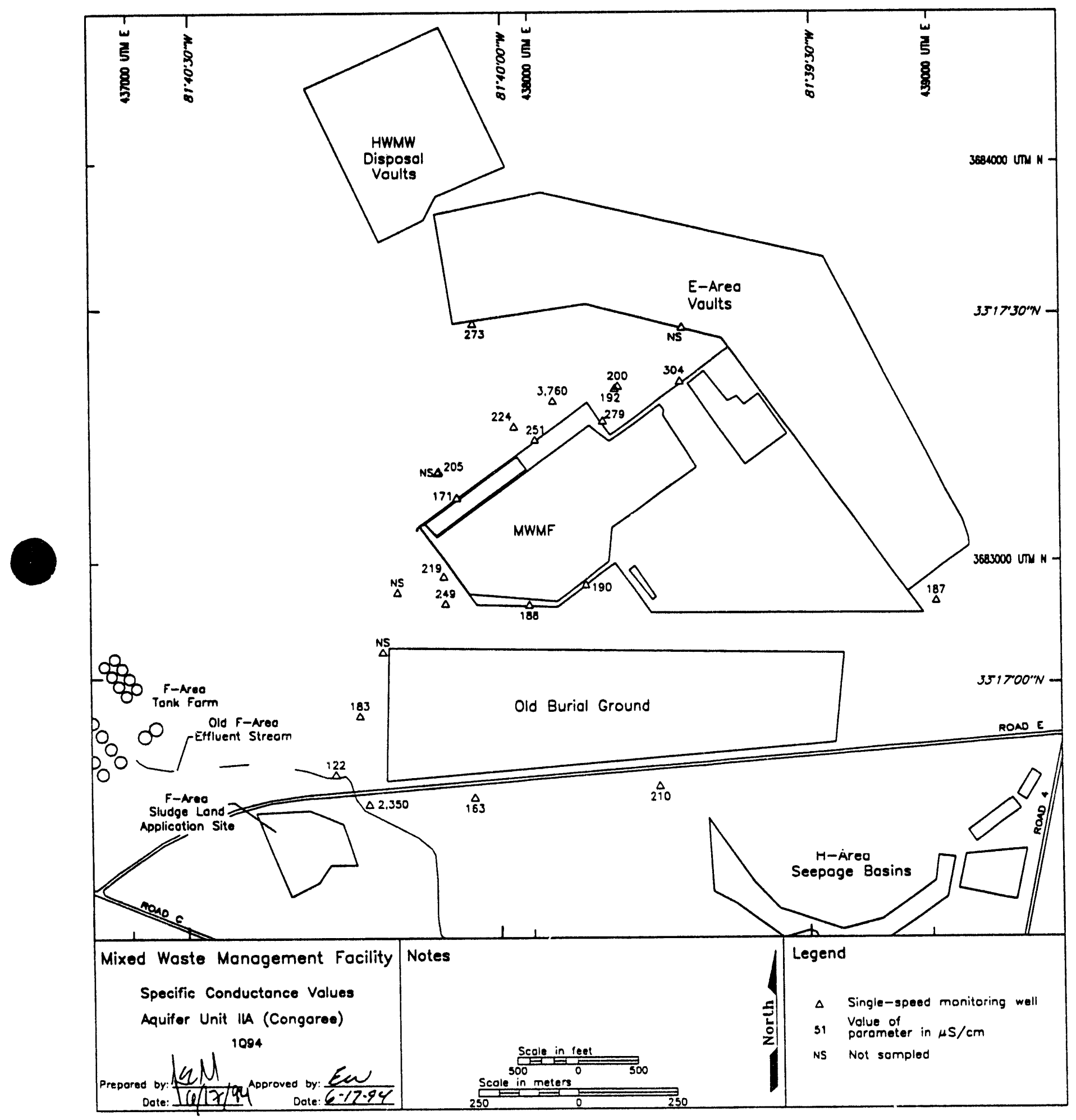

Figure 16. Specific Conductance in Aquifer Unit IIA (Congaree) at the Burial Ground Complex, First Quarter 1994 


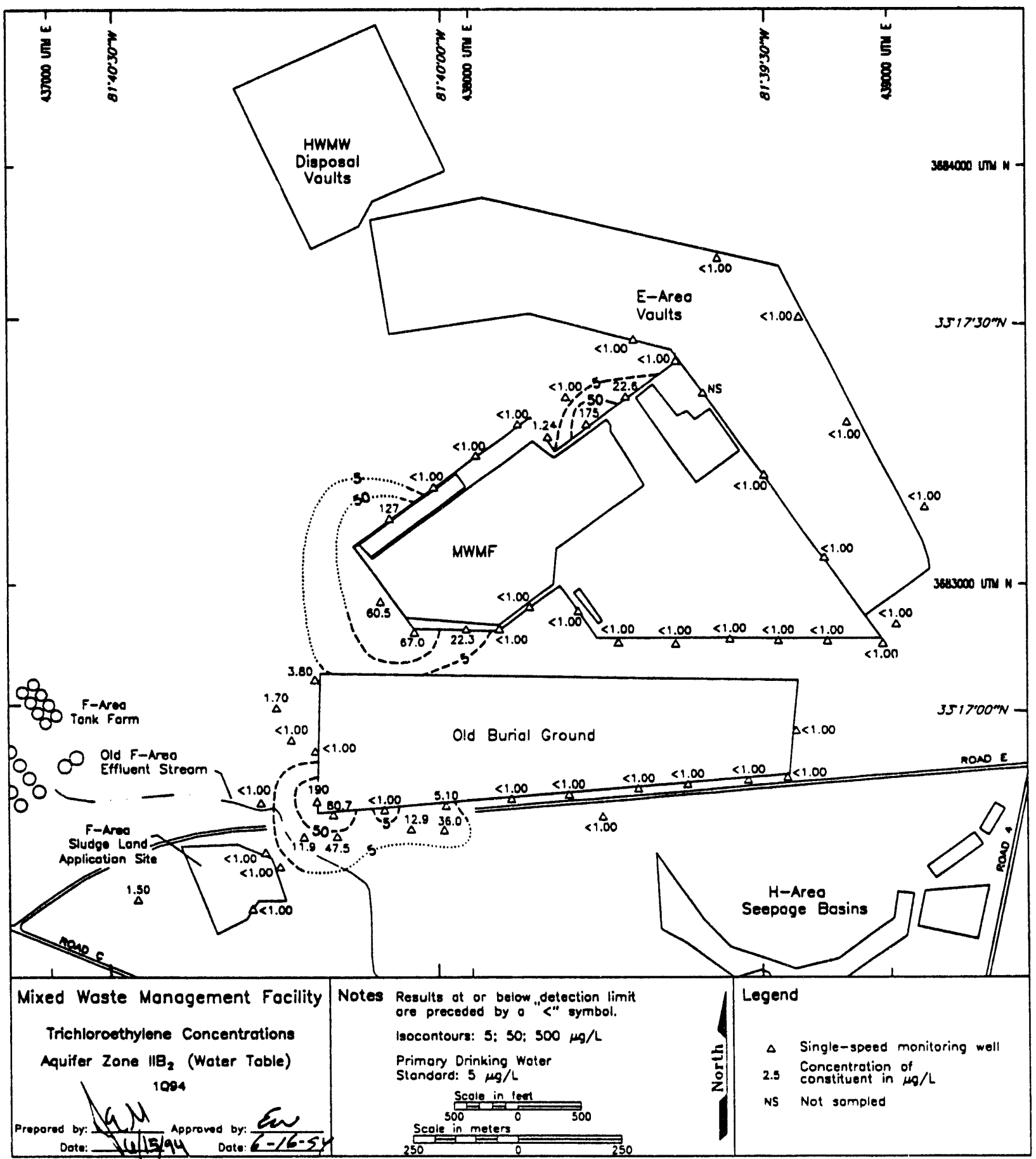

Figure 17. Trichloroethylene Concentrations in Aquifer Zone $\| B_{2}$ (Water Table) at the Burial Ground Complex, First Quarter 1994 


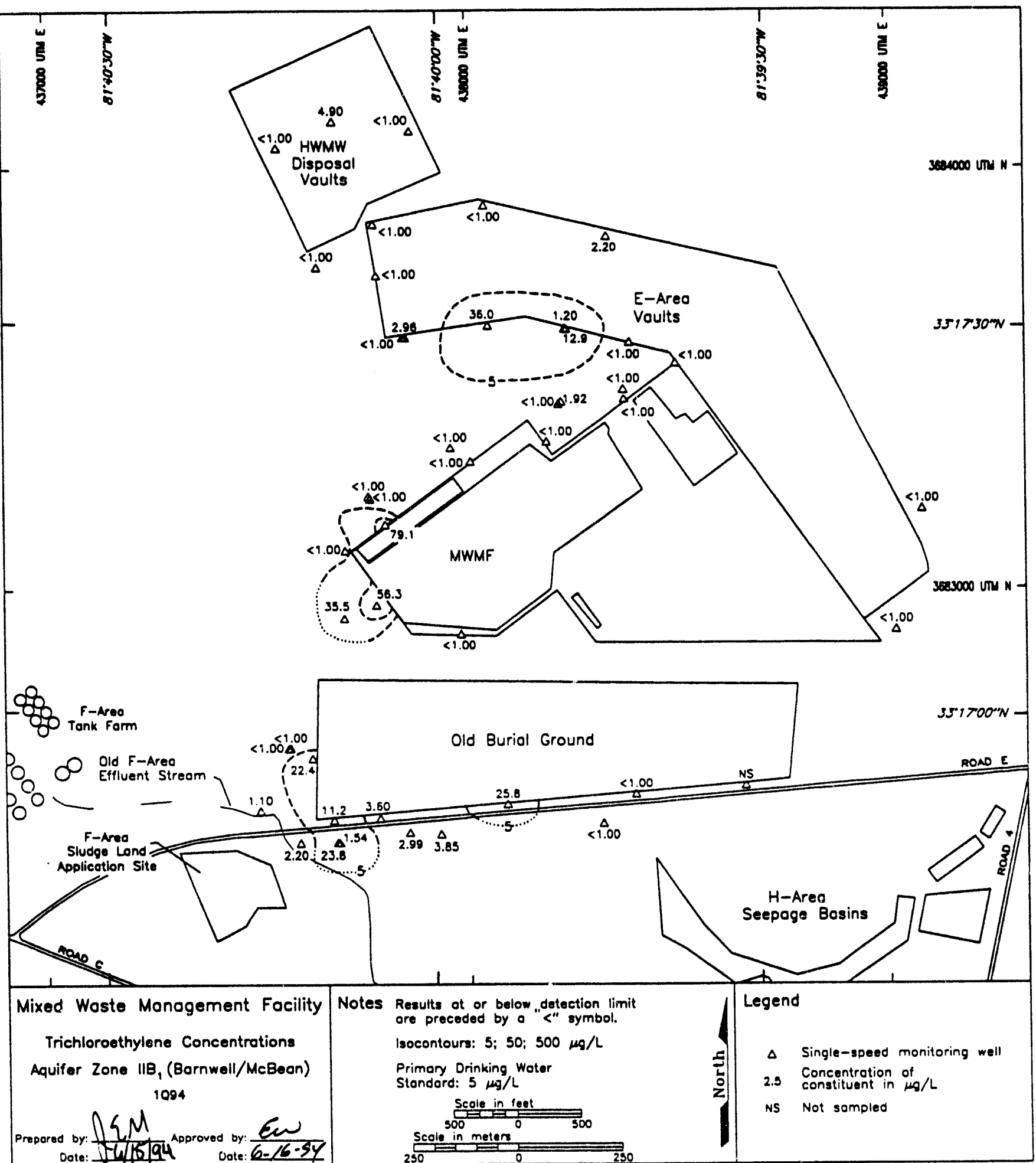

Figure 18. Trichloroethylene Concentrations in Aquifer Zone IIB, (Barnwell/McBean) at the Burial Ground Complex, First Quarter 1994 


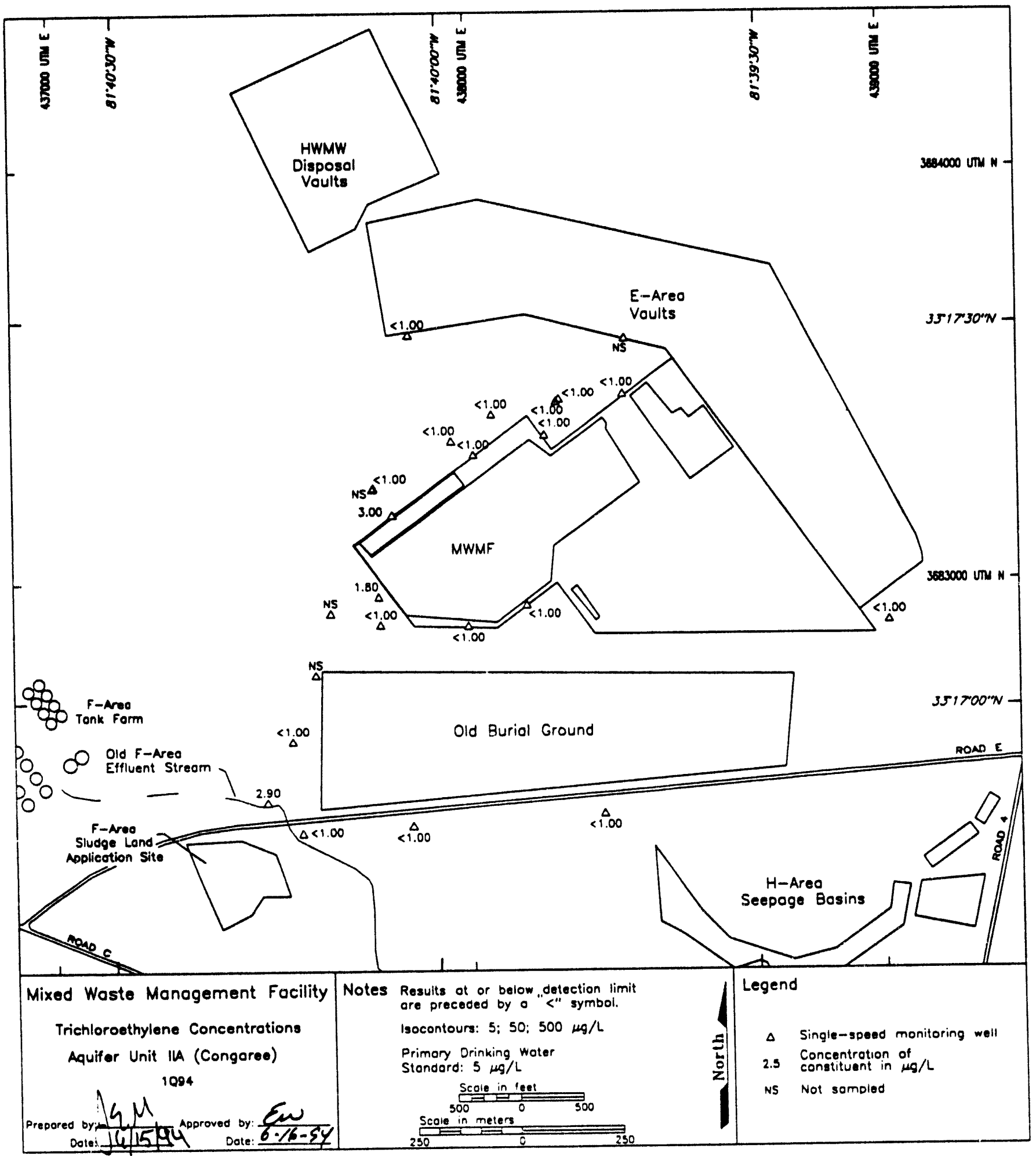

Figure 19. Trichloroethylene Concentrations in Aquifer Unit IIA (Congaree) at the Burial Ground Complex, First Quarter 1994 


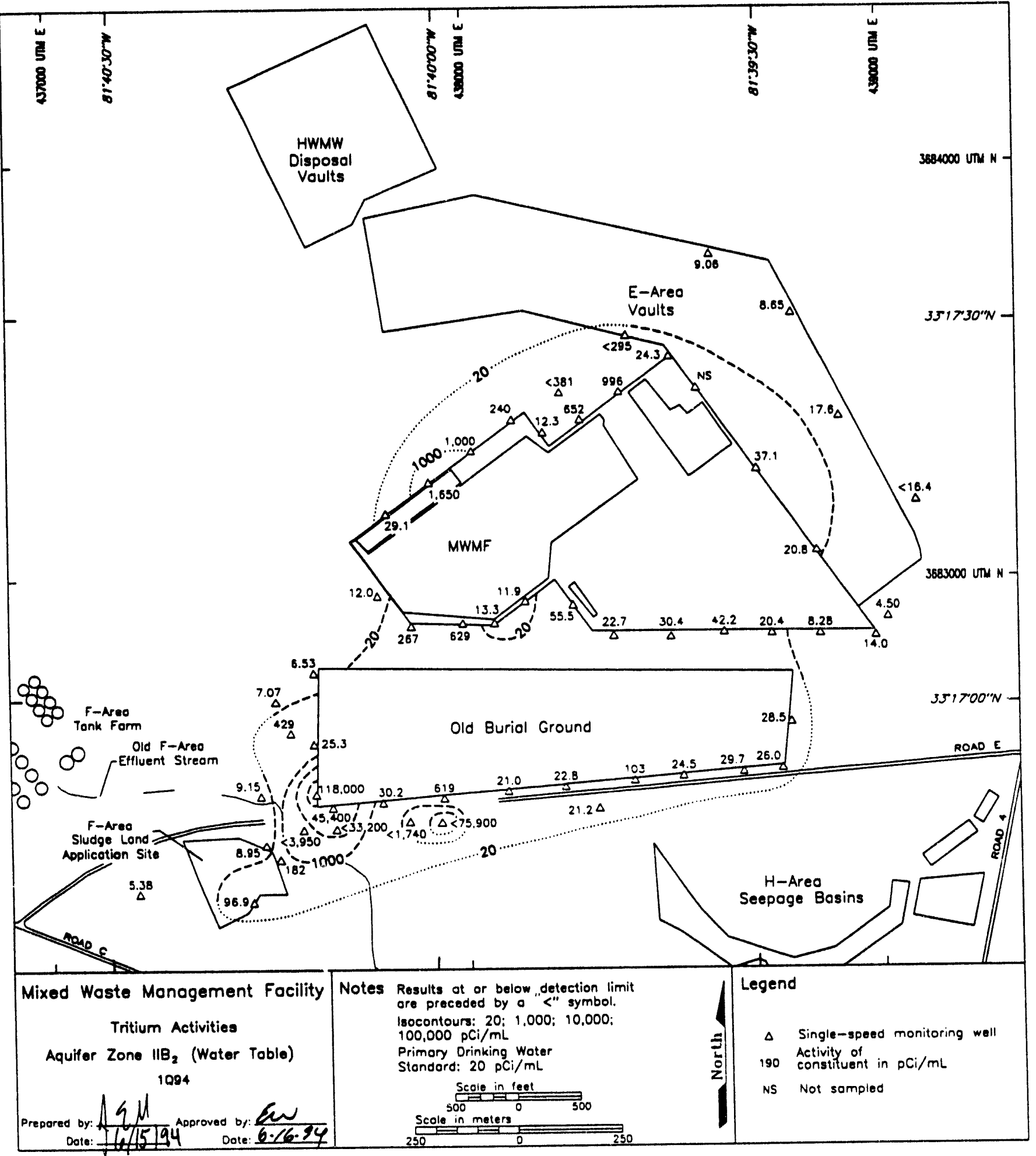

Figure 20. Tritium Activities in Aquifer Zone $\|_{2} B_{2}$ (Water Table) at the Burial Ground Complex, First Quarter 1994 


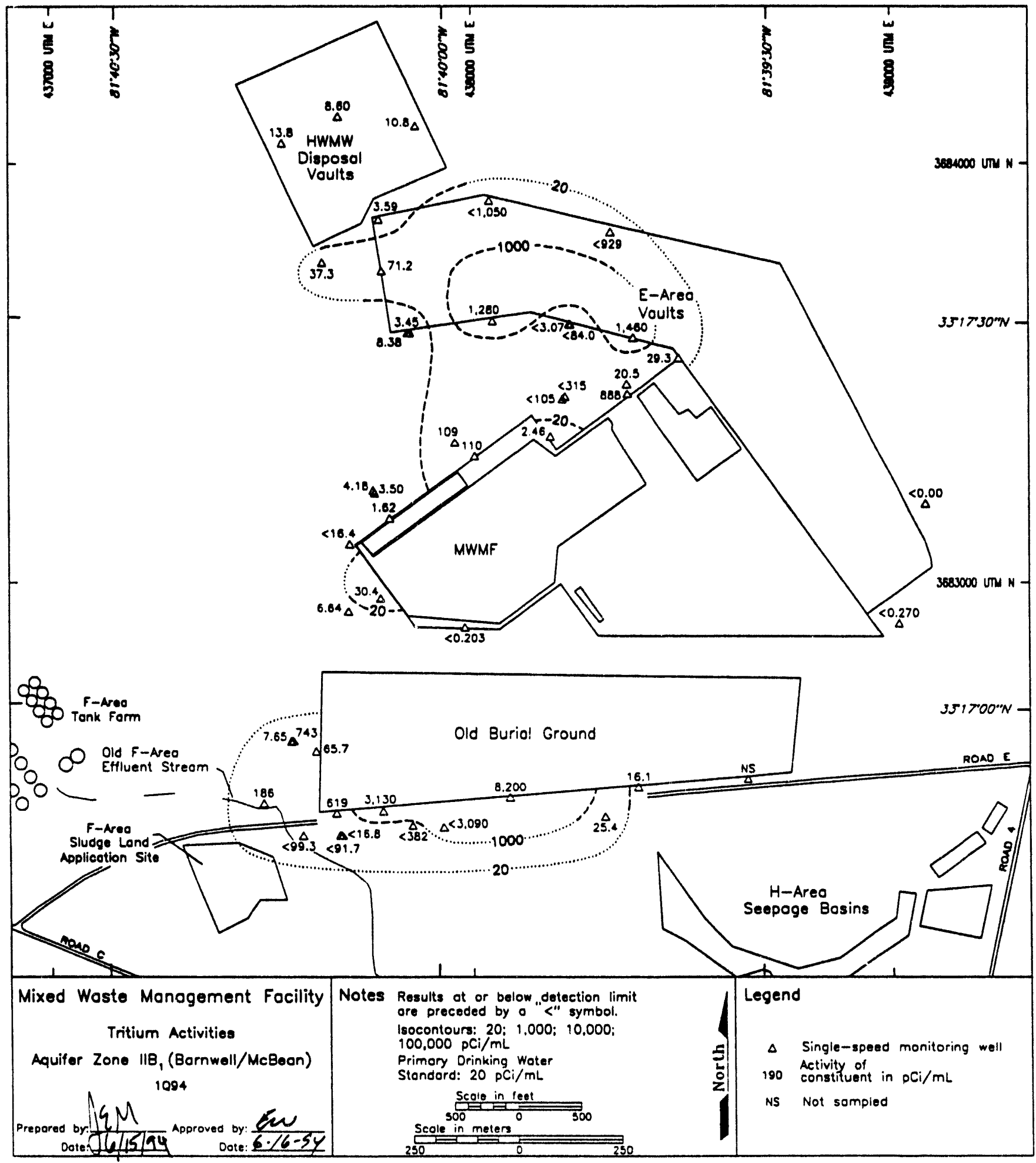

Figure 21. Tritium Activities in Aquifer Zone $\| B_{1}$ (Barnwell/McBean) at the Burial Ground Complex, First Quarter 1994 


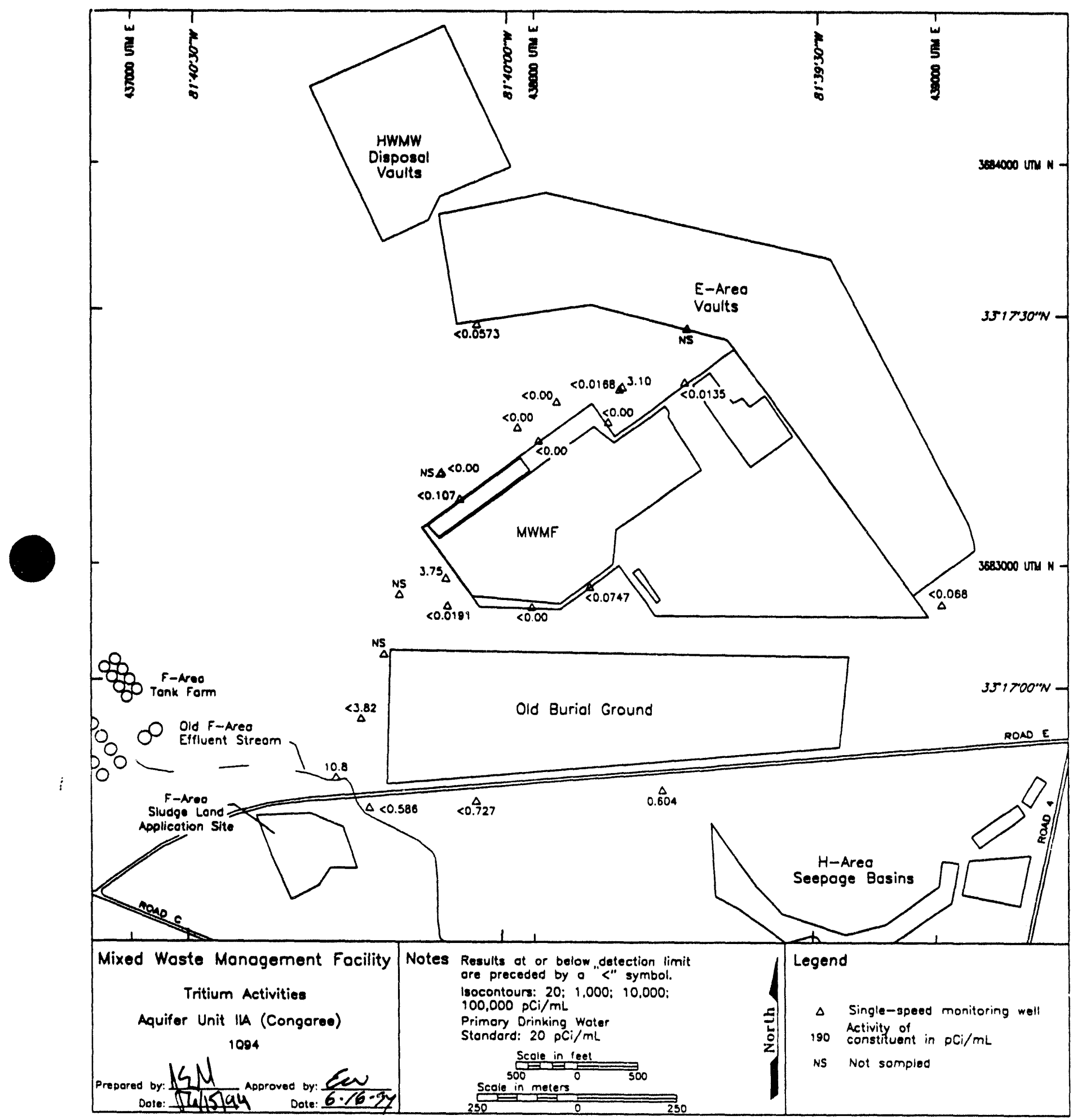

Figure 22. Tritium Activities in Aquifer Unit IIA (Congaree) at the Burial Ground Complex, First Quarter 1994 


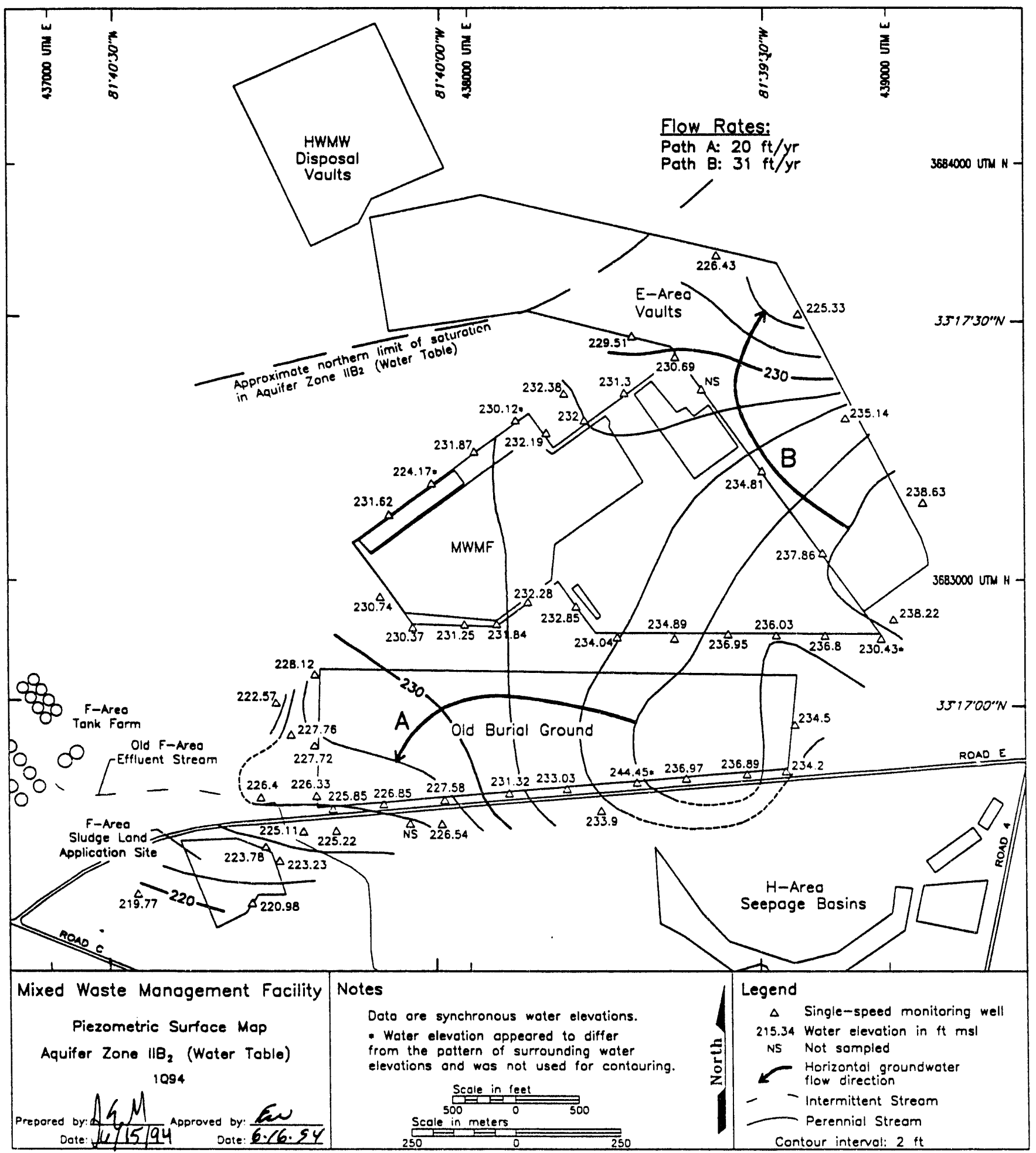

Figure 23. Piezometric Surface Map of Aquifer Zone $\| B_{2}$ (Water Table) at the Burial Ground Complex 


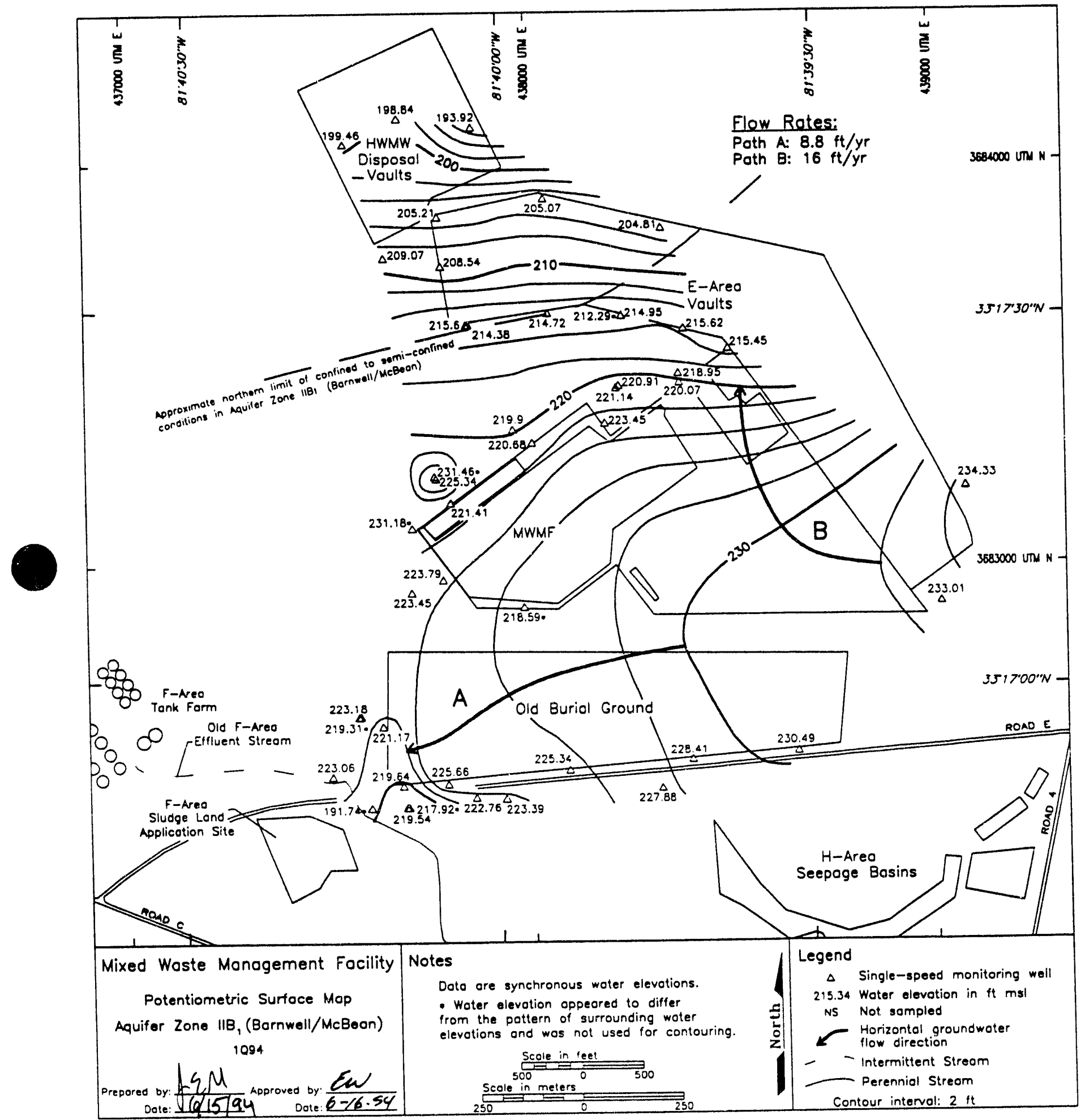

Figure 24. Potentiometric Surface Map of Aquifer Zone IIB, (Barnwell/McBean) at the Burial Ground Complex 


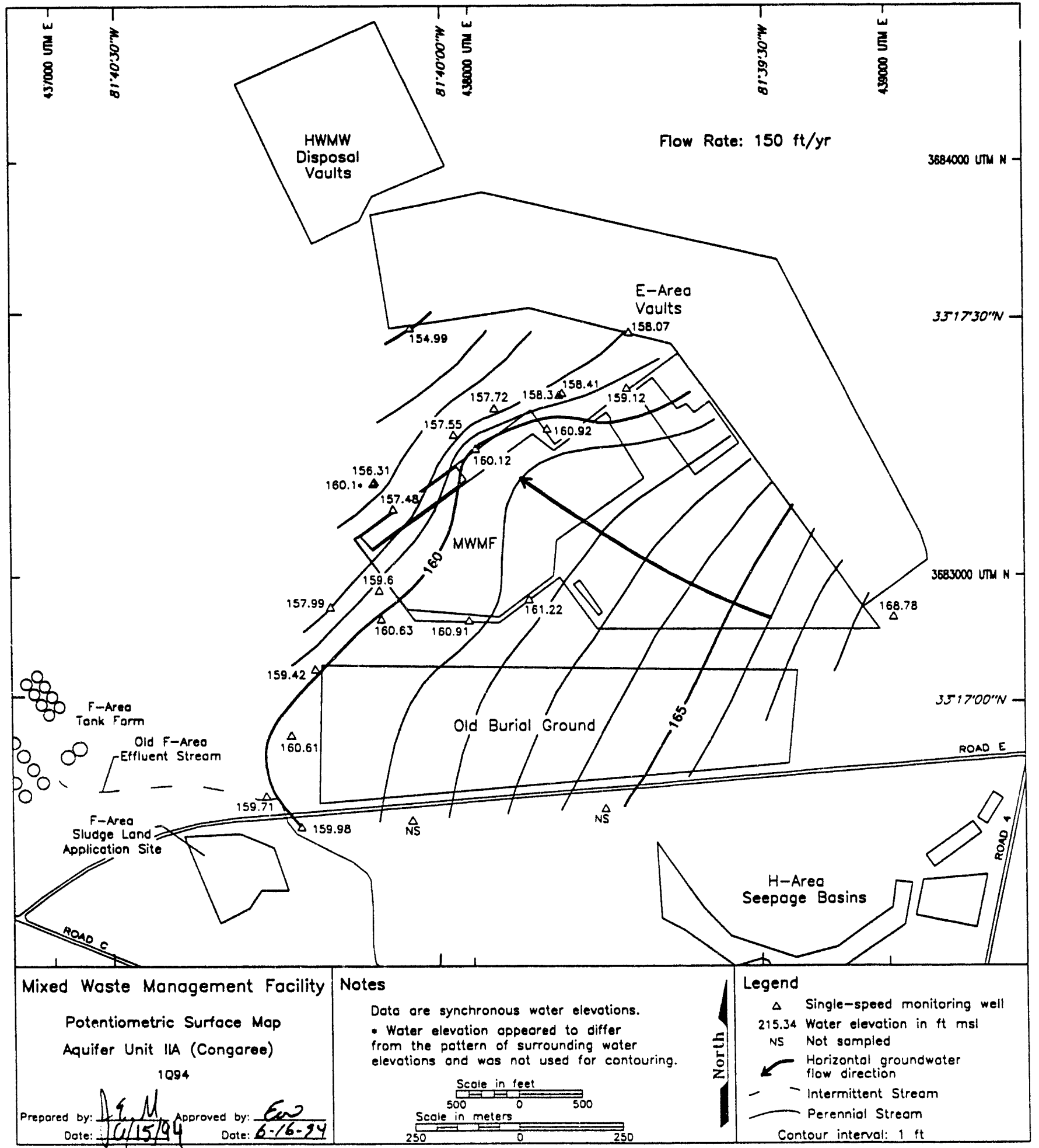

Figure 25. Potentiometric Surface Map of Aquifer Unit IIA (Congaree) at the Burial Ground Complex 


\section{References}

Aadland, R. K., and H. W. Bledsoe, 1990. Classification of Hydrostratigraphic Units at the Savannah River Site, South Carolina, WSRC-RP-90-987. Westinghouse Savannah River Company, Savannah River Site, Aiken, SC.

Aucott, W. R., M. E. Davis, and G. K. Speiran, 1987. Geohydrologic Framework of the Coastal Plain Aquifers of South Carolina, U.S. Geological Survey Water-Resources Investigations Report 85-4271.

Du Pont (E. I. du Pont de Nemours \& Company), 1989. Final Safety Analysis Report of the Defense Waste Processing Facility, DPSTSA-200-10. Savannah River Plant, Aiken, SC.

GeoTrans, Inc., 1988. A Numerical Model of the Hydrogeological System Underlying the Savannah River Plant, Final report submitted to Savannah River Laboratory. GeoTrans, Inc., Sterling, VA.

Siple, G. E., 1967. Geology and Ground Water of the Savannah River Plant and Vicinity, South Carolina. Geological Survey Water-Supply Paper 1841, Reston, VA. 
WSRC-TR-94-0240

Unclassified

THIS PAGE LEFT BLANK INTENTIONALLY. 
WSRC-TR-94-0240

Unclassified

\section{Appendix D}

\section{Groundwater Monitoring Results Tables}




\section{Key to Reading the Tables}

The following abbreviations may appear in the data tables:

\section{Constituents}

$1,2,3,4,6,7,8-H P C D D$

$1,2,3,4,6,7,8-\mathrm{HPCDF}$

$1,2,3,4,7,8-\mathrm{HXCDD}$

$1,2,3,4,7,8-H X C D F$

Lindane

PCB

$1,2,3,7,8-P C D D$

$1,2,3,7,8-\mathrm{PCDF}$

Sp. conductance

TCDD

TCDF

\section{Laboratories}

CN

EM

GE and GP

SC

SP

TM

WA and WS

\section{Sampling Codes}

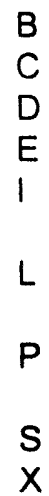

$\mathrm{s}$

\section{Sampling Methods}

$$
\begin{aligned}
& \text { B } \\
& \text { P } \\
& \text { S } \\
& \text { V }
\end{aligned}
$$

1,2,3,4,6,7,8-heptachlorodibenzo-p-dioxin

$1,2,3,4,6,7,8$-heptachlorodibenzo-p-furan

$1,2,3,4,7,8$-hexachlorodibenzo-p-dioxin

$1,2,3,4,7,8$-hexachlorodibenzo-p-furan

gamma-benzene hexachloride

polychlorinated biphenyl

1,2,3,7,8-pentachlorodibenzo-p-dioxin

1,2,3,7,8-pentachlorodibenzo-p-furan

specific conductance

tetrachlorodibenzo-p-dioxin

tetrachlorodibenzo-p-furan

Clemson Technical Center, Inc.

Environmental Protection Department/ Environmental Monitoring Section (EPD/EMS) Laboratory

General Engineering Laboratories

Savannah River Technology Center

Spencer Testing Services, Inc.

TMAVEherline

Roy F. Weston, Inc.

blank sample was collected

well was pumping continuously

well was dry

equipment blank was collected

well went dry during sampling; insufficient water to collect all samples

well went dry before sampling began; only depth to water can be determined

inaccessibility or mechanical failure prevented sample collection and field analysis of the water no water in standpipe; for water level events only well went dry during purging; samples collected after well recovered

sample collected using an open-bucket bailer sample collected using a bladder pump sample collected using a single-speed centrifugal downhole pump

sample collected using a variable-speed pump 
Units

E

$\mathrm{mg} / \mathrm{L}$

msl

MSL

NTU

pCi/L

$\mathrm{pCi} / \mathrm{mL}$

$\mathrm{pH}$

$\mu g / L$

$\mu \mathrm{S} / \mathrm{cm}$

Other

CS

D

DF

GS

$\mathrm{H}$

Mod

PDWS

PVC

TOC exponential notation (e.g., $1.1 E-09=1.1 \times 10^{-9}=$

0.0000000011 )

milligrams per liter

mean sea level

million structures per liter

turbidity unit

picocuries per liter

picocuries per milliliter

$\mathrm{pH}$ unit

micrograms per liter

microsiemens per centimeter

carbon steel

exceeded primary drinking water standard (PDWS) or screening level column in data tables

dilution factor column in data tables

groundwater protection standard column in data tables

holding time column in data tables

modifier column in data tables

primary drinking water standard

polyvinyl chloride

top of casing

\section{Holding Times}

Standard analytical methods include a limit, called holding time, on the maximum elapsed time between sample collection and extraction or analysis by the laboratory. In the data tables, a large bullet $(\cdot)$ in the $H$ (holding time) column indicates that holding time was exceeded.

Analyses performed beyond holding times may not yield valid results.

The South Carolina Department of Health and Environmental Control allows only 15 minutes to elapse between sampling and analysis for $\mathrm{pH}$. Thus, only field $\mathrm{pH}$ measurements can meet the holding time criterion; laboratory $\mathrm{pH}$ analyses always will exceed it.

The laboratory procedure used for the determination of specific conductance allows one day to elapse between sampling and analysis. Thus, laboratory specific conductance measurements may exceed the holding time criterion.

\section{Data Rounding}

Constituent results in analytical results tables that appear to equal the final PDWS but are not marked in the $D$ (exceeded the final PDWS or screening level) column are below the final PDWS in the database. Values stored in the database contain more significant digits than the reported results. Apparent discrepancies in the tables are due to the rounding of reported results. 


\section{Data Qualification}

The contract laboratories continually assess their own accuracy and precision according to U.S. Environmental Protection Agency (EPA) guidelines. They submit sample- or batch-specific quality assurance/quality control information either at the same time as analytical results or in a quarterly summary. Properly defined and used result modifiers (also referred to as qualifiers) can be a key component in assessing data useability. Result modifiers designed by the Environmental Protection Department/Environmental Monitoring Section and provided to the primary laboratories are defined below. These modifiers appear in the data tables under the column Mod. The lettered modifiers are based on EPA's STORET codes.

\section{Result modifier Definition}

(Blank)

J

$L$

M

R

T

V

Y

1

2

3

4

6
Data are not qualified. Numbers should be interpreted exactly as reported.

Value is estimated because quantitation in the sample or in associated quality control samples did not meet specifications.

Value is off-scale high. The actual value is not known but is known to be greater than the value shown.

Presence of the analyte is verified but not quantified.

Result was rejected because performance requirements in the sample analysis or associated quality control analyses were not met.

Analyte was not detected; if present, it was below the criteria for detection.

Analyte was detected in an associated method blank.

Result was obtained from an unpreserved or improperly preserved sample. Data may not be accurate.

Result may be an underestimation of the true value due to analytical bias.

Result may be an overestimation of the true value due to analytical bias.

The associated result may be of poor precision (high variability) due to analytical bias.

Result is associated with QA results indicating matrix interference.

The associated result is from a reanalysis performed out of holding time due to problems with an earlier analysis. 
Table 1. Maximum Levels of Constituents Exceeding the Final Primary Drinking Water Standards

Aquifer Zone $\mathrm{IB}_{2}$ (Water Table)

\begin{tabular}{|c|c|c|c|c|c|c|c|}
\hline Well & Constituent & $\underline{\text { Unit }}$ & $\underline{2093}$ & 3Q93 & $4 Q 93$ & $\underline{1094}$ & Mod \\
\hline$B G O 2 D$ & Tritium & $\mathrm{pCi} / \mathrm{mL}$ & $-^{a}$ & - & $2.0 E+01$ & $2.1 E+01$ & \\
\hline BGO 3D & Tritium & $\mathrm{pCi} / \mathrm{mL}$ & 4.3E+01 & $4.0 E+01$ & $3.9 E+01$ & $3.7 E+01$ & \\
\hline BGO 5D & Tritium & $\mathrm{pCi} / \mathrm{mL}$ & - & $2.7 E+01$ & - & $2.4 E+01$ & \\
\hline$B G O \quad 6 D$ & $\begin{array}{l}\text { Tetrachloroethylene } \\
\text { Trichloroethylene } \\
\text { Tritium }\end{array}$ & $\begin{array}{l}\mu \mathrm{g} / \mathrm{L} \\
\mu \mathrm{g} / \mathrm{L} \\
\mathrm{pCi} / \mathrm{mL}\end{array}$ & $\begin{array}{l}- \\
26 \\
1.3 E+03\end{array}$ & $\begin{array}{l}5.2 \\
40 \\
1.4 E+03\end{array}$ & $\begin{array}{l}- \\
23 \\
1.2 E+03\end{array}$ & $\begin{array}{l}- \\
23 \\
1.0 E+03\end{array}$ & \\
\hline BGO $7 D$ & $\begin{array}{l}\text { Dichloromethane } \\
\text { Tetrachloroethylene } \\
\text { Trichloroethylene } \\
\text { Tritium }\end{array}$ & $\begin{array}{l}\mu g / \mathrm{L} \\
\mu \mathrm{g} / \mathrm{L} \\
\mu \mathrm{g} / \mathrm{L} \\
\mathrm{pCi} / \mathrm{mL}\end{array}$ & $\begin{array}{l}7.7 \\
- \\
41 \\
1.2 E+02\end{array}$ & $\begin{array}{l}13 \\
- \\
55 \\
1.6 E+02\end{array}$ & $\begin{array}{l}\overline{7.0} \\
98 \\
5.2 E+02\end{array}$ & $\begin{array}{l}- \\
13 \\
175 \\
6.5 E+02\end{array}$ & $J$ \\
\hline BGO $8 D$ & Tritium & $\mathrm{pCi} / \mathrm{mL}$ & - & $2.9 E+01$ & - & - & \\
\hline BGO $3 D$ & Tritium & $\mathrm{pCi} / \mathrm{mL}$ & $2.0 E+01$ & 2.7E+02 & $2.1 E+02$ & $2.4 E+n 2$ & \\
\hline BGO 10DR & Tritium & $\mathrm{pCi} / \mathrm{mL}$ & $2.0 E+03$ & $8.6 E+02$ & $6.7 E+02$ & $1.0 E+03$ & \\
\hline BGO 11D & Tritium & $\mathrm{pCi} / \mathrm{mL}$ & $9.5 E+02$ & $1.4 E+03$ & $1.5 E+03$ & $1.7 E+03$ & \\
\hline BGO 12D & $\begin{array}{l}\text { Dichloromethane } \\
\text { Trichloroethylene } \\
\text { Tritium }\end{array}$ & $\begin{array}{l}\mu \mathrm{g} / \mathrm{L} \\
\mu \mathrm{g} / \mathrm{L} \\
\mathrm{pCi} / \mathrm{mL}\end{array}$ & $\begin{array}{l}8.5 \\
83 \\
-\end{array}$ & $\begin{array}{l}15 \\
139 \\
2.6 E+01\end{array}$ & $\begin{array}{l}- \\
100 \\
3.1 E+01\end{array}$ & $\begin{array}{l}- \\
127 \\
2.9 E+01\end{array}$ & \\
\hline BGO 14DR & $\begin{array}{l}\text { Dichloromethane } \\
\text { Trichloroethylene }\end{array}$ & $\begin{array}{l}\mu \mathrm{g} / \mathrm{L} \\
\mu \mathrm{g} / \mathrm{L}\end{array}$ & - & $\overline{86}$ & $\begin{array}{l}6.6 \\
252\end{array}$ & $\overline{61}$ & \\
\hline BGO 15D & $\begin{array}{l}\text { Tetrachloroethylene } \\
\text { Trichloroethylene } \\
\text { Tritium }\end{array}$ & $\begin{array}{l}\mu \mathrm{g} / \mathrm{L} \\
\mu \mathrm{g} / \mathrm{L} \\
\mathrm{pCi} / \mathrm{mL}\end{array}$ & $\begin{array}{l}6.0 \\
80 \\
5.3 E+02\end{array}$ & $\begin{array}{l}8.2 \\
105 \\
4.6 E+02\end{array}$ & $\begin{array}{l}5.0 \\
54 \\
3.2 E+02\end{array}$ & $\begin{array}{l}- \\
67 \\
2.7 E+02\end{array}$ & \\
\hline$B G O 16 D$ & $\begin{array}{l}\text { Trichloroethylene } \\
\text { Tritium }\end{array}$ & $\begin{array}{l}\mu \mathrm{g} / \mathrm{L} \\
\mathrm{pCi} / \mathrm{mL}\end{array}$ & $\begin{array}{l}19 \\
1.3 E+03\end{array}$ & $\begin{array}{l}16 \\
1.1 E+03\end{array}$ & $\begin{array}{l}10 \\
6.9 E+02\end{array}$ & $\begin{array}{l}22 \\
6.3 E+02\end{array}$ & \\
\hline BGO 19D & Tritium & $\mathrm{pCi} / \mathrm{mL}$ & $N A^{b}$ & NA & $4.0 E+01$ & $5.6 \mathrm{E}+01$ & \\
\hline BGO 20D & Tritium & $\mathrm{pCi} / \mathrm{mL}$ & - & $2.1 E+01$ & $2.2 E+01$ & $2.3 E+01$ & \\
\hline BGO 21D & Tritium & $\mathrm{pCi} / \mathrm{mL}$ & 3.1E+01 & $3.1 E+01$ & $3.2 E+01$ & $3.0 E+01$ & \\
\hline$B G O 22 D R$ & Tritium & $\mathrm{pCi} / \mathrm{mL}$ & $5.0 \mathrm{E}+01$ & $4.6 E+01$ & $4.4 E+01$ & $4.2 E+01$ & \\
\hline BGO $23 D$ & Tritium & $\mathrm{pCi} / \mathrm{mL}$ & $2.2 \mathrm{E}+01$ & $2.3 E+01$ & $2.4 E+01$ & $2.0 E+01$ & \\
\hline BGO 26D & Lead & $\mu g / L$ & - & - & 73 & - & \\
\hline
\end{tabular}


Aquifer Zone $\mathrm{IB}_{2}$ (Water Table)

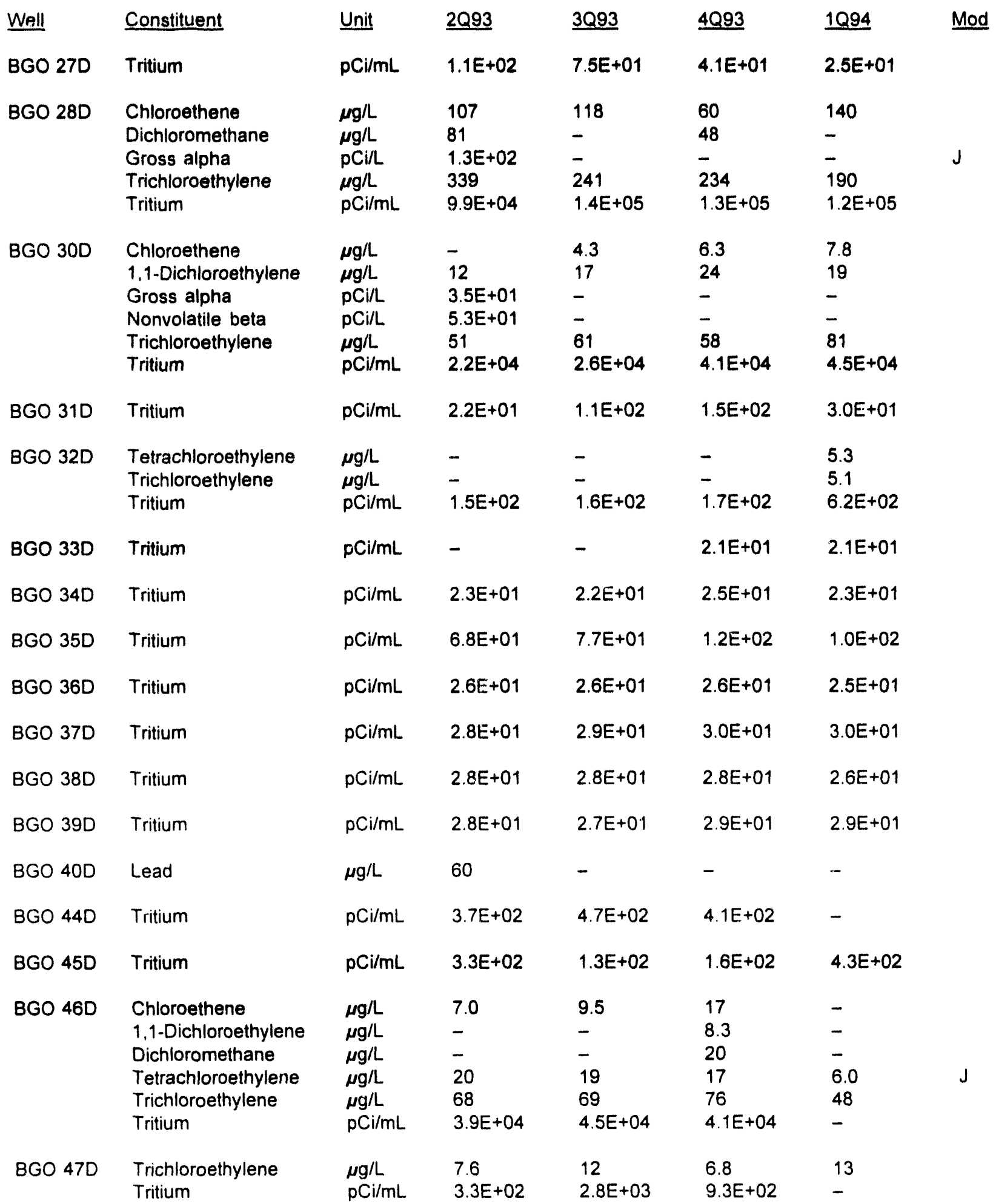


Aquifer Zone $\| B_{2}$ (Water Table)

\begin{tabular}{|c|c|c|c|c|c|c|}
\hline Well & Constituent & Unit & 2093 & 3093 & $4 Q 93$ & 1094 \\
\hline BGO 48D & $\begin{array}{l}\text { Carbon tetrachloride } \\
\text { Dichloromethane } \\
\text { Tetrachloroethylene } \\
\text { Trichloroethylene } \\
\text { Tritium }\end{array}$ & $\begin{array}{l}\mu g / L \\
\mu g / L \\
\mu g / L \\
\mu g / L \\
p C i / m L\end{array}$ & $\begin{array}{l}- \\
13 \\
21 \\
89 \\
4.1 E+04\end{array}$ & $\begin{array}{l}- \\
- \\
29 \\
125 \\
4.8 E+04\end{array}$ & $\begin{array}{l}5.5 \\
- \\
304 \\
300 \\
8.8 E+04\end{array}$ & $\begin{array}{l}- \\
\overline{68} \\
36 \\
-\end{array}$ \\
\hline BGO 49D & Tritium & $\mathrm{pCi} / \mathrm{mL}$ & $2.1 E+01$ & 2.1E+01 & $2.1 E+01$ & $2.1 E+01$ \\
\hline BGO 50D & $\begin{array}{l}\text { Trichloroethylene } \\
\text { Tritium }\end{array}$ & $\begin{array}{l}\mu \mathrm{g} / \mathrm{L} \\
\mathrm{pCi} / \mathrm{mL}\end{array}$ & $\begin{array}{l}24 \\
6.3 E+03\end{array}$ & $\begin{array}{l}17 \\
4.5 E+03\end{array}$ & $\begin{array}{l}11 \\
3.1 E+03\end{array}$ & $\begin{array}{l}12 \\
-\end{array}$ \\
\hline$B G X \quad 1 D$ & Tritium & $\mathrm{pCi} / \mathrm{mL}$ & $3.8 E+02$ & $3.3 E+02$ & $3.5 E+02$ & - \\
\hline$B G \times 10 D$ & Lead & $\mu g / L$ & 108 & 59 & 53 & - \\
\hline FSS 1D & $\begin{array}{l}\text { Copper } \\
\text { Lead }\end{array}$ & $\begin{array}{l}\mu g / L \\
\mu g / L\end{array}$ & $\begin{array}{l}\text { NA } \\
\text { NA }\end{array}$ & $\begin{array}{l}\text { NA } \\
58\end{array}$ & $\begin{array}{l}\text { NA } \\
\text { NA }\end{array}$ & $\begin{array}{l}1,400 \\
119\end{array}$ \\
\hline FSS 20 & Tritium & $\mathrm{pCi} / \mathrm{mL}$ & NA & $7.7 E+01$ & NA & $1.8 E+02$ \\
\hline FSS 3D & $\begin{array}{l}\text { Lead } \\
\text { Tritium }\end{array}$ & $\begin{array}{l}\mu g / L \\
p C i / m L\end{array}$ & $\begin{array}{l}\text { NA } \\
\text { NA }\end{array}$ & $\begin{array}{l}329 \\
4.3 E+01\end{array}$ & $\begin{array}{l}\text { NA } \\
\text { NA }\end{array}$ & $\overline{9} .7 E+01$ \\
\hline
\end{tabular}

Aquifer Zone IIB, (Barnwell/McBean)

\begin{tabular}{|c|c|c|c|c|c|c|}
\hline Well & Constituent & Unit & $\underline{2093}$ & 3Q93 & 4093 & 1094 \\
\hline $\mathrm{BGO} 5 \mathrm{C}$ & Tritium & $\mathrm{pCi} / \mathrm{mL}$ & $3.0 E+01$ & $2.5 E+01$ & $2.5 E+01$ & $2.9 E+01$ \\
\hline BGO $6 B$ & Tritium & $\mathrm{pCi} / \mathrm{mL}$ & $3.4 E+01$ & - & $2.5 E+01$ & 2.1E+01 \\
\hline$B G O \quad 6 C$ & Tritium & $\mathrm{pCi} / \mathrm{mL}$ & $9.5 \mathrm{E}+02$ & $9.2 E+02$ & $8.8 E+02$ & $8.9 E+02$ \\
\hline BGO 10B & Tritium & $\mathrm{pCi} / \mathrm{mL}$ & $7.9 E+01$ & $1.9 E+02$ & $7.8 E+01$ & 1.1E+02 \\
\hline BGO $10 \mathrm{C}$ & Tritium & $\mathrm{pCi} / \mathrm{mL}$ & $1.6 \mathrm{E}+02$ & $14 E+02$ & - & 1.1E+02 \\
\hline BGO 12CR & Trichloroethylene & $\mu g / L$ & 24 & 81 & 71 & 79 \\
\hline BGO 13DR & Tritium & $\mathrm{pCi} / \mathrm{mL}$ & $3.1 E+01$ & $2.6 E+01$ & $2.1 E+01$ & - \\
\hline BGO 14CR & $\begin{array}{l}\text { Trichloroethylene } \\
\text { Tritium }\end{array}$ & $\begin{array}{l}\mu \mathrm{g} / \mathrm{L} \\
\mathrm{pCi} / \mathrm{mL}\end{array}$ & $\begin{array}{l}48 \\
3.5 E+01\end{array}$ & $\begin{array}{l}52 \\
3.4 E+01\end{array}$ & $\begin{array}{l}45 \\
3.0 E+01\end{array}$ & $\begin{array}{l}56 \\
3.0 E+01\end{array}$ \\
\hline BGO 16B & Tritium & $\mathrm{pCi} / \mathrm{mL}$ & $4.2 E+01$ & - & - & - \\
\hline
\end{tabular}


Aquifer Zone IIB, (Barnwell/McBean)

\begin{tabular}{|c|c|c|c|c|c|c|}
\hline Well & Constifuent & Unit & $\underline{2 Q 93}$ & $\underline{3093}$ & 4093 & 1094 \\
\hline BGO 27C & $\begin{array}{l}\text { Trichloroethylene } \\
\text { Tritium }\end{array}$ & $\begin{array}{l}\mu g / L \\
\mathrm{pCi} / \mathrm{mL}\end{array}$ & $\begin{array}{l}25 \\
5.8 E+01\end{array}$ & $\begin{array}{l}25 \\
7.8 E+01\end{array}$ & $\begin{array}{l}21 \\
6.5 E+01\end{array}$ & $\begin{array}{l}22 \\
6.6 E+01\end{array}$ \\
\hline BGO 29C & Tritium & $\mathrm{pCi} / \mathrm{mL}$ & $9.6 \mathrm{E}+01$ & $1.2 E+02$ & $1.5 E+02$ & $1.9 E+02$ \\
\hline BGO $30 \mathrm{C}$ & $\begin{array}{l}\text { Trichloroethylene } \\
\text { Tritium }\end{array}$ & $\begin{array}{l}\mu \mathrm{g} / \mathrm{L} \\
\mathrm{pCi} / \mathrm{mL}\end{array}$ & $\begin{array}{l}11 \\
3.9 E+02\end{array}$ & $\begin{array}{l}11 \\
6.2 E+02\end{array}$ & $\begin{array}{l}11 \\
7.3 E+02\end{array}$ & $\begin{array}{l}11 \\
6.2 E+02\end{array}$ \\
\hline BGO 31C & $\begin{array}{l}\text { Dichloromethane } \\
\text { Tritium }\end{array}$ & $\underset{p \mathrm{Ci} / \mathrm{m}, \mathrm{L}}{\mu / \mathrm{L}}$ & $\begin{array}{l}5.4 \\
2.5 E+03\end{array}$ & $\overline{2.4 E+03}$ & $3.4 E+03$ & $3.1 E+03$ \\
\hline BGD 33C & $\begin{array}{l}\text { Dichloromethane } \\
\text { Mercury } \\
\text { Tetrachloroethylene } \\
\text { Trichloroethylene } \\
\text { Tritium }\end{array}$ & $\begin{array}{l}\mu g / L \\
\mu g / L \\
\mu g / L \\
\mu g / L \\
p C i / m L\end{array}$ & $\begin{array}{l}5.1 \\
- \\
5.9 \\
27 \\
7.2 . E+03\end{array}$ & $\begin{array}{l}\overline{2.2} \\
\overline{28} \\
8.2 E+03\end{array}$ & $\begin{array}{l}\overline{2 .} \\
\overline{2} \\
22 \\
8.0 E+03\end{array}$ & $\begin{array}{l}- \\
2.8 \\
5.1 \\
26 \\
8.2 E+03\end{array}$ \\
\hline$B G O 42 C$ & $\begin{array}{l}\text { Dichloromethane } \\
\text { Trichloroethylene }\end{array}$ & $\begin{array}{l}\mu g / L \\
\mu g / L\end{array}$ & $\overline{76}$ & - & $\begin{array}{l}10 \\
47\end{array}$ & $\overline{36}$ \\
\hline BGO 44B & $\begin{array}{l}\text { Lead } \\
\text { Tritium }\end{array}$ & $\underset{\mathrm{pCi} / \mathrm{mL}}{\mu \mathrm{L}}$ & $\overline{8.4 E+02}$ & $\overline{4} .7 E+02$ & $\overline{2} .8 E+02$ & $\begin{array}{l}55 \\
-\end{array}$ \\
\hline BGO 44C & Tritium & $\mathrm{pCi} / \mathrm{mL}$ & $5.5 E+02$ & $4.1 E+02$ & $2.9 E+02$ & - \\
\hline BGO $45 \mathrm{C}$ & Tritium & $\mathrm{pCi} / \mathrm{mL}$ & $5.6 \mathrm{E}+02$ & $6.9 E+02$ & $7.5 E+02$ & $7.4 E+02$ \\
\hline BGO 468 & Tritium & $\mathrm{pCi} / \mathrm{mL}$ & $5.9 E+01$ & $2.2 E+01$ & $4.0 E+01$ & - \\
\hline BGO $46 C$ & $\begin{array}{l}\text { Trichloroethylene } \\
\text { Tritium }\end{array}$ & $\begin{array}{l}\mu \mathrm{g} / \mathrm{L} \\
\mathrm{pCi} / \mathrm{mL}\end{array}$ & $\begin{array}{l}24 \\
7.8 E+01\end{array}$ & $\begin{array}{l}26 \\
7.9 E+01\end{array}$ & $\begin{array}{l}22 \\
9.0 E+01\end{array}$ & $\begin{array}{l}24 \\
-\end{array}$ \\
\hline $\mathrm{BGO} 47 \mathrm{C}$ & Tritium & $\mathrm{pCi} / \mathrm{mL}$ & $1.0 E+03$ & $3.4 E+02$ & $3.5 E+02$ & - \\
\hline $\mathrm{BGO} 48 \mathrm{C}$ & $\begin{array}{l}\text { Trichloroethylene } \\
\text { Tritium }\end{array}$ & $\begin{array}{l}\mu \mathrm{g} / \mathrm{L} \\
\mathrm{pCi} / \mathrm{mL}\end{array}$ & $\overline{2} .7 E+03$ & $\overline{3.1 E}+03$ & $\begin{array}{l}5.5 \\
3.2 E+03\end{array}$ & - \\
\hline$B G O 49 \mathrm{C}$ & Tritium & $\mathrm{pCi} / \mathrm{mL}$ & $3.6 E+01$ & $2.6 \mathrm{E}+01$ & $3.5 E+01$ & $2.5 E+01$ \\
\hline BGO 50C & $\begin{array}{l}\text { Trichloroethylene } \\
\text { Tritium }\end{array}$ & $\begin{array}{l}\mu \mathrm{g} / \mathrm{L} \\
\mathrm{pCi} / \mathrm{mL}\end{array}$ & $\begin{array}{l}15 \\
6.9 E+01\end{array}$ & $\begin{array}{l}12 \\
7.9 E+01\end{array}$ & $\overline{8.5 E}+01$ & - \\
\hline$B G X \quad 1 C$ & Tritium & $\mathrm{pCi} / \mathrm{mL}$ & $8.4 E+02$ & $8.7 E+02$ & $1.2 E+03$ & $1.5 E+03$ \\
\hline$B G X \quad 2 D$ & $\begin{array}{l}\text { Trichloroethylene } \\
\text { Tritium }\end{array}$ & $\underset{p C i / m L}{\mu g / L}$ & $\begin{array}{l}12 \\
8.8 E+01\end{array}$ & $\begin{array}{l}12 \\
8.7 E+01\end{array}$ & $\begin{array}{l}12 \\
8.6 E+01\end{array}$ & $\begin{array}{l}13 \\
-\end{array}$ \\
\hline$B G X \quad 3 D$ & $\begin{array}{l}\text { Trichloroethylene } \\
\text { Tritium }\end{array}$ & $\begin{array}{l}\mu g / L \\
\mathrm{pCi} / \mathrm{mL}\end{array}$ & $\overline{1.1 E+03}$ & $\overline{1.2 E}+03$ & $\overline{1.2 E+03}$ & $\begin{array}{l}36 \\
1.3 E+03\end{array}$ \\
\hline
\end{tabular}


Aquifer Zone IIB, (Barnwell/McBean)

\begin{tabular}{|c|c|c|c|c|c|c|c|c|}
\hline Well & & Constituent & Jnit & $\underline{2 Q 93}$ & $\underline{3 Q 93}$ & 4Q93 & 1094 & Mod \\
\hline$B G X$ & $5 D$ & $\begin{array}{l}\text { Nonvolatile beta } \\
\text { Tritium }\end{array}$ & $\begin{array}{l}\mathrm{pCiiL} \\
\mathrm{pCi} / \mathrm{mL}\end{array}$ & $\overline{5.5 E}+01$ & $\overline{5.3 E}+01$ & $\overline{6} .1 E+01$ & $\begin{array}{l}1.5 E+02 \\
7.1 E+01\end{array}$ & \\
\hline$B G X$ & $7 D$ & Tritium & $\mathrm{pCi} / \mathrm{mL}$ & NA & $1.6 \mathrm{E}+03$ & $1.4 E+03$ & - & \\
\hline$B G X$ & 8DR & Tritium & $\mathrm{pCi} / \mathrm{mL}$ & $8.9 E+02$ & $9.2 E+02$ & 9.7E+02 & - & \\
\hline$B G X$ & $12 C$ & Dichloromethane & $\mu g / L$ & 14 & - & - & - & $J$ \\
\hline HMD & $1 D$ & Tritium & $\mathrm{pCi} / \mathrm{mL}$ & - & - & $3.1 E+01$ & $3.7 E+01$ & \\
\hline HMD & $4 D$ & Lead & $\mu g / L$ & - & - & 53 & - & \\
\hline \multicolumn{9}{|c|}{ Aquifer Unit IIA (Congaree) } \\
\hline Well & & Constituent & Unit & $\underline{2 Q 93}$ & $3 Q 93$ & 4093 & $1 Q 94$ & Mod \\
\hline BGO & $9 A A$ & Nonvolatile beta & $\mathrm{pCi} / \mathrm{L}$ & $6.4 E+01$ & - & - & $7.8 E+01$ & \\
\hline BGO & 12AR & Trichloroethylene & $\mu g / L$ & 5.5 & - & 5.2 & - & \\
\hline BGO & $50 \mathrm{~A}$ & Chloroform & $\mu g / L$ & - & - & 191 & - & \\
\hline
\end{tabular}

Notes: The groundwater samples are unfiltered. Thus, the results for metals are for total recoverable metais. The modifier column applies to first quarter 1994 results only.

a $-=$ analyzed but not above final PDWS.

b $N A=$ not analyzed. 
Table 2. Maximum Levels of Constituents Exceeding Other Flag 2 Criteria

Aquifer Zone $\| \mathrm{B}_{2}$ (Water Table)

\begin{tabular}{|c|c|c|c|c|c|}
\hline Well & & Constituent & Unit & 1094 & Mod \\
\hline BGO & 10 & $\begin{array}{l}\text { Aluminum } \\
\text { Iron }\end{array}$ & $\mu g / L$ & $\begin{array}{l}1,120 \\
426\end{array}$ & \\
\hline BGO & $2 D$ & $\begin{array}{l}\text { Aluminum } \\
\text { Total organic halogens }\end{array}$ & $\begin{array}{l}\mu g / L \\
\mu g / L\end{array}$ & $\begin{array}{l}173 \\
59\end{array}$ & \\
\hline$B G O$ & $3 D$ & Aluminum & $\mu g / L$ & 213 & \\
\hline $\mathrm{BGO}$ & $5 \mathrm{D}$ & Aluminum & $\mu g / L$ & 71 & \\
\hline BGO & $6 \mathrm{D}$ & Aluminum & $\mu g / L$ & 206 & \\
\hline BGO & 70 & Total organic halogens & $\mu g / L$ & 149 & \\
\hline BGO & 10DR & $\begin{array}{l}\text { Aluminum } \\
\text { Iron }\end{array}$ & $\begin{array}{l}\mu g / L \\
\mu g / L\end{array}$ & $\begin{array}{l}72 \\
431\end{array}$ & \\
\hline BGO & $12 D$ & $\begin{array}{l}\text { Aluminum } \\
\text { Total organic halogens }\end{array}$ & $\underset{\mu g / L}{\mu g / L}$ & $\begin{array}{l}76 \\
105\end{array}$ & \\
\hline BGO & 14DR & Total organic halogens & $\mu g / L$ & 124 & \\
\hline BGO & 150 & Total organic halogens & $\mu g / L$ & 55 & \\
\hline BGO & $16 D$ & $\begin{array}{l}\text { Aluminum } \\
\text { Iron } \\
\text { Lithium } \\
\text { Tin }\end{array}$ & $\begin{array}{l}\mu g / L \\
\mu g / L \\
\mu g / L \\
\mu g / L\end{array}$ & $\begin{array}{l}560 \\
311 \\
105 \\
22\end{array}$ & \\
\hline BGO & 17DR & Aluminum & $\mu \mathrm{g} / \mathrm{L}$ & 126 & \\
\hline BGO & $19 D$ & Aluminum & $\mu \mathrm{g} / \mathrm{L}$ & 63 & \\
\hline BGO & 210 & $\begin{array}{l}\text { Aluminum } \\
\text { Lithium }\end{array}$ & $\begin{array}{l}\mu g / L \\
\mu g / L\end{array}$ & $\begin{array}{l}309 \\
53\end{array}$ & $J$ \\
\hline BGO & 22DR & $\begin{array}{l}\text { Aluminum } \\
\text { Iron }\end{array}$ & $\begin{array}{l}\mu g / L \\
\mu g / L\end{array}$ & $\begin{array}{l}883 \\
354\end{array}$ & \\
\hline BGO & $23 D$ & Total organic halogens & $\mu g / L$ & 146 & \\
\hline BGO & $24 D$ & $\begin{array}{l}\text { Aluminum } \\
\text { Iron }\end{array}$ & $\begin{array}{l}\mu g / L \\
\mu g / L\end{array}$ & $\begin{array}{l}749 \\
304\end{array}$ & \\
\hline$B G O$ & 260 & Aluminum & $\mu \mathrm{g} / \mathrm{L}$ & 206 & \\
\hline BGO & 270 & Aluminum & $\mu g / L$ & 231 & \\
\hline BGO & $28 D$ & $\begin{array}{l}\text { Aluminum } \\
1,1 \text {-Dichloroethane }\end{array}$ & $\begin{array}{l}\mu \mathrm{g} / \mathrm{L} \\
\mu \mathrm{g} / \mathrm{L}\end{array}$ & $\begin{array}{l}1,660 \\
54\end{array}$ & \\
\hline
\end{tabular}


Aquifer Zone $\mathrm{IIB}_{2}$ (Water Table)

\begin{tabular}{|c|c|c|c|c|}
\hline \multirow[t]{4}{*}{ Well } & Constituent & Unit & 1094 & Mod \\
\hline & Iron & $\mu g / L$ & 643 & \\
\hline & Manganese & $\mu g / L$ & 73 & \\
\hline & Total organic halogens & $\mu \mathrm{g} / \mathrm{L}$ & 790 & J \\
\hline \multirow[t]{3}{*}{ BGO 29D } & Aluminum & $\mu g / L$ & 1,170 & \\
\hline & Iron & $\mu \mathrm{g} / \mathrm{L}$ & 637 & \\
\hline & Manganese & $\mu g / L$ & 68 & \\
\hline \multirow[t]{4}{*}{ BGO 30D } & Aluminum & $\mu \mathrm{g} / \mathrm{L}$ & 396 & \\
\hline & 1,1-Dichloroethane & $\mu g / L$ & 108 & \\
\hline & Manganese & $\mu g / L$ & 58 & \\
\hline & Total organic halogens & $\mu g / L$ & 1,250 & $J$ \\
\hline BGO 31D & Aluminum & $\mu g / L$ & 123 & \\
\hline BGO 32D & Aluminum & $\mu g / L$ & 910 & \\
\hline \multirow[t]{3}{*}{ BGO 33D } & Aluminum & $\mu \mathrm{g} / \mathrm{L}$ & 2,380 & \\
\hline & Iron & $\mu g / L$ & 959 & \\
\hline & Tin & $\mu g / L$ & 22 & \\
\hline BGO 34D & Aluminum & $\mu \mathrm{g} / \mathrm{L}$ & 143 & \\
\hline \multirow[t]{2}{*}{ BGO 35D } & Aluminum & $\mu g / L$ & 3,360 & \\
\hline & Iron & $\mu g / L$ & 1,270 & \\
\hline BGO 36D & Aluminum & $\mu g / L$ & 637 & \\
\hline BGO 37D & Aluminum & $\mu g / L$ & 221 & \\
\hline \multirow[t]{2}{*}{ BGO 38D } & Aluminum & $\mu \mathrm{g} / \mathrm{L}$ & 336 & \\
\hline & Total orgchic halogens & $\mu \mathrm{g} / \mathrm{L}$ & 56 & \\
\hline BGO 39D & Aluminum & $\mu \mathrm{g} / \mathrm{L}$ & 121 & \\
\hline \multirow[t]{3}{*}{ BGO 40D } & Aluminum & $\mu \mathrm{g} / \mathrm{L}$ & 276 & \\
\hline & Lithium & $\mu \mathrm{g} / \mathrm{L}$ & 611 & \\
\hline & Tin & $\mu g / L$ & 72 & \\
\hline \multirow[t]{2}{*}{ BGO 46D } & 1,1-Dichloroethane & $\mu g / L$ & 29 & \\
\hline & Total organic halogens & $\mu g / L$ & 191 & \\
\hline \multirow[t]{2}{*}{ BGO 48D } & Aluminum & $\mu g / L$ & 119 & \\
\hline & Total organic halogens & $\mu \mathrm{g} / L$ & 144 & \\
\hline BGO 49D & Aluminum & $\mu \mathrm{g} / \mathrm{L}$ & 473 & \\
\hline \multirow[t]{2}{*}{ BGO 50D } & Aluminum & $\mu g / L$ & 81 & \\
\hline & Total organic halogens & $\mu \mathrm{g} / \mathrm{L}$ & 169 & $J$ \\
\hline$B G \times \quad 1 D$ & Aluminum & $\mu \mathrm{g} / \mathrm{L}$ & 385 & \\
\hline
\end{tabular}


Aquifer Zone IIB $_{2}$ (Water Table)

\begin{tabular}{|c|c|c|c|}
\hline Well & Constituent & $\underline{\text { Unit }}$ & 1094 \\
\hline$B G X 9 D$ & Aluminum & $\mu g / L$ & 53 \\
\hline$B G X 10 D$ & $\begin{array}{l}\text { Aluminum } \\
\text { Iron } \\
\text { Manganese }\end{array}$ & $\begin{array}{l}\mu g / L \\
\mu g / L \\
\mu g / L\end{array}$ & $\begin{array}{l}179 \\
405 \\
64\end{array}$ \\
\hline$B G \times 11 D$ & Aluminum & $\mu \mathrm{g} / \mathrm{L}$ & 539 \\
\hline$B G \times 12 D$ & Aluminum & $\mu g / L$ & 186 \\
\hline FSS 10 & $\begin{array}{l}\text { Aluminum } \\
\text { Iron }\end{array}$ & $\begin{array}{l}\mu g / L \\
\mu g / L\end{array}$ & $\begin{array}{l}3,190 \\
572\end{array}$ \\
\hline FSS 2D & $\begin{array}{l}\text { Aluminum } \\
\text { Iron } \\
\text { Manganese }\end{array}$ & $\begin{array}{l}\mu \mathrm{g} / \mathrm{L} \\
\mu \mathrm{g} / \mathrm{L} \\
\mu \mathrm{g} / \mathrm{L}\end{array}$ & $\begin{array}{l}2,450 \\
795 \\
96\end{array}$ \\
\hline FSS 3D & $\begin{array}{l}\text { Aluminum } \\
\text { Manganese }\end{array}$ & $\begin{array}{l}\mu g / L \\
\mu g / L\end{array}$ & $\begin{array}{l}204 \\
91\end{array}$ \\
\hline FSS 4D & $\begin{array}{l}\text { Aluminum } \\
\text { Iron }\end{array}$ & $\begin{array}{l}\mu g / L \\
\mu g / L\end{array}$ & $\begin{array}{l}1,010 \\
501\end{array}$ \\
\hline HSB $85 \mathrm{C}$ & Total organic carbon & $\mu g / L$ & 20,400 \\
\hline
\end{tabular}

Ayuifer Zone IIB, (Barnwell/McBean)

\begin{tabular}{|c|c|c|c|}
\hline Well & Constituent & Unit & 1094 \\
\hline $\mathrm{BGO} 5 \mathrm{C}$ & Aluminum & $\mu g / L$ & 408 \\
\hline BGO 6B & $\begin{array}{l}\text { Iron } \\
\text { Total organic halogens }\end{array}$ & $\begin{array}{l}\mu \mathrm{g} / \mathrm{L} \\
\mu \mathrm{g} / \mathrm{L}\end{array}$ & $\begin{array}{l}348 \\
10,300\end{array}$ \\
\hline BGO 10B & $\begin{array}{l}\text { Aluminum } \\
\text { Total organic halogens }\end{array}$ & $\begin{array}{l}\mu \mathrm{g} / \mathrm{L} \\
\mu \mathrm{g} / \mathrm{L}\end{array}$ & $\begin{array}{l}70 \\
197\end{array}$ \\
\hline BGO 10C & Aluminum & $\mu \mathrm{g} / \mathrm{L}$ & 266 \\
\hline BGO $12 C R$ & Aluminum & $\mu g / L$ & 296 \\
\hline BGO 13DR & Manganese & $\mu \mathrm{g} / \mathrm{L}$ & 70 \\
\hline BGO 14CR & $\begin{array}{l}\text { Aluminum } \\
\text { Total organic halogens }\end{array}$ & $\begin{array}{l}\mu g / L \\
\mu g / L\end{array}$ & $\begin{array}{l}338 \\
73\end{array}$ \\
\hline BGO 29C & Aluminum & $\mu g / L$ & 101 \\
\hline $\mathrm{BGO} 30 \mathrm{C}$ & $\begin{array}{l}\text { Aluminum } \\
\text { Iron }\end{array}$ & $\begin{array}{l}\mu \mathrm{g} / \mathrm{L} \\
\mu \mathrm{g} / \mathrm{L}\end{array}$ & $\begin{array}{l}794 \\
549\end{array}$ \\
\hline
\end{tabular}


Aquifer Zone IIB, (Barnwell/McBean)

\begin{tabular}{|c|c|c|c|c|}
\hline Well & Constituent & Unit & 1094 & Mod \\
\hline BGO 31C & Aluminum & $\mu g / L$ & 319 & \\
\hline \multirow{2}{*}{ BGO 33C } & Aluminum & $\mu g / L$ & 251 & \\
\hline & Total organic halogens & $\mu g / L$ & 96 & $J$ \\
\hline \multirow[t]{3}{*}{ BGO 42C } & Aluminum & $\mu \mathrm{g} / \mathrm{L}$ & 73 & \\
\hline & Iron & $\mu \mathrm{g} / \mathrm{L}$ & 365 & \\
\hline & Total organic halogens & $\mu \mathrm{g} / \mathrm{L}$ & 75 & \\
\hline \multirow[t]{2}{*}{ BGO 43CR } & Aluminum & $\mu \mathrm{g} / \mathrm{L}$ & 153 & \\
\hline & Iron & $\mu g / L$ & 304 & \\
\hline \multirow[t]{3}{*}{ BGO 44B } & Aluminum & $\mu g / L$ & 161 & \\
\hline & Manganese & $\mu g / L$ & 88 & \\
\hline & Total organic carbon & $\mu g / L$ & 18,100 & \\
\hline \multirow[t]{4}{*}{ BGO 44C } & Aluminum & $\mu g / L$ & 585 & \\
\hline & Iron & $\mu \mathrm{g} / \mathrm{L}$ & 408 & \\
\hline & Lithium & $\mu \mathrm{g} / \mathrm{L}$ & 71 & \\
\hline & Manganese & $\mu g / L$ & 294 & \\
\hline \multirow[t]{2}{*}{ BGO 45B } & Aluminum & $\mu g / L$ & 98 & \\
\hline & $\mathrm{pH}$ & $\mathrm{pH}$ & 11 & $J$ \\
\hline BGO 45C & Aluminum & $\mu g / L$ & 55 & \\
\hline \multirow[t]{2}{*}{ BGO 50C } & Aluminum & $\mu g / L$ & 228 & \\
\hline & Iron & $\mu g / L$ & 438 & \\
\hline \multirow[t]{3}{*}{$B G X \quad 1 C$} & Aluminum & $\mu g / L$ & 741 & \\
\hline & $\mathrm{pH}$ & $\mathrm{pH}$ & 12 & $J$ \\
\hline & Specific conductance & $\mu \mathrm{S} / \mathrm{cm}$ & 1,800 & \\
\hline$B G X \quad 2 B$ & Aluminum & $\mu g / L$ & 197 & \\
\hline$B G X 2 D$ & Aluminum & $\mu g / L$ & 63 & \\
\hline$B G X \quad 4 C$ & Tin & $\mu g / L$ & 31 & \\
\hline \multirow[t]{2}{*}{$B G X \quad 5 D$} & Aluminum & $\mu g / L$ & 92 & \\
\hline & Manganese & $\mu g / L$ & 346 & \\
\hline BGX 8DR & Aluminum & $\mu g / L$ & 84 & \\
\hline \multirow[t]{3}{*}{ HMD 1D } & Aluminum & $\mu \mathrm{g} / \mathrm{L}$ & 601 & \\
\hline & Iron & $\mu \mathrm{g} / \mathrm{L}$ & 777 & \\
\hline & Manganese & $\mu g / L$ & 52 & \\
\hline \multirow[t]{2}{*}{ HMD 4D } & Aluminum & $\mu \mathrm{g} / \mathrm{L}$ & 747 & \\
\hline & Iron & $\mu g / L$ & 487 & \\
\hline HSB 85B & Aluminum & $\mu g / L$ & 1,440 & \\
\hline
\end{tabular}


Aquifer Unit IIA (Congaree)

\begin{tabular}{|c|c|c|c|c|}
\hline Well & Constituent & Unit & $\underline{1 Q 94}$ & $\underline{\text { Mor }}$ \\
\hline BGO 9AA & $\begin{array}{l}\text { Aluminum } \\
\text { Lithium } \\
\text { pH } \\
\text { Specific conductance } \\
\text { Tin }\end{array}$ & $\begin{array}{l}\mu \mathrm{g} / \mathrm{L} \\
\mu \mathrm{g} / \mathrm{L} \\
\mathrm{pH} \\
\mu \mathrm{S} / \mathrm{cm} \\
\mu \mathrm{g} / \mathrm{L}\end{array}$ & $\begin{array}{l}1,070 \\
1,200 \\
13 \\
4,130 \\
294\end{array}$ & $J$ \\
\hline BGO 10AR & Manganese & $\mu \mathrm{g} / \mathrm{L}$ & 51 & \\
\hline BGO 12AR & $\begin{array}{l}\text { Aluminum } \\
\text { Total organic halogens }\end{array}$ & $\begin{array}{l}\mu g / L \\
\mu g / L\end{array}$ & $\begin{array}{l}244 \\
59\end{array}$ & \\
\hline BGO 14AR & $\begin{array}{l}\text { Aluminum } \\
\text { Lithium } \\
\mathrm{pH} \\
\text { Tin }\end{array}$ & $\begin{array}{l}\mu \mathrm{g} / \mathrm{L} \\
\mu \mathrm{g} / \mathrm{L} \\
\mathrm{pH} \\
\mu \mathrm{g} / \mathrm{L}\end{array}$ & $\begin{array}{l}404 \\
54 \\
10 \\
22\end{array}$ & $J$ \\
\hline BGO 29A & $\begin{array}{l}\text { Aluminum } \\
\text { Total organic halogens }\end{array}$ & $\begin{array}{l}\mu g / L \\
\mu g / L\end{array}$ & $\begin{array}{l}94 \\
67\end{array}$ & \\
\hline BGO 43AA & Aluminum & $\mu g / L$ & 78 & \\
\hline BGO 44AA & $\begin{array}{l}\text { Aluminum } \\
\text { Lithium }\end{array}$ & $\begin{array}{l}\mu \mathrm{g} / \mathrm{L} \\
\mu \mathrm{g} / \mathrm{L}\end{array}$ & $\begin{array}{l}165 \\
79\end{array}$ & \\
\hline BGO 47A & Aluminum & $\mu g / L$ & 88 & \\
\hline BGO 49A & $\begin{array}{l}\text { Aluminum } \\
\mathrm{pH} \\
\text { Lithium }\end{array}$ & $\begin{array}{l}\mu \mathrm{g} / \mathrm{L} \\
\mathrm{pH} \\
\mu \mathrm{g} / \mathrm{L}\end{array}$ & $\begin{array}{l}501 \\
10 \\
51\end{array}$ & $J$ \\
\hline $\mathrm{BGO} 50 \mathrm{~A}$ & $\begin{array}{l}\text { Aluminum } \\
\text { Lithium } \\
\text { pH } \\
\text { Specific conductance } \\
\text { Tin } \\
\text { Total organic halogens }\end{array}$ & $\begin{array}{l}\mu \mathrm{g} / \mathrm{L} \\
\mu \mathrm{g} / \mathrm{L} \\
\mathrm{pH} \\
\mu \mathrm{S} / \mathrm{cm} \\
\mu \mathrm{g} / \mathrm{L} \\
\mu \mathrm{g} / \mathrm{L}\end{array}$ & $\begin{array}{l}641 \\
343 \\
12 \\
950 \\
36 \\
179\end{array}$ & J \\
\hline HSB $85 A$ & Total organic halogens & $\mu \mathrm{g} / \mathrm{L}$ & 54 & \\
\hline
\end{tabular}

Notes: These results do not include field data.

The groundwater samples are unfiltered. Thus, the results for metals are for total recoverable metals. Flags are established by EPD/EMS and are based on PDWS, Secondary Drinking Water Standards, or method detection limits (see Appendix B). 
Table 3. Groundwater Monitoring Results for Individual Wells

WELL BGO 1D

\begin{tabular}{|c|c|c|c|c|c|c|}
\hline SRS Coord. & Lat/Longitude & Screen Zone Elevation & Top of Casing & Casing & Pump & Formation \\
\hline $\begin{array}{l}N 73737.9 \\
E 58779.3\end{array}$ & $\begin{array}{l}33.284765^{\circ} \mathrm{N} \\
81.655257^{\circ} \mathrm{W}\end{array}$ & $245.0-225.0 \mathrm{ft} \mathrm{msl}$ & $295.1 \mathrm{ft} \mathrm{msl}$ & 4" PVC & $\mathbf{S}$ & Water Table $\left(11 \mathrm{~B}_{2}\right)$ \\
\hline
\end{tabular}

\section{FIELD MEASUREMENTS}

Sample date: 02/01/94

Depth to water: $64.79 \mathrm{ft}(19.75 \mathrm{~m})$ below TOC

Water elevation: $230.31 \mathrm{ft}(70.20 \mathrm{~m}) \mathrm{msl}$

Sp. conductance: $48 \mu \mathrm{S} / \mathrm{cm}$

Turbidity: 26.3 NTU

Water evacuated before sampling: $8 \mathrm{gal}$

The well went dry during purging.

\section{LABORATORY ANALYSES}

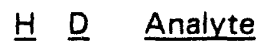

- $\quad \mathrm{pH}$

Specific conductance

Turbidity

Acetophenone

Aldrin

Aluminum, total recoverable

Aluminum, total recoverable

Antimony, total recoverable

Arsenic, total recoverable

Barium, total recoverable

Barium, total recoverable

Benzene

Bromodichloromethane

Bromoform

Bromomethane (Methyl bromide)

Cadmium, total recoverable

Cadmium, total recoverable

Calcium, total recoverable

Calcium, total recoverable

Carbon tetrachloride

Chloride

Chlorobenzene

Chloroethane

Chloroethene (Vinyl chloride)

2-Chloroethyl vinyl ether

Chloroform

Chloromethane (Methyl chloride)

Chromium, total recoverable

Chromium, total recoverable

Copper, total recoverable

Copper, total recoverable

Cyanide

$p, p^{\prime}$-DDT

Dibromochloromethane

1,1-Dichloroethane

1,2-Dichloroethane

1,1-Dichloroethylene

trans-1,2-Dichloroethylene

Dichloromethane (Methylene chloride)

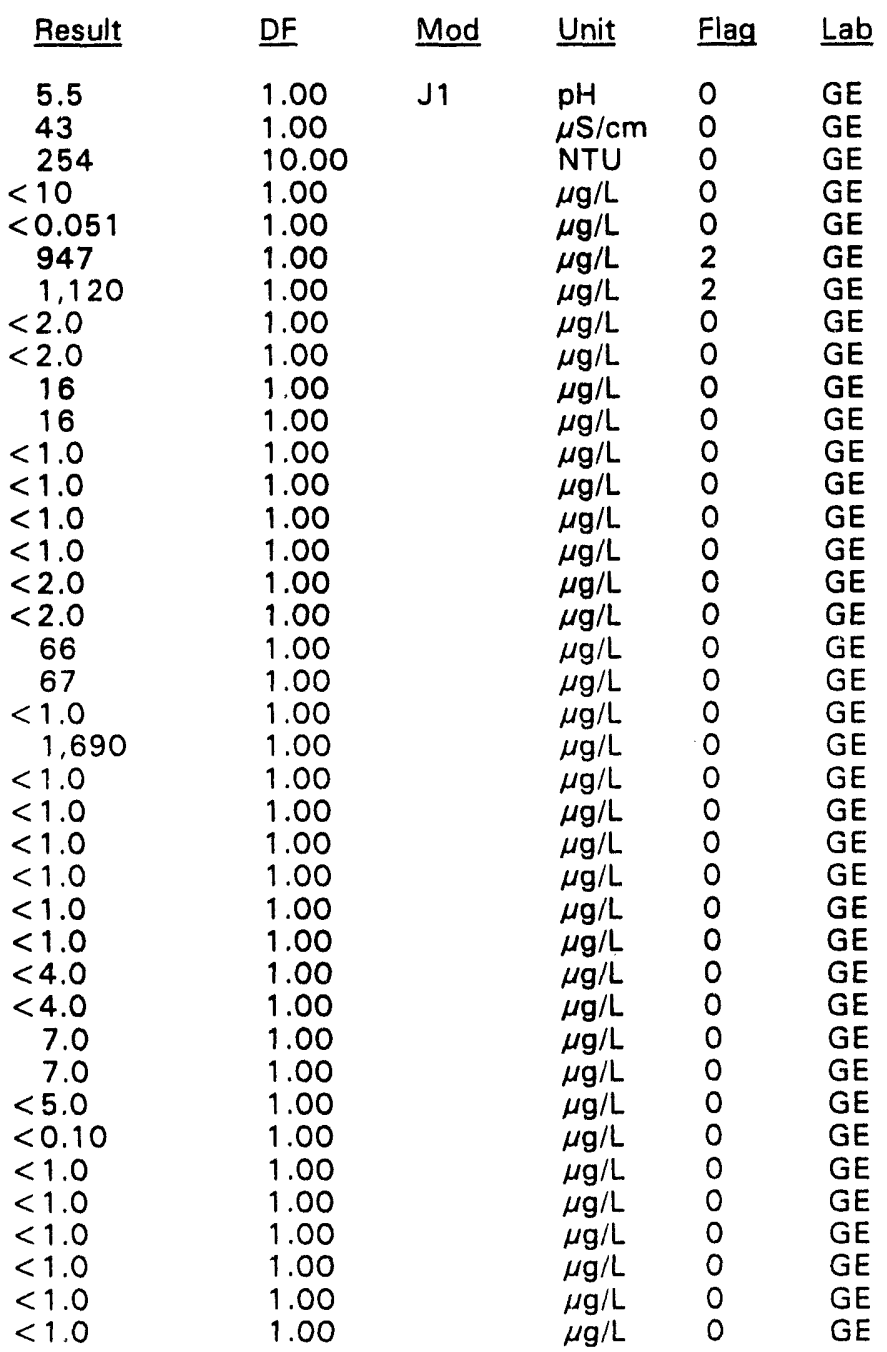

Time: $12: 23$

$\mathrm{pH}: 4.7$

Alkalinity: $0 \mathrm{mg} / \mathrm{L}$

Water temperature: $17.2^{\circ} \mathrm{C}$

Volumes purged: 2.3 well volumes

\footnotetext{
- = exceeded holding time. = exceeded screening level or final primary drinking water standard.
} 
WELL BGO 1D collected on 02/01/94, laboratory analyses (cont.)

H D Analyte

2,4-Dichlorophenoxyacetic acid 1,2-Dichloropropane cis-1,3-Dichloropropene trans-1,3-Dichloropropene Dieldrin

Endrin

Ethylbenzene

Fluoride

Heptachlor

Iron, total recoverable

Iron, total recoverable

Lead, total recoverable

Lindane

Lithium, total recoverable

Lithium, total recoverable

Magnesium, total recoverable

Magnesium, total recoverable

Manganese, total recoverable

Manganese, total recoverable

Mercury, total recoverable

Methoxychlor

Naphthalene

Nickel, total recoverable

Nickel, total recoverable

Nitrate-nitrite as nitrogen

Phenols

Potassium, total recoverable

Potassium, total recoverable

Selenium, total recoverable

Silica, total recoverable

Silica, total recoverable

Silver, total recoverable

Silver, total recoverable

Sodium, total recoverable

Sodium, total recoverable

Sulfate

1,1,2,2-Tetrachloroethane

Tetrachloroethylene

Tin, total recoverable

Tin, total recoverable

Toluene

Total dissolved solids

Total organic carbon

Total organic halogens

Total phosphates (as P)

Toxaphene

2,4,5-TP (Silvex)

1,1,1-Trichloroethane

1,1,2-Trichloroethane

Trichloroethylene

Trichlorofluoromethane

Vanadium, total recoverable

Vanadium, total recoverable Xylenes

Zinc, total recoverable

Zinc, total recoverable

\begin{tabular}{|c|c|}
\hline \multicolumn{2}{|l|}{ Result } \\
\hline$<0.0016$ & 1.00 \\
\hline$<1.0$ & 1.00 \\
\hline$<1.0$ & 1.00 \\
\hline $\begin{array}{l}<1.0 \\
<0.51\end{array}$ & $\begin{array}{l}1.00 \\
1.00\end{array}$ \\
\hline $\begin{array}{l}<0.51 \\
<0.0061\end{array}$ & 1.00 \\
\hline$<1.0$ & 1.00 \\
\hline$<100$ & 1.00 \\
\hline$<0.051$ & 1.00 \\
\hline $\begin{array}{l}362 \\
426\end{array}$ & $\begin{array}{l}1.00 \\
1.00\end{array}$ \\
\hline 7.3 & 1.00 \\
\hline$<0.0051$ & 1.00 \\
\hline$<5.0$ & 1.00 \\
\hline $\begin{aligned}<5.0 \\
171\end{aligned}$ & 1.00 \\
\hline $\begin{array}{l}171 \\
173\end{array}$ & 1.00 \\
\hline 26 & 1.00 \\
\hline 26 & 1.00 \\
\hline$<0.20$ & 1.00 \\
\hline$<0.51$ & 1.00 \\
\hline $\begin{array}{l}<10 \\
<40\end{array}$ & 1.00 \\
\hline $\begin{array}{l}<4.0 \\
<4.0\end{array}$ & 1.00 \\
\hline $\begin{array}{r}<4.0 \\
670\end{array}$ & $\begin{array}{l}1.00 \\
1.00\end{array}$ \\
\hline$<5.0$ & 1.00 \\
\hline$<500$ & 1.00 \\
\hline$<500$ & 1.00 \\
\hline$<2.0$ & 1.00 \\
\hline 7,130 & 1.00 \\
\hline $\begin{array}{r}7,510 \\
<20\end{array}$ & 1.00 \\
\hline $\begin{array}{l}<2.0 \\
<2.0\end{array}$ & 1.00 \\
\hline $\begin{array}{l}<2.0 \\
7.040\end{array}$ & 1.00 \\
\hline 7,080 & 1.00 \\
\hline$<1,000$ & 1.00 \\
\hline$<1.0$ & 1.00 \\
\hline$<1.0$ & 1.00 \\
\hline 5.3 & 1.00 \\
\hline 3.2 & 1.00 \\
\hline$<1.0$ & 1.00 \\
\hline 30,000 & 1.00 \\
\hline$<1,000$ & 1.00 \\
\hline 26 & 1.00 \\
\hline$<50$ & 1.00 \\
\hline$<0.25$ & $\begin{array}{l}1.00 \\
1.00\end{array}$ \\
\hline $\begin{array}{l}<0.00047 \\
<1.0\end{array}$ & 1.00 \\
\hline$<1.0$ & 1.00 \\
\hline$<1.0$ & 1.00 \\
\hline$<1.0$ & 1.00 \\
\hline$<8.0$ & 1.00 \\
\hline$<8.0$ & 1.00 \\
\hline$<2.0$ & 1.00 \\
\hline 17 & 1.00 \\
\hline 17 & \\
\hline
\end{tabular}

Mod Unit Flag Lab

$\mu \mathrm{g} / \mathrm{L} \quad \mathrm{O} \quad \mathrm{GE}$

$\mu g / L \quad O \quad G E$

$\mu \mathrm{g} / \mathrm{L} \quad 0 \quad \mathrm{GE}$

$\mu g / L \quad 0 \quad G E$

$\mu \mathrm{g} / \mathrm{L} \quad 0 \quad \mathrm{GE}$

$\mu \mathrm{g} / \mathrm{L} \quad \mathrm{O} \quad \mathrm{GE}$

$\mu \mathrm{g} / \mathrm{L} \quad \mathrm{O} \quad \mathrm{GE}$

$\mu \mathrm{g} / \mathrm{L} \quad \mathrm{O} \quad \mathrm{GE}$

$\mu \mathrm{g} / \mathrm{L} \quad 0 \quad \mathrm{GE}$

$\mu g / L \quad 2 \quad G E$

$\mu \mathrm{g} / \mathrm{L} \quad 2 \quad \mathrm{GE}$

$\mu \mathrm{g} / \mathrm{L} \quad \mathrm{O} \quad \mathrm{GE}$

$\mu \mathrm{g} / \mathrm{L} \quad 0 \quad \mathrm{GE}$

$\mu \mathrm{g} / \mathrm{L} \quad \mathrm{O} \quad \mathrm{GE}$

$\mu \mathrm{g} / \mathrm{L} \quad \mathrm{O} \quad \mathrm{GE}$

$\mu g / L \quad 0 \quad G E$

$\mu \mathrm{g} / \mathrm{L} \quad 0 \quad \mathrm{GE}$

$\mu \mathrm{g} / \mathrm{L} \quad 1 \quad \mathrm{GE}$

$\mu \mathrm{g} / \mathrm{L} \quad 1 \quad \mathrm{GE}$

$\mu \mathrm{g} / \mathrm{L} \quad 0 \quad \mathrm{GE}$

$\mu \mathrm{g} / \mathrm{L} \quad \mathrm{O} \quad \mathrm{GE}$

$\mu \mathrm{g} / \mathrm{L} \quad 0 \quad \mathrm{GE}$

$\mu \mathrm{g} / \mathrm{L} \quad 0 \quad \mathrm{GE}$

$\mu \mathrm{g} / \mathrm{L} \quad 0 \quad \mathrm{GE}$

$\mu \mathrm{g} / \mathrm{L} \quad \mathrm{O} \quad \mathrm{GE}$

$\mu \mathrm{g} / \mathrm{L} \quad 0 \quad \mathrm{GE}$

$\mu \mathrm{g} / \mathrm{L} \quad 0 \quad \mathrm{GE}$

$\mu \mathrm{g} / \mathrm{L} \quad 0 \quad \mathrm{GE}$

JV2 $\mu \mathrm{g} / \mathrm{L} \quad 0 \quad \mathrm{GE}$

$\mu \mathrm{g} / \mathrm{L} \quad \mathrm{O} \quad \mathrm{GE}$

$\mu g / L \quad 0 \quad G E$

$\mu \mathrm{g} / \mathrm{L} \quad 0 \quad \mathrm{GE}$

$\mu \mathrm{g} / \mathrm{L} \quad 0 \quad \mathrm{GE}$

$\mu \mathrm{g} / \mathrm{L} \quad 0 \quad \mathrm{GE}$

$\mu \mathrm{g} / \mathrm{L} \quad 0 \quad \mathrm{GE}$

$\mu \mathrm{g} / \mathrm{L} \quad 0 \quad \mathrm{GE}$

$\mu \mathrm{g} / \mathrm{L} \quad 0 \quad \mathrm{GE}$

$\mu \mathrm{g} / \mathrm{L} \quad 0 \quad \mathrm{GE}$

$\mu \mathrm{g} / \mathrm{L} \quad 0 \quad \mathrm{GE}$

$\mu \mathrm{g} / \mathrm{L} \quad 0 \quad \mathrm{GE}$

$\mu \mathrm{g} / \mathrm{L} \quad 0 \quad \mathrm{GE}$

$\mu \mathrm{g} / \mathrm{L} \quad 0 \quad \mathrm{GE}$

$\mu \mathrm{g} / \mathrm{L} \quad 0 \quad \mathrm{GE}$

$\mu \mathrm{g} / \mathrm{L} \quad 1 \quad \mathrm{GE}$

$\mu \mathrm{g} / \mathrm{L} \quad 0 \quad \mathrm{GE}$

$\mu \mathrm{g} / \mathrm{L} \quad 0 \quad \mathrm{GE}$

$\mu \mathrm{g} / \mathrm{L} \quad 0 \quad \mathrm{GE}$

$\mu \mathrm{g} / \mathrm{L} \quad 0 \quad \mathrm{GE}$

$\mu \mathrm{g} / \mathrm{L} \quad 0 \quad \mathrm{GE}$

$\mu \mathrm{g} / \mathrm{L} \quad 0 \quad \mathrm{GE}$

$\mu g / L \quad O \quad G E$

$\mu \mathrm{g} / \mathrm{L} \quad 0 \quad \mathrm{GE}$

$\mu \mathrm{g} / \mathrm{L} \quad 0 \quad \mathrm{GE}$

$\mu \mathrm{g} / \mathrm{L} \quad 0$

$\mu \mathrm{g} / \mathrm{L} \quad \mathrm{O} \quad \mathrm{GE}$

$\mu \mathrm{g} / \mathrm{L} \quad \mathrm{O} \quad \mathrm{GE}$

- = exceeded holding time. $\square=$ exceeded screening level or final primary drinking water standard. 
WELL BGO 10 collected on $02 / 01 / 94$, laboratory analyses (cont.)

\begin{tabular}{|c|c|c|c|c|c|}
\hline Analyte & Result & $\underline{D F}$ & Mod & Unit & Flag \\
\hline $\begin{array}{l}\text { Carbon- } 14 \\
\text { Gross alpha } \\
\text { Nonvolatile beta } \\
\text { Radium, total alpha-emitting } \\
\text { Tritium } \\
\text { Uranium-233/234 } \\
\text { Uranium-235 } \\
\text { Uranium-238 }\end{array}$ & $\begin{aligned}<-4.8 E+00 \\
7.0 \mathrm{E}-01 \\
<5.3 \mathrm{E}-01 \\
2.1 \mathrm{E}+00 \\
1.4 \mathrm{E}+01 \\
1.2 \mathrm{E}-01 \\
<7.1 \mathrm{E}-02 \\
<7.1 \mathrm{E}-02\end{aligned}$ & $\begin{array}{l}1.00 \\
1.00 \\
1.00 \\
1.00 \\
1.00 \\
1.00 \\
1.00 \\
1.00\end{array}$ & $\begin{array}{l}\mathrm{J} \\
\mathrm{JV} 2 \\
\mathrm{~J}\end{array}$ & $\begin{array}{l}\mathrm{pCi} / L \\
\mathrm{pCi} / L \\
\mathrm{pCi} / \mathrm{L} \\
\mathrm{pCi} / \mathrm{L} \\
\mathrm{pCi} / \mathrm{mL} \\
\mathrm{pCi} / \mathrm{L} \\
\mathrm{pCi} / \mathrm{L} \\
\mathrm{pCi} / \mathrm{L}\end{array}$ & $\begin{array}{l}0 \\
0 \\
0 \\
0 \\
1 \\
0 \\
0 \\
0\end{array}$ \\
\hline
\end{tabular}

\section{WELL BGO 2D}

\begin{tabular}{|c|c|c|c|c|c|c|}
\hline SRS Coord. & Lat/Longitude & Screen Zone Elevation & Top of Casing & Casing & Pump & Formation \\
\hline $\begin{array}{l}N 74552.9 \\
E 58809.7\end{array}$ & $\begin{array}{l}33.286617^{\circ} \mathrm{N} \\
81.656760^{\circ} \mathrm{W}\end{array}$ & $238.9-218.9 \mathrm{ft} \mathrm{msl}$ & $296.9 \mathrm{ft} \mathrm{msl}$ & 4" PVC & $\mathrm{S}$ & Water Table $\left(\| \mathrm{B}_{2}\right)$ \\
\hline
\end{tabular}

\section{FIELD MEASUREMENTS}

Sample date: $02 / 03 / 94$

Depth to water: $58.95 \mathrm{ft}(17.97 \mathrm{~m})$ below TOC

Water elevation: $237.95 \mathrm{ft}(72.53 \mathrm{~m}) \mathrm{msl}$

Sp. conductance: $43 \mu \mathrm{S} / \mathrm{cm}$

Turbidity: 1.3 NTU

Water evacuated before sampling: 42 gal

\section{LABORATORY ANALYSES}

- $D \quad$ Analyte
pH
pH
pH
pH
Specific conductance
Specific conductance
Specific conductance
Specific conductance
Turbidity
Turbidity
Turbidity
Turbidity
Turbidity
Acetophenone
Acetophenone
Acetophenone
Acetophenone
Aldrin
Aldrin
Aluminum, total recoverable
Aluminum, total recoverable
Aluminum, total recoverable
Aluminum, total recoverable
Aluminum, total recoverable
Antimony, total recoverable

\footnotetext{
$\overline{-}=$ exceeded holding time. $=$ exceeded screening level or final primary drinking water standard.
}

$\begin{array}{llllll}\text { Result } & \text { DF } & \text { Mod } & \text { Unit } & \text { Flag } & \text { Lab } \\ 4.9 & 1.00 & \mathrm{~J} 1 & \mathrm{pH} & 0 & \mathrm{GE} \\ 5.1 & 1.00 & \mathrm{~J} 1 & \mathrm{pH} & 0 & \mathrm{GE} \\ 6.4 & 1.00 & \mathrm{~J} & \mathrm{pH} & 0 & \text { WA } \\ 6.0 & 1.00 & \mathrm{~J} & \mathrm{pH} & 0 & \text { WA } \\ 6.0 & 1.00 & \mathrm{~J} & \mathrm{pH} & 0 & \text { WA } \\ 37 & 1.00 & & \mu \mathrm{S} / \mathrm{cm} & 0 & \mathrm{GE} \\ 38 & 1.00 & & \mu \mathrm{S} / \mathrm{cm} & 0 & \mathrm{GE} \\ 33 & 1.00 & & \mu \mathrm{S} / \mathrm{cm} & 0 & \text { WA } \\ 33 & 1.00 & & \mu \mathrm{S} / \mathrm{cm} & 0 & \text { WA } \\ 16 & 1.00 & & \mathrm{NTU} & 0 & \mathrm{GE} \\ 12 & 1.00 & & \mathrm{NTU} & 0 & \mathrm{GE} \\ 5.5 & 1.00 & \mathrm{~J} & \mathrm{NTU} & 0 & \text { WA } \\ 6.3 & 1.00 & \mathrm{~J} & \mathrm{NTU} & 0 & \text { WA } \\ 6.4 & 1.00 & \mathrm{~J} & \mathrm{NTU} & 0 & \mathrm{WA} \\ <10 & 1.00 & & \mu \mathrm{g} / \mathrm{L} & 0 & \mathrm{GE} \\ <10 & 1.00 & & \mu \mathrm{g} / \mathrm{L} & 0 & \mathrm{GE} \\ <11 & 1.10 & & \mu \mathrm{g} / \mathrm{L} & 0 & \text { WA } \\ <11 & 1.10 & & \mu \mathrm{g} / \mathrm{L} & 0 & \text { WA } \\ <10.052 & 1.00 & \mathrm{~J} 1 & \mu \mathrm{g} / \mathrm{L} & 0 & \mathrm{GE} \\ <0.051 & 1.00 & \mathrm{~J} 1 & \mu \mathrm{g} / \mathrm{L} & 0 & \mathrm{GE} \\ 91 & 1.00 & & \mu \mathrm{g} / \mathrm{L} & 2 & \mathrm{GE} \\ 93 & 1.00 & & \mu \mathrm{g} / \mathrm{L} & 2 & \mathrm{GE} \\ 101 & 1.00 & & \mu \mathrm{g} / \mathrm{L} & 2 & \mathrm{GE} \\ 170 & 1.00 & & \mu \mathrm{g} / \mathrm{L} & 2 & \text { WA } \\ 173 & 1.00 & & \mu \mathrm{g} / \mathrm{L} & 2 & \text { WA } \\ <2.0 & 1.00 & & \mu \mathrm{g} / \mathrm{L} & 0 & \mathrm{GE}\end{array}$

Time: $14: 26$

$\mathrm{pH}: 4.4$

Alkalinity: $0 \mathrm{mg} / \mathrm{L}$

Water temperature: $19.0^{\circ} \mathrm{C}$

Volumes purged: 3.4 weil volumes 
WELL BGO 2D collected on 02/03/94, laboratory analyses (cont.)

\section{H $\underline{\text { Analyte }}$}

Antimony, total recoverable

Antimony, total recoverable

Antimony, total recoverable

Antimony, total recoverable

Arsenic, total recoverable

Arsenic, total recoverable

Arsenic, total recoverable

Arsenic, total recoverable

Arsenic, total recoverable

Barium, total recoverable

Barium, total recoverable

Barium, total recoverable

Barium, total recoverable

Barium, total recoverable

Benzene

Benzene

Benzene

Benzene

Benzene

Bromodichloromethane

Bromodichloromethane

Bromodichloromethane

Bromodichloromethane

Bromodichloromethane

Bromodichloromethane

Bromoform

Bromoform

Bromoform

Bromoform

Bromoform

Bromoform

Bromomethane (Methyl bromide)

Bromomethane (Methyl bromide)

Bromomethane (Methyl bromide)

Bromomethane (Methyl bromide)

Bromomethane (Methyl bromide)

Bromomethane (Methyl bromide)

Cadmium, total recoverable

Cadmium, total recoverable

Cadmium, total recoverable

Cadmium, total recoverable

Cadmium, total recoverable

Calcium, total recoverable

Calcium, total recoverable

Calcium, total recoverable

Calcium, total recoverable

Calcium, total recoverable

Carbon tetrachloride

Carbon tetrar:hloride

Carbon tetrachloride

Carbon tetrachloride

Carbon tetrachloride

Carbon tetrachloride

Chloride

Chloride

Chloride

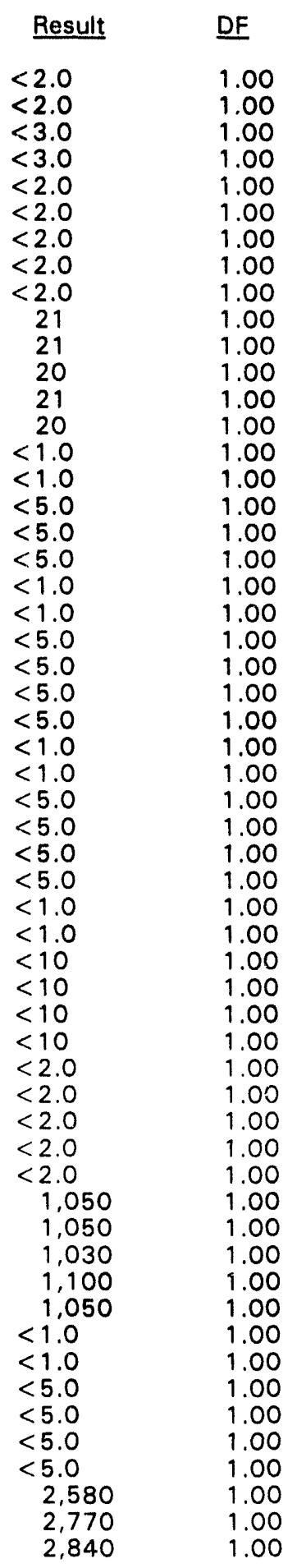

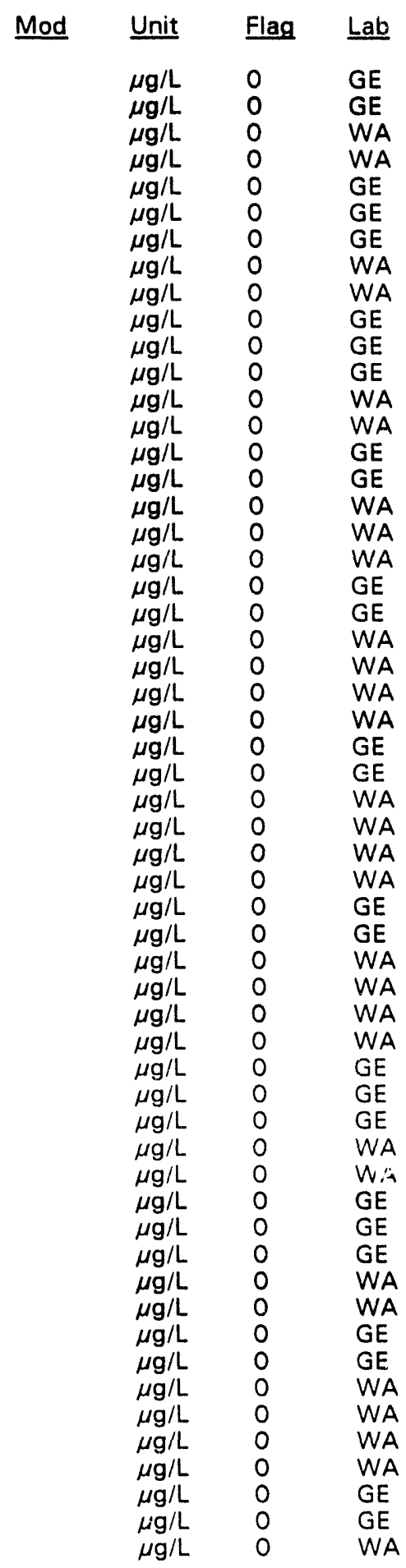

- = exceeded holding time. $\mathbf{a}=$ exceeded screening level or final primary drinking water standard. 
WELL BGO 20 collected on $02 / 03 / 94$, laboratory analyses (cont.)

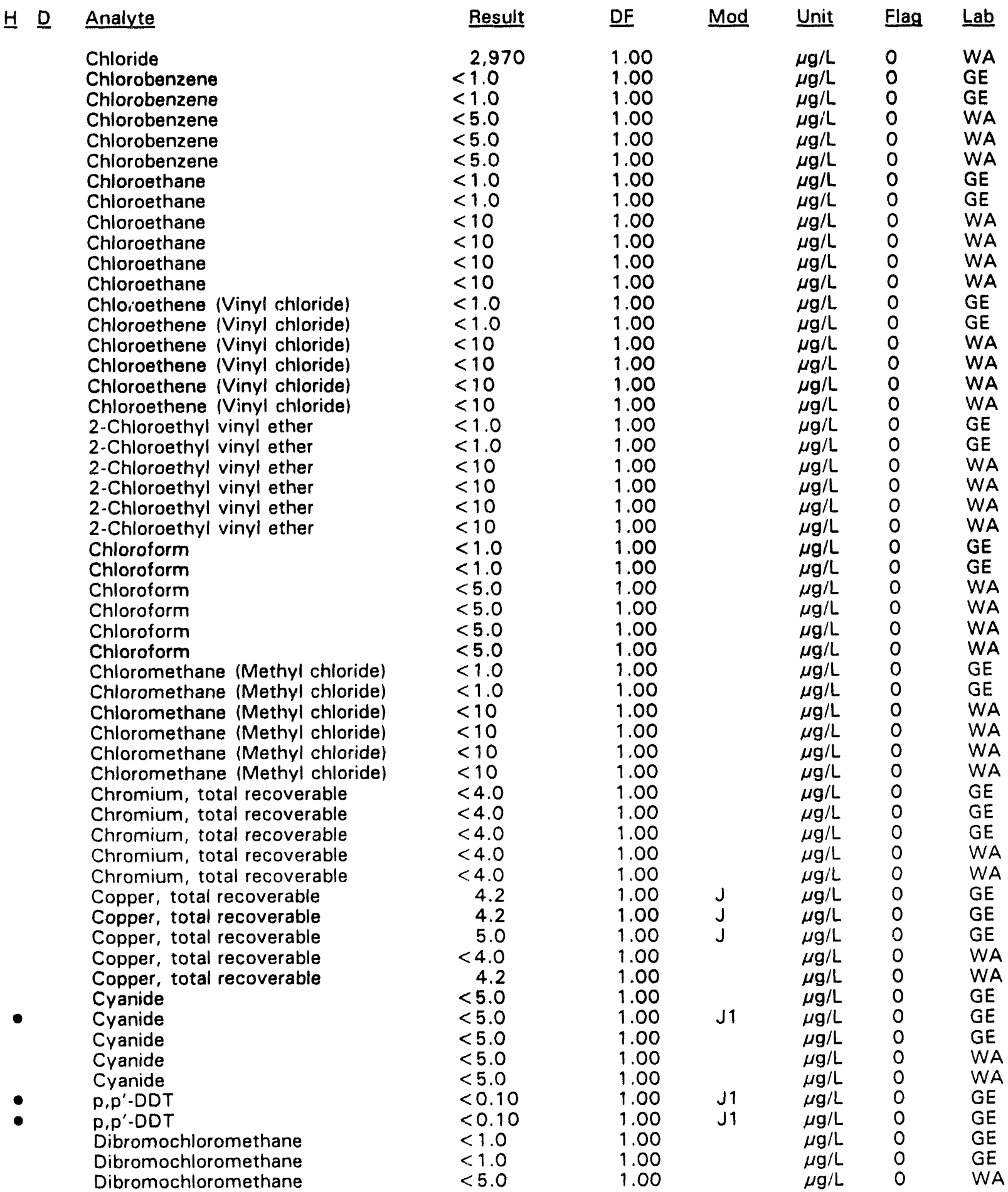

\footnotetext{
- = exceeded holding time. = exceeded screening level or final primary drinking water standard.
} 
WELL BGO 2D collected on $02 / 03 / 94$, laboratory analyses (cont.)

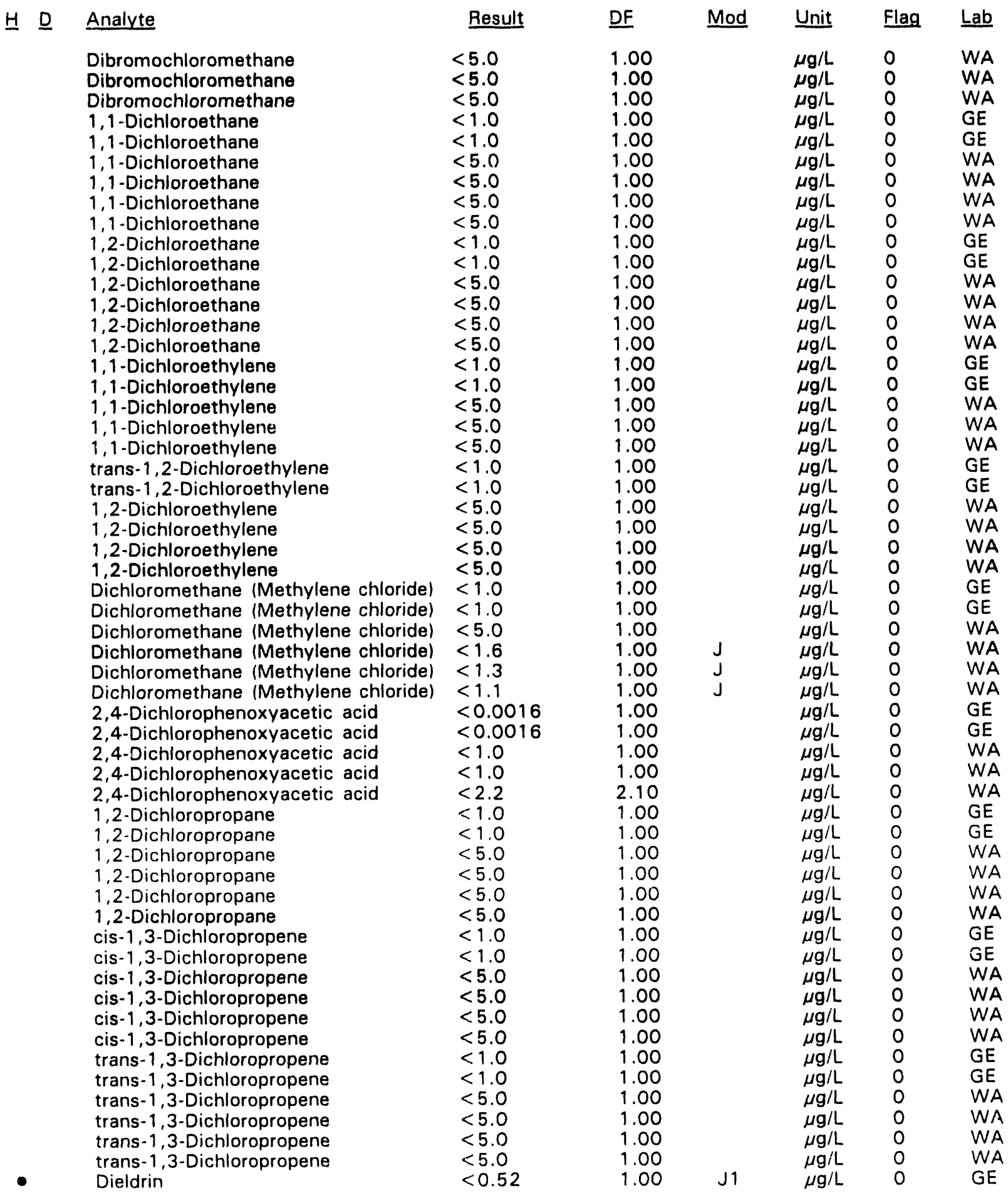

\footnotetext{
$\overline{-}=$ exceeded holding time. = exceeded screening level or final primary drinking water standard.
} 
WELL BGO 2D collected on 02/03/94, laboratory analyses (cont.)

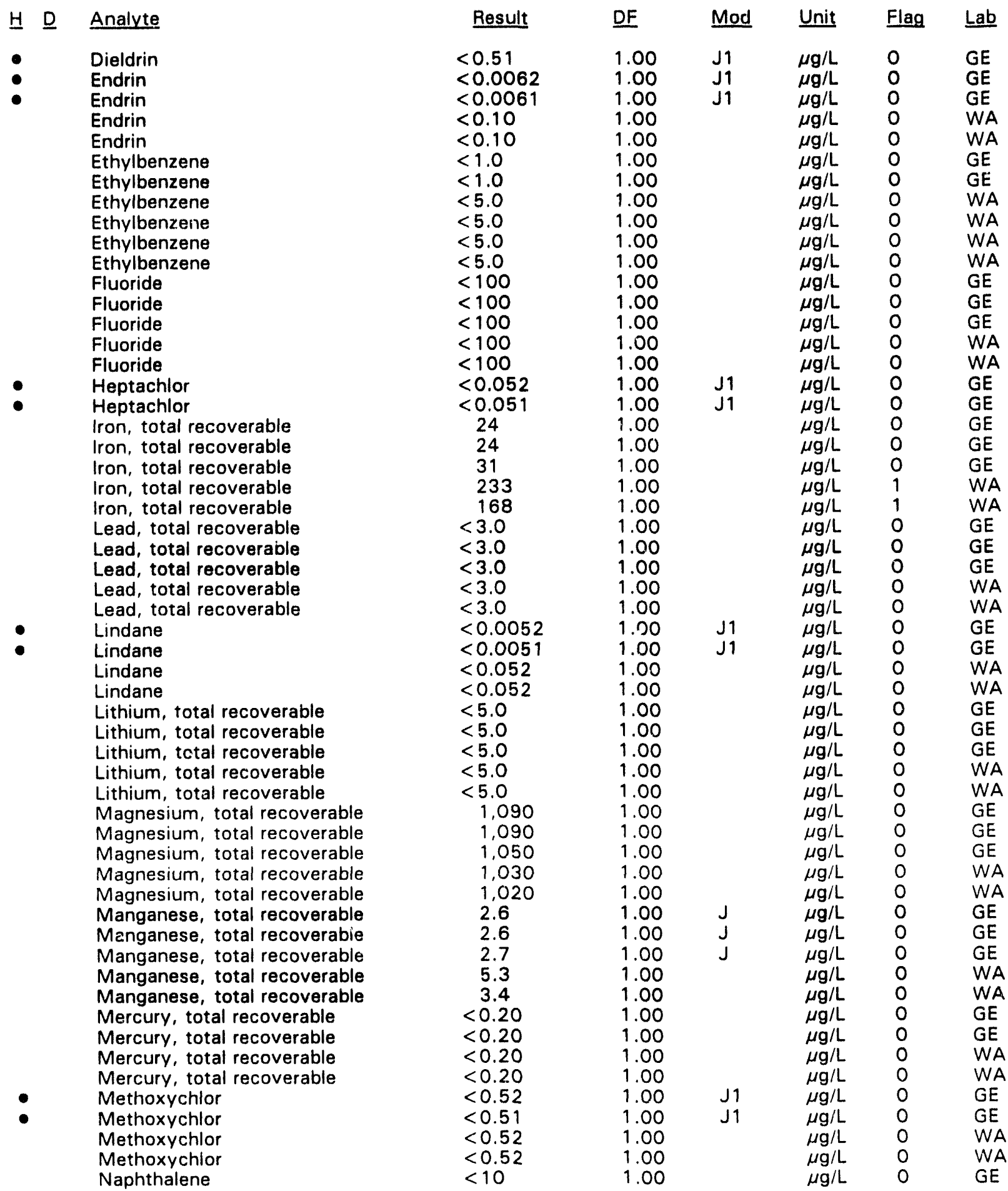

$\overline{-}=$ exceeded holding time. $=$ exceeded screening level or final primary drinking water standard. 
WELL. BGO 2D collected on 02/03/94, laboratory analyses (cont.)

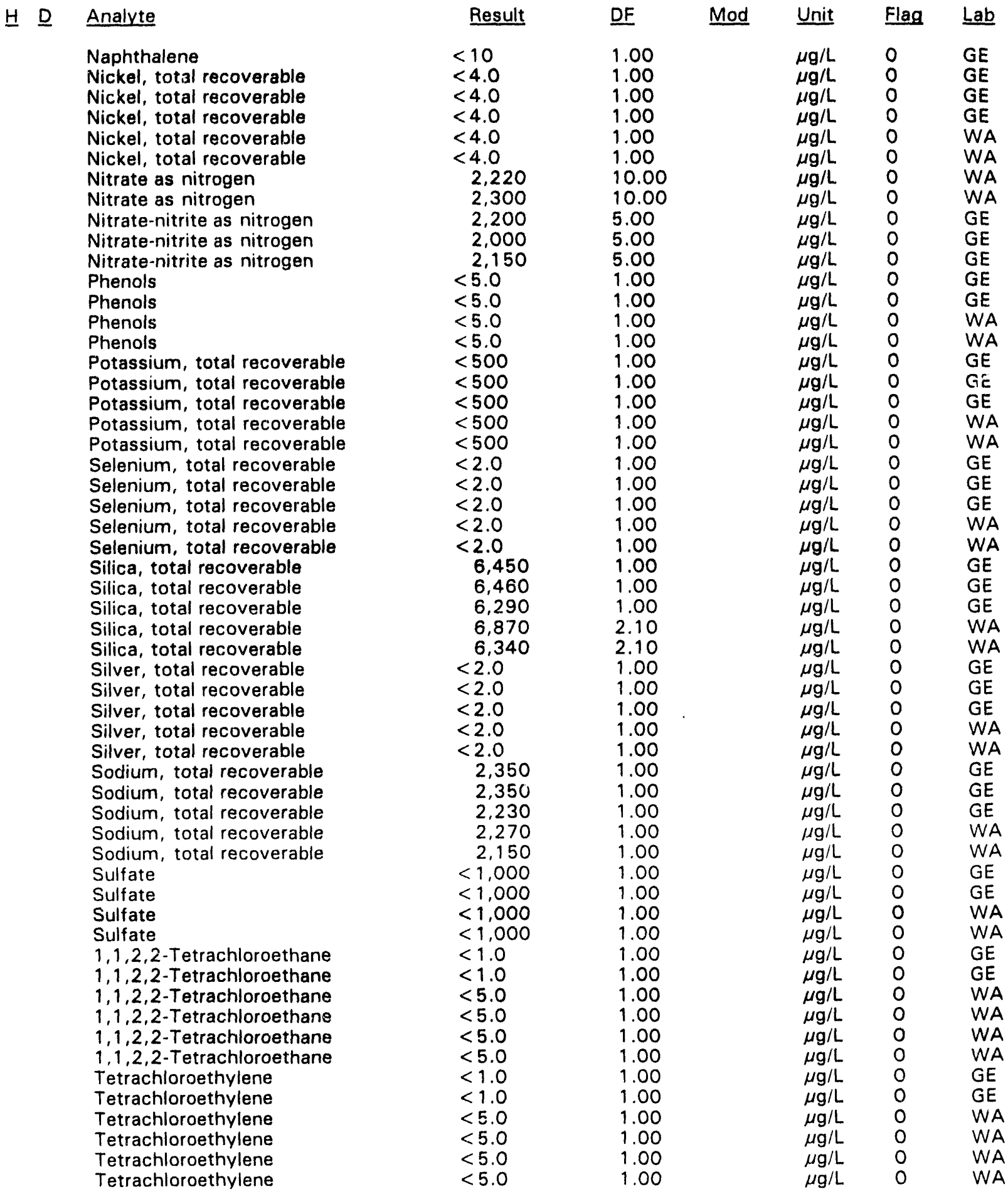

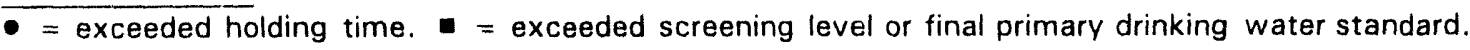



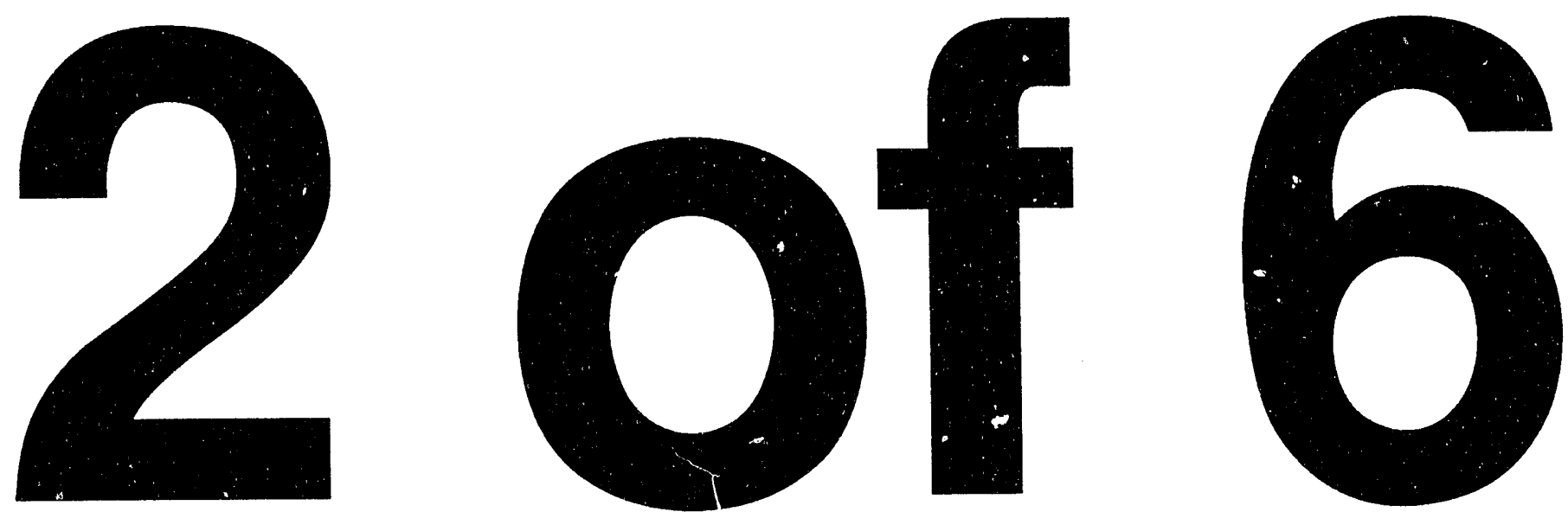
WELL BGO 2D collected on $02 / 03 / 94$, laboratory analyses (cont.)

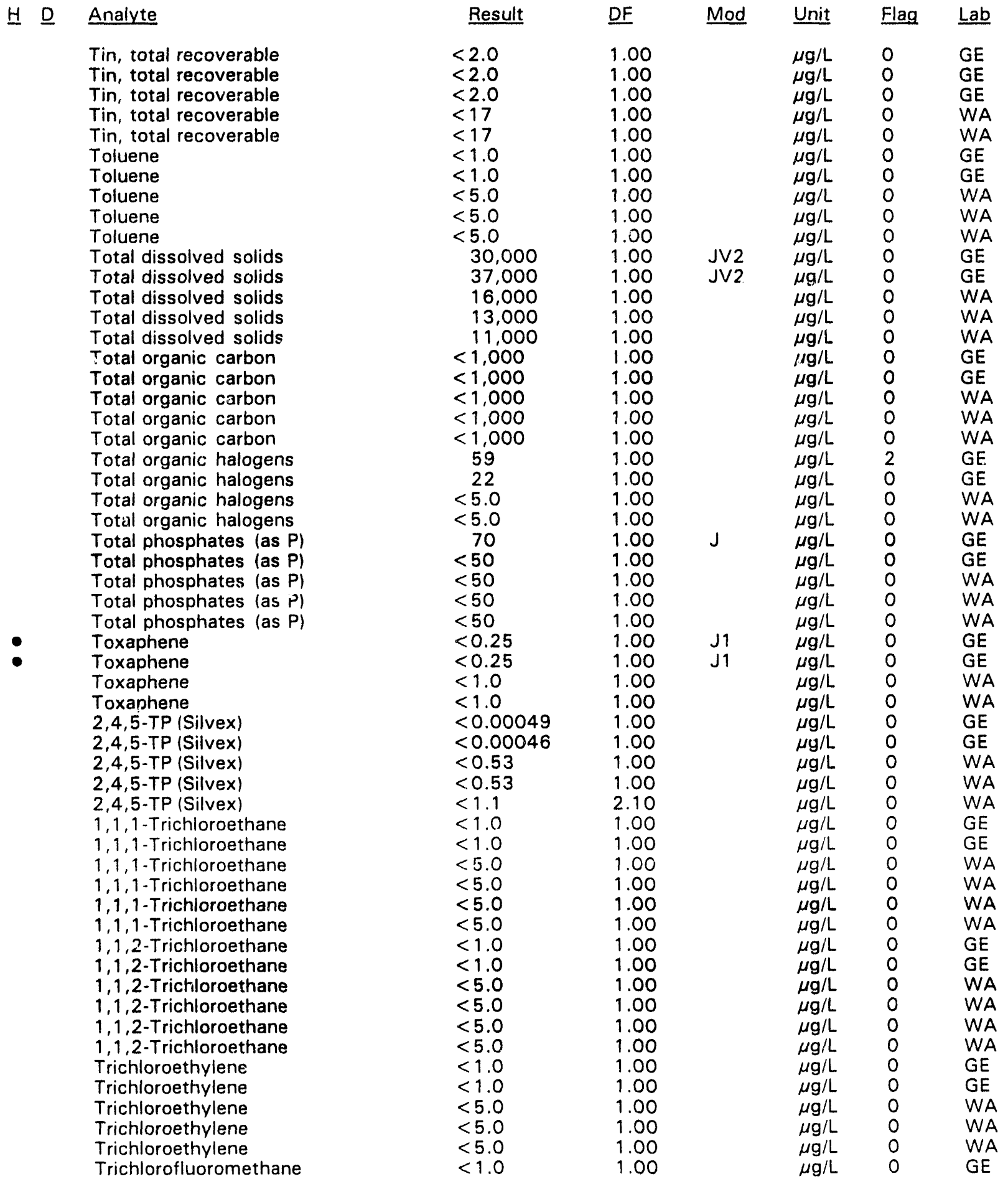

\footnotetext{
- = exceeded holding time. $\mathbf{m}=$ exceeded screening level or final primary drinking water standard.
} 
WELL BGO 2D collected on 02/03/94, laboratory analyses (cont.)

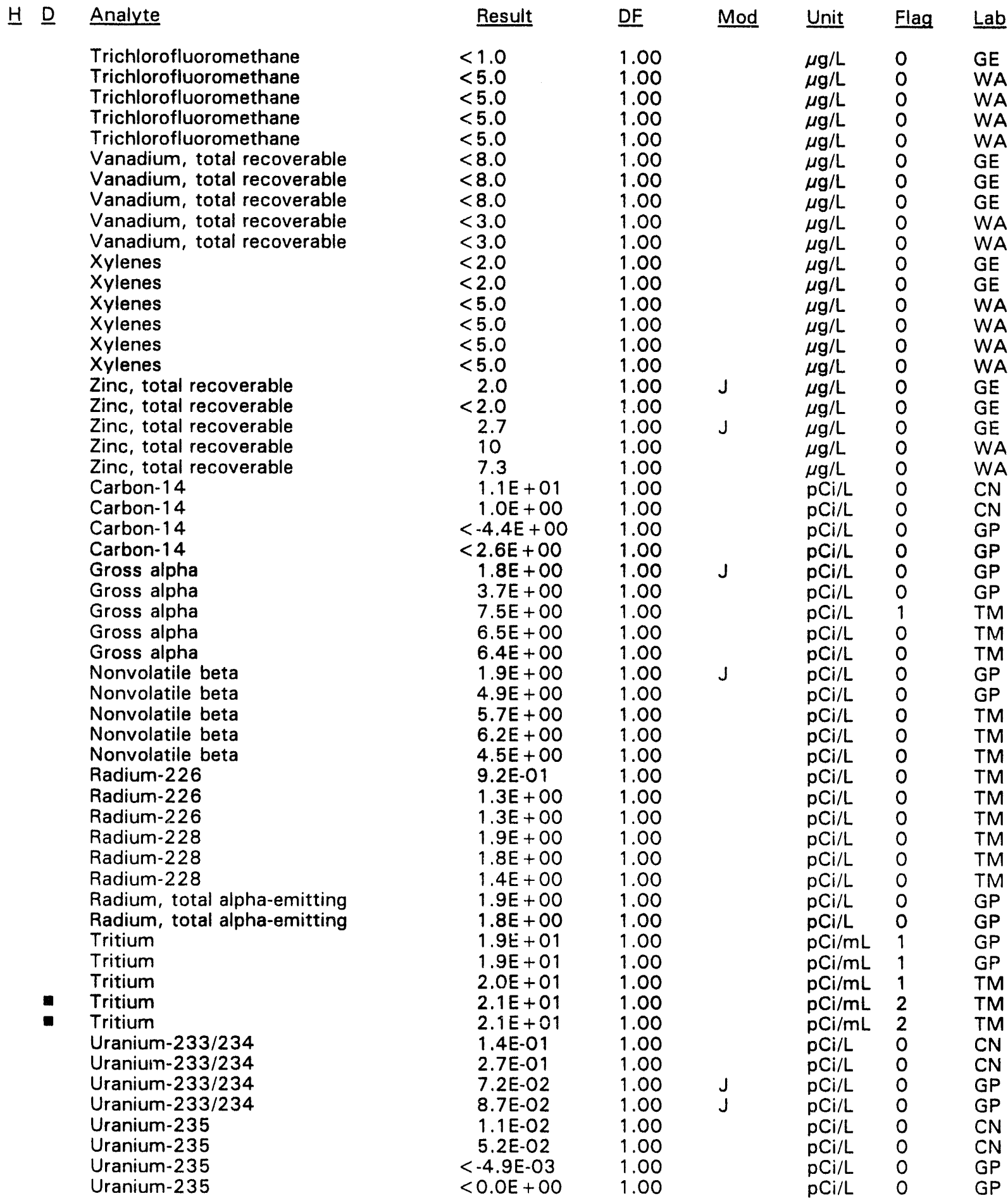

\footnotetext{
- = exceeded holding time. = exceeded screening level or final primary drinking water standard.
} 
WELL BGO 2D collected on $02 / 03 / 94$, laboratory analyses (cont.)

\begin{tabular}{|c|c|c|c|c|c|}
\hline$\underline{H}$ D Analyte & Result & DF & Mod & Unit & Flag \\
\hline $\begin{array}{l}\text { Uranium-238 } \\
\text { Uranium-238 } \\
\text { Uranium-238 } \\
\text { Uranium-238 }\end{array}$ & $\begin{array}{r}2.1 \mathrm{E}-01 \\
1.8 \mathrm{E}-01 \\
9.5 \mathrm{E}-02 \\
<8.0 \mathrm{E}-03\end{array}$ & $\begin{array}{l}1.00 \\
1.00 \\
1.00 \\
1.00\end{array}$ & $J$ & $\begin{array}{l}\mathrm{pCi} / \mathrm{L} \\
\mathrm{pCi} / \mathrm{L} \\
\mathrm{pCi} / \mathrm{L} \\
\mathrm{pCi} / \mathrm{L}\end{array}$ & $\begin{array}{l}0 \\
0 \\
0 \\
0\end{array}$ \\
\hline
\end{tabular}

\section{WELL BGO 3D}

$\begin{array}{lllllll}\text { SRS Coord. } & \text { Lat/Longitude } & \text { Screen Zone Elevation } & \text { Top of Casing } & \text { Casing } & \text { Pump } & \text { Formation } \\ \text { N75351.3 } & 33.288382^{\circ} \mathrm{N} & 247.6-227.6 \mathrm{ft} \mathrm{msl} & 292.7 \mathrm{ft} \mathrm{msl} & 4 \text { " PVC } & \text { S } & \left.\text { Water Table (IIB }{ }_{2}\right) \\ \text { E58809.2 } & 81.658312^{\circ} \mathrm{W} & & & \end{array}$

\section{FIELD MEASUREMENTS}

Sample date: 02/04/94

Depth to water: $57.95 \mathrm{ft}(17.66 \mathrm{~m})$ helow TOC

Water elevation: $234.75 \mathrm{ft}(71.55 \mathrm{~m}) \mathrm{msl}$

Sp. conductance: $55 \mu \mathrm{S} / \mathrm{cm}$

Turbidity: 16.4 NTU

Water evacuated before sampling: $4 \mathrm{gal}$

The well went dry during purging.

\section{LABORATORY ANALYSES}

- $D \quad$ Analyte
pH
Specific conductance
Turbidity
Acetophenone
Aldrin
Aluminum, total recoverable
Antimony, total recoverable
Arsenic, total recoverable
Barium, total recoverable
Benzene
Benzene
Bromodichloromethane
Bromodichloromethane
Bromoform
Bromoform
Bromomethane (Methyl bromide)
Bromomethane (Methyl bromide)
Cadmium, total recoverable
Calcium, total recoverable
Carbon tetrachloride
Carbon tetrachloride
Chloride
Chlorobenzene
Chlorobenzene
Chloroethane
Chloroethane
Chloroethene (Vinyl chloride)
Chloroethene (Vinyl chloride)
2-Chloroethyl vinyl ether
2-Chloroethyl vinyl ether

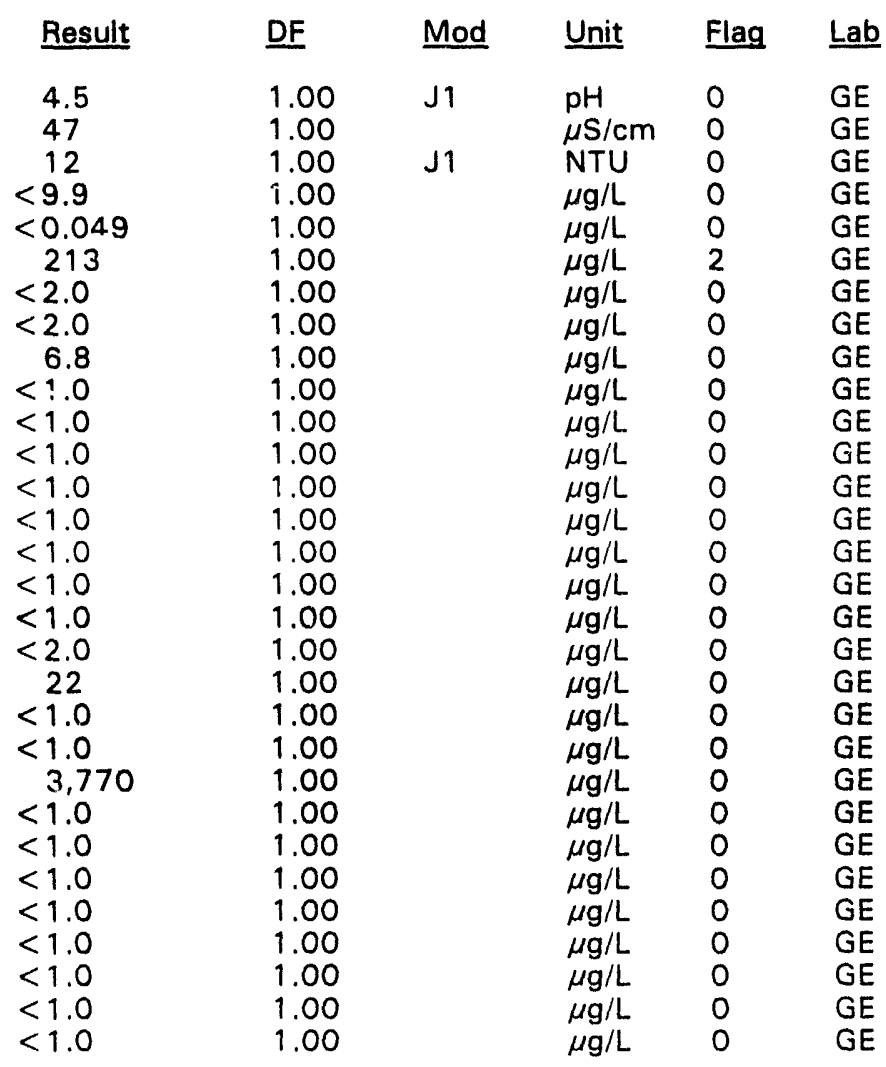

Time: 9: 35

pH: 4.2

Alkalinity: $0 \mathrm{mg} / \mathrm{L}$

Water temperature: $9.4^{\circ} \mathrm{C}$

Volumes purged: 0.9 well volumes 
WELL BGO 3D collected on 02/04/94, laboratory analyses (cont.)

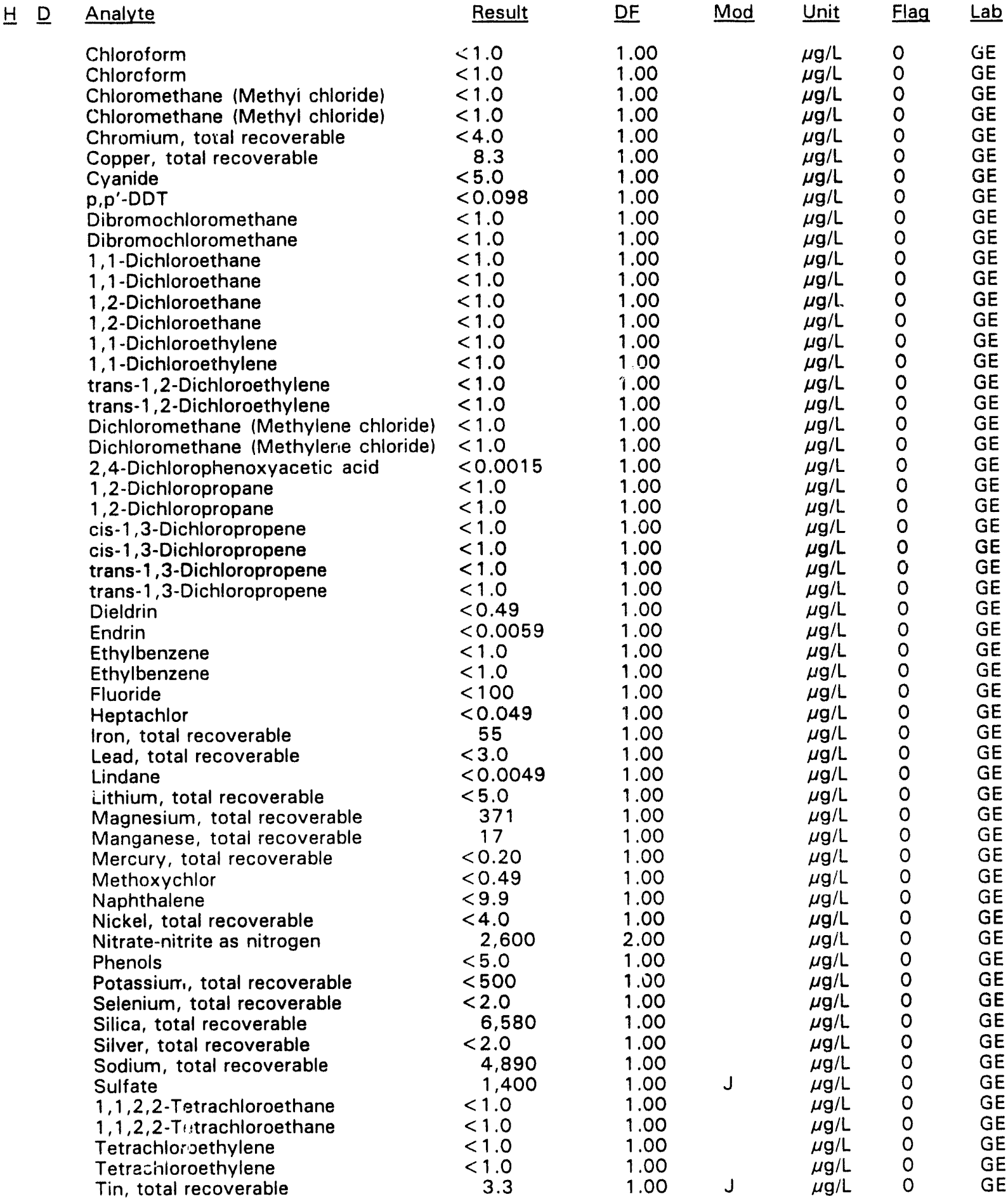

\footnotetext{
- =xceeded holding time. $=$ exceeded screening level or final primary drinking water standard.
} 
WELL BGO 3D collected on 02/04/94, laboratory analyses (cont.)

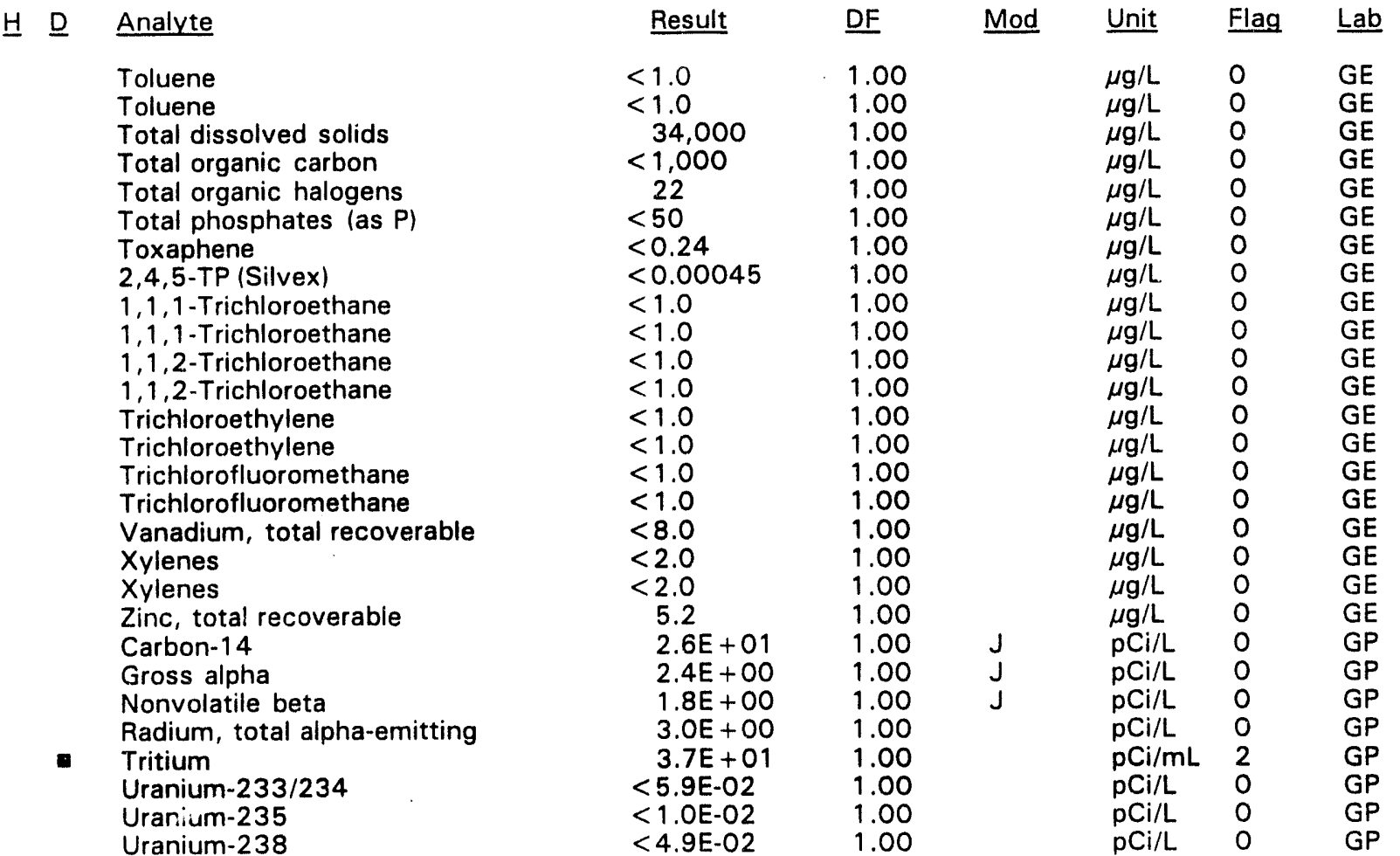

\section{WELL BGO 5C}

$\begin{array}{lllllll}\text { SRS Coord. } & \text { Lat/Longitude } & \text { Screen Zone Elevation } & \text { Top of Casing } & \text { Casing } & \text { Pump } & \text { Formation } \\ \text { N76476.9 } & 33.290848^{\circ} \mathrm{N} & 193.2-183.2 \mathrm{ft} \mathrm{msl} & 296.1 \mathrm{ft} \mathrm{msl} & \text { 4" PVC } & \text { S } & \text { McBean (IIB,) } \\ \text { E58794.5 } & 81.660537^{\circ} \mathrm{W} & & & \end{array}$

\section{FIELD MEASUREMENTS}

Sample date: $02 / 04 / 94$

Depth to water: $80.76 \mathrm{ft}(24.62 \mathrm{~m})$ below TOC

Water elevation: $215.34 \mathrm{ft}(65.64 \mathrm{~m}) \mathrm{msl}$

Sp. conductance: $50 \mu \mathrm{S} / \mathrm{cm}$

Turbidity: 10.6 NTU

Water evacuated before sampling: $17 \mathrm{gal}$

The well went dry during purging.

\section{LABORATORY ANALYSES}

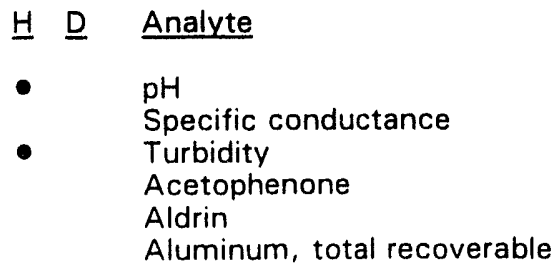

Time: 9: 55

$\mathrm{pH}: 6.5$

Alkalinity: $13 \mathrm{mg} / \mathrm{L}$

Water temperature: $18.1^{\circ} \mathrm{C}$

Volumes purged: 0.8 well volumes

- = exceeded holding time. = exceeded screening level or final primary drinking water standard. 
WELL BGO 5C collected on 02/04/94, laboratory analyses (cont.)

H D Analyte

Antimony, total recoverable

Arsenic, total recoverable

Barium, total recoverable

Benzene

Bromodichloromethane

Bromoform

Bromomethane (Methyl bromide)

Cadmium, total recoverable

Calcium, total recoverable

Carbon tetrachloride

Chloride

Chlorobenzene

Chloroethane

Chloroethene (Vinyl chloride)

2-Chloroethyl vinyl ether

Chloroform

Chloromethane (Methyl chloride)

Chromium, total recoverable

Copper, total recoverable

Cyanide

$p, p^{\prime}-D D T$

Dibromochloromethane

1,1-Dichloroethane

1,2-Dichloroethane

1,1-Dichloroethylene

trans-1,2-Dichloroethylene

Dichloromethane (Methylene chloride)

2.,4-Dichlorophenoxyacetic acid

1,2-Dichloropropane

cis-1,3-Dichloropropene

trans-1,3-Dichloropropene

Dieldrin

Endrin

Ethylbenzene

Fluoride

Heptachlor

Iron, total recoverable

Lead, total recoverable

Lindane

Lithium, total recoverable

Magnesium, total recoverable

Manganese, total recoverable

Mercury, total recoverable

Methoxychior

Naphthalene

Nickel, total recoverable

Nitrate-nitrite as nitrogen

Nitrate-nitrite as nitrogen

Phenols

Potassium, total recoverable

Selenium, total recoverable

Silica, total recoverable

Silver, total recoverable

Sodium, total recoverable

Sulfate

1,1,2,2-Tetrachloroethane

\begin{tabular}{|c|c|}
\hline \multicolumn{2}{|l|}{ Result } \\
\hline$<2.0$ & 1.00 \\
\hline$<2.0$ & 1.00 \\
\hline 10 & 1.00 \\
\hline$<1.0$ & 1.00 \\
\hline$<1.0$ & 1.00 \\
\hline $\begin{array}{l}<1.0 \\
<1.0\end{array}$ & $\begin{array}{l}1.00 \\
1.00\end{array}$ \\
\hline$<2.0$ & 1.00 \\
\hline 6,490 & 1.00 \\
\hline$<1.0$ & 1.00 \\
\hline 1,860 & 1.00 \\
\hline$<1.0$ & 1.00 \\
\hline$<1.0$ & 1.00 \\
\hline$<1.0$ & 1.00 \\
\hline$<1.0$ & 1.00 \\
\hline$<1.0$ & 1.00 \\
\hline 6.7 & 1.00 \\
\hline 4.6 & 1.00 \\
\hline$<5.0$ & 1.00 \\
\hline$<0.10$ & 1.00 \\
\hline$<1.0$ & 1.00 \\
\hline$<1.0$ & 1.00 \\
\hline$<1.0$ & 1.00 \\
\hline$<1.0$ & 1.00 \\
\hline$<1.0$ & 1.00 \\
\hline$<1.0$ & 1.00 \\
\hline$<0.0015$ & 1.00 \\
\hline$<1.0$ & 1.00 \\
\hline$<1.0$ & 1.00 \\
\hline$<1.0$ & 1.00 \\
\hline$<0.50$ & 1.00 \\
\hline $\begin{array}{l}<0.0060 \\
<1.0\end{array}$ & $\begin{array}{l}1.00 \\
1.00\end{array}$ \\
\hline $\begin{array}{l}<1.0 \\
<100\end{array}$ & 1.00 \\
\hline$<0.050$ & 1.00 \\
\hline 44 & 1.00 \\
\hline$<3.0$ & 1.00 \\
\hline$<0.0050$ & 1.00 \\
\hline$<5.0$ & 1.00 \\
\hline 412 & 1.00 \\
\hline 17 & 1.00 \\
\hline$<0.20$ & 1.00 \\
\hline$<0.50$ & 1.00 \\
\hline$<10$ & 1.00 \\
\hline $\begin{array}{r}<4.0 \\
940\end{array}$ & $\begin{array}{l}1.00 \\
1.00\end{array}$ \\
\hline 970 & 1.00 \\
\hline$<5.0$ & 1.00 \\
\hline$<500$ & 1.00 \\
\hline $\begin{array}{r}<2.0 \\
13\end{array}$ & OC \\
\hline $\begin{array}{r}13,5 \\
<2.0\end{array}$ & 1 \\
\hline 1,890 & 1 \\
\hline$<1,000$ & \\
\hline$<1.0$ & \\
\hline
\end{tabular}

Mod Unit Flag Lab

$\mu g / L \quad 0 \quad$ GE

$\mu \mathrm{g} / \mathrm{L} \quad 0 \quad \mathrm{GE}$

$\mu g / L \quad 0 \quad$ GE

$\mu \mathrm{g} / \mathrm{L} \quad 0 \quad \mathrm{GE}$

$\mu \mathrm{g} / \mathrm{L} \quad 0 \quad \mathrm{GE}$

$\mu g / L \quad 0 \quad G E$

$\mu \mathrm{g} / \mathrm{L} \quad 0 \quad \mathrm{GE}$

$\mu \mathrm{g} / \mathrm{L} \quad 0$

$\mu \mathrm{g} / \mathrm{L} \quad 0 \quad \mathrm{GE}$

$\mu \mathrm{g} / \mathrm{L} \quad 0 \quad \mathrm{GE}$

$\mu \mathrm{g} / \mathrm{L} \quad 0 \quad \mathrm{GE}$

$\mu \mathrm{g} / \mathrm{L} \quad 0 \quad \mathrm{GE}$

$\mu \mathrm{g} / \mathrm{L} \quad 0 \quad \mathrm{GE}$

$\mu \mathrm{g} / \mathrm{L} \quad 0 \quad \mathrm{GE}$

$\mu \mathrm{g} / \mathrm{L} \quad 0$

$\mu g / L \quad 0 \quad \mathrm{GE}$

$\mu g / L \quad 0 \quad$ GE

$\mu \mathrm{g} / \mathrm{L} \quad 0 \quad \mathrm{GE}$

$J \quad \mu g / L \quad 0 \quad G E$

$\mu \mathrm{g} / \mathrm{L} \quad \mathrm{O} \quad \mathrm{GE}$

$\mu \mathrm{g} / \mathrm{L} \quad 0 \quad \mathrm{GE}$

$\mu \mathrm{g} / \mathrm{L} \quad 0 \quad \mathrm{GE}$

$\mu g / L \quad O \quad G E$

$\mu \mathrm{g} / \mathrm{L} \quad 0 \quad \mathrm{GE}$

$\mu \mathrm{g} / \mathrm{L} \quad 0 \quad \mathrm{GE}$

$\mu \mathrm{g} / \mathrm{L} \quad 0 \quad \mathrm{GE}$

$\mu \mathrm{g} / \mathrm{L} \quad \mathrm{O} \quad \mathrm{GE}$

$J 1 \mu \mathrm{g} / \mathrm{L} \quad 0 \quad \mathrm{GE}$

$\mu \mathrm{g} / \mathrm{L} \quad 0 \quad \mathrm{GE}$

$\mu \mathrm{g} / \mathrm{L} \quad \mathrm{O} \quad \mathrm{GE}$

$\mu \mathrm{g} / \mathrm{L} \quad \mathrm{O} \quad \mathrm{GE}$

$\mu \mathrm{g} / \mathrm{L} \quad \mathrm{O} \quad \mathrm{GE}$

$\mu \mathrm{g} / \mathrm{L} \quad 0 \quad \mathrm{GE}$

$\mu \mathrm{g} / \mathrm{L} \quad 0 \quad \mathrm{GE}$

$\mu \mathrm{g} / \mathrm{L} \quad 0 \quad \mathrm{GE}$

$\mu \mathrm{g} / \mathrm{L} \quad \mathrm{O} \quad \mathrm{GE}$

$\mu \mathrm{g} / \mathrm{L} \quad 0 \quad \mathrm{GE}$

$\mu \mathrm{g} / \mathrm{L} \quad \mathrm{O} \quad \mathrm{GE}$

$\mu g / L \quad 0 \quad G E$

$\mu \mathrm{g} / \mathrm{L} \quad 0 \quad \mathrm{GE}$

$\mu \mathrm{g} / \mathrm{L} \quad \mathrm{C} \quad \mathrm{GE}$

$\mu \mathrm{g} / \mathrm{L} \quad 0 \quad \mathrm{GE}$

$\mu \mathrm{g} / \mathrm{L} \quad \mathrm{O} \quad \mathrm{GE}$

$\mu \mathrm{g} / \mathrm{L} \quad 0 \quad \mathrm{GE}$

$\mu \mathrm{g} / \mathrm{L} \quad 0 \quad \mathrm{GE}$

$\mu \mathrm{g} / \mathrm{L} \quad \mathrm{O} \quad \mathrm{GE}$

$\mu \mathrm{g} / \mathrm{L} \quad 0 \quad \mathrm{GE}$

$\mu \mathrm{g} / \mathrm{L} \quad \mathrm{O} \quad \mathrm{GE}$

$\mu \mathrm{g} / \mathrm{L} \quad \mathrm{O} \quad \mathrm{GE}$

$\mu \mathrm{g} / \mathrm{L} \quad \mathrm{O} \quad \mathrm{GE}$

$\mu \mathrm{g} / \mathrm{L} \quad \mathrm{O} \quad \mathrm{GE}$

$\mu \mathrm{g} / \mathrm{L} \quad \mathrm{O} \quad \mathrm{GE}$

$\mu \mathrm{g} / \mathrm{L} \quad \mathrm{O} \quad \mathrm{GE}$

$\mu \mathrm{g} / \mathrm{L} \quad \mathrm{O} \quad \mathrm{GE}$

$\mu \mathrm{g} / \mathrm{L} \quad \mathrm{O} \quad \mathrm{GE}$

- = exceeded holding time. = exceeded screenirig level or final primary drinking water standard. 
WELL BGO 5C collected on $02 / 04 / 94$, laboratory analyses icont.)

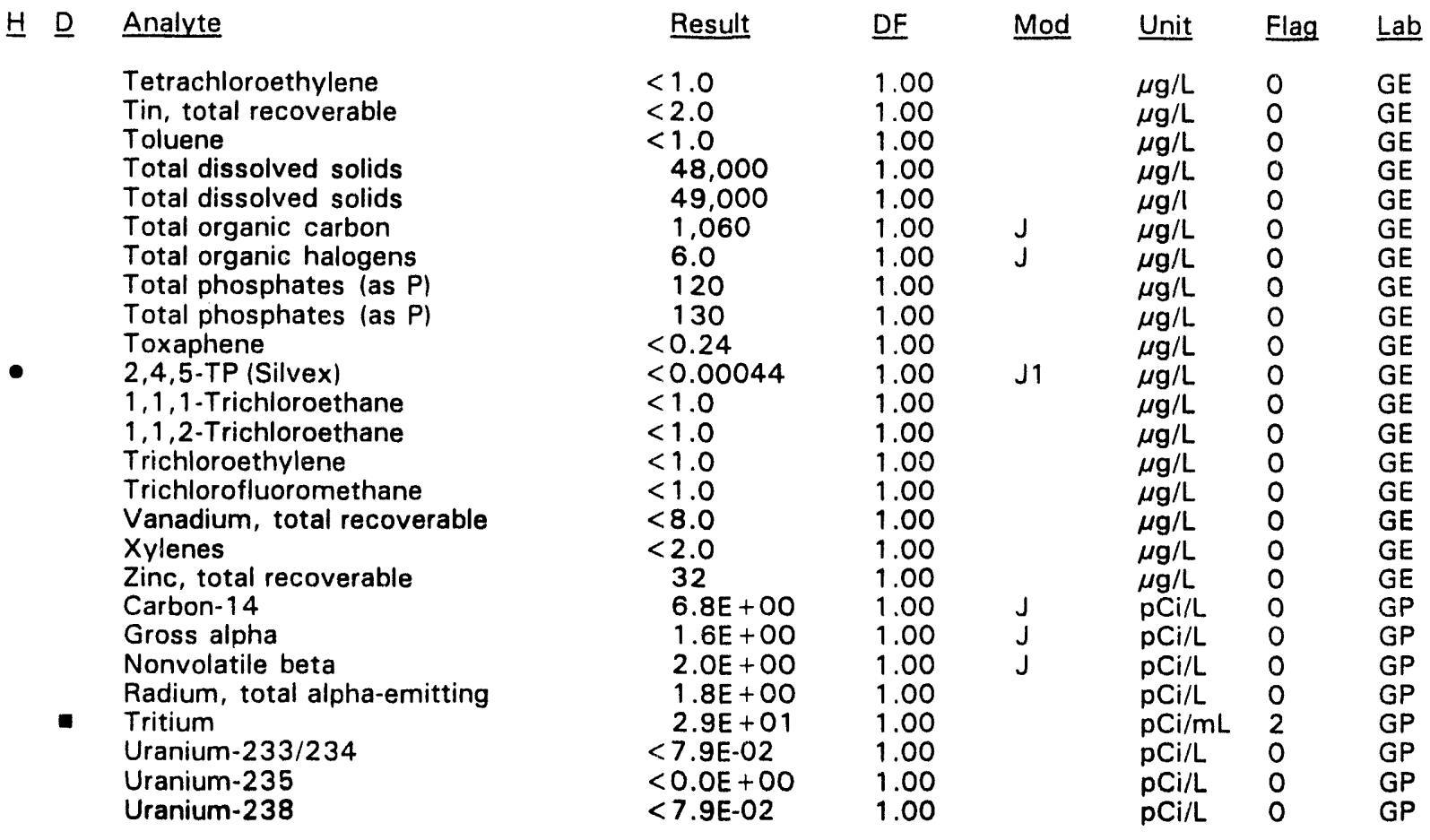

WELL BGO 5D

\begin{tabular}{|c|c|c|c|c|c|c|}
\hline SRS Coord. & Lat/Longitude & Screen Zone Elevation & Top of Casing & Casing & Pump & Formation \\
\hline $\begin{array}{l}N 76477.5 \\
E 58784.8\end{array}$ & $\begin{array}{l}33.290833^{\circ} \mathrm{N} \\
81.660564^{\circ} \mathrm{W}\end{array}$ & $239.3-219.3 \mathrm{ft} \mathrm{msl}$ & $296.3 \mathrm{ft} \mathrm{msl}$ & 4" PVC & $\mathrm{S}$ & Water Table $\left(\| B_{2}\right)$ \\
\hline
\end{tabular}

\section{FIELD MEASUREMENTS}

Sample date: 02/04/94

Depth to water: $65.35 \mathrm{ft}(19.92 \mathrm{~m})$ below TOC

Water elevation: $230.95 \mathrm{ft}(70.39 \mathrm{~m}) \mathrm{msl}$

Sp. conductance: $44 \mu \mathrm{S} / \mathrm{cm}$

Turbidity: 5.4 NTU

Water evacuated before sampling: $6 \mathrm{gal}$

The well went dry during purging.

\section{LABORATORY ANALYSES}

H $\underline{\text { Analyte }}$

$\mathrm{pH}$

- $\quad \mathrm{pH}$

Specific conductance

Turbidity

Turbidity

Acetophenone

Aldrin

Aluminum, total recoverable

\begin{tabular}{|c|c|c|c|c|}
\hline Result & $\underline{D F}$ & Mod & Unit & Flag \\
\hline $\begin{array}{l}5.0 \\
5.0 \\
39 \\
12 \\
13 \\
<10 \\
<0.050 \\
71\end{array}$ & $\begin{array}{l}1.00 \\
1.00 \\
1.00 \\
1.00 \\
1.00 \\
1.00 \\
1.00 \\
1.00\end{array}$ & J1 & $\begin{array}{l}\mathrm{pH} \\
\mathrm{pH} \\
\mu \mathrm{S} / \mathrm{cm} \\
N T U \\
N T U \\
\mu \mathrm{g} / \mathrm{L} \\
\mu \mathrm{g} / \mathrm{L} \\
\mu \mathrm{g} / \mathrm{L}\end{array}$ & $\begin{array}{l}0 \\
0 \\
0 \\
0 \\
0 \\
0 \\
0 \\
2\end{array}$ \\
\hline
\end{tabular}

Time: 10: 02

$\mathrm{pH}: 4.7$

Alkalinity: $0 \mathrm{mg} / \mathrm{L}$

Water temperature: $18.9^{\circ} \mathrm{C}$

Volumes purged: 0.8 well volumes

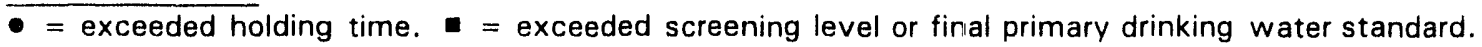


WELL BGO 5D collected on 02/04/94, laboratory analyses (cont.)

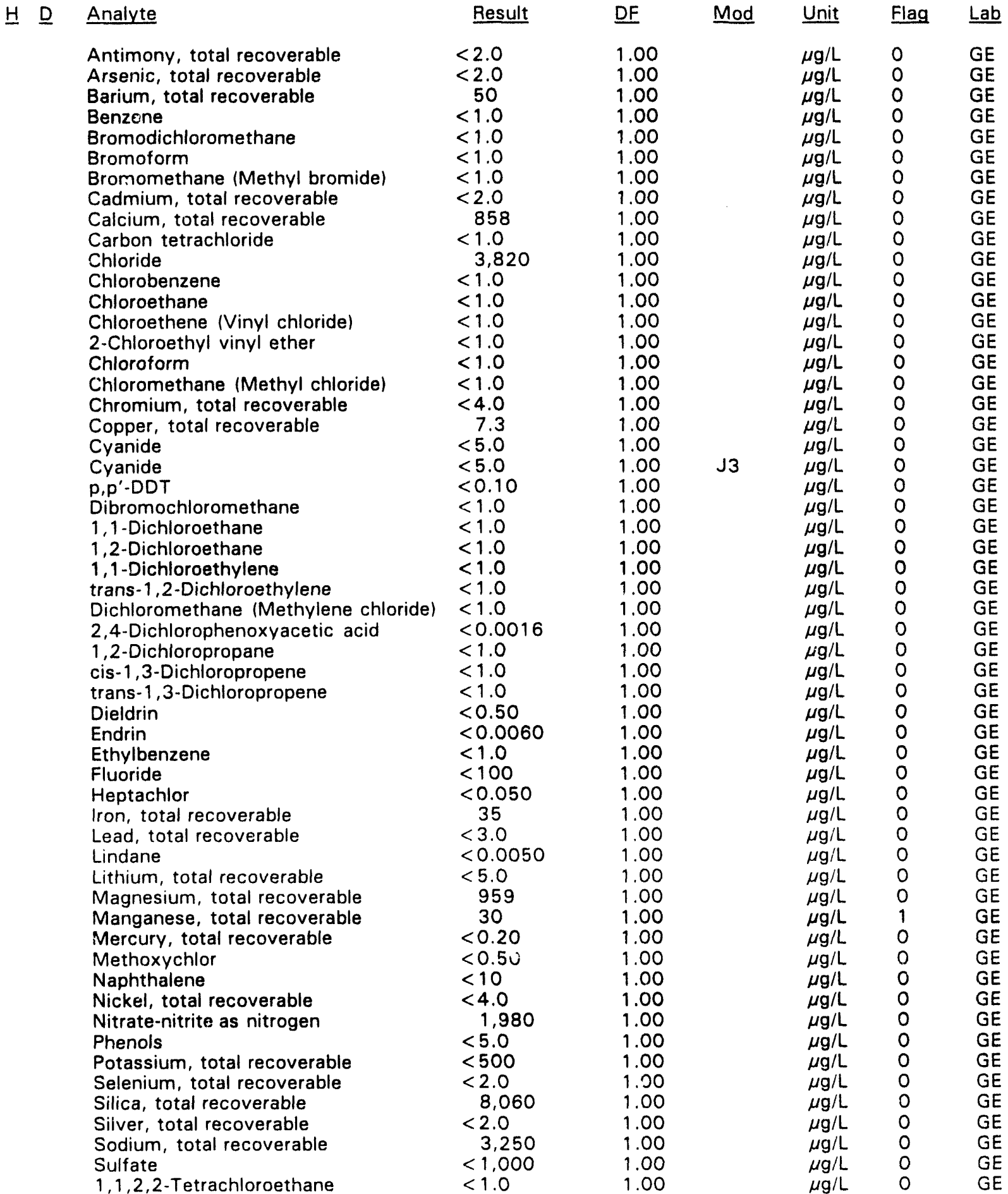

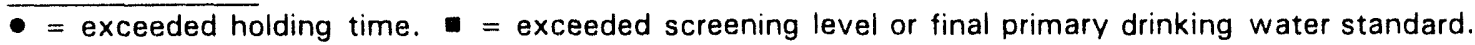


WELL BGO 5D collected on 02/04/94, laboratory analyses (cont.)

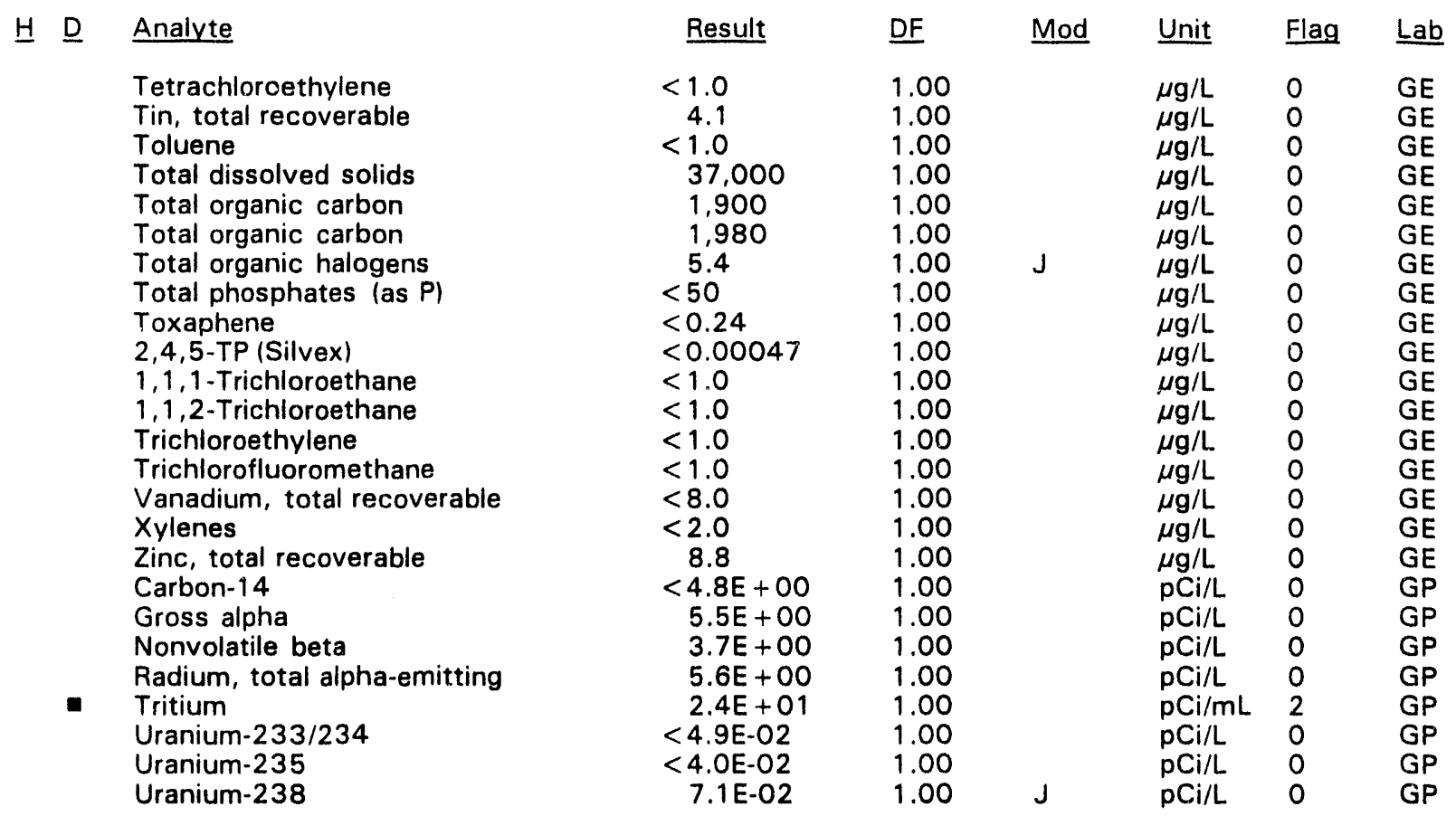

WELL BGO 6A

\begin{tabular}{|c|c|c|c|c|c|c|}
\hline SRS Coord. & Lat/Longitude & Screen Zone Elevation & Top of Casing & Casing & Pump & Formation \\
\hline $\begin{array}{l}N 76487.2 \\
E 58316.8\end{array}$ & $\begin{array}{l}33.290091^{\circ} \mathrm{N} \\
81.661815^{\circ} \mathrm{W}\end{array}$ & $117.5-107.5 \mathrm{ft} \mathrm{msl}$ & $285.6 \mathrm{ft} \mathrm{msl}$ & 4" PVC & $\mathbf{S}$ & ree (IIA) \\
\hline
\end{tabular}

\section{FIELD MEASUREMENTS}

Sample date: $02 / 24 / 94$

Depth to water: $126.46 \mathrm{ft}(38.55 \mathrm{~m})$ below TOC

Water elevation: $159.14 \mathrm{ft}(48.51 \mathrm{~m}) \mathrm{ms}$ l

Sp. conductance: $304 \mu \mathrm{S} / \mathrm{cm}$

Turbidity: 1.8 NTU

Water evacuated before sampling: $127 \mathrm{gal}$

LABORATORY ANALYSES

H D Analyte

- $\mathrm{pH}$

Specific conductance

Turbidity

Turbidity

Acetophenone

Aldrin

Aluminum, total recoverable

Antimony, total recoverable

Arsenic, total recoverable
Time: $9: 48$

$\mathrm{pH}: 7.7$

Alkalinity: $123 \mathrm{mg} / \mathrm{L}$

Water temperature: $18.7^{\circ} \mathrm{C}$

Volumes purged: 3.7 well volumes

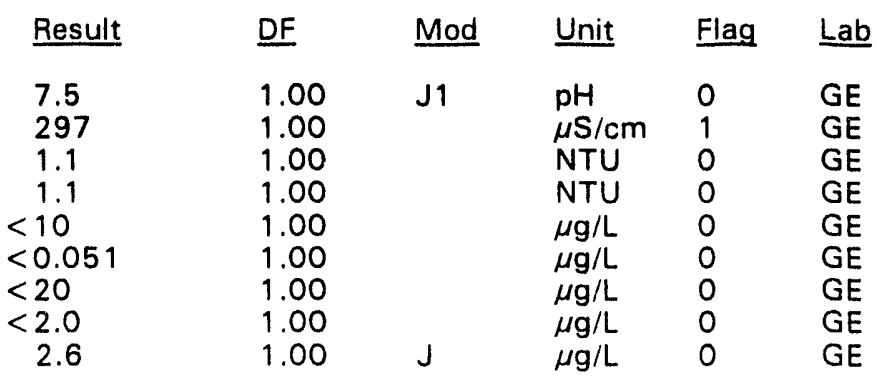

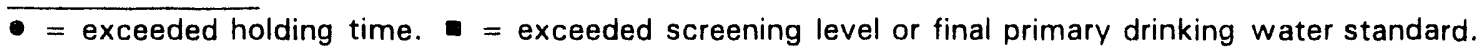


WELL BGO 6 A collected on $02 / 24 / 94$, laboratory analyses (cont.)

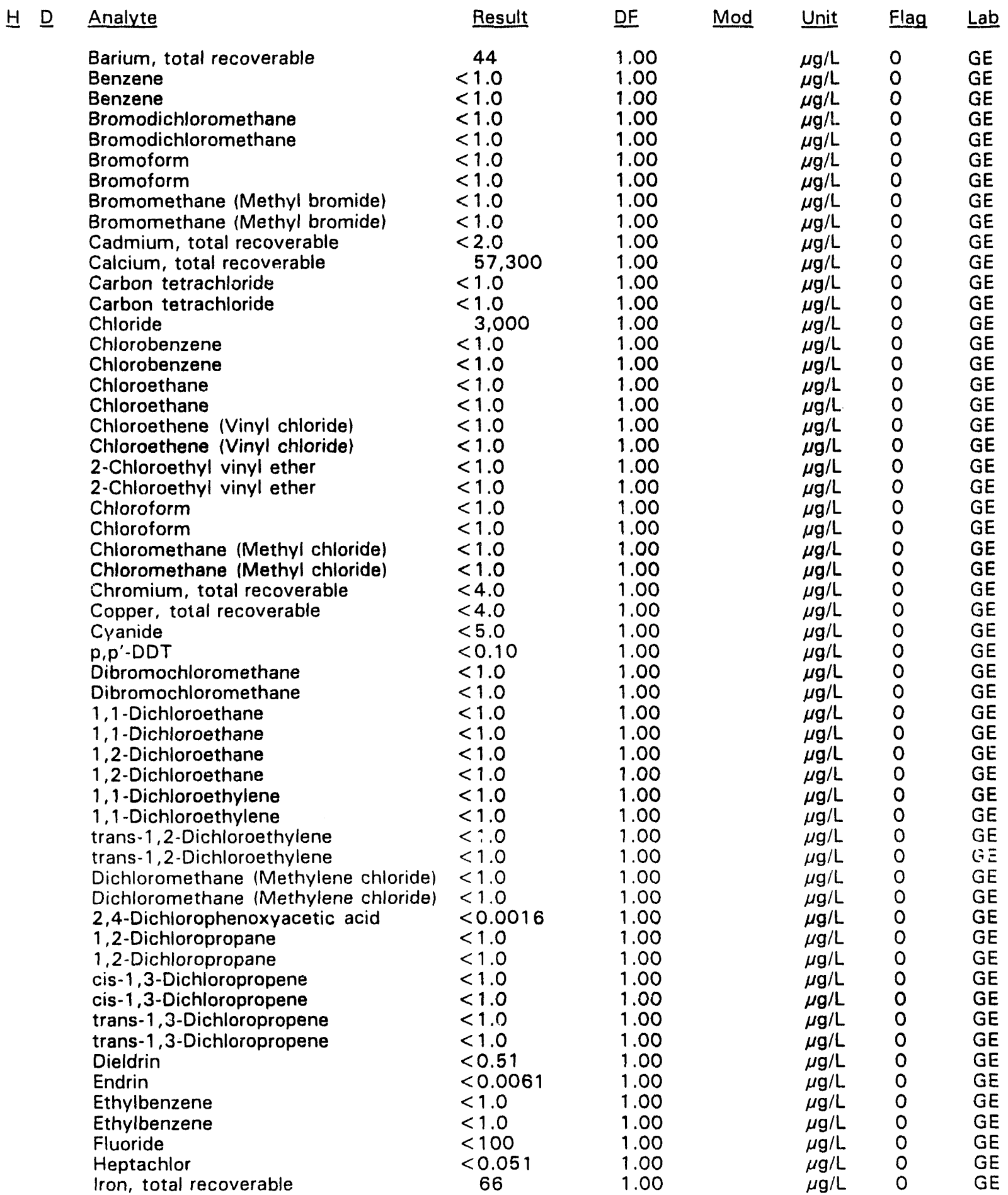

\footnotetext{
$\overline{-=\text { exceeded holding time. }} \mathbf{-}=$ exceeded screening level or final primary drinking water standard.
} 
WELL BGO 6 A collected on $02 / 24 / 94$, laboratory analyses (cont.)

\begin{tabular}{|c|c|c|c|c|c|c|c|}
\hline \multirow[t]{50}{*}{$\underline{H} \underline{D}$} & Analyte & Result & $\underline{D F}$ & Mod & $\underline{\text { Unit }}$ & Flag & La \\
\hline & $\begin{array}{l}\text { Lead, total recoverable } \\
\text { Lindane }\end{array}$ & $\begin{array}{l}<3.0 \\
<0.0051\end{array}$ & 1.00 & & $\mu \mathrm{g} / \mathrm{L}$ & 0 & $\mathrm{GE}$ \\
\hline & $\begin{array}{l}\text { Lindane } \\
\text { Lithium, total recoverable }\end{array}$ & $\begin{array}{l}<0.0051 \\
<5.0\end{array}$ & $\begin{array}{l}1.00 \\
1.00\end{array}$ & & $\begin{array}{l}\mu \mathrm{g} / \mathrm{L} \\
\mu \mathrm{g} / \mathrm{L}\end{array}$ & $\begin{array}{l}0 \\
0\end{array}$ & \\
\hline & Magnesium, total recoverable & 1.470 & 1.00 & & $\mu \mathrm{g} / \mathrm{L}$ & 0 & \\
\hline & Manganese, total recoverable & 4.6 & 1.00 & & $\mu \mathrm{g} / \mathrm{L}$ & 0 & $\mathrm{GL}$ \\
\hline & Mercury, total recoverable & $<0.20$ & 1.00 & & $\mu \mathrm{g} / \mathrm{L}$ & 0 & \\
\hline & Methoxychlor & $<0.51$ & 1.00 & & $\mu g / L$ & 0 & \\
\hline & Naphthaiene & $<10$ & 1.00 & & $\mu \mathrm{g} / \mathrm{L}$ & 0 & \\
\hline & Nickel, total recoverable & $<4.0$ & 1.00 & & $\mu \mathrm{g} / \mathrm{L}$ & 0 & \\
\hline & Nitrate-nitrite as nitrogen & $<50$ & 1.00 & & $\mu \mathrm{g} / \mathrm{L}$ & 0 & \\
\hline & Phenols & $<5.0$ & 1.00 & & $\mu \mathrm{g} / \mathrm{L}$ & 0 & \\
\hline & Potassium, total recoverable & $\begin{array}{r}835 \\
<20\end{array}$ & 1.00 & & $\mu g / L$ & 0 & \\
\hline & $\begin{array}{l}\text { Selenium, total recoverable } \\
\text { Silica, total recoverable }\end{array}$ & $\begin{array}{l}<2.0 \\
41,400\end{array}$ & $\begin{array}{l}1.00 \\
1.00\end{array}$ & & $\begin{array}{l}\mu \mathrm{g} / \mathrm{L} \\
\mu \mathrm{g} / \mathrm{L}\end{array}$ & $\begin{array}{l}0 \\
0\end{array}$ & \\
\hline & Silver, total recoverable & $<2.0$ & 1.00 & & $\mu \mathrm{g} / \mathrm{L}$ & 0 & \\
\hline & Sodium, total recoverable & 2,290 & 1.00 & & $\mu g / L$ & 0 & \\
\hline & Sulfate & 7,920 & 1.00 & & $\mu \mathrm{g} / \mathrm{L}$ & 0 & \\
\hline & 1,1,2,2-Tetrachloroethane & $<1.0$ & 1.00 & & $\mu g / L$ & 0 & \\
\hline & $\begin{array}{l}1,1,2,2 \text {-Tetrachloroethane } \\
\text { Tetrachloroethvlene }\end{array}$ & $\begin{array}{l}<1.0 \\
<1.0\end{array}$ & $\begin{array}{l}1.00 \\
1.00\end{array}$ & & $\mu \mathrm{g} / \mathrm{L}$ & 0 & \\
\hline & Tetrachloroethylene & $\begin{array}{l}<1.0 \\
<1.0\end{array}$ & 1.00 & & $\begin{array}{l}\mu \mathrm{g} / \mathrm{L} \\
\mu \mathrm{g} / \mathrm{L}\end{array}$ & $\begin{array}{l}0 \\
0\end{array}$ & $\mathrm{Gt}$ \\
\hline & Tin, total recoverable & $<2.0$ & 1.00 & & $\mu \mathrm{g} / \mathrm{L}$ & 0 & \\
\hline & Toluene & $<1.0$ & 1.00 & & $\mu \mathrm{g} / \mathrm{L}$ & 0 & \\
\hline & Toluene & $<1.0$ & 1.00 & & $\mu \mathrm{g} / \mathrm{L}$ & 0 & \\
\hline & Total dissolved solids & 208,000 & 1.00 & & $\mu \mathrm{g} / \mathrm{L}$ & 0 & \\
\hline & Total organic carbon & $<1,000$ & 1.00 & & $\mu \mathrm{g} / \mathrm{L}$ & 0 & \\
\hline & Total organic halogens & 7.2 & 1.00 & J & $\mu \mathrm{g} / \mathrm{L}$ & 0 & \\
\hline & Total organic halogens & 7.8 & 1.00 & J & $\mu \mathrm{g} / \mathrm{L}$ & 0 & \\
\hline & Total phosphates (as P) & $<50$ & 1.00 & & $\mu g / L$ & 0 & \\
\hline & Toxaphene & $<0.25$ & 1.00 & & $\mu \mathrm{g} / \mathrm{L}$ & 0 & \\
\hline & $2,4,5$-TP (Silvex) & $<0.00047$ & 1.00 & & $\mu \mathrm{g} / \mathrm{L}$ & 0 & \\
\hline & 1,1,1-Trichloroethane & $<1.0$ & 1.00 & & $\mu g / L$ & 0 & \\
\hline & 1,1,1-Trichloroethane & $<1.0$ & 1.00 & & $\mu g / L$ & 0 & \\
\hline & $1,1,2$-Trichloroethane & $<1.0$ & 1.00 & & $\mu \mathrm{g} / \mathrm{L}$ & 0 & \\
\hline & 1,1,2-Trichloroethane & $<1.0$ & 1.00 & & $\mu \mathrm{g} / \mathrm{L}$ & 0 & \\
\hline & Trichloroethylene & $<1.0$ & 1.00 & & $\mu \mathrm{g} / \mathrm{L}$ & 0 & \\
\hline & Trichloroethylene & $<1.0$ & 1.00 & & $\mu g / L$ & 0 & \\
\hline & Trichlorofluoromethane & $<1.0$ & 1.00 & & $\mu \mathrm{g} / \mathrm{L}$ & 0 & \\
\hline & Trichlorofluoromethane & $<1.0$ & 1.00 & & $\mu \mathrm{g} / \mathrm{L}$ & 0 & \\
\hline & Vanadium, total recoverable & $<8.0$ & 1.00 & & $\mu \mathrm{g} / \mathrm{L}$ & 0 & \\
\hline & Xylenes & $<2.0$ & 1.00 & & $\mu \mathrm{g} / \mathrm{L}$ & 0 & \\
\hline & Xylenes & $<2.0$ & 1.00 & & $\mu \mathrm{g} / \mathrm{L}$ & 0 & \\
\hline & Zinc, total recoverable & $<2.0$ & 1.00 & & $\mu \mathrm{g} / \mathrm{L}$ & 0 & \\
\hline & Carbon-14 & $<4.1 E+00$ & 1.00 & & $\mathrm{pCi} / \mathrm{L}$ & 0 & \\
\hline & Carbon-14 & $<3.5 E+00$ & 1.00 & & $\mathrm{pCi} / \mathrm{L}$ & 0 & \\
\hline & Gross alpha & $<2.6 \mathrm{E}-01$ & 1.00 & & $\mathrm{pCi} / \mathrm{L}$ & 0 & \\
\hline & Nonvolatile beta & $2.1 E+00$ & 1.00 & J & $\mathrm{pCi} / \mathrm{L}$ & 0 & \\
\hline & Radium, total alpha-emitting & 6.0E-01 & 1.00 & $J$ & $\mathrm{pCi} / \mathrm{L}$ & 0 & \\
\hline & Tritium & $<1.4 \mathrm{E}-02$ & 1.00 & & $\mathrm{pCi} / \mathrm{mL}$ & 0 & \\
\hline & Uranium-233/234 & 8.0E-01 & 1.00 & $J$ & $\mathrm{pCi} / \mathrm{L}$ & 0 & \\
\hline & Uranium-235 & $1.9 E+00$ & 1.00 & & $\mathrm{pCi} / \mathrm{L}$ & 0 & \\
\hline & Uranium-238 & $1.9 E+00$ & 1.00 & & $\mathrm{pCi} / \mathrm{L}$ & 0 & \\
\hline
\end{tabular}

- exceeded holding time. = exceeded screening level or final primary drinking water standard. 
WSRC-TR-94-0240

Unclassified

WELL BGO 6B

\begin{tabular}{|c|c|c|c|c|c|c|}
\hline SRS Coord. & Lat/Longitude & Screen Zone Elevation & Top of Casing & Casing & Pump & Formatic \\
\hline $\begin{array}{l}76 \\
58\end{array}$ & $\begin{array}{l}33.290286^{\circ} \mathrm{N} \\
81.661865^{\circ} \mathrm{W}\end{array}$ & $149.7-139.7$ & 286.8 & 4" PVC & $\mathrm{s}$ & \\
\hline
\end{tabular}

\section{FIELD MEASUREMENTS}

Sample date: 01/25/94

Depth to water: $67.76 \mathrm{ft}(20.65 \mathrm{~m})$ below TOC

Water elevation: $219.04 \mathrm{ft}(66.76 \mathrm{~m}) \mathrm{ms}$

Sp. conductance: $192 \mu \mathrm{S} / \mathrm{cm}$

Turbidity: 6.1 NTU

Water evacuated before sampling: $41 \mathrm{gal}$

The well went dry during purging.

\section{LABORATORY ANALYSES}

\section{H D Analyte}

$\bullet$

$\mathrm{pH}$

Specific conductance

Turbidity

Turbidity

Acetophenone

Aldrin

Aluminum, total recoverable

Antimony, total recoverable

Arsenic, total recoverable

Barium, total recoverable

Benzene

Bromodichloromethane

Bromoform

Bromomethane (Methyl bromide)

Cadmium, total recoverable

Calcium, total recoverable

Carbon tetrachloride

Chloride

Chlorobenzene

Chloroethane

Chloroethene (Vinyl chloride)

2-Chloroethyl vinyl ether

Chloroform

Chloromethane (Methyl chloride)

Chromium, total recoverable

Copper, total recoverable

Cyanide

$p, p^{\prime}-D D T$

Dibromochloromethane

1,1-Dichloroethane

1,2-Dichloroethane

1,1-Dichloroethylene

trans-1,2-Dichloroethylene

Dichloromethane (Methylene chloride

2,4-Dichlorophenoxyacetic acid

1,2-Dichloropropane

cis-1,3-Dichloropropene

trans-1,3-Dichloropropene

\begin{tabular}{|c|c|c|c|c|}
\hline Result & DF & Mod & Unit & Flag \\
\hline 6.7 & 1.00 & J1 & $\mathrm{pH}$ & 0 \\
\hline 6.8 & 1.00 & Ji & $\mathrm{pH}$ & 0 \\
\hline 193 & 1.00 & & $\mu \mathrm{S} / \mathrm{cm}$ & \\
\hline 1.2 & 1.00 & & NTU & 0 \\
\hline 1.2 & 1.00 & & NTU & 0 \\
\hline$<11$ & 1.00 & & $\mu \mathrm{g} / \mathrm{L}$ & 0 \\
\hline$<0.056$ & 1.00 & & $\mu \mathrm{g} / \mathrm{L}$ & 0 \\
\hline$<20$ & 1.00 & & $\mu \mathrm{g} / \mathrm{L}$ & 0 \\
\hline$<2.0$ & 1.00 & & $\mu \mathrm{g} / \mathrm{L}$ & 0 \\
\hline$<2.0$ & 1.00 & & $\mu \mathrm{g} / \mathrm{L}$ & 0 \\
\hline 35 & 1.00 & & $\mu \mathrm{g} / \mathrm{L}$ & 0 \\
\hline$<1.0$ & 1.00 & & $\mu \mathrm{g} / \mathrm{L}$ & 0 \\
\hline$<1.0$ & 1.00 & & $\mu \mathrm{g} / \mathrm{L}$ & 0 \\
\hline$<1.0$ & 1.00 & & $\mu \mathrm{g} / \mathrm{L}$ & 0 \\
\hline$<1.0$ & 1.00 & & $\mu \mathrm{g} / \mathrm{L}$ & 0 \\
\hline 2.0 & 1.00 & & $\mu \mathrm{g} / \mathrm{L}$ & 0 \\
\hline 32,200 & 1.00 & & $\mu \mathrm{g} / \mathrm{L}$ & 0 \\
\hline$<1.0$ & 1.00 & & $\mu \mathrm{g} / \mathrm{L}$ & 0 \\
\hline 2,340 & 1.00 & & $\mu \mathrm{g} / \mathrm{L}$ & 0 \\
\hline$<1.0$ & 1.00 & & $\mu \mathrm{g} / \mathrm{L}$ & 0 \\
\hline$<1.0$ & 1.00 & & $\mu \mathrm{g} / \mathrm{L}$ & 0 \\
\hline$<1.0$ & 1.00 & & $\mu \mathrm{g} / \mathrm{L}$ & 0 \\
\hline$<1.0$ & 1.00 & & $\mu \mathrm{g} / \mathrm{L}$ & 0 \\
\hline$<1.0$ & 1.00 & & $\mu \mathrm{g} / \mathrm{L}$ & 0 \\
\hline$<1.0$ & 1.00 & & $\mu \mathrm{g} / \mathrm{L}$ & 0 \\
\hline$<4.0$ & 1.00 & & $\mu \mathrm{g} / \mathrm{L}$ & 0 \\
\hline$<4.0$ & 1.00 & & $\mu \mathrm{g} / \mathrm{L}$ & 0 \\
\hline$<5.0$ & 1.00 & & $\mu \mathrm{g} / \mathrm{L}$ & 0 \\
\hline$<0.11$ & 1.00 & & $\mu \mathrm{g} / \mathrm{L}$ & 0 \\
\hline$<1.0$ & 1.00 & & $\mu \mathrm{g} / \mathrm{L}$ & 0 \\
\hline$<1.0$ & 1.00 & & $\mu g / L$ & 0 \\
\hline$<1.0$ & 1.00 & & $\mu g / L$ & 0 \\
\hline$<1.0$ & 1.00 & & $\mu \mathrm{g} / \mathrm{L}$ & 0 \\
\hline$<1.0$ & 1.00 & & $\mu \mathrm{g} / \mathrm{L}$ & 0 \\
\hline$<1.0$ & 1.00 & JV2 & $\mu \mathrm{g} / \mathrm{L}$ & 0 \\
\hline$<0.0015$ & 1.00 & & $\mu \mathrm{g} / \mathrm{L}$ & 0 \\
\hline$<1.0$ & 1.00 & & $\mu \mathrm{g} / \mathrm{L}$ & 0 \\
\hline 61.0 & 1.00 & & $\mu \mathrm{g} / \mathrm{L}$ & 0 \\
\hline$<1.0$ & 1.00 & & $\mu \mathrm{g} / \mathrm{L}$ & 0 \\
\hline
\end{tabular}

Time: 10: 57

$\mathrm{pH}: 9.5$

Alkalinity: $70 \mathrm{mg} / \mathrm{L}$

Water temperature: $18.8^{\circ} \mathrm{C}$

Volumes purged: 0.8 well volumes 
WELL BGO 6B collected on 01/25/94, laboratory analyses (cont.)

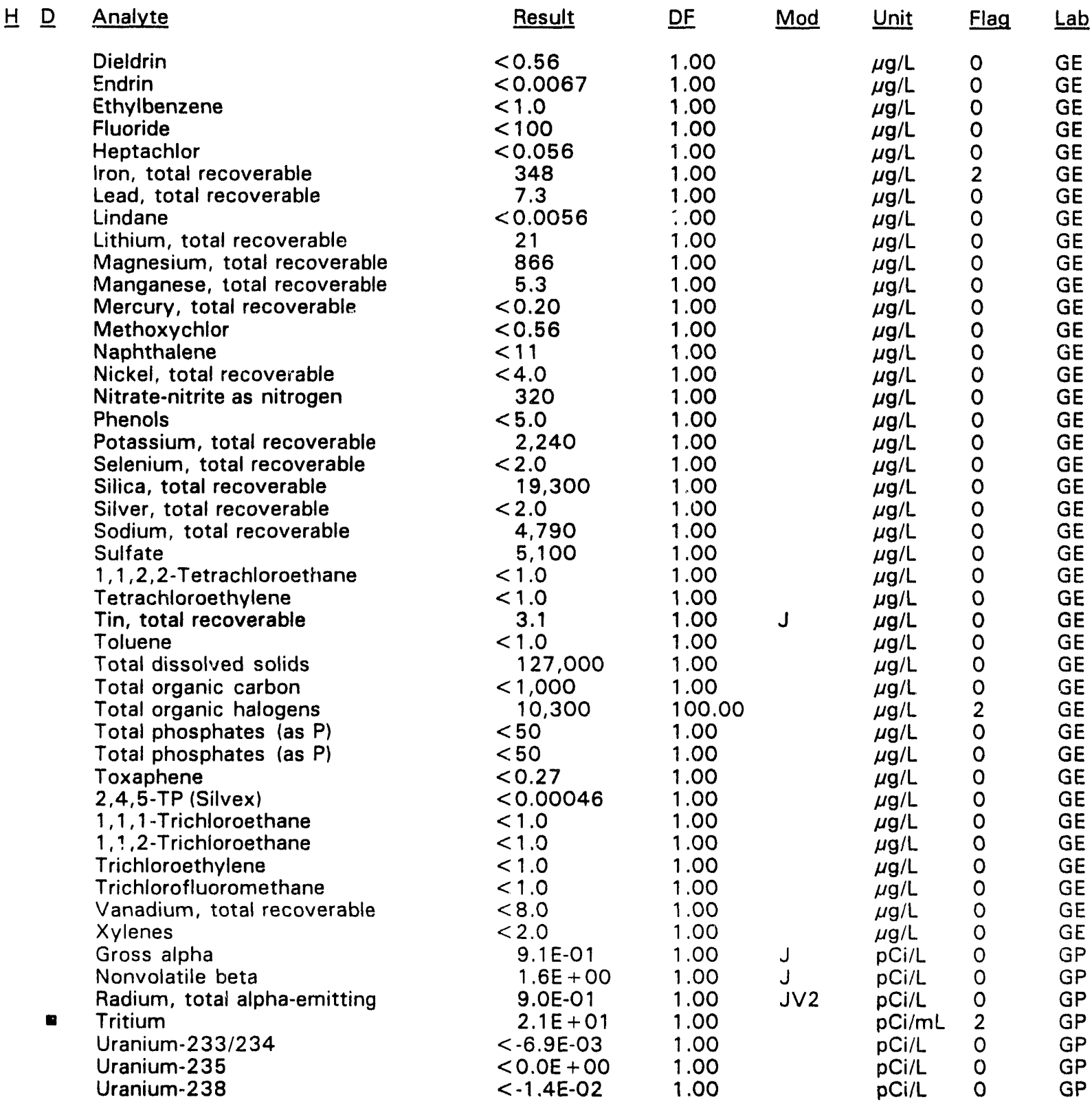

- = exceeded holding time. = exceeded screening level or final primary drinking water standard. 
WELL BGO 6C

\begin{tabular}{|c|c|c|c|c|c|c|}
\hline SRS Coord. & Lat/Longitude & Screen Zone Elevation & Top of Casing & Casing & Pump & Formation \\
\hline $\begin{array}{l}N 76487.1 \\
E 58307.0\end{array}$ & $\begin{array}{l}33.290075^{\circ} \mathrm{N} \\
81.661841^{\circ} \mathrm{W}\end{array}$ & $168.0-158.0 \mathrm{ft} \mathrm{msl}$ & $285.6 \mathrm{ft} \mathrm{msl}$ & 4" PVC & $\mathrm{s}$ & $\left(\| B_{1}\right)$ \\
\hline
\end{tabular}

\section{FIELD MEASUREMENTS}

Sample date: $01 / 25 / 94$

Depth to water: $65.47 \mathrm{ft}(19.96 \mathrm{~m})$ below TOC

Water elevation: $220.13 \mathrm{ft}(67.10 \mathrm{~m}) \mathrm{msl}$

Sp. conductance: $136 \mu \mathrm{S} / \mathrm{cm}$

Turbidity: 0.3 NTU

Water evacuated before sampling: $108 \mathrm{gal}$

\section{LABORATORY ANALYSES}

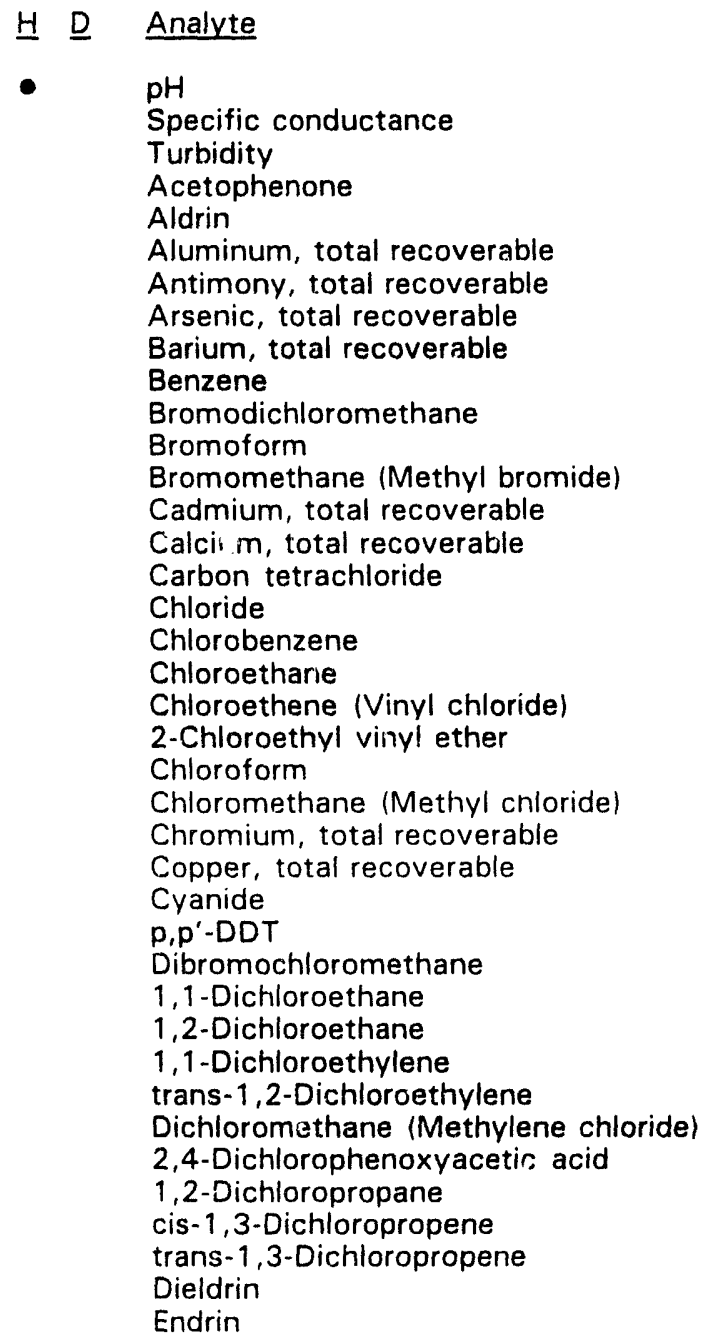

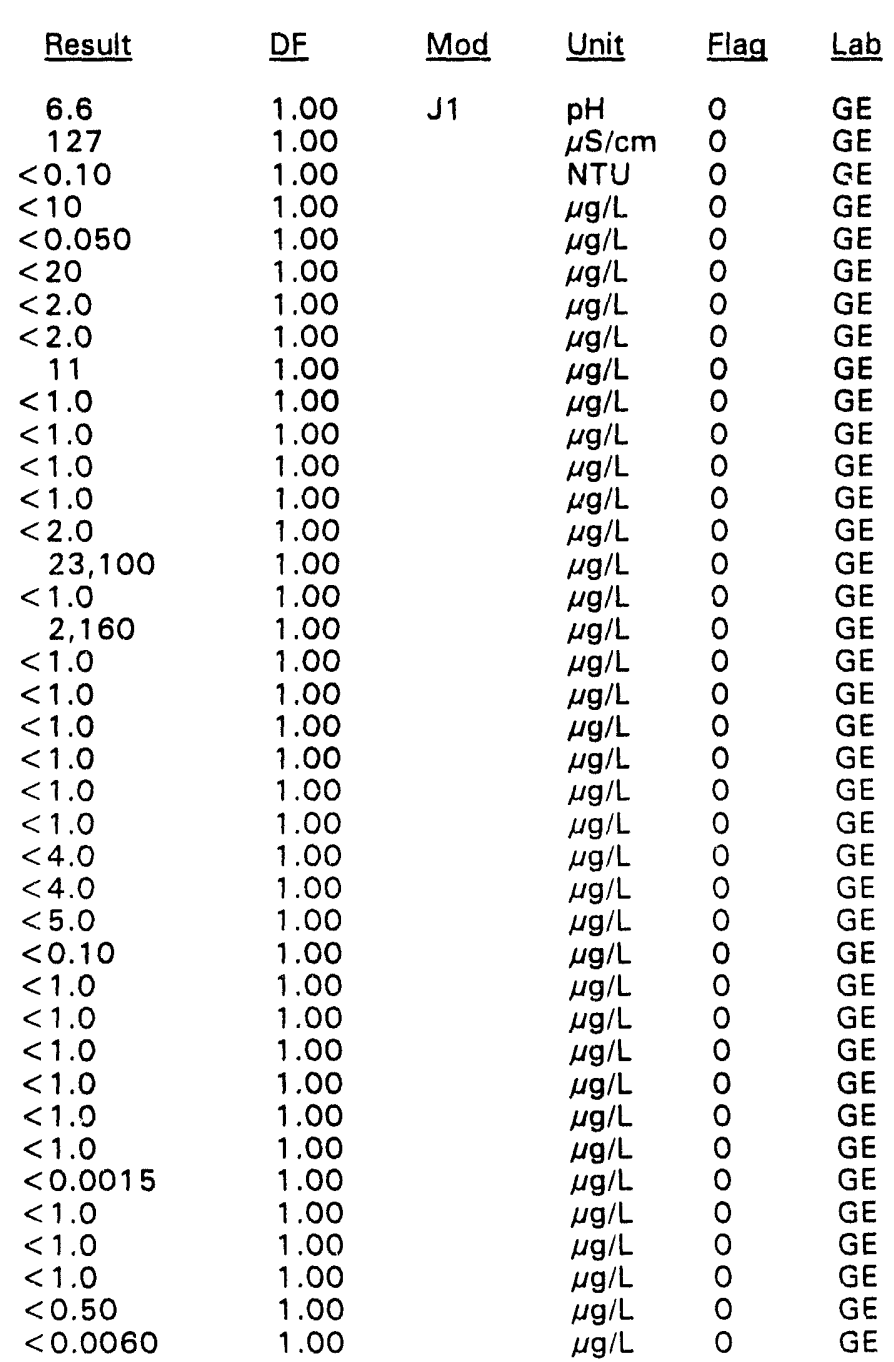

Time: 10: 29

$\mathrm{pH}: 7.5$

Alkalinity: $53 \mathrm{mg} / \mathrm{L}$

Water temperature: $19.6{ }^{\circ} \mathrm{C}$

Volumes purged: 2.6 well volumes
GE
GE
$\mathrm{GE}$
$\mathrm{GE}$
$\mathrm{GE}$
$\mathrm{GE}$
$\mathrm{GE}$
$\mathrm{GE}$
$\mathrm{GE}$
$\mathrm{GE}$
$\mathrm{GE}$
$\mathrm{GE}$
$\mathrm{GE}$
$\mathrm{GE}$
$\mathrm{GE}$
$\mathrm{GE}$
$\mathrm{GE}$
$\mathrm{GE}$
$\mathrm{GE}$
$\mathrm{GE}$
$\mathrm{GE}$
$\mathrm{GE}$
$\mathrm{GE}$
$\mathrm{GE}$
$\mathrm{GE}$
$\mathrm{GE}$
$\mathrm{GE}$
$\mathrm{GE}$
$\mathrm{GE}$
$\mathrm{GE}$
$\mathrm{GE}$
$\mathrm{GE}$
$\mathrm{GE}$
$\mathrm{GE}$
$\mathrm{GE}$
$\mathrm{GE}$
$\mathrm{GE}$
$\mathrm{GE}$
$\mathrm{GE}$

\footnotetext{
- = exceeded holding time. = exceeded screening level or final primary drinking water standard.
} 
WELL BGO 6 C collected on $01 / 25 / 94$, laboratory analyses (cont.)

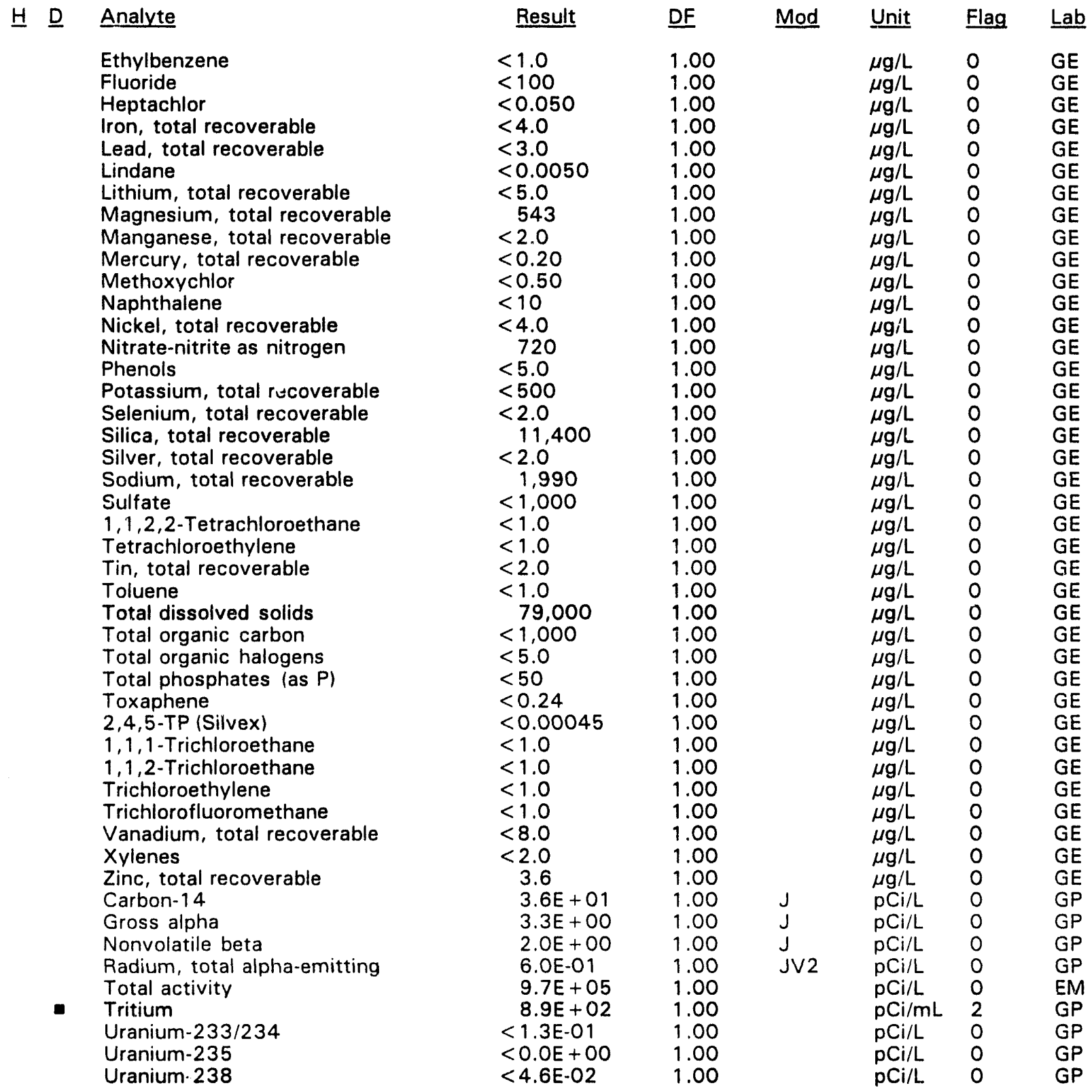

\footnotetext{
- exceeded holding time. = exceeded screening level or final primary drinking water standard.
} 


\section{WELL BGO 6D}

$\begin{array}{lllllll}\text { SRS Coord. } & \text { Lat/Longitude } & \text { Screen Zone Elevation } & \text { Top of Casing } & \text { Casing } & \text { Pump } & \text { Formation } \\ \text { N76487.3 } & \begin{array}{llll}33.290059^{\circ} \mathrm{N} \\ \text { E } 58297.1\end{array} & 81.661867 .2-217.2 \mathrm{ft} \mathrm{msl} & 285.5 \mathrm{ft} \mathrm{msl} & \text { 4" PVC } & \text { S } & \text { Water Table (IIB })\end{array}$

\section{E58297.1 $81.661867^{\circ} \mathrm{W}$}

\section{FIELD MEASUREMENTS}

Sample date: $01 / 25 / 94$

Depth to water: $53.85 \mathrm{ft}(16.41 \mathrm{~m})$ below TOC

Water elevation: $231.65 \mathrm{ft}(70.61 \mathrm{~m}) \mathrm{msl}$

Sp. conductance: $130 \mu \mathrm{S} / \mathrm{cm}$

Turbidity: 2.3 NTU

Water evacuated before sampling: 8 gal

The well went dry during purging.

\section{LABORATORY ANALYSES}

H D Analyte

$\mathrm{pH}$

Specific conductance

Specific conductance

Turbidity

Acetophenone

Acetophenone

Aldrin

Aluminum, total recoverable

Antimony, total recoverable

Arsenic, total recoverable

Barium, total recoverable

Benzene

Bromodichloromethane

Bromoform

Bromomethane (Methyl bromide)

Cadmium, total recoverable

Calcium, total recoverable

Carbon tetrachloride

Chloride

Chlorobenzene

Chloroethane

Chloroethene (Vinyl chloride)

2.Chloroethyl vinyl ether

Chloroform

Chloromethane (Methyl chloride)

Chromium, total recoverable

Copper, total recoverable

Cyanide

$p, p^{\prime}-D D T$

Dibromochloromethane

1,1-Dichloroethane

1.2-Dichloroethane

1,1-Dichloroethylene

trans-1,2-Dichloroethylene

Dichloromethane (Methylene chloride)

2,4-Dichlorophenoxyacetic acid

1,2-Dichloropropane

cis-1,3-Dichloropropene

trans-1,3-Dichloropropene

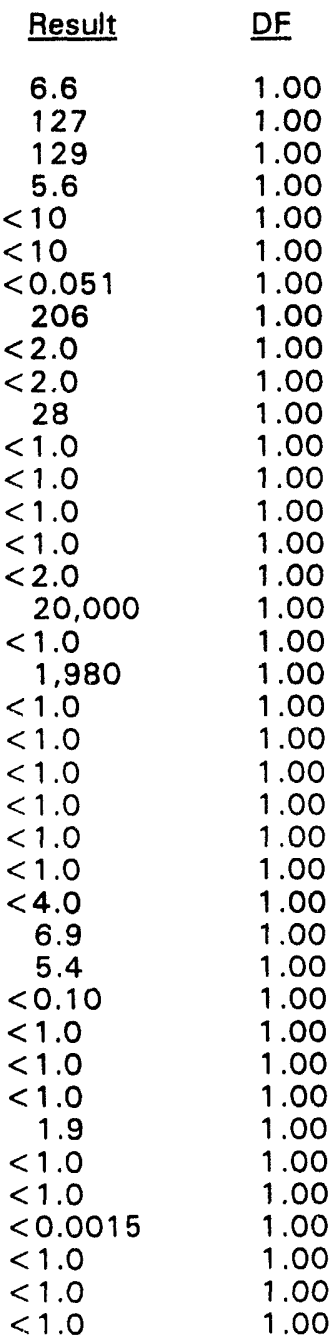

Time: 10:04

$\mathrm{pH}: 6.6$

Alkalinity: $51 \mathrm{mg} / \mathrm{L}$

Water temperature: $17.1^{\circ} \mathrm{C}$

Volumes purged: 0.8 well volumes 
WELL BGO $6 D$ collected on $01 / 25 / 94$, laboratory analyses (cont.)

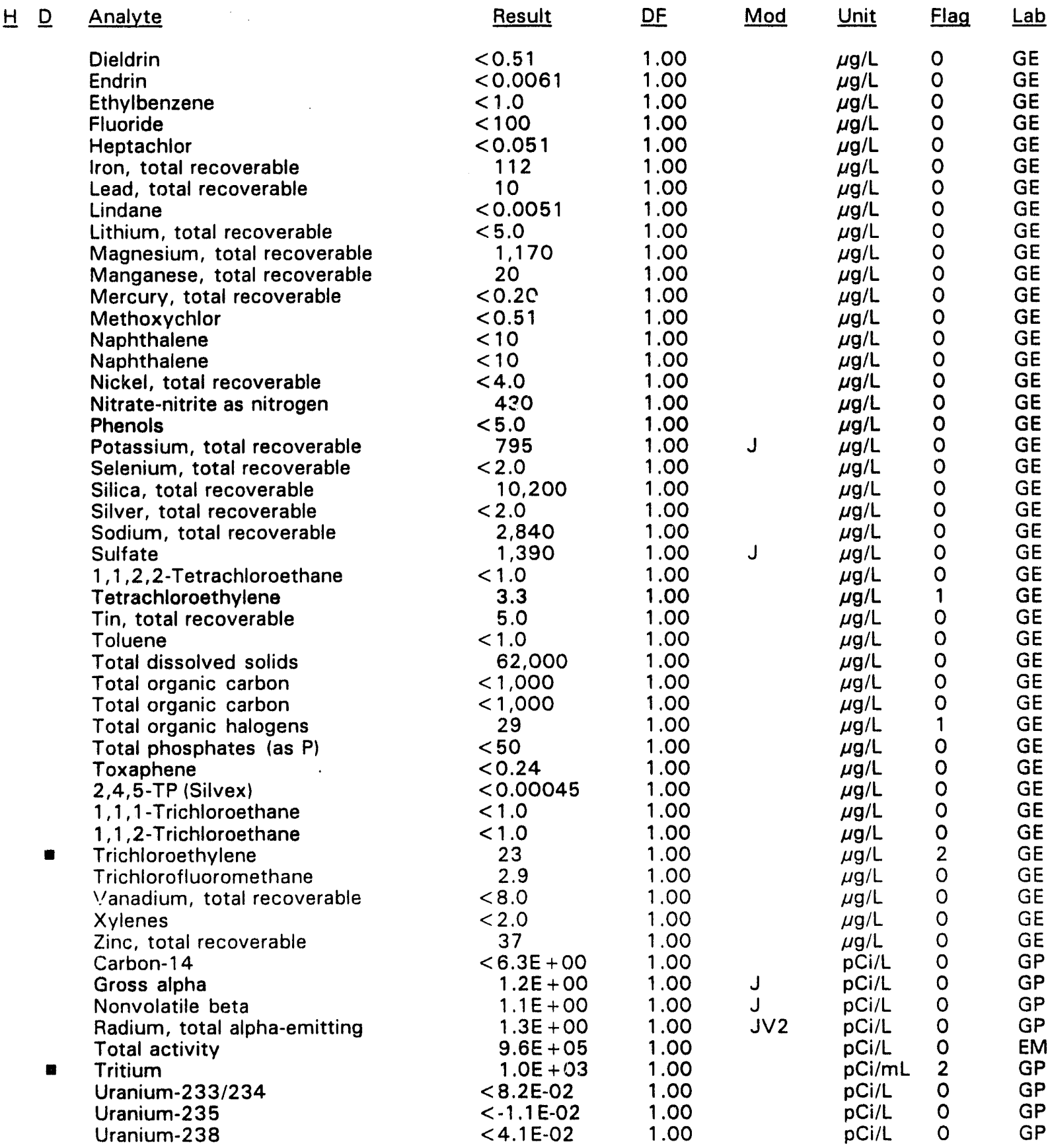

\footnotetext{
- = exceeded holding time. = exceeded screening level or final primary drinking water standard.
} 


\section{WELL BGO 7D}

\begin{tabular}{|c|c|c|c|c|c|c|}
\hline SRS Coord. & Lat/Longitude & Screen Zone Elevation & Top of Casing & Casing & Pump & Formation \\
\hline $\begin{array}{l}N 76494.5 \\
E 57917.2\end{array}$ & $\begin{array}{l}33.289455^{\circ} \mathrm{N} \\
81.662882^{\circ} \mathrm{W}\end{array}$ & $240.2-220.2 \mathrm{ft} \mathrm{msl}$ & $287 \mathrm{ft} \mathrm{msl}$ & 4" PVC & S & Water Table $\left(\| B_{2}\right)$ \\
\hline
\end{tabular}

\section{FIELD MEASUREMENTS}

Sample date: $01 / 25 / 94$

Depth to water: $54.82 \mathrm{ft}(16.71 \mathrm{~m})$ below TOC

Water elevation: $232.18 \mathrm{ft}(70.77 \mathrm{~m}) \mathrm{msl}$

Sp. conductance: $32 \mu \mathrm{S} / \mathrm{cm}$

Turbidity: 1.1 NTU

Water evacuated before sampling: $105 \mathrm{gal}$

\section{LABORATORY ANALYSES}

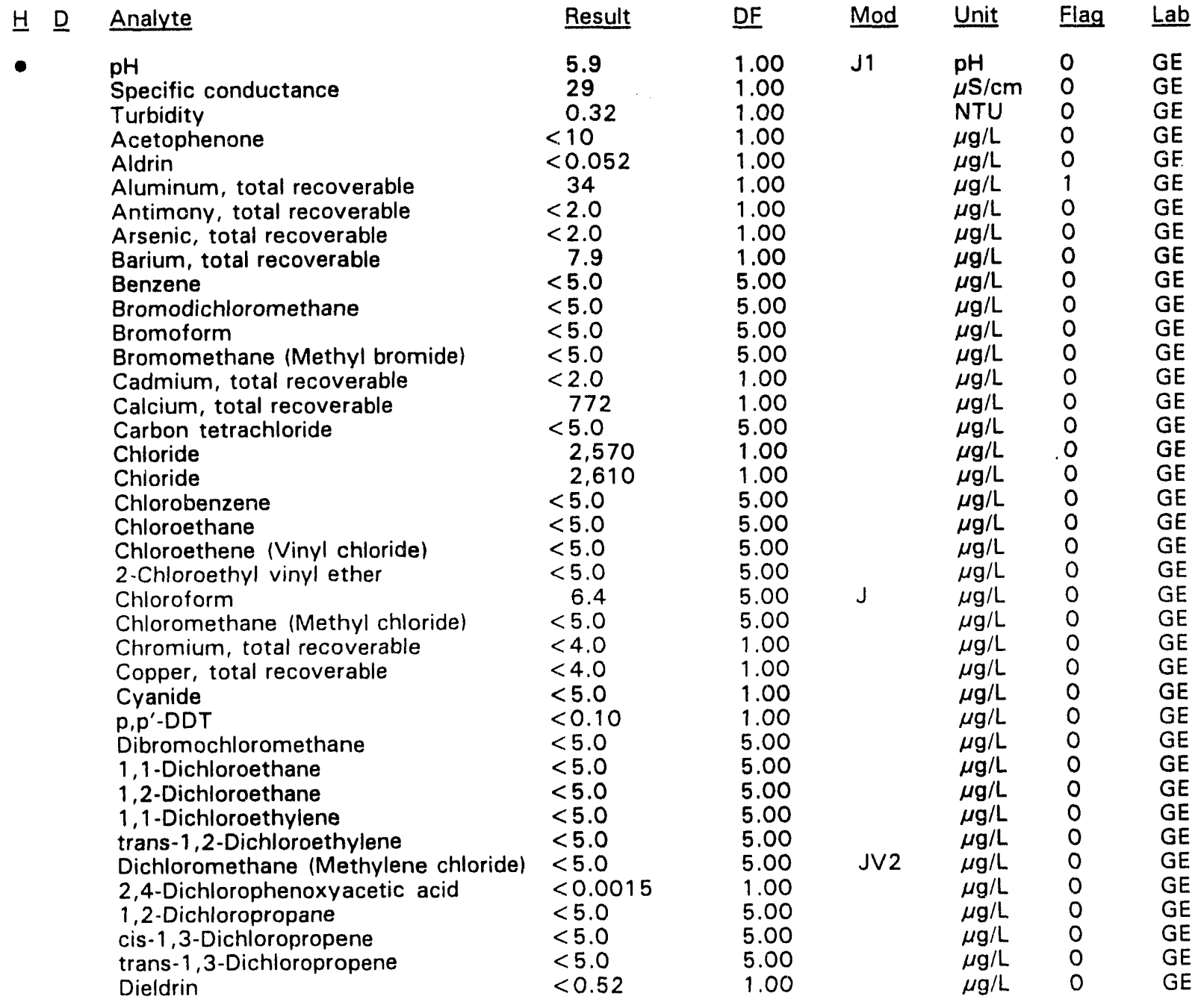

Time: $11: 27$

$\mathrm{pH}: 4.6$

Alkalinity: $0 \mathrm{mg} / \mathrm{L}$

Water temperature: $19.4^{\circ} \mathrm{C}$

Volumes purged: 13.4 well volumes
Bromoform

Chlorobenzene

Chloroethane

2-Chloroethyl vinyl ether

Chloroform

Chromium, total recoverable

Dibromochloromethane

1 ,-Dichloroethan

Dichloroethane

2,4-Dichlorophenoxyacetic acid

cis-1,3-Dichloropropen

Dieldrin
$<0.52$

$\overline{-}=$ exceeded holding time. - = exceeded screening level or final primary drinking water standard. 
WELL BGO 7D collected on 01/25/94, laboratory analyses (cont.)

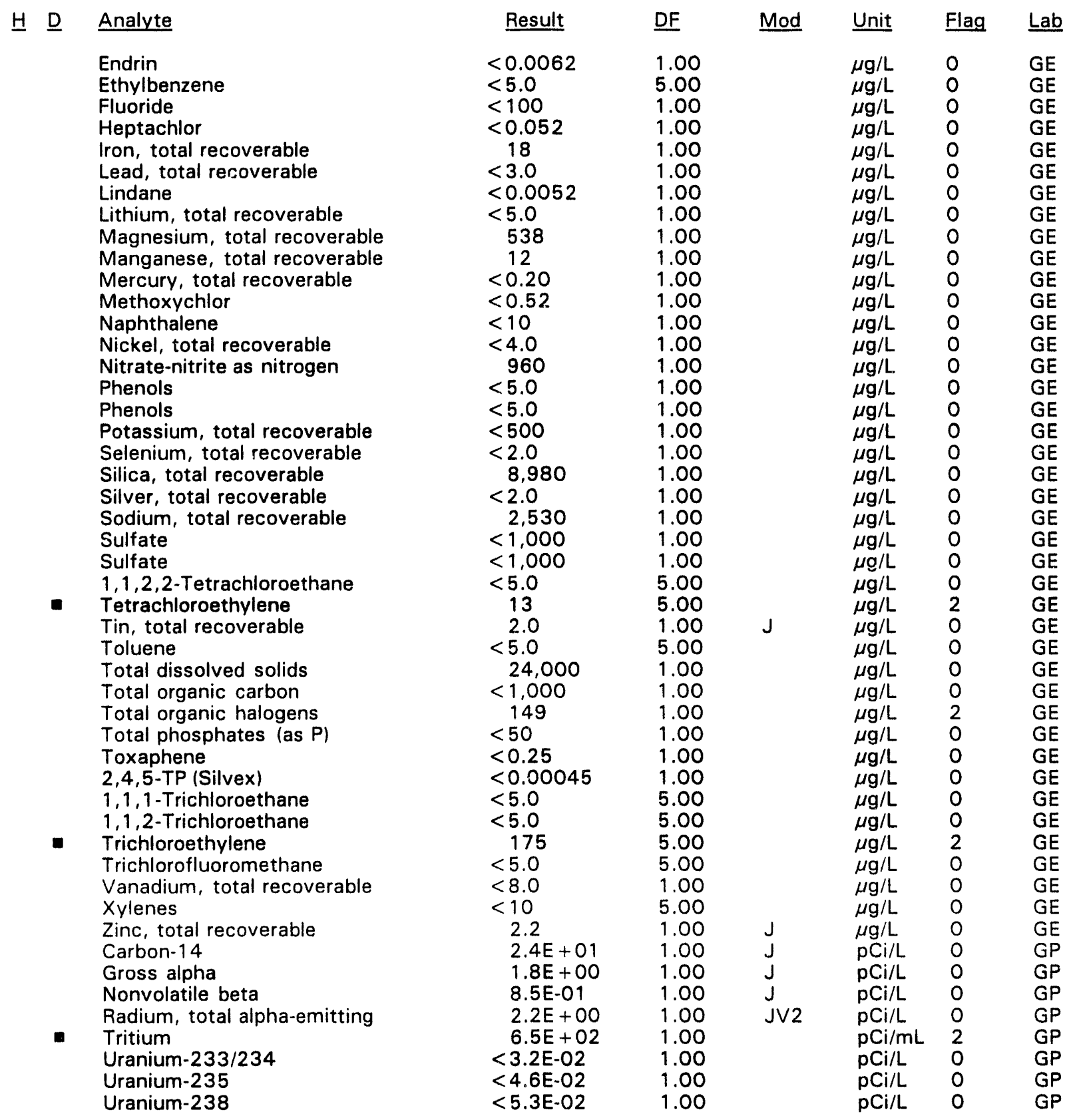

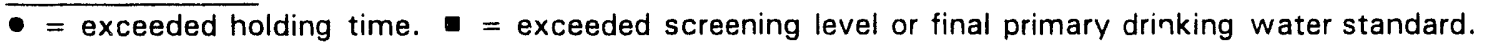


WELL BGO 8AR

\begin{tabular}{|c|c|c|c|c|c|c|}
\hline SRS Coord. & Lat/Longitude & Screen Zone Elevation & Top of Casing & Casing & Pump & Formation \\
\hline & ON & $104.6-94.6 \mathrm{ft} \mathrm{msl}$ & $6 \mathrm{ft} \mathrm{msl}$ & 4" PVC & S & U. $\mathrm{Cc}$ \\
\hline
\end{tabular}

\section{FIELD MEASUREMENTS}

Sample date: $01 / 25 / 94$

Depth to water: $126.51 \mathrm{ft}(38.56 \mathrm{~m})$ below TOC

Water elevation: $160.09 \mathrm{ft}(48.80 \mathrm{~m}) \mathrm{ms}$ l

Sp. conductance: $279 \mu \mathrm{S} / \mathrm{cm}$

Turbidity: 0.2 NTU

Water evacuated before sampling: $158 \mathrm{gal}$

Time: $12: 43$

$\mathrm{pH}: 7.4$

Alkalinity: $107 \mathrm{mg} / \mathrm{L}$

Water temperature: $19.7^{\circ} \mathrm{C}$

Volumes purged: 3.7 well volumes

LABORATORY ANALYSES

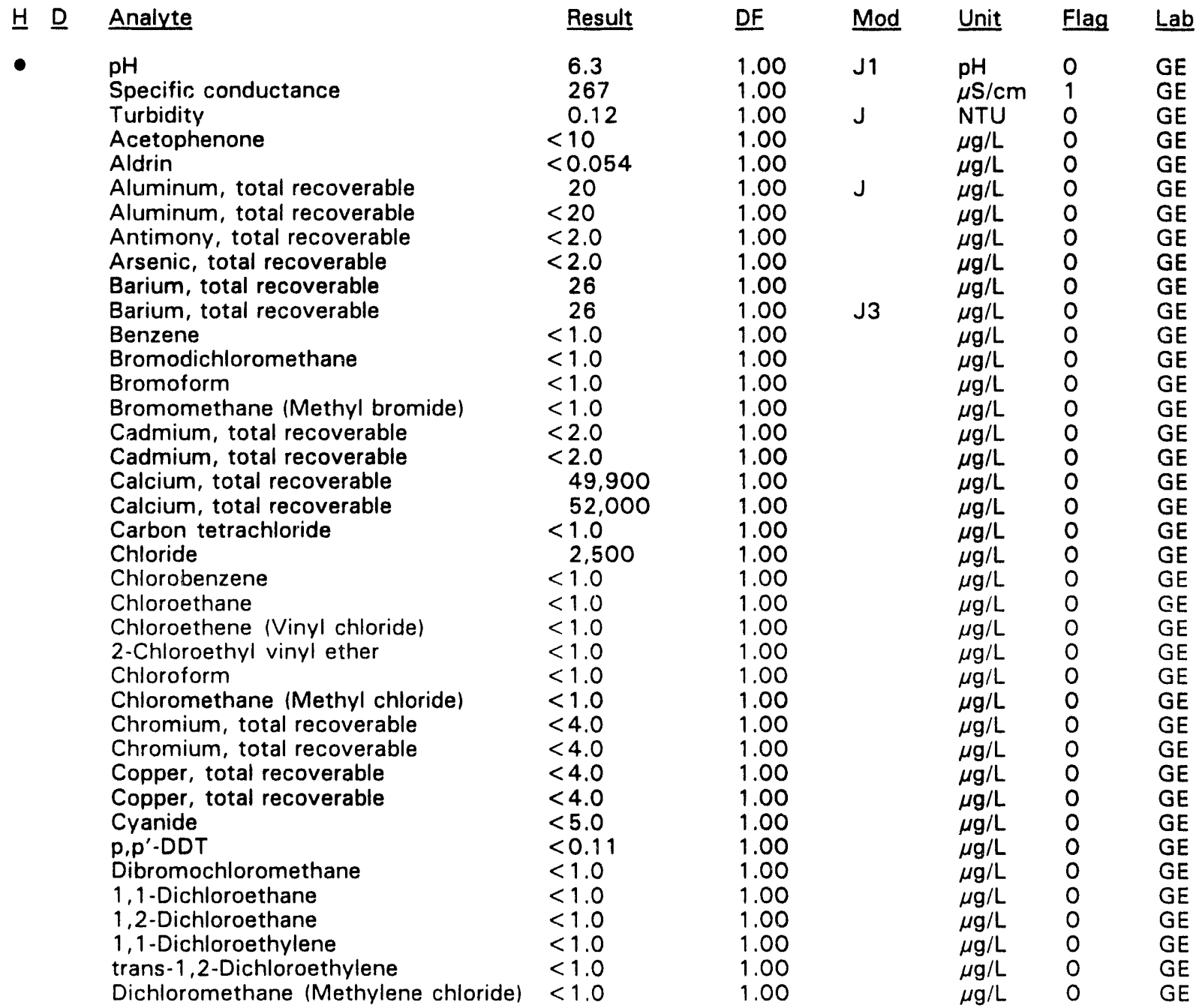

$\overline{0}=$ exceeded holding time. $=$ exceeded screening level or final primary drinking water standard. 
WELL BGO 8AR collected on 01/25/94, laboratory analyses (cont.)

\section{H D Analyte}

2,4-Dichlorophenoxyacetic acid 1,2-Dichloropropane cis-1,3-Dichloropropene trans-1,3-Dichloropropene Dieldrin

Endrin

Ethylbenzene

Fluoride

Heptachlor

Iron, total recoverable

Iron, total recoverable

Lead, total recoverable

Lindane

Lithium, total recoverable

Lithium, total recoverable

Magnesium, total recoverable

Magnesium, total recoverable

Manganese, total recoverable

Manganese, total recoverable

Mercury, total recoverable

Mercury, total recoverable

Methoxychlor

Naphthalene

Nickel, total recoverable

Nickel, total recoverable

Nitrate-nitrite as nitrogen

Phenols

Potassium, total recoverable

Potassium, total recoverable

Selenium, total recoverable

Silica, total recoverable

Silica, total recoverable

Silver, total recoverable

Silver, total recoverable

Sodium, total recoverable

Sodium, total recoverable

Sulfate

1,1,2,2-Tetrachloroethane

Tetrachloroethylene

Tin, total recoverable

Tin, total recoverable

Toluene

Total dissolved solids

Total organic carbon

Total organic halogens

Total phosphates (as $P$ )

Toxaphene

2,4,5-TP (Silvex)

Tributyl phosphate

1,1,1-Trichloroethane

1,1,2-Trichloroethane

Trichloroethylene

Trichlorofluoromethane

Vanadium, total recoverable

Vanadium, total recoverable

Xylenes

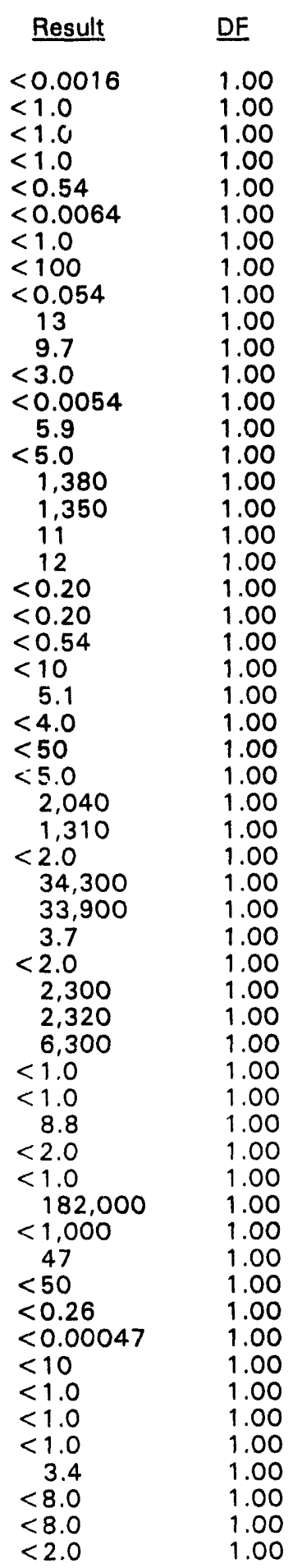

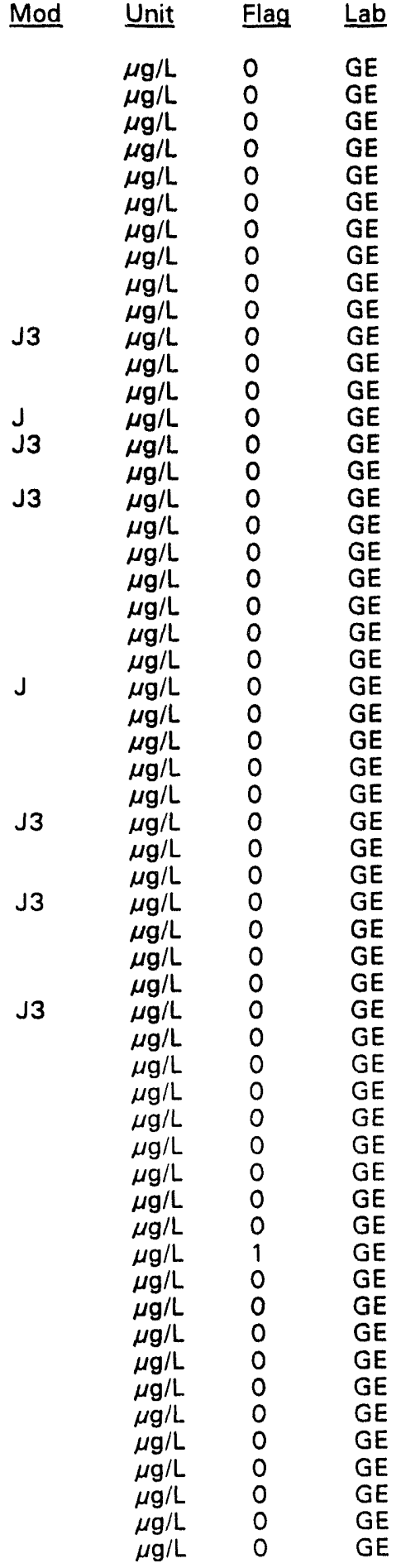

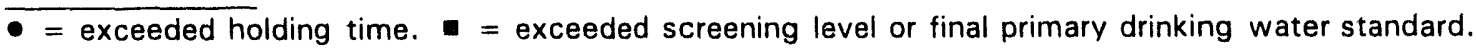


WELL BGO 8AR collected on 01/25/94, laboratory analyses (cont.)

\begin{tabular}{|c|c|c|c|c|c|c|}
\hline$\underline{H}$ D & Analyte & Result & DF & Mod & Unit & Flag \\
\hline & $\begin{array}{l}\text { Zinc, total recoverable } \\
\text { Zinc, total recoverable } \\
\text { Carbon- } 14 \\
\text { Gross alpha } \\
\text { Nonvolatile beta } \\
\text { Radium, total alpha-emitting } \\
\text { Tritium } \\
\text { Tritium } \\
\text { Uranium-233/234 } \\
\text { Uranium-235 } \\
\text { Uranium-238 }\end{array}$ & $\begin{aligned}< & 2.0 \\
< & 2.0 \\
& 3.0 \mathrm{E}+01 \\
< & 2.5 \mathrm{E}-01 \\
& 1.7 \mathrm{E}+00 \\
& 7.0 \mathrm{E}-01 \\
< & 5.0 \mathrm{E}-02 \\
< & 0.0 \mathrm{E}+00 \\
< & -1.6 \mathrm{E}-02 \\
< & -1.6 \mathrm{E}-02 \\
< & 3.8 \mathrm{E}-02\end{aligned}$ & $\begin{array}{l}1.00 \\
1.00 \\
1.00 \\
1.00 \\
1.00 \\
1.00 \\
1.00 \\
1.00 \\
1.00 \\
1.00 \\
1.00\end{array}$ & $\begin{array}{l}\mathrm{J} \\
\mathrm{J} \\
\mathrm{JV} 2\end{array}$ & $\begin{array}{l}\mu \mathrm{g} / \mathrm{L} \\
\mu \mathrm{g} / \mathrm{L} \\
\mathrm{pCi} / \mathrm{L} \\
\mathrm{pCi} / \mathrm{L} \\
\mathrm{pCi} / \mathrm{L} \\
\mathrm{pCi} / \mathrm{L} \\
\mathrm{pCi} / \mathrm{mL} \\
\mathrm{pCi} / \mathrm{mL} \\
\mathrm{pCi} / \mathrm{L} \\
\mathrm{pCi} / \mathrm{L} \\
\mathrm{pCi} / \mathrm{L}\end{array}$ & $\begin{array}{l}0 \\
0 \\
0 \\
0 \\
0 \\
0 \\
0 \\
0 \\
0 \\
0 \\
0\end{array}$ \\
\hline
\end{tabular}

\section{WELL BGO 8C}

\begin{tabular}{|c|c|c|c|c|c|c|}
\hline SRS Coord. & Lat/Lorigitude & Screen Zone Elevation & Top of Casing & Casing & Pump & Formation \\
\hline $\begin{array}{l}N 76579.2 \\
E 57618.7\end{array}$ & $\begin{array}{l}33.289156^{\circ} \mathrm{N} \\
81.663832^{\circ} \mathrm{W}\end{array}$ & $184.3-174.3 \mathrm{ft} \mathrm{msl}$ & $287.9 \mathrm{ft} \mathrm{msl}$ & 4" PVC & $\mathbf{S}$ & McBean $\left(I I B_{1}\right)$ \\
\hline
\end{tabular}

FIELD MEASUREMENTS

Sample date: $01 / 28 / 94$

Depth to water: $64.20 \mathrm{ft}(19.57 \mathrm{~m})$ below TOC

Water elevation: $223.70 \mathrm{ft}(68.18 \mathrm{~m}) \mathrm{msl}$

Sp. conductance: $133 \mu \mathrm{S} / \mathrm{cm}$

Turbidity: 0.4 NTU

Water evacuated before sampling: $135 \mathrm{gal}$

\section{LABORATORY ANALYSES}

H D Analyte

$\mathrm{pH}$

$\mathrm{pH}$

$\mathrm{pH}$

$\mathrm{pH}$

$\mathrm{pH}$

Specific conductance

Specific conductance

Specific conductance

Specific conductance
Turbidity

Turbidity

Turbidity

- Turbidity

Turbidity

Acetophenone

Acetophenone

Acetophenone

Acetophenone

Aldrin

Aldrin

Aluminum, total recoverable

Aluminum, total recoverable

Aluminum, total recoverable
Time: 13: 14

$\mathrm{pH}: 7.2$

Alkalinity: $51 \mathrm{mg} / \mathrm{L}$

Water temperature: $19.9^{\circ} \mathrm{C}$

Volumes purged: 4.2 well volumes

\begin{tabular}{llllll} 
Result & DF & Mod & Unit & Flag & Lab \\
\cline { 5 - 6 } 7.0 & 1.00 & $\mathrm{~J} 1$ & $\mathrm{pH}$ & 0 & $\mathrm{GE}$ \\
7.2 & 1.00 & $\mathrm{~J} 1$ & $\mathrm{pH}$ & 0 & $\mathrm{GE}$ \\
7.2 & 1.00 & $\mathrm{~J} 1$ & $\mathrm{pH}$ & 0 & $\mathrm{GE}$ \\
7.2 & 1.00 & $\mathrm{~J}$ & $\mathrm{pH}$ & 0 & WA \\
7.2 & 1.00 & $\mathrm{~J}$ & $\mathrm{pH}$ & 0 & WA \\
106 & 1.00 & & $\mu \mathrm{S} / \mathrm{cm}$ & 0 & $\mathrm{GE}$ \\
108 & 1.00 & & $\mu \mathrm{S} / \mathrm{cm}$ & 0 & $\mathrm{GE}$ \\
110 & 1.00 & & $\mu \mathrm{S} / \mathrm{cm}$ & 0 & WA \\
104 & 1.00 & & $\mu \mathrm{S} / \mathrm{cm}$ & 0 & WA \\
1.3 & 1.00 & $\mathrm{~J} 1$ & $\mathrm{NTU}$ & 0 & $\mathrm{GE}$ \\
0.51 & 1.00 & & $\mathrm{NTU}$ & 0 & $\mathrm{GE}$ \\
0.47 & 1.00 & $\mathrm{~J} 1$ & $\mathrm{NTU}$ & 0 & $\mathrm{GE}$ \\
0.59 & 1.00 & $\mathrm{~J}$ & $\mathrm{NTU}$ & 0 & WA \\
0.54 & 1.00 & $\mathrm{~J}$ & $\mathrm{NTU}$ & 0 & WA \\
$<10$ & 1.00 & & $\mu \mathrm{g} / \mathrm{L}$ & 0 & $\mathrm{GE}$ \\
$<10$ & 1.00 & & $\mu \mathrm{g} / \mathrm{L}$ & 0 & $\mathrm{GE}$ \\
$<10$ & 1.00 & & $\mu \mathrm{g} / \mathrm{L}$ & 0 & WA \\
$<10$ & 1.00 & & $\mu \mathrm{g} / \mathrm{L}$ & 0 & WA \\
$<0.051$ & 1.00 & & $\mu \mathrm{g} / \mathrm{L}$ & 0 & $\mathrm{GE}$ \\
$<0.052$ & 1.00 & & $\mu \mathrm{g} / \mathrm{L}$ & 0 & $\mathrm{GE}$ \\
41 & 1.00 & & $\mu \mathrm{g} / \mathrm{L}$ & 1 & $\mathrm{GE}$ \\
35 & 1.00 & & $\mu \mathrm{g} / \mathrm{L}$ & 1 & $\mathrm{GE}$ \\
39 & 1.00 & & $\mu \mathrm{g} / \mathrm{L}$ & 1 & WA
\end{tabular}

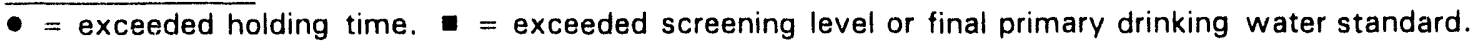


WELL BGO $8 \mathrm{C}$ collected on $01 / 28 / 94$, laboratory analyses (cont.)

\section{H $\underline{\text { Analyte }}$}

Aluminum, total recoverable

Antimony, total recoverable

Antimony, total recoverable

Antimony, total recoverable

Antimony, total recoverable

Antimony, total recoverabie

Arsenic, total recoverable

Arsenic, total recoverable

Arsenic, total recoverable

Arsenic, total recoverable

Arsenic, total recoverable

Barium, total recoverable

Barium, total recoverable

Barium, total recoverable

Barium, total recoverable

Benzene

Benzene

Benzene

Benzene

Bromodichloromethane

Bromodichloromethane

Bromodichloromethane

Bromodichloromethane

Bromoform

Bromoform

Bromoform

Bromoform

Bromomethane (Methyl bromide)

Bromomethane (Methyl bromide)

Bromomethane (Methyl bromide)

Bromomethane (Methyl bromide)

Cadmium, total recoverable

Cadmium, total recoverable

Cadmium, total recoverable

Cadmium, total recoverable

Calcium, total recoverable

Calcium, total recoverable

Calcium, total recoverable

Calcium, total recoverable

Carbon tetrachloride

Carbon tetrachloride

Carbon tetrachloride

Carbon tetrachloride

Chloride

Chloride

Chloride

Chloride

Chloride

Chlorobenzene

Chlorobenzene

Chlorobenzene

Chlorobenzene

Chloroethane

Chloroethane

Chloroethane

Chloroethane

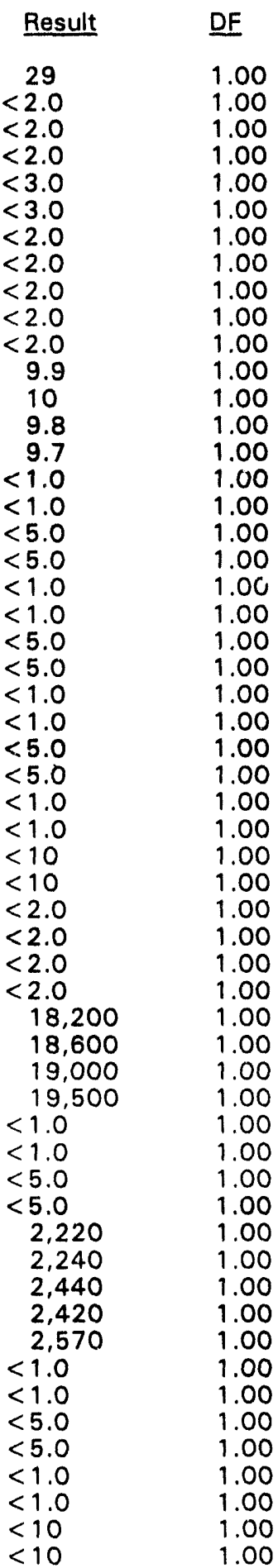

Mod

Unit Flag Lab

$\mu \mathrm{g} / \mathrm{L}$

$\mu g / L$

$\mu \mathrm{g} / \mathrm{L}$

$\mu \mathrm{g} / \mathrm{L}$

$\mu \mathrm{g} / \mathrm{L}$

$\mu \mathrm{g} / \mathrm{L}$

$\mu \mathrm{g} / \mathrm{L}$

$\mu \mathrm{g} / \mathrm{L}$

$\mu \mathrm{g} / \mathrm{L}$

$\mu \mathrm{g} / \mathrm{L}$

$\mu \mathrm{g} / \mathrm{L}$

$\mu g / L$

$\mu g / L$

$\mu g / L$

$\mu g / L$

$\mu g / L$

$\mu \mathrm{g} / \mathrm{L}$

$\mu \mathrm{g} / \mathrm{L}$

$\mu g / L$

$\mu \mathrm{g} / \mathrm{L}$

$\mu \mathrm{g} / \mathrm{L}$

$\mu \mathrm{g} / \mathrm{L}$

$\mu \mathrm{g} / \mathrm{L}$

$\mu \mathrm{g} / \mathrm{L}$

$\mu \mathrm{g} / \mathrm{L}$

$\mu g / L$

$\mu \mathrm{g} / \mathrm{L}$

$\mu \mathrm{g} / \mathrm{L}$

$\mu \mathrm{g} / \mathrm{L}$

$\mu \mathrm{g} / \mathrm{L}$

$\mu \mathrm{g} / \mathrm{L}$

$\mu \mathrm{g} / \mathrm{L}$

$\mu \mathrm{g} / \mathrm{L}$

$\mu \mathrm{g} / \mathrm{L}$

$\mu \mathrm{g} / \mathrm{L}$

$\mu \mathrm{g} / \mathrm{L}$

$\mu \mathrm{g} / \mathrm{L}$

$\mu \mathrm{g} / \mathrm{L}$

$\mu \mathrm{g} / \mathrm{L}$

$\mu \mathrm{g} / \mathrm{L}$

$\mu \mathrm{g} / \mathrm{L}$

$\mu \mathrm{g} / \mathrm{L}$

$\mu \mathrm{g} / \mathrm{L}$

$\mu \mathrm{g} / \mathrm{L}$

$\mu \mathrm{g} / \mathrm{L}$

$\mu \mathrm{g} / \mathrm{L}$

$\mu \mathrm{g} / \mathrm{L}$

$\mu \mathrm{g} / \mathrm{L}$

$\mu g / L$

$\mu \mathrm{g} / \mathrm{L}$

$\mu \mathrm{g} / \mathrm{L}$

$\mu \mathrm{g} / \mathrm{L}$

$\mu \mathrm{g} / \mathrm{L}$

$\mu \mathrm{g} / \mathrm{L}$

$\mu \mathrm{g} / \mathrm{L}$

$\mu \mathrm{g} / \mathrm{L}$ $\begin{array}{ll}1 & \text { WA } \\ 0 & \text { GE } \\ 0 & \text { GE } \\ 0 & \text { GE }\end{array}$

$\begin{array}{ll}0 & \text { WA } \\ 0 & \text { WA }\end{array}$

O GE

O GE

O WA

0 WA

0 GE

O GE

VJA

WA

GE

GE

WA

WA

GE

GE

WA

WA

GE

GE

WA

WA

GE

GE

WA

WA

GE

GE

WA

WA

GE

GE

WA

WA

GE

GE

WA

WA

GE

GE

WA

WA

WA

GE

GE

WA

WA

GE

GE

WA

WA

$\overline{- \text { = exceeded holding time. }}$ = exceeded screening level or final primary drinking water standard. 
WELL BGO $8 \mathrm{C}$ collected on $01 / 28 / 94$, laboratory analyses (cont.)

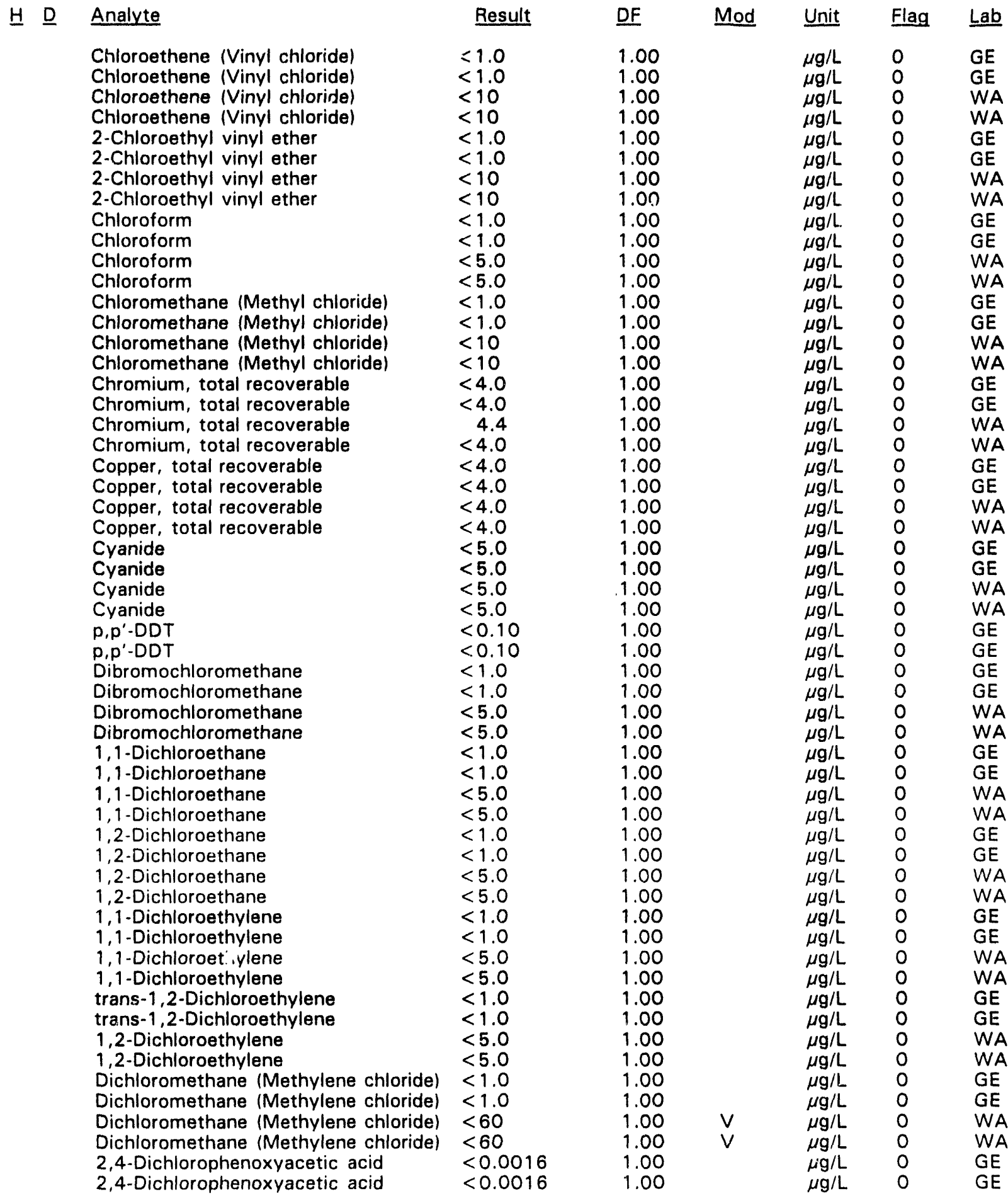

- = exceeded holding time. $\mathbf{a}=$ exceeded screening level or final primary drinking water standard. 
WELL BGO $8 \mathrm{C}$ collected on $01 / 28 / 94$, laboratory analyses (cont.)

H $\underline{\text { Analyte }}$

2,4-Dichlorophenoxyacetic acid

2,4-Dichlorophenoxyacetic acid

1,2-Dichloropropane

1,2-Dichloropropane

1,2-Dichloropropane

1,2-Dichloropropane

cis-1,3-Dichloropropene

cis-1,3-Dichloropropene

cis-1,3-Dichioropropene

cis-1,3-Dichloropropene

trans-1,3-Dichloropropene

trans-1,3-Dichloropropene

trans-1,3-Dichloropropene

trans-1,3-Dichloropropene

Dieldrin

Dieldrin

Endrin

Endrin

Endrin

Endrin

Ethylbenzene

Ethylbenzene

Ethylbenzene

Ethylbenzene

Fluoride

Fluoride

Fluoride

Fluoride

Heptachlor

Heptachlor

Iron, total recoverable

Iron, total recoverable

Iron, total recoverable

Iron, total recoverable

Lead, total recoverable

Lead, total recoverable

Lead, total recoverable

Lead, total recoverable

Lead, total recoverable

Lindane

Lindane

Lindane

Lindane

Lithium, total recoverable

Lithium, total recoverable

Lithium, total recoverable

Lithium, total recoverable

Magnesium, total recoverable

Magnesium, total recoverable

Magnesium, total recoverable

Magnesium, total recoverable

Manganese, total recoverable

Manganese, total recoverable

Manganese, total recoverable

Manganese, total recoverable

Mercury, total recoverable
$<1.0$

$<1.0$

$<1.0$

$<1.0$

$<5.0$

$<5.0$

$<1.0$

$<1.0$

$<5.0$

$<5.0$

$<1.0$

$<1.0$

$<5.0$

$<5.0$

$<0.51$

$<0.52$

$<0.0061$

$<0.0062$

$<0.11$

$<0.10$

$<1.0$

$<1.0$

$<5.0$

$<5.0$

$<100$

$<100$

$<100$

$<100$

$<0.051$

$<0.052$

18

16

29

16

$<3.0$

$<3.0$

$<3.0$

$<3.0$

$<3.0$

$<0.0051$

$<0.0052$

$<0.053$

$<0.052$

$<5.0$

$<5.0$

$<5.0$

$<5.0$

435

441

417

411

$<2.0$

$<2.0$

2.2

$<2.0$

$<0.20$
DF

1.03

1.03

1.00

1.00

1.00

1.00

1.00

1.00

1.00

1.00

1.00

1.00

1.00

1.00

1.00

1.00

1.00

1.00

1.05

1.03

1.00

1.00

1.00

1.00

1.00

1.00

1.00

1.00

1.00

1.00

1.00

1.00

1.00

1.00

1.00

1.00

1.00

1.00

1.00

1.00

1.00

1.05

1.03

1.00

1.00

1.00

1.00

1.00

1.00

1.00

1.00

1.00

1.00

1.00

1.00

1.00
Mod

Unit

Flag

Lab

$\mu \mathrm{g} / \mathrm{L}$

$\mu \mathrm{g} / \mathrm{L}$

$\mu \mathrm{g} / \mathrm{L}$

$\mu \mathrm{g} / \mathrm{L}$

$\mu \mathrm{g} / \mathrm{L}$

$\mu \mathrm{g} / \mathrm{L}$

$\mu \mathrm{g} / \mathrm{L}$

$\mu \mathrm{g} / \mathrm{L}$

$\mu \mathrm{g} / \mathrm{L}$

$\mu \mathrm{g} / \mathrm{L}$

$\mu \mathrm{g} / \mathrm{L}$

$\mu \mathrm{g} / \mathrm{L}$

$\mu \mathrm{g} / \mathrm{L}$

$\mu \mathrm{g} / \mathrm{L}$

$\mu g / L$

$\mu \mathrm{g} / \mathrm{L}$

$\mu \mathrm{g} / \mathrm{L}$

$\mu \mathrm{g} / \mathrm{L}$

$\mu \mathrm{g} / \mathrm{L}$

$\mu \mathrm{g} / \mathrm{L}$

$\mu \mathrm{g} / \mathrm{L}$

$\mu \mathrm{g} / \mathrm{L}$

$\mu \mathrm{g} / \mathrm{L}$

$\mu \mathrm{g} / \mathrm{L}$

$\mu \mathrm{g} / \mathrm{L}$

$\mu \mathrm{g} / \mathrm{L}$

$\mu \mathrm{g} / \mathrm{L}$

$\mu \mathrm{g} / \mathrm{L}$

$\mu \mathrm{g} / \mathrm{L}$

$\mu \mathrm{g} / \mathrm{L}$

$\mu \mathrm{g} / \mathrm{L}$

$\mu \mathrm{g} / \mathrm{L}$

$\mu \mathrm{g} / \mathrm{L}$

$\mu \mathrm{g} / \mathrm{L}$

$\mu \mathrm{g} / \mathrm{L}$

$\mu \mathrm{g} / \mathrm{L}$

$\mu \mathrm{g} / \mathrm{L}$

$\mu \mathrm{g} / \mathrm{L}$

$\mu \mathrm{g} / \mathrm{L}$

$\mu \mathrm{g} / \mathrm{L}$

$\mu \mathrm{g} / \mathrm{L}$

$\mu \mathrm{g} / L$

$\mu \mathrm{g} / \mathrm{L}$

$\mu \mathrm{g} / \mathrm{L}$

$\mu \mathrm{g} / \mathrm{L}$

$\mu \mathrm{g} / \mathrm{L}$

$\mu \mathrm{g} / \mathrm{L}$

$\mu \mathrm{g} / \mathrm{L}$

$\mu \mathrm{g} / \mathrm{L}$

$\mu \mathrm{g} / \mathrm{L}$

$\mu \mathrm{g} / \mathrm{L}$

$\mu \mathrm{g} / \mathrm{L}$

$\mu \mathrm{g} / \mathrm{L}$

$\mu \mathrm{g} / \mathrm{L}$

$\mu \mathrm{g} / \mathrm{L}$

$\mu \mathrm{g} / \mathrm{L}$
0 WA

0 WA

GE

WA

WA

GE

GE

WA

WA

GE

GE

WA

WA

GE

GE

GE

GE

WA

WA

GE

GE

WA

WA

GE

GE

WA

WA

GE

GE

GE

GE

WA

WA

GE

GE

GE

WA

WA

GE

GE

WA

WA

GE

GE

WA

WA

GE

GE

WA

WA

GE

GE

WA

WA

GE 
WELL BGO $8 \mathrm{C}$ collected on 01/28/94, laboratory analyses (cont.)

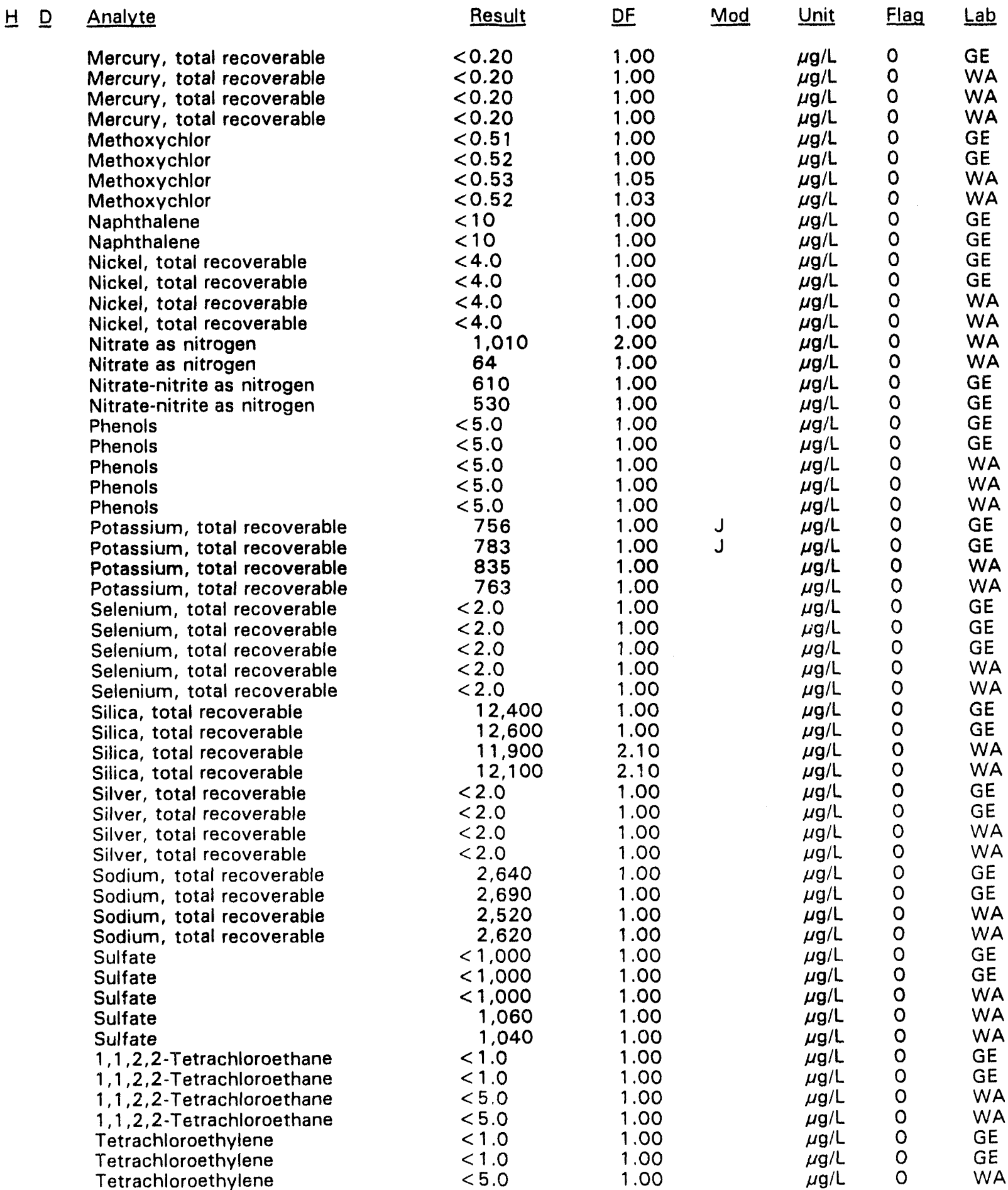

- = exceeded holding time. = exceeded screening level or final primary drinking water standard. 
WELL BGO $8 \mathrm{C}$ collected on $01 / 28 / 94$, laboratory analyses (cont.)

\section{H D Analyte}

Tetrachloroethylene

Tin, total recoverable

Tin, total recoverable

Tin, total recoverable

Tin, total recoverable

Toluene

Toluene

Toluene

Toluene

Total dissolved solids

Total dissolved solids

Total dissolved solids

Total dissolved solids

Total dissolved solids

Total organic carbon

Total organic carbon

Total organic carton

Total organic carbon

Total organic halogens

Total organic halogens

Total organic halogens

Total organic halogeins

Total organic halogens

Total phosphates (as P)

Total phosphates (as P)

Total phosphates (as $P$ )

Total phosphates (as P)

Toxaphene

Toxaphene

Toxaphene

Toxaphene

2,4,5-TP (Silvex)

2,4,5-TP (Silvex)

$2,4,5$-TP (Silvex)

2,4,5-TP (Silvex)

$1,1,1$-Trichloroethane

1,1,1-Trichloroethane

$1,1, \hat{i}$-Trichloroethane

1,1,1-Trichloroethane

1,1,2-Trichloroethane

1,1,2-Trichloroethane

1,1,2-Trichloroethane

1,1,2-Trichluroethane

Trichloroethylene

Trichloroethylene

Trichloroethylene

Trichloroethylene

Trict:iorofluoromethane

Trichlorofluoromethane

Trichlorofluoromethane

Trichlorofluoromethane

Vanadium, total recoverable

Vanadium, total recoverable

Vanadium, total recoverable

$\checkmark$ anadium, total recoverable

Xylenes

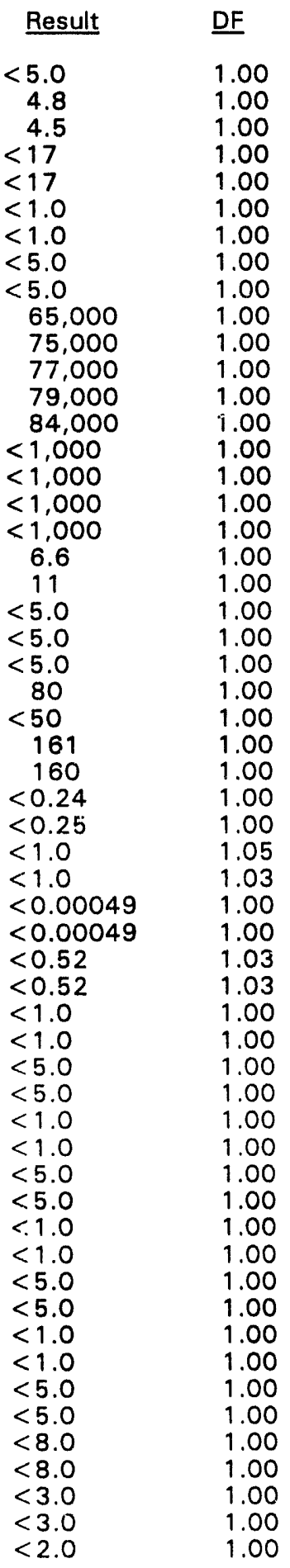

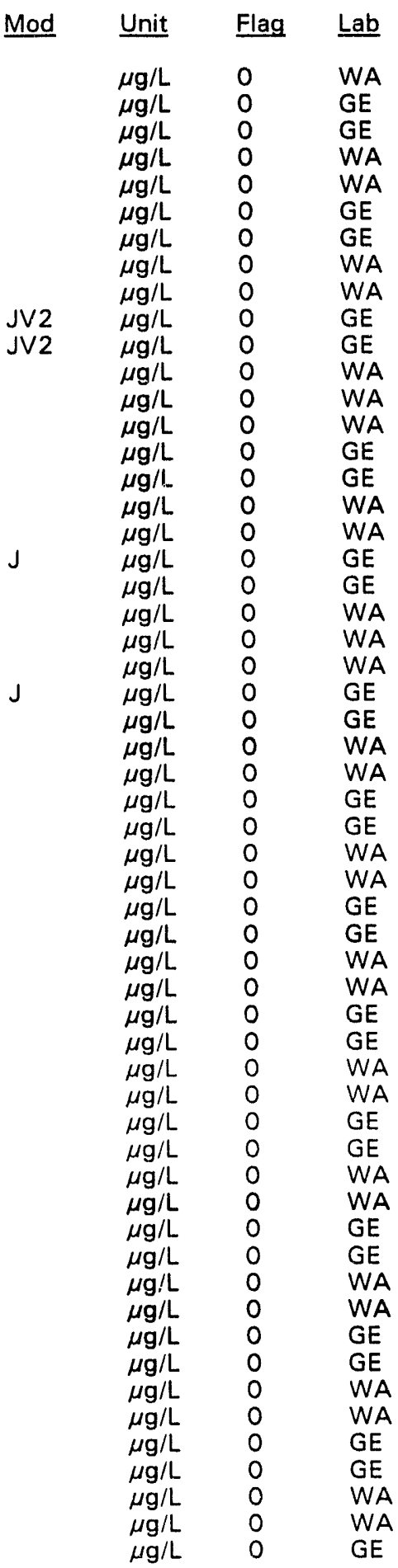

$\overline{- \text { = exceeded holding time. }} \mathbf{\square}=$ exceeded screening level or final primary drinking water standard. 
WELL BGO $8 \mathrm{C}$ collected on 01/28/94, laboratory analyses (cont.)

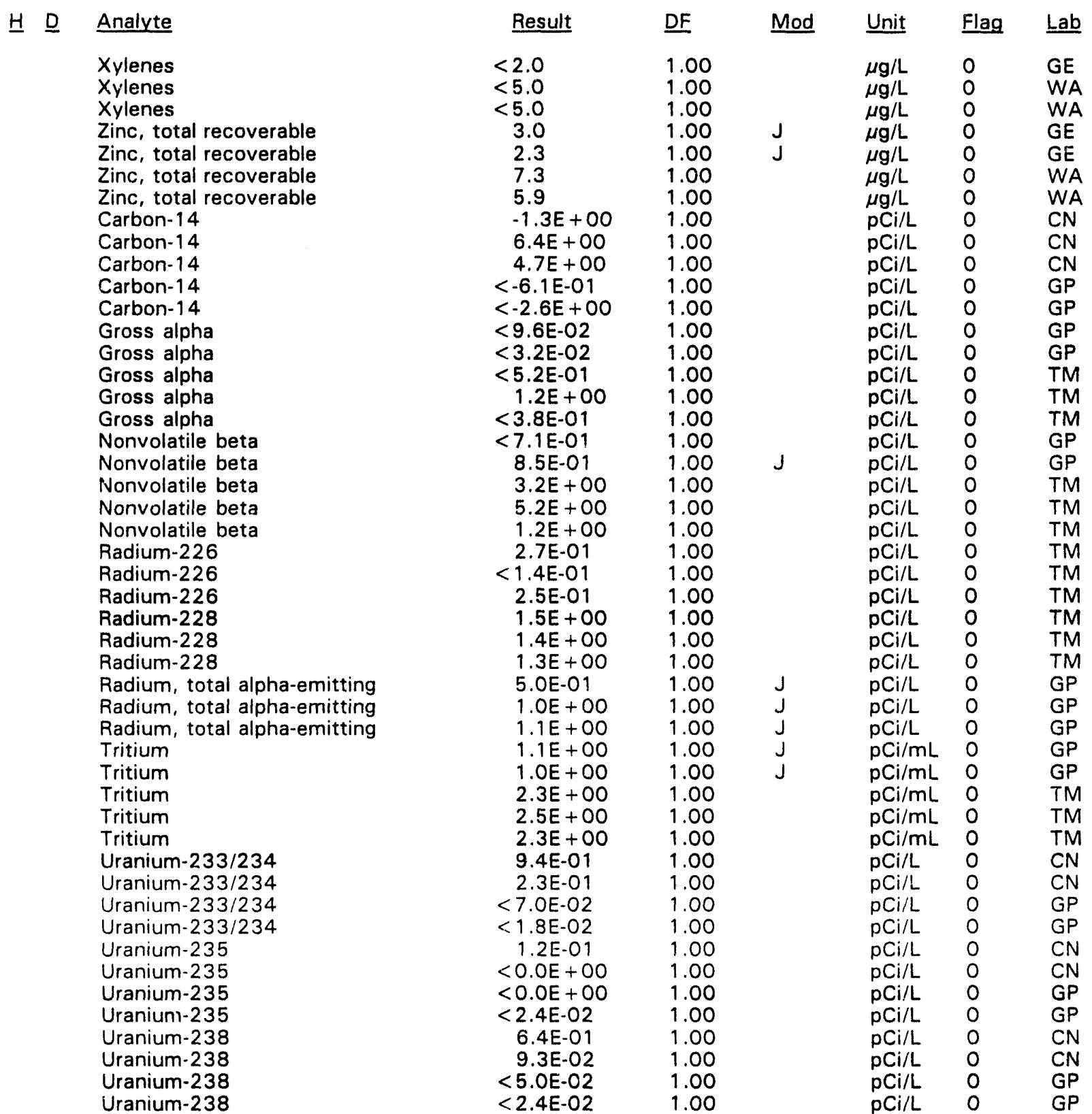

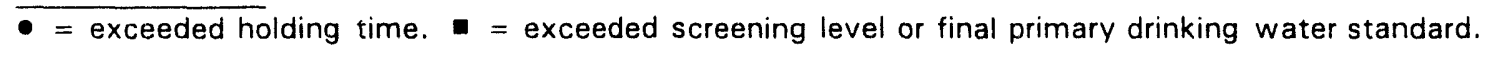




\section{WELL BGO 8D}

\begin{tabular}{|c|c|c|c|c|c|c|}
\hline SRS Coord. & Lat/Longitude & Screen Zone Elevation & Top of Casing & Casing & Pump & Formation \\
\hline $\begin{array}{l}N 76588.8 \\
E 57617.8\end{array}$ & $\begin{array}{l}33.289175^{\circ} \mathrm{N} \\
81.663853^{\circ} \mathrm{W}\end{array}$ & $240.6-220.6 \mathrm{ft} \mathrm{msl}$ & $287.8 \mathrm{ft} \mathrm{msl}$ & 4" PVC & $S$ & Water Table $\left(\|_{2}\right)$ \\
\hline
\end{tabular}

\section{FIELD MEASUREMENTS}

Sample date: $01 / 25 / 94$

Depth to water: $55.52 \mathrm{ft}(16.92 \mathrm{~m})$ below TOC

Water elevation: $232.28 \mathrm{ft}(70.80 \mathrm{~m}) \mathrm{msl}$

Sp. conductance: $28 \mu \mathrm{S} / \mathrm{cm}$

Turbidity: 0.7 NTU

Water evacuated before sampling: $107 \mathrm{gal}$

Time: $12: 24$

pH: 4.8

Alkalinity: $0 \mathrm{mg} / \mathrm{L}$

Water temperature: $19.5^{\circ} \mathrm{C}$

Volumes purged: 14.0 well volumes

\section{LABORATORY ANALYSES}

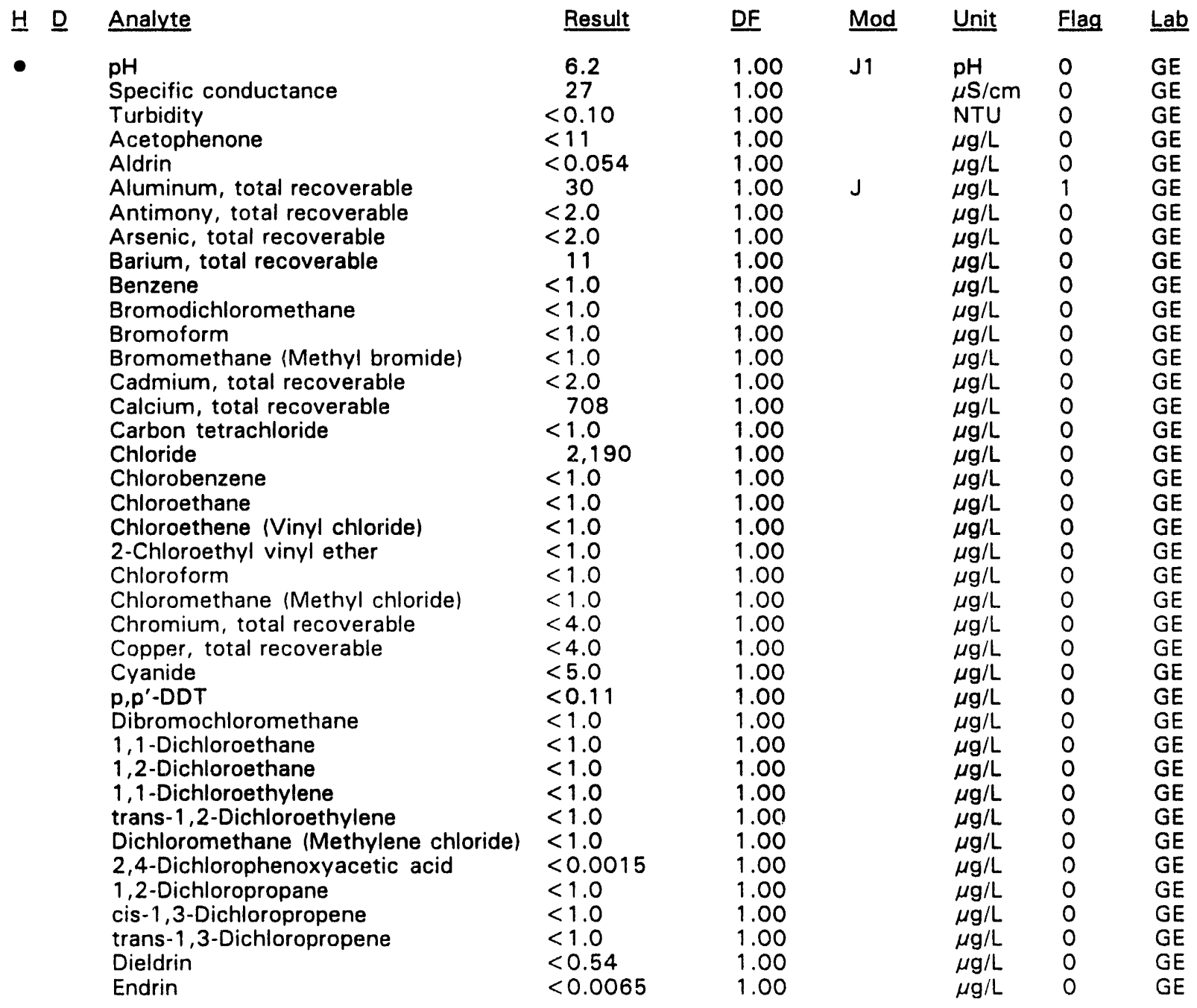

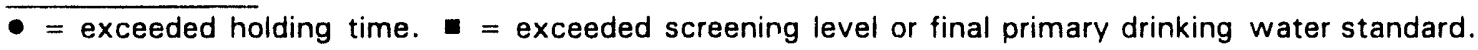


WELL BGO 8D collected on 01/25/94, laboratory analyses (cont.)

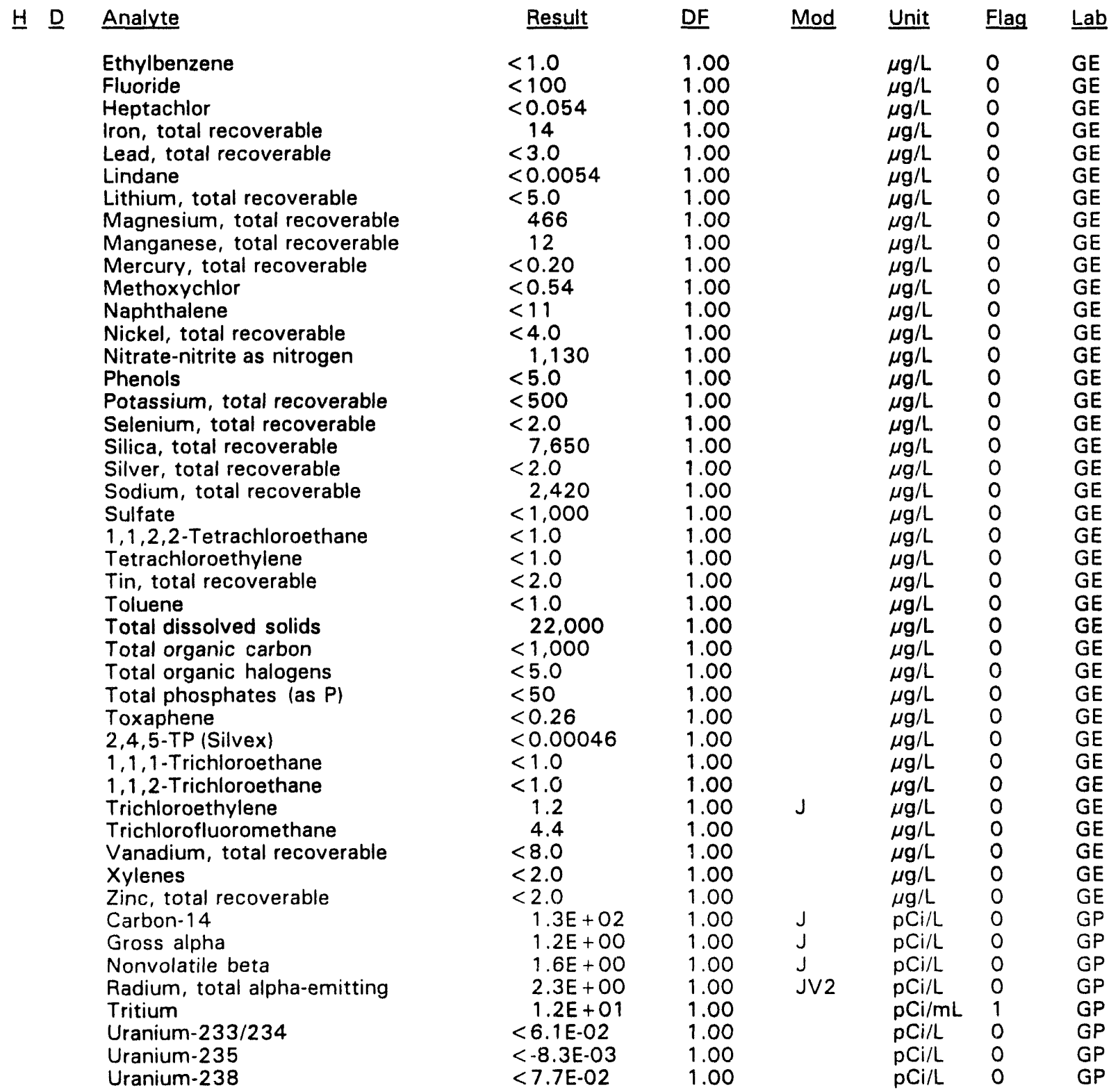

- = exceeded holding time. = exceeded screening level or final primary drinking water standard. 


\section{WELL BGO 9AA}

\begin{tabular}{|c|c|c|c|c|c|c|}
\hline SRS Coord. & Lat/Longitude & Screen Zone Elevation & Top of Casing & Casing & Pump & Formation \\
\hline $\begin{array}{l}\text { N76975.7 } \\
\text { E57371.9 }\end{array}$ & $\begin{array}{l}33.289630^{\circ} \mathrm{N} \\
81.665252^{\circ} \mathrm{W}\end{array}$ & $83.8-73.8 \mathrm{ft} \mathrm{msl}$ & $284.8 \mathrm{ft} \mathrm{msl}$ & 4" PVC & S & aree (IIA) \\
\hline
\end{tabular}

\section{FIELD MEASUREMENTS}

Sample date: $01 / 26 / 94$

Depth to water: $127.20 \mathrm{ft}(38.77 \mathrm{~m})$ below TOC

Water elevation: $157.60 \mathrm{ft}(48.04 \mathrm{~m}) \mathrm{msl}$

Sp. conductance: $3760 \mu \mathrm{S} / \mathrm{cm}$

Turbidity: 2.6 NTU

Water evacuated before sampling: $43 \mathrm{gal}$

The well went dry during purging.

Time: 9: 30

$\mathrm{pH}: 12.6$

Alkalinity: $864 \mathrm{mg} / \mathrm{L}$

Water temperature: $17.5^{\circ} \mathrm{C}$

Volumes purged: 0.8 well volumes

\section{LABORATORY ANALYSES}

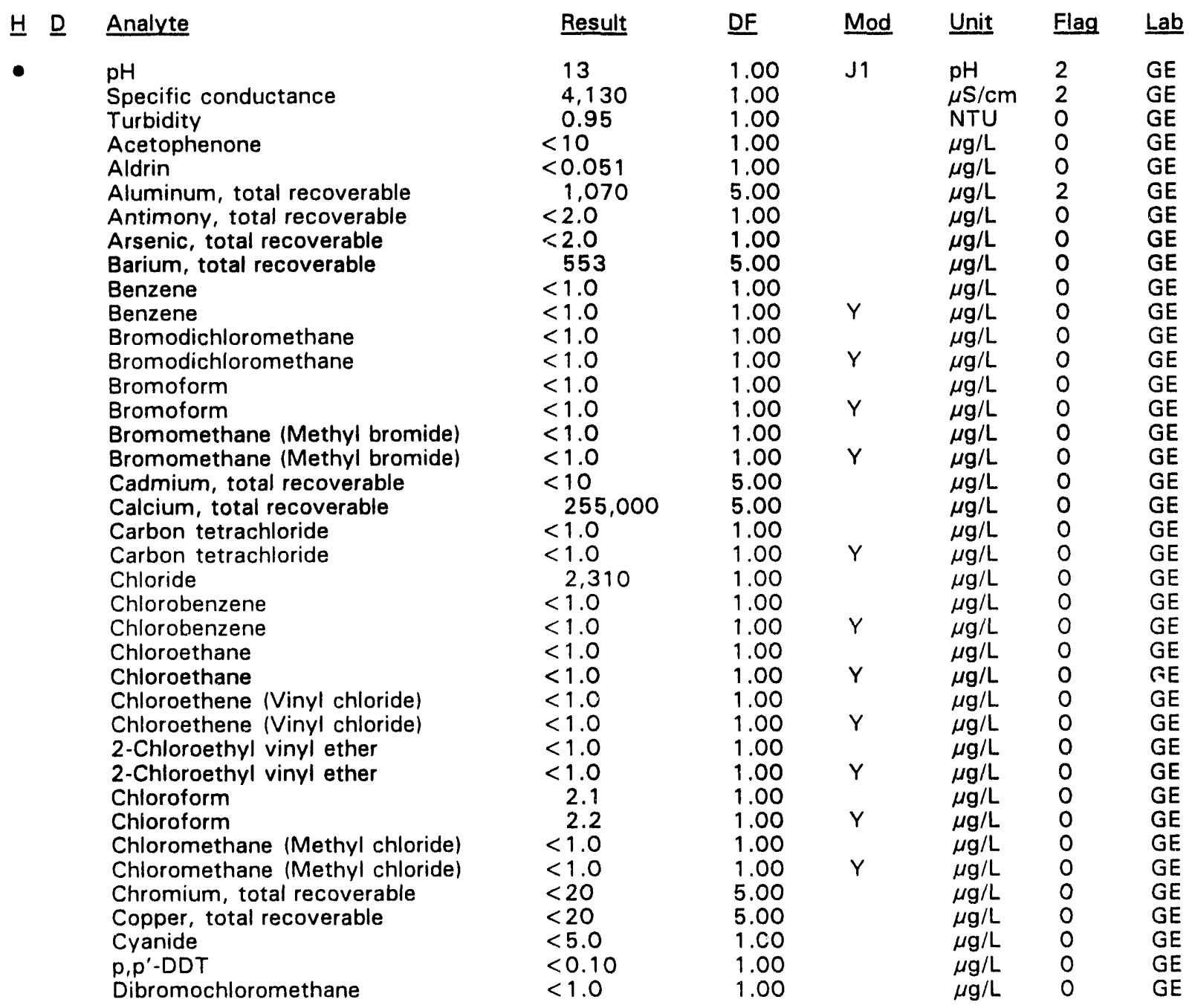

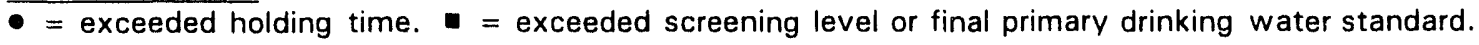


WELL BGO 9AA collected on 01/26/94, laboratory analyses (cont.)

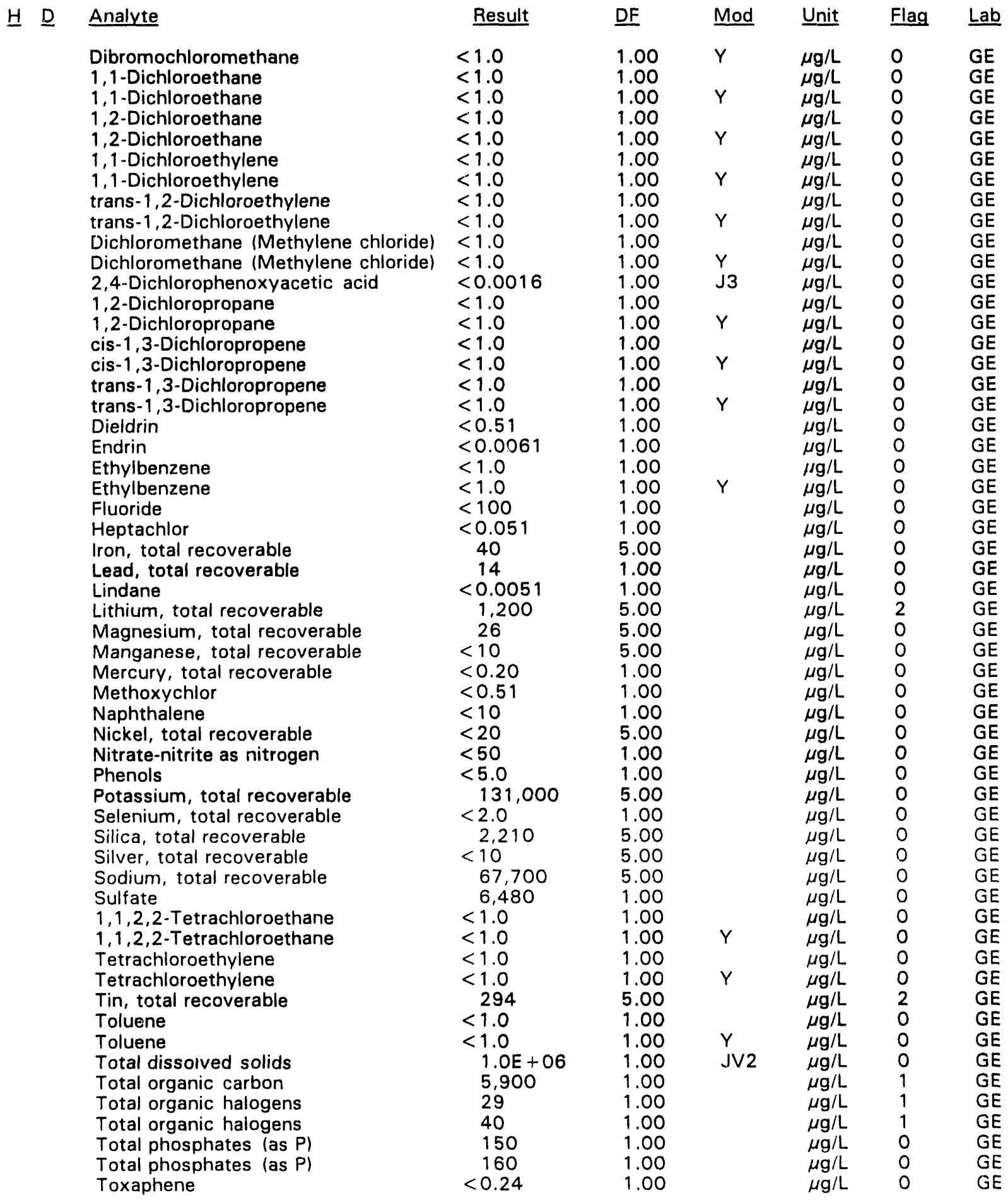

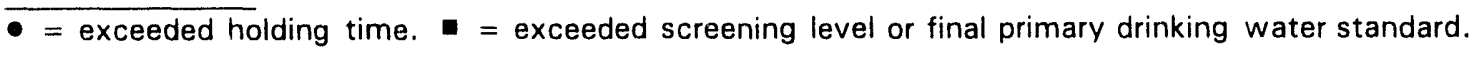


WELL BGO 9AA collected on $01 / 26 / 94$, laboratory analyses (cont.)

H D Analyte

2,4,5-TP (Silvex)

$1,1,1$-Trichloroethane

1,1,1-Trichloroethane

1,1,2-Trichloroethane

1,1,2-Trichloroethane

Trichloroethylene

Trichloroethylene

Trichlorofluoromethane

Trichlorofluoromethane

Vanadium, total recoverable

Xylenes

Xylenes

Gross alpha

- Nonvolatile beta

Radium, total alpha-emitting

Tritium

Uranium-233/234

Uranium-235

Uranium-238

\begin{tabular}{|c|c|c|c|c|c|}
\hline Result & $\underline{D F}$ & Mod & Unit & Flag & La \\
\hline$<0.00046$ & 1.00 & J3 & $\mu \mathrm{g} / \mathrm{L}$ & 0 & $\mathbf{G}$ \\
\hline$<1.0$ & 1.00 & & $\mu \mathrm{g} / \mathrm{L}$ & 0 & \\
\hline$<1.0$ & 1.00 & $Y$ & $\mu \mathrm{g} / \mathrm{L}$ & 0 & \\
\hline$<1.0$ & 1.00 & & $\mu \mathrm{g} / \mathrm{L}$ & 0 & \\
\hline$<1.0$ & 1.00 & $Y$ & $\mu \mathrm{g} / \mathrm{L}$ & 0 & \\
\hline$<1.0$ & 1.00 & & $\mu \mathrm{g} / \mathrm{L}$ & 0 & \\
\hline$<1.0$ & 1.00 & $Y$ & $\mu \mathrm{g} / \mathrm{L}$ & 0 & \\
\hline$<1.0$ & 1.00 & & $\mu \mathrm{g} / \mathrm{L}$ & 0 & \\
\hline$<1.0$ & 1.00 & $Y$ & $\mu \mathrm{g} / \mathrm{L}$ & 0 & \\
\hline$<40$ & 5.00 & & $\mu \mathrm{g} / \mathrm{L}$ & 0 & \\
\hline$<2.0$ & 1.00 & & $\mu \mathrm{g} / \mathrm{L}$ & 0 & \\
\hline$<2.0$ & 1.00 & Y & $\mu \mathrm{g} / \mathrm{L}$ & 0 & \\
\hline $6.1 E+00$ & 1.00 & & $\mathrm{pCi} / \mathrm{L}$ & 0 & \\
\hline $7.8 E+01$ & 1.00 & & $\mathrm{pCi} / \mathrm{L}$ & 2 & \\
\hline $9.0 E+00$ & 1.00 & & $\mathrm{pCi} / \mathrm{L}$ & 0 & \\
\hline$<0.0 E+00$ & 1.00 & & $\mathrm{pCi} / \mathrm{mL}$ & 0 & \\
\hline$<1.4$ & 1.00 & & $\mathrm{pCi} / \mathrm{L}$ & 0 & \\
\hline & 1.0 & & $\mathrm{pCi} / \mathrm{L}$ & 0 & \\
\hline & & & $\mathrm{pCi} / \mathrm{L}$ & 0 & \\
\hline
\end{tabular}

WELL BGO 9D

\begin{tabular}{|c|c|c|c|c|c|c|}
\hline SRS Coord. & Lat/Longitude & Screen Zone Elevation & Top of Casing & Casing & Pump & Formation \\
\hline $\begin{array}{l}\text { N76811.6 } \\
\text { E57478.9 }\end{array}$ & $\begin{array}{l}33.289442^{\circ} \mathrm{N} \\
81.664652^{\circ} \mathrm{W}\end{array}$ & 229 & 28 & vc & s & ble \\
\hline
\end{tabular}

\section{FIELD MEASUREMENTS}

Sample date: $01 / 25 / 94$

Depth to water: $69.20 \mathrm{ft}(21.09 \mathrm{~m})$ below TOC

Water elevation: $215.90 \mathrm{ft}(65.81 \mathrm{~m}) \mathrm{msl}$

Sp. conductance: $31 \mu \mathrm{S} / \mathrm{cm}$

Turbidity: 1.2 NTU

Water evacuated before sampling: $23 \mathrm{gal}$

\section{LABORATORY ANALYSES}

H D Analyte

$\mathrm{pH}$

Specific conductance

Specific conductance

Turbidity

Acetophenone

Aldrin

Aluminum, total recoverable

Antimony, total recoverable

Arsenic, total recoverable

Barium, total recoverable

Benzene

Bromodichloromethane

Bromoform

Bromomethane (Methyl bromide)

Cadmium, total recoverable
Time: 13: 26

$\mathrm{pH}: 5.0$

Alkalinity: $0 \mathrm{mg} / \mathrm{L}$

Water temperature: $20.3^{\circ} \mathrm{C}$

Volumes purged: 5.2 well volumes

\begin{tabular}{|c|c|c|c|c|}
\hline Result & DF & Mod & Unit & Flag \\
\hline 5.3 & 1.00 & J1 & $\mathrm{pH}$ & 0 \\
\hline 28 & 1.00 & & $\mu \mathrm{S} / \mathrm{cm}$ & 0 \\
\hline 29 & 1.00 & & $\mu \mathrm{S} / \mathrm{cm}$ & 0 \\
\hline$<0.10$ & 1.00 & & NTU & 0 \\
\hline$<10$ & 1.00 & & $\mu \mathrm{g} / \mathrm{L}$ & 0 \\
\hline$<0.051$ & 1.00 & & $\mu \mathrm{g} / \mathrm{L}$ & 0 \\
\hline 25 & 1.00 & $\mathrm{~J}$ & $\mu \mathrm{g} / \mathrm{L}$ & 0 \\
\hline$<2.0$ & 1.00 & & $\mu \mathrm{g} / \mathrm{L}$ & 0 \\
\hline$<2.0$ & 1.00 & & $\mu \mathrm{g} / \mathrm{L}$ & 0 \\
\hline 13 & 1.00 & & $\mu \mathrm{g} / \mathrm{L}$ & 0 \\
\hline$<1.0$ & 1.00 & & $\mu \mathrm{g} / \mathrm{L}$ & 0 \\
\hline$<1.0$ & 1.00 & & $\mu \mathrm{g} / \mathrm{L}$ & 0 \\
\hline$<1.0$ & 1.00 & & $\mu \mathrm{g} / \mathrm{L}$ & 0 \\
\hline$<1.0$ & 1.00 & & $\mu \mathrm{g} / \mathrm{L}$ & 0 \\
\hline$<2.0$ & 1.00 & & $\mu \mathrm{g} / \mathrm{L}$ & 0 \\
\hline
\end{tabular}

- = exceeded holding time. = exceeded screening level or final primary drinking water standard. 
WELL BGO 9D collected on 01/25/94, laboratory analyses (cont.)

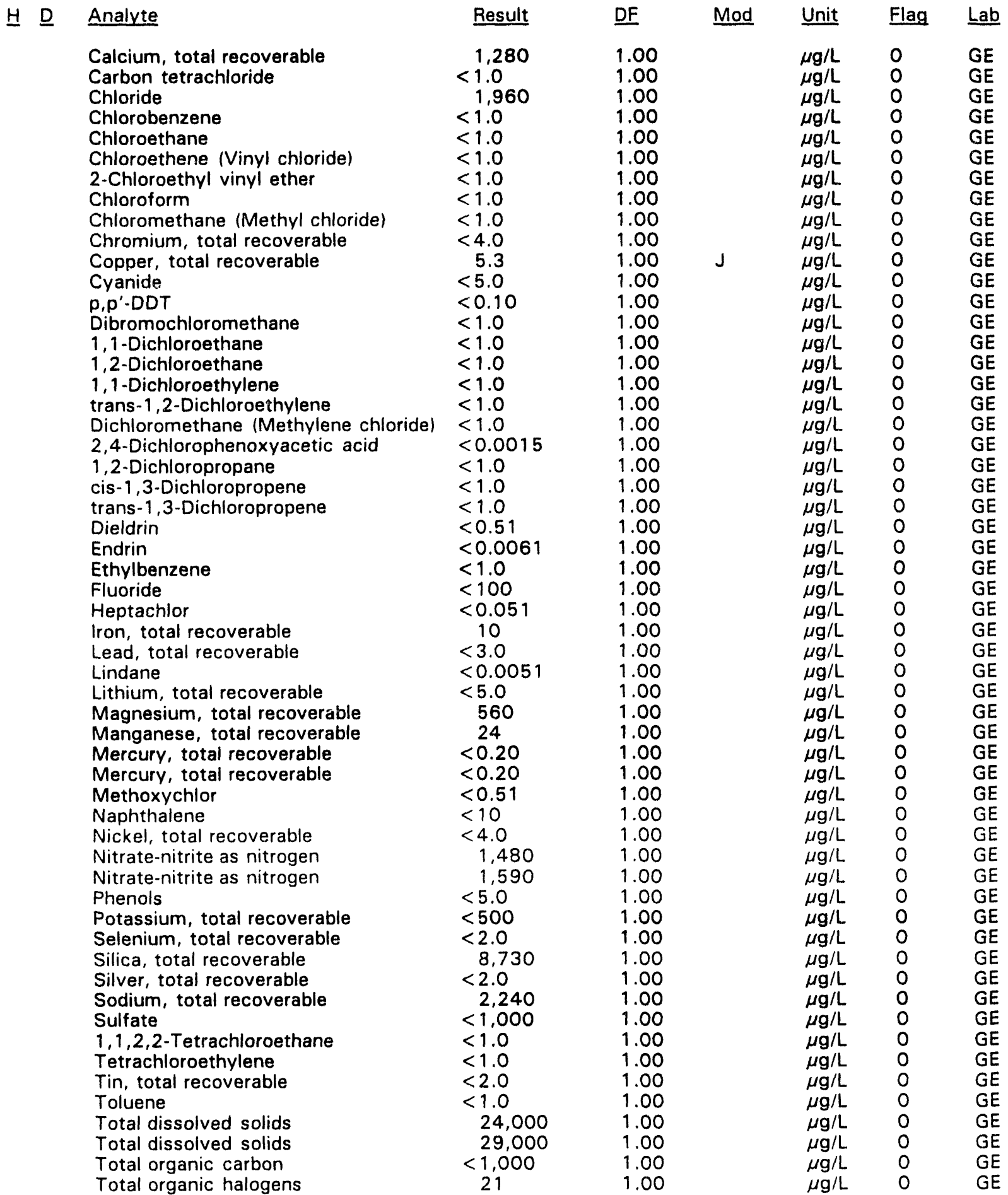

$\overline{-=}$ exceeded holding time. $=$ exceeded screening level or final primary drinking water standard 
WELL BGO 9D collected on 01/25/94, laboratory analyses (cont.)

H D Analyte

Total organic halogens

Total phosphates (as P)

Toxaphene

2,4,5-TP (Silvex)

$1,1,1$-Trichloroethane

1,1,2-Trichloroethane

Trichloroethylene

Trichlorofluoromethane

Vanadium, total recoverable

Xylenes

Zinc, total recoverable

Carbon-14

Gross alpha

Nonvolatile beta

Radium, total alpha-emitting

Radium, total alpha-emitting

Total activity

- Tritium

Uranium-233/234

Uranium-235

Uranium-238

\begin{tabular}{|c|c|}
\hline Result & DF \\
\hline $\begin{array}{rl} & 24 \\
< & 50 \\
< & 0.24 \\
< & 0.00045 \\
< & 1.0 \\
< & 1.0 \\
< & 1.0 \\
< & 1.0 \\
< & 8.0 \\
< & 2.0 \\
& 15 \\
& 5.7 E+01 \\
& 1.7 E+00 \\
& 5.9 E-01 \\
& 3.3 E+00 \\
& 3.5 E+00 \\
& 2.1 E+05 \\
& 2.4 E+02 \\
< & 1.9 E-01 \\
<0 & 0.0 E+00 \\
< & 6.2 E-02\end{array}$ & $\begin{array}{l}1.00 \\
1.00 \\
1.00 \\
1.00 \\
1.00 \\
1.00 \\
1.00 \\
1.00 \\
1.00 \\
1.00 \\
1.00 \\
1.00 \\
1.00 \\
1.00 \\
1.00 \\
1.00 \\
10.00 \\
1.00 \\
1.00 \\
1.00 \\
1.00\end{array}$ \\
\hline
\end{tabular}

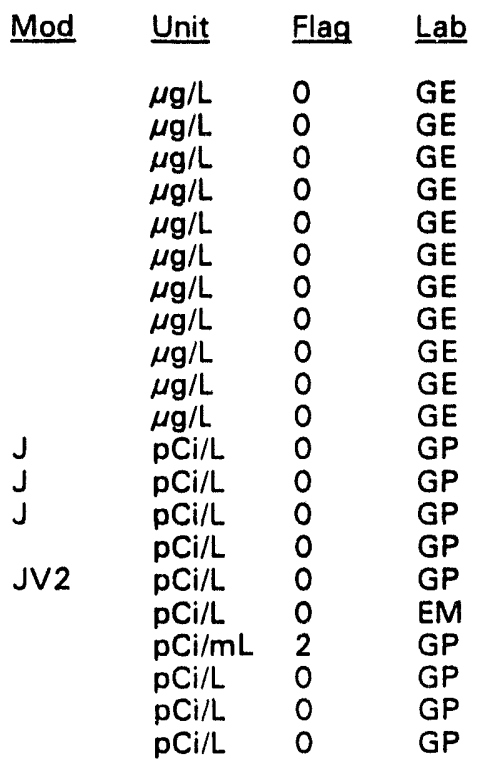

\section{WELL BGO 10AA}

\begin{tabular}{|c|c|c|c|c|c|c|}
\hline SRS Coord. & Lat/Longitude & Screen Zone Elevation & Top of Casing & Casing & Pump & Formation \\
\hline $\begin{array}{l}\text { N76997.9 } \\
\text { E56990.5 }\end{array}$ & $\begin{array}{l}33.289057^{\circ} \mathrm{N} \\
81.666300^{\circ} \mathrm{W}\end{array}$ & $90.8-80.8 \mathrm{ft} \mathrm{msl}$ & $300.7 \mathrm{ft} \mathrm{msl}$ & 4" PVC & $\mathrm{s}$ & e (IIA) \\
\hline
\end{tabular}

\section{FIELD MEASUREMENTS}

Sample date: $01 / 25 / 94$

Depth to water: $143.30 \mathrm{ft}(43.68 \mathrm{~m})$ below TOC

Water elevation: $157.40 \mathrm{ft}(47.98 \mathrm{~m}) \mathrm{msl}$

Sp. conductance: $224 \mu \mathrm{S} / \mathrm{cm}$

Turbidity: $1.8 \mathrm{NTU}$

Water evacuated before sampling: $136 \mathrm{gal}$

\section{LABORATORY ANALYSES}

\begin{tabular}{|c|c|c|c|c|c|c|c|}
\hline$\underline{H} \underline{D}$ & Analyte & Result & DF & Mod & Unit & Flag & $\underline{\mathrm{Lab}}$ \\
\hline$\bullet$ & $\begin{array}{l}\text { pH } \\
\text { Specific conductance } \\
\text { Turbidity } \\
\text { Acetophenone } \\
\text { Aldrin } \\
\text { Aluminum, total recoverable } \\
\text { Aluminum, total recoverable } \\
\text { Antimony, total recoverable } \\
\text { Arsenic, total recoverable } \\
\text { Barium, total recoverable } \\
\text { Barium, total recoverable } \\
\text { Benzene } \\
\text { Bromodichloromethane }\end{array}$ & $\begin{array}{rl} & 6.5 \\
& 207 \\
1.6 \\
< \\
<11 \\
< & 0.051 \\
21 & 22 \\
& 22 \\
< & 2.0 \\
< & 2.0 \\
53 \\
53 \\
<1.0 \\
<1.0\end{array}$ & $\begin{array}{l}1.00 \\
1.00 \\
1.00 \\
1.00 \\
1.00 \\
1.00 \\
1.00 \\
1.00 \\
1.00 \\
1.00 \\
1.00 \\
1.00 \\
1.00\end{array}$ & $\mathrm{~J}$ & $\begin{array}{l}\mathrm{pH} \\
\mu \mathrm{S} / \mathrm{cm} \\
N T U \\
\mu \mathrm{g} / \mathrm{L} \\
\mu \mathrm{g} / \mathrm{L} \\
\mu \mathrm{g} / \mathrm{L} \\
\mu \mathrm{g} / \mathrm{L} \\
\mu \mathrm{g} / \mathrm{L} \\
\mu \mathrm{g} / \mathrm{L} \\
\mu \mathrm{g} / \mathrm{L} \\
\mu \mathrm{g} / \mathrm{L} \\
\mu \mathrm{g} / \mathrm{L} \\
\mu \mathrm{g} / \mathrm{L}\end{array}$ & $\begin{array}{l}0 \\
0 \\
0 \\
0 \\
0 \\
0 \\
0 \\
0 \\
0 \\
0 \\
0 \\
0 \\
0\end{array}$ & $\begin{array}{l}\mathrm{GE} \\
\mathrm{GE} \\
\mathrm{GE} \\
\mathrm{GE} \\
\mathrm{GE} \\
\mathrm{GE} \\
\mathrm{GE} \\
\mathrm{GE} \\
\mathrm{GE} \\
\mathrm{GE} \\
\mathrm{GE} \\
\mathrm{GE} \\
\mathrm{GE}\end{array}$ \\
\hline
\end{tabular}

Time: 14: 32

$\mathrm{pH}: 8.8$

Alkalinity: $85 \mathrm{mg} / \mathrm{L}$

Water temperature: $19.5^{\circ} \mathrm{C}$

Volumes purged: 2.7 well volumes

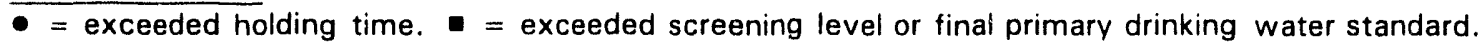


WELL BGO 1OAA collected on 01/25/94, laboratory analyses (cont.)

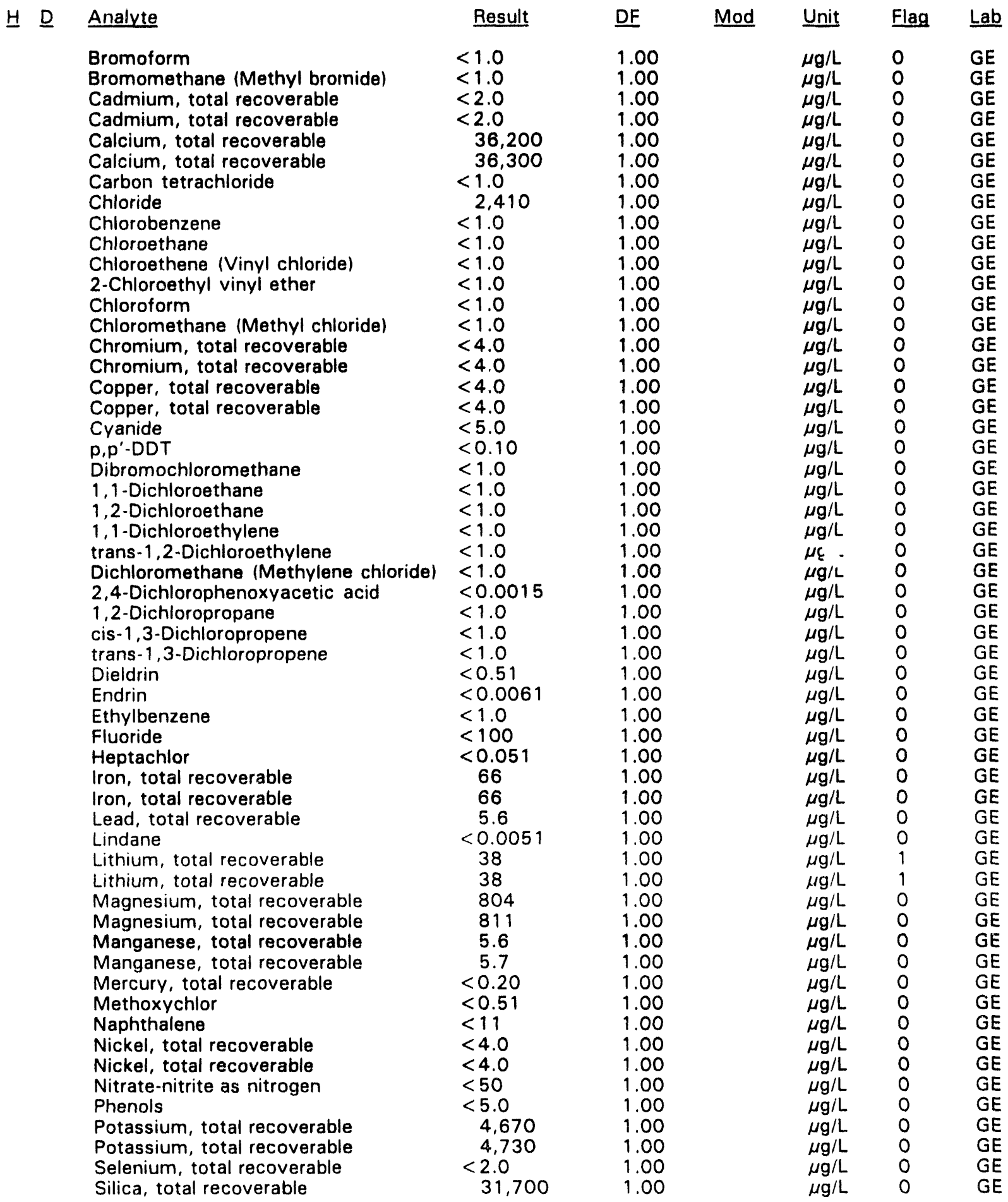

$\overline{- \text { = exceeded holding time. }}$ = exceeded screening level or final primary drinking water standard. 
WELL BGO 1OAA collected on 01/25/94, laboratory analyses (cont.)

\section{브 $\underline{\text { Analyte }}$}

Silica, total recoverable

Silver, total recoverable

Silver, total recoverable

Sodium, total recoverable

Sodium, total recoverable

Sulfate

1,1,2,2-Tetrachloroethane

Tetrachloroethylene

Tin, total recoverable

Tin, total recoverable

Toluene

Total dissolved solids

Total dissolved solids

Total organic carbon

Total organic halogens

Total phosphates (as P)

Toxaphene

2,4,5-TP (Silvex)

1,1,1-Trichloroethane

1,1,2-Trichloroethane

Trichloroethylene

Trichlorofluoromethane

Vanadium, total recoverable

Vanadium, total recoverable

Xylenes

Gross alpha

Nonvolatile beta

Radium, total alpha-emitting

Tritium

Uranium-233/234

Uranium-235

Uranium-238

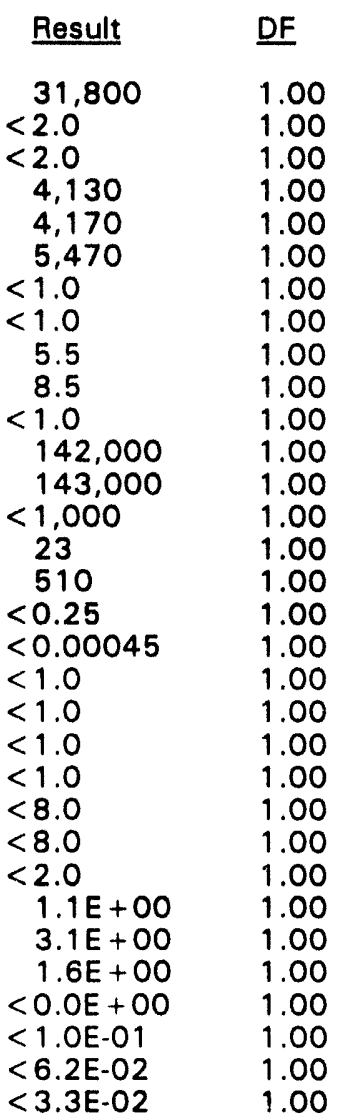

\begin{tabular}{|c|c|c|}
\hline Mod & Unit & Flag \\
\hline $\begin{array}{l}\mathrm{J} \\
\mathrm{J} \\
\mathrm{J} V 2\end{array}$ & $\begin{array}{l}\mu \mathrm{g} / \mathrm{L} \\
\mu \mathrm{g} / \mathrm{L} \\
\mu \mathrm{g} / \mathrm{L} \\
\mu \mathrm{g} / \mathrm{L} \\
\mu \mathrm{g} / \mathrm{L} \\
\mu \mathrm{g} / \mathrm{L} \\
\mu \mathrm{g} / \mathrm{L} \\
\mu \mathrm{g} / \mathrm{L} \\
\mu \mathrm{g} / \mathrm{L} \\
\mu \mathrm{g} / \mathrm{L} \\
\mu \mathrm{g} / \mathrm{L} \\
\mu \mathrm{g} / \mathrm{L} \\
\mu \mathrm{g} / \mathrm{L} \\
\mu \mathrm{g} / \mathrm{L} \\
\mu \mathrm{g} / \mathrm{L} \\
\mu \mathrm{g} / \mathrm{L} \\
\mu \mathrm{g} / \mathrm{L} \\
\mu \mathrm{g} / \mathrm{L} \\
\mu \mathrm{g} / \mathrm{L} \\
\mu \mathrm{g} / \mathrm{L} \\
\mu \mathrm{g} / \mathrm{L} \\
\mu \mathrm{g} / \mathrm{L} \\
\mu \mathrm{g} / \mathrm{L} \\
\mu \mathrm{g} / \mathrm{L} \\
\mu \mathrm{g} / \mathrm{L} \\
\mathrm{pCi} / \mathrm{L} \\
\mathrm{p} C \mathrm{i} \\
\mathrm{p} \mathrm{i} / \mathrm{L} \\
\mathrm{pCi}\end{array}$ & $\begin{array}{l}0 \\
0 \\
0 \\
0 \\
0 \\
0 \\
0 \\
0 \\
0 \\
0 \\
0 \\
0 \\
0 \\
0 \\
0 \\
0 \\
0 \\
0 \\
0 \\
0 \\
0 \\
0 \\
0 \\
0 \\
0 \\
0 \\
0 \\
0 \\
0 \\
0 \\
0 \\
0\end{array}$ \\
\hline
\end{tabular}

\section{WELL BGO 10AR}

\begin{tabular}{|c|c|c|c|c|c|c|}
\hline SRS Coord. & Lat/Longitude & Screen Zone Elevation & Top of Casing & Casing & Pump & Formation \\
\hline & N & $106.5-96.5 \mathrm{ft} \mathrm{msl}$ & $300.5 \mathrm{ft} \mathrm{msl}$ & 4" PVC & $\mathrm{S}$ & garee 1 \\
\hline
\end{tabular}

\section{FIELD MEASUREMENTS}

Sample date: 01/25/94

Depth to water: $142.55 \mathrm{ft}(43.45 \mathrm{~m})$ below TOC

Water elevation: $157.95 \mathrm{ft}(48.14 \mathrm{~m}) \mathrm{ms}$

Sp. conductance: $251 \mu \mathrm{S} / \mathrm{cm}$

Turbidity: 1.1 NTU

Water evacuated before sampling: $125 \mathrm{gal}$

\section{LABORATORY ANALYSES}

$\begin{array}{llllllll}\text { H } & \text { Analyte } & \text { Result } & \text { DF } & \text { Mod } & \text { Unit } & \text { Flag } & \text { Lab } \\ \text { - } & \text { pH } & 6.6 & 1.00 & J 1 & \text { pH } & 0 & \text { GE } \\ & \text { Specific conductance } & 240 & 1.00 & & \mu S / c r n & 0 & G E\end{array}$

Time: $15: 32$

$\mathrm{pH}: 7.6$

Alkalinity: $90 \mathrm{mg} / \mathrm{L}$

Water temperature: $19.3^{\circ} \mathrm{C}$

Volumes purged: 3.1 well volumes 
WELL BGO 1OAR collected on 01/25/94, laboratory analyses (cont.)

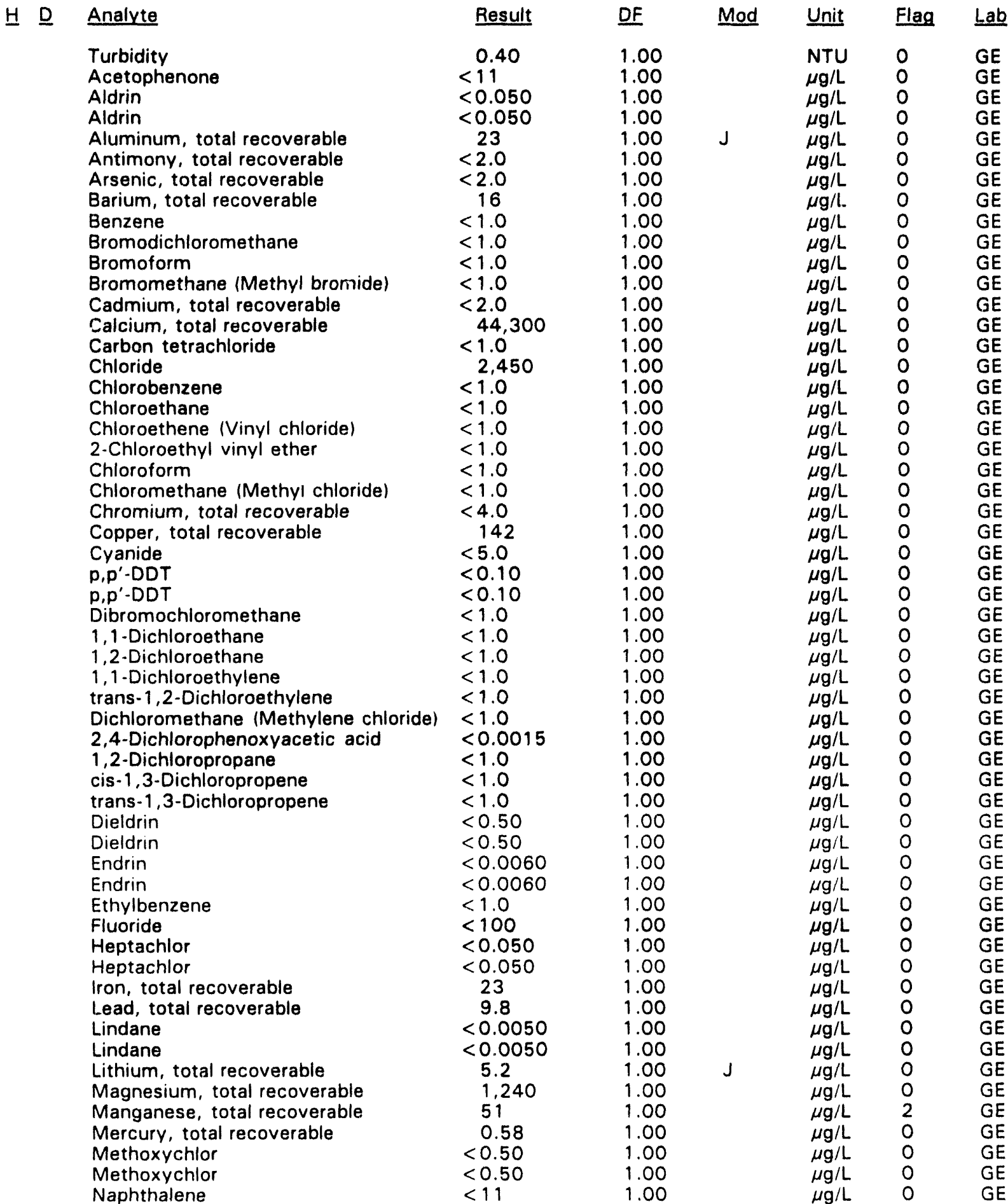

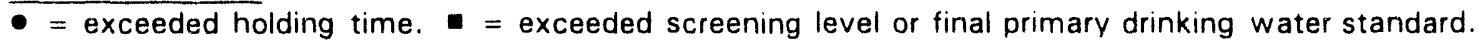


WELL BGO 1OAR collected on 01/25/94, laboratory analyses (cont.)

\section{H D Analyte}

Nickel, total recoverable

Nitrate-nitrite as nitrogen

Nitrate-nitrite as nitrogen

Phenols

Potassium, total recoverable

Selenium, total recoverable

Silica, total recoverable

Silver, total recoverable

Sodium, total recoverable

Sulfate

$1,1,2,2$-Tetrachloroethane

Tetrachloroethylene

Tin, total recoverable

Toluene

Total dissolved solids

Total organic carbon

Total organic halogens

Total phosphates (as P)

Toxaphene

Toxaphene

2,4,5-TP (Silvex)

Tributyl phosphate

1,1,1-Trichloroethane

1,1,2-Trichloroethane

Trichloroethylene

Trichlorofluoromethane

Vanadium, total recoverable

Xylenes

Zinc, total recoverable

Carbon-14

Gross alpha

Gross alpha

Nonvolatile beta

Nonvolatile beta

Radium, total alpha-emitting

Tritium

Uranium-233/234

Uranium-235

Uranium-238
Result DF

$<4.0 \quad 1.00$

$<50$

$<50$

$<5.0$

1,400

$<2.0$

29,400

$<2.0$

2,020

6,110

$<1.0$

$<1.0$

$<2.0$

$<1.0$

162,000

$<1,000$

14

$<50$

$<0.24$

$<0.24$

$<0.00045$

$<11$

$<1.0$

$<1.0$

$<1.0$

$<1.0$

$<8.0$

$<2.0$

69

$<5.0 E+00$

$1.5 E+00$

$1.4 E+00$

$<9.6 \mathrm{E}-01$

1.5E + 00

$1.1 E+00$

$<0.0 E+00$

2.2E-O?

$<0.0 E+00$

$<8$. OE-O2

1.00

1.00

1.00

1.00

1.00

1.00

1.00

1.00

1.00

1.00

1.00

1.00

1.00

1.00

1.00
Mod

Unit

Flag Lab

1.00

1.00

1.00

1.00

1.00

1.00

1.00

1.00

1.00

1.00

1.00

1.00

1.00

1.00

1.00

1.00

1.00

1.00

1.00

1.00

1.00

1.00

1.00

$\mu \mathrm{g} / \mathrm{L} \quad 0 \quad \mathrm{GE}$

J3

$\mu \mathrm{g} / \mathrm{L} \quad 0 \quad \mathrm{GE}$

$\mu g / L \quad 0 \quad$ GE

$\mu \mathrm{g} / \mathrm{L} \quad 0 \quad \mathrm{GE}$

$\mu g / L \quad 0 \quad G E$

$\mu \mathrm{g} / \mathrm{L} \quad 0 \quad \mathrm{GE}$

$\mu \mathrm{g} / \mathrm{L} \quad 0 \quad \mathrm{GE}$

$\mu \mathrm{g} / \mathrm{L} \quad \mathrm{O} \quad \mathrm{GE}$

$\mu \mathrm{g} / \mathrm{L} \quad 0 \quad \mathrm{GE}$

$\mu g / L \quad 0 \quad$ GE

$\mu \mathrm{g} / \mathrm{L} \quad 0 \quad \mathrm{GE}$

$\mu \mathrm{g} / \mathrm{L} \quad \mathrm{O} \quad \mathrm{GE}$

$\mu \mathrm{g} / \mathrm{L} \quad 0 \quad \mathrm{GE}$

$\mu \mathrm{g} / \mathrm{L} \quad 0 \quad \mathrm{GE}$

$\mu \mathrm{g} / \mathrm{L} \quad 0 \quad \mathrm{GE}$

$\mu \mathrm{g} / \mathrm{L} \quad 0 \quad \mathrm{GE}$

$\mu \mathrm{g} / \mathrm{L} \quad 0 \quad \mathrm{GE}$

$\mu \mathrm{g} / \mathrm{L} \quad 0 \quad \mathrm{GE}$

$\mu \mathrm{g} / \mathrm{L} \quad 0 \quad \mathrm{GE}$

$\mu \mathrm{g} / \mathrm{L} \quad 0 \quad \mathrm{GE}$

$\mu \mathrm{g} / \mathrm{L} \quad 0 \quad \mathrm{GE}$

$\mu \mathrm{g} / \mathrm{L} \quad 0 \quad \mathrm{GE}$

$\mu \mathrm{g} / \mathrm{L} \quad 0 \quad \mathrm{GE}$

$\mu g / L \quad 0 \quad$ GE

$\mu g / L \quad 0 \quad G E$

$\mu \mathrm{g} / \mathrm{L} \quad 0 \quad \mathrm{GE}$

$\mu \mathrm{g} / \mathrm{L} \quad \mathrm{O} \quad \mathrm{GE}$

$\mu \mathrm{g} / \mathrm{L} \quad 0 \quad \mathrm{GE}$

$\mu \mathrm{g} / \mathrm{L} \quad 0 \quad \mathrm{GE}$

$\mathrm{pCi} / \mathrm{L} \quad 0 \quad \mathrm{GP}$

$\mathrm{pCi} / \mathrm{O} \quad \mathrm{GP}$

$\mathrm{pCi} / \mathrm{L} \quad 0 \quad \mathrm{GP}$

pCi/L $0 \quad$ GP

$\mathrm{pCi} / \mathrm{L} \quad 0 \quad \mathrm{GP}$

$\mathrm{pCi} / \mathrm{L} \quad 0 \quad \mathrm{GP}$

$\mathrm{pCi} / \mathrm{mL} \quad 0 \quad \mathrm{GP}$

$\mathrm{pCi} / \mathrm{L} \quad 0 \quad \mathrm{GP}$

$\mathrm{pCi} / \mathrm{L} \quad \mathrm{GP}$

$\mathrm{pCi} / \mathrm{L} \quad 0 \quad \mathrm{GP}$

$\overline{-}=$ exceeded holding time. $=$ exceeded screening level or final primary drinking water standard. 
WELL BGO 10B

\begin{tabular}{|c|c|c|c|c|c|c|}
\hline SRS Coord. & Lat/Longitude & Screen Zone Elevation & Top of Casing & Casing & Pump & Formation \\
\hline $\begin{array}{l}\text { N76982.1 } \\
\text { E56978.8 }\end{array}$ & $\begin{array}{l}33.289003^{\circ} \mathrm{N} \\
81.666300^{\circ} \mathrm{W}\end{array}$ & $149.0-139.0 \mathrm{ft} \mathrm{msl}$ & $301 \mathrm{ft} \mathrm{msl}$ & 4" PVC & $\mathbf{S}$ & $\left(\| B_{1}\right)$ \\
\hline
\end{tabular}

\section{FIELD MEASUREMENTS}

Sample date: $01 / 26 / 94$

Depth to water: $80.75 \mathrm{ft}(24.61 \mathrm{mi}$ below TOC

Water elevation: $220.25 \mathrm{ft}(67.13 \mathrm{~m}) \mathrm{msl}$

Sp. conductance: $215 \mu \mathrm{S} / \mathrm{cm}$

Turbidity: 0.9 NTU

Water evacuated before sampling: $49 \mathrm{gal}$

The well went dry during purging.

\section{LABORATORY ANALYSES}

\section{H D Analyte}

- $\mathrm{pH}$

Specific conductance

Turbidity

Acetophenone

Aldrin

Aldrin

Aluminum, total recoverable

Aluminum, total recoverable

Antimony, total recoverable

Arsenic, total recoverable

Barium, total recoverable

Barium, total recoverable

Benzene

Bromodichloromethane

Bromoform

Bromomethane (Methyl bromide)

Cadmium, total recoverable

Cadmium, total recoverable

Calcium, total recoverable

Calcium, total recoverable

Carbon tetrachloride

Chloride

Chlorobenzene

Chloroethane

Chloroethene (Vinyl chloride)

2-Chloroethyl vinyl ether

Chloroform

Chloromethane (Methyl chloride)

Chromium, total recoverable

Chromium, total recoverable

Copper, total recoverable

Copper, total recoverable

Cyanide

$p, p^{\prime}-D D T$

$p, p^{\prime}-D D T$

Dibromochloromethane

1,1-Dichloroethane

1,2-Dichloroethane

1,1-Dichloroethylene
Time: 9: 08

$\mathrm{pH}: \mathbf{8 . 3}$

Alkalinity: $82 \mathrm{mg} / \mathrm{L}$

Water temperature: $16.9^{\circ} \mathrm{C}$

Volumes purged: 0.9 well volumes

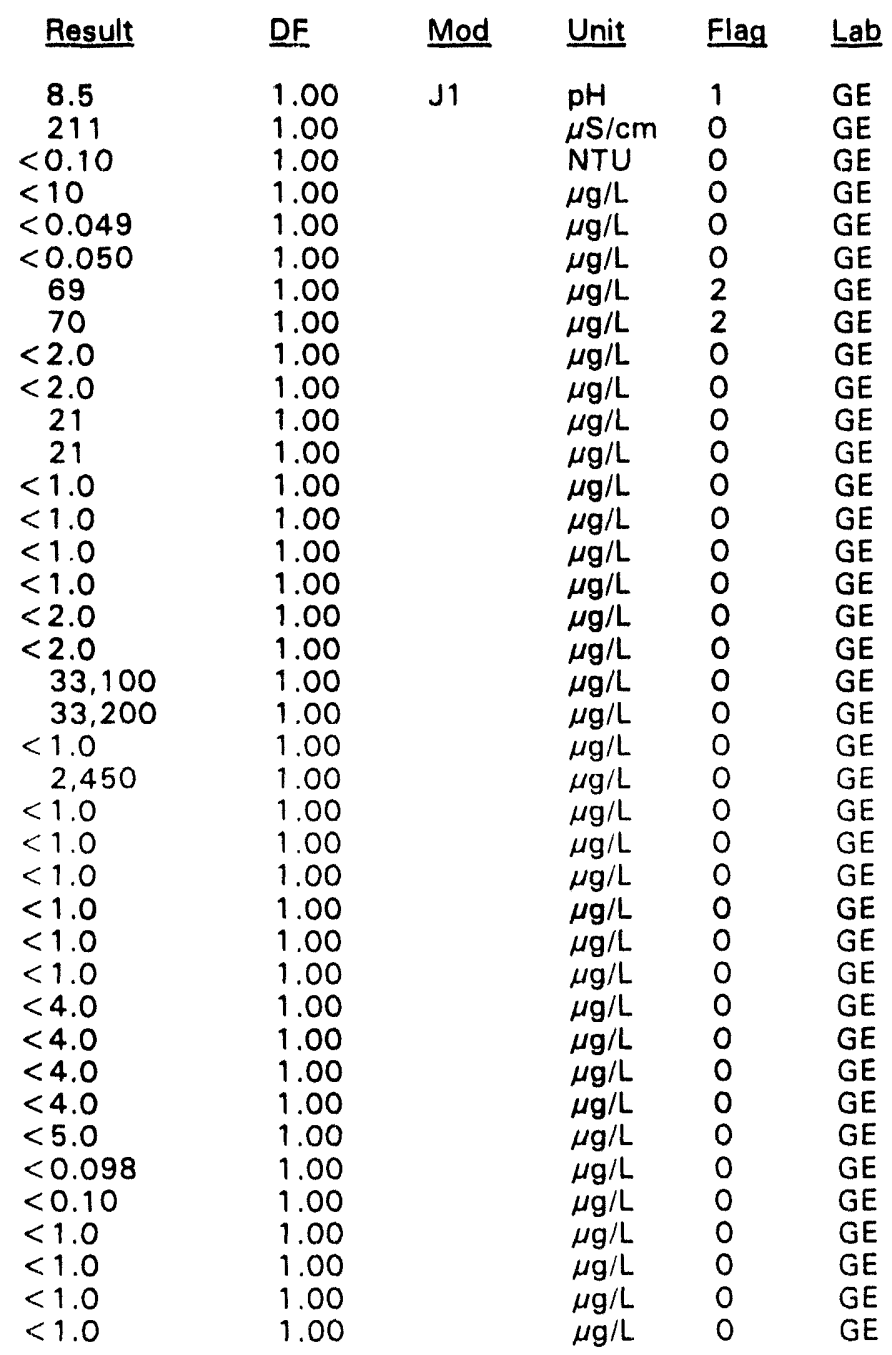

\footnotetext{
- = exceeded holding time. $=$ exceeded screening level or final primary drinking water standard.
} 
WELL BGO 10B collected on 01/26/94, laboratory analyses (cont.)

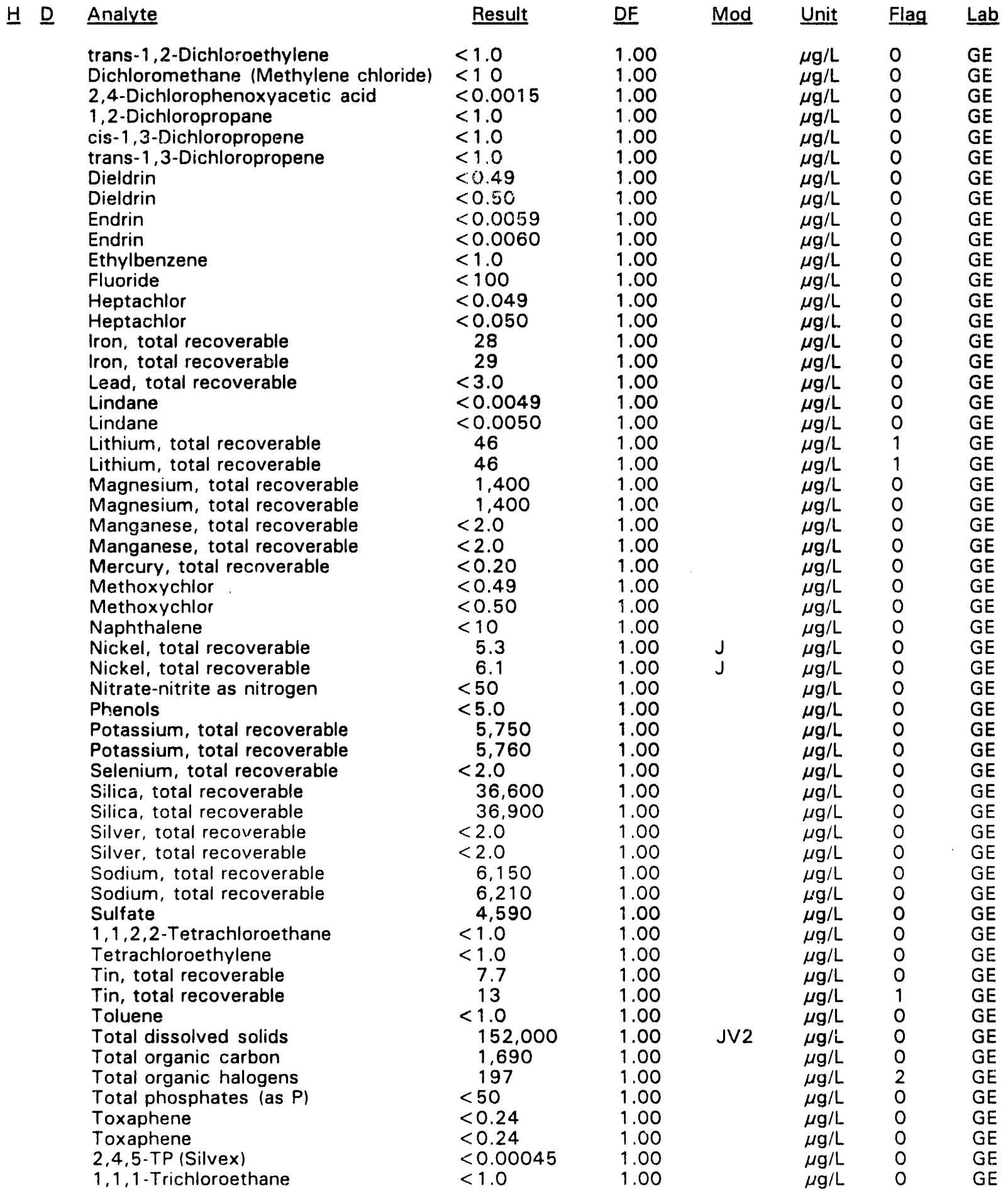

\footnotetext{
- =xceeded holding time. = exceeded screening level or final primary drinking water standard.
} 
WELL BGO $10 B$ collected on $01 / 26 / 94$, laboratory analyses (cont.)

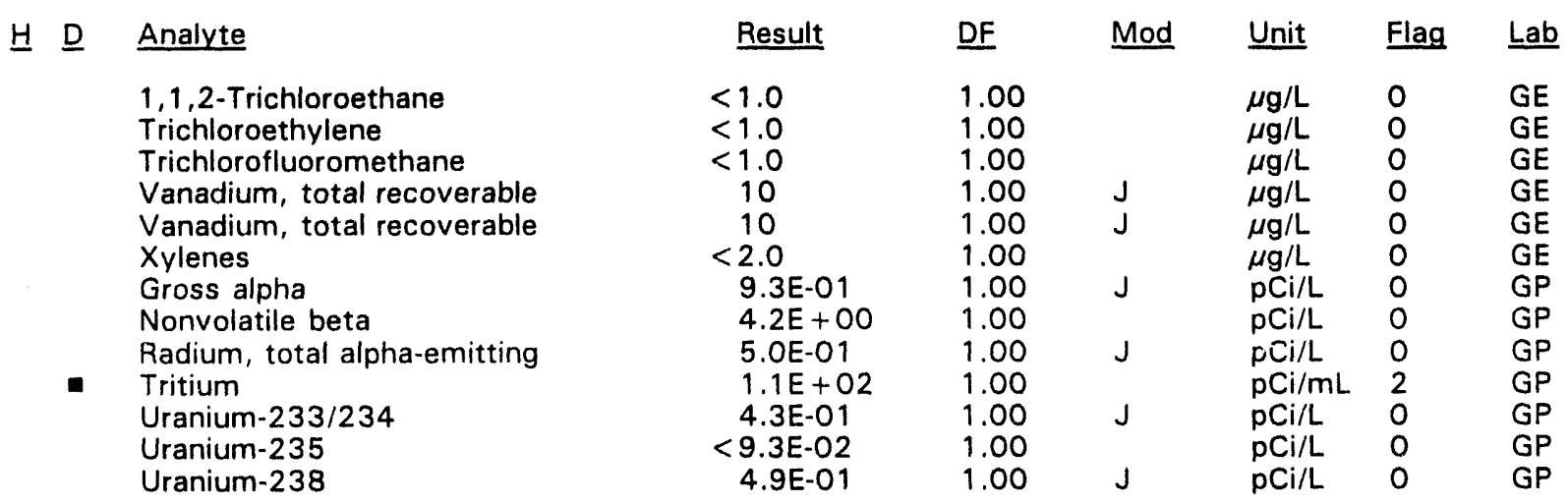

\section{WELL BGO 10C}

\begin{tabular}{|c|c|c|c|c|c|c|}
\hline SRS Coord. & Lat/Longitude & Screen Zone Elevation & Top of Casing & Casing & Pump & Formation \\
\hline $\begin{array}{l}N 76805.2 \\
E 57041.1\end{array}$ & $\begin{array}{l}33.288713^{\circ} \mathrm{N} \\
81.665792^{\circ} \mathrm{W}\end{array}$ & $167.3-157.3 \mathrm{ft} \mathrm{msl}$ & $301.3 \mathrm{ft} \mathrm{msl}$ & 4" PVC & $\mathrm{S}$ & ell (IIB, ) \\
\hline
\end{tabular}

\section{FIELD MEASUREMENTS}

Sample date: $01 / 26 / 94$

Depth to water: $80.33 \mathrm{ft}(24.48 \mathrm{~m})$ below TOC

Water elevation: $220.97 \mathrm{ft}(67.35 \mathrm{~m}) \mathrm{msl}$

Sp. conductance: $108 \mu \mathrm{S} / \mathrm{cm}$

Turbidity: 23.6 NTU

Water evacuated before sampling: $39 \mathrm{gal}$

The well went dry during purging.

\section{L.ABORATORY ANALYSES}

\section{H D Analyte}

- $\mathrm{pH}$

Specific conductance
Turbidity

Acetophenone

Aldrin

Aluminum, total recoverable

Antimony, total recoverable

Antimony, total recoverable

Arsenic, total recoverable

Arsenic, total recoverable

Barium, total recoverable

Benzene

Benzene

Bromodichloromethane

Bromodichloromethane

Bromoform

Bromoform

Bromomethane (Methyl bromide)

Bromomethane (Methyl bromide)

Cadmium, total recoverable

Calcium, total recoverable
Time: $9: 51$

pH: 9.8

Alkalinity: $21 \mathrm{mg} / \mathrm{L}$

Water temperature: $18.1^{\circ} \mathrm{C}$

Volumes purged: 0.9 well volumes

$\begin{array}{llllll}\text { Result } & \text { DF } & \text { Mod } & \text { Unit } & \text { Flag } & \text { Lab } \\ 9.5 & 1.00 & \mathrm{~J} 1 & \mu \mathrm{pH} & 1 & \mathrm{GE} \\ 83 & 1.00 & & \mu \mathrm{S} / \mathrm{cm} & 0 & \mathrm{GE} \\ 39 & 1.00 & & \mathrm{NTU} & 0 & \mathrm{GE} \\ <10 & 1.00 & & \mu \mathrm{g} / \mathrm{L} & 0 & \mathrm{GE} \\ <0.050 & 1.00 & & \mu \mathrm{g} / \mathrm{L} & 0 & \mathrm{GE} \\ 266 & 1.00 & & \mu \mathrm{g} / \mathrm{L} & 2 & \mathrm{GE} \\ <2.0 & 1.00 & & \mu \mathrm{g} / \mathrm{L} & 0 & \mathrm{GE} \\ <2.0 & 1.00 & & \mu \mathrm{g} / \mathrm{L} & 0 & \mathrm{GE} \\ <2.0 & 1.00 & & \mu \mathrm{g} / \mathrm{L} & 0 & \mathrm{GE} \\ <2.0 & 1.00 & & \mu \mathrm{g} / \mathrm{L} & 0 & \mathrm{GE} \\ 69 & 1.00 & & \mu \mathrm{g} / \mathrm{L} & 0 & \mathrm{GE} \\ <1.0 & 1.00 & & \mu \mathrm{g} / \mathrm{L} & 0 & \mathrm{GE} \\ <1.0 & 1.00 & & \mu \mathrm{g} / \mathrm{L} & 0 & \mathrm{GE} \\ <1.0 & 1.00 & & \mu \mathrm{g} / \mathrm{L} & 0 & \mathrm{GE} \\ <1.0 & 1.00 & & \mu \mathrm{g} / \mathrm{L} & 0 & \mathrm{GE} \\ <1.0 & 1.00 & & \mu \mathrm{g} / \mathrm{L} & 0 & \mathrm{GE} \\ <1.0 & 1.00 & & \mu \mathrm{g} / \mathrm{L} & 0 & \mathrm{GE} \\ <1.0 & 1.00 & & \mu \mathrm{g} / \mathrm{L} & 0 & \mathrm{GE} \\ <1.0 & 1.00 & & \mu \mathrm{g} / \mathrm{L} & 0 & \mathrm{GE} \\ <2.0 & 1.00 & & \mu \mathrm{g} / \mathrm{L} & 0 & \mathrm{GE} \\ 23,300 & 1.00 & & \mu \mathrm{g} / \mathrm{L} & 0 & \mathrm{GE}\end{array}$

- = exceeded holding time. = exceeded screening level or final primary drinking water standard. 
WELL BGO $10 \mathrm{C}$ collected on 01/26/94, laboratory analyses (cont.)

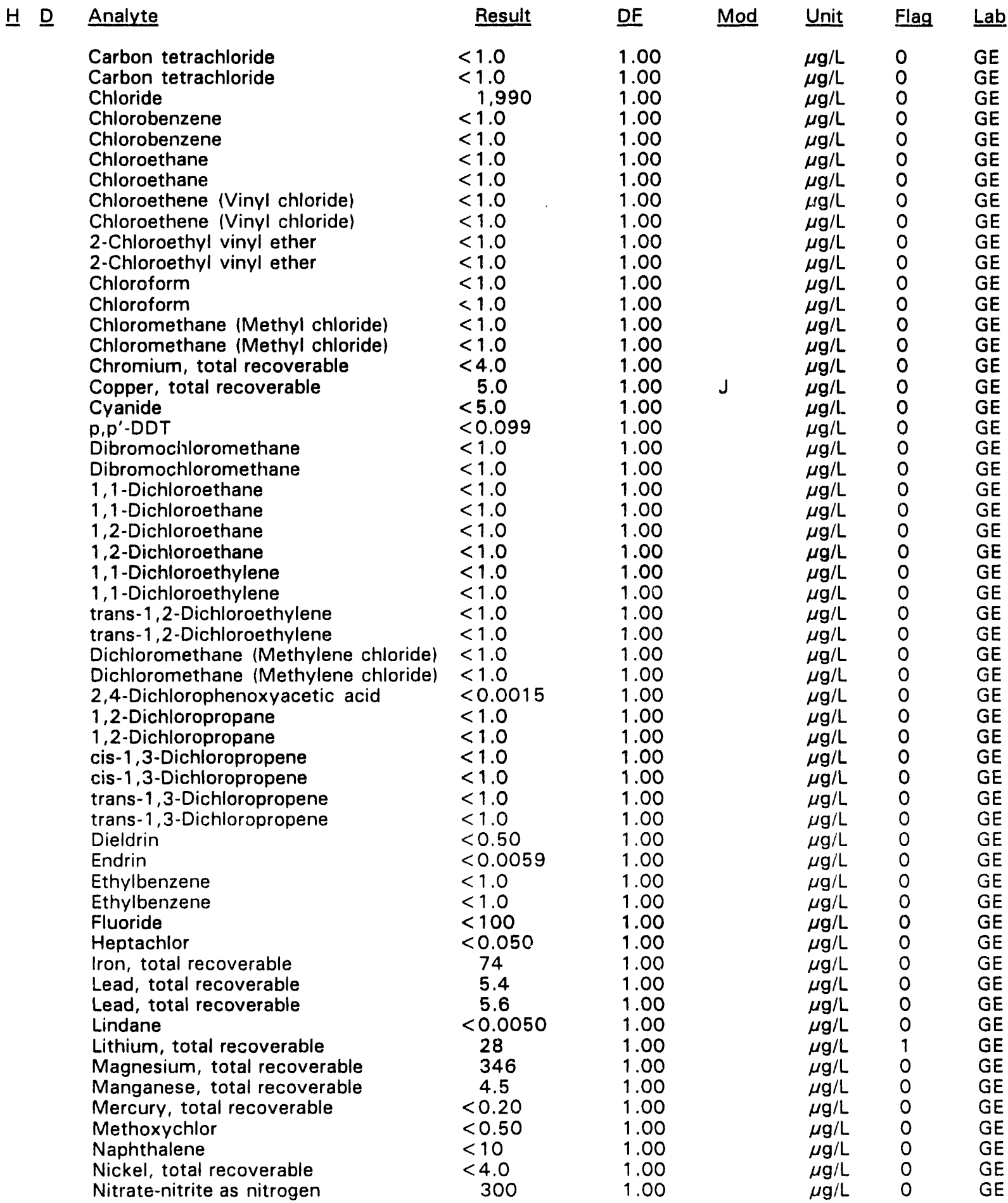

\footnotetext{
$\overline{0}=$ exceeded holding time. = exceeded screening level or final primary drinking water standard.
} 
WELL BGO $10 \mathrm{C}$ collected on 01/26/94, laboratory analyses (cont.)

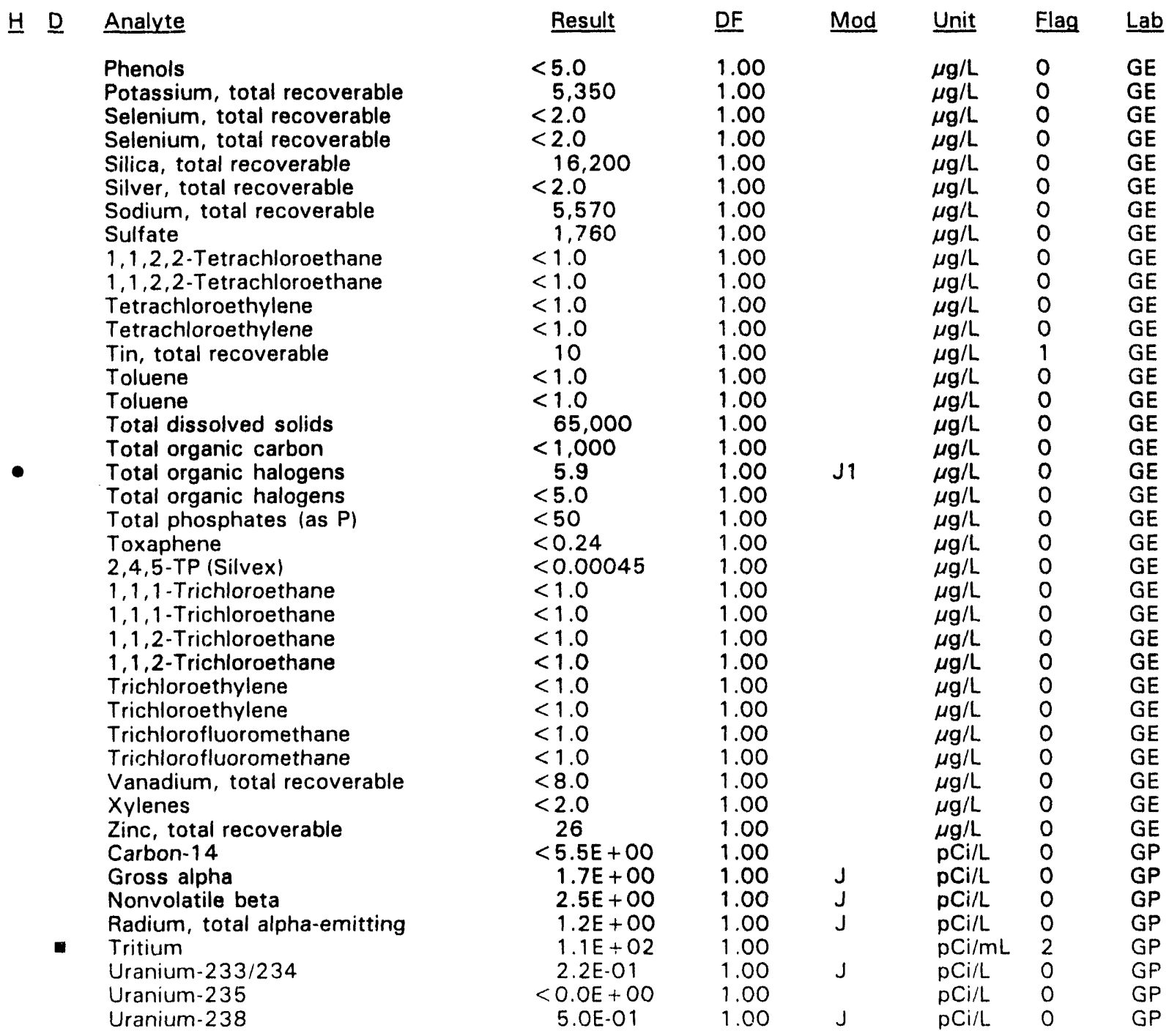

$\overline{\bullet=}$ exceeded holding time. $\boldsymbol{\square}=$ exceeded screening level or final primary drinking water standard. 
WSRC-TR-94-0240

Unclassified

\section{WELL BGO 10DR}

$\begin{array}{lllllll}\text { SRS Coord. } & \text { Lat/Longitude } & \text { Screen Zone Elevation } & \text { Top of Casing } & \text { Casing } & \text { Pump } & \text { Formation } \\ \text { iN76804.8 } & 33.288765^{\circ} \mathrm{N} & 238.3-218.3 \mathrm{ft} \mathrm{msl} & 300.4 \mathrm{ft} \mathrm{msl} & \text { 4" PVC } & \text { S } & \left.\text { Water Table (IIB }{ }_{2}\right) \\ \text { E57073.7 } & 81.665706^{\circ} \mathrm{W} & & & \end{array}$

FIELD MEASUREMENTS

Sample date: $01 / 26 / 94$

Depth to water: $68.04 \mathrm{ft}(20.74 \mathrm{~m})$ below TOC

Water elevation: $232.36 \mathrm{ft}(70.82 \mathrm{~m}) \mathrm{msl}$

Sp. conductance: $89 \mu \mathrm{S} / \mathrm{cm}$

Turbidity: 38.4 NTU

Water evacuated before sampling: $3 \mathrm{gal}$

The well went dry during purging.

\section{LABORATORY ANALYSES}

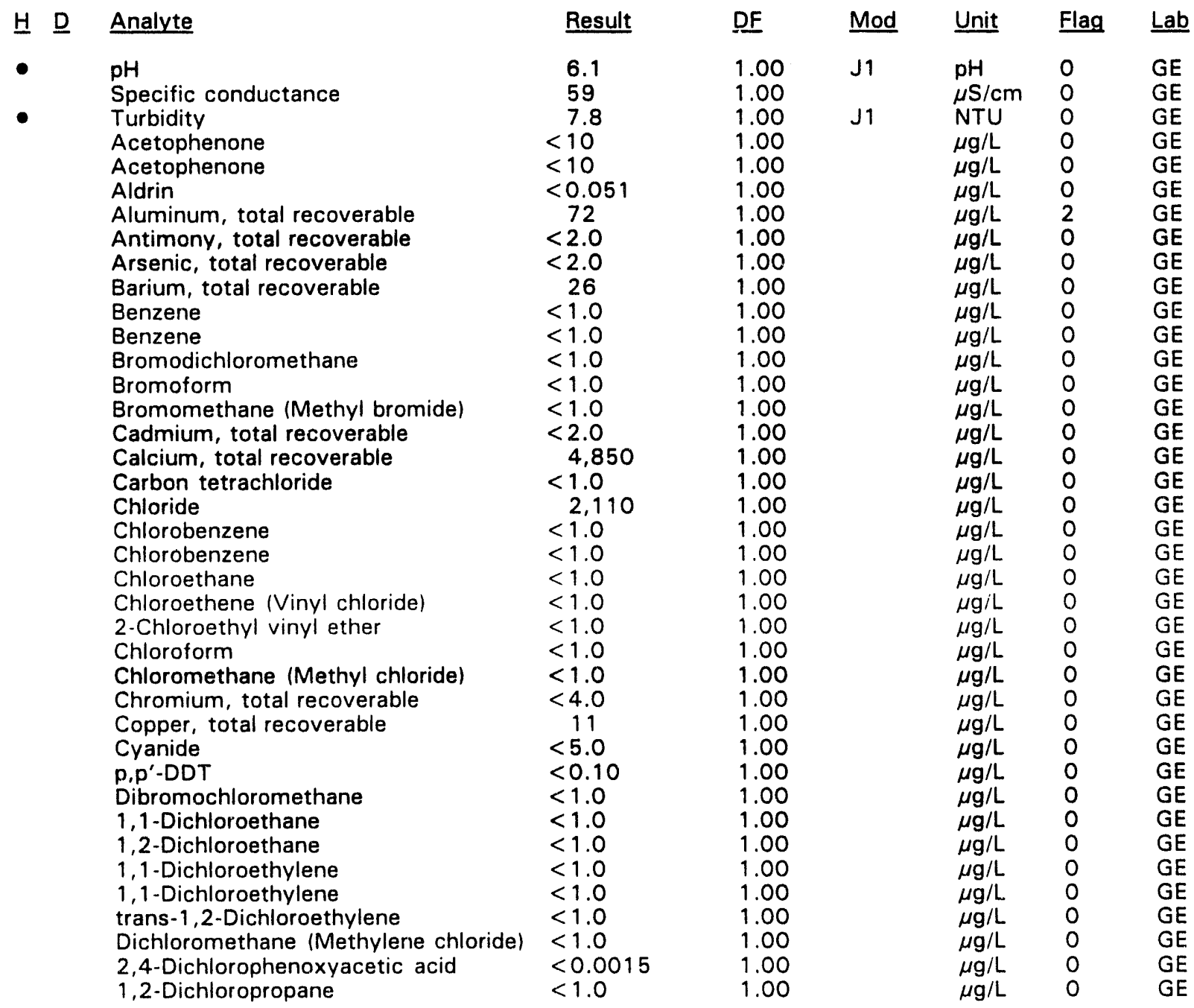

\footnotetext{
- = exceeded holding time. - = exceeded screening level or final primary drinking water standard.
}

Time: 10: 12

$\mathrm{pH}: 6.0$

Alkalinity: $30 \mathrm{mg} / \mathrm{L}$

Volumes purged: 0.3 well volumes 
WELL BGO 10DR collected on 01/26/94, laboratory analyses (cont.)

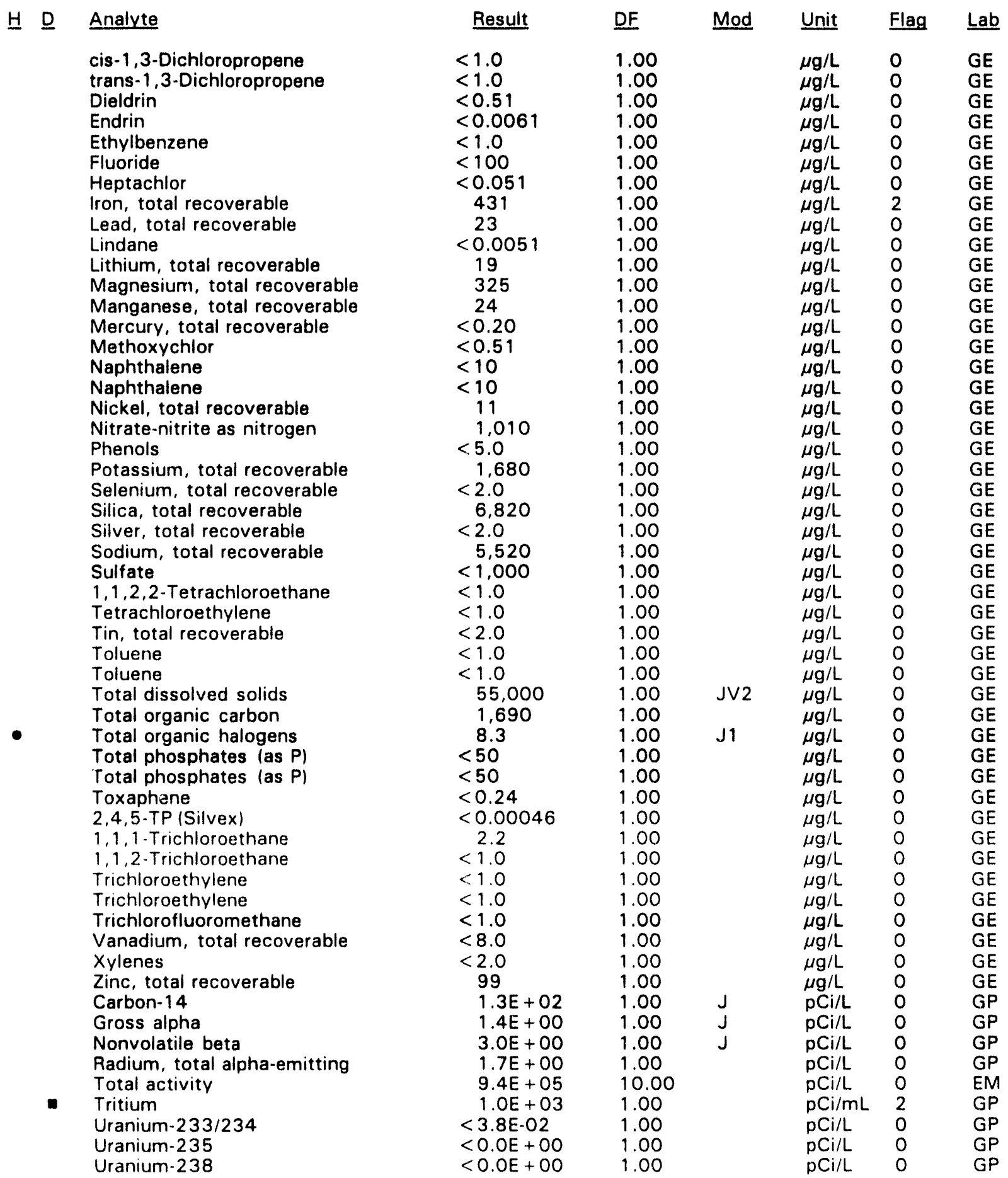

$\overline{-}=$ exceeded holding time. $\|=$ exceeded screening level or final primary drinking water standard. 


\section{WELL BGO 11D}

\begin{tabular}{|c|c|c|c|c|c|c|}
\hline RS Coord. & Lat/Longitude & Screen Zone Elevation & Top of Casing & Casing & Pump & Formation \\
\hline 10 & $\begin{array}{l}33.288077^{\circ} \mathrm{N} \\
81.666819^{\circ} \mathrm{W}\end{array}$ & 23 & & & $\mathbf{S}$ & $W E$ \\
\hline
\end{tabular}

\section{FIELD MEASUREMENTS}

Sample date: 01/26/94

Depth to water: $81.16 \mathrm{ft}(24.74 \mathrm{~m})$ below TOC

Water elevation: $224.14 \mathrm{ft}(68.32 \mathrm{~m}) \mathrm{ms}$

Sp. conductance: $37 \mu \mathrm{S} / \mathrm{cm}$

Turbidity: 1.0 NTU

Water evacuated before sampling: $35 \mathrm{gal}$

\section{LABORATORY ANALYSES}

\begin{tabular}{|c|}
\hline \multirow[t]{2}{*}{ Analyte } \\
\hline \\
\hline \\
\hline \\
\hline \\
\hline \\
\hline \\
\hline \\
\hline \\
\hline \\
\hline Cadmium, total recoverable \\
\hline Calcium, total recoverable \\
\hline $\begin{array}{l}\text { Carbon tetrachloride } \\
\text { Chloride }\end{array}$ \\
\hline \\
\hline \\
\hline \\
\hline \\
\hline \\
\hline \\
\hline \\
\hline \\
\hline \\
\hline \\
\hline \\
\hline \\
\hline \\
\hline \\
\hline \\
\hline \\
\hline \\
\hline \\
\hline \\
\hline $\mathrm{pH}$ \\
\hline Specific conductance \\
\hline Turbidity \\
\hline Acetophenone \\
\hline Aldrin \\
\hline Antimiony, total recoverable \\
\hline Arsenic, total recoverable \\
\hline Barium, total recoverable \\
\hline Benzene \\
\hline Bromodichloromethane \\
\hline Bromoform \\
\hline Bromomethane (Methyl bromide) \\
\hline \\
\hline Carbon tetrachloride \\
\hline Chloride \\
\hline Chlorobenzene \\
\hline Chloroethane \\
\hline Chloroethene (Vinyl chloride) \\
\hline 2-Chloroethyl vinyl ether \\
\hline Chloroform \\
\hline Chloromethane (Methyl chloride) \\
\hline Chromium, total recoverable \\
\hline Copper, total recoverable \\
\hline Cyanide \\
\hline p,p'-DDT \\
\hline Dibromochloromethane \\
\hline 1, 1-Dichioroethane \\
\hline 1,1 -Dichloroethylene \\
\hline trans-1,2-Dichloroethylene \\
\hline Dichloromethane (Methylene chloride) \\
\hline 2,4-Dichlorophenoxyacetic acid \\
\hline 1,2-Dichloropropane \\
\hline $\begin{array}{l}\text { CIS-1, 3-Dichloropropene } \\
\text { trans-1, 3-Dichloropropene }\end{array}$ \\
\hline Dieldrin \\
\hline Endrin \\
\hline
\end{tabular}

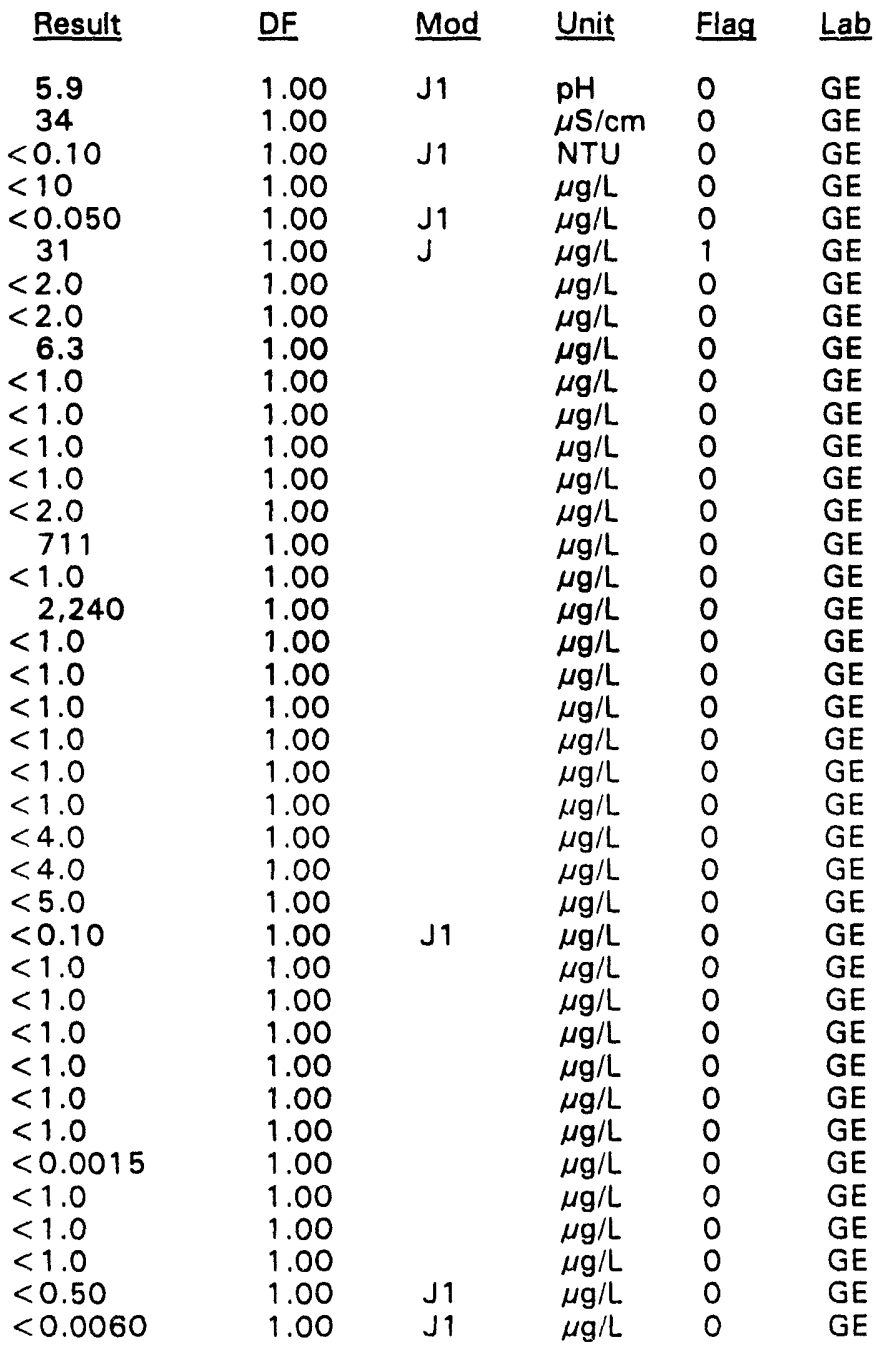

pH: 4.6

Alkalinity: $0 \mathrm{mg} / \mathrm{L}$

Water temperature: $19.9^{\circ} \mathrm{C}$

Volumes purged: 6.8 well volumes 
WELL BGO 110 collected on 01/26/94, laboratory analyses (cont.)

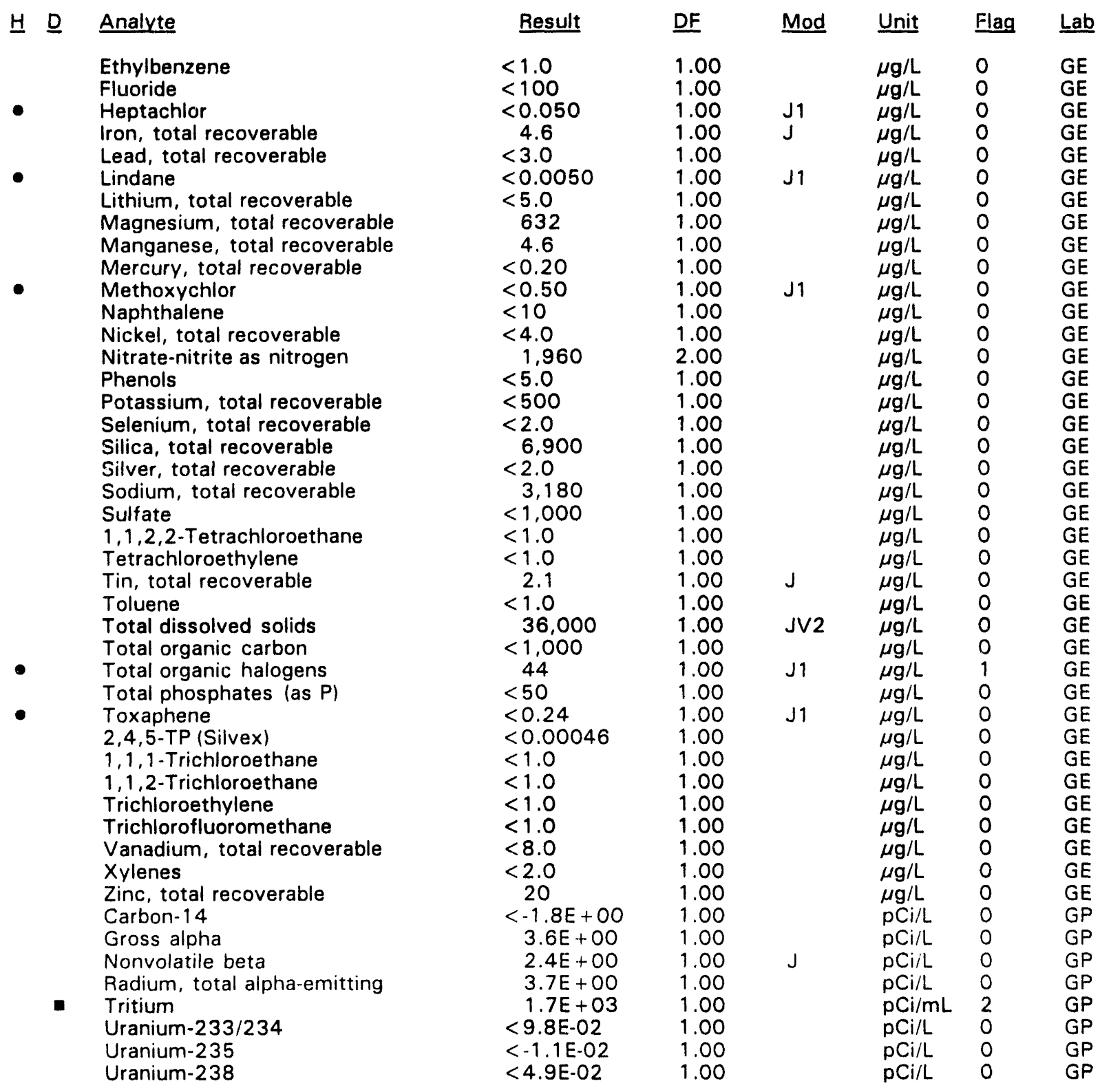

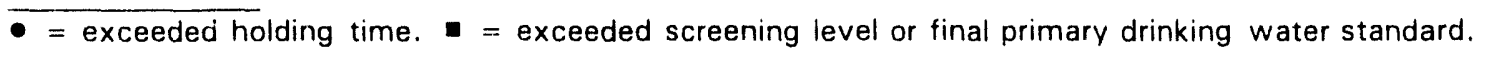


WELL BGO 12AR

\begin{tabular}{|c|c|c|c|c|c|c|}
\hline SRS Coord. & Lat/Longitude & Screen Zone Elevation & Top of Casing & Casing & Pump & Formation \\
\hline $\begin{array}{l}N 76803.8 \\
E 56209.9\end{array}$ & $\begin{array}{l}33.287435^{\circ} \mathrm{N} \\
81.667847^{\circ} \mathrm{W}\end{array}$ & $109.3-99.3 \mathrm{ft} \mathrm{msl}$ & $313.4 \mathrm{ft} \mathrm{msl}$ & 4" PVC & $\mathbf{s}$ & aree (IIA) \\
\hline
\end{tabular}

\section{FIELD MEASUREMENTS}

Sample date: $01 / 26 / 94$

Depth to water: $156.09 \mathrm{ft}(47.58 \mathrm{~m})$ below TOC

Water elevation: $157.31 \mathrm{ft}(47.95 \mathrm{~m}) \mathrm{msl}$

Sp. conductance: $171 \mu \mathrm{S} / \mathrm{cm}$

Turbidity: 0.1 NTU

Water evacuated before sampling: $205 \mathrm{gal}$

\section{LABORATORY ANALYSES}

H $\underline{\text { Analyte }}$

$\mathrm{pH}$

Specific conductance

Turbidity

Turbidity

Acetophenone

Aldrin

Aluminum, total recoverable

Aluminum, total recoverable

Antimony, total recoverable

Arsenic, total recoverable

Barium, total recoverable

Barium, total recoverable

Benzene

Bromodichloromethane

Bromoform

Bromomethane (Methyl bromide)

Cadmium, total recoverable

Cadmium, total recoverable

Calcium, total recoverable

Calcium, total recoverable

Carbon tetrachloride

Chloride

Chlorobenzene

Chloroethane

Chloroethene (Vinyl chloride)

2-Chloroethyl vinyl ether

Chloroform

Chloromethane (Methyl chloride)

Chromium, total recoverable

Chromium, total recoverable

Copper, total recoverable

Copper, total recoverable

Cyanide

$p, p^{\prime}$-DDT

Dibromochloromethane

1.1-Dichloroethane

1,2-Dichloroethane

1,1-Dichloroethylene

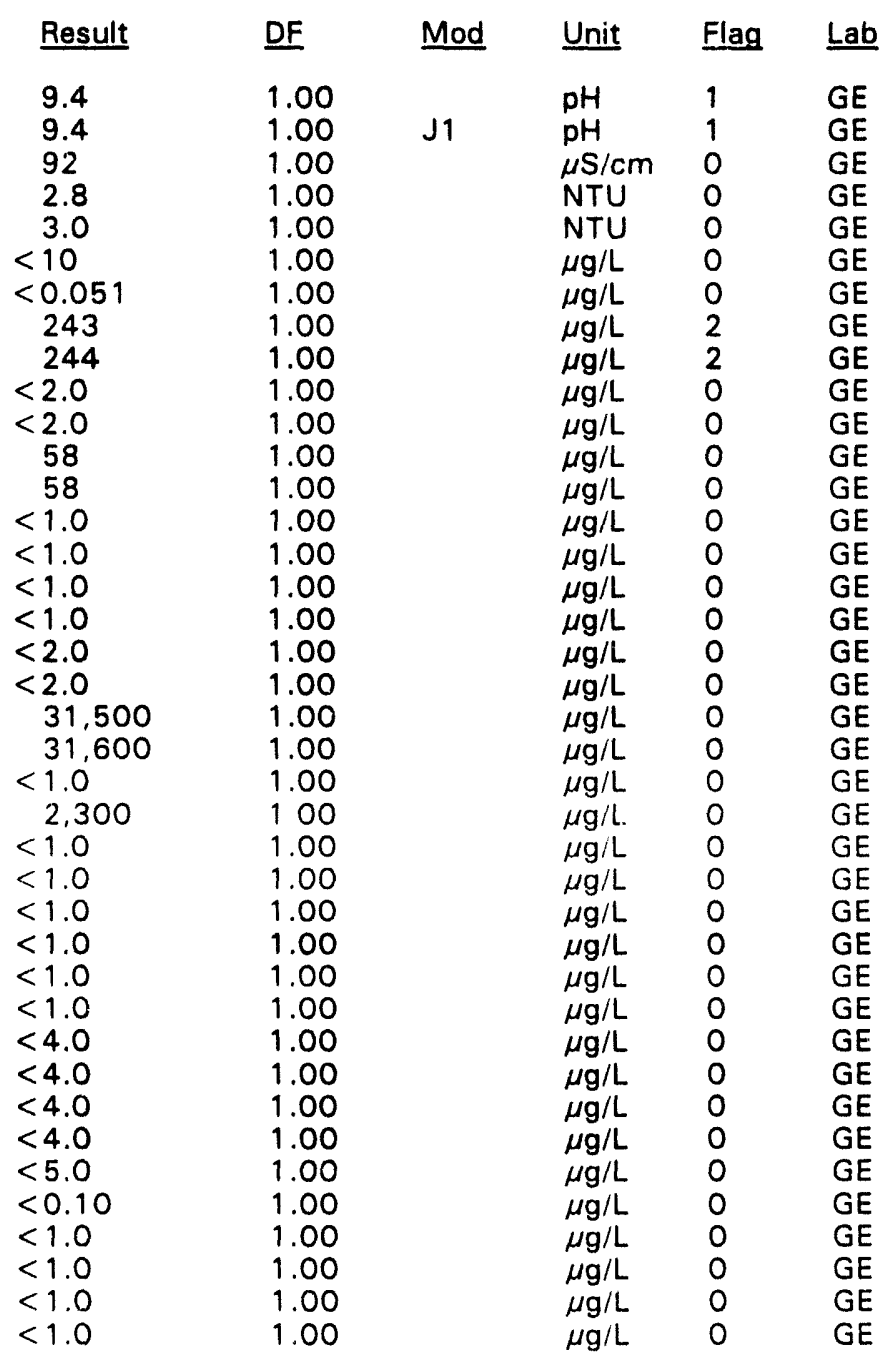

Time: $11: 52$

pH: 9.9

Alkalinity: $67 \mathrm{mg} / \mathrm{L}$

Water temperature: $19.8^{\circ} \mathrm{C}$

Volumes purged: 5.4 well volumes 
WELL BGO $12 A R$ collected on 01/26/94, laboratory analyses (cont.)

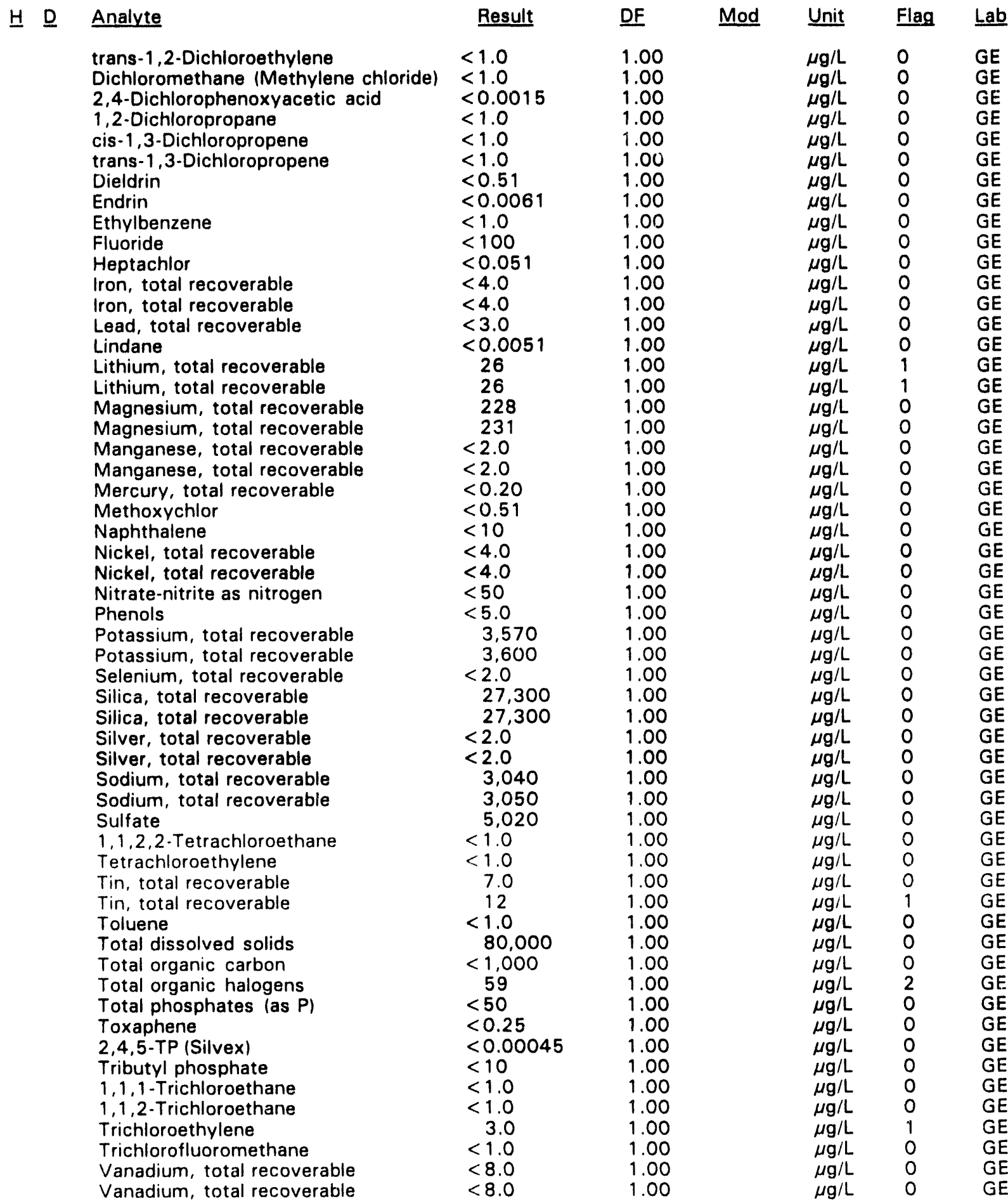

\footnotetext{
- = exceeded holding time. = exceeded screening level or final primary drinking water standard.
} 
WELL BGO $12 A R$ collected on $01 / 26 / 94$, laboratory analyses (cont.)

H D Analyte

\section{Xylenes}

Zinc, total recoverable

Zinc, total recoverable

Carbon-14

Gross alpha

Nonvolatile beta

Radium, total alpha-emitting

Tritium

Uranium-233/234

Uranium-235

Uranium-238

\begin{tabular}{ll}
\multicolumn{1}{l}{ Result } & DF \\
$<2.0$ & \\
18 & 1.00 \\
18 & 1.00 \\
$<5.4 E+00$ & 1.00 \\
$5.9 E-01$ & 1.00 \\
$2.6 E+00$ & 1.00 \\
$1.0 E+00$ & 1.00 \\
$<1.1 E-01$ & 1.00 \\
$2.7 E-01$ & 1.00 \\
$<0.0 E+00$ & 1.00 \\
$<8.4 E-02$ & 1.00
\end{tabular}

Mod

Unit

Flag Lab

$\begin{array}{llll} & \mu g / L & 0 & \text { GE } \\ & \mu g / L & 0 & \text { GE } \\ & \mu \mathrm{g} / \mathrm{L} & 0 & \mathrm{GE} \\ & \mathrm{pCi} / \mathrm{L} & 0 & \mathrm{GP} \\ \mathrm{j} & \mathrm{pCi} / \mathrm{L} & 0 & \mathrm{GP} \\ \mathrm{J} & \mathrm{pCi} / \mathrm{L} & 0 & \mathrm{GP} \\ \mathrm{J} V 2 & \mathrm{pCi} / \mathrm{L} & 0 & \mathrm{GP} \\ & \mathrm{pCi} / \mathrm{mL} & 0 & \mathrm{GP} \\ \mathrm{J} & \mathrm{pCi} / \mathrm{L} & 0 & \mathrm{GP} \\ & \mathrm{pCi} / \mathrm{L} & 0 & \mathrm{GP} \\ & \mathrm{pCi} / \mathrm{L} & 0 & \mathrm{GP}\end{array}$

\section{WELL BGO 12CR}

\begin{tabular}{|c|c|c|c|c|c|c|}
\hline SRS Coord. & Lat/Longitude & Screen Zone Elevation & Top of Casing & Casing & Pump & Formation \\
\hline $\begin{array}{l}N 76806.0 \\
E 56215.2\end{array}$ & $\begin{array}{l}33.287367^{\circ} \mathrm{N} \\
81.667969^{\circ} \mathrm{W}\end{array}$ & $154.0-144.0 \mathrm{ft} \mathrm{msl}$ & $314 \mathrm{ft} \mathrm{msl}$ & 4" PVC & $\mathbf{S}$ & $\|\left(\| B_{1}\right)$ \\
\hline
\end{tabular}

\section{FIELD MEASUREMENTS}

Sample date: 01/26/94

Depth to water: $92.27 \mathrm{ft}(28.12 \mathrm{~m})$ below TOC

Water elevation: $221.73 \mathrm{ft}(67.58 \mathrm{~m}) \mathrm{msl}$

Sp. conductance: $112 \mu \mathrm{S} / \mathrm{cm}$

Turbidity: 1.3 NTU

Water evacuated before sampling: $43 \mathrm{gal}$

The well went dry during purging.

\section{LABORATORY ANALYSES}

$\begin{array}{ll}\text { H. } & \text { Analyte } \\ \text { pH } & \\ \text { Specific conductance } \\ \text { Turbidity } \\ \text { Acetophenone } \\ \text { Aldrin } \\ \text { Aluminum, total recoverable } \\ \text { Aluminum, total recoverable } \\ \text { Antimony, total recoverable } \\ \text { Arsenic, total recoverable } \\ \text { Barium, total recoverable } \\ \text { Barium, total recoverable } \\ \text { Benzene } \\ \text { Bromodichloromethane } \\ \text { Bromoform } \\ \text { Bromomethane (Methyl bromide) } \\ \text { Cadmium, total recoverable } \\ \text { Cadmium, total recoverable } \\ \text { Calcium, total recoverable } \\ \text { Calcium, total recoverable } \\ \text { Carbon tetrachloride } \\ \text { Chloride } \\ \text { Chlorobenzene } \\ \text { Chloroethane }\end{array}$

Time: $11: 27$

$\mathrm{pH}: 9.7$

Alkalinity: $37 \mathrm{mg} / \mathrm{L}$

Water temperature: $18.6{ }^{\circ} \mathrm{C}$

Volumes purged: 0.8 well volumes

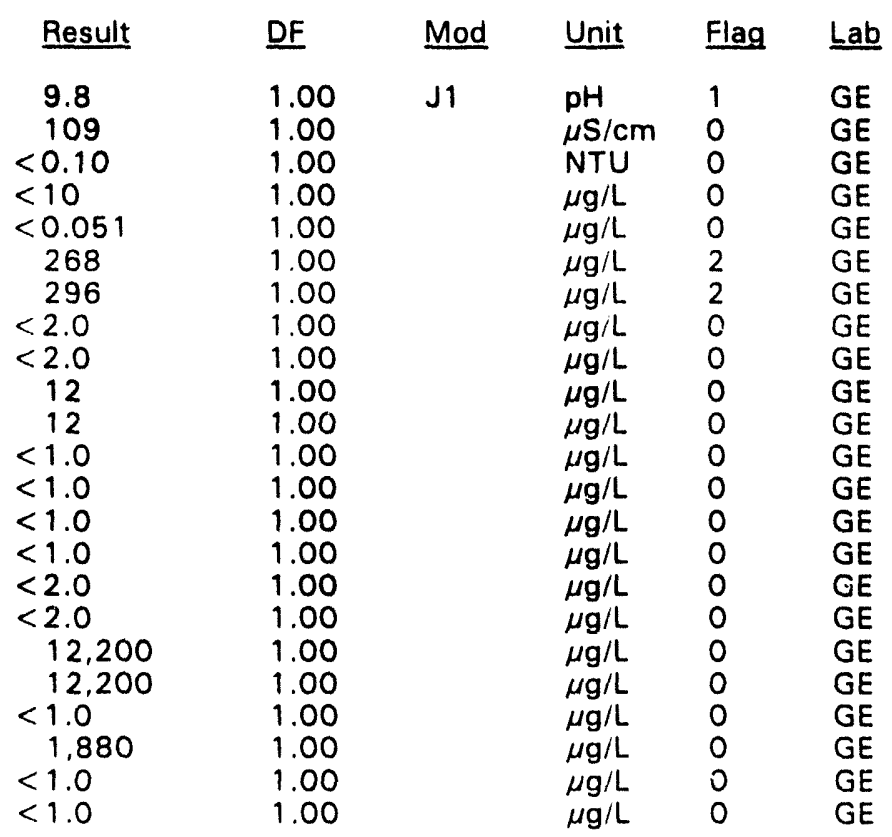

- = exceeded holding time. $\mathbf{a}=$ exceeded screening level or final primary drinking water standard. 
WELL BGO 12CR collected on 01/26/94, laboratory analyses (cont.)

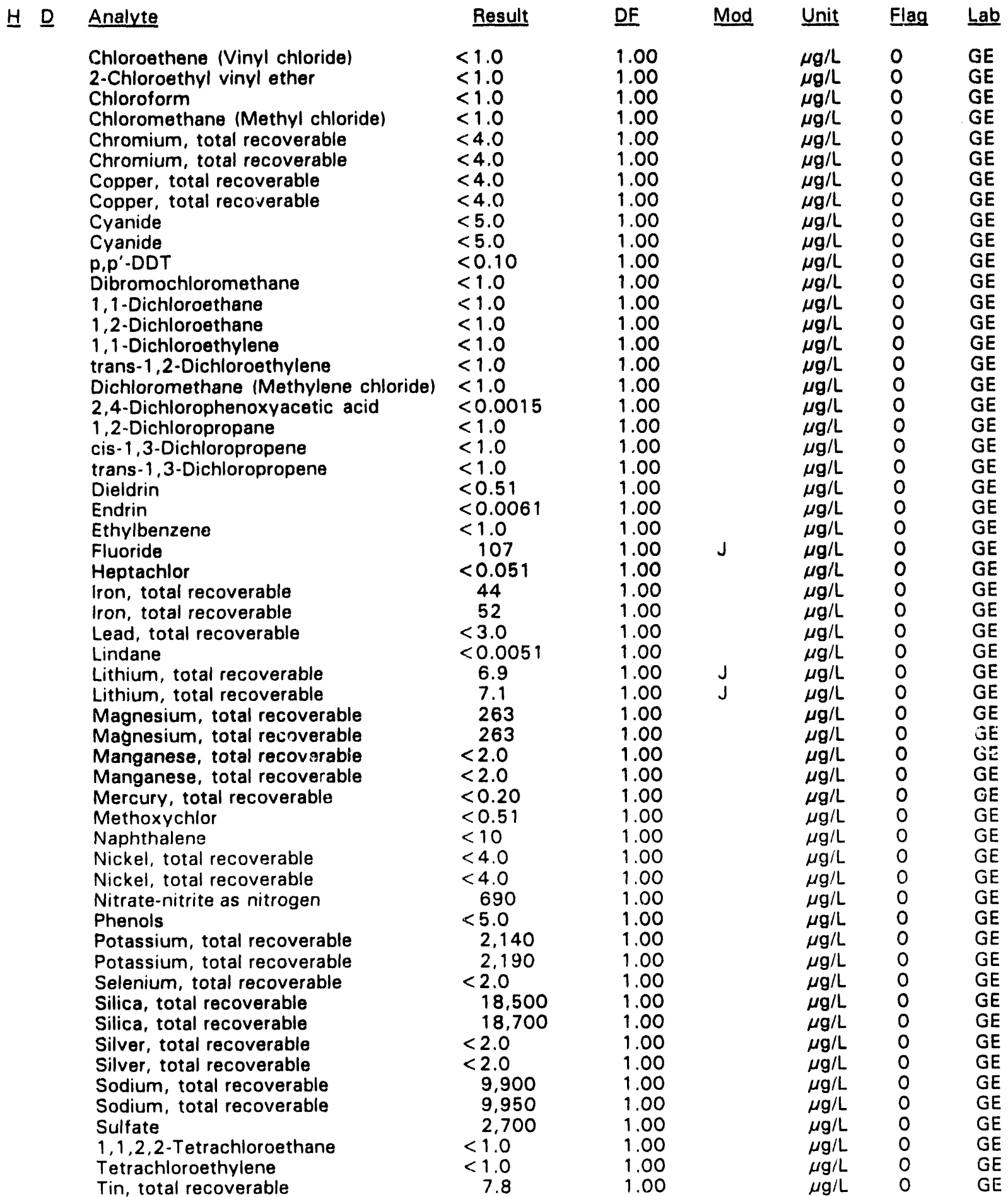

= exceeded holding time. = exceeded screening level or final primary drinking water standard. 
WELL BGO 12 CR collected on 01/26/94, laboratory analyses (cont.)

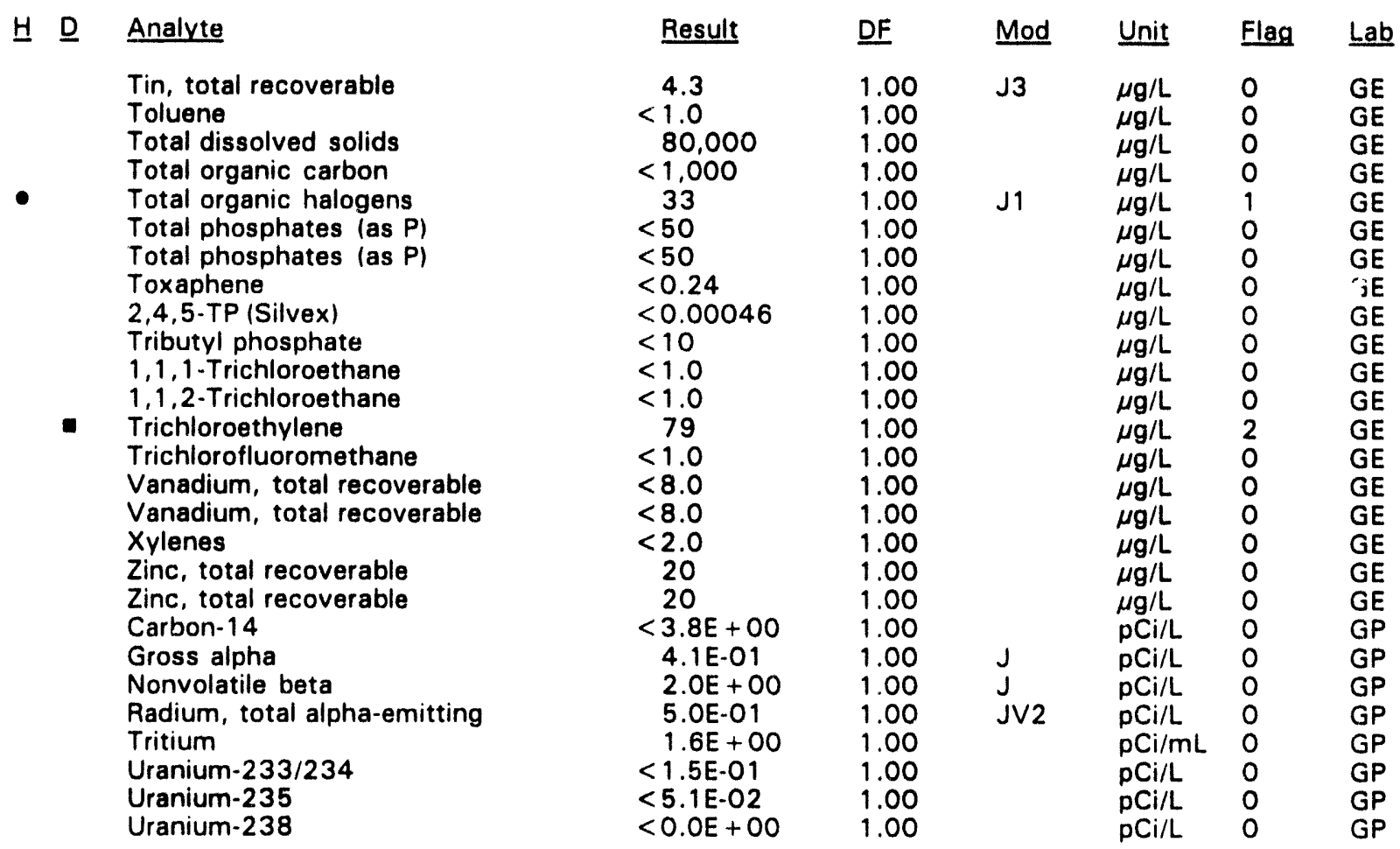

WELL BGO 12D

\begin{tabular}{|c|c|c|c|c|c|c|}
\hline SRS Coord. & Lat/Longitude & Screen Zone Elevation & Top of Casing & Casing & Pump & Formation \\
\hline $\begin{array}{l}N 76805.2 \\
E 56231.1\end{array}$ & $\begin{array}{l}33.287391^{\circ} \mathrm{N} \\
81.667925^{\circ} \mathrm{W}\end{array}$ & $237.8-217.8 \mathrm{ft} \mathrm{msl}$ & $313.7 \mathrm{ft} \mathrm{msl}$ & 4" PVC & $s$ & le $\left(I \mid B_{2}\right)$ \\
\hline
\end{tabular}

\section{FIELD MEASUREMENTS}

Sample date: $01 / 26 / 94$

Depth to water: $81.48 \mathrm{ft}(24.84 \mathrm{~m})$ below TOC

Water elevation: $232.22 \mathrm{ft}(70.78 \mathrm{~m}) \mathrm{msl}$

Sp. conductance: $70 \mu \mathrm{S} / \mathrm{cm}$

Turbidity: 4.8 NTU

Water evacuated before sampling: $4 \mathrm{gal}$

The well went dry during purging.

\section{LABORATORY ANALYSES}

\begin{tabular}{|c|c|c|c|c|c|}
\hline Analyte & Result & $\underline{D F}$ & Mod & Unit & Flag \\
\hline $\begin{array}{l}\mathrm{pH} \\
\mathrm{pH} \\
\text { Specific conductance } \\
\text { Turbidity } \\
\text { Turbidity } \\
\text { Acetophenone } \\
\text { Aldrin }\end{array}$ & $\begin{array}{l}6.6 \\
6.9 \\
68 \\
2.6 \\
2.7 \\
<9.7 \\
<0.050\end{array}$ & $\begin{array}{l}1.00 \\
1.00 \\
1.00 \\
1.00 \\
1.00 \\
1.00 \\
1.00\end{array}$ & J1 & $\begin{array}{l}\mathrm{pH} \\
\mathrm{pH} \\
\mu \mathrm{S} / \mathrm{cm} \\
\mathrm{NTU} \\
\mathrm{NTU} \\
\mu \mathrm{g} / \mathrm{L} \\
\mu \mathrm{g} / \mathrm{L}\end{array}$ & $\begin{array}{l}0 \\
0 \\
0 \\
0 \\
0 \\
0 \\
0\end{array}$ \\
\hline
\end{tabular}

\footnotetext{
- = exceeded holding time. = exceeded screening level or final primary drinking water standard.
}

Time: $11: 10$

$\mathrm{pH}: 6.1$

Alkalinity: $15 \mathrm{mg} / \mathrm{L}$

Water temperature: $12.4^{\circ} \mathrm{C}$

Volumes purged: 0.4 well volumes 
WELL BGO 12D collected on 01/26/94, laboratory analyses (cont.)

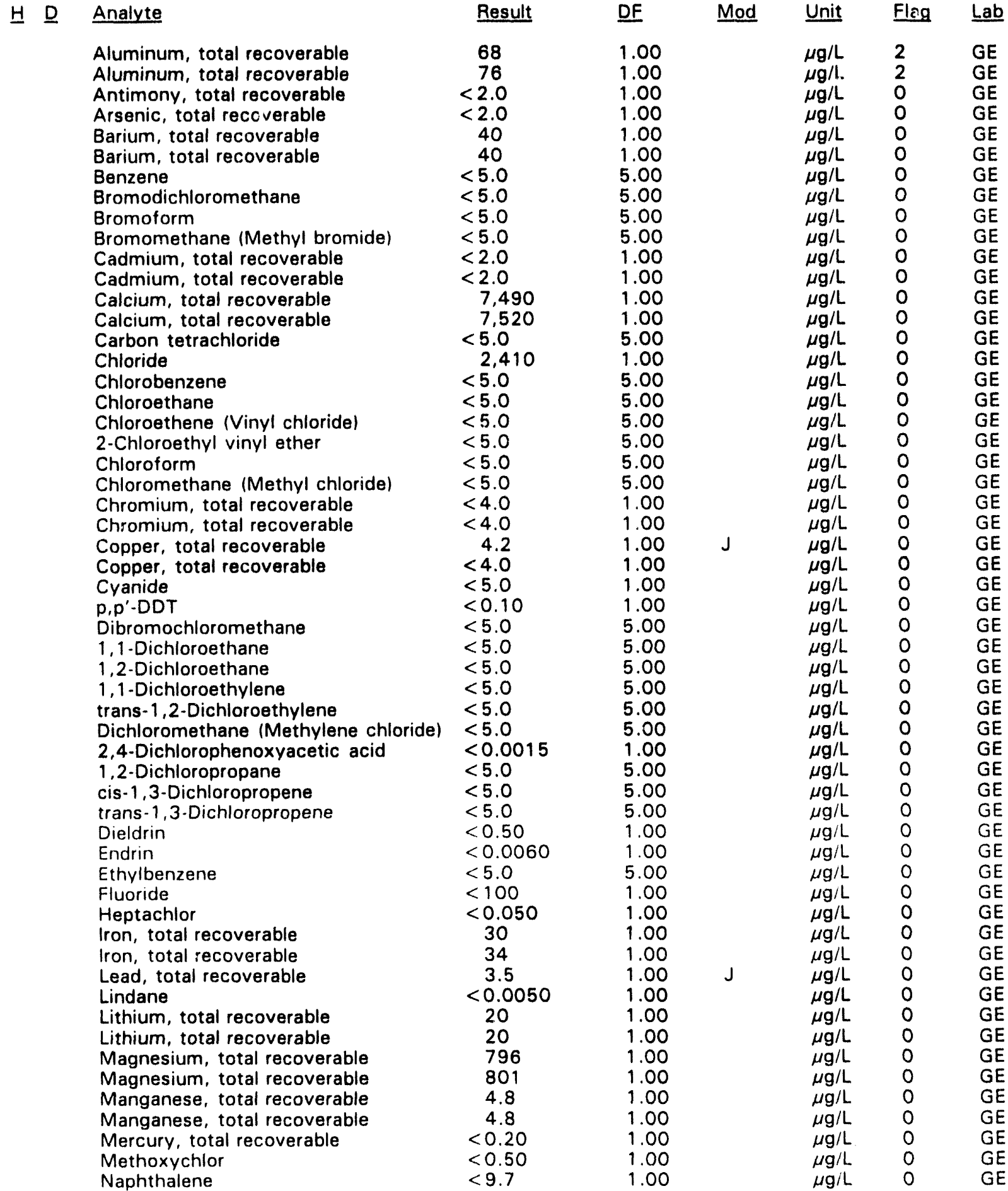

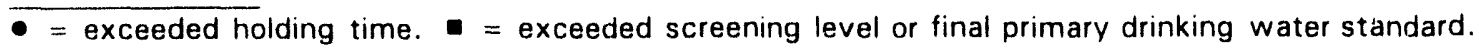


WELL BGO 120 collected on 01/26/94, laboratory analyses (cont.)

H $\underline{\text { Analyte }}$

Nickel, total recoverable

Nickel, total recoverable

Nitrate-nitrite as nitrogen

Phenols

Potassium, total recoverable

Potassium, total recoverable

Selenium, total recoverable

Silica, total recoverable

Silica, total recoverable

Silver, total recoverable

Silver, total recoverable

Sodium, total recoverable

Sodium, total recoverable

Sulfate

1,1,2,2-Tetrachloroethane

Tetrachloroethylene

Tin, total recoverable

Tin, total recoverable

Toluene

Total dissolved solids

Total organic carbon

Total organic halogens

Total phosphates (as P)

Toxaphene

2,4,5-TP (Silvex)

1,1,1-Trichloroethane

1,1,2-Trichloroethane

- Trichloroethylene

Trichlorofluoromethane

Vanadium, total recoverable

Vanadium, total recoverable

Xylenes

Zinc, total recoverable

Zinc, total recoverable

Carbon-14

Gross alpha

Nonvolatile beta

Radium, total alpha-emitting

- Tritium

Uranium-233/234

Uranium-235

Uranium-238
Result DF

$<4.0$

$<4.0$

1,480

$<5.0$

1,220

1,290

$<2.0$

6,680

6,690

$<2.0$

$<2.0$

2,980

2,990

1,500

$<5.0$

$<5.0$

2.6

3.2

$<5.0$

48,000

$<1,000$

105

$<50$

$<0.24$

$<0.00045$

$<5.0$

$<5.0$

127

$<5.0$

$<8.0$

$<8.0$

$<2.0$

29

29

1.7E + 01

2. $0 E+00$

$2.1 E+00$

$1.5 E+00$

$2.9 E+01$

$<0 . O E+00$

$<O . O E+O O$

$<-1.1 \mathrm{E}-02$

\section{DF}

1.00

1.00

1.00

1.00

1.00

1.00

1.00

1.00

1.00

1.00

1.00

1.00

1.00

1.00

5.00

5.00

1.00

1.00

5.00

1.00

1.00

1.00

1.00

1.00

1.00

5.00

5.00

5.00

5.00

1.00

1.00

1.00

1.00

1.00

1.00

1.00

1.00

1.00

1.00

1.00

1.00

1.00
Mod Unit Flag Lab

$\mu \mathrm{g} / \mathrm{L} \quad 0 \quad \mathrm{GE}$

$\mu \mathrm{g} / \mathrm{L} \quad \mathrm{O} \quad \mathrm{GE}$

$\mu \mathrm{g} / \mathrm{L} \quad 0 \quad \mathrm{GE}$

$\mu \mathrm{g} / \mathrm{L} \quad \mathrm{O} \quad \mathrm{GE}$

$\mu \mathrm{g} / \mathrm{L} \quad \mathrm{O} \quad \mathrm{GE}$

$\mu g / L \quad O \quad G E$

$\mu \mathrm{g} / \mathrm{L} \quad 0 \quad \mathrm{GE}$

$\mu \mathrm{g} / \mathrm{L} \quad 0 \quad \mathrm{GE}$

$\mu \mathrm{g} / \mathrm{L} \quad 0 \quad \mathrm{GE}$

$\mu g / L \quad 0 \quad G E$

$G E$

$\mu \mathrm{g} / \mathrm{L} \quad 0 \quad \mathrm{GE}$

$\mu \mathrm{g} / \mathrm{L} \quad 0 \quad \mathrm{GE}$

$\mu \mathrm{g} / \mathrm{L} \quad 0$

$\mu \mathrm{g} / \mathrm{L} \quad \mathrm{O} \quad \mathrm{GE}$

$\mu \mathrm{g} / \mathrm{L} \quad 0$

$\mu \mathrm{g} / \mathrm{L} \quad 0 \quad \mathrm{GE}$

$\mu \mathrm{g} / \mathrm{L} \quad 0$

$\mu \mathrm{g} / \mathrm{L} \quad 0 \quad \mathrm{GE}$

$\mu g / L \quad 0 \quad G E$

$\mu \mathrm{g} / \mathrm{L} \quad 0 \quad \mathrm{GE}$

$\mu \mathrm{g} / \mathrm{L} \quad 2 \quad \mathrm{GE}$

$\mu \mathrm{g} / \mathrm{L} \quad 0 \quad \mathrm{GE}$

$\mu \mathrm{g} / \mathrm{L} \quad \mathrm{O} \quad \mathrm{GE}$

$\mu \mathrm{g} / \mathrm{L} \quad 0 \quad \mathrm{GE}$

$\mu \mathrm{g} / \mathrm{L} \quad 0 \quad \mathrm{GE}$

$\mu \mathrm{g} / \mathrm{L} \quad \mathrm{O} \quad \mathrm{GE}$

$\mu \mathrm{g} / \mathrm{L} \quad 2 \quad \mathrm{GE}$

$\mu \mathrm{g} / \mathrm{L} \quad \mathrm{O} \quad \mathrm{GE}$

$\mu \mathrm{g} / \mathrm{L} \quad 0 \quad \mathrm{GE}$

$\mu \mathrm{g} / \mathrm{L} \quad \mathrm{O} \quad \mathrm{GE}$

$\mu \mathrm{g} / \mathrm{L} \quad 0 \quad \mathrm{GE}$

$\mu \mathrm{g} / \mathrm{L} \quad 0 \quad \mathrm{GE}$

$\mu \mathrm{g} / \mathrm{L} \quad 0 \quad \mathrm{GE}$

$\mathrm{pCi} / \mathrm{L} \quad 0 \quad \mathrm{GP}$

pCi/L 0 GP

pCi/L $\quad 0 \quad$ GP

$\mathrm{pCi} / \mathrm{L} \quad 0 \quad \mathrm{GP}$

$\mathrm{pCi} / \mathrm{mL} \quad 2 \quad \mathrm{GP}$

$\mathrm{pCi} / \mathrm{L} \quad 0 \quad \mathrm{GP}$

$\mathrm{pCi} / \mathrm{L} \quad 0 \quad \mathrm{GP}$

$\mathrm{pCi} / \mathrm{L} \quad 0 \quad \mathrm{GP}$

- = exceeded holding time. $\|$ = exceeded screening level or final primary drinking water standard. 
WELL BGO 13DR

\begin{tabular}{|c|c|c|c|c|c|c|}
\hline SRS Coord. & Lat/Longitude & Screen Zone Elevation & Top of Casing & Casing & Pump & Formation \\
\hline $\begin{array}{l}\text { N76824.7 } \\
\text { E55840.4 }\end{array}$ & $\begin{array}{l}33.286797^{\circ} \mathrm{N} \\
81.668992^{\circ} \mathrm{W}\end{array}$ & $220.3-210.3 \mathrm{ft} \mathrm{msl}$ & $319.3 \mathrm{ft} \mathrm{msl}$ & 4" PVC & S & ell $\left(\| B_{1}\right)$ \\
\hline
\end{tabular}

\section{FIELD MEASUREMENTS}

Sample date: $02 / 08 / 94$

Depth to water: $87.80 \mathrm{ft}(26.76 \mathrm{~m})$ below TOC

Water elevation: $231.50 \mathrm{ft}(70.56 \mathrm{~m}) \mathrm{msl}$

Sp. conductance: $107 \mu \mathrm{S} / \mathrm{cm}$

Turbidity: 10.6 NTU

Water evacuated before sampling: $9 \mathrm{gal}$

The well went dry during purging.

Time: 9: 45

$\mathrm{pH}: 7.4$

Alkalinity: $36 \mathrm{mg} / \mathrm{L}$

Water temperature: $18.2^{\circ} \mathrm{C}$

Volumes purged: 0.6 well volumes

\section{LABORATORY ANALYSES}

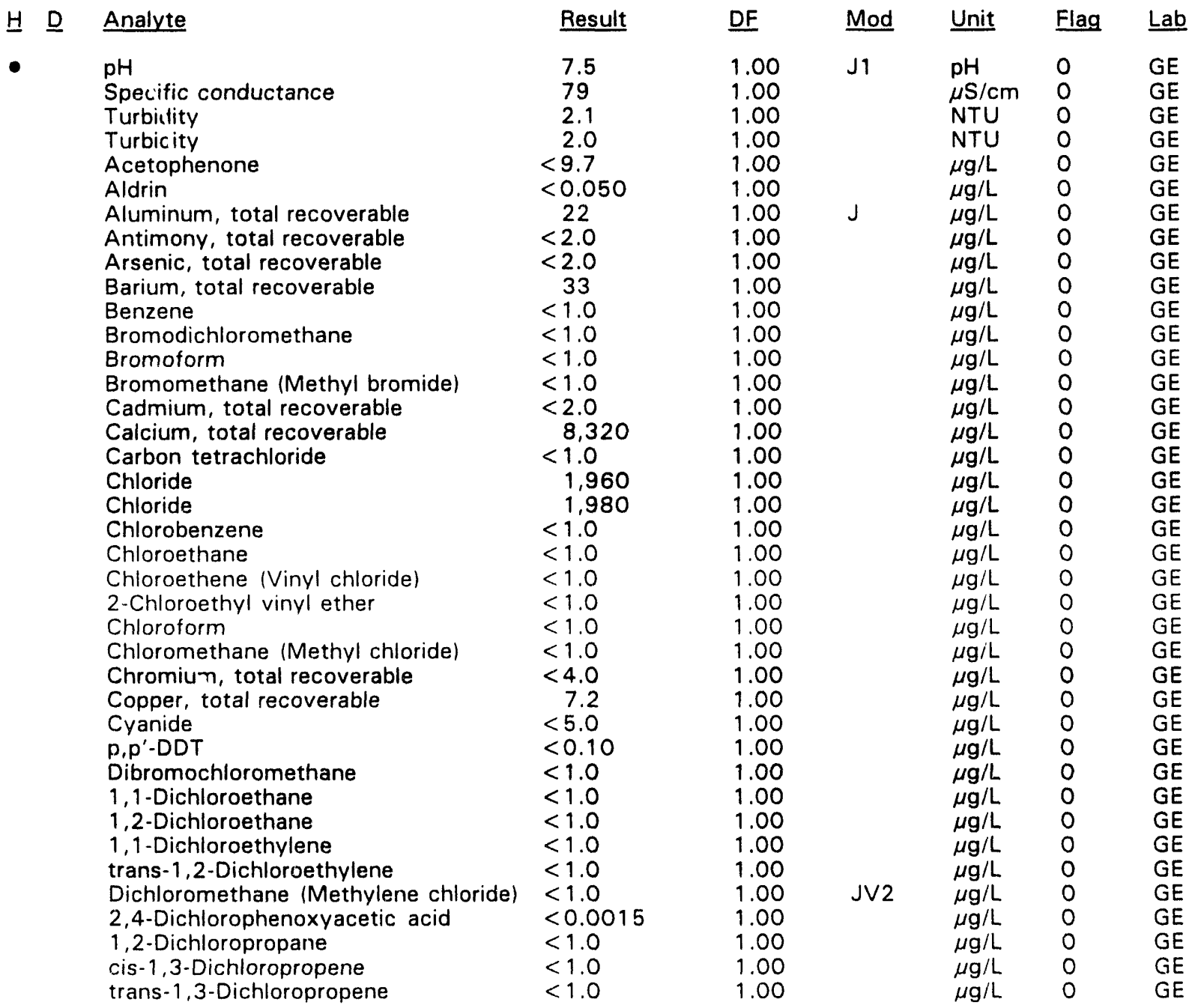

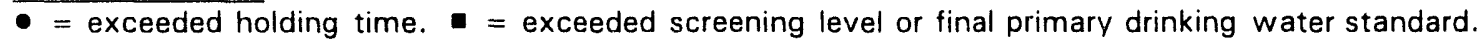


WELL BGO 13DR collected on 02/08/94, laboratory analyses (cont.)

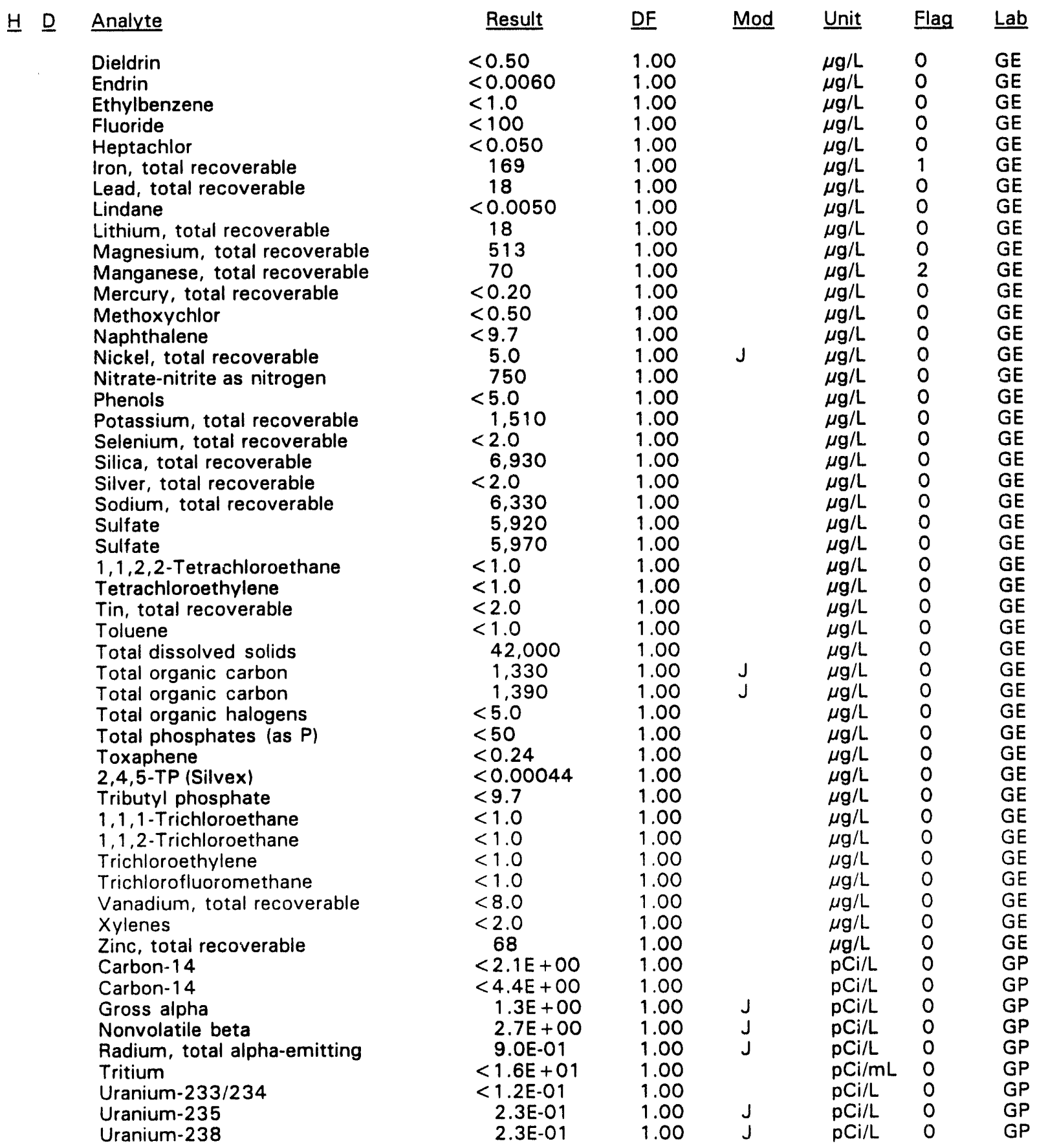

- = exceeded holding time. = exceeded screening level or final primary drinking water standard. 


\section{WELL BGO 14AR}

$\begin{array}{lllllll}\text { SRS Coord. } & \text { Lat/Longitude } & \text { Screen Zone Elevation } & \text { Top of Casing } & \text { Casing } & \text { Pump } & \text { Formation } \\ \text { N76351.8 } & \begin{array}{lll}33.285667^{\circ} \mathrm{N} \\ \text { E55788.9 }\end{array} & \begin{array}{l}106.8-96.8 \mathrm{ft} \mathrm{msl} \\ 81.668209^{\circ} \mathrm{W}\end{array} & 300.7 \mathrm{ft} \mathrm{msl} & \text { 4" PVC } & \text { S } & \text { U. Congaree (IIA) }\end{array}$

\section{FIELD MEASUREMENTS}

Sample date: $01 / 26 / 94$

Depth to water: $141.86 \mathrm{ft}(43.24 \mathrm{~m})$ below TOC

Water elevation: $158.84 \mathrm{ft}(48.42 \mathrm{~m}) \mathrm{msl}$

Sp. conductance: $219 \mu \mathrm{S} / \mathrm{cm}$

Turbidity: 0.2 NTU

Water evacuated before sampling: $176 \mathrm{gal}$

Time: 13: 15

$\mathrm{pH}: 10.2$

Alkalinity: $97 \mathrm{mg} / \mathrm{L}$

Water temperature: $19.7^{\circ} \mathrm{C}$

Volumes purged: 4.3 well volumes

\section{LABORATORY ANALYSES}

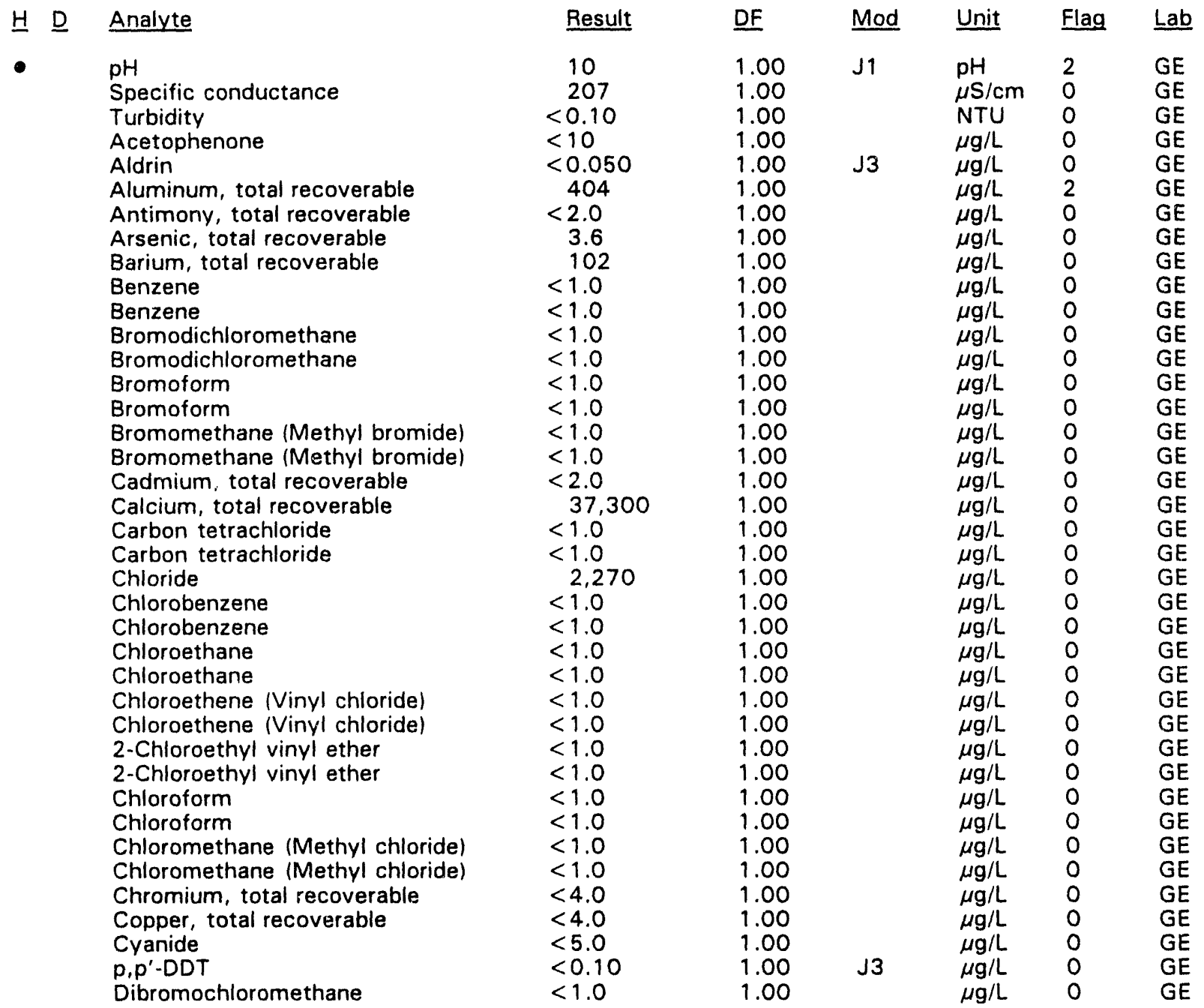

\footnotetext{
- = exceeded holding time. - = exceeded screening level or final primary drinking water standard.
} 
WELL BGO 14AR collected on $01 / 26 / 94$, laboratory analyses (cont.)

H ㅁ Analyte

Dibromochloromethane

1,1-Dichloroethane

1.1-Dichloroethane

1,2-Dichloroethane

1,2-Dichloroethane

1,1-Dichloroethylene

1,1-Dichloroethylene

trans-1,2-Dichloroethylene

trans-1,2-Dichloroethylene

Dichloromethane (Methylene chloride)

Dichloromethane (Methylene chloride)

2,4-Dichlorophenoxyacetic acid

1,2-Dichloropropane

1,2-Dichloropropane

cis-1,3-Dichloropropene

cis-1,3-Dichloropropene

trans-1,3-Dichloropropene

trans-1,3-Dichloropropene

Dieldrin

Endrin

Ethylbenzene

Ethylbenzene

Fluoride

Heptachlor

Iron, total recoverable

Lead, total recoverable

Lindane

Lithium, total recoverable

Magnesium, total recoverable

Manganese, total recoverable

Mercury, total recoverable

Methoxychlor

Naphthalene

Nickel, total recoverable

Nitrate-nitrite as nitrogen

Phenols

Potassium, total recoverable

Selenium, total recoverable

Silica, total recoverable

Silver, total recoverable

Sodium, total recoverable

Sulfate

$1,1,2,2-$ Tetrachloroethane

$1,1,2,2$-Tetrachloroethane

Tetrachloroethylene

Tetrachloroethylene

Tin, total recoverable

Toluene

Toluene

Total dissolved solids

Total organic carbon

Total organic halogens

Total phosphates las P)

Toxaphene

2,4,5-TP (Silvex)

Tributyl phosphate
$<1.0$

$<1.0$

$<1.0$

$<1.0$

$<1.0$

$<1.0$

$<1.0$

$<1.0$

$<1.0$

$<1.0$

$<1.0$

$<0.0015$

$<1.0$

$<1.0$

$<1.0$

$<1.0$

$<1.0$

$<1.0$

$<0.50$

$<0.0060$

$<1.0$

$<1.0$

$<100$

$<0.050$

9.0

$<3.0$

$<0.0050$

54

510

11

$<0.20$

$<0.50$

$<10$

$<4.0$

110

$<5.0$

8,670

$<2.0$

24,200

$<2.0$

5,830

3,260

$<1.0$

$<1.0$

$<1.0$

$<1.0$

22

$<1.0$

$<1.0$

146,000

$<1,000$

49

$<50$

$<0.24$

$<0.00045$

$<10$

\section{DF}

1.00

1.00

1.00

1.00

1.00

1.00

1.00

1.00

1.00

1.00

1.00

1.00

1.00

1.00

1.00

1.00

1.00

1.00

1.00

1.00

1.00

1.00

1.00

1.00

1.00

1.00

1.00

1.00

1.00

1.00

1.00

1.00

1.00

1.00

1.00

1.00

1.00

1.00

1.00

1.00

1.00

1.00

1.00

1.00

1.00

1.00

1.00

1.00

1.00

1.00

1.00

1.00

1.00

1.00

1.00

1.00
Mod Unit Flag Lab

$\mu \mathrm{g} / \mathrm{L}$

$$
\mu g / L
$$

$\mu \mathrm{g} / \mathrm{L}$

$\mu \mathrm{g} / \mathrm{L}$

$\mu \mathrm{g} / \mathrm{L}$

$\mu g / L$

$\mu \mathrm{g} / \mathrm{L}$

$\mu \mathrm{g} / \mathrm{L}$

$\mu \mathrm{g} / \mathrm{L}$

$\mu \mathrm{g} / \mathrm{L}$

$\mu \mathrm{g} / \mathrm{L}$

$\mu g / L$

$\mu \mathrm{g} / \mathrm{L}$

$\mu \mathrm{g} / \mathrm{L}$

$\mu \mathrm{g} / \mathrm{L}$

$\mu \mathrm{g} / \mathrm{L}$

$\mu \mathrm{g} / \mathrm{L}$

$\mu \mathrm{g} / \mathrm{L}$

J3

J3

J3

13

$\mu g / L$

$\mu \mathrm{g} / \mathrm{L}$

$\mu \mathrm{g} / \mathrm{L}$

$\mu \mathrm{g} / \mathrm{L}$

$\mu \mathrm{g} / \mathrm{L}$

$\mu \mathrm{g} / \mathrm{L}$

$\mu \mathrm{g} / \mathrm{L}$

$\mu \mathrm{g} / \mathrm{L}$

$\mu \mathrm{g} / \mathrm{L}$

$\mu \mathrm{g} / \mathrm{L}$

$\mu \mathrm{g} / \mathrm{L}$

$\mu \mathrm{g} / \mathrm{L}$

$\mu \mathrm{g} / \mathrm{L}$

J3

$\mu \mathrm{g} / \mathrm{L}$

$\mu \mathrm{g} / \mathrm{L}$

$\mu \mathrm{g} / \mathrm{L}$

$\mu \mathrm{g} / \mathrm{L}$

$\mu g / L$

$\mu \mathrm{g} / \mathrm{L}$

$\mu \mathrm{g} / \mathrm{L}$

$\mu g / L$

$\mu \mathrm{g} / \mathrm{L}$

$\mu \mathrm{g} / \mathrm{L}$

$\mu \mathrm{g} / \mathrm{L}$

$\mu \mathrm{g} / \mathrm{L}$

$\mu \mathrm{g} / \mathrm{L}$

$\mu \mathrm{g} / \mathrm{L}$

$\mu \mathrm{g} / \mathrm{L}$

$\mu \mathrm{g} / \mathrm{L}$

$\mu \mathrm{g} / \mathrm{L}$

$\mu \mathrm{g} / \mathrm{L}$

$\mu \mathrm{g} / \mathrm{L}$

$\mu \mathrm{g} / \mathrm{L}$

$\mu \mathrm{g} / \mathrm{L}$

$\mu \mathrm{g} / \mathrm{L}$

J3

$\mu \mathrm{g} / \mathrm{L}$

$\mu \mathrm{g} / \mathrm{L}$

$\mu \mathrm{g} / \mathrm{L}$

Flag Lab

GE

$\mathrm{GE}$

GE

GE

$\mathrm{GE}$

$G E$

$G E$

GE

$G E$

GE

GE

GE

GE

GE

$G E$

GE

$\mathrm{GE}$

GE

$\mathrm{GE}$

$G E$

GE

$G E$

$G E$

GE

GE

GE

GE

GE

GE

GE

GE

$\mathrm{GE}$

GE

GE

GE

GE

GE

GE

$\mathrm{GE}$

GE

GE

GE

GE

$\mathrm{GE}$

GE

$\mathrm{GE}$

GE

GE

GE

GE 
WELL BGO 14AR collected on 01/26/94, laboratory analyses (cont.)

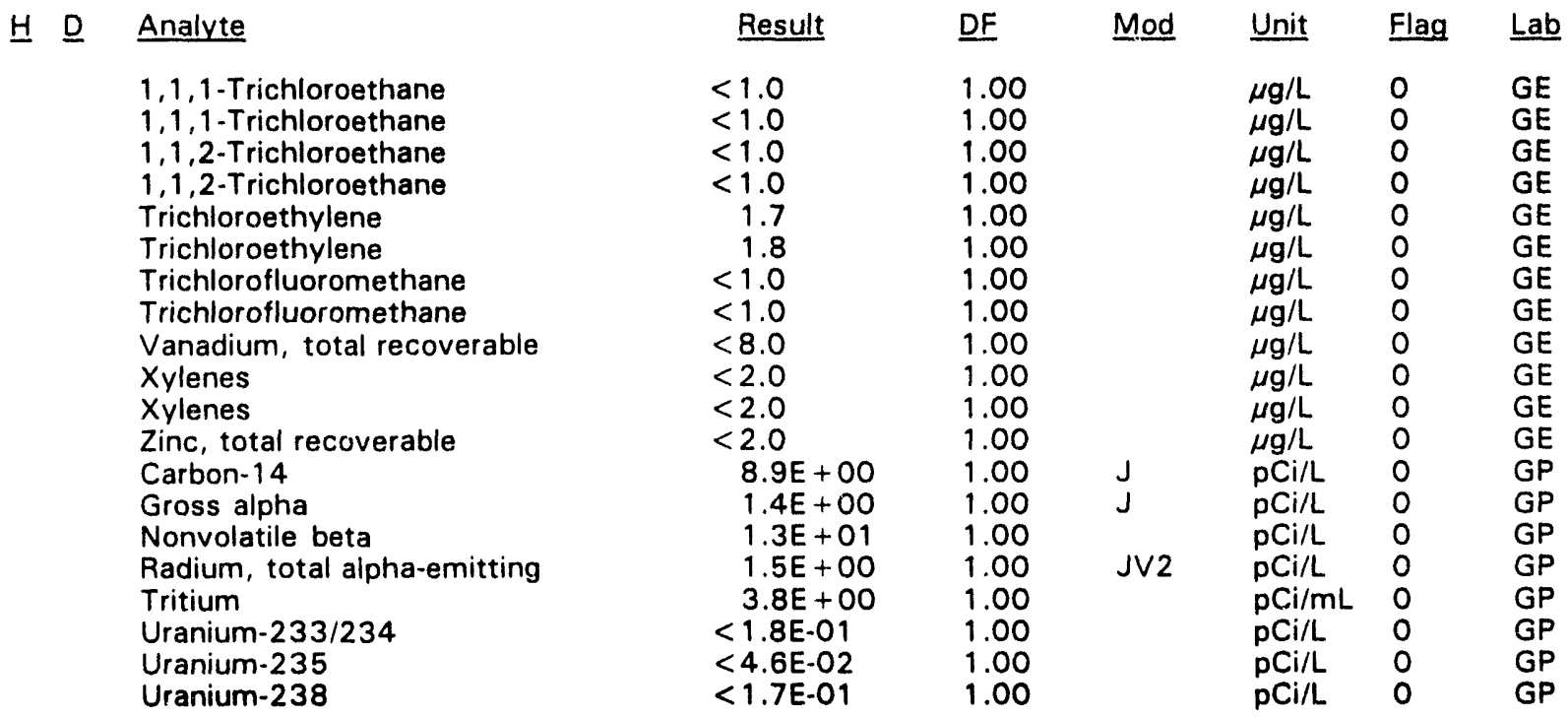

WELL BGO 14CR

\begin{tabular}{|c|c|c|c|c|c|c|}
\hline SRS Coord. & Lat/Longitude & Screen Zone Elevation & Top of Casing & Casing & Pump & Formation \\
\hline $\begin{array}{l}N 76337.8 \\
\text { E55789.0 }\end{array}$ & $\begin{array}{l}33.285636^{\circ} \mathrm{N} \\
81.668181^{\circ} \mathrm{W}\end{array}$ & 200 & 300 & DVC & $\mathrm{s}$ & \\
\hline
\end{tabular}

\section{FIELD MEASUREMENTS}

Sample date: $01 / 26 / 94$

Depth to water: $76.40 \mathrm{ft}(23.29 \mathrm{~m})$ below TOC

Water elevation: $224.10 \mathrm{ft}(68.31 \mathrm{~m}) \mathrm{ms}$ l

Sp. conductance: $91 \mu \mathrm{S} / \mathrm{cm}$

Turbidity: 6.5 NTU

Water evacuated before sampling: $17 \mathrm{gal}$

The well went dry during purging.

\section{LABORATORY ANALYSES}

H $\underline{\text { Analyte }}$

- $\mathrm{pH}$

Specific conductance

Turbidity

Acetophenone

Aldrin

Aluminum, total recoverable

Antimony, total recoverable

Arsenic, total recoverable

Barium, total recoverable

Benzene

Bromodichloromethane

Bromoform

Bromomethane (Methyl bromide)

Cadmium, total recoverable

\begin{tabular}{lll}
\multicolumn{1}{l}{ Result } & & DF \\
\hline & & \\
8.9 & & 1.00 \\
85 & & 1.00 \\
2.5 & & 1.00 \\
$<9.9$ & & 1.00 \\
$<0.050$ & & 1.00 \\
338 & & 1.00 \\
$<2.0$ & & 1.00 \\
$<2.0$ & & 1.00 \\
15 & & 1.00 \\
$<1.0$ & & 1.00 \\
$<1.0$ & & 1.00 \\
$<1.0$ & & 1.00 \\
$<1.0$ & 1.00 \\
$<2.0$ & 1.00
\end{tabular}

Time: $12: 32$

pH: 6.2

Alkalinity: $23 \mathrm{mg} / \mathrm{L}$

Water temperature: $19.3^{\circ} \mathrm{C}$

Volumes purged: 0.8 well volumes

\footnotetext{
- = exceeded holding time, = exceeded screening level or final primary drinking water standard.
} 
WELL BGO 14CR collected on 01/26/94, laboratory analyses (cont.)

\section{H $\underline{\text { Analyte }}$}

Calcium, total recoverable

Carbon tetrachloride

Chloride

Chloride

Chlorobenzene

Chloroethane

Chloroethene (Vinyl chloride)

2-Chloroethyl vinyl ether

Chloroform

Chloromethane (Methyl chloride)

Chromium, total recoverable

Copper, total recoverable

Cyanide

Cyanide

$p, p^{\prime}-$ DDT

Dibromochloromethane

1,1-Dichloroethane

1,2-Dichloroethane

1,1-Dichloroethylene

trans-1,2-Dichloroethylene

Dichloromethane (Methylene chloride)

2,4-Dichlorophenoxyacetic acid

1,2-Dichloropropane

cis-1,3-Dichloropropene

trans-1,3-Dichloropropene

Dieldrin

Endrin

Ethylbenzene

Fluoride

Heptachlor

Iron, total recoverable

Lead, total recoverable

Lindane

Lithium, total recoverable

Magnesium, total recoverable

Manganese, total recoverable

Mercury, total recoverable

Methoxychlor

Naphthalene

Nickel, total recoverable

Nitrate-nitrite as nitrogen

Phenols

Potassium, total recoverable

Selenium, total recoverable

Silica, total recoverable

Silver, total recoverable

Sodium, total recoverable

Sulfate

Sulfate

$1,1,2,2$-Tetrachloroethane

Tetrachloroethylene

Tin, total recoverable

Toluene

Total dissolved solids

Total organic carbon

Total organic halogens
Result

7,740

$<1.0$

2,460

2,490

$<1.0$

$<1.0$

$<1.0$

$<1.0$

$<1.0$

$<1.0$

13

$<4.0$

$<5.0$

$<5.0$

$<0.10$

$<1.0$

$<1.0$

$<1.0$

$<1.0$

$<1.0$

$<1.0$

$<0.0015$

$<1.0$

$<1.0$

$<1.0$

$<0.50$

$<0.0060$

$<1.0$

$<100$

$<0.050$

133

3.9

$<0.0050$

22 .

870

20

$<0.20$

$<0.50$

$<9.9$

$<4.0$

810

$<5.0$

4,020

$<2.0$

10,900

$<2.0$

5,960

6,230

6,420

$<1.0$

$<1.0$

11

$<1.0$

62,000

$<1,000$

73
DF

1.00

1.00

1.00

1.00

1.00

1.00

1.00

1.00

1.00

1.00

1.00

1.00

1.00

1.00

1.00

1.00

1.00

1.00

1.00

1.00

1.00

1.00

1.00

1.00

1.00

1.00

1.00

1.00

1.00

1.00

1.00

1.00

1.00

1.00

1.00

1.00

1.00

1.00

1.00

1.00

1.00

1.00

1.00

1.00

1.00

1.00

1.00

1.00

1.00

1.00

1.00

1.00

1.00

1.00

1.00

1.00
Mod

Unit

Flag

$\underline{L a b}$

$\mu \mathrm{g} / \mathrm{L} \quad 0 \quad \mathrm{GE}$

$\mu g / L \quad 0 \quad G E$

$\mu \mathrm{g} / \mathrm{L} \quad 0 \quad \mathrm{GE}$

$\mu g / L \quad 0 \quad$ GE

$\mu \mathrm{g} / \mathrm{L} \quad 0 \quad \mathrm{GE}$

$\mu \mathrm{g} / \mathrm{L} \quad 0 \quad \mathrm{GE}$

$\mu \mathrm{g} / \mathrm{L} \quad 0 \quad \mathrm{GE}$

$\mu \mathrm{g} / \mathrm{L} \quad 0 \quad \mathrm{GE}$

$\mu \mathrm{g} / \mathrm{L} \quad 0 \quad \mathrm{GE}$

$\mu \mathrm{g} / \mathrm{L} \quad \mathrm{O} \quad \mathrm{GE}$

$\mu \mathrm{g} / \mathrm{L} \quad 0 \quad \mathrm{GE}$

$\mu \mathrm{g} / \mathrm{L} \quad 0 \quad \mathrm{GE}$

$\mu \mathrm{g} / \mathrm{L} \quad 0 \quad \mathrm{GE}$

$\mu \mathrm{g} / \mathrm{L} \quad 0 \quad \mathrm{GE}$

$\mu \mathrm{g} / \mathrm{L} \quad 0 \quad \mathrm{GE}$

$\mu \mathrm{g} / \mathrm{L} \quad 0 \quad \mathrm{GE}$

$\mu \mathrm{g} / \mathrm{L} \quad 0 \quad \mathrm{GE}$

$\mu \mathrm{g} / \mathrm{L} \quad 0 \quad \mathrm{GE}$

$\mu g / L \quad 0 \quad G E$

$\mu g / L \quad 0 \quad G E$

$\mu \mathrm{g} / \mathrm{L} \quad 0 \quad \mathrm{GE}$

$\mu \mathrm{g} / \mathrm{L} \quad 0 \quad \mathrm{GE}$

$\mu \mathrm{g} / \mathrm{L} \quad 0 \quad \mathrm{GE}$

$\mu \mathrm{g} / \mathrm{L} \quad 0 \quad \mathrm{GE}$

$\mu g / L \quad 0 \quad G E$

$\mu g / L \quad O \quad G E$

$\mu \mathrm{g} / \mathrm{L} \quad 0 \quad \mathrm{GE}$

$\mu \mathrm{g} / \mathrm{L} \quad 0 \quad \mathrm{GE}$

$\mu \mathrm{g} / \mathrm{L} \quad 0 \quad \mathrm{GE}$

$\mu \mathrm{g} / \mathrm{L} \quad 0 \quad \mathrm{GE}$

$\mu \mathrm{g} / \mathrm{L} \quad 0 \quad \mathrm{GE}$

$\mu \mathrm{g} / \mathrm{L} \quad \mathrm{O} \quad \mathrm{GE}$

$\mu \mathrm{g} / \mathrm{L} \quad 0 \quad \mathrm{GE}$

$\mu \mathrm{g} / \mathrm{L} \quad 0 \quad \mathrm{GE}$

$\mu g / L \quad 0 \quad G E$

$\mu g / L \quad 0 \quad G E$

$\mu \mathrm{g} / \mathrm{L} \quad 0 \quad \mathrm{GE}$

$\mu \mathrm{g} / \mathrm{L} \quad 0 \quad \mathrm{GE}$

$\mu \mathrm{g} / \mathrm{L} \quad 0 \quad \mathrm{GE}$

$\mu \mathrm{g} / \mathrm{L} \quad 0 \quad \mathrm{GE}$

$\mu \mathrm{g} / \mathrm{L} \quad 0 \quad \mathrm{GE}$

$\mu \mathrm{g} / \mathrm{L} \quad 0 \quad \mathrm{GE}$

$\mu \mathrm{g} / \mathrm{L} \quad 0 \quad \mathrm{GE}$

$\mu \mathrm{g} / \mathrm{L} \quad 0 \quad \mathrm{GE}$

$\mu \mathrm{g} / \mathrm{L} \quad 0 \quad \mathrm{GE}$

$\mu \mathrm{g} / \mathrm{L} \quad 0 \quad \mathrm{GE}$

$\mu \mathrm{g} / \mathrm{L} \quad 0 \quad \mathrm{GE}$

$\mu \mathrm{g} / \mathrm{L} \quad 0 \quad \mathrm{GE}$

$\mu \mathrm{g} / \mathrm{L} \quad 0 \quad \mathrm{GE}$

$\mu \mathrm{g} / \mathrm{L} \quad 0 \quad \mathrm{GE}$

$\mu g / L \quad 0 \quad G E$

$\mu \mathrm{g} / \mathrm{L} \quad 1 \quad \mathrm{GE}$

$\mu \mathrm{g} / \mathrm{L} \quad \mathrm{O} \quad \mathrm{GE}$

$\mu \mathrm{g} / \mathrm{L} \quad 0 \quad \mathrm{GE}$

$\mu \mathrm{g} / \mathrm{L} \quad 0 \quad \mathrm{GE}$

$\mu \mathrm{g} / \mathrm{L} \quad 2 \quad \mathrm{GE}$

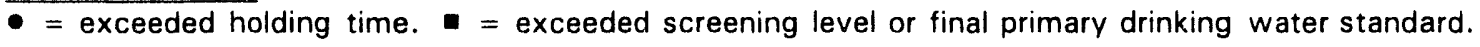


WELL BGO 14CR collected on 01/26/94, laboratory analyses (cont.)

\begin{tabular}{|c|c|c|c|c|c|c|}
\hline$\underline{H} \quad \underline{D}$ & Analyte & Result & $\underline{D F}$ & Mod & Unit & Flag \\
\hline$\square$ & $\begin{array}{l}\text { Total phosphates (as P) } \\
\text { Toxaphene } \\
2,4,5-T P \text { (Silvex) } \\
\text { Tributyl phosphate } \\
1,1,1 \text {-Trichloroethane } \\
1,1,2-\text { Trichloroethane } \\
\text { Trichloroethylene } \\
\text { Trichlorofluoromethane } \\
\text { Vanadium, total recoverable } \\
\text { Xylenes } \\
\text { Zinc, total recoverable } \\
\text { Carbon-14 } \\
\text { Gross alpha } \\
\text { Nonvolatile beta } \\
\text { Radium, total alpha-emitting } \\
\text { Tritium } \\
\text { Uranium-233/234 } \\
\text { Uranium-235 } \\
\text { Uranium-238 }\end{array}$ & $\begin{aligned}<50 \\
<0.24 \\
<0.00045 \\
<9.9 \\
1.8 \\
<1.0 \\
56 \\
<1.0 \\
<8.0 \\
<2.0 \\
22 \\
9.6 \mathrm{E}+00 \\
4.2 \mathrm{E}-01 \\
1.3 \mathrm{E}+00 \\
8.0 \mathrm{E}-01 \\
3.0 \mathrm{E}+01 \\
<7.1 \mathrm{E}-02 \\
<7.1 \mathrm{E}-02 \\
<7.1 \mathrm{E}-02\end{aligned}$ & $\begin{array}{l}1.00 \\
1.00 \\
1.00 \\
1.00 \\
1.00 \\
1.00 \\
1.00 \\
1.00 \\
1.00 \\
1.00 \\
1.00 \\
1.00 \\
1.00 \\
1.00 \\
1.00 \\
1.00 \\
1.00 \\
1.00 \\
1.00\end{array}$ & $\begin{array}{l}J \\
J \\
J \\
J \vee 2\end{array}$ & $\begin{array}{l}\mu \mathrm{g} / \mathrm{L} \\
\mu \mathrm{g} / \mathrm{L} \\
\mu \mathrm{g} / \mathrm{L} \\
\mu \mathrm{g} / \mathrm{L} \\
\mu \mathrm{g} / \mathrm{L} \\
\mu \mathrm{g} / \mathrm{L} \\
\mu \mathrm{g} / \mathrm{L} \\
\mu \mathrm{g} / \mathrm{L} \\
\mu \mathrm{g} / \mathrm{L} \\
\mu \mathrm{g} / \mathrm{L} \\
\mu \mathrm{g} / \mathrm{L} \\
\mathrm{pCi} / \mathrm{L} \\
\mathrm{pCi} / \mathrm{L} \\
\mathrm{pCi} / \mathrm{L} \\
\mathrm{pCi} / \mathrm{L} \\
\mathrm{pCi} / \mathrm{mL} \\
\mathrm{pCi} / \mathrm{L} \\
\mathrm{pCi} / \mathrm{L} \\
\mathrm{pCi} / \mathrm{L}\end{array}$ & $\begin{array}{l}0 \\
0 \\
0 \\
0 \\
0 \\
0 \\
2 \\
0 \\
0 \\
0 \\
0 \\
0 \\
0 \\
0 \\
0 \\
2 \\
0 \\
0 \\
0\end{array}$ \\
\hline
\end{tabular}

\section{WELL BGO 14DR}

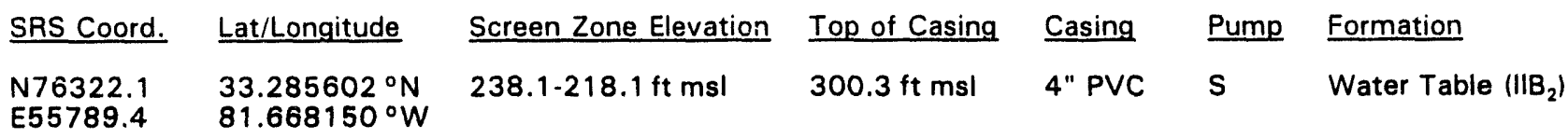

\section{FIELD MEASUREMENTS}

Sample date: $01 / 26 / 94$

Depth to water: $68.98 \mathrm{ft}(21.03 \mathrm{~m})$ below TOC

Water elevation: $231.32 \mathrm{ft}(70.51 \mathrm{~m}) \mathrm{msl}$

Sp. conductance: $41 \mu \mathrm{S} / \mathrm{cm}$

Turbidity: 0.3 NTU

Water evacuated before sampling: $128 \mathrm{gal}$

\section{LABORATORY ANALYSES}

H $\underline{\text { Analyte }}$

- $\mathrm{pH}$

Specific conductance

Turbidity

Acetophenone

Aldrin

Aluminum, total recoverable

Antimony, total recoverable

Arsenic, total recoverable

Barium, total recoverable

Benzene

Bromodichloromethane

Bromoform

Bromomethane (Methyl bromide)

Cadmium, total recoverable

Calcium, total recoverable
Time: $13: 35$

$\mathrm{pH}: 5.0$

Alkalinity: $1 \mathrm{mg} / \mathrm{L}$

Water temperature: $19.7^{\circ} \mathrm{C}$

Volumes purged: 14.8 well volumes

\begin{tabular}{|c|c|c|c|c|}
\hline Result & $\underline{D F}$ & Mod & Unit & Flag \\
\hline $\begin{array}{l}5.5 \\
38\end{array}$ & 1.00 & 31 & $\mathrm{pH}$ & 0 \\
\hline$<0.10$ & 1.00 & & NTU & 0 \\
\hline$<10$ & 1.00 & & $\mu \mathrm{g} / \mathrm{L}$ & 0 \\
\hline$<0.051$ & 1.00 & & $\mu \mathrm{g} / \mathrm{L}$ & 0 \\
\hline$<20$ & 1.00 & & $\mu \mathrm{g} / \mathrm{L}$ & 0 \\
\hline$<2.0$ & 1.00 & & $\mu \mathrm{g} / \mathrm{L}$ & 0 \\
\hline$<2.0$ & 1.00 & & $\mu \mathrm{g} / \mathrm{L}$ & 0 \\
\hline 6.4 & 1.00 & & $\mu \mathrm{g} / \mathrm{L}$ & 0 \\
\hline$<1.0$ & 1.00 & & $\mu \mathrm{g} / \mathrm{L}$ & 0 \\
\hline$<1.0$ & 1.00 & & $\mu \mathrm{g} / \mathrm{L}$ & 0 \\
\hline$<1.0$ & 1.00 & & $\mu \mathrm{g} / \mathrm{L}$ & 0 \\
\hline$<1.0$ & 1.00 & & $\mu \mathrm{g} / \mathrm{L}$ & 0 \\
\hline$<2.0$ & 1.00 & & $\mu \mathrm{g} / \mathrm{L}$ & 0 \\
\hline 857 & 1.00 & & $\mu \mathrm{g} / \mathrm{L}$ & 0 \\
\hline
\end{tabular}

- = exceeded holding time. = exceeded screening level or final primary drinking water standard. 
WELL BGO 14DR collected on 01/26/94, laboratory analyses (cont.)

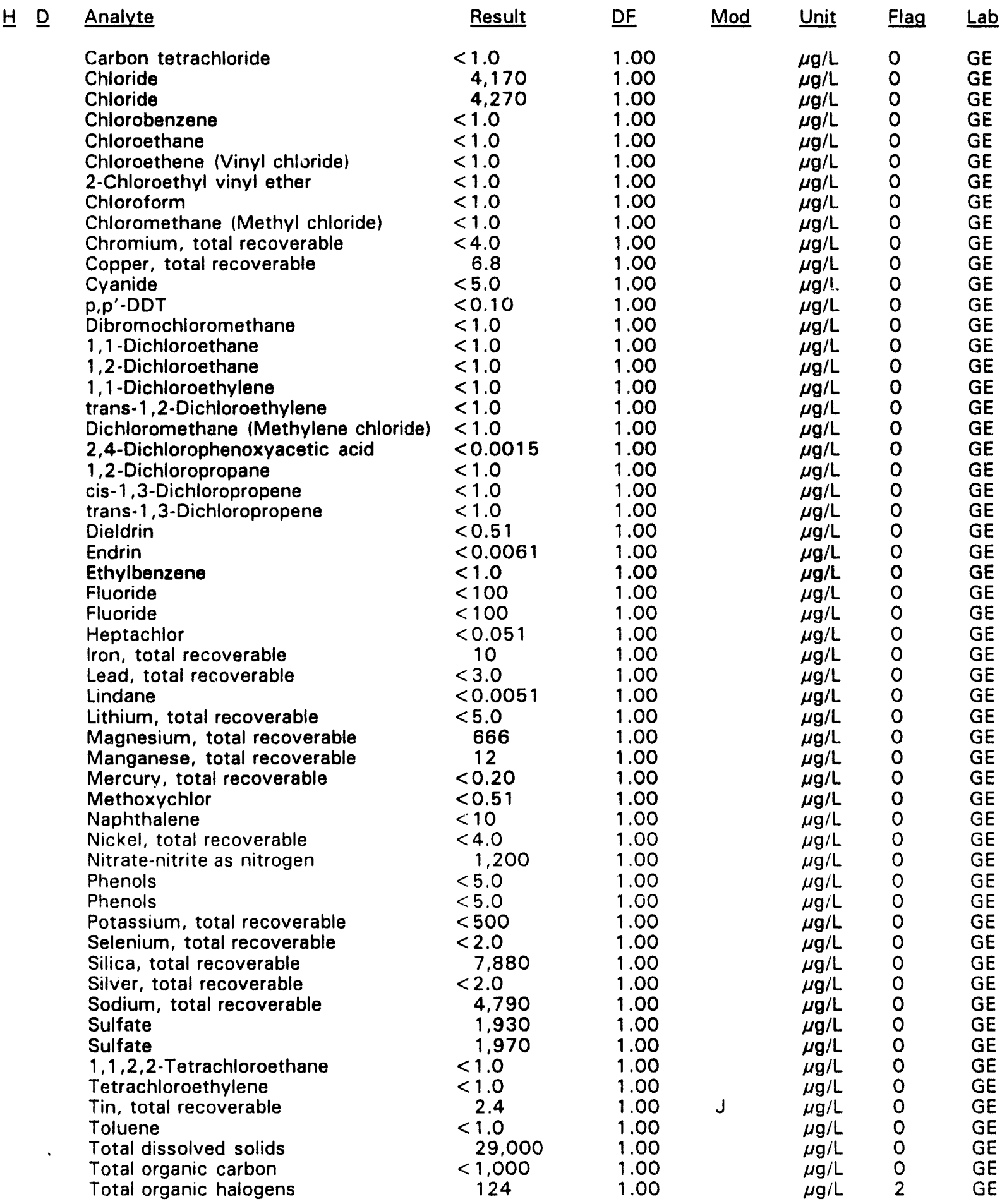

- exceeded holding time. = exceeded screening level or final primary drinking water standard. 
WELL BGO 14DR collected on 01/26/94, laboratory analyses (cont.)

\begin{tabular}{|c|c|c|c|c|c|c|}
\hline$\underline{D}$ & Analyte & Result & $\underline{D F}$ & Mod & Unit & Flag \\
\hline - & $\begin{array}{l}\text { Total phosphates (as PI } \\
\text { Toxaphene } \\
\text { 2,4,5-TP (Silvex) } \\
\text { Tributyl phosphate } \\
1,1,1-\text { Trichloroethane } \\
1,1,2-\text { Trichloroethane } \\
\text { Trichloroethylene } \\
\text { Trichlorofluoromethane } \\
\text { Vanadium, total recoverable } \\
\text { Xylenes } \\
\text { Zinc, total recoverable } \\
\text { Carbon-14 } \\
\text { Carbon-14 } \\
\text { Gross alpha } \\
\text { Nonvolatile beta } \\
\text { Radium, total alpha-emitting } \\
\text { Tritium } \\
\text { Uranium-233/234 } \\
\text { Uranium-235 } \\
\text { Uranium-238 }\end{array}$ & $\begin{aligned} &<50 \\
&<0.24 \\
&<0.00045 \\
&<10 \\
&<1.0 \\
&<1.0 \\
& \quad 61 \\
&<1.0 \\
&<8.0 \\
&<2.0 \\
& 13 \\
&<3.8 E+00 \\
& 8.0 E+00 \\
& 1.9 E+00 \\
& 1.8 E+00 \\
& 1.6 E+00 \\
& 1.2 E+01 \\
&<-2.0 E-02 \\
&<-6.6 E-03 \\
&< 1.8 E-01\end{aligned}$ & $\begin{array}{l}1.00 \\
1.00 \\
1.00 \\
1.00 \\
1.00 \\
1.00 \\
5.00 \\
1.00 \\
1.00 \\
1.00 \\
1.00 \\
1.00 \\
1.00 \\
1.00 \\
1.00 \\
1.00 \\
1.00 \\
1.00 \\
1.00 \\
1.00\end{array}$ & $\begin{array}{l}J \\
J \\
J \\
J V 2\end{array}$ & $\begin{array}{l}\mu g / L \\
\mu g / L \\
\mu g / L \\
\mu g / L \\
\mu g / L \\
\mu g / L \\
\mu g / L \\
\mu g / L \\
\mu g / L \\
\mu g / L \\
\mu g / L \\
\mathrm{pCi} / \mathrm{L} \\
\mathrm{pCi} / \mathrm{L} \\
\mathrm{pCi} / \mathrm{L} \\
\mathrm{pCi} / \mathrm{L} \\
\mathrm{pCi} / \mathrm{L} \\
\mathrm{pCi} / \mathrm{mL} \\
\mathrm{pCi} / \mathrm{L} \\
\mathrm{pCi} / \mathrm{L} \\
\mathrm{pCi} / \mathrm{L}\end{array}$ & $\begin{array}{l}0 \\
0 \\
0 \\
0 \\
0 \\
0 \\
2 \\
0 \\
0 \\
0 \\
0 \\
0 \\
0 \\
0 \\
0 \\
0 \\
1 \\
0 \\
0 \\
0\end{array}$ \\
\hline
\end{tabular}

\section{WELL BGO 15D}

\begin{tabular}{|c|c|c|c|c|c|c|}
\hline SRS Coord. & Lat/Longitude & Screen Zone Elevation & Top of Casing & Casing & Pump & Formation \\
\hline $\begin{array}{l}N 75973.5 \\
\text { E55859.1 }\end{array}$ & $\begin{array}{l}33.284945^{\circ} \mathrm{N} \\
81.667289^{\circ} \mathrm{W}\end{array}$ & $238.7-218.7 \mathrm{ft} \mathrm{msl}$ & $298.7 \mathrm{ft} \mathrm{msl}$ & 4" PVC & $\mathbf{s}$ & $\mathrm{Ie} \| 11 \mathrm{~B}$ \\
\hline
\end{tabular}

\section{FIELD MEASUREMENTS}

Sample date: $01 / 26 / 94$

Depth to water: $67.89 \mathrm{ft}(20.69 \mathrm{~m})$ below TOC

Water elevation: $230.81 \mathrm{ft}(70.35 \mathrm{~m}) \mathrm{msl}$

Sp. conductance: $29 \mu \mathrm{S} / \mathrm{cm}$

Turbidity: 2.3 NTU

Water evacuated before sampling: $45 \mathrm{gal}$

\section{LABORATORY ANALYSES}

므 Analyte

- $\quad \mathrm{pH}$

Specific conductance

Turbidity

Acetophenone

Aldrin

Aluminum, total recoverable

Antimony, total recoverable

Arsenic, total recoverable

Barium, total recoverable

Benzene

Bromodichloromethane

Bromoform

Bromomethane (Methyl bromide)

Cadmium, total recoverable
Time: $14: 24$

$\mathrm{pH}: 5.0$

Alkalinity: $1 \mathrm{mg} / \mathrm{L}$

W'ater temperature: $20.2^{\circ} \mathrm{C}$

Volumes purged: 5.7 well volumes

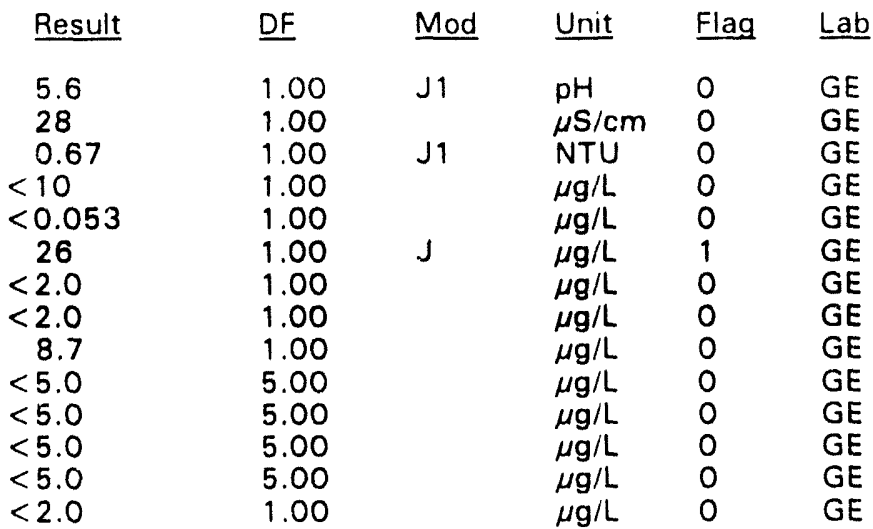

- = exceeded holding time. = exceeded screening level or final primary drinking water standard. 
WELL BGO 15D collected on 01/26/94, laboratory analyses (cont.)

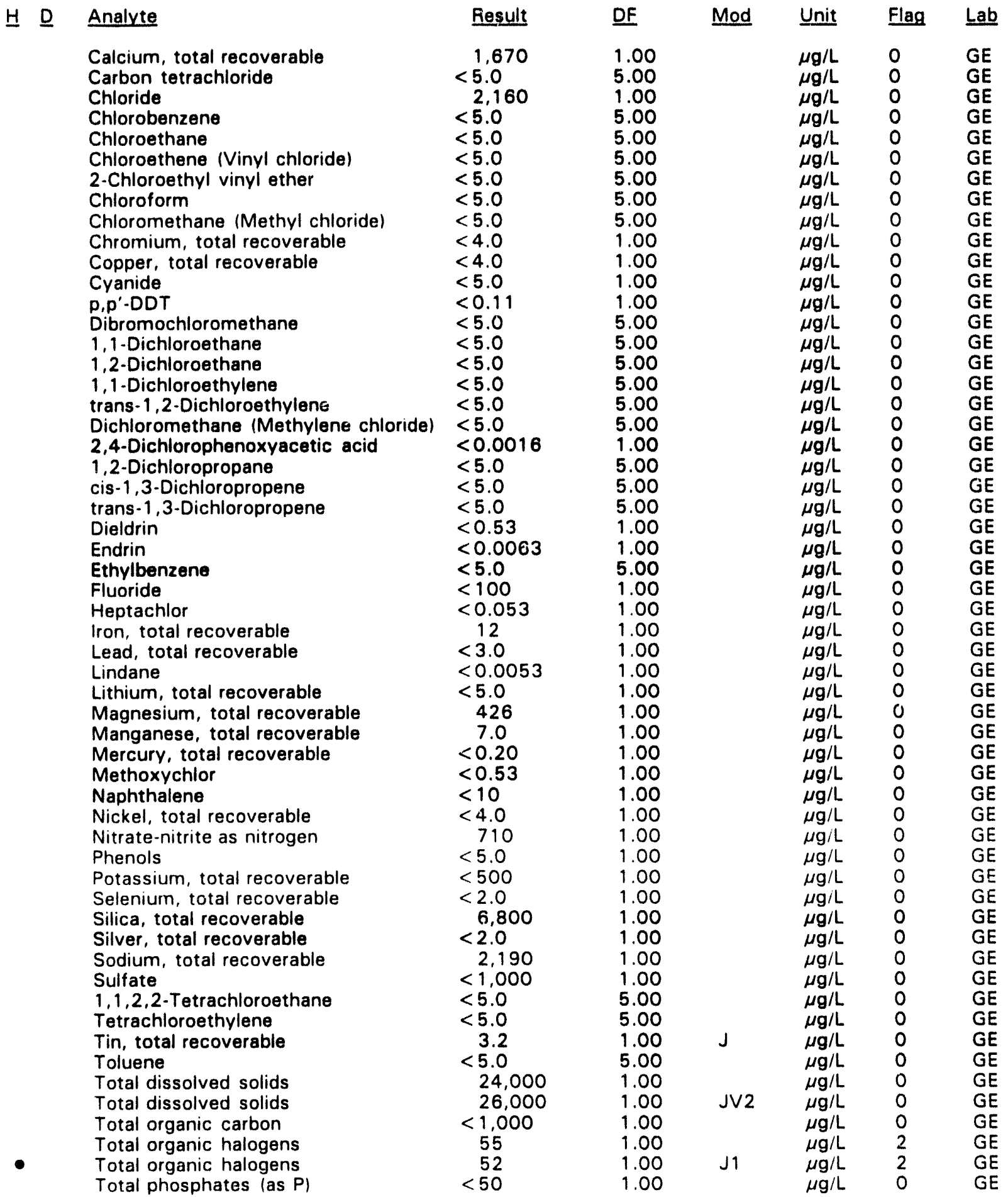

- = exceeded holding time. - = exceeded screening level or final primary drinking water standard. 
WELL BGO $15 D$ collected on $01 / 26 / 94$, laboratory analyses (cont.)

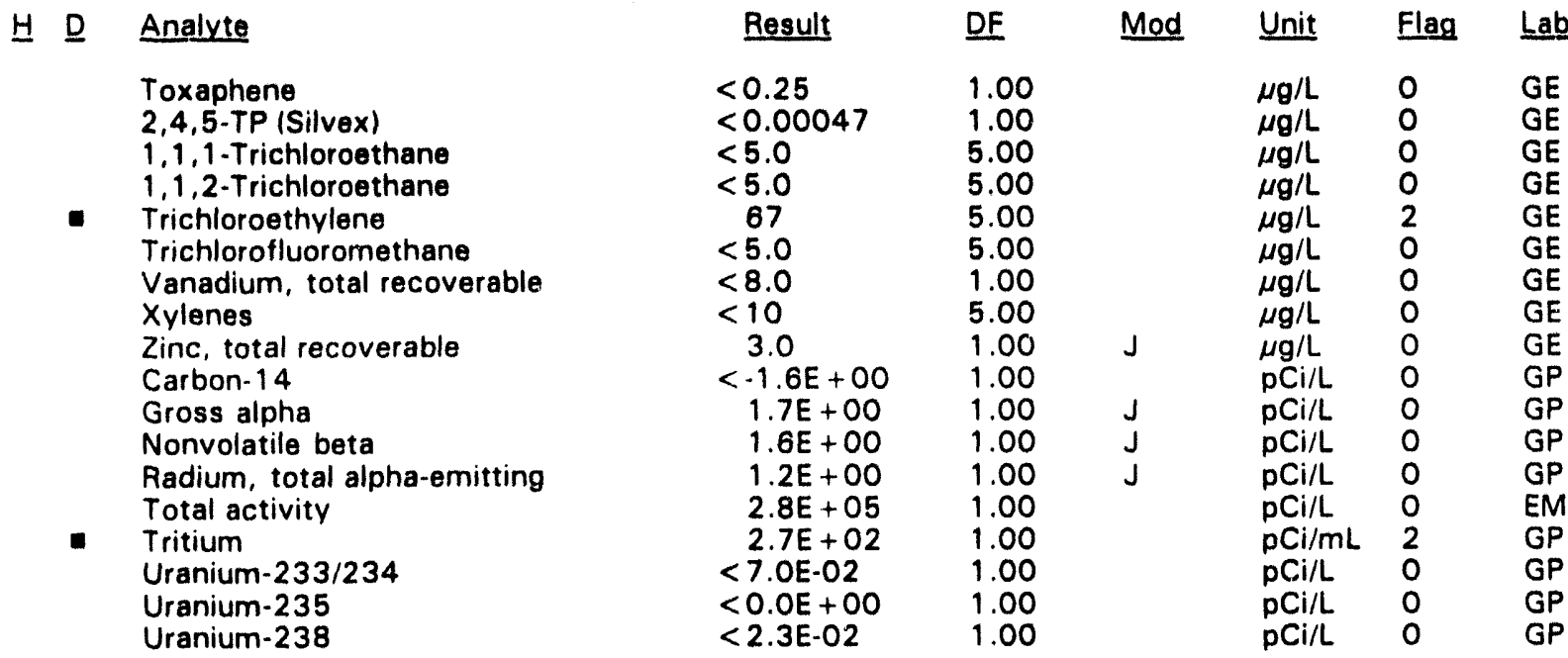

WELL BGO 16AR

$\begin{array}{lllllll}\text { SRS Coord. } & \text { Lat/Longitude } & \text { Screen Zone Elevation } & \text { Top of Casing } & \text { Casing } & \text { Pump } & \text { Formation } \\ \text { N75743.2 } & 33.285020^{\circ} \mathrm{N} & 113.7-103.7 \mathrm{ft} \mathrm{msl} & 303.7 \mathrm{ft} \mathrm{msl} & 4 " \mathrm{PVC} & \text { S } & \text { Congaree (IIA) } \\ \text { E56217.1 } & 81.665899^{\circ} \mathrm{W} & & & & \end{array}$

\section{FIELD MEASUREMENTS}

Sample date: $02 / 02 / 94$

Depth to water: $142.99 \mathrm{ft}(43.58 \mathrm{~m})$ below TOC

Water elevation: $160.71 \mathrm{ft}(48.99 \mathrm{~m}) \mathrm{msl}$

Sp. conductance: $188 \mu \mathrm{S} / \mathrm{cm}$

Turbidity: 0.9 NTU

Water evacuated before sampling: $113 \mathrm{gal}$

Time: 13: 31

$\mathrm{pH}: 7.7$

Alkalinity: $80 \mathrm{mg} / \mathrm{L}$

Water temperature: $18.9^{\circ} \mathrm{C}$

Volumes purged: 3.0 well volumes

\section{LABORATORY ANALYSES}

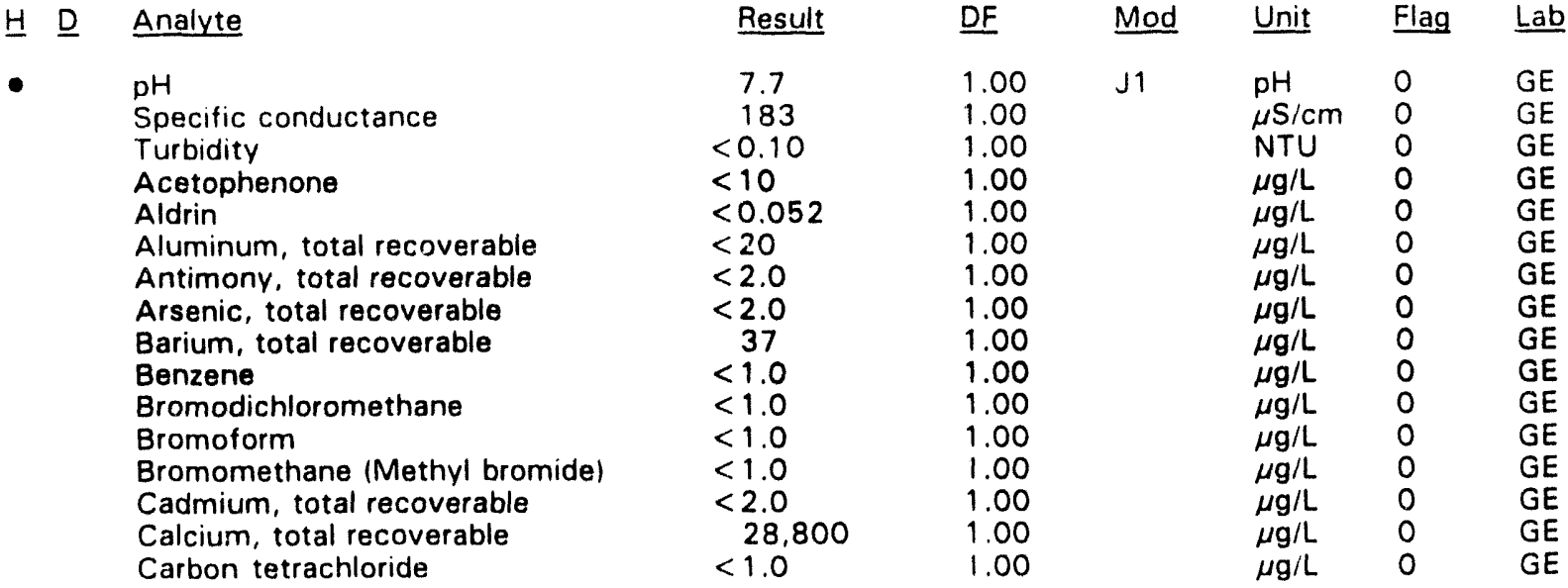

\footnotetext{
- exceeded holding time. = exceeded screening level or final primary drinking water standard.
} 
WELL BGO 16AR collected on 02/02/94, laboratory analyses (cont.)

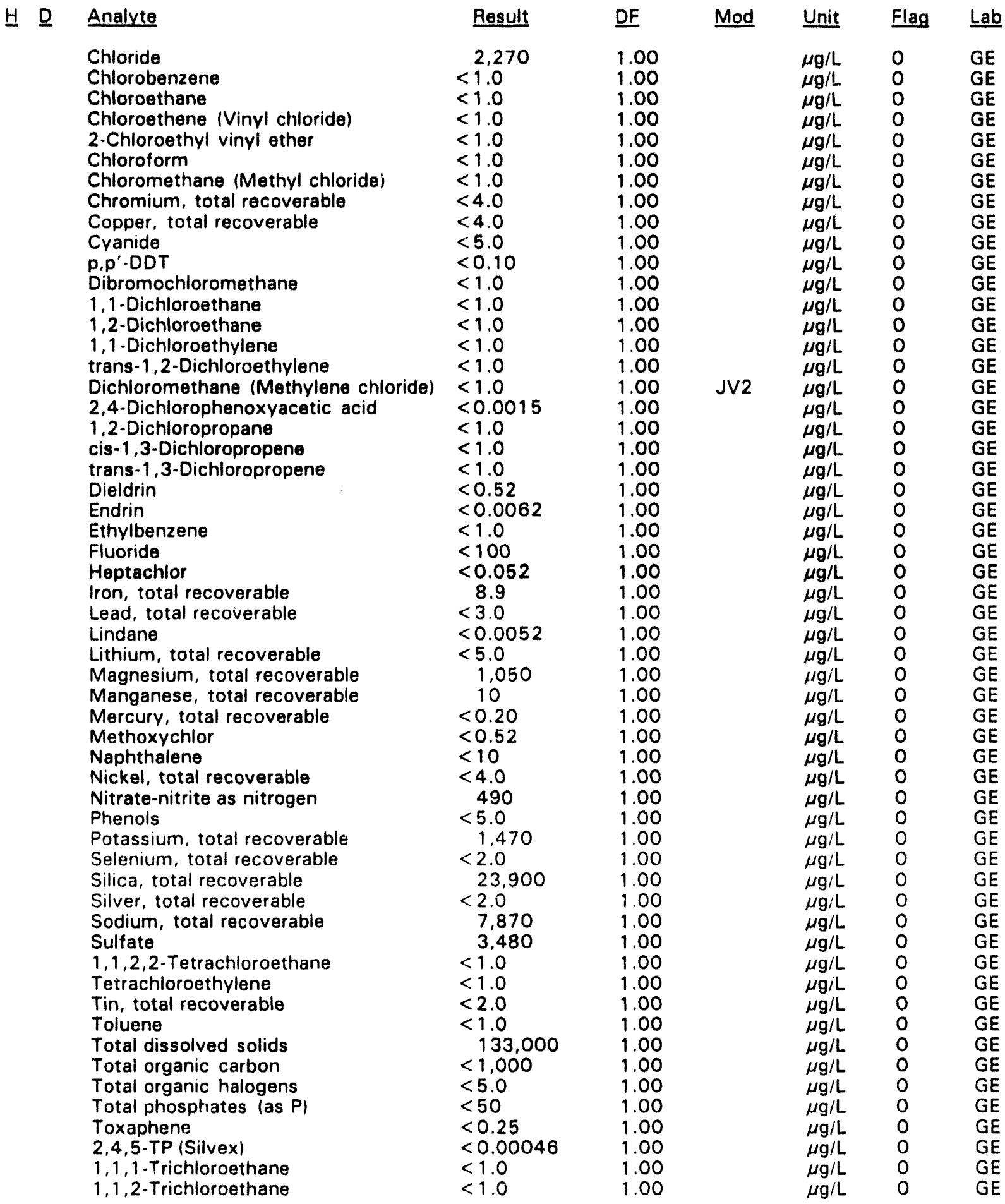

- = exceeded holding time. = exceeded screening level or final primary drinking water standard. 
WELL BGO 16AR collected on 02/02/94, laboratory analyses (cont.)

\begin{tabular}{|c|c|c|c|c|c|c|}
\hline$\underline{D}$ & Analyte & Result & DF & Mod & Unit & Flag \\
\hline & $\begin{array}{l}\text { Trichloroethylene } \\
\text { Trichlorofluoromethane } \\
\text { Vanadium, total recoverable } \\
\text { Xylenes } \\
\text { Zinc, total recoverable } \\
\text { Carbon-14 } \\
\text { Gross alpha } \\
\text { Nonvolatile beta } \\
\text { Radium, total alpha-emitting } \\
\text { Tritium } \\
\text { Uranium-233/234 } \\
\text { Uranium-233/234 } \\
\text { Uranium-235 } \\
\text { Uranium-235 } \\
\text { Uranium-238 } \\
\text { Uranium-238 }\end{array}$ & $\begin{aligned} &< 1.0 \\
&<1.0 \\
&<8.0 \\
&<2.0 \\
&<2.0 \\
&<-2.9 E+00 \\
& 9.2 E-01 \\
&< 4.3 E-01 \\
& 1.7 E+00 \\
&< 0.0 E+00 \\
& 3.8 E-01 \\
& 3.3 E-01 \\
&< 0.0 E+00 \\
&< 0.0 E+00 \\
& 2.3 E-01 \\
& 2.0 E-01\end{aligned}$ & $\begin{array}{l}1.00 \\
1.00 \\
1.00 \\
1.00 \\
1.00 \\
1.00 \\
1.00 \\
1.00 \\
1.00 \\
1.00 \\
1.00 \\
1.00 \\
1.00 \\
1.00 \\
1.00 \\
1.00\end{array}$ & $\begin{array}{l}J \\
J\end{array}$ & $\begin{array}{l}\mu g / L \\
\mu g / L \\
\mu g / L \\
\mu \tilde{g} / L \\
\mu g / L \\
\mathrm{pCi} / L \\
\mathrm{pCi} / \mathrm{L} \\
\mathrm{pCi} / \mathrm{L} \\
\mathrm{pCi} / \mathrm{L} \\
\mathrm{pCi} / \mathrm{mL} \\
\mathrm{pCi} / \mathrm{L} \\
\mathrm{pCi} / \mathrm{L} \\
\mathrm{pCi} / \mathrm{L} \\
\mathrm{pCi} / \mathrm{L} \\
\mathrm{pCi} / \mathrm{L} \\
\mathrm{pCi} / \mathrm{L}\end{array}$ & $\begin{array}{l}0 \\
0 \\
0 \\
0 \\
0 \\
0 \\
0 \\
0 \\
0 \\
0 \\
0 \\
0 \\
0 \\
0 \\
0 \\
0\end{array}$ \\
\hline
\end{tabular}

\section{WELL BGO 16B}

$\begin{array}{lllllll}\text { SRS Coord. } & \text { Lat/Longitude } & \text { Screen Zone Elevation } & \text { Top of Casing } & \text { Casing } & \text { Pump } & \text { Formation } \\ \text { N75767.5 } & 33.285019^{\circ} \mathrm{N} & 146.0 .136 .0 \mathrm{ft} \mathrm{msl} & 305.1 \mathrm{ft} \mathrm{msl} & \text { 4"PVC } & \text { S } & \text { McBean (IIB,) } \\ \text { E56183.8 } & 81.666034^{\circ} \mathrm{W} & & & & \end{array}$

\section{FIELD MEASUREMENTS}

Sample date: 02/03/94

Depth to water: $86.52 \mathrm{ft}(26.37 \mathrm{~m})$ below TOC

Water elevation: $218.58 \mathrm{ft}(66.62 \mathrm{~m}) \mathrm{msl}$

Sp. conductance: $229 \mu \mathrm{S} / \mathrm{cm}$

Turbidity: 8.5 NTU

Water evacuated before sampling: $39 \mathrm{gal}$

The well went dry during purging.

\section{LABORATORY ANALYSES}

H $\underline{\text { Analyte }}$

- $\mathrm{pH}$

Specific conductance

Turbidity

Acetophenone

- Aldrin

Aluminum, total recoverable

Antimony, total recoverable

Arsenic, total recoverable

Barium, total recoverable

Benzene

Bromodichloromethane

Bromoform

Bromomethane (Methyl bromide)

Cadmium, total recoverable

Calcium, total recoverable

Carbon tetrachloride

Chloride

Chlorobenzene
Time: 9: 04

$\mathrm{pH}: 8.3$

Alkalinity: $92 \mathrm{mg} / \mathrm{L}$

Water temperature: $16.7^{\circ} \mathrm{C}$

Volumes purged: 0.7 well volumes
Lab
GE
GE
GE
GE
GE
GP
GP
GP
GP
GP
GP
GP
GP
GP
GP
GP 
WELL BGO 16B collected on 02/03/94, laboratory analyses (cont.)

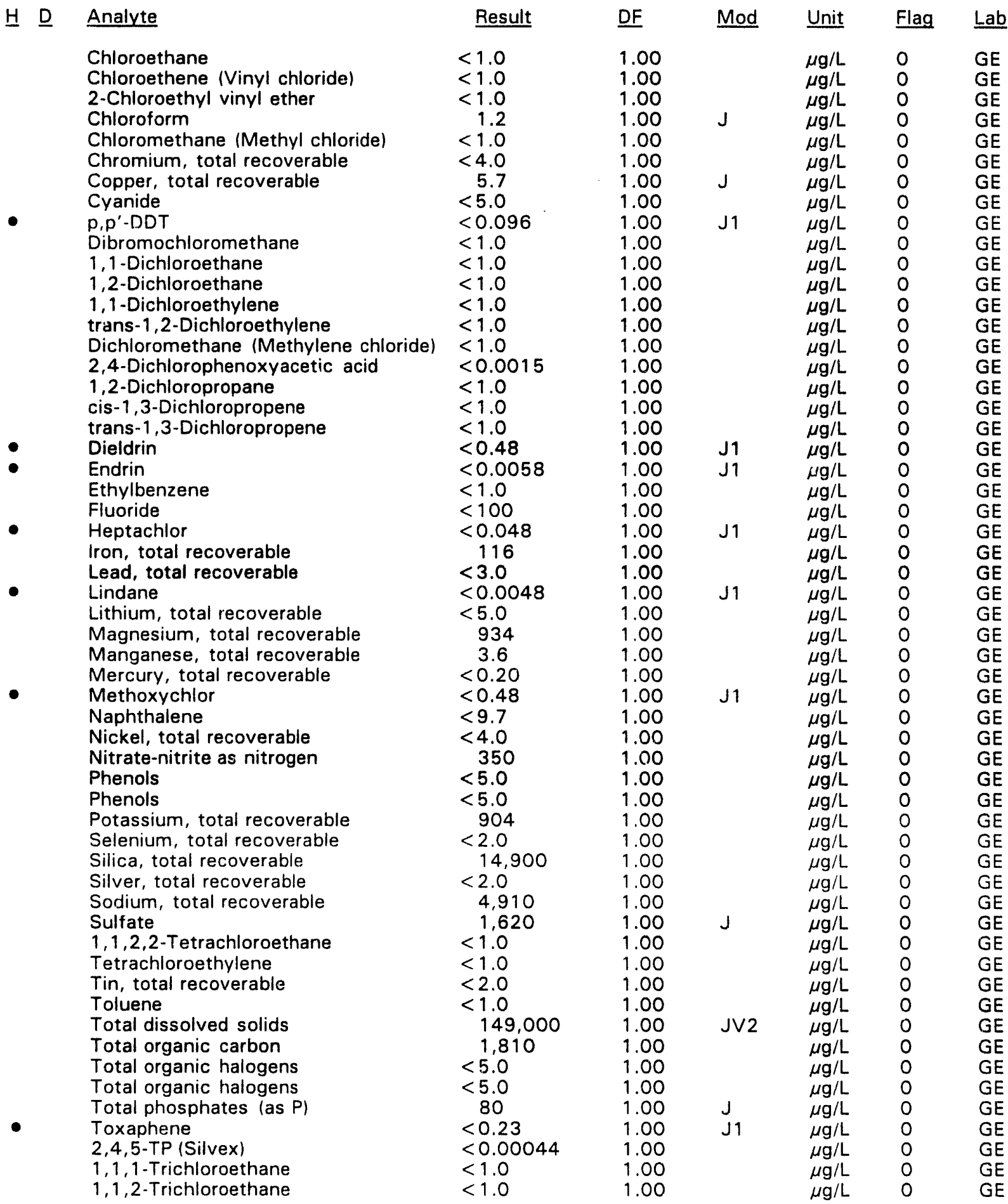

\footnotetext{
- = exceeded holding time. = exceeded screening level or final primary drinking water standard.
} 
WELL BGO $16 \mathrm{~B}$ collected on $02 / 03 / 94$, laboratory analyses (cont.)

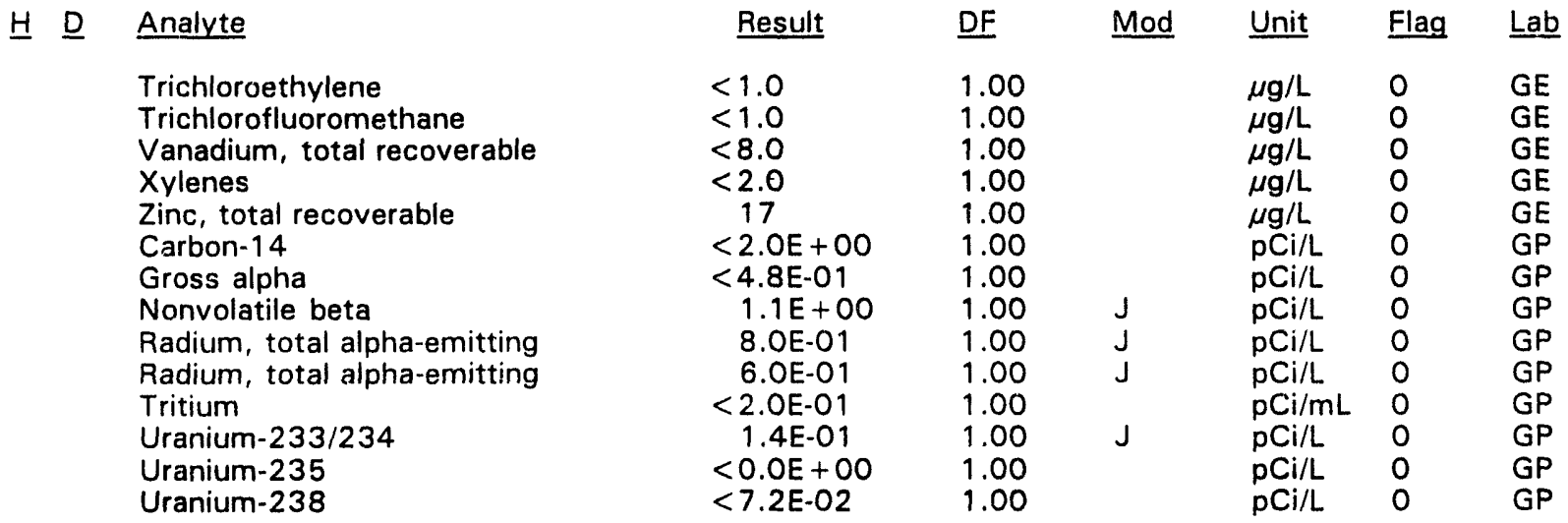

\section{WELL BGO 16D}

\begin{tabular}{|c|c|c|c|c|c|c|}
\hline RS Coord. & Lat/Longitude & Screen Zone Elevation & Top of Casing & Casing & Pump & Formation \\
\hline & $5013^{\circ} \mathrm{N}$ & 237 & 30 & VC & $\mathbf{S}$ & \\
\hline
\end{tabular}

\section{FIELD MEASUREMENTS}

Sample date: 02/03/94

Depth to water: $73.15 \mathrm{ft}(22.30 \mathrm{~m})$ below TOC

Water elevation: $231.45 \mathrm{ft}(70.55 \mathrm{~m}) \mathrm{msl}$

Sp. conductance: $184 \mu \mathrm{S} / \mathrm{cm}$

Turbidity: 4.0 NTU

Water evacuated before sampling: $4 \mathrm{gal}$

The well went dry during purging.

\section{LABORATORY ANALYSES}

H D Analyte

- $\quad \mathrm{pH}$
$\mathrm{pH}$
Specific conductance
Turbidity
- Turbidity
Acetophenone
Acetophenone
- Aldrin
Aldrin

Aldrin

Aluminum, total recoverable

Alumirum, total recoverable

Antimony, total recoverable

Antimony, total recoverable

Arsenic, total recoverable

Arsenic, total recoverable

Barium, total recoverable

Barium, total recoverable

Benzene

Bromodichloromethane

Bromoform
Time: 9: 21

$\mathrm{pH}: 9.3$

Alkalinity: $80 \mathrm{mg} / \mathrm{L}$

Water temperature: $16.3^{\circ} \mathrm{C}$

Volumes purged: 0.4 well volumes

\begin{tabular}{|c|c|c|c|c|}
\hline Result & DF & Mod & Unit & Flag \\
\hline 9.1 & 1.00 & & $\mathrm{pH}$ & 1 \\
\hline 9.1 & 1.00 & J1 & $\mathrm{pH}$ & 1 \\
\hline 163 & 1.00 & & $\mu \mathrm{S} / \mathrm{cm}$ & 0 \\
\hline 6.0 & 1.00 & & NTU & 0 \\
\hline 5.5 & 1.00 & $\mathrm{~J} 1$ & NTU & 0 \\
\hline$<10$ & 1.00 & & $\mu \mathrm{g} / \mathrm{L}$ & 0 \\
\hline$<10$ & 1.00 & & $\mu \mathrm{g} / \mathrm{L}$ & 0 \\
\hline$<0.050$ & 1.00 & $J$ & $\mu \mathrm{g} / \mathrm{L}$ & 0 \\
\hline$<0.050$ & 1.00 & J1 & $\mu \mathrm{g} / \mathrm{L}$ & 0 \\
\hline 560 & 1.00 & & $\mu \mathrm{g} / \mathrm{L}$ & 2 \\
\hline 546 & 1.00 & J3 & $\mu \mathrm{g} / \mathrm{L}$ & 2 \\
\hline $\begin{array}{l}<10 \\
<10\end{array}$ & $\begin{array}{l}5.00 \\
5.00\end{array}$ & & $\mu \mathrm{g} / \mathrm{L}$ & $\begin{array}{l}0 \\
0\end{array}$ \\
\hline$<2.0$ & 1.00 & & $\mu \mathrm{g} / \mathrm{L}$ & 0 \\
\hline$<2.0$ & 1.00 & & $\mu \mathrm{g} / \mathrm{L}$ & 0 \\
\hline 31 & 1.00 & & $\mu \mathrm{g} / \mathrm{L}$ & 0 \\
\hline 31 & 1.00 & & $\mu \mathrm{g} / \mathrm{L}$ & 0 \\
\hline$<1.0$ & 1.00 & & $\mu \mathrm{g} / \mathrm{L}$ & 0 \\
\hline$<1.0$ & 1.00 & & $\mu \mathrm{g} / \mathrm{L}$ & 0 \\
\hline$<1.0$ & 1.00 & & $\mu \mathrm{g} / \mathrm{L}$ & 0 \\
\hline
\end{tabular}

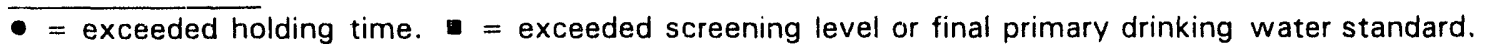


WELL BGO 16D collected on 02/03/94, laboratory analyses (cont.)

\section{H $\underline{\text { Analyte }}$}

Bromomethane (Methyl bromide)

Cadmium, total recoverable

Cadmium, total recoverable

Calcium, total recoverable

Calcium, total recoverable

Carbon tetrachloride

Chloride

Chlorobenzene

Chloroethane

Chloroethene (Vinyl chloride)

2-Chloroethyl vinyl ether

Chloroform

Chloromethane (Methyl chloride)

Chromium, total recoverable

Chromium, total recoverable

Copper, total recoverable

Copper, total recoverable

Cyanide

- $\quad$ Cyanide

- p, p.'DDT

Dibromochloromethane

1,1-Dichloroethane

1,2-Dichloroethane

1,1-Dichloroethylene

trans-1,2-Dichloroethylene

Dichloromethane (Methylene chloride)

2,4-Dichlorophenoxyacetic acid

1,2-Dichloropropane

cis-1,3-Dichloropropene

trans-1,3-Dichloropropene

- Dieldrin

- Dieldrin

- Endrin

- Endrin

Ethylbenzene

Fluoride

- Heptachlor

Heptachlor

Iron, total recoverable

Iron, total recoverable

Lead, total recoverable

Lead, total recoverable

- Lindane

- Lindane

Litfium, total recoverable

Lithium, total recoverable

Magnesium, total recoverable

Magnesium, total recoverable

Manganese, total recoverable

Manganese, total recoverable

Mercury, total recoverable

Mercury, total recoverable

- Methoxychlor

- Methoxychlor

Naphthalene
Result DF

$<1.0$

$<2.0$

$<2.0$

4,780

4,790

$<1.0$

1.00

$<1.0 \quad 1.00$

$<1.0$

$<1.0$

$<1.0$

$<1.0$

$<4.0$

$<4.0$

4.0

4.1

$<5.0$

$<5.0$

$<0.10$

$<0.10$

$<1.0$

$<1.0$

$<1.0$

$<1.0$

$<1.0$

$<1.0$

$<0.0015$

$<1.0$

$<1.0$

$<1.0$

$<0.50$

$<0.50$

$<0.0060$

$<0.0060$

$<1.0$

$<100$

$<0.050$

$<0.050$

311

308

11

11

$<0.0050$

$<0.0050$

105

105

607

607

9.8

9.9

$<0.20$

$<0.20$

$<0.50$

$<0.50$

$<10$
DF

1.00

1.00

1.00

1.00

1.00

1.00

1.00

1.00
1.00

1.00

1.00

1.00

1.00

1.00

1.00

1.00

1.00

1.00

1.00

1.00

1.00

1.00

1.00

1.00

1.00

1.00

1.00

1.00

1.00

1.00

1.00

1.00

1.00

1.00

1.00

1.00

1.00

1.00

1.00

1.00

1.00

1.00

1.00

1.00

1.00

1.00

1.00

1.00

1.00

1.00

1.00

1.00

1.00
Mod

Unit

Flag

$\underline{L a b}$

跑

$\mu \mathrm{g} / \mathrm{L} \quad 0 \quad \mathrm{GE}$

$\begin{array}{lll}\mu \mathrm{g} / \mathrm{L} & 0 & \mathrm{GE} \\ \mu \mathrm{g} / \mathrm{L} & 0 & \mathrm{GE}\end{array}$

$\mu \mathrm{g} / \mathrm{L} \quad 0 \quad \mathrm{GE}$

$\mu \mathrm{g} / \mathrm{L} \quad 0 \quad \mathrm{GE}$

$\mu g / L \quad 0 \quad G E$

$\mu \mathrm{g} / \mathrm{L} \quad 0 \quad \mathrm{GE}$

$\mu g / L \quad 0 \quad$ GE

$\mu \mathrm{g} / \mathrm{L} \quad \mathrm{O} \quad \mathrm{GE}$

$\mu \mathrm{g} / \mathrm{L} \quad \mathrm{O} \quad \mathrm{GE}$

$\mu \mathrm{g} / \mathrm{L} \quad \mathrm{O} \quad \mathrm{GE}$

$\mu \mathrm{g} / \mathrm{L} \quad 0 \quad \mathrm{GE}$

$\mu \mathrm{g} / \mathrm{L} \quad 0 \quad \mathrm{GE}$

$\mu \mathrm{g} / \mathrm{L} \quad 0 \quad \mathrm{GE}$

$\mu \mathrm{g} / \mathrm{L} \quad \mathrm{O} \quad \mathrm{GE}$

$J \quad \mu g / L \quad 0 \quad$ GE

$J \quad \mu g / L \quad 0 \quad G E$

J3 $\mu \mathrm{g} / \mathrm{L} \quad \mathrm{O} \quad \mathrm{GE}$

$J \quad \mu g / L \quad 0 \quad G E$

$\mathrm{J} 1 \mu \mathrm{g} / \mathrm{L} \quad 0 \quad \mathrm{GE}$

$\mu g / L \quad 0 \quad$ GE

$\mu \mathrm{g} / \mathrm{L} \quad \mathrm{O} \quad \mathrm{GE}$

$\mu \mathrm{g} / \mathrm{L} \quad \mathrm{O} \quad \mathrm{GE}$

$\mu \mathrm{g} / \mathrm{L} \quad 0 \quad \mathrm{GE}$

$\mu g / L \quad O \quad G E$

$\mu \mathrm{g} / \mathrm{L} \quad \mathrm{O} \quad \mathrm{GE}$

$\mu g / L \quad 0 \quad G E$

$\mu \mathrm{g} / \mathrm{L} \quad \mathrm{O} \quad \mathrm{GE}$

$\mu g / L \quad 0 \quad G E$

$\mu \mathrm{g} / \mathrm{L} \quad 0 \quad \mathrm{GE}$

J1 $\mu \mathrm{g} / \mathrm{L} \quad \mathrm{O} \quad \mathrm{GE}$

$J \quad \mu g / L \quad 0 \quad G E$

J1 $\mu \mathrm{g} / \mathrm{L} \quad 0 \quad \mathrm{GE}$

$\begin{array}{lll}\mu g / L & 0 & G E \\ \mu g / L & 0 & G E\end{array}$

$\begin{array}{llll}J & \mu \mathrm{g} / \mathrm{L} & 0 & \mathrm{GE}\end{array}$

$J 1 \mu \mathrm{g} / \mathrm{L} \quad \mathrm{O} \quad \mathrm{GE}$

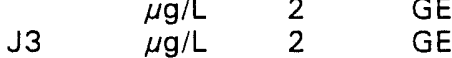

$\mu \mathrm{g} / \mathrm{L} \quad 0 \quad \mathrm{GE}$

$\mu g / L \quad 0 \quad G E$

$\mu \quad \mu g / L \quad O \quad G E$

GE

GE

GE

GE

GE

GE

$\mathrm{GE}$

GE

$J \mu g / L \quad 0 \quad$ GE

J1 $\mu \mathrm{g} / \mathrm{L} \quad \mathrm{O} \quad \mathrm{GE}$

$\mu \mathrm{g} / \mathrm{L} \quad \mathrm{O} \quad \mathrm{GE}$

$\overline{-=\text { exceeded holding time. }} \mathbf{-}=$ exceeded screening level or final primary drinking water standard. 
WELL BGO 160 collected on $02 / 03 / 94$, laboratory analyses (cont.)

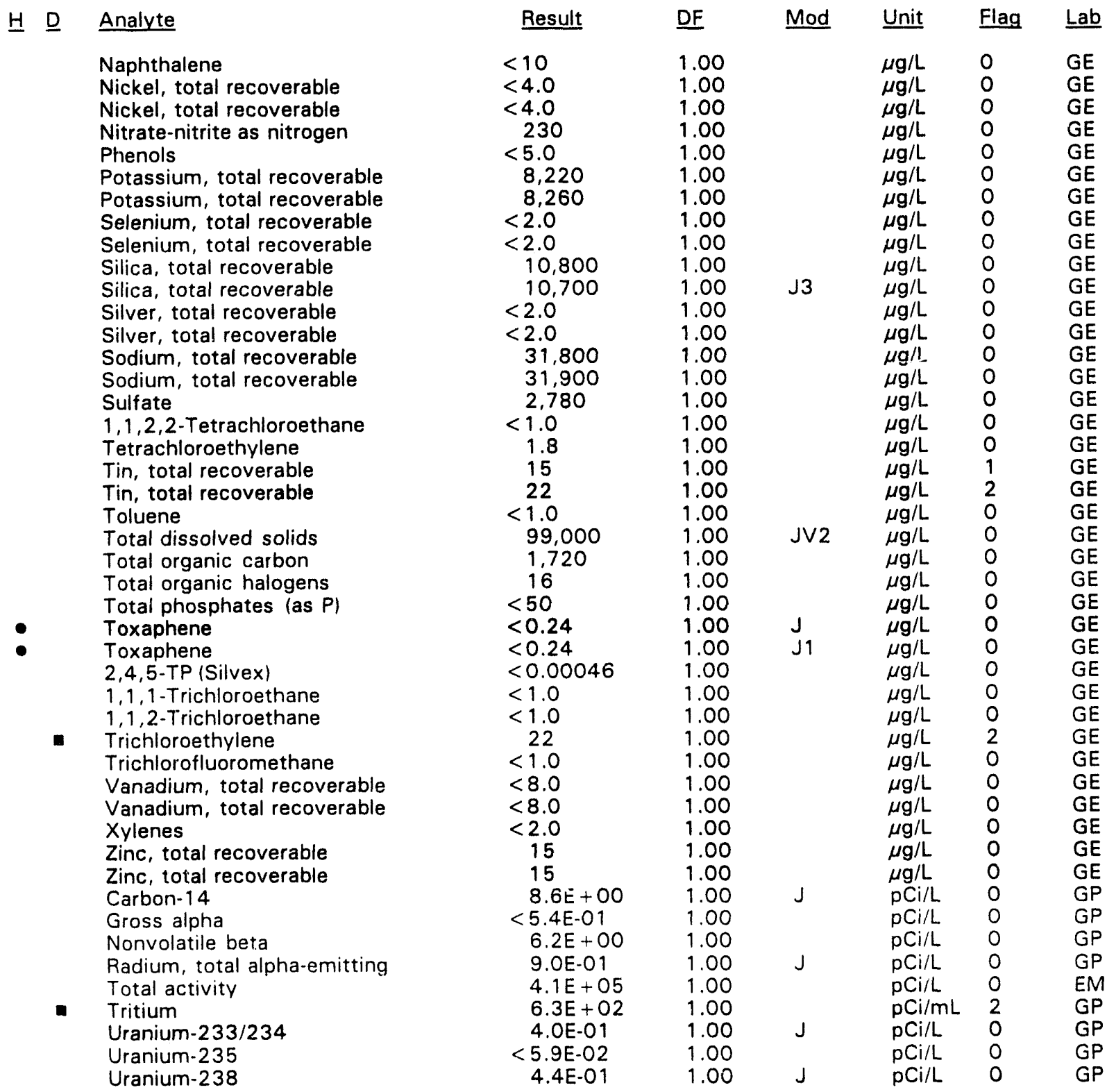

$\overline{-}=$ exceeded holding time. - = exceeded screening level or final primary drinking water standard. 


\section{WELL BGO 17DR}

\begin{tabular}{|c|c|c|c|c|c|c|}
\hline SRS Coord. & Lat/Longitude & Screen Zone Elevation & Top of Casing & C.asing & Pump & Formation \\
\hline $\begin{array}{l}\text { N75604.0 } \\
\text { E56407.2 }\end{array}$ & $\begin{array}{l}33.285022^{\circ} \mathrm{N} \\
81.665128^{\circ} \mathrm{W}\end{array}$ & $236.9-216.9 \mathrm{ft} \mathrm{msl}$ & $299.2 \mathrm{ft} \mathrm{msl}$ & 4" PVC & 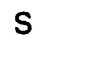 & Water Table $\left(I I B_{2}\right)$ \\
\hline
\end{tabular}

\section{FIELD MEASUREMENTS}

Sample date: $02 / 03 / 94$

Depth to water: $67.85 \mathrm{ft}(20.68 \mathrm{~m})$ below TOC

Water elevation: $231.35 \mathrm{ft}(70.52 \mathrm{~m}) \mathrm{msl}$

Sp. conductance: $22 \mu \mathrm{S} / \mathrm{cm}$

Turbidity: 31.2 NTU

Water evacuated before sampling: $7 \mathrm{gal}$

The well went dry during purging.

Time: $10: 36$

$\mathrm{pH}: 5.6$

Alkalinity: $2 \mathrm{mg} / \mathrm{L}$

Water temperature: $16.9^{\circ} \mathrm{C}$

Volumes purged: 0.7 well volumes

\section{LABORATORY ANALYSES}

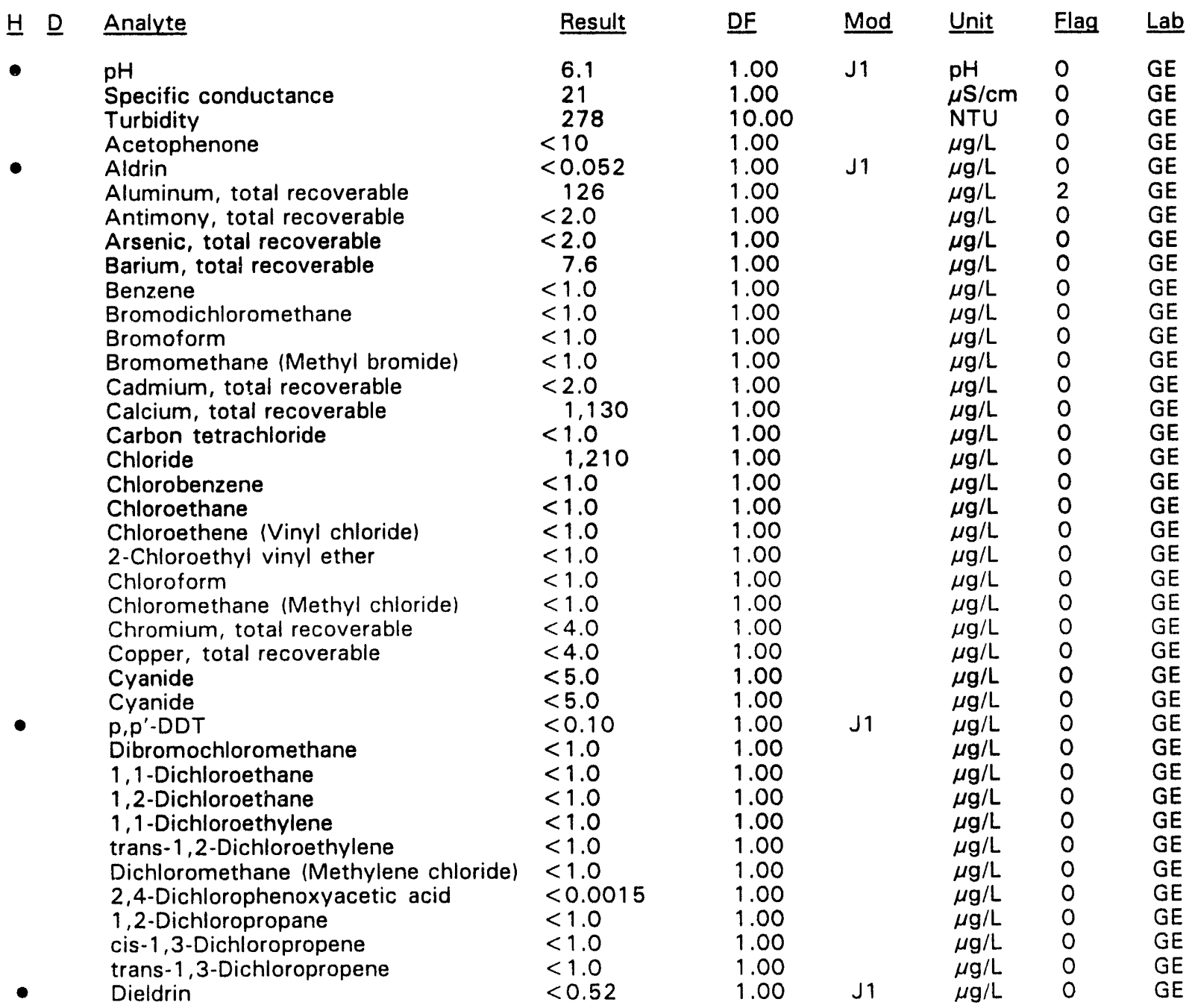

- = exceeded holding time. = exceeded screening level or final primary drinking water standard. 
WELL BGO 170R collected on 02/03/94, laboratory analyses (cont.)

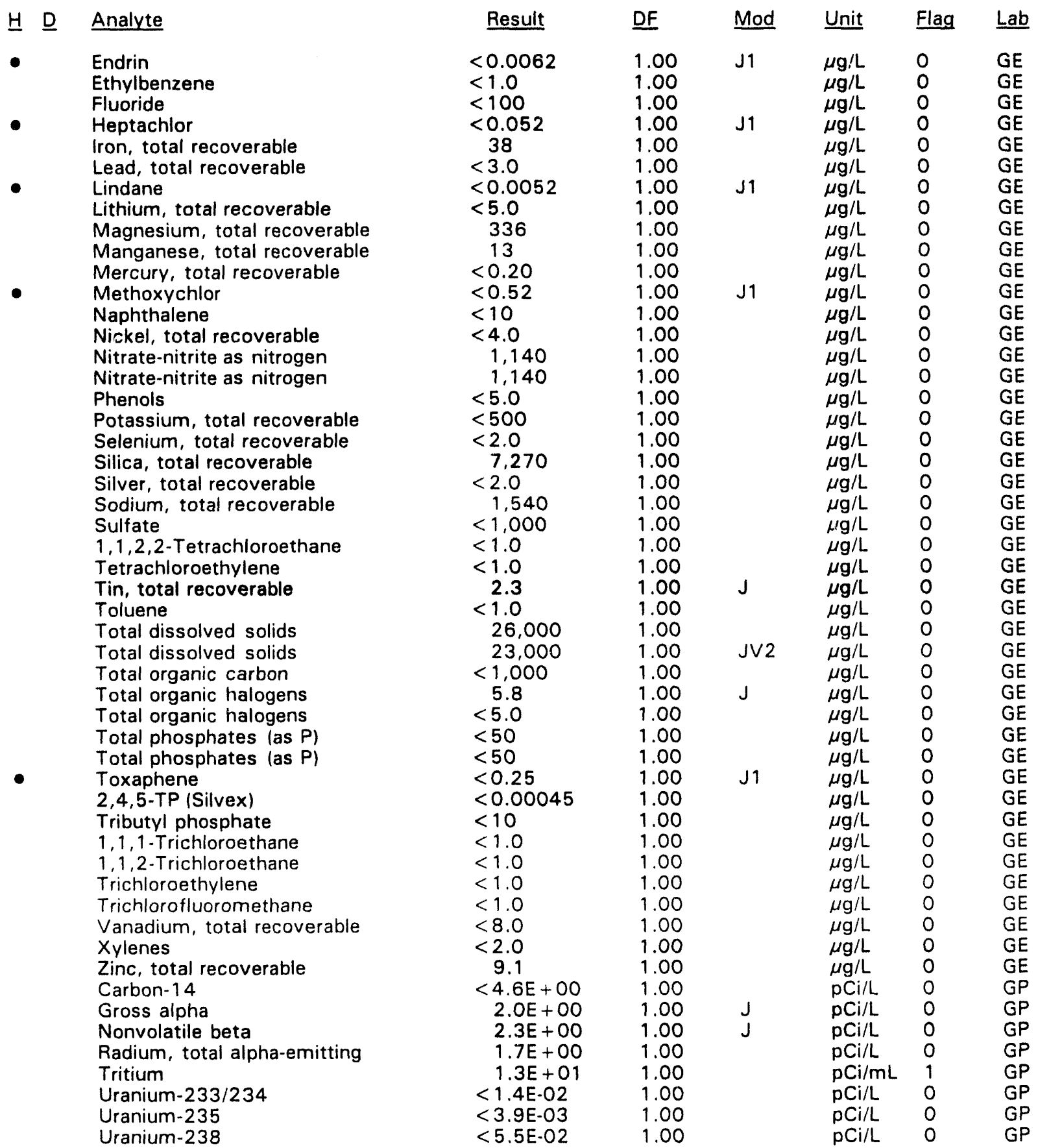

- = exceeded holding time. = exceeded screening level or final primary drinking water standard. 


\section{WELL BGO 18A}

\begin{tabular}{|c|c|c|c|c|c|c|}
\hline SRS Coord. & Lat/Longitude & Screen Zone Elevation & Top of Casing & Casing & Pump & Formation \\
\hline $\begin{array}{l}N 75599.9 \\
E 56699.7\end{array}$ & $\begin{array}{l}33.285490^{\circ} \mathrm{N} \\
81.664350^{\circ} \mathrm{W}\end{array}$ & $109.5-99.5 \mathrm{ft} \mathrm{msl}$ & $295.2 \mathrm{ft} \mathrm{msl}$ & 4" PVC & $\mathbf{S}$ & ree (IIA) \\
\hline
\end{tabular}

\section{FIELD MEASUREMENTS}

Sample date: $02 / 02 / 94$

Depth to water: $134.22 \mathrm{ft}(40.91 \mathrm{~m})$ below TOC

Water elevation: $160.98 \mathrm{ft}(49.07 \mathrm{~m}) \mathrm{msl}$

Sp. conductance: $190 \mu \mathrm{S} / \mathrm{cm}$

Turbidity: 0.2 NTU

Water evacuated before sampling: $150 \mathrm{gal}$

Time: 10: 29

pH: 7.1

Alkalinity: $74 \mathrm{mg} / \mathrm{L}$

Water temperature: $18.6^{\circ} \mathrm{C}$

Volumes purged: 3.7 well volumes

\section{LABORATORY ANALYSES}

H $\underline{\text { Analyta }}$

$\mathrm{pH}$

Specific conductance

Specific conductance

Turbidity

Acetophenone

Aldrin

Aluminum, total recoverable

Antimony, total recoverable

Arsenic, total recoverable

Barium, total recoverable

Benzene

Bromodichloromethane

Bromoform

Bromomethane (Methyl bromide)

Cadmium, total recoverable

Calcium, total recoverable

Carbon tetrachloride

Chloride

Chlorobenzene

Chloroethane

Chloroethene (Vinyl chloride)

2-Chloroethyl vinyl ether

Chloroform

Chloromethane (Methyl chloride)

Chromium, total recoverable

Copper, total recoverable

Cyanide

$p, p^{\prime}$-DDT

Dibromochloromethane

1,1-Dichloroethane

1,2-Dichloroethane

1,1-Dichloroethylene

trans-1,2-Dichloroethylene

Dichloromethane (Methylene chloride)

2,4-Dichlorophenoxyacetic acid

1,2-Dichloropropane

cis-1,3-Dichloropropene

trans-1,3-Dichloropropene

Dieldrin
Result

7.0

185

186

$<0.10$

$<9.8$

$<0.050$

$<20$

$<2.0$

$<2.0$

32

$<1.0$

$<1.0$

$<1.0$

$<1.0$

$<2.0$

33,500

$<1.0$

2,460

$<1.0$

$<1.0$

$<1.0$

$<1.0$

$<1.0$

$<1.0$

$<4.0$

$<4.0$

$<5.0$

$<0.099$

$<1.0$

$<1.0$

$<1.0$

$<1.0$

$<1.0$

$<1.0$

$<0.0015$

$<1.0$

$<1.0$

$<1.0$

$<0.50$

DF
1.00
1.00
1.00
1.00
1.00
1.00
1.00
1.00
1.00
1.00
1.00
1.00
1.00
1.00
1.00
1.00
1.00
1.00
1.00
1.00
1.00
1.00
1.00
1.00
1.00
1.00
1.00
1.00
1.00
1.00
1.00
1.00
1.00
1.00
1.00
1.00
1.00
1.00
1.00

DF

Mod

Unit

Flag

Lab

.00

1.00

1.00

1.00

1.00

1.00

1.00

1.00

1.00

1.00

1.00

1.00

1.00

1.00

1.00

1.00

1.00

1.00

1.00

1.00

1.00

1.00

1.00

1.00

1.00

1.00

1.00

1.00

J1

$\begin{array}{lll}\mathrm{pH} & 0 & \mathrm{GE} \\ \mu \mathrm{S} / \mathrm{cm} & 0 & \mathrm{GE} \\ \mu \mathrm{S} / \mathrm{cm} & 0 & \mathrm{GE} \\ \mathrm{NTU} & 0 & \mathrm{GE}\end{array}$

$\mu \mathrm{g} / \mathrm{L}$

$\mu \mathrm{g} / \mathrm{L}$

$\mu \mathrm{g} / \mathrm{L}$

$\mu \mathrm{g} / \mathrm{L}$

$\mu g / L$

$\mu \mathrm{g} / \mathrm{L}$

$\mu \mathrm{g} / \mathrm{L}$

$\mu \mathrm{g} / \mathrm{L}$

$\mu \mathrm{g} / \mathrm{L}$

$\mu \mathrm{g} / \mathrm{L}$

$\mu \mathrm{g} / \mathrm{L}$

$\mu \mathrm{g} / \mathrm{L}$

$\mu \mathrm{g} / \mathrm{L}$

$\mu g / L$

$\mu \mathrm{g} / \mathrm{L}$

$\mu \mathrm{g} / \mathrm{L}$

$\mu \mathrm{g} / \mathrm{L}$

$\mu \mathrm{g} / \mathrm{L}$

$\mu \mathrm{g} / \mathrm{L}$

$\mu \mathrm{g} / \mathrm{L}$

$\mu \mathrm{g} / \mathrm{L}$

$\mu \mathrm{g} / \mathrm{L}$

$\mu \mathrm{g} / \mathrm{L}$

$\mu \mathrm{g} / \mathrm{L}$

$\mu \mathrm{g} / \mathrm{L}$

$\mu \mathrm{g} / \mathrm{L}$

$\mu \mathrm{g} / \mathrm{L}$

$\mu \mathrm{g} / \mathrm{L}$

$\mu \mathrm{g} / \mathrm{L}$

$\mu g / L$

$\mu \mathrm{g} / \mathrm{L}$

$\mu \mathrm{g} / \mathrm{L}$

$\mu \mathrm{g} / \mathrm{L}$

$\mu \mathrm{g} / \mathrm{L}$

$\mu \mathrm{g} / \mathrm{L}$
GE
$G E$
$G E$
$G E$
$G E$
$G E$
$G E$
$G E$
$G E$
$G E$
$G E$
$G E$
$G E$
$G E$
$G E$
$G E$
$G E$
$G E$
$G E$
$G E$
$G E$
$G E$
$G E$
$G E$
$G E$
$G E$
$G E$
$G E$
$G E$
$G E$
$G E$
$G E$
$G E$
$G E$
$G E$
$G E$
$G E$
$G E$
$G E$

$\overline{-}=$ exceeded holding time. $=$ exceeded screening level or final primary drinking water standard. 
WELL BGO 18A collected on 02/02/94, laboratory analyses (cont.)

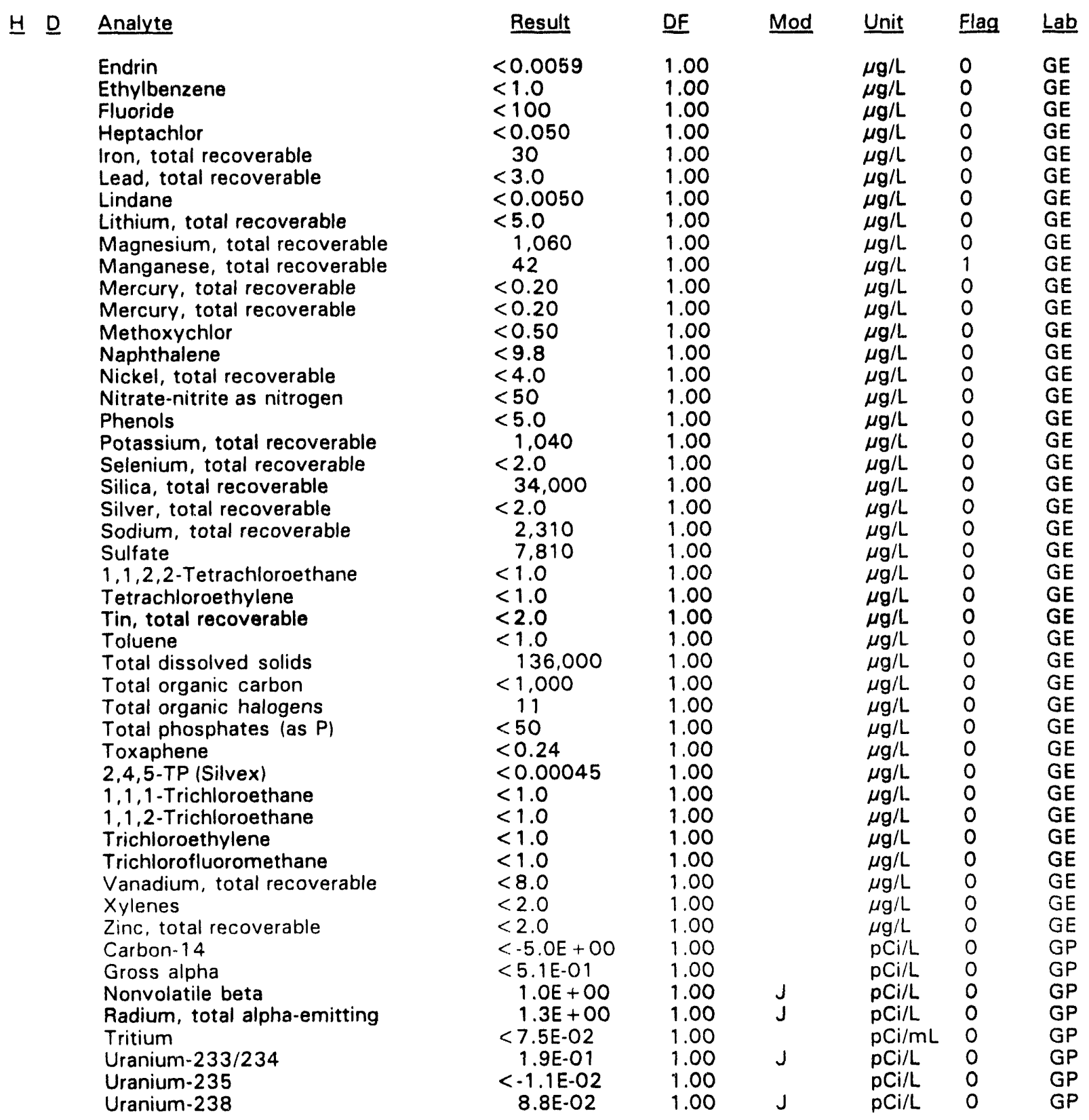

\footnotetext{
$\overline{-=}$ exceeded holding time. $\boldsymbol{\omega}=$ exceeded screening level or final primary drinking water standard.
} 


\section{WELL BGO 18D}

\begin{tabular}{|c|c|c|c|c|c|c|}
\hline SRS Coord. & Lat/Longitude & Screen Zone Elevation & Top of Casing & Casing & Pump & Formation \\
\hline $\begin{array}{l}\text { N75600.0 } \\
\text { E56711.2 }\end{array}$ & $\begin{array}{l}33.285509^{\circ} \mathrm{N} \\
81.664320^{\circ} \mathrm{W}\end{array}$ & $239.6-219.6 \mathrm{ft} \mathrm{msl}$ & $294.9 \mathrm{ft} \mathrm{msl}$ & 4" PVC & $\mathbf{S}$ & Water Table $\left(I 1 B_{2}\right)$ \\
\hline
\end{tabular}

\section{FIELD MEASUREMENTS}

Sample date: $02 / 02 / 94$

Depth to water: $62.45 \mathrm{ft}(19.03 \mathrm{~m})$ below TOC

Water elevation: $232.45 \mathrm{ft}(70.85 \mathrm{~m}) \mathrm{msl}$

Sp. conductance: $26 \mu \mathrm{S} / \mathrm{cm}$

Turbidity: 0.2 NTU

Water evacuated before sampling: $115 \mathrm{gal}$

\section{LABORATORY ANALYSES}

느 Analyte

\section{$\mathrm{pH}$}

Specific conductance

Turbidity

Turbidity

Acetophenone

Aldrin

Aldrin

Aluminum, total recoverable

Antimony, total recoverable

Arsenic, total recoverable

Barium, total recoverable

Benzene

Benzene

Bromodichloromethane

Bromodichloromethane

Bromoform

Bromoform

Bromomethane (Methyl bromide)

Bromomethane (Methyl bromide)

Cadmium, total recoverable

Calcium, total recoverable

Carbon tetrachloride

Carbon tetrachloride

Chloride

Chlorobenzene

Chlorobenzene

Chloroethane

Chloroethane

Chloroethene (Vinyl chloride)

Chloroethene (Vinyl chloride)

2-Chloroethyl vinyl ether

2-Chloroethyl vinyl ether

Chloroform

Chloroform

Chloromethane (Methyl chloride)

Chloromethane (Methyl chloride)

Chromium, total recoverable

Copper, total recoverable

Cyanide
Time: 10: 02

pH: 4.8

Alkalinity: $0 \mathrm{mg} / \mathrm{L}$

Water temperature: $18.8^{\circ} \mathrm{C}$

Volumes purged: 13.6 well volumes

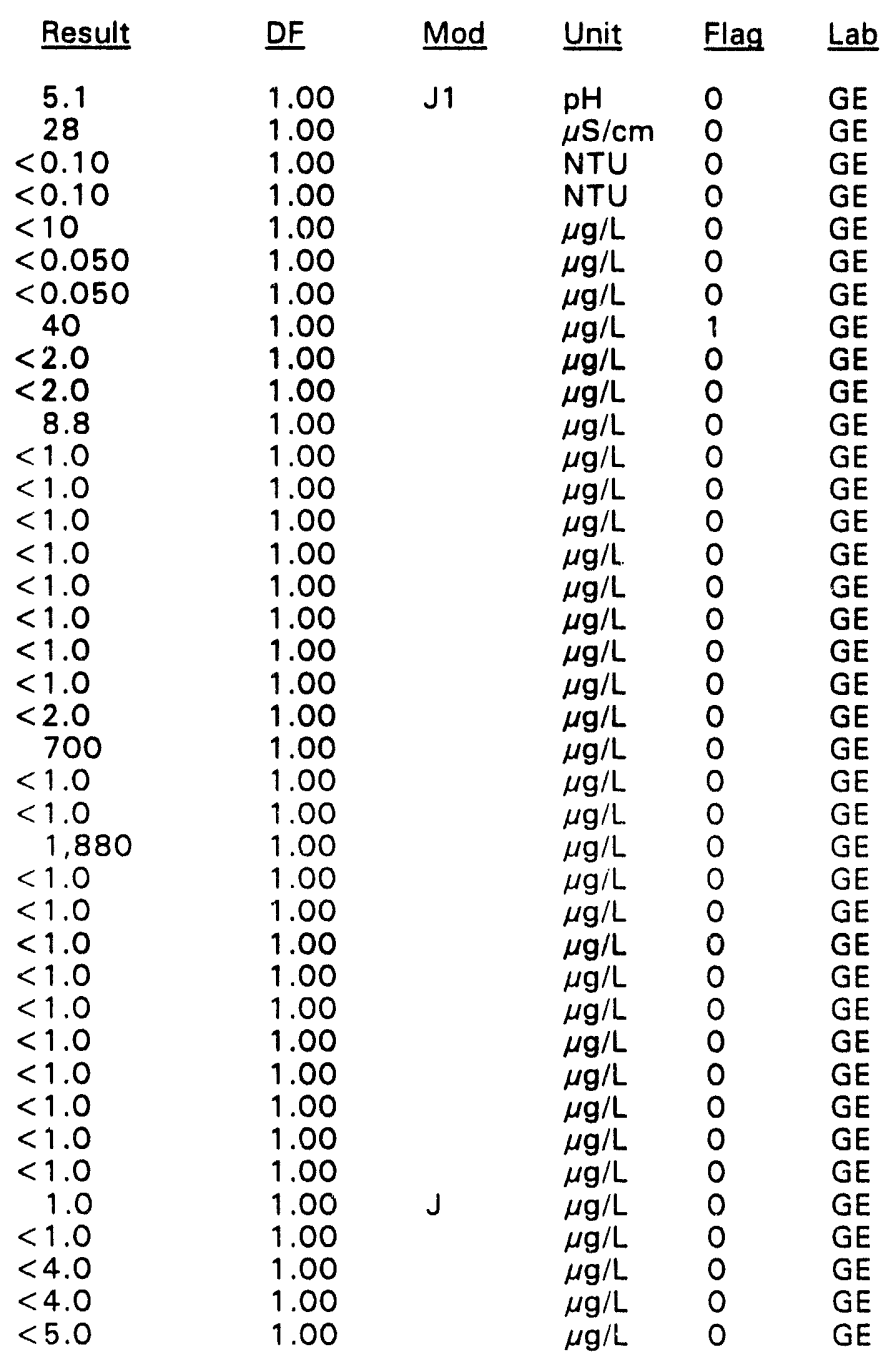

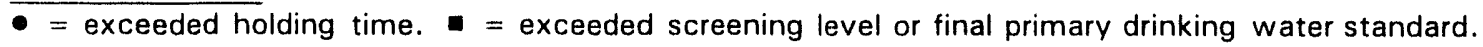


WELL BGO 180 collected on 02/02/94, laboratory analyses (cont.)

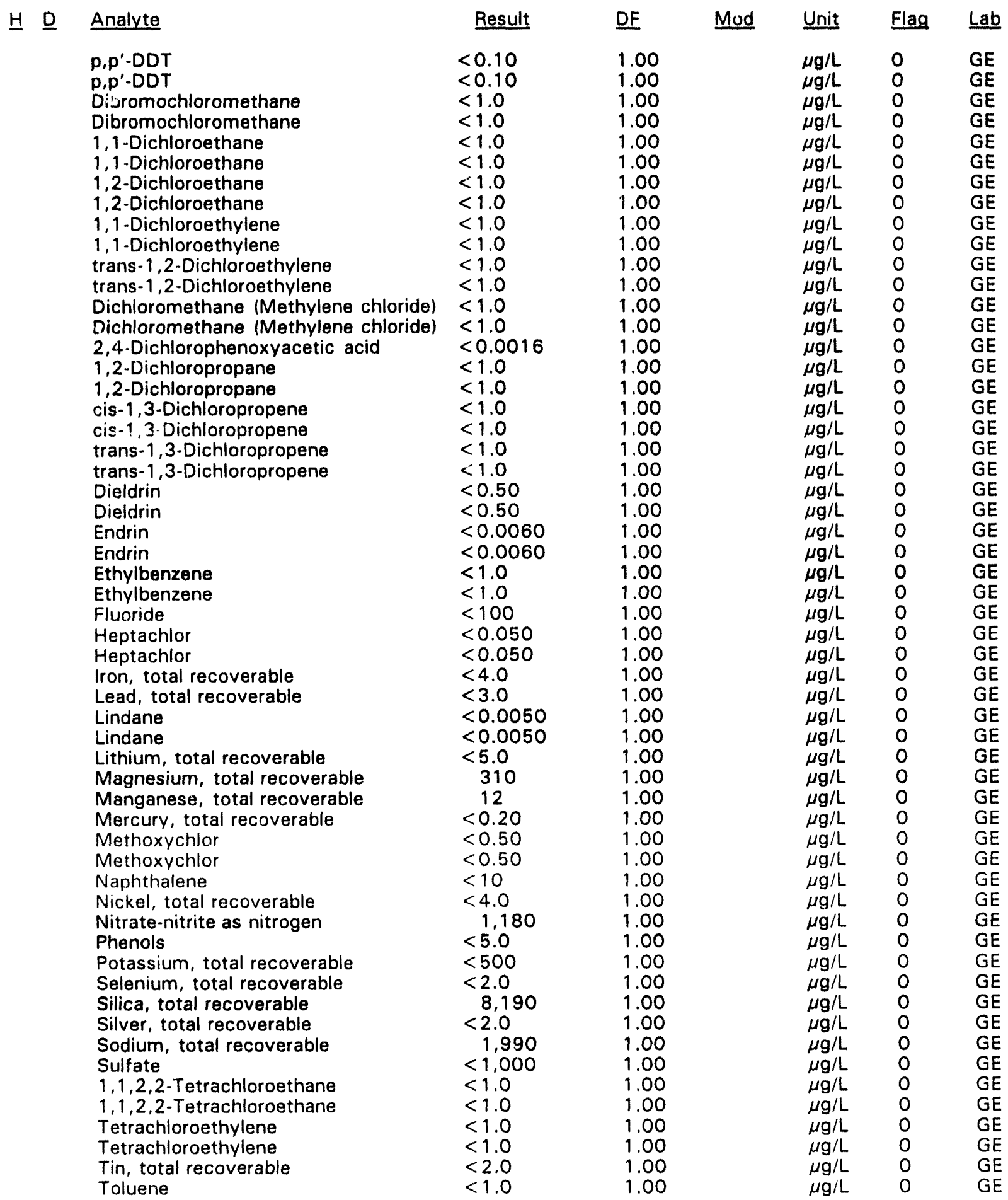

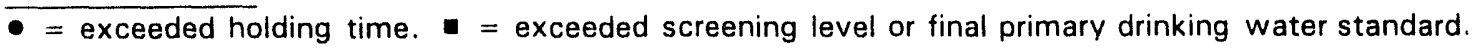


WELL BGO 18D collected on 02/02/94, laboratory analyses (cont.)

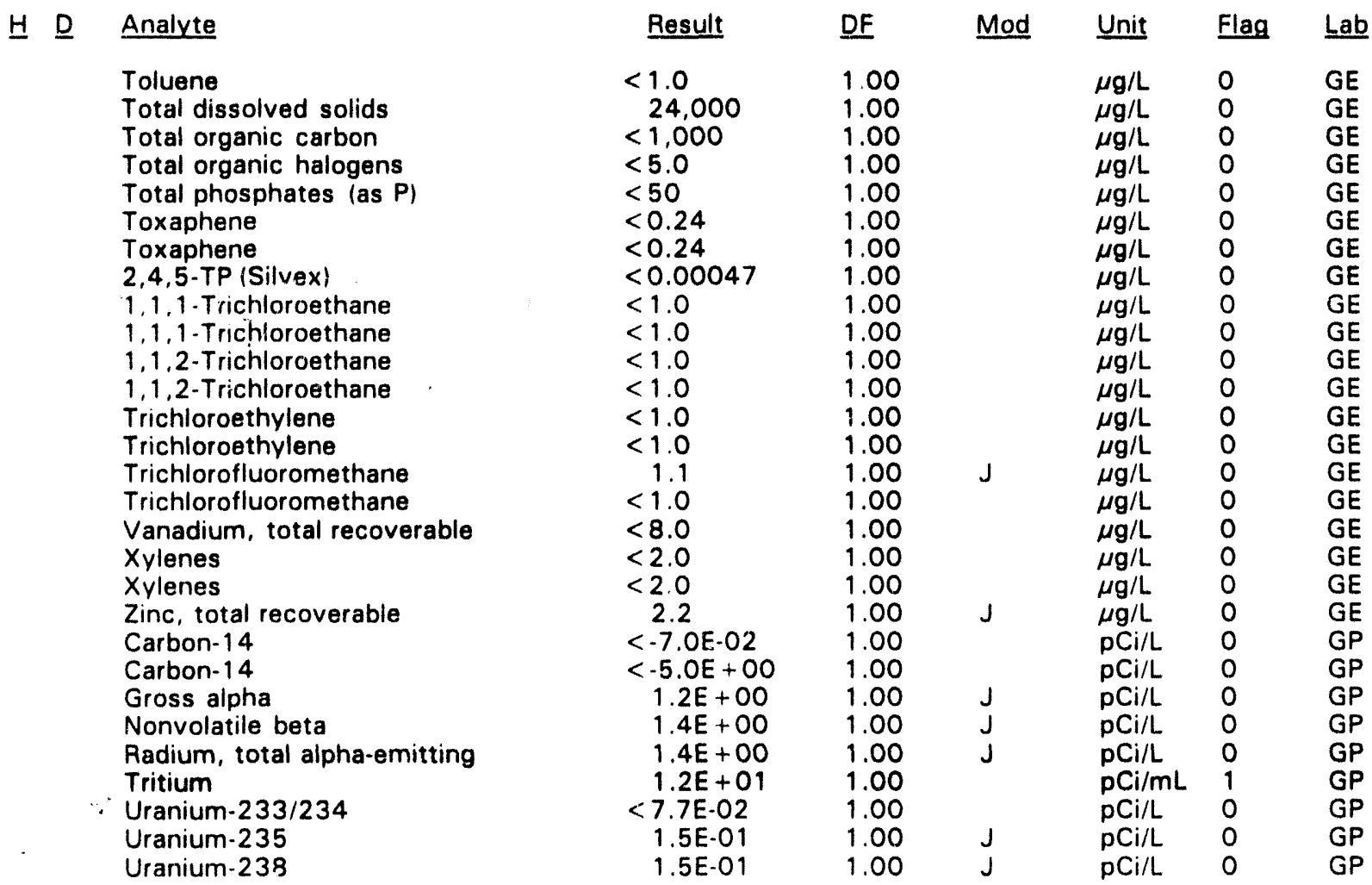

\section{WELL BGO 19D}

$\begin{array}{lllllll}\text { SRS Coord. } & \text { Lat/Longitude } & \text { Screen Zone Elevation } & \text { Iop of Casing } & \text { Casing } & \text { Pump } & \text { Formation } \\ \text { N75350.0 } & 33.285423^{\circ} \mathrm{N} & 213.9-193.9 \mathrm{ft} \mathrm{msl} & 287.2 \mathrm{ft} \mathrm{msl} & \text { 4" PVC } & \text { S } & \left.\text { Water Table (IIB }{ }_{2}\right) \\ \text { E56997.3 } & 81.663081^{\circ} \mathrm{W} & & & \end{array}$

\section{FIELD MEASUREMENTS}

Sample date: 02/02/94

Depth to water: $57.07 \mathrm{ft}(17.40 \mathrm{~m})$ below TOC

Water elevation: $230.13 \mathrm{ft}(70.14 \mathrm{~m}) \mathrm{msl}$

Sp. conductance: $34 \mu \mathrm{S} / \mathrm{cm}$

Turbidity: 3.1 NTU

Water evacuated before sampling: $158 \mathrm{gal}$

\section{LABORATORY ANALYSES}

H $\underline{\text { Analyte }}$

$\mathrm{pH}$

Specific conductance

Turbidity

Acetophenone

Aldrin
Time: $11: 26$

$\mathrm{pH}: 5.7$

Alkalinity: $3 \mathrm{mg} / \mathrm{L}$

Water temperature: $18.0^{\circ} \mathrm{C}$

Volumes purged: 6.6 well volumes
Lab
GE
GE
GE
GE
GE
GE
GE
GE
GE
GE
GE
GE
GE
$G E$
$G E$
$G E$
$G E$
$G E$
$G E$
$G E$
$G P$
$G P$
$G P$
$G P$
$G P$
$G P$
$G P$
$G P$
$G P$ 
WELL BGO 190 collected on $02 / 02 / 94$, laboratory analyses (cont.)

\section{H D Analyte}

Aluminum, total recoverable Antimony, total recoverable

Arsenic, total recoverable

Barium, total recoverable

Benzene

Bromodichloromethane

Bromoform

Bromomethane (Methyl bromide)

Cadmium, total recoverable

Calcium, total recoverable

Carbon tetrachloride

Chloride

Chlorobenzene

Chloroethane

Chloroethene (Vinyl chloride)

2-Chloroethyl vinyl ether

Chloroform

Chloromethane (Methyl chloride)

Chromium, total recoverable

Copper, total recoverable

Cyanide

Cyanide

p, $p^{\prime}$-DDT

Dibromochloromethane

1,1-Dichloroethane

1,2-Dichloroethane

1,1-Dichloroethylene

trans-1,2-Dichloroethylene

Dichloromethane (Methylene chloride)

2,4-Dichlorophenoxyacetic acid

1,2-Dichloropropane

cis-1,3-Dichloropropene

trans-1,3-Dichloropropene

Dieldrin

Endrin

Ethylbenzene

Fluoride

Heptachlor

Iron, total recoverable

Lead, total recoverable

Lindane

Lithium, total recoverable

Magnesium, total recoverable

Manganese, total recoverable

Mercury, total recoverable

Methoxychlor

Naphthalene

Nickel, total recoverable

Nitrate-nitrite as nitrogen

Phenols

Potassium, total recoverable

Selenium, total recoverable

Silica, total recoverable

Silver, total recoverable

Sodium, total recoverable

Sulfate

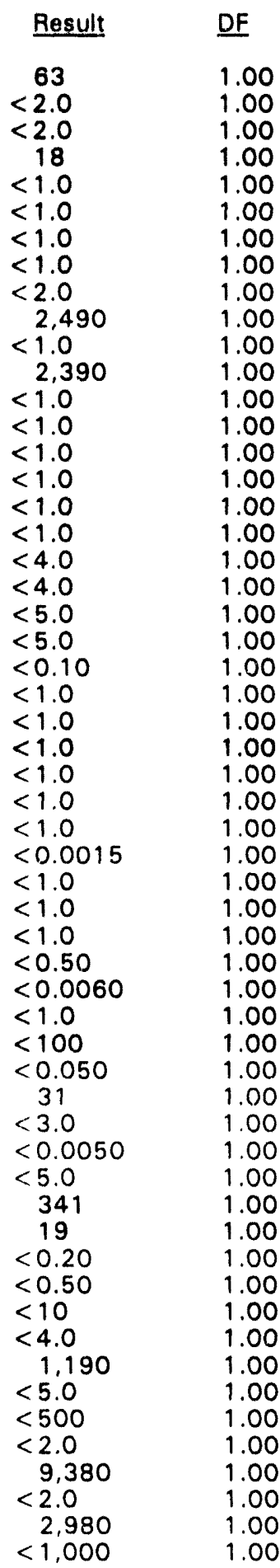

Mod

Unit Flag La

$\mu \mathrm{g} / \mathrm{L}$

$\mu g / L$

$\mu g / L$

$\mu g / L$

$\mu \mathrm{g} / \mathrm{L}$

$\mu \mathrm{g} / \mathrm{L}$

$\mu g / L$

$\mu g / L$

$\mu \mathrm{g} / \mathrm{L}$

$\mu \mathrm{g} / \mathrm{L}$

$\mu \mathrm{g} / \mathrm{L}$

$\mu g / L$

$\mu \mathrm{g} / \mathrm{L}$

$\mu \mathrm{g} / \mathrm{L}$

$\mu \mathrm{g} / \mathrm{L}$

$\mu \mathrm{g} / \mathrm{L}$

$\mu \mathrm{g} / \mathrm{L}$

$\mu \mathrm{g} / \mathrm{L}$

$\mu \mathrm{g} / \mathrm{L}$

$\mu \mathrm{g} / \mathrm{L}$

$\mu g / L$

$\mu g / L$

$\mu \mathrm{g} / \mathrm{L}$

$\mu \mathrm{g} / \mathrm{L}$

$\mu \mathrm{g} / \mathrm{L}$

$\mu \mathrm{g} / \mathrm{L}$

$\mu \mathrm{g} / \mathrm{L}$

$\mu \mathrm{g} / \mathrm{L}$

$\mu \mathrm{g} / \mathrm{L}$

$\mu \mathrm{g} / \mathrm{L}$

$\mu \mathrm{g} / \mathrm{L}$

$\mu \mathrm{g} / \mathrm{L}$

$\mu \mathrm{g} / \mathrm{L}$

$\mu \mathrm{g} / \mathrm{L}$

$\mu \mathrm{g} / \mathrm{L}$

$\mu g / L$

$\mu \mathrm{g} / \mathrm{L}$

$\mu \mathrm{g} / \mathrm{L}$

$\mu g / L$

$\mu \mathrm{g} / \mathrm{L}$

$\mu \mathrm{g} / \mathrm{L}$

$\mu \mathrm{g} / \mathrm{L}$

$\mu \mathrm{g} / \mathrm{L}$

$\mu g / L$

$\mu \mathrm{g} / \mathrm{L}$

$\mu \mathrm{g} / \mathrm{L}$

$\mu \mathrm{g} / \mathrm{L}$

$\mu \mathrm{g} / \mathrm{L}$

$\mu \mathrm{g} / \mathrm{L}$

$\mu \mathrm{g} / \mathrm{L}$

$\mu \mathrm{g} / \mathrm{L}$

$\mu \mathrm{g} / \mathrm{L}$

$\mu \mathrm{g} / \mathrm{L}$

$\mu \mathrm{g} / \mathrm{L}$

$\mu \mathrm{g} / \mathrm{L}$

$\mu \mathrm{g} / \mathrm{L}$
2 GE

GE

GE

GE

GE

GE

GE

GE

GE

GE

GE

GE

GE

GE

GE

GE

GE

GE

GE

GE

GE

GE

GE

GE

GE

GE

GE

GE

GE

GE

GE

GE

GE

GE

GE

GE

GE

GE

$\mathrm{GE}$

$G E$

GE

$G E$

GE

GE

GE

GE

$\mathrm{GE}$

GE

$G E$

GE

GE

GE

GE

- = exceeded holding time. $\square=$ exceeded screening level or final primary drinking water standard. 
WELL BGO 190 collected on $02 / 02 / 94$, laboratory analyses (cont.)

\begin{tabular}{|c|c|c|c|c|c|c|}
\hline$\underline{H} \underline{D}$ & Analyte & Result & $\underline{D F}$ & Mod & $\underline{\text { Unit }}$ & Flag \\
\hline w & $\begin{array}{l}1,1,2,2-\text { Tetrachloroethane } \\
\text { Tetrachloroethylene } \\
\text { Tin, total recoverable } \\
\text { Toluene } \\
\text { Total dissolved solids } \\
\text { Total organic carbon } \\
\text { Total organic halogens } \\
\text { Total phosphates (as P) } \\
\text { Toxaphene } \\
2,4,5-\text { TP (Silvex) } \\
1,1,1-\text { Trichloroethane } \\
1,1,2-\text { Trichloroethane } \\
\text { Trichloroethylene } \\
\text { Trichlorofluoromethane } \\
\text { Vanadium, total recoverable } \\
\text { Xylenes } \\
\text { Zinc, total recoverable } \\
\text { Carbon- } 14 \\
\text { Gross alpha } \\
\text { Nonvolatile beta } \\
\text { Radium, total alpha-emitting } \\
\text { Tritium } \\
\text { Uranium-233/234 } \\
\text { Uranium-235 } \\
\text { Uranium-238 }\end{array}$ & $\begin{aligned}< & 1.0 \\
< & 1.0 \\
& 2.3 \\
< & 1.0 \\
& 30,000 \\
< & 1.000 \\
< & 5.0 \\
< & 50 \\
< & 0.24 \\
< & 0.00046 \\
< & 1.0 \\
< & 1.0 \\
< & 1.0 \\
< & 1.0 \\
< & 8.0 \\
< & 2.0 \\
& 10.0 \\
< & -4.7 E+00 \\
& 1.2 E+00 \\
& 1.8 E+00 \\
& 1.5 E+00 \\
& 5.6 E+01 \\
& 1.0 E-01 \\
< & -4.8 E-03 \\
& 1.2 E-01\end{aligned}$ & $\begin{array}{l}1.00 \\
1.00 \\
1.00 \\
1.00 \\
1.00 \\
1.00 \\
1.00 \\
1.00 \\
1.00 \\
1.00 \\
1.00 \\
1.00 \\
1.00 \\
1.00 \\
1.00 \\
1.00 \\
1.00 \\
1.00 \\
1.00 \\
1.00 \\
1.00 \\
1.00 \\
1.00 \\
1.00 \\
1.00\end{array}$ & $\begin{array}{l}\mathrm{J} \\
\mathrm{J} \\
\mathrm{J}\end{array}$ & $\begin{array}{l}\mu g / L \\
\mu g / L \\
\mu g / L \\
\mu g / L \\
\mu g / L \\
\mu g / L \\
\mu g / L \\
\mu g / L \\
\mu g / L \\
\mu g / L \\
\mu g / L \\
\mu g / L \\
\mu g / L \\
\mu g / L \\
\mu g / L \\
\mu g / L \\
\mu g / L \\
\mathrm{pCi} / L \\
\mathrm{pCi} / \mathrm{L} \\
\mathrm{pCi} / \mathrm{L} \\
\mathrm{pCi} / \mathrm{L} \\
\mathrm{pCi} / \mathrm{mL} \\
\mathrm{pCi} / \mathrm{L} \\
\mathrm{pCi} / \mathrm{L} \\
\mathrm{pCi} / \mathrm{L}\end{array}$ & $\begin{array}{l}0 \\
0 \\
0 \\
0 \\
0 \\
0 \\
0 \\
0 \\
0 \\
0 \\
0 \\
0 \\
0 \\
0 \\
0 \\
0 \\
0 \\
0 \\
0 \\
0 \\
0 \\
2 \\
0 \\
0 \\
0\end{array}$ \\
\hline
\end{tabular}

\section{WELL BGO 20D}

\begin{tabular}{|c|c|c|c|c|c|c|}
\hline SRS Coord. & Lat/Longitude & Screen Zone Elevation & Top of Casing & Casing & Pump & Formation \\
\hline $\begin{array}{l}N 74962.2 \\
E 57113.8\end{array}$ & $\begin{array}{l}33.284755^{\circ} \mathrm{N} \\
81.662021^{\circ} \mathrm{W}\end{array}$ & $236.3-216.3 \mathrm{ft} \mathrm{msl}$ & $283.7 \mathrm{ft} \mathrm{msl}$ & 4" PVC & $\mathbf{S}$ & Water Table $\left(\| \mathrm{B}_{2}\right)$ \\
\hline
\end{tabular}

\section{FIELD MEASUREMENTS}

Sample date: $02 / 03 / 94$

Depth to water: $49.40 \mathrm{ft}(15.06 \mathrm{~m})$ below TOC

Water elevation: $234.30 \mathrm{ft}(71.42 \mathrm{~m}) \mathrm{msl}$

Sp. conductance: $68 \mu \mathrm{S} / \mathrm{cm}$

Turbidity: 7.7 NTU

Water evacuated before sampling: $8 \mathrm{gal}$

The well went dry during purging.

\section{LABORATORY ANALYSES}

$\begin{array}{ll}\text { HD } & \text { Analyte } \\ \text { pH } & \text { Specific conductance } \\ \text { Turbidity } \\ \text { Acetophenone } \\ \text { Aldrin } \\ \text { Aluminum, total recoverable } \\ \text { Antimony, total recoverable } \\ \text { Arsenic, total recoverable } \\ \text { Barium, total recoverable }\end{array}$

\begin{tabular}{|c|c|}
\hline Result & DF \\
\hline $\begin{aligned} & 5.8 \\
& 64 \\
& 2.7 \\
< & 9.9 \\
< & 0.050 \\
& 49 \\
< & 2.0 \\
< & 2.0 \\
& 46\end{aligned}$ & $\begin{array}{l}1.00 \\
1.00 \\
1.00 \\
1.00 \\
1.00 \\
1.00 \\
1.00 \\
1.00 \\
1.00\end{array}$ \\
\hline
\end{tabular}

Time: 10: 52

$\mathrm{pH}: 5.5$

Alkalinity: $16 \mathrm{mg} / \mathrm{L}$

Water temperature: $16.0^{\circ} \mathrm{C}$

Volumes purged: 0.7 well volumes

$\overline{-}=$ exceeded holding time. $\mathbf{E}=$ exceeded screening level or final primary drinking water standard. 
WELL BGO 200 collected on $02 / 03 / 94$, laboratory analyses (cont.)

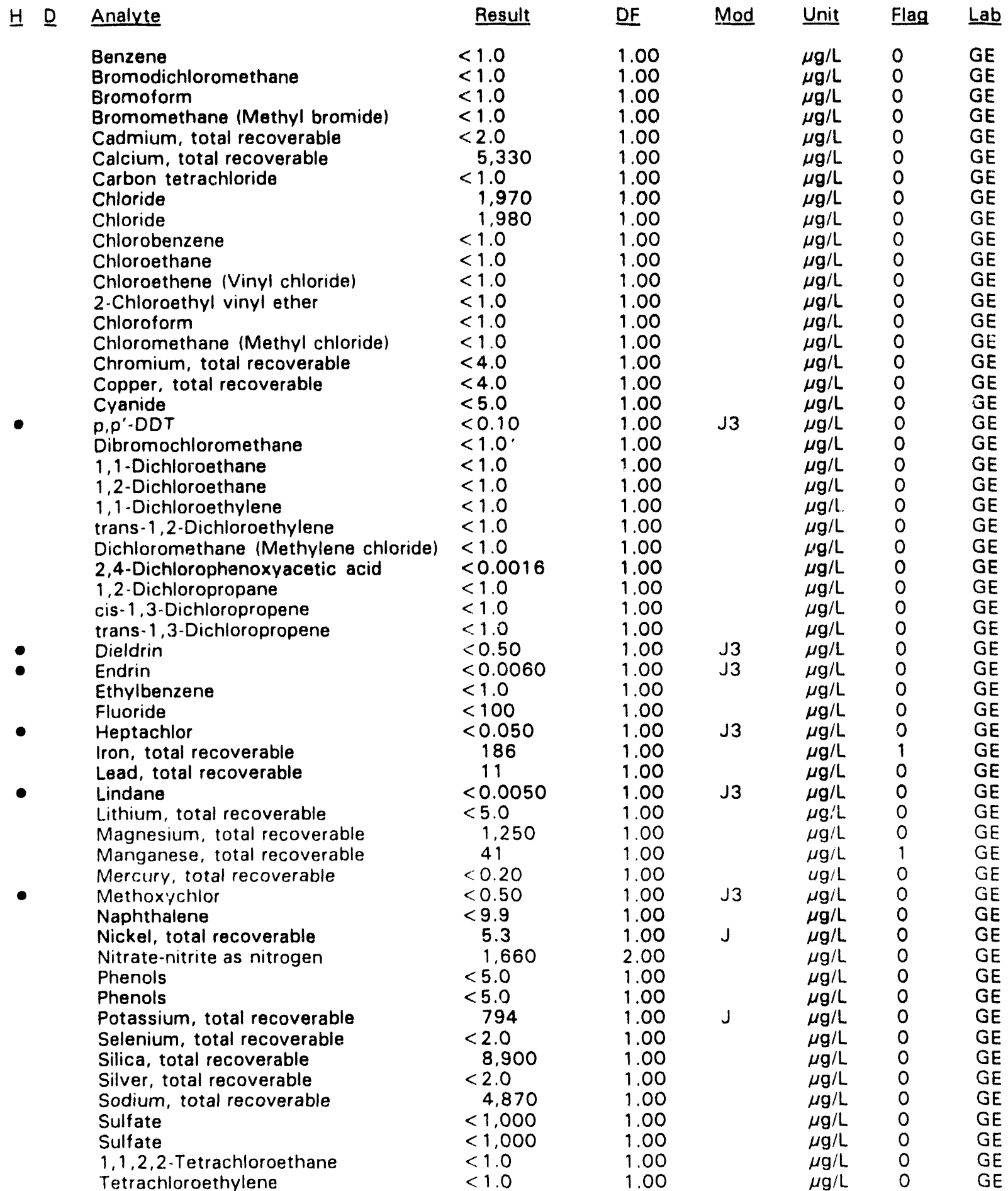

- = exceeded holding time. = exceeded screening level or final primary drinking water standard. 
WELL BGO 200 collected on $02 / 03 / 94$, laboratory analyses (cont.)

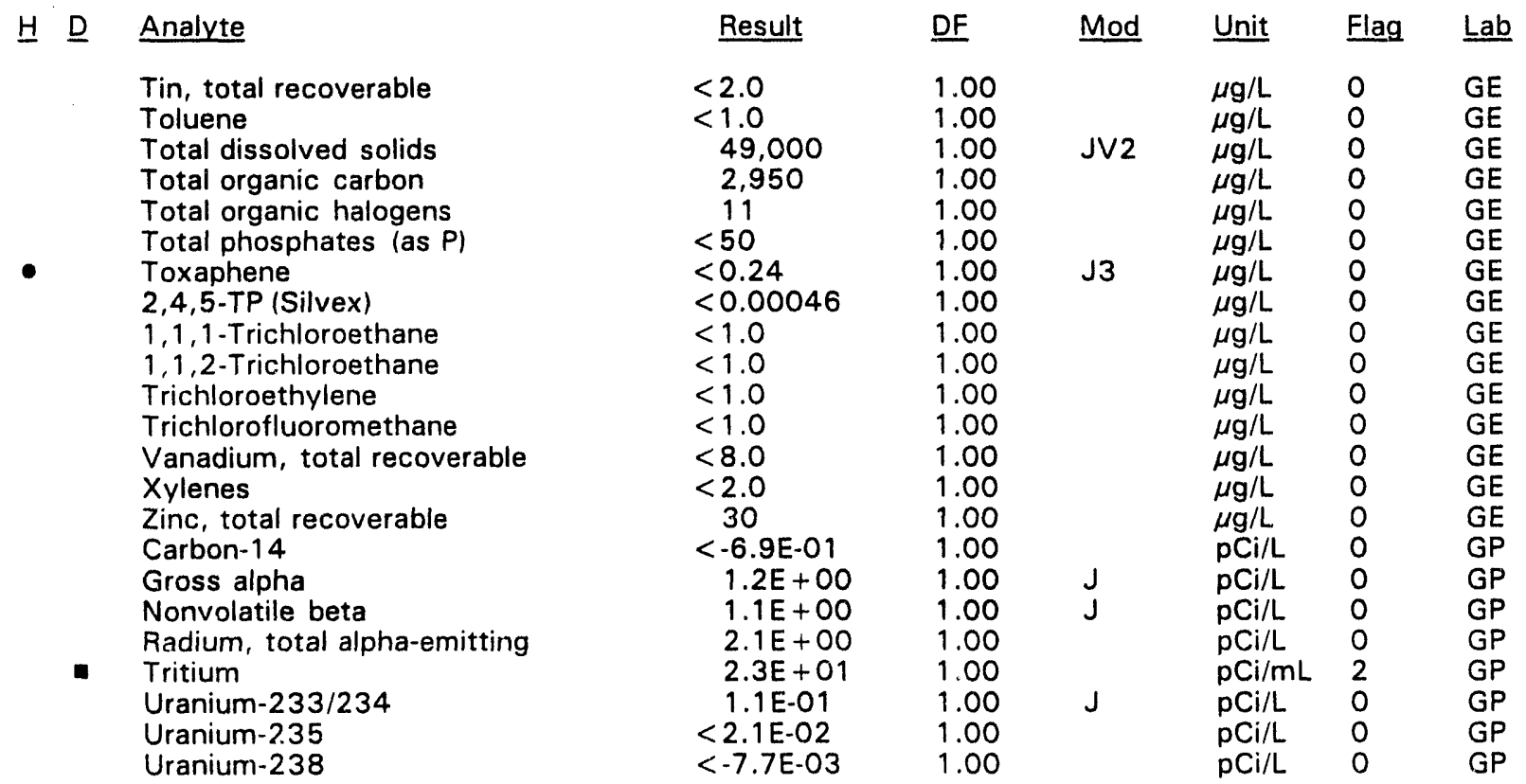

\section{WELL BGO 21D}

\begin{tabular}{|c|c|c|c|c|c|c|}
\hline SRS Coord. & Lat/Longitude & Screen Zone Elevation & Top of Casing & Casing & Pump & Formation \\
\hline $\begin{array}{l}N 74688.5 \\
\text { E57470.7 }\end{array}$ & $\begin{array}{l}33.284732^{\circ} \mathrm{N} \\
81.660549^{\circ} \mathrm{W}\end{array}$ & $237.7-217.7 \mathrm{ft} \mathrm{msl}$ & $285.4 \mathrm{ft} \mathrm{msl}$ & 4" PVC & s & $e\left(\mid 1 B_{2}\right)$ \\
\hline
\end{tabular}

\section{FIELD MEASUREMENTS}

Sample date: 02/03/94

Depth to water: $50.41 \mathrm{ft}(15.37 \mathrm{~m})$ below TOC

Water elevation: $234.99 \mathrm{ft}(71.63 \mathrm{~m}) \mathrm{msl}$

Sp. conductance: $81 \mu \mathrm{S} / \mathrm{cm}$

Turbidity: 23.6 NTU

Water evacuated before sampling: $6 \mathrm{gal}$

The well went dry during purging.

\section{LABORATORY ANALYSES}

H D Analyte

- $\mathrm{pH}$

Specific conductance

Specific conductance

Turbidity

Acetophenone

- Aldrin

Aluminum, total recoverable

Aluminum, total recoverable

Antimony, total recoverable

Arsenic, total recoverable

Barium, total recoverable
Time: 10: 19

$\mathrm{pH}: 6.0$

Alkalinity: $15 \mathrm{mg} / \mathrm{L}$

Water temperature: $16.6^{\circ} \mathrm{C}$

Volumes purged: 0.5 well volumes

$\begin{array}{llllll}\text { Result } & \text { DF } & \text { Mod } & \text { Unit } & \text { Flag } & \text { Lab } \\ 6.1 & 1.00 & \mathrm{~J} 1 & \mathrm{pH} & 0 & \mathrm{GE} \\ 76 & 1.00 & & \mu \mathrm{S} / \mathrm{cm} & 0 & \mathrm{GE} \\ 77 & 1.00 & & \mu \mathrm{S} / \mathrm{cm} & 0 & \mathrm{GE} \\ 12 & 1.00 & & \mathrm{NTU} & 0 & \mathrm{GE} \\ <10.0 & 1.00 & & \mu \mathrm{g} / \mathrm{L} & 0 & \mathrm{GE} \\ <0.052 & 1.00 & \mathrm{~J} 1 & \mu \mathrm{g} / \mathrm{L} & 0 & \mathrm{GE} \\ 274 & 1.00 & & \mu \mathrm{g} / \mathrm{L} & 2 & \mathrm{GE} \\ 309 & 1.00 & \mathrm{~J} 3 & \mu \mathrm{g} / \mathrm{L} & 2 & \mathrm{GE} \\ <2.0 & 1.00 & & \mu \mathrm{g} / \mathrm{L} & 0 & \mathrm{GE} \\ <2.0 & 1.00 & & \mu \mathrm{g} / \mathrm{L} & 0 & \mathrm{GE} \\ 49 & 1.00 & & \mu \mathrm{g} / \mathrm{L} & 0 & \mathrm{GE}\end{array}$

- exceeded holding time. = exceeded screening level or final primary drinking water standard. 
WELL BGO 21D collected on 02/03/94, laboratory analyses (cont.)

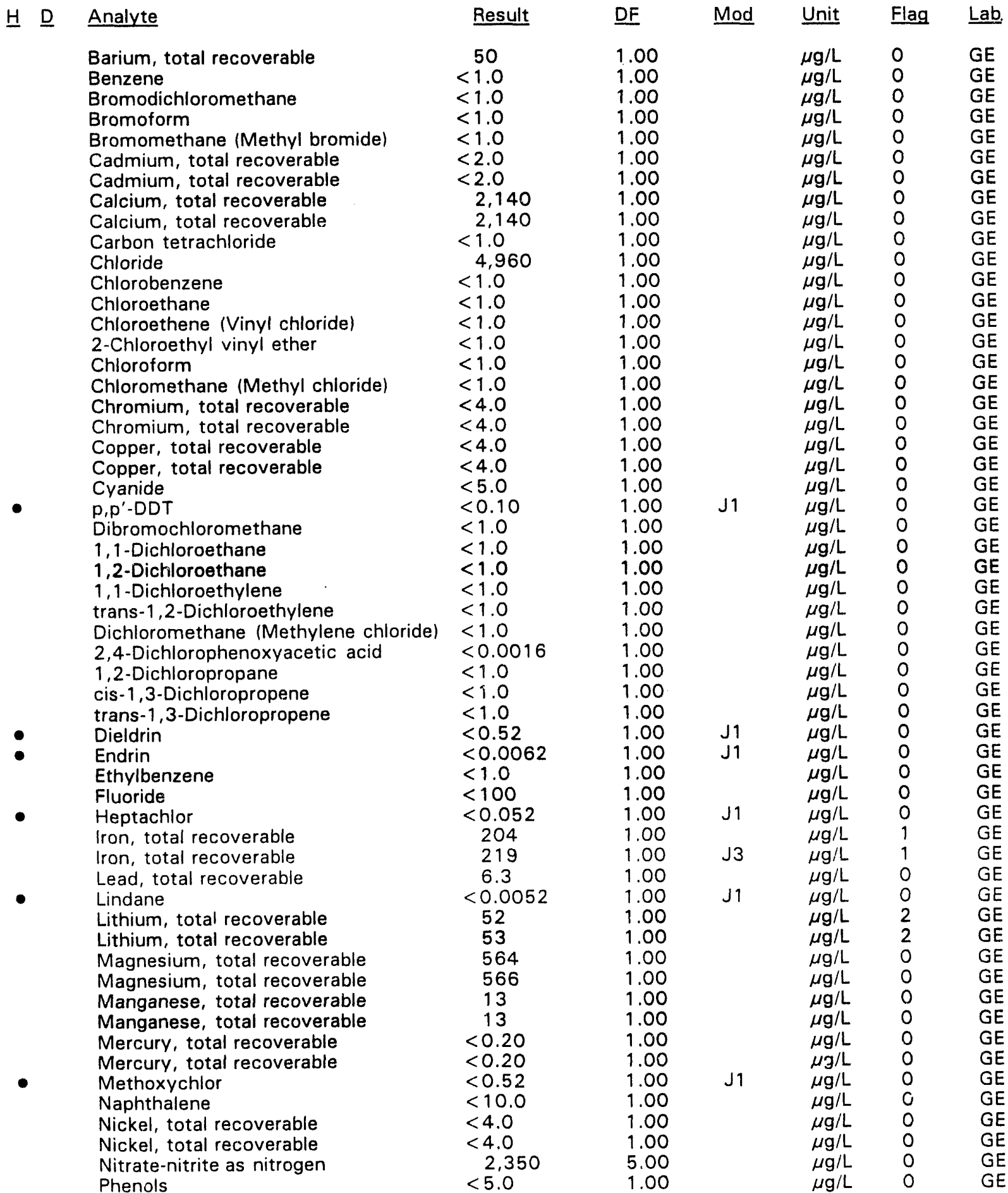

- = exceeded holding time. = exceeded screening level or final primary drinking water standard. 
WELL BGO 21D collected on 02/03/94, laboratory analyses (cont.)

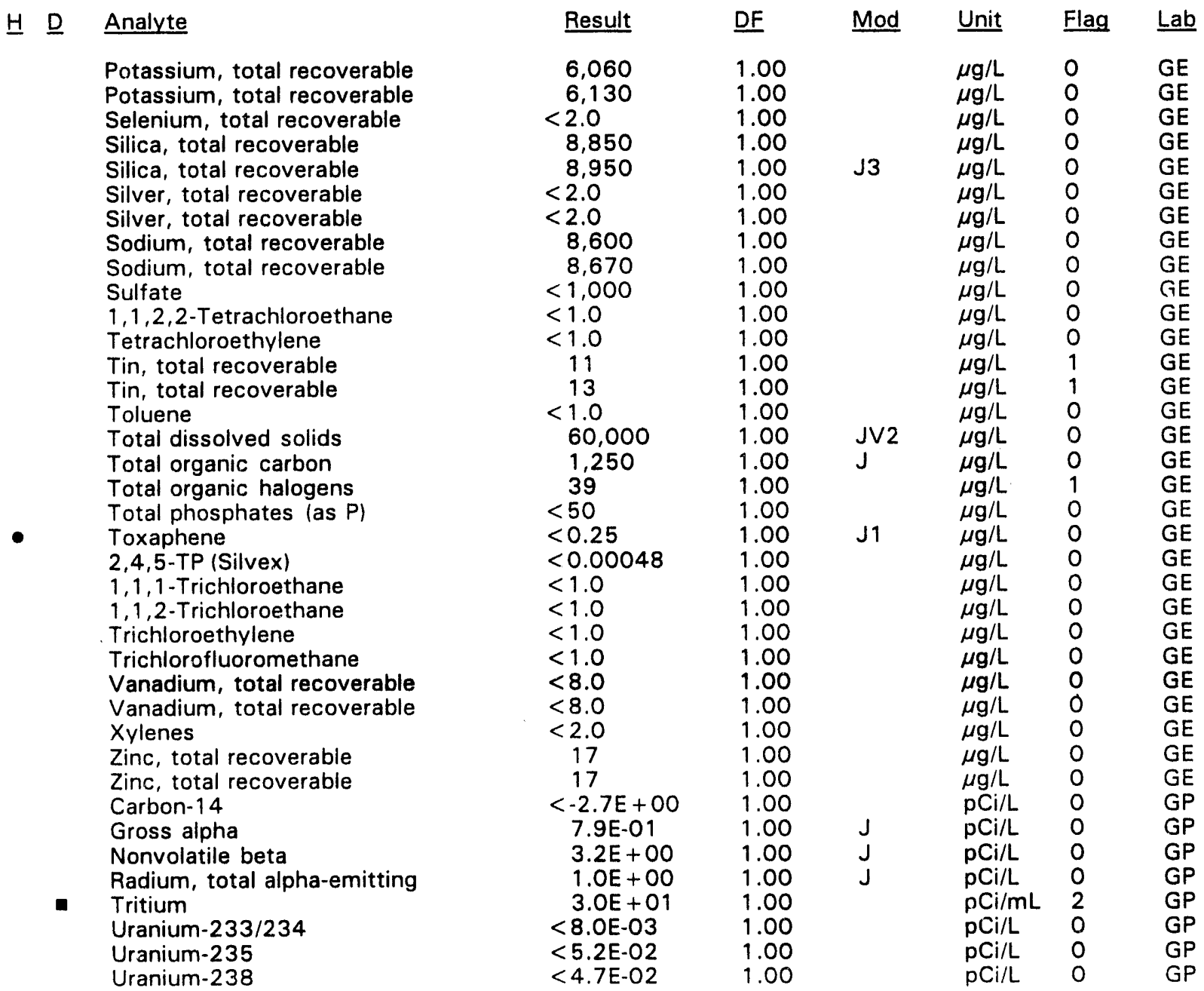

- exceeded holding time. = exceeded screening level or final primary drinking water standard. 
WELL BGO 22DR

\begin{tabular}{|c|c|c|c|c|c|c|}
\hline SRS Coord. & Lat/Longitude & Screen Zone Elevation & Top of Casing & Casing & Pump & Formation \\
\hline $\begin{array}{l}N 74471.5 \\
\text { E57831.5 }\end{array}$ & $\begin{array}{l}33.284841^{\circ} \mathrm{N} \\
81.659178^{\circ} \mathrm{W}\end{array}$ & $239.2-219.2 \mathrm{ft} \mathrm{msl}$ & $286.1 \mathrm{ft} \mathrm{msl}$ & 4" PVC & $\mathrm{s}$ & Water Table $\left(\mathrm{IIB}_{2}\right)$ \\
\hline
\end{tabular}

\section{FIELD MEASUREMENTS}

Sample date: $02 / 03 / 94$

Depth to water: $67.75 \mathrm{ft}(20.65 \mathrm{~m})$ below TOC

Water elevation: $218.35 \mathrm{ft}(66.55 \mathrm{~m}) \mathrm{msl}$

Sp. conductance: $24 \mu \mathrm{S} / \mathrm{cm}$

Turbidity: 20.6 NTU

Water evacuated before sampling: $15 \mathrm{gal}$

The well went dry during purging.

\section{LABORATORY ANALYSES}

H D Analyte

- $\mathrm{pH}$

Specific conductance

Turbidity

Acetophenone

- Aldrin

Aluminum, total recoverable

Antimony, total recoverable

Arsenic, total recoverable

Barium, total recoverable

Benzene

Bromodichloromethane

Bromoform

Bromomethane (Methyl bromide)

Cadmium, total recoverable

Calcium, total recoverable

Carbon tetrachloride

Chloride

Chlorobenzene

Chloroethane

Chloroethene (Vinyl chloride)

2-Chloroethyl vinyl ether

Chloroform

Chloromethane (Methyl chloride)

Chromium, total recoverable

Copper, total recoverable

Cyanide

- p.p'-DDT

Dibromochloromethane

1,1-Dichloroethane

1,2-Dichloroethane

1,1-Dichloroethylene

trans-1,2-Dichloroethylene

Dichloromethane (Methylene chloride)

2,4-Dichlorophenoxyacetic acid

1,2-Dichloropropane

cis-1,3-Dichloropropene

trans-1,3-Dichloropropene

- Dieldrin

Endrin

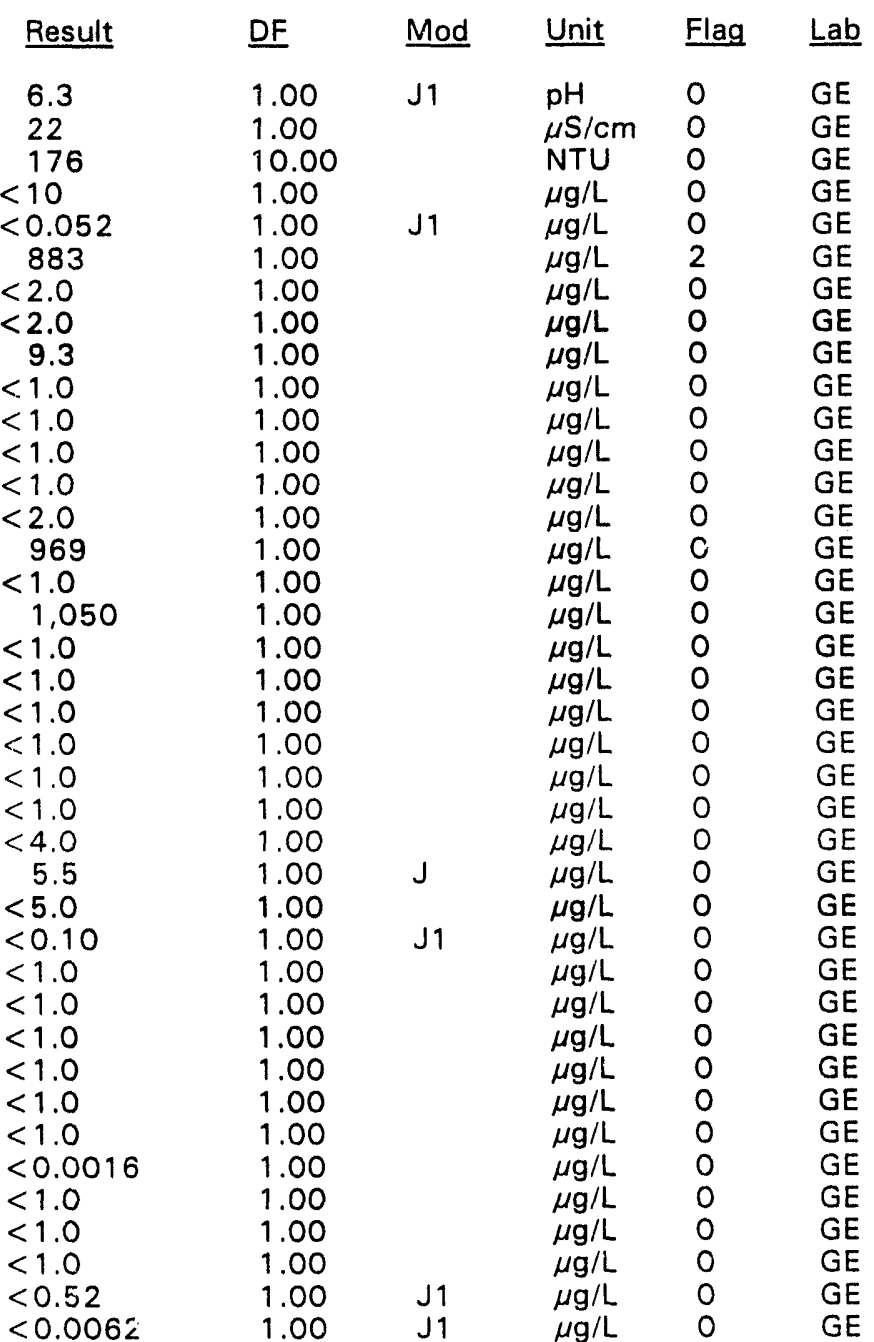

Time: 10: 02

pH: 5.4

Alkalinity: $2 \mathrm{mg} / \mathrm{L}$

Water temperature: $17.3^{\circ} \mathrm{C}$ 
WELL BGO 22DR collected on 02/03/94, laboratory analyses (cont.)

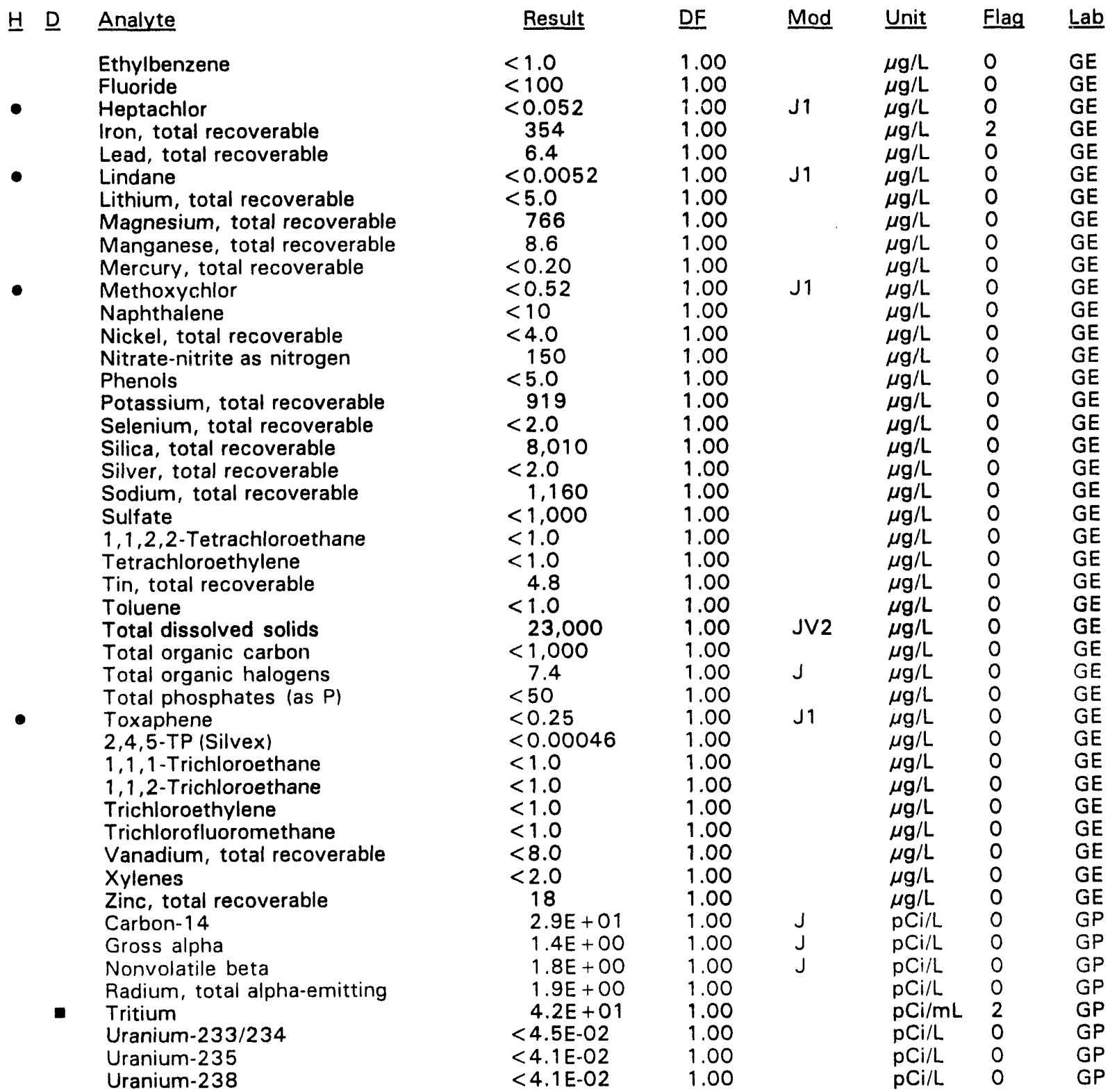

- = exceeded holding time. $=$ exceeded screening level or final primary drinking water standard. 
WELL BGO 23D

\begin{tabular}{|c|c|c|c|c|c|c|}
\hline RS Coord. & Lat/Longitude & Screen Zone Elevation & Top of Casing & Casing & Pump & Formation \\
\hline & $\begin{array}{l}33.284817^{\circ} \mathrm{N} \\
81.657930^{\circ} \mathrm{W}\end{array}$ & & & 4" PVC & $\mathrm{s}$ & \\
\hline
\end{tabular}

FIELD MEASUREMENTS

Sample date: 02/02/94

Depth to water: $53.16 \mathrm{ft}(16.20 \mathrm{~m})$ below TOC

Water elevation: $236.04 \mathrm{ft}(71.95 \mathrm{~m}) \mathrm{msl}$

Sp. conductance: $36 \mu \mathrm{S} / \mathrm{cm}$

Turbidity: 0.8 NTU

Water evacuated before sampling: $40 \mathrm{gal}$

\section{LABORATORY ANALYSES}

H D Analyte

$\mathrm{pH}$

Specific conductance

Turbidity

Acetophenone

Aldrin

Aluminum, total recoverable

Antimony, total recoverable

Antimony, total recoverable

Arsenic, total recoverable

Arsenic, total recoverable

Barium, total recoverable

Benzene

Bromodichloromethane

Bromoform

Bromomethane (Methyl bromide)

Cadmium, total recoverable

Calcium, total recoverable

Carbon tetrachloride

Chloride

Chloride

Chlorobenzene

Chloroethane

Chloroethene (Vinyl chloride)

2-Chloroethyl vinyl ether

Chloroform

Chloromethane (Methyl chloride)

Chromium, total recoverable

Copper, total recoverable

Cyanide

$p, p^{\prime}-D D T$

Dibromiochloromethane

1,1-Dichloroethane

1,2-Dichloroethane

1,1-Dichloroethylene

trans-1,2-Dichloroethylene

Dichloromethane (Methylene chloride)

2,4-Dichlorophenoxyacetic acid

2,4-Dichlorophenoxyacetic acid

1,2-Dichloropropane
Time: 12: 31

$\mathrm{pH}: 6.0$

Alkalinity: $3 \mathrm{mg} / \mathrm{L}$

Water temperature: $19.9^{\circ} \mathrm{C}$

Volumes purged: 4.3 well volumes

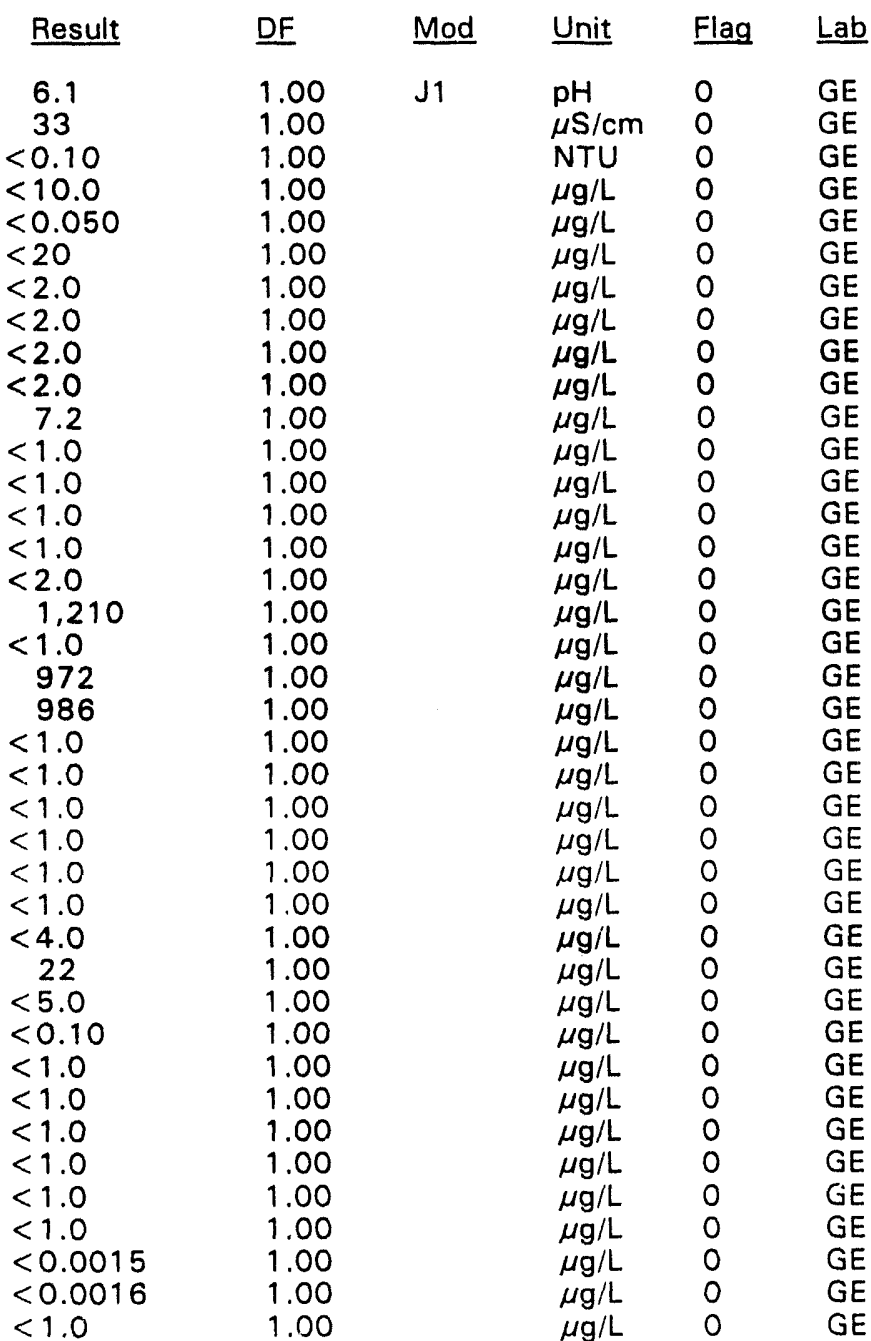

$\overline{-}=$ exceeded holding time. $\quad$ = exceeded screening level or final primary drinking water standard. 
WELL BGO 230 collected on $02 / 02 / 94$, laboratory analyses (cont.)

\section{H $\underline{\text { Analyte }}$}

cis-1,3-Dichloropropene

trans-1,3-Dichloropropene

Dieldrin

Endrin

Ethylbenzene

Fluoride

Fluoride

Heptachlor

Iron, total recoverable

Lead, total recoverable

Lead, total recoverable

Lindane

Lithium, total recoverable

Magnesium, total recoverable

Manganese, total recoverable

Mercury, total recoverable

Methoxychlor

Naphthalene

Nickel, total recoverable

Nitrate-nitrite as nitrogen

Nitrate-nitrite as nitrogen

Phenols

Potassium, total recoverable

Selenium, total recoverable

Selenium, total recoverable

Silica, total recoverable

Silver, total recoverable

Sodium, total recoverable

Sulfate

Sulfate

$1,1,2,2$-Tetrachloroethane

Tetrachloroethylene

Tin, total recoverable

Toluene

Total dissolved solids

Total organic carben

Total organic halogens

Total phosphates (as P)

Toxaphene

2,4,5-TP (Silvex)

2,4,5-TP (Silvex)

1,1,1-Trichloroethane

1,1,2-Trichloroethane

Trichioroethylene

Trichlorofluoromethane

Vanadium, total recoverable Xylenes

Zinc, total recoverable

Carbon-14

Gross alpha

Nonvolatile beta

Radium, total alpha-emitting

- Tritium

Uranium-233/234

Uranium-235

Uranium-238

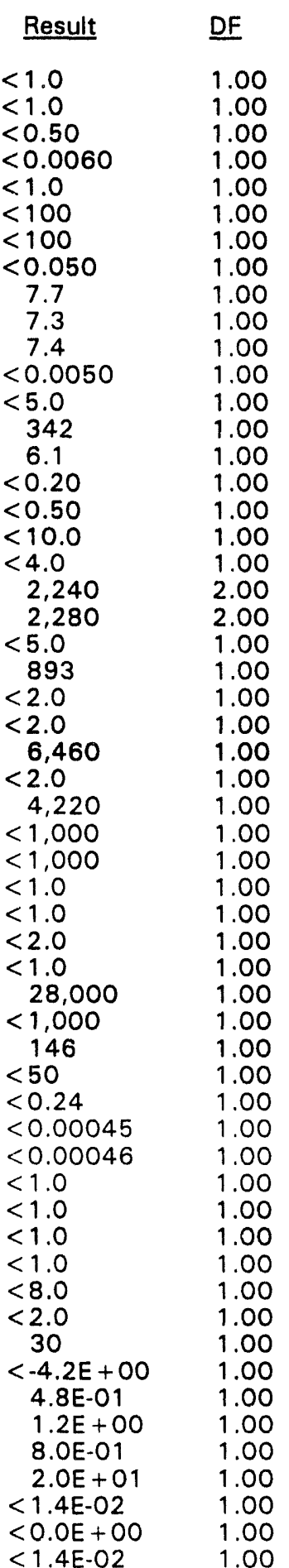

\section{Mod}

$\underline{\text { Unit }}$

Flag

$\underline{\text { Lab }}$

$\mu \mathrm{g} / \mathrm{L} \quad 0 \quad \mathrm{GE}$

$\mu \mathrm{g} / \mathrm{L} \quad 0 \quad \mathrm{GE}$

$\mu \mathrm{g} / \mathrm{L} \quad \mathrm{O} \quad \mathrm{GE}$

$\mu \mathrm{g} / \mathrm{L} \quad 0 \quad \mathrm{GE}$

$\mu g / L \quad 0 \quad G E$

$\mu \mathrm{g} / \mathrm{L} \quad 0 \quad \mathrm{GE}$

$\mu g / L \quad 0 \quad G E$

$\mu \mathrm{g} / \mathrm{L} \quad 0 \quad \mathrm{GE}$

$\mu g / L \quad 0 \quad G E$

$\mu \mathrm{g} / \mathrm{L} \quad \mathrm{O} \quad \mathrm{GE}$

$\mu \mathrm{g} / \mathrm{L} \quad \mathrm{O} \quad \mathrm{GE}$

$\mu \mathrm{g} / \mathrm{L} \quad 0 \quad \mathrm{GE}$

$\mu \mathrm{g} / \mathrm{L} \quad \mathrm{O} \quad \mathrm{GE}$

$\mu \mathrm{g} / \mathrm{L} \quad \mathrm{O} \quad \mathrm{GE}$

$\mu \mathrm{g} / \mathrm{L} \quad 0 \quad \mathrm{GE}$

$\mu \mathrm{g} / \mathrm{L} \quad 0 \quad \mathrm{GE}$

$\mu \mathrm{g} / \mathrm{L} \quad \mathrm{O} \quad \mathrm{GE}$

$\mu \mathrm{g} / \mathrm{L} \quad 0 \quad \mathrm{GE}$

$\mu \mathrm{g} / \mathrm{L} \quad 0 \quad \mathrm{GE}$

$\mu \mathrm{g} / \mathrm{L} \quad 0 \quad \mathrm{GE}$

$\mu \mathrm{g} / \mathrm{L} \quad 0 \quad \mathrm{GE}$

$\mu \mathrm{g} / \mathrm{L} \quad 0 \quad \mathrm{GE}$

$\mu \mathrm{g} / \mathrm{L} \quad 0 \quad \mathrm{GE}$

$\mu \mathrm{g} / \mathrm{L} \quad \mathrm{O} \quad \mathrm{GE}$

$\mu \mathrm{g} / \mathrm{L} \quad 0 \quad \mathrm{GE}$

$\mu \mathrm{g} / \mathrm{L} \quad 0 \quad \mathrm{GE}$

$\mu \mathrm{g} / \mathrm{L} \quad \mathrm{O} \quad \mathrm{GE}$

$\mu \mathrm{g} / \mathrm{L} \quad \mathrm{O} \quad \mathrm{GE}$

$\mu \mathrm{g} / \mathrm{L} \quad 0 \quad \mathrm{GE}$

$\mu \mathrm{g} / \mathrm{L} \quad \mathrm{O} \quad \mathrm{GE}$

$\mu \mathrm{g} / \mathrm{L} \quad 0 \quad \mathrm{GE}$

$\mu \mathrm{g} / \mathrm{L} \quad \mathrm{O} \quad \mathrm{GE}$

$\mu \mathrm{g} / \mathrm{L} \quad 0 \quad \mathrm{GE}$

JV2. $\mu \mathrm{g} / \mathrm{L} \quad 0 \quad \mathrm{GE}$

$\mu \mathrm{g} / \mathrm{L} \quad \mathrm{O} \quad \mathrm{GE}$

$\mu \mathrm{g} / \mathrm{L} \quad 2 \quad \mathrm{GE}$

$\mu \mathrm{g} / \mathrm{L} \quad 0 \quad \mathrm{GE}$

$\mu \mathrm{g} / \mathrm{L} \quad \mathrm{O} \quad \mathrm{GE}$

$\mu \mathrm{g} / \mathrm{L} \quad \mathrm{O} \quad \mathrm{GE}$

$\mu \mathrm{g} / \mathrm{L} \quad 0 \quad \mathrm{GE}$

$\mu \mathrm{g} / \mathrm{L} \quad 0 \quad \mathrm{GE}$

$\mu \mathrm{g} / \mathrm{L} \quad 0 \quad \mathrm{GE}$

$\mu \mathrm{g} / \mathrm{L} \quad 0 \quad \mathrm{GE}$

$\mu \mathrm{g} / \mathrm{L} \quad 0 \quad \mathrm{GE}$

$\mu \mathrm{g} / \mathrm{L} \quad \mathrm{O} \quad \mathrm{GE}$

$\mu g / L \quad 0 \quad G E$

$\mu \mathrm{g} / \mathrm{L} \quad \mathrm{O} \quad \mathrm{GE}$

$\mathrm{pCi} / \mathrm{L} \quad 0 \quad \mathrm{GP}$

$\mathrm{pCi} / \mathrm{L} \quad 0 \quad \mathrm{GP}$

$\mathrm{pCi} / L$ L $\quad \mathrm{GP}$

$\mathrm{PCi} / \mathrm{L} \quad \mathrm{GP}$

$\mathrm{pCi} / \mathrm{mL} 2 \mathrm{GP}$

$\mathrm{pCi} / \mathrm{L} \quad 0 \quad \mathrm{GP}$

$\mathrm{pCi} / L \quad O \quad G P$

$\mathrm{pCi} / \mathrm{L} \quad 0 \quad \mathrm{GP}$

- = excesded holding time. - = exceeded screening level or final primary drinking water standard. 


\section{WELL BGO 24D}

\begin{tabular}{|c|c|c|c|c|c|c|}
\hline SRS Coord. & Lat/Longitude & Screen Zone Elevation & Top of Casing & Casing & Pump & Formation \\
\hline $\begin{array}{l}N 74012.4 \\
\text { E58438.8 }\end{array}$ & $\begin{array}{l}33.284816^{\circ} \mathrm{N} \\
81.656687^{\circ} \mathrm{W}\end{array}$ & $241.0-221.0 \mathrm{ft} \mathrm{msl}$ & $293.2 \mathrm{ft} \mathrm{msl}$ & 4" PVC & s & ble $\left(\| B_{2}\right)$ \\
\hline
\end{tabular}

\section{FIELD MEASUREMENTS}

Sample date: 02/03/94

Depth to water: $56.25 \mathrm{ft}(17.15 \mathrm{~m})$ below TOC

Water elevation: $236.95 \mathrm{ft}(72.22 \mathrm{~m}) \mathrm{ms}$ l

Sp. conductance: $69 \mu \mathrm{S} / \mathrm{cm}$

Turbidity: 27.5 NTU

Water evacuated before sampling: 7 gal

The well went dry during purging.

Time: $9: 44$

$\mathrm{pH}: 9.8$

Alkalinity: $18 \mathrm{mg} / \mathrm{L}$

Water temperature: $17.5^{\circ} \mathrm{C}$

Volumes purged: 0.7 well volumes

\section{LABORATORY ANALYSES}

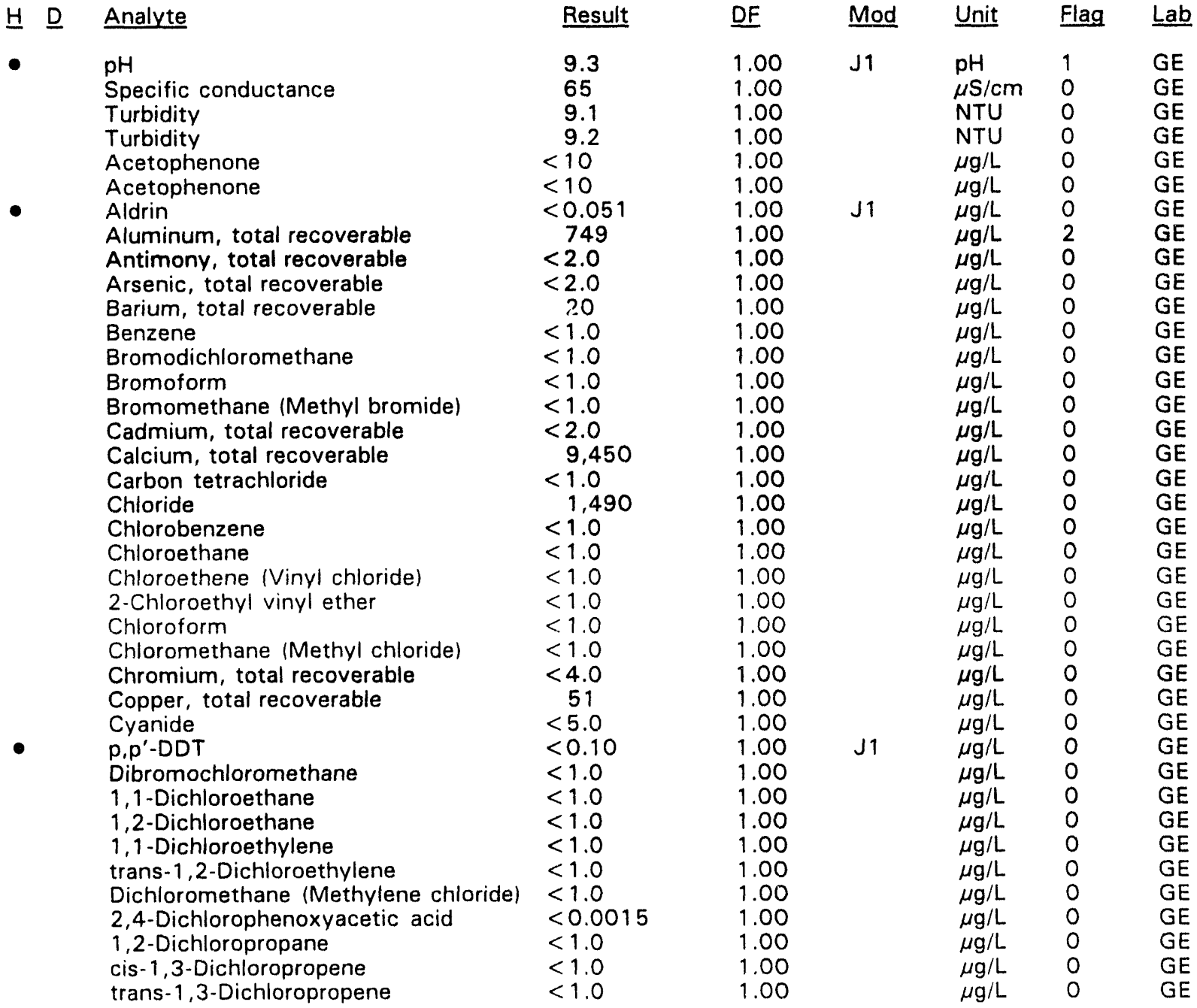

\footnotetext{
$\overline{-}$ = exceeded holding time. = exceeded screening level or final primary drinking water standard.
} 
WELL BGO 240 collected on $02 / 03 / 94$, laboratory analyses (cont.)

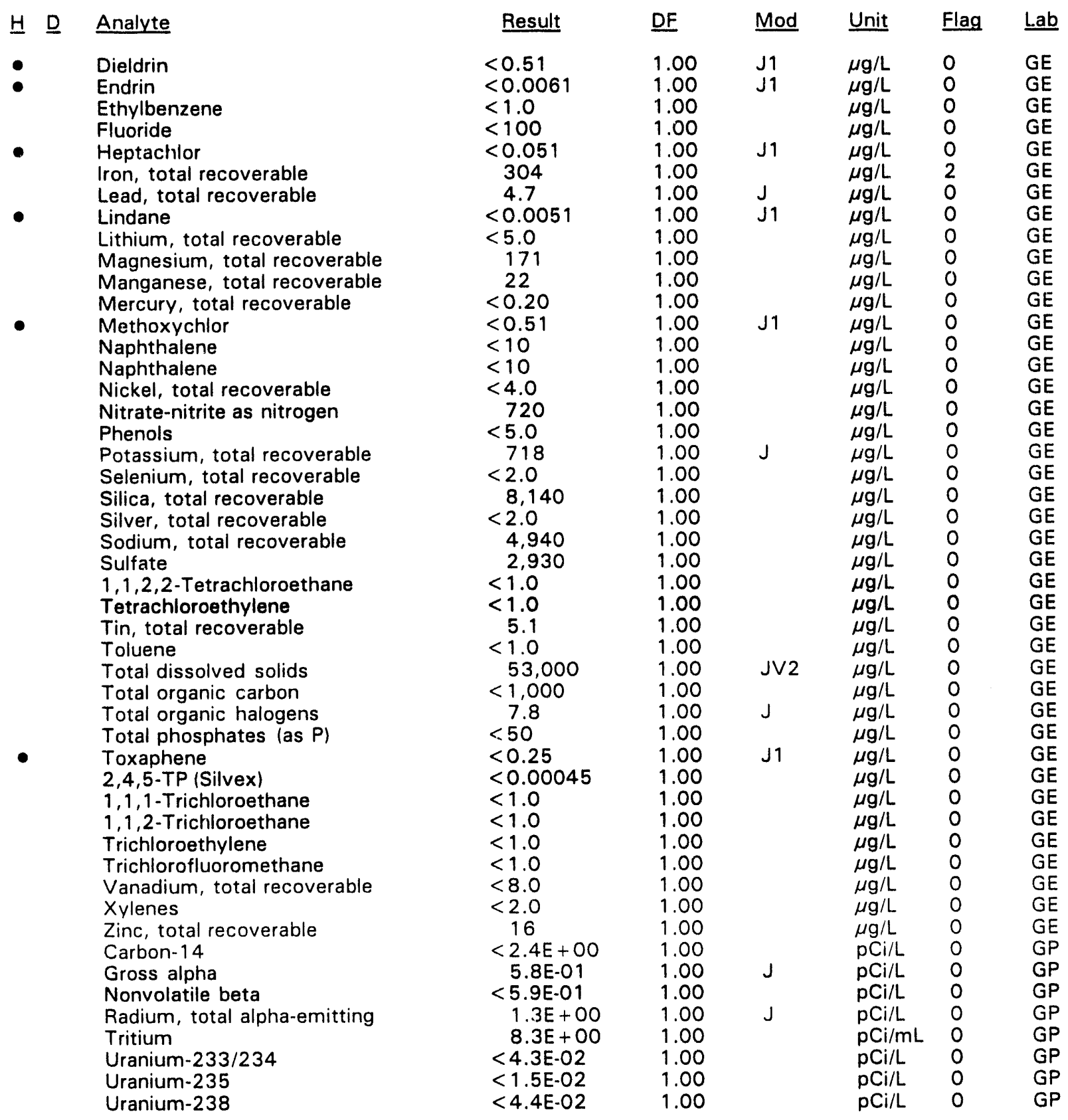

$\overline{-}=$ exceeded holding time. = exceeded screening level or final primary drinking water standard. 
WELL BGO 25A

$\begin{array}{lllllll}\text { SRS Coord. } & \text { Lat/Longitude } & \text { Screen Zone Elevation } & \text { Top of Casing } & \text { Casing } & \text { Pump } & \text { Formation } \\ \text { N76158.5 } & 33.285042^{\circ} \mathrm{N} & 114.1-104.1 \mathrm{ft} \mathrm{msl} & 296.5 \mathrm{ft} \mathrm{msl} & \text { 4" PVC } & \text { S } & \text { U. Congaree (IIA) } \\ \text { E55668.1 } & 81.668151^{\circ} \mathrm{W} & & & \end{array}$

\section{FIELD MEASUREMENTS}

Sample date: 02/25/94

Depth to water: $135.69 \mathrm{ft}(41.36 \mathrm{~m})$ below TOC

Water elevation: $160.81 \mathrm{ft}(49.02 \mathrm{~m}) \mathrm{msl}$

Sp. conductance: $249 \mu \mathrm{S} / \mathrm{cm}$

Turbidity: 5.4 NTU

Water evacuated before sampling: $16 \mathrm{gal}$

The well went dry during purging.

\section{LABORATORY ANALYSES}

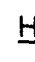

-

\section{$\mathrm{pH}$}

Specific conductance

Turbidity

- Turbidity

Acetophenone

- $\quad$ Aldrin

Aluminum, total recoverable

Aluminum, total recoverable

Antimony, total recoverable

Arsenic, total recoverable

Barium, total recoverable

Barium, total recoverable

Benzene

Bromodichloromethane

Bromoform

Bromomethane (Methyl bromide)

Cadmium, total recoverable

Cadmium, total recoverable

Calcium, total recoverable

Calcium, total recoverable

Carbon tetrachloride

Chloride

Chlorobenzene

Chloroethane

Chloroethene (Vinyl chloride)

2-Chloroethyl vinyl ether

Chloroform

Chloromethane (Methyl chloride)

Chromium, total recoverable

Chromium, total recoverable

Copper, total recoverable

Copper, total recoverable

Cyanide

- $\quad$ p, p'-DDT

Dibromochloromethane

1,1-Dichloroethane

1,2-Dichloroethane

1,1-Dichloroethylene

trans-1,2-Dichloroethylene
Time: 9: 40

$\mathrm{pH}: 7.7$

Alkalinity: $101 \mathrm{mg} / \mathrm{L}$

Water temperature: $15.2^{\circ} \mathrm{C}$

Volumes purged: 0.4 well volumes

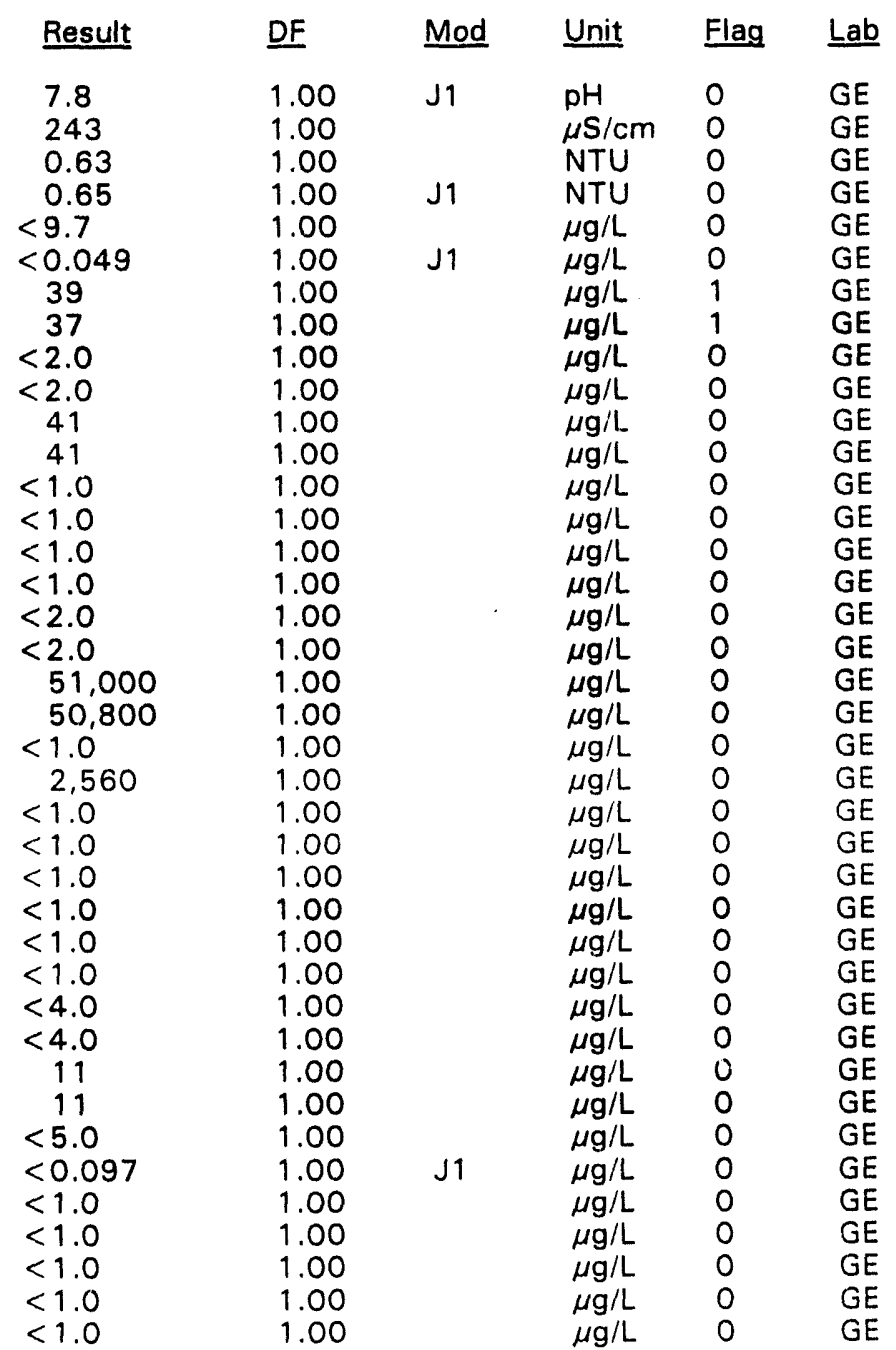

$\overline{-}=$ exceeded holding time. $=$ exceeded screening level or final primary drinking water standard.

Mixed Waste Management Facility 
WELL BGO 25A collected on 02/25/94, laboratory analyses (cont.)

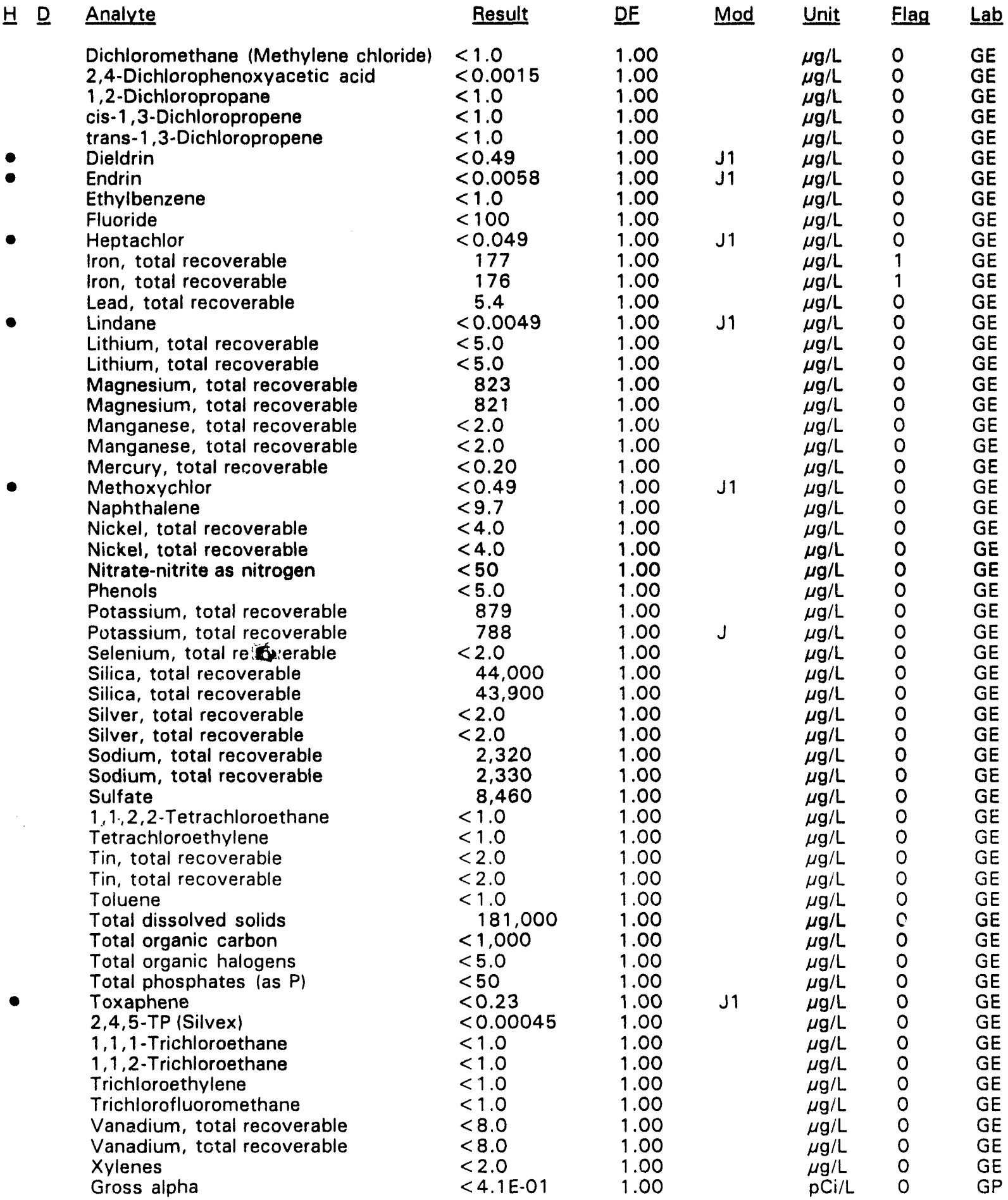

\footnotetext{
$\overline{0}=$ exceeded holding time. $a=$ exceeded screening level or final primary drinking water standard.
} 
WELL BGO 25A collected on $02 / 25 / 94$, laboratory analyses (cont.)

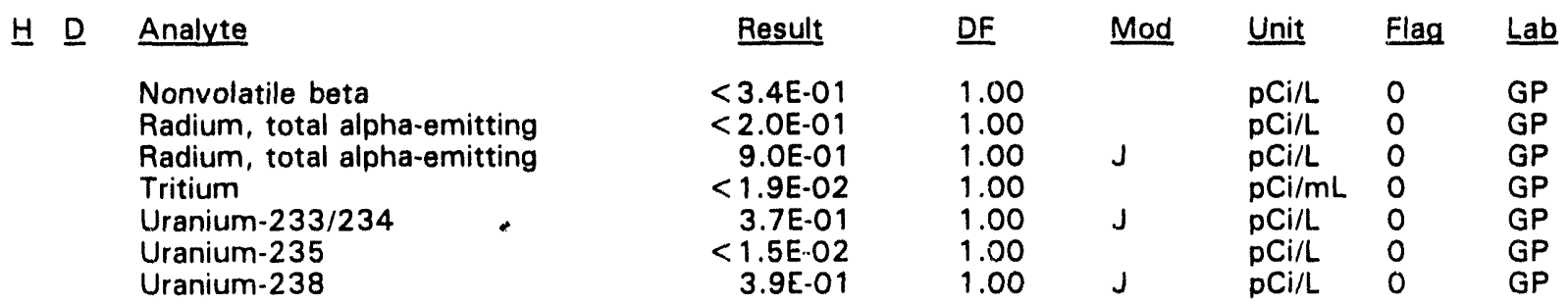

\section{WELL BGO 26D}

\begin{tabular}{|c|c|c|c|c|c|c|}
\hline SRS Coord. & Lat/Longitude & Screen Zone Elevation & Top of Casing & Casing & Pump & Formation \\
\hline $\begin{array}{l}N 76128.0 \\
E 55015.2\end{array}$ & $\begin{array}{l}33.283910^{\circ} \mathrm{N} \\
81.669811^{\circ} \mathrm{W}\end{array}$ & $233.5-213.4 \mathrm{ft} \mathrm{msl}$ & $285.5 \mathrm{ft} \mathrm{msl}$ & 4" PVC & $\mathrm{S}$ & Water Table $\left(\| B_{2}\right)$ \\
\hline
\end{tabular}

\section{FIELD MEASUREMENTS}

Sample date: $01 / 27 / 94$

Depth to water: $57.05 \mathrm{ft}(17.39 \mathrm{~m})$ below TOC

Water elevation: $228.45 \mathrm{ft}(69.63 \mathrm{~m}) \mathrm{msl}$

Sp. conductance: $29 \mu \mathrm{S} / \mathrm{cm}$

Turbidity: 5.1 NTU

Water evacuated before sampling: 9 gal

The well went dry during purging.

\section{LABORATORY ANALYSES}

- $\mathrm{D} \quad$ Analyte
$\mathrm{pH}$
$\mathrm{pH}$
Specific conductance
Turbidity
Turbidity
Acetophenone
Aldrin
Aluminum, total recoverable
Antimony, total recoverable
Antimony, total recoverable
Arsenic, total recoverable
Arsenic, total recoverable
Barium, total recoverable
Benzene
Bromodichloromethane
Bromoform
Bromomethane (Methyl bromide)
Cadmium, total recoverable
Calcium, total recoverable
Carbon tetrachloride
Chloride
Chlorobenzene
Chloroethane
Chloroethene (Vinyl chloride)
2-Chloroethyl vinyl ether
Chloroform
Chloromethane (Methyl chloride)

\begin{tabular}{ll} 
Result & DF \\
\hline 5.6 & 1.00 \\
5.8 & 1.00 \\
28 & 1.00 \\
11 & 1.00 \\
11 & 1.00 \\
$<9.7$ & 1.00 \\
$<0.049$ & 1.00 \\
206 & 1.00 \\
$<2.0$ & 1.00 \\
$<2.0$ & 1.00 \\
$<2.0$ & 1.00 \\
$<2.0$ & 1.00 \\
7.7 & 1.00 \\
$<1.0$ & 1.00 \\
$<1.0$ & 1.00 \\
$<1.0$ & 1.00 \\
$<1.0$ & 1.00 \\
$<2.0$ & 1.00 \\
1.070 & 1.00 \\
$<1.0$ & 1.00 \\
2.340 & 1.00 \\
$<1.0$ & 1.00 \\
$<1.0$ & 1.00 \\
$<1.0$ & 1.00 \\
$<1.0$ & 1.00 \\
$<1.0$ & 1.00 \\
$<1.0$ & 1.00 \\
$<1.0$ &
\end{tabular}

Time: 10: 06

pH: 5.0

Alkalinity: $0 \mathrm{mg} / \mathrm{L}$

Water temperature: $16.9^{\circ} \mathrm{C}$

Volumes purged: 0.9 well volumes
Flag Lab

$0 \quad \mathrm{GE}$ $\mathrm{pH} \quad \mathrm{O} \quad \mathrm{GE}$ O GE NTU $0 \quad$ GE N $\quad 0 \quad$ GE O GE $\mu \mathrm{g} / \mathrm{L} \quad 0 \quad \mathrm{GE}$ $\mu$ GE g $/ L \quad O \quad G E$ GE $\mu \mathrm{g} / \mathrm{L} \quad 0 \quad \mathrm{GE}$ $\begin{array}{lll}\mu g / L & 0 & G E\end{array}$ GE $\mu \mathrm{g} / \mathrm{L} \quad \mathrm{O} \quad \mathrm{GE}$ GE $\mu \mathrm{g} / \mathrm{L} \quad \mathrm{O} \quad \mathrm{GE}$ O GE - GE O GE $\begin{array}{llll}.00 & \mu \mathrm{g} / \mathrm{L} & 0 & \mathrm{GE}\end{array}$ 
WELL BGO 26D collected on 01/27/94, laboratory analyses (cont.)

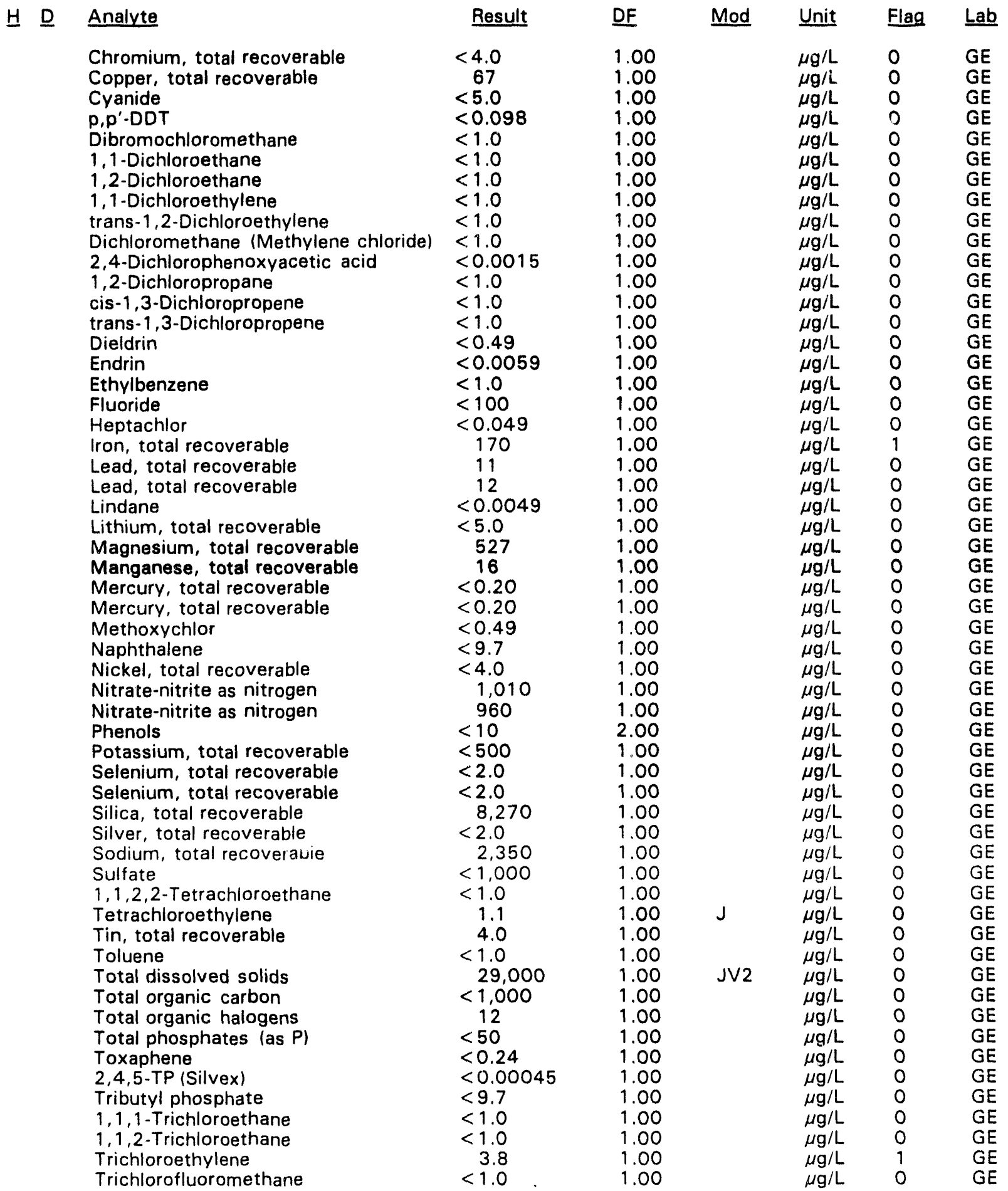

$\overline{-}=$ exceeded holding time. $=$ exceeded screening level or final primary drinking water standard. 
WELL BGO 26D collected on 01/27/94, laboratory analyses (cont.)

$\begin{aligned} & \mathrm{H} D \quad \text { Analyte } \\ & \text { Vanadium, total recoverable } \\ & \text { Xylenes } \\ & \text { Gross alpha } \\ & \text { Nonvolatile beta } \\ & \text { Radium, total alpha-emitting } \\ & \text { Tritium } \\ & \text { Tritium } \\ & \text { Uranium-233/234 } \\ & \text { Uranium-235 } \\ & \text { Uranium-238 }\end{aligned}$

\section{WELL BGO 27C}

\begin{tabular}{|c|c|c|c|c|c|c|}
\hline SRS Coord. & Lat/Longitude & Screen Zone Elevation & Top of Casing & Casing & Pump & Formation \\
\hline $\begin{array}{l}\text { N7566 } \\
\text { E5467 }\end{array}$ & $\begin{array}{l}33.282328^{\circ} \mathrm{N} \\
81.669820^{\circ} \mathrm{W}\end{array}$ & $163.9-154.9 \mathrm{ft} \mathrm{msl}$ & $276 \mathrm{ft} \mathrm{msl}$ & 4" PVC & $s$ & \\
\hline
\end{tabular}

\begin{tabular}{|c|c|c|c|c|}
\hline Result & DF & Mod & Unit & Flag \\
\hline $\begin{array}{l}<8.0 \\
<2.0\end{array}$ & $\begin{array}{l}1.00 \\
1.00\end{array}$ & & $\mu \mathrm{g} / \mathrm{L}$ & $\begin{array}{l}0 \\
0\end{array}$ \\
\hline $3.3 E+00$ & 1.00 & $\mathrm{~J}$ & $\mathrm{pCi} / \mathrm{L}$ & 0 \\
\hline $3.6 \mathrm{E}+00$ & 1.00 & & $\mathrm{pCi} / \mathrm{L}$ & 0 \\
\hline $1.5 \mathrm{E}+00$ & 1.00 & $J$ & $\mathrm{pCi} / \mathrm{L}$ & 0 \\
\hline $6.5 \mathrm{E}+00$ & 1.00 & & $\mathrm{pCi} / \mathrm{mL}$ & 0 \\
\hline $\begin{array}{r}6.4 \mathrm{E}+00 \\
<3.7 \mathrm{E} \cdot 02\end{array}$ & 1.00 & & $\mathrm{pCi} / \mathrm{mL}$ & 0 \\
\hline$<3.7 \mathrm{E}-02$ & 1.00 & & $\mathrm{pCi} / \mathrm{L}$ & 0 \\
\hline$<0.0 E+00$ & 1.00 & & $\mathrm{pCi} / \mathrm{L}$ & 0 \\
\hline$<4.3 \mathrm{E} \cdot 02$ & 1.00 & & $\mathrm{pCi} / \mathrm{L}$ & 0 \\
\hline
\end{tabular}

Time: $11: 00$

pH: 7.3

Alkalinity: $40 \mathrm{mg} / \mathrm{L}$

Water temperature: $18.8^{\circ} \mathrm{C}$

Volumes purged: 4.2 well volumes
Water elevation: $221.27 \mathrm{ft} / 67$
Sp. conductance: $111 \mu \mathrm{S} / \mathrm{cm}$

Turbidity: 0.8 NTU

Water evacuated before sampling: $181 \mathrm{gal}$

\section{LABORATORY ANALYSES}

H $\underline{\text { Analyte }}$

- $\quad \mathrm{pH}$

Specific conductance

Specific conductance

Turbidity

Acetophenone

Aldrin

Aluminum, total recoverable

Antimony, total recoverable

Arsenic, total recoverable

Barium, total recoverable

Benzene

Bromodichloromethane

Bromoform

Bromomethane (Methyl bromide)

Cadmium, total recoverable

Calcium, total recoverable

Carbon tetrachloride

Chloride

Chlorobenzene

Chloroethane

Chloroethene (Vinyl chloride)

2-Chloroethyl vinyl ether

Chloroform

Chlorometiane (Methyl chloride)

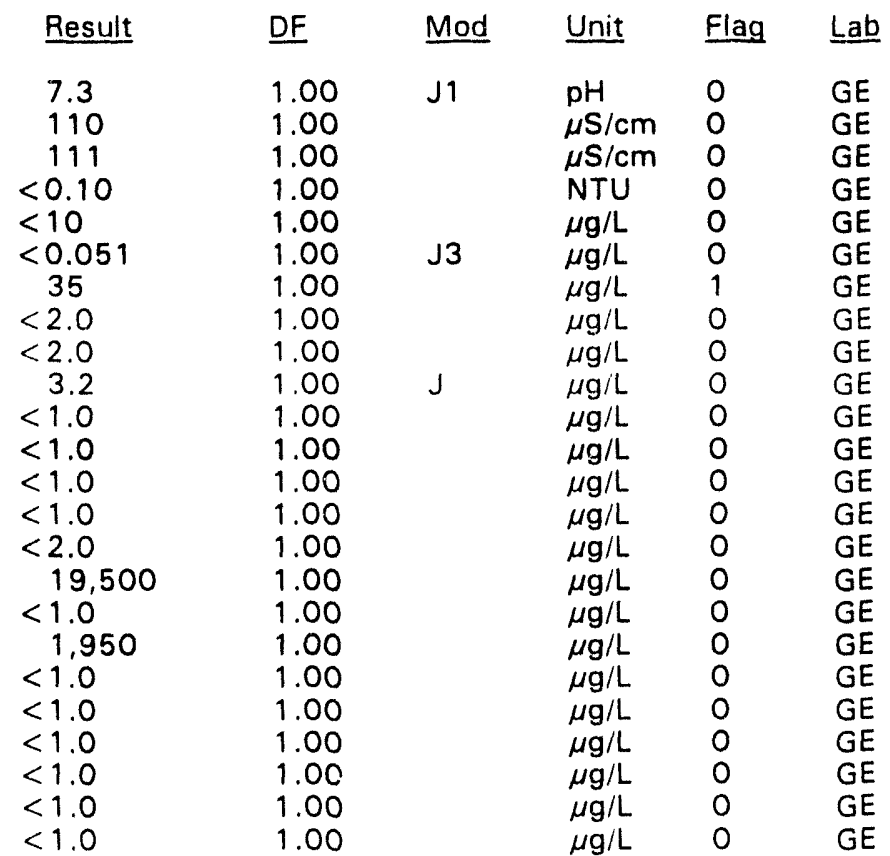

- = exceeded holding time. = exceeded screening level or final primary drinking water standard. 

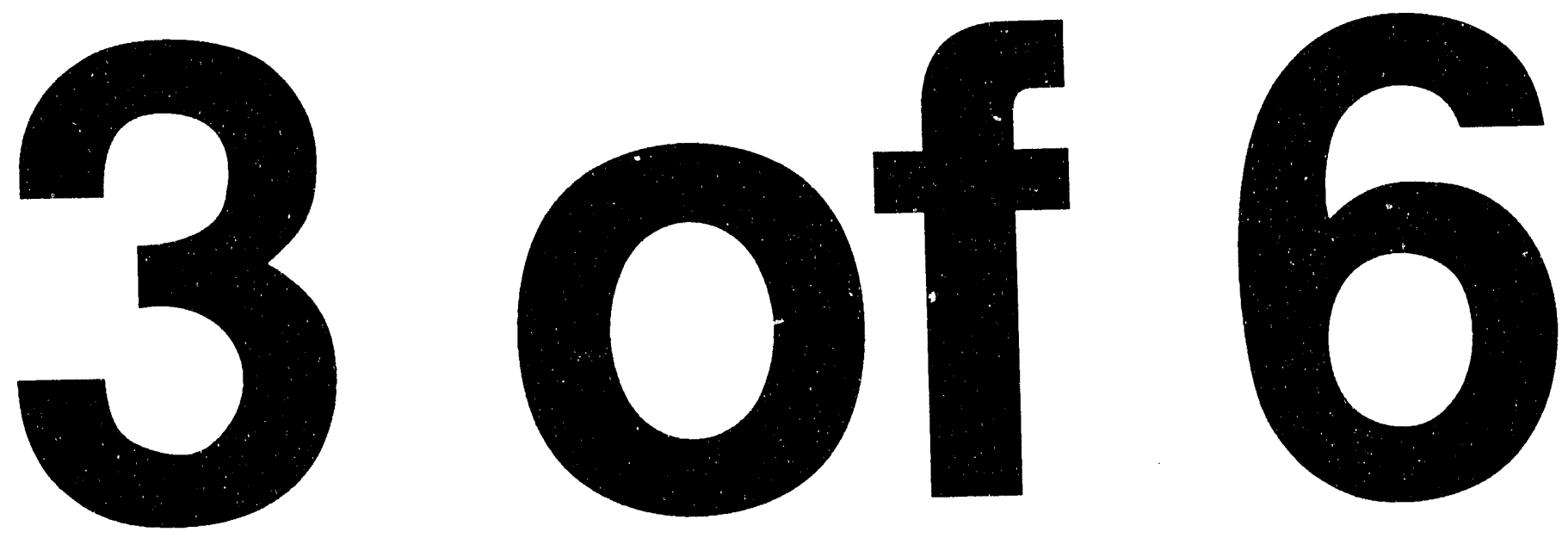
WELL. BGO $27 \mathrm{C}$ collected on $01 / 27 / 94$, laboratory analyses (cont.)

\section{H $\underline{\text { Analyte }}$}

Chromium, total recoverable

Copper, total recoverable

Cyanide

$p, p^{\prime}-D D T$

Dibromochloromethane

1,1-Dichloroethane

1,2-Dichluroethane

1,1-Dichloroethylene

trans-1,2-Dichloroethylene

Dichloromethane (Methylene chloride)

2,4-Dichlorophenoxyacetic acid

1,2-Dichloropropane

cis-1,3-Dichloropropene

trans-1,3-Dichloropropene

Dieldrin

Endrin

Ethylbenzene

Fluoride

Heptachlor

Iron, total recoverable

Lead, total recoverable

Lindane

Lithium, total recoverable

Magnesium, total recoverable

Manganese, total recoverable

Mercury, total recoverable

Methoxychlor

Naphthalene

Nickel, total recoverable

Nitrate-nitrite as nitrogen

Phenols

Phenols

Potassium, total recoverable

Selenium, total recoverable

Silica, total recoverable

Silver, total recoverable

Sodium, total recoverable

Sulfate

1,1,2,2-Tetrachloroethane

Tetrachloroethylene

Tin, total recoverable

Toluene

Total dissolved solids

Total organic carbon

Total organic halogens

Total phosphates (as P)

Toxaphene

2,4,5-TP (Silvex)

Tributyl phosphate

1,1,1-Trichloroethane

1,1,2-Trichloroethane

- Trichloroethylene

Trichlorofluoromethane

Vanadium, total recoverable

Xylenes

Gross alpha
Result DF

$<4.0 \quad 1.00$

17

$<5.0$

$<0.10$

$<1.0$

$<1.0$

$<1.0$

$<1.0$

$<1.0$

$<1.0$

$<0.0015$

$<1.0$

$<1.0$

$<1.0$

$<0.51$

$<0.0061$

$<1.0$

117

$<0.051$

19

$<3.0$

$<0.0051$

$<5.0$

325

$<2.0$

$<0.20$

$<0.51$

$<10$

$<4.0$

680

$<5.0$

$<5.0$

$<500$

$<2.0$

9,770

$<2.0$

1,730

$<1,000$

$<1.0$

$<1.0$

$<2.0$

$<1.0$

73,000

$<1,000$

45

280

$<0.25$

$<0.00046$

$<10$

$<1.0$

$<1.0$

22

$<1.0$

$<8.0$

$<2.0$

$<9.2 \mathrm{E}-02$

1.00

1.00

1.00

1.00

1.00

1.00

1.00

1.00

1.00

1.00

1.00

1.00

1.00

1.00

1.00

1.00

1.00

1.00

1.00

1.00

$1 . \mathrm{CO}$

1.00

1.00

1.00

1.00

1.00

1.00

1.00

1.00

1.00

1.00

1.00

1.00

1.00

1.00

1.00

1.00

1.00

1.00

1.00

1.00

1.00

1.00

1.00

1.00

1.00

1.00

1.00

1.00

1.00

1.00

1.00

1.00

1.00

Mod Unit

Flag

$\underline{L a b}$

1.00

$\mu \mathrm{g} / \mathrm{L}$

J3 $\begin{array}{r}\mu \mathrm{g} / \mathrm{L} \\ \mu \mathrm{g} / \mathrm{L} \\ \mu \mathrm{g} / \mathrm{L}\end{array}$

$\mu \mathrm{g} / \mathrm{L}$
$\mu \mathrm{g} / \mathrm{L}$

$\mu \mathrm{g} / \mathrm{L}$

$\mu \mathrm{g} / \mathrm{L}$

$\mu \mathrm{g} / \mathrm{L}$

$\mu \mathrm{g} / \mathrm{L}$

$\mu \mathrm{g} / \mathrm{L}$

$\mu \mathrm{g} / \mathrm{L}$

$\mu \mathrm{g} / \mathrm{L}$

$\mu \mathrm{g} / \mathrm{L}$

J3 $\mu \mathrm{g} / \mathrm{L}$

J3 $\mu \mathrm{g} / \mathrm{L}$

$\mu \mathrm{g} / \mathrm{L}$

$J \mu g / L$

J3 $\mu \mathrm{g} / \mathrm{L}$

$\mu \mathrm{g} / \mathrm{L} \quad 0 \quad \mathrm{GE}$

$\mu g / L \quad O \quad G E$

$\begin{array}{llll}\mu \mathrm{g} / \mathrm{L} & 0 & \mathrm{GE} \\ \mu \mathrm{g} / \mathrm{L} & 0 & \mathrm{GE}\end{array}$

$\mu \mathrm{g} / \mathrm{L} \quad 0 \quad \mathrm{GE}$

$\mu g / L \quad 0 \quad G E$

J3 $\mu \mathrm{g} / \mathrm{L} \quad 0 \quad \mathrm{~g} \quad \mathrm{GE}$

$\mu \mathrm{g} / \mathrm{L} \quad \mathrm{O} \quad \mathrm{GE}$

$\mu \mathrm{g} / \mathrm{L} \quad \mathrm{O} \quad \mathrm{GE}$

$\mu \mathrm{g} / \mathrm{L}$

$\mu \mathrm{g} / \mathrm{L}$

$\mu \mathrm{g} / \mathrm{L}$

$\mu g / L$

$\mu \mathrm{g} / \mathrm{L}$

$\mu \mathrm{g} / \mathrm{L}$

$\mu g / L$

$\mu \mathrm{g} / L$

$\mu \mathrm{g} / \mathrm{L}$

$\mu \mathrm{g} / \mathrm{L}$

$\mu \mathrm{g} / \mathrm{L}$

$\mu \mathrm{g} / \mathrm{L}$

$\mu \mathrm{g} / \mathrm{L}$

JV2

$\mu \mathrm{g} / \mathrm{L}$

$\mu \mathrm{g} / \mathrm{L}$

$\mu \mathrm{g} / \mathrm{L}$

J3

$\mu g / L$

$\mu \mathrm{g} / \mathrm{L}$

$\mu \mathrm{g} / \mathrm{L}$

$\mu \mathrm{g} / \mathrm{L}$

$\mu \mathrm{g} / \mathrm{L}$

$\mu \mathrm{g} / \mathrm{L}$

$\mu \mathrm{g} / \mathrm{L}$

$\mu \mathrm{g} / \mathrm{L}$

$\mathrm{pCi} / \mathrm{L}$

0
0
0
0
0
0
0
0
0
0
0
0
0
0
0
1
0
0
0
0
0
0
2
0
0
0

GE

GE

GE

GE

GE

GE

GE

GE

GE

$G E$

GE

GE

$\mathrm{GE}$

$\mathrm{GE}$

GE

GE

GE

GE

$G E$

GE

$\mathrm{GE}$

GE

GE

GE

GP

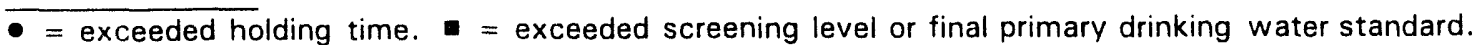


WELL BGO 27C collected on 01/27/94, laboratory analyses (cont.)

\begin{tabular}{|c|c|c|c|c|c|c|}
\hline$\underline{D}$ & Analyte & Result & $\underline{D F}$ & Mod & Unit & Flag \\
\hline 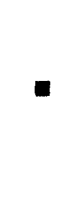 & $\begin{array}{l}\text { Nonvolatile beta } \\
\text { Radium, total alpha-emitting } \\
\text { Tritium } \\
\text { Uranium-233/234 } \\
\text { Uranium-235 } \\
\text { Uranium-238 }\end{array}$ & $\begin{aligned}< & 4.2 \mathrm{E}-01 \\
& 4.0 \mathrm{E}-01 \\
& 6.6 \mathrm{E}+01 \\
< & 3.8 \mathrm{E}-02 \\
< & 9.6 \mathrm{E}-03 \\
< & -4.7 \mathrm{E}-03\end{aligned}$ & $\begin{array}{l}1.00 \\
1.00 \\
1.00 \\
1.00 \\
1.00 \\
1.00\end{array}$ & $J$ & $\begin{array}{l}\mathrm{pCi} / \mathrm{L} \\
\mathrm{pCi} / \mathrm{L} \\
\mathrm{pCi} / \mathrm{mL} \\
\mathrm{pCi} / \mathrm{L} \\
\mathrm{pCi} / \mathrm{L} \\
\mathrm{pCi} / \mathrm{L}\end{array}$ & $\begin{array}{l}0 \\
0 \\
2 \\
0 \\
0 \\
0\end{array}$ \\
\hline
\end{tabular}

WELL BGO 27D

$\begin{array}{lllllll}\text { SRS Coord. } & \text { Lat/Longitude } & \text { Screen Zone Elevation } & \text { Top of Casing } & \text { Casing } & \text { Pump } & \text { Formation } \\ \text { N75677.3 } & 33.282366^{\circ} \mathrm{N} & 229.3-209.3 \mathrm{ft} \mathrm{msl} & 276.3 \mathrm{ft} \mathrm{msl} & \text { 4" PVC } & \text { S } & \text { Water Table (IIB })_{2} \\ \text { E54680.2 } & 81.669818^{\circ} \mathrm{W} & & & \end{array}$

\section{FIELD MEASUREMENTS}

Sample date: $01 / 27 / 94$

Depth to water: $48.57 \mathrm{ft}(14.80 \mathrm{~m})$ below TOC

Water elevation: $227.73 \mathrm{ft}(69.41 \mathrm{~m}) \mathrm{msl}$

Sp. conductance: $35 \mu \mathrm{S} / \mathrm{cm}$

Turbidity: 40.4 NTU

Water evacuated before sampling: $12 \mathrm{gal}$

The well went diy during purging.

\section{LABORATORY ANALYSES}

\section{H $\underline{D}$ Analyte}

$\mathrm{pH}$

Specific conductance

Turbidity

Acetophenone

Aldrin

Aluminum, total recoverable

Aluminum, total recoverable

Antimony, total recoverable

Arsenic, total recoverable

Barium, total recoverable

Barium, total recoverable

Benzene

Benzene

Bromodichloromethane

Bromodichloromethane

Bromoform

Bromoform

Bromomethane (Methyl bromide)

Bromomethane (Methyl bromide)

Cadmium, total recoverable

Cadmium, total recoverable

Calcium, total recoverable

Calcium, total recoverable

Carbon tetrachloride

Carbon tetrachloride

Chloride

Chlorobenzene

Chlorobenzene
Time: $10: 35$

pH: 4.9

Alkalinity: $0 \mathrm{mg} / \mathrm{L}$

Water temperature: $17.4{ }^{\circ} \mathrm{C}$

Volumes furged: 1.0 well volumes

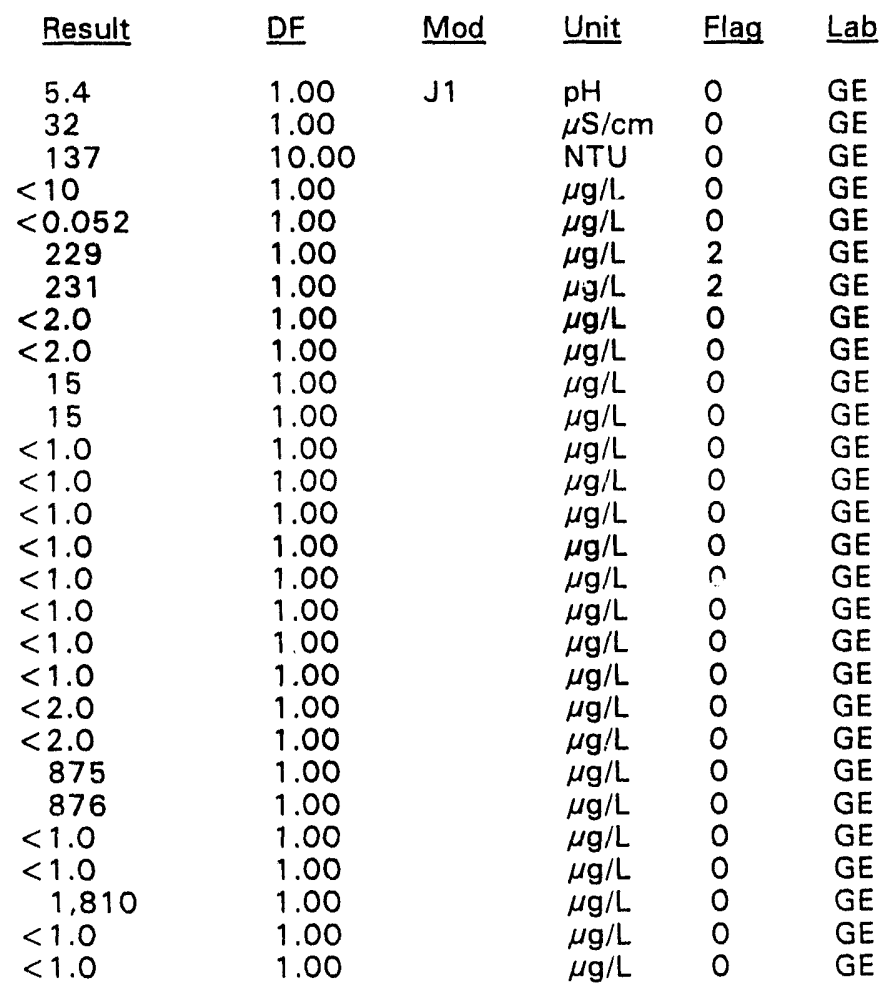

\footnotetext{
- = exceeded holding time. = exceeded screening level or final primary drinking water standard
} 
WELL BGO 27D collected on $01 / 27 / 94$, laboratory analyses (cont.)

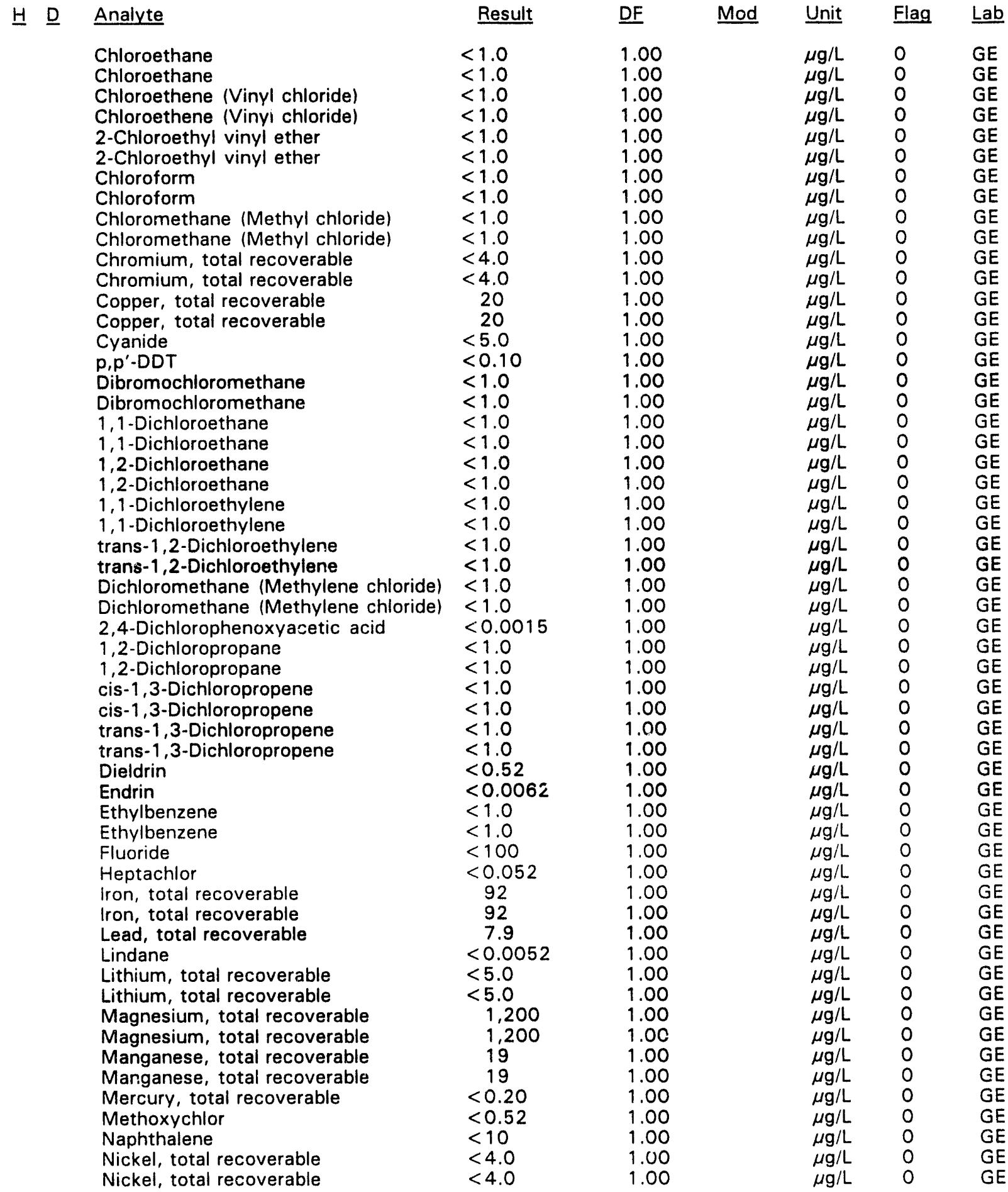

\footnotetext{
$\overline{-}=$ exceeded holding time. $=$ exceeded screening level or final primary drinking water standard.
} 
WELL BGO 27D collected on $01 / 27 / 94$, laboratory analyses (cont.)

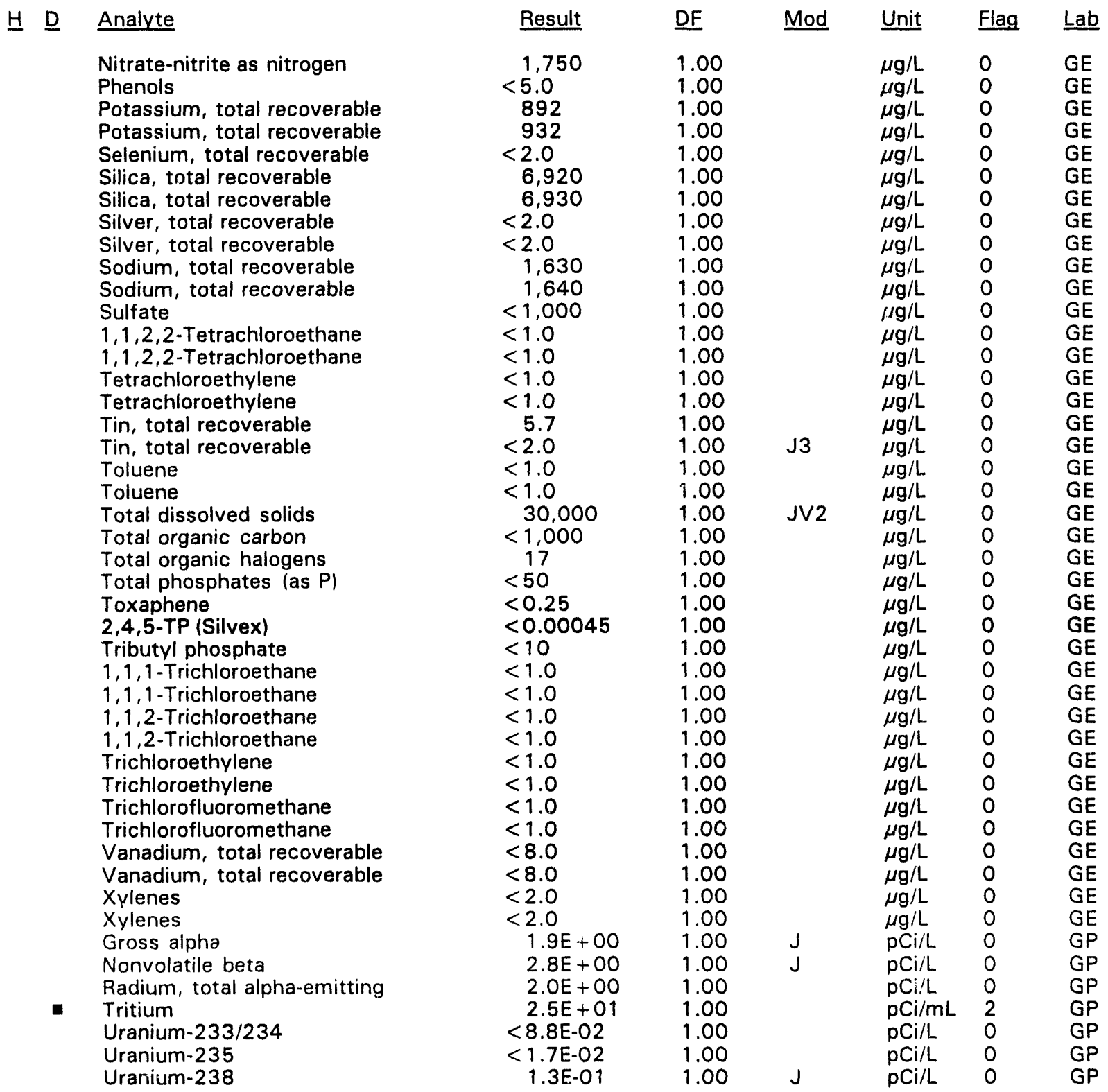

- = exceeded holding time. = exceeded screening level or final primary drinking water standard. 
WELL BGO 28D

\begin{tabular}{|c|c|c|c|c|c|c|}
\hline SRS Coord. & Lat/Longitude & Screen Zone Elevation & Top of Casing & Casing & Pump & Formation \\
\hline $\begin{array}{l}N 75348.3 \\
E 54457.9\end{array}$ & $\begin{array}{l}33.281276^{\circ} \mathrm{N} \\
81.669764^{\circ} \mathrm{W}\end{array}$ & $230.1-210.1 \mathrm{ft} \mathrm{msl}$ & $277.4 \mathrm{ft} \mathrm{msl}$ & 4" PVC & s & Water Table $\left(\| \mathrm{B}_{2}\right)$ \\
\hline
\end{tabular}

\section{FIELD MEASUREMENTS}

Sample date: 02/01/94

Depth to water: $51.31 \mathrm{ft}(15.64 \mathrm{~m})$ below TOC

Water elevation: $226.09 \mathrm{ft}(68.91 \mathrm{~m}) \mathrm{msl}$

Sp. conductance: $98 \mu \mathrm{S} / \mathrm{cm}$

Turbidity: 30.9 NTU

Water evacuated before sampling: 8 gal

The well went dry during purging.

\section{LABORATORY ANALYSES}

H D Analyte

$\mathrm{pH}$

Specific conductance

Turbidity

Acetophenone

Aldrin

Aluminum, total recoverable

Antimony, total recoverable

Antimony, total recoverable

Arsenic, total recoverable

Arsenic, total recoverable

Barium, total recoverable

Benzene

Bromodichloromethane

Bromoform

Bromomethane (Methyl bromide)

Cadmium, total recoverable

Calcium, total recoverable

Carbon tetrachloride

Chloride

Chlorobenzene

Chloroethane

- Chloroethene (Vinyl chloride)

2-Chloroethyl vinyl ether

Chloroform

Chloromethane (Methyl chloride)

Chromium, total recoverable

Copper, total recoverable

Cyanide

$p, p^{\prime}$-DDT

Dibromochloromethane

1,1-Dichloroethane

1,2-Dichloroethane

1,1-Dichloroethylene

trans-1,2-Dichloroethylene

Dichloromethane (Methylene chloride)

2,4-Dichlorophenoxyacetic acid

1,2-Dichloropropane

cis-1,3-Dichloropropene

trans-1,3-Dichloropropene
Time: 9: 24

$\mathrm{pH}: 5.5$

Alkalinity: $8 \mathrm{mg} / \mathrm{L}$

Water temperature: $14.4^{\circ} \mathrm{C}$

Volumes purged: 0.8 well volumes

\begin{tabular}{|c|c|c|c|c|c|}
\hline Result & DF & Mod & Unit & Flag & Lab \\
\hline $\begin{array}{l}5.6 \\
88\end{array}$ & 1.00 & J1 & & 0 & GE \\
\hline $\begin{array}{l}88 \\
68\end{array}$ & $\begin{array}{l}1.00 \\
2.00\end{array}$ & & $\begin{array}{l}\mu \mathrm{S} / \mathrm{cm} \\
\text { NTU }\end{array}$ & $\begin{array}{l}0 \\
0\end{array}$ & \\
\hline$<10$ & 1.00 & & $\mu \mathrm{g} / \mathrm{L}$ & 0 & \\
\hline$<0.050$ & 1.00 & J3 & $\mu \mathrm{g} / \mathrm{L}$ & 0 & GE \\
\hline 1,660 & 1.00 & & $\mu \mathrm{g} / \mathrm{L}$ & 2 & GE \\
\hline $\begin{array}{l}<2.0 \\
<2.0\end{array}$ & 1.00 & & $\mu \mathrm{g} / \mathrm{L}$ & 0 & GE \\
\hline $\begin{array}{l}<2.0 \\
<2.0\end{array}$ & 1.00 & & $\mu \mathrm{g} / \mathrm{L}$ & 0 & 5 \\
\hline $\begin{array}{l}<2.0 \\
<2.0\end{array}$ & 1.00 & & $\mu \mathrm{g} / \mathrm{L}$ & 0 & GE \\
\hline $\begin{array}{l}<2.0 \\
32\end{array}$ & $\begin{array}{l}1.00 \\
1.00\end{array}$ & & $\begin{array}{l}\mu \mathrm{g} / \mathrm{L} \\
\mu \mathrm{g} / \mathrm{L}\end{array}$ & $\begin{array}{l}0 \\
0\end{array}$ & $\begin{array}{l}\text { GE } \\
\text { GE }\end{array}$ \\
\hline$<5.0$ & 5.00 & & $\mu \mathrm{g} / \mathrm{L}$ & 0 & $\mathrm{GE}$ \\
\hline$<5.0$ & 5.00 & & $\mu \mathrm{g} / \mathrm{L}$ & 0 & GE \\
\hline$<5.0$ & 5.00 & & $\mu \mathrm{g} / \mathrm{L}$ & 0 & GE \\
\hline$<5.0$ & 5.00 & & $\mu \mathrm{g} / \mathrm{L}$ & 0 & $\mathrm{E}$ \\
\hline $\begin{array}{r}<2.0 \\
\quad 4,190\end{array}$ & $\begin{array}{l}1.00 \\
1.00\end{array}$ & & $\mu \mathrm{g} / \mathrm{L}$ & $\begin{array}{l}0 \\
0\end{array}$ & GE \\
\hline $\begin{aligned} & 4,190 \\
< & 5.0\end{aligned}$ & 5.00 & & $\begin{array}{l}\mu \mathrm{g} / \mathrm{L} \\
\mu \mathrm{g} / \mathrm{L}\end{array}$ & $\begin{array}{l}0 \\
0\end{array}$ & $\checkmark$ \\
\hline 10,400 & 1.00 & & $\mu \mathrm{g} / \mathrm{L}$ & 0 & 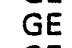 \\
\hline$<5.0$ & 5.00 & & $\mu \mathrm{g} / \mathrm{L}$ & 0 & GE \\
\hline$<5.0$ & 5.00 & & $\mu \mathrm{g} / \mathrm{L}$ & 0 & GE \\
\hline 140 & 5.00 & & $\mu \mathrm{g} / \mathrm{L}$ & 2 & $\mathrm{E}$ \\
\hline$<5.0$ & 5.00 & & $\mu \mathrm{g} / \mathrm{L}$ & 0 & $\mathrm{E}$ \\
\hline$<5.0$ & 5.00 & & $\mu \mathrm{g} / \mathrm{L}$ & 0 & 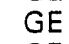 \\
\hline$<5.0$ & 5.00 & & $\mu \mathrm{g} / \mathrm{L}$ & 0 & S \\
\hline$<4.0$ & 1.00 & & $\mu \mathrm{g} / \mathrm{L}$ & 0 & $\mathrm{iE}$ \\
\hline 13 & 1.00 & & $\mu \mathrm{g} / \mathrm{L}$ & 0 & \\
\hline$<5.0$ & 1.00 & & $\mu \mathrm{g} / \mathrm{L}$ & 0 & G \\
\hline $\begin{array}{l}<0.10 \\
<5.0\end{array}$ & 1.00 & J3 & $\mu \mathrm{g} / \mathrm{L}$ & 0 & \\
\hline $\begin{array}{c}<5.0 \\
54\end{array}$ & $\begin{array}{l}5.00 \\
5.00\end{array}$ & & $\underset{\mu \mathrm{g} / \mathrm{L}}{\mu \mathrm{g} / \mathrm{L}}$ & $\begin{array}{l}0 \\
2\end{array}$ & \\
\hline$<5.0$ & 5.00 & & $\mu \mathrm{g} / \mathrm{L}$ & 0 & $\mathrm{GE}$ \\
\hline$<5.0$ & 5.00 & & $\mu \mathrm{g} / \mathrm{L}$ & 0 & \\
\hline$<5.0$ & 5.00 & & $\mu \mathrm{g} / \mathrm{L}$ & 0 & \\
\hline$<5.0$ & 5.00 & & $\mu \mathrm{g} / \mathrm{L}$ & 0 & G \\
\hline$<0.0015$ & 1.00 & J3 & $\mu \mathrm{g} / \mathrm{L}$ & 0 & \\
\hline $\begin{array}{l}<5.0 \\
<5.0\end{array}$ & 5.00 & & $\mu \mathrm{g} / \mathrm{L}$ & 0 & \\
\hline $\begin{array}{l}<5.0 \\
<5.0\end{array}$ & $\begin{array}{l}5.00 \\
5.00\end{array}$ & & $\underset{\mu \mathrm{g} / \mathrm{L}}{\mu \mathrm{L}}$ & $\begin{array}{l}0 \\
0\end{array}$ & \\
\hline & & & $\mu \mathrm{g} / \mathrm{L}$ & & \\
\hline
\end{tabular}

$\overline{-}=$ exceeded holding time. = exceeded screening level or final primary drinking water standard. 
WELL BGO 28D collected on $02 / 01 / 94$, laboratory analyses (cont.)

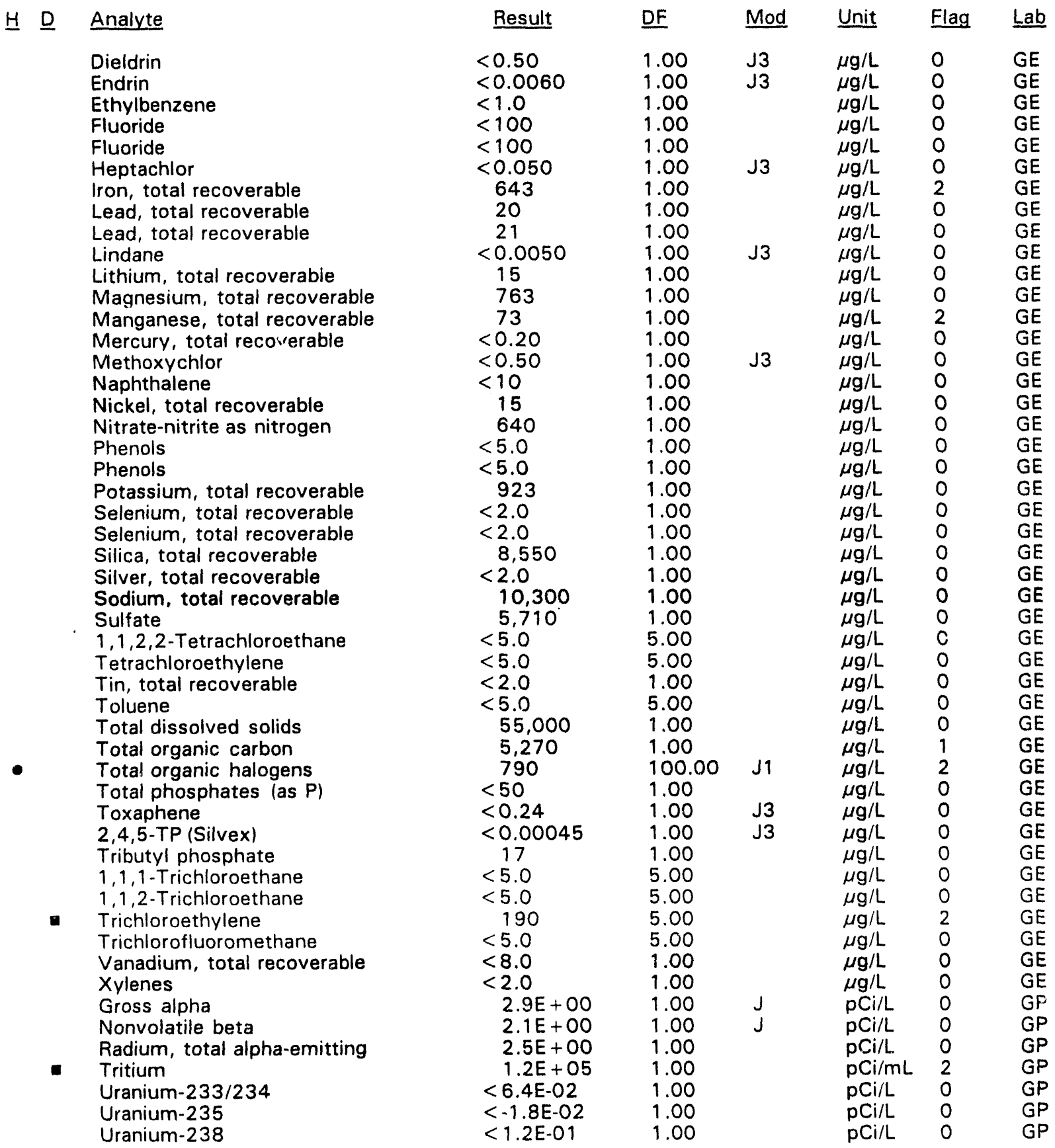

- = exceeded holding time. = exceeded screening level or final primary drinking water standard. 


\section{WELL BGO 29A}

\begin{tabular}{|c|c|c|c|c|c|c|}
\hline SRS Coord. & Lat/Longitude & Screen Zone Elevation & Top of Casing & Casing & Pump & Formation \\
\hline $\begin{array}{l}N 75560.0 \\
\text { E54103.5 }\end{array}$ & $\begin{array}{l}33.281166^{\circ} \mathrm{N} \\
81.671108^{\circ} \mathrm{W}\end{array}$ & $112.5-102.5 \mathrm{ft} \mathrm{msl}$ & $264.2 \mathrm{ft} \mathrm{msl}$ & 4" PVC & $\mathrm{S}$ & garee (IIA) \\
\hline
\end{tabular}

\section{FIELD MEASUREMENTS}

Sample date: $01 / 28 / 94$

Depth to water: $104.63 \mathrm{ft}(31.89 \mathrm{~m})$ below TOC

Water elevation: $159.57 \mathrm{ft}(48.64 \mathrm{~m}) \mathrm{ms}$ )

Sp. conductance: $122 \mu \mathrm{S} / \mathrm{cm}$

Turbidity: 9.8 NTU

Water evacuated before sampling: $38 \mathrm{gal}$

The well went dry during purging.

Time: 10: 07

$\mathrm{pH}: \mathbf{8 . 2}$

Alkalinity: $45 \mathrm{mg} / \mathrm{L}$

Water temperature: $18.2^{\circ} \mathrm{C}$

Volumes purged: 1.0 well volumes

\section{LABORATORY ANALYSES}

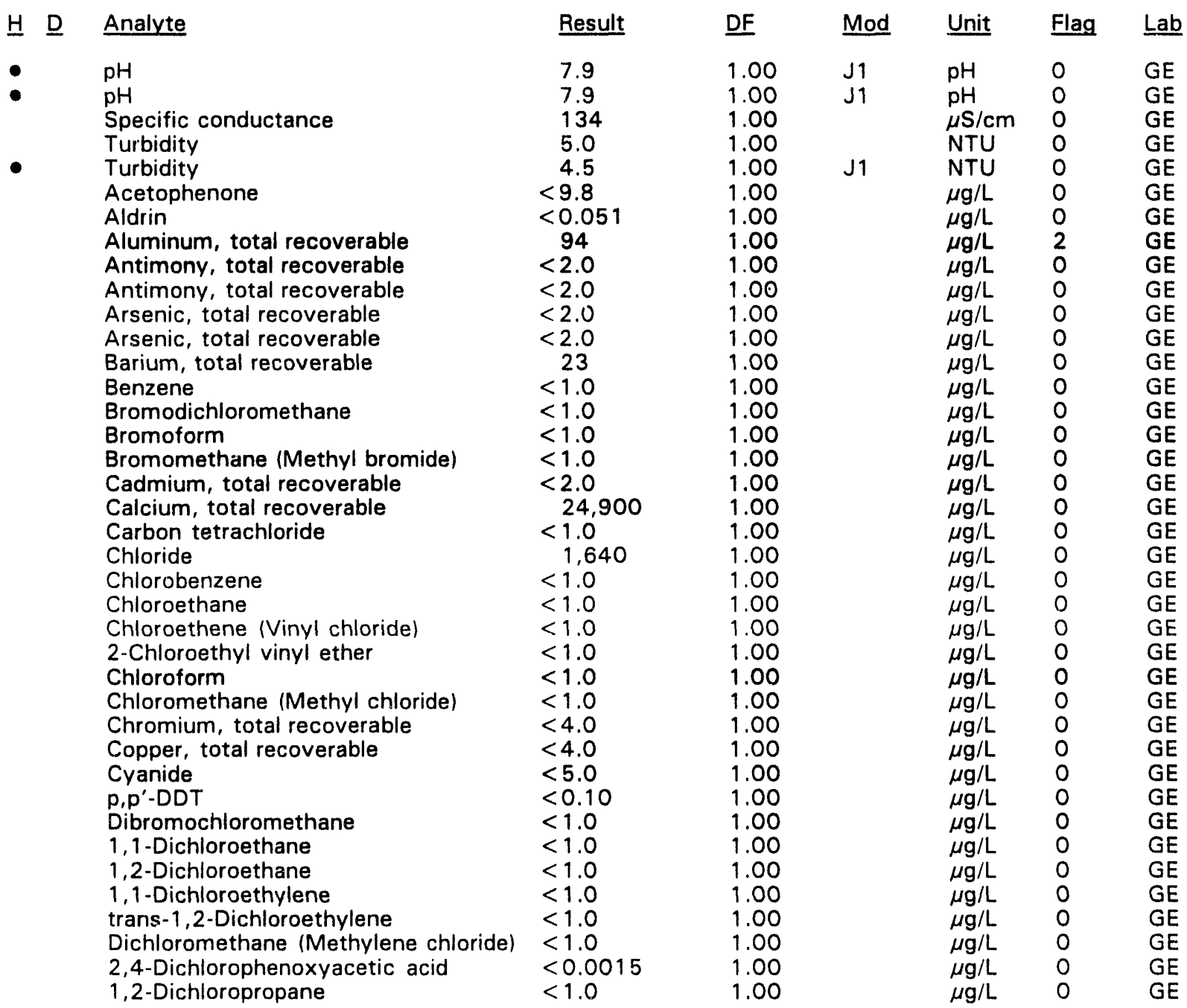

\footnotetext{
- = exceeded holding time. = exceeded screening level or final primary drinking water standard.
} 
WELL BGO 29A collected on 01/28/94, laboratory analyses (cont.)

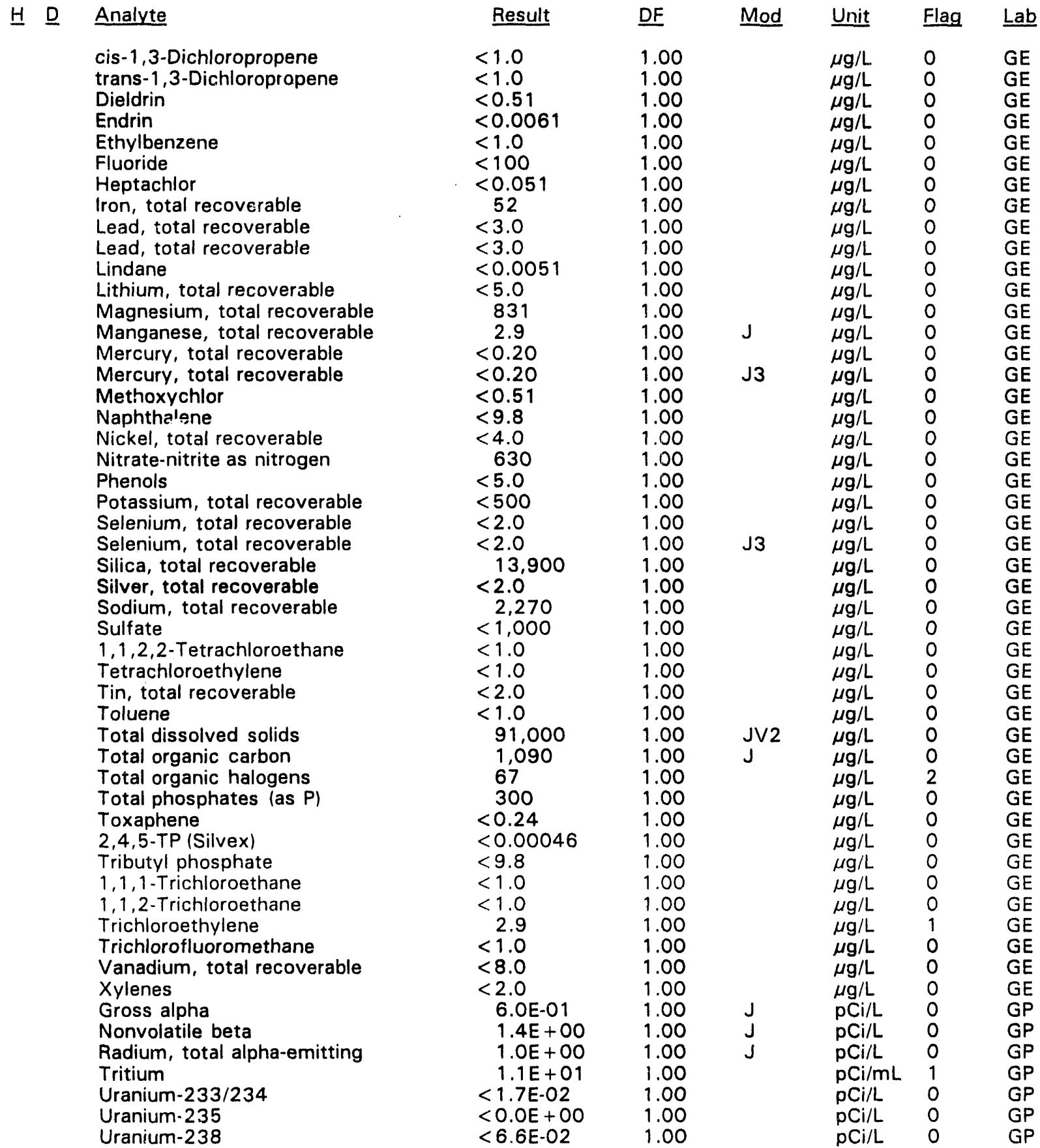

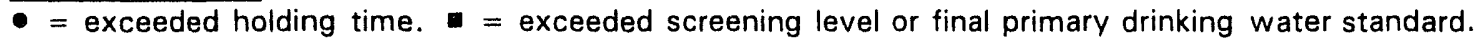


WSRC.TR-94-0240

Unclassified

WELL BGO 29C

\begin{tabular}{|c|c|c|c|c|c|c|}
\hline SRS Coord. & Lat/Longitude & Screen Zone Elevation & Top of Casing & Casing & Pump & Formation \\
\hline $\begin{array}{l}N 75577.8 \\
E 54099.1\end{array}$ & $\begin{array}{l}33.281198^{\circ} \mathrm{N} \\
81.671154^{\circ} \mathrm{W}\end{array}$ & $186.8-176.8 \mathrm{ft} \mathrm{msl}$ & $264.8 \mathrm{ft} \mathrm{msl}$ & 4" PVC & $\mathrm{S}$ & $(I I B)$, \\
\hline
\end{tabular}

\section{FIELD MEASUREMENTS}

Sample date: $01 / 28 / 94$

Depth to water: $41.72 \mathrm{ft}(12.72 \mathrm{~m})$ below TOC Water elevation: $223.08 \mathrm{ft}(68.00 \mathrm{~m}) \mathrm{ms}$ Sp. conductance: $31 \mu \mathrm{S} / \mathrm{cm}$

Turbidity: 2.2 NTU

Water evacuated before sampling: $28 \mathrm{gal}$

The well went dry during purging.

\section{LABORATORY ANALYSES}

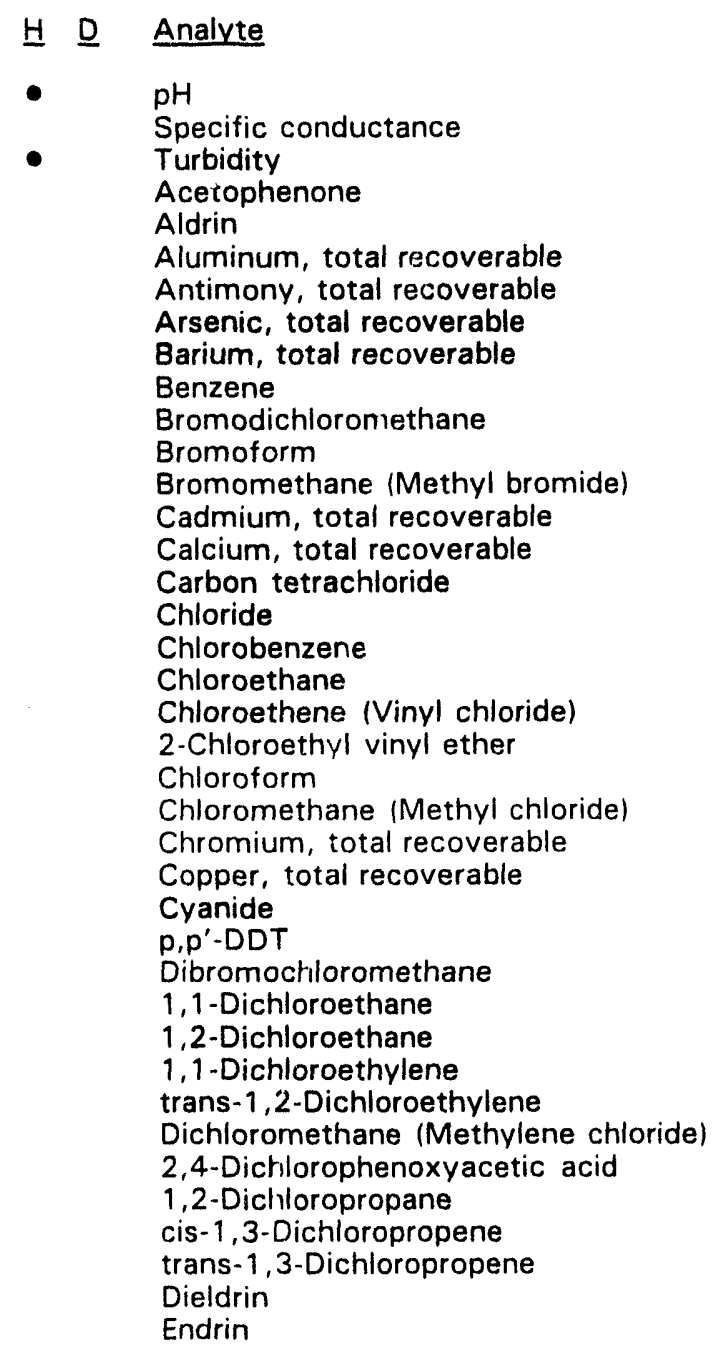

Time: 9: 47

$\mathrm{pH}: 5.3$

Alkalinity: $2 \mathrm{mg} / \mathrm{L}$

Water temperature: $18.1^{\circ} \mathrm{C}$

Volumes purged: 0.9 well volumes

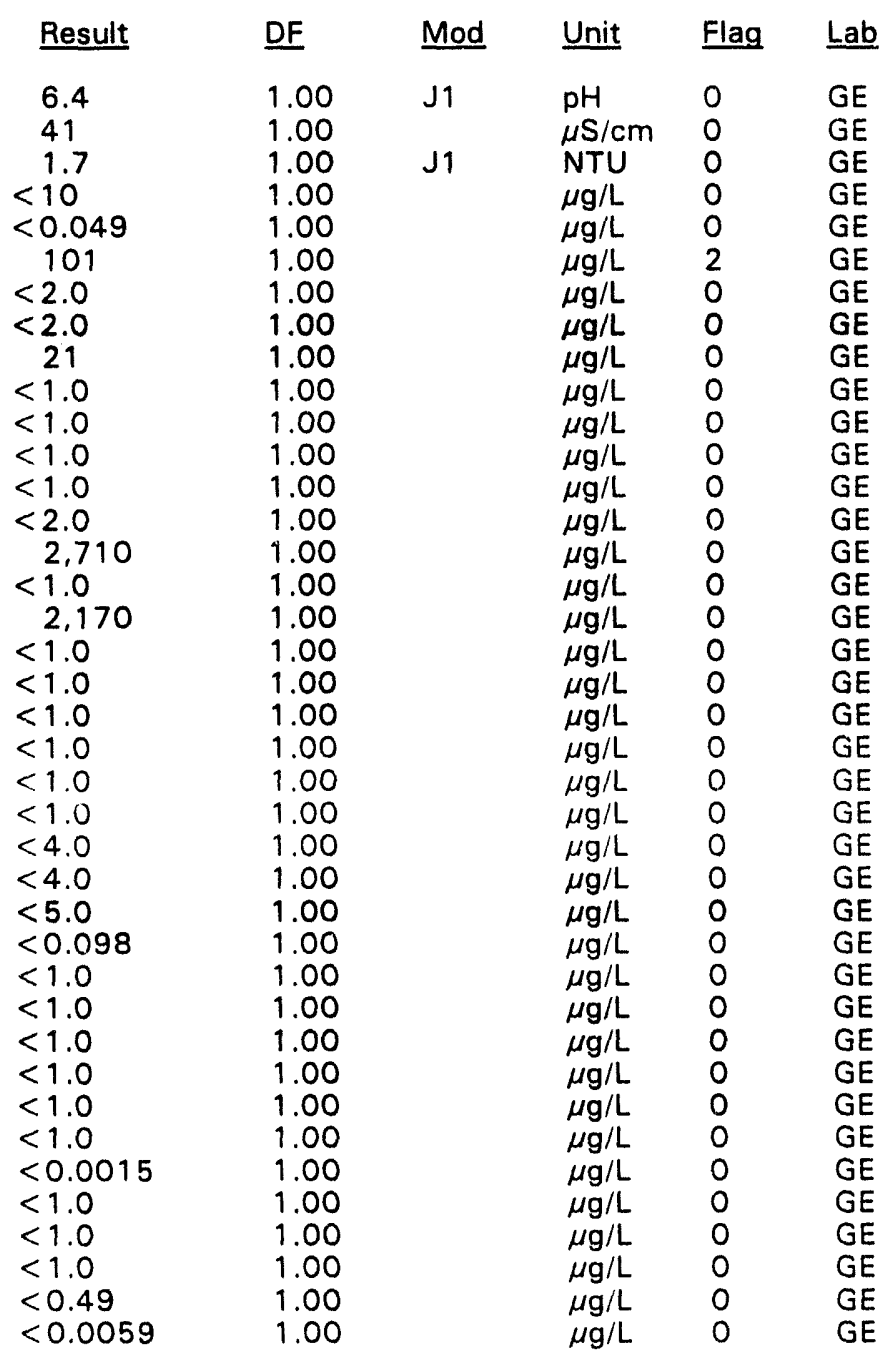

\footnotetext{
$\overline{\bullet=}$ exceeded holding time. $=$ exceeded screening level or final primary drinking water standard.
} 
WELL BGO 29 C collected on $01 / 28 / 94$, laboratory analyses (cont.)

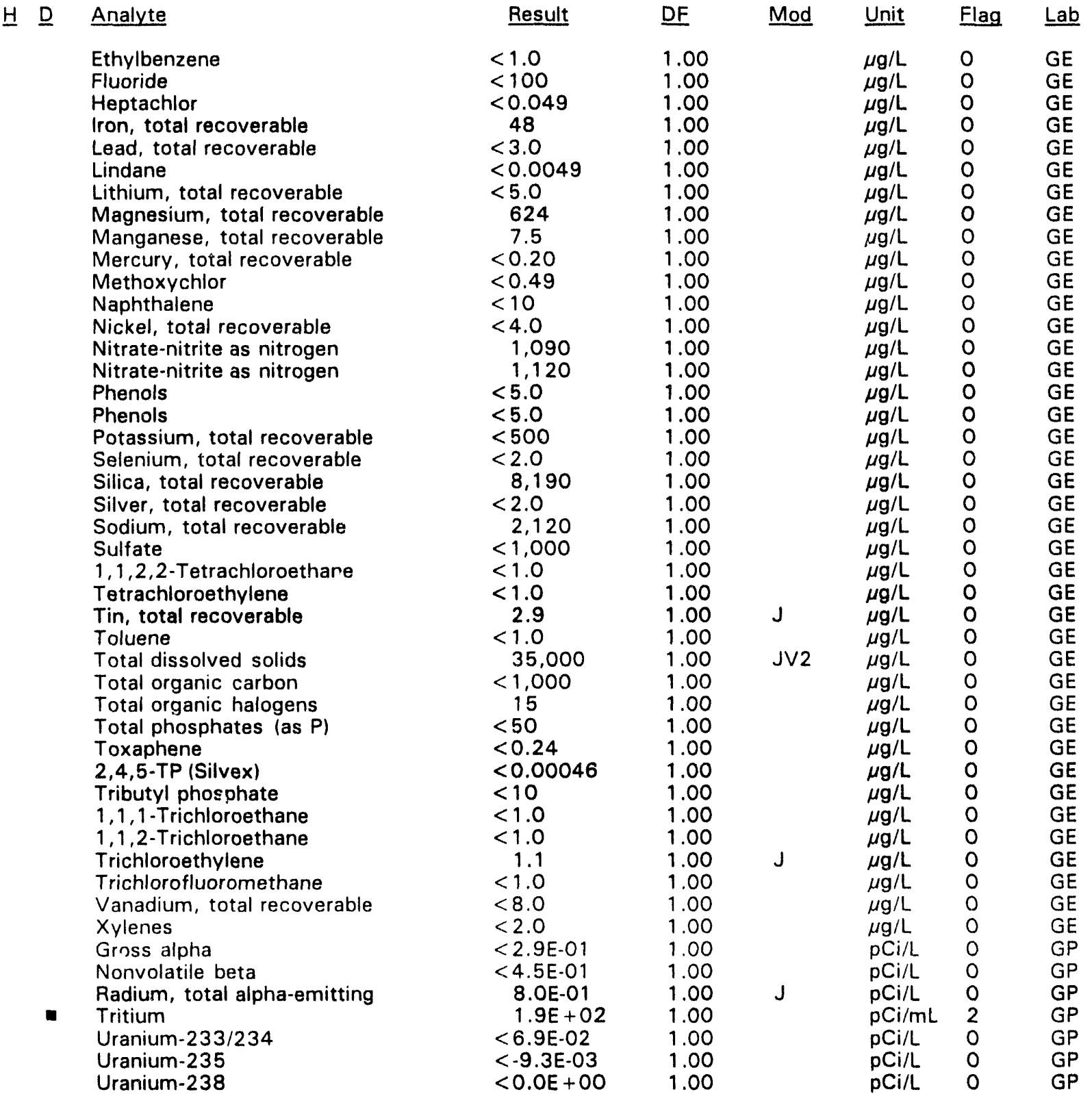

$\overline{- \text { = exceeded holding time. }} \mathbf{-}=$ exceeded screening level or final primary drinking water standard. 


\section{WELL BGO 29D}

\begin{tabular}{|c|c|c|c|c|c|c|}
\hline SRS Coord. & Lat/Longitude & Screen Zone Elevation & Top of Casing & Casing & Pump & Formation \\
\hline $\begin{array}{l}N 75592.5 \\
\text { E54099.4 }\end{array}$ & $\begin{array}{l}33.281231^{\circ} \mathrm{N} \\
81.671182^{\circ} \mathrm{W}\end{array}$ & $228.5-208.5 \mathrm{ft} \mathrm{msl}$ & $265.5 \mathrm{ft} \mathrm{msl}$ & 4" PVC & $S$ & - 111 \\
\hline
\end{tabular}

\section{FIELD MEASUREMENTS}

Sample date: $01 / 28 / 94$

Depth to water: $39.07 \mathrm{ft}(11.91 \mathrm{~m})$ below TOC

Water elevation: $226.43 \mathrm{ft}(69.02 \mathrm{~m}) \mathrm{msl}$

Sp. conductance: $68 \mu \mathrm{S} / \mathrm{cm}$

Turbidity: 18.7 NTU

Water evacuated before sampling: $10 \mathrm{gal}$

The well went dry during purging.

\section{LABORATORY ANALYSES}

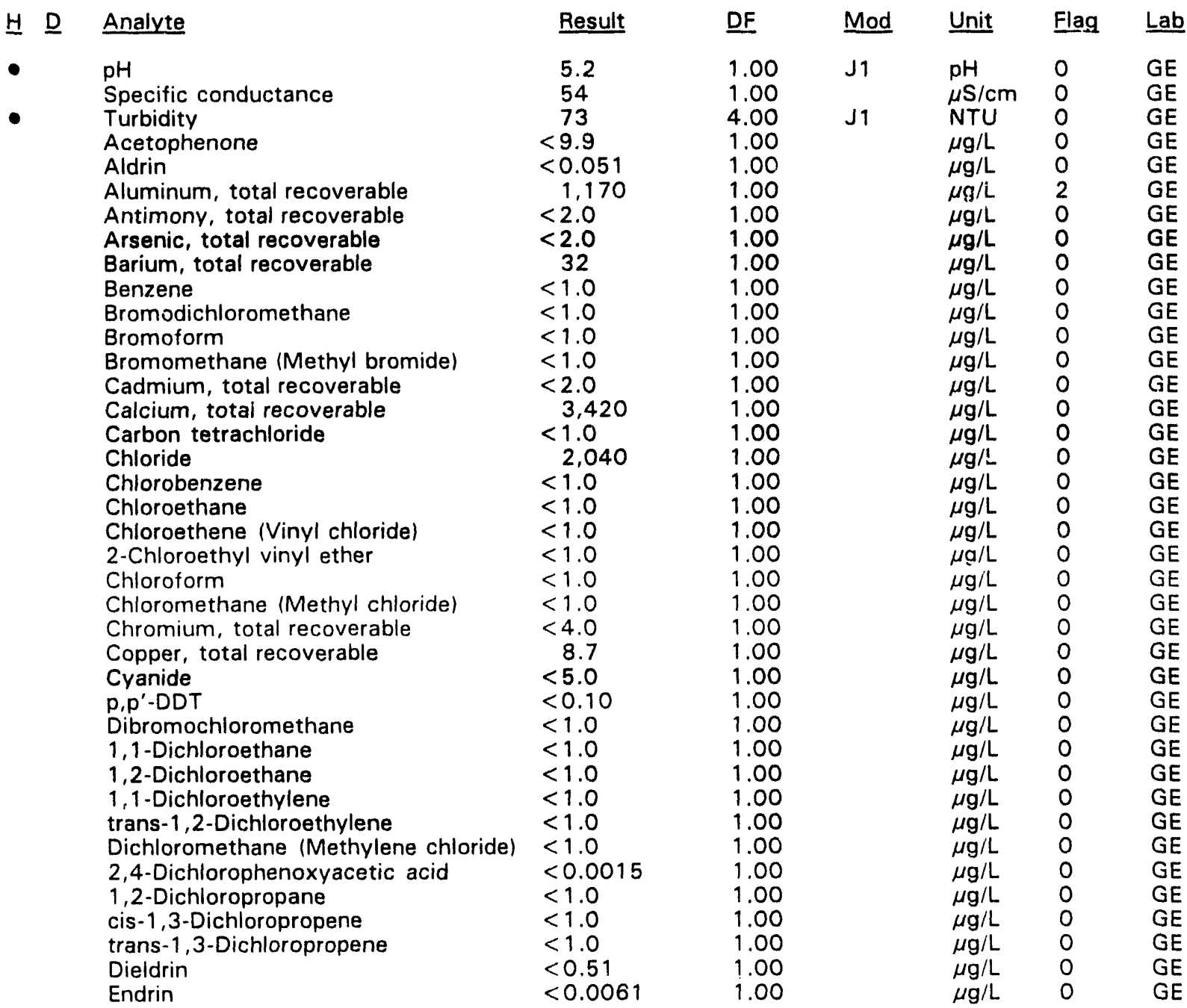

$\overline{-}=$ exceeded holding time. - = exceeded screening level or final primary drinking water standard.
$\mathrm{pH}: 5.0$

Alkalinity: $0 \mathrm{mg} / \mathrm{L}$

Water temperature: $17.5^{\circ} \mathrm{C}$

Volumes purged: 0.9 well volumes 
WELL BGO 290 collected on $01 / 28 / 94$, laboratory analyses (cont.)

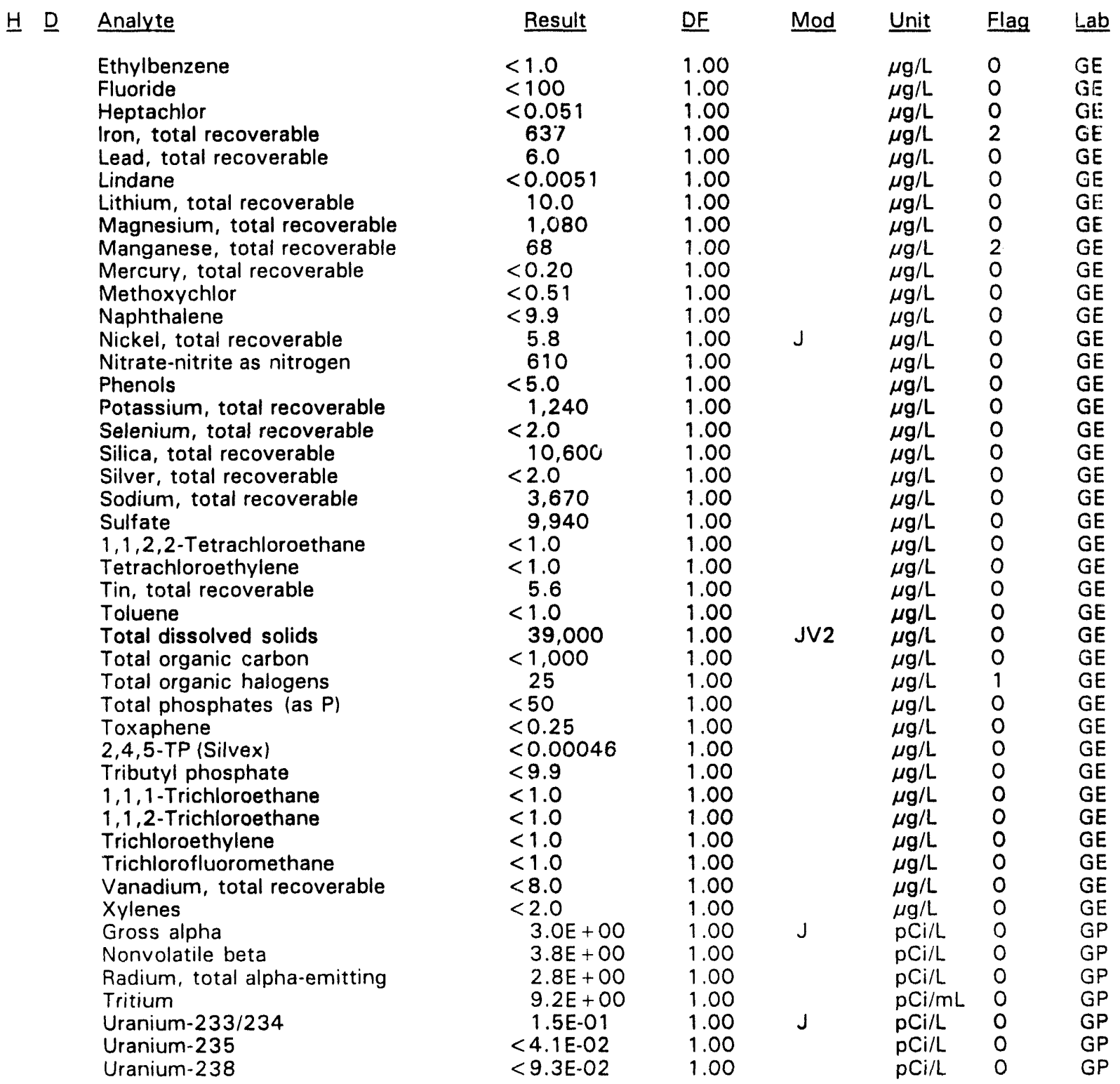

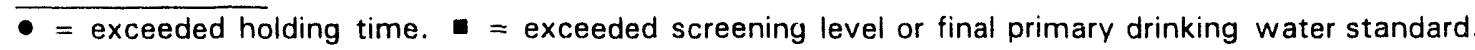


WELL BGO 30C

\begin{tabular}{|c|c|c|c|c|c|c|}
\hline SRS Coord. & Lat/Longitude & Screen Zone Elevation & Top of Casing & Casing & Pump & Formation \\
\hline $\begin{array}{l}75181.0 \\
54512.3\end{array}$ & $\begin{array}{l}33.280995^{\circ} \mathrm{N} \\
81.669296^{\circ} \mathrm{W}\end{array}$ & $188.4-178.4 \mathrm{ft} \mathrm{msl}$ & $274.5 \mathrm{ft} \mathrm{msl}$ & 4" PVC & $\mathrm{S}$ & \\
\hline
\end{tabular}

\section{FIELD MEASUREMENTS}

Sample date: $02 / 01 / 94$

Depth to water: $55.00 \mathrm{ft}(16.76 \mathrm{~m})$ below TOC

Water elevation: $219.50 \mathrm{ft}(66.90 \mathrm{~m}) \mathrm{msl}$

Sp. conductance: $40 \mu \mathrm{S} / \mathrm{cm}$

Turbidity: 58.9 NTU

Water evacuated before sampling: $25 \mathrm{gal}$

The well went dry during purging.

Time: $9: 36$

pH: 6.2

Alkalinity: $11 \mathrm{mg} / \mathrm{L}$

VVater temperature. $15.2 \mathrm{C}$

Volumes purged: 0.9 well volumes

\section{LABORATORY ANALYSES}

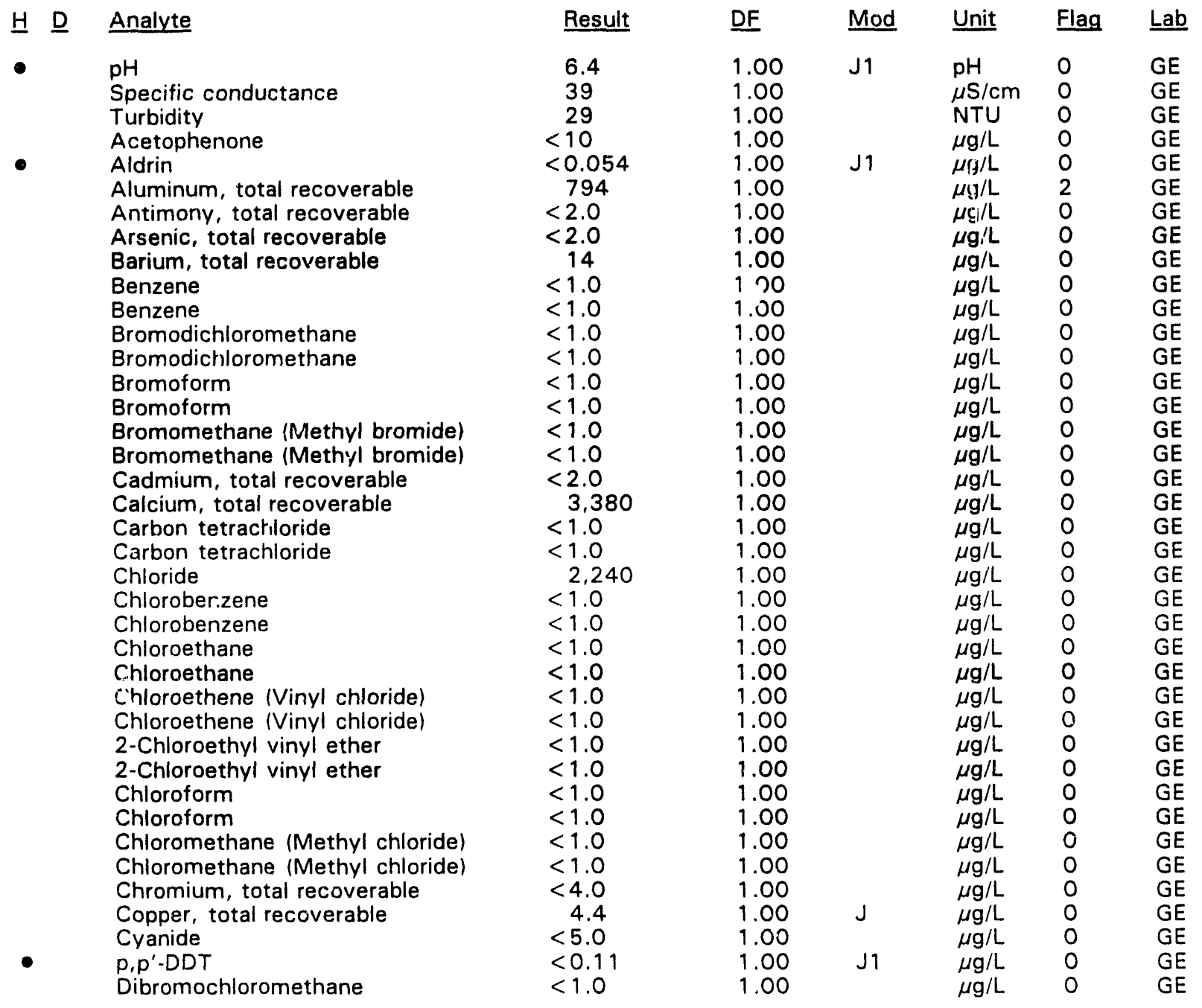

- = exceeded holding time. = exceeded screening level or final primary drinking water standard. 
WELL BGO $30 \mathrm{C}$ collected on $02 / 01 / 94$, laboratory analyses (cont.)

\begin{tabular}{|c|c|c|c|c|c|c|}
\hline$\underline{H} \underline{D}$ & Analyte & Result & DF & Mod & Unit & Flag \\
\hline$\bullet$ & 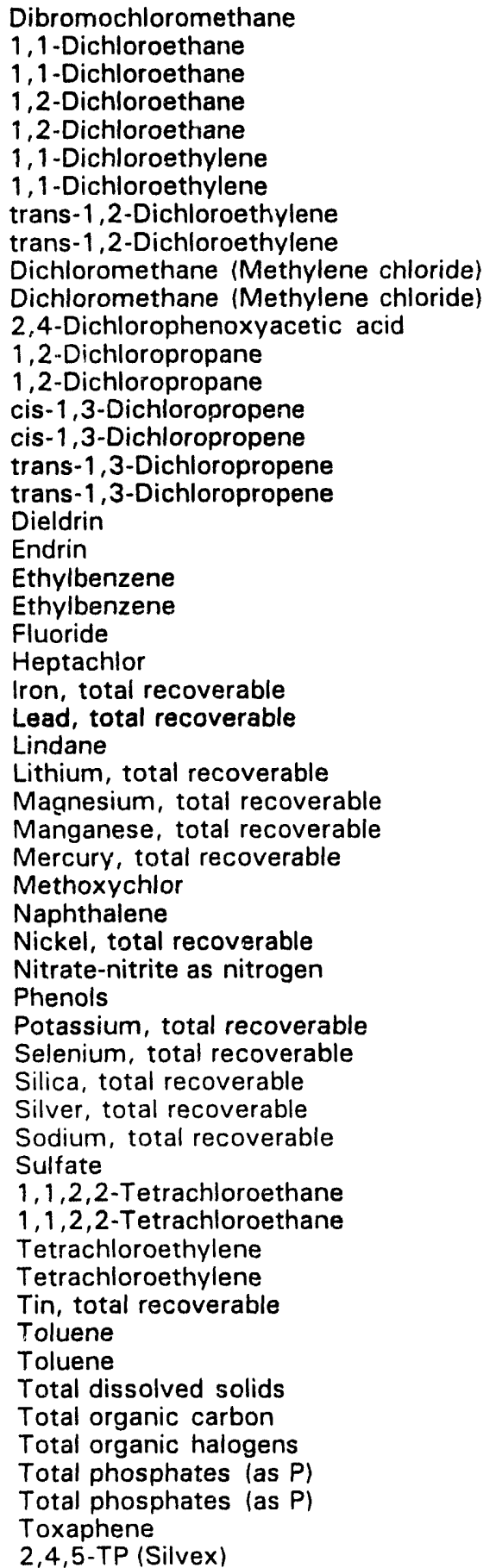 & 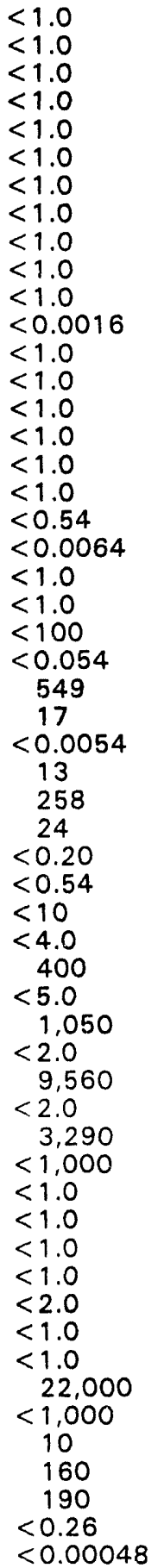 & $\begin{array}{l}1.00 \\
1.00 \\
1.00 \\
1.00 \\
1.00 \\
1.00 \\
1.00 \\
1.00 \\
1.00 \\
1.00 \\
1.00 \\
1.00 \\
1.00 \\
1.00 \\
1.00 \\
1.00 \\
1.00 \\
1.00 \\
1.00 \\
1.00 \\
1.00 \\
1.00 \\
1.00 \\
1.00 \\
1.00 \\
1.00 \\
1.00 \\
1.00 \\
1.00 \\
1.00 \\
1.00 \\
1.00 \\
1.00 \\
1.00 \\
1.00 \\
1.00 \\
1.00 \\
1.00 \\
1.00 \\
1.00 \\
1.00 \\
1.00 \\
1.00 \\
1.00 \\
1.00 \\
1.00 \\
1.00 \\
1.00 \\
1.00 \\
1.00 \\
1.00 \\
1.00 \\
1.00 \\
1.00 \\
1.00 \\
1.00\end{array}$ & $\begin{array}{l}\mathrm{J} 1 \\
\mathrm{~J} 1\end{array}$ & $\begin{array}{l}\mu \mathrm{g} / \mathrm{L} \\
\mu \mathrm{g} / \mathrm{L} \\
\mu \mathrm{g} / \mathrm{L} \\
\mu \mathrm{g} / \mathrm{L} \\
\mu \mathrm{g} / \mathrm{L} \\
\mu \mathrm{g} / \mathrm{L} \\
\mu \mathrm{g} / \mathrm{L} \\
\mu \mathrm{g} / \mathrm{L} \\
\mu \mathrm{g} / \mathrm{L} \\
\mu \mathrm{g} / \mathrm{L} \\
\mu \mathrm{g} / \mathrm{L} \\
\mu \mathrm{g} / \mathrm{L} \\
\mu \mathrm{g} / \mathrm{L} \\
\mu \mathrm{g} / \mathrm{L} \\
\mu \mathrm{g} / \mathrm{L} \\
\mu \mathrm{g} / \mathrm{L} \\
\mu \mathrm{g} / \mathrm{L} \\
\mu \mathrm{g} / \mathrm{L} \\
\mu \mathrm{g} / \mathrm{L} \\
\mu \mathrm{g} / \mathrm{L} \\
\mu \mathrm{g} / \mathrm{L} \\
\mu \mathrm{g} / \mathrm{L} \\
\mu \mathrm{g} / \mathrm{L} \\
\mu \mathrm{g} / \mathrm{L} \\
\mu \mathrm{g} / \mathrm{L} \\
\mu \mathrm{g} / \mathrm{L} \\
\mu \mathrm{g} / \mathrm{L} \\
\mu \mathrm{g} / \mathrm{L} \\
\mu \mathrm{g} / \mathrm{L} \\
\mu \mathrm{g} / \mathrm{L} \\
\mu \mathrm{g} / \mathrm{L} \\
\mu \mathrm{g} / \mathrm{L} \\
\mu \mathrm{g} / \mathrm{L} \\
\mu \mathrm{g} / \mathrm{L} \\
\mu \mathrm{g} / \mathrm{L} \\
\mu \mathrm{g} / \mathrm{L} \\
\mu \mathrm{g} / \mathrm{L} \\
\mu \mathrm{g} / \mathrm{L} \\
\mu \mathrm{g} / \mathrm{L} \\
\mu \mathrm{g} / \mathrm{L} \\
\mu \mathrm{g} / \mathrm{L} \\
\mu \mathrm{g} / \mathrm{L} \\
\mu \mathrm{g} / \mathrm{L} \\
\mu \mathrm{g} / \mathrm{L} \\
\mu \mathrm{g} / \mathrm{L} \\
\mu \mathrm{g} / \mathrm{L} \\
\mu \mathrm{g} / \mathrm{L} \\
\mu \mathrm{g} / \mathrm{L} \\
\mu \mathrm{g} / \mathrm{L} \\
\mu \mathrm{g} / \mathrm{L} \\
\mu \mathrm{g} / \mathrm{L} \\
\mu \mathrm{g} / \mathrm{L} \\
\mu \mathrm{g} / \mathrm{L} \\
\mu \mathrm{g} / \mathrm{L} \\
\mu \mathrm{g} / \mathrm{L} \\
\mu \mathrm{g} / \mathrm{L}\end{array}$ & $\begin{array}{l}0 \\
0 \\
0 \\
0 \\
0 \\
0 \\
0 \\
0 \\
0 \\
0 \\
0 \\
0 \\
0 \\
0 \\
0 \\
0 \\
0 \\
0 \\
0 \\
0 \\
0 \\
0 \\
0 \\
0 \\
2 \\
0 \\
0 \\
0 \\
0 \\
0 \\
0 \\
0 \\
0 \\
0 \\
0 \\
0 \\
0 \\
0 \\
0 \\
0 \\
0 \\
0 \\
0 \\
0 \\
0 \\
0 \\
0 \\
0 \\
0 \\
0 \\
0 \\
0 \\
0 \\
0 \\
0 \\
0\end{array}$ \\
\hline
\end{tabular}

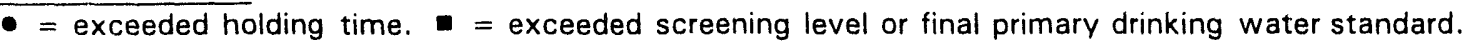


WELL BGO $30 \mathrm{C}$ collected on $02 / 01 / 94$, laboratory analyses (cont.)

\begin{tabular}{|c|c|c|c|c|c|c|}
\hline$\underline{D}$ & Analyte & Result & DF & Mod & Unit & Flag \\
\hline 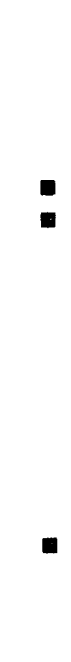 & $\begin{array}{l}\text { Tributyl phosphate } \\
\text { 1,1,1-Trichloroethane } \\
\text { 1,1,1-Trichloroethane } \\
\text { 1,1,2-Trichloroethane } \\
\text { 1,1,2-Trichloroethane } \\
\text { Trichloroethylene } \\
\text { Trichloroethylene } \\
\text { Trichlorofluoromethane } \\
\text { Trichlorofluoromethane } \\
\text { Vanadium, total recoverable } \\
\text { Xylenes } \\
\text { Xylenes } \\
\text { Gross alpha } \\
\text { Nonvolatile beta } \\
\text { Radium, total alpha-emitting } \\
\text { Total activity } \\
\text { Tritium } \\
\text { Uranium-233/234 } \\
\text { Uranium-235 } \\
\text { Uranium-238 }\end{array}$ & $\begin{aligned}< & 10 \\
< & 1.0 \\
< & 1.0 \\
< & 1.0 \\
< & 1.0 \\
& 11 \\
& 11 \\
< & 1.0 \\
< & 1.0 \\
< & 8.0 \\
< & 2.0 \\
< & 2.0 \\
& 4.6 \mathrm{E}-01 \\
& 8.6 \mathrm{E}-01 \\
& 7.0 \mathrm{E}-01 \\
& 6.8 \mathrm{E}+05 \\
& 6.2 \mathrm{E}+02 \\
< & 8.6 \mathrm{E}-02 \\
< & -2.6 \mathrm{E}-02 \\
< & 2.4 \mathrm{E}-02\end{aligned}$ & $\begin{array}{l}1.00 \\
1.00 \\
1.00 \\
1.00 \\
1.00 \\
1.00 \\
1.00 \\
1.00 \\
1.00 \\
1.00 \\
1.00 \\
1.00 \\
1.00 \\
1.00 \\
1.00 \\
1.00 \\
1.00 \\
1.00 \\
1.00 \\
1.00\end{array}$ & $\begin{array}{l}J \\
J\end{array}$ & $\begin{array}{l}\mu \mathrm{g} / \mathrm{L} \\
\mu \mathrm{g} / \mathrm{L} \\
\mu \mathrm{g} / \mathrm{L} \\
\mu \mathrm{g} / \mathrm{L} \\
\mu \mathrm{g} / \mathrm{L} \\
\mu \mathrm{g} / \mathrm{L} \\
\mu \mathrm{g} / \mathrm{L} \\
\mu \mathrm{g} / \mathrm{L} \\
\mu \mathrm{g} / \mathrm{L} \\
\mu \mathrm{g} / \mathrm{L} \\
\mu \mathrm{g} / \mathrm{L} \\
\mu \mathrm{g} / \mathrm{L} \\
\mathrm{pCi} / \mathrm{L} \\
\mathrm{pCi} / \mathrm{L} \\
\mathrm{pCi} / \mathrm{L} \\
\mathrm{pCi} / \mathrm{L} \\
\mathrm{pCi} / \mathrm{mL} \\
\mathrm{pCi} / \mathrm{L} \\
\mathrm{pCi} / \mathrm{L} \\
\mathrm{pCi} / \mathrm{L}\end{array}$ & $\begin{array}{l}0 \\
0 \\
0 \\
0 \\
0 \\
2 \\
2 \\
0 \\
0 \\
0 \\
0 \\
0 \\
0 \\
0 \\
0 \\
0 \\
2 \\
0 \\
0 \\
0\end{array}$ \\
\hline
\end{tabular}

WELL BGO 30D

\begin{tabular}{|c|c|c|c|c|c|c|}
\hline SRS Coord. & Lat/Longitude & Screen Zone Elevation & Top of Casing & Casing & Pump & Formation \\
\hline $\begin{array}{l}N 75187.7 \\
E 54499.2\end{array}$ & $\begin{array}{l}33.280988^{\circ} \mathrm{N} \\
81.669343^{\circ} \mathrm{W}\end{array}$ & $227.8-207.8$ & $274.8 \mathrm{ft} \mathrm{msl}$ & 4" PVC & $s$ & le $\left(\| B_{2}\right)$ \\
\hline
\end{tabular}

\section{FIELD MEASUREMENTS}

Sample date: $02 / 01 / 94$

Depth to water: $49.30 \mathrm{ft}(15.03 \mathrm{~m})$ below TOC

Water elevation: $225.50 \mathrm{ft}(68.73 \mathrm{~m}) \mathrm{msl}$

Sp. conductance: $152 \mu \mathrm{S} / \mathrm{cm}$

Turbidity: 11.6 NTU

Water evacuated before sampling: $11 \mathrm{gal}$

The well went dry during purging.

\section{LABORATORY ANALYSES}

H D Analyte

- $\mathrm{pH}$

Specific conductance

Turbidity

Acetophenone

Aldrin

Aluminum, total recoverable

Antimony, total recoverable

Arsenic, total recoverable

Barium, total recoverable

Benzene

Bromodichloromethane

Bromoform

Bromomethane (Methyl bromide)

Cadmium, total recoverable
Time: 9: 44

$\mathrm{pH}: 5.8$

Alkalinity: $23 \mathrm{mg} / \mathrm{L}$

Water temperature: $17.3^{\circ} \mathrm{C}$

Volumes purged: 0.9 well volumes

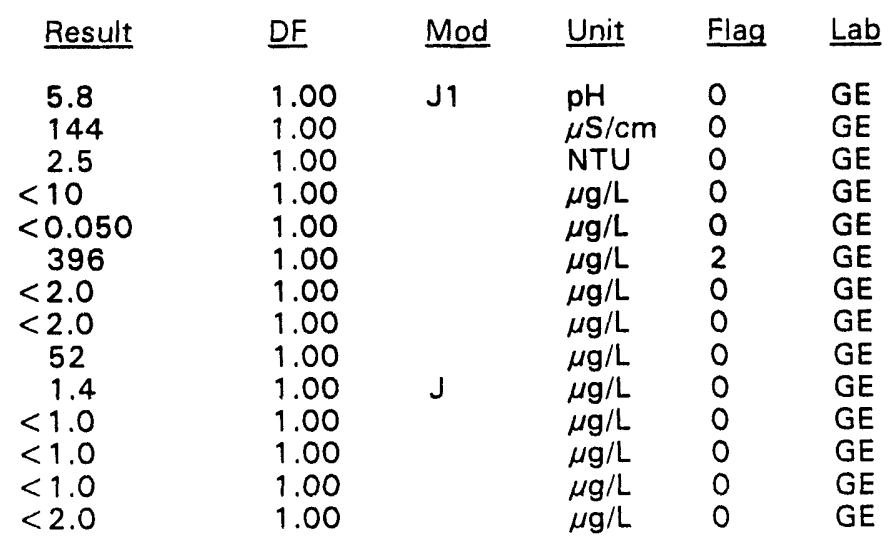

$\overline{- \text { = exceeded holding time. }}$ = exceeded screening level or final primary drinking water standard. 
WELL BGO $30 D$ collected on $02 / 01 / 94$, laboratory analyses (cont.)

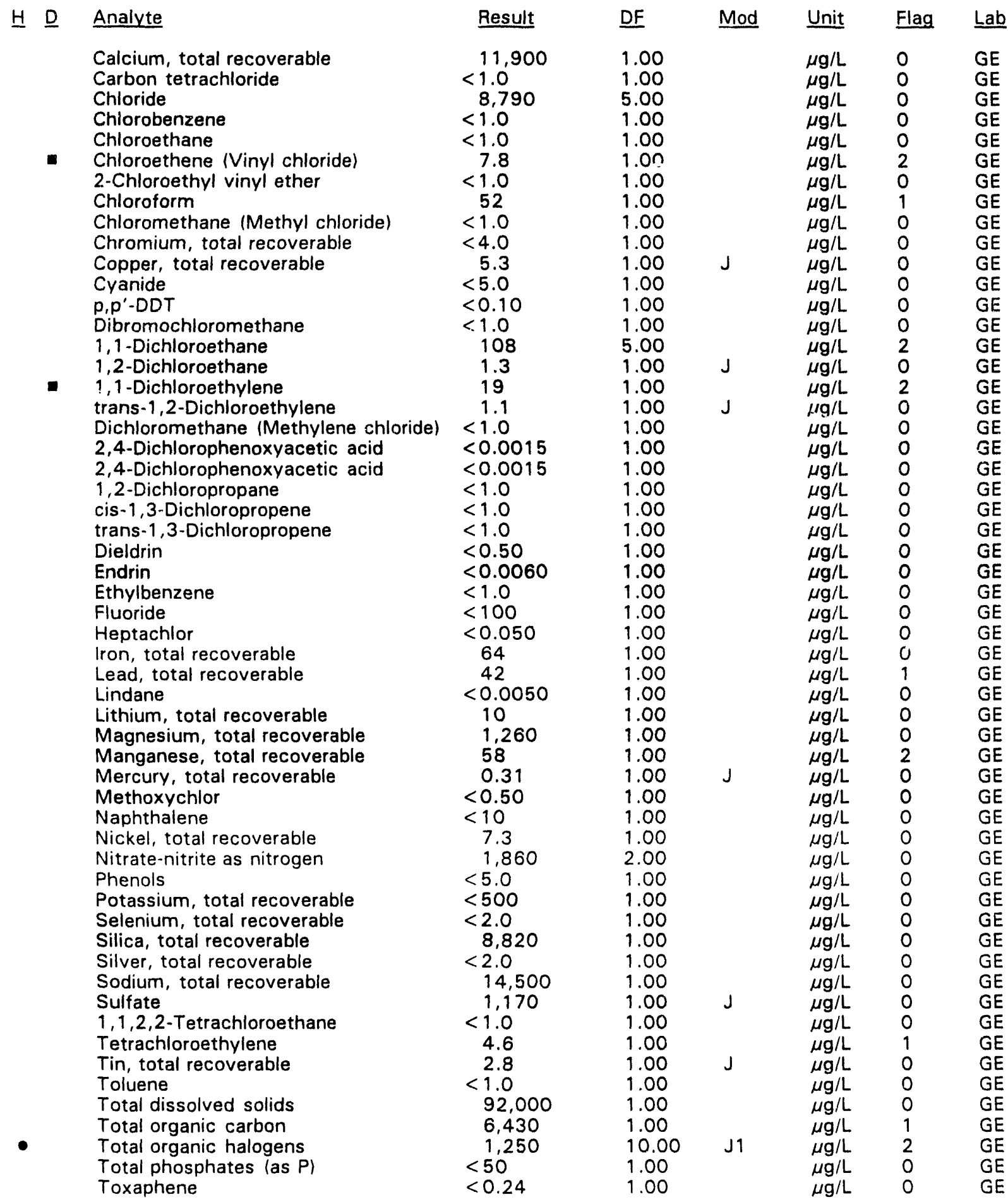

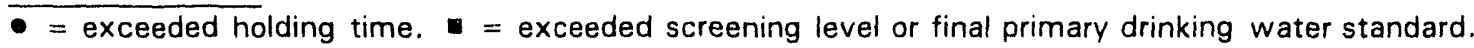


WELL BGO 3OD collected on 02/01/94, laboratory analyses (cont.)

\section{H D Analyte}

2,4,5-TP (Silvex)

2,4,5-TP (Silvex)

Tributyl phosphate

$1,1,1$-Trichloroethane

1,1,2-Trichloroethane

- Trichloroethylene

Trichlorofluoromethane

Vanadium, total recoverable

Xylenes

Gross alpha

Nonvolatile beta

Radium, total alpha-emitting

- Tritium

Uranium-233/234

Uranium-235

Uranium-238

\begin{tabular}{ll}
\multicolumn{1}{l}{ Result } & DF \\
$<0.00044$ & 1.00 \\
$<0.00045$ & 1.00 \\
$<10$ & 1.00 \\
$<1.0$ & 1.00 \\
$<1.0$ & 1.00 \\
81 & 1.00 \\
$<1.0$ & 1.00 \\
$<8.0$ & 1.00 \\
6.5 & 1.00 \\
$9.2 E+00$ & 1.00 \\
$5.6 E+00$ & 1.00 \\
$5.6 E+00$ & 1.00 \\
$4.5 E+04$ & 1.00 \\
$<6.0 E-02$ & 1.00 \\
$<0.0 E+00$ & 1.00 \\
$<1.4 E-01$ & 1.00
\end{tabular}

Mod

$\begin{array}{llll}\text { Unit } & \text { Flag } & \text { Lab } \\ \mu \mathrm{g} / \mathrm{L} & 0 & \mathrm{GE} \\ \mu \mathrm{g} / \mathrm{L} & 0 & \mathrm{GE} \\ \mu \mathrm{g} / \mathrm{L} & 0 & \mathrm{GE} \\ \mu \mathrm{g} / \mathrm{L} & 0 & \mathrm{GE} \\ \mu \mathrm{g} / \mathrm{L} & 0 & \mathrm{GE} \\ \mu \mathrm{g} / \mathrm{L} & 2 & \mathrm{GE} \\ \mu \mathrm{g} / \mathrm{L} & 0 & \mathrm{GE} \\ \mu \mathrm{g} / \mathrm{L} & 0 & \mathrm{GE} \\ \mu \mathrm{g} / \mathrm{L} & 0 & \mathrm{GE} \\ \mathrm{pCi} / \mathrm{L} & 1 & \mathrm{GP} \\ \mathrm{pCi} / \mathrm{L} & 0 & \mathrm{GP} \\ \mathrm{pCi} / \mathrm{L} & 0 & \mathrm{GP} \\ \mathrm{pCi} / \mathrm{mL} & 2 & \mathrm{GP} \\ \mathrm{pCi} / \mathrm{L} & 0 & \mathrm{GP} \\ \mathrm{pCi} / \mathrm{L} & 0 & \mathrm{GP} \\ \mathrm{pCi} / \mathrm{L} & 0 & \mathrm{GP}\end{array}$

\section{WELL BGO 31C}

$\begin{array}{llllllll}\text { SRS Coord. } & \text { Lat/Longitude } & \text { Screen Zone Elevation } & \text { Top of Casing } & \text { Casing } & \text { Pump } & \text { Formation } \\ \text { N74978.0 } & 33.281042^{\circ} \mathrm{N} & 186.4-176.4 \mathrm{ft} \mathrm{msl} & 273.1 \mathrm{ft} \mathrm{msl} & \text { 4" PVC } & \text { S } & \text { McBean (IIB, }) \\ \text { E54816.2 } & 81.668101^{\circ} \mathrm{W} & & & \end{array}$

\section{FIELD MEASUREMENTS}

Sample date: 02/01/94

Depth to water: $47.78 \mathrm{ft}(14.56 \mathrm{~m})$ below TOC

Water elevation: $225.32 \mathrm{ft}(68.68 \mathrm{~m}) \mathrm{ms} \mid$

$\mathrm{Sp}$. conductance: $27 \mu \mathrm{S} / \mathrm{cm}$

Turbidity: 12.9 NTU

Water evacuated before sampling: 29 gal

The well went dry during purging.

\section{LABORATORY ANALYSES}

H D Analyte

- $\mathrm{pH}$

Specific conductance

Turbidity

Acetophenone

Acetophenone

Aldrin

Aldrin

Aluminum, total recoverable

Antimony, total recoverable

Arsenic, total recoverable

Barium, total recoverable

Benzene

Bromodichloromethane

Bromoform

Bromomethane (Methyl bromide)

Cadmium, total recoverable

Calcium, total recoverable

Carbon tetrachloride
Time: 10:10

$\mathrm{pH}: 5.4$

Alkalinity: $1 \mathrm{mg} / \mathrm{L}$

Water temperature: $15.9^{\circ} \mathrm{C}$

Volumes purged: 0.9 well volumes

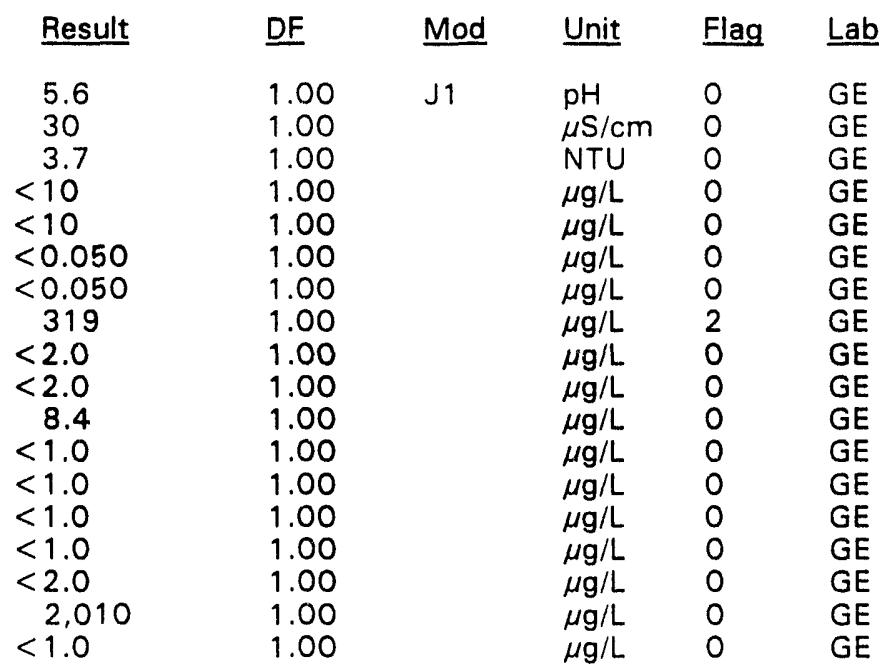

- exceeded holding time. = exceeded screening level or final primary drinking water standard. 
WELL BGO $31 \mathrm{C}$ collected on 02/01/94, laboratory analyses (cont.)

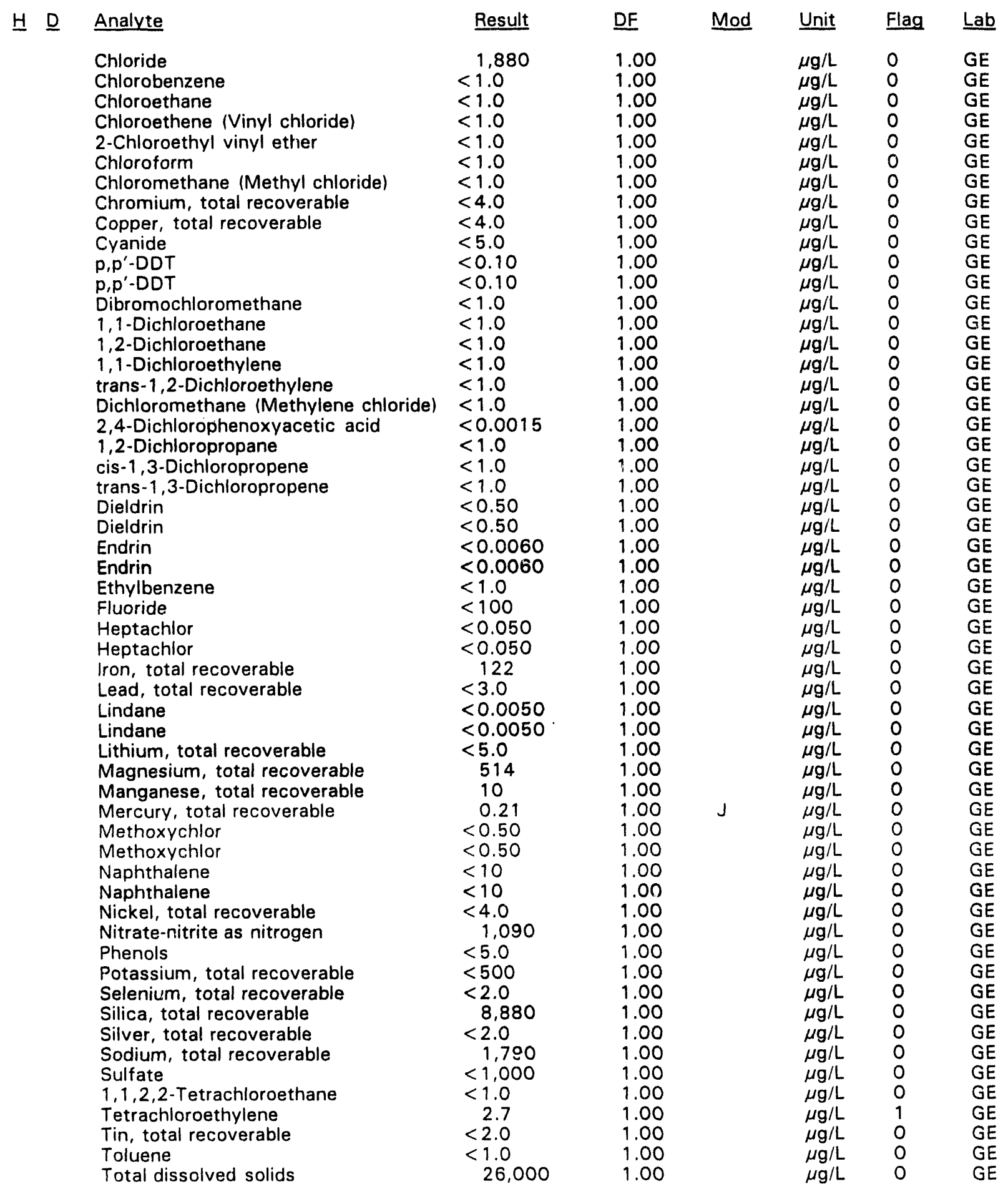

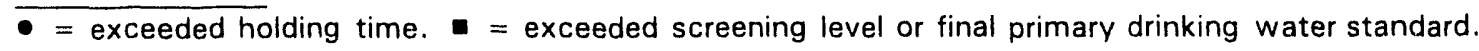


WELL BGO $31 \mathrm{C}$ collected on $02 / 01 / 94$, laboratory analyses (cont.)

H. $\quad$ Analyte
Total dissolved solids
Total organic carbon
Total organic halogens
Total organic halogens
Total phosphates (as P)
Total phosphates (as P)
Toxaphene
Toxaphene
2,4,5-TP (Silvex)
Tributyl phosphate
Tributyl phosphate
1,1,1-Trichloroethane
1,1,2-Trichloroethane
Trichloroethylene
Trichlorofluoromethane
Vanadium, total recoverable
Xylenes
Gross alpha
Nonvolatile beta
Radium, total alpha-emitting
Radium, total alpha-emitting
Tritium
Uranium-233/234
Uranium-235
Uranium-238

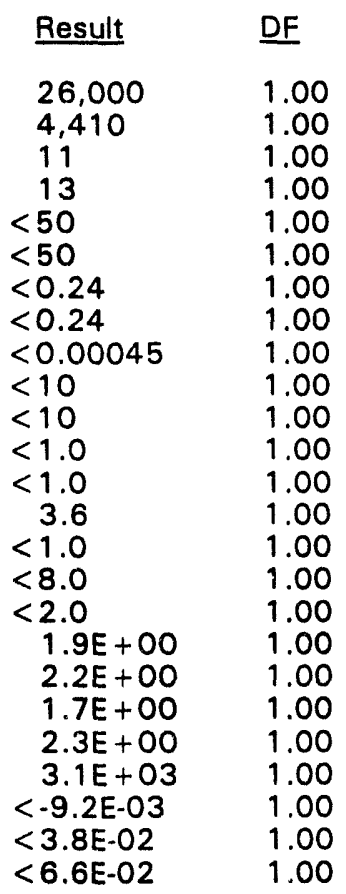

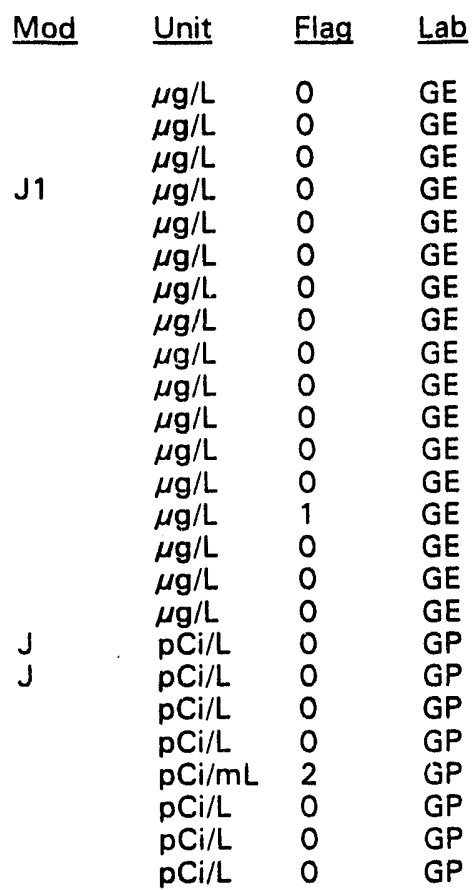

WELL BGO 31D

\begin{tabular}{|c|c|c|c|c|c|c|}
\hline SRS Coord. & Lat/Longitude & Screen Zone Elevation & Top of Casing & Casing & Pump & Formation \\
\hline $\begin{array}{l}\text { N74985.3 } \\
\text { E54841.7 }\end{array}$ & $\begin{array}{l}33.281099^{\circ} \mathrm{N} \\
81.668048^{\circ} \mathrm{W}\end{array}$ & $231.1-211.1 \mathrm{ft} \mathrm{msl}$ & $273.7 \mathrm{ft} \mathrm{msl}$ & 4" PVC & S & Water Table $\left(\| \mathrm{B}_{2}\right)$ \\
\hline
\end{tabular}

\section{FIELD MEASUREMENTS}

Sample date: 02/01/94

Depth to water: $47.30 \mathrm{ft}(14.42 \mathrm{~m})$ below TOC

Water elevation: $226.40 \mathrm{ft}(69.01 \mathrm{~m}) \mathrm{msl}$

Sp. conductance: $33 \mu \mathrm{S} / \mathrm{cm}$

Turbidity: 7.6 NTU

Water evacuated before sampling: $5 \mathrm{gal}$

The well went dry during purging.

\section{LABORATORY ANALYSES}

H $\underline{\text { Analyte }}$

$\mathrm{pH}$

Specific conductance

Turbidity

Acetophenone

Aldrin

Aluminum, total recoverable

Antimony, total recoverable

Arsenic, total recoverable

Barium, total recoverable
Time: 10:01

$\mathrm{pH}: 4.9$

Alkalinity: $0 \mathrm{mg} / \mathrm{L}$

Water temperature: $9.9^{\circ} \mathrm{C}$

Volumes purged: 0.5 well volumes

$\overline{- \text { = exceeded holding time. }}$ = exceeded screening level or final primary drinking water standard. 
WELL BGO 31D collected on 02/01/94, laboratory analyses (cont.)

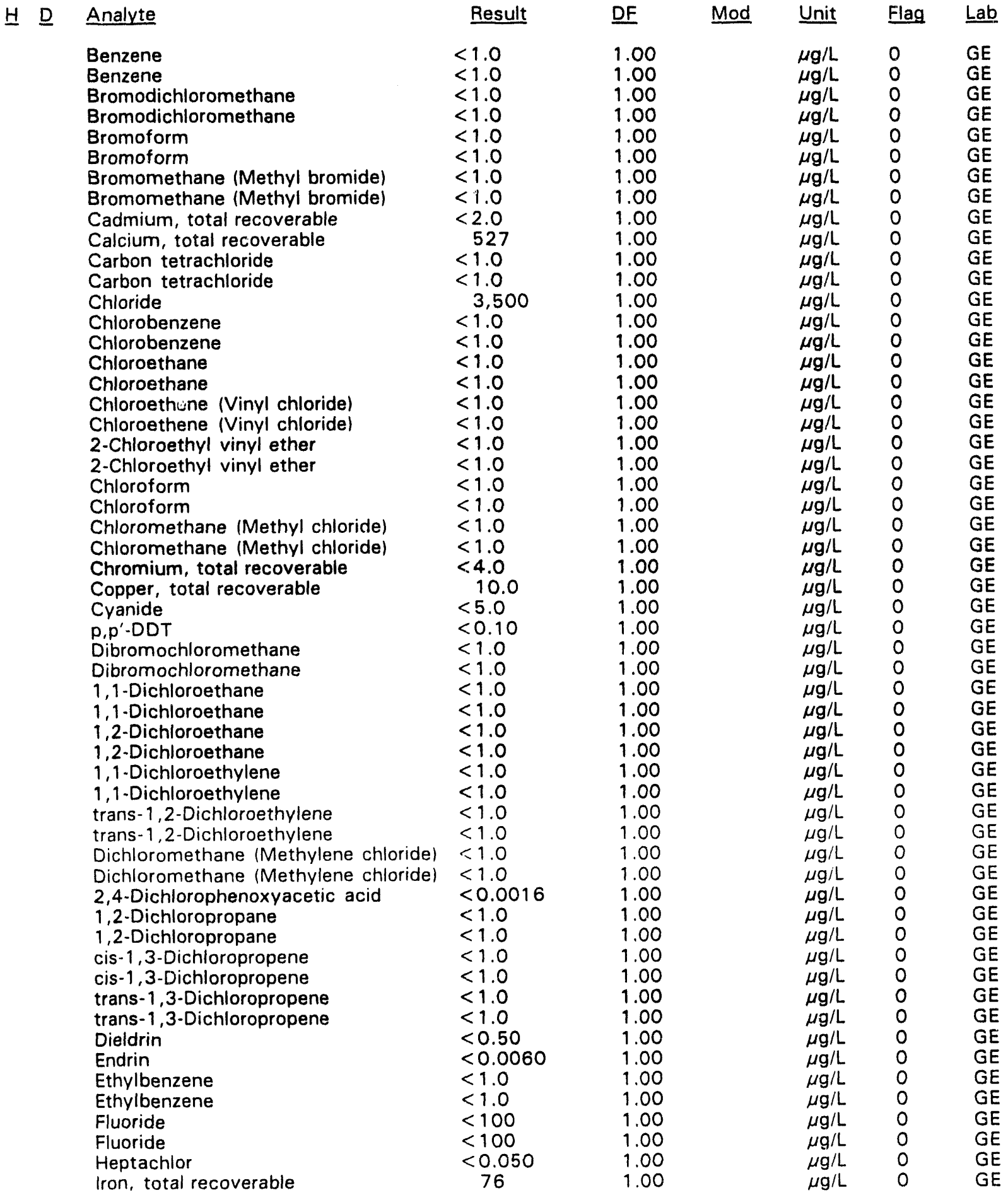

$\overline{-=\text { exceeded holding time. }} \mathbf{a}=$ exceeded screening level or final primary drinking water standard. 
WELL BGO 31D collected on 02/01/94, laboratory analyses (cont.)

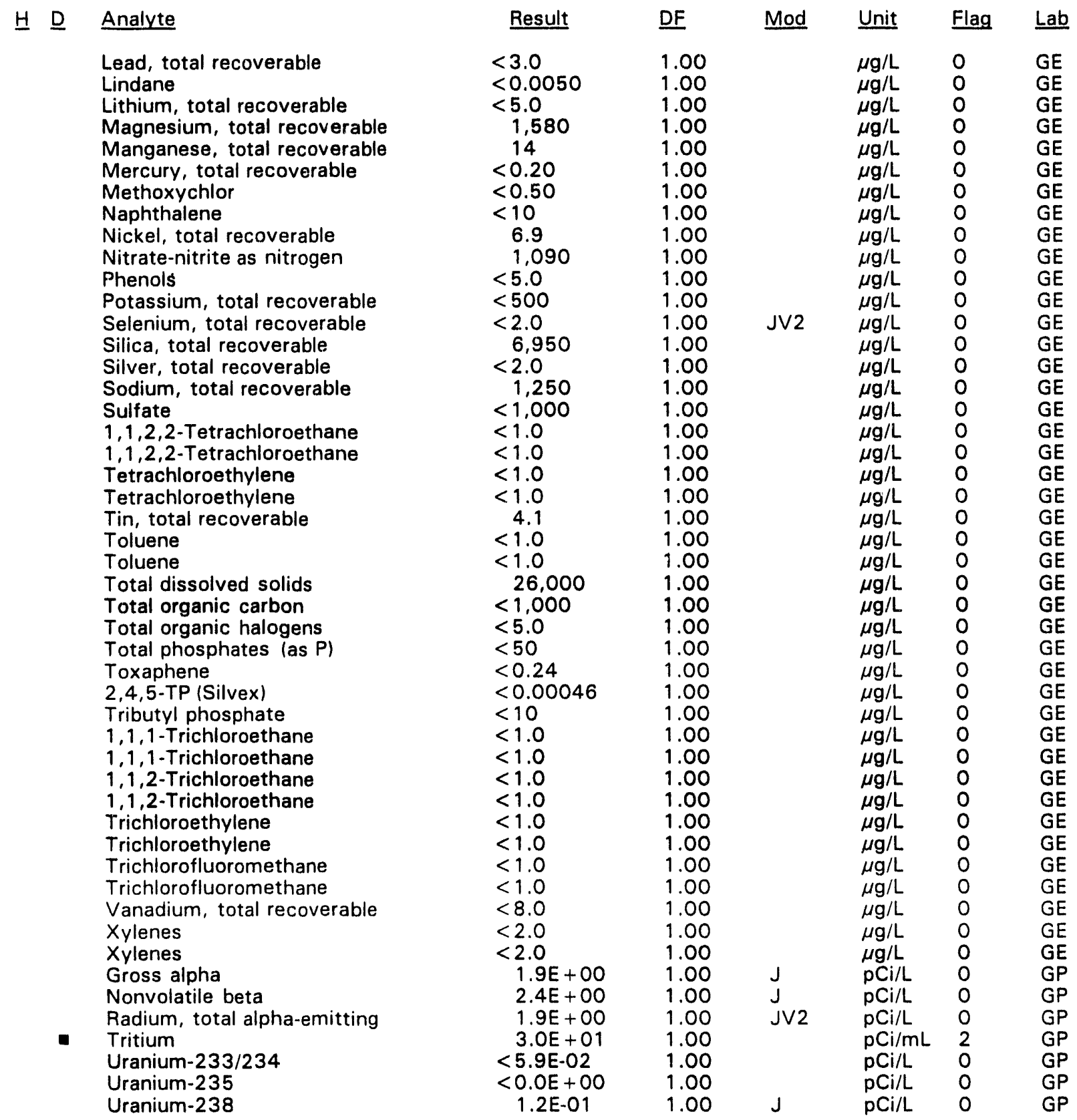

\footnotetext{
$\overline{-}=$ exceeded holding time. $\boldsymbol{\omega}$ = exceeded screening level or final primary drinking water standard.
} 


\section{WELL BGO 32D}

\begin{tabular}{|c|c|c|c|c|c|c|}
\hline SRS Coord. & Lat/Longitude & Screen Zone Elevation & Top of Casing & Casing & Pump & Formation \\
\hline $\begin{array}{l}N 74727.0 \\
E 55250.2\end{array}$ & $\begin{array}{l}33.281195^{\circ} \mathrm{N} \\
81.666471^{\circ} \mathrm{W}\end{array}$ & $234.5-214.5 \mathrm{ft} \mathrm{msl}$ & $281.7 \mathrm{ft} \mathrm{msl}$ & 4" PVC & $\mathrm{S}$ & ble $\left(I \mid B_{2}\right)$ \\
\hline
\end{tabular}

\section{FIELD MEASUREMENTS}

Sample date: 02/01/94

Depth to water: $54.42 \mathrm{ft}(16.59 \mathrm{~m})$ below TOC

Water elevation: $227.28 \mathrm{ft}(69.28 \mathrm{~m}) \mathrm{ms}$ l

Sp. conductance: $67 \mu \mathrm{S} / \mathrm{cm}$

Turbidity: 55.0 NTU

Water evacuated before sampling: $6 \mathrm{gal}$

The well went dry during purging.

\section{LABORATORY ANALYSES}

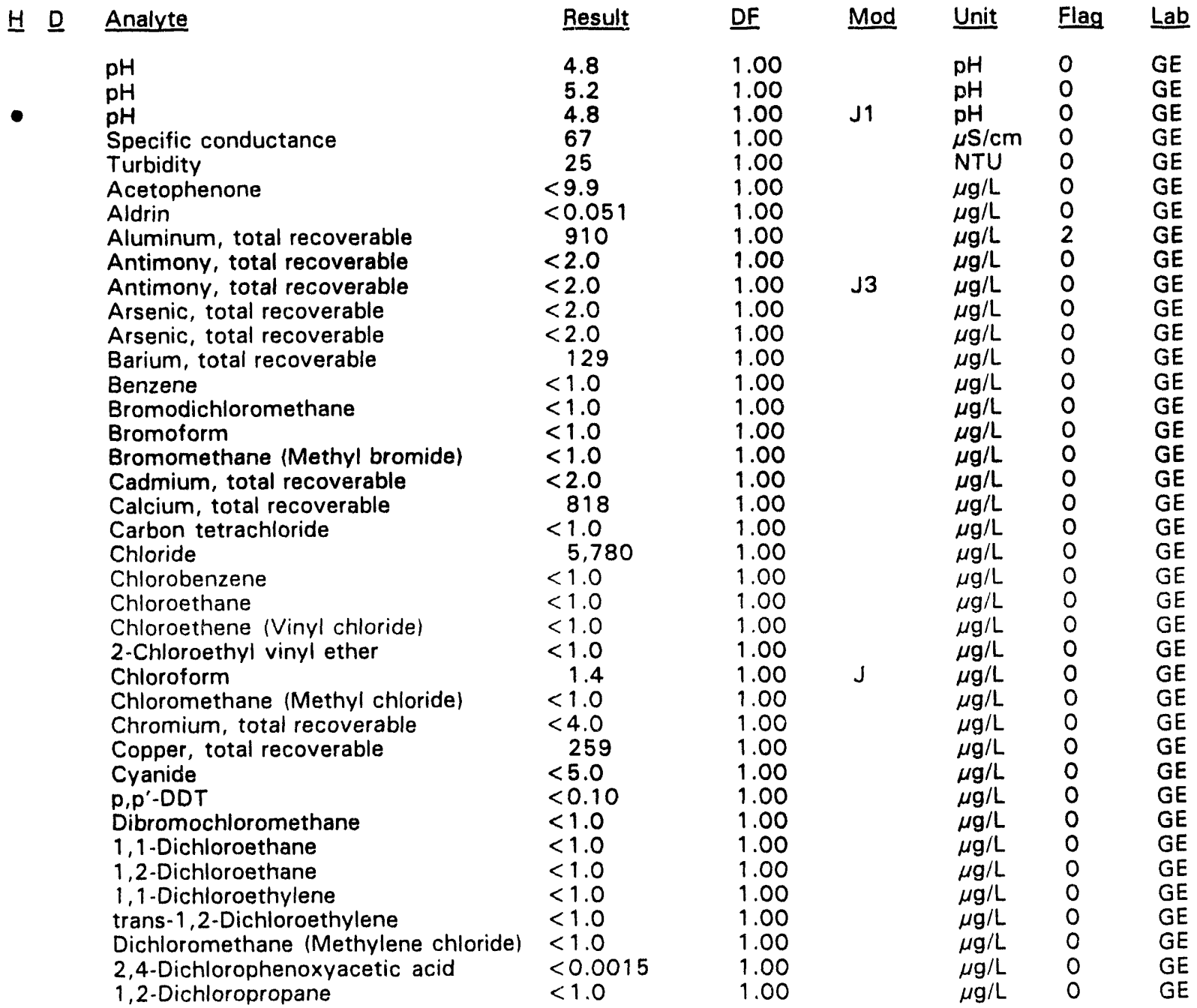

\footnotetext{
- = exceeded holding time. - = exceeded screening level or final primary drinking water standard.
}

Time: $10: 57$

$\mathrm{pH}: 4.7$

Alkalinity: $0 \mathrm{mg} / \mathrm{L}$

Volumes purged: 0.7 well volumes 
WELL BGO 32D collected on $02 / 01 / 94$, laboratory analyses (cont.)

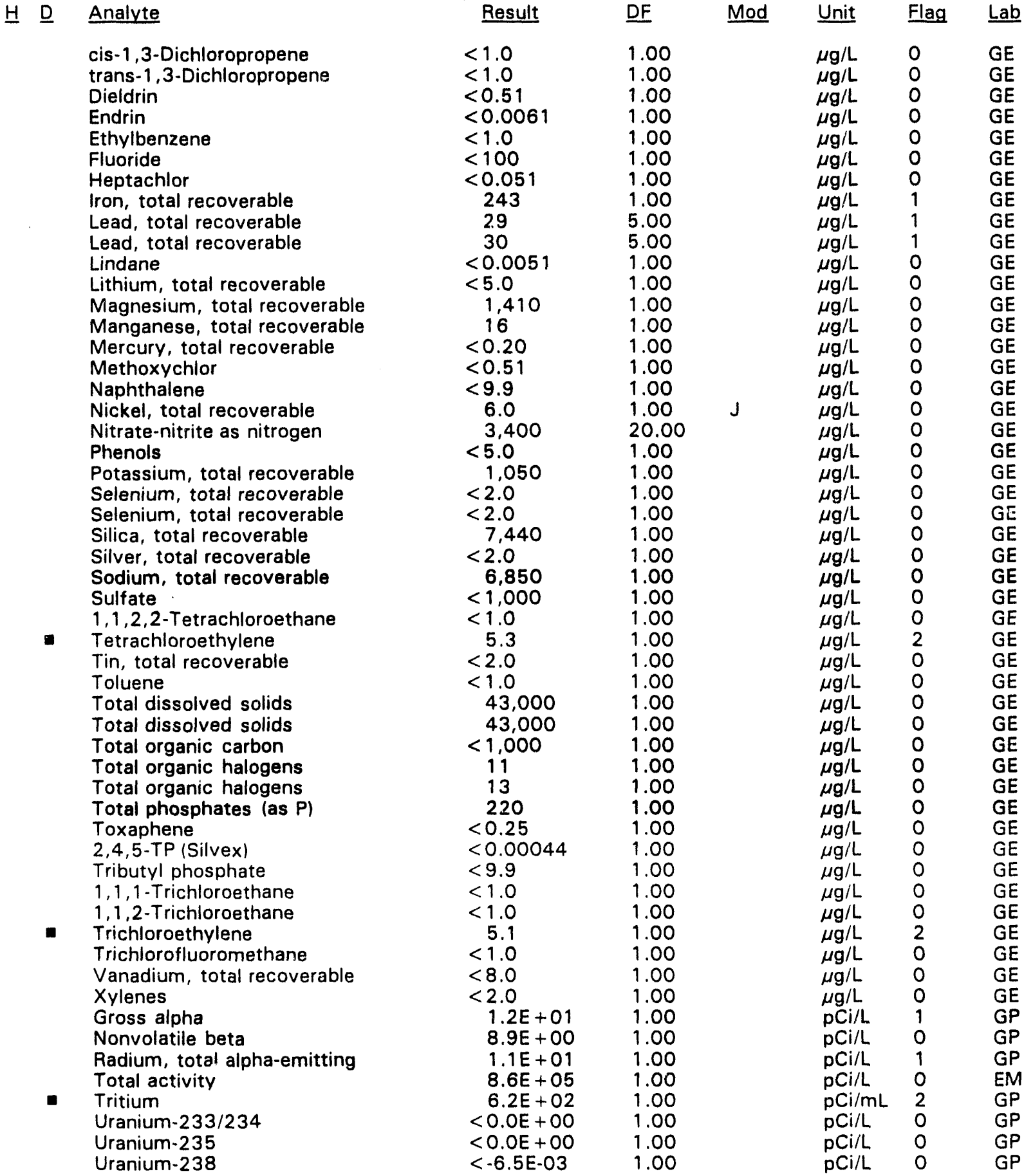

\footnotetext{
$\overline{-}=$ exceeded holding time. $\square=$ exceeded screening level or final primary drinking water standard.
} 
WELL BGO 33C

\begin{tabular}{|c|c|c|c|c|c|c|}
\hline SRS Coord. & Lat/Longitude & Screen Zone Elevation & Top of Casing & Casing & Pump & Formation \\
\hline $\begin{array}{l}\text { N74479.7 } \\
\text { E55681.4 }\end{array}$ & $\begin{array}{l}33.281351^{\circ} \mathrm{N} \\
81.664855^{\circ} \mathrm{W}\end{array}$ & $187.8-177.8 \mathrm{ft} \mathrm{msl}$ & $279.4 \mathrm{ft} \mathrm{msl}$ & 7" PVC & $\mathbf{S}$ & $\left(\| B_{1}\right)$ \\
\hline
\end{tabular}

\section{FIELD MEASUREMENTS}

Sample date: 01/27/94

Depth to water: $54.37 \mathrm{ft}(16.57 \mathrm{~m})$ below TOC

Water elevation: $225.03 \mathrm{ft}(68.59 \mathrm{~m}) \mathrm{msl}$

Sp. conductance: $55 \mu \mathrm{S} / \mathrm{cm}$

Turbidity: 0.7 NTU

Water evacuated before sampling: $220 \mathrm{gal}$

\section{LABORATORY ANALYSES}

H $\underline{\text { Analyte }}$

- $\quad \mathrm{pH}$

Specific conductance

Specific conductance

Turbidity

Acetophenone

Acetophenone

Aldrin

Aldrin

Aluminum, total recoverable

Antimony, total recoverable

Arsenic, total recoverable

Barium, total recoverable

Benzene

Bromodichloromethane

Bromoform

Bromomethane (Methyl bromide)

Cadmium, total recoverable

Calcium, total recoverable

Carbon tetrachloride

Chloride

Chlorobenzene

Chloroethane

Chloroethene (Vinyl chloride)

2-Chloroethyl vinyl ether

Chloroform

Chloromethane (Methyl chloride)

Chromium, total recoverable

Copper, total recoverable

Cyanide

$p, p^{\prime}-D D T$

p.p'-DDT

Dibromochloromethane

1,1-Dichloroethane

1,2-Dichloroethane

1,1-Dichloroethylene

trans-1,2-Dichloroethylene

Dichloromethane (Methylene chloride)

2,4-Dichlorophenoxyacetic acid

2,4-Dichlorophenoxyacetic acid
Result

6.0

50

50

0.24

$<10$

$<10$

$<0.050$

$<0.050$

251

$<2.0$

$<2.0$

11

$<1.0$

$<1.0$

$<1.0$

$<1.0$

$<2.0$

4,240

$<1.0$

5,420

$<1.0$

$<1.0$

$<1.0$

$<1.0$

12

$<1.0$

$<4.0$

$<4.0$

$<5.0$

$<0.10$

$<0.10$

$<1.0$

$<1.0$

$<1.0$

$<1.0$

$<1.0$

$<1.0$

$<0.0015$

$<0.0015$
Time: 14: 41

pH: 5.7

Alkalinity: $5 \mathrm{mg} / \mathrm{L}$

Water temperature: $19.3^{\circ} \mathrm{C}$

Volumes purged: 7.1 well volumes 
WELL BGO $33 \mathrm{C}$ collected on $01 / 27 / 94$, laboratory analyses (cont.)

H D Analyte

1,2-Dichloropropane

cis-1,3-Dichloropropene

trans-1,3-Dichloropropene

Dieldrin

Dieldrin

Endrin

Endrin

Ethylbenzene

Fluoride

Heptachlor

Heptachlor

Iron, total recoverable

Lead, total recoverable

Lindane

Lindane

Lithium, total recoverable

Magnesium, total recoverable

Manganese, total recoverable

- Mercury, total recoverable

Methoxychlor

Methoxychlor

Naphthalene

Naphthalene

Nickel, total recoverable

Nitrate-nitrite as nitrogen

Nitrate-nitrite as nitrogen

Phenols

Potassium, total recoverable

Sclenium, total recoverable

Silica, total recoverable

Silver, total recoverable

Sodium, total recoverable

Sulfate

$1,1,2,2$-Tetrachloroethane

- Tetrachloroethylene

Tin, total recoverable

Toluene

Total dissolved solids

Total dissolved solids

Total organic carbon

- Total organic halogens

Total phosphates (as P)

Toxaphene

Toxaphene

2,4,5-TP (Silvex)

2,4,5-TP (Silvex)

Tributyl phosphate

Tributyl phosphate

1,1,1-Trichloroethane

1,1,2-Trichloroethane

- Trichloroethylene

Trichlorofluoromethane

Vanadium, total recoverable

Xylenes

Gross alpha

Nonvolatile beta
Result DF

$<1.0$

$<1.0$

$<1.0$

$<0.50$

$<0.50$

$<0.0060$

$<0.0060$

$<1.0$

$<100$

$<0.050$

$<0.050$

8.4

$<3.0$

$<0.0050$

$<0.0050$

$<5.0$

676

29

2.8

$<0.50$

$<0.50$

$<10$

$<10$

$<4.0$

930

940

$<5.0$

504

$<2.0$

10.800

$<2.0$

3,250

$<1,000$

$<1.0$

5.1

$<2.0$

$<1.0$

35,000

35,000

1,400

96

$<50$

$<0.24$

$<0.24$

$<0.00045$

$<0.00045$

$<10$

$<10$

$<1.0$

$<1.0$

26

$<1.0$

$<8.0$

$<2.0$

$<4$. OE-O

$<6$. OE-01
DF

1.00

1.00

1.00

1.00

1.00

1.00

1.00

1.00

1.00

1.00

1.00

1.00

1.00

1.00

1.00

1.00

1.00

1.00

1.00

1.00

1.00

1.00

1.00

1.00

1.00

1.00

1.00

1.00

1.00

1.00

1.00

1.00

1.00

1.00

1.00

1.00

1.00

1.00

1.00

1.00

1.00

1.00

1.00

1.00

1.00

1.00

1.00

1.00

1.00

1.00

1.00

1.00

1.00

1.00

1.00

1.00
Mod Unit Flag Lab

$\mu \mathrm{g} / \mathrm{L} \quad \mathrm{O} \quad \mathrm{GE}$

$\mu g / L \quad O \quad G E$

$\mu \mathrm{g} / \mathrm{L} \quad 0 \quad \mathrm{GE}$

$\mu \mathrm{g} / \mathrm{L} \quad \mathrm{U} \quad \mathrm{GE}$

$\mu \mathrm{g} / \mathrm{L} \quad \mathrm{O} \quad \mathrm{GE}$

$\mu \mathrm{g} / \mathrm{L} \quad \mathrm{O} \quad \mathrm{GE}$

$\mu \mathrm{g} / \mathrm{L} \quad \mathrm{O} \quad \mathrm{GE}$

$\mu \mathrm{g} / \mathrm{L} \quad \mathrm{O} \quad \mathrm{GE}$

$\mu \mathrm{g} / \mathrm{L} \quad \mathrm{O} \quad \mathrm{GE}$

$\mu \mathrm{g} / \mathrm{L} \quad 0 \quad \mathrm{GE}$

$\mu g / L \quad 0 \quad G E$

$\mu \mathrm{g} / \mathrm{L} \quad 0 \quad \mathrm{GE}$

$\mu \mathrm{g} / \mathrm{L} \quad \mathrm{O} \quad \mathrm{GE}$

$\mu \mathrm{g} / \mathrm{L} \quad \mathrm{O} \quad \mathrm{GE}$

$\mu \mathrm{g} / \mathrm{L} \quad \mathrm{O} \quad \mathrm{GE}$

$\mu \mathrm{g} / \mathrm{L} \quad 0 \quad \mathrm{GE}$

$\mu \mathrm{g} / \mathrm{L} \quad 0 \quad \mathrm{GE}$

$\mu \mathrm{g} / \mathrm{L} \quad 1 \quad \mathrm{GE}$

$\mu \mathrm{g} / \mathrm{L} \quad 2 \quad \mathrm{GE}$

$\mu g / L \quad 0 \quad G E$

$\mu \mathrm{g} / \mathrm{L} \quad 0 \quad \mathrm{GE}$

$\mu \mathrm{g} / \mathrm{L} \quad 0 \quad \mathrm{GE}$

$\mu \mathrm{g} / \mathrm{L} \quad 0 \quad \mathrm{GE}$

$\mu \mathrm{g} / \mathrm{L} \quad 0 \quad \mathrm{GE}$

$\mu \mathrm{g} / \mathrm{L} \quad 0 \quad \mathrm{GE}$

$\mu \mathrm{g} / \mathrm{L} \quad 0 \quad \mathrm{GE}$

$\mu \mathrm{g} / \mathrm{L}, 0 \quad \mathrm{GE}$

$\mu \mathrm{g} / \mathrm{L} \quad 0 \quad \mathrm{GE}$

$\mu \mathrm{g} / \mathrm{L} \quad 0 \quad \mathrm{GE}$

$\mu \mathrm{g} / \mathrm{L} \quad 0 \quad \mathrm{GE}$

$\mu \mathrm{g} / \mathrm{L} \quad 0 \quad \mathrm{GE}$

$\mu \mathrm{g} / \mathrm{L} \quad 0 \quad \mathrm{GE}$

$\mu \mathrm{g} / \mathrm{L} \quad 0 \quad \mathrm{GE}$

$\mu \mathrm{g} / \mathrm{L} \quad 0 \quad \mathrm{GE}$

$\mu \mathrm{g} / \mathrm{L} \quad 2 \quad \mathrm{GE}$

$\mu \mathrm{g} / \mathrm{L} \quad 0 \quad \mathrm{GE}$

$\mu \mathrm{g} / \mathrm{L} \quad 0 \quad \mathrm{GE}$

$\mu \mathrm{g} / \mathrm{L} \quad \mathrm{O} \quad \mathrm{GE}$

$\mu \mathrm{g} / \mathrm{L} \quad 0 \quad \mathrm{GE}$

$\mu \mathrm{g} / \mathrm{L} \quad 0 \quad \mathrm{GE}$

$\mu \mathrm{g} / \mathrm{L} \quad 2 \quad \mathrm{GE}$

$\mu \mathrm{g} / \mathrm{L} \quad 0 \quad \mathrm{GE}$

$\mu \mathrm{g} / \mathrm{L} \quad 0 \quad \mathrm{GE}$

$\mu \mathrm{g} / \mathrm{L} \quad 0 \quad \mathrm{GE}$

$\mu \mathrm{g} / \mathrm{L} \quad 0 \quad \mathrm{GE}$

$\mu \mathrm{g} / \mathrm{L} \quad 0 \quad \mathrm{GE}$

$\mu \mathrm{g} / \mathrm{L} \quad 0 \quad \mathrm{GE}$

$\mu \mathrm{g} / \mathrm{L} \quad \mathrm{O} \quad \mathrm{GE}$

$\mu \mathrm{g} / \mathrm{L} \quad 0 \quad \mathrm{GE}$

$\mu \mathrm{g} / \mathrm{L} \quad 0 \quad \mathrm{GE}$

$\mu \mathrm{g} / \mathrm{L} \quad 2 \quad \mathrm{GE}$

$\mu \mathrm{g} / \mathrm{L} \quad \mathrm{O} \quad \mathrm{GE}$

$\mu \mathrm{g} / \mathrm{L} \quad 0 \quad \mathrm{GE}$

$\mu \mathrm{g} / \mathrm{L} \quad 0 \quad \mathrm{GE}$

$\mathrm{pCi} / \mathrm{L} \quad 0 \quad \mathrm{GP}$

$\mathrm{pCi} / \mathrm{L} \quad 0 \quad \mathrm{GP}$

- = exceeded holding time. = exceeded screening level or final primary drinking water standard. 
WELL BGO $33 \mathrm{C}$ collected on $01 / 27 / 94$, laboratory analyses (cont.)

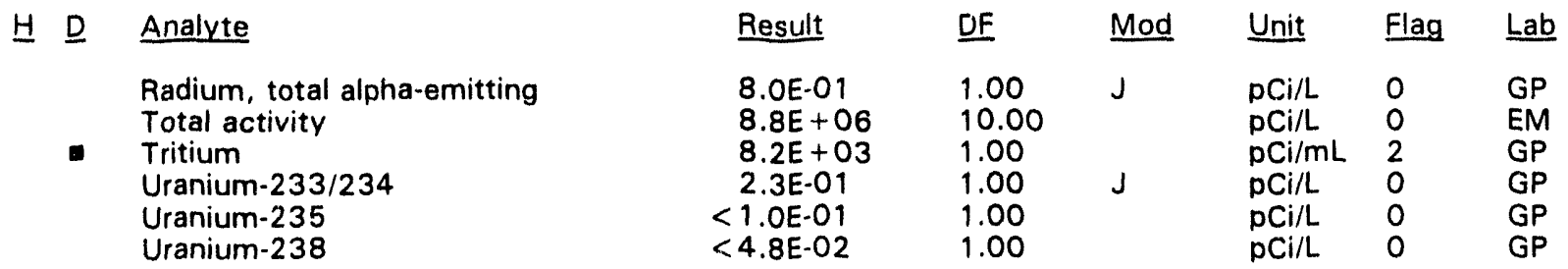

\section{WELL BGO 33D}

$\begin{array}{lllllll}\text { SRS Coord. } & \text { Lat/Longitude } & \text { Screen Zone Elevation } & \text { Top of Casing } & \text { Casing } & \text { Pump } & \text { Formation } \\ \text { N74468.7 } & 33.281350^{\circ} \mathrm{N} & 233.1-213.1 \mathrm{ft} \mathrm{msl} & 280.3 \mathrm{ft} \mathrm{msl} & \text { 4" PVC } & \text { S } & \left.\text { Water Table (IIB }{ }_{2}\right) \\ \text { E55695.4 } & 81.664797^{\circ} \mathrm{W} & & & \end{array}$

\section{FIELD MEASUREMENTS}

Sample date: 02/01/94

Depth to water: $50.45 \mathrm{ft}(15.38 \mathrm{~m})$ below TOC

Water elevation: $229.85 \mathrm{ft}(70.06 \mathrm{~m}) \mathrm{ms}$

Sp. conductance: $62 \mu \mathrm{S} / \mathrm{cm}$

Turbidity: 25.1 NTU

Water evacuated before sampling: 7 gal

The well went dry during purging.

Time: 11: 11

pH: 5.0

Alkalinity: $0 \mathrm{mg} / \mathrm{L}$

Water temperature: $14.8^{\circ} \mathrm{C}$

Volumes purged: 0.6 well volumes

\section{LABORATORY ANALYSES}

H D Analyte

$\because \quad \mathrm{pH}$

Specific conductance
Turbidity
Acetophenone
Aldrin
Aluminum, total recoverable
Antimony, total recoverable
Arsenic, total recoverable
Barium, total recoverable
Benzene
Bromodichloromethane
Bromoform
Bromomethane (Methyl bromide)
Cadmium, total recoverable
Calcium, total recoverable
Carbon tetrachloride
Chloride
Chlorobenzene
Chloroethane
Chloroethene (Vinyl chloride)
2-Chloroethyl vinyl ether
Chloroform
Chloromethane (Methyl chloride)
Chromium, total recoverable
Copper, total recoverable
Cyanide
Cyanide

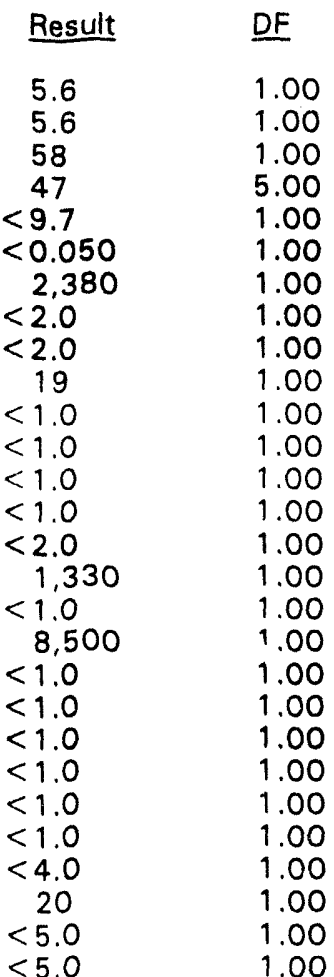

\begin{tabular}{ll} 
Mod & Unit \\
\hline$J 1$ & $\mathrm{pH}$ \\
$\mathrm{J} 1$ & $\mathrm{pH}$ \\
& $\mu \mathrm{S} / \mathrm{cm}$ \\
& $\mathrm{NTU}$ \\
& $\mu \mathrm{g} / \mathrm{L}$ \\
$\mu \mathrm{g} / \mathrm{L}$ \\
$\mu \mathrm{g} / \mathrm{L}$ \\
$\mu \mathrm{g} / \mathrm{L}$ \\
$\mu \mathrm{g} / \mathrm{L}$ \\
$\mu \mathrm{g} / \mathrm{L}$ \\
$\mu \mathrm{g} / \mathrm{L}$ \\
$\mu \mathrm{g} / \mathrm{L}$ \\
$\mu \mathrm{g} / \mathrm{L}$ \\
$\mu \mathrm{g} / \mathrm{L}$ \\
$\mu \mathrm{g} / \mathrm{L}$ \\
$\mu \mathrm{g} / \mathrm{L}$ \\
$\mu \mathrm{g} / \mathrm{L}$ \\
$\mu \mathrm{g} / \mathrm{L}$ \\
$\mu \mathrm{g} / \mathrm{L}$ \\
$\mu \mathrm{g} / \mathrm{L}$ \\
$\mu \mathrm{g} / \mathrm{L}$ \\
$\mu \mathrm{g} / \mathrm{L}$ \\
$\mu \mathrm{g} / \mathrm{L}$ \\
$\mu \mathrm{g} / \mathrm{L}$ \\
$\mu \mathrm{g} / \mathrm{L}$ \\
$\mu \mathrm{g} / \mathrm{L}$ \\
$\mu \mathrm{g} / \mathrm{L}$ \\
$\mu \mathrm{g} / \mathrm{L}$
\end{tabular}

\begin{tabular}{ll} 
Flag & Lab \\
\hline 0 & GE \\
0 & $G E$ \\
0 & $G E$ \\
0 & $G E$ \\
0 & $G E$ \\
0 & GE \\
2 & GE \\
0 & GE \\
0 & GE \\
0 & $G E$ \\
0 & $G E$ \\
0 & $G E$ \\
0 & $G E$ \\
0 & $G E$ \\
0 & $G E$ \\
0 & $G E$ \\
0 & $G E$ \\
0 & $G E$ \\
0 & $G E$ \\
0 & $G E$ \\
0 & $G E$ \\
0 & $G E$ \\
0 & $G E$ \\
0 & $G E$ \\
0 & $G E$ \\
0 & $G E$ \\
0 & $G E$ \\
0 & $G E$
\end{tabular}

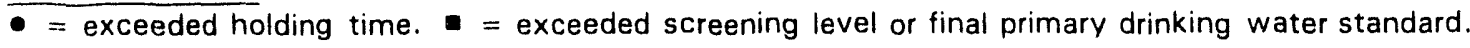


WELL BGO 33D collected on $02 / 01 / 94$, laboratory analyses (cont.)

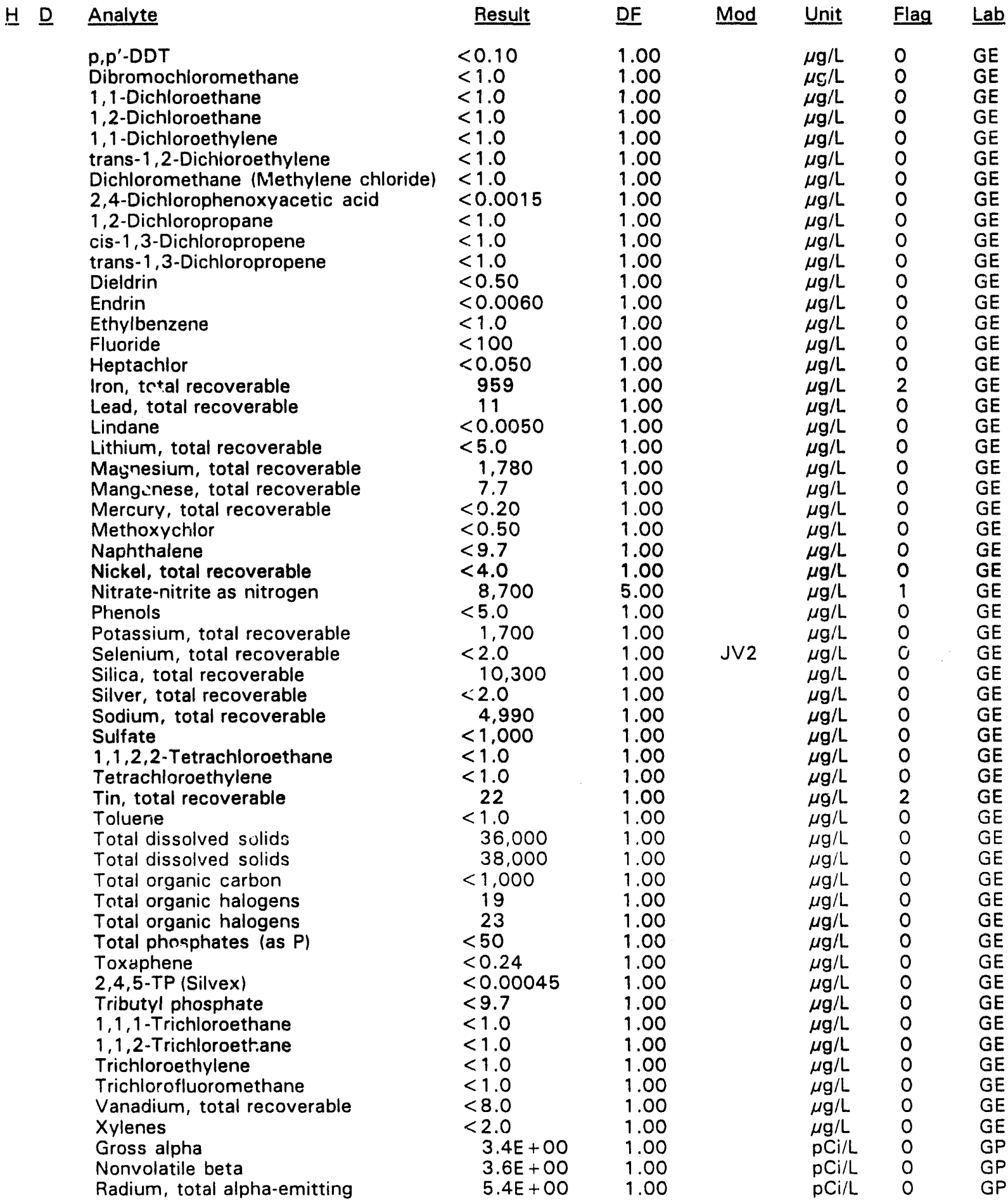

- exceeded holding time. = exceeded screening level or final primary drinking water standard. 
WELL BGO 33D collected on $02 / 01 / 94$, laboratory analyses (cont.)

\begin{tabular}{|c|c|c|c|c|c|c|}
\hline$\underline{D}$ & Analyte & Result & DF & Mod & Unit & Flag \\
\hline 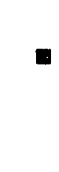 & $\begin{array}{l}\text { Radium, total alpha-emitting } \\
\text { Tritium } \\
\text { Uranium-233/234 } \\
\text { Uranium-235 } \\
\text { Uranium-238 }\end{array}$ & $\begin{aligned} & 4.7 E+00 \\
& 2.1 E+01 \\
& 1.1 E-01 \\
&< 8.4 E-03 \\
&< 8.4 E-03\end{aligned}$ & $\begin{array}{l}1.00 \\
1.00 \\
1.00 \\
1.00 \\
1.00\end{array}$ & $\begin{array}{l}\mathrm{JV} 2 \\
\mathrm{~J}\end{array}$ & $\begin{array}{l}\mathrm{pCi} / \mathrm{L} \\
\mathrm{pCi} / \mathrm{mL} \\
\mathrm{pCi} / \mathrm{L} \\
\mathrm{pCi} / \mathrm{L} \\
\mathrm{pCi} / \mathrm{L}\end{array}$ & $\begin{array}{l}0 \\
2 \\
0 \\
0 \\
0\end{array}$ \\
\hline
\end{tabular}

WELL BGO 34D

$\begin{array}{lllllll}\text { SRS Coord. } & \text { Lat/Longitude } & \text { Screen Zone Elevation } & \text { Top of Casing } & \text { Casing } & \text { Pump Formation } \\ \text { N74228.8 } & 33.281451^{\circ} \mathrm{N} & 232.7-212.7 \mathrm{ft} \mathrm{msl} & 274.9 \mathrm{ft} \mathrm{msl} & \text { 4" PVC } & \text { S } & \left.\text { Water Table (IIB })_{2}\right) \\ \text { E56082.6 } & 81.663311^{\circ} \mathrm{W} & & & \end{array}$

FIELD MEASUREMENTS

Sample date: 02/01/94

Depth to water: $42.58 \mathrm{ft}(12.98 \mathrm{~m})$ below TOC

Water elevation: $232.32 \mathrm{ft}(70.81 \mathrm{~m}) \mathrm{msl}$

Sp. conductance: $33 \mu \mathrm{S} / \mathrm{cm}$

Turbidity: 5.0 NTU

Water evacuated before sampling: $13 \mathrm{gal}$

The well went dry during purging.

\section{LABORATORY ANALYSES}

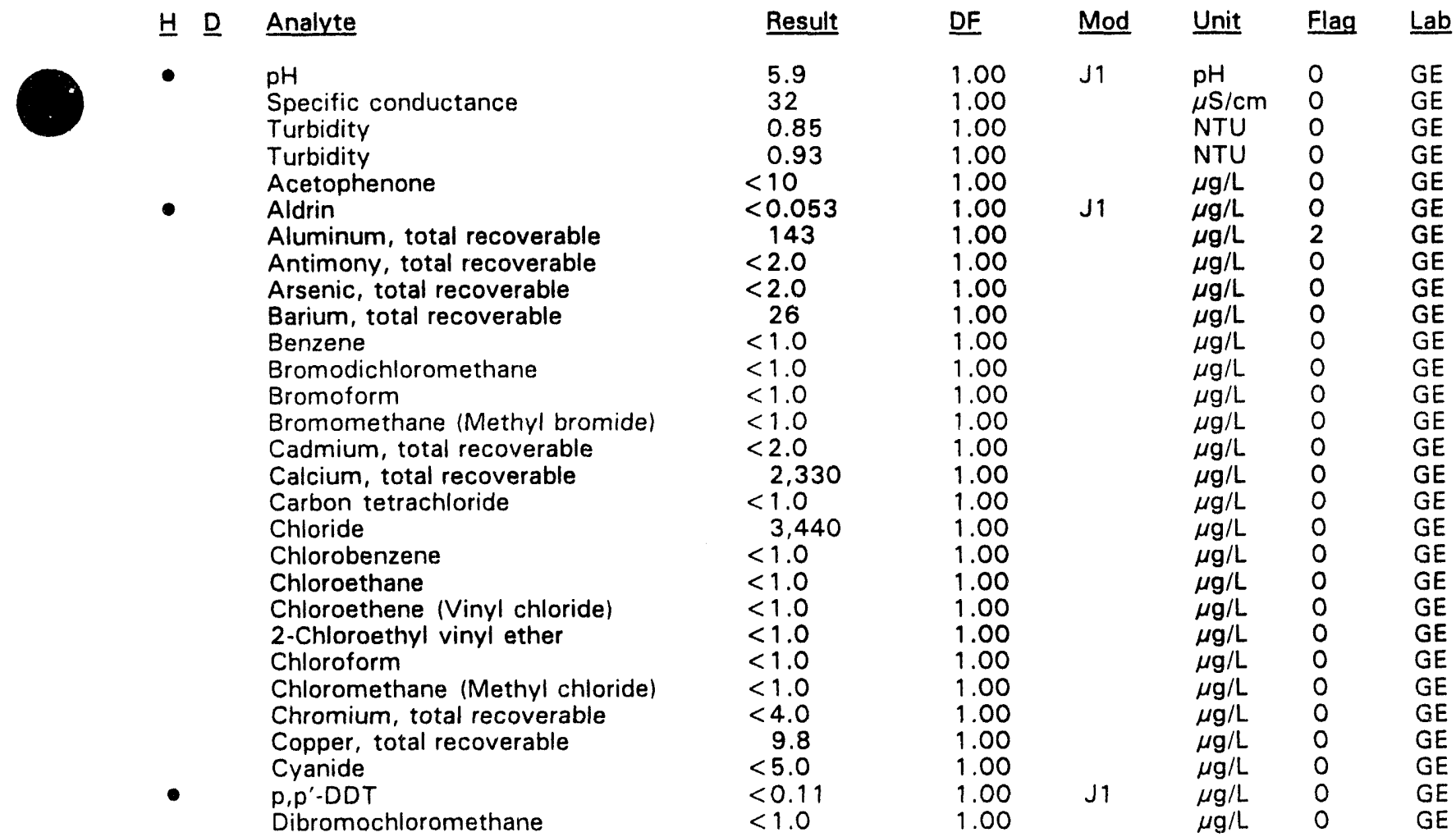

Time: $11: 24$

$\mathrm{pH}: 5.7$

Alkalinity: $2 \mathrm{mg} / \mathrm{L}$

Water temperature: $15.1^{\circ} \mathrm{C}$

Volumes purged: 1.0 well volumes

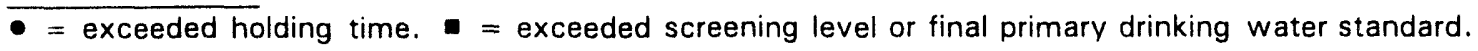


WELL BGO 34D collected on 02/01/94, laboratory analyses (cont.)

H D Analyte

1,1-Dichloroethane

1,2-Dichloroethane

1,1-Dichloroethylene

trans-1,2-Dichloroethylene

Dichloromethane (Methylene chloride)

2,4-Dichlorophenoxyacetic acid

1,2-Dichloropropane

cis-1,3-Dichloropropene

trans-1,3-Dichloropropene

- $\quad$ Dieldrin

Ethylbenzene

Fluoride

- Heptachlor

Iron, total recoverable

Lead, total recoverable

Lindane

Lithium, total recoverable

Magnesium, total recoverable

Manganese, total recoverable

Mercury, total recoverable

Methoxychlor

Naphthalene

Nickel, total recoverable

Nitrate-nitrite as nitrogen

Phenols

Potassium, total recoverable

Selenium, total recoverable

Silica, total recoverable

Silver, total recoverable

Sodium, total recoverable

Sulfate

1,1,2,2-Tetrachloroethane

Tetrachloroethylene

Tin, total recoverable

Toluene

Total dissolved solids

Total organic carbon

Total organic halogens

Total phosphates (as P)

Total phosphates (as $P$ )

- Toxaphene

2,4,5-TP (Silvex)

Tributyl phosphate

1,1,1-Trichloroethane

1,1,2-Trichloroethane

Trichloroethylene

Trichlorofluoromethane

Vanadium, total recoverable

Xylenes

Gross alpha

Nonvolatile beta

Radium, total alpha-emitting

- Tritium

Uranium-233/234

Uranium-235
Result DF

$<1.0$

$<1.0$

$<1.0$

$<1.0$

$<1.0$

$<0.0015$

$<1.0$

$<1.0$

$<1.0$

$<0.53$

$<0.0064$

$<1.0$

$<100$

$<0.053$

21

8.9

$<0.0053$

$<5.0$

788

3.6

$<0.20$

$<0.53$

$<10$

$<4.0$

1,050

$<5.0$

$<500$

$<2.0$

6,620

$<2.0$

1,750

$<1,000$

$<1.0$

$<1.0$

9.2

$<1.0$

26,000

$<1,000$

19

$<50$

$<50$

$<0.26$

$<0.00045$

$<10$

$<1.0$

$<1.0$

$<1.0$

$<1.0$

$<8.0$

$<2.0$

1.7E+OO

$1.7 E+00$

$2.0 E+00$

$2.3 E+01$

$<-1.1 \mathrm{E}-03$

$<0.0 E+00$
DF

1.00

1.00

1.00

1.00

1.00

1.00

1.00

1.00

1.00

1.00

1.00

1.00

1.00

1.00

1.00

1.00

1.00

1.00

1.00

1.00

1.00

1.00

1.00

1.00

1.00

1.00

1.00

1.00

1.00

1.00

1.00

1.00

1.00

1.00

1.00

1.00

1.00

1.00

1.00

1.00

1.00

1.00

1.00

1.00

1.00

1.00

1.00

1.00

1.00

1.00

1.00

1.00

1.00

1.00

1.00
Mod Unit Flag Lab

$\begin{array}{lll}\mu \mathrm{g} / \mathrm{L} & 0 & \mathrm{GE} \\ \mu \mathrm{g} / \mathrm{L} & 0 & \mathrm{GE}\end{array}$

$\mu g / L \quad 0 \quad G E$

$\mu \mathrm{g} / \mathrm{L} \quad 0 \quad \mathrm{GE}$

$\mu \mathrm{g} / \mathrm{L} \quad 0 \quad \mathrm{GE}$

$\mu \mathrm{g} / \mathrm{L} \quad 0 \quad \mathrm{GE}$

$\mu \mathrm{g} / \mathrm{L} \quad 0 \quad \mathrm{GE}$

$\mu \mathrm{g} / \mathrm{L} \quad 0 \quad \mathrm{GE}$

$\mu \mathrm{g} / \mathrm{L} \quad \mathrm{O} \quad \mathrm{GE}$

$J 1 \mu g / L \quad 0 \quad G E$

$J 1 \mu g / L \quad 0 \quad$ GE

$\mu g / L \quad 0 \quad$ GE

$\begin{array}{llll}J 1 & \mu g / L & 0 & G E\end{array}$

$\mu \mathrm{g} / \mathrm{L} \quad 0 \quad \mathrm{GE}$

J1 $\mu \mathrm{g} / \mathrm{L} \quad 0 \quad \mathrm{GE}$

GE

GE

$\mathrm{GE}$

GE

J1 $\mu \mathrm{g} / \mathrm{L} \quad 0 \quad \mathrm{GE}$

GE

GE

GE

$\begin{array}{llll} & \mu g / L & 0 & G E \\ J V 2 & \mu g / L & 0 & G E\end{array}$

GE

GE

GE

GE

GE

GE

GE

GE

GE

GE

GE

GE

GE

GE

$\mathrm{GE}$

GE

GE

GE

GE

$G E$

GP

GP

$G P$

$\begin{array}{lll}\mathrm{pCi} / \mathrm{mL} & 2 & \mathrm{GP} \\ \mathrm{pCi} / \mathrm{L} & 0 & \mathrm{GP} \\ \mathrm{pCi} / \mathrm{L} & 0 & \mathrm{GP}\end{array}$

- exceeded holding time. = exceeded screening level or final primary drinking water standard. 
WELL BGO 34D collected on 02/01/94, laboratory analyses (cont.)

\begin{tabular}{|c|c|c|c|c|c|}
\hline Analyte & Result & DF & Mod & Unit & Flag \\
\hline Uranium-238 & $<4.2 \mathrm{E}-02$ & 1.00 & & $\mathrm{pCi} / \mathrm{L}$ & 0 \\
\hline
\end{tabular}

\section{WELL BGO 35C}

\begin{tabular}{|c|c|c|c|c|c|c|}
\hline SRS Coord. & Lat/Longitude & Screen Zone Elevation & Top of Casing & Casing & Pump & Formation \\
\hline $\begin{array}{l}N 73953.9 \\
\text { E56545.7 }\end{array}$ & $\begin{array}{l}33.281598^{\circ} \mathrm{N} \\
81.661558^{\circ} \mathrm{W}\end{array}$ & $171.9-161.9 \mathrm{ft} \mathrm{msl}$ & $273.4 \mathrm{ft} \mathrm{msl}$ & 4" PVC & $\mathrm{S}$ & $\left(|| B_{1}\right)$ \\
\hline
\end{tabular}

\section{FIELD MEASUREMENTS}

Sample date: $01 / 27 / 94$

Depth to water: $45.48 \mathrm{ft}(13.86 \mathrm{~m})$ below TOC

Water elevation: $227.92 \mathrm{ft}(69.47 \mathrm{~m}) \mathrm{ms}$

Sp. conductance: $43 \mu \mathrm{S} / \mathrm{cm}$

Turbidity: 0.3 NTU

Water evacuated before sampling: $192 \mathrm{gal}$

\section{LABORATORY ANALYSES}

H D Analyte

- $\quad \mathrm{pH}$

Specific conductance

Turbidity

Acetophenone

Aldrin

Aluminum, total recoverable

Aluminum, total recoverable

Antimony, total recoverable

Arsenic, total recoverable

Barium, total recoverable

Barium, total recoverable

Benzene

Bromodichloromethane

Bromoform

Bromomethane (Methyl bromide)

Cadmium, total recoverable

Cadmium, total recoverable

Calcium, total recoverable

Calcium, total recoverable

Carbon tetrachloride

Chloride

Chlorobenzene

Chloroethane

Chloroethene (Vinyl chloride)

2-Chloroethyl vinyl ether

Chloroform

Chloromethane (Methyl chloride)

Chromium, total recoverable

Chromium, total recoverable

Copper, total recoverable

Copper, total recoverable

Cyanide

$p, p^{\prime}-D D T$
Time: 15: 24

pH: 6.4

Alkalinity: $11 \mathrm{mg} / \mathrm{L}$

Water temperature: $19.0^{\circ} \mathrm{C}$

Volumes purged: 4.4 well volumes

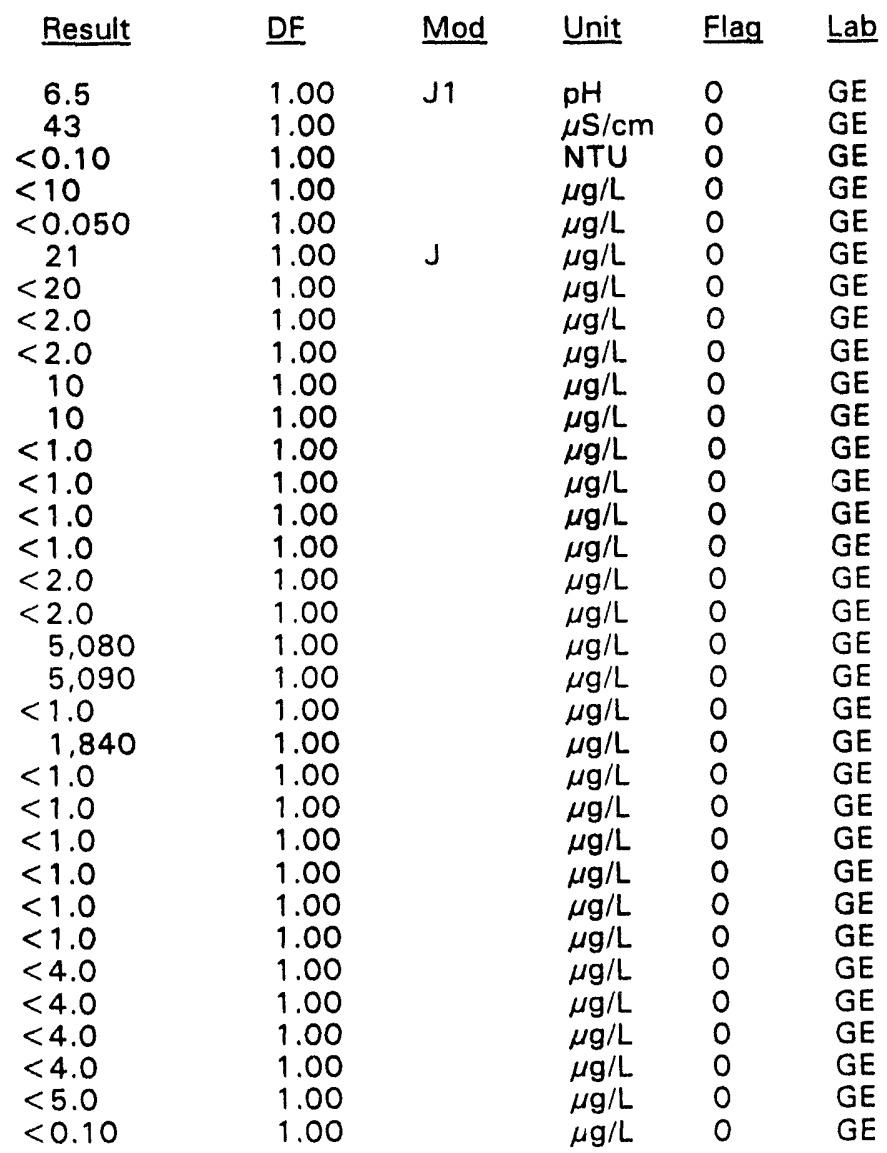

- = exceeded holding time. = exceeded screening level or final primary drinking water standard. 
WELL BGO $35 \mathrm{C}$ collected on $01 / 27 / 94$, laboratory analyses (cont.)

\section{H D Analyte}

Dibromochloromethane

1,1-Dichloroethane

1,2-Dichloroethane

1,1-Dichloroethylene

trans-1,2-Dichloroethylene

Dichloromethane (Methylene chloride)

2,4-Dichlorophenoxyacetic acid

1,2-Dichloropropane

cis-1,3-Dichloropropene

trans-1,3-Dichloropropene

Dieldrin

Endrin

Ethylbenzene

Fluoride

Heptachlor

Iron, total recoverable

Iron, total recoverable

Lead, total recoverable

Lindane

Lithium, total recoverable

Lithium, total recoverable

Magnesium, total recoverable

Magnesium, total recoverable

Manganese, total recoverable

Manganese, total recoverable

Mercury, total recoverable

Methoxychlor

Naphthalene

Nickel, total recoverable

Nickel, total recoverable

Nitrate-nitrite as nitrogen

Phenols

Potassium, total recoverable

Potassium, total recoverable

Selenium, total recoverable

Silica, total recoverable

Silica, total recoverable

Silver, total recoverable

Silver, total recoverable

Sodium, total recoverable

Sodium, total recoverable

Sulfate

$1,1,2,2$-Tetrachloroethane

Tetrachloroethylene

Tin, total recoverable

Tin, total recoverable

Toluene

Total dissolved solids

Total organic carbon

Total organic halogens

Total phosphates (as P)

Toxaphene

2,4,5-TP (Silvex)

Tributyl phosphate

1,1,1-Trichloroethane

1,1,2-Trichloroethane
Result

$<1.0$

$<1.0$

$<1.0$

$<1.0$

$<1.0$

$<1.0$

$<0.0015$

$<1.0$

$<1.0$

$<1.0$

$<0.50$

$<0.0060$

$<1.0$

$<100$

$<0.050$

$<4.0$

$<4.0$

$<3.0$

$<0.0050$

$<5.0$

$<5.0$

397

399

6.7

6.8

$<0.20$

$<0.50$

$<10$

$<4.0$

$<4.0$

980

$<5.0$

$<500$

$<500$

$<2.0$

9,660

9,700

$<2.0$

$<2.0$

1,950

1,960

$<1,000$

$<1.0$

$<1.0$

3.1

$<2.0$

$<1.0$

34,000

$<1,000$

15

$<50$

$<0.24$

$<0.00045$

$<10$

$<1.0$

$<1.0$
DF

1.00

1.00

1.00

1.00

1.00

1.00

1.00

1.00

1.00

1.00

1.00

1.00

1.00

1.00

1.00

1.00

1.00

1.00

1.00

1.00

1.00

1.00

1.00

1.00

1.00

1.00

1.00

1.00

1.00

1.00

1.00

1.00

1.00

1.00

1.00

1.00

1.00

1.00

1.00

1.00

1.00

1.00

1.00

1.00

1.00

1.00

1.00

1.00

1.00

1.00

1.00

1.00

1.00

1.00

1.00

1.00

Mod Unit

Flag

Lab

$\mu \mathrm{g} / \mathrm{L}$

$\mu g / L$

$\mu \mathrm{g} / \mathrm{L}$

$\mu \mathrm{g} / \mathrm{L}$

$\mu \mathrm{g} / \mathrm{L}$

$\mu \mathrm{g} / \mathrm{L}$

$\mu \mathrm{g} / \mathrm{L}$

$\mu \mathrm{g} / \mathrm{L}$

$\mu \mathrm{g} / \mathrm{L}$

$\mu \mathrm{g} / \mathrm{L}$

$\mu \mathrm{g} / \mathrm{L}$

$\mu \mathrm{g} / \mathrm{L}$

$\mu \mathrm{g} / \mathrm{L}$

$\mu \mathrm{g} / \mathrm{L}$

$\mu \mathrm{g} / \mathrm{L}$

$\mu \mathrm{g} / \mathrm{L}$

$\mu \mathrm{g} / \mathrm{L}$

$\mu \mathrm{g} / \mathrm{L}$

$\mu \mathrm{g} / \mathrm{L}$

$\mu \mathrm{g} / \mathrm{L}$

$\mu \mathrm{g} / \mathrm{L}$

$\mu \mathrm{g} / \mathrm{L}$

$\mu \mathrm{g} / \mathrm{L}$

$\mu \mathrm{g} / \mathrm{L}$

$\mu \mathrm{g} / \mathrm{L}$

$\mu \mathrm{g} / \mathrm{L}$

$\mu \mathrm{g} / \mathrm{L}$

$\mu \mathrm{g} / \mathrm{L}$

$\mu \mathrm{g} / \mathrm{L}$

$$
\mu \mathrm{g} / \mathrm{L}
$$

$\mu g / L$

$\mu \mathrm{g} / \mathrm{L}$

$\mu g / L$

$\mu \mathrm{g} / \mathrm{L}$

$\mu \mathrm{g} / \mathrm{L}$

$$
\mu \mathrm{g} / \mathrm{L}
$$

$\mu \mathrm{g} / \mathrm{L}$

$\mu \mathrm{g} / \mathrm{L}$

$\mu \mathrm{g} / \mathrm{L}$

$\mu \mathrm{g} / \mathrm{L}$

$\mu \mathrm{g} / \mathrm{L}$

$\mu \mathrm{g} / \mathrm{L}$

$\mu \mathrm{g} / \mathrm{L}$

$\mu \mathrm{g} / \mathrm{L}$

J

JV2

$\mu \mathrm{g} / \mathrm{L}$

$\mu \mathrm{g} / \mathrm{L}$

$\mu \mathrm{g} / \mathrm{L}$.

$\mu \mathrm{g} / \mathrm{L}$

$\mu \mathrm{g} / \mathrm{L}$

$\mu \mathrm{g} / \mathrm{L}$

$\mu \mathrm{g} / \mathrm{L}$

$\mu \mathrm{g} / \mathrm{L}$

$\mu \mathrm{g} / \mathrm{L}$

$\mu \mathrm{g} / \mathrm{L}$

$\mu \mathrm{g} / \mathrm{L}$

o GE

O GE

GE

GE

GE

GE

GE

GE

GE

GE

GE

GE

GE

GE

GE

GE

GE

GE

GE

GE

GE

GE

GE

GE

GE

GE

GE

GE

GE

GE

GE

GE

- exceeded holding time. = exceeded screening level or final primary drinking water standard. 
WELL BGO 35C collected on 01/27/94, laboratory analyses (cont.)

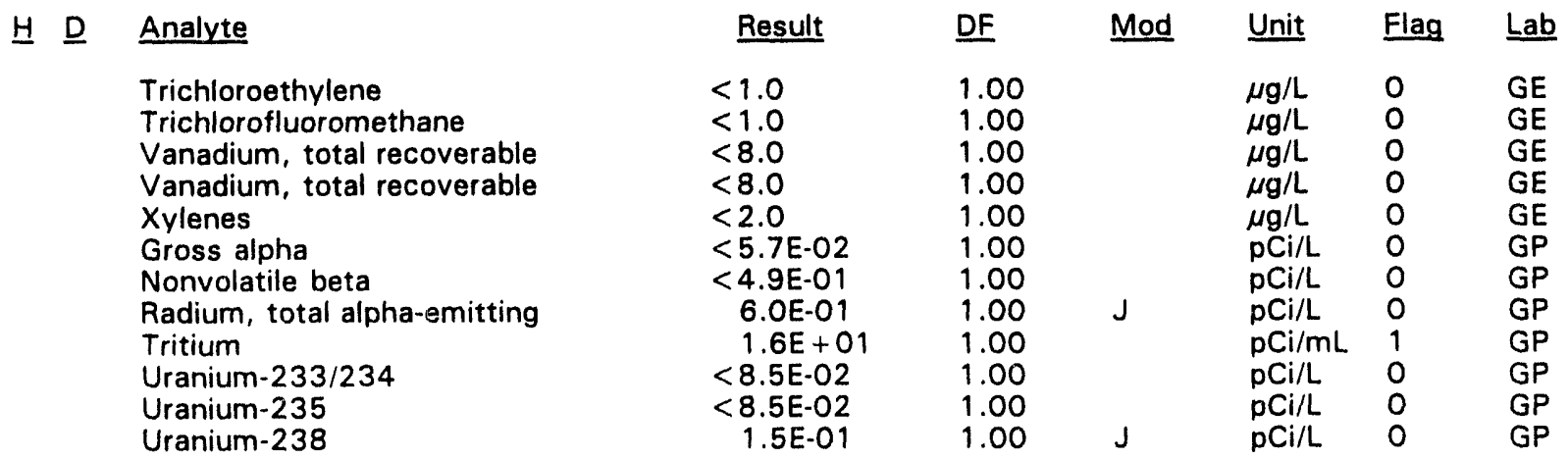

\section{WELL BGO 35D}

\begin{tabular}{|c|c|c|c|c|c|c|}
\hline SRS Coord. & Lat/Longitude & Screen Zone Elevation & Top of Casing & Casing & Pump & Formation \\
\hline $\begin{array}{l}N 73946.0 \\
E 56556.5\end{array}$ & $\begin{array}{l}33.281599^{\circ} \mathrm{N} \\
81.661514^{\circ} \mathrm{W}\end{array}$ & $239.4-219.4 \mathrm{ft} \mathrm{msl}$ & $273.5 \mathrm{ft} \mathrm{msl}$ & 4" PVC & $s$ & Water Table $\left(\| B_{2}\right)$ \\
\hline
\end{tabular}

\section{FIELD MEASUREMENTS}

Sample date: $02 / 01 / 94$

Depth to water: $39.88 \mathrm{ft}(12.16 \mathrm{~m})$ below TOC

Water elevation: $233.62 \mathrm{ft}(71.21 \mathrm{~m}) \mathrm{ms}$

Sp. conductance: $37 \mu \mathrm{S} / \mathrm{cm}$

Turbidity: 30.3 NTU

Water evacuated before sampling: $7 \mathrm{gal}$

The well went dry during purging.

\section{LABORATORY ANALYSES}

\section{H $\underline{\text { Analyte }}$}

- $\mathrm{pH}$

Specific conductance

Turbidity

Acetophenone

Aldrin

Aluminum, total recoverable

Antimony, total recoverable

Arsenic, total recoverable

Barium, total recoverable

Benzene

Benzene

Bromodichloromethane

Bromodichloromethane

Bromoform

Bromoform

Bromomethane (Methyl bromide)

Bromomethane (Methyl bromide)

Cadmium, total recoverable

Calcium, total recoverable

Carbon tetrachloride

Carbon tetrachloride

Chloride
Time: $11: 35$

$\mathrm{pH}: 4.6$

Alkalinity: $0 \mathrm{mg} / \mathrm{L}$

Water temperature: $15.2^{\circ} \mathrm{C}$

Volumes purged: 0.8 well volumes

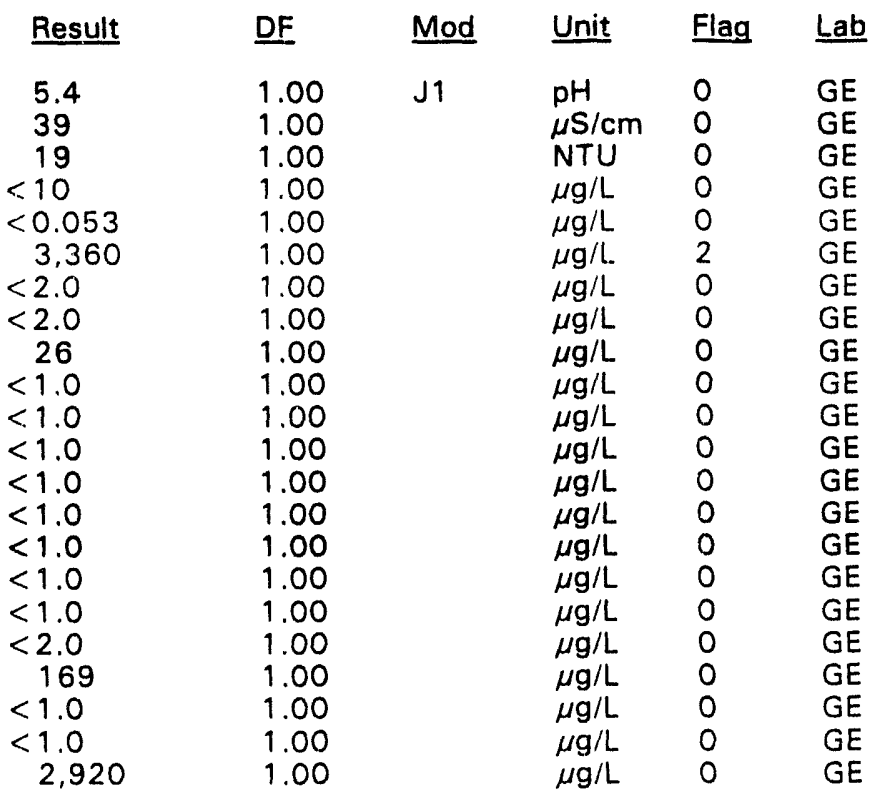

- = exceeded holding time. = exceeded screening level or final primary drinking water standard. 
WELL BGO 35D collected on 02/01/94, laboratory analyses (cont.)

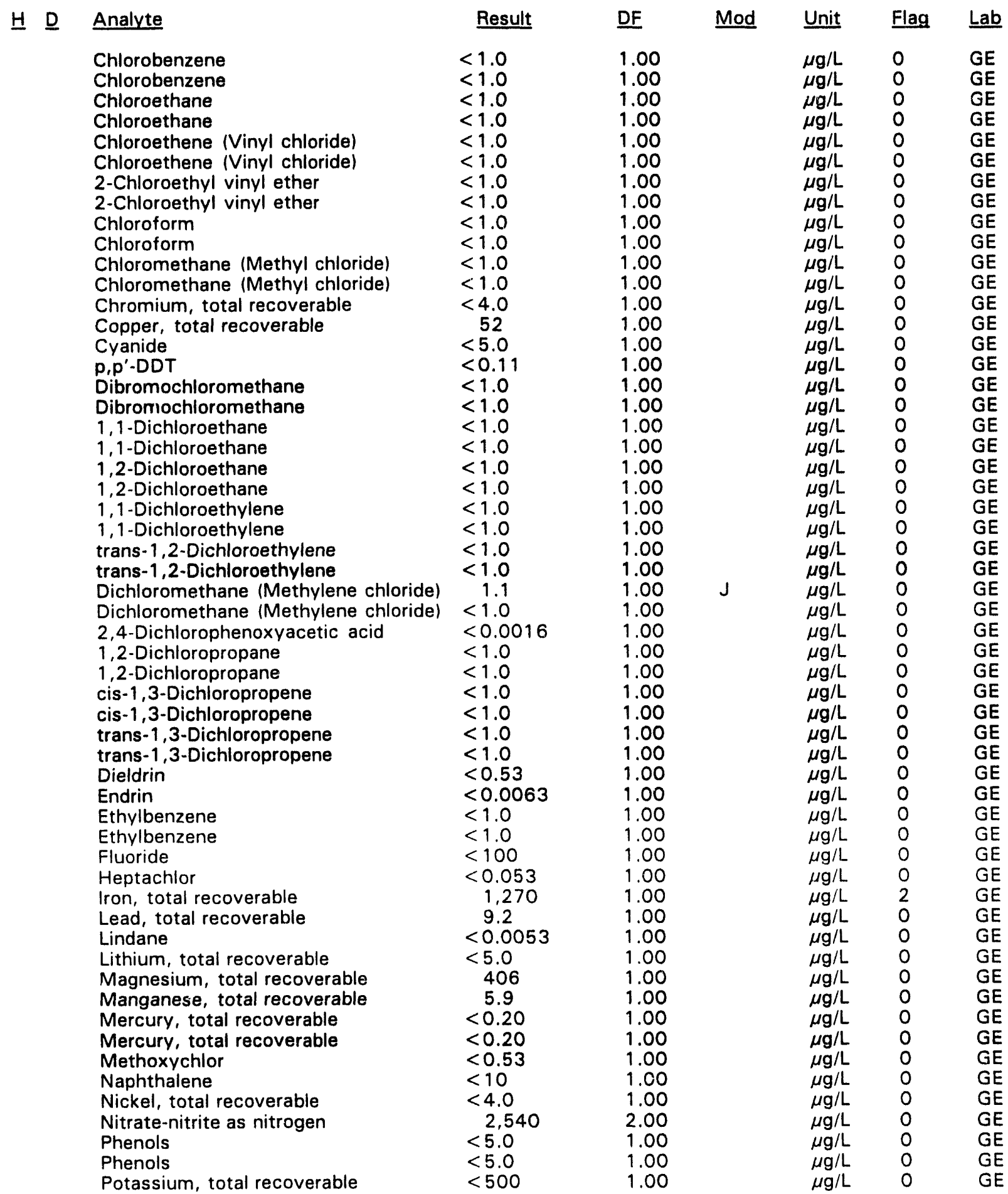

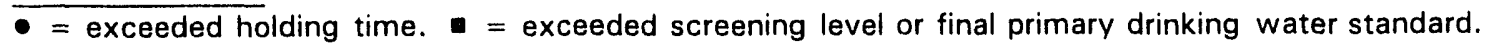


WELL BGO 35D collected on 02/01/94, laboratory analyses (cont.)

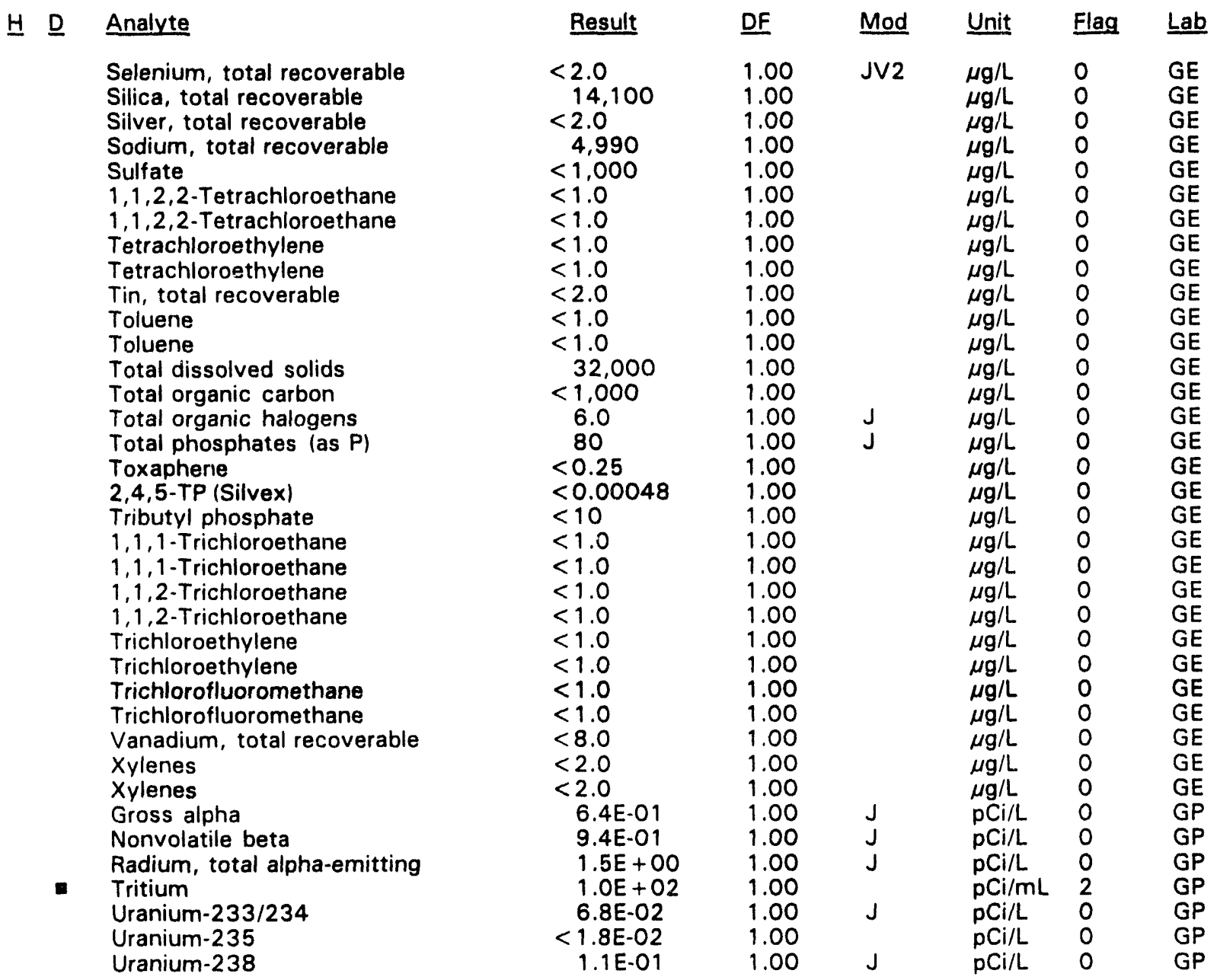

- = exceeded holding time. = exceeded screening level or final primary drinking water standard. 
WELL BGO 36D

\begin{tabular}{|c|c|c|c|c|c|c|}
\hline SRS Coord. & Lat/Longitude & Screen Zone Elevation & Top of Casing & Casing & Pump & Formation \\
\hline $\begin{array}{l}N 73743.8 \\
E 56888.1\end{array}$ & $\begin{array}{l}33.281692^{\circ} \mathrm{N} \\
81.660248^{\circ} \mathrm{W}\end{array}$ & $243.3-223.3 \mathrm{ft} \mathrm{msl}$ & $275.4 \mathrm{ft} \mathrm{msl}$ & 4" PVC & $\mathbf{S}$ & Water Table $\left(I \mid B_{2}\right)$ \\
\hline
\end{tabular}

\section{FIELD MEASUREMENTS}

Sample date: 02/01/94

Depth to water: $39.13 \mathrm{ft}(11.93 \mathrm{~m})$ below TOC

Water elevation: $236.27 \mathrm{ft}(72.02 \mathrm{~m}) \mathrm{msl}$

Sp. conductance: $29 \mu \mathrm{S} / \mathrm{cm}$

Turbidity: 90.6 NTU

Water evacuated before sampling: $9 \mathrm{gal}$

The well went dry during purging.

\section{LABORATORY ANALYSES}

H $\underline{\text { Analyte }}$

- $\mathrm{pH}$

Specific conductance

Turbidity

Acetophenone

Aldrin

Aluminum, total recoverable

Antimony, total recoverable

Arsenic, total recoverable

Barium, total recoverable

Benzene

Bromodichloromethane

Bromoform

Bromomethane (Methyl bromide)

Cadmium, total recoverable

Calcium, total recoverable

Carbon tetrachloride

Chloride

Chlorobenzene

Chloroethane

Chloroethene (Vinyl chloride)

2-Chloroethyl vinyl ether

Chloroform

Chloromethane (Methyl chloride)

Chromium, total recoverable

Copper, total recoverable

Cyanide

$p, p^{\prime}-D D T$

Dibromochloromethane

1,1-Dichloroethane

1,2-Dichloroethane

1,1-Dichloroethylene

trans-1,2-Dichloroethylene

Dichloromethane (Methylene chloride)

2,4-Dichlorophenoxyacetic acid

2,4-Dichlorophenoxyacetic acid

1,2-Dichloropropane

cis-1,3-Dichloropropene

trans-1,3-Dichloropropene

Dieldrin

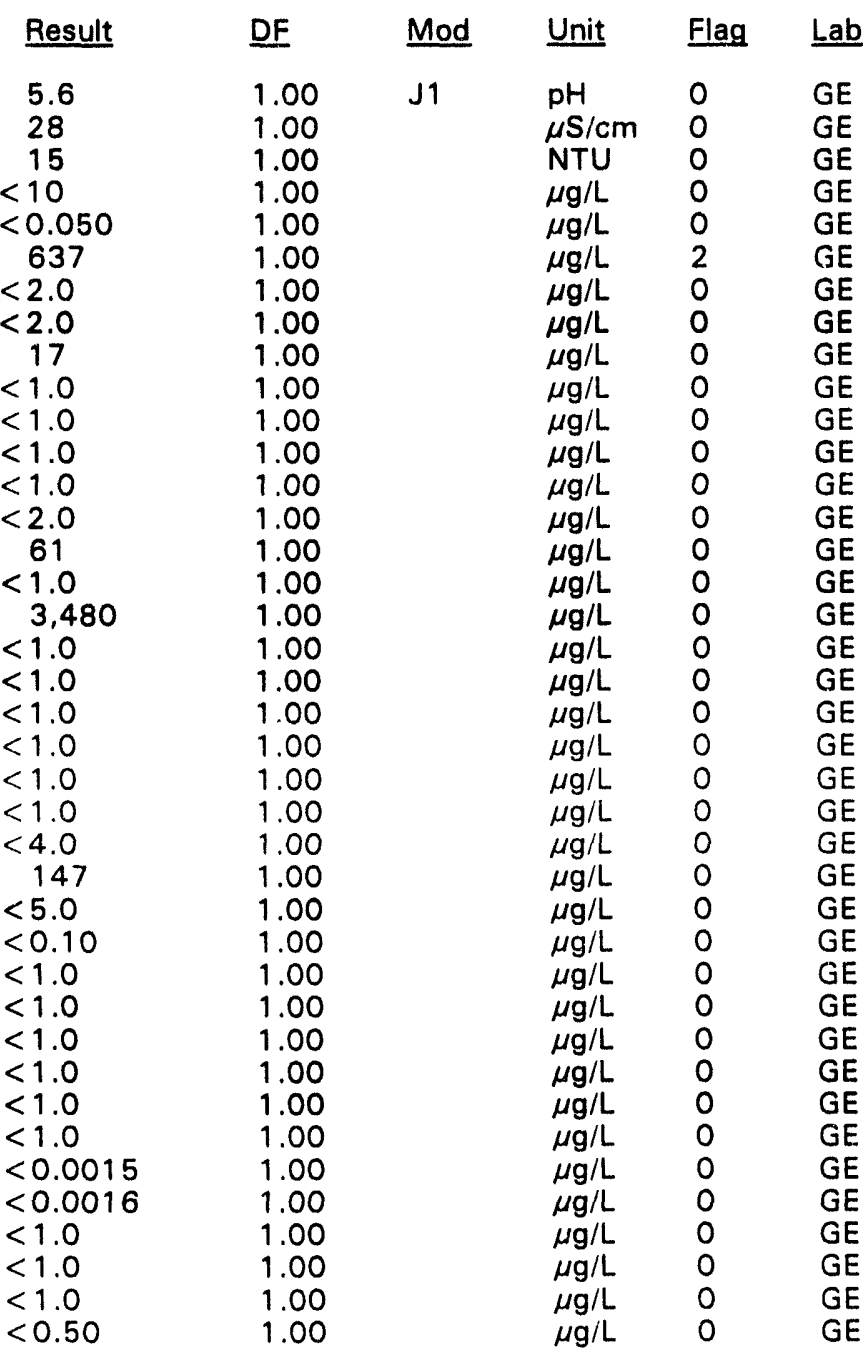

Time: 11:50

$\mathrm{pH}: 4.8$

Alkalinity: $0 \mathrm{mg} / \mathrm{L}$

Water temperature: $15.9^{\circ} \mathrm{C}$

Volumes purged: 1.1 well volumes 
WELL BGO 36D collected on 02/01/94, laboratory analyses (cont.)

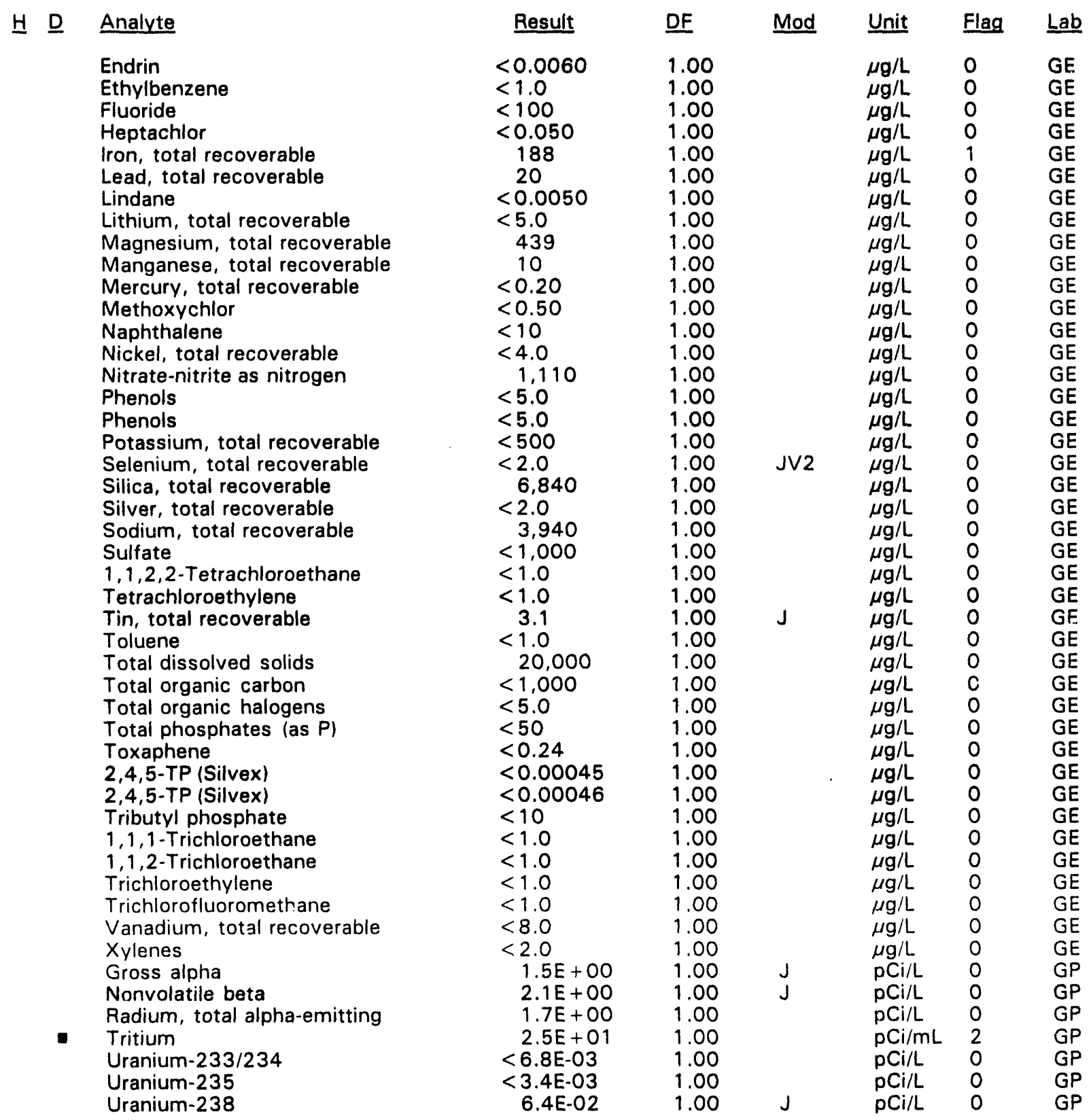

$\overline{-=\text { exceeded holding time. }}=$ exceeded screening level or final primary drinking water standard. 
WELL BGO 37D

\begin{tabular}{|c|c|c|c|c|c|c|}
\hline SRS Coord. & Lat/Longitude & Screen Zone Elevation & Top of Casing & Casing & Pump & Formation \\
\hline $\begin{array}{l}N 73490.8 \\
E 57292.9\end{array}$ & $\begin{array}{l}33.281793^{\circ} \mathrm{N} \\
81.658691^{\circ} \mathrm{W}\end{array}$ & $246.1-226.1 \mathrm{ft} \mathrm{msl}$ & $287.3 \mathrm{ft} \mathrm{msl}$ & 4" PVC & $\mathbf{s}$ & able $\left(\| B_{2}\right)$ \\
\hline
\end{tabular}

\section{FIELD MEASUREMENTS}

Sample date: 02/01/94

Depth to water: $51.30 \mathrm{ft}(15.64 \mathrm{~m})$ below TOC

Water elevation: $236.00 \mathrm{ft}(71.93 \mathrm{~m}) \mathrm{ms}$

Sp. conductance: $31 \mu \mathrm{S} / \mathrm{cm}$

Turbidity: 32.1 NTU

Water evacuated before sampling: $7 \mathrm{gal}$

The well went dry during purging.

\section{LABORATORY ANALYSES}

$\underline{H}$ D Analyte

$\mathrm{pH}$

Specific conductance

Turbidity

Acetophenone

Aldrin

Aluminum, total recoverable

Antimony, total recoverable

Arsenic, total recoverable

Barium, total recoverable

Benzene

Bromodichloromethane

Bromoform

Bromomethane (Methyl bromide)

Cadmium, total recoverable

Calcium, total recoverable

Carbon tetrachloride

Chloride

Chlorobenzene

Chloroethane

Chloroethene (Vinyl chloride)

2-Chloroethyl vinyl ether

Chloroform

Chloromethane (Methyl chloride)

Chromium, total recoverable

Copper, total recoverable

Cyanide

$p, p^{\prime}-D D T$

Dibromochloromethane

1,1-Dichloroethane

1,2-Dichloroethane

1,1-Dichloroethylene

trans-1,2-Dichloroethylene

Dichloromethane (Methylene chloride)

2,4-Dichlorophenoxyacetic acid

1,2-Dichloropropane

cis-1,3-Dichloropropene

trans-1,3-Dichloropropene

Dieldrin

Endrin

\begin{tabular}{|c|c|c|c|c|c|}
\hline Result & DF & Mod & $\underline{\text { Unit }}$ & Flag & $\underline{L a b}$ \\
\hline 6.1 & 1.00 & J1 & $\mathrm{pH}$ & 0 & GE \\
\hline 34 & 1.00 & & $\mu \mathrm{S} / \mathrm{cm}$ & 0 & \\
\hline 25 & 1.00 & & NTU & 0 & GE \\
\hline$<10$ & 1.00 & & $\mu \mathrm{g} / \mathrm{L}$ & 0 & $\overline{G F}$ \\
\hline$<0.050$ & 1.00 & & $\mu \mathrm{g} / \mathrm{L}$ & 0 & GE \\
\hline 221 & 1.00 & & $\mu \mathrm{g} / \mathrm{L}$ & 2 & GE \\
\hline$<2.0$ & 1.00 & & $\mu \mathrm{g} / \mathrm{L}$ & 0 & $E$ \\
\hline $\begin{array}{r}<.0 \\
11\end{array}$ & 1.00 & & $\mu \mathrm{g} / \mathrm{L}$ & 0 & GE \\
\hline $\begin{array}{r}11 \\
-11\end{array}$ & 1.00 & & $\mu \mathrm{g} / \mathrm{L}$ & 0 & GE \\
\hline$<1.0$ & 1.00 & & $\mu \mathrm{g} / \mathrm{L}$ & 0 & $\mathrm{G}$ \\
\hline$<1.0$ & 1.00 & & $\mu \mathrm{g} / \mathrm{L}$ & 0 & GE \\
\hline$<1.0$ & 1.00 & & $\mu \mathrm{g} / \mathrm{L}$ & 0 & $\mathrm{GE}$ \\
\hline$<1.0$ & 1.00 & & $\mu \mathrm{g} / \mathrm{L}$ & 0 & GE \\
\hline 2.0 & 1.00 & & $\mu \mathrm{g} / \mathrm{L}$ & 0 & G \\
\hline 406 & 1.00 & & $\mu \mathrm{g} / \mathrm{L}$ & 0 & GE \\
\hline$=1.0$ & 1.00 & & $\mu \mathrm{g} / \mathrm{L}$ & 0 & \\
\hline 1,510 & 1.00 & & $\mu \mathrm{g} / \mathrm{L}$ & 0 & $\mathrm{iE}$ \\
\hline$=1.0$ & 1.00 & & $\mu \mathrm{g} / \mathrm{L}$ & 0 & GE \\
\hline 1.0 & 1.00 & & $\mu \mathrm{g} / \mathrm{L}$ & 0 & $\mathrm{GE}$ \\
\hline$=1.0$ & 1.00 & & $\mu \mathrm{g} / \mathrm{L}$ & 0 & GE \\
\hline 1.0 & 1.00 & & $\mu \mathrm{g} / \mathrm{L}$ & 0 & GE \\
\hline$=1.0$ & 1.00 & & $\mu \mathrm{g} / \mathrm{L}$ & 0 & GE \\
\hline$=1.0$ & 1.00 & & $\mu \mathrm{g} / \mathrm{L}$ & 0 & \\
\hline 4.0 & 1.00 & & $\mu \mathrm{g} / \mathrm{L}$ & 0 & GE \\
\hline 25 & 1.00 & & $\mu \mathrm{g} / \mathrm{L}$ & 0 & $\mathrm{E}$ \\
\hline$<5.0$ & 1.00 & & $\mu \mathrm{g} / \mathrm{L}$ & 0 & \\
\hline$=0.10$ & 1.00 & & $\mu \mathrm{g} / \mathrm{L}$ & 0 & $\mathrm{GE}$ \\
\hline$<1.0$ & 1.00 & & $\mu \mathrm{g} / \mathrm{L}$ & 0 & \\
\hline$<1.0$ & 1.00 & & $\mu g / L$ & 0 & \\
\hline$<1.0$ & 1.00 & & $\mu \mathrm{g} / \mathrm{L}$ & 0 & \\
\hline$<1.0$ & 1.00 & & $\mu \mathrm{g} / \mathrm{L}$ & 0 & \\
\hline$<1.0$ & 1.00 & & $\mu \mathrm{g} / \mathrm{L}$ & 0 & \\
\hline$<1.0$ & 1.00 & & $\mu \mathrm{g} / \mathrm{L}$ & 0 & GE \\
\hline$<0.0015$ & 1.00 & & $\mu \mathrm{g} / \mathrm{L}$ & 0 & \\
\hline$<1.0$ & 1.00 & & $\mu \mathrm{g} / \mathrm{L}$ & 0 & \\
\hline$<1.0$ & 1.00 & & $\mu \mathrm{g} / \mathrm{L}$ & 0 & \\
\hline$<1.0$ & 1.00 & & $\mu \mathrm{g} / \mathrm{L}$ & 0 & $E$ \\
\hline$<0.50$ & 1.00 & & $\mu \mathrm{g} / \mathrm{L}$ & 0 & \\
\hline$<0.0060$ & 1.00 & & $\mu \mathrm{g} / \mathrm{L}$ & 0 & \\
\hline
\end{tabular}

Time: 13: 10

pH: 5.3

Alkalinity: $1 \mathrm{mg} / \mathrm{L}$

Water temperature: $17.5^{\circ} \mathrm{C}$

Volumes purged: 1.1 well volumes 
WELL BGO 370 collected on $02 / 01 / 94$, laboratory analyses (cont.)

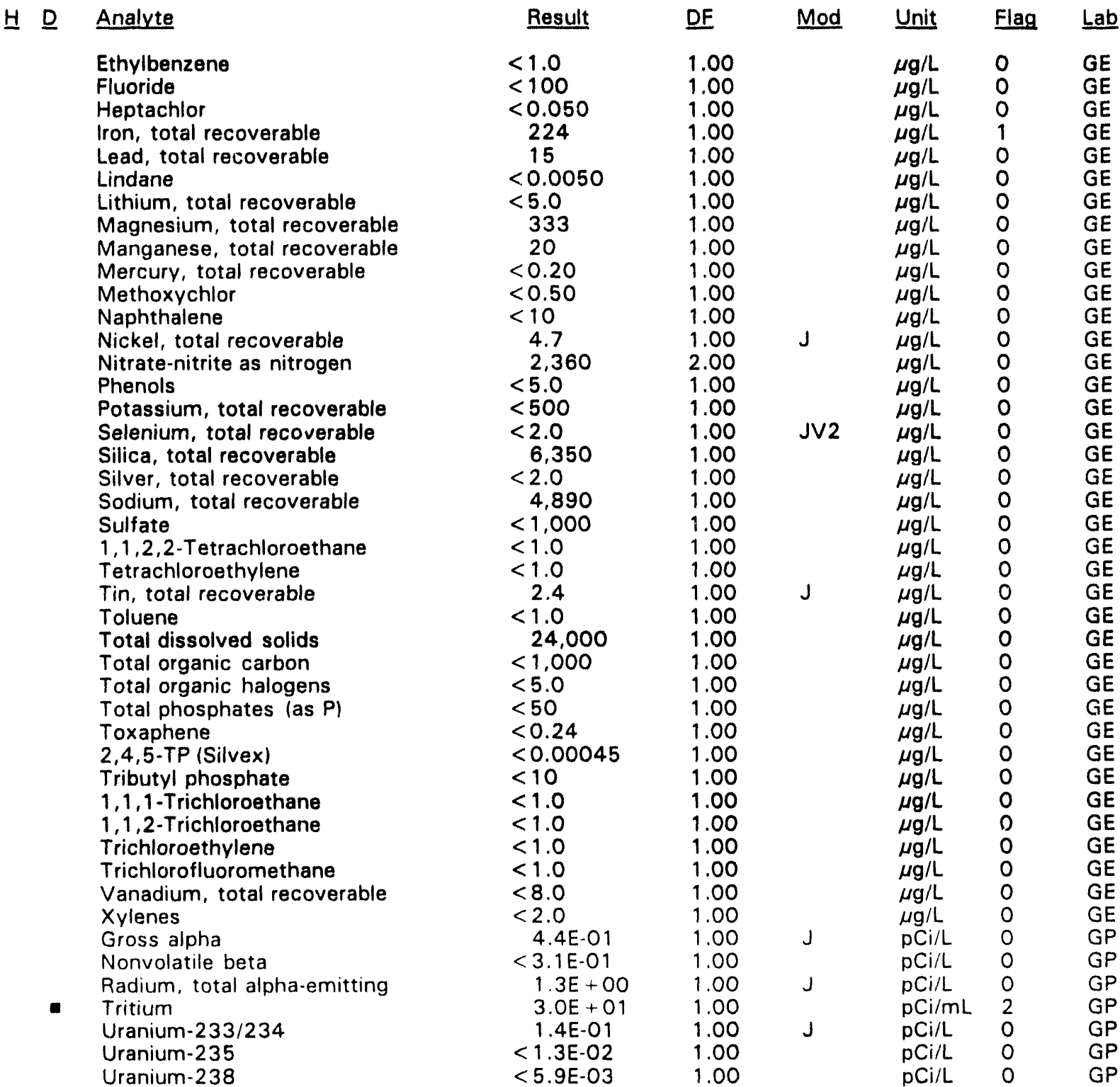

\footnotetext{
- = exceeded holding time. = exceeded screening level or final primary drinking water standard.
} 
WELL BGO 38D

\begin{tabular}{|c|c|c|c|c|c|c|}
\hline SRS Coord. & Lat/Longitude & Screen Zone Elevation & Top of Casing & Casing & Pump & Formation \\
\hline $\begin{array}{l}N 73329.3 \\
\text { E57557.5 }\end{array}$ & $\begin{array}{l}33.281868^{\circ} \mathrm{N} \\
81.657681^{\circ} \mathrm{W}\end{array}$ & $242.3-222.3 \mathrm{ft} \mathrm{msl}$ & $291.6 \mathrm{ft} \mathrm{msl}$ & 4" PVC & $\mathbf{S}$ & Water \\
\hline
\end{tabular}

\section{FIELD MEASUREMENTS}

Sample date: 02/01/94

Depth to water: $57.69 \mathrm{ft}(17.58 \mathrm{~m})$ below TOC

Water elevation: $233.91 \mathrm{ft}(71.30 \mathrm{~m}) \mathrm{msl}$

Sp. conductance: $32 \mu \mathrm{S} / \mathrm{cm}$

Turbidity: $26.0 \mathrm{NTU}$

Water evacuated before sampling: $8 \mathrm{gal}$

The well went dry during purging.

\section{LABORATORY ANALYSES}

H $\underline{\text { Analyte }}$

$\mathrm{pH}$

Specific conductance

Turbidity

Acetophenone

Aldrin

Aluminum, total recoverable

Antimony, total recoverable

Antimony, total recoverable

Arsenic, total recoverable

Arsenic, total recoverable

Barium, total recoverable

Benzene

Bromodichloromethane

Bromoform

Bromomethane (Methyl bromide)

Cadmium, total recoverable

Calcium, total recoverable

Carbon tetrachloride

Chloride

Chlorobenzene

Chloroethane

Chloroethene (Vinyl chloride)

2-Chloroethyl vinyl ether

Chloroform

Chloromethane (Methyl chloride)

Chromium, total recoverable

Copper, total recoverable

Cyanide

$p, p^{\prime}$-DDT

Dibromochloromethane

1,1-Dichloroethane

1,2-Dichloroethane

1,1-Dichloroethylene

trans-1,2-Dichloroethylene

Dichloromethane (Methylene chloride)

2,4-Dichlorophenoxyacetic acid

1,2-Dichloropropane

cis-1,3-Dichloropropene

trans-1,3-Dichloropropene

\section{Result}

4.8

27

64

$<10$

$<0.053$

336

$<2.0$

$<2.0$

$<2.0$

$<2.0$

15

$<1.0$

$<1.0$

$<1.0$

$<1.0$

$<2.0$

76

$<1.0$

1,360

$<1.0$

$<1.0$

$<1.0$

$<1.0$

$<1.0$

$<1.0$

$<4.0$

14

$<5.0$

$<0.11$

$<1.0$

$<1.0$

$<1.0$

$<1.0$

$<1.0$

$<1.0$

$<0.0015$

$<1.0$

$<1.0$

$<1.0$
Time: 12: 52

pH: 4.4

Alkalinity: $0 \mathrm{mg} / \mathrm{L}$

Water temperature: $16.3^{\circ} \mathrm{C}$

Volumes purged: 1.1 well volumes

\begin{tabular}{|c|c|c|c|}
\hline DF & Mod & Unit & Flag \\
\hline $\begin{array}{l}1.00 \\
1.00 \\
5.00 \\
1.00 \\
1.00 \\
1.00 \\
1.00 \\
1.00 \\
1.00 \\
1.00 \\
1.00 \\
1.00 \\
1.00 \\
1.00 \\
1.00 \\
1.00 \\
1.00 \\
1.00 \\
1.00 \\
1.00 \\
1.00 \\
1.00 \\
1.00 \\
1.00 \\
1.00 \\
1.00 \\
1.00 \\
1.00 \\
1.00 \\
1.00 \\
1.00 \\
1.00 \\
1.00 \\
1.00 \\
1.00 \\
1.00 \\
1.00 \\
1.00 \\
1.00\end{array}$ & J1 & $\begin{array}{l}\mathrm{pH} \\
\mu \mathrm{S} / \mathrm{lm} \\
\mathrm{NT} \\
\mu \mathrm{g} / \mathrm{L} \\
\mu \mathrm{g} / \mathrm{L} \\
\mu \mathrm{g} / \mathrm{L} \\
\mu \mathrm{g} / \mathrm{L} \\
\mu \mathrm{g} / \mathrm{L} \\
\mu \mathrm{g} / \mathrm{L} \\
\mu \mathrm{g} / \mathrm{L} \\
\mu \mathrm{g} / \mathrm{L} \\
\mu \mathrm{g} / \mathrm{L} \\
\mu \mathrm{g} / \mathrm{L} \\
\mu \mathrm{g} / \mathrm{L} \\
\mu \mathrm{g} / \mathrm{L} \\
\mu \mathrm{g} / \mathrm{L} \\
\mu \mathrm{g} / \mathrm{L} \\
\mu \mathrm{g} / \mathrm{L} \\
\mu \mathrm{g} / \mathrm{L} \\
\mu \mathrm{g} / \mathrm{L} \\
\mu \mathrm{g} / \mathrm{L} \\
\mu \mathrm{g} / \mathrm{L} \\
\mu \mathrm{g} / \mathrm{L} \\
\mu \mathrm{g} / \mathrm{L} \\
\mu \mathrm{g} / \mathrm{L} \\
\mu \mathrm{g} / \mathrm{L} \\
\mu \mathrm{g} / \mathrm{L} \\
\mu \mathrm{g} / \mathrm{L} \\
\mu \mathrm{g} / \mathrm{L} \\
\mu \mathrm{g} / \mathrm{L} \\
\mu \mathrm{g} / \mathrm{L} \\
\mu \mathrm{g} / \mathrm{L} \\
\mu \mathrm{g} / \mathrm{L} \\
\mu \mathrm{g} / \mathrm{L} \\
\mu \mathrm{g} / \mathrm{L} \\
\mu \mathrm{g} / \mathrm{L} \\
\mu \mathrm{g} / \mathrm{L} \\
\mu \mathrm{g} / \mathrm{L} \\
\mu \mathrm{g} / \mathrm{L}\end{array}$ & $\begin{array}{l}0 \\
0 \\
0 \\
0 \\
0 \\
2 \\
0 \\
0 \\
0 \\
0 \\
0 \\
0 \\
0 \\
0 \\
0 \\
0 \\
0 \\
0 \\
0 \\
0 \\
0 \\
0 \\
0 \\
0 \\
0 \\
0 \\
0 \\
0 \\
0 \\
0 \\
0 \\
0 \\
0 \\
0 \\
0 \\
0 \\
0 \\
0 \\
0\end{array}$ \\
\hline
\end{tabular}

$\overline{-}=$ exceeded holding time. $\boldsymbol{\square}=$ exceeded screening level or final primary drinking water standard. 
WELL BGO 38 D collected on $02 / 01 / 94$, laboratory analyses (cont.)

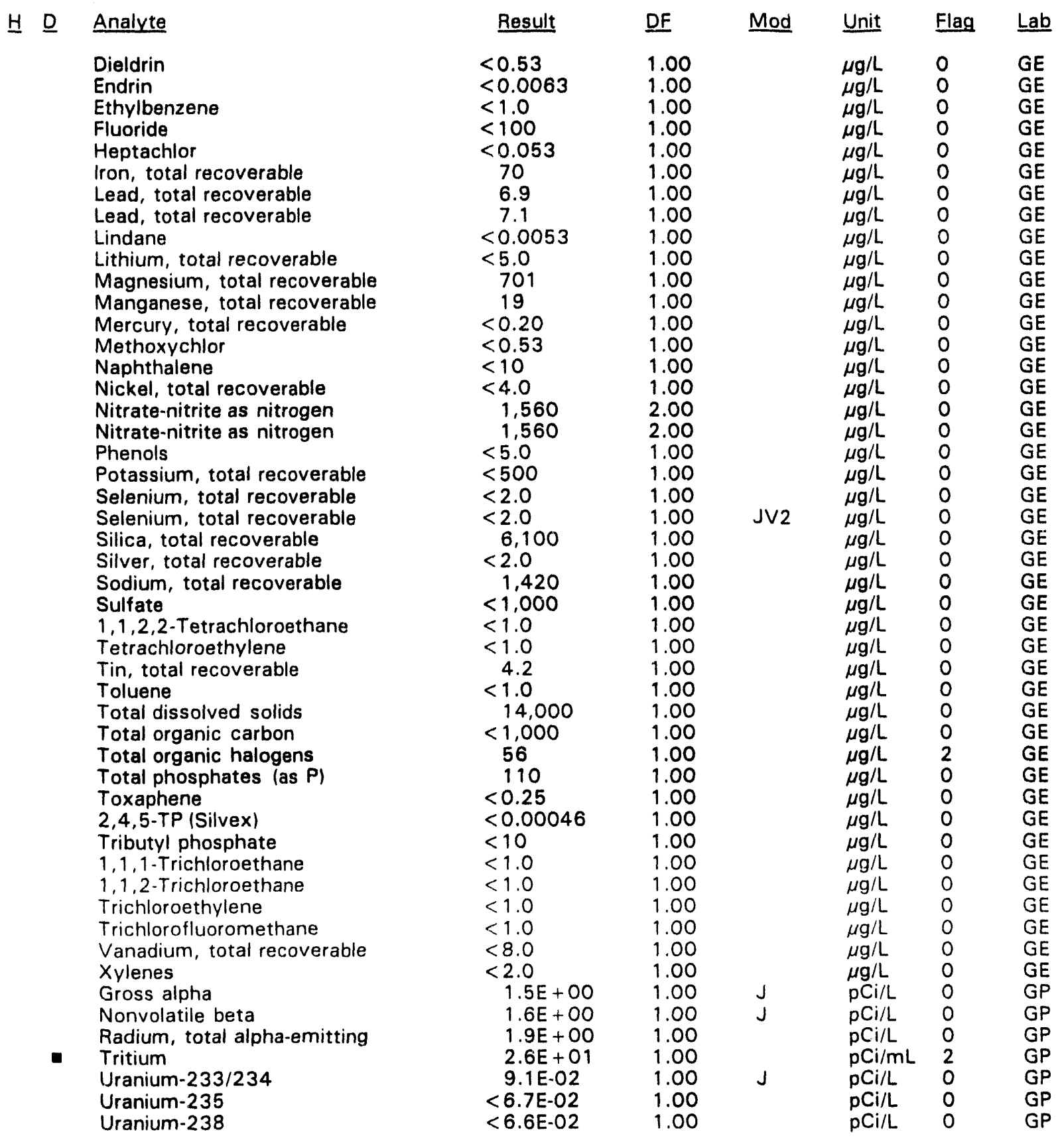

\footnotetext{
$\overline{-=\text { exceeded holding time. }}$ - = exceeded screening level or final primary drinking water standard.
} 
WSRC-TR-94-0240

Unclassified

WELL BGO 39D

\begin{tabular}{|c|c|c|c|c|c|c|}
\hline SRS Coord. & Lat/Longitude & Screen Zone Elevation & Top of Casing & Casing & Pump & Formation \\
\hline $\begin{array}{l}N 73583.5 \\
\text { E57831.0 }\end{array}$ & $\begin{array}{l}33.282876^{\circ} \mathrm{N} \\
81.657454^{\circ} \mathrm{W}\end{array}$ & $244.7-224.7 \mathrm{ft} \mathrm{msl}$ & $295.7 \mathrm{ft} \mathrm{msl}$ & 4" PVC & $\mathbf{S}$ & le $\left(\| B_{2}\right)$ \\
\hline
\end{tabular}

\section{FIELD MEASUREMENTS}

Sample date: 02/01/94

Depth to water: $60.95 \mathrm{ft}(18.58 \mathrm{~m})$ below TOC

Water elevation: $234.75 \mathrm{ft}(71.55 \mathrm{~m}) \mathrm{ms}$ !

Sp. conductance: $33 \mu \mathrm{S} / \mathrm{cm}$

Turbidity: 22.8 NTU

Water evacuated before sampling. $3 \mathrm{gal}$

The well went dry during purging.

\section{LABORATOFY ANALYSES}

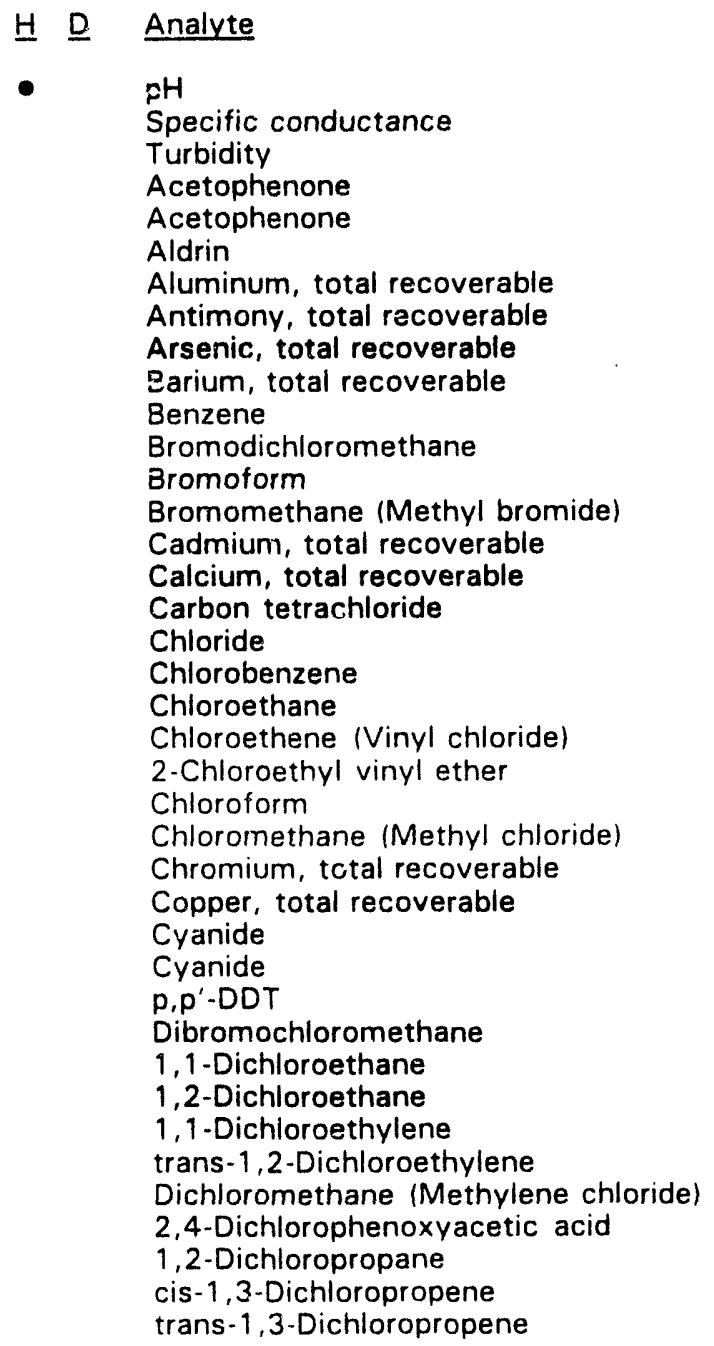

\begin{tabular}{|c|c|c|c|c|c|}
\hline Result & $\underline{D F}$ & Mod & Unit & Flag & $\underline{\mathrm{Lab}}$ \\
\hline 4.9 & 1.00 & J1 & $\mathrm{pH}$ & 0 & GE \\
\hline 29 & 1.00 & & $\mu \mathrm{S} / \mathrm{cm}$ & 0 & GE \\
\hline 19 & 1.00 & & NTU & 0 & GE \\
\hline$<10$ & 1.00 & & $\mu \mathrm{g} / \mathrm{L}$ & 0 & GE \\
\hline$<11$ & 1.00 & & $\mu \mathrm{g} / \mathrm{L}$ & 0 & GE \\
\hline$<0.053$ & 1.00 & & $\mu \mathrm{g} / \mathrm{L}$ & 0 & GE \\
\hline 121 & 1.00 & & $\mu \mathrm{g} / \mathrm{L}$ & 2 & GE \\
\hline$<2.0$ & 1.00 & & $\mu \mathrm{g} / \mathrm{L}$ & 0 & GE \\
\hline$<2.0$ & 1.00 & & $\mu \mathrm{g} / \mathrm{L}$ & 0 & GE \\
\hline 5.9 & 1.00 & & $\mu \mathrm{g} / \mathrm{L}$ & 0 & GE \\
\hline$<1.0$ & 1.00 & & $\mu \mathrm{g} / \mathrm{L}$ & 0 & GE \\
\hline$<1.0$ & 1.00 & & $\mu \mathrm{g} / \mathrm{L}$ & 0 & GE \\
\hline$<1.0$ & 1.00 & & $\mu \mathrm{g} / \mathrm{L}$ & 0 & GE \\
\hline$<1.0$ & 1.00 & & $\mu \mathrm{g} / \mathrm{L}$ & 0 & $\mathrm{GE}$ \\
\hline$<2.0$ & 1.00 & & $\mu \mathrm{g} / \mathrm{L}$ & 0 & GE \\
\hline $\begin{array}{r}55 \\
<10\end{array}$ & 1.00 & & $\mu \mathrm{g} / \mathrm{L}$ & 0 & GE \\
\hline $\begin{aligned}< & 1.0 \\
& 3.020\end{aligned}$ & 1.00 & & $\mu \mathrm{g} / \mathrm{L}$ & 0 & GE \\
\hline $\begin{aligned} & 3.020 \\
< & 1.0\end{aligned}$ & $\begin{array}{l}1.00 \\
1.00\end{array}$ & & $\mu \mathrm{g} / \mathrm{L}$ & 0 & GE \\
\hline $\begin{array}{l}<1.0 \\
<1.0\end{array}$ & $\begin{array}{l}1.00 \\
1.00\end{array}$ & & $\mu \mathrm{g} / \mathrm{L}$ & 0 & GE \\
\hline $\begin{array}{l}<1.0 \\
<1.0\end{array}$ & 1.00 & & $\mu \mathrm{g} / \mathrm{L}$ & 0 & GE \\
\hline $\begin{array}{l}<1.0 \\
<10\end{array}$ & 1.00 & & $\mu \mathrm{g} / \mathrm{L}$ & 0 & $\mathrm{GE}$ \\
\hline$<1.0$ & 1.00 & & $\mu \mathrm{g} / \mathrm{L}$ & 0 & GE \\
\hline$<1.0$ & 1.00 & & $\mu \mathrm{g} / \mathrm{L}$ & 0 & GE \\
\hline$<1.0$ & 1.00 & & $\mu \mathrm{g} / \mathrm{L}$ & 0 & $\mathrm{GE}$ \\
\hline$<4.0$ & 1.00 & & $\mu \mathrm{g} / \mathrm{L}$ & 0 & $\mathrm{GE}$ \\
\hline 10 & 1.00 & & $\mu \mathrm{g} / \mathrm{L}$ & 0 & $\mathrm{GE}$ \\
\hline$<5.0$ & 1.00 & & $\mu \mathrm{g} / \mathrm{L}$ & 0 & $\mathrm{GE}$ \\
\hline$<5.0$ & 1.00 & & $\mu \mathrm{g} / \mathrm{L}$ & 0 & GE \\
\hline$<0.11$ & 1.00 & & $\mu \mathrm{g} / \mathrm{L}$ & 0 & $\mathrm{GE}$ \\
\hline$<1.0$ & 1.00 & & $\mu \mathrm{g} / \mathrm{L}$ & 0 & GE \\
\hline$<1.0$ & 1.00 & & $\mu \mathrm{g} / \mathrm{L}$ & 0 & GE \\
\hline$<1.0$ & 1.00 & & $\mu \mathrm{g} / \mathrm{L}$ & 0 & GE \\
\hline$<1.0$ & 1.00 & & $\mu \mathrm{g} / \mathrm{L}$ & 0 & GE \\
\hline$<1.0$ & 1.00 & & $\mu \mathrm{g} / \mathrm{L}$ & 0 & $\mathrm{BE}$ \\
\hline$<1.0$ & 1.00 & & $\mu \mathrm{g} / \mathrm{L}$ & 0 & G \\
\hline$<0.0016$ & 1.00 & & $\mu \mathrm{g} / \mathrm{L}$ & 0 & G \\
\hline$<1.0$ & 1.00 & & $\mu \mathrm{g} / \mathrm{L}$ & 0 & $\mathrm{GE}$ \\
\hline$<1.0$ & 1.00 & & $\mu \mathrm{g} / \mathrm{L}$ & 0 & GE \\
\hline$<1.0$ & 1.00 & & $\mu \mathrm{g} / \mathrm{L}$ & 0 & $E$ \\
\hline
\end{tabular}

Time: $12: 36$

pH: 4.5

Aikalinity: $0 \mathrm{mg} / \mathrm{L}$

Water temperature: $10.6^{\circ} \mathrm{C}$

Volumes purged: 0.5 well volumes 
WELL BGO 39D collected on 02/01/94, laboratory analyses (cont.)

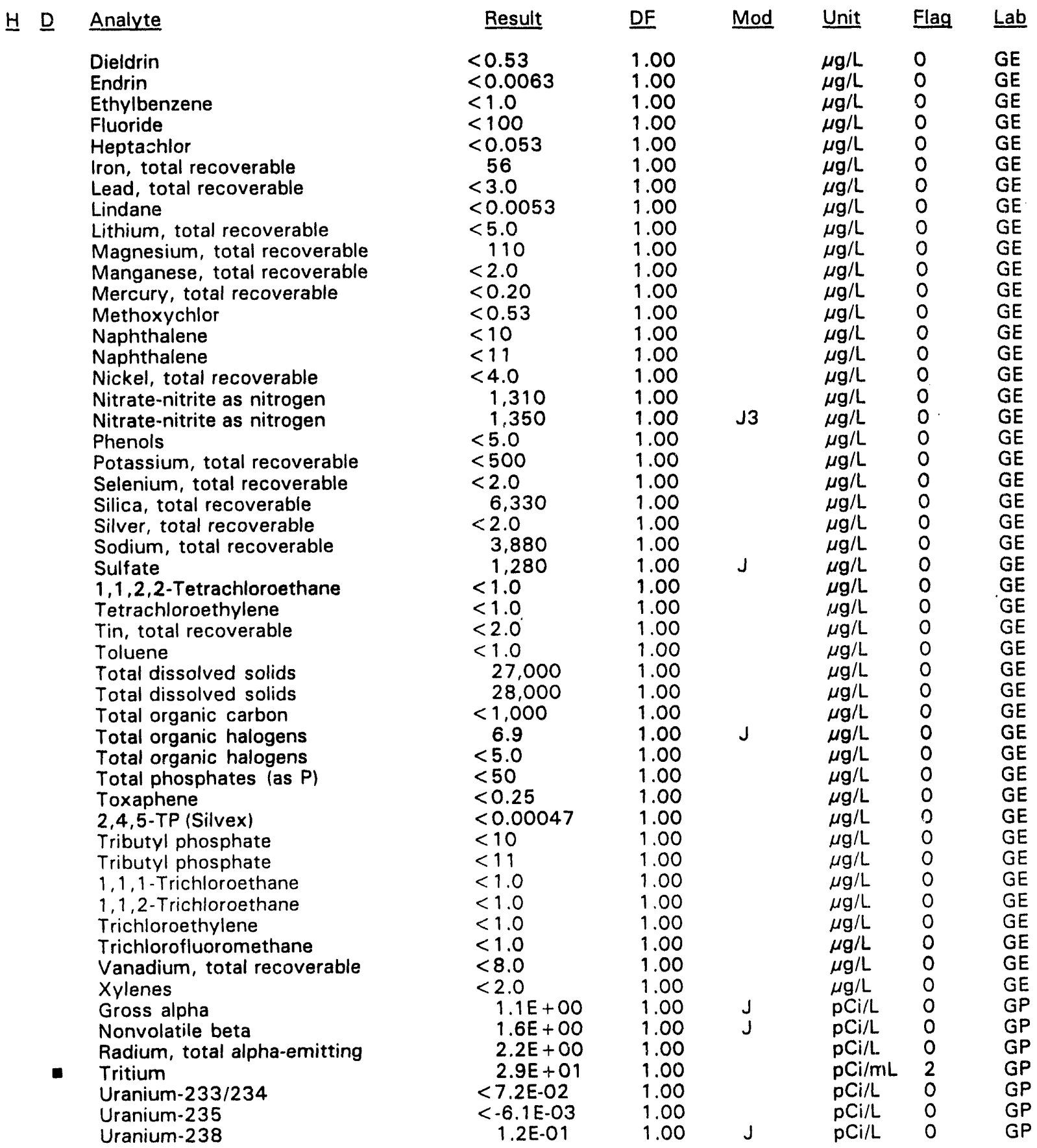

- = exceeded holding time. $\|$ exceeded screening level or final primary drinking water standard. 
WSRC-TR-94-0240

Unclassified

WELL BGO 40D

\begin{tabular}{|c|c|c|c|c|c|c|}
\hline SRS Coord. & Lat/Longitude & Screen Zone Elevation & Top of Casing & Casing & Pump & Formation \\
\hline $\begin{array}{l}N 76125.8 \\
E 54638.6\end{array}$ & $\begin{array}{l}33.283290^{\circ} \mathrm{N} \\
81.670799^{\circ} \mathrm{W}\end{array}$ & $226.5-216.6 \mathrm{ft} \mathrm{msl}$ & $288.4 \mathrm{ft} \mathrm{msl}$ & 4" PVC & $\mathbf{S}$ & ble $\left(\| B_{2}\right)$ \\
\hline
\end{tabular}

\section{FIELD MEASUREMENTS}

Sample date: $01 / 27 / 94$

Depth to water: $65.46 \mathrm{ft}(19.95 \mathrm{~m})$ below TOC

Water elevation: $222.94 \mathrm{ft}(67.95 \mathrm{~m}) \mathrm{msl}$

Sp. conductance: $302 \mu \mathrm{S} / \mathrm{cm}$

Turbidity: 8.8 NTU

Water evacuated before sampling: 2 gal

The well went dry during purging.

\section{LABORATORY ANALYSES}

H D Analyt

$\mathrm{pH}$

Specific conductance

Turbidity

Acetophenone

Aldrin

Aluminum, total recoverable

Antimony, total recoverable

Arsenic, total recoverable

Barium, total recoverable

Benzene

Bromodichloromethane

Bromoform

Bromomethane (Methyl bromide)

Cadmium, total recoverable

Calcium, total recoverable

Carbon tetrachloride

Chloride

Chloride

Chlorobenzene

Chloroethane

Chloroethene (Vinyl chloride)

2-Chloroethyl vinyl ether

Chloroform

Chloromethane (Methyl chloride)

Chromium, total recoverable

Copper, total recoverable

Cyanide

Cyanide

$p, p^{\prime}-D D T$

Dibromochloromethane

1,1-Dichloroethane

1,2-Dichloroethane

1,1-Dichloroethylene

trans-1,2-Dichloroethylene

Dichloromethane (Methylene chloride)

2,4-Dichlorophenoxyacetic acid

1,2-Dichloropropane

cis-1,3-Dichloropropene

trans-1,3-Dichloropropene
Time: 12: 21

$\mathrm{pH}: 7.0$

Alkalinity: $125 \mathrm{mg} / \mathrm{L}$

Water temperature: $17.1^{\circ} \mathrm{C}$

Volumes purged: 0.5 well volumes

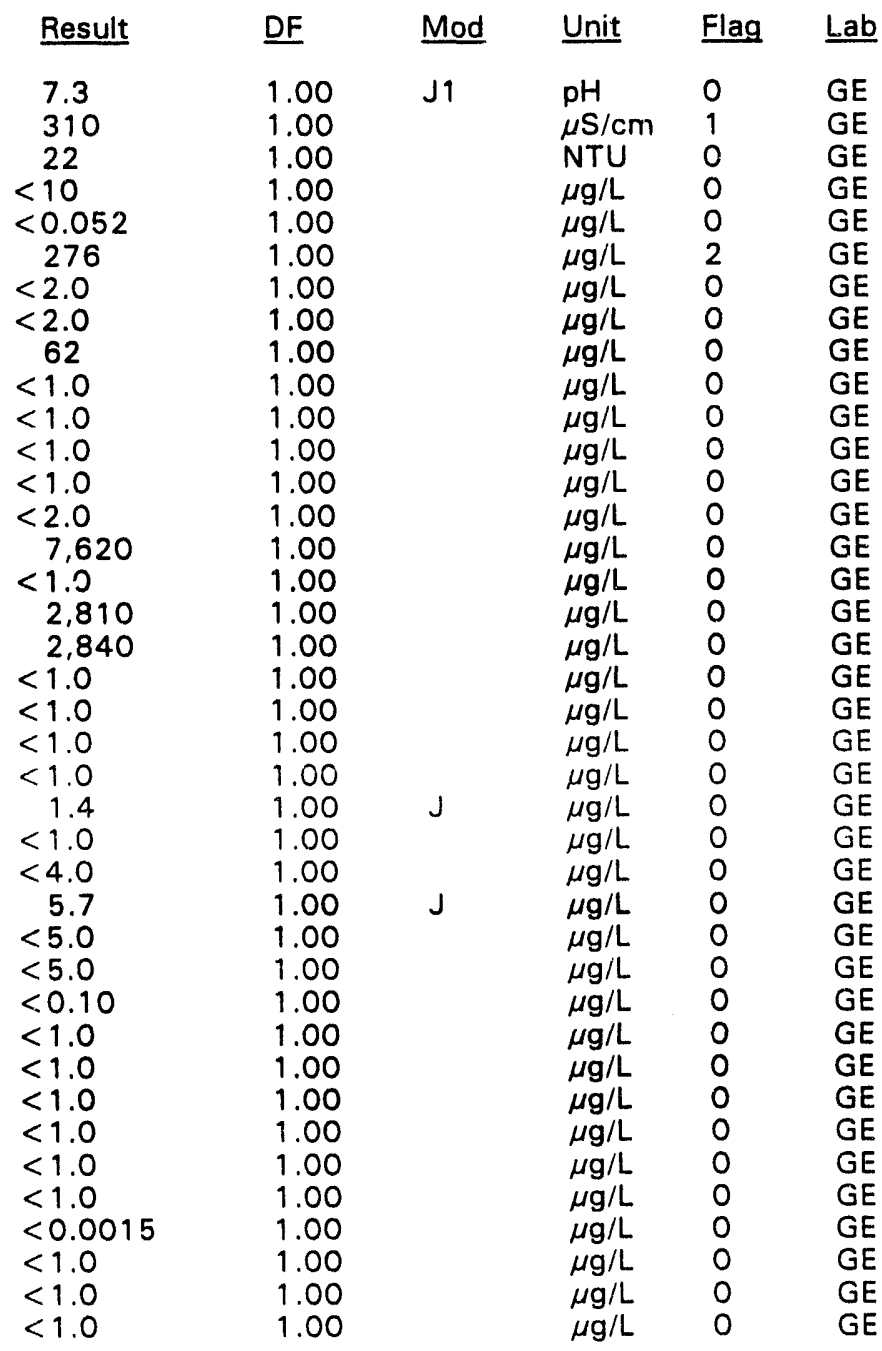

$\overline{-}$ = exceeded holding time. $=$ exceeded screening level or final primary drinking water standard. 
WELL BGO $40 D$ collected on $01 / 27 / 94$, laboratory analyses (cont.)

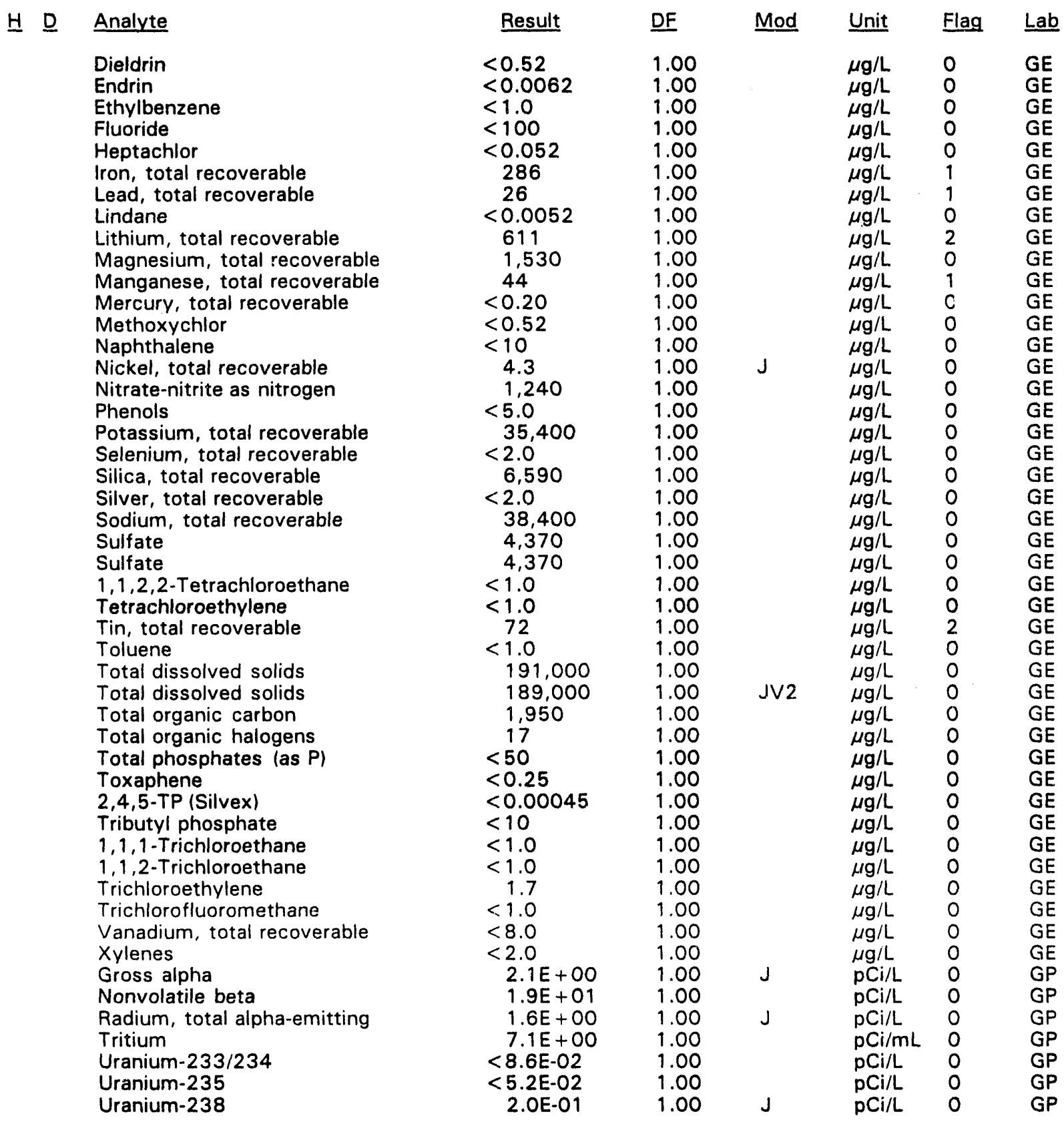

$\overline{-=\text { exceeded holding time. }}$ = exceeded screening level or final primary drinking water standard. 
WELL BGO 42C

\begin{tabular}{|c|c|c|c|c|c|c|}
\hline SRS Coord. & Lat/Longitude & Screen Zone Elevation & Top of Casing & Casing & Pump & Formation \\
\hline $\begin{array}{l}\text { N76404.7 } \\
\text { E55522.3 }\end{array}$ & $\begin{array}{l}33.285349^{\circ} \mathrm{N} \\
81.669014^{\circ} \mathrm{W}\end{array}$ & $195.9-185.9 \mathrm{ft} \mathrm{msl}$ & $297.9 \mathrm{ft} \mathrm{msl}$ & 4" PVC & $\mathbf{S}$ & ell $\left(I I B_{1}\right)$ \\
\hline
\end{tabular}

\section{FIELD MEASUREMENTS}

Sample date: $01 / 27 / 94$

Depth to water: $74.14 \mathrm{ft}(22.60 \mathrm{~m})$ below TOC

Water elevation: $223.76 \mathrm{ft}(68.20 \mathrm{~m}) \mathrm{ms}$ l

Sp. conductance: $48 \mu \mathrm{S} / \mathrm{cm}$

Turbidity: 18.0 NTU

Water evacuated before sampling: $16 \mathrm{gal}$

The well went dry during purging.

\section{LABORATORY ANALYSES}

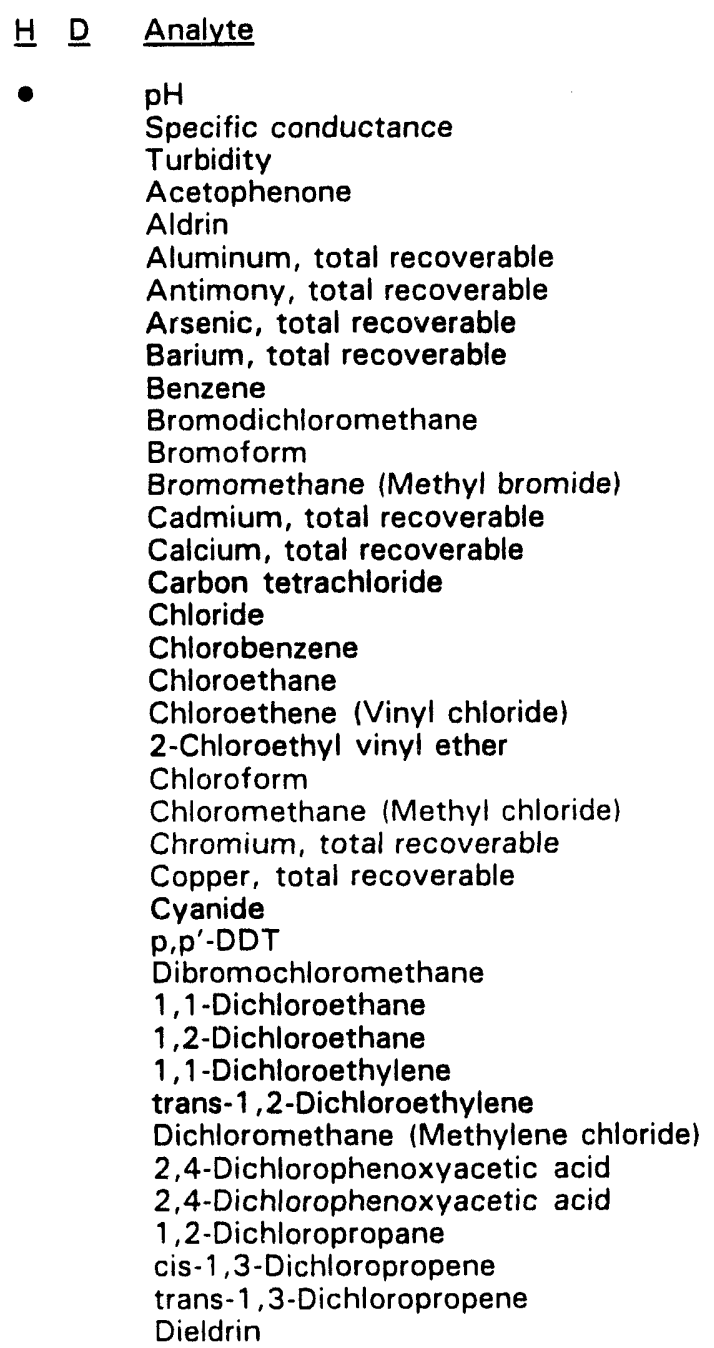

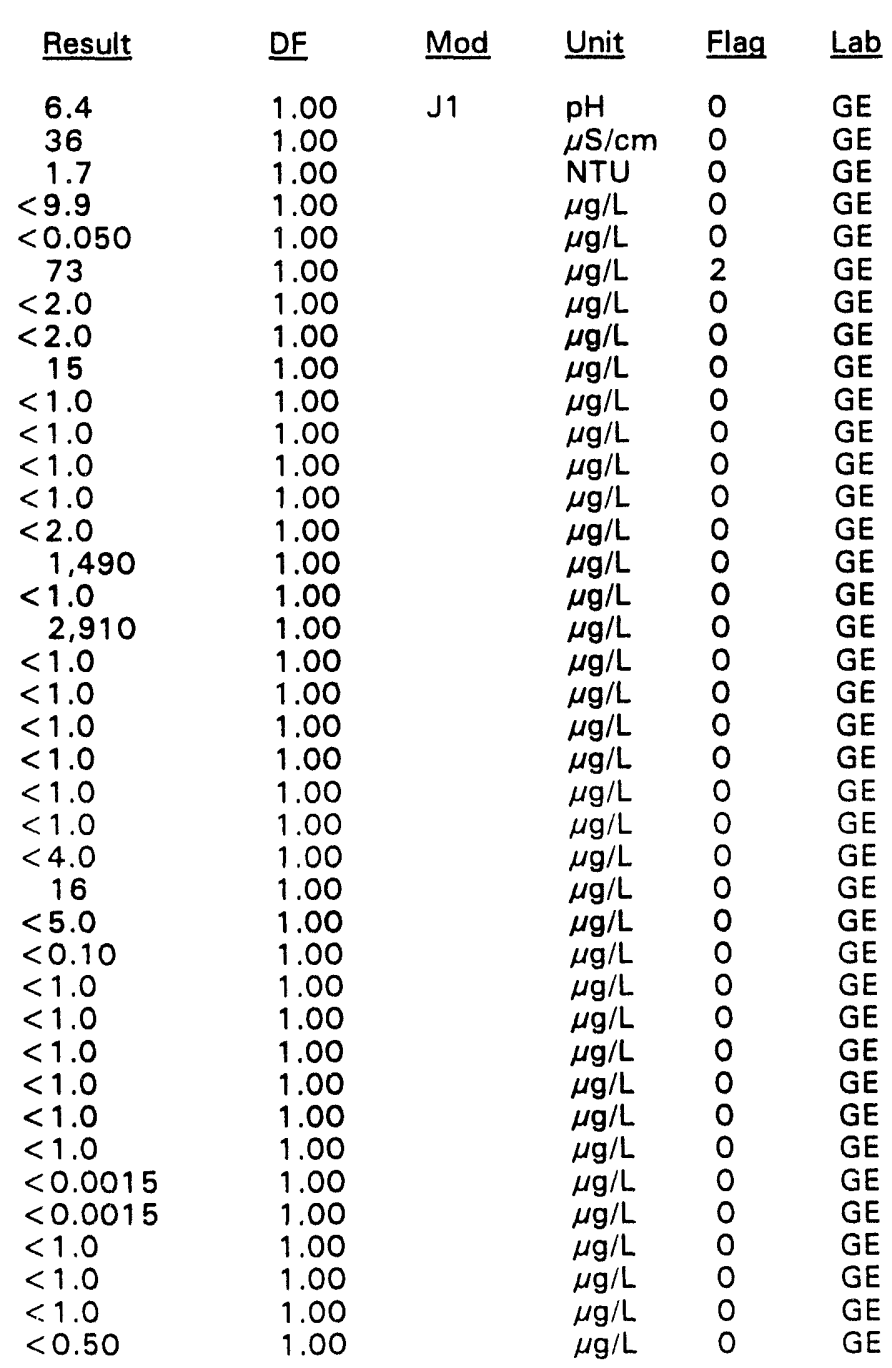

Time: 9: 07

$\mathrm{pH}: 5.9$

Alkalinity: $11 \mathrm{mg} / \mathrm{L}$

Water temperature: $16.9^{\circ} \mathrm{C}$

Volumes purged: 0.6 well volumes

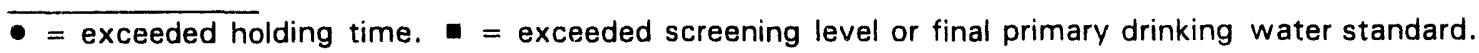


WELL BGO $42 \mathrm{C}$ collected on $01 / 27 / 94$, laboratory analyses (cont.)

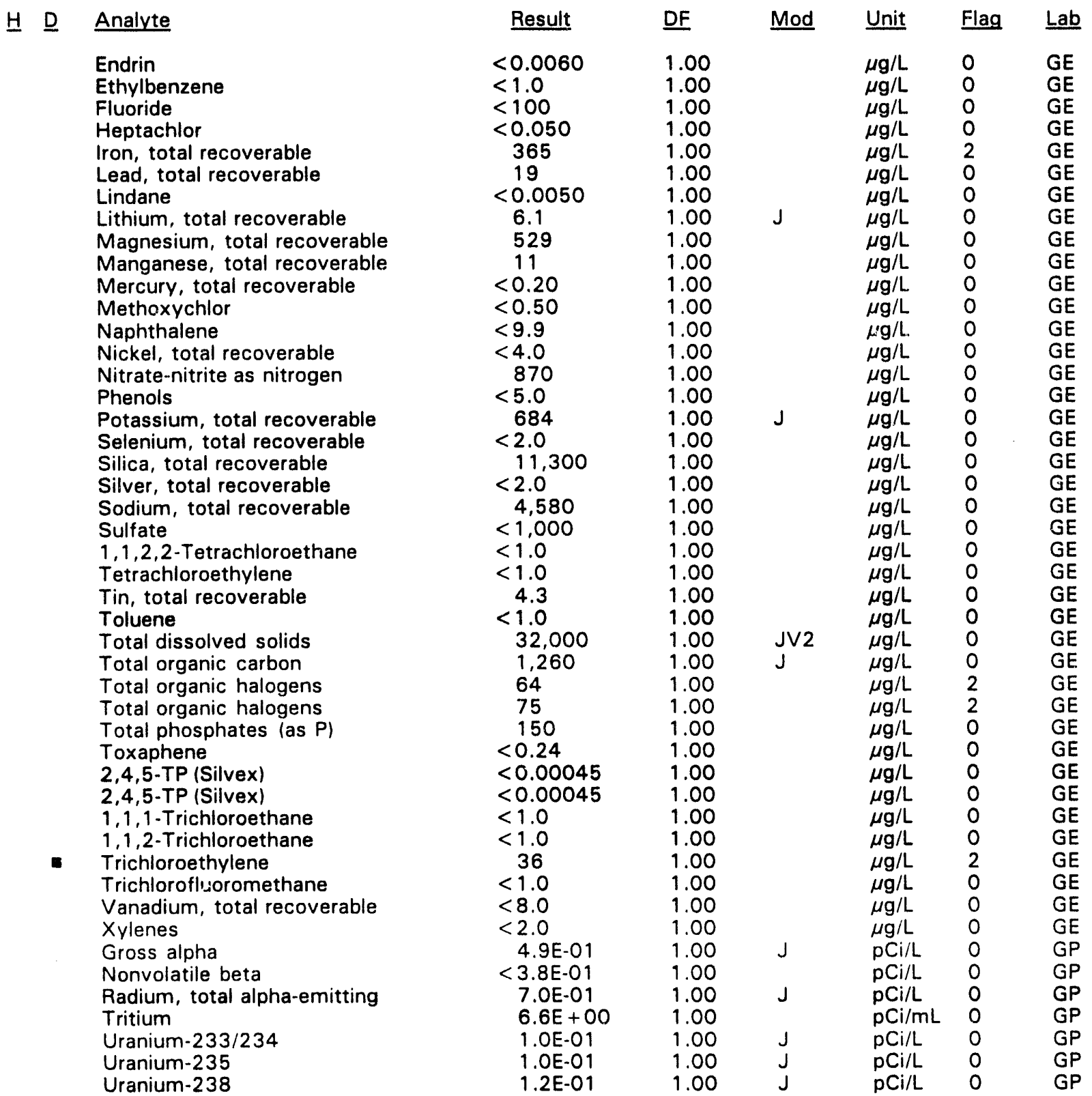

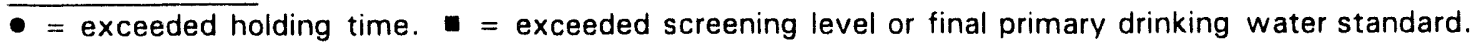


WELL BGO 43AA

\begin{tabular}{|c|c|c|c|c|c|c|}
\hline SRS Coord. & Lat/Longitude & Screen Zone Elevation & Top of Casing & Casing & Pump & Formation \\
\hline $\begin{array}{l}N 77066.0 \\
E 56268.6\end{array}$ & $\begin{array}{l}33.288029^{\circ} \mathrm{N} \\
81.668333^{\circ} \mathrm{W}\end{array}$ & $72.2-62.2$ & msl & VC & $\mathbf{S}$ & ee (IIA) \\
\hline
\end{tabular}

\section{FIELD MEASUREMENTS}

Sample date: $01 / 26 / 94$

Depth to water: $158.16 \mathrm{ft}(48.21 \mathrm{~m})$ below TOC

Water elevation: $156.14 \mathrm{ft}(47.59 \mathrm{~m}) \mathrm{msl}$

Sp. conductance: $205 \mu \mathrm{S} / \mathrm{cm}$

Turbidity: 0.6 NTU

Water evacuated before sampling: $258 \mathrm{gal}$

Time: $15: 39$

$\mathrm{pH}: 9.1$

Alkalinity: $78 \mathrm{mg} / \mathrm{L}$

Water temperature: $19.5^{\circ} \mathrm{C}$

Volumes purged: 4.2 well volumes

\section{LABORATORY ANALYSES}

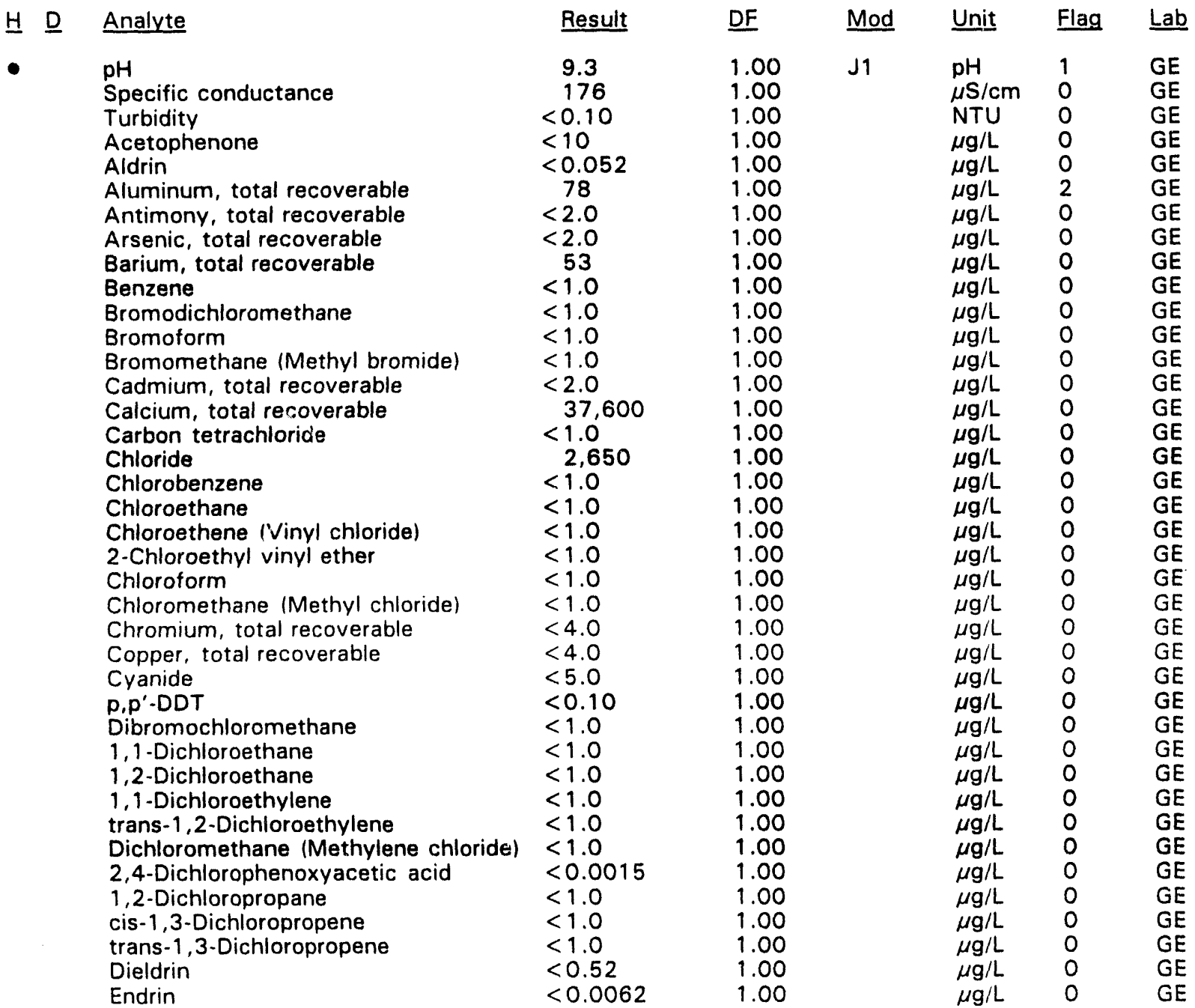

\footnotetext{
$\overline{-}=$ exceeded holding time. $=$ exceeded screening level or final primary drinking water standard.
} 
WELL BGO 43AA collected on 01/26/94, laboratory analyses (cont.)

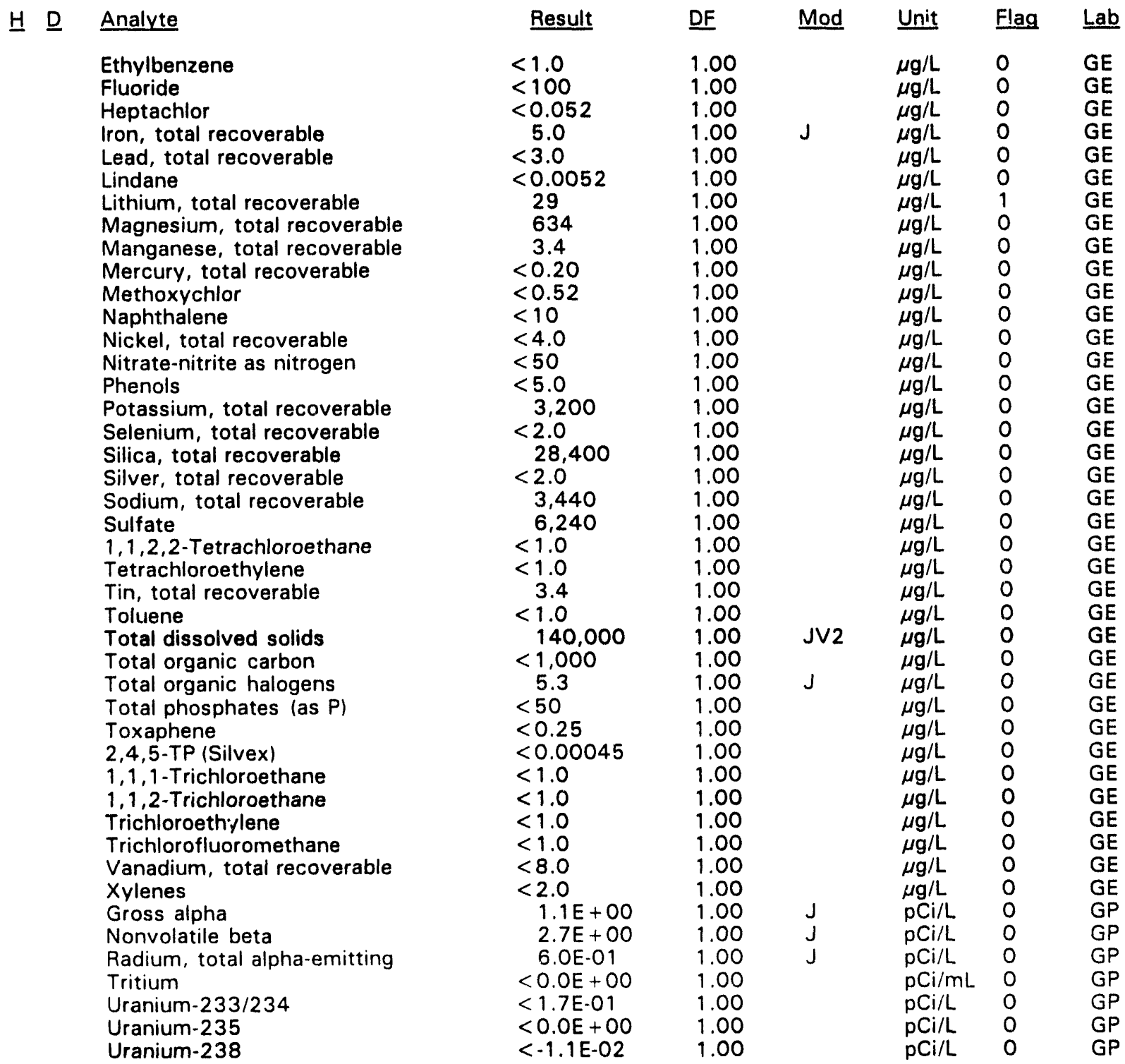

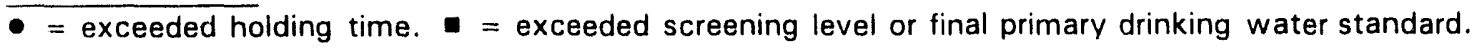




\section{WELL. BGO 43CR}

\begin{tabular}{|c|c|c|c|c|c|c|}
\hline SRS Coord. & Lat/Longitude & Screen Zone Elevation & Top of Casing & Casing & Pump & Formation \\
\hline $\begin{array}{l}\text { N77035.2 } \\
\text { E56237.2 }\end{array}$ & $\begin{array}{l}33.287910^{\circ} \mathrm{N} \\
81.668356^{\circ} \mathrm{W}\end{array}$ & $188.4-178.4 \mathrm{ft} \mathrm{msl}$ & $315.3 \mathrm{ft} \mathrm{msl}$ & 4" PVC & s & $\mid\left(|| B_{1}\right)$ \\
\hline
\end{tabular}

\section{FIELD MEASUREMENTS}

Sample date: 01/27/94

Depth to water: $89.33 \mathrm{ft}(27.23 \mathrm{~m})$ below TOC Water elevation: $225.97 \mathrm{ft}(68.88 \mathrm{~m}) \mathrm{rns}$

Sp. conductance: $115 \mu \mathrm{S} / \mathrm{cm}$

Turbidity: 11.4 NTU

Water evacuated before sampling: $21 \mathrm{gal}$

The well went dry during purging.

\section{LABORATORY ANALYSES}

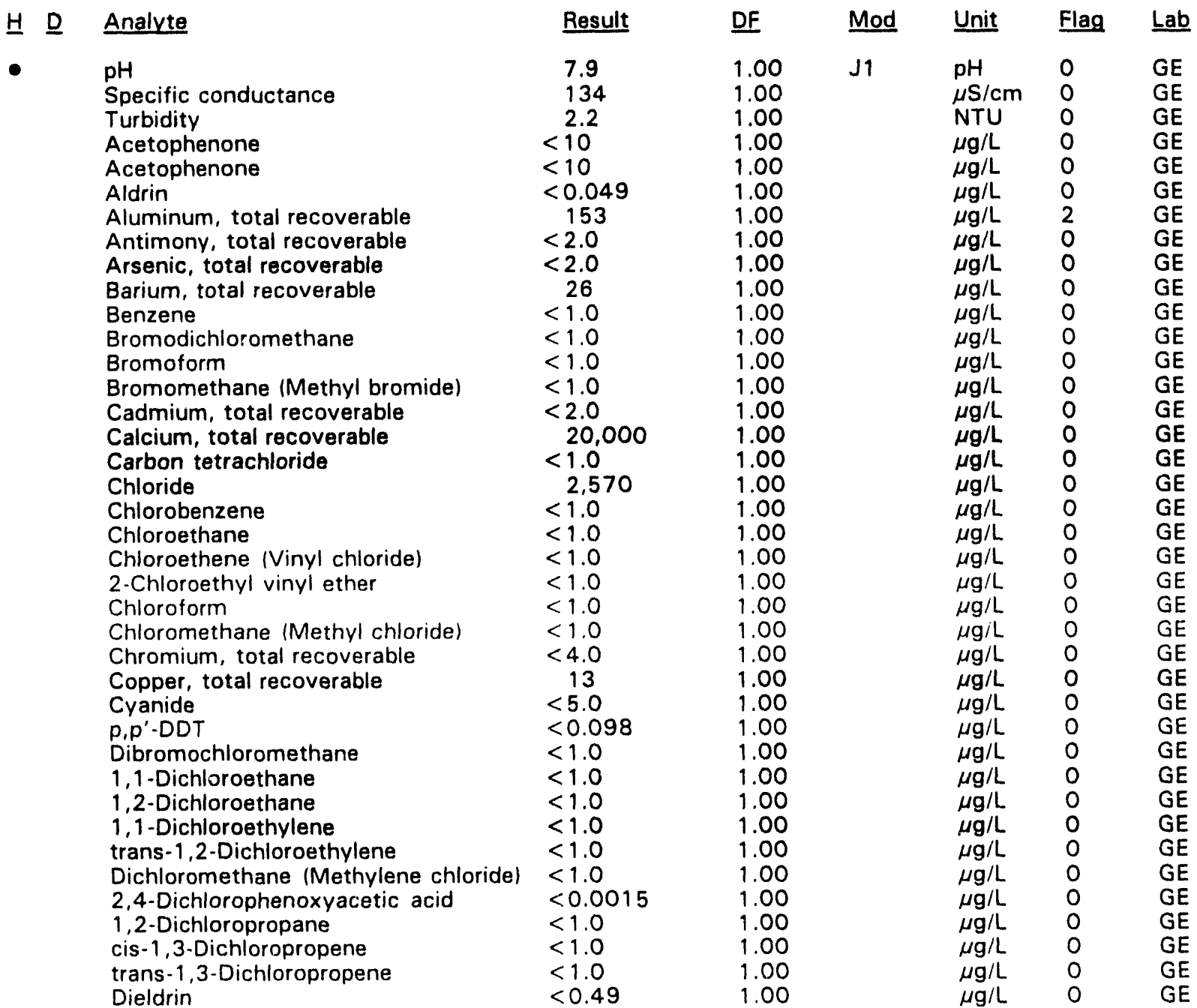

\footnotetext{
- exceeded holding time. = exceeded screening level or final primary drinking water standard.
}

$\mathrm{pH}: 8.3$

Alkalinity: $33 \mathrm{mg} / \mathrm{L}$

Water temperature: $17.0^{\circ} \mathrm{C}$

Volumes purged: 0.7 well volumes 
WELL BGO 43CR collected on 01/27/94, laboratory analyses (cont.)

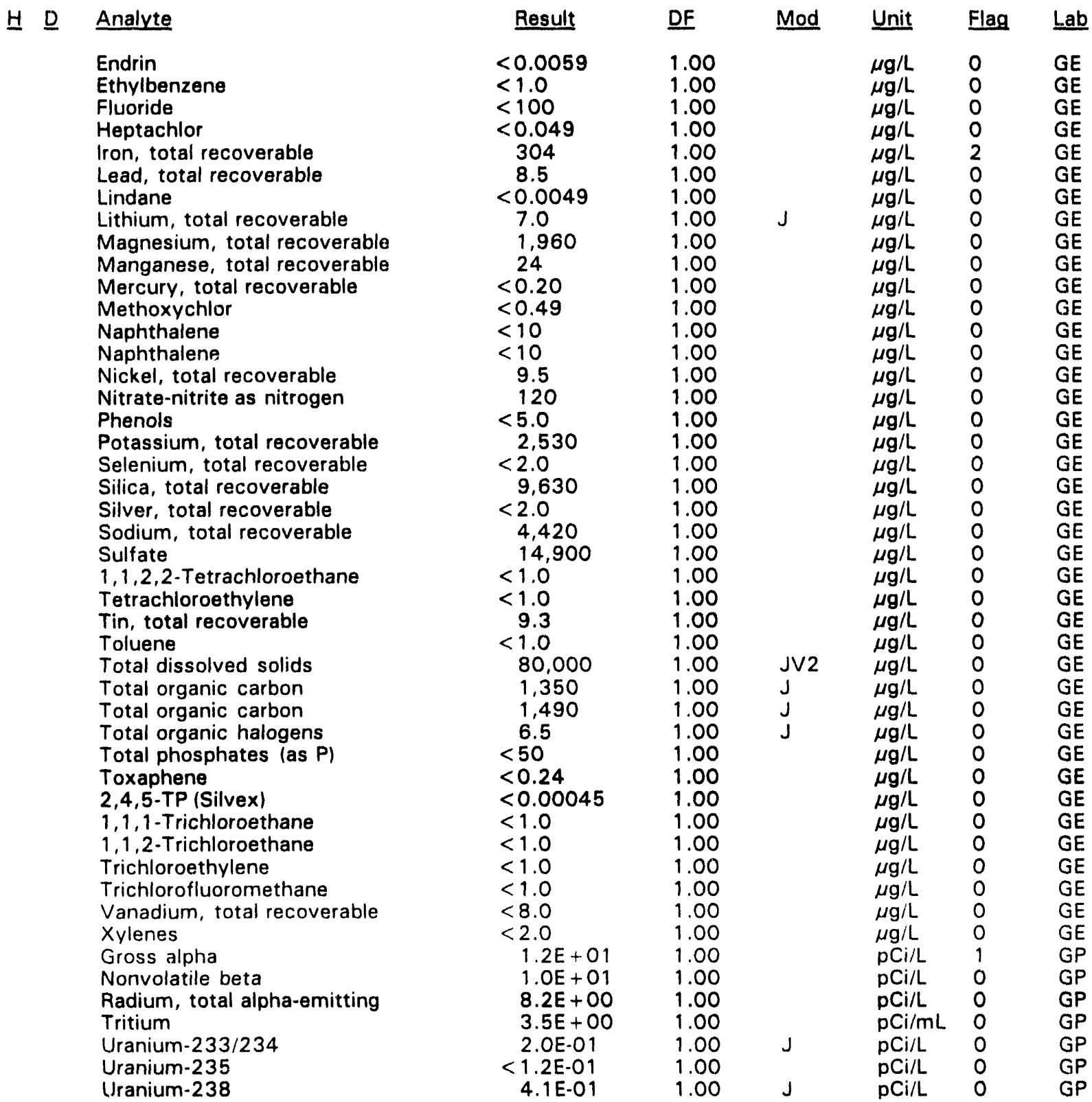

- = exceeded holding time. = exceeded screening level or final primary drinking water standard. 


\section{WELL BGO 43D}

\begin{tabular}{|c|c|c|c|c|c|c|}
\hline SRS Coord. & Lat/Longitude & Screen Zone Elevation & Top of Casing & Casing & Pump & Formation \\
\hline $\begin{array}{l}N 77056.7 \\
E 56238.8\end{array}$ & $\begin{array}{l}33.287960^{\circ} \mathrm{N} \\
81.668394^{\circ} \mathrm{W}\end{array}$ & $208.2-198.2 \mathrm{ft} \mathrm{msl}$ & $315.3 \mathrm{ft} \mathrm{msl}$ & 4" PVC & $\mathbf{s}$ & (II $\left(I B_{1}\right)$ \\
\hline
\end{tabular}

\section{FIELD MEASUREMENTS}

Sample date: 01/26/94

Depth to water: $83.10 \mathrm{ft}(25.33 \mathrm{~m})$ below TOC

Water elevation: $232.20 \mathrm{ft}(70.78 \mathrm{~m}) \mathrm{msl}$

Sp. conductance: $62 \mu \mathrm{S} / \mathrm{cm}$

Turbidity: 0.6 NTU

Water evacuated before sampling: $125 \mathrm{gal}$

\section{LABORATORY ANALYSES}

-. Analyte
pH
Specific conductance
Turbidity
Acetophenone
Aldrin
Aluminum, total recoverable
Antimony, total recoverable
Arsenic, total recoverable
Barium, total recoverable
Benzene
Bromodichloromethane
Bromoform
Bromomethane (Methyl brornide)
Cadmium, total recoverable
Calcium, total recoverable
Carbon tetrachloride
Chloride
Chlorobenzene
Chloroethane
Chloroethene (Vinyl chloride)
2-Chloroethyl vinyl ether
Chloroform
Chloromethane (Methyl chloride)
Chromium, total recoverable
Copper, total recoverable
Cyanide
p,p'-DDT
Dibromochloromethane
1,1-Dichloroethane
1,2-Dichloroethane
$1,1-$ Dichloroethylene
trans-1,2-Dichloroethylene
Dichloromethane (Methylene chloride)
2,4-Dichlorophenoxyacetic acid
$1,2-$ Dichloropropane
cis-1,3-Dichloropropene
trans-1,3-Dichloropropene
Dieldrin
Endrin

Time: 15: 14

$\mathrm{pH}: 5.1$

Alkalinity: $1 \mathrm{mg} / \mathrm{L}$

Water temperature: $18.9^{\circ} \mathrm{C}$

Volumes purged: 5.6 well volumes

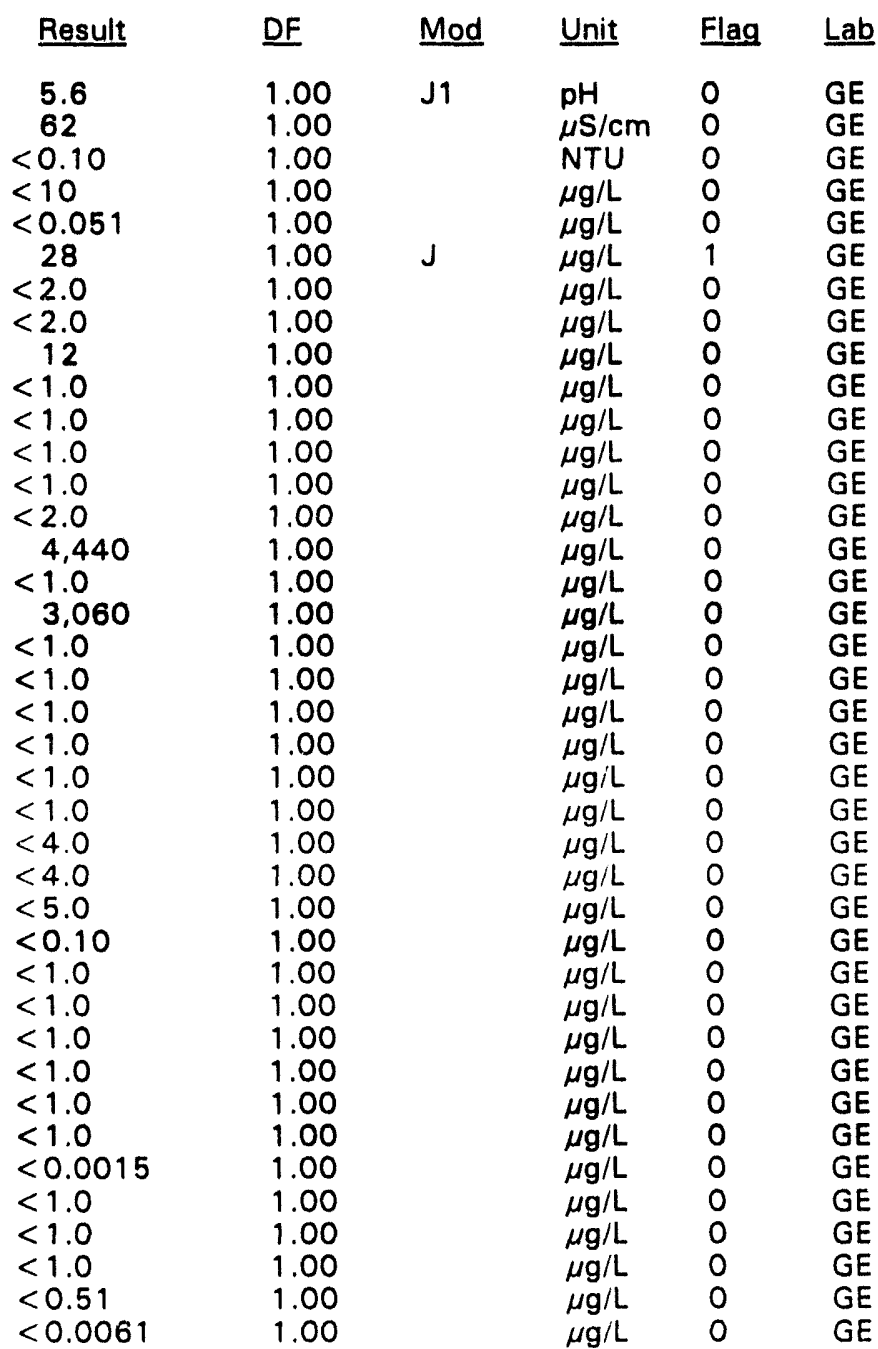

\footnotetext{
$\overline{- \text { = exceeded holding time. }}$ = exceeded screening level or final primary drinking water standard.
} 
WELL BGO 43D collected on 01/26/94, laboratory analyses (cont.)

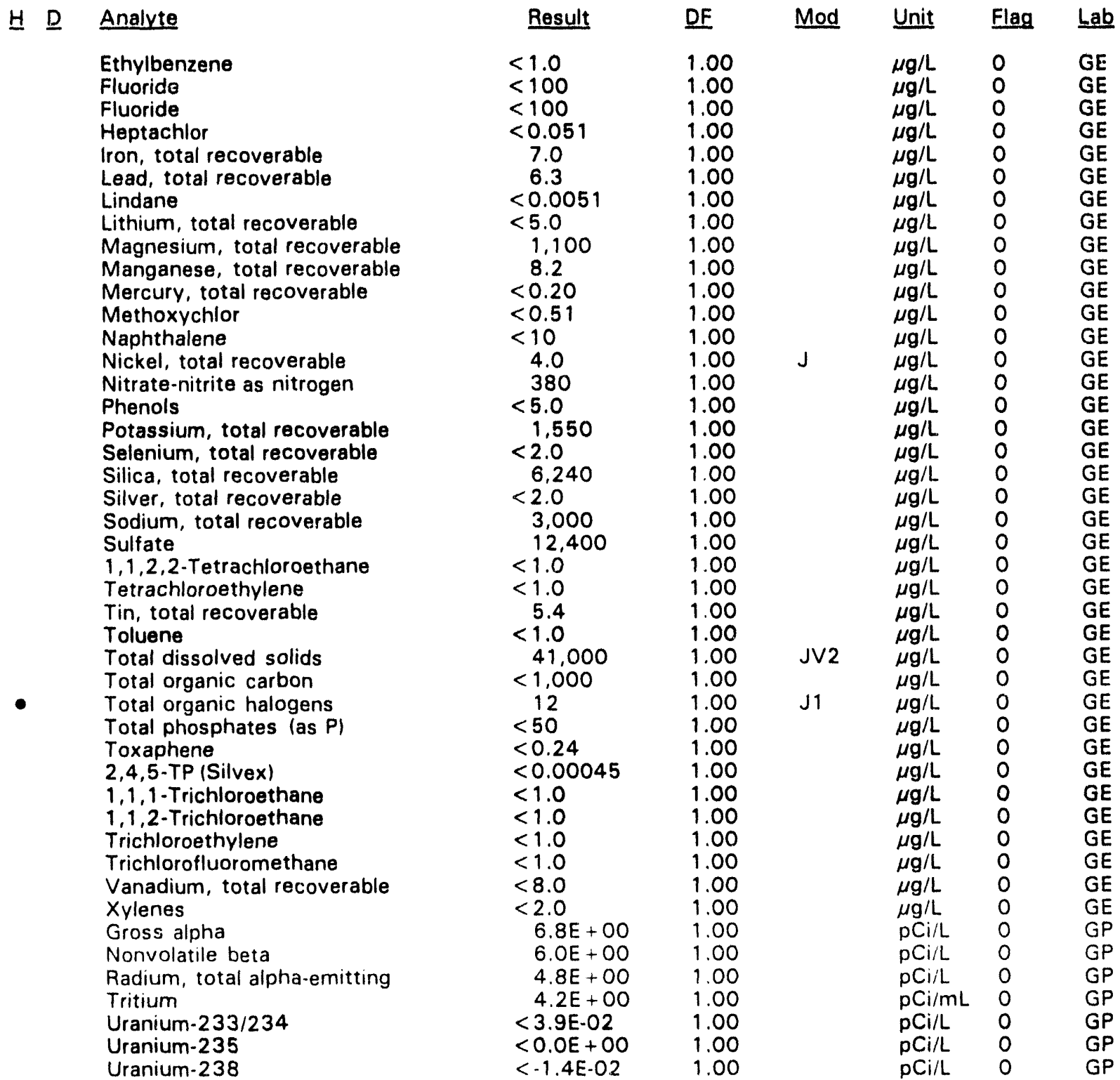

- = exceeded holding time. $\square=$ exceeded screening level or final primary drinking water standard. 


\section{WELL BGO 44A}

\begin{tabular}{|c|c|c|c|c|c|c|}
\hline SRS Coord. & Lat/Longitude & Screen Zone Elevation & Top of Casing & Casing & Pump & Formation \\
\hline $\begin{array}{l}N 76755.2 \\
E 57851.2\end{array}$ & $\begin{array}{l}33.289924^{\circ} \mathrm{N} \\
81.663562^{\circ} \mathrm{W}\end{array}$ & $108.0-98.0 \mathrm{ft} \mathrm{msl}$ & $285.3 \mathrm{ft} \mathrm{msl}$ & 4" PVC & $\mathbf{S}$ & U. Congaree (IIA) \\
\hline
\end{tabular}

\section{FIELD MEASUREMENTS}

Sample date: $01 / 28 / 94$

Depth to water: $127.09 \mathrm{ft}(38.74 \mathrm{~m})$ below TOC

Water elevation: $158.21 \mathrm{ft}(48.22 \mathrm{~m}) \mathrm{ms}$

Sp. conductance: $192 \mu \mathrm{S} / \mathrm{cm}$

Turbidity: 0.4 NTU

Water evacuated before sampling: $174 \mathrm{gal}$

\section{LABORATORY ANALYSES}

\begin{tabular}{|c|}
\hline $\begin{array}{l}\text { Analyte } \\
\text { pH } \\
\text { Specific conductance } \\
\text { Turbidity } \\
\text { Acetophenone } \\
\text { Aldrin } \\
\text { Aluminum, total recoverable } \\
\text { Antimony, total recoverable } \\
\text { Arsenic, total recoverable } \\
\text { Barium, total recoverable } \\
\text { Benzene } \\
\text { Bromodichloromethane } \\
\text { Bromoform } \\
\text { Bromomethane (Methyl bromide) } \\
\text { Cadmium, total recoverable } \\
\text { Calcium, total recoverable } \\
\text { Carbon tetrachloride } \\
\text { Chloride } \\
\text { Chlorobenzene } \\
\text { Chloroethane } \\
\text { Chloroethene (Vinyl chloride) } \\
2 \text {-Chloroethyl vinyl ether } \\
\text { Chloroform } \\
\text { Chloromethane (Methyl chloride) } \\
\text { Chromium, total recoverable } \\
\text { Copper, total recoverable } \\
\text { Cyanide } \\
\text { p,p'-DDT } \\
\text { Dibromochloromethane } \\
1,1 \text {-Dichloroethane } \\
1,2-\text { Dichloroethane } \\
1,1 \text {-Dichloroethylene } \\
\text { trans-1,2-Dichloroethylene } \\
\text { Dichloromethane (Methylene chloride) } \\
2,4-\text { Dichlorophenoxyacetic acid } \\
1,2-\text { Dichloropropane } \\
\text { cis-1,3-Dichloropropene } \\
\text { trans-i,3-Dichloropropene } \\
\text { Dieldrin } \\
\text { Endrin }\end{array}$ \\
\hline
\end{tabular}

\begin{tabular}{|c|c|c|c|}
\hline Result & DF & Mod & Unit \\
\hline 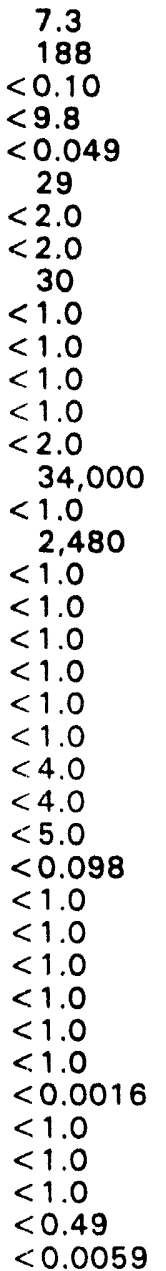 & $\begin{array}{l}1.00 \\
1.00 \\
1.00 \\
1.00 \\
1.00 \\
1.00 \\
1.00 \\
1.00 \\
1.00 \\
1.00 \\
1.00 \\
1.00 \\
1.00 \\
1.00 \\
1.00 \\
1.00 \\
1.00 \\
1.00 \\
1.00 \\
1.00 \\
1.00 \\
1.00 \\
1.00 \\
1.00 \\
1.00 \\
1.00 \\
1.00 \\
1.00 \\
1.00 \\
1.00 \\
1.00 \\
1.00 \\
1.00 \\
1.00 \\
1.00 \\
1.00 \\
1.00 \\
1.00 \\
1.00\end{array}$ & $\begin{array}{l}\text { J1 } \\
\mathrm{J1} \\
\mathrm{J}\end{array}$ & $\begin{array}{l}\mathrm{pH} \\
\mu \mathrm{S} / \mathrm{l} \\
N T \operatorname{l} \\
\mu \mathrm{g} / \mathrm{L} \\
\mu \mathrm{g} / \mathrm{L} \\
\mu \mathrm{g} / \mathrm{L} \\
\mu \mathrm{g} / \mathrm{L} \\
\mu \mathrm{g} / \mathrm{L} \\
\mu \mathrm{g} / \mathrm{L} \\
\mu \mathrm{g} / \mathrm{L} \\
\mu \mathrm{g} / \mathrm{L} \\
\mu \mathrm{g} / \mathrm{L} \\
\mu \mathrm{g} / \mathrm{L} \\
\mu \mathrm{g} / \mathrm{L} \\
\mu \mathrm{g} / \mathrm{L} \\
\mu \mathrm{g} / \mathrm{L} \\
\mu \mathrm{g} / \mathrm{L} \\
\mu \mathrm{g} / \mathrm{L} \\
\mu \mathrm{g} / \mathrm{L} \\
\mu \mathrm{g} / \mathrm{L} \\
\mu \mathrm{g} / \mathrm{L} \\
\mu \mathrm{g} / \mathrm{L} \\
\mu \mathrm{g} / \mathrm{L} \\
\mu \mathrm{g} / \mathrm{L} \\
\mu \mathrm{g} / \mathrm{L} \\
\mu \mathrm{g} / \mathrm{L} \\
\mu \mathrm{g} / \mathrm{L} \\
\mu \mathrm{g} / \mathrm{L} \\
\mu \mathrm{g} / \mathrm{L} \\
\mu \mathrm{g} / \mathrm{L} \\
\mu \mathrm{g} / \mathrm{L} \\
\mu \mathrm{g} / \mathrm{L} \\
\mu \mathrm{g} / \mathrm{L} \\
\mu \mathrm{g} / \mathrm{L} \\
\mu \mathrm{g} / \mathrm{L} \\
\mu \mathrm{g} / \mathrm{L} \\
\mu \mathrm{g} / \mathrm{L} \\
\mu \mathrm{g} / \mathrm{L} \\
\mu \mathrm{g} / \mathrm{L}\end{array}$ \\
\hline
\end{tabular}

Time: 10: 52

$\mathrm{pH}: 7.2$

Alkalinity: $76 \mathrm{mg} / \mathrm{L}$

Water temperature: $19.3^{\circ} \mathrm{C}$

Volumes purged: 4.4 well volumes 
WELL BGO 44A collected on 01/28/94, laboratory analyses (cont.)

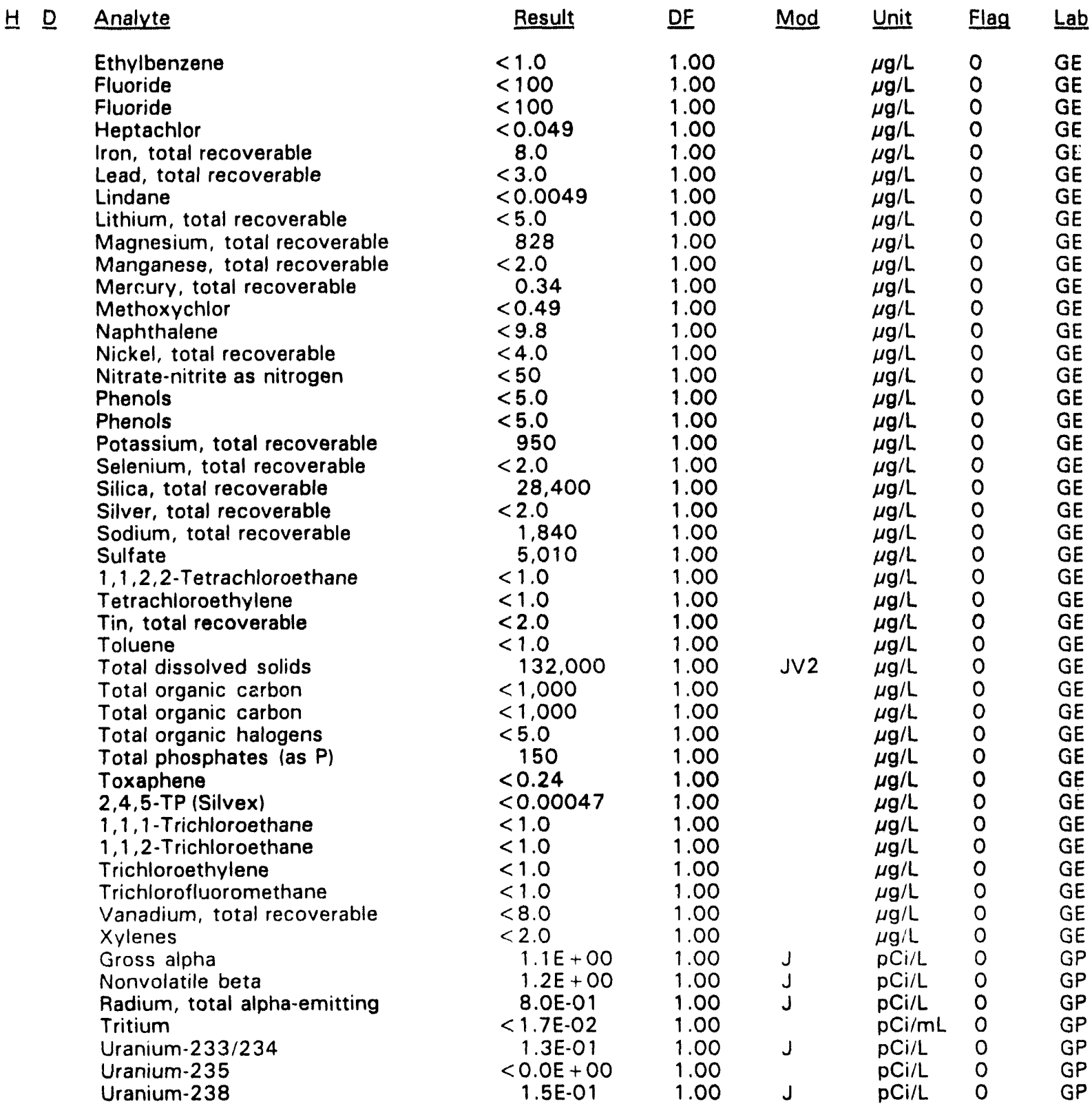

- = exceeded holding time. - = exceeded screening level or final primary drinking water standard. 


\section{WELL BGO 44AA}

$\begin{array}{lllllll}\text { SRS Coord. } & \text { Lat/Longitude } & \text { Screen Zone Elevation } & \text { Top of Casing } & \text { Casing } & \text { Pump } & \text { Formation } \\ \text { N76757.0 } & 33.289976^{\circ} \mathrm{N} & 71.3-61.2 \mathrm{ft} \mathrm{msl} & 285.3 \mathrm{ft} \mathrm{msl} & \text { 4" PVC } & \mathrm{S} & \text { L. Congaree (IIA) } \\ \text { E57880.5 } & 81.663488^{\circ} \mathrm{W} & & & \end{array}$

\section{FIELD MEASUREMENTS}

Sample date: $01 / 28 / 94$

Depth to water: $126.86 \mathrm{ft}(38.67 \mathrm{~m})$ below TOC

Water elevation: $158.44 \mathrm{ft}(48.29 \mathrm{~m}) \mathrm{ms}$ i

Sp. conductance: $200 \mu \mathrm{S} / \mathrm{cm}$

Turbidity: 0.6 NTU

Water evacuated before sampling: $302 \mathrm{gal}$
Time: $11: 19$

$\mathrm{pH}: 10.4$

Alkalinity: $77 \mathrm{mg} / \mathrm{L}$

Water temperature: $19.6^{\circ} \mathrm{C}$

Volumes purged: 4.7 well volumes

\section{LABORATORY ANALYSES}

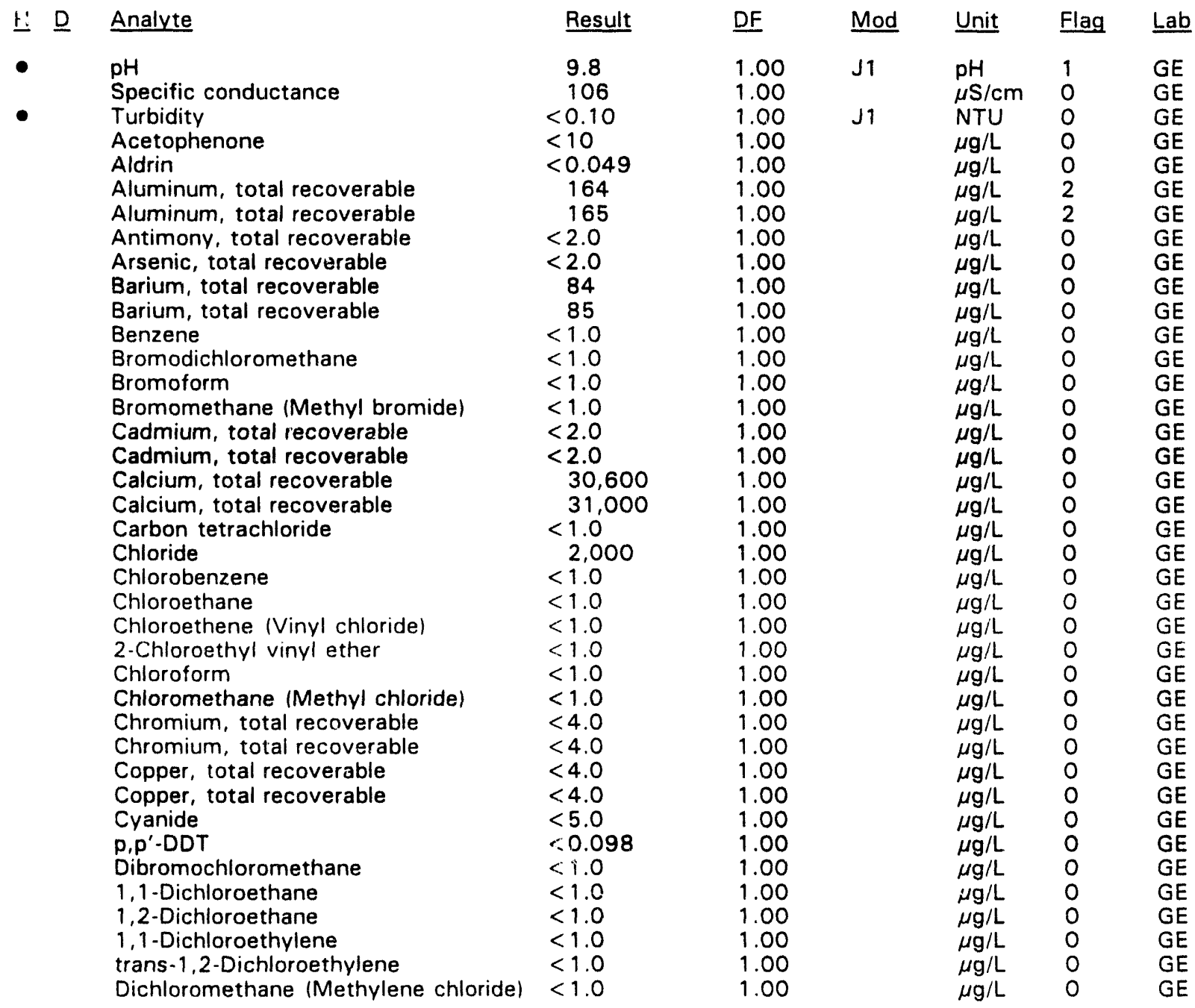

$\overline{- \text { = exceeded holding time. }}$ = exceeded screening level or final primary drinking water standard. 
WELL BGO 44AA collected on 01/28/94, laboratory analyses (cont.)

\section{H D $\quad$ Analyte}

2,4-Dichlorophenoxyacetic acid 2,4-Dichlorophenoxyacetic acid 1,2-Dichloropropane cis-1,3-Dichloropropene trans-1,3-Dichloropropene Dieldrin

Endrin

Ethylbenzene

Fluoride

Heptachlor

Iron, total recoverable

Iron, total recoverable

Lead, total recoverable

Lindane

Lithium, total recoverable

Lithium, total recoverable

Magnesium, total recoverable

Magnesium, total recoverable

Manganese, total recoverable

Manganese, total recoverable

Mercury, total recoverable

Mercury, total recoverable

Methoxychlor

Naphthalene

Nickel, total recoverable

Nickel, total recoverable

Nitrate-nitrite as nitrogen

Phenols

Potassium, total recoverable

Potassium, total recoverable

Selenium, total recoverable

Silica, total recoverable

Silica, total recoverable

Silver, total recoverable

Silver, total recoverable

Sodium, total recoverable

Sodium, total recoverable

Sulfate

$1,1,2,2$-Tetrachloroethane

Tetrachloroethylene

Tin, total recoverable

Tin, total recoverable

Toluene

Total dissolved solids

Total organic carbun

Total organic halogens

Total phosphates (as P)

Toxaphene

2,4,5-TP (Silvex)

2,4,5-TP (Silvex)

1,1,1-Trichloroethane

1,1,2-Trichloroethane

Trichloroethylene

Trichiorofluoromethane

$\checkmark$ anadium, total recoverable

Vanadium, total recoverable

\begin{tabular}{|c|c|}
\hline Result & DF \\
\hline$<0.0015$ & 1.00 \\
\hline$<0.0015$ & 1.00 \\
\hline $\begin{array}{l}<1.0 \\
<1.0\end{array}$ & 1.00 \\
\hline $\begin{array}{l}<1.0 \\
<1.0\end{array}$ & 1.00 \\
\hline$<0.49$ & 1.00 \\
\hline$<0.0059$ & 1.00 \\
\hline$<1.0$ & 1.00 \\
\hline 117 & 1.00 \\
\hline$<0.049$ & 1.00 \\
\hline 16 & 1.00 \\
\hline 16 & 1.00 \\
\hline$<3.0$ & 1.00 \\
\hline$<0.0049$ & 1.00 \\
\hline 79 & 1.00 \\
\hline $\begin{array}{l}79 \\
504\end{array}$ & $\begin{array}{l}1.00 \\
1.00\end{array}$ \\
\hline 511 & 1.00 \\
\hline$<2.0$ & 1.00 \\
\hline$<2.0$ & 1.00 \\
\hline $\begin{array}{l}<0.20 \\
<0.20\end{array}$ & $\begin{array}{l}1.00 \\
1.00\end{array}$ \\
\hline $\begin{array}{l}<0.20 \\
<0.49\end{array}$ & 1.00 \\
\hline$<10$ & 1.00 \\
\hline$<4.0$ & 1.00 \\
\hline$<4.0$ & 1.00 \\
\hline$<50$ & 1.00 \\
\hline$<5.0$ & 1.00 \\
\hline $\begin{array}{l}6,750 \\
6,760\end{array}$ & $\begin{array}{l}1.00 \\
1.00\end{array}$ \\
\hline $\begin{aligned} & 6,760 \\
< & 2.0\end{aligned}$ & 1.00 \\
\hline 26,400 & 1.00 \\
\hline 26,700 & 1.00 \\
\hline$<2.0$ & 1.00 \\
\hline$<2.0$ & 1.00 \\
\hline 6,320 & 1.00 \\
\hline 6,380 & 1.00 \\
\hline 8,380 & 1.00 \\
\hline$<1.0$ & 1.00 \\
\hline$<1.0$ & 1.00 \\
\hline 13 & 1.00 \\
\hline 15 & 1.00 \\
\hline$<1.0$ & 1.00 \\
\hline 88,000 & 1.00 \\
\hline$<1,000$ & 1.00 \\
\hline$<5.0$ & 1.00 \\
\hline$<50$ & 1.00 \\
\hline$<0.24$ & 1.00 \\
\hline$<0.00045$ & 1.00 \\
\hline$<0.00045$ & 1.00 \\
\hline$<1.0$ & 1.00 \\
\hline$<1.0$ & 1.00 \\
\hline$<1.0$ & 1.00 \\
\hline$<1.0$ & 1.00 \\
\hline$<8.0$ & 1.00 \\
\hline$<8.0$ & 1.00 \\
\hline
\end{tabular}

- exceeded holding time. = exceeded screening level or final primary drinking water standard. 
WELL BGO 44AA collected on 01/28/94, laboratory analyses (cont.)

\begin{tabular}{|c|c|c|c|c|c|}
\hline Analyte & Result & $\underline{D F}$ & Mod & Unit & Flag \\
\hline $\begin{array}{l}\text { Xylenes } \\
\text { Gross alpha } \\
\text { Nonvolatile beta } \\
\text { Radium, total alpha-emitting } \\
\text { Tritium } \\
\text { Uranium-233/234 } \\
\text { Uranium-235 } \\
\text { Uranium-238 }\end{array}$ & $\begin{array}{l}<2.0 \\
7.4 E-01 \\
5.7 E+00 \\
1.7 E+00 \\
3.1 E+00 \\
2.1 E-01 \\
2.1 E-01 \\
2.1 E-01\end{array}$ & $\begin{array}{l}1.00 \\
1.00 \\
1.00 \\
1.00 \\
1.00 \\
1.00 \\
1.00 \\
1.00\end{array}$ & $\begin{array}{l}\mathrm{J} \\
\mathrm{J}\end{array}$ & $\begin{array}{l}\mu \mathrm{g} / \mathrm{L} \\
\mathrm{pCi} / \mathrm{L} \\
\mathrm{pCi} / \mathrm{L} \\
\mathrm{pCi} / \mathrm{L} \\
\mathrm{pCi} / \mathrm{mL} \\
\mathrm{pCi} / \mathrm{L} \\
\mathrm{pCi} / \mathrm{L} \\
\mathrm{pCi} / \mathrm{L}\end{array}$ & $\begin{array}{l}0 \\
0 \\
0 \\
0 \\
0 \\
0 \\
0 \\
0\end{array}$ \\
\hline
\end{tabular}

WELL BGO 44B

$\begin{array}{lllllll}\text { SRS Coord. } & \text { Lat/Longitude } & \text { Screen Zone Elevation } & \text { Top of Casing } & \text { Casing } & \text { Pump } & \text { Formation } \\ \text { N76756.0 } & 33.289950^{\circ} \mathrm{N} & 158.1-148.1 \mathrm{ft} \mathrm{msl} & 285.2 \mathrm{ft} \mathrm{msl} & \text { 4" PVC } & \text { S } & \text { McBean (IIB } 1 \text { ) } \\ \text { E57865.8 } & 81.663525^{\circ} \mathrm{W} & & \end{array}$

\section{FIELD MEASUREMENTS}

Sample date: $02 / 08 / 94$

Depth to water: $64.00 \mathrm{ft}(19.51 \mathrm{~m})$ below TOC

Water elevation: $221.20 \mathrm{ft}(67.42 \mathrm{~m}) \mathrm{msl}$

Sp. conductance: $399 \mu \mathrm{S} / \mathrm{cm}$

Turbidity: 127 NTU

Water evacuated before sampling: $39 \mathrm{gal}$

The well went dry during purging.

\section{LABORATORY ANALYSES}

$\begin{array}{ll}\text { H. } & \text { Analyte } \\ \text { pH } \\ \text { Specific conductance } \\ \text { Turbidity } \\ \text { Acetophenone } \\ \text { Acetophenone } \\ \text { Aldrin } \\ \text { Aluminum, total recoverable } \\ \text { Antimony, total recoverable } \\ \text { Arsenic, total recoverable } \\ \text { Barium, total recoverable } \\ \text { Benzene } \\ \text { Benzene } \\ \text { Bromodichloromethane } \\ \text { Bromodichloromethane } \\ \text { Bromoform } \\ \text { Bromoform } \\ \text { Bromomethane (Methyl bromide) } \\ \text { Bromomethane (Methyl bromide) } \\ \text { Cadmium, total recoverable } \\ \text { Calcium, total recoverable } \\ \text { Carbon tetrachloride } \\ \text { Carbon tetrachloride } \\ \text { Chioride } \\ \text { Chlorobenzene } \\ \text { Chlorobenzene }\end{array}$

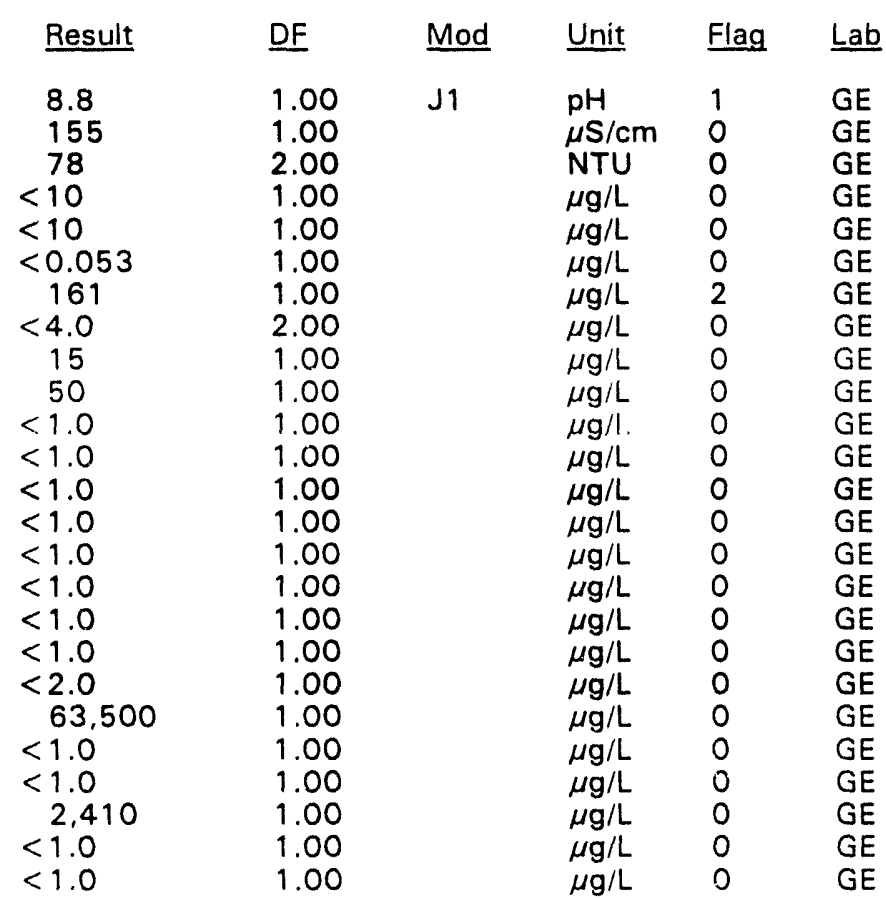

Time: $12: 35$

pH: 11.3

Alkalinity: $90 \mathrm{mg} / \mathrm{L}$

Water temperature: $17.5^{\circ} \mathrm{C}$

Volumes purged: 0.8 well volumes 
WELL BGO 44B collected on 02/08/94, laboratory analyses (cont.)

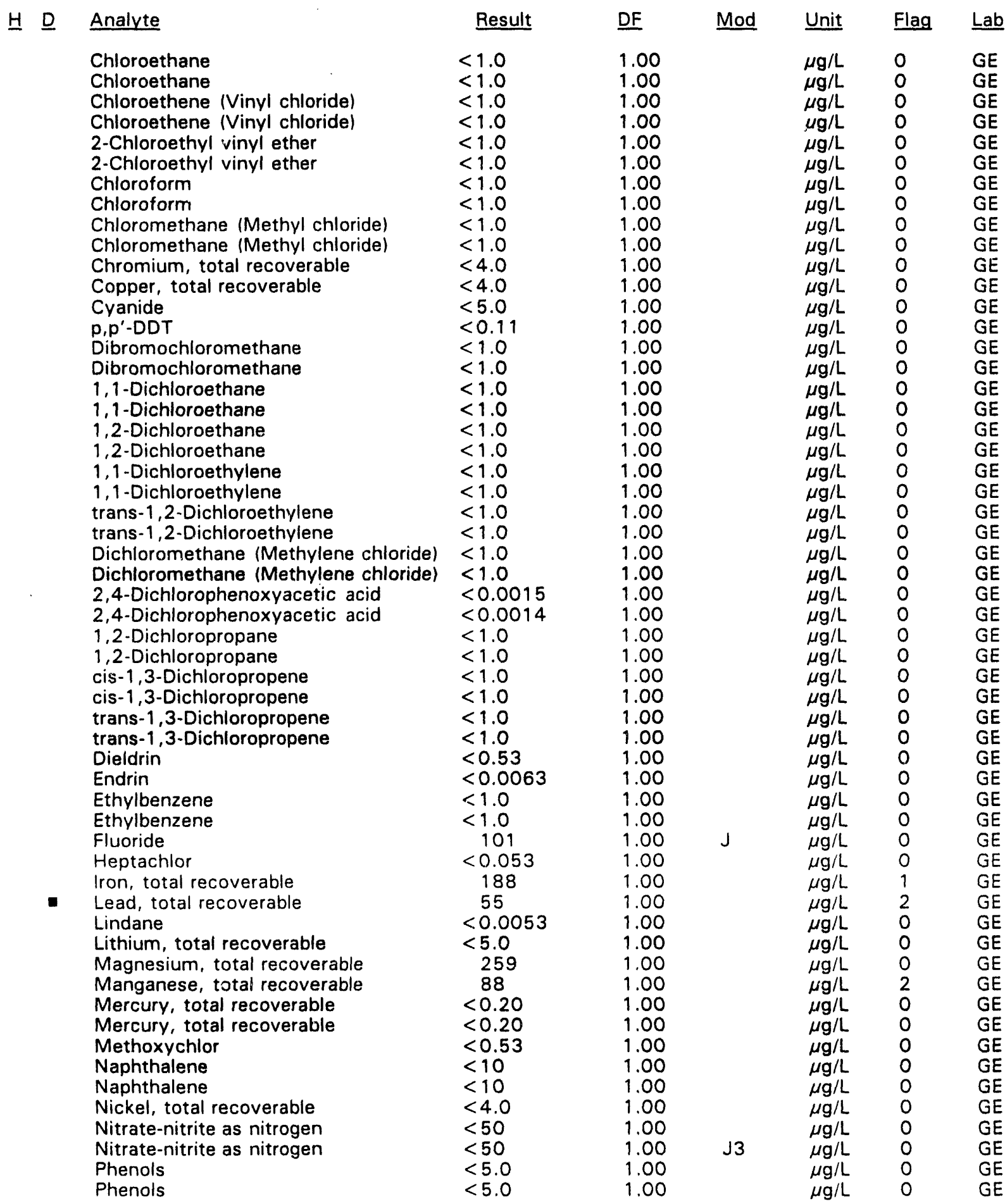

\footnotetext{
- = exceeded holding time. = exceeded screening level or final primary drinking water standard.
} 
WELL BGO 44B collected on 02/08/94, laboratory analyses (cont.)

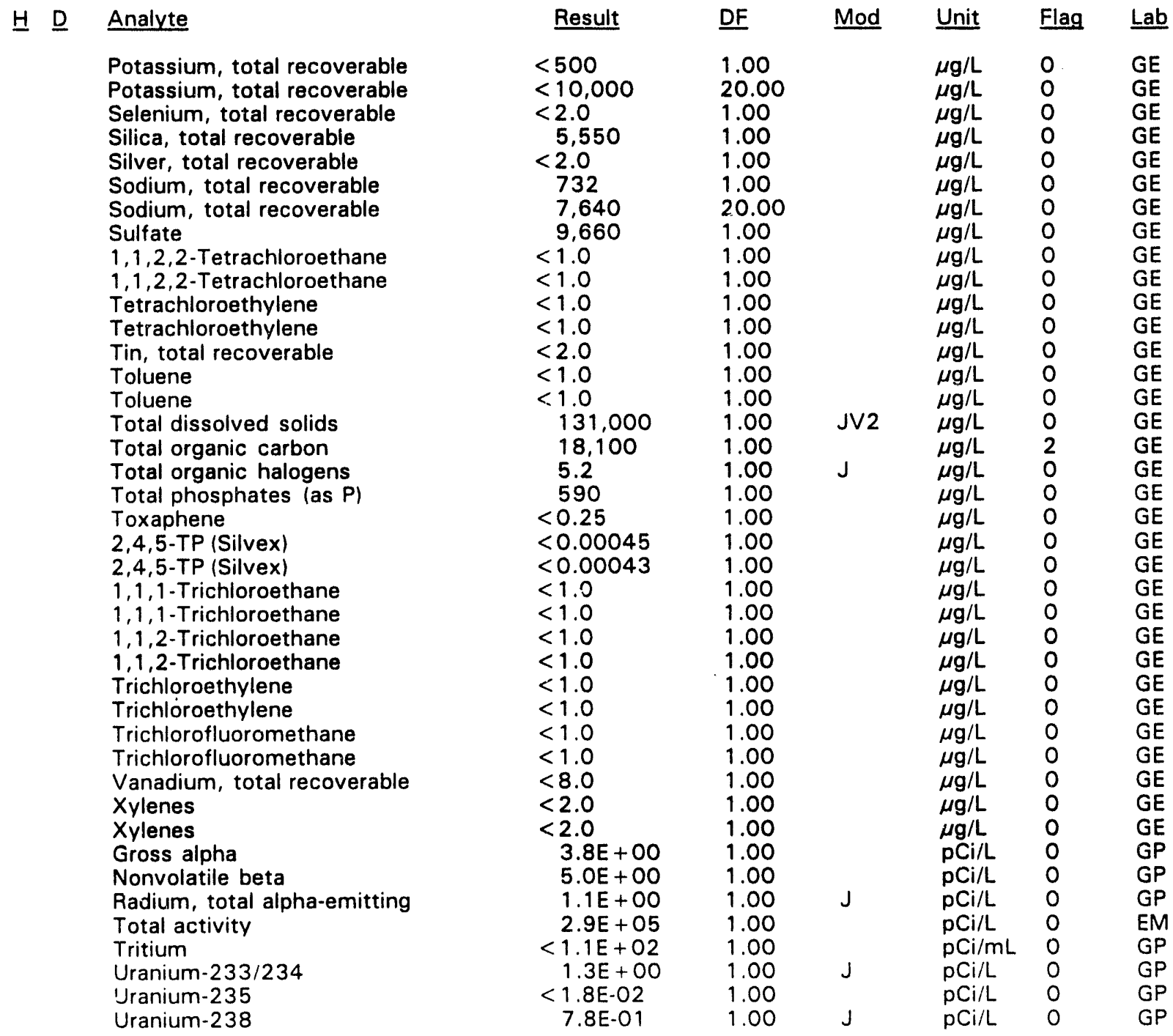

- = exceeded holding time. = exceeded screening level or final primary drinking water standard. 
WELL BGO 44C

\begin{tabular}{|c|c|c|c|c|c|c|}
\hline SRS Coord. & Lat/Longitude & Screen Zone Elevation & Top of Casing & Casing & Pump & Formation \\
\hline $\begin{array}{l}N 76757.8 \\
E 57894.9\end{array}$ & $\begin{array}{l}33.290001^{\circ} \mathrm{N} \\
81.663452^{\circ} \mathrm{W}\end{array}$ & $200.6-190.6 \mathrm{ft} \mathrm{msl}$ & $285.6 \mathrm{ft} \mathrm{msl}$ & 4" PVC & s & $\left.\| B_{1}\right\rangle$ \\
\hline
\end{tabular}

\section{FIELD MEASUREMENTS}

Sample date: 02/08/94

Depth to water: $64.65 \mathrm{ft}(19.71 \mathrm{~m})$ below TOC

Water elevation: $220.95 \mathrm{ft}(67.35 \mathrm{~m}) \mathrm{ms} /$

Sp. conductance: $176 \mu \mathrm{S} / \mathrm{cm}$

Turbidity: 38.1 NTU

Water evacuated before sampling: $15 \mathrm{gal}$

The well went dry during purging.

\section{LABORATORY ANALYSES}

$\underline{H}$ D Analyte

\section{$\mathrm{pH}$}

Specific conductance

Turbidity

Acetophenone

Aldrin

Aldrin

Aluminum, total recoverable

Aluminum, total recoverable

Antimony, total recoverable

Arsenic, total recoverable

Barium, total recoverable

Barium, total recoverable

Benzene

Bromodichloromethane

Bromoform

Bromomethane (Methyl bromide)

Cadmium, total recoverable

Cadmium, total recoverable

Calcium, total recoverable

Calcium, total recoverable

Carbon tetrachloride

Chloride

Chloride

Chlorobenzene

Chloroethane

Chloroethene (Vinyl chloride)

2-Chloroethyl vinyl ether

Chloroform

Chloromethane (Methyl chloride)

Chromium, total recoverable

Chromium, total recoverable

Copper, total recoverable

Copper, total recoverable

Cyanide

$p, p^{\prime}-D D T$

$p, p^{\prime}-D D T$

Dibromochloromethane

1,1-Dichloroethane

1,2-Dichloroethane
Time: 12: 51

$\mathrm{pH}: 10.7$

Alkalinity: $33 \mathrm{mg} / \mathrm{L}$

Water temperature: $18.0^{\circ} \mathrm{C}$

Volumes purged: 0.8 well volumes

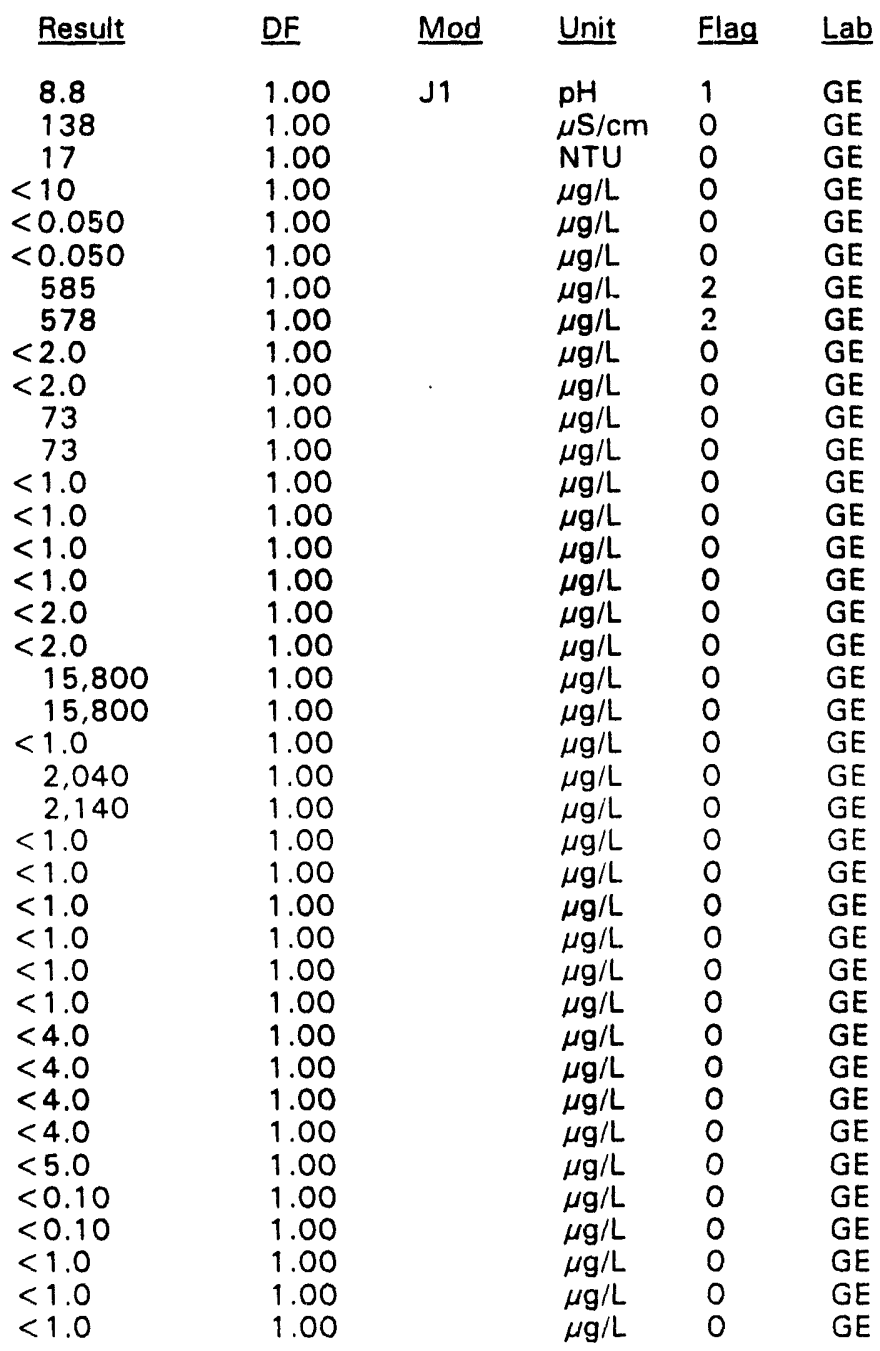

- = exceeded holding time. = exceeded screening level or final primary drinking water standard. 
WELL BGO 44C collected on 02/08/94, laboratory analyses (cont.)

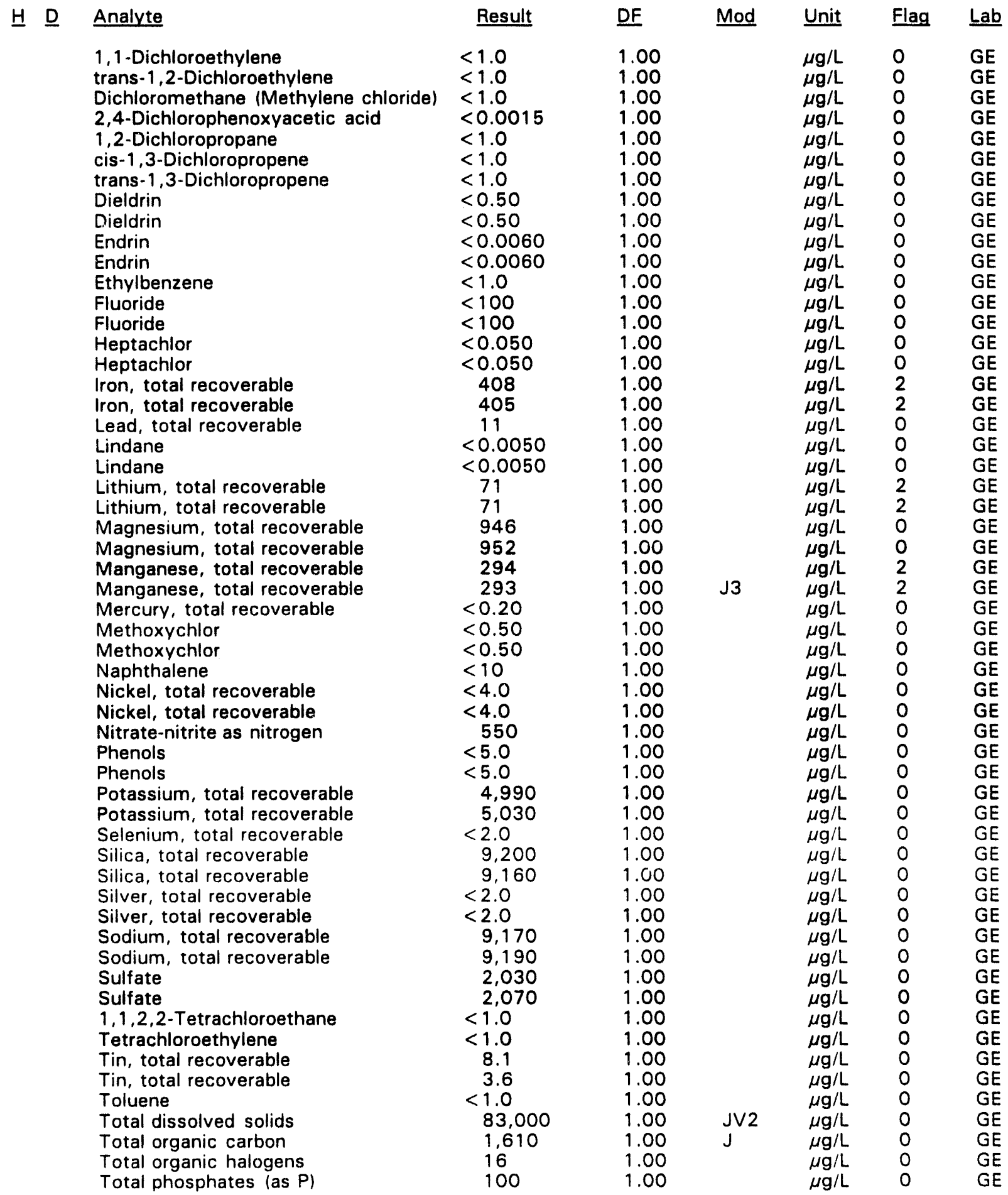

- = exceeded holding time. = exceeded screening level or final primary drinking water standard. 
WELL BGO 44C collected on $02 / 08 / 94$, laboratory analyses (cont.)

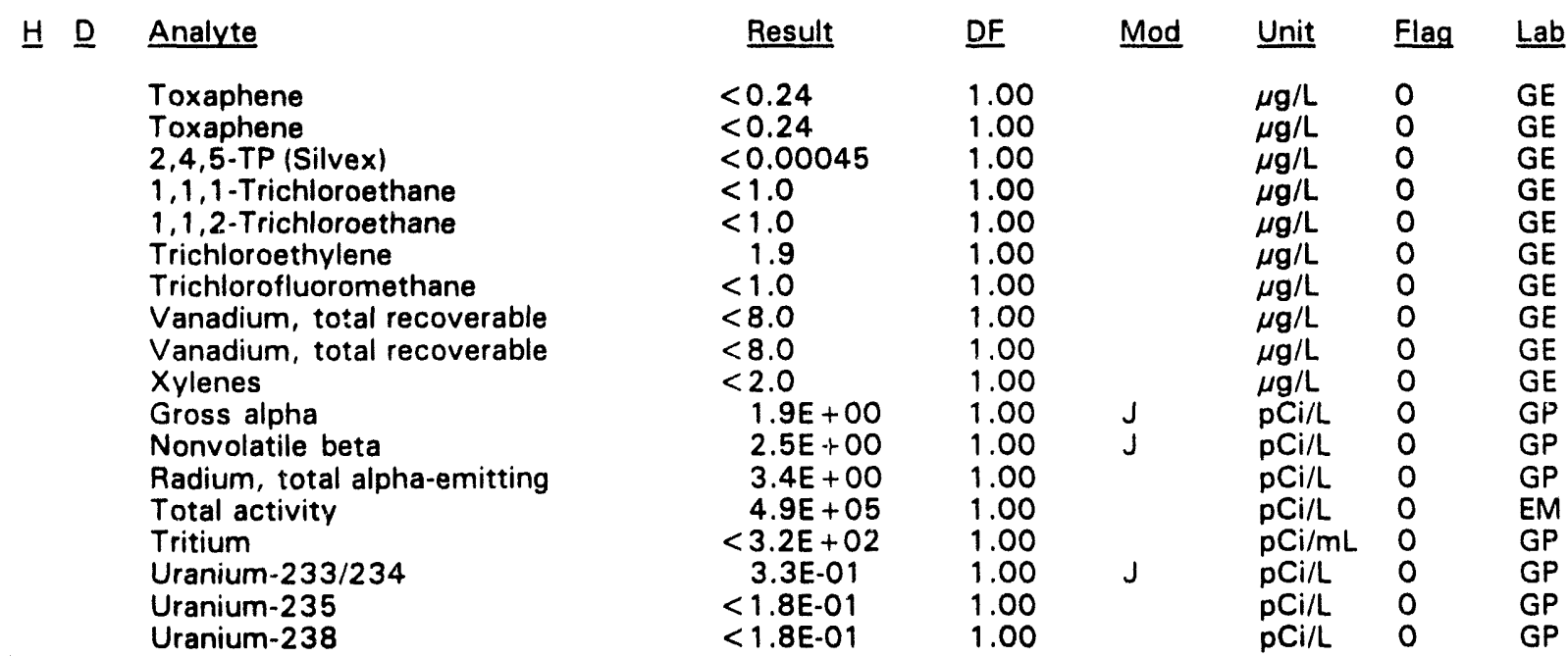

WELL BGO 44D

\begin{tabular}{|c|c|c|c|c|c|c|}
\hline SRS Coord. & Lat/Longitude & Screen Zone Elevation & Top of Casing & Casing & Pump & Formation \\
\hline $\begin{array}{l}N 76759.5 \\
\text { E57910.0 }\end{array}$ & $\begin{array}{l}33.290030^{\circ} \mathrm{N} \\
81.663415^{\circ} \mathrm{W}\end{array}$ & $233.4-223.4 \mathrm{ft} \mathrm{msl}$ & $285.4 \mathrm{ft} \mathrm{msl}$ & 4" PVC & $\mathrm{s}$ & Water Table $\left(\| B_{2}\right)$ \\
\hline
\end{tabular}

\section{FIELD MEASUREMENTS}

Sample date: $02 / 08 / 94$

Depth to water: $53.00 \mathrm{ft}(16.15 \mathrm{~m})$ below TOC

Water elevation: $232.40 \mathrm{ft}(70.84 \mathrm{~m}) \mathrm{msl}$

Sp. conductance: $25 \mu \mathrm{S} / \mathrm{cm}$

Turbidity: 0.4 NTU

Water evacuated before sampling: $113 \mathrm{gal}$

\section{LABORATORY ANALYSES}

H D Analyte

- $\quad \mathrm{pH}$

Specific conductance

Specific conductance

Turbidity

Acetophenone

Aldrin

Aluminum, total recoverable

Aluminum, total recoverable

Antimony, total recoverable

Antimony, total recoverable

Arsenic, total recoverable

Arsenic, total recoverable

Barium, total recoverable

Barium, total recoverable

Benzene

Bromodichloromethane
Time: 13: 01

$\mathrm{pH}: 4.7$

Alkalinity: $0 \mathrm{mg} / \mathrm{L}$

Water temperature: $19.2{ }^{\circ} \mathrm{C}$

Volumes purged: 19.1 well volumes

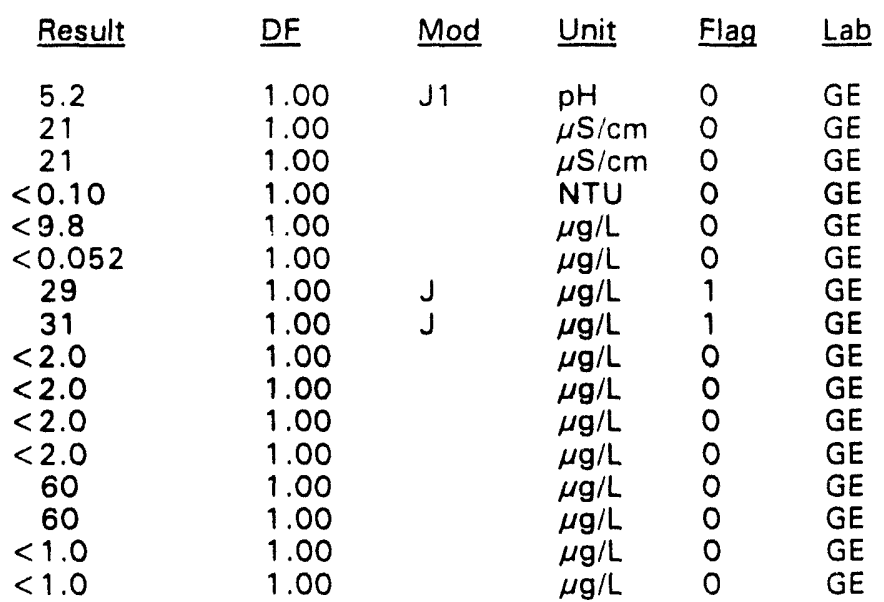

$\overline{-}=$ exceeded holding time. $=$ exceeded screening level or final primary drinking water standard. 
WELL BGO $44 D$ collected on $02 / 08 / 94$, laboratory analyses (cont.)

H D Analyte

Bromoform

Bromomethane (Methyl bromide)

Cadmium, total recoverable

Cadmium, total recoverable

Calcium, total recoverable

Calcium, total recoverable

Carbon tetrachloride

Chloride

Chloride

Chlorobenzene

Chloroethane

Chloroethene (Vinyl chloride)

2-Chloroethyl vinyl ether

Chloroform

Chloromethane (Methyl chloride)

Chromium, total recoverable

Chromium, total recoverable

Copper, total recoverable

Copper, total recoverable

Cyanide

Cyanide

p.p'-DDT

Dibromochloromethane

1.1-Dichloroethane

1,2-Dichloroethane

1,1-Dichloroethylene

trans-1,2-Dichloroethylene

Dichloromethane (Methylene chloride)

2,4-Dichlorophenoxyacetic acid

1,2-Dichloropropane

cis-1,3-Dichloropropene

trans-1,3-Dichloropropene

Dieldrin

Endrin

Ethylbenzene

Fluoride

Heptachlor

Iron, total recoverable

Iron, total recoverable

Lead, total recoverable

Lead, total recoverable

Lindane

Lithium, total recoverable

Lithium, total recoverable

Magnesium, total recoverable

Magnesium, total recoverable

Manganese, total recoverable

Manganese, total recoverable

Mercury, total recoverable

Methoxychlor

Naphthalene

Nickel, total recoverable

Nickel, total recoverable

Nitrate-nitrite as nitrogen

Phenols

Potassium, total recoverable

Result D

$<1.0$

$<1.0$

$<2.0$

$<2.0$

758

760

$<1.0$

1,980

1,980

$<1.0$

$<1.0$

$<1.0$

$<1.0$

$<1.0$

$<1.0$

$<4.0$

$<4.0$

$<4.0$

$<4.0$

$<5.0$

$<5.0$

$<0.10$

$<1.0$

$<1.0$

$<1.0$

$<1.0$

$<1.0$

$<1.0$

$<0.0015$

$<1.0$

$<1.0$

$<1.0$

$<0.52$

$<0.0062$

$<1.0$

$<100$

$<0.052$

$<4.0$

$<4.0$

$<3.0$

$<3.0$

$<0.0052$

$<5.0$

$<5.0$

422

421

11

11

0.25

$<0.52$

$<9.8$

$<4.0$

$<4.0$

760

$<5.0$

$<500$
DF

1.00

1.00

1.00

1.00

1.00

1.00

1.00

1.00

1.00

1.00

1.00

1.00

1.00

1.00

1.00

1.00

1.00

1.00

1.00

1.00

1.00

1.00

1.00

1.00

1.00

1.00

1.00

1.00

1.00

1.00

1.00

1.00

1.00

1.00

1.00

1.00

1.00

1.00

1.00

1.00

1.00

1.00

1.00

1.00

1.00

1.00

1.00

1.00

1.00

1.00

1.00

1.00

1.00

1.00

1.00

1.00
Mod

Unit

Flag

Lab

$\mu g / L \quad 0 \quad$ GE

$\mu g / L \quad 0 \quad G E$

$\mu g / L \quad 0 \quad G E$

$\mu \mathrm{g} / \mathrm{L} \quad 0 \quad \mathrm{GE}$

$\mu \mathrm{g} / \mathrm{L} \quad 0 \quad \mathrm{GE}$

$\mu g / L \quad 0 \quad G E$

$\mu \mathrm{g} / \mathrm{L} \quad 0 \quad \mathrm{G}$

$\mu \mathrm{g} / \mathrm{L} \quad 0 \quad \mathrm{GE}$

GE

$\mu \mathrm{g} / \mathrm{L} \quad 0 \quad \mathrm{GE}$

$\mu g / L \quad 0 \quad$ GE

$\mu \mathrm{g} / \mathrm{L} \quad 0 \quad \mathrm{GE}$

$\mu g / L \quad 0 \quad G E$

$\mu \mathrm{g} / \mathrm{L} \quad \mathrm{O} \quad \mathrm{GE}$

$\mu \mathrm{g} / \mathrm{L} \quad 0 \quad \mathrm{GE}$

$\mu g / L \quad 0 \quad$ GE

$\mu g / L \quad 0 \quad$ GE

$\mu \mathrm{g} / \mathrm{L} \quad 0 \quad \mathrm{GE}$

$\mu \mathrm{g} / \mathrm{L} \quad 0 \quad \mathrm{GE}$

$\mu \mathrm{g} / \mathrm{L} \quad 0 \quad \mathrm{GE}$

$\mu g / L \quad 0 \quad$ GE

$\mu \mathrm{g} / \mathrm{L} \quad 0 \quad \mathrm{GE}$

$\mu \mathrm{g} / \mathrm{L} \quad 0 \quad \mathrm{GE}$

$\mu \mathrm{g} / \mathrm{L} \quad \mathrm{O} \quad \mathrm{GE}$

$\mu \mathrm{g} / \mathrm{L} \quad 0 \quad \mathrm{GE}$

$\mu g / L \quad 0 \quad$ GE

$\mu \mathrm{g} / \mathrm{L} \quad 0 \quad \mathrm{GE}$

$\mu \mathrm{g} / \mathrm{L} \quad \mathrm{O} \quad \mathrm{GE}$

$\mu g / L \quad 0 \quad$ GE

$\mu \mathrm{g} / \mathrm{L} \quad 0 \quad \mathrm{GE}$

$\mu g / L \quad 0 \quad$ GE

$\mu g / L \quad O \quad G E$

$\mu g / L \quad 0 \quad$ GE

$\mu \mathrm{g} / \mathrm{L} \quad 0 \quad \mathrm{GE}$

$\mu g / L \quad 0 \quad$ GE

$\mu g / L \quad 0 \quad$ GE

$\mu \mathrm{g} / \mathrm{L} \quad 0 \quad \mathrm{GE}$

$\mu \mathrm{g} / \mathrm{L} \quad 0 \quad \mathrm{GE}$

$\mu \mathrm{g} / \mathrm{L} \quad \mathrm{O} \quad \mathrm{GE}$

$\mu \mathrm{g} / \mathrm{L} \quad \mathrm{O} \quad \mathrm{GE}$

$\mu \mathrm{g} / \mathrm{L} \quad \mathrm{O} \quad \mathrm{GE}$

$\mu \mathrm{g} / \mathrm{L} \quad \mathrm{O} \quad \mathrm{GE}$

$\mu g / L \quad 0 \quad$ GE

$\mu \mathrm{g} / \mathrm{L} \quad 0 \quad \mathrm{GE}$

$\mu \mathrm{g} / \mathrm{L} \quad 0 \quad \mathrm{GE}$

$\mu g / L \quad O \quad G E$

$\mu g / L \quad 0$

$\mu \mathrm{g} / \mathrm{L} \quad 0 \quad \mathrm{GE}$

$\mu g / L \quad 0 \quad G E$

$\mu g / L \quad 0 \quad G E$

$\mu \mathrm{g} / \mathrm{L} \quad 0 \quad \mathrm{GE}$

$\mu \mathrm{g} / \mathrm{L} \quad \mathrm{O} \quad \mathrm{GE}$

$\mu \mathrm{g} / \mathrm{L} \quad \mathrm{O} \quad \mathrm{GE}$

$\mu \mathrm{g} / \mathrm{L} \quad 0$

$\begin{array}{lll}\mu \mathrm{g} / \mathrm{L} & 0 & \mathrm{GE} \\ \mu \mathrm{g} / \mathrm{L} & 0 & \mathrm{GE}\end{array}$ 
WELL BGO 440 collected on $02 / 08 / 94$, laboratory analyses (cont.)

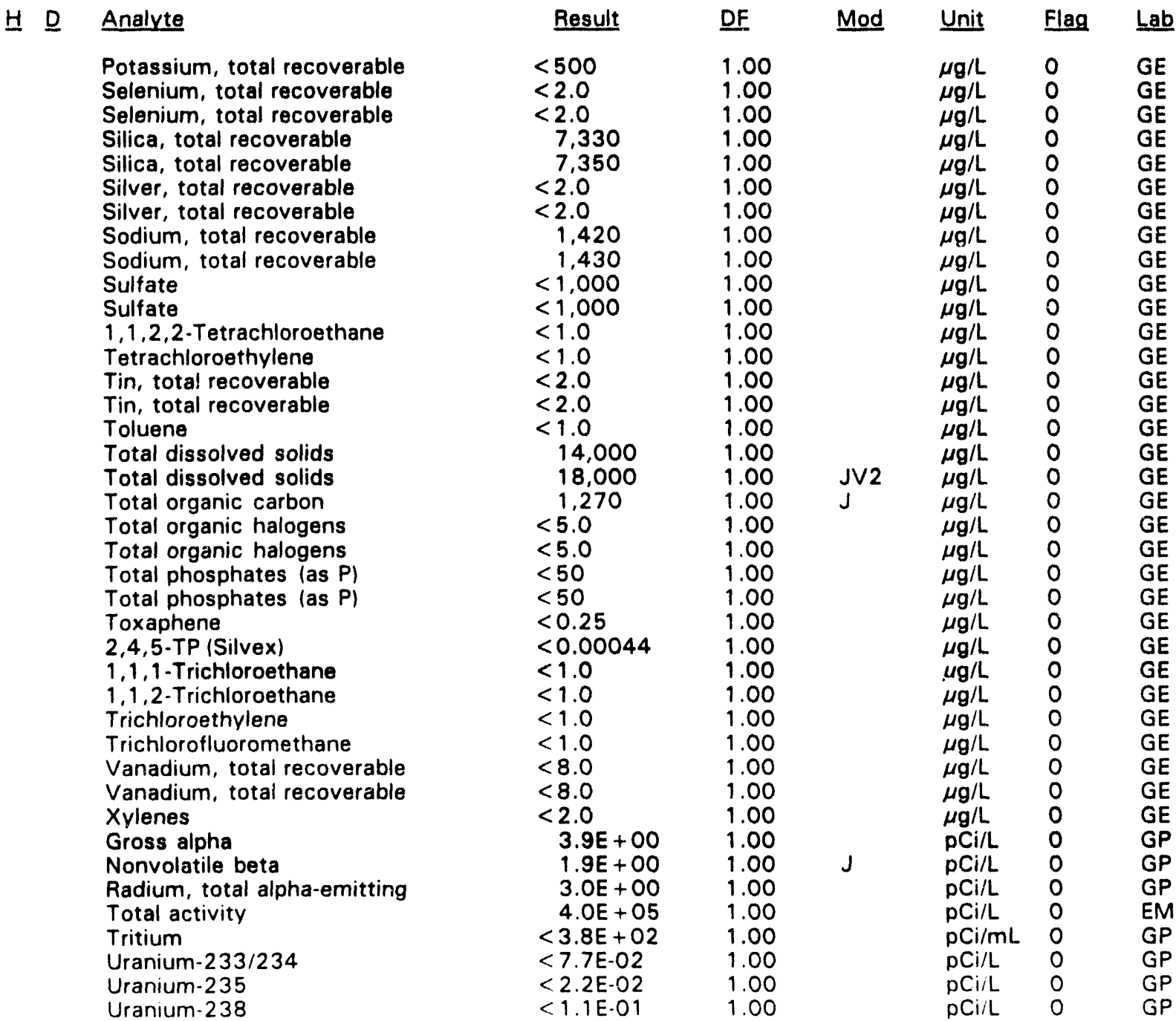

\footnotetext{
$\overline{-}=$ exceeded holding time. $\quad$ = exceeded screening level or final primary drinking water standard.
} 
WELL BGO 45A

\begin{tabular}{|c|c|c|c|c|c|c|}
\hline SRS Coord. & Lat/Longitude & Screen Zone Elevation & Top of Casing & Casing & Pump & Formation \\
\hline $\begin{array}{l}N 75830.0 \\
\text { E54550.1 }\end{array}$ & $\begin{array}{l}33.282492^{\circ} \mathrm{N} \\
81.670457^{\circ} \mathrm{W}\end{array}$ & $126.9-116.9 \mathrm{ft} \mathrm{msl}$ & $278.9 \mathrm{ft} \mathrm{msl}$ & 4" PVC & $\mathbf{S}$ & aree (IIA) \\
\hline
\end{tabular}

\section{FIELD MEASUREMENTS}

Sample date: 02/24/94

Depth to water: $118.34 \mathrm{ft}(36.07 \mathrm{~m})$ below TOC

Water elevation: $160.56 \mathrm{ft}(48.94 \mathrm{~m}) \mathrm{msl}$

Sp. conductance: $183 \mu \mathrm{S} / \mathrm{cm}$

Turbidity: 0.6 NTU

Water evacuated before sampling: $145 \mathrm{gal}$

\section{LABORATORY ANALYSES}

H $\quad$ Analyte

- $\quad \mathrm{pH}$

Specific conductance

Turbidity

Acetophenone

Aldrin

Aluminum, total recoverable

Antimony, total recoverable

Arsenic, total recoverable

Barium, total recoverable

Benzene

Benzene

Bromodichloromethane

Bromodichloromethane

Bromoform

Bromoform

Bromomethane (Methyl bromide)

Bromomethane (Methyl bromide)

Cadmium, total recoverable

Calcium, total recoverable

Carbon tetrachloride

Carbon tetrachloride

Chloride

Chloride

Chlorobenzene

Chlorobenzene

Chloroethane

Chloroethane

Chloroethene (Vinyl chloride)

Chloroethene (Vinyl chloride)

2-Chloroethyl vinyl ether

2-Chloroethyl vinyl ether

Chloroform

Chloroform

Chloromethane (Methyl chloride)

Chloromethane (Methyl chloride)

Chromium, total recoverable

Copper, total recoverable

Cyanide

p.p'-DDT
Time: 10: 27

$\mathrm{pH}: 8.0$

Alkalinity: $6 \mathrm{mg} / \mathrm{L}$

Water temperature: $18.0^{\circ} \mathrm{C}$

Volumes purged: 5.1 well volumes

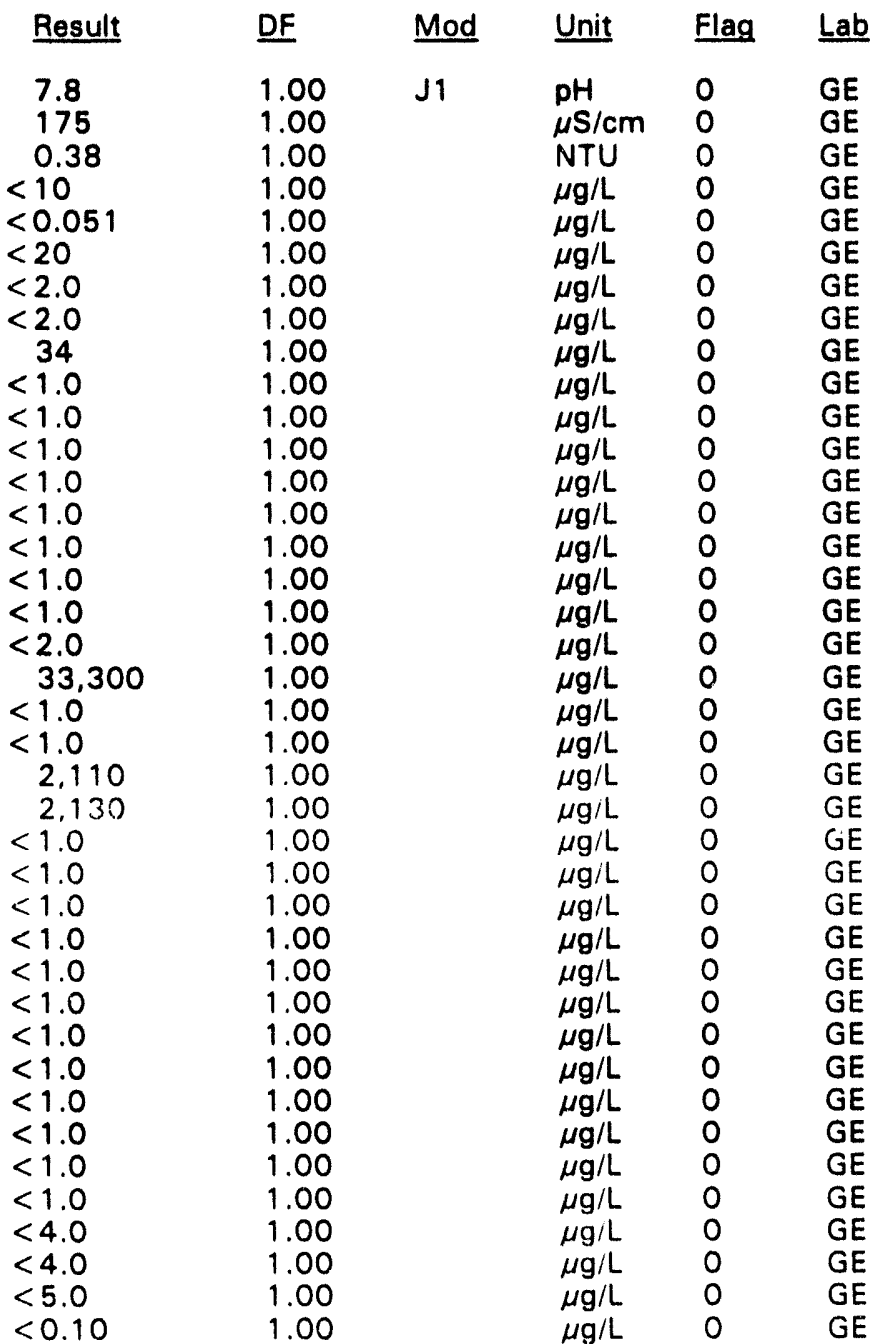

- exceeded holding time. $\quad=$ exceeded screening level or final primary drinking water standard. 
WELL BGO 45A collected on 02/24/94, laboratory analyses (cont.)

H D Analyte

Dibromochloromethane

Dibromochloromethane

1,1-Dichloroethane

1,1-Dichloroethane

1,2-Dichloroethane

1,2-Dichloroethane

1,1-Dichloroethylene

1,1-Dichloroethylene

trans-1,2-Dichloroethylene

trans-1,2-Dichloroethylene

Dichloromethane (Methylene chloride)

Dichloromethane (Methylene chloride)

2,4-Dichlorophenoxyacetic acid

1.2-Dichloropropane

1,2-Dichloropropane

cis-1,3-Dichloropropene

cis-1,3-Dichloropropene

trans-1,3-Dichloropropene

trans-1,3-Dichloropropene

Dieldrin

Endrin

Ethylbenzene

Ethylbenzene

Fluoride

Fluoride

Heptachlor

Iron, total recoverable

Lead, total recoverable

Lindane

Lithium, total recoverable

Magnesium, total recoverable

Manganese, total recoverable

Mercury, total recoverable

Methoxychlor

Naphthalene

Nickel, total recoverable

Nitrate-nitrite as nitrogen

Phenols

Potassium, total recoverable

Selenium, total recoverable

Silica, total recoverable

Silver, total recoverable

Sodium, total recoverable

Sulfate

Sulfate

$1,1,2,2$-Tetrachloroethane

1,1,2,2-Tetrachloroethane

Tetrachloroethylene

Tetrachloroethylene

Tin, total recoverable

Toluene

Toluene

Total dissolved solids

Total organic carbon

Total organic halogens

Total phosphates (as P)
Result DF

$<1.0$

$<1.0$

$<1.0$

$<1.0$

$<1.0$

$<1.0$

$<1.0$

$<1.0$

$<1.0$

$<1.0$

$<1.0$

$<1.0$

$<0.0016$

$<1.0$

$<1.0$

$<1.0$

$<1.0$

$<1.0$

$<1.0$

$<0.51$

$<0.0061$

$<1.0$

$<1.0$

$<100$

$<100$

$<0.051$

16

$<3.0$

$<0.0051$

$<5.0$

463

$<2.0$

$<0.20$

$<0.51$

$<10$

$<4.0$

540

$<5.0$

574

$<2.0$

18,100

$<2.0$

1,980

1,630

1,640

$<1.0$

$<1.0$

$<1.0$

$<1.0$

$<2.0$

$<1.0$

$<1.0$

113,000

$<1,000$

$<5.0$

$<50$

\section{F}

1.00

1.00

1.00

1.00

1.00

1.00

1.00

1.00

1.00

1.00

1.00

1.00

1.00

1.00

1.00

1.00

1.00

1.00

1.00

1.00

1.00

1.00

1.00

1.00

1.00

1.00

1.00

1.00

1.00

1.00

1.00

1.00

1.00

1.00

1.00

1.00

1.00

1.00

1.00

1.00

1.00

1.00

1.00

1.00

1.00

1.00

1.00

1.00

1.00

1.00

1.00

1.00

1.00

1.00

1.00
Mod Unit Flag Lab

$\mu \mathrm{g} / \mathrm{L} \quad 0 \quad \mathrm{GE}$

$\mu g / L \quad 0 \quad$ GE

$\mu g / L \quad 0 \quad G E$

$\mu g / L \quad 0 \quad$ GE

$\mu g / L \quad 0 \quad$ GE

$\mu g / L \quad 0 \quad$ GE

$\mu g / L \quad 0 \quad$ GE

$\mu g / L \quad 0 \quad G E$

$\mu g / L \quad O \quad G E$

$\mu g / L \quad 0 \quad$ GE

$\mu g / L \quad 0 \quad$ GE

$\mu g / L \quad 0 \quad$ GE

$\mu g / L \quad 0 \quad$ GE

$\mu \mathrm{g} / \mathrm{L} \quad \mathrm{O} \quad \mathrm{GE}$

$\mu \mathrm{g} / \mathrm{L} \quad 0 \quad \mathrm{GE}$

$\mu \mathrm{g} / \mathrm{L} \quad 0 \quad \mathrm{GE}$

$\mu g / L \quad 0 \quad$ GE

$\mu g / L \quad O \quad G E$

$\mu g / L \quad O \quad G E$

$\mu g / L \quad 0 \quad$ GE

$\mu g / L \quad 0 \quad$ GE

$\mu \mathrm{g} / \mathrm{L} \quad 0 \quad \mathrm{GE}$

$\mu g / L \quad 0 \quad G E$

$\mu \mathrm{g} / \mathrm{L} \quad \mathrm{O} \quad \mathrm{GE}$

$\mu \mathrm{g} / \mathrm{L} \quad \mathrm{O} \quad \mathrm{GE}$

$\mu \mathrm{g} / \mathrm{L} \quad \mathrm{O} \quad \mathrm{GE}$

$\mu \mathrm{g} / \mathrm{L} \quad \mathrm{O} \quad \mathrm{GE}$

$\mu \mathrm{g} / \mathrm{L} \quad 0 \quad \mathrm{GE}$

$\mu \mathrm{g} / \mathrm{L} \quad 0 \quad \mathrm{GE}$

$\mu \mathrm{g} / \mathrm{L} \quad 0 \quad \mathrm{GE}$

$\mu \mathrm{g} / \mathrm{L} \quad 0 \quad \mathrm{GE}$

$\mu \mathrm{g} / \mathrm{L} \quad 0 \quad \mathrm{GE}$

$\mu \mathrm{g} / \mathrm{L} \quad 0 \quad \mathrm{GE}$

$\mu g / L \quad 0 \quad$ GE

$\mu \mathrm{g} / \mathrm{L} \quad 0 \quad \mathrm{GE}$

$\mu g / L \quad 0 \quad G E$

$\mu \mathrm{g} / \mathrm{L} \quad 0 \quad \mathrm{GE}$

$\mu \mathrm{g} / \mathrm{L} \quad 0 \quad \mathrm{GE}$

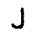

$\mu \mathrm{g} / \mathrm{L}$

$\mu \mathrm{g} / \mathrm{L}$

$\mu \mathrm{g} / \mathrm{L}$

$\mu \mathrm{g} . \mathrm{L}$

$\mu \mathrm{g} / \mathrm{L}$

$\mu \mathrm{g} / \mathrm{L}$

$\mu \mathrm{g} / \mathrm{L}$

$\mu \mathrm{g} / \mathrm{L}$

$\mu g / L$

$\mu g / L$

$\mu \mathrm{g} / \mathrm{L}$

$\mu g / L$

$\mu \mathrm{g} / \mathrm{L}$

$\mu g / L$

$\mu \mathrm{g} / \mathrm{L}$

$\mu g / L$

$\mu \mathrm{g} / \mathrm{L}$

$\mu \mathrm{g} / \mathrm{L}$ 
WELL. BGO 45A collected on 02/24/94, laboratory analyses (cont.)

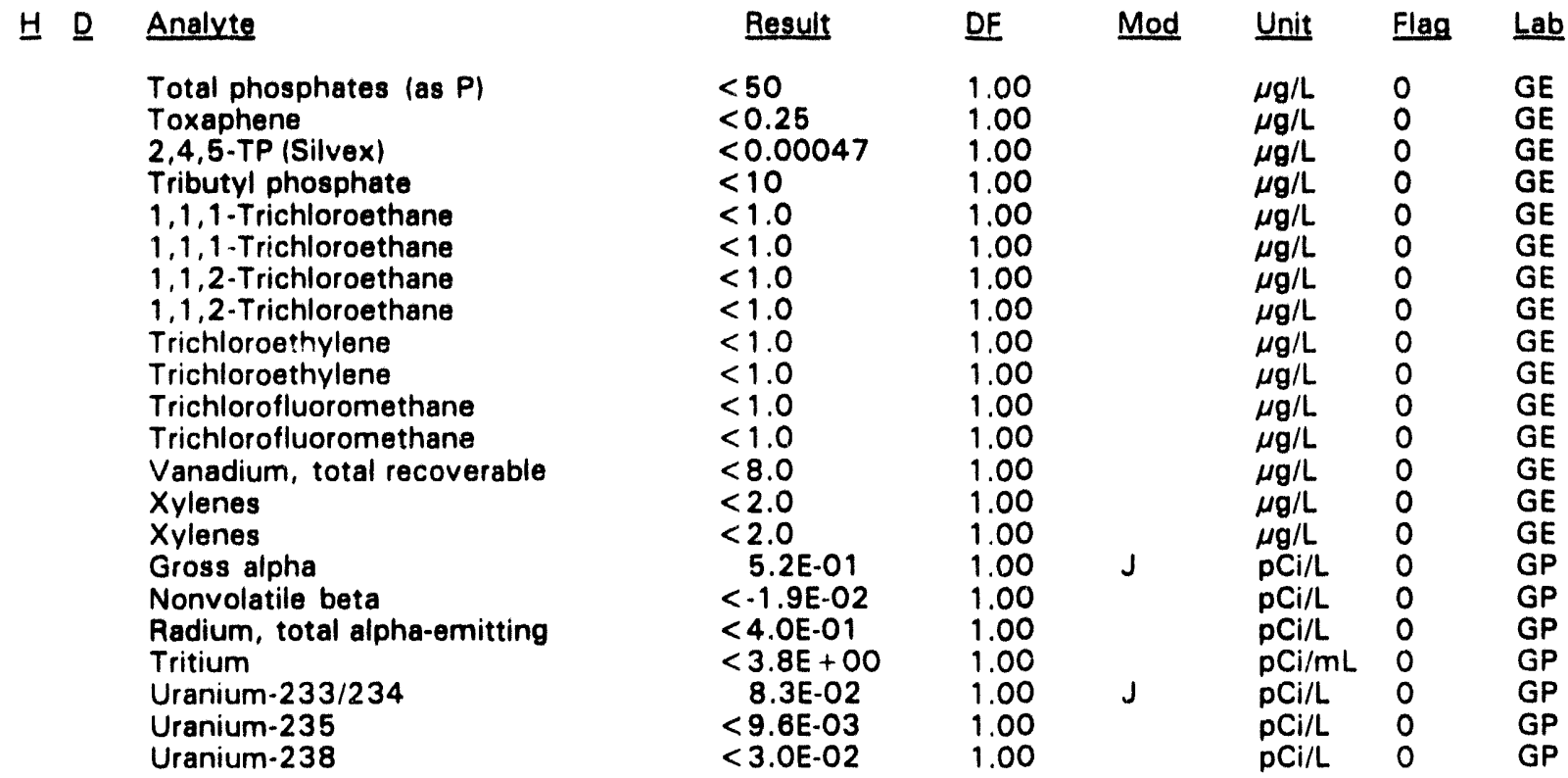

\section{WELL BGO 45B}

\begin{tabular}{|c|c|c|c|c|c|c|}
\hline SRS Coord. & Lat/Longitude & Screen Zone Elevation & Top of Casing & Casing & Pump & Formation \\
\hline $\begin{array}{l}\text { N75840.3 } \\
\text { E54563.6 }\end{array}$ & $\begin{array}{l}33.282536^{\circ} \mathrm{N} \\
81.670441^{\circ} \mathrm{W}\end{array}$ & $147.0-137.0 \mathrm{ft} \mathrm{msl}$ & $278.6 \mathrm{ft} \mathrm{msl}$ & 4" PVC & $\mathrm{S}$ & $n\left(I I B_{1}\right)$ \\
\hline
\end{tabular}

\section{FIELD MEASUREMENTS}

Sample date: $01 / 27 / 94$

Depth to water: $59.15 \mathrm{ft}(18.03 \mathrm{~m})$ below TOC

Water elevation: $219.45 \mathrm{ft}(66.89 \mathrm{~m}) \mathrm{msl}$

Sp. conductance: $113 \mu \mathrm{S} / \mathrm{cm}$

Turbidity: 1.6 NTU

Water evacuated before sampling: $44 \mathrm{gal}$

The well went dry during purging.

\section{LABORATORY ANALYSES}

$\begin{array}{ll}\text { H } & \text { Analyte } \\ \text { pH } & \text { Specific conductance } \\ \text { Turbidity } \\ \text { Acetophenone } \\ \text { Aldrin } \\ \text { Aluminum, total recoverable } \\ \text { Antimony, total recoverable } \\ \text { Arsenic, total recoverable } \\ \text { Barium, total recoverable } \\ \text { Benzene } \\ \text { Benzene } \\ \text { Bromodichloromethane }\end{array}$

- exceeded holding time. = exceeded screening level or final primary drinking water standard.
Time: 11: 55

pH: 10.6

Alkalinity: $26 \mathrm{mg} / \mathrm{L}$

Water temperature: $17.3^{\circ} \mathrm{C}$

Volumes purged: 0.8 well volumes

$\begin{array}{llllll}\text { Result } & \text { DF } & \text { Mod } & \text { Unit } & \text { Flag } & \text { Lab } \\ 11 & 1.00 & \mathrm{~J} 1 & \mathrm{pH} & 2 & \mathrm{GE} \\ 297 & 1.00 & & \mu \mathrm{S} / \mathrm{cm} & 1 & \mathrm{GE} \\ 0.23 & 1.00 & & \mathrm{NTU} & 0 & \mathrm{GE} \\ <10 & 1.00 & & \mu \mathrm{g} / \mathrm{L} & 0 & \mathrm{GE} \\ <0.049 & 1.00 & & \mu \mathrm{g} / \mathrm{L} & 0 & \mathrm{GE} \\ 98 & 1.00 & & \mu \mathrm{g} / \mathrm{L} & 2 & \mathrm{GE} \\ <2.0 & 1.00 & & \mu \mathrm{g} / \mathrm{L} & 0 & \mathrm{GE} \\ <2.0 & 1.00 & & \mu \mathrm{g} / \mathrm{L} & 0 & \mathrm{GE} \\ 61 & 1.00 & & \mu \mathrm{g} / \mathrm{L} & 0 & \mathrm{GE} \\ <1.0 & 1.00 & & \mu \mathrm{g} / \mathrm{L} & 0 & \mathrm{GE} \\ <1.0 & 1.00 & & \mu \mathrm{g} / \mathrm{L} & 0 & \mathrm{GE} \\ <1.0 & 1.00 & & \mu \mathrm{g} / \mathrm{L} & 0 & \mathrm{GE}\end{array}$


WELL BGO 458 collected on 01/27/94, laboratory analyses (cont.)

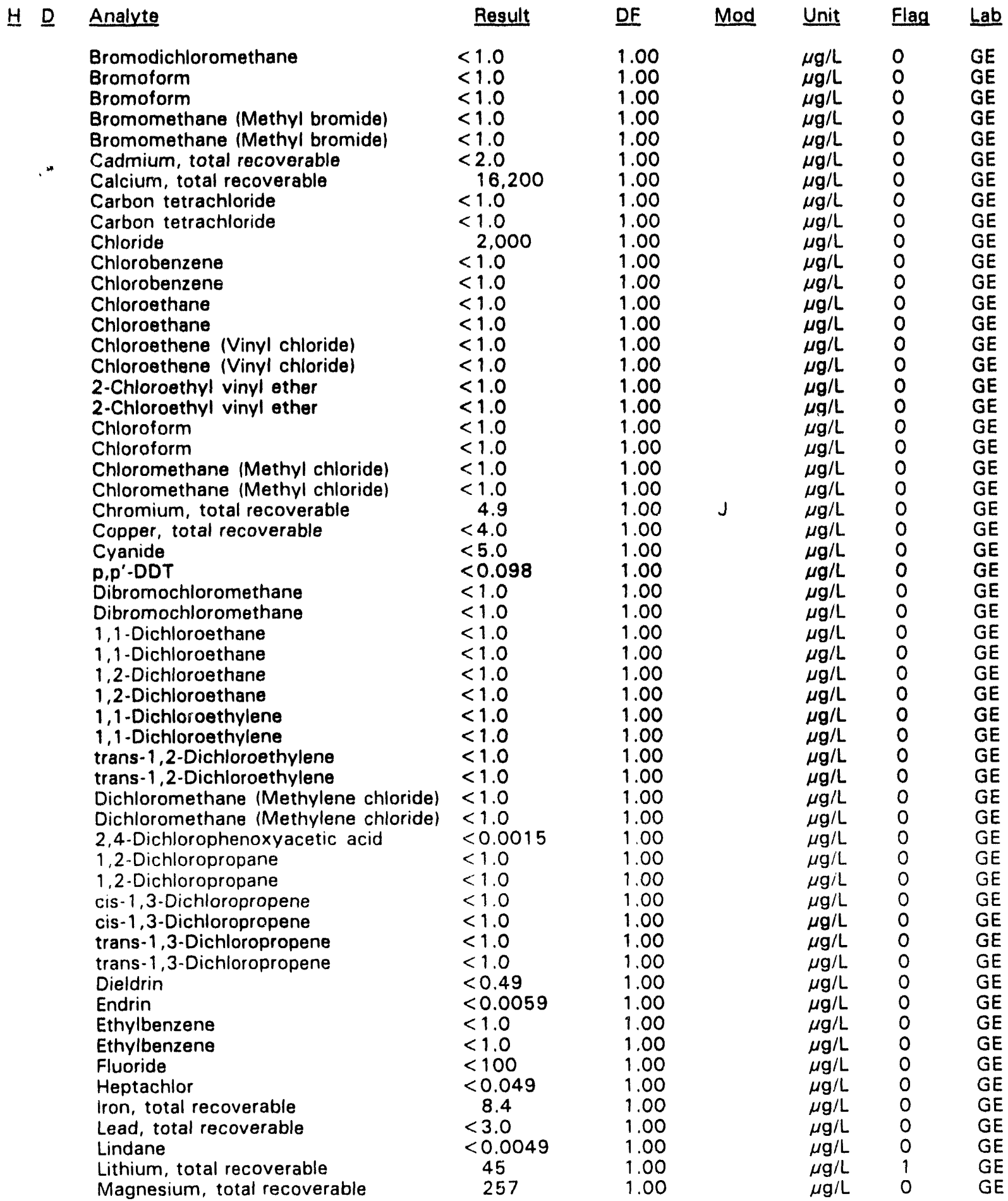

- = exceeded holding time. = exceeded screening level or final primary drinking water standard. 
WELL BGO 45B collected on 01/27/94, laboratory analyses (cont.)

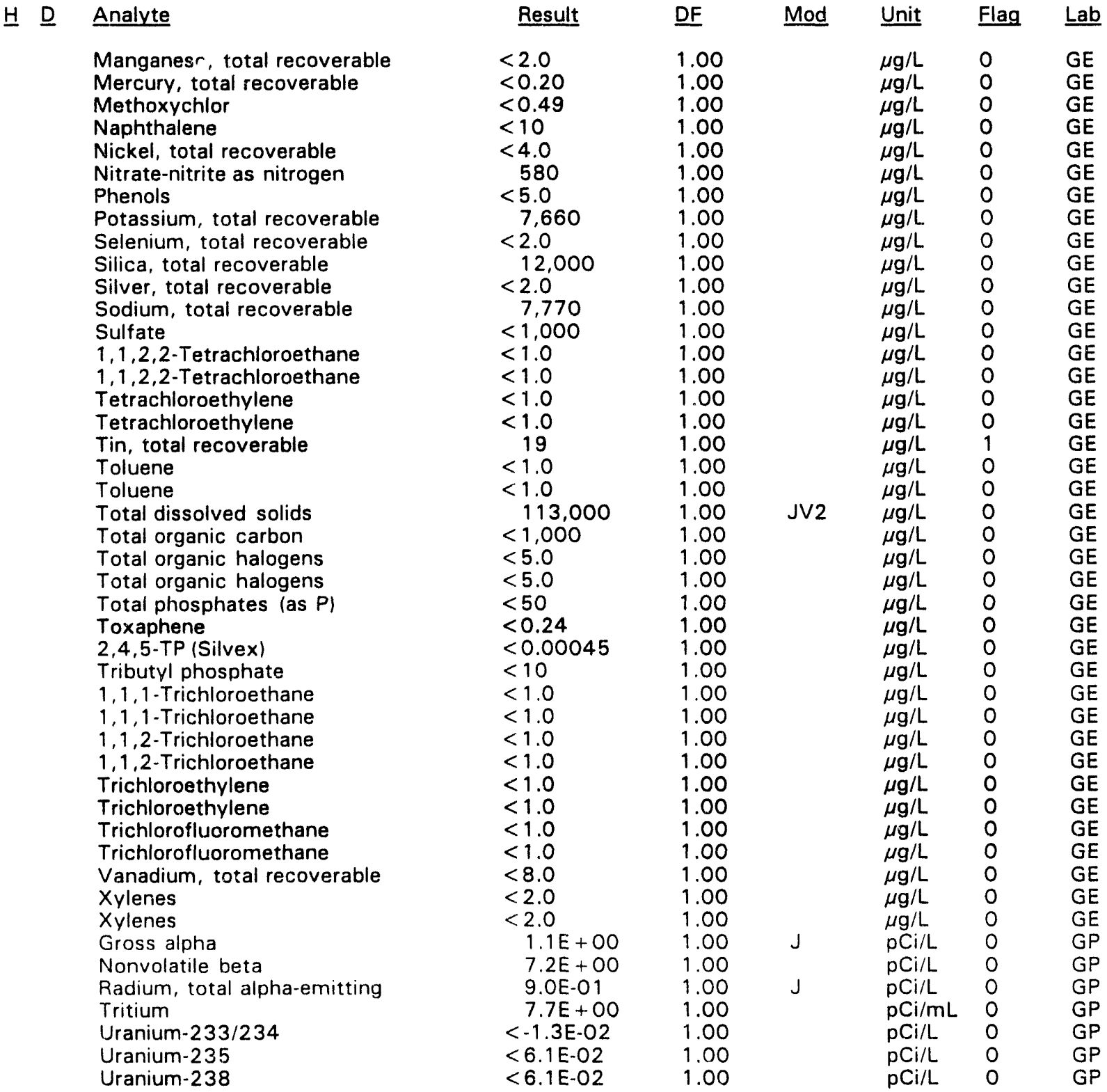

\footnotetext{
$\overline{-=}$ exceeded holding time. $=$ exceeded screening level or final primary drinking water standard.
} 
WELL BGO 45C

\begin{tabular}{|c|c|c|c|c|c|c|}
\hline SRS Coord. & Lat/Longitude & Screen Zone Elevation & Top of Casing & Casing & Pump & Formation \\
\hline $\begin{array}{l}\text { N75835.0 } \\
\text { E54577.4 }\end{array}$ & $\begin{array}{l}33.282547^{\circ} \mathrm{N} \\
81.670395^{\circ} \mathrm{W}\end{array}$ & $200.5-190.5 \mathrm{ft} \mathrm{msl}$ & $278.6 \mathrm{ft} \mathrm{msl}$ & 4" PVC & $\mathrm{S}$ & Barr \\
\hline
\end{tabular}

\section{FIELD MEASUREMENTS}

Sample date: $01 / 27 / 94$

Depth to water: $55.16 \mathrm{ft}(16.81 \mathrm{~m})$ below TOC

Water elevation: $223.44 \mathrm{ft}(68.11 \mathrm{~m}) \mathrm{msl}$

Sp. conductance: $32 \mu \mathrm{S} / \mathrm{cm}$

Turbidity: 2.1 NTU

Water evacuated before sampling: $20 \mathrm{gal}$

The well went dry during purging.

\section{LABORATORY ANALYSES}

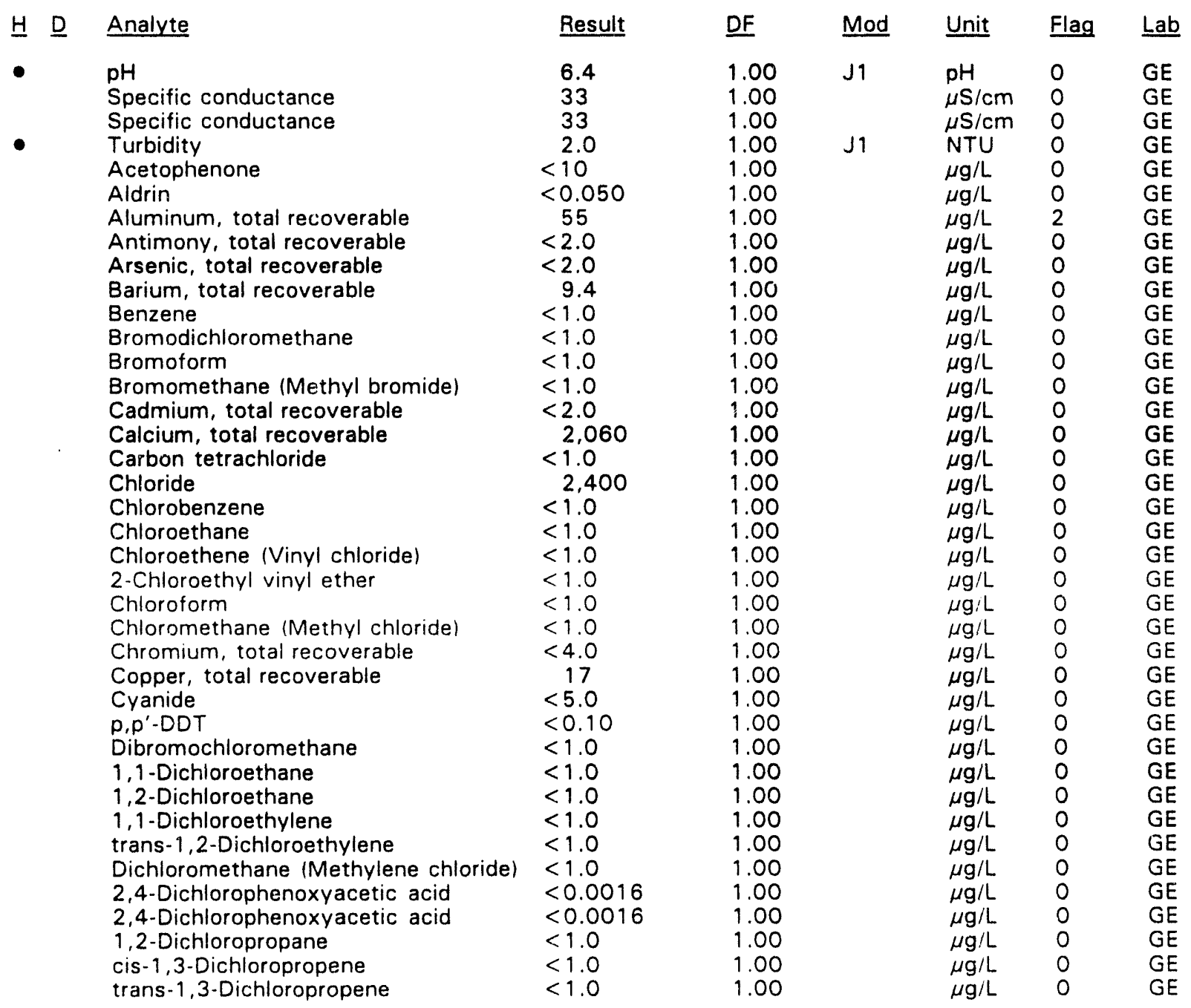

Time: $11: 36$

$\mathrm{pH}: 5.5$

Alkalinity: $3 \mathrm{mg} / \mathrm{L}$

Water temperature: $16.9^{\circ} \mathrm{C}$

Volumes purged: 0.9 well volumes
Bromodichloromethane

Bromomethane (Methyl bromide)

inium, total recoverable

Carbon tetrachloride

Chloroethane

Chloroethene (Vinyl chloride)

-Chioroethyl vinyl ether

oform

Copper, total recoverable

Dibromochloromethane

1,1-Dichioroethane

trans-1,2-Dichloroethylene

- = exceeded holding time. = exceeded ucreening level or final primary drinking water standard. 
WELL BGO $45 \mathrm{C}$ collected on $01 / 27 / 94$, laboratory analyses (cont.)

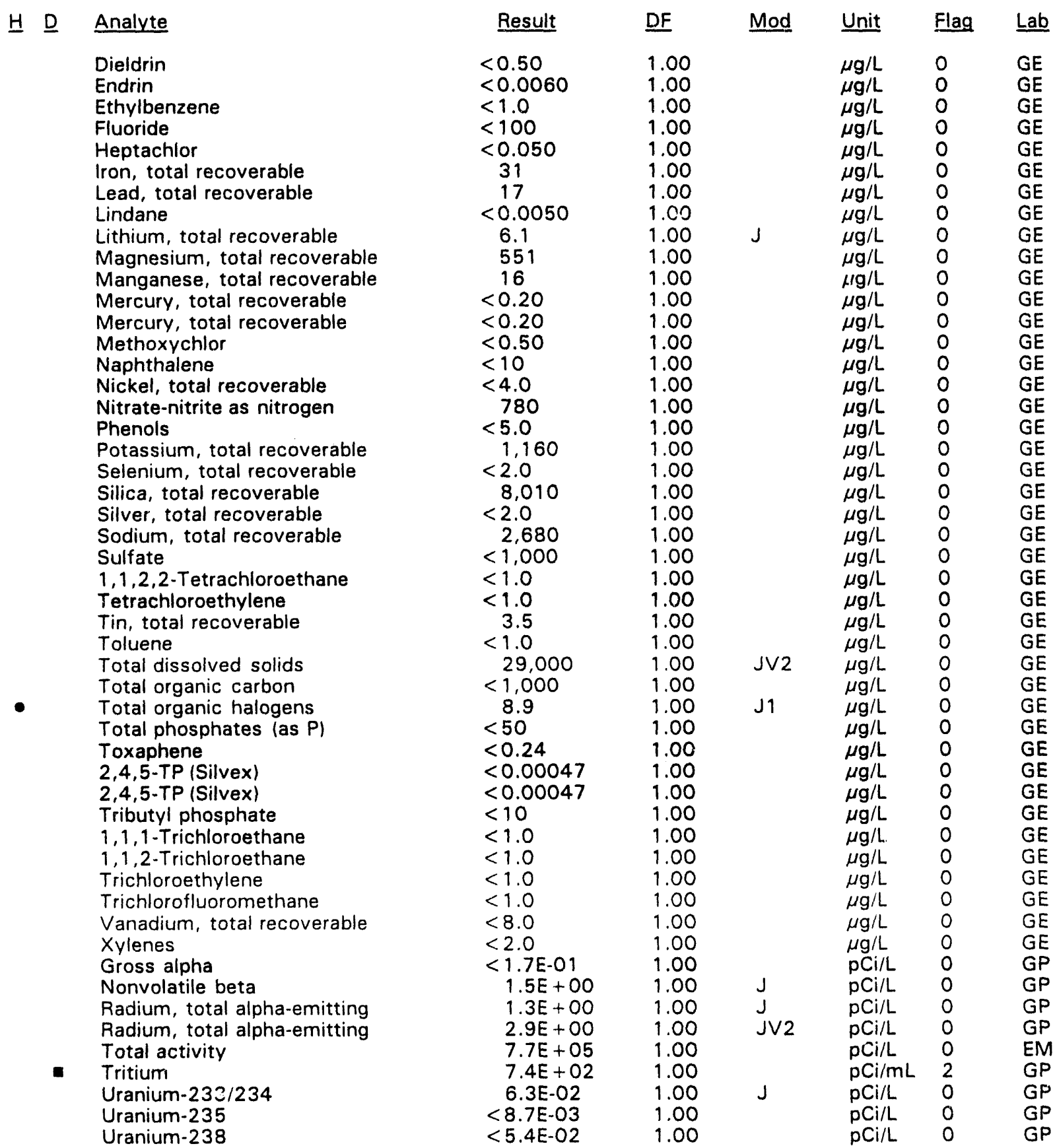

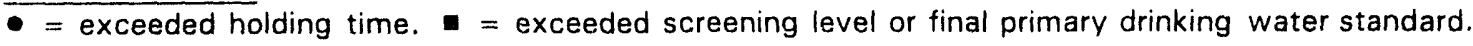




\begin{tabular}{|c|c|c|c|c|c|c|}
\hline SRS Coord. & Lat/Longitude & Screen Zone Elevation & Top of Casing & Casing & Pump & Formation \\
\hline $\begin{array}{l}N 75854.3 \\
E 54585.6\end{array}$ & $\begin{array}{l}33.282603^{\circ} \mathrm{N} \\
81.670411^{\circ} \mathrm{W}\end{array}$ & $229.6-209.6 \mathrm{ft} \mathrm{msl}$ & $278.6 \mathrm{ft} \mathrm{msl}$ & 4" PVC & S & Water Table $\left(11 B_{2}\right)$ \\
\hline
\end{tabular}

\section{FIELD MEASUREMENTS}

Sample date: $01 / 26 / 94$

Depth to water: $50.81 \mathrm{ft}(15.49 \mathrm{~m})$ below TOC

Water elevation: $227.79 \mathrm{ft}(69.43 \mathrm{~m}) \mathrm{ms}$

Sp. conductance: $26 \mu \mathrm{S} / \mathrm{cm}$

Turbidity: 0.9 NTU

Water evacuated before sampling: $106 \mathrm{gal}$

\section{LABORATORY ANALYSES}

\section{H $\underline{\text { Analyte }}$}

- $\quad \mathrm{pH}$

Specific conductance

Turbidity

Acetophenone

Aldrin

Aluminum, total recoverable

Antimony, total recoverable

Arsenic, total recoverable

Barium, total recoverable

Benzene

Bromodichloromethane

Bromoform

Bromomethane (Methyl bromide)

Cadmium, total recoverable

Calcium, total recoverable

Carbon tetrachloride

Chloride

Chlorobenzene

Chloroethane

Chloroethene (Vinyl chloride)

2-Chloroethyl vinyl ether

Chloroform

Chloromethane (Methyl chloride)

Chromium, total recoverable

Copper, total recoverable

Cyanide

p.p'-DDT

Dibromochloromethane

1,1-Dichloroethane

1.2-Dichloroethane

1,1-Dichloroethylene

trans-1,2-Dichloroethylene

Dichloromethane (Methylene chloride)

2,4-Dichlorophenoxyacetic acid

2,4-Dichlorophenoxyacetic acid

1,2-Dichloropropane

cis-1,3-Dichloropropene

trans-1,3-Dichloropropene

Dieldrin

\begin{tabular}{|c|c|c|c|c|c|}
\hline Result & DF & Mod & Unit & Flag & $\underline{L a b}$ \\
\hline 7.3 & 1.00 & $J 1$ & $\mathrm{pH}$ & 0 & GE \\
\hline $\begin{array}{l}23 \\
<0.10\end{array}$ & 1.00 & & $\mu \mathrm{S} / \mathrm{cm}$ & 0 & E \\
\hline $\begin{array}{l}<0.10 \\
<10\end{array}$ & 1.00 & & NTU & 0 & $3 E$ \\
\hline $\begin{array}{l}<10 \\
<0.051\end{array}$ & 1.00 & & $\mu \mathrm{g} / \mathrm{L}$ & 0 & GE \\
\hline $\begin{array}{c}<0.051 \\
27\end{array}$ & $\begin{array}{l}1.00 \\
1.00\end{array}$ & & $\mu \mathrm{g} / \mathrm{L}$ & 0 & GE \\
\hline $\begin{array}{r}27 \\
<2.0\end{array}$ & $\begin{array}{l}1.00 \\
1.00\end{array}$ & $\mathrm{~J}$ & $\begin{array}{l}\mu \mathrm{g} / \mathrm{L} \\
\mu \mathrm{g} / \mathrm{L}\end{array}$ & $\begin{array}{l}1 \\
0\end{array}$ & $G E$ \\
\hline$<2.0$ & 1.00 & & $\mu \mathrm{g} / \mathrm{L}$ & 0 & $\mathrm{GE}$ \\
\hline 8.3 & 1.00 & & $\mu \mathrm{g} / \mathrm{L}$ & 0 & $\mathrm{GE}$ \\
\hline$<1.0$ & 1.00 & & $\mu \mathrm{g} / \mathrm{L}$ & 0 & $G E$ \\
\hline$<1.0$ & 1.00 & & $\mu \mathrm{g} / \mathrm{L}$ & 0 & $\mathrm{GE}$ \\
\hline$<1.0$ & 1.00 & & $\mu \mathrm{g} / \mathrm{L}$ & 0 & $\mathrm{SE}$ \\
\hline$<1.0$ & 1.00 & & $\mu \mathrm{g} / \mathrm{L}$ & 0 & GE \\
\hline$<2.0$ & 1.00 & & $\mu \mathrm{g} / \mathrm{L}$ & 0 & $\overline{G E}$ \\
\hline 840 & 1.00 & & $\mu \mathrm{g} / \mathrm{L}$ & 0 & GE \\
\hline$<1.0$ & 1.00 & & $\mu \mathrm{g} / \mathrm{L}$ & 0 & \\
\hline $\begin{aligned} & 1,990 \\
< & 1.0\end{aligned}$ & $\begin{array}{l}1.00 \\
1.00\end{array}$ & & $\begin{array}{l}\mu \mathrm{g} / \mathrm{L} \\
\mu \mathrm{g} / \mathrm{L}\end{array}$ & $\begin{array}{l}0 \\
0\end{array}$ & GE \\
\hline$<1.0$ & 1.00 & & $\mu \mathrm{g} / \mathrm{L}$ & 0 & $\mathrm{GE}$ \\
\hline$<1.0$ & 1.00 & & $\mu \mathrm{g} / \mathrm{L}$ & 0 & $G E$ \\
\hline$<1.0$ & 1.00 & & $\mu \mathrm{g} / \mathrm{L}$ & 0 & $\overline{G E}$ \\
\hline$<1.0$ & 1.00 & & $\mu \mathrm{g} / \mathrm{L}$ & 0 & GE \\
\hline$<1.0$ & 1.00 & & $\mu \mathrm{g} / \mathrm{L}$ & 0 & GE \\
\hline$<4.0$ & 1.00 & & $\mu \mathrm{g} / \mathrm{L}$ & 0 & GE \\
\hline 11 & 1.00 & & $\mu \mathrm{g} / \mathrm{L}$ & 0 & GE \\
\hline$<5.0$ & 1.00 & & $\mu \mathrm{g} / \mathrm{L}$ & 0 & GE \\
\hline$<0.10$ & 1.00 & & $\mu \mathrm{g} / \mathrm{L}$ & 0 & GE \\
\hline$<1.0$ & 1.00 & & $\mu g / L$ & 0 & GE \\
\hline$<1.0$ & 1.00 & & $\mu \mathrm{g} / \mathrm{L}$ & 0 & GE \\
\hline$<1.0$ & 1.00 & & $\mu \mathrm{g} / \mathrm{L}$ & 0 & GE \\
\hline$<1.0$ & 1.00 & & $\mu \mathrm{g} / \mathrm{L}$ & 0 & GE \\
\hline$<1.0$ & 1.00 & & $\mu \mathrm{g} / \mathrm{L}$ & 0 & GE \\
\hline$<1.0$ & 1.00 & & $\mu \mathrm{g} / \mathrm{L}$ & 0 & GE \\
\hline$<0.0015$ & 1.00 & & $\mu \mathrm{g} / \mathrm{L}$ & 0 & SE \\
\hline$<0.0015$ & 1.00 & & $\mu \mathrm{g} / \mathrm{L}$ & 0 & GE \\
\hline$<1.0$ & 1.00 & & $\mu \mathrm{g} / \mathrm{L}$ & 0 & $\mathrm{E}$ \\
\hline$<1.0$ & 1.00 & & $\mu \mathrm{g} / \mathrm{L}$ & 0 & $E$ \\
\hline$<1.0$ & 1.00 & & $\mu \mathrm{g} / \mathrm{L}$ & 0 & \\
\hline$<0.51$ & 1.00 & & $\mu \mathrm{g} / \mathrm{L}$ & 0 & \\
\hline
\end{tabular}

Time: $16: 26$

$\mathrm{pH}: 4.9$

Alkalinity: $0 \mathrm{mg} / \mathrm{L}$

Water temperature: $18.7^{\circ} \mathrm{C}$

Volumes purged: 8.9 well volumes 
WELL BGO 45D collected on 01/26/94, laboratory analyses (cont.)

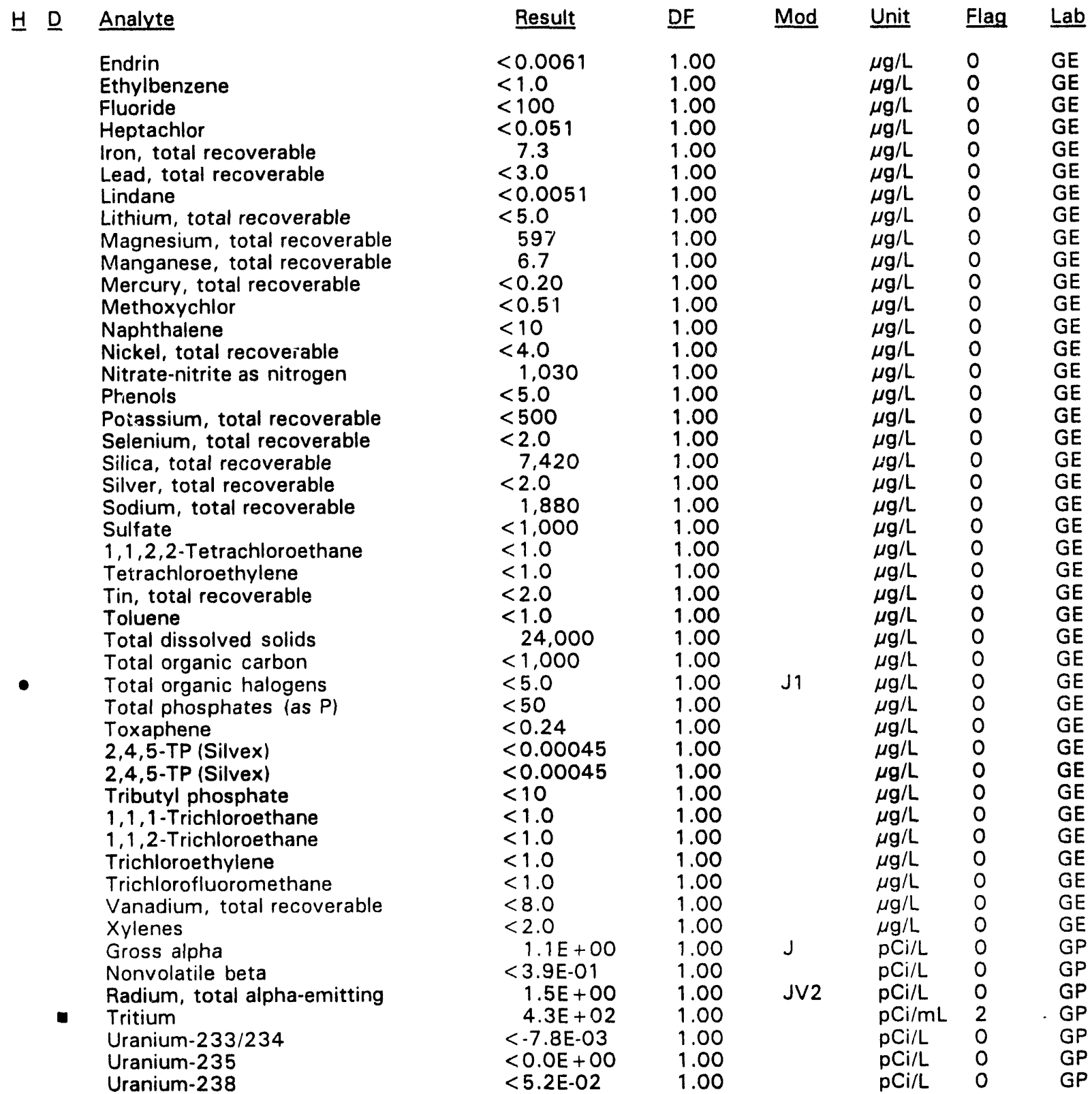

$\overline{-}=$ exceeded holding time. $=$ exceeded screening level or final primary drinking water standard. 
WELL BGO 46B

$\begin{array}{lllllll}\text { SRS Coord. Lat/Longitude } & \text { Screen Zone Elevation } & \text { Top of Casing } & \text { Casing } & \text { Pump } & \text { Formation } \\ \text { N75012.1 } & 33.280511^{\circ} \mathrm{N} & 150.4-140.4 \mathrm{ft} \mathrm{msl} & 265.4 \mathrm{ft} \mathrm{msl} & \text { 4" PVC } & \text { S } & \text { McBean (IIB, }) \\ \text { E54444.7 } & 81.669146^{\circ} \mathrm{W} & & & \end{array}$

\section{FIELD MEASUREMENTS}

Sample date: $02 / 21 / 94$

Depth to water: $47.59 \mathrm{ft}(14.51 \mathrm{~m})$ below TOC

Water elevation: $217.81 \mathrm{ft}(66.39 \mathrm{~m}) \mathrm{ms}$

Sp. conductance: $59 \mu \mathrm{S} / \mathrm{cm}$

Turbidity: 0.5 NTU

Water evacuated before sampling: $137 \mathrm{gal}$

\section{LABORATORY ANALYSES}

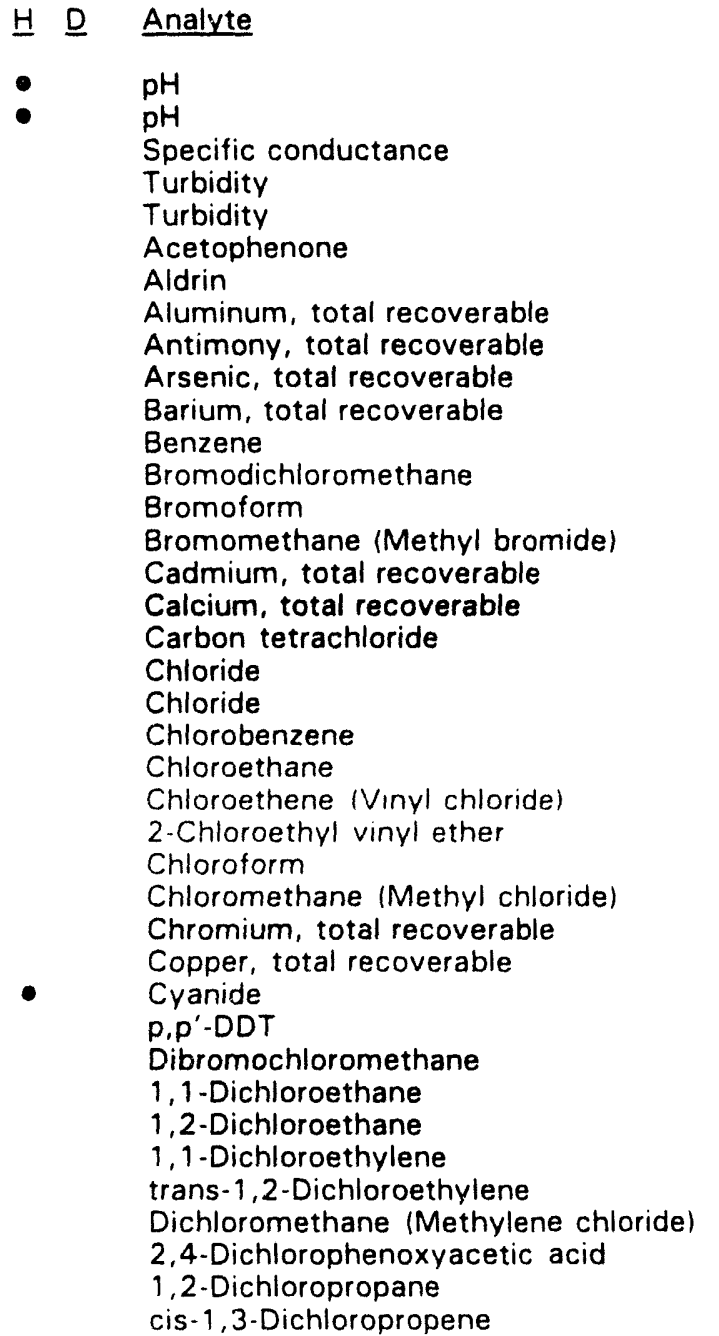

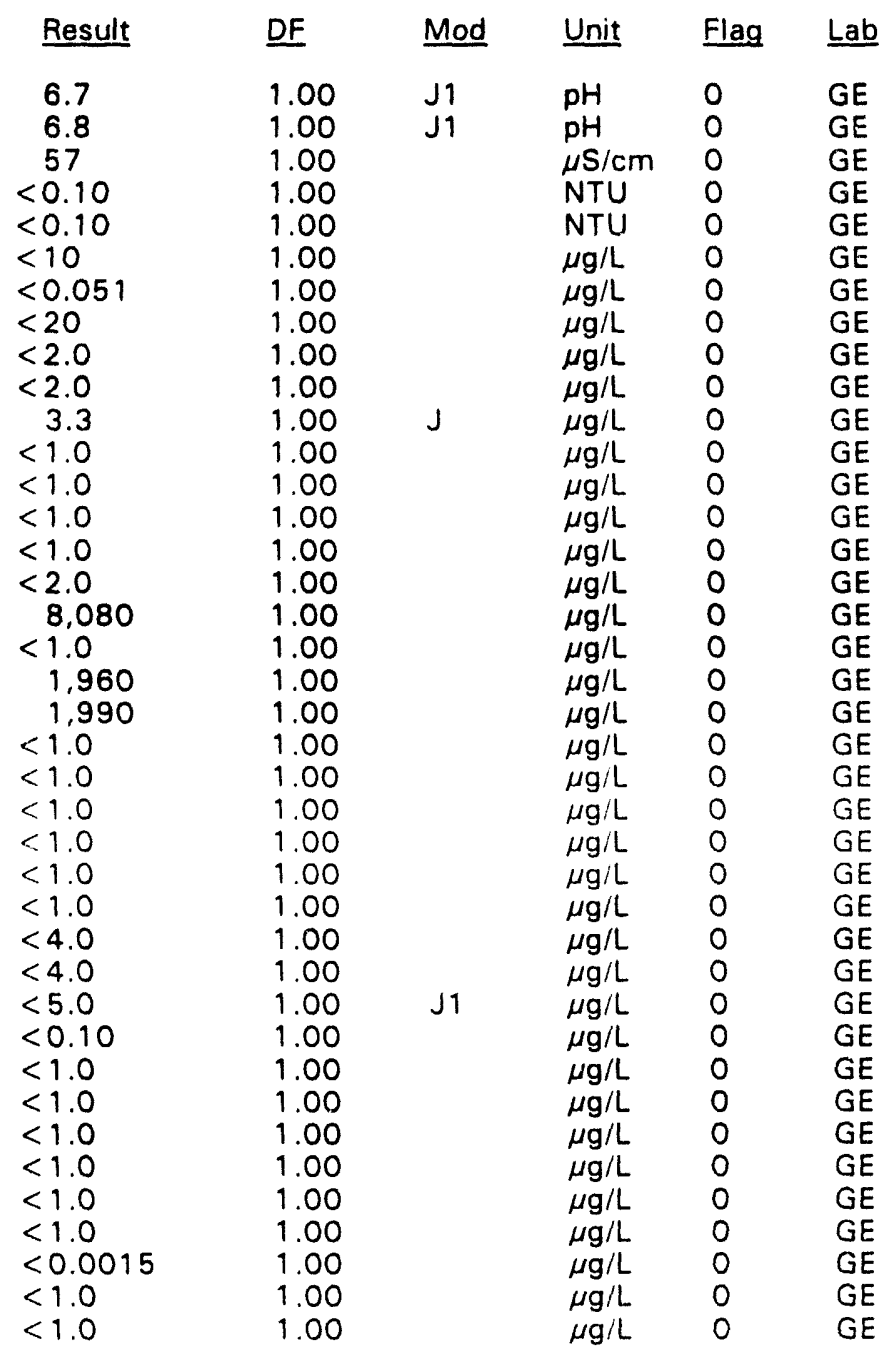

Time: $11: 55$

$\mathrm{pH}: 6.4$

Alkalinity: $18 \mathrm{mg} / \mathrm{L}$

Water temperature: $19.7^{\circ} \mathrm{C}$

Volumes purged: 2.7 well volumes 
WELL BGO 46B collected on 02/21/94, laboratory analyses (cont.)

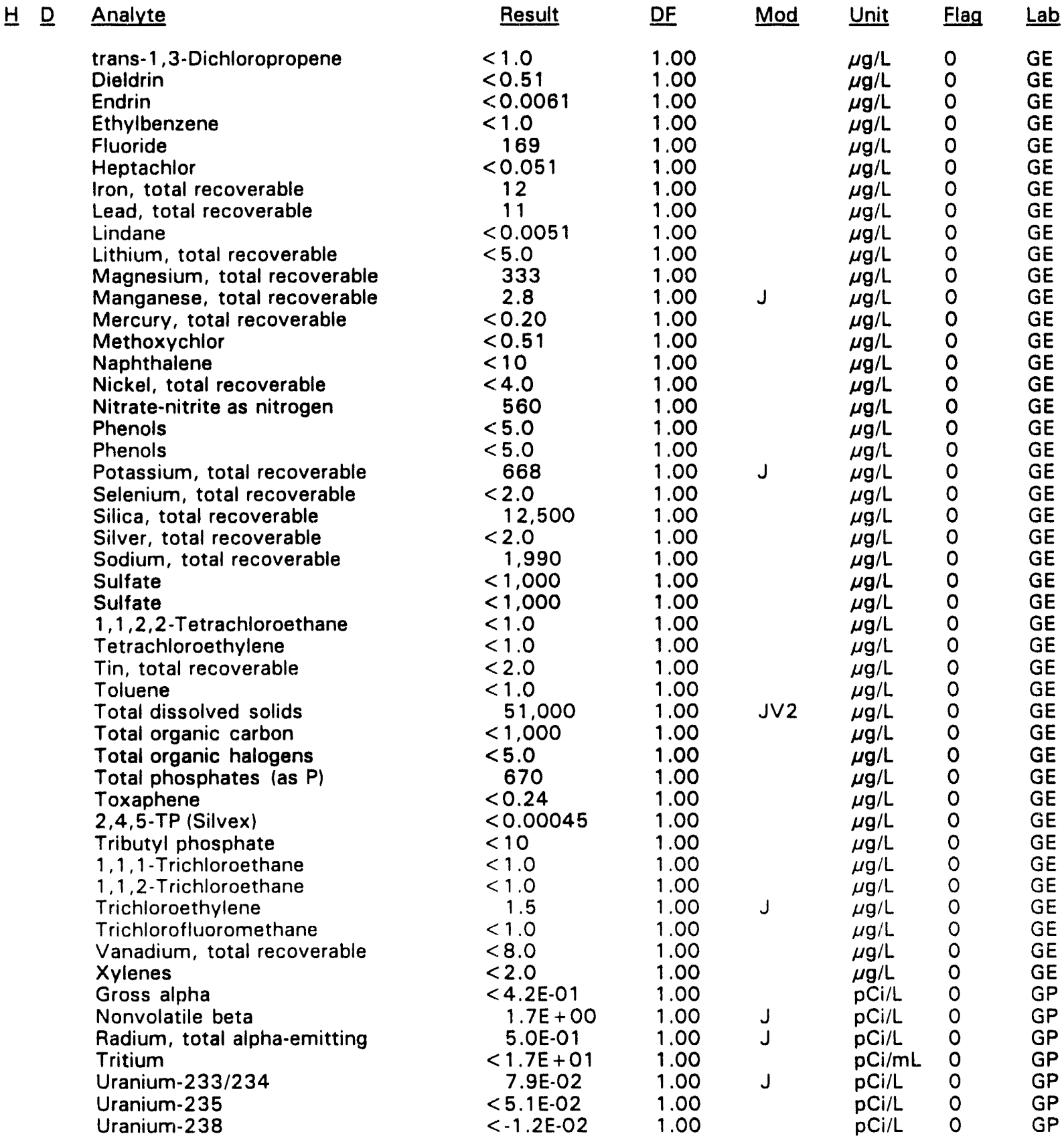

- = exceeded holding time. = exceeded screening level or final primary drinking water standard. 


\begin{tabular}{|c|c|c|c|c|c|c|}
\hline SRS Coord. & Lat/Longitude & Screen Zone Elevation & Top of Casing & Casing & Pump & Formation \\
\hline $\begin{array}{l}N 75022.2 \\
\text { E54433.9 }\end{array}$ & $\begin{array}{l}33.280515^{\circ} \mathrm{N} \\
81.669194^{\circ} \mathrm{W}\end{array}$ & $188.0-178.0 \mathrm{ft} \mathrm{msl}$ & $265.1 \mathrm{ft} \mathrm{msl}$ & 4" PVC & $\mathbf{S}$ & lell $\left(I I B_{1}\right)$ \\
\hline
\end{tabular}

\section{FIELD MEASUREMENTS}

Sample date: $02 / 22 / 94$

Depth to water: $45.74 \mathrm{ft}(13.94 \mathrm{~m})$ below TOC

Water elevation: $219.36 \mathrm{ft}(66.86 \mathrm{~m}) \mathrm{ms}$

Sp. conductance: $55 \mu \mathrm{S} / \mathrm{cm}$

Turbidity: 98.9 NTU

Water evacuated before sampling: 23 gal

The well went dry during purging.

Time: $9: 33$

pH: 6.2

Alkalinity: $12 \mathrm{mg} / \mathrm{L}$

Water temperature: $18.0^{\circ} \mathrm{C}$

Volumes purged: 0.8 well volumes

\section{LABORATORY ANALYSES}

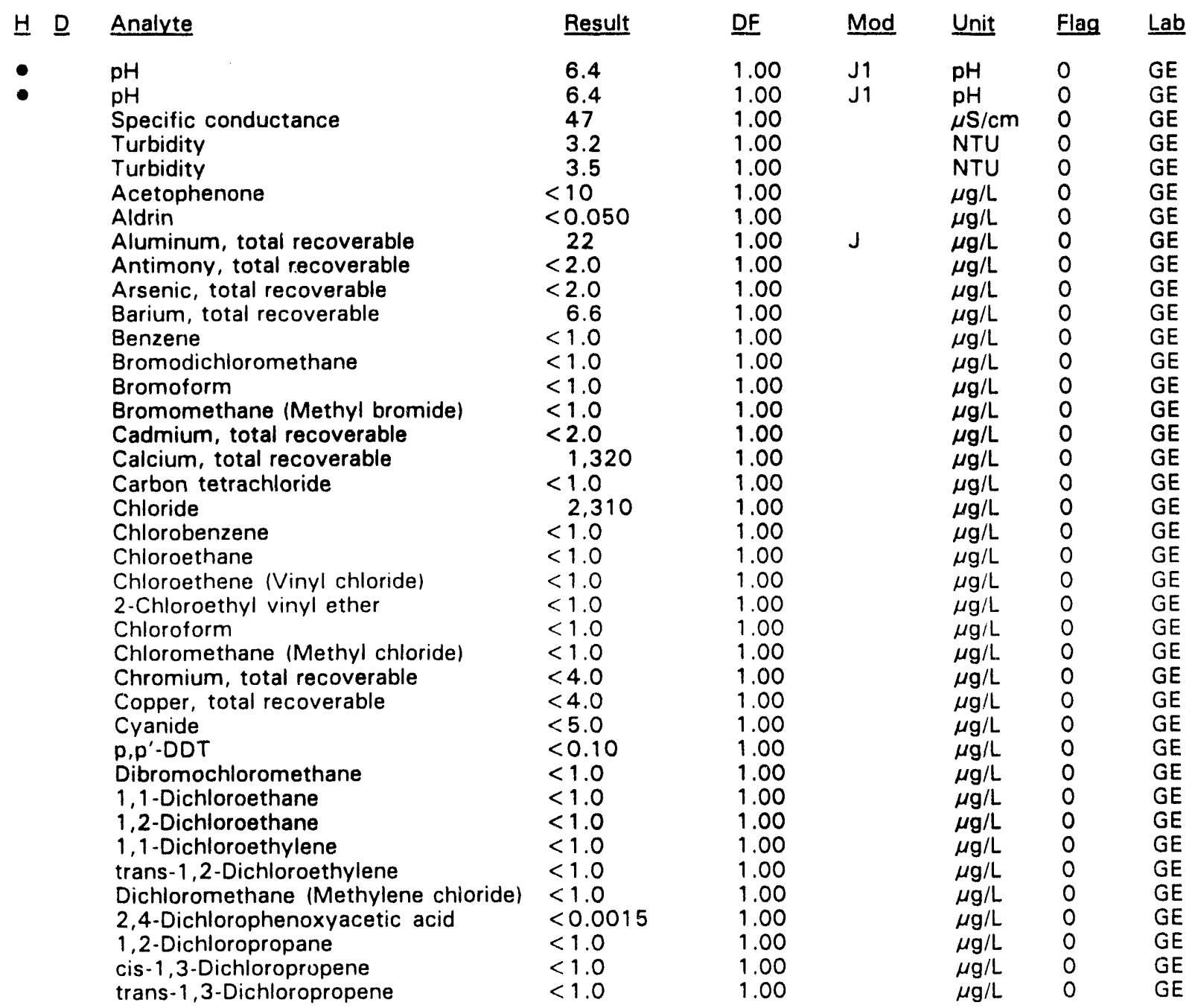

$\overline{-=\text { exceeded holding time. }} \boldsymbol{-}=$ exceeded screening level or final primary drinking water standard. 
WELL BGO $46 \mathrm{C}$ collected on $02 / 22 / 94$, laboratory analyses (cont.)

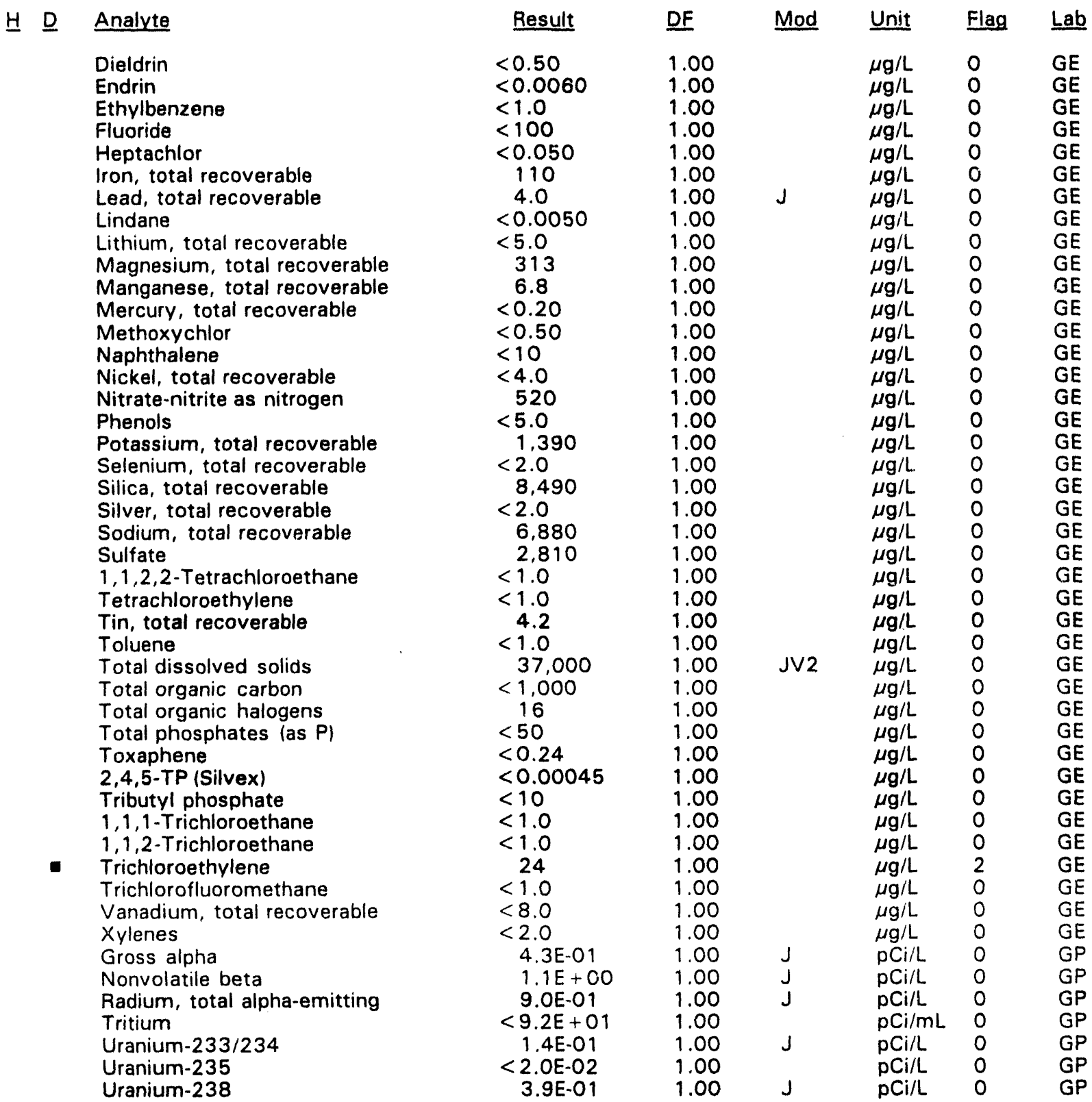

- exceeded holding time. = exceeded screening level or final primary drinking water standard. 


\section{WELL BGO 46D}

\begin{tabular}{|c|c|c|c|c|c|c|}
\hline SRS Coord. & Lat/Longitude & Screen Zone Elevation & Top of Casing & Casing & Pump & Formation \\
\hline $\begin{array}{l}N 75033.8 \\
E 54420.0\end{array}$ & $\begin{array}{l}33.280518^{\circ} \mathrm{N} \\
81.669253^{\circ} \mathrm{W}\end{array}$ & $212.1-202.1 \mathrm{ft} \mathrm{msl}$ & $265.1 \mathrm{ft} \mathrm{msl}$ & 4" PVC & S & $\theta\left(\| B_{2}\right)$ \\
\hline
\end{tabular}

\section{FIELD MEASUREMENTS}

Sample date: $02 / 21 / 94$

Depth to water: $40.27 \mathrm{ft}(12.27 \mathrm{~m})$ below TOC

Water elevation: $224.83 \mathrm{ft}(68.53 \mathrm{~m}) \mathrm{msl}$

Sp. conductance: $57 \mu \mathrm{S} / \mathrm{cm}$

Turbidity: 0.5 NTU

Water evacuated before sampling: $266 \mathrm{gal}$

Time: 12: 16

pH: 4.9

Alkalinity: $0 \mathrm{mg} / \mathrm{L}$

Water temperature: $20.1{ }^{\circ} \mathrm{C}$

Volumes purged: 17.8 well volumes

\section{LABORATORY ANALYSES}

H D Analyte

- $\quad \mathrm{pH}$

Specific conductance

Turbidity

Acetophenone

Acetophenone

Aldrin

Aluminum, total recoverable

Antimony, total recoverable

Arsenic, total recoverable

Barium, total recoverable

Benzene

Bromodichloromethane

Bromoform

Bromomethane (Methyl bromide)

Cadmium, total recoverable

Calcium, total recoverable

Carbon tetrachloride

Chloride

Chlorobenzene

Chloroethane

Chloroethene (Vinyl chloride)

2-Chloroethyl vinyl ether

Chloroform

Chloromethane (Methyl chloride)

Chromium, total recoverable

Copper, total recoverable

Cyanide

Cyanide

p.p'-DDT

Dibromochloromethane

1,1-Dichloroethane

1,2-Dichloroethane

1,1-Dichloroethylene

trans-1,2-Dichloroethylene

Dichloromethane (Methylene chloride)

2,4-Dichlorophenoxyacetic acid

2,4-Dichlorophenoxyacetic acid

1,2-Dichloropropane

cis-1,3-Dichloropropene

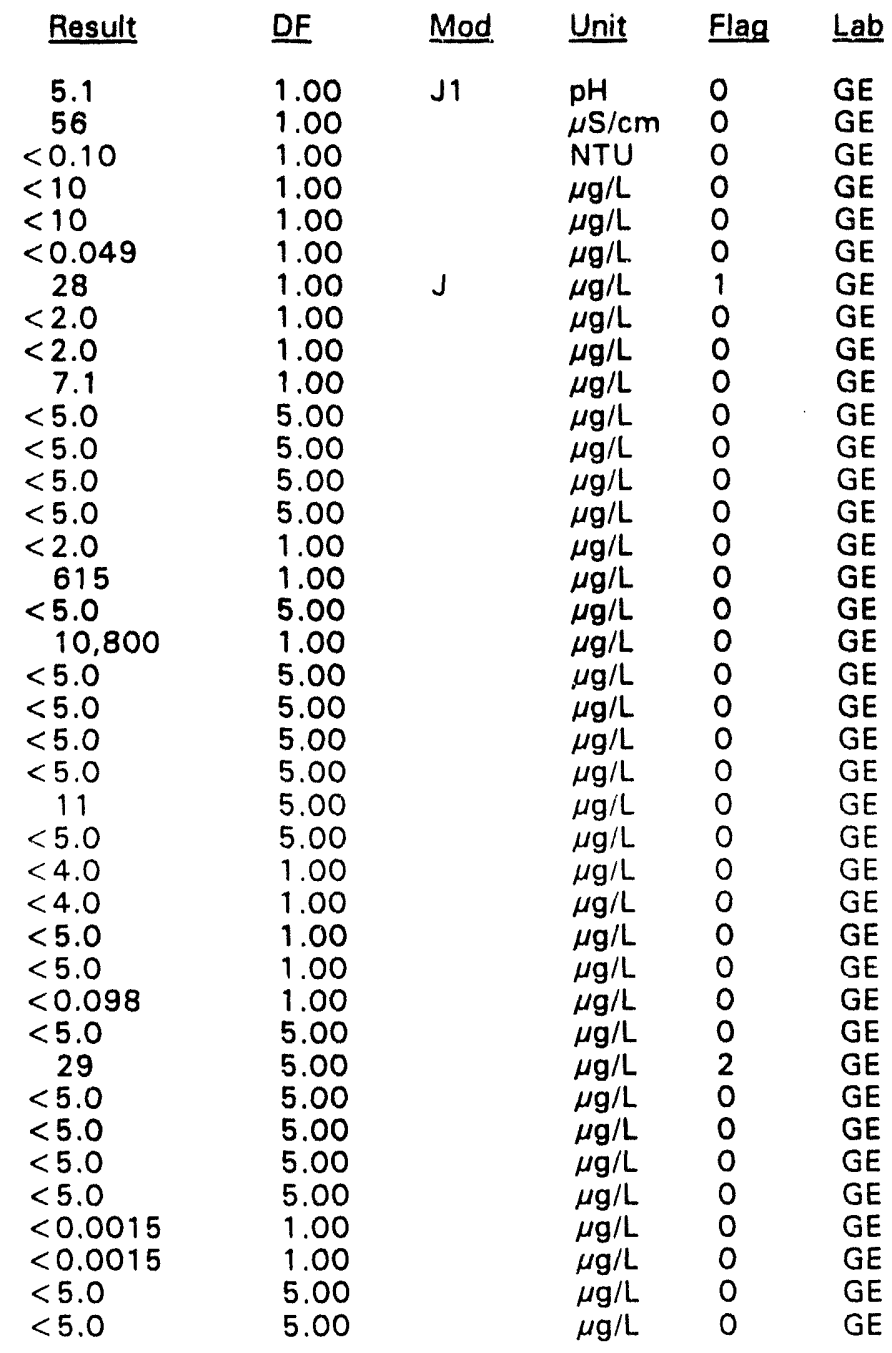

- = exceeded holding time. = exceeded screening level or final primary drinking water standard. 
WELL BGO 46D collected on 02/21/94, laboratory analyses (cont.)

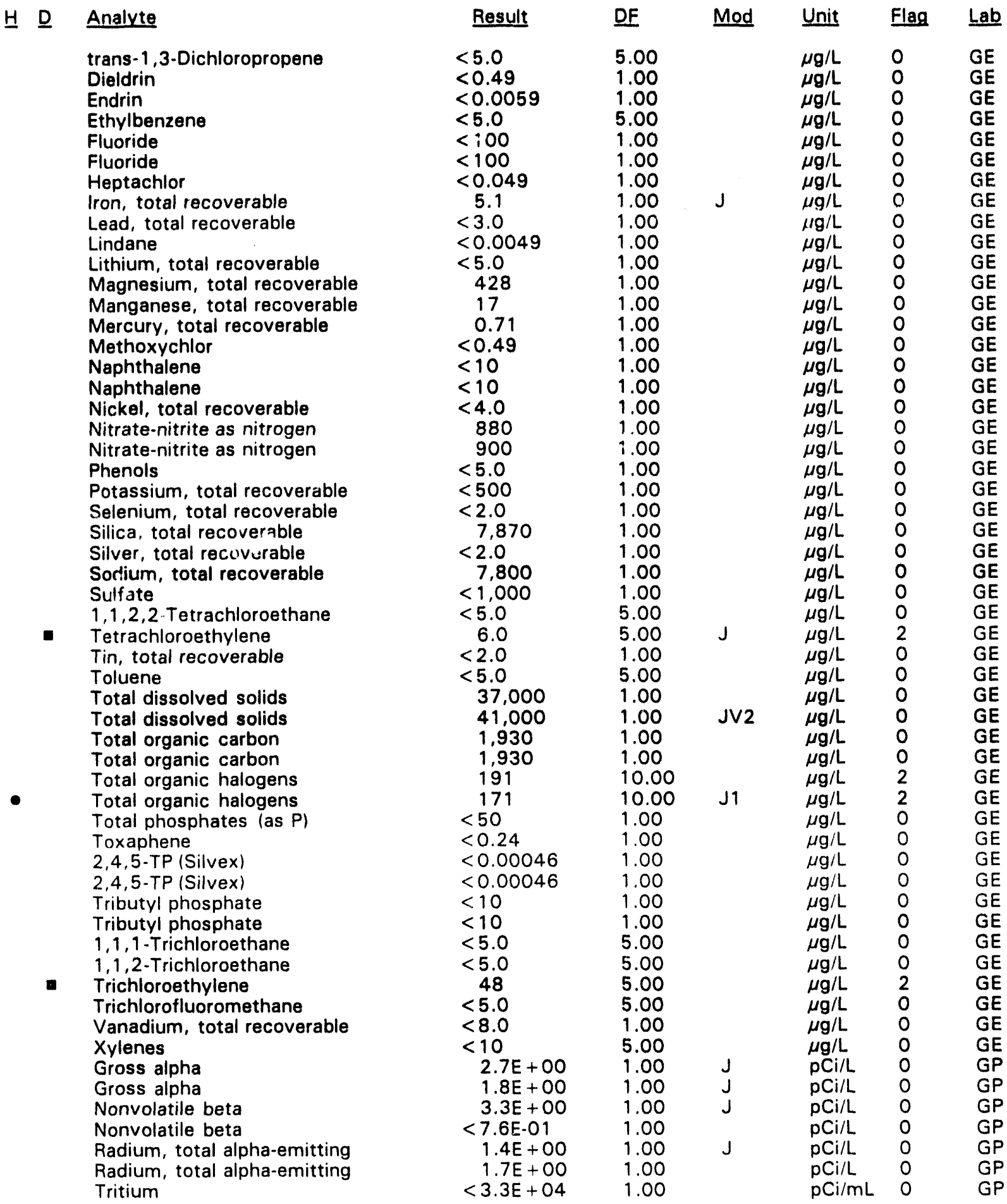

\footnotetext{
$\overline{-}=$ exceeded holding time. - exceeded screening level or final primary drinking water standard.
} 
WELL BGO $46 D$ collected on $02 / 21 / 94$, laboratory analyses (cont.)

\begin{tabular}{|c|c|c|c|c|c|}
\hline H $\quad \underline{\text { Analyte }}$ & Result & DF & Mod & Unit & Flag \\
\hline $\begin{array}{l}\text { Tritium } \\
\text { Uranium-233/234 } \\
\text { Uranium-235 } \\
\text { Uranium-238 }\end{array}$ & $\begin{array}{c}<3.4 E+04 \\
3.7 E-01 \\
<1.1 E-01 \\
1.2 E+00\end{array}$ & $\begin{array}{l}1.00 \\
1.00 \\
1.00 \\
1.00\end{array}$ & $J$ & $\begin{array}{l}\mathrm{pCi} / \mathrm{mL} \\
\mathrm{pCi} / \mathrm{L} \\
\mathrm{pCi} / \mathrm{L} \\
\mathrm{pCi} / \mathrm{L}\end{array}$ & $\begin{array}{l}0 \\
0 \\
0 \\
0\end{array}$ \\
\hline
\end{tabular}

\section{WELL BGO 47A}

\begin{tabular}{|c|c|c|c|c|c|c|}
\hline SRS Coord. & Lat/Longitude & Screen Zone Elevation & Top of Casing & Casing & Pump & Formation \\
\hline $\begin{array}{l}N 74728.8 \\
E 54914.0\end{array}$ & $\begin{array}{l}33.280650^{\circ} \mathrm{N} \\
81.667360^{\circ} \mathrm{W}\end{array}$ & $96.8-86.8 \mathrm{ft} \mathrm{msl}$ & $266.9 \mathrm{ft} \mathrm{msl}$ & 4" PVC & $\mathrm{S}$ & ree $(I \mid A)$ \\
\hline
\end{tabular}

\section{FIELD MEASUREMENTS}

Sample date: $02 / 25 / 94$

Depth to water: $104.74 \mathrm{ft}(31.93 \mathrm{~m})$ below TOC

Water elevation: $162.16 \mathrm{ft}(49.43 \mathrm{~m}) \mathrm{ms} /$

Sp. conductance: $163 \mu \mathrm{S} / \mathrm{cm}$

Turbidity: 3.0 NTU

Water evacuated before sampling: $464 \mathrm{gal}$

Time: 10: 49

pH: 7.4

Alkalinity: $5 \mathrm{mg} / \mathrm{L}$

Water temperature: $18.7^{\circ} \mathrm{C}$

Volumes purged: 9.4 well volumes

\section{LABORATORY ANALYSES}

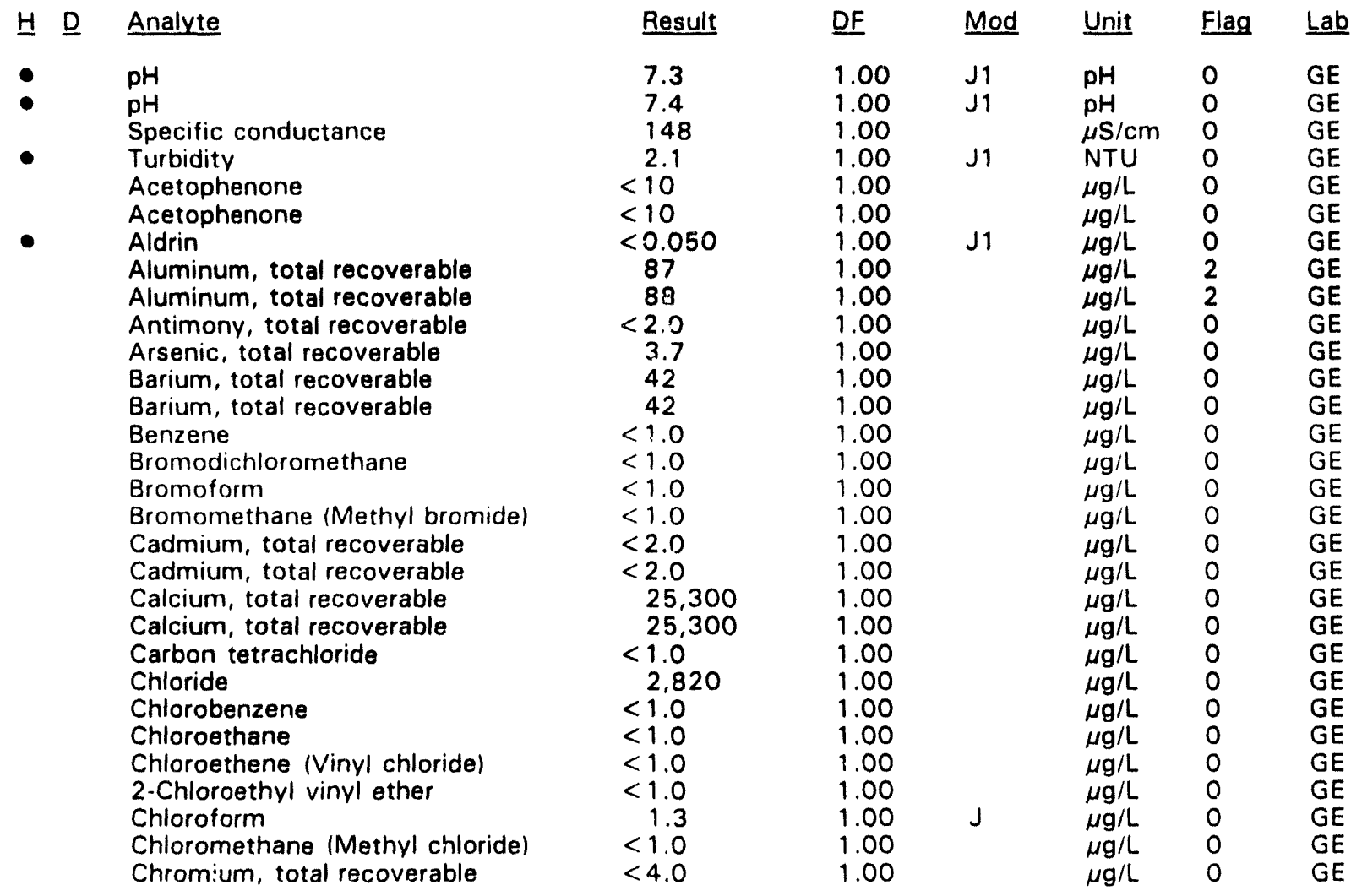

- = exceeded holding time. = exceeded screening level or final primary drinking water standard. 
WELL BGO 47A collected on 02/25/94, laboratory analyses (cont.)

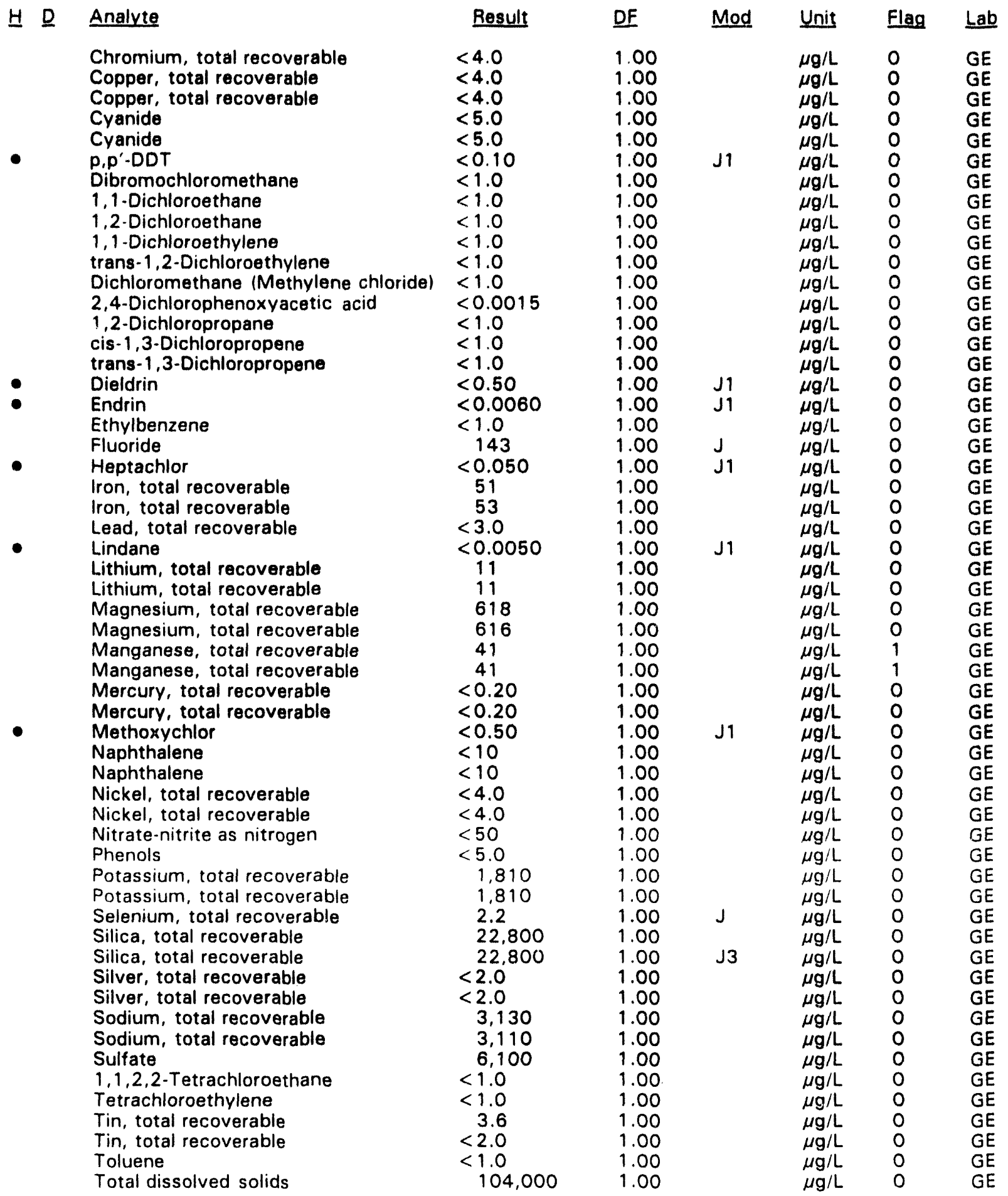

- = exceeded holding time. = exceeded screening level or final primary drinking water standard. 
WELL BGO 47A collected on 02/25/94, laboratory analyses (cont.)

\begin{tabular}{|c|c|c|c|c|c|c|}
\hline $1 \underline{D}$ & Analyte & Result & DF & Mod & Unit & Flag \\
\hline & $\begin{array}{l}\text { Total organic carbon } \\
\text { Total organic halogens } \\
\text { Total phosphates (as P) } \\
\text { Toxaphene } \\
2,4,5-T P \text { (Silvex) } \\
\text { Tributyl phosphate } \\
\text { Tributyl phosphate } \\
1,1,1-\text { Trichloroethane } \\
1,1,2-\text { Trichloroethane } \\
\text { Trichloroethylene } \\
\text { Trichlorofluoromethane } \\
\text { Vanadium, total recoverable } \\
\text { Vanadium, total recoverable } \\
\text { Xylenes } \\
\text { Gross alpha } \\
\text { Nonvolatile beta } \\
\text { Radium, total alpha-emitting } \\
\text { Tritium } \\
\text { Uranium-233/234 } \\
\text { Uranium-235 } \\
\text { Uranium-238 }\end{array}$ & $\begin{aligned} &< 1.000 \\
& 5.5 \\
& 330 \\
&< 0.24 \\
&< 0.00046 \\
&< 10 \\
&< 10 \\
&< 1.0 \\
&< 1.0 \\
&< 1.0 \\
&< 1.0 \\
&< 8.0 \\
&< 8.0 \\
&< 2.0 \\
& 8.8 E-01 \\
&< 7.3 E-01 \\
& 8.0 E-01 \\
&<7.3 E-01 \\
& 3.8 E-01 \\
&<0.0 E+00 \\
& 5.0 E-01\end{aligned}$ & $\begin{array}{l}1.00 \\
1.00 \\
1.00 \\
1.00 \\
1.00 \\
1.00 \\
1.00 \\
1.00 \\
1.00 \\
1.00 \\
1.00 \\
1.00 \\
1.00 \\
1.00 \\
1.00 \\
1.00 \\
1.00 \\
1.00 \\
1.00 \\
1.00 \\
1.00\end{array}$ & $\begin{array}{l}\mathrm{J} \\
\mathrm{J} \\
\mathrm{J} \\
\mathrm{J}\end{array}$ & $\begin{array}{l}\mu g / L \\
\mu g / L \\
\mu g / L \\
\mu g / L \\
\mu g / L \\
\mu g / L \\
\mu g / L \\
\mu g / L \\
\mu g / L \\
\mu g / L \\
\mu g / L \\
\mu g / L \\
\mu g / L \\
\mu g / L \\
\mathrm{pCi} / L \\
\mathrm{pCi} / L \\
\mathrm{pCi} / L \\
\mathrm{pCi} / \mathrm{mL} \\
\mathrm{pCi} / L \\
\mathrm{pCi} / L \\
\mathrm{pCi} / L\end{array}$ & $\begin{array}{l}0 \\
0 \\
0 \\
0 \\
0 \\
0 \\
0 \\
0 \\
0 \\
0 \\
0 \\
0 \\
0 \\
0 \\
0 \\
0 \\
0 \\
0 \\
0 \\
0 \\
0\end{array}$ \\
\hline
\end{tabular}

\section{WELL BGO 47C}

\begin{tabular}{|c|c|c|c|c|c|c|}
\hline SRS Coort. & Lat/Longitude & Screen Zone Elevation & Top of Casing & Casing & Pump & Formation \\
\hline $\begin{array}{l}\text { iv } 74752.0 \\
\text { E54933.4 }\end{array}$ & $\begin{array}{l}33.280733^{\circ} \mathrm{N} \\
81.667354^{\circ} \mathrm{W}\end{array}$ & $188.6 .178 .6 \mathrm{ft} \mathrm{msl}$ & $267.6 \mathrm{ft} \mathrm{msl}$ & 4" PVC & S & $\left(\mathrm{B}_{1}\right)$ \\
\hline
\end{tabular}

\section{FIELD MEASUREMENTS}

Sample date: 02/21/94

Depth to water: $45.08 \mathrm{ft}(13.74 \mathrm{~m})$ below TOC

Water elevation: $222.52 \mathrm{ft}(67.82 \mathrm{~m}) \mathrm{msl}$

Sp. conductance: $35 \mu \mathrm{S} / \mathrm{cm}$

Turbidity: 0.3 NTU

Water evacuated before sampling: $152 \mathrm{gal}$

\section{LABORATORY ANALYSES}

H $\underline{\text { Analyte }}$

-

$\mathrm{pH}$

Specific conductance

Turbidity

Acetophenone

Aldrin

Aluminum, total recoverable

Aluminum, total recoverable

Antimony, total recoverable

Arsenic, total recoverable

Barium, total recoverable

Barium, total recoverable

Benzene

Bromodichloromethane
Time: $9: 58$

pH: 5.7

Alkalinity: $4 \mathrm{mg} / \mathrm{L}$

Water temperature: $20.2^{\circ} \mathrm{C}$

Volumes purged: 5.3 well volumes 
WELL BGO $47 \mathrm{C}$ collected on $02 / 21 / 94$, laboratory analyses (cont.)

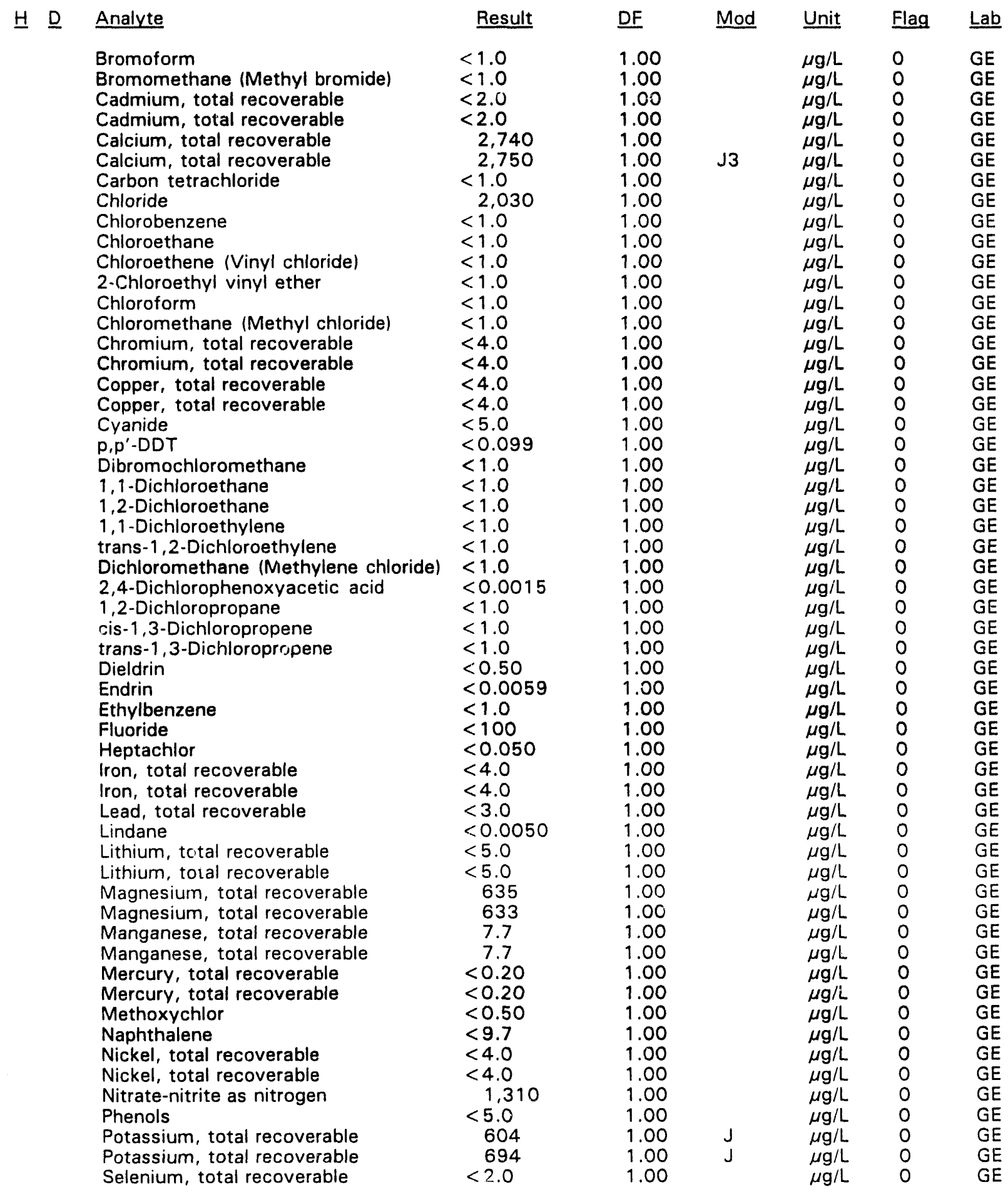

$\overline{-}=$ exceeded holding time. - = exceeded screening level oi final primary drinking water standard. 
WELL BGO $47 \mathrm{C}$ collected on $02 / 21 / 94$, laboratory analyses (cont.)

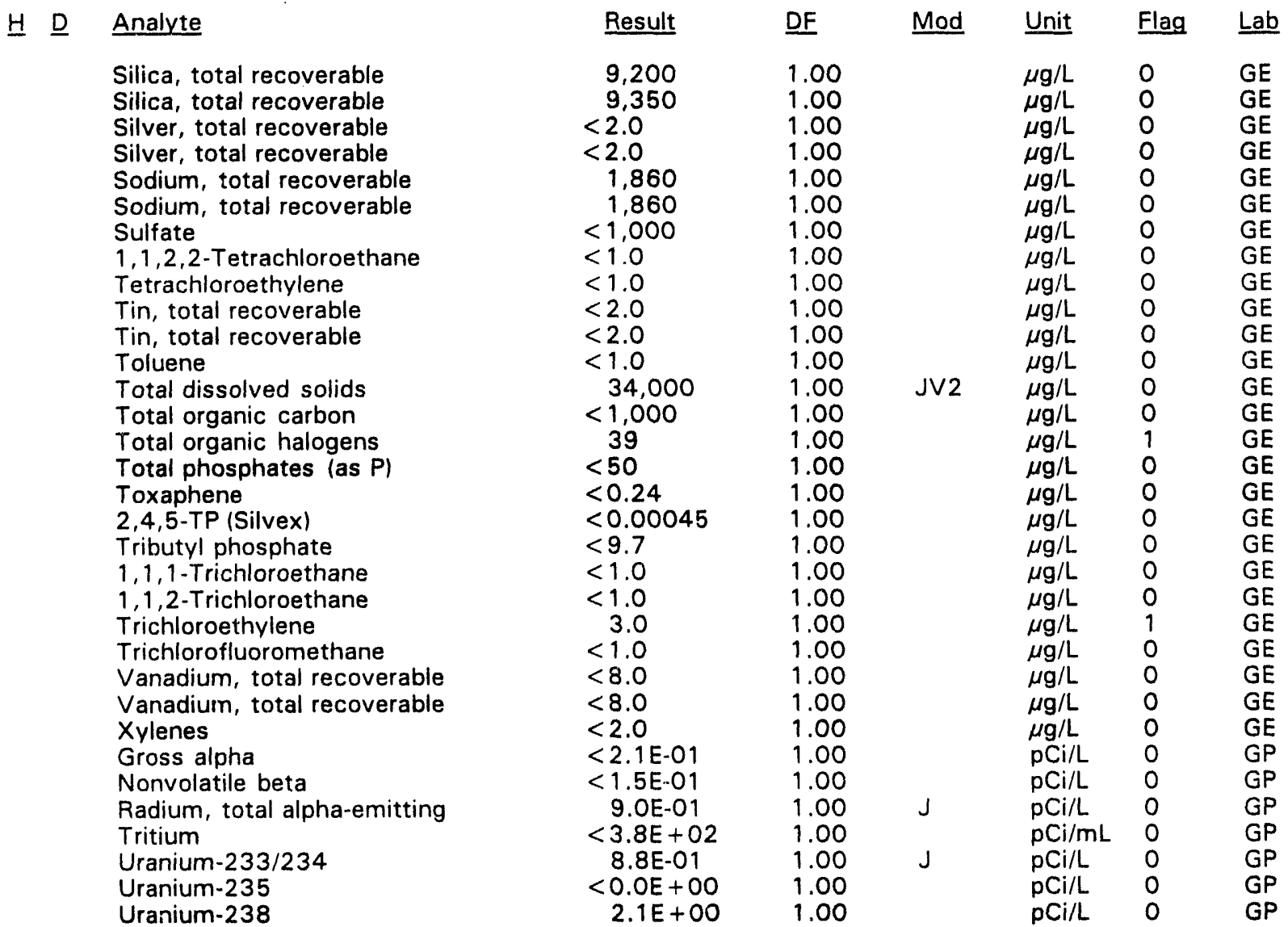

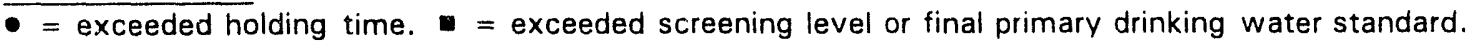


WELL BGO 47D

\begin{tabular}{|c|c|c|c|c|c|c|}
\hline SRS Coord. & Lat/Longitude & Screen Zone Elevation & Top of Casing & Casing & Pump & Formation \\
\hline $\begin{array}{l}N 74739.7 \\
E 54922.9\end{array}$ & $\begin{array}{l}33.280689^{\circ} \mathrm{N} \\
81.667357^{\circ} \mathrm{W}\end{array}$ & $213.4-203.4 \mathrm{ft} \mathrm{msl}$ & $267.4 \mathrm{ft} \mathrm{msl}$ & 4" PVC & $\mathrm{s}$ & Water Table $\left(\| B_{2}\right)$ \\
\hline
\end{tabular}

\section{FIELD MEASUREMENTS}

\section{Sample date: $02 / 21 / 94$}

Depth to water: $41.68 \mathrm{ft}(12.70 \mathrm{~m})$ below TOC

Water elevation: $225.72 \mathrm{ft}(68.80 \mathrm{~m}) \mathrm{msl}$

Sp. conductance: $41 \mu \mathrm{S} / \mathrm{cm}$

Turbidity: 0.4 NTU

Water evacuated before sampling: $122 \mathrm{gal}$

\section{LABORATORY ANALYSES}

\section{H D Analyte}

- $\mathrm{pH}$

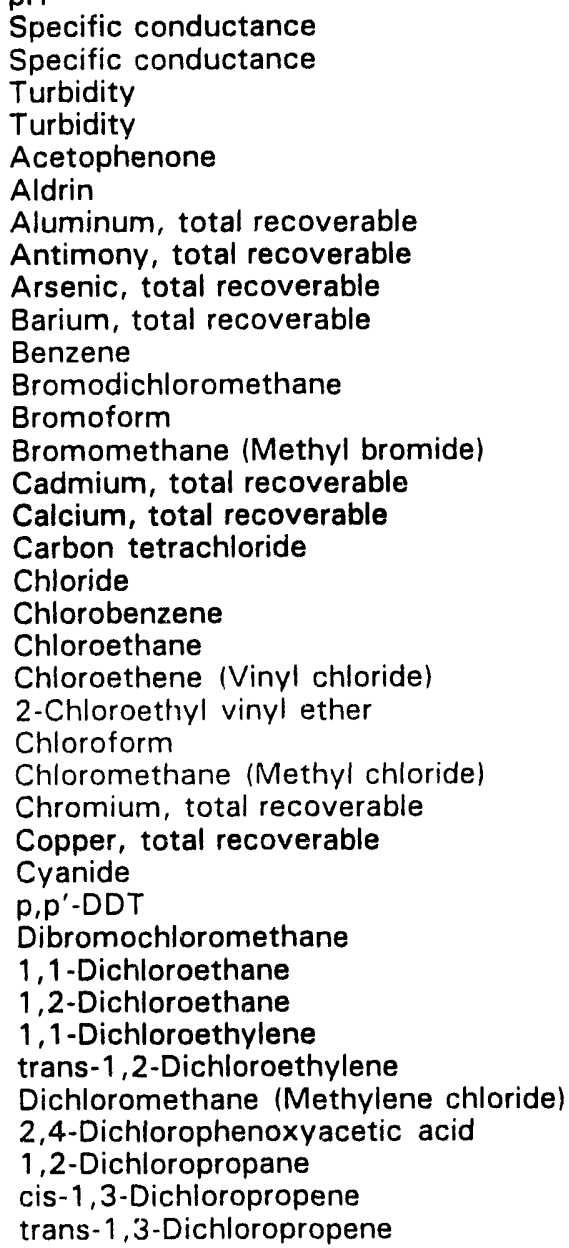

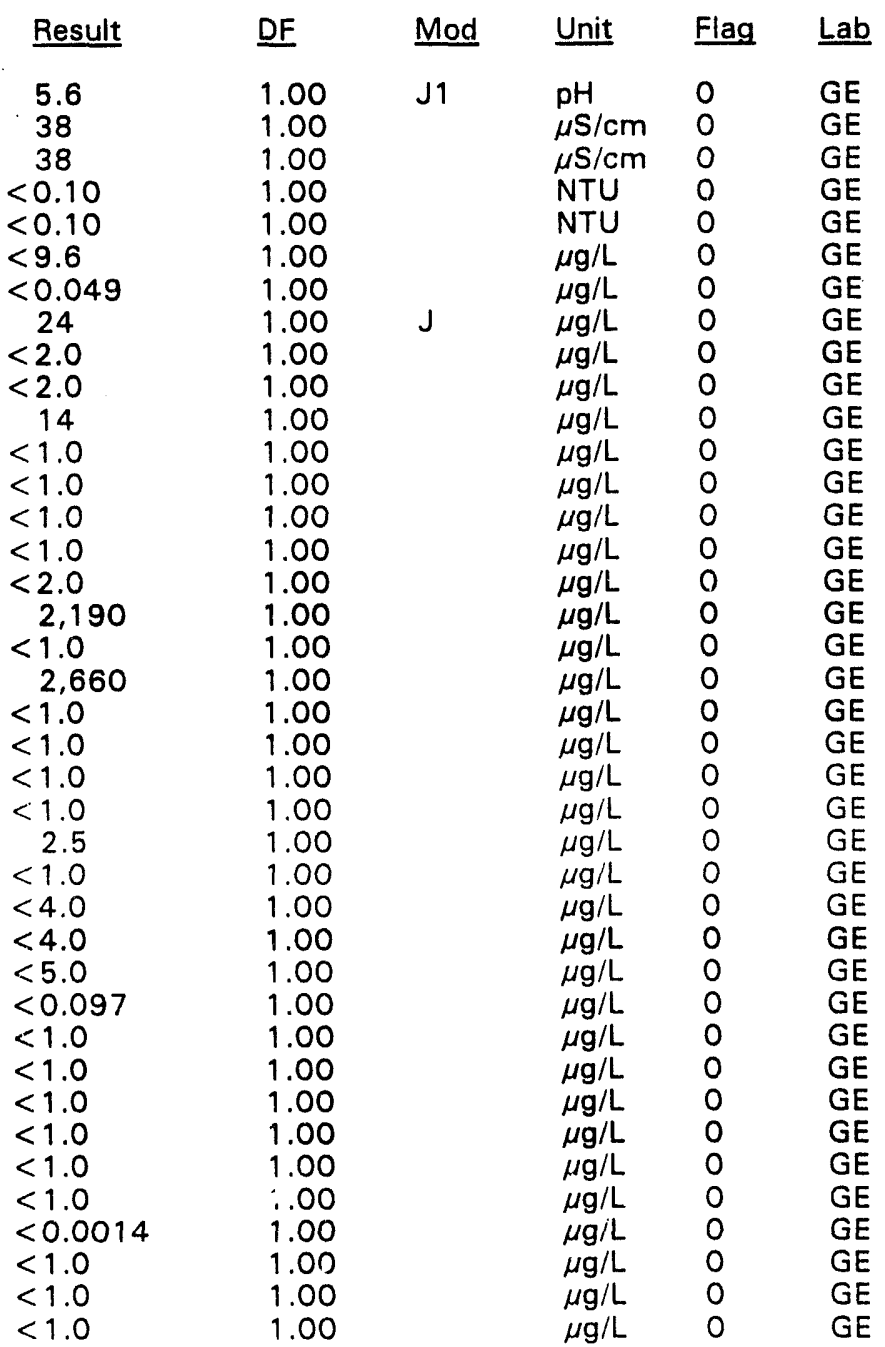

Time: 9: 27

$\mathrm{pH}: 5.3$

Alkalinity: $1 \mathrm{mg} / \mathrm{L}$

Water temperature: $20.0^{\circ} \mathrm{C}$

Volumes purged: 8.3 well volumes 
WELL BGO 47D collected on 02/21/94, laboratory analyses (cont.)

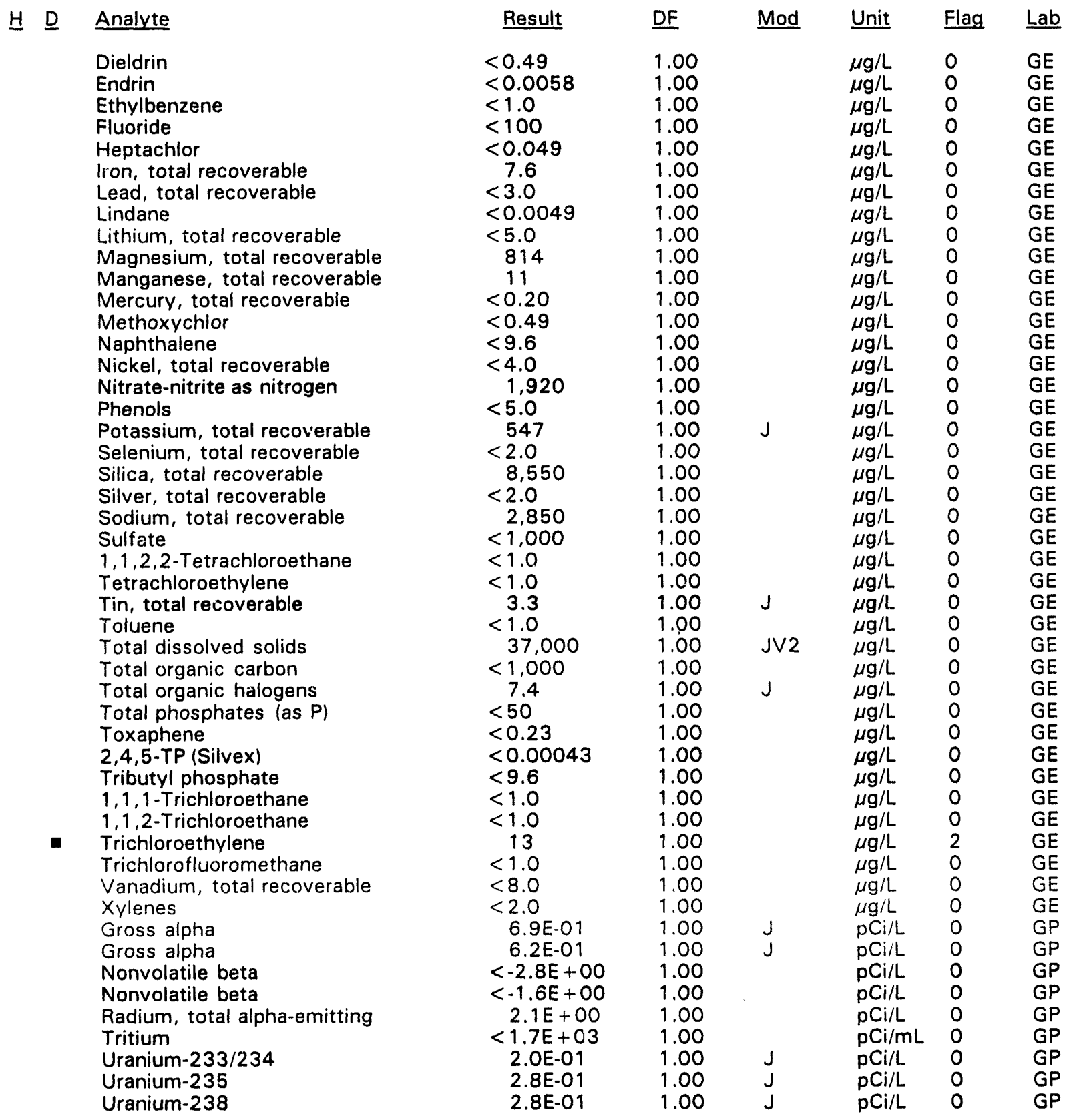

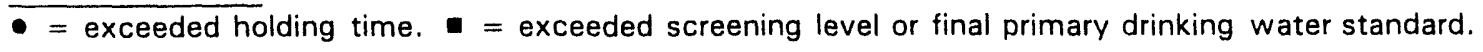


WELL BGO 48C

$\begin{array}{lllllll}\text { SRS Coord. } & \text { Lat/Longitude } & \text { Screen Zone Elevation } & \text { Top of Casing } & \text { Casing } & \text { Pump } & \text { Formation } \\ \text { N74599.6 } & 33.280708^{\circ} \mathrm{N} & 186.7-176.7 \mathrm{ft} \mathrm{msl} & 276.6 \mathrm{ft} \mathrm{msl} & \text { 4" PVC } & \text { S } & \text { Barnwell (IIB,) } \\ \text { E55124.4 } & 81.666555^{\circ} \mathrm{W} & & & & \end{array}$

\section{FIELD MEASUREMENTS}

Sample date: $02 / 21 / 94$

Depth to water: $53.64 \mathrm{ft}(16.35 \mathrm{~m})$ below TOC

Water elevation: $222.96 \mathrm{ft}(67.96 \mathrm{~m}) \mathrm{ms}$ )

Sp. conductance: $35 \mu \mathrm{S} / \mathrm{cm}$

Turbidity: 0.8 NTU

Water evacuated before sampling: $199 \mathrm{gal}$

\section{LABORATORY ANALYSES}

H. Analyte
pH
Specific conductance
Turbidity
Acetophenone
Aldrin
Aldrin
Aluminum, total recoverable
Antimony, total recoverable
Arsenic, total recoverable
Barium, total recoverable
Benzene
Bromodichloromethane
Bromoform
Bromomethane (Methyl bromide)
Cadmium, total recoverable
Calcium, total recoverable
Carbon tetrachloride
Chloride
Chlorobenzene
Chloroethane
Chloroethene (Vinyl chloride)
2-Chloroethyl vinyl ether
Chloroform
Chloromethane (Methyl chloride)
Chromium, total recoverable
Copper, total recoverable
Cyanide
p,p'-DDT
p,p'-DDT
Dibromochloromethane
1,1 -Dichloroethane
$1,2-$ Dichloroethane
1,1 -Dichloroethylene
trans-1,2-Dichloroethylene
Dichloromethane (Methylene chloride)
$2,4-$ Dichlorophenoxyacetic acid
$1,2-$ Dichloropropane
cis-1,3-Dichloropropene
trans-1,3-Dichloropropene

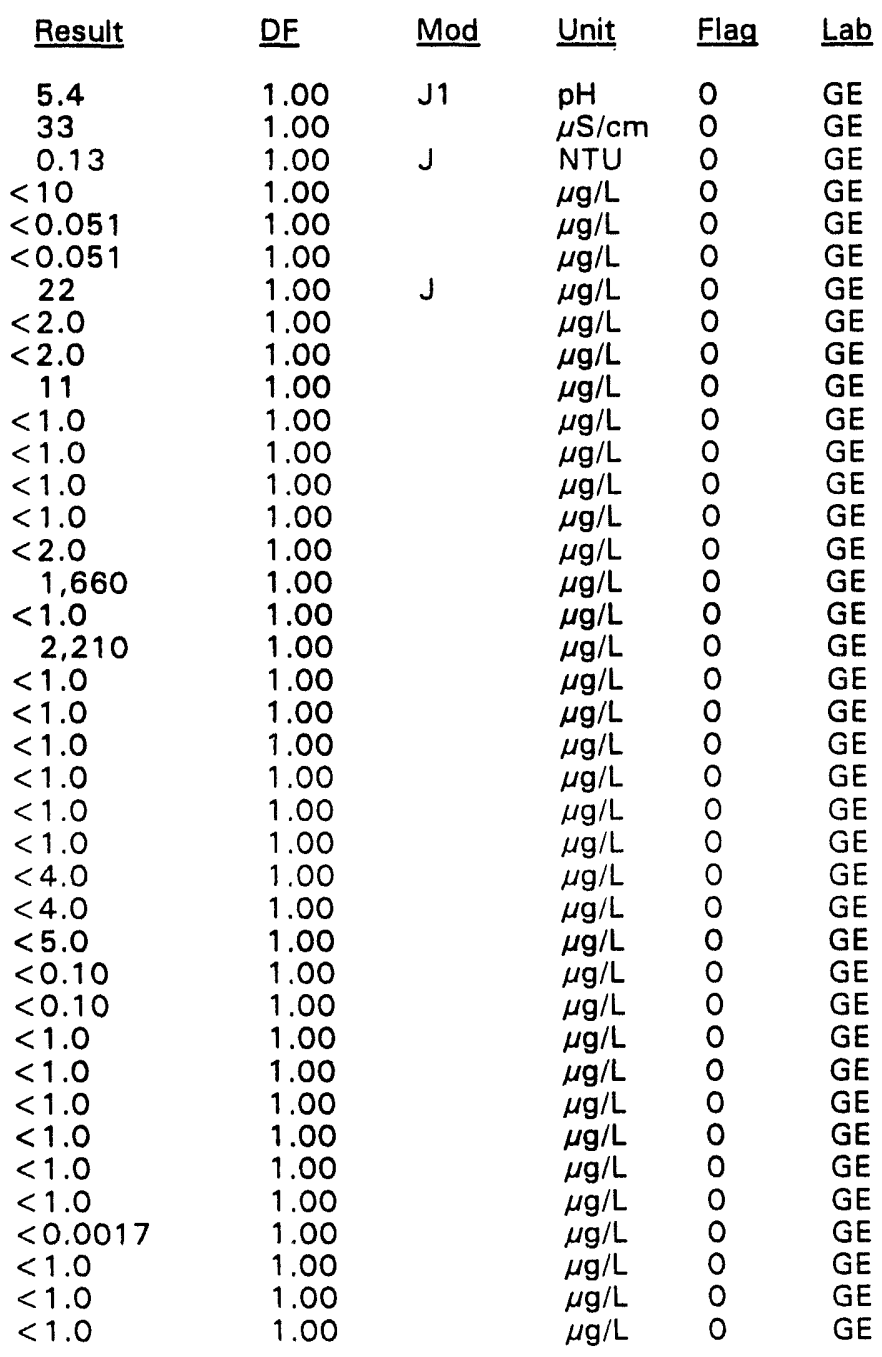

Time: $10: 40$

$\mathrm{pH}: 5.4$

Alkalinity: $1 \mathrm{mg} / \mathrm{L}$

Water temperature: $20.1{ }^{\circ} \mathrm{C}$

Volumes purged: 6.6 well volumes 
WELL BGO $48 \mathrm{C}$ collected on $02 / 21 / 94$, laboratory analyses (cont.)

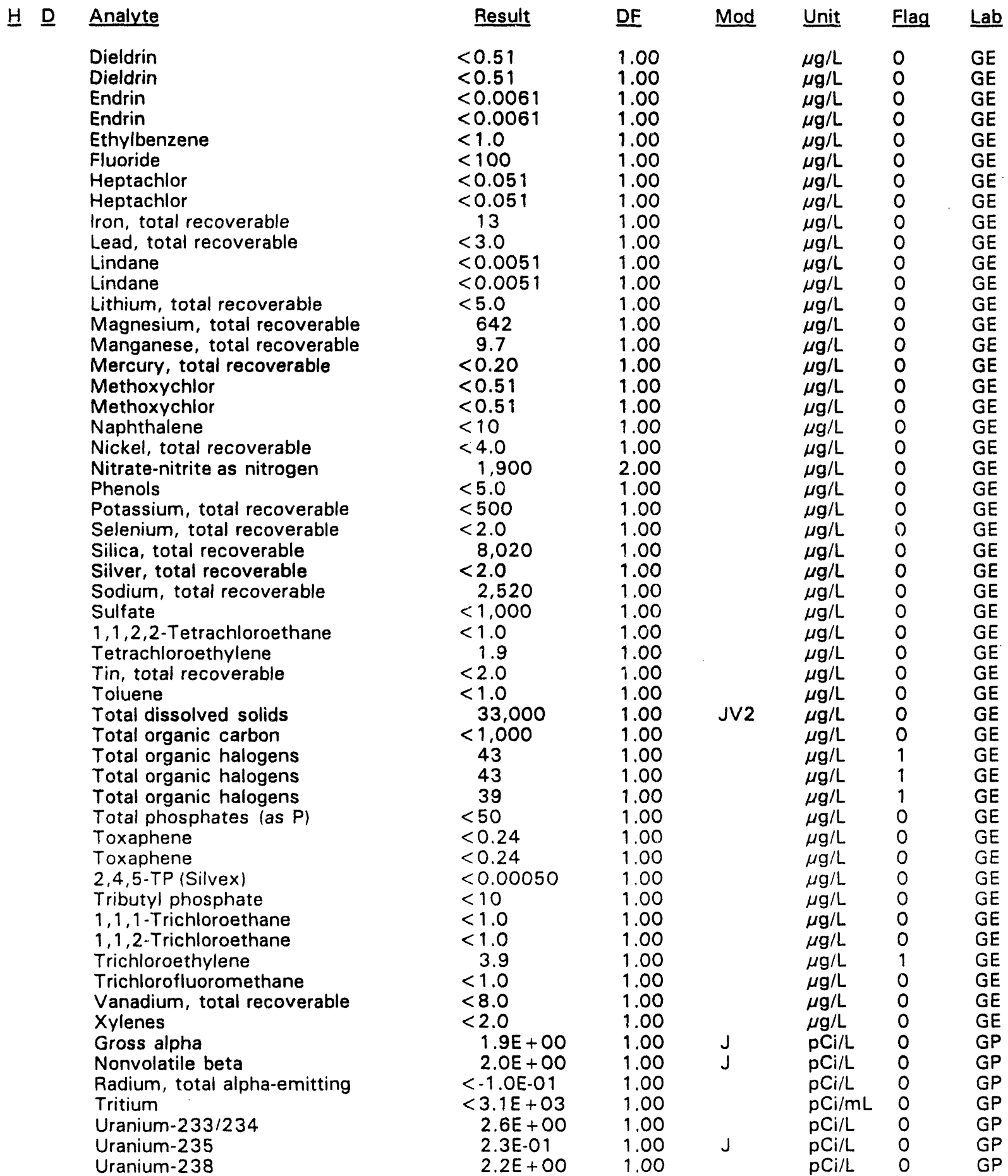

- = exceeded holding time. = exceeded screening level or final primary drinking water standard. 


\section{WELL BGO 48D}

\begin{tabular}{|c|c|c|c|c|c|c|}
\hline SRS Coord. & Lat/Longitude & Screen Zone Elevation & Top of Casing & Casing & Pump & Formation \\
\hline $\begin{array}{l}\text { N74586.4 } \\
\text { E55121.0 }\end{array}$ & $\begin{array}{l}33.280673^{\circ} \mathrm{N} \\
81.666538^{\circ} \mathrm{W}\end{array}$ & $212.0-202.0 \mathrm{ft} \mathrm{msl}$ & $276.9 \mathrm{ft} \mathrm{msl}$ & 4" PVC & $S$ & $e\left(\| \mid B_{2}\right)$ \\
\hline
\end{tabular}

\section{FIELD MEASUREMENTS}

Sample date: $02 / 21 / 94$

Depth to water: $50.73 \mathrm{ft}(15.46 \mathrm{~m})$ below TOC

Water elevation: $226.17 \mathrm{ft}(68.94 \mathrm{~m}) \mathrm{ms}$ l

Sp. conductance: $57 \mu \mathrm{S} / \mathrm{cm}$

Turbidity: 1.6 NTU

Water evacuated before sampling: $277 \mathrm{gal}$

Time: 11:00

$\mathrm{pH}: 4.7$

Alkalinity: $0 \mathrm{mg} / \mathrm{L}$

Water temperature: $20.5^{\circ} \mathrm{C}$

Volumes purged: 17.5 well volumes

\section{LABORATORY ANALYSES}

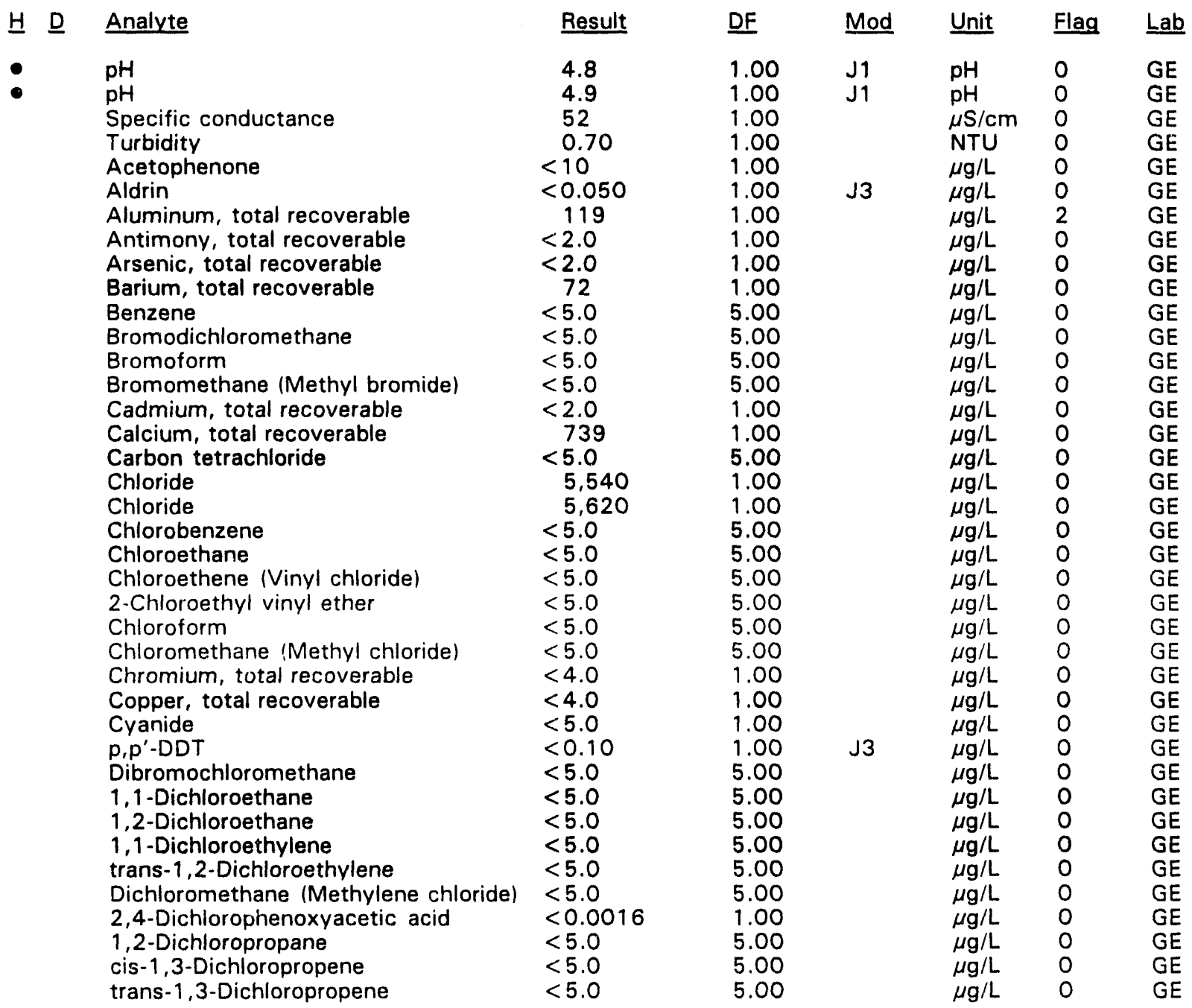

\footnotetext{
- = exceeded holding time. $\mathbf{a}=$ exceeded screening level or final primary drinking water standard.
} 
WELL BGO $48 D$ collected on $02 / 21 / 94$, laboratory analyses (cont.)

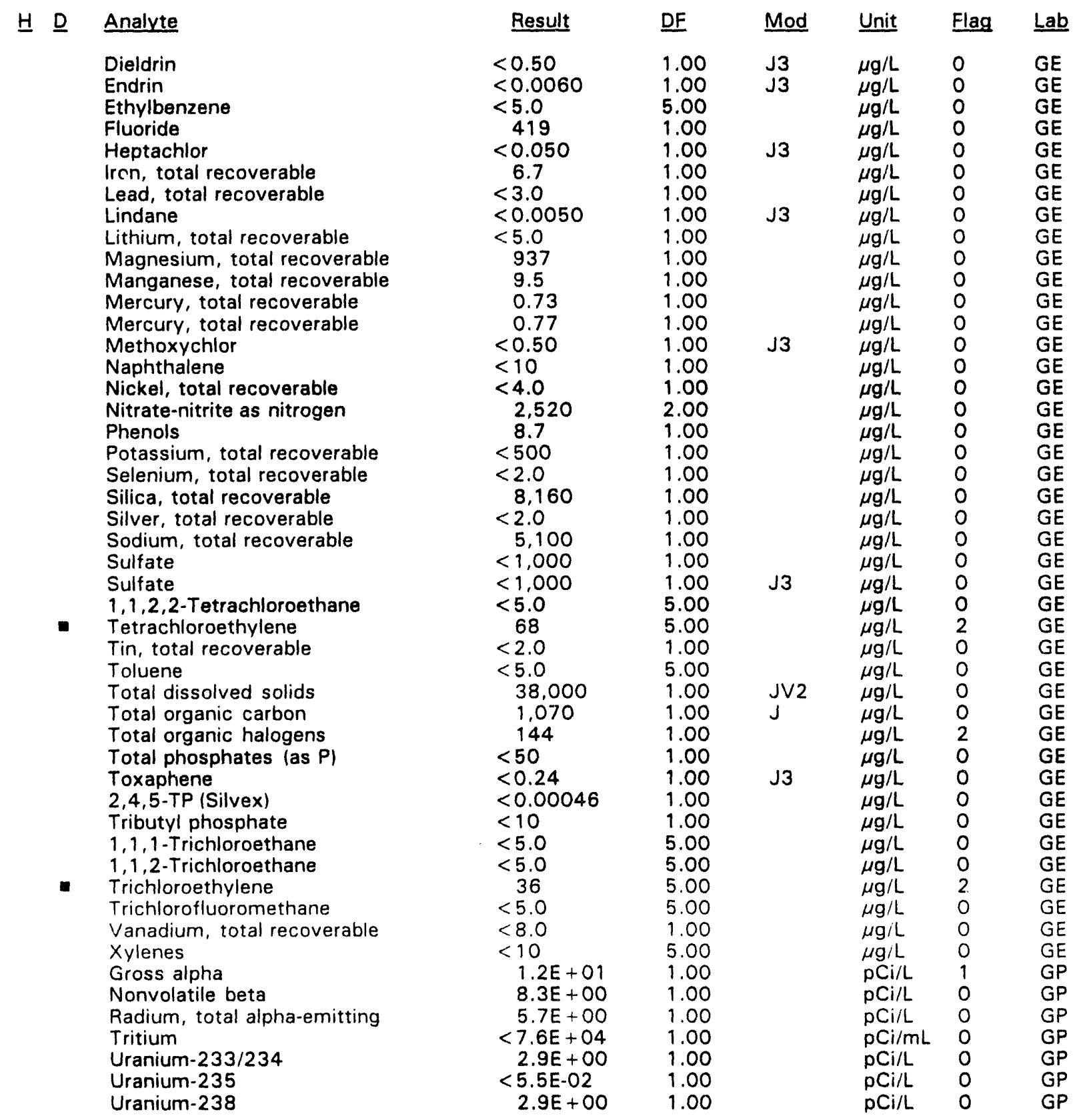

\footnotetext{
- = exceeded holding time. = exceeded screening level or final primary drinking water standard.
} 
WSRC-TR-94-0240

Unclassified

\section{WELL BGO 49A}

\begin{tabular}{|c|c|c|c|c|c|c|}
\hline SRS Coord. & Lat/Longitude & Screen Zone Elevation & Top of Casing & Casing & Pump & Formation \\
\hline $\begin{array}{l}N 73902.8 \\
E 56205.1\end{array}$ & $\begin{array}{l}33.280930^{\circ} \mathrm{N} \\
81.662356^{\circ} \mathrm{W}\end{array}$ & $85.1-75.1 \mathrm{ft} \mathrm{msl}$ & $271.2 \mathrm{ft} \mathrm{msl}$ & 4" PVC & $\mathrm{S}$ & $U$. Congaree (IIA) \\
\hline
\end{tabular}

\section{FIELD MEASUREMENTS}

Sample date: 01/27/94

Depth to water: Not available

Water elevation: Not available

Sp. conductance: $210 \mu \mathrm{S} / \mathrm{cm}$

Turbidity: 0.4 NTU

Water evacuated before sampling: $189 \mathrm{gal}$

\section{LABORATORY ANALYSES}

\section{H $\quad$ Analyte}

pH
Specific conductance
Turbidity
Acetophenone
Aldrin
Aluminum, total recoverable
Antimony, total recoverable
Arsenic, total recoverable
Barium, total recoverable
Benzene
Bromodichloromethane
Bromoform
Bromomethane (Methyl bromide)
Cadmium, total recoverable
Calcium, total recoverable
Carbon tetrachloride
Chloride
Chlorobenzene
Chloroethane
Chloroethene (Vinyl chloride)
2-Chloroethyl vinyl ether
Chloroform
Chloromethane (Methyl chloride)
Chromium, total recoverable
Copper, total recoverable
Cyanide
p,p'-DDT
Dibromochloromethane
1,1 -Dichloroethane
$1,2-$ Dichloroethane
1,1 -Dichloroethylene
trans-1,2-Dichloroethylene
Dichloromethane (Methylene chloride)
$2,4-$ Dichlorophenoxyacetic acid
$1,2-$ Dichloropropane
cis-1,3-Dichloropropene
trans-1,3-Dichloropropene
Dieldrin
Endrin

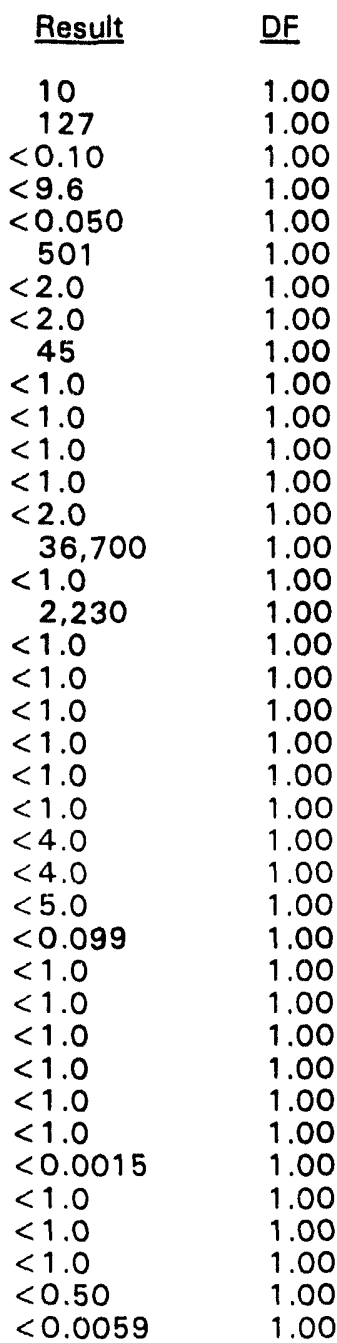

Time: 13: 59

pH: 10.7

Alkalinity: $85 \mathrm{mg} / \mathrm{L}$

Water temperature: $18.8^{\circ} \mathrm{C}$

\section{$\bullet$}


WELL BGO 49A collected on 01/27/94, laboratory analysee (cont.)

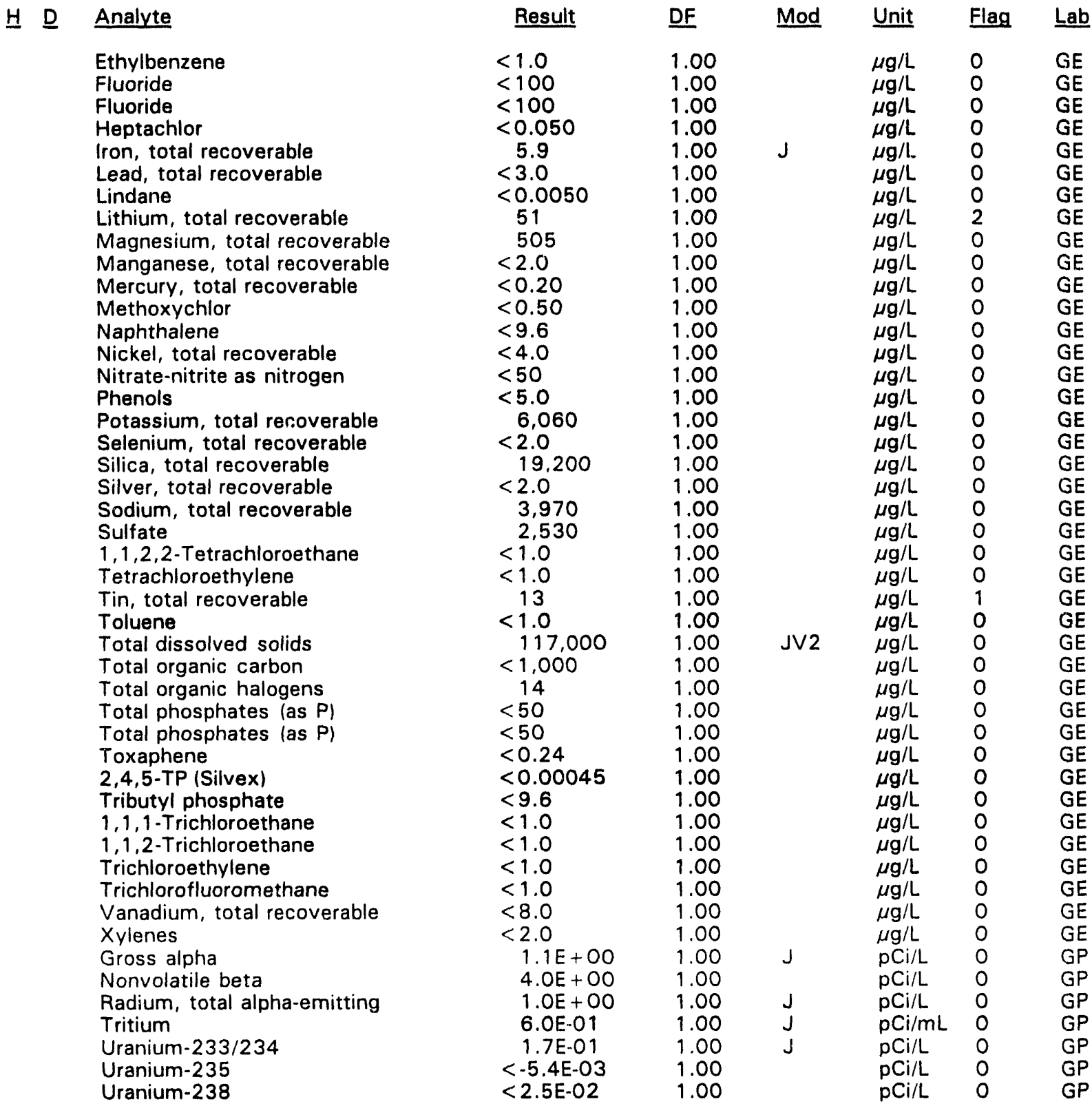

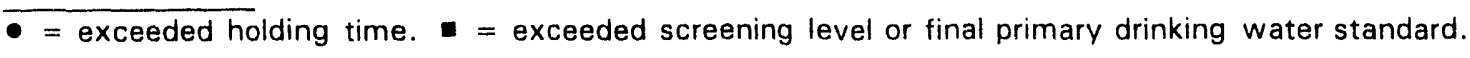


WELL BGO 49C

\begin{tabular}{|c|c|c|c|c|c|c|}
\hline SRS Coord. & Lat/Longitude & Screen Zone Elevation & Top of Casing & Casing & Pump & Formation \\
\hline $\begin{array}{l}\text { N73917.2 } \\
\text { E56202.2 }\end{array}$ & $\begin{array}{l}33.280957^{\circ} \mathrm{N} \\
81.662391^{\circ} \mathrm{W}\end{array}$ & 176.0 & $\mathrm{ft} \mathrm{msl}$ & 4" PVC & $S$ & \\
\hline
\end{tabular}

\section{FIELD MEASUREMENTS}

Sample date: $01 / 31 / 94$

Depth to water: $43.74 \mathrm{ft}(13.33 \mathrm{~m})$ below TOC

Water elevation: $227.36 \mathrm{ft}(69.30 \mathrm{~m}) \mathrm{msl}$

Sp. conductance: $69 \mu \mathrm{S} / \mathrm{cm}$

Turbidity: 0.3 NTU

Water evacuated before sampling: $157 \mathrm{gal}$

\section{LABORATORY ANALYSES}

Time: 9: 55

pH: 7.6

Alkalinity: $22 \mathrm{mg} / \mathrm{L}$

Water temperature: $18.0^{\circ} \mathrm{C}$

Volumes purged: 3.9 well volumes

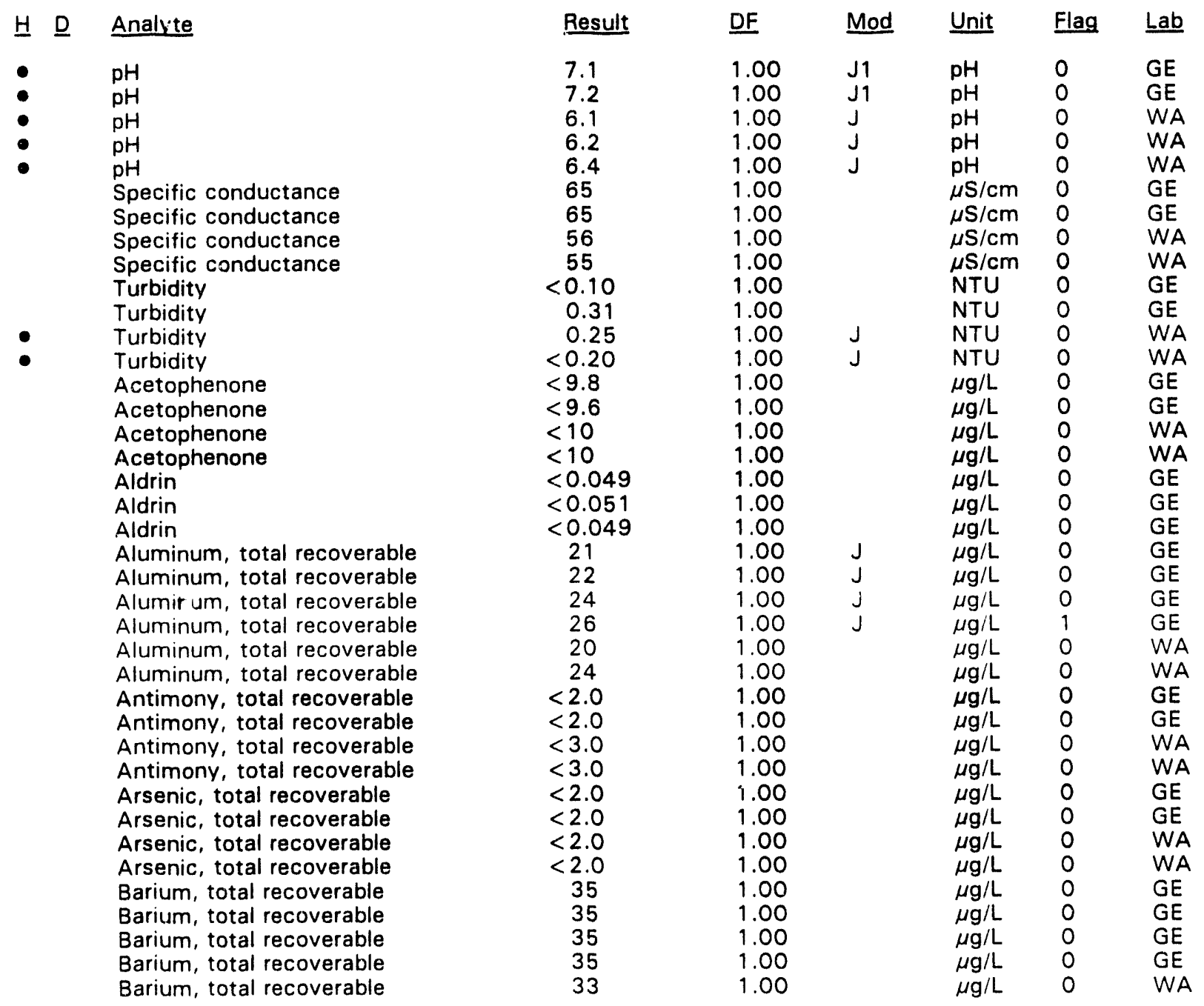

$\overline{- \text { = exceeded holding time. }}$ = exceeded screening level or final primary drinking water standard. 
WELL BGO $49 \mathrm{C}$ collected on $01 / 31 / 94$, laboratory analyses (cont.)

H D Analyte

Barium, total recoverable

Benzene

Benzene

Benzene

Benzene

Bromodichloromethane

Bromodichloromethane

Bromodichloromethane

Bromodichloromethane

Bromoform

Bromoform

Bromoform

Bromoform

Bromomethane (Methyl bromide)

Bromomethane (Methyl bromide)

Bromomethane (Methyl bromide)

Bromomethane (Methyl bromide)

Cadmium, total recoverable

Cadmium, total recoverable

Cadmium, total recoverable

Cadmium, total recoverable

Cadmium, total recoverable

Cadmium, total recoverable

Calcium, total recoverable

Calcium, total recoverable

Calcium, total recoverable

Calcium, total recoverable

Calcium, total recoverable

Calcium, total recoverable

Carbon tetrachloride

Carbon tetrachloride

Carbon tetrachloride

Carbon tetrachloride

Chloride

Chloride

Chloride

Chloride

Chlorobenzene

Chlorobenzene

Chlorobenzene

Chlorobenzene

Chloroethane

Chloroethane

Chloroethane

Chloroethane

Chloroethene (Vinyl chloride)

Chloroethene (Vinyl chloride)

Chloroethene (Vinyl chloride)

Chloroethene (Vinyl chloride)

2-Chloroethyl vinyl ether

2-Chloroethyl vinyl ether

2-Chloroethyl vinyl ether

2-Chloroethyl vinyl ether

Chloroform

Chloroform

Chloroform

Result $\quad$ DF

32

$<1.0$

$<1.0$

$<5.0$

$<5.0$

$<1.0$

$<1.0$

$<5.0$

$<5.0$

$<1.0$

$<1.0$

$<5.0$

$<5.0$

$<1.0$

$<1.0$

$<10$

$<10$

$<2.0$

$<2.0$

$<2.0$

$<2.0$

$<2.0$

$<2.0$

6,270

6,290

6,520

6,570

6,320

6,340

$<1.0$

$<1.0$

$<5.0$

$<5.0$

2,460

2,420

2,720

2.720

$<1.0$

$<1.0$

$<5.0$

$<5.0$

$<1.0$

$<1.0$

$<10$

$<10$

$<1.0$

$<1.0$

$<10$

$<10$

$<1.0$

$<1.0$

$<10$

$<10$

$<1.0$

$<1.0$

$<5.0$
DF

1.00
1.00

1.00

1.00

1.00

1.00

1.00

1.00

1.00

1.00

1.00

1.00

1.00

1.00

1.00

1.00

1.00

1.00

1.00

1.00

1.00

1.00

1.00

1.00

1.00

1.00

1.00

1.00

1.00

1.00

1.00

1.00

1.00

1.00

1.00

1.00

1.00

1.00

1.00

1.00

1.00

1.00

1.00

1.00

1.00

1.00

1.00

1.00

1.00

1.00

1.00

1.00

1.00

1.00

1.00

1.00
Mod Unit Flag Lab

$\mu g / L \quad 0 \quad$ WA

$\mu g / L \quad 0 \quad G E$

$\mu g / L \quad 0 \quad G E$

$\mu g / L \quad 0 \quad$ WA

$\mu g / L \quad 0 \quad$ WA

$\mu \mathrm{g} / \mathrm{L} \quad 0 \quad \mathrm{GE}$

$\mu \mathrm{g} / \mathrm{L} \quad \mathrm{O} \quad \mathrm{GE}$

$\mu g / L \quad 0 \quad$ WA

$\mu g / L \quad 0 \quad W A$

$\mu g / L \quad 0 \quad G E$

$\mu \mathrm{g} / \mathrm{L} \quad \mathrm{O} \quad \mathrm{GE}$

$\mu g / L \quad 0$

$\mu \mathrm{g} / \mathrm{L} \quad 0 \quad W A$

$\mu \mathrm{g} / \mathrm{L} \quad \mathrm{O} \quad \mathrm{GE}$

$\mu \mathrm{g} / \mathrm{L} \quad 0 \quad \mathrm{GE}$

$\mu g / L \quad 0 \quad$ WA

$\mu \mathrm{g} / \mathrm{L} \quad 0 \quad$ WA

$\mu \mathrm{g} / \mathrm{L} \quad 0 \quad \mathrm{GE}$

$\mu \mathrm{g} / \mathrm{L} \quad 0 \quad \mathrm{GE}$

$\mu g / L \quad 0 \quad$ GE

$\mu g / L \quad 0 \quad$ GE

$\mu g / L \quad 0 \quad$ WA

$\mu \mathrm{g} / \mathrm{L} \quad 0 \quad$ WA

$\mu g / L \quad 0 \quad$ GE

$\mu g / L \quad O \quad G E$

$\mu g / L \quad 0 \quad G E$

$\mu g / L \quad O \quad G E$

$\mu \mathrm{g} / \mathrm{L} \quad \mathrm{O}$ WA

$\mu \mathrm{g} / \mathrm{L} \quad 0 \quad$ WA

$\mu g / L \quad O \quad G E$

$\mu \mathrm{g} / \mathrm{L} \quad \mathrm{O} \quad \mathrm{GE}$

$\mu \mathrm{g} / \mathrm{L} \quad 0 \quad$ WA

$\mu g / L \quad 0 \quad$ WA

$\mu g / L \quad 0 \quad G E$

$\mu g / L \quad 0 \quad$ GE

$\mu g / L \quad 0 \quad W A$

$\mu g / L \quad 0 \quad$ WA

$\mu g / L \quad 0 \quad$ GE

$\mu \mathrm{g} / \mathrm{L} \quad \mathrm{O} \quad \mathrm{GE}$

$\mu \mathrm{g} / \mathrm{L} \quad \mathrm{O}$ WA

$\mu \mathrm{g} / \mathrm{L} \quad \mathrm{O} \quad$ WA

$\mu \mathrm{g} / \mathrm{L} \quad \mathrm{O} \quad \mathrm{GE}$

$\mu \mathrm{g} / \mathrm{L} \quad \mathrm{O} \quad \mathrm{GE}$

$\mu g / L \quad O \quad W A$

$\mu \mathrm{g} / \mathrm{L} \quad 0 \quad$ WA

$\mu g / L \quad O \quad$ GE

$\mu \mathrm{g} / \mathrm{L} \quad \mathrm{O} \quad \mathrm{GE}$

$\mu g / L \quad 0 \quad W A$

$\mu g / L \quad 0 \quad W A$

$\mu \mathrm{g} / \mathrm{L} . \quad 0 \quad \mathrm{GE}$

$\mu \mathrm{g} / \mathrm{L} \quad \mathrm{O} \quad \mathrm{GE}$

$\mu g / L \quad 0 \quad W A$

$\mu \mathrm{g} / \mathrm{L} \quad 0 \quad$ WA

$\mu \mathrm{g} / \mathrm{L} \quad 0 \quad \mathrm{GE}$

$\mu \mathrm{g} / \mathrm{L} \quad 0 \quad \mathrm{GE}$

$\mu \mathrm{g} / \mathrm{L}$

- = exceeded holding time. = exceeded screening level or final primary drinking water standard. 
WELL BGO $49 \mathrm{C}$ collected on 01/31/94, laboratory analyses (cont.)

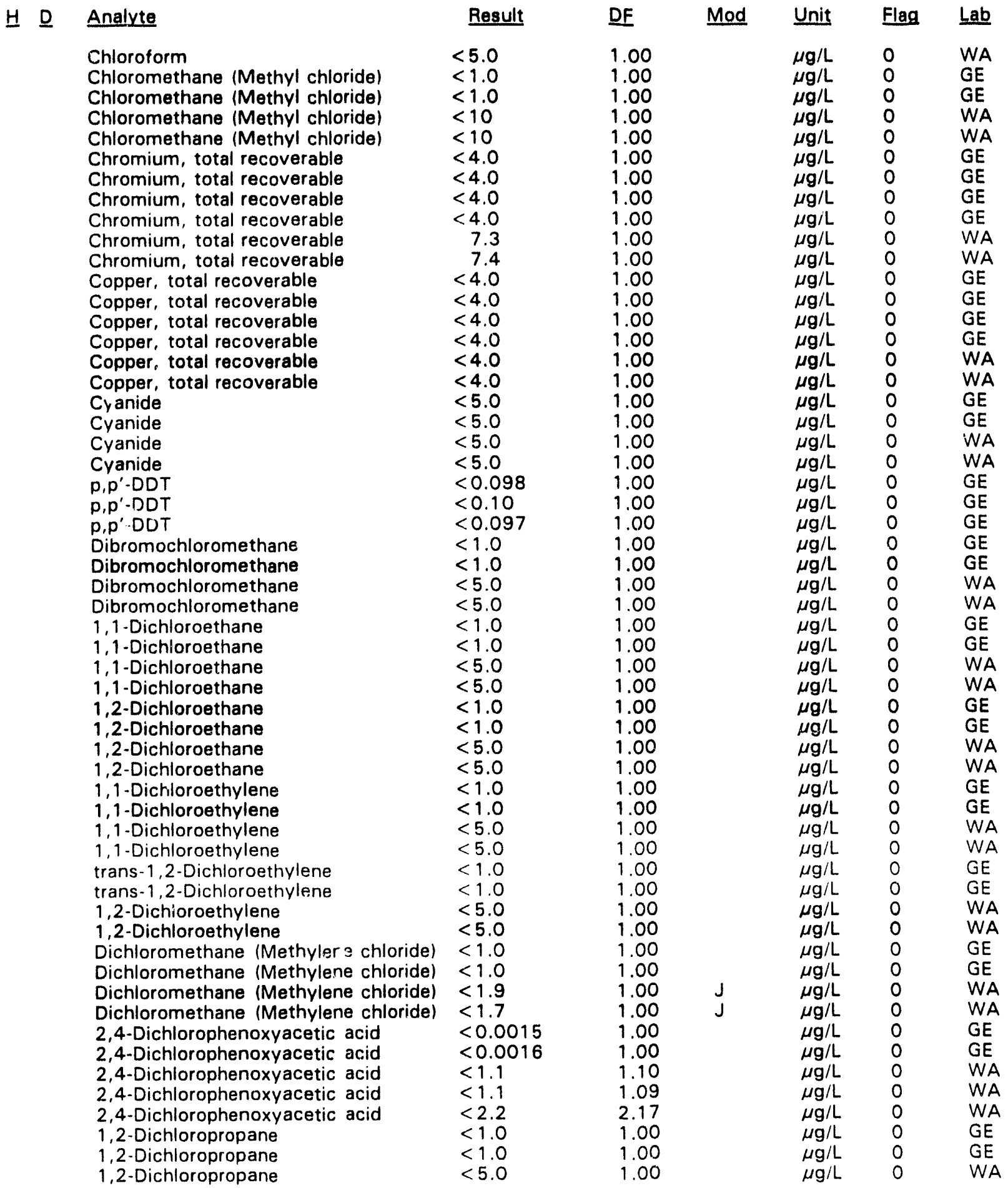

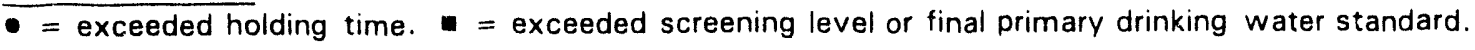


WELL BGO $49 \mathrm{C}$ collected on $01 / 31 / 94$, laboratory analyses (cont.)

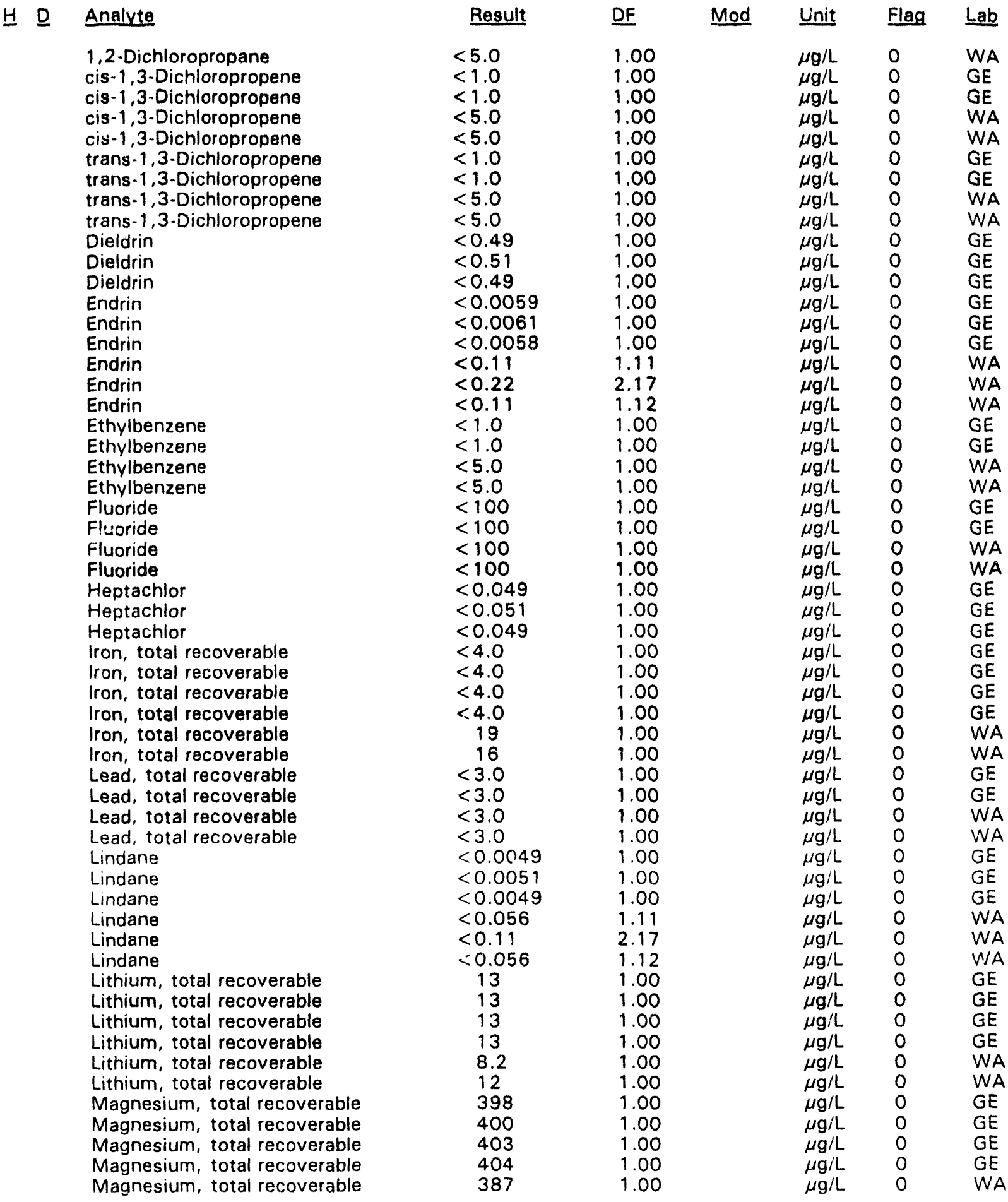

- = exceeded holding time. = exceeded screening level or final primary drinking water standard. 

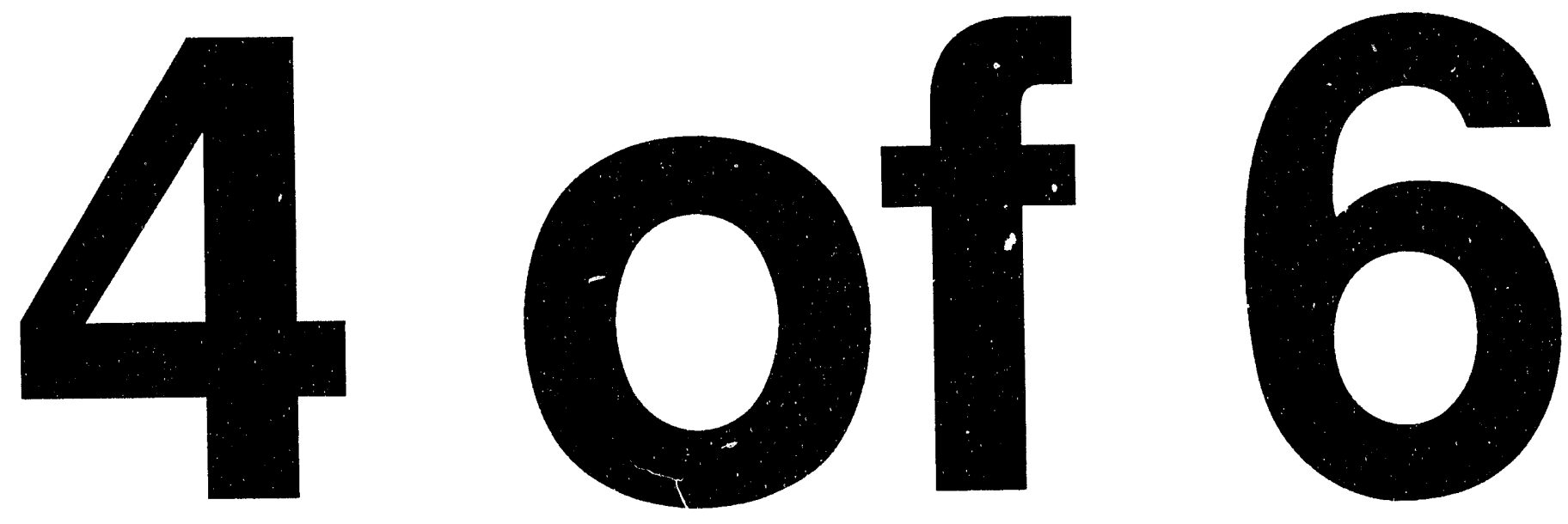
WELL BGO 49 C collected on $01 / 31 / 94$, laboratory analyses (cont.)

\section{H $\underline{\text { Analyte }}$}

Magnesium, total recoverable

Manganese, total recoverable

Manganese, total recoverable

Manganese, total recoverable

Manganese, total recoverable

Manganese, total recoverable

Manganese, total recoverable

Mercury, total recoverable

Mercury, total recoverable

Mercury, total recoverable

Mercury, total recoverable

Mercury, total recoverable

Methoxychlor

Methoxychlor

Methoxychlor

Methoxychlor

Methoxychlor

Methoxychlor

Methoxychlor

Naphthalene

Naphthalene

Nickel. total recoverable

Nickel, total recoverable

Nickel, total recoverable

Nickel, total recoverable

Nickel, total recoverable

Nickel, total recoverable

Nitrate as nitrogen

Nitrate as nitrogen

Nitrate-nitrite as nitrogen

Nitrate-nitrite as nitrogen

Phenols

Phenols

Phenols

Phenols

Potassium, total recoverable

Potassium, total recoverable

Potassium, total recoverable

Potassium, total recoverable

Potassium, total recoverable

Potassium, total recoverable

Selenium, total recoverable

Selenium, total recoverable

Selenium, total recoverable

Selenium, total recoverable

Silica, total recoverable

Silica, total recoverable

Silica, total recoverable

Silica, total recoverable

Silica, total recoverable

Silica, total recoverable

Silver, total recoverable

Silver, total recoverable

Silver, total recoverable

Silver, total recoverable

Silver, total recoverable

\begin{tabular}{|c|c|}
\hline Result & DF \\
\hline 388 & 1.00 \\
\hline$<2.0$ & 1.00 \\
\hline$<2.0$ & 1.00 \\
\hline$<2.0$ & 1.00 \\
\hline$<2.0$ & 1.00 \\
\hline$<2.0$ & 1.00 \\
\hline $\begin{array}{l}<2.0 \\
<0.20\end{array}$ & 1.00 \\
\hline$<0.20$ & 1.00 \\
\hline$<0.20$ & 1.00 \\
\hline$<0.20$ & 1.00 \\
\hline$<0.20$ & 1.00 \\
\hline$<0.49$ & 1.00 \\
\hline$<0.51$ & 1.00 \\
\hline$<0.49$ & 1.00 \\
\hline$<0.56$ & 1.11 \\
\hline$<1.1$ & 2.17 \\
\hline $\begin{array}{l}<1.1 \\
<056\end{array}$ & 2.17 \\
\hline $\begin{array}{l}<0.56 \\
<9.8\end{array}$ & $\begin{array}{l}1.12 \\
1.00\end{array}$ \\
\hline$<9.6$ & 1.00 \\
\hline$<4.0$ & 1.00 \\
\hline$<4.0$ & 1.00 \\
\hline$<4.0$ & 1.00 \\
\hline$<4.0$ & 1.00 \\
\hline$<4.0$ & 1.00 \\
\hline$<4.0$ & 1.00 \\
\hline 578 & 1.00 \\
\hline 568 & 1.00 \\
\hline 770 & 1.00 \\
\hline 440 & 1.00 \\
\hline$<5.0$ & 1.00 \\
\hline$<5.0$ & 1.00 \\
\hline $\begin{array}{l}<5.0 \\
<5.0\end{array}$ & $\begin{array}{l}1.00 \\
1.00\end{array}$ \\
\hline 3,280 & 1.00 \\
\hline 3,330 & 1.00 \\
\hline 3,370 & 1.00 \\
\hline 3,430 & 1.00 \\
\hline 3,080 & 1.00 \\
\hline 2,990 & 1.00 \\
\hline$<2.0$ & 1.00 \\
\hline$<2.0$ & 1.00 \\
\hline $\begin{array}{l}<2.0 \\
<2.0\end{array}$ & $\begin{array}{l}1.00 \\
1.00\end{array}$ \\
\hline $\begin{array}{l}<2.0 \\
9,660\end{array}$ & 1.00 \\
\hline 9,680 & 1.00 \\
\hline 9,690 & 1.00 \\
\hline 9,740 & 1.00 \\
\hline 9,300 & 2.10 \\
\hline 9,340 & 2.10 \\
\hline$<2.0$ & 1.00 \\
\hline$<2.0$ & 1.00 \\
\hline$<2.0$ & 1. \\
\hline$<2.0$ & \\
\hline$<2.0$ & \\
\hline
\end{tabular}

Mod Unit Fiag Lab

$\mu \mathrm{g} / \mathrm{L} \quad \mathrm{O} \quad$ WA

$\mu \mathrm{g} / \mathrm{L} \quad \mathrm{O} \quad \mathrm{GE}$

$\mu g / L \quad 0 \quad G E$

$\mu g / L \quad O \quad G E$

$\mu \mathrm{g} / \mathrm{L} \quad 0 \quad \mathrm{GE}$

$\mu g / L \quad O \quad W A$

$\mu \mathrm{g} / \mathrm{L} \quad 0 \quad$ WA

$\mu \mathrm{g} / \mathrm{L} \quad \mathrm{O} \quad \mathrm{GE}$

$\mu \mathrm{g} / \mathrm{L} \quad 0 \quad \mathrm{GE}$

$\mu g / L \quad 0 \quad W A$

$\mu \mathrm{g} / \mathrm{L} \quad 0$

$\mu \mathrm{g} / \mathrm{L} \quad 0 \quad$ WA

$\mu \mathrm{g} / \mathrm{L} \quad 0 \quad \mathrm{GE}$

$\mu g / L \quad 0 \quad G E$

$\mu \mathrm{g} / \mathrm{L} \quad \mathrm{O} \quad \mathrm{GE}$

$\mu g / L \quad 0 \quad W A$

$\mu g / L \quad 0 \quad$ WA

$\mu g / L \quad 0 \quad$ WA

$\mu g / L \quad 0 \quad W A$

$\mu \mathrm{g} / \mathrm{L} \quad 0 \quad \mathrm{GE}$

$\mu \mathrm{g} / \mathrm{L} \quad \mathrm{O} \quad \mathrm{GE}$

$\mu \mathrm{g} / \mathrm{L} \quad \mathrm{O} \quad \mathrm{GE}$

$\mu \mathrm{g} / \mathrm{L} \quad 0 \quad \mathrm{GE}$

$\mu \mathrm{g} / \mathrm{L} \quad \mathrm{O} \quad \mathrm{GE}$

$\mu g / L \quad 0 \quad G E$

$\mu \mathrm{g} / \mathrm{L} \quad 0 \quad$ WA

$\mu g / L \quad 0 \quad$ WA

$\mu \mathrm{g} / \mathrm{L} \quad 0 \quad$ WA

$\mu \mathrm{g} / \mathrm{L} \quad 0 \quad$ WA

$\mu \mathrm{g} / \mathrm{L} \quad 0 \quad \mathrm{GE}$

$\mu \mathrm{g} / \mathrm{L} \quad \mathrm{O} \quad \mathrm{GE}$

$\mu \mathrm{g} / \mathrm{L} \quad 0 \quad \mathrm{GE}$

$\mu \mathrm{g} / \mathrm{L} \quad 0 \quad \mathrm{GE}$

$\mu g / L \quad 0 \quad$ WA

$\mu \mathrm{g} / \mathrm{L} \quad 0 \quad$ WA

$\mu g / L \quad 0 \quad G E$

$\mu \mathrm{g} / \mathrm{L} \quad \mathrm{O} \quad \mathrm{GE}$

$\mu \mathrm{g} / \mathrm{L} \quad 0 \quad \mathrm{GE}$

$\mu \mathrm{g} / \mathrm{L}$

$\mu \mathrm{g} / \mathrm{L}$

$\mu \mathrm{g} / \mathrm{L}$

$\mu \mathrm{g} / \mathrm{L}$

$\mu g / L$

$\mu \mathrm{g} / \mathrm{L}$

$\mu \mathrm{g} / \mathrm{L}$

$\mu \mathrm{g} / \mathrm{L}$

$\mu \mathrm{g} / \mathrm{L}$

$\mu \mathrm{g} / \mathrm{L}$

$\mu \mathrm{g} / \mathrm{L}$

$\mu \mathrm{g} / \mathrm{L}$

$\mu \mathrm{g} / \mathrm{L}$

$\mu \mathrm{g} / \mathrm{L}$

$\mu \mathrm{g} / \mathrm{L}$

$\mu \mathrm{g} / \mathrm{L}$

$\mu \mathrm{g} / \mathrm{L}$

$\mu \mathrm{g} / \mathrm{L}$

WA

WA

- = exceeded holding time. = exceeded screening level or final primary drinking water standard. 
WELL BGO $49 \mathrm{C}$ collected on $01 / 31 / 94$, laboratory analyses (cont.)

\section{H D Analyte}

Silver, total recoverable

Sodium, total recoverable

Sodium, total recoverable

Sodium, total recoverable

Sodium, total recoverable

Sodium, total recoverable

Sodium, total recoverable

Sulfate

Sulfate

Sulfate

Sulfate

Sulfate

1,1,2,2-Tetrachloroethane

$1,1,2,2$-Tetrachloroethane

$1,1,2,2$-Tetrachloroethane

1,1,2,2-Tetrachloroethane

Tetrachloroethylene

Tetrachloroethylene

Tetrachloroethylene

Tetrachloroethylene

Tin, total recoverable

Tin, total recoverable

Tin, total recoverable

Tin, total recoverable

Toluene

Toluene

Toluene

Toluene

Total dissolved solids

Total dissolved solids

Total dissolved solids

Total dissolved solids

Total organic carwon

Total organic carbon

Total organic carbon

Total organic carbon

Total organic halogens

Total organic halogens

Total organic halogens

Total organic halogens

Total organic halogens

Total phosphates (as P)

Total phosphates (as P)

Total phosphates (as P)

Total phosphates (as P)

Toxaphene

Toxaphene

Toxaphene

Toxaphene

Toxaphene

Toxaphene

Toxaphene

2,4,5-TP (Silvex)

2,4,5-TP (Silvex)

2,4,5-TP (Silvex)

2,4,5-TP (Silvex)

Result DF

$<2$.

4,640

$4,640 \quad 1.00$

$4,700 \quad 1.00$

$4.710 \quad 1.00$

$4,160 \quad 1.00$

$4,060 \quad 1.00$

$<1,000 \quad 1.00$

$<1,000 \quad 1.00$

$1,400 \quad 1.00$

$1,380 \quad 1.00$

$1,380 \quad 1.00$

$<1.0$

$<1.0$

$<5.0$

$<5.0$

$<1.0$

$<1.0$

$<5.0$

$<5.0$

6.5

13

5.0

8.6

$<1.0$

$<1.0$

$<5.0$

$<5.0$

50,000

52,000

40,000

39,000

$<1,000$

$<1,000$

$<1,000$

$<1,000$

$<5.0$

$<5.0$

$<5.0$

$<5.0$

$<5.0$

$<50$

$<50$

86

95

$<0.24$
$<0.25$

$<0.25$

$<1.1$

$<2.2$

$<2.2$

$<1.1$

$<0.00045$

$<0.00047$

$<0.55$

$<0.55$
Mod

Unit Flag Lab

$\mu \mathrm{g} / \mathrm{L} \quad 0 \quad$ WA

$\mu g / L \quad 0 \quad$ GE

$\begin{array}{lll}\mu \mathrm{g} / \mathrm{L} & 0 & \mathrm{GE} \\ \mu \mathrm{g} / \mathrm{L} & 0 & \mathrm{GE}\end{array}$

$\mu g / L \quad 0 \quad G E$

$\mu g / L$ WA

$\mu g / L \quad 0 \quad W A$

$\mu g / L \quad 0 \quad G E$

$\mu \mathrm{g} / \mathrm{L} \quad \mathrm{O} \quad \mathrm{GE}$

$\mu \mathrm{g} / \mathrm{L} \quad \mathrm{O} \quad W A$

$\mu \mathrm{g} / \mathrm{L} \quad 0 \quad$ WA

$\mu g / L \quad 0 \quad W A$

$\mu g / L \quad O \quad G E$

$\mu \mathrm{g} / \mathrm{L} \quad \mathrm{O} \quad \mathrm{GE}$

$\mu \mathrm{g} / \mathrm{L} \quad \mathrm{O} \quad W A$

$\mu g / L \quad 0 \quad W A$

$\mu \mathrm{g} / \mathrm{L} \quad \mathrm{O} \quad \mathrm{GE}$

$\mu g / L \quad O \quad G E$

$\mu \mathrm{g} / \mathrm{L} \quad 0 \quad W A$

$\mu g / L \quad 0 \quad$ WA

$\mu \mathrm{g} / \mathrm{L} \quad \mathrm{O} \quad \mathrm{GE}$

$\mu \mathrm{g} / \mathrm{L} \quad 1 \quad \mathrm{GE}$

$\mu \mathrm{g} / \mathrm{L} \quad \mathrm{O} \quad \mathrm{GE}$

$\mu \mathrm{g} / \mathrm{L} \quad \mathrm{O} \quad \mathrm{GE}$

$\mu \mathrm{g} / \mathrm{L} \quad \mathrm{O} \quad \mathrm{GE}$

$\mu \mathrm{g} / \mathrm{L} \quad \mathrm{O} \quad \mathrm{GE}$

$\mu \mathrm{g} / \mathrm{L} \quad 0 \quad$ WA

$\begin{array}{lllll}1.00 & \mu \mathrm{g} / \mathrm{L} & 0 & \text { WA } \\ 1.00 & \mathrm{~J} 2 & \mu \mathrm{g} / \mathrm{L} & 0 & \mathrm{GE}\end{array}$

$\begin{array}{lllll}1.00 & \mathrm{JV} 2 & \mu \mathrm{g} / \mathrm{L} & 0 & \mathrm{GE} \\ 1.00 & \mathrm{JV} 2 & \mu \mathrm{g} / \mathrm{L} & 0 & \mathrm{GE}\end{array}$

$\mu \mathrm{g} / \mathrm{L} \quad 0 \quad$ WA

$1.00 \quad \mu \mathrm{g} / \mathrm{L} \quad 0 \quad$ WA

$\mu g / L \quad 0 \quad G E$

$\mu g / L \quad 0 \quad G E$

$\mu g / L \quad O \quad W A$

$\mu \mathrm{g} / \mathrm{L} \quad \mathrm{O}$ WA

$\mu \mathrm{g} / \mathrm{L} \quad 0 \quad \mathrm{GE}$

$\mu \mathrm{g} / \mathrm{L} \quad \mathrm{O} \quad \mathrm{GE}$

$\mu \mathrm{g} / \mathrm{L} \quad \mathrm{O} \quad \mathrm{WE}$

$\mu \mathrm{g} / \mathrm{L} \quad 0 \quad$ WA

$\mu g / L \quad O \quad G E$

$\mu \mathrm{g} / \mathrm{L} \quad \mathrm{O} \quad \mathrm{GE}$

$\mu \mathrm{g} / \mathrm{L} \quad \mathrm{O} \quad$ WA

$\mu \mathrm{g} / \mathrm{L} \quad \mathrm{O}$ WA

$\mu \mathrm{g} / \mathrm{L} \quad \mathrm{O} \quad \mathrm{GE}$

$\mu \mathrm{g} / \mathrm{L} \quad \mathrm{O} \quad \mathrm{GE}$

$\mu \mathrm{g} / \mathrm{L} \quad 0 \quad \mathrm{GE}$

$\mu \mathrm{g} / \mathrm{L} \quad 0 \quad$ WA

$\mu \mathrm{g} / \mathrm{L} \quad 0 \quad$ WA

$\mu \mathrm{g} / \mathrm{L} \quad 0 \quad$ WA

$\mu g / L \quad 0 \quad$ WA

$\mu \mathrm{g} / \mathrm{L} \quad 0 \quad \mathrm{GE}$

$\mu g / L \quad 0 \quad G E$

$\mu \mathrm{g} / \mathrm{L} \quad 0 \quad$ WA 
WELL BGO 49C collected on 01/31/94, laboratory analyses (cont.)

\section{H D Analyte}

2,4,5-TP (Silvex)

Tributyl phosphate

Tributyl phosphate

1,1,1-Trichloroethane

1,1,1-Trichloroethane

1,1,1-Trichloroethane

1,1,1-Trichloroethane

1,1,2-Trichloroethane

1,1,2-Trichloroethane

1,1,2-Trichloroethane

1,1,2-Trichloroethane

Trichloroethylene

Trichloroethylene

Trichloroethylene

Trichloroethylene

Trichlorofluoromethane

Trichlorofluoromethane

Trichlorofluoromethane

Trichlorofluoromethane

Vanadium, total recoverable

Vanadium, total recoverable

Vanadium, total recoverable

Vanadium, total recoverable

Vanadium, total recoverable

Vanadium, total recoverable

Xylenes

Xylenes

Xylenes

Xylenes

Gross alpha

Gross alpha

Gross alpha

Gross alpha

Nonvolatile beta

Nonvolatile beta

Nonvolatile beta

Nonvolatile beta

Radium-226

Radium-226

Radium-228

Radium-228

Radium, total alpha-emitting

Radium, total alpha-emitting

- Tritium

- Tritium

- Tritium

- Tritium

Uranium-233/234

Uranium-233/234

Uranium-233/234

Uranium-233/234

Uranium-235

Uranium-235

Uranium-235

Uranium-235

Uranium-238

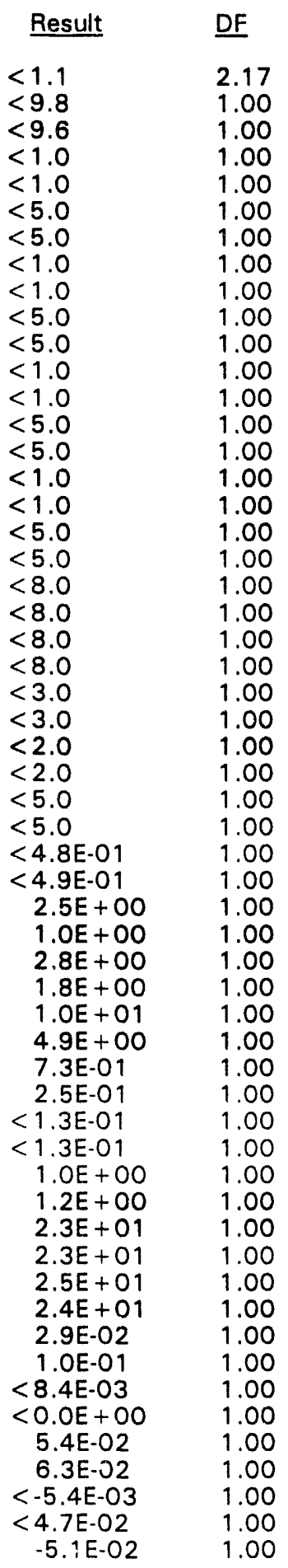

Mod

$\begin{array}{llll}\text { Unit } & \text { Flag } & \text { Lab } \\ \mu & & \\ \mu \mathrm{g} / \mathrm{L} & 0 & \text { WA } \\ \mu \mathrm{g} / \mathrm{L} & 0 & \mathrm{GE} \\ \mu \mathrm{g} / \mathrm{L} & 0 & \mathrm{GE} \\ \mu \mathrm{g} / \mathrm{L} & 0 & \mathrm{GE} \\ \mu \mathrm{g} / \mathrm{L} & 0 & \mathrm{GE}\end{array}$

$\mu \mathrm{g} / \mathrm{L}$

$\mu g / L$

$\mu \mathrm{g} / \mathrm{L}$

$\mu \mathrm{g} / \mathrm{L}$

$\mu \mathrm{g} / \mathrm{L}$

$\mu \mathrm{g} / \mathrm{L}$

$\mu \mathrm{g} / \mathrm{L}$

$\mu \mathrm{g} / \mathrm{L}$

$\mu \mathrm{g} / \mathrm{L}$

$\mu g / L$

$\mu \mathrm{g} / \mathrm{L}$

$\mu g / L$

$\mu \mathrm{g} / \mathrm{L}$

$\mu \mathrm{g} / \mathrm{L}$

$\mu \mathrm{g} / \mathrm{L}$

$\mu \mathrm{g} / \mathrm{L}$

$\mu \mathrm{g} / \mathrm{L}$

$\mu \mathrm{g} / \mathrm{L}$

$\mu \mathrm{g} / \mathrm{L}$

$\mu \mathrm{g} / \mathrm{L}$

$\mu \mathrm{g} / \mathrm{L}$

$\mu \mathrm{g} / \mathrm{L}$

$\mu \mathrm{g} / \mathrm{L}$

pCi/L

$\mathrm{pCi} / \mathrm{L}$

$\mathrm{pCi} / \mathrm{L}$

pCi/L

$\mathrm{pCi} / \mathrm{L}$

pCi/L

$\mathrm{pCi} / \mathrm{L}$

$\mathrm{pCi} / \mathrm{L}$

$\mathrm{pCi} / \mathrm{L}$

$\mathrm{pCi} / \mathrm{L}$

$p C i / L$

JV2

$\mathrm{pCi} / \mathrm{L}$

JV2

pCi/mL

$\mathrm{pCi} / \mathrm{mL}$

$\mathrm{pCi} / \mathrm{mL}$

$\mathrm{pCi} / \mathrm{mL}$

$\mathrm{pCi} / \mathrm{L}$

$\mathrm{pCi} / \mathrm{L}$

$\mathrm{pCi} / \mathrm{L}$

$\mathrm{pCi} / \mathrm{L}$

$\mathrm{pCi} / \mathrm{L}$

pCi/L

$\mathrm{pCi} / \mathrm{L}$

$\mathrm{pCi} / \mathrm{L}$

$\mathrm{pCi} / \mathrm{L}$

$\underline{L a b}$

GE

GE

WA

WA

GE

GE

WA

WA

GE

GE

WA

WA

GE

WE

WA

GE

GE

$\mathrm{GE}$

WE

WA

GE

GE

WA

WA

GP

TM

TM

GP

GP

TM

TM

TM

TM

TM

$T M$

GP

GP

GP

GP

TM

TM

$\mathrm{CN}$

$\mathrm{CN}$

GP

GP

$\mathrm{CN}$

$\mathrm{CN}$

GP

GP

$\mathrm{CN}$

$\overline{- \text { = exceeded holding time. }} \boldsymbol{-}$ = exceeded screening level or final primary drinking water standard. 
WELL BGO $49 \mathrm{C}$ collected on $01 / 31 / 94$, laboratory analyses (cont.)

\begin{tabular}{|c|c|c|c|c|c|c|}
\hline$\underline{H} \underline{D}$ & Analyte & Result & DF & Mod & Unit & Flag \\
\hline & $\begin{array}{l}\text { Uranium-238 } \\
\text { Uranium-238 } \\
\text { Uranium-238 }\end{array}$ & $\begin{array}{r}1.5 \mathrm{E}-01 \\
<3.0 \mathrm{E}-02 \\
<4.6 \mathrm{E}-02\end{array}$ & $\begin{array}{l}1.00 \\
1.00 \\
1.00\end{array}$ & & $\begin{array}{l}\mathrm{pCi} / \mathrm{L} \\
\mathrm{pCi} / \mathrm{L} \\
\mathrm{pCi} / \mathrm{L}\end{array}$ & $\begin{array}{l}0 \\
0 \\
0\end{array}$ \\
\hline
\end{tabular}

\section{WELL BGO 49D}

\begin{tabular}{|c|c|c|c|c|c|c|}
\hline SRS Coord. & Lat/Longitude & Screen Zone Elevation & Top of Casing & Casing & Pump & Formation \\
\hline $\begin{array}{l}N 73931.5 \\
E 56198.8\end{array}$ & $\begin{array}{l}33.280983^{\circ} \mathrm{N} \\
81.662428^{\circ} \mathrm{W}\end{array}$ & $238.5-218.5 \mathrm{ft} \mathrm{msl}$ & $271.5 \mathrm{ft} \mathrm{msl}$ & 4" PVC & $\mathrm{S}$ & Jle $\left(\| B_{2}\right)$ \\
\hline
\end{tabular}

\section{FIELD MEASUREMENTS}

Sample date: $01 / 28 / 94$

Depth to water: $38.44 \mathrm{ft}(11.72 \mathrm{~m})$ below TOC

Water elevation: $233.06 \mathrm{ft}(71.04 \mathrm{~m}) \mathrm{msl}$

Sp. conductance: $29 \mu \mathrm{S} / \mathrm{cm}$

Turbidity: 161 NTU

Water evacuated before sampling: $8 \mathrm{gal}$

The well went dry during purging.

\section{LABORATORY ANALYSES}

- $D \quad$ Analyte
pH
Specific conductance
Turbidity
Acetophenone
Aldrin
Aluminum, total recoverable
Antimony, total recoverable
Arsenic, total recoverable
Barium, total recoverable
Benzene
Benzene
Bromodichloromethane
Bromodichloromethane
Bromoform
Bromoform
Bromomethane (Methyl bromide)
Bromomethane (Methyl bromide)
Cadmium, total recoverable
Calcium, total recoverable
Carbon tetrachloride
Carbon tetrachloride
Chloride
Chlorobenzene
Chlorobenzene
Chloroethane
Chloroethane
Chloroethene (Vinyl chloride)
Chloroethene (Vinyl chloride)
2-Chloroe tnyl vinyl ether
2-Chloroethyl vinyl ether

Time: 9: 11

$\mathrm{pH}: 5.1$

Alkalinity: $1 \mathrm{mg} / \mathrm{L}$

Water temperature: $17.0^{\circ} \mathrm{C}$

Volumes purged: 0.8 well volumes

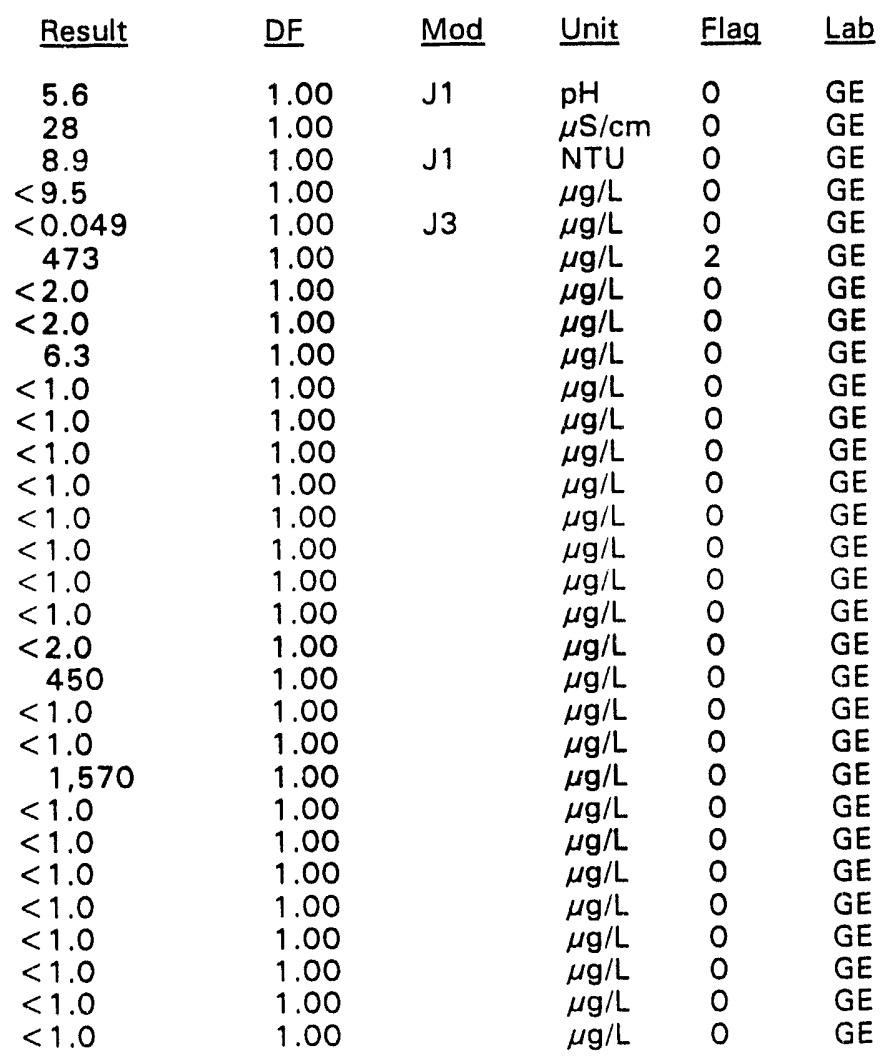

\footnotetext{
$\overline{-}=$ exceeded holding time. - = exceeded screening level or final primary drinking water standard.
} 
WELL BGO 49D collected on 01/28/94, laboratory analyses (cont.)

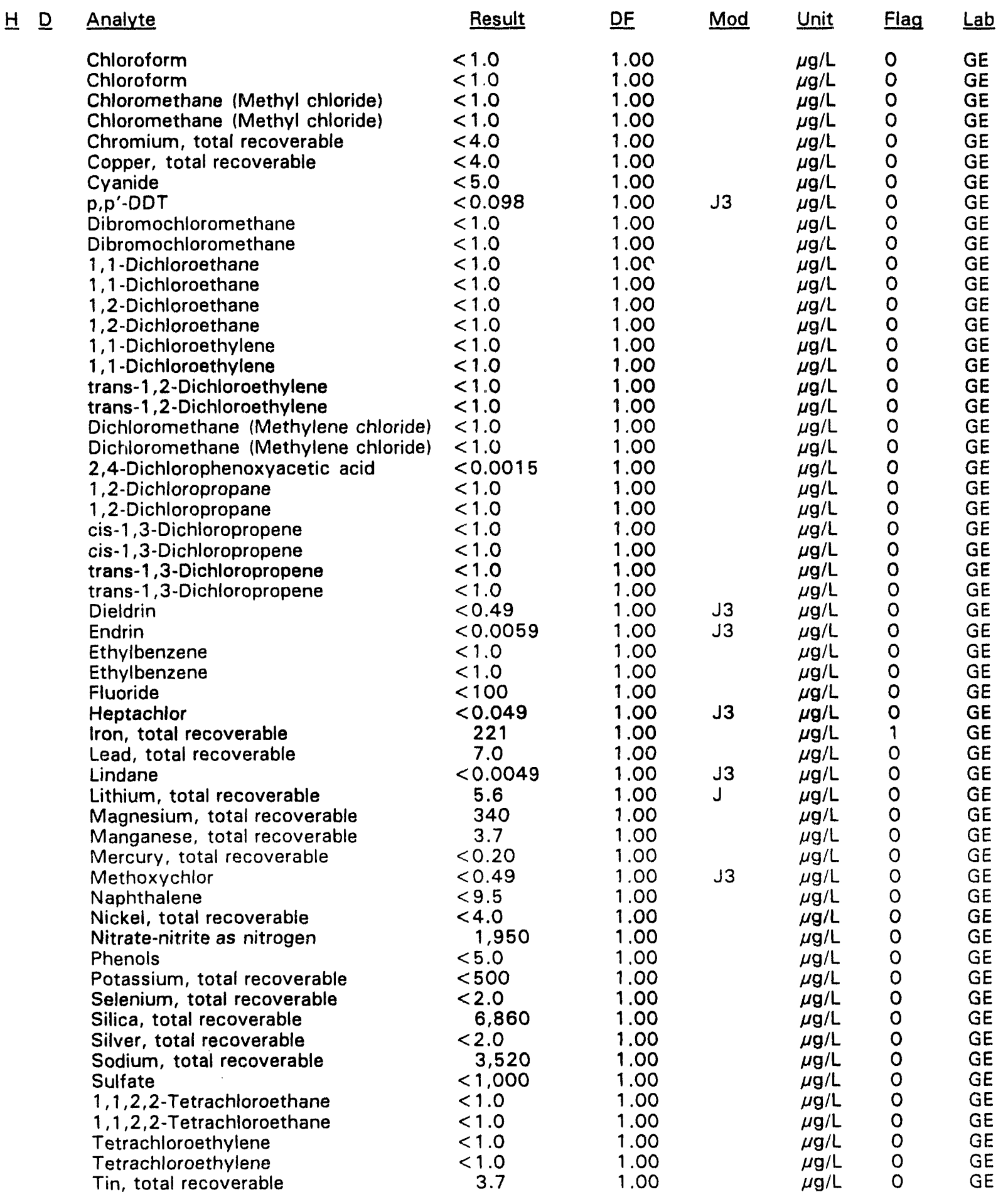

\footnotetext{
= exceeded holding time. $=$ exceeded screening level or final primary drinking water standard.
} 
WELL BGO 49D collected on 01/28/94, laboratory analyses (cont.)

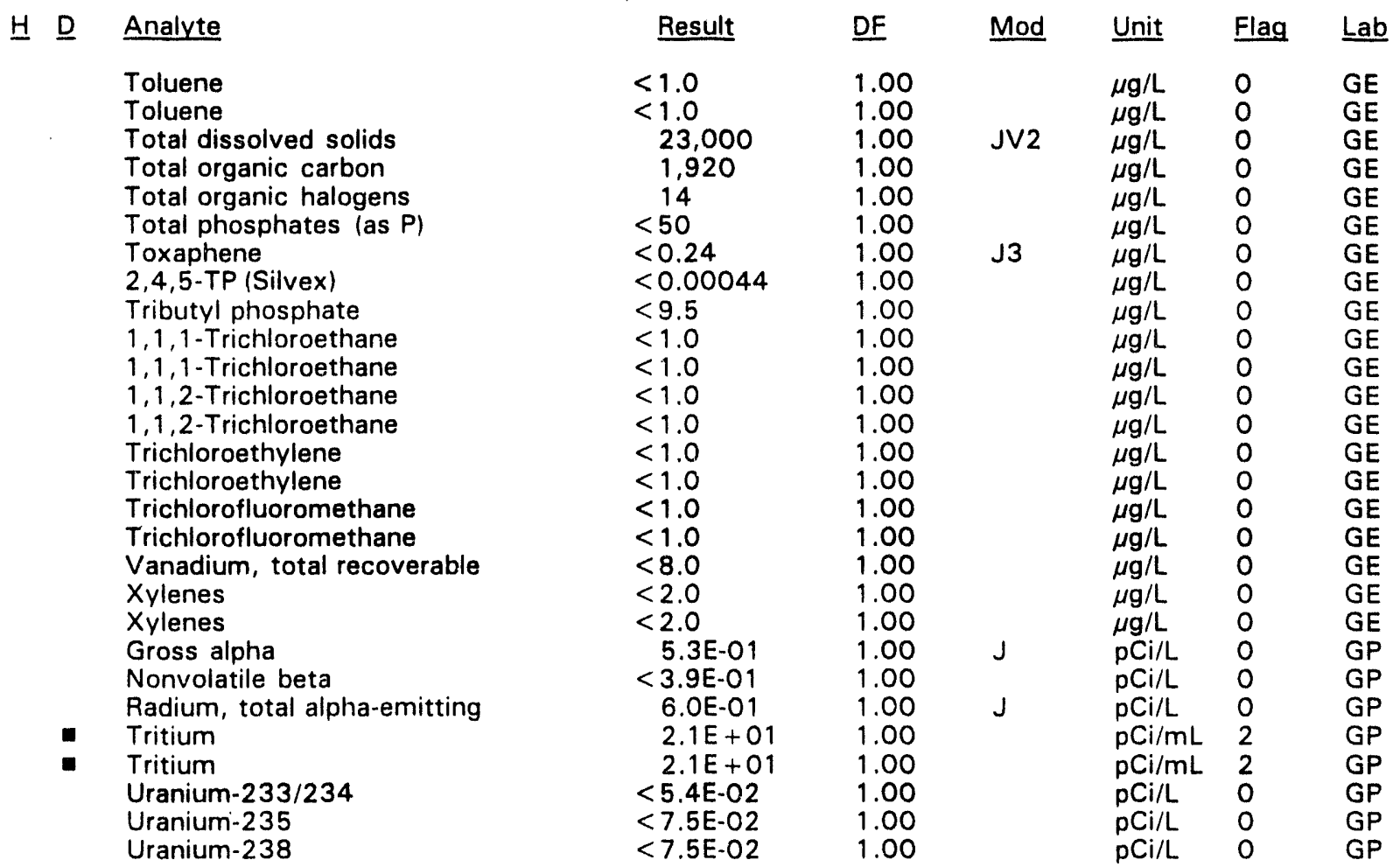

\section{WELL BGO 50A}

\begin{tabular}{|c|c|c|c|c|c|c|}
\hline SRS Coord. & Lat/Longitude & Screen Zone Elevation & Top of Casing & Casing & Pump & Formation \\
\hline $\begin{array}{l}\text { N75201.2 } \\
\text { E54179.8 }\end{array}$ & $\begin{array}{l}33.280497^{\circ} \mathrm{N} \\
81.670210^{\circ} \mathrm{W}\end{array}$ & $100.5-90.5 \mathrm{ft} \mathrm{msl}$ & $255.4 \mathrm{ft} \mathrm{msl}$ & 4" PVC & $\mathrm{s}$ & U. Congaree (IIA) \\
\hline
\end{tabular}

\section{FIELD MEASUREMENTS}

Sample date: $02 / 22 / 94$

Depth to water: $95.51 \mathrm{ft}(29.11 \mathrm{~m})$ below TOC

Water elevation: $159.89 \mathrm{ft}(48.74 \mathrm{~m}) \mathrm{msl}$

Sp. conductance: $2350 \mu \mathrm{S} / \mathrm{cm}$

Turbidity: 7.0 NTU

Water evacuated before sampling: $36 \mathrm{gal}$

The well went dry during purging.

\section{LABORATORY ANALYSES}

- $D \quad$ Analyte
pH
Specific conductance
Turbidity
Acetophenone
Aldrin
Aluminum, total recoverable

$\begin{array}{llllll}\text { Result } & \text { DF } & \text { Mod } & \text { Unit } & \text { Flag } & \text { Lab } \\ 12 & 1.00 & \mathrm{~J} 1 & \mathrm{pH} & 2 & \mathrm{GE} \\ 950 & 1.00 & & \mu \mathrm{S} / \mathrm{cm} & 2 & \mathrm{GE} \\ 1.3 & 1.00 & & \mathrm{NTU} & 0 & \mathrm{GE} \\ <10 & 1.00 & & \mu \mathrm{g} / \mathrm{L} & 0 & \mathrm{GE} \\ <0.050 & 1.00 & & \mu \mathrm{g} / \mathrm{L} & 0 & \mathrm{GE} \\ 641 & 1.00 & & \mu \mathrm{g} / \mathrm{L} & 2 & \mathrm{GE}\end{array}$

Time: 9: 57

$\mathrm{pH}: 12.2$

Alkalinity: $264 \mathrm{mg} / \mathrm{L}$

Water temperature: $18.0^{\circ} \mathrm{C}$

Volumes purged: 0.8 well volumes

\footnotetext{
- = exceeded holding time. = exceeded screening level or final primary drinking water standard.
} 
WELL BGO 50A collected on $02 / 22 / 94$, laboratory analyses (cont.)

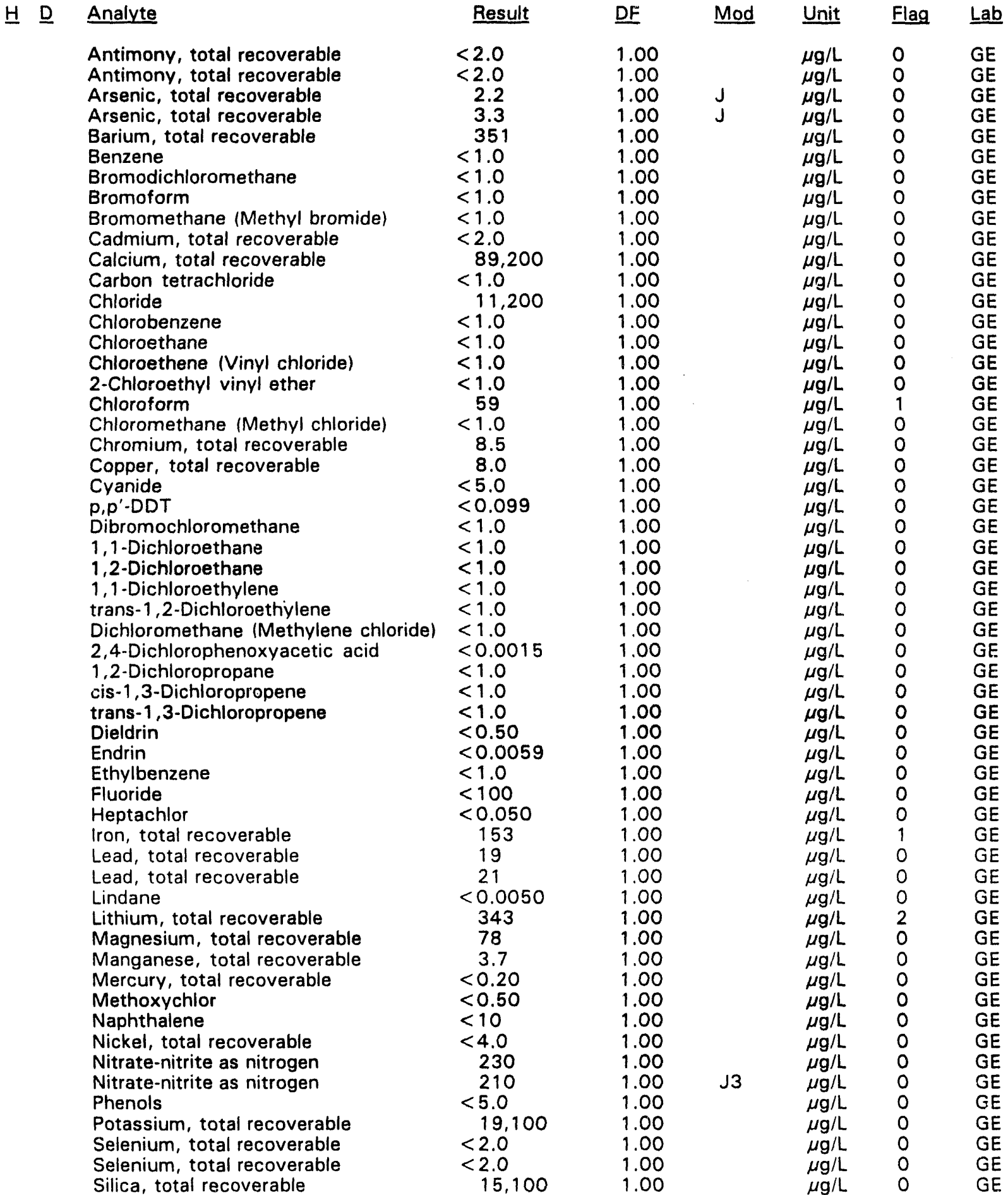

- = exceeded holding time. = exceeded screening level or final primary drinking water standard. 
WELL. BGO 50A collected on $02 / 22 / 94$, laboratory analyses (cont.)

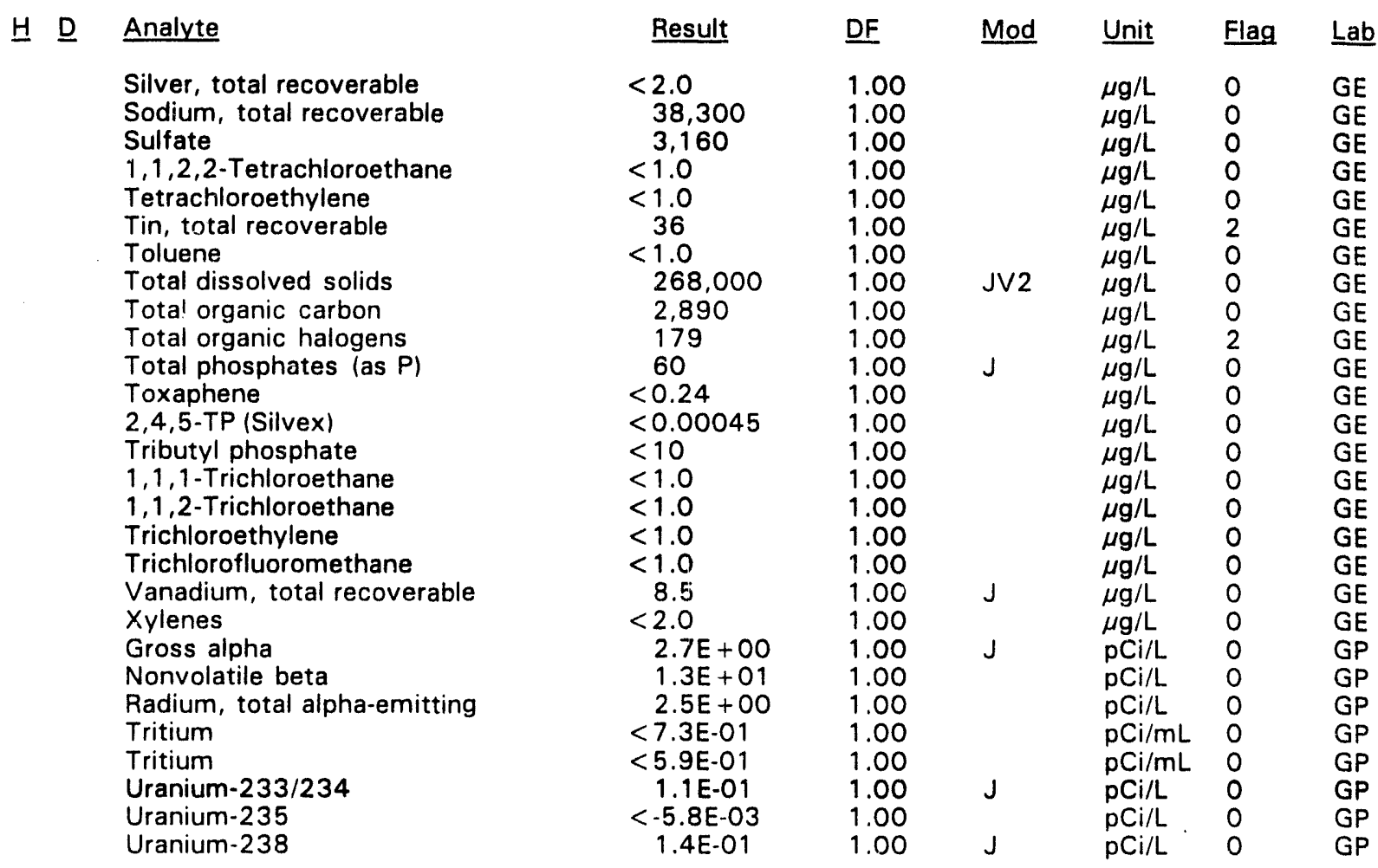

\section{WELL BGO 50C}

\begin{tabular}{|c|c|c|c|c|c|c|}
\hline SRS Coord. & Lat/Longitude & Screen Zone Elevation & Top of Casing & $\underline{\text { Casing }}$ & Pump & Formation \\
\hline $\begin{array}{l}\text { N75190.4 } \\
\text { E54197.0 }\end{array}$ & $\begin{array}{l}33.280501^{\circ} \mathrm{N} \\
81.670144^{\circ} \mathrm{W}\end{array}$ & 17 & 25 & PVC & $s$ & 1) \\
\hline
\end{tabular}

\section{FIELD MEASUREMENTS}

Sample date: $02 / 22 / 94$

Depth to water: $37.05 \mathrm{ft}(11.29 \mathrm{~m})$ below TOC

Water elevation: $218.45 \mathrm{ft}(66.58 \mathrm{~m}) \mathrm{msl}$

Sp. conductance: $36 \mu \mathrm{S} / \mathrm{cm}$

Turbidity: 27.1 NTU

Water evacuated before sampling: $32 \mathrm{gal}$

The well went dry during purging.

\section{LABORATORY ANALYSES}

H $\underline{\text { Analyte }}$ Aluminum, total recoverable
$\mathrm{pH}$
Specific conductance
Turbidity
Acetophenone
Aldrin
- $\quad \mathrm{pH}$

Time: 9: 48

$\mathrm{pH}: 5.2$

Alkalinity: $4 \mathrm{mg} / \mathrm{L}$

Water temperature: $17.9^{\circ} \mathrm{C}$

Volumes purged: 0.9 well volumes

$\begin{array}{llllll}\text { Result } & \text { DF } & \text { Mod } & \text { Unit } & \text { Flag } & \text { Lab } \\ 5.7 & 1.00 & \mathrm{~J} 1 & \mathrm{pH} & 0 & \mathrm{GE} \\ 26 & 1.00 & & \mu \mathrm{S} / \mathrm{cm} & 0 & \mathrm{GE} \\ 34 & 1.00 & & \mathrm{NTU} & 0 & \mathrm{GE} \\ <10 & 1.00 & & \mu \mathrm{g} / \mathrm{L} & 0 & \mathrm{GE} \\ <0.052 & 1.00 & & \mu \mathrm{g} / \mathrm{L} & 0 & \mathrm{GE} \\ 228 & 1.00 & & \mu \mathrm{g} / \mathrm{L} & 2 & \mathrm{GE}\end{array}$

\footnotetext{
- exceeded holding time. $=$ exceeded screening level or final primary drinking water standard.
} 
WELL BGO $50 \mathrm{C}$ collected on $02 / 22 / 94$, laboratory analyses (cont.)

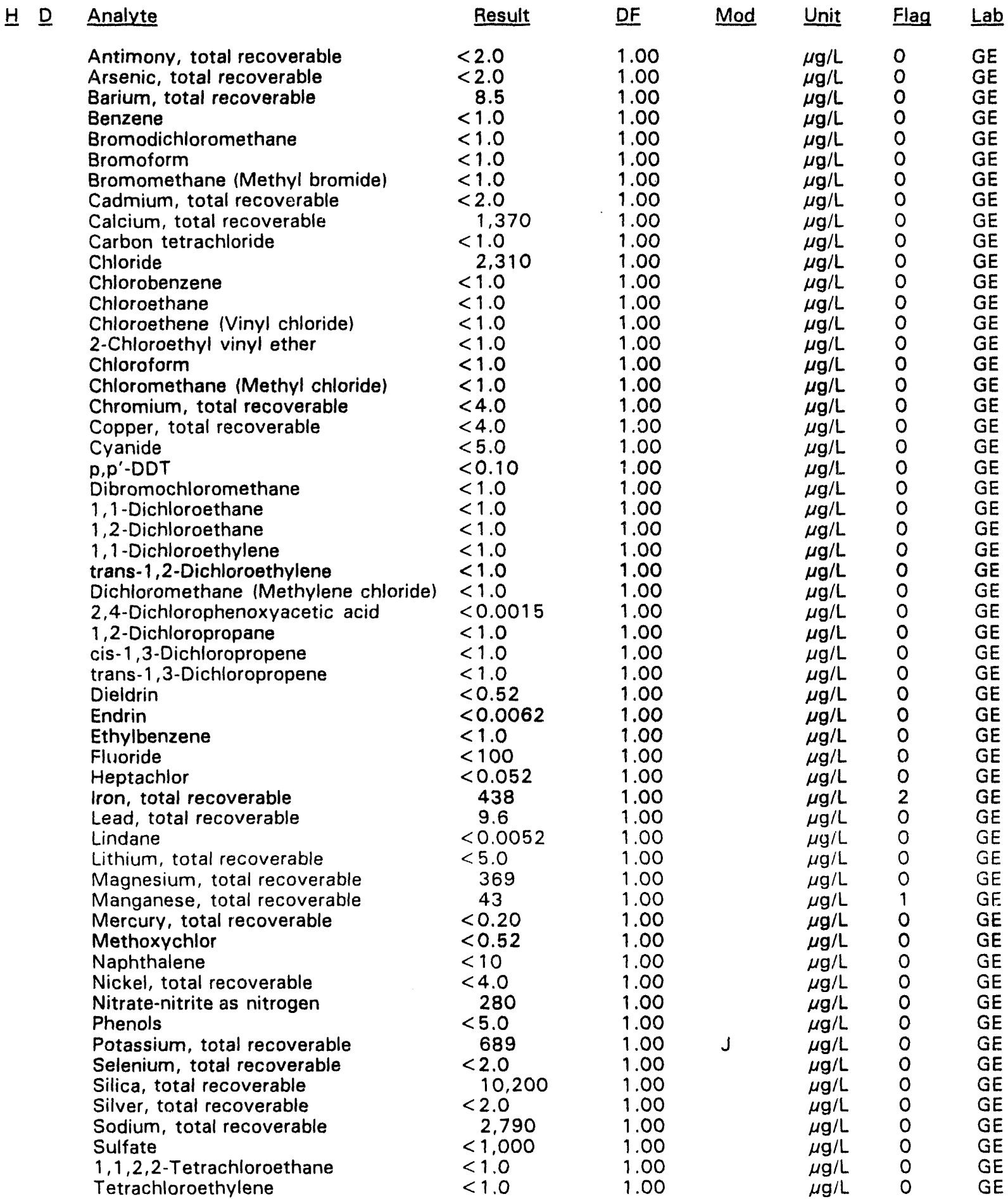

- = exceeded holding time. = exceeded screening level or final primary drinking water standard. 
WELL BGO $50 \mathrm{C}$ collected on $02 / 22 / 94$, laboratory analyses (cont.)

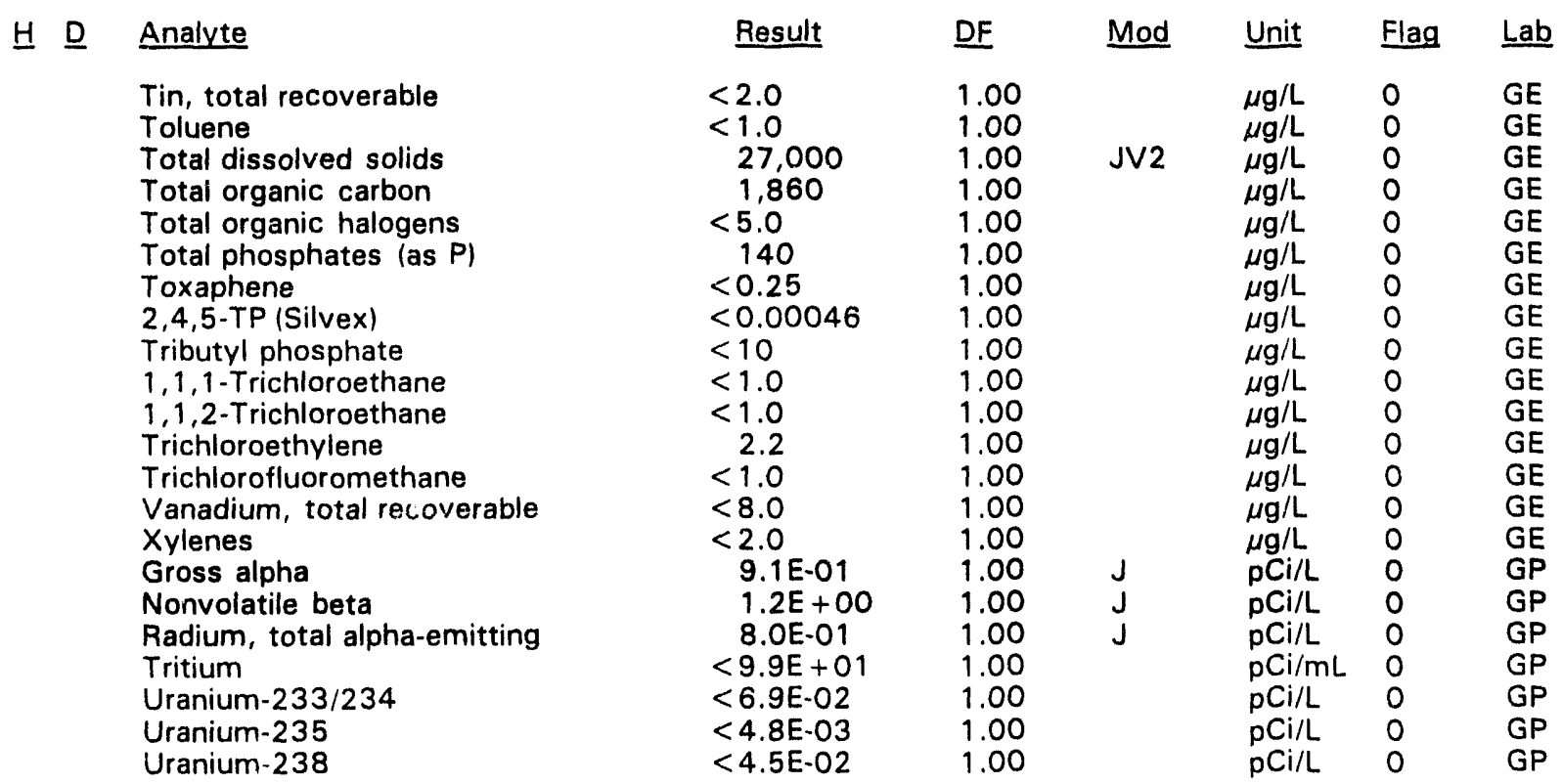

\section{WELL BGO 50D}

\begin{tabular}{|c|c|c|c|c|c|c|}
\hline SRS Coord. & Lat/Longitude & Screen Zone Elevation & Top of Casing & Casing & Pump & Formation \\
\hline & $0501^{\circ} \mathrm{N}$ & 28.0 & & $v \mathrm{C}$ & $\mathrm{S}$ & \\
\hline
\end{tabular}

\section{FIELD MEASUREMENTS}

Sample date: $02 / 21 / 94$

Depth to water: $31.23 \mathrm{ft}(9.52 \mathrm{~m})$ below TOC

Water elevation: $224.77 \mathrm{ft}(68.51 \mathrm{~m}) \mathrm{msl}$

Sp. conductance: $63 \mu \mathrm{S} / \mathrm{cm}$

Turbidity: 1.0 NTU

Water evacuated before sampling: 50 gal

\section{LABORATORY ANALYSES}

H $\underline{\text { Analyte }}$

- $\quad \mathrm{pH}$

Specific conductance

Turbidity

Acetophenone

Aldrin

Aluminum, total recoverable

Antimony, total recoverable

Arsenic, total recoverable

Barium, total recoverable

Benzene

Bromodichloromethane

Bromoform
Time: 13: 12

pH: 6.1

Alkalinity: $18 \mathrm{mg} / \mathrm{L}$

Water temperature: $20.0^{\circ} \mathrm{C}$

Volumes purged: 4.5 well volumes

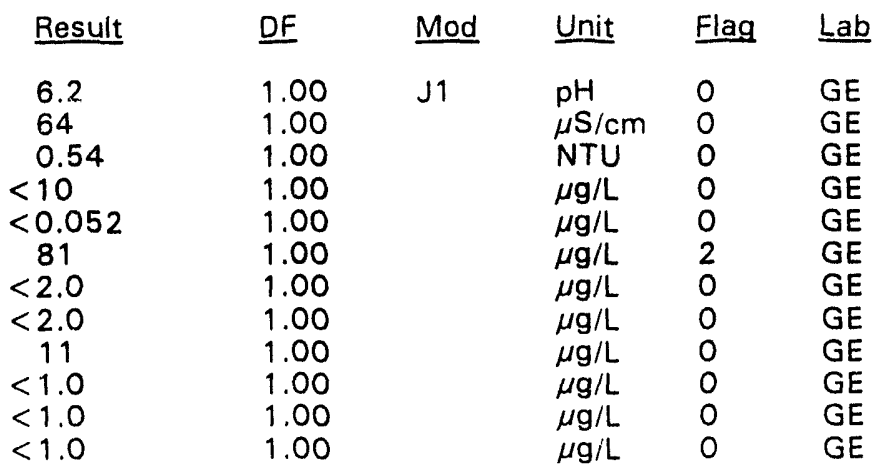

\footnotetext{
- = exceeded holding time. = exceeded screening level or final primary drinking water standard.
} 
WELL BGO $50 D$ collected on $02 / 21 / 94$, laboratory analyses (cont.)

\section{H $\underline{D}$}

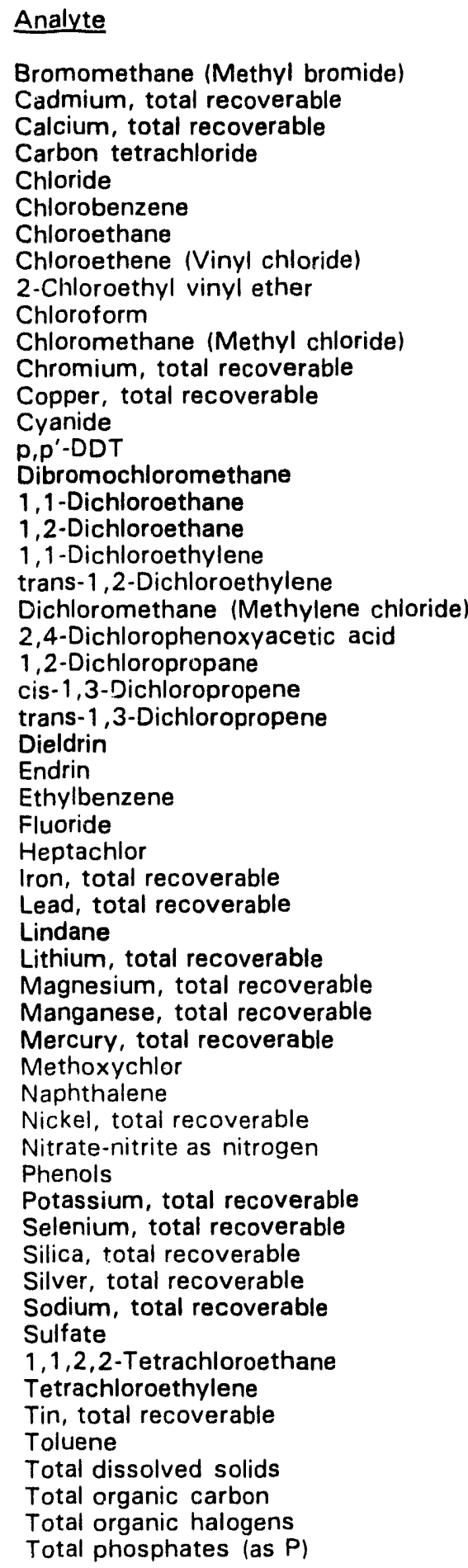

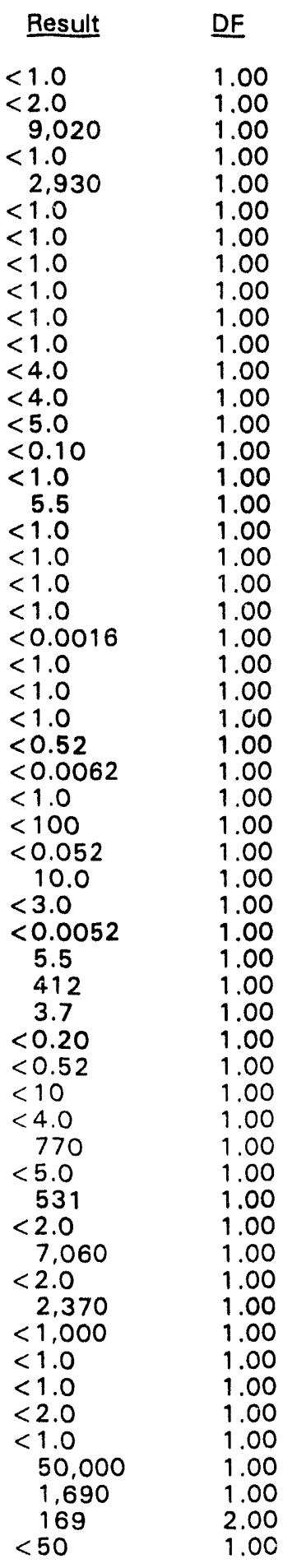

Mod Unit Flag Lab

$\mu \mathrm{g} / \mathrm{L} \quad 0 \quad \mathrm{GE}$

$\mu \mathrm{g} / \mathrm{L} \quad \mathrm{O} \quad \mathrm{GE}$

$\mu \mathrm{g} / \mathrm{L} \quad 0 \quad \mathrm{GE}$

$\mu \mathrm{g} / \mathrm{L} \quad \mathrm{O} \quad \mathrm{GE}$

$\mu \mathrm{g} / \mathrm{L} \quad \mathrm{O} \quad \mathrm{GE}$

$\mu \mathrm{g} / \mathrm{L} \quad 0 \quad \mathrm{GE}$

$\mu \mathrm{g} / \mathrm{L} \quad \mathrm{O} \quad \mathrm{GE}$

$\mu \mathrm{g} / \mathrm{L} \quad \mathrm{O} \quad \mathrm{GE}$

$\mu \mathrm{g} / \mathrm{L} \quad 0 \quad \mathrm{GE}$

$\mu \mathrm{g} / \mathrm{L} \quad 0 \quad \mathrm{GE}$

$\mu \mathrm{g} / \mathrm{L} \quad 0 \quad \mathrm{GF}$

$\mu \mathrm{g} / \mathrm{L} \quad 0 \quad \mathrm{GE}$

$\mu \mathrm{g} / \mathrm{L} \quad 0 \quad \mathrm{GE}$

$\mu \mathrm{g} / \mathrm{L} \quad 0 \quad \mathrm{GE}$

$\mu \mathrm{g} / \mathrm{L} \quad 0 \quad \mathrm{GE}$

$\mu \mathrm{g} / \mathrm{L} \quad \mathrm{O} \quad \mathrm{GE}$

$\mu \mathrm{g} / \mathrm{L} \quad 1 \quad \mathrm{GE}$

$\mu \mathrm{g} / \mathrm{L} \quad \mathrm{O} \quad \mathrm{GE}$

$\mu \mathrm{g} / \mathrm{L} \quad 0 \quad \mathrm{GE}$

$\mu \mathrm{g} / \mathrm{L} \quad \mathrm{O} \quad \mathrm{GE}$

$\mu \mathrm{g} / \mathrm{L} \quad 0 \quad \mathrm{GE}$

$\mu \mathrm{g} / \mathrm{L} \quad 0 \quad \mathrm{GE}$

$\mu \mathrm{g} / \mathrm{L} \quad 0 \quad \mathrm{GE}$

$\mu \mathrm{g} / \mathrm{L} \quad 0 \quad \mathrm{GE}$

$\mu \mathrm{g} / \mathrm{L} \quad 0 \quad \mathrm{GE}$

$\mu \mathrm{g} / \mathrm{L} \quad 0 \quad \mathrm{GE}$

$\mu \mathrm{g} / \mathrm{L} \quad 0 \quad \mathrm{GE}$

$\mu \mathrm{g} / \mathrm{L} \quad 0 \quad \mathrm{GE}$

$\mu \mathrm{g} / \mathrm{L} \quad 0 \quad \mathrm{GE}$

$\mu \mathrm{g} / \mathrm{L} \quad 0 \quad \mathrm{GE}$

$\mu \mathrm{g} / \mathrm{L} \quad \mathrm{O} \quad \mathrm{GE}$

$\mu \mathrm{g} / \mathrm{L} \quad 0 \quad \mathrm{GE}$

$\mu g / L \quad O \quad G E$

$\mu \mathrm{g} / \mathrm{L} \quad 0 \quad \mathrm{GE}$

$\mu \mathrm{g} / \mathrm{L} \quad \mathrm{D} \quad \mathrm{GE}$

$\mu \mathrm{g} / \mathrm{L} \quad \mathrm{O} \quad \mathrm{GE}$

$\mu \mathrm{g} / \mathrm{L} \quad 0 \quad \mathrm{GE}$

$\mu \mathrm{g} / \mathrm{L} \quad \mathrm{O} \quad \mathrm{GE}$

$\mu \mathrm{g} / \mathrm{L} \quad \mathrm{O} \quad \mathrm{GE}$

$\mu \mathrm{g} / \mathrm{L} \quad \mathrm{O} \quad \mathrm{GE}$

$\mu \mathrm{g} / \mathrm{L} \quad \mathrm{O} \quad \mathrm{GE}$

$\mu \mathrm{g} / \mathrm{L} \quad \mathrm{O} \quad \mathrm{GE}$

$\mathrm{J} \quad \mu \mathrm{g} / \mathrm{L} \quad 0 \quad \mathrm{GE}$

$\mu \mathrm{g} / \mathrm{L} \quad \mathrm{O} \quad \mathrm{GE}$

$\mu \mathrm{g} / \mathrm{L} \quad 0 \quad \mathrm{GE}$

$\mu \mathrm{g} / \mathrm{L} \quad \mathrm{O} \quad \mathrm{GE}$

$\mu \mathrm{g} / \mathrm{L} \quad \mathrm{O} \quad \mathrm{GE}$

$\mu \mathrm{g} / \mathrm{L} \quad \mathrm{O} \quad \mathrm{GE}$

$\mu \mathrm{g} / \mathrm{L} \quad \mathrm{O} \quad \mathrm{GE}$

$\mu \mathrm{g} / \mathrm{L} \quad 0 \quad \mathrm{GE}$

$\mu \mathrm{g} / \mathrm{L} \quad \mathrm{O} \quad \mathrm{GE}$

$\mu \mathrm{g} / \mathrm{L} \quad 0 \quad \mathrm{GE}$

JV2 $\mu \mathrm{g} / \mathrm{L} \quad 0 \quad \mathrm{GE}$

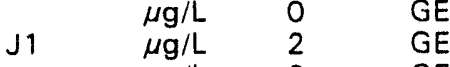

$\mu \mathrm{g} / \mathrm{L} \quad 0 \quad \mathrm{GE}$

- = exceeded holding time. = exceeded screening level or final primary drinking water standard. 
WELL BGO 5OD collected on 0.2/21/94, laboratory analyses (cont.)

\begin{tabular}{|c|c|c|c|c|c|c|}
\hline$\underline{H} \quad \underline{D}$ & Analyte & Result & DF & Mod & Unit & Flag \\
\hline • & $\begin{array}{l}\text { Toxaphene } \\
2,4,5-T P \text { (Silvex) } \\
\text { Tributyl phosphate } \\
1,1,1-\text { Trichloroethane } \\
1,1,2-\text { Trichloroethane } \\
\text { Trichloroethylene } \\
\text { Trichlorofluoromethane } \\
\text { Vanadium, total recoverable } \\
\text { Xylenes } \\
\text { Gross alpha } \\
\text { Nonvolatile beta } \\
\text { Radium, total alpha-emitting } \\
\text { Tritium } \\
\text { Uranium-233/234 } \\
\text { Uranium-235 } \\
\text { Uranium-238 }\end{array}$ & $\begin{aligned} &< 0.25 \\
&<0.00047 \\
&< 10 \\
&< 1.0 \\
&< 1.0 \\
& 1.2 \\
&< 1.0 \\
&< 8.0 \\
&< 2.0 \\
& 3.6 E+00 \\
& 3.1 E+00 \\
& 1.6 E+00 \\
&< 4.0 E+03 \\
& 2.1 E+00 \\
& 2.1 E-01 \\
& 4.2 E+00\end{aligned}$ & $\begin{array}{l}1.00 \\
1.00 \\
1.00 \\
1.00 \\
1.00 \\
1.00 \\
1.00 \\
1.00 \\
1.00 \\
1.00 \\
1.00 \\
1.00 \\
1.00 \\
1.00 \\
1.00 \\
1.00\end{array}$ & $\mathrm{~J}$ & $\begin{array}{l}\mu \mathrm{g} / \mathrm{L} \\
\mu \mathrm{g} / \mathrm{L} \\
\mu \mathrm{g} / \mathrm{L} \\
\mu \mathrm{g} / \mathrm{L} \\
\mu \mathrm{g} / \mathrm{L} \\
\mu \mathrm{g} / \mathrm{L} \\
\mu \mathrm{g} / \mathrm{L} \\
\mu \mathrm{g} / \mathrm{L} \\
\mu \mathrm{g} / \mathrm{L} \\
\mathrm{pCi} / \mathrm{L} \\
\mathrm{pCi} / \mathrm{L} \\
\mathrm{pCi} / \mathrm{L} \\
\mathrm{pCi} / \mathrm{mL} \\
\mathrm{pCi} / \mathrm{L} \\
\mathrm{pCi} / \mathrm{L} \\
\mathrm{pCi} / \mathrm{L}\end{array}$ & $\begin{array}{l}0 \\
0 \\
0 \\
0 \\
0 \\
2 \\
0 \\
0 \\
0 \\
0 \\
0 \\
0 \\
0 \\
0 \\
0 \\
0\end{array}$ \\
\hline
\end{tabular}

\section{WELL BGX $1 \mathrm{C}$}

$\begin{array}{lllllll}\text { SRS Coord. } & \text { Lat/Longitude } & \text { Screen Zone Elevation } & \text { Top of Casing } & \text { Casing } & \text { Pump } & \text { Formation } \\ \text { N76820.0 } & 33.291289^{\circ} \mathrm{N} & 186.0-176.0 \mathrm{ft} \mathrm{msl} & 291.3 \mathrm{ft} \mathrm{msl} & \text { 4" PVC } & \text { S } & \text { Barnwell (IIB,) } \\ \text { E58599.8 } & 81.661716^{\circ} \mathrm{W} & & & \end{array}$

\section{FIELD MEASUREMENTS}

Sample date: 02/08/94

Depth to water: $75.65 \mathrm{ft}(23.06 \mathrm{~m})$ below TOC

Water elevation: $215.65 \mathrm{ft}(65.73 \mathrm{~m}) \mathrm{msl}$

Sp. conductance: $2930 \mu \mathrm{S} / \mathrm{cm}$

Turbidity: 5.0 NTU

Water evacuated before sampling: $13 \mathrm{gal}$

The well went dry during purging.

\section{LABORATORY ANALYSES}

H $\underline{\text { Analyte }}$

-

$\mathrm{pH}$
Specific conductance
Turbidity
Acetophenone
Acetophenone
Aldrin
Aldrin
Aluminum, total recoverable
Antimony, total recoverable
Arsenic, total recoverable
Barium, total recoverable
Benzene
Bromodichloromethane
Bromoform
Bromomethane (Methyl bromide)
Cadmium, total recoverable
Calcium, total recoverable
Carbon tetrachloride

Time: 13: 55

$\mathrm{pH}: 12.2$

Alkalinity: $644 \mathrm{mg} / \mathrm{L}$

Water temperature: $18.2^{\circ} \mathrm{C}$

Volumes purged: 0.5 well volumes

\begin{tabular}{|c|c|c|c|c|c|}
\hline Result & $\underline{\mathrm{DF}}$ & Mod & Unit & Flag & Lal \\
\hline 12 & 1.00 & J1 & $\mathrm{pH}$ & 2 & GE \\
\hline 1,800 & 1.00 & & $\mu \mathrm{S} / \mathrm{cm}$ & 2 & \\
\hline 3.8 & 1.00 & & NTU & 0 & \\
\hline$<10$ & 1.00 & & $\mu \mathrm{g} / \mathrm{L}$ & 0 & \\
\hline$<10$ & 1.00 & & $\mu \mathrm{g} / \mathrm{L}$ & 0 & \\
\hline$<0.050$ & 1.00 & & $\mu \mathrm{g} / \mathrm{L}$ & 0 & \\
\hline$<0.050$ & 1.00 & J3 & $\mu \mathrm{g} / \mathrm{L}$ & 0 & \\
\hline 741 & 5.00 & & $\mu \mathrm{g} / \mathrm{L}$ & 2 & \\
\hline $\begin{array}{r}2.7 \\
<2.0\end{array}$ & 1.00 & $J$ & $\mu \mathrm{g} / \mathrm{L}$ & $\begin{array}{l}0 \\
0\end{array}$ & \\
\hline $\begin{array}{r}<2.0 \\
223\end{array}$ & $\begin{array}{l}1.00 \\
5.00\end{array}$ & & $\mu \mathrm{g} / \mathrm{L}$ & 0 & $G$ \\
\hline$<1.0$ & 1.00 & $Y$ & $\mu \mathrm{g} / \mathrm{L}$ & 0 & 0 \\
\hline$<1.0$ & 1.00 & $Y$ & $\mu \mathrm{g} / \mathrm{L}$ & 0 & \\
\hline$<1.0$ & 1.00 & $Y$ & $\mu \mathrm{g} / \mathrm{L}$ & 0 & \\
\hline$<1.0$ & 1.00 & $Y$ & $\mu \mathrm{g} / \mathrm{L}$ & 0 & \\
\hline$<10$ & 5.00 & & $\mu g / L$ & 0 & \\
\hline 146,000 & 5.00 & & $\mu \mathrm{g} / \mathrm{L}$ & 0 & \\
\hline$<1.0$ & 1.00 & $\mathrm{Y}$ & $\mu \mathrm{g} / \mathrm{L}$ & 0 & \\
\hline
\end{tabular}

\footnotetext{
$\overline{-=}$ exceeded holding time. $=$ exceeded screening level or final primary drinking water standard.
} 
WELL BGX 1C collected on 02/08/94, laboratory analyses (cont.)

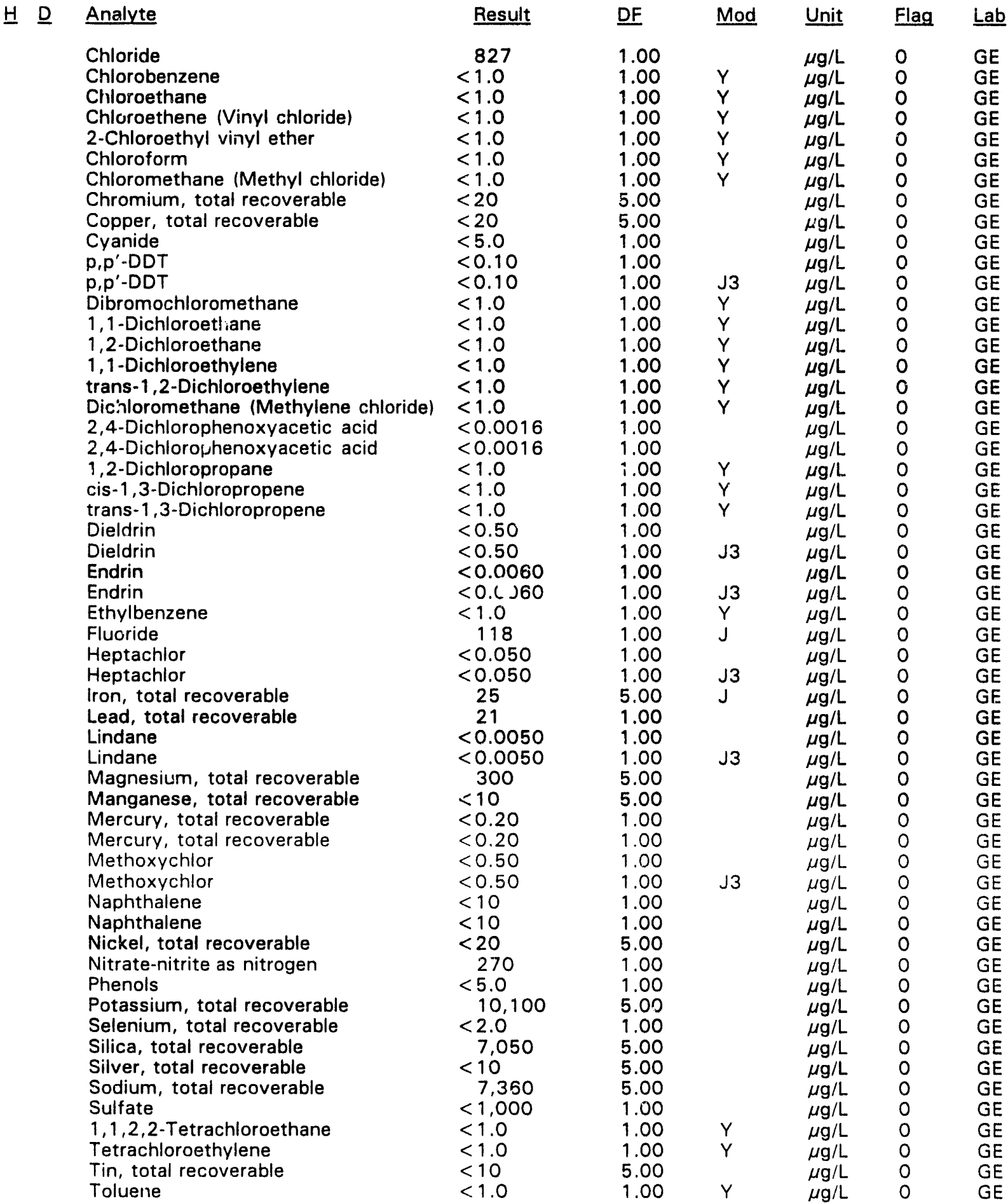

- = exceeded holding time. $-=$ exceeded screening level or final primary drinking water standard. 
WELL BGX 1C collected on 02/08/94, laboratory analyses (cont.)

\begin{tabular}{|c|c|c|c|c|c|c|c|}
\hline \multirow[t]{18}{*}{$\underline{H} \underline{D}$} & Analyte & Result & $\underline{D F}$ & Mod & $\underline{\text { Unit }}$ & Flag & Lab \\
\hline & Total dissolved solids & 430,000 & 1.00 & $J \vee 2$ & $\mu \mathrm{g} / \mathrm{L}$ & 0 & $\mathrm{EE}$ \\
\hline & $\begin{array}{l}\text { Total organic carbon } \\
\text { Total organic halogens }\end{array}$ & $<1,000$ & 1.00 & & $\mu \mathrm{g} / \mathrm{L}$ & 0 & SE \\
\hline & $\begin{array}{l}\text { Total organic halogens } \\
\text { Total phosphates (as P) }\end{array}$ & $\begin{array}{l}5.4 \\
100\end{array}$ & $\begin{array}{l}1.00 \\
1.00\end{array}$ & $\mathrm{~J}$ & $\underset{\mu \mathrm{g} / \mathrm{L}}{\mu \mathrm{L}}$ & $\begin{array}{l}0 \\
0\end{array}$ & SE \\
\hline & Toxaphene & $<0.24$ & 1.00 & & $\mu \mathrm{g} / \mathrm{L}$ & 0 & $\mathrm{GE}$ \\
\hline & Toxaphene & $<0.24$ & 1.00 & $\mathrm{~J} 3$ & $\mu \mathrm{g} / \mathrm{L}$ & 0 & E \\
\hline & $2,4,5-\mathrm{TP}$ (Silvex) & $<0.00047$ & 1.00 & & $\mu \mathrm{g} / \mathrm{L}$ & 0 & E \\
\hline & $2,4,5$-TP (Silvex) & $<0.00047$ & 1.00 & & $\mu \mathrm{g} / \mathrm{L}$ & 0 & $\mathrm{GE}$ \\
\hline & $1,1,1$-Trichloroethane & $<1.0$ & 1.00 & Y & $\mu \mathrm{g} / \mathrm{L}$ & 0 & $\mathrm{GE}$ \\
\hline & 1,1,2-Trichloroethane & $<1.0$ & 1.00 & Y & $\mu \mathrm{g} / \mathrm{L}$ & 0 & $\mathrm{E}$ \\
\hline & Trichloroethylene & $<1.0$ & 1.00 & $\mathrm{Y}$ & $\mu \mathrm{g} / \mathrm{L}$ & 0 & \\
\hline & Trichlorofluoromethane & $<1.0$ & 1.00 & $\mathrm{Y}$ & $\mu \mathrm{g} / \mathrm{L}$ & 0 & GE \\
\hline & Vanadium, total recoverable & $<40$ & 5.00 & & $\mu \mathrm{g} / \mathrm{L}$ & 0 & $\mathrm{E}$ \\
\hline & Xylenes & $<2.0$ & 1.00 & $\mathrm{Y}$ & $\mu \mathrm{g} / \mathrm{L}$ & 0 & \\
\hline & Gross alpha & $7.0 E+00$ & 1.00 & & $\mathrm{pC \textrm {i } i} / \mathrm{L}$ & 0 & $p^{p}$ \\
\hline & Nonvolatile beta & $1.7 E+01$ & 1.00 & & $\mathrm{pCi} / \mathrm{L}$ & 0 & ? \\
\hline & Radium, total alpha-emitting & $2.1 E+00$ & 1.00 & & $\mathrm{Ci} / \mathrm{L}$ & 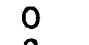 & \\
\hline & Tritium & $1.5 E+03$ & 1.00 & & $\mathrm{i} / \mathrm{mL}$ & 2 & \\
\hline
\end{tabular}

\section{WELL BGX 1D}

\begin{tabular}{|c|c|c|c|c|c|c|}
\hline SRS Coord. & Lat/Longitude & Screen Zone Elevation & Top of Casing & Casing & Pump & Formation \\
\hline $\begin{array}{l}N 76809.5 \\
E 58608.6\end{array}$ & $\begin{array}{l}33.291280^{\circ} \mathrm{N} \\
81.661673^{\circ} \mathrm{W}\end{array}$ & $234.7-214.7$ & $291.3 \mathrm{ft} \mathrm{msl}$ & 4" PVC & $\mathrm{s}$ & I Table III \\
\hline
\end{tabular}

\section{FIELD MEASUREMENTS}

Sample date: 02/08/94

Depth to water: $61.62 \mathrm{ft}(18.78 \mathrm{~m})$ below TOC

Water elevátion: $229.68 \mathrm{ft}(70.01 \mathrm{~m}) \mathrm{msl}$

Sp. conductance: $131 \mu \mathrm{S} / \mathrm{cm}$

Turbidity: 42.6 NTU

Water evacuated before sampling: $7 \mathrm{gal}$

The well went dry during purging.

\section{LABORATORY ANALYSES}

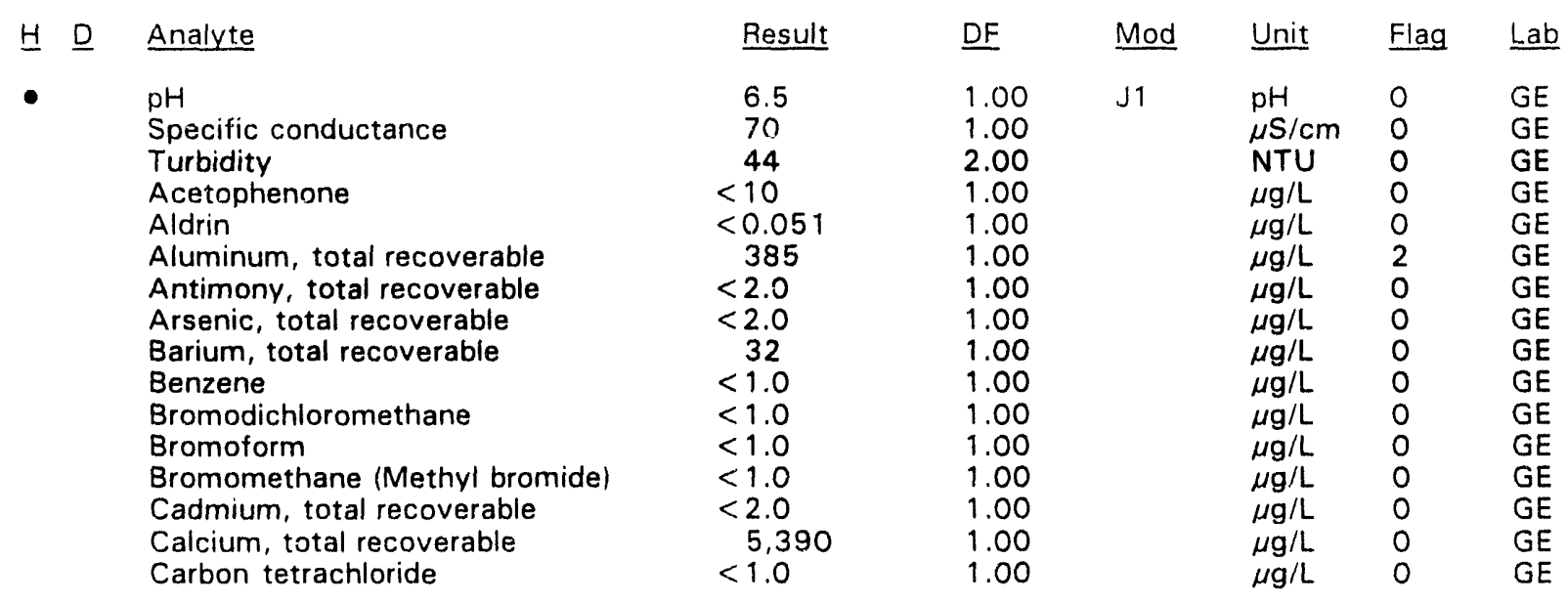

Time: 14:06

pH: 5.9

Alkalinity: $21 \mathrm{mg} / \mathrm{L}$

Water temperature: $18.5^{\circ} \mathrm{C}$

Volumes purged: 0.7 well volumes

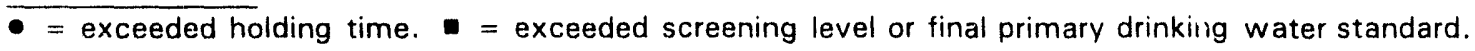


WELL BGX 1D collected on 02/08/94, laboratory analyses (cont.)

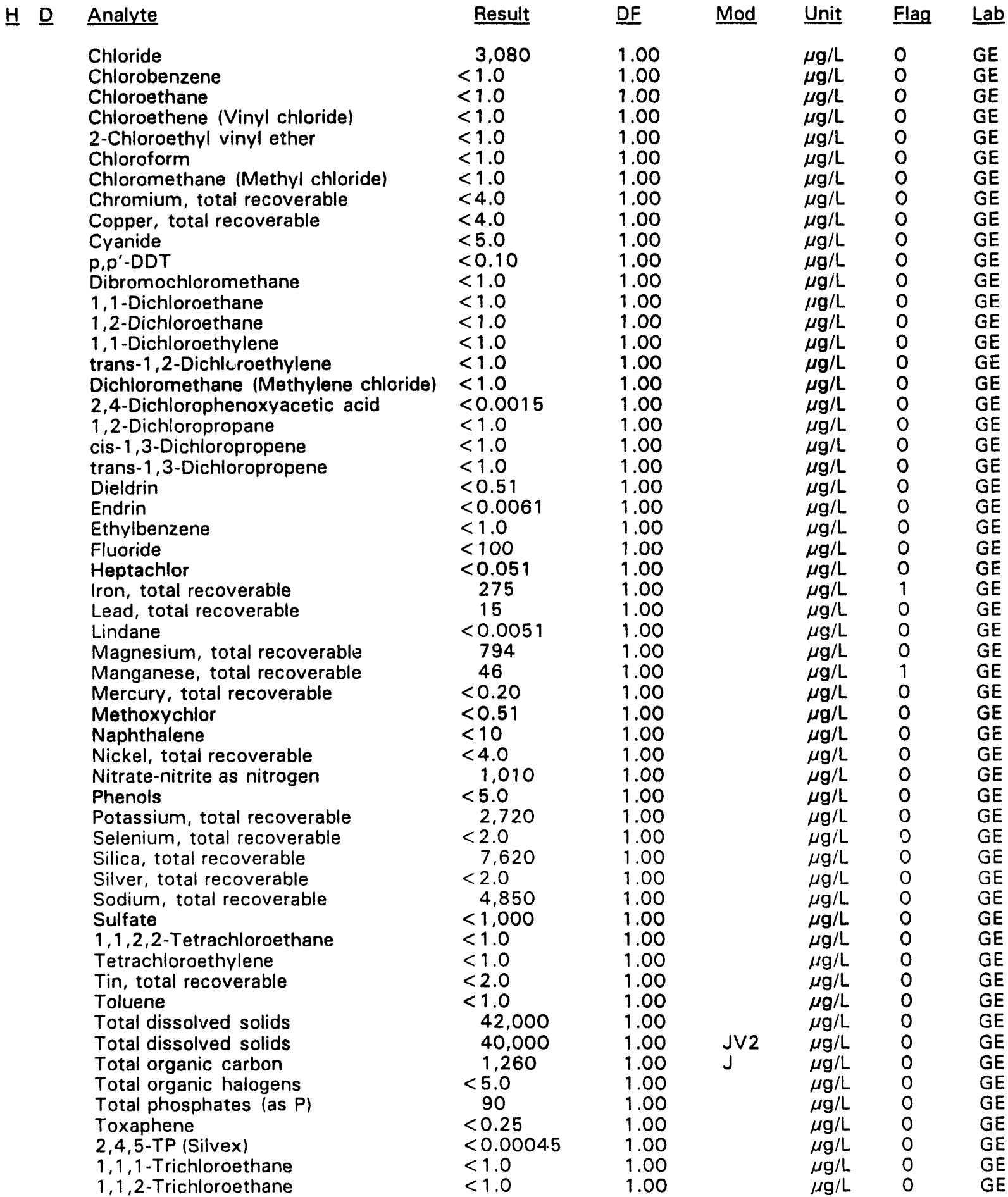

- = exceeded holding time. = exceeded screening level or final primary drinking water standard. 
WELL BGX $1 D$ collected on $\mathrm{C} 2 / 08 / 94$, laboratory analyses (cont.)

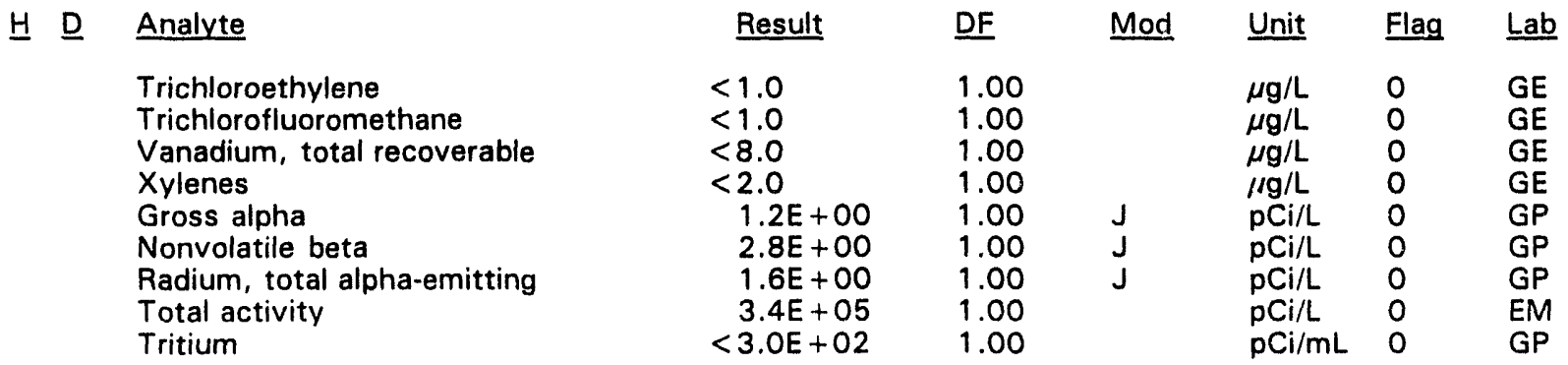

\section{WELL BGX 2B}

\begin{tabular}{|c|c|c|c|c|c|c|}
\hline SRS Coord. & Lat/Longitude & Screen Zone Elevation & Top of Casing & Casing & Pump & Formation \\
\hline & 3365 ow & $147.2-137.2 \mathrm{ft} \mathrm{msl}$ & $291.3 \mathrm{ft} \mathrm{msl}$ & 4" PVC & $\mathrm{s}$ & \\
\hline
\end{tabular}

\section{FIELD MEASUREMENTS}

Sample date: $02 / 08 / 94$

Depth to water: $78.78 \mathrm{ft}(24.01 \mathrm{~m})$ below TOC

Water elevation: $212.52 \mathrm{ft}(64.78 \mathrm{~m}) \mathrm{msl}$

Sp. conductance: $272 \mu \mathrm{S} / \mathrm{cm}$

Turbidity: 213 NTU

Water evacuated before sampling: $49 \mathrm{gal}$

The well went dry during purging.

\section{LABORATORY ANALYSES}

H $\underline{\text { Analyte }}$

- $\mathrm{pH}$

Specific conductarice
Turbidity

Acetophenone

Aldrin

Aluminum, total recoverable

Antimony, total recoverable

Arsenic, total recoverable

Barium, total recoverable

Benzene

Bromodichloromethane

Bromoform

Bromomethane (Methyl bromide)

Cadmium, total recoverable

Calcium, total recoverable

Carbon tetrachloride

Chloride

Chlorobenzene

Chloroethane

Chloroethene (Vinyl chloride)

2-Chloroethyl vinyl ether

Chloroform

Chloromethane (Methyl chloride)

Chromium, total recoverable
Time: 13: 28

$\mathrm{pH}: 7.3$

Alkalinity: $102 \mathrm{mg} / \mathrm{L}$

Water temperature: $17.8^{\circ} \mathrm{C}$

Volumes purged: 1.0 well volumes

\begin{tabular}{|c|c|c|c|c|}
\hline Result & $\underline{D F}$ & Mod & Unit & Flag \\
\hline $\begin{array}{l}7.8 \\
232 \\
4.6\end{array}$ & $\begin{array}{l}1.00 \\
1.00\end{array}$ & J1 & $\begin{array}{l}\mathrm{pH} \\
\mu \mathrm{S} / \mathrm{cm}\end{array}$ & $\begin{array}{l}0 \\
0\end{array}$ \\
\hline $\begin{array}{r}4.6 \\
<10\end{array}$ & 1.00 & & NTU & 0 \\
\hline$<10$ & 1.00 & & $\mu \mathrm{g} / \mathrm{L}$ & 0 \\
\hline$<0.053$ & 1.00 & & $\mu \mathrm{g} / \mathrm{L}$ & 0 \\
\hline 197 & 1.00 & & $\mu \mathrm{g} / \mathrm{L}$ & 2 \\
\hline$<2.0$ & 1.00 & & $\mu \mathrm{g} / \mathrm{L}$ & 0 \\
\hline$<2.0$ & 1.00 & & $\mu \mathrm{g} / \mathrm{L}$ & 0 \\
\hline 159 & 1.00 & & $\mu \mathrm{g} / \mathrm{L}$ & 0 \\
\hline$<1.0$ & 1.00 & & $\mu \mathrm{g} / \mathrm{L}$ & 0 \\
\hline$<1.0$ & 1.00 & & $\mu \mathrm{g} / \mathrm{L}$ & 0 \\
\hline$<1.0$ & 1.00 & & $\mu \mathrm{g} / \mathrm{L}$ & 0 \\
\hline$<1.0$ & 1.00 & & $\mu \mathrm{g} / \mathrm{L}$ & 0 \\
\hline$<2.0$ & 1.00 & & $\mu \mathrm{g} / \mathrm{L}$ & 0 \\
\hline 91,300 & 1.00 & & $\mu \mathrm{g} / \mathrm{L}$ & 0 \\
\hline$<1.0$ & 1.00 & & $\mu \mathrm{g} / \mathrm{L}$ & 0 \\
\hline 2,530 & 1.00 & & $\mu \mathrm{g} / \mathrm{L}$ & 0 \\
\hline$<1.0$ & 1.00 & & $\mu \mathrm{g} / \mathrm{L}$ & 0 \\
\hline$<1.0$ & 1.00 & & $\mu \mathrm{g} / \mathrm{L}$ & 0 \\
\hline$<1.0$ & 1.00 & & $\mu \mathrm{g} / \mathrm{L}$ & 0 \\
\hline$<1.0$ & 1.00 & & $\mu \mathrm{g} / \mathrm{L}$ & 0 \\
\hline$<1.0$ & 1.00 & & $\mu \mathrm{g} / \mathrm{L}$ & 0 \\
\hline$<1.0$ & 1.00 & & $\mu \mathrm{g} / \mathrm{L}$ & 0 \\
\hline$<4.0$ & 1.00 & & $\mu \mathrm{g} / \mathrm{L}$ & 0 \\
\hline
\end{tabular}

\footnotetext{
- exceeded holding time. = exceeded screening level or final primary drinking water standard.
} 
WELL BGX 2B collected on 02/08/94, laboratory analyses (cont.)

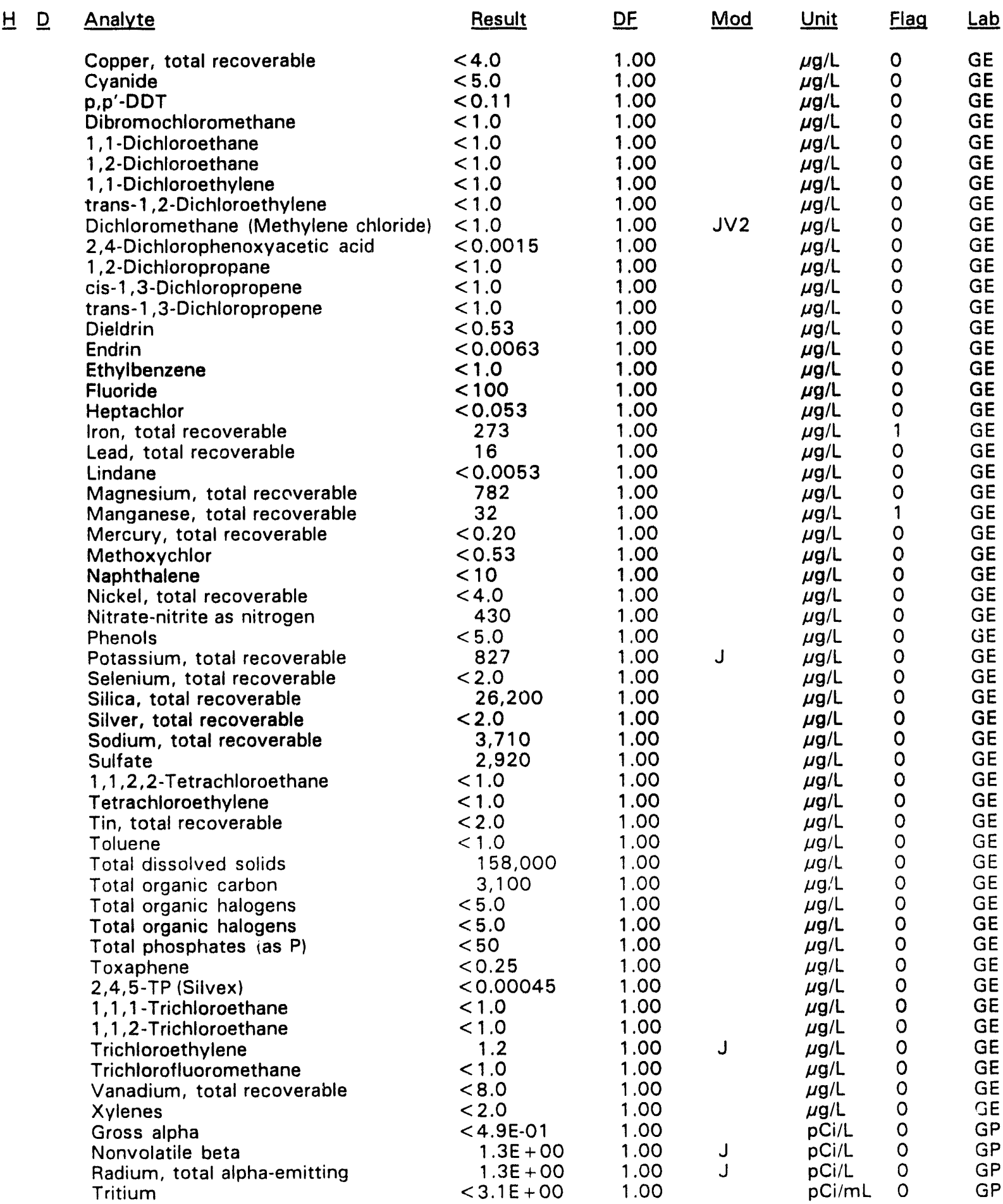

\footnotetext{
- exceeded holding time. $=$ exceeded screening level or final primary drinking water standard.
} 
WELL BGX 2D

\begin{tabular}{|c|c|c|c|c|c|c|}
\hline SRS Coord. & Lat/Longitude & Screen Zone Elevation & Top of Casing & Casing & Pump & Formation \\
\hline & $\begin{array}{l}{ }^{\circ} \mathrm{N} \\
{ }^{\circ} \mathrm{W}\end{array}$ & al & $291.1 \mathrm{ft} \mathrm{msl}$ & VC & $\mathrm{s}$ & \\
\hline
\end{tabular}

\section{FIELD MEASUREMENTS}

Sample date: 02/08/94

Depth to water: $76.00 \mathrm{ft}(23.17 \mathrm{~m})$ below TOC

Water elevation: $215.10 \mathrm{ft}(65.56 \mathrm{~m}) \mathrm{msl}$

Sp. conductance: $37 \mu \mathrm{S} / \mathrm{cm}$

Turbidity: 4.6 NTU

Water evacuated before sampling: $19 \mathrm{gal}$

The well went dry during purging.

Time: $13: 37$

$\mathrm{pH}: 5.3$

Alkalinity: $3 \mathrm{mg} / \mathrm{L}$

Water temperature: $18.1^{\circ} \mathrm{C}$

Volumes purged: 0.9 well volumes

\section{LABORATORY ANALYSES}

\section{H D Analyte}

- $\mathrm{pH}$

Specific conductance

Turbidity

Acetophenone

Aldrin

Aluminum, total recoverable

Antimony, total recoverable

Arsenic, total receverable

Barium, total recoverable

Benzene

Bromodichloromethane

Bromoform

Bromomethane (Methyl bromide)

Cadmium, total recoverable

Calcium, total recoverable

Carbon tetrachloride

Chloride

Chlorobenzene

Chloroethane

Chloroethene (Vinyl chloride)

2-Chloroethyl vinyl ether

Chloroform

Chloromethane (Methyl chloride)

Chromium, total recoverable

Copper, total recoverable

Cyanide

p, p'-DDT

Dibromochloromethane

1,1-Dichloroethane

1,2-Dichloroethane

1,1-Dichloroethylene

trans-1,2-Dichloroethylene

Dichloromethane (Methylene chloride)

2,4-Dichlorophenoxyacetic acid

1,2-Dichloropropane

cis-1,3-Dichloropropene

trans-1,3-Dichloropropene

Dieldrin

Endrin

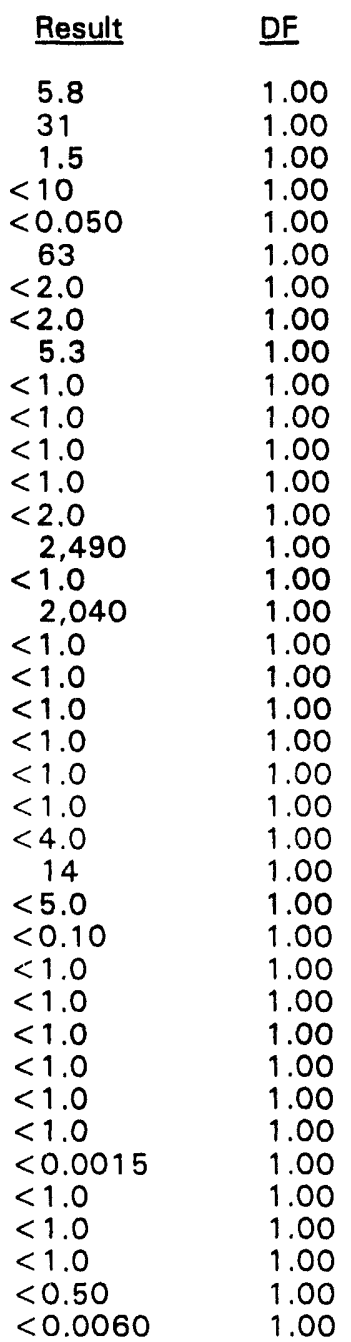

\begin{tabular}{|c|c|c|}
\hline Mod & Unit & Flag \\
\hline JV2 & $\begin{array}{l}\mathrm{pH} \\
\mu \mathrm{S} / \mathrm{cm} \\
\mathrm{NTU} \\
\mu \mathrm{g} / \mathrm{L} \\
\mu \mathrm{g} / \mathrm{L} \\
\mu \mathrm{g} / \mathrm{L} \\
\mu \mathrm{g} / \mathrm{L} \\
\mu \mathrm{g} / \mathrm{L} \\
\mu \mathrm{g} / \mathrm{L} \\
\mu \mathrm{g} / \mathrm{L} \\
\mu \mathrm{g} / \mathrm{L} \\
\mu \mathrm{g} / \mathrm{L} \\
\mu \mathrm{g} / \mathrm{L} \\
\mu \mathrm{g} / \mathrm{L} \\
\mu \mathrm{g} / \mathrm{L} \\
\mu \mathrm{g} / \mathrm{L} \\
\mu \mathrm{g} / \mathrm{L} \\
\mu \mathrm{g} / \mathrm{L} \\
\mu \mathrm{g} / \mathrm{L} \\
\mu \mathrm{g} / \mathrm{L} \\
\mu \mathrm{g} / \mathrm{L} \\
\mu \mathrm{g} / \mathrm{L} \\
\mu \mathrm{g} / \mathrm{L} \\
\mu \mathrm{g} / \mathrm{L} \\
\mu \mathrm{g} / \mathrm{L} \\
\mu \mathrm{g} / \mathrm{L} \\
\mu \mathrm{g} / \mathrm{L} \\
\mu \mathrm{g} / \mathrm{L} \\
\mu \mathrm{g} / \mathrm{L} \\
\mu \mathrm{g} / \mathrm{L} \\
\mu \mathrm{g} / \mathrm{L} \\
\mu \mathrm{g} / \mathrm{L} \\
\mu \mathrm{g} / \mathrm{L} \\
\mu \mathrm{g} / \mathrm{L} \\
\mu \mathrm{g} / \mathrm{L} \\
\mu \mathrm{g} / \mathrm{L} \\
\mu \mathrm{g} / \mathrm{L} \\
\mu \mathrm{g} / \mathrm{L} \\
\mu \mathrm{g} / \mathrm{L}\end{array}$ & $\begin{array}{l}0 \\
0 \\
0 \\
0 \\
0 \\
2 \\
0 \\
0 \\
0 \\
0 \\
0 \\
0 \\
0 \\
0 \\
0 \\
0 \\
0 \\
0 \\
0 \\
0 \\
0 \\
0 \\
0 \\
0 \\
0 \\
0 \\
0 \\
0 \\
0 \\
0 \\
0 \\
0 \\
0 \\
0 \\
0 \\
0 \\
0 \\
0 \\
0 \\
0 \\
0\end{array}$ \\
\hline
\end{tabular}

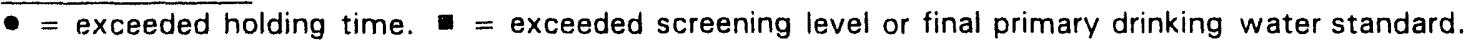


WELL BGX 2D collected on 02/08/94, laboratory analyses (cont.)

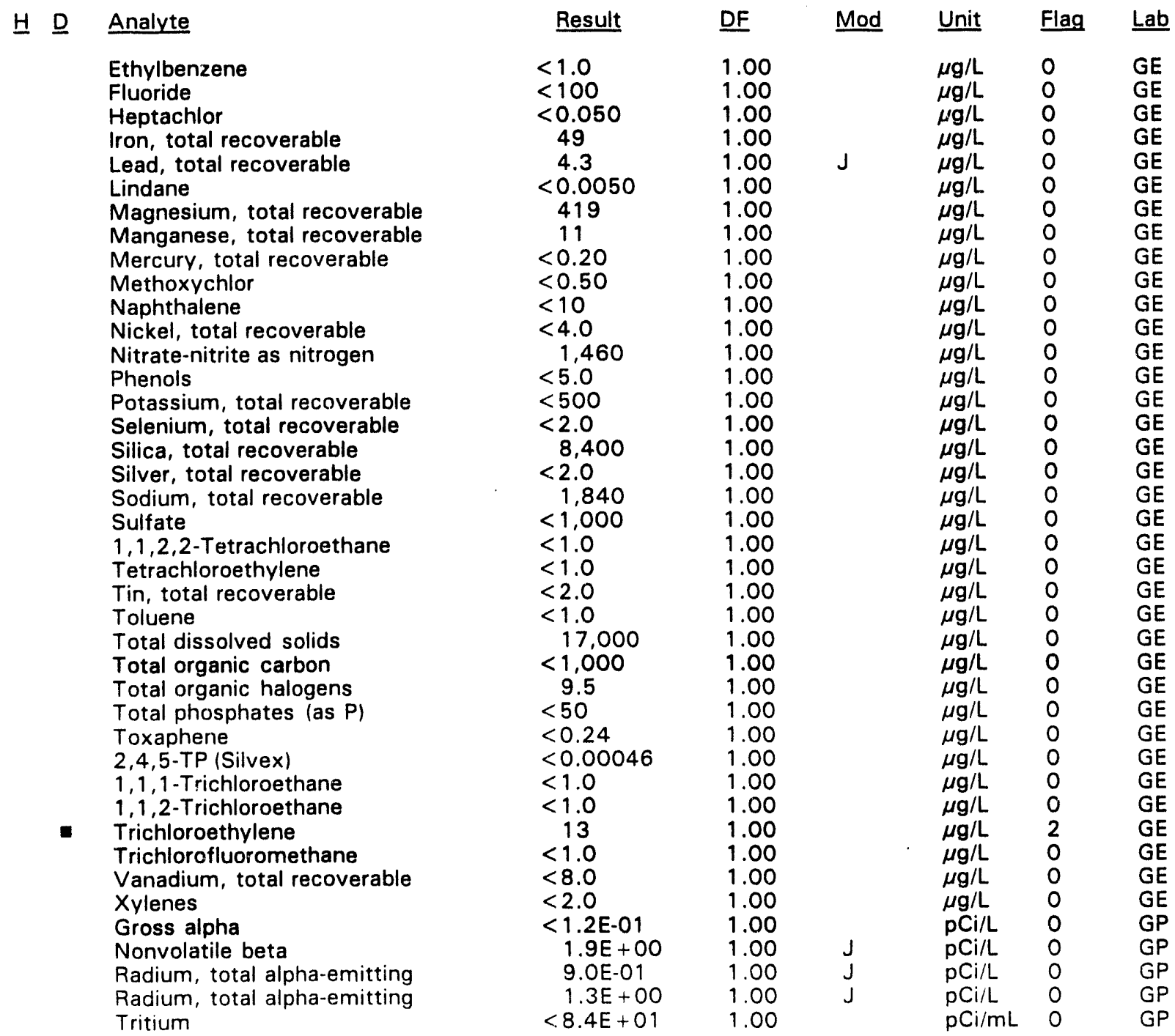

$\overline{-}=$ exceeded holding time. $=$ exceeded screening level or final primary drinking water standard. 


\section{WELL BGX 3D}

$\begin{array}{lllllll}\text { SRS Coord. } & \text { Lat/Longitude } & \text { Screen Zone Elevation } & \text { Top of Casing } & \text { Casing } & \text { Pump } & \text { Formation } \\ \text { N77577.0 } & 33.291626^{\circ} \mathrm{N} & 221.6-201.6 \mathrm{ft} \mathrm{msl} & 291.2 \mathrm{ft} \mathrm{msl} & \text { 4" PVC } & \text { S } & \text { Barnwell (IIB,) } \\ \text { E57780.1 } & 81.665346^{\circ} \mathrm{W} & & & \end{array}$

\section{FIELD MEASUREMENTS}

Sample date: $01 / 31 / 94$

Depth to water: $76.25 \mathrm{ft}(23.24 \mathrm{~m})$ below TOC

Water elevation: $214.95 \mathrm{ft}(65.52 \mathrm{~m}) \mathrm{msl}$

Sp. conductance: $29 \mu \mathrm{S} / \mathrm{cm}$

Turbidity: 0.6 NTU

Water evacuated before sampling: $38 \mathrm{gal}$

Time: 13: 04

$\mathrm{pH}: 5.7$

Alkalinity: $2 \mathrm{mg} / \mathrm{L}$

Water temperature: $17.7^{\circ} \mathrm{C}$

Volumes purged: 4.3 well volumes

\section{LABORATORY ANALYSES}

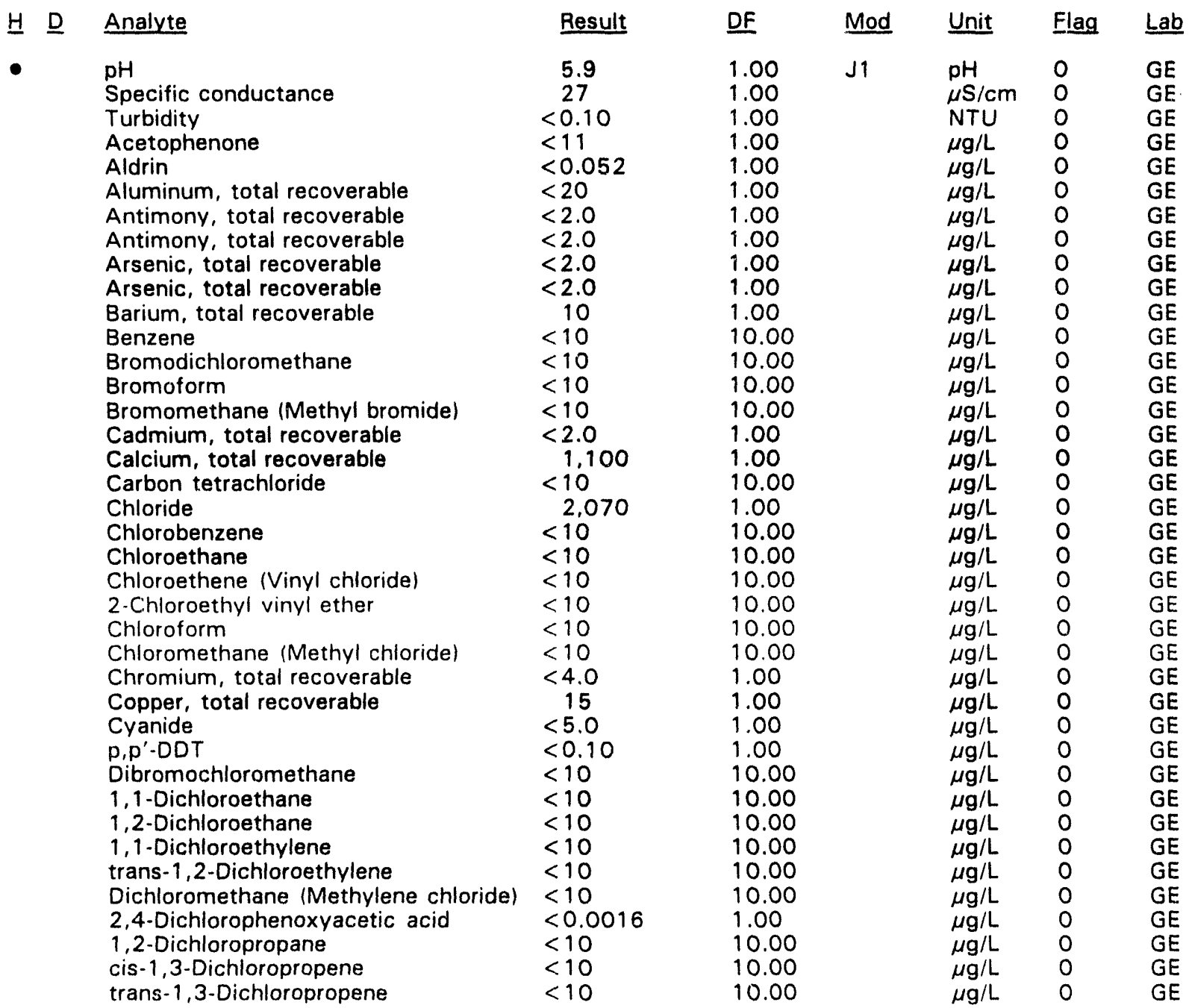

- = exceeded holding time. :- exceeded screening level or final primary drinking water standard. 
WELL BGX 3D collected on 01/31/94, laboratory analyses (cont.)

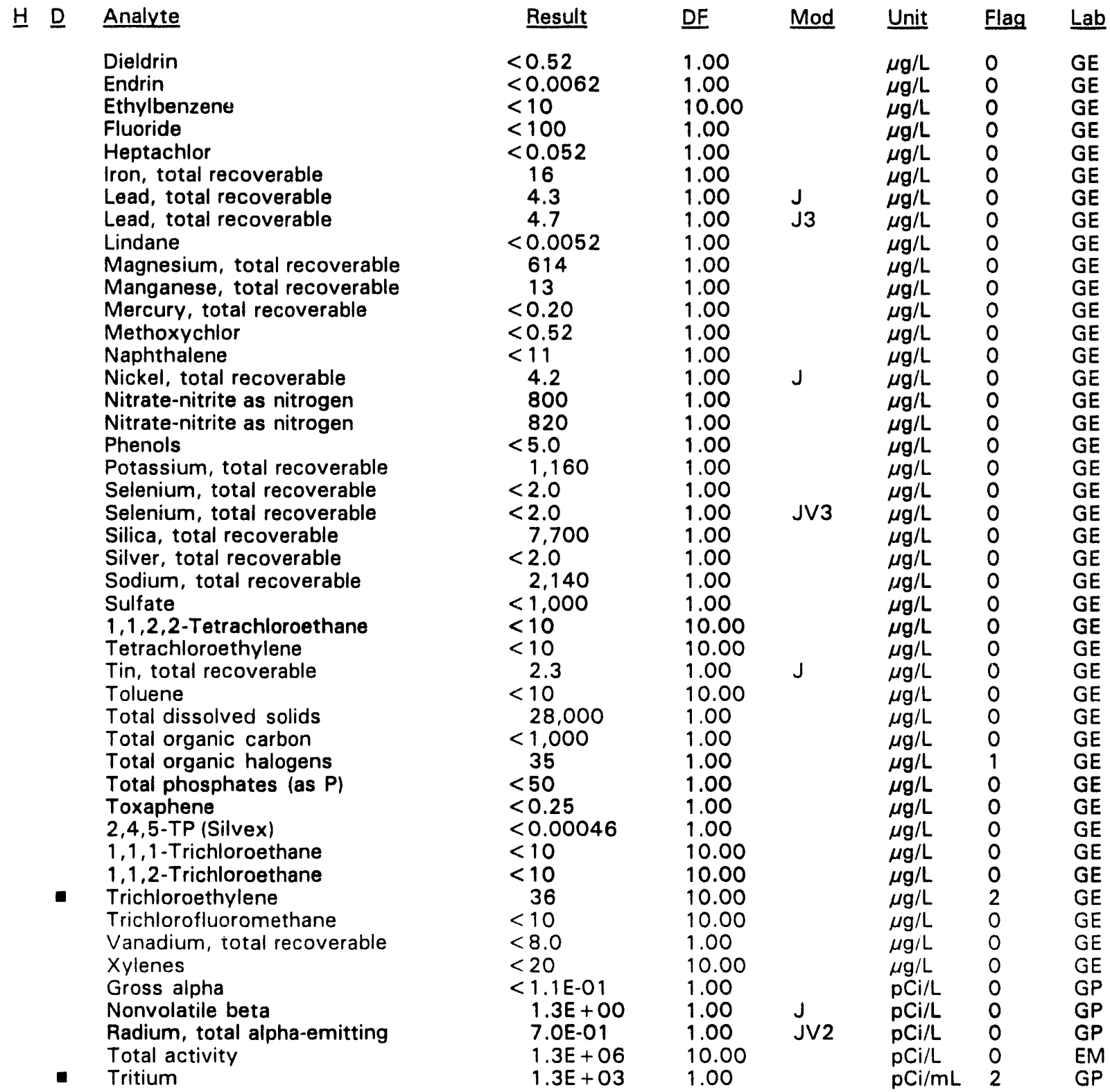

- = exceeded holding time. $\quad=$ exceeded screening level or final primary drinking water standard. 
WELL BGX 4A

$\begin{array}{lllllll}\text { SRS Coord. Lat/Longitude } & \text { Screen Zone Elevation } & \text { Top of Casing } & \text { Casing } & \text { Pump } & \text { Formation } \\ \text { N77879.2 } & 33.291373^{\circ} \mathrm{N} & 116.8-106.8 \mathrm{ft} \mathrm{msl} & 290.9 \mathrm{ft} \mathrm{msl} & \text { 4" PVC } & \text { S } & \text { U. Congaree (IIA) } \\ \text { E57215.6 } & 81.667419^{\circ} \mathrm{W} & & & \end{array}$

\section{FIELD MEASUREMENTS}

Sample date: $01 / 31 / 94$

Depth to water: $135.96 \mathrm{ft}(41.44 \mathrm{~m})$ below TOC

Water elevation: $154.94 \mathrm{ft}(47.23 \mathrm{~m}) \mathrm{ms}$

Sp. conductance: $273 \mu \mathrm{S} / \mathrm{cm}$

Turbidity: 1.3 NTU

Water evacuated before sampling: $91 \mathrm{gal}$

\section{LABORATORY ANALYSES}$$
\text { 븜 }
$$

Analyte
pH
pH
Specific conductance
Turbidity
Acetophenone
Aldrin
Aluminum, total recoverable
Antimony, total recoverable
Antimony, total recoverable
Arsenic, total recoverable
Arsenic, total recoverable
Barium, total recoverable
Benzene
Bromodichloromethane
Bromoform
Bromomethane (Methyl bromide)
Cadmium, total recoverable
Calcium, total recoverable
Carbon tetrachloride
Chloride
Chloride
Chlorobenzene
Chloroethane
Chloroethene (Vinyl chloride)
2-Chloroethyl vinyl ether
Chloroform
Chloromethane (Methyl chloride)
Chromium, total recoverable
Copper, total recoverable
Cyanide
p,p'-DDT
Dibromochloromethane
1,1 -Dichloroethane
1,2 -Dichloroethane
1,1 -Dichloroethylene
trans-1,2-Dichloroethylene
Dichloromethane (Methylene chloride)
$2,4-$ Dichlorophenoxyacetic acid
1,2 -Dichloropropane
(n)

Time: $12: 38$

$\mathrm{pH}: 7.8$

Alkalinity: $11 \mathrm{mg} / \mathrm{L}$

Water temperature: $19.0^{\circ} \mathrm{C}$

Volumes p:urged: 2.9 well volumes

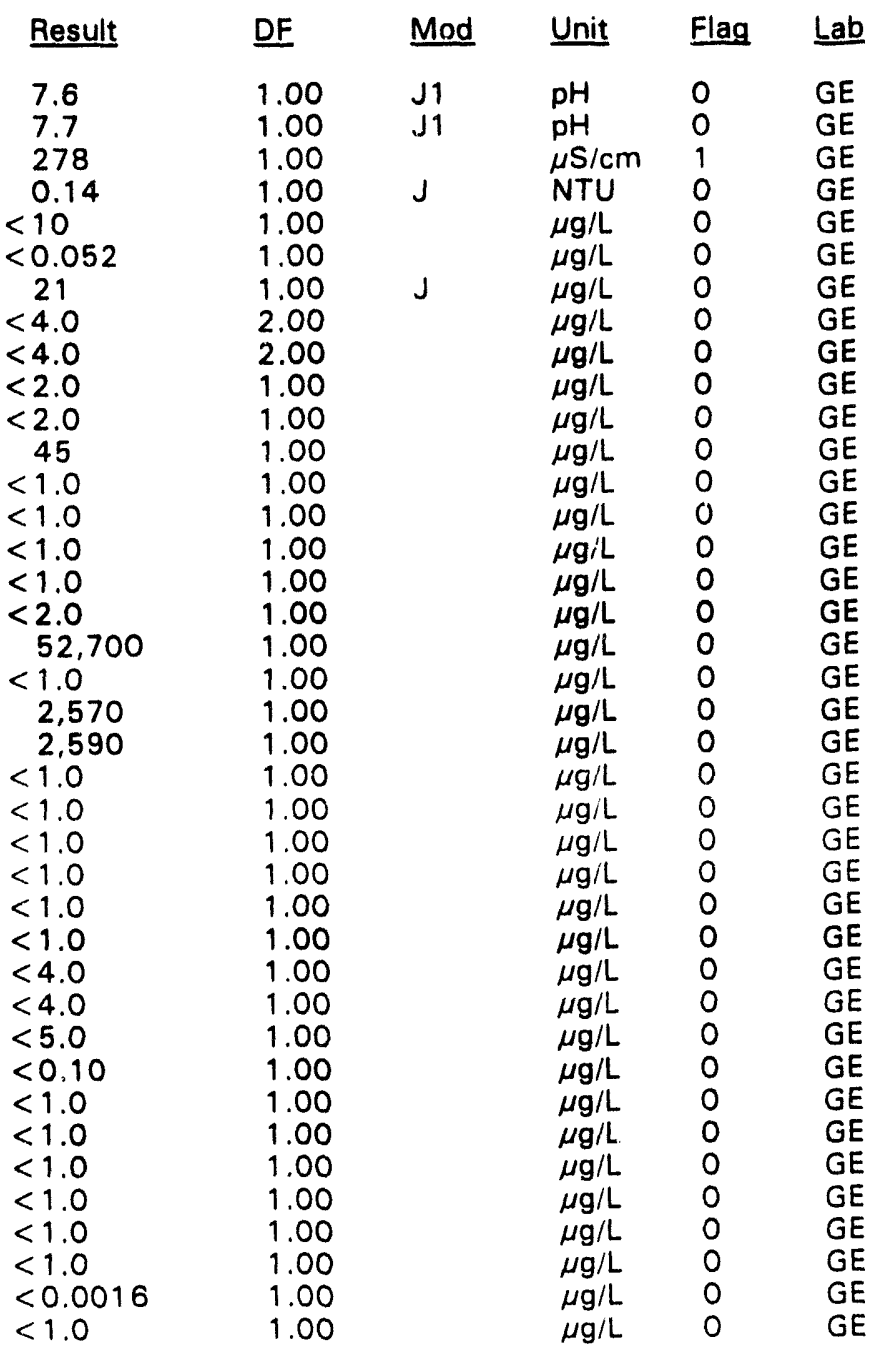

\footnotetext{
- = exceeded holding time, = exceeded screening level or final primary drinking water standard.
} 
WELL BGX 4A collected on 01/31/94, laboratory analyses (cont.)

\section{H D Analyte}

cis-1,3-Dichloropropene trans-1,3-Dichloropropene

Dieldrin

Endrin

Ethylbenzene

Fluoride

Heptachlor

Iron, total recoverable

Lead, total recoverable

Lead, total recoverable

Lindane

Magnesium, total recoverable

Manganese, total recoverable

Mercury, total recoverable

Methoxychlor

Naphthalene

Nickel, total recoverable

Nitrate-nitrite as nitrogen

Phenols

Phenois

Potassium, total recoverable

Selenium, total recoverable

Selenium, total recoverable

Silica, total recoverable

Silver, total recoverable

Sodium, total recoverable

Sulfate

Sulfate

1,1,2,2-Tetrachloroethane

Tetrachloroethylene

Tin, total recoverable

Toluene

Total dissolved solids

Total organic carbon

Total organic halogens

Total phosphates (as P)

Toxaphene

2,4,5-TP (Silvex)

$1,1,1$-Trichloroethane

1,1,2-Trichloroethane

Trichloroethylene

Trichlorofluoromethane

Vanadium, total recoverable

Xylenes

Gross alpha

Nonvolatile beta

Radium, total alpha-emitting Tritium

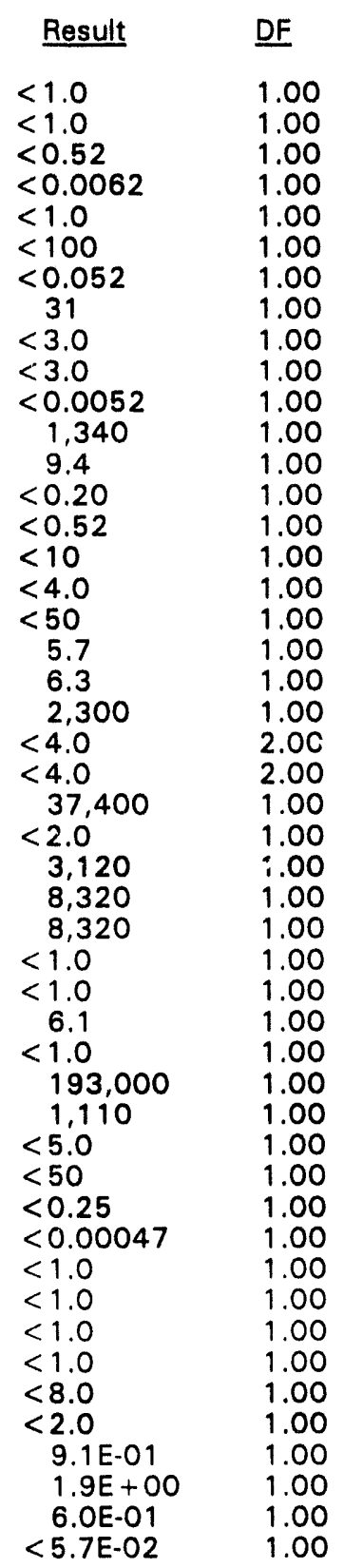

Mod

Unit

Flag Lab

$\mu g / L \quad 0 \quad G E$

$\mu \mathrm{g} / \mathrm{L} \quad 0 \quad \mathrm{GE}$

$\mu \mathrm{g} / \mathrm{L} \quad 0 \quad \mathrm{GE}$

$\mu \mathrm{g} / \mathrm{L} \quad 0 \quad \mathrm{GE}$

$\mu \mathrm{g} / \mathrm{L} \quad \mathrm{O} \quad \mathrm{GE}$

$\mu g / L \quad 0 \quad$ GE

O GE

$\mu \mathrm{g} / \mathrm{L} \quad 0 \quad \mathrm{GE}$

$\mu \mathrm{g} / \mathrm{L} \quad 0 \quad \mathrm{GE}$

$\mu \mathrm{g} / \mathrm{L} \quad \mathrm{O} \quad \mathrm{GE}$

$\mu \mathrm{g} / \mathrm{L} \quad 0 \quad \mathrm{GE}$

$\mu \mathrm{g} / \mathrm{L} \quad \mathrm{O} \quad \mathrm{GE}$

$\mu \mathrm{g} / \mathrm{L} \quad 0 \quad \mathrm{GE}$

$\mu \mathrm{g} / \mathrm{L} \quad \mathrm{O} \quad \mathrm{GE}$

$\mu g / L \quad 0 \quad$ GE

$\mu g / L \quad O \quad G E$

$\mu \mathrm{g} / \mathrm{L} \quad \mathrm{O} \quad \mathrm{GE}$

$\mu \mathrm{g} / \mathrm{L} \quad \mathrm{O} \quad \mathrm{GE}$

$J \quad \mu g / L \quad 0 \quad G E$

$J \quad \mu g / L \quad 0 \quad$ GE

$\begin{array}{lll}\mu \mathrm{g} / \mathrm{L} & 0 & \mathrm{GE} \\ \mu \mathrm{g} / \mathrm{L} & 0 & \mathrm{GE}\end{array}$

J3 $\mu \mathrm{g} / \mathrm{L} \quad 0 \quad \mathrm{GE}$

$\mu \mathrm{g} / \mathrm{L} \quad 0 \quad \mathrm{GE}$

$\mu \mathrm{g} / \mathrm{L} \quad \mathrm{O} \quad \mathrm{GE}$

$\mu \mathrm{g} / \mathrm{L} \quad \mathrm{O} \quad \mathrm{GE}$

$\mu \mathrm{g} / \mathrm{L} \quad \mathrm{O} \quad \mathrm{GE}$

$\mu \mathrm{g} / \mathrm{L} \quad \mathrm{O} \quad \mathrm{GE}$

$\mu \mathrm{g} / \mathrm{L} \quad \mathrm{O} \quad \mathrm{GE}$

$\mu \mathrm{g} / \mathrm{L} \quad \mathrm{O} \quad \mathrm{GE}$

$\mu \mathrm{g} / \mathrm{L} \quad \mathrm{O} \quad \mathrm{GE}$

$\mu \mathrm{g} / \mathrm{L} \quad \mathrm{O} \quad \mathrm{GE}$

JV2 $\mu g / L \quad 0 \quad$ GE

$\begin{array}{llll}J & \mu \mathrm{g} / \mathrm{L} & 0 & \mathrm{GE}\end{array}$

$\mu \mathrm{g} / \mathrm{L} \quad \mathrm{O} \quad \mathrm{GE}$

$\mu \mathrm{g} / \mathrm{L} \quad \mathrm{O} \quad \mathrm{GE}$

$\mu \mathrm{g} / \mathrm{L} \quad \mathrm{O} \quad \mathrm{GE}$

$\mu \mathrm{g} / \mathrm{L} \quad 0 \quad \mathrm{GE}$

$\mu \mathrm{g} / \mathrm{L} \quad \mathrm{O} \quad \mathrm{GE}$

$\mu \mathrm{g} / \mathrm{L} \quad \mathrm{O} \quad \mathrm{GE}$

$\mu \mathrm{g} / \mathrm{L} \quad \mathrm{O} \quad \mathrm{GE}$

$\mu \mathrm{g} / \mathrm{L} \quad \mathrm{O} \quad \mathrm{GE}$

$\mu \mathrm{g} / \mathrm{L} \quad \mathrm{O} \quad \mathrm{GE}$

$\mu \mathrm{g} / \mathrm{L} \quad 0 \quad \mathrm{GE}$

$\begin{array}{llll}J & \mathrm{pCi} / L & 0 & \mathrm{GP} \\ \mathrm{J} & \mathrm{pCi} / \mathrm{L} & 0 & \mathrm{GP}\end{array}$

JV2 $\quad \mathrm{pCi} / \mathrm{L} \quad 0 \quad \mathrm{GP}$

$\mathrm{pCi} / \mathrm{mL} \quad 0 \quad \mathrm{GP}$

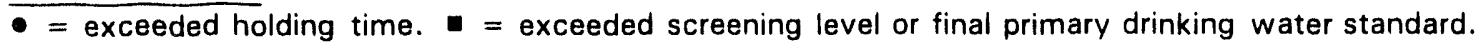


WELL BGX 4C

\begin{tabular}{|c|c|c|c|c|c|c|}
\hline SRS Coord. & Lat/Longitude & Screen Zone Elevation & Top of Casing & Casing & Pump & Formation \\
\hline $\begin{array}{l}N 77886.2 \\
E 57202.2\end{array}$ & $\begin{array}{l}33.291367^{\circ} \mathrm{N} \\
81.667468^{\circ} \mathrm{W}\end{array}$ & $180.7 \cdot 170.7 \mathrm{ft} \mathrm{msl}$ & 290.8 & 4" PVC & S & $\mathrm{McB}$ \\
\hline
\end{tabular}

\section{FIELD MEASUREMENTS}

Sample date: 02/01/94

Depth to water: $76.10 \mathrm{ft}(23.20 \mathrm{~m})$ below TOC

Water elevation: $214.70 \mathrm{ft}(65.44 \mathrm{~m}) \mathrm{msl}$

Sp. conductance: $72 \mu \mathrm{S} / \mathrm{cm}$

Turbidity: 0.8 NTU

Water evacuated before sampling: $110 \mathrm{gal}$

\section{LABORATORY ANALYSES}

$\begin{array}{ll}\text { H } & \text { Analyte } \\ \text { - } & \text { pH } \\ \text { pH } \\ \text { pH } \\ \text { pH } \\ \text { Specific conductance } \\ \text { Specific conductance } \\ \text { Specific conductance } \\ \text { Specific conductance } \\ \text { Specific conductance } \\ \text { Turbidity } \\ \text { Turbidity } \\ \text { Turbidity } \\ \text { Turbidity } \\ \text { Acetophenone } \\ \text { Acetophenone } \\ \text { Acetophenone } \\ \text { Acetophenone } \\ \text { Acetophenone } \\ \text { Aldrin } \\ \text { Aldrin } \\ \text { Aldrin }\end{array}$

Aluminum, total recoverable

Aluminum, total recoverable

Aluminum, total recoverable

Aluminum, total recoverable

Aluminum, total recoverable

Antimony, total recoverable

Antimony, total recoverable

Antimony, total recoverable

Antimony, total recoverable

Antimony, tucal recoverable

Arsenic, total recoverable

Arsenic, total recoverable

Arsenic, total recoverable

Arsenic, total recoverable

Arsenic, total recoverable

Barium, total recoverable

Barium, total recoverable

Barium, total recoverable
Time: 14:51

$\mathrm{pH}: 6.4$

Alkalinity: $23 \mathrm{mg} / \mathrm{L}$

Water temperature: $18.4^{\circ} \mathrm{C}$

Volumes purged: 3.8 well volumes

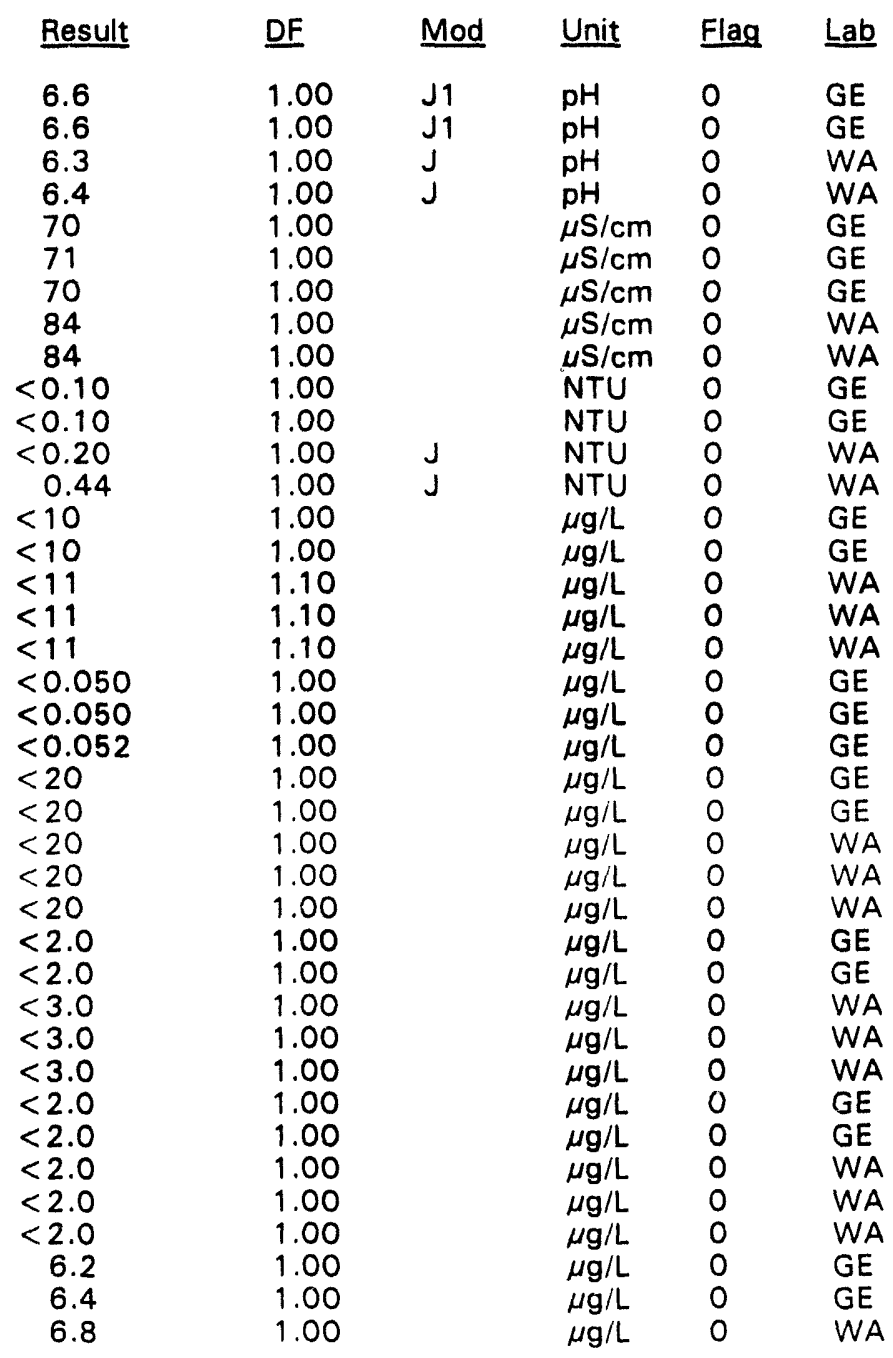

- exceeded holding time. = exceeded screening level or final primary drinking water standard. 
WELL BGX 4C collected on 02/01/94, laboratory analyses (cont.)

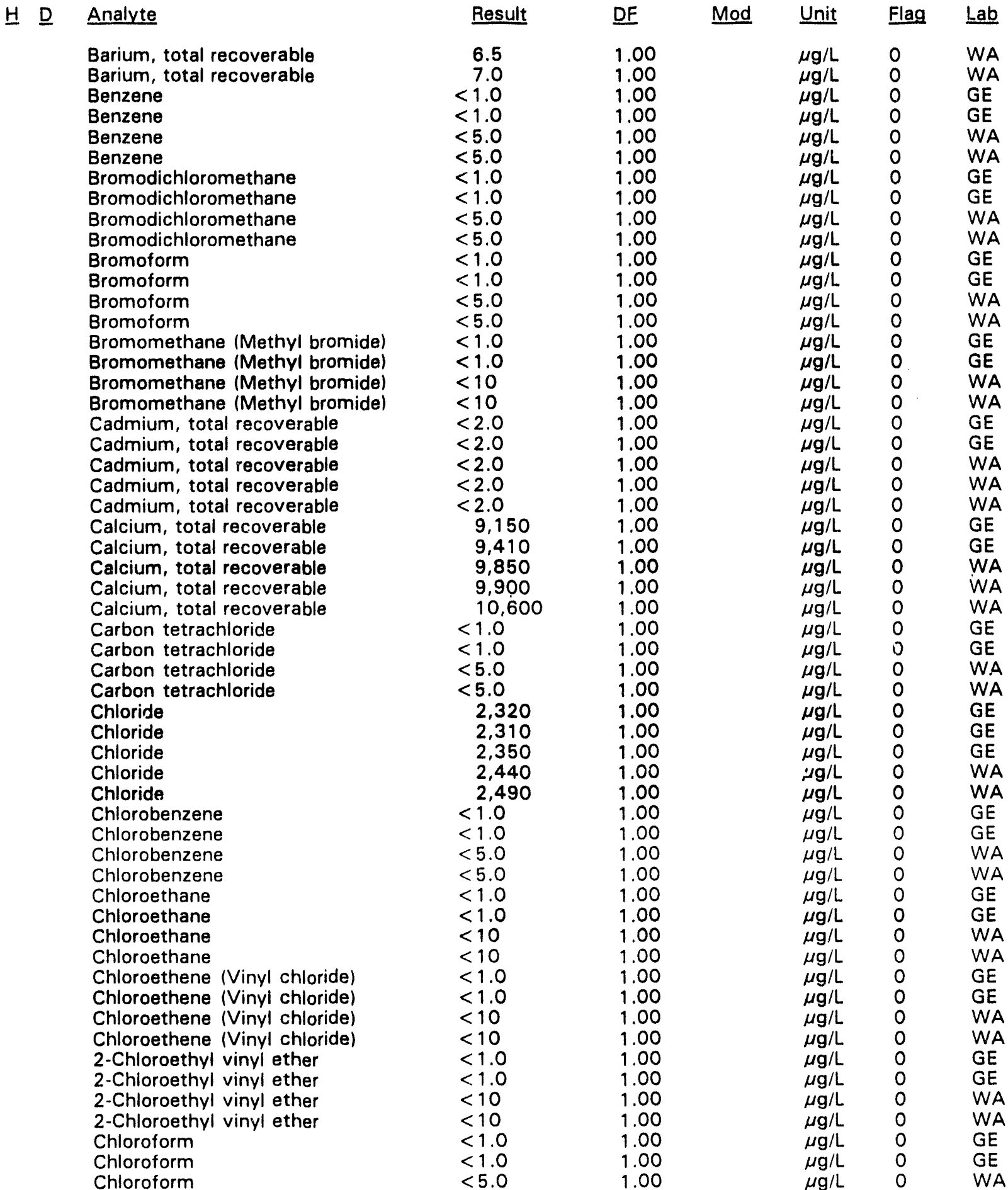

- = exceeded holding time. $=$ exceeded screening level or final primary drinking water standard. 
WELL BGX 4C collected on $02 / 01 / 94$, laboratory analyses (cont.)

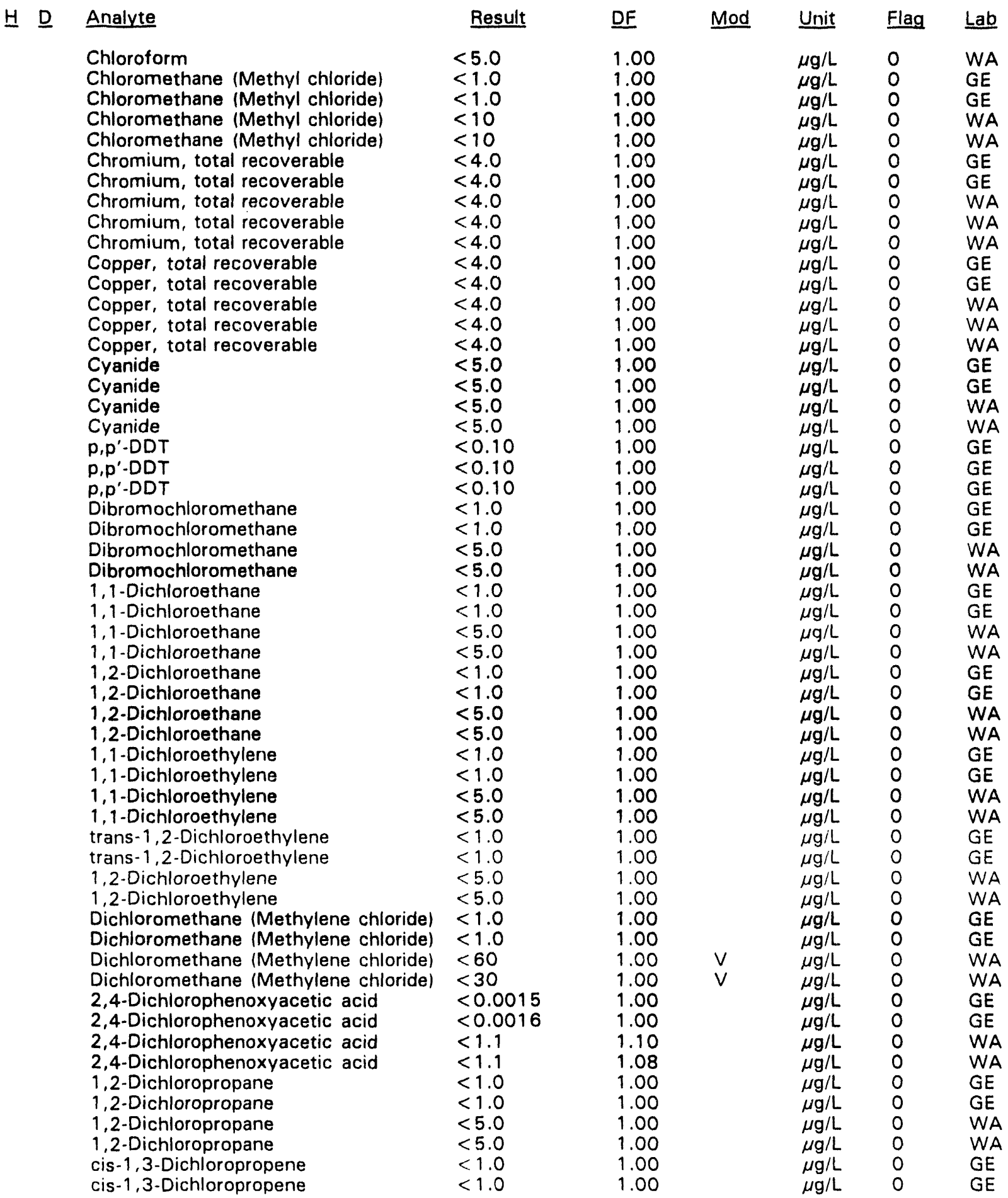

$\overline{-}=$ exceeded holding time. - = exceeded screening level or final primary drinking water standard. 
WELL BGX 4C collected on 02/01/94, laboratory analyses (cont.)

H D Analyte

cis-1,3-Dichloropropene

cis-1,3-Dichloropropene

trans-1,3-Dichloropropene

trans-1,3-Dichloropropene

trans-1,3-Dichloropropene

trans-1,3-Dichloropropene

Dieldrin

Dieldrin

Dieldrin

Endrin

Endrin

Endrin

Endrin

Endrin

Endrin

Ethylbenzene

Ethylbenzene

Ethylbenzene

Ethylbenzene

Fluoride

Fluoride

Fluoride

Fluoride

Heptachlor

Heptachlor

Heptachlor

Iron, total recoverable

tron, total recoverable

Iron, total recoveraisle

Iron, total recoverable

Iron, total recoverable

Lead, total recoverable

Lead, total recoverable

Lead, total recoverable

Lead, total recoverable

Lead, total recoverable

Lindane

Lindane

Lindane

Lindane

Lindane

Lindane

Magnesium, total recoverable

Magnesium, total recoverable

Magnesium, total recoverable

Magnesium, total recoverable

Magnesium, total recoverable

Manganese, total recoverable

Manganese, total recoverable

Manganese, total recoverable

Manganese, total recoverable

Manganese, total recoverable

Mercury, total recoverable

Mercury, total recoverable

Mercury, total recoverable

Mercury, total recoverable

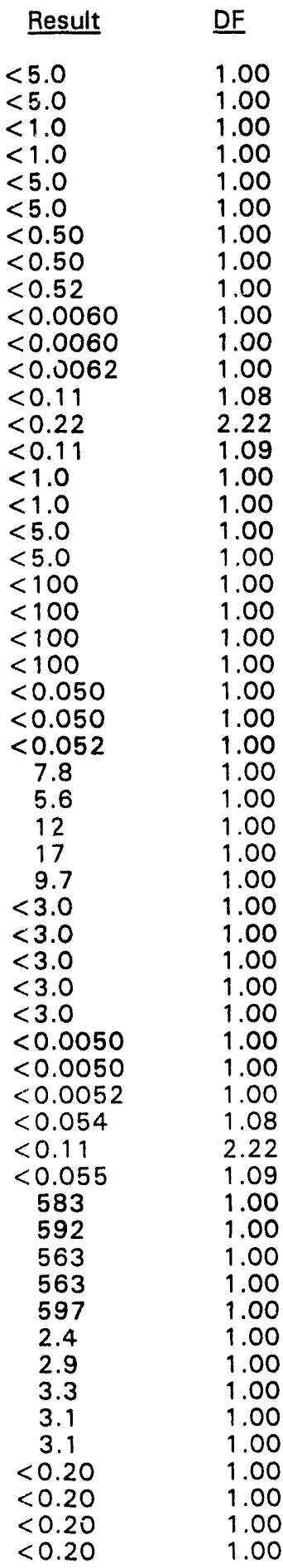

Mod Unit Flag Lab

$\mu g / L \quad 0 \quad$ WA

$\mu g / L \quad 0 \quad W A$

$\mu \mathrm{g} / \mathrm{L} \quad 0 \quad \mathrm{GE}$

$\mu \mathrm{g} / \mathrm{L} \quad \mathrm{O} \quad \mathrm{GE}$

$\mu \mathrm{g} / \mathrm{L} \quad 0 \quad$ WA

$\mu \mathrm{g} / L \quad O \quad W A$

$\mu \mathrm{g} / \mathrm{L} \quad 0 \quad \mathrm{GE}$

$\mu \mathrm{g} / \mathrm{L} \quad 0 \quad \mathrm{GE}$

$\mu \mathrm{g} / \mathrm{L} \quad \mathrm{O} \quad \mathrm{GE}$

$\mu \mathrm{g} / \mathrm{L} \quad 0 \quad \mathrm{GE}$

$\mu \mathrm{g} / \mathrm{L} \quad 0 \quad \mathrm{GE}$

$\mu \mathrm{g} / \mathrm{L} \quad 0 \quad \mathrm{GE}$

$\mu \mathrm{g} / \mathrm{L} \quad 0 \quad$ WA

$\mu \mathrm{g} / \mathrm{L} \quad 0 \quad$ WA

$\mu \mathrm{g} / \mathrm{L} \quad 0 \quad$ WA

$\mu \mathrm{g} / \mathrm{L} \quad 0 \quad \mathrm{GE}$

$\mu \mathrm{g} / \mathrm{L} \quad 0 \quad \mathrm{GE}$

$\mu \mathrm{g} / \mathrm{L} \quad 0 \quad$ WA

$\mu \mathrm{g} / \mathrm{L} \quad 0 \quad$ WA

$\mu \mathrm{g} / \mathrm{L} \quad 0 \quad \mathrm{GE}$

$\mu \mathrm{g} / \mathrm{L} \quad \mathrm{O} \quad \mathrm{GE}$

$\mu g / L \quad O \quad W A$

$\mu \mathrm{g} / \mathrm{L} \quad 0 \quad$ WA

$\mu \mathrm{g} / \mathrm{L} \quad \mathrm{O} \quad \mathrm{GE}$

$\mu \mathrm{g} / \mathrm{L} \quad 0 \quad \mathrm{GE}$

$\mu g / L \quad 0 \quad G E$

$\mu \mathrm{g} / \mathrm{L} \quad 0 \quad \mathrm{GE}$

$\mu \mathrm{g} / \mathrm{L} \quad 0 \quad \mathrm{GE}$

$\mathrm{J} 3 \mu \mathrm{g} / \mathrm{L}$

$3 \mu \mathrm{g} / \mathrm{L}$

$\mu \mathrm{g} / \mathrm{L}$

$\mu g / L$

$\mu g / L$

$\mu \mathrm{g} / \mathrm{L}$

$\mu \mathrm{g} / \mathrm{L}$

$\mu \mathrm{g} / \mathrm{L}$

$\mu \mathrm{g} / \mathrm{L}$

$\mu \mathrm{g} / \mathrm{L}$

$\mu \mathrm{g} / \mathrm{L}$

$\mu \mathrm{g} / \mathrm{L}$

$\mu \mathrm{g} / \mathrm{L}$

$\mu \mathrm{g} / \mathrm{L}$

$\mu \mathrm{g} / \mathrm{L}$

$\mu \mathrm{g} / \mathrm{L}$

$\mu \mathrm{g} / \mathrm{L}$

$\mu \mathrm{g} / \mathrm{L}$

$\mu \mathrm{g} / \mathrm{L}$

$\mu \mathrm{g} / \mathrm{L}$

$\mu \mathrm{g} / \mathrm{L}$

$\mu \mathrm{g} / \mathrm{L}$

$\mu \mathrm{g} / \mathrm{L}$

$\mu \mathrm{g} / \mathrm{L}$

$\mu \mathrm{g} / \mathrm{L}$

$\mu \mathrm{g} / \mathrm{L}$

$\mu \mathrm{g} / \mathrm{L}$

$\mu \mathrm{g} / \mathrm{L}$

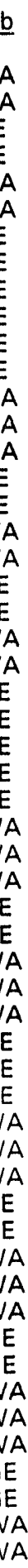

WA

GE

WA

WA

WA

GE

GE

WA

WA

WA

GE

WA

WA

WA

GE

GE

WA

WA

GE

WE

WA

- = exceeded holding time. = exceeded screening level or final primary drinking water standard. 
WELL BGX 4C collected on 02/01/94, laboratory analyses (cont.)

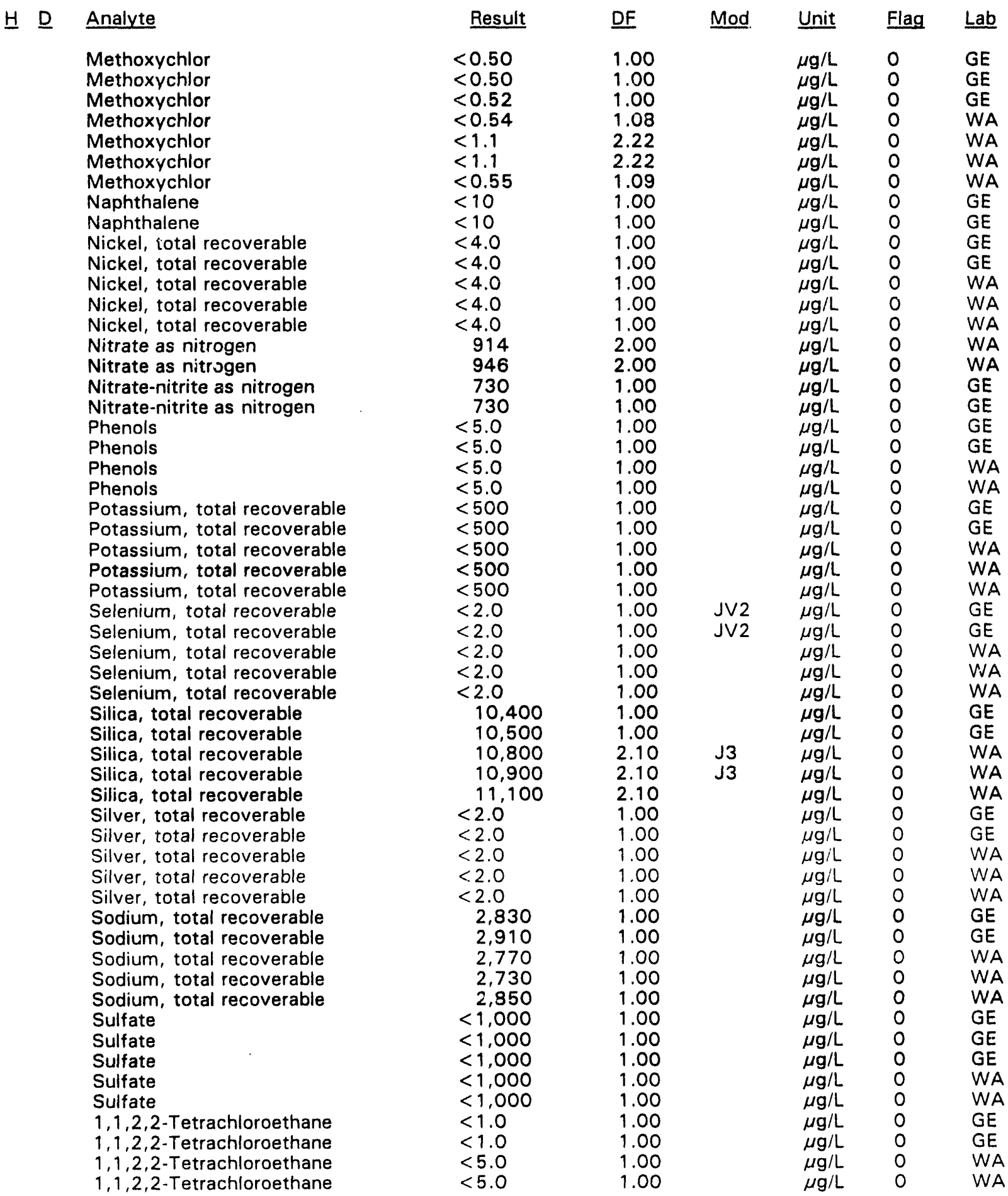

$\overline{0}=$ exceeded holding time. $\mathbf{u}=$ exceeded screening level or final primary drinking water standard. 
WELL BGX 4C collected on 02/01/94, laboratory analyses (cont.)

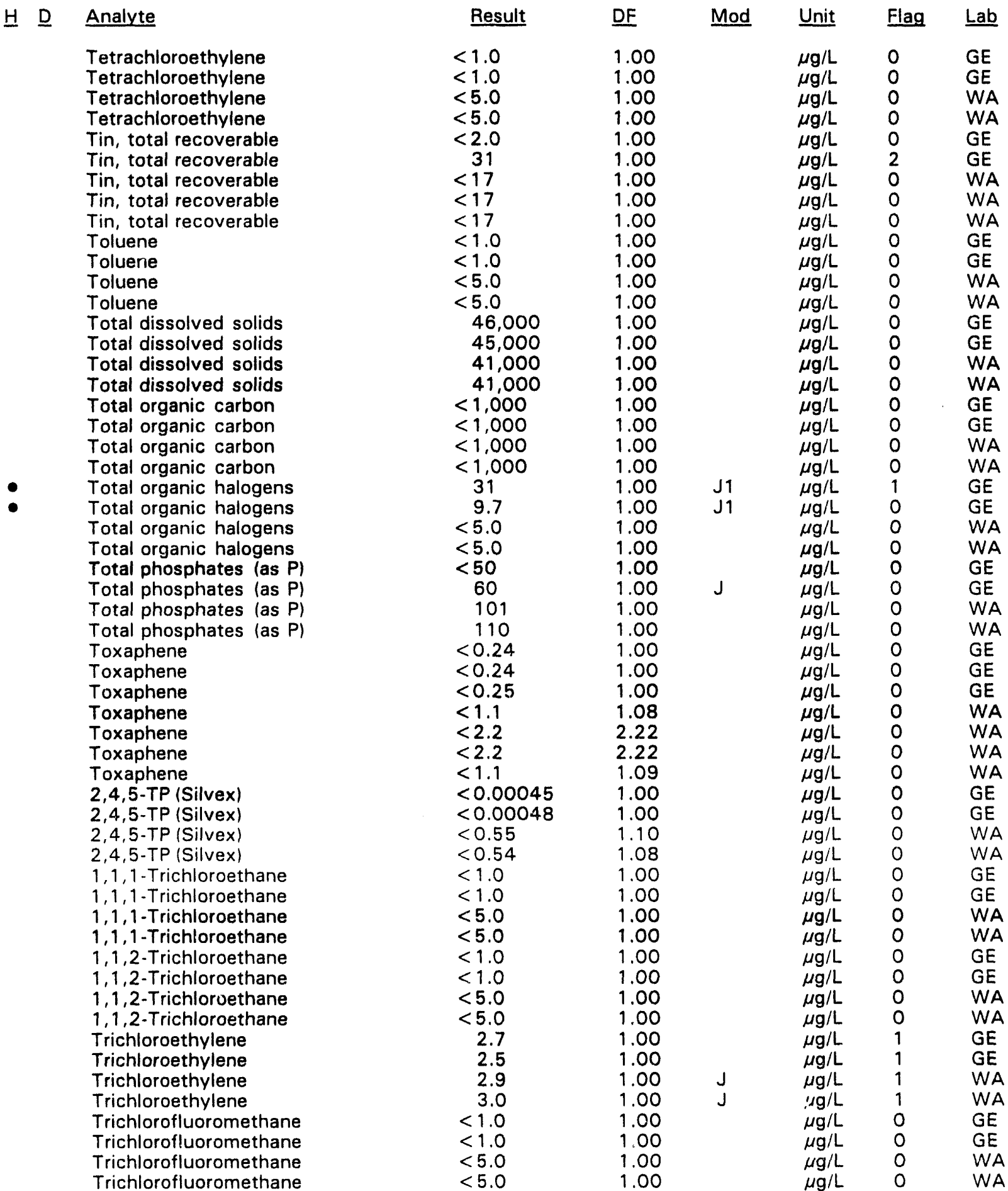

- = exceeded holding time. = exceeded screening level or final primary drinking water standard. 
WELL BGX 4C collected on 02/01/94, laboratory analyses (cont.)

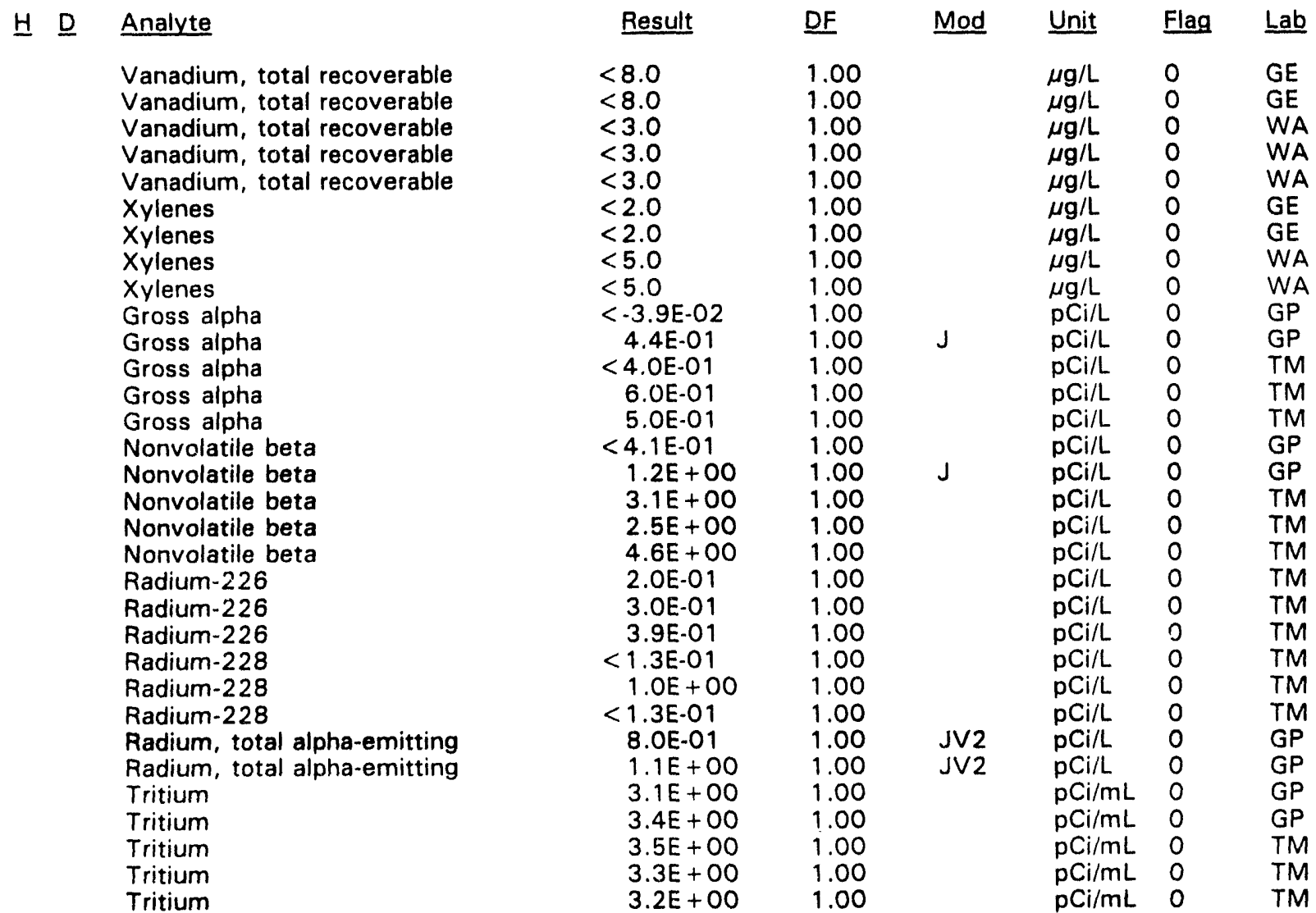

\section{WELL BGX 4D}

\begin{tabular}{|c|c|c|c|c|c|c|}
\hline SRS Coord. & Lat/Longitude & Screen Zone Elevation & Top of Casing & Casing & Pump & Formation \\
\hline $\begin{array}{l}N 77893.9 \\
E 57186.2\end{array}$ & $\begin{array}{l}33.291358^{\circ} \mathrm{N} \\
81.667525^{\circ} \mathrm{W}\end{array}$ & $223.8-203.8 \mathrm{ft} \mathrm{msl}$ & $290.9 \mathrm{ft} \mathrm{msl}$ & 4" PVC & $s$ & $\|\left(\| B_{1}\right)$ \\
\hline
\end{tabular}

\section{FIELD MEASUREMENTS}

Sample date: $01 / 31 / 94$

Depth to water: $75.00 \mathrm{ft}(22.86 \mathrm{~m})$ below TOC

Water elevation: $215.90 \mathrm{ft}(65.81 \mathrm{~m}) \mathrm{msl}$

Sp. conductance: $34 \mu \mathrm{S} / \mathrm{cm}$

Turbidity: 0.4 NTU

Water evacuated before sampling: $53 \mathrm{gal}$

\section{LABORATORY ANALYSES}

$\underline{H}$ Analyte
$\mathrm{pH}$
Specific conductance

$\mathrm{pH}$
Specific conductance
Time: $12: 16$

pH: 5.9

Alkalinity: $4 \mathrm{mg} / \mathrm{L}$

Water temperature: $17.6{ }^{\circ} \mathrm{C}$

Volumes purged: 6.7 well volumes

$\begin{array}{llllll}\text { Result } & \text { DF } & \text { Mod } & \text { Unit } & \text { Flag } & \text { Lab } \\ 6.4 & 1.00 & \mathrm{~J} 1 & \mathrm{pH} & 0 & \mathrm{GE} \\ 33 & 1.00 & & \mu \mathrm{S} / \mathrm{cm} & 0 & \mathrm{GE}\end{array}$

- = exceeded holding time. = exceeded screening level or final primary drinking water standard. 
WELL BGX 4D collected on 01/31/94, laboratory analyses (cont.)

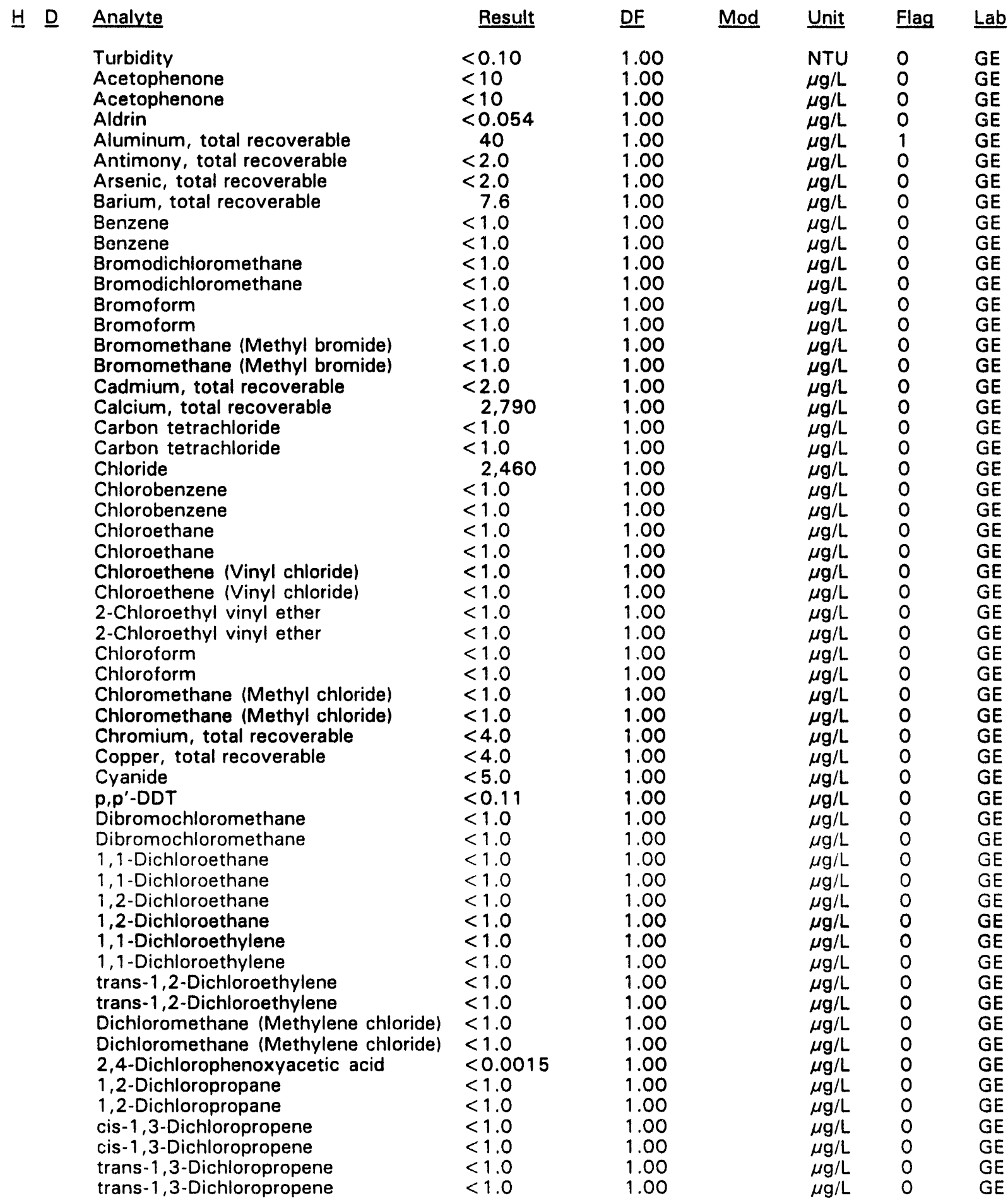

- =xceeded holding time. $=$ exceeded screening level or final primary drinking water standard. 
WELL BGX 4D collected on 01/31/94, laboratory analyses (cont.)

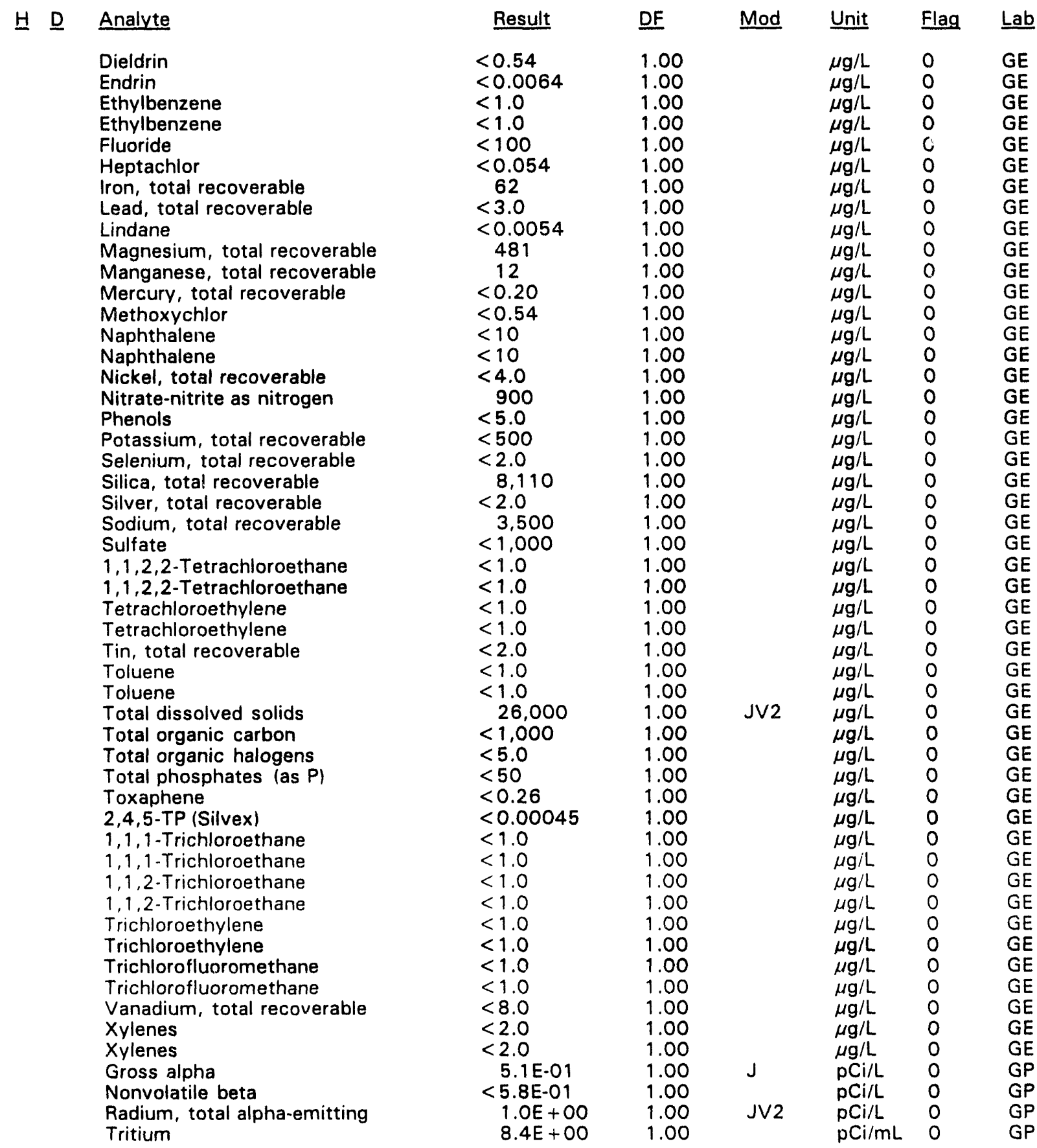

$\overline{- \text { = exceeded holding time. }}$ = exceeded screening level or final primary drinking water standard. 
WELL BGX 5D

\begin{tabular}{|c|c|c|c|c|c|c|}
\hline SRS Coord. & Lat/Longitude & Screen Zone Elevation & Top of Casing & Casing & Pump & Formation \\
\hline $\begin{array}{l}\text { N78402.0 } \\
\text { E57308.6 }\end{array}$ & $\begin{array}{l}33.292681^{\circ} \mathrm{N} \\
81.668190^{\circ} \mathrm{W}\end{array}$ & $215.0-195.0 \mathrm{ft} \mathrm{msl}$ & $285 \mathrm{ft} \mathrm{msl}$ & 4" PVC & S & Barnwell (IIB, ) \\
\hline
\end{tabular}

\section{FIELD MEASUREMENTS}

Sample date: 01/31/94

Depth to water: $76.10 \mathrm{ft}(23.20 \mathrm{~m})$ below TOC

Water elevation: $208.90 \mathrm{ft}(63.67 \mathrm{~m}) \mathrm{msl}$

Sp. conductance: $56 \mu \mathrm{S} / \mathrm{cm}$

Turbidity: 1.1 NTU

Water evacuated before sampling: $31 \mathrm{gal}$

\section{LABORATORY ANALYSES}

H D Analyte

$\mathrm{pH}$

Specific conductance

Turbidity

Acetophenone

Aldrin

Aluminum, total recoverable

Antimony, total recoverable

Arsenic, total recoverable

Barium, total recoverable

Benzene

Bromodichloromethane

Bromoform

Bromomethane (Methyl bromide)

Cadmium, total recoverable

Calcium, total recoverable

Carbon tetrachloride

Chloride

Chlorobenzene

Chloroethane

Chloroethene (Vinyl chloride)

2-Chloroethyl vinyl ether

Chloroform

Chloromethane (Methyl chloride)

Chromium, total recoverable

Copper, total recoverable

Cyanide

$p, p^{\prime}$-DDT

Dibromochloromethane

1,1-Dichloroethane

1,2-Dichloroethane

1,1-Dichloroethylene

trans-1,2-Dichloroethylene

Dichloromethane (Methylene chloride)

2,4-Dichlorophenoxyacetic acid

1,2-Dichloropropane

cis-1,3-Dichloropropene

trans-1,3-Dichloropropene

Dieldrin

Endrin
Time: 11:45

$\mathrm{pH}: 5.5$

Alkalinity: $1 \mathrm{mg} / \mathrm{L}$

Water temperature: $18.3^{\circ} \mathrm{C}$

Volumes purged: 3.4 well volumes

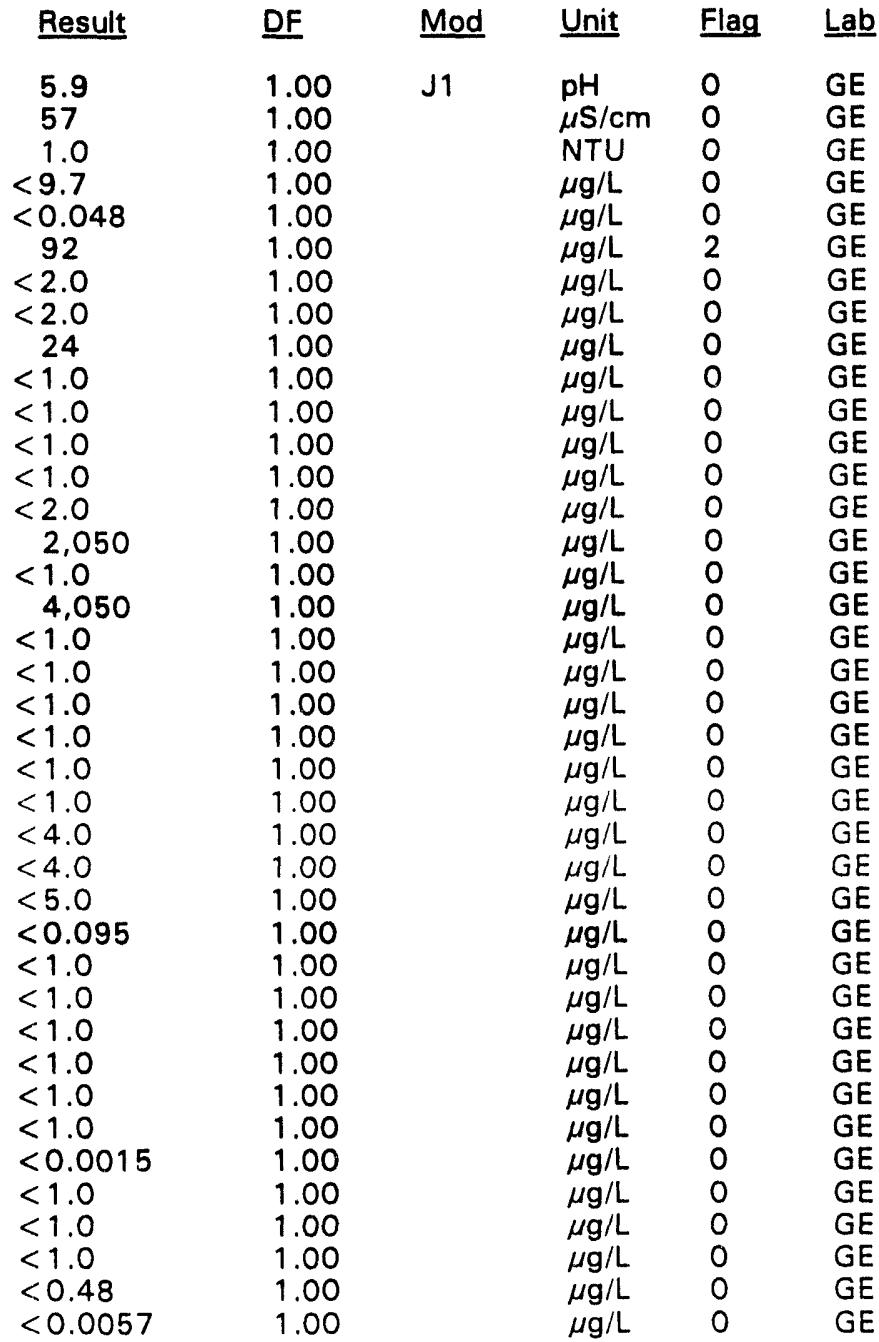

- = exceeded holding time. $\square=$ exceeded screening level or final primary drinking water standard. 
WELL BGX 5D collected on 01/31/94, laboratory analyses (cont.)

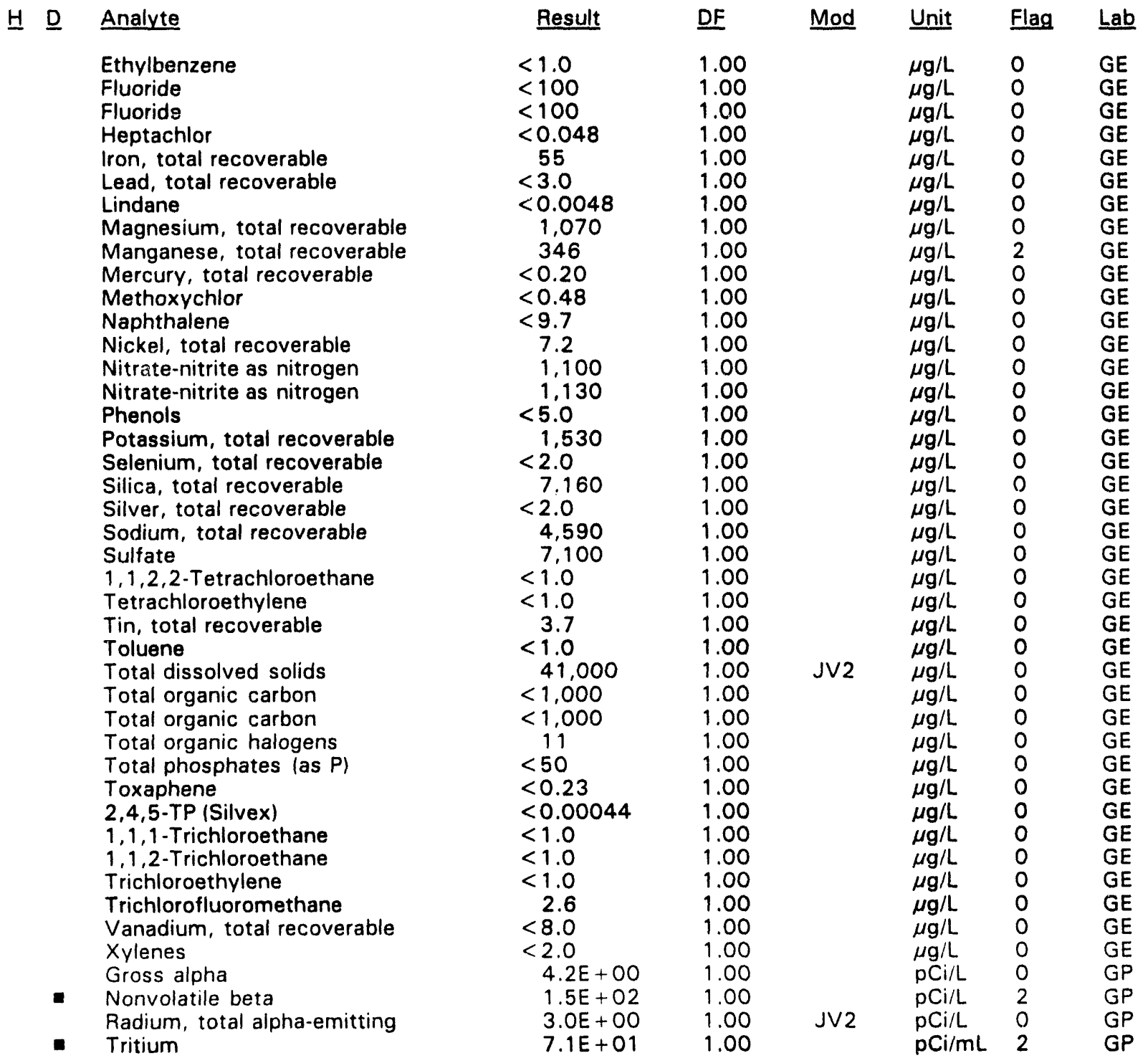

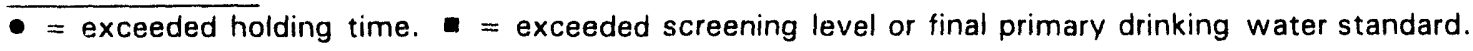


WELL BGX 6D

\begin{tabular}{|c|c|c|c|c|c|c|}
\hline SRS Coord. & Lat/Longitude & Screen Zone Elevation & Iop of Casing & Casing & Pump & Formation \\
\hline $\begin{array}{l}\text { N78740.1 } \\
\text { E57524.9 }\end{array}$ & $\begin{array}{l}33.293782^{\circ} \mathrm{N} \\
81.668277^{\circ} \mathrm{W}\end{array}$ & $211.0-191.0 \mathrm{ft} \mathrm{msl}$ & $277 \mathrm{ft} \mathrm{msl}$ & 4" PVC & $\mathbf{S}$ & $\left(\| B_{1}\right)$ \\
\hline
\end{tabular}

\section{FIELD MEASUREMENTS}

Sample date: 02/07/94

Depth to water: $71.58 \mathrm{ft}(21.82 \mathrm{~m})$ below TOC

Water elevation: $205.42 \mathrm{ft}(62.61 \mathrm{~m}) \mathrm{ms}$

Sp. conductance: $69 \mu \mathrm{S} / \mathrm{cm}$

Turbidity: 0.8 NTU

Water evacuated before sampling: $60 \mathrm{gal}$

\section{LABORATORY ANALYSES}

\section{H D Analyte}

- $\mathrm{pH}$

Specific conductance

Turbidity

Acetophenone

Aldrin

Aldrin

Aluminum, total recoverable

Antimony, total recoverable

Arsenic, total recoverable

Barium, total recoverable

Benzene

Benzene

Bromodichloromethane

Bromodichloromethane

Bromoform

Bromoform

Bromomethane (Methyl bromide)

Bromomethane (Methyl bromide)

Cadmium, total recoverable

Calcium, total recoverable

Carbon tetrachloride

Carbon tetrachloride

Chloride

Chlorobenzene

Chlorobenzene

Chloroethane

Chloroethane

Chloroethene (Vinyl chloride)

Chloroethene (Vinyl chloride)

2-Chloroethyl vinyl ether

2-Chloroethyl vinyl ether

Chloroform

Chloroform

Chloromethane (Methyl chloride)

Chloromethane (Methyl chloride)

Chromium, total recoverable

Copper, total recoverable

Cyanide

p,p'-DDT
Time: 9: 31

$\mathrm{pH}: 6.4$

Alkalinity: $16 \mathrm{mg} / \mathrm{L}$

Water temperature: $18.4^{\circ} \mathrm{C}$

Volumes purged: 6.3 well volumes

\begin{tabular}{|c|c|c|c|c|c|}
\hline Result & DF & Mod & Unit & Flag & Lab \\
\hline $\begin{array}{l}6.8 \\
66\end{array}$ & 1.00 & J1 & $\mathrm{pH}$ & 0 & GE \\
\hline $\begin{array}{l}66 \\
0.36\end{array}$ & 1.00 & & $\mu \mathrm{S} / \mathrm{cm}$ & 0 & iE \\
\hline $\begin{array}{l}0.36 \\
<9.9\end{array}$ & 1.00 & & NTU & 0 & GE \\
\hline$<0.050$ & 1.00 & & $\begin{array}{c}\mu \mathrm{g} / \mathrm{L} \\
\mu \mathrm{g} / \mathrm{L}\end{array}$ & 0 & $\begin{array}{l}\text { GE } \\
G E\end{array}$ \\
\hline$<0.050$ & 1.00 & & $\mu \mathrm{g} / \mathrm{L}$ & 0 & $\mathrm{GE}$ \\
\hline$<20$ & 1.00 & & $\mu \mathrm{g} / \mathrm{L}$ & 0 & GE \\
\hline$<2.0$ & 1.00 & & $\mu \mathrm{g} / \mathrm{L}$ & 0 & GE \\
\hline $\begin{array}{r}<2.0 \\
38\end{array}$ & 1.00 & & $\mu g / L$ & 0 & GE \\
\hline $\begin{array}{r}38 \\
<1.0\end{array}$ & 1.00 & & $\mu \mathrm{g} / \mathrm{L}$ & 0 & SE \\
\hline $\begin{array}{l}<1.0 \\
<1.0\end{array}$ & 1.00 & & $\mu \mathrm{g} / \mathrm{L}$ & 0 & G \\
\hline$<1.0$ & 1.00 & & $\mu \mathrm{g} / \mathrm{L}$ & 0 & $\mathrm{GE}$ \\
\hline $\begin{array}{l}<1.0 \\
<1.0\end{array}$ & 1.00 & & $\mu \mathrm{g} / \mathrm{L}$ & 0 & GE \\
\hline$<1.0$ & 1.00 & & $\mu \mathrm{g} / \mathrm{L}$ & 0 & GE \\
\hline$<1.0$ & 1.00 & & $\mu \mathrm{g} / \mathrm{L}$ & 0 & GE \\
\hline$<1.0$ & 1.00 & & $\mu \mathrm{g} / \mathrm{L}$ & 0 & GE \\
\hline$<1.0$ & 1.00 & & $\mu g / L$ & 0 & GE \\
\hline$<1.0$ & 1.00 & & $\mu \mathrm{g} / \mathrm{L}$ & 0 & $\mathrm{GE}$ \\
\hline$<2.0$ & 1.00 & & $\mu \mathrm{g} / \mathrm{L}$ & 0 & G \\
\hline $\begin{array}{r}8,730 \\
<1.0\end{array}$ & $\begin{array}{l}1.00 \\
1.00\end{array}$ & & $\mu \mathrm{g} / \mathrm{L}$ & 0 & GE \\
\hline$<1.0$ & 1.00 & & $\mu \mathrm{g} / \mathrm{L}$ & 0 & $\mathrm{GE}$ \\
\hline 2,590 & 1.00 & & $\mu \mathrm{g} / \mathrm{L}$ & 0 & GE \\
\hline$<1.0$ & 1.00 & & $\mu \mathrm{g} / \mathrm{L}$ & 0 & GE \\
\hline$<1.0$ & 1.00 & & $\mu \mathrm{g} / \mathrm{L}$ & 0 & GE \\
\hline$<1.0$ & 1.00 & & $\mu \mathrm{g} / \mathrm{L}$ & 0 & GE \\
\hline$<1.0$ & 1.00 & & $\mu \mathrm{g} / \mathrm{L}$ & 0 & GE \\
\hline$<1.0$ & 1.00 & & $\mu \mathrm{g} / \mathrm{L}$ & 0 & GE \\
\hline$<1.0$ & 1.00 & & $\mu \mathrm{g} / \mathrm{L}$ & 0 & GE \\
\hline$<1.0$ & 1.00 & & $\mu \mathrm{g} / \mathrm{L}$ & 0 & GE \\
\hline$<1.0$ & 1.00 & & $\mu \mathrm{g} / \mathrm{L}$ & 0 & \\
\hline$<1.0$ & 1.00 & & $\mu \mathrm{g} / \mathrm{L}$ & 0 & GE \\
\hline$<1.0$ & 1.00 & & $\mu \mathrm{g} / \mathrm{L}$ & 0 & GE \\
\hline$<1.0$ & 1.00 & & $\mu \mathrm{g} / \mathrm{L}$ & 0 & \\
\hline$<1.0$ & 1.00 & & $\mu \mathrm{g} / \mathrm{L}$ & 0 & GE \\
\hline$<4.0$ & 1.00 & & $\mu \mathrm{g} / \mathrm{L}$ & 0 & \\
\hline$<4.0$ & 1.00 & & $\mu \mathrm{g} / \mathrm{L}$ & 0 & \\
\hline$<5.0$ & 1.00 & & $\mu \mathrm{g} / \mathrm{L}$ & 0 & \\
\hline$<0.10$ & 1.00 & & $\mu \mathrm{g} / \mathrm{L}$ & 0 & \\
\hline
\end{tabular}

- = exceeded holding time. = exceeded screening level or final primary drinking water standard. 
WELL BGX 6D collected on 02/07/94, laboratory analyses (cont.)

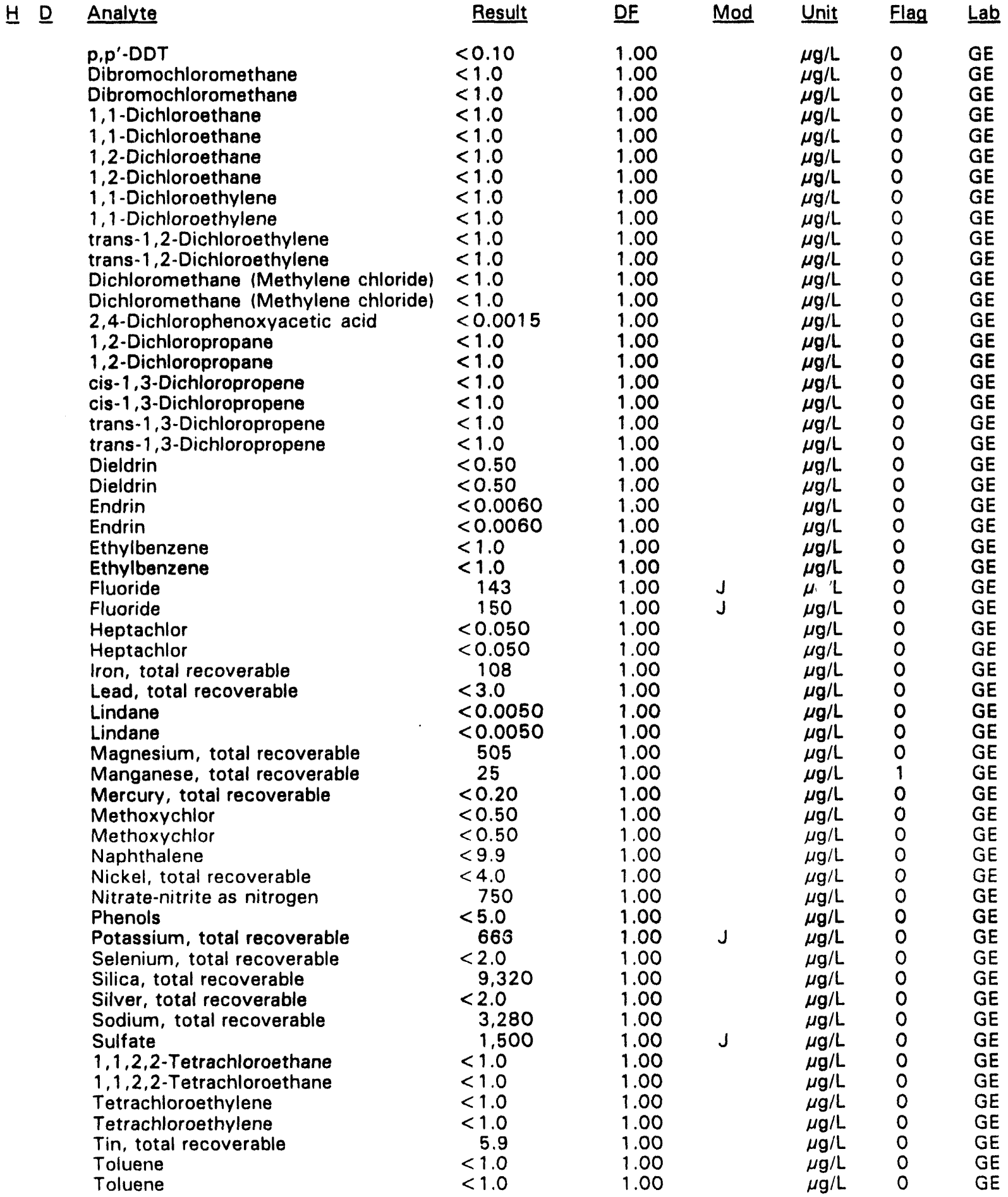

- = exceeded holding time. = exceeded screening level or final primary drinking water standard. 
WELL BGX 6D collected on 02/07/94, laboratory analyses (cont.)

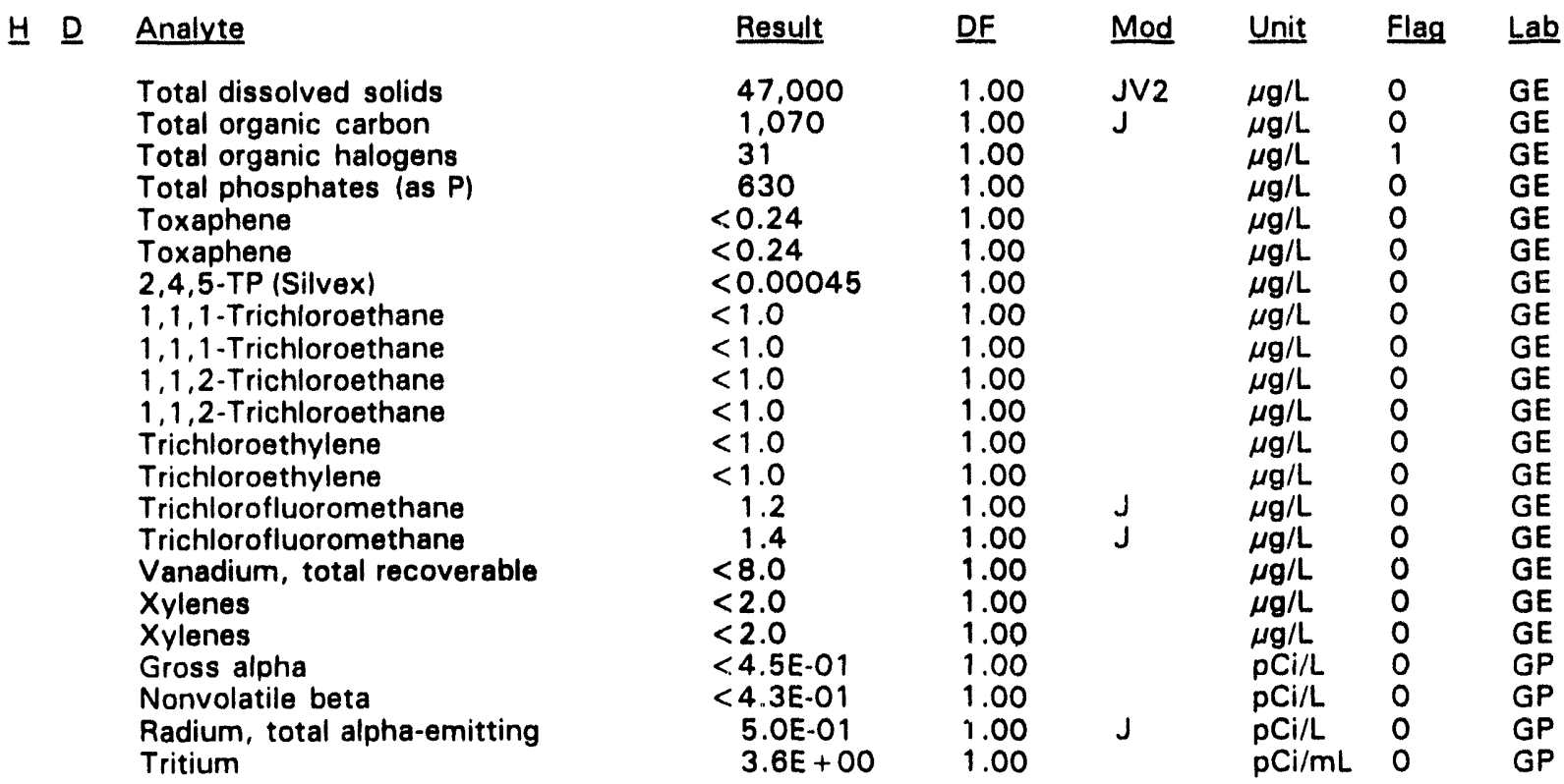

\section{WELL BGX 7D}

\begin{tabular}{|c|c|c|c|c|c|c|}
\hline SRS Coord. & Lat/Longitude & Screen Zone Elevation & Top of Casing & Casing & Pump & Formation \\
\hline $\begin{array}{l}\text { N78349.3 } \\
E 58312.8\end{array}$ & $\begin{array}{l}33.294203^{\circ} \mathrm{N} \\
81.665443^{\circ} \mathrm{W}\end{array}$ & $214.1-194.1 \mathrm{ft} \mathrm{msl}$ & $279.2 \mathrm{ft} \mathrm{msl}$ & 4" PVC & $\mathbf{S}$ & Barnwell $\left(\| \mathrm{B}_{1}\right)$ \\
\hline
\end{tabular}

\section{FIELD MEASUREMENTS}

Sample date: 02/07/94

Depth to water: $73.95 \mathrm{ft}(22.54 \mathrm{~m})$ below TOC

Water elevation: $205.25 \mathrm{ft}(62.56 \mathrm{~m}) \mathrm{msl}$

Sp. conductance: $21 \mu \mathrm{S} / \mathrm{cm}$

Turbidity: 0.5 NTU

Water evacuated before sampling: 42 gal

\section{LABORATORY ANALYSES}

\section{H D Analyte}

- $\mathrm{pH}$

Specific conductance
Turbidity
Acetophenone
Aldrin
Aluminum, total recoverable
Antimony, total recoverable
Arsenic, total recoverable
Barium, total recoverable
Benzene
Bromodichloromethane
Bromoform

Bromoform
Time: $9: 59$

$\mathrm{pH}: 5.1$

Alkalinity: $0 \mathrm{mg} / \mathrm{L}$

Water temperature: $18.3^{\circ} \mathrm{C}$

Volumes purged: 5.7 well volumes

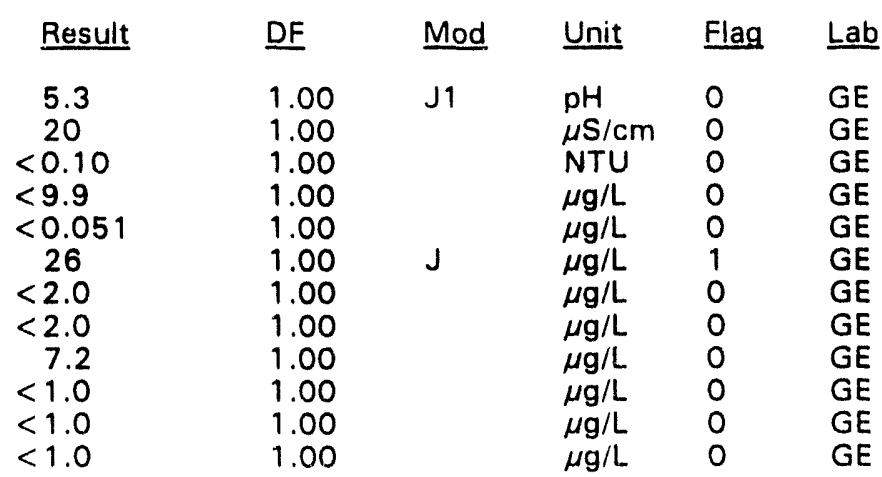

- = exceeded holding time. - = exceeded screening level or final primary drinking water standard. 
WELL BGX 7D collected on 02/07/94, laboratory analyses (cont.)

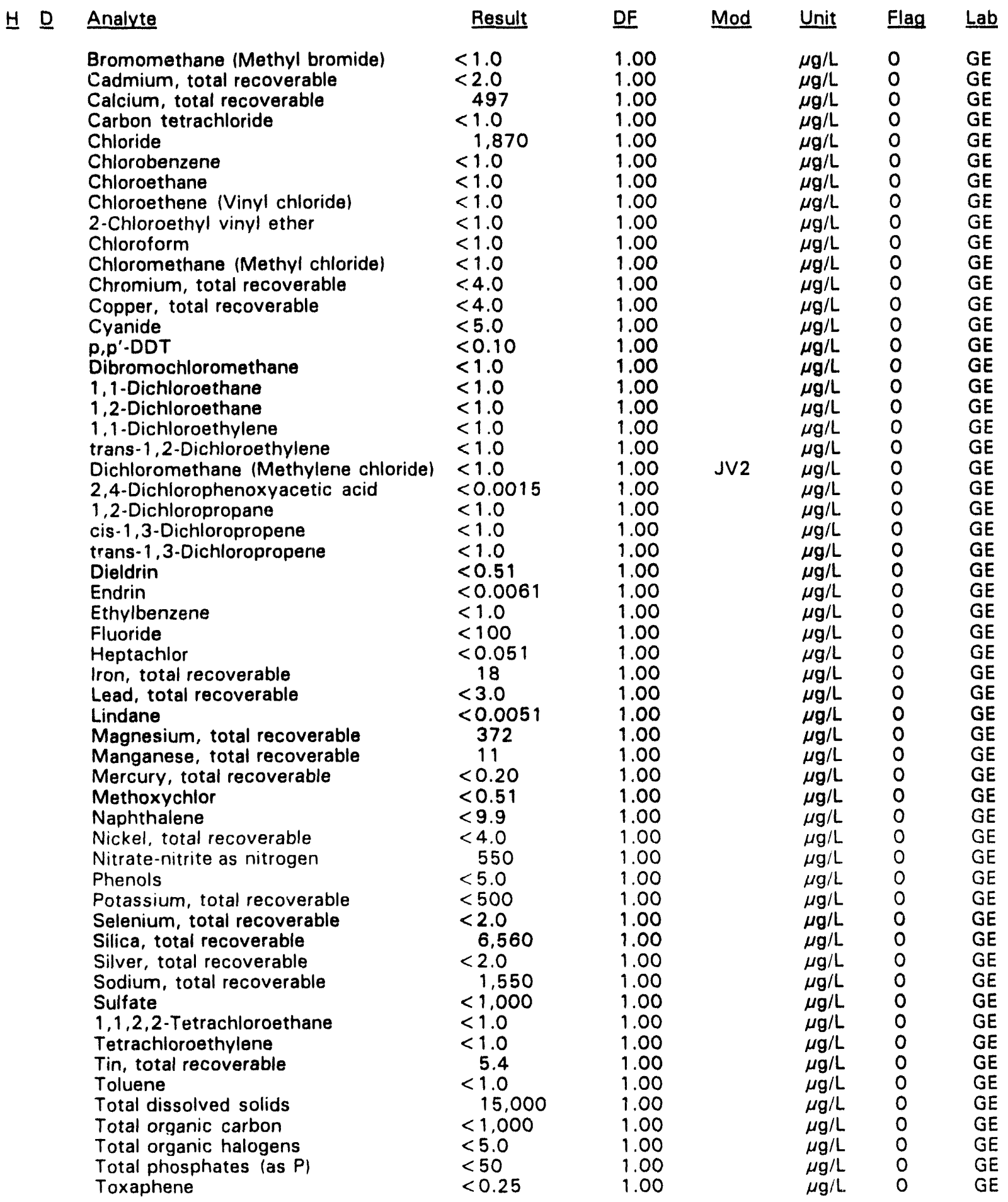

- exceeded holding time. = exceeded screening level or final primary drinking water standard. 
WELL BGX 7D collected on 02/07/94, laboratory analyses (cont.)

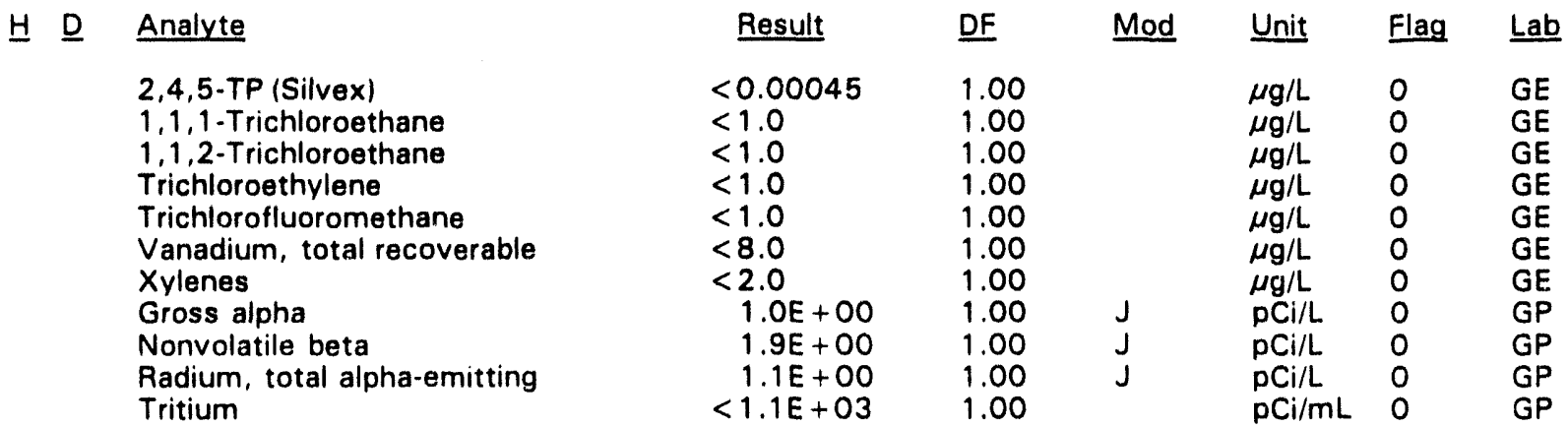

\section{WELL BGX 8DR}

\begin{tabular}{|c|c|c|c|c|c|c|}
\hline SRS Coord. & Lat/Longitude & Screen Zone Elevation & Top of Casing & Casing & Pump & Formation \\
\hline $\begin{array}{l}\text { N77589.6 } \\
\text { E58942.5 }\end{array}$ & $\begin{array}{l}33.293550^{\circ} \mathrm{N} \\
81.662309^{\circ} \mathrm{W}\end{array}$ & $203.1-183.1 \mathrm{ft} \mathrm{msl}$ & $278.2 \mathrm{ft} \mathrm{msl}$ & 4" PVC & $\mathbf{S}$ & Barnwell (IIB, \\
\hline
\end{tabular}

\section{FIELD MEASUREMENTS}

Sample date: 02/07/94

Depth to water: $73.63 \mathrm{ft}(22.44 \mathrm{~m})$ below TOC

Water elevation: $204.57 \mathrm{ft}(62.35 \mathrm{~m}) \mathrm{ms}$ l

Sp. conductance: $44 \mu \mathrm{S} / \mathrm{cm}$

Turbidity: 0.8 NTU

Water evacuated before sampling: $50 \mathrm{gal}$

\section{LABORATORY ANALYSES}

$\begin{array}{ll}\text { H. } & \text { Analyte } \\ \text { - } & \\ \text { Specific conductance } \\ \text { Turbidity } \\ \text { Acetophenone } \\ \text { Aldrin } \\ \text { Aldrin } \\ \text { Aluminum, total recoverable } \\ \text { Aluminum, total recoverable } \\ \text { Antimony, total recoverable } \\ \text { Arsenic, total recoverable } \\ \text { Barium, total recoverable } \\ \text { Barium, total recoverable } \\ \text { Benzene } \\ \text { Bromodichloromethane } \\ \text { Bromoform } \\ \text { Bromomethane (Methyl bromide) } \\ \text { Cadmium, total recoverable } \\ \text { Cadmium, total recoverable } \\ \text { Calcium, total recoverable } \\ \text { Calcium, total recoverable } \\ \text { Carbon tetrachloride } \\ \text { Chloride } \\ \text { Chlorobenzene }\end{array}$

Chlorobenzene

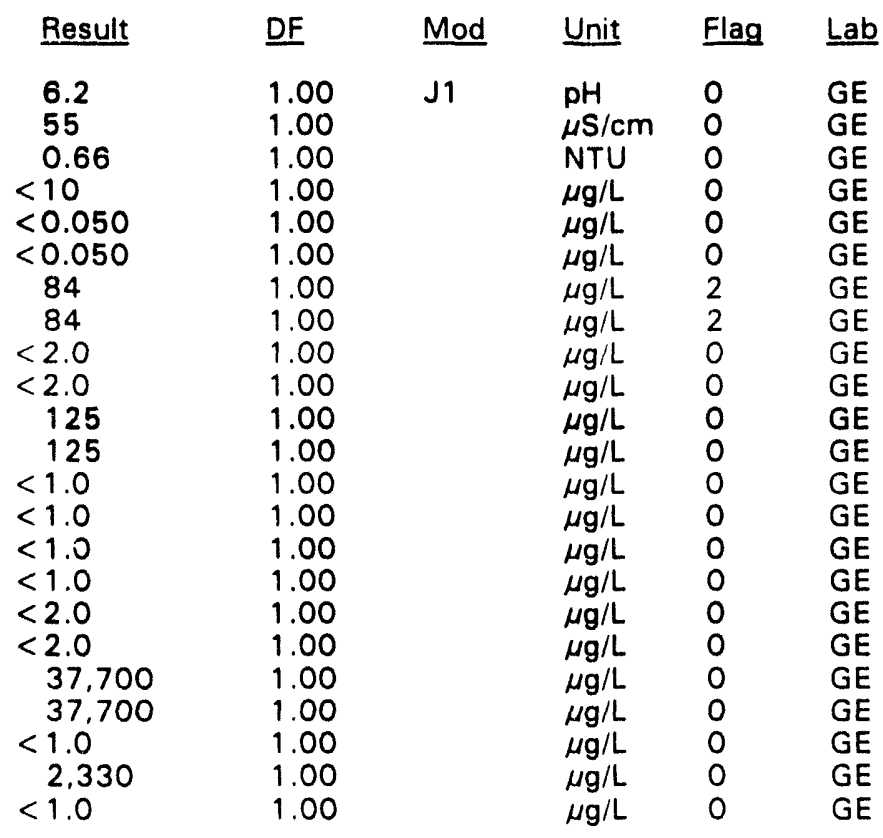

Time: 10: 32

$\mathrm{pH}: 6.0$

Alkalinity: $7 \mathrm{mg} / \mathrm{L}$

Water temperature: $18.8^{\circ} \mathrm{C}$

Volumes purged: 3.6 well volumes 
WELL BGX 8DR collected on $02 / 07 / 94$, laboratory analyses (cont.)

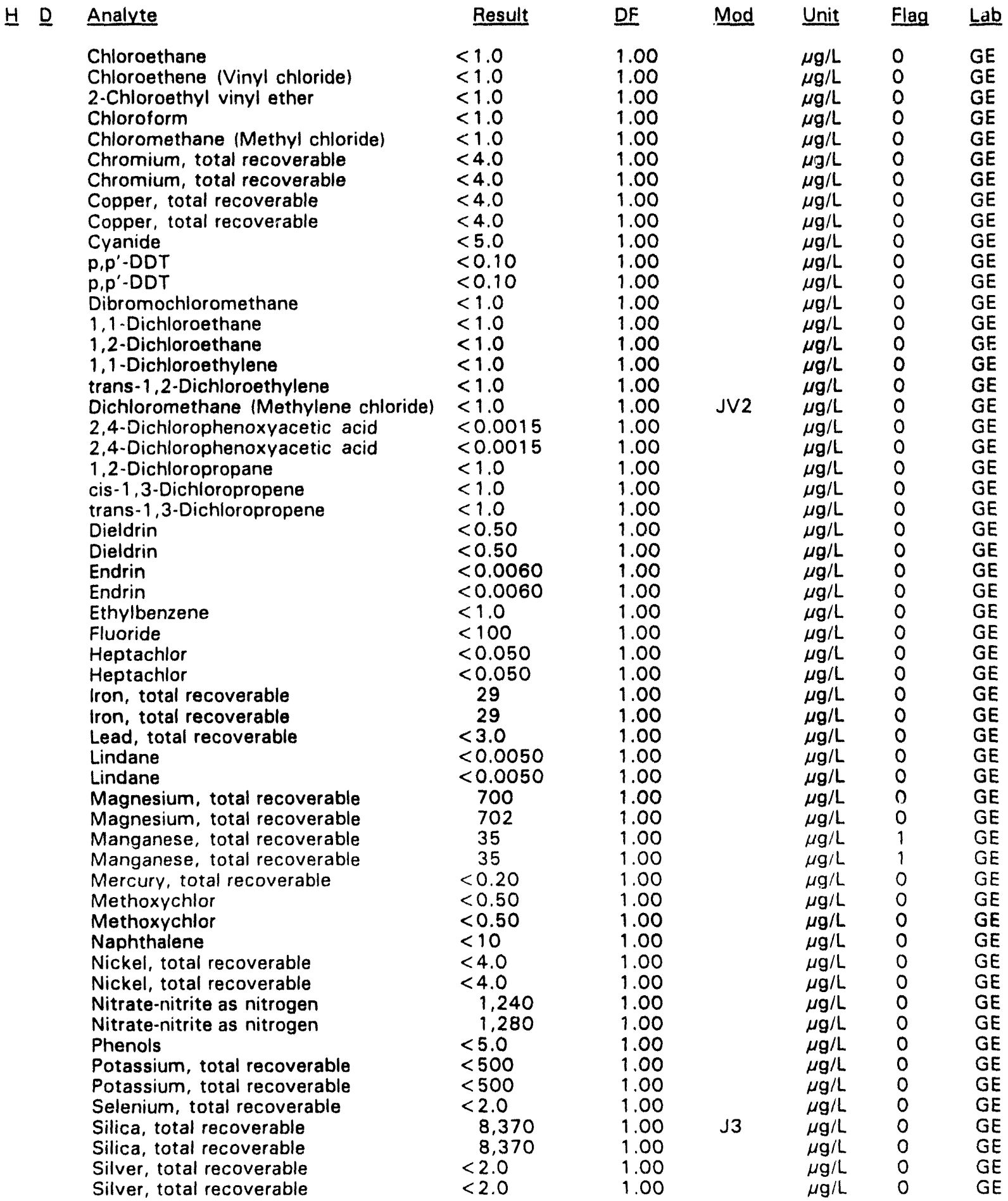

- = exceeded holding time. = exceeded screening level or final primary drinking water standard. 
WELL BGX 8DR collected on 02/07/94, laboratory analyses (cont.)

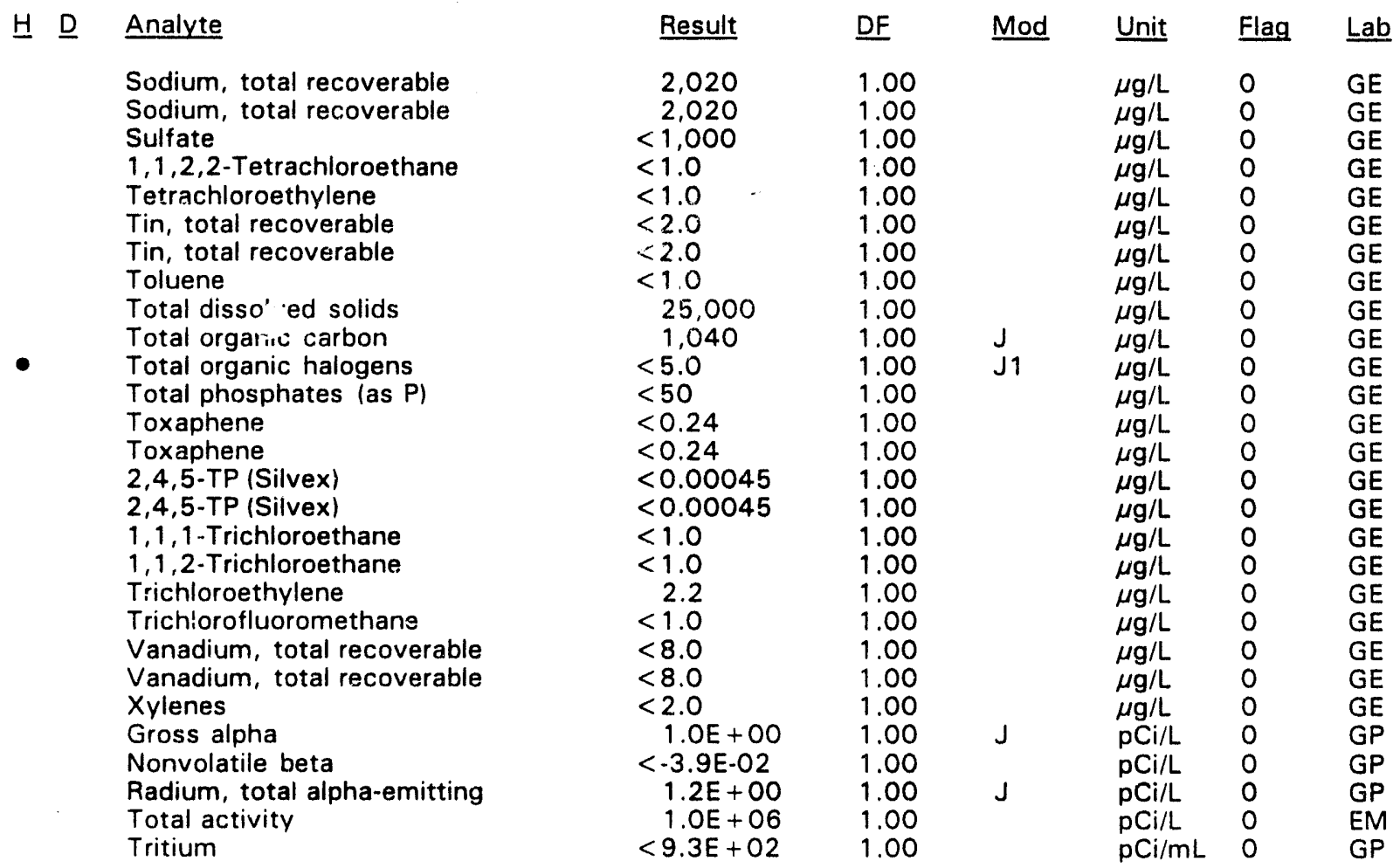

\section{WELL BGX 9D}

\begin{tabular}{|c|c|c|c|c|c|c|}
\hline SRS Coord. & Lat/Longitude & Screen Zone Elevation & Top of Casing & Casing & Pump & Formation \\
\hline $\begin{array}{l}\text { N76936.0 } \\
\text { E59522.1 }\end{array}$ & $\begin{array}{l}33.293050^{\circ} \mathrm{N} \\
81.659513^{\circ} \mathrm{W}\end{array}$ & $232.4-212.4 \mathrm{ft} \mathrm{msl}$ & $279.4 \mathrm{ft} \mathrm{msl}$ & 4" PVC & $\mathrm{S}$ & Water Table $\left(I \mid B_{2}\right)$ \\
\hline
\end{tabular}

\section{FIELD MEASUREMENTS}

Sample date: $02 / C 7 / 94$

Depth to water: $52.99 \mathrm{ft}(16.15 \mathrm{~m})$ below TOC

Water elevation: $226.41 \mathrm{ft}(69.01 \mathrm{~m}) \mathrm{ms}$ l

Sp. conductance: $26 \mu \mathrm{S} / \mathrm{cm}$

Turbidity: 0.2 NTU

Water evacuated before sampling: $80 \mathrm{gal}$

\section{LABORATORY ANALYSES}

\section{H D Analyte}

- $\mathrm{pH}$

Specific conductance

Turbidity

Acetophenone

Aldrin

Aluminum, total recoverable
Time: 10: 55

$\mathrm{pH}: 5.0$

Alkalinity: $0 \mathrm{mg} / \mathrm{L}$

Water temperature: $18.6^{\circ} \mathrm{C}$

Volumes purged: 8.7 well volumes

$\begin{array}{llllll}\text { Result } & \text { DF } & \text { Mod } & \text { Unit } & \text { Flag } & \underline{\text { Lab }} \\ 5.4 & 1.00 & \mathrm{~J} 1 & \mathrm{pH} & 0 & \mathrm{GE} \\ 25 & 1.00 & & \mu \mathrm{S} / \mathrm{cm} & 0 & \mathrm{GE} \\ 1.5 & 1.00 & & \mathrm{NTU} & 0 & \mathrm{GE} \\ <10 & 1.00 & & \mu \mathrm{g} / \mathrm{L} & 0 & \mathrm{GE} \\ <0.049 & 1.00 & & \mu \mathrm{g} / \mathrm{L} & 0 & \mathrm{GE} \\ 53 & 1.00 & & \mu \mathrm{g} / \mathrm{L} & 2 & \mathrm{GE}\end{array}$

$\bar{\bullet}=$ exceeded holding time. $=$ exceeded screening level or final primary drinking water standard. 
WELL BGX 9D collected on 02/07/94, laboratory analyses (cont.)

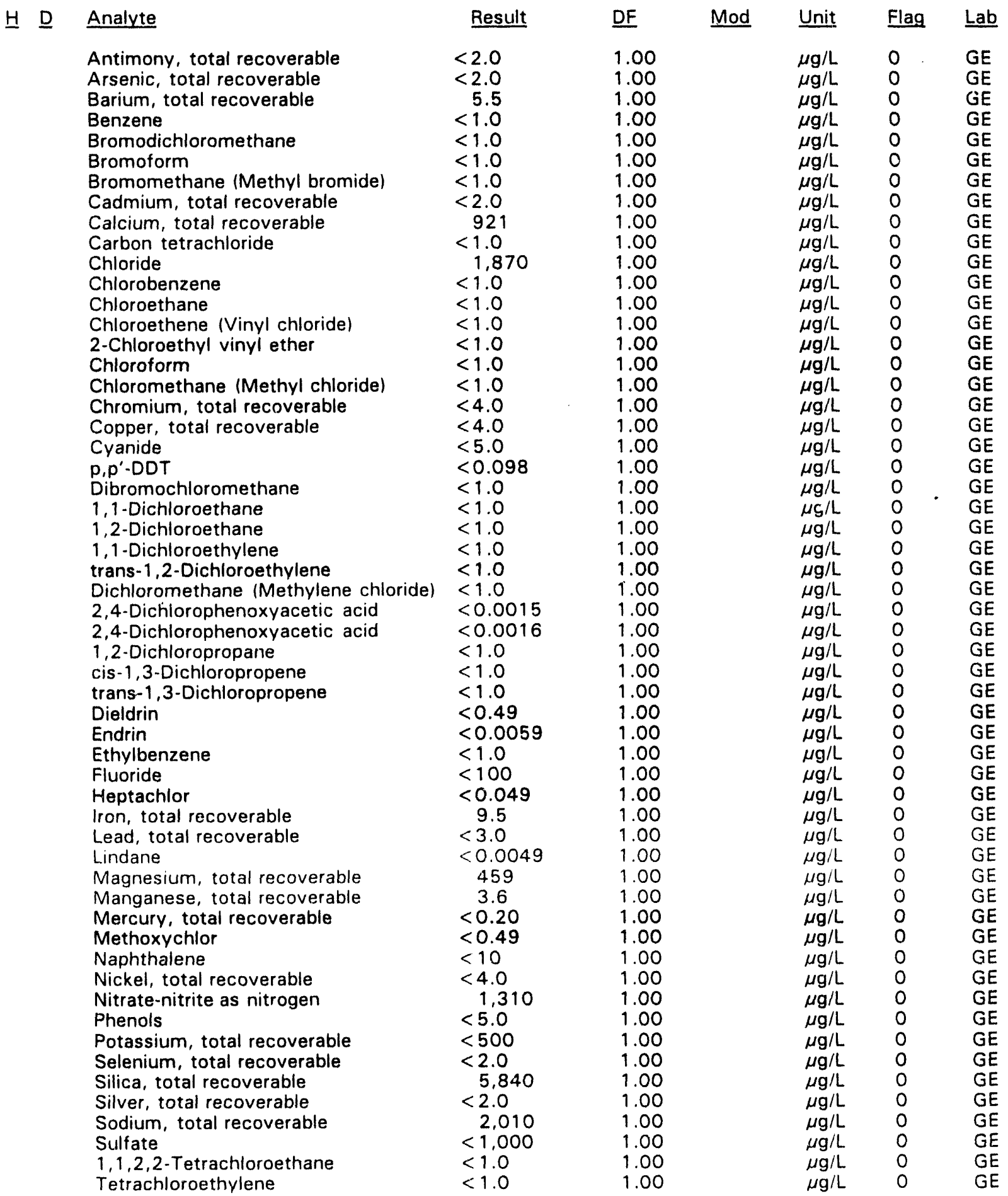

- = exceeded holding time. = exceeded screening level or final primary drinking water standard. 
WELL BGX 9D collected on 02/07/94, laboratory analyses (cont.)

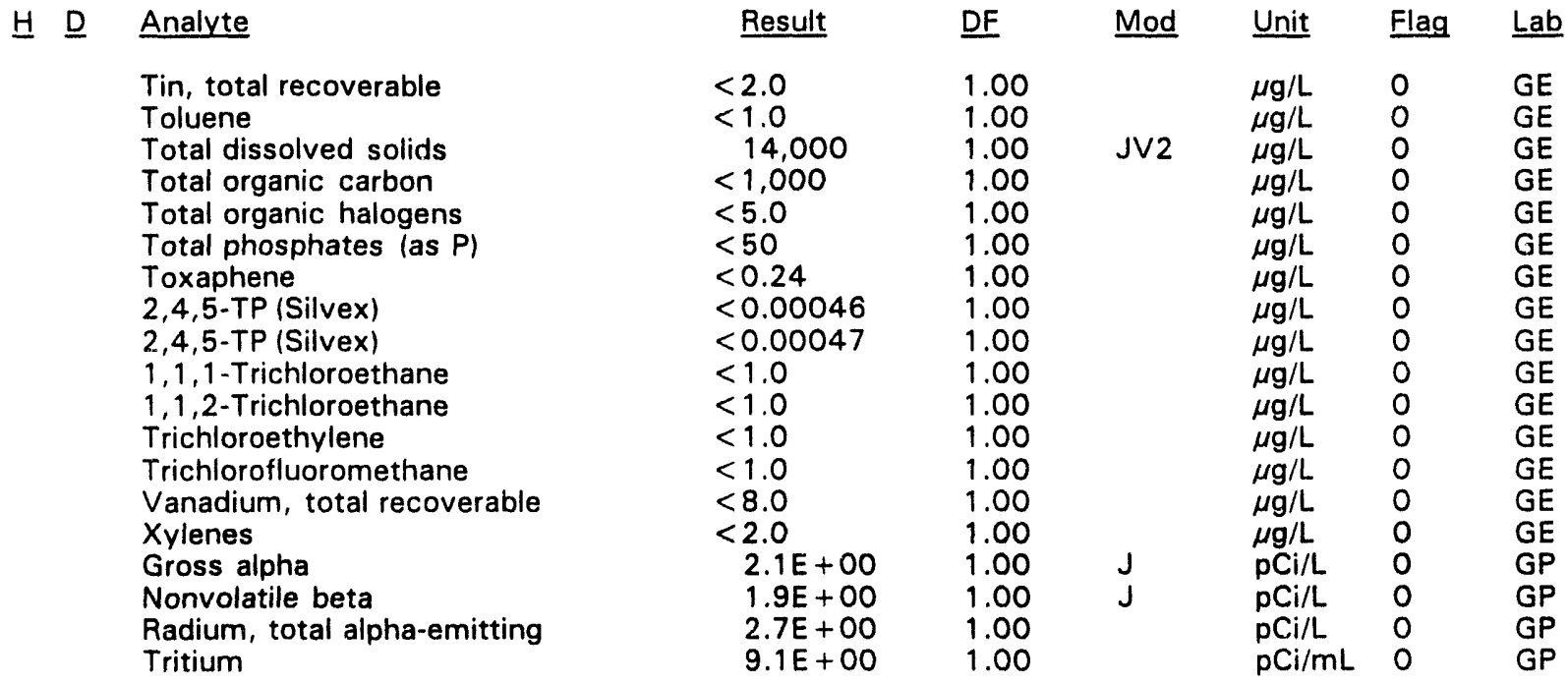

WELL BGX 10D

\begin{tabular}{|c|c|c|c|c|c|c|}
\hline SRS Coord. & Lat/Longitude & Screen Zone Elevation & Top of Casing & Casing & Pump & Formation \\
\hline $\begin{array}{l}\text { N76183.3 } \\
\text { E59765.5 }\end{array}$ & $\begin{array}{l}33.291783^{\circ} \mathrm{N} \\
81.657410^{\circ} \mathrm{W}\end{array}$ & $2-21$ & $\mathrm{nsl}$ & DVC & $S$ & \\
\hline
\end{tabular}

\section{FIELD MEASUREMENTS}

Sample date: $02 / 04 / 94$

Depth to water: $51.34 \mathrm{ft}(15.65 \mathrm{~m})$ below TOC Water elevation: $225.56 \mathrm{ft}(68.75 \mathrm{~m})$ misl

Sp. conductance: $29 \mu \mathrm{S} / \mathrm{cm}$

Turbidity: 20.1 NTU

Water evacuated before sampling: $2 \mathrm{gal}$

The well went dry during purging.

\section{LABORATORY ANALYSES}

H $\underline{\text { Analyte }}$

- $\mathrm{pH}$

Specific conductance

Specific conductance

Turbidity

Acetophenone

Aldrin

Aluminum, total recoverable

Antimony, total recoverable

Arsenic, total recoverable

Barium, total recoverable

Benzene

Bromodichloromethane

Bromoform

Biomomethane (Methyl bromide)

Cadmium, total recoverable
Time: 10: 34

$\mathrm{pH}: 5.7$

Alkalinity: $3 \mathrm{mg} / \mathrm{L}$

Water temperature: $16.5^{\circ} \mathrm{C}$

Volumes purged: 0.3 well volumes

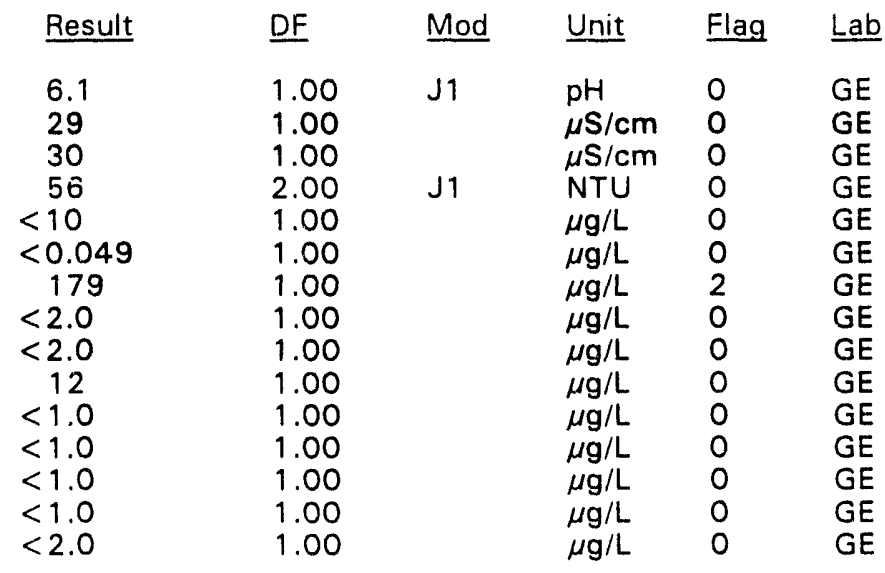

- = exceeded holding time. $\mathbf{a}=$ exceeded screening level or final primary drinking water standard. 
WELL BGX $10 D$ collected on 02/04/94, laboratory analyses (cont.)

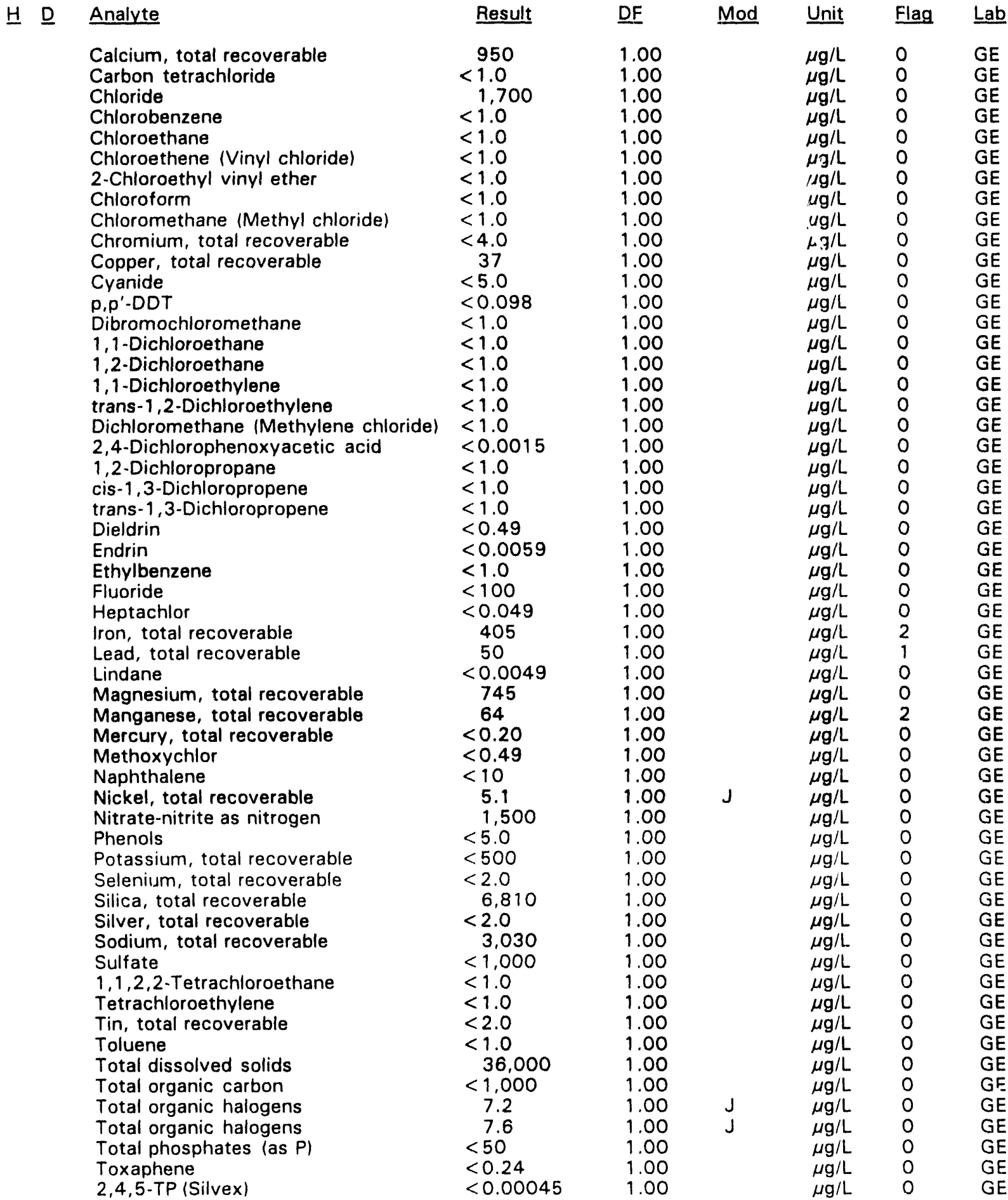

- = exceeded holding time. = exceeded screening level or final primary drinking water standard. 
WELL BGX $10 D$ collected on 02/04/94, laboratory analyses (cont.)

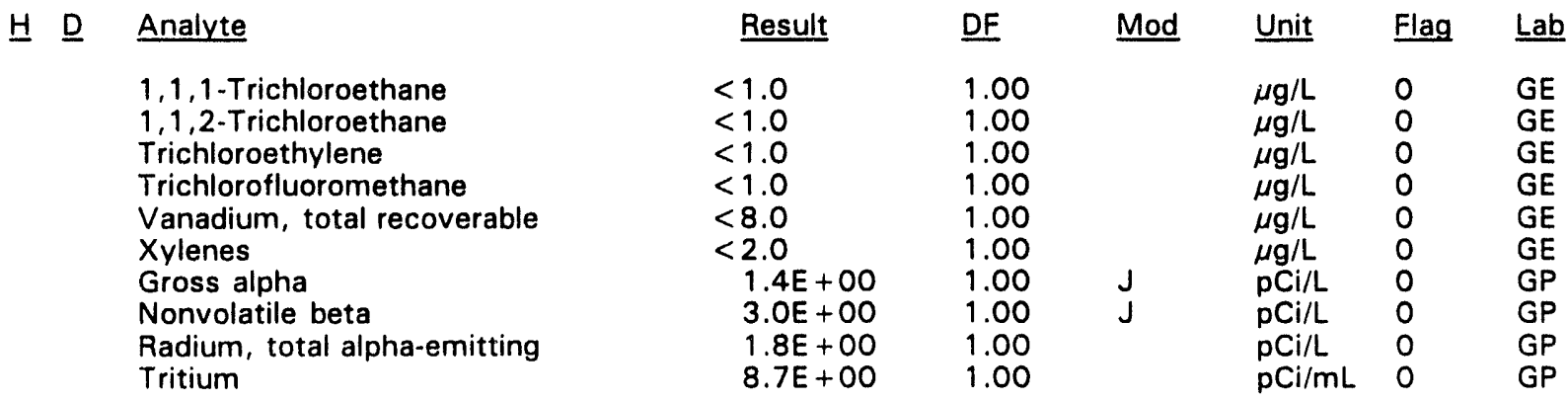

\section{WELL BGX 11D}

\begin{tabular}{|c|c|c|c|c|c|c|}
\hline SRS Coord. & Lat/Longitude & Screen Zone Elevation & Top of Casing & Casing & Pump & Formation \\
\hline $\begin{array}{l}N 75300.7 \\
E 59581.4\end{array}$ & $\begin{array}{l}33.289530^{\circ} \mathrm{N} \\
81.656180^{\circ} \mathrm{W}\end{array}$ & $236.7-216.7 \mathrm{ft} \mathrm{msl}$ & $276.3 \mathrm{ft} \mathrm{msl}$ & 4" PVC & $S$ & Water Table $\left(\| \mathrm{B}_{2}\right)$ \\
\hline
\end{tabular}

\section{FIELD MEASUREMENTS}

Sample date: 02/04/94

Depth to water: $41.51 \mathrm{ft}(12.65 \mathrm{~m})$ below TOC

Water elevation: $234.79 \mathrm{ft}(71.56 \mathrm{~m}) \mathrm{msl}$

Sp. conductance: $49 \mu \mathrm{S} / \mathrm{cm}$

Turbidity: 57.1 NTU

Water evacuated before sampling: $4 \mathrm{gal}$

The well went dry during purging.

\section{LABORATORY ANALYSES}

- $D \quad$ Analyte
-
- Sp
Turbidic conductance
Acetophenone
Aldrin
Aluminum, total recoverable
Aluminum, total recoverable
Antimony, total recoverable
Arsenic, total recoverable
Barium, total recoverable
Barium, total recoverable
Benzene
Bromodichloromethane
Bromoform
Bromomethane (Methyl bromide)
Cadmium, total recoverable
Cadmium, total recoverable
Calcium, total recoverable
Calcium, total recoverable
Carbon tetrachloride
Chloride
Chlorobenzene
Chloroethane
Chloroethene (Vinyl chloride)

Time: 10: 57

$\mathrm{pH}: 5.6$

Alkalinity: $6 \mathrm{mg} / \mathrm{L}$

Water temperature: $15.5^{\circ} \mathrm{C}$

Volumes purged: 0.3 well volumes

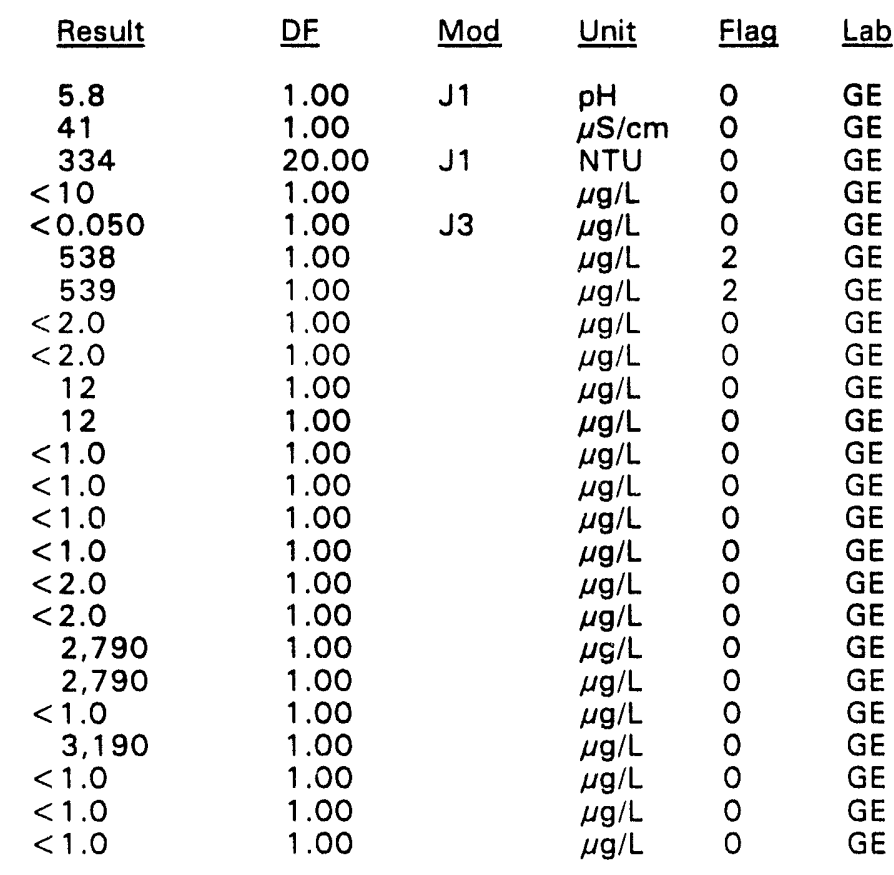

\footnotetext{
$\overline{-}=$ exceeded holding time. $=$ exceeded screening level or final primary drinking water standard.
} 
WELL BGX 11D collected on 02/04/94, laboratory analyses (cont.)

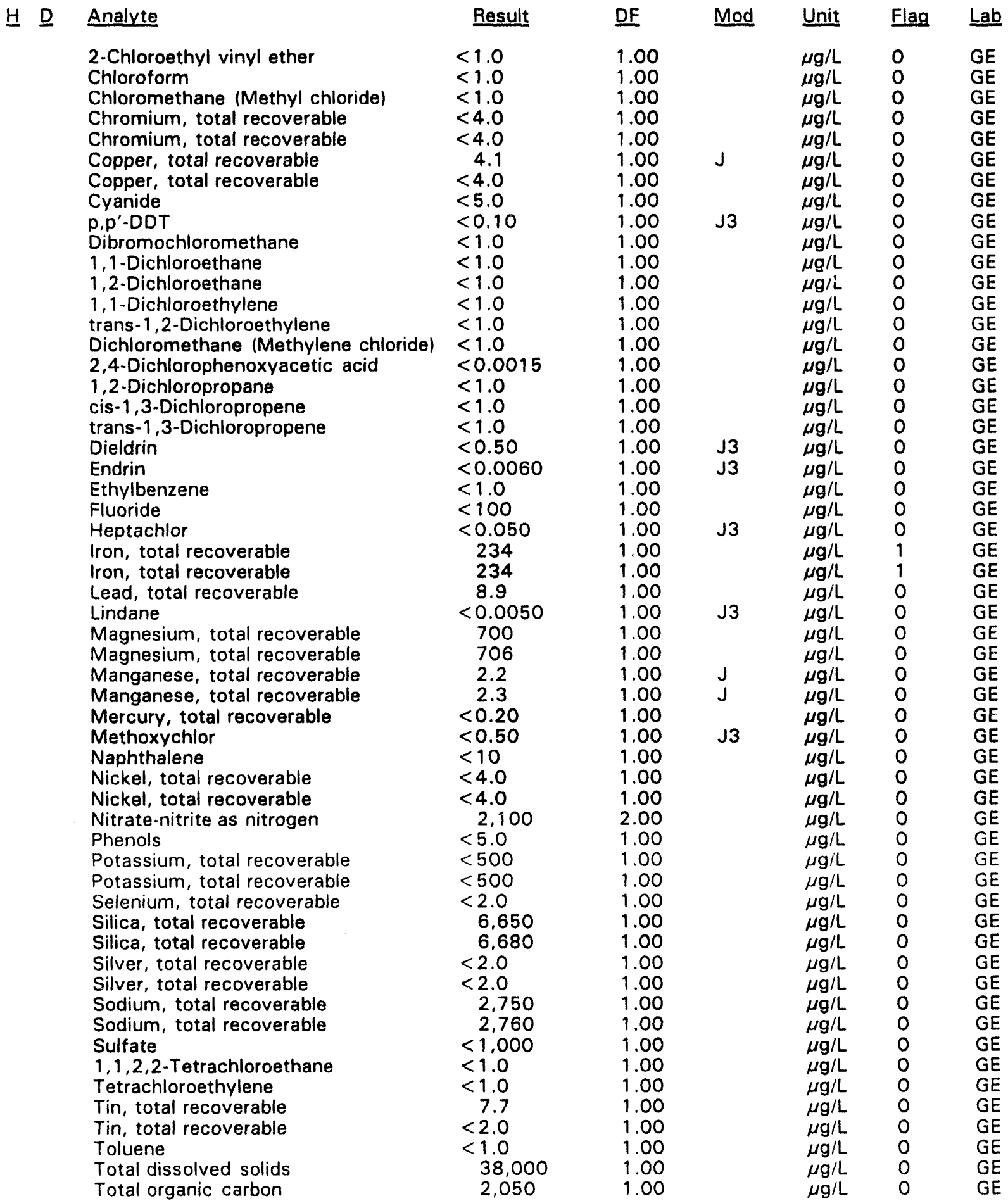

- = exceeded holding time. $\quad$ = exceeded screening level or final primary drinking water standard. 
WELL BGX 110 collected on $02 / 04 / 94$, laboratory analyses (cont.)

H D Analyte

Total organic halogens

Total phosphates (as P)

Toxaphene

2,4,5-TP (Silvex)

$1,1,1-$ Trichloroethane

1,1,2-Trichloroethane

Trichloroethylene

Trichlorofluoromethane

Vanadium, total recoverable

Vanadium, total recoverable

Xylenes

Gross alpha

Nonvolatile beta

Radium, total alpha-emitting

Tritium

\begin{tabular}{ll}
\multicolumn{1}{l}{ Result } & DF \\
\hline$<5.0$ & 1.00 \\
1.210 & 1.00 \\
$<0.24$ & 1.00 \\
$<0.00046$ & 1.00 \\
$<1.0$ & 1.00 \\
$<1.0$ & 1.00 \\
$<1.0$ & 1.00 \\
$<1.0$ & 1.00 \\
$<8.0$ & 1.00 \\
$<8.0$ & 1.00 \\
$<2.0$ & 1.00 \\
$3.0 E+00$ & 1.00 \\
$3.0 E+00$ & 1.00 \\
$3.6 E+00$ & 1.00 \\
$1.8 E+01$ & 1.00
\end{tabular}

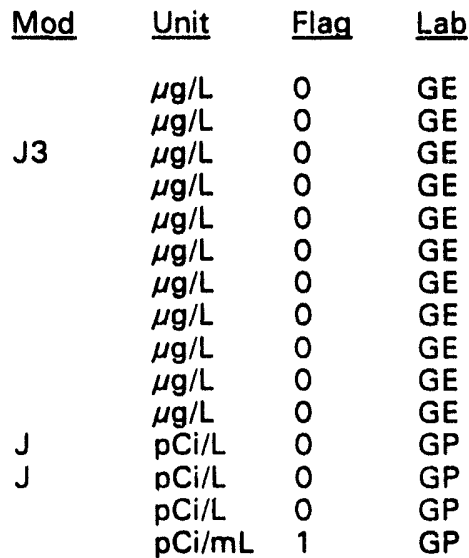

\section{WELL BGX 12C}

$\begin{array}{lllllll}\text { SRS Coord, } & \text { Lat/Longitude } & \text { Screen Zone Elevation } & \text { Top of Casing } & \text { Casing } & \text { Pump Formation } \\ \text { N74427.9 } & 33.287753^{\circ} \mathrm{N} & 184.1-174.1 \mathrm{ft} \mathrm{msl} & 275.1 \mathrm{ft} \mathrm{msl} & \text { 4" PVC } & \text { S } & \text { Barnwell (IIB,) } \\ \text { E59675.3 } & 81.654237^{\circ} \mathrm{W} & & & \end{array}$

\section{FIELD MEASUREMENTS}

Sample date: $02 / 02 / 94$

Depth to water: $41.45 \mathrm{ft}(12.63 \mathrm{~m})$ below TOC

Water elevation: $233.65 \mathrm{ft}(71.22 \mathrm{~m}) \mathrm{msl}$

Sp. conductance: $29 \mu \mathrm{S} / \mathrm{cm}$

Turbidity: 1.4 NTU

Water evacuated before sampling: $112 \mathrm{gal}$

Time: $15: 40$

pH: 5.7

Alkalinity: $5 \mathrm{mg} / \mathrm{L}$

Water temperature: $17.9^{\circ} \mathrm{C}$

Volumes purged: 2.9 well volumes

\section{LABORATORY ANALYSES}

H D Analyte

- $\mathrm{pH}$

Specific conductance

Turbidity

Turbidity

Acetophenone

Aldrin

Aluminum, total recoverable

Aluminum, total recoverable

Antimony, total recoverable

Arsenic, total recoverable

Barium, total recoverable

Barium, total recoverable

Benzene

Bromodichloromethane

Bromoform

Bromomethane (Methyl bromide)

Cadmium, total recoverable

Cadmium, total recoverable

Calcium, total recoverable

\begin{tabular}{lll}
\multicolumn{1}{ll}{ Result } & & DF \\
\cline { 1 - 1 } 6.0 & & 1.00 \\
27 & & 1.00 \\
0.11 & 1.00 \\
0.11 & 1.00 \\
$<9.8$ & 1.00 \\
$<0.051$ & 1.00 \\
21 & 1.00 \\
23 & 1.00 \\
$<2.0$ & 1.00 \\
$<2.0$ & 1.00 \\
5.6 & 1.00 \\
5.6 & 1.00 \\
$<1.0$ & 1.00 \\
$<1.0$ & 1.00 \\
$<1.0$ & 1.00 \\
$<1.0$ & 1.00 \\
$<2.0$ & 1.00 \\
$<2.0$ & 1.00 \\
814 & 1.00
\end{tabular}

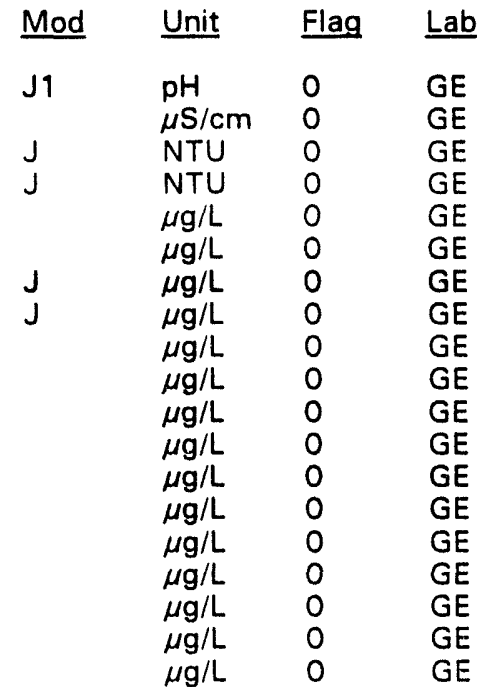

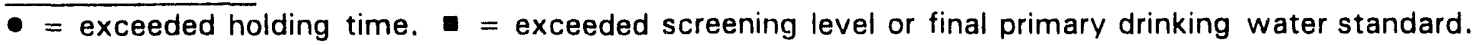


WELL BGX 12C collected on 02/02/94, laboratory analyses (cont.)

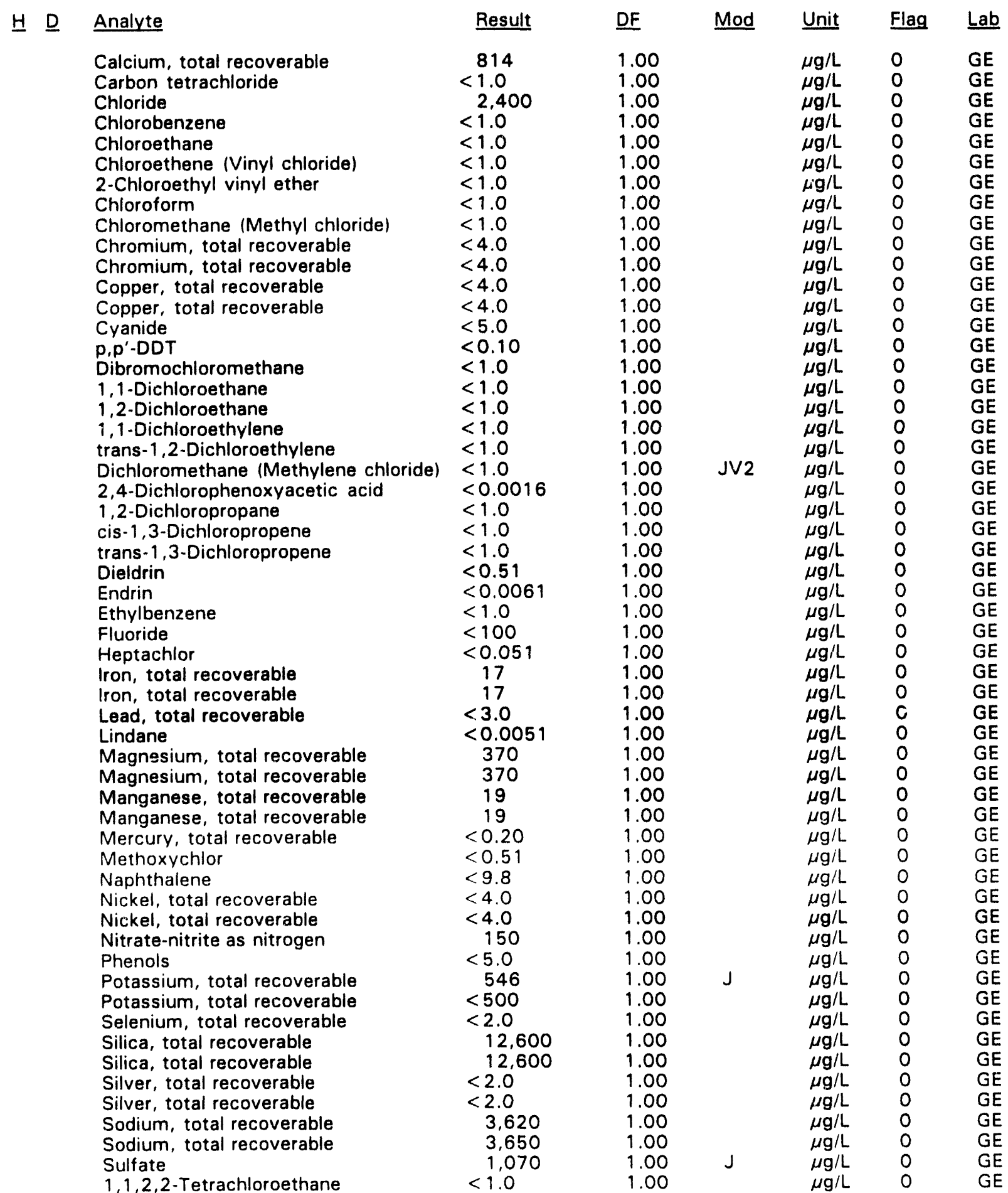

- exceeded holding time. = exceeded screening level or final primary drinking water standard. 
WELL BGX $12 \mathrm{C}$ collected on $02 / 02 / 94$, laboratory analyses (cont.)

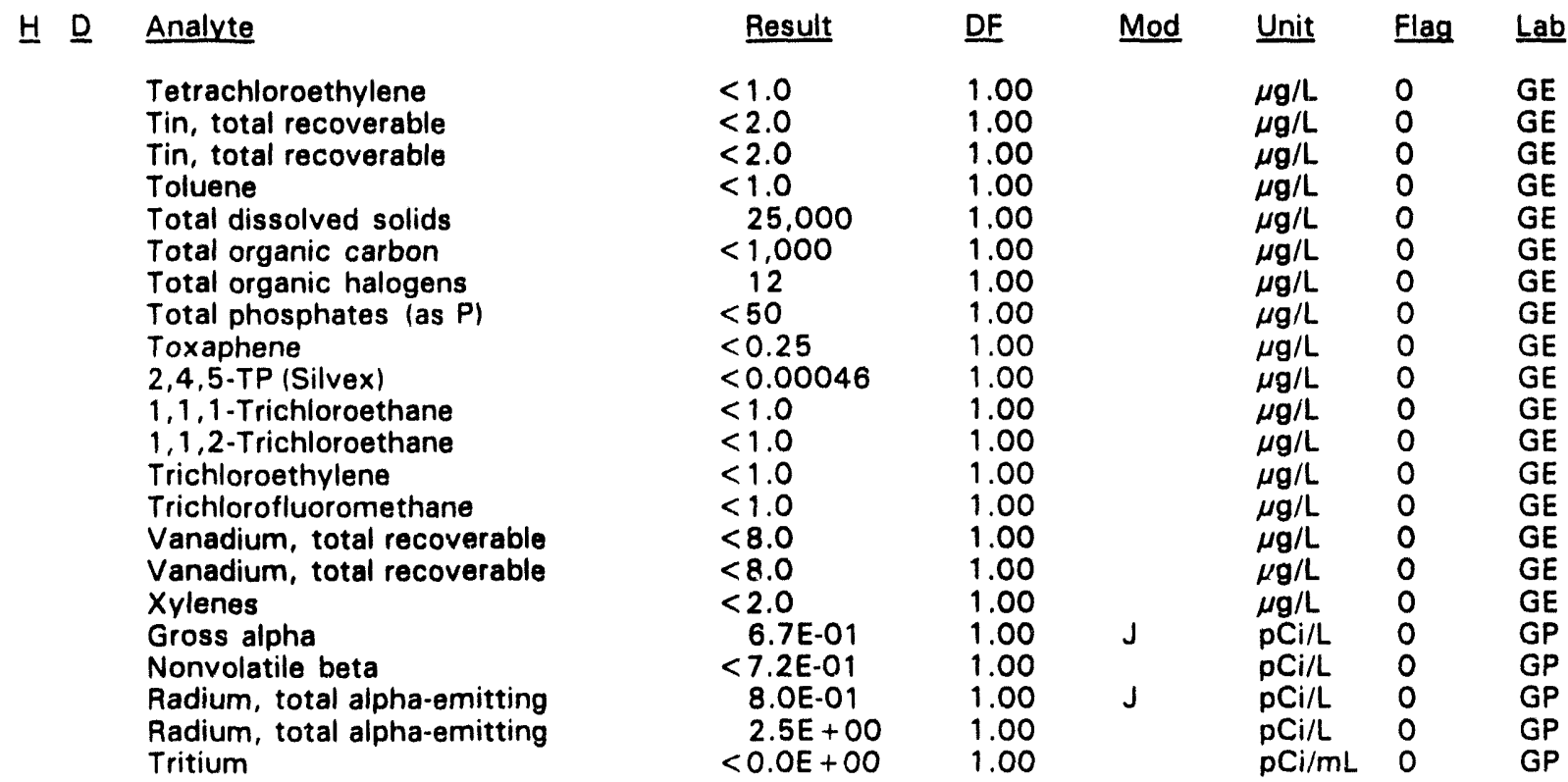

\section{WELL BGX 12D}

$\begin{array}{lllllll}\text { SRS Coord. Lat/Longitude } & \text { Screen Zone Elevation } & \text { Top of Casing } & \text { Casing } & \text { Pump } & \text { Formation } \\ \text { N74410.9 } & 33.287714^{\circ} \mathrm{N} & 243.7-223.7 \mathrm{ft} \mathrm{msl} & 275.2 \mathrm{ft} \mathrm{msl} & \text { 4" PVC } & \text { S } & \left.\text { Water Table (IIB }{ }_{2}\right) \\ \text { E59674.3 } & 81.654207^{\circ} \mathrm{W} & 24.72 & & \end{array}$

\section{FIELD MEASUREMENTS}

Sample date: 02/08/94

Depth to water: $37.11 \mathrm{ft}(11.31 \mathrm{~m})$ below TOC

Water elevation: $238.09 \mathrm{ft}(72.57 \mathrm{~m}) \mathrm{ms}$

Sp. conductance: $19 \mu \mathrm{S} / \mathrm{cm}$

Turbidity: 24.9 NTU

Water evacuated before sampling: $7 \mathrm{gal}$

The well went dry during purging.

\section{LABORATORY ANALYSES}

H D $\quad$ Analyte
pH
Specific conductance
Turbidity
Acetophenone
Acetophenone
Aldrin
Aluminum, total recoverable
Aluminum, total recoverable
Antimony, total recoverable
Arsenic, total recoverable
Barium, total recoverable
Barium, total recoverable

Barium, total recoverable
Time: 9: 10

$\mathrm{pH}: 5.1$

Alkalinity: $1 \mathrm{mg} / \mathrm{L}$

Water temperature: $18.0^{\circ} \mathrm{C}$

Volumes purged: 0.7 well volumes

\begin{tabular}{|c|c|c|c|c|}
\hline Result & DF & Mod & Unit & Flag \\
\hline $\begin{aligned} & 5.7 \\
& 19 \\
& 95 \\
&<10 \\
&<10 \\
&<0.053 \\
& 181 \\
& 186 \\
&<2.0 \\
&<2.0 \\
& 19 \\
& 19\end{aligned}$ & $\begin{array}{l}1.00 \\
1.00 \\
5.00 \\
1.00 \\
1.00 \\
1.00 \\
1.00 \\
1.00 \\
1.00 \\
1.00 \\
1.00 \\
1.00\end{array}$ & J1 & $\begin{array}{l}\mathrm{pH} \\
\mu \mathrm{S} / \mathrm{cm} \\
N T U \\
\mu \mathrm{g} / \mathrm{L} \\
\mu \mathrm{g} / \mathrm{L} \\
\mu \mathrm{g} / \mathrm{L} \\
\mu \mathrm{g} / \mathrm{L} \\
\mu \mathrm{g} / \mathrm{L} \\
\mu \mathrm{g} / \mathrm{L} \\
\mu \mathrm{g} / \mathrm{L} \\
\mu \mathrm{g} / \mathrm{L} \\
\mu \mathrm{g} / \mathrm{L}\end{array}$ & $\begin{array}{l}0 \\
0 \\
0 \\
0 \\
0 \\
0 \\
2 \\
2 \\
0 \\
0 \\
0 \\
0\end{array}$ \\
\hline
\end{tabular}

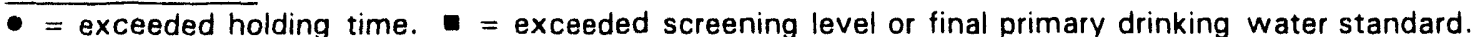


WELL BGX $12 D$ collected on $02 / 08 / 94$, laboratory analyses (cont.)

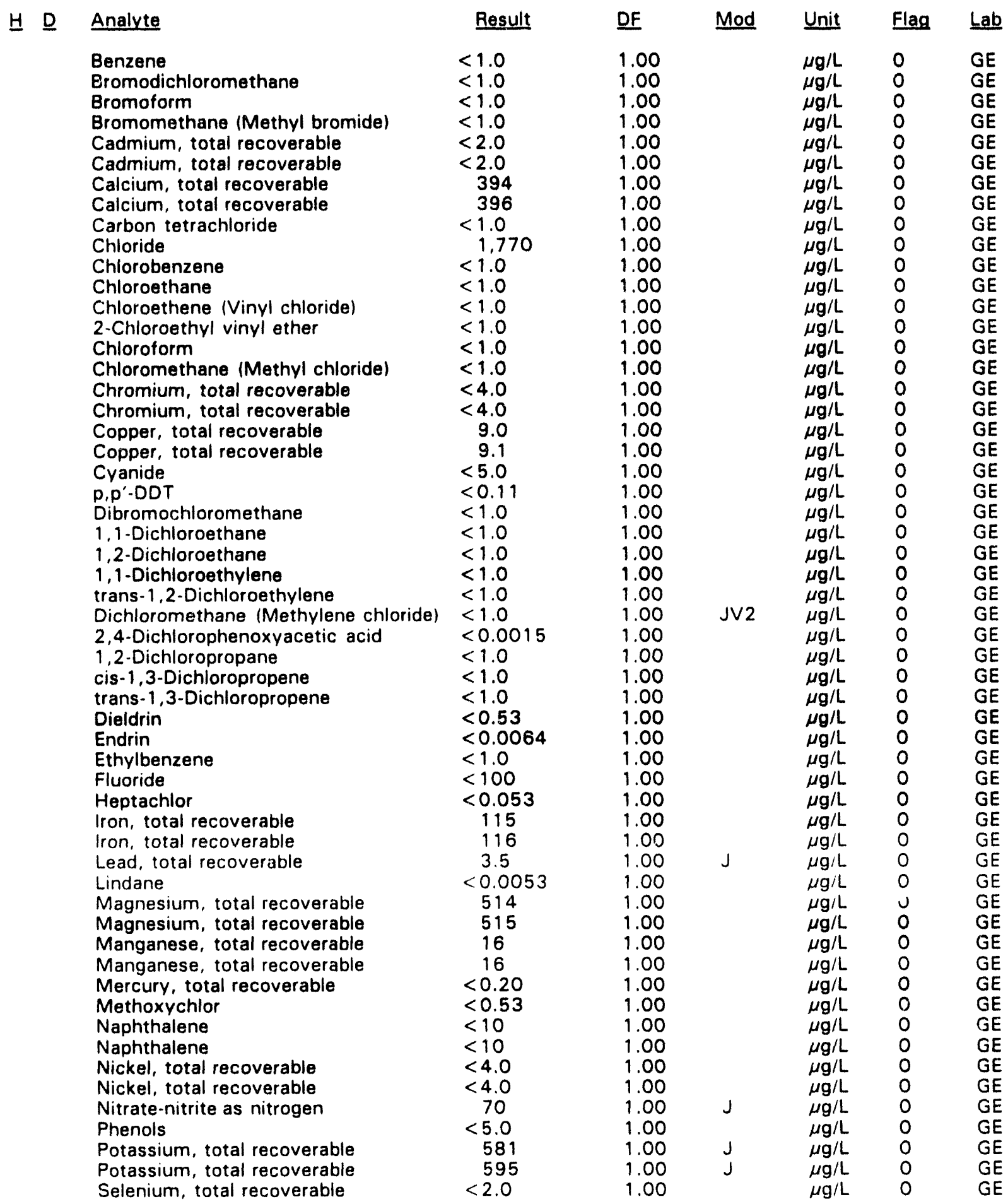

- exceeded holding time. = exceeded screening level or final primary drinking water standard. 
WELL BGX 12D collected on 02/08/94, laboratory analyses (cont.)

\section{H D Analyte}

Silica, total recoverable

Silica, total recoverable

Silver, total recoverable

Silver, total recoverable

Sodium, total recoverable

Sodium, total recoverable

Sulfate

1,1,2,2-Tetrachloroethane

Tetrachloroethylene

Tin, total recoverable

Tin, total recoverable

Toluene

Total dissolved solids

Total organic carbon

Total organic halogens

Total phosphates (as P)

Toxaphene

2,4,5-TP (Silvex)

$1,1,1$-Trichloroethane

1,1,2-Trichloroethane

Trichloroethylene

Trichlorofluoromethane

Vanadium, total recoverable

Vanadium, total recoverable

Xylenes

Gross alpha

Nonvolatile beta

Radium, total alpha-emitting

Tritium

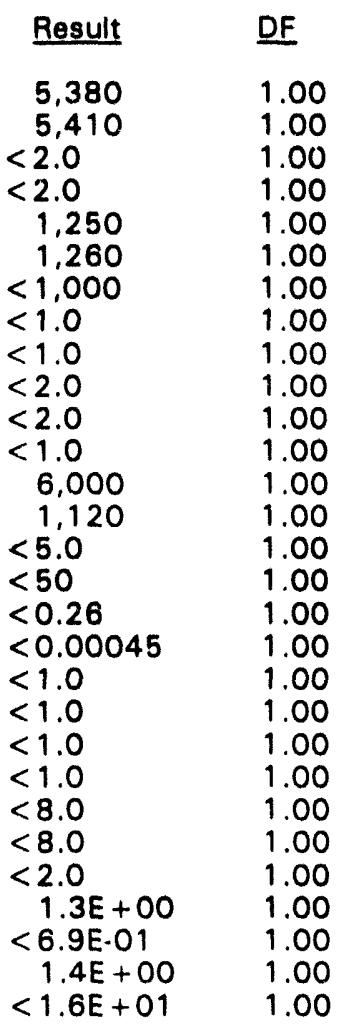

Mod

\begin{tabular}{lll} 
Unit & Flag & Lab \\
\hline$\mu g / L$ & 0 & GE \\
$\mu g / L$ & 0 & GE \\
$\mu \mathrm{g} / \mathrm{L}$ & 0 & $\mathrm{GE}$ \\
$\mu \mathrm{g} / \mathrm{L}$ & 0 & $\mathrm{GE}$ \\
$\mu \mathrm{g} / \mathrm{L}$ & 0 & $\mathrm{GE}$ \\
$\mu \mathrm{g} / \mathrm{L}$ & 0 & $\mathrm{GE}$ \\
$\mu \mathrm{g} / \mathrm{L}$ & 0 & $\mathrm{GE}$ \\
$\mu \mathrm{g} / \mathrm{L}$ & 0 & $\mathrm{GE}$ \\
$\mu \mathrm{g} / \mathrm{L}$ & 0 & $\mathrm{GE}$ \\
$\mu \mathrm{g} / \mathrm{L}$ & 0 & $\mathrm{GE}$ \\
$\mu \mathrm{g} / \mathrm{L}$ & 0 & $\mathrm{GE}$ \\
$\mu \mathrm{g} / \mathrm{L}$ & 0 & $\mathrm{GE}$ \\
$\mu \mathrm{g} / \mathrm{L}$ & 0 & $\mathrm{GE}$ \\
$\mu \mathrm{g} / \mathrm{L}$ & 0 & $\mathrm{GE}$ \\
$\mu \mathrm{g} / \mathrm{L}$ & 0 & $\mathrm{GE}$ \\
$\mu \mathrm{g} / \mathrm{L}$ & 0 & $\mathrm{GE}$ \\
$\mu \mathrm{g} / \mathrm{L}$ & 0 & $\mathrm{GE}$ \\
$\mu \mathrm{g} / \mathrm{L}$ & 0 & $\mathrm{GE}$ \\
$\mu \mathrm{g} / \mathrm{L}$ & 0 & $\mathrm{GE}$ \\
$\mu \mathrm{g} / \mathrm{L}$ & 0 & $\mathrm{GE}$ \\
$\mu \mathrm{g} / \mathrm{L}$ & 0 & $\mathrm{GE}$ \\
$\mu \mathrm{g} / \mathrm{L}$ & 0 & $\mathrm{GE}$ \\
$\mu \mathrm{g} / \mathrm{L}$ & 0 & $\mathrm{GE}$ \\
$\mu \mathrm{g} / \mathrm{L}$ & 0 & $\mathrm{GE}$ \\
$\mu \mathrm{g} / \mathrm{L}$ & 0 & $\mathrm{GE}$ \\
$\mathrm{pC \textrm {i }} / \mathrm{L}$ & 0 & $\mathrm{GP}$ \\
$\mathrm{pCi} / \mathrm{L}$ & 0 & $\mathrm{GP}$ \\
$\mathrm{pCi} / \mathrm{L}$ & 0 & $\mathrm{GP}$ \\
$\mathrm{pC \textrm {Ci }} / \mathrm{mL}$ & 0 & $\mathrm{GP}$
\end{tabular}

\section{WELL FSS 1D}

\begin{tabular}{|c|c|c|c|c|c|c|}
\hline SRS Coord. & Lat/Longitude & Screen Zone Elevation & Top of Casing & Casing & Pump & Formation \\
\hline $\begin{array}{l}N 75257.6 \\
E 53897.6\end{array}$ & $\begin{array}{l}33.280161^{\circ} \mathrm{N} \\
81.671063^{\circ} \mathrm{W}\end{array}$ & $229.9-209.9 \mathrm{ft} \mathrm{msl}$ & $266 \mathrm{ft} \mathrm{msl}$ & 4" PVC & $\mathbf{S}$ & Water Table \\
\hline
\end{tabular}

\section{FIELD MEASUREMENTS}

Sample date: 02/01/94

Depth to water: $42.57 \mathrm{ft}(12.98 \mathrm{~m})$ below TOC

Water elevation: $223.43 \mathrm{ft}(68.10 \mathrm{~m}) \mathrm{msl}$

Sp. conductance: $44 \mu \mathrm{S} / \mathrm{cm}$

Turbidity: 28.3 NTU

Water evacuated before sampling: 5 gal

The well went dry during purging.

\section{LABORATORY ANALYSES}

H D Analyte

- $\mathrm{pH}$

Specific conductance

Turbidity

Turbidity

Acetophenone
Time: 9: 00

$\mathrm{pH}: 5.8$

Alkalinity: $10 \mathrm{mg} / \mathrm{L}$

Water temperature: $15.1^{\circ} \mathrm{C}$

Volumes purged: 0.6 well volumes 
WELL FSS 10 collected on $02 / 01 / 94$, laboratory analyses (cont.)

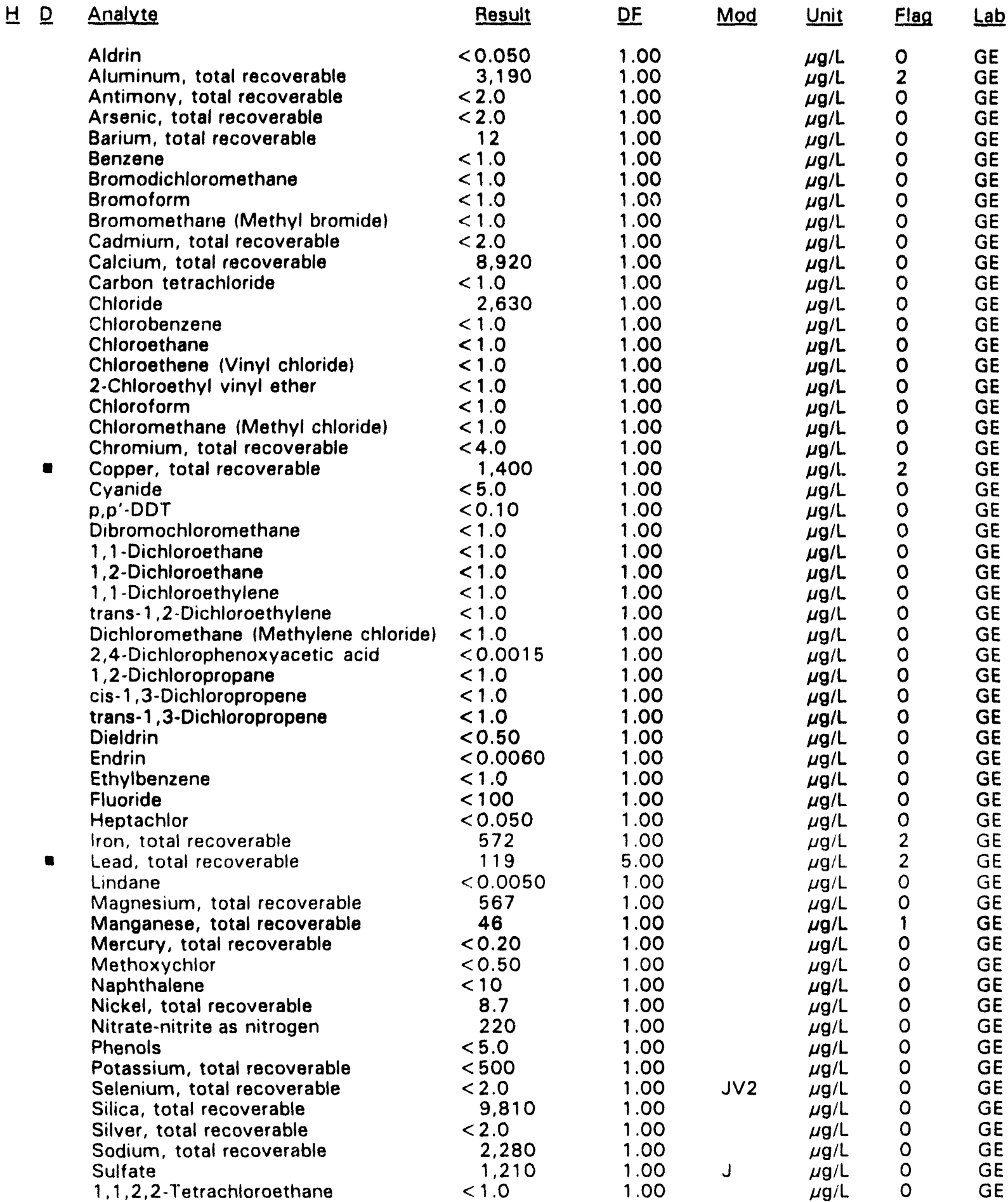

\footnotetext{
- = exceeded holding time. - exceeded screening level or final primary drinking water standard.
} 
WELL FSS 10 collected on 02/01/94, laboratory analyses (cont.)

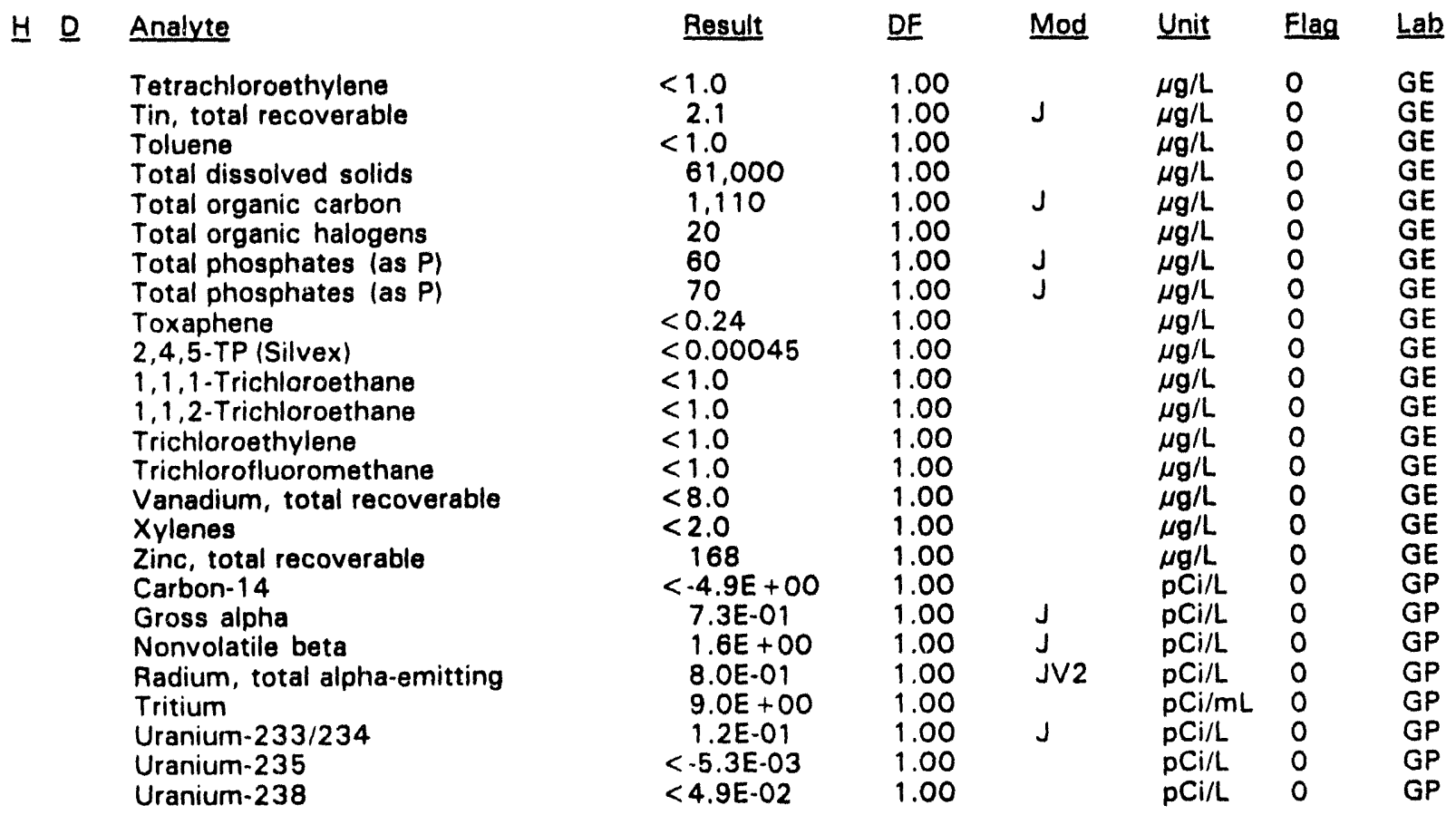

WELL FSS 2D

\begin{tabular}{|c|c|c|c|c|c|c|}
\hline SRS Coord. & Lat/Longitude & Screen Zone Elevation & Top of Casing & Casing & Pump & Formation \\
\hline $\begin{array}{l}\text { N75103.5 } \\
\text { E53918.9 }\end{array}$ & $\begin{array}{l}33.279855^{\circ} \mathrm{N} \\
81.670708^{\circ} \mathrm{W}\end{array}$ & $224.4-204.4 \mathrm{ft} \mathrm{msl}$ & $261.6 \mathrm{ft} \mathrm{msl}$ & 4" PVC & s & Water Table \\
\hline
\end{tabular}

\section{FIELD MEASUREMENTS}

\section{Sample date: $02 / 01 / 94$}

Depth to water: $38.82 \mathrm{ft}(11.83 \mathrm{~m})$ below TOC

Water elevation: $222.78 \mathrm{ft}(67.90 \mathrm{~m}) \mathrm{msl}$

Sp. conductance: $88 \mu \mathrm{S} / \mathrm{cm}$

Turbidity: 46.3 NTU

Water evacuated before sampling: 8 gal

The well went dry during purging.

\section{LABORATORY ANALYSES}

H D Analyte
pH
Specific conductance
Turbidity
Acetophenone
Aldrin
Aluminum, total recoverable
Antimony, total recoverable
Arsenic, total recoverable
Barium, total recoverable

\footnotetext{
- = exceeded holding time.

$=$

Mixed Waste Management Facility
}

$D-268$

Time: $8: 48$

$\mathrm{pH}: 6.1$

Alkalinity: $19 \mathrm{mg} / \mathrm{L}$

Water temperature: $14.2{ }^{\circ} \mathrm{C}$

Volumes purged: 0.7 well volumes

$\begin{array}{llllll}\text { Result } & \text { DF } & \text { Mod } & \text { Unit } & \text { Flag } & \text { Lab } \\ 6.1 & 1.00 & \mathrm{~J} 1 & \mathrm{pH} & 0 & \mathrm{GE} \\ 84 & 1.00 & & \mu \mathrm{S} / \mathrm{cm} & 0 & \mathrm{GE} \\ 102 & 5.00 & & \mathrm{NTU} & 0 & \mathrm{GE} \\ <10 & 1.00 & & \mu \mathrm{g} / \mathrm{L} & 0 & \mathrm{GE} \\ <0.050 & 1.00 & & \mu \mathrm{g} / \mathrm{L} & 0 & \mathrm{GE} \\ 2.450 & 1.00 & & \mu \mathrm{g} / \mathrm{L} & 2 & \mathrm{GE} \\ <2.0 & 1.00 & & \mu \mathrm{g} / \mathrm{L} & 0 & \mathrm{GE} \\ <2.0 & 1.00 & & \mu \mathrm{g} / \mathrm{L} & 0 & \mathrm{GE} \\ 44 & 1.00 & & \mu \mathrm{g} / \mathrm{L} & 0 & \mathrm{GE}\end{array}$


WELL FSS 20 collected on $02 / 01 / 94$, laboratory analyses (cont.)

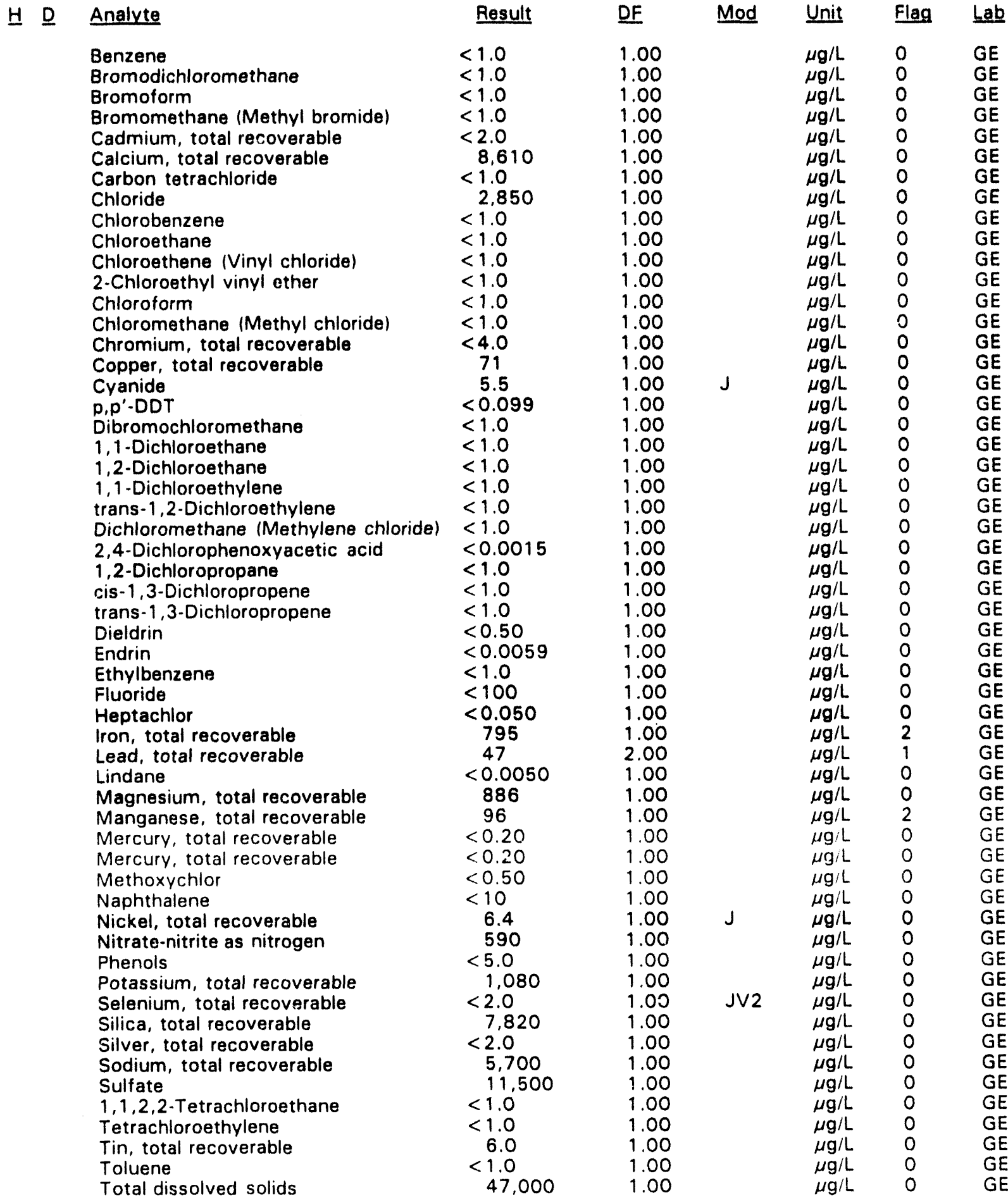

- = exceeded holding time. = exceeded screening level or final primary drinking water standard. 
WELL FSS 2D collected on 02/01/94, laboratory analyses (cont.)

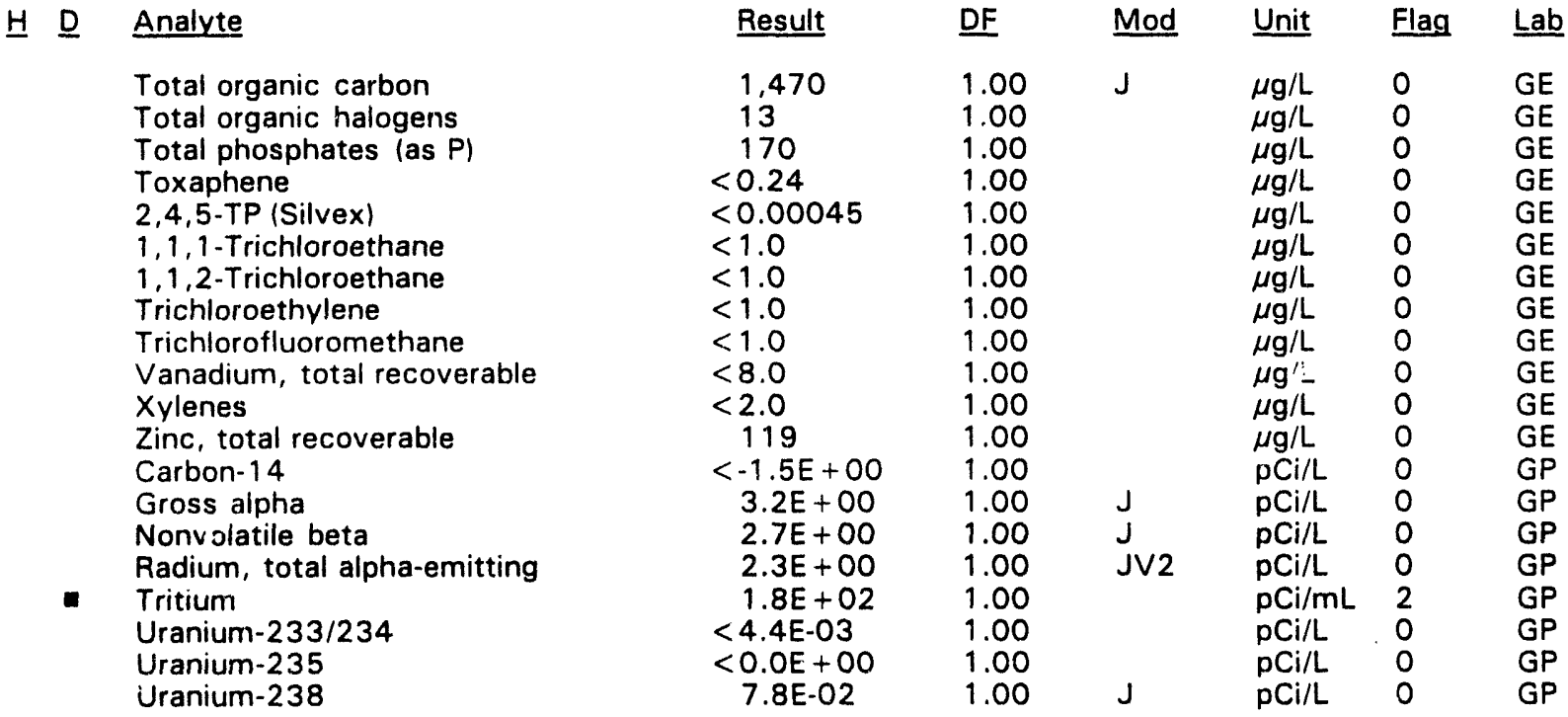

WELL FSS 3D

\begin{tabular}{|c|c|c|c|c|c|c|}
\hline SRS Coord. & Lat/Longitude & Screen Zone Elevation & Top of Casing & Casing & Pump & Formation \\
\hline $\begin{array}{l}N 74960.5 \\
\text { E53548.0 }\end{array}$ & $\begin{array}{l}33.278933^{\circ} \mathrm{N} \\
81.671406^{\circ} \mathrm{W}\end{array}$ & 22 & 2 & 4 & $S$ & \\
\hline
\end{tabular}

FIELD MEASUREMENTS

Sample date: $02 / 01 / 94$

Depth to water: $40.89 \mathrm{ft}(12.46 \mathrm{~m})$ below TOC

Water elevation: $217.31 \mathrm{ft}(66.24 \mathrm{~m}) \mathrm{msl}$

Sp. conductance: $38 \mu \mathrm{S} / \mathrm{cm}$

Turbidity: 13.9 NTU

Water evacuated before sampling: 8 gal

The well went dry during purging.

\section{LABORATORY ANALYSES}

H $\underline{\text { Analyte }}$

- $\mathrm{pH}$

Specific conductance

Specific conductance

Turbidity

Acetophenone

Aldrin

Aluminum, total recoverable

Antimony, total recoverable

Arsenic, total recoverable

Barium, total recoverable

Benzene

Bromodichloromethane

Bromoform

Bromomethane (Methyl bromide)
Time: 8: 21

$\mathrm{pH}: 5.2$

Alkalinity: $1 \mathrm{mg} / \mathrm{L}$

Water temperature: $9.8^{\circ} \mathrm{C}$

Volumes purged: 1.1 well volumes

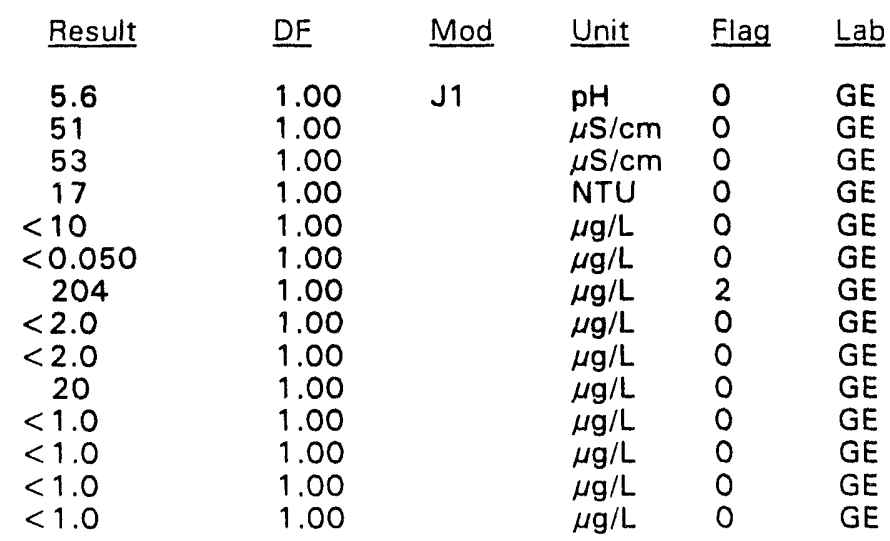

\footnotetext{
- = exceeded holding time. $\mathbf{m}=$ exceeded screening level or final primary drinking water standard.
} 
WELL FSS 3D collected on $02 / 01 / 94$, laboratory analyses (cont.)

\section{H $\underline{\text { Analyte }}$}

Cadmium, total recoverable

Calcium, total recoverable

Carbon tetrachloride

Chloride

Chlorobenzene

Chloroethane

Chloroethene (Vinyl chloride)

2-Chloroethyl vinyl ether

Chloroform

Chloromethane (Methyl chloride)

Chromium, total recoverable

Copper, total recoverable

Cyanide

$p, p^{\prime}$-DDT

Dibromochloromethane

1,1-Dichloroethane

1,2-Dichloroethane

1,1-Dichloroethylene

trans-1,2-Dichloroethylene

Dichloromethane (Methylene chloride)

2,4-Dichlorophenoxyacetic acid

1,2-Dichloropropane

cis-1,3-Dichloropropene

trans-1,3-Dichloropropene

Dieldrin

Endrin

Ethylbenzene

Fluoride

Heptachlor

Iron, total recoverable

Lead, total recoverable

Lindane

Magnesium, total recoverable

Manganese, total recoverable

Mercury, total recoverable

Methoxychlor

Naphthalene

Nickel, total recoverable

Nitrate-nitrite as nitrogen

Phenols

Potassium, total recoverable

Selenium, total recoverable

Silica, total recoverable

Silver, total recoverable

Sodium, total recoverable

Sulfate

1,1,2,2-Tetrachloroethane

Tetrachloroethylene

Tin, total recoverable

Toluene

Total dissolved solids

Total organic carbon

Total organic halogens

Total phosphates (as P)

Toxaphene

2,4,5-TP (Silvex)

\section{Result}

$<2.0$

767

$<1.0$

3,040

$<1.0$

$<1.0$

$<1.0$

$<1.0$

$<1.0$

$<1.0$

$<4.0$

14

$<5.0$

$<0.10$

$<1.0$

$<1.0$

$<1.0$

$<1.0$

$<1.0$

$<1.0$

$<0.0015$

$<1.0$

$<1.0$

$<1.0$

$<0.50$

$<0.0060$

$<1.0$

$<100$

$<0.050$

71

29

$<0.0050$

631

91

$<0.20$

$<0.50$

$<10$

6.2

640

$<5.0$

$<500$

$<2.0$

7,050

$<2.0$

5,340

8,570

$<1.0$

$<1.0$

3.5

$<1.0$

38,000

$<1,000$

$<5.0$

$<50$

$<0.24$

$<0.00045$

\section{DF}

1.00

1.00

1.00

1.00

1.00

1.00

1.00

1.00

1.00

1.00

1.00

1.00

1.00

1.00

1.00

1.00

1.00

1.00

1.00

1.00

1.00

1.00

1.00

1.00

1.00

1.00

1.00

1.00

1.00

1.00

1.00

1.00

1.00

1.00

1.00

1.00

1.00

1.00

1.00
1.00

1.00

1.00

1.00

1.00

1.00

1.00

1.00

1.00

1.00

1.00

1.00

1.00

1.00

1.00

1.00

1.00
Mod Unit Flag Lab

$\mu \mathrm{g} / \mathrm{L} \quad \mathrm{O} \quad \mathrm{GE}$

$\mu \mathrm{g} / \mathrm{L} \quad \mathrm{O} \quad \mathrm{GE}$

$\mu \mathrm{g} / \mathrm{L} \quad 0 \quad \mathrm{GE}$

$\mu \mathrm{g} / \mathrm{L} \quad \mathrm{O} \quad \mathrm{GE}$

$\mu \mathrm{g} / \mathrm{L} \quad \mathrm{O} \quad \mathrm{GE}$

$\mu \mathrm{g} / \mathrm{L} \quad \mathrm{O} \quad \mathrm{GE}$

$\mu \mathrm{g} / \mathrm{L} \quad \mathrm{O} \quad \mathrm{GE}$

$\mu g / L \quad O \quad G E$

$\mu \mathrm{g} / \mathrm{L} \quad \mathrm{O} \quad \mathrm{GE}$

$\mu \mathrm{g} / \mathrm{L} \quad 0 \quad \mathrm{GE}$

$\mu g / L \quad 0 \quad G E$

$\mu \mathrm{g} / \mathrm{L} \quad 0 \quad \mathrm{GE}$

$\mu g / L \quad O \quad G E$

$\mu \mathrm{g} / \mathrm{L} \quad \mathrm{O} \quad \mathrm{GE}$

$\mu \mathrm{g} / \mathrm{L} \quad \mathrm{O} \quad \mathrm{GE}$

$\mu g / L \quad 0 \quad G E$

$\mu \mathrm{g} / \mathrm{L} \quad \mathrm{O} \quad \mathrm{GE}$

$\mu \mathrm{g} / \mathrm{L} \quad 0 \quad \mathrm{GE}$

$\mu g / L \quad 0 \quad G E$

$\mu \mathrm{g} / \mathrm{L} \quad 0 \quad \mathrm{GE}$

$\mu \mathrm{g} / \mathrm{L} \quad 0 \quad \mathrm{GE}$

$\mu \mathrm{g} / \mathrm{L} \quad 0 \quad \mathrm{GE}$

$\mu \mathrm{g} / \mathrm{L} \quad \mathrm{O} \quad \mathrm{GE}$

$\mu g / L \quad 0 \quad G E$

$\mu \mathrm{g} / \mathrm{L} \quad 0 \quad \mathrm{GE}$

$\mu \mathrm{g} / \mathrm{L} \quad 0 \quad \mathrm{GE}$

$\mu \mathrm{g} / \mathrm{L} \quad 0 \quad \mathrm{GE}$

$\mu \mathrm{g} / \mathrm{L} \quad 0 \quad \mathrm{GE}$

$\mu \mathrm{g} / \mathrm{L} \quad 0 \quad \mathrm{GE}$

$\mu \mathrm{g} / \mathrm{L} \quad 0 \quad \mathrm{GE}$

$\mu \mathrm{g} / \mathrm{L} \quad 1 \quad \mathrm{GE}$

$\mu \mathrm{g} / \mathrm{L} \quad 0 \quad \mathrm{GE}$

$\mu g / L \quad 0 \quad G E$

$\mu \mathrm{g} / \mathrm{L} \quad 2 \quad \mathrm{GE}$

$\mu \mathrm{g} / \mathrm{L} \quad 0 \quad \mathrm{GE}$

$\mu \mathrm{g} / \mathrm{L} \quad 0 \quad \mathrm{GE}$

$\mu \mathrm{g} / \mathrm{L} \quad 0 \quad \mathrm{GE}$

J $\mu \mathrm{g} / \mathrm{L} \quad 0 \quad \mathrm{GE}$

$\mu g / L \quad O \quad G E$

$\mu \mathrm{g} / \mathrm{L} \quad \mathrm{O} \quad \mathrm{GE}$

$\mu \mathrm{g} / \mathrm{L} \quad \mathrm{O} \quad \mathrm{GE}$

$\mu \mathrm{g} / \mathrm{L} \quad \mathrm{O} \quad \mathrm{GE}$

$\mu \mathrm{g} / \mathrm{L} \quad 0 \quad \mathrm{GE}$

$\mu \mathrm{g} / \mathrm{L} \quad \mathrm{O} \quad \mathrm{GE}$

$\mu \mathrm{g} / \mathrm{L} \quad 0 \quad \mathrm{GE}$

$\mu \mathrm{g} / \mathrm{L} \quad \mathrm{O} \quad \mathrm{GE}$

$\mu g / L \quad 0 \quad G E$

$\mu g / L \quad O \quad G E$

$\mu \mathrm{g} / \mathrm{L} \quad 0 \quad \mathrm{GE}$

JV2

$\mu \mathrm{g} / \mathrm{L}$

$\mu \mathrm{g} / \mathrm{L}$

$\mu \mathrm{g} / \mathrm{L}$

$\mu \mathrm{g} / \mathrm{L}$

$\mu \mathrm{g} / \mathrm{L}$

$\mu \mathrm{g} / \mathrm{L}$

0
0
0
0
0
0

$G E$

$G E$

GE

$G E$ 
WELL FSS 3D collected on 02/01/94, laboratory analyses (cont.)

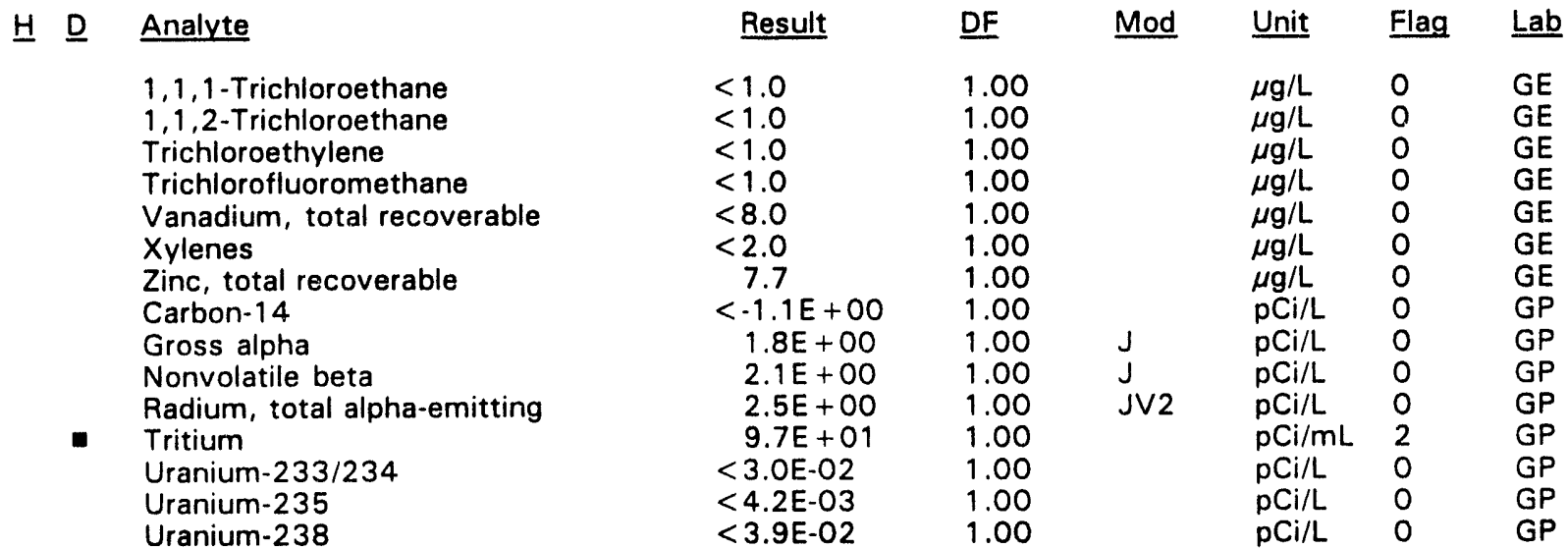

WELL FSS 4D

\begin{tabular}{|c|c|c|c|c|c|c|}
\hline SRS Coord. & Lat/Longitude & Screen Zone Elevation & Top of Casing & $\underline{\text { Casing }}$ & Pump & Formation \\
\hline $\begin{array}{l}N 75537.8 \\
\text { E52876.1 }\end{array}$ & $\begin{array}{l}33.279114^{\circ} \mathrm{N} \\
81.674297^{\circ} \mathrm{W}\end{array}$ & 222 & $n s 1$ & PVC & $S$ & le \\
\hline
\end{tabular}

\section{FIELD MEASUREMENTS}

Sample date: 02/01/94

Depth to water: $71.77 \mathrm{ft}(21.88 \mathrm{~m})$ below TOC

Water elevation: $220.03 \mathrm{ft}(67.07 \mathrm{~m}) \mathrm{msl}$

Sp. conductance: $46 \mu \mathrm{S} / \mathrm{cm}$

Turbidity: 30.6 NTU

Water evacuated before sampling: $12 \mathrm{gal}$

The well went dry during purging.

\section{LABORATORY ANALYSES}

$\underline{H} \quad \underline{\text { Analyte }}$

$\mathrm{pH}$

Specific conductance

Turbidity

Acetophenone

Aldrin

Aluminum, total recoverable

Aluminum, total recoverable

Antimony, total recoverable

Arsenic, total recoverable

Barium, total recoverable

Barium, total recoverable

Benzene

Bromodichloromethane

Bromoform

Bromomethane (Methyl bromide)

Cadmium, total recoverable

Cadmium, total recoverable

Calcium, total recoverable

Calcium, total recoverable
Time: 9: 13

pH: 5.1

Alkalinity: $1 \mathrm{mg} / \mathrm{L}$

Water temperature: $13.5^{\circ} \mathrm{C}$

Volumes purged: 1.0 well volumes

$\begin{array}{llllll}\text { Result } & \text { DF } & \text { Mod } & \text { Unit } & \text { Flag } & \text { Lab } \\ 5.6 & 1.00 & \mathrm{~J} 1 & \mathrm{pH} & 0 & \mathrm{GE} \\ 50 & 1.00 & & \mu \mathrm{S} / \mathrm{cm} & 0 & \mathrm{GE} \\ 237 & 10.00 & & \mathrm{NTU} & 0 & \mathrm{GE} \\ <10 & 1.00 & & \mu \mathrm{g} / \mathrm{L} & 0 & \mathrm{GE} \\ <0.049 & 1.00 & & \mu \mathrm{g} / \mathrm{L} & 0 & \mathrm{GE} \\ 1.010 & 1.00 & & \mu \mathrm{g} / \mathrm{L} & 2 & \mathrm{GE} \\ 973 & 1.00 & \mathrm{~J} 3 & \mu \mathrm{g} / \mathrm{L} & 2 & \mathrm{GE} \\ <2.0 & 1.00 & & \mu \mathrm{g} / \mathrm{L} & 0 & \mathrm{GE} \\ <2.0 & 1.00 & & \mu \mathrm{g} / \mathrm{L} & 0 & \mathrm{GE} \\ 14 & 1.00 & & \mu \mathrm{g} / \mathrm{L} & 0 & \mathrm{GE} \\ 14 & 1.00 & & \mu \mathrm{g} / \mathrm{L} & 0 & \mathrm{GE} \\ <1.0 & 1.00 & & \mu \mathrm{g} / \mathrm{L} & 0 & \mathrm{GE} \\ <1.0 & 1.00 & & \mu \mathrm{g} / \mathrm{L} & 0 & \mathrm{GE} \\ <1.0 & 1.00 & & \mu \mathrm{g} / \mathrm{L} & 0 & \mathrm{GE} \\ <1.0 & 1.00 & & \mu \mathrm{g} / \mathrm{L} & 0 & \mathrm{GE} \\ <2.0 & 1.00 & & \mu \mathrm{g} / \mathrm{L} & 0 & \mathrm{GE} \\ <2.0 & 1.00 & & \mu \mathrm{g} / \mathrm{L} & 0 & \mathrm{GE} \\ 1.570 & 1.00 & & \mu \mathrm{g} / \mathrm{L} & 0 & \mathrm{GE} \\ 1.580 & 1.00 & & \mu \mathrm{g} / \mathrm{L} & 0 & \mathrm{GE}\end{array}$

\footnotetext{
- = exceeded holding time. = exceeded screening level or final primary drinking water standard.
} 
WELL FSS 4D collected on $02 / 01 / 94$, laboratory analyses (cont.)

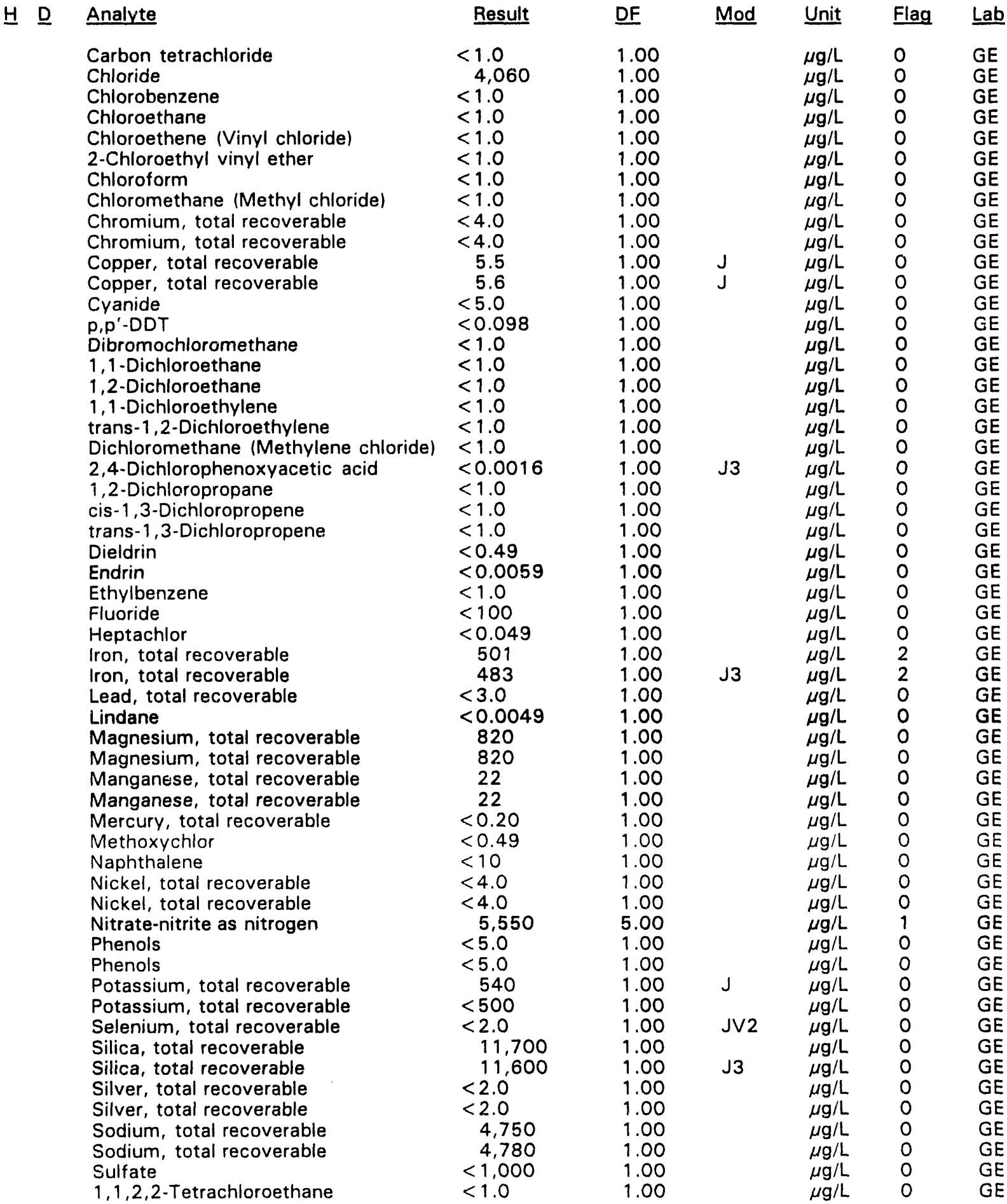

$\overline{0=\text { exceeded holding time. }} \mathbf{a}=$ exceeded screening level or final primary drinking water standard. 
WELL FSS 4D collected on $02 / 01 / 94$, laboratory analyses (çont.)

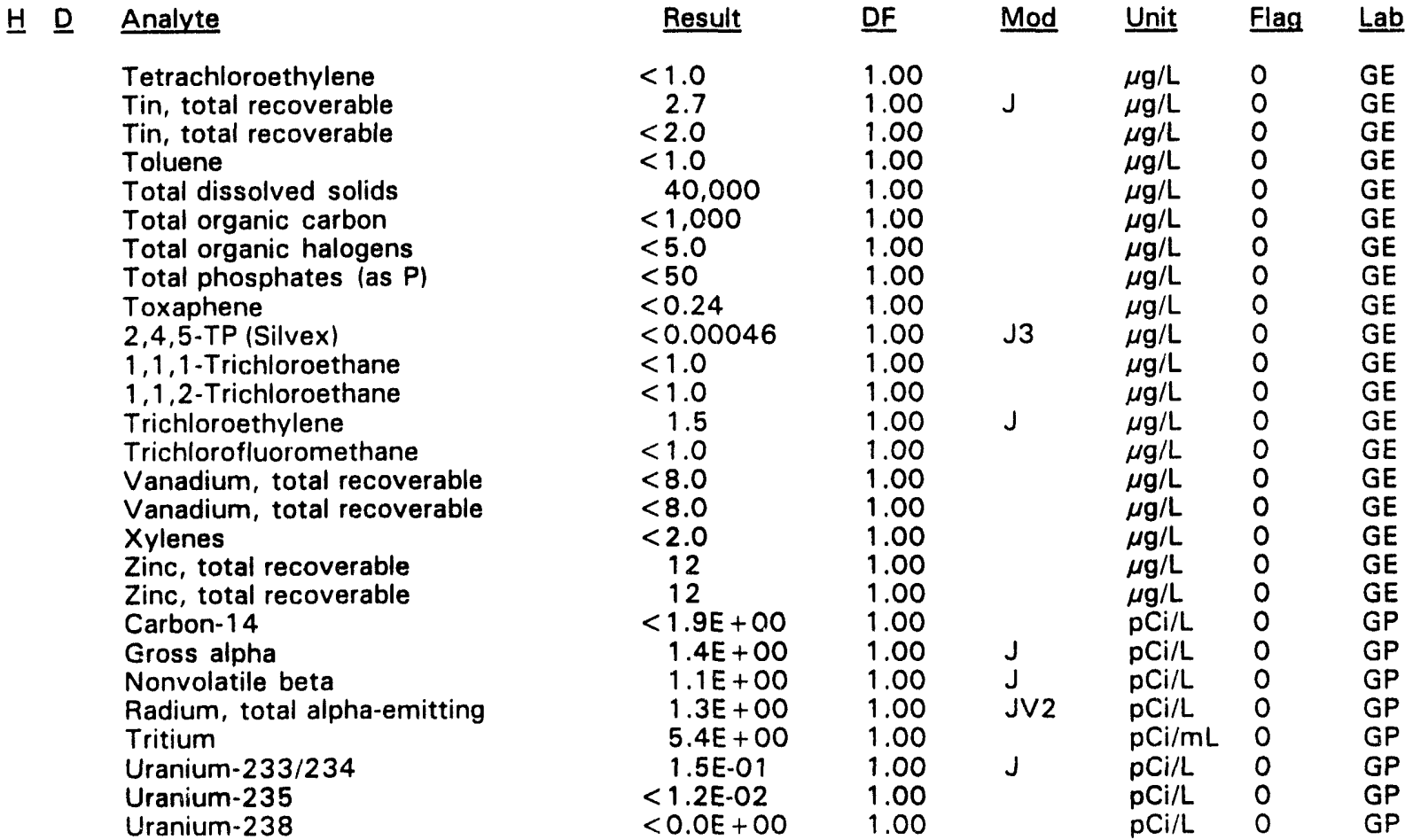

\section{WELL HMD 1D}

\begin{tabular}{|c|c|c|c|c|c|c|}
\hline SRS Coord. & Lat/Longitude & Screen Zone Elevation & Top of Casing & Casing & Pump & Formation \\
\hline $\begin{array}{l}\text { N78731.7 } \\
\text { E56973.3 }\end{array}$ & $\begin{array}{l}33.292863^{\circ} \mathrm{N} \\
81.669714^{\circ} \mathrm{W}\end{array}$ & $219.7-199.7 \mathrm{ft} \mathrm{msl}$ & $264.5 \mathrm{ft} \mathrm{msl}$ & 4" PVC & $\mathbf{S}$ & $\| l \mid\left(I \mid B_{1}\right)$ \\
\hline
\end{tabular}

\section{FIELD MEASUREMENTS}

Sample date: 02/04/94

Depth to water: $55.20 \mathrm{ft}(16.83 \mathrm{~m})$ below TOC

Water elevation: $209.30 \mathrm{ft}(63.80 \mathrm{~m}) \mathrm{msl}$

Sp. conductance: $91 \mu \mathrm{S} / \mathrm{cm}$

Turbidity: 20.2 NTU

Water evacuated before sampling: $4 \mathrm{gal}$

The well went dry during purging.

\section{LABORATORY ANALYSES}

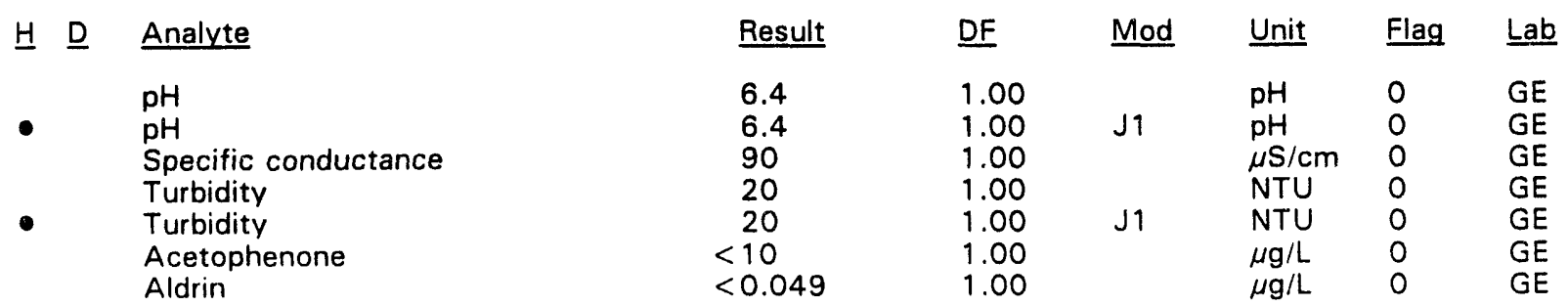

\footnotetext{
- = exceeded holding time. $\boldsymbol{\omega}=$ exceeded screening level or final primary drinking water standard.
}

AH: 5.7

Alkalinity: $22 \mathrm{mg} / \mathrm{L}$

Water temperature: $10.2^{\circ} \mathrm{C}$

Volumes purged: 0.6 well volumes 
WELL HMD 1D collected on 02/04/94, laboratory analyses (cont.)

\section{H D Analyte}

Aluminum, total recoverable

Antimony, total recoverable

Arsenic, total recoverable

Barium, total recoverable

Benzene

Benzene

Bromodichloromethane

Bromodichloromethane

Bromoform

Bromoform

Bromomethane (Methyl bromide)

Bromomethane (Methyl bromide)

Cadmium, total recoverable

Calcium, total recoverable

Carbon tetrachloride

Carbon tetrachloride

Chloride

Chloride

Chlorobenzene

Chlorobenzene

Chloroethane

Chloroethane

Chloroethene (Vinyl chloride)

Chloroethene (Vinyl chloride)

2. Chloroethyl vinyl ether

2-Chloroethyl vinyl ether

Chloroform

Chloroform

Chloromethane (Methyl chloride)

Chloromethane (Methyl chloride)

Chromium, total recoverable

Copper, total recoverable

Cyanide

Cyanide

p.p'-DDT

Dibromochloromethane

Dibromochloromethane

1.1-Dichloroethane

1,1-Dichloroethane

1,2-Dichloroethane

1.2-Dichloroethane

1,1-Dichloroethylene

1,1-Dichloroethylene

trans-1,2-Dichloroethylene

trans-1,2-Dichloroethylene

Dichloromethane (Methylene chloride

Dichloromethane (Methylene chloride)

2,4-Dichlorophenoxyacetic acid

1,2-Dichloropropane

1,2-Dichloropropane

cis-1,3-Dichloropropene

cis-1,3-Dichloropropene

trans-1,3-Dichloropropene

trans-1,3-Dichloropropene

Dieldrin

Endrin

\begin{tabular}{|c|c|}
\hline \multicolumn{2}{|l|}{ Result } \\
\hline 601 & 1.00 \\
\hline$<2.0$ & 1.00 \\
\hline$<2.0$ & 1.00 \\
\hline $\begin{array}{r}7.4 \\
<1.0\end{array}$ & 1.00 \\
\hline $\begin{array}{l}<1.0 \\
<1.0\end{array}$ & 1.00 \\
\hline$<1.0$ & 1.00 \\
\hline$<1.0$ & 1.00 \\
\hline$<1.0$ & 1.00 \\
\hline$<1.0$ & 1.00 \\
\hline$<1.0$ & 1.00 \\
\hline$<1.0$ & 1.00 \\
\hline$<2.0$ & 1.00 \\
\hline 985 & 1.00 \\
\hline$<1.0$ & 1.00 \\
\hline$<1.0$ & 1.00 \\
\hline $\begin{array}{l}2,140 \\
2,150\end{array}$ & $\begin{array}{l}1.00 \\
1.00\end{array}$ \\
\hline$<1.0$ & 1.00 \\
\hline$<1.0$ & 1.00 \\
\hline$<1.0$ & 1.00 \\
\hline$<1.0$ & 1.00 \\
\hline$<1.0$ & 1.00 \\
\hline$<1.0$ & 1.00 \\
\hline$<1.0$ & 1.00 \\
\hline$<1.0$ & 1.00 \\
\hline$<1.0$ & 1.00 \\
\hline$<1.0$ & 1.00 \\
\hline$<1.0$ & 1.00 \\
\hline$<1.0$ & 1.00 \\
\hline$<4.0$ & 1.00 \\
\hline$<4.0$ & 1.00 \\
\hline$<5.0$ & 1.00 \\
\hline$<5.0$ & 1.00 \\
\hline $\begin{array}{l}<0.097 \\
<1.0\end{array}$ & 1.00 \\
\hline$<1.0$ & 1.00 \\
\hline$<1.0$ & 1.00 \\
\hline$<1.0$ & 1.00 \\
\hline$<1.0$ & 1.00 \\
\hline$<1.0$ & 1.00 \\
\hline$<1.0$ & 1.00 \\
\hline$<1.0$ & 1.00 \\
\hline$<1.0$ & 1.00 \\
\hline$<1.0$ & 1.00 \\
\hline$<1.0$ & 1.00 \\
\hline$<1.0$ & 1.00 \\
\hline$<0.0015$ & 1.00 \\
\hline$<1.0$ & 1.00 \\
\hline$<1.0$ & 1.00 \\
\hline$<1.0$ & 1.00 \\
\hline$<1.0$ & 1.00 \\
\hline$<1.0$ & 1.00 \\
\hline$<0.49$ & 1.00 \\
\hline$<0.0058$ & \\
\hline
\end{tabular}

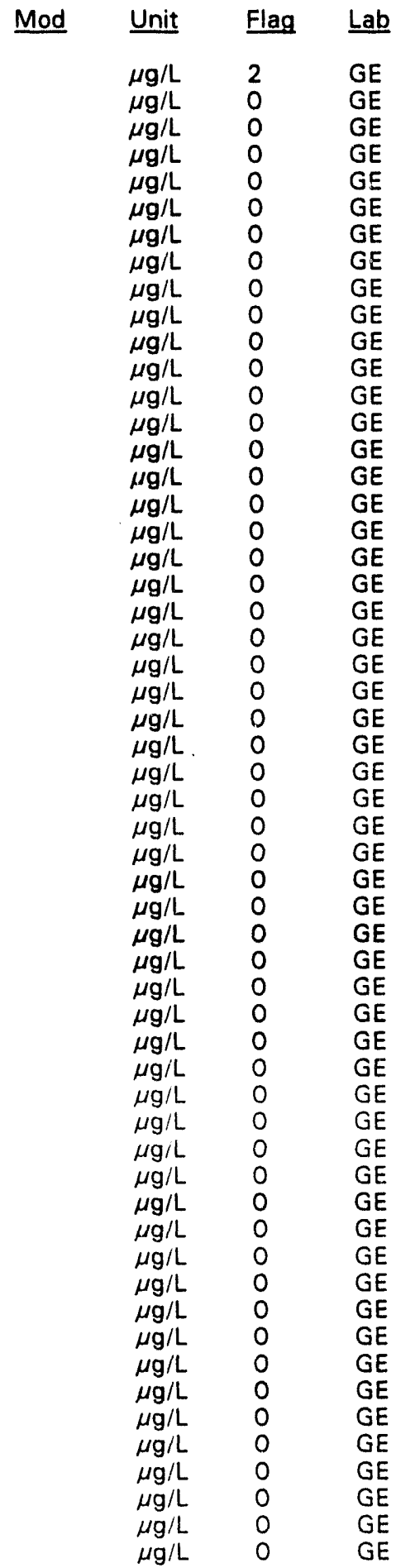

- = exceeded holding time. $=$ exceeded screening level or final primary drinking water standard. 
WELL HMD $1 D$ collected on 02/04/94, laboratory analyses (cont.)

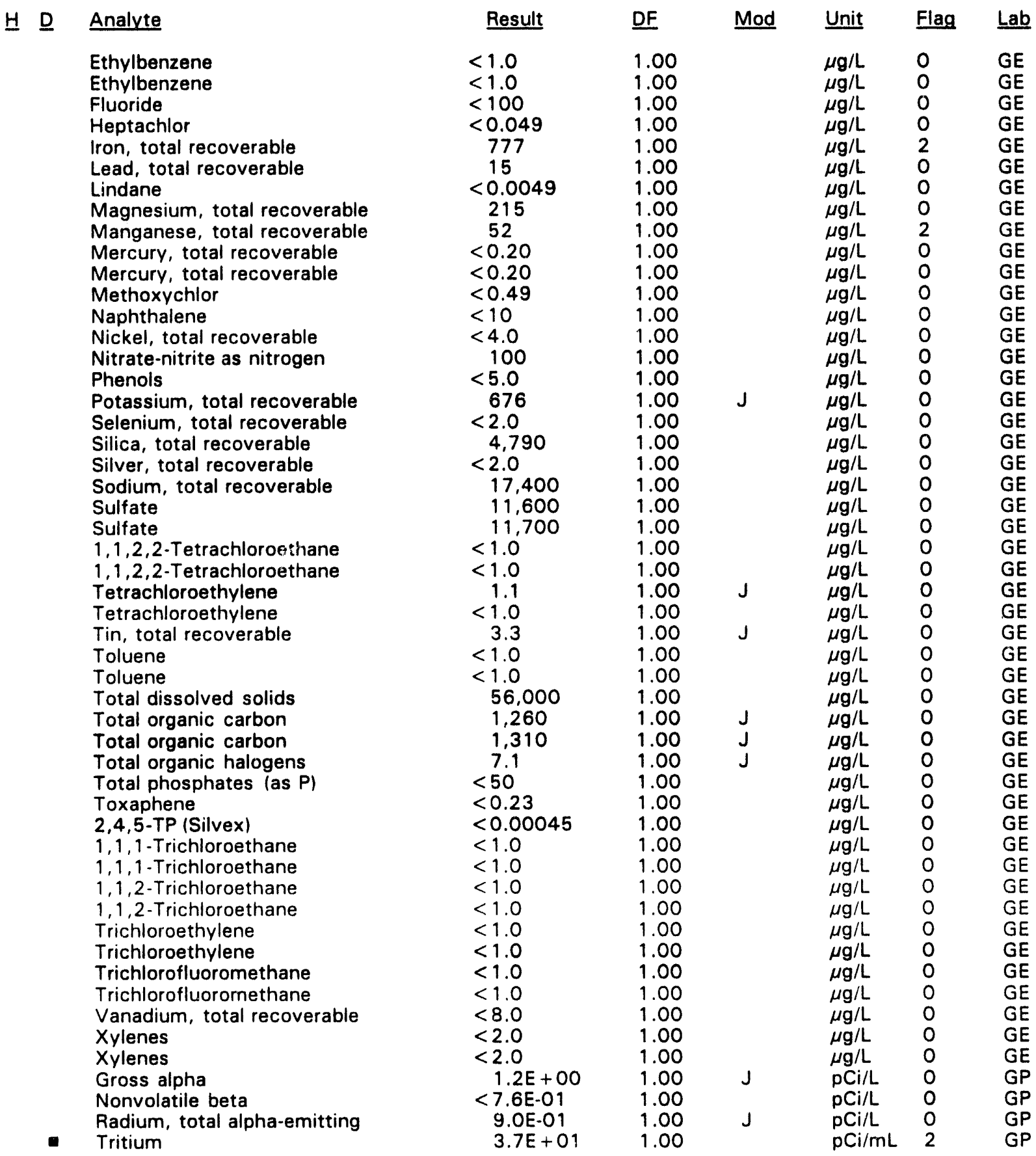

\footnotetext{
- = exceeded holding time. = exceeded screening level or final primary drinking water standard.
} 
WELL HMD 2D

\begin{tabular}{|c|c|c|c|c|c|c|}
\hline SRS Coord. & Lat/Longitude & Screen Zone Elevation & Top of Casing & Casing & Pump & Formation \\
\hline $\begin{array}{l}N 79665.8 \\
E 57269.7\end{array}$ & $\begin{array}{l}33.295413^{\circ} \mathrm{N} \\
81.670748^{\circ} \mathrm{W}\end{array}$ & $210.8-190.8 \mathrm{ft} \mathrm{msl}$ & $261.1 \mathrm{ft} \mathrm{msl}$ & 4" PVC & $\mathbf{s}$ & ell $\left(\| B_{1}\right)$ \\
\hline
\end{tabular}

\section{FIELD MEASUREMENTS}

Sample date: 02/04/94

Depth to water: $61.50 \mathrm{ft}(18.75 \mathrm{~m})$ below TOC

Water elevation: $199.60 \mathrm{ft}(60.84 \mathrm{~m}) \mathrm{ms}$

Sp. conductance: $71 \mu \mathrm{S} / \mathrm{cm}$

Turbidity: 0.6 NTU

Water evacuated before sampling: $121 \mathrm{gal}$

Time: 13: 18

pH: 5.5

Alkalinity: $10 \mathrm{mg} / \mathrm{L}$

Water temperature: $18.6^{\circ} \mathrm{C}$

Volumes purged: 21.0 well volumes

\section{LABORATORY ANALYSES}

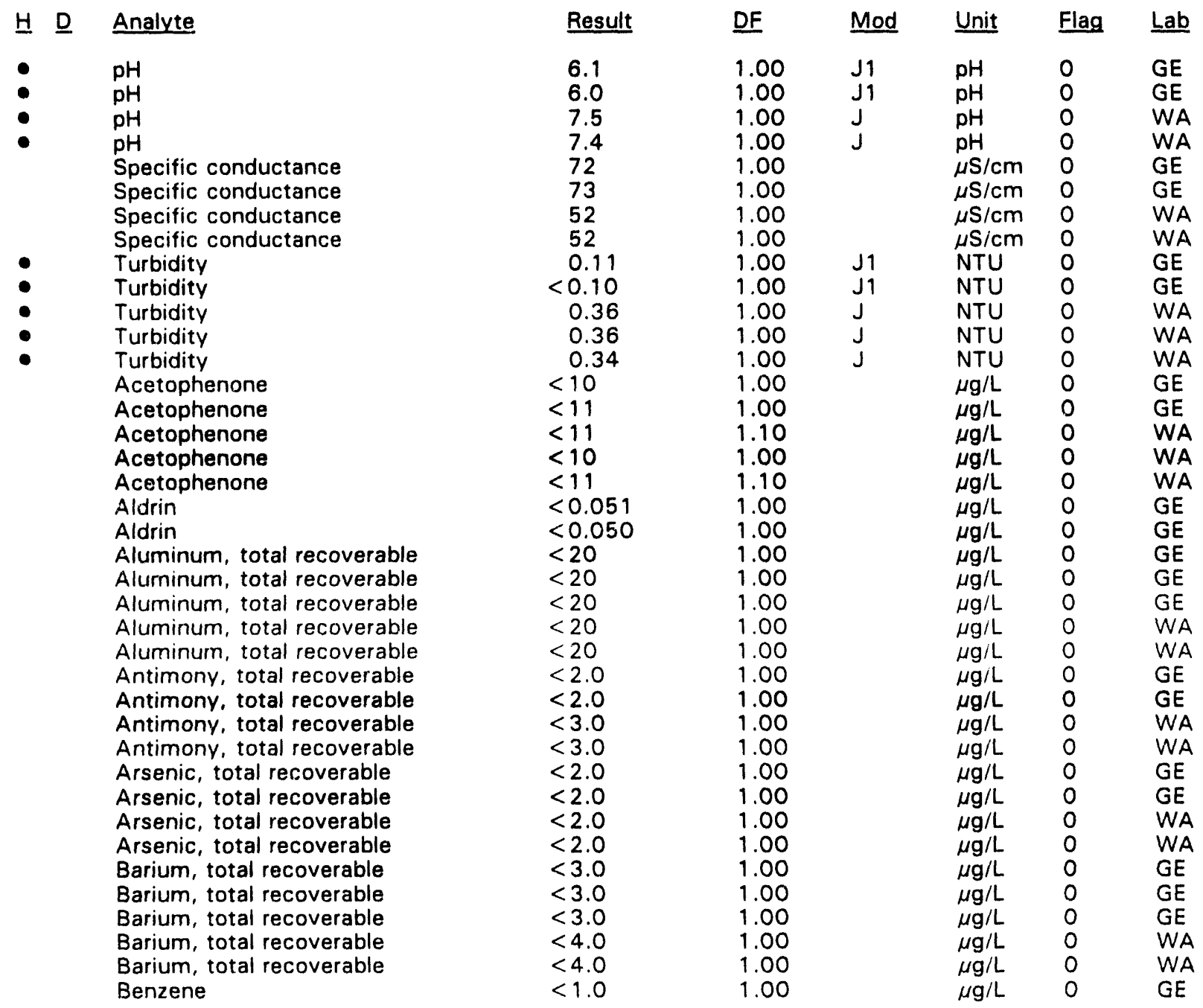

\footnotetext{
- = exceeded holding time. $\|$ =xceeded screening level or final primary drinking water standard.
} 
WELL HMD 2D collected on $02 / 04 / 94$, laboratory analyses (cont.)

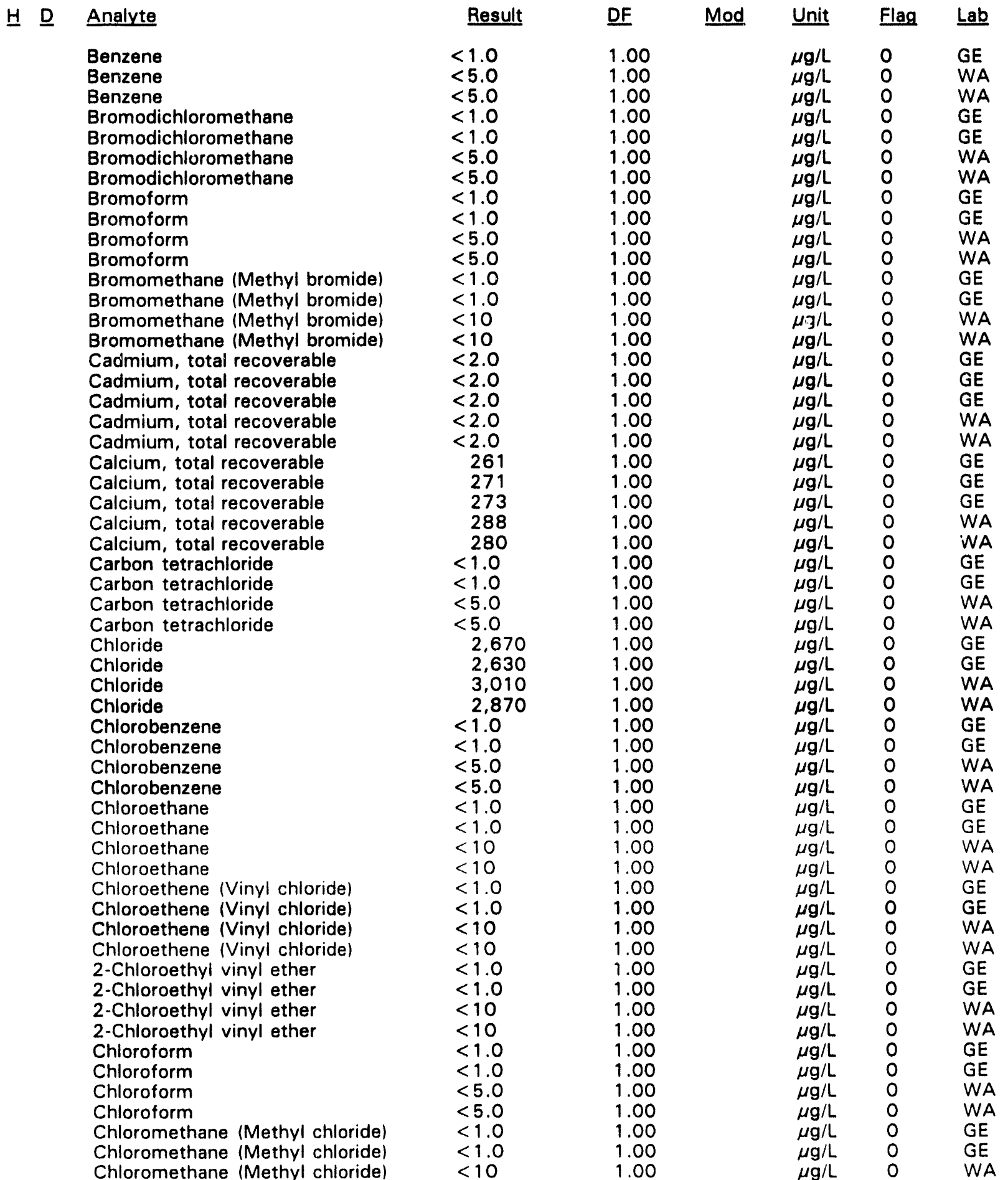

- = exceeded holding time. = exceeded screening level or final primary drinking water standard. 
WELL HMD 2D collected on 02/04/94, laboratory analyses (cont.)

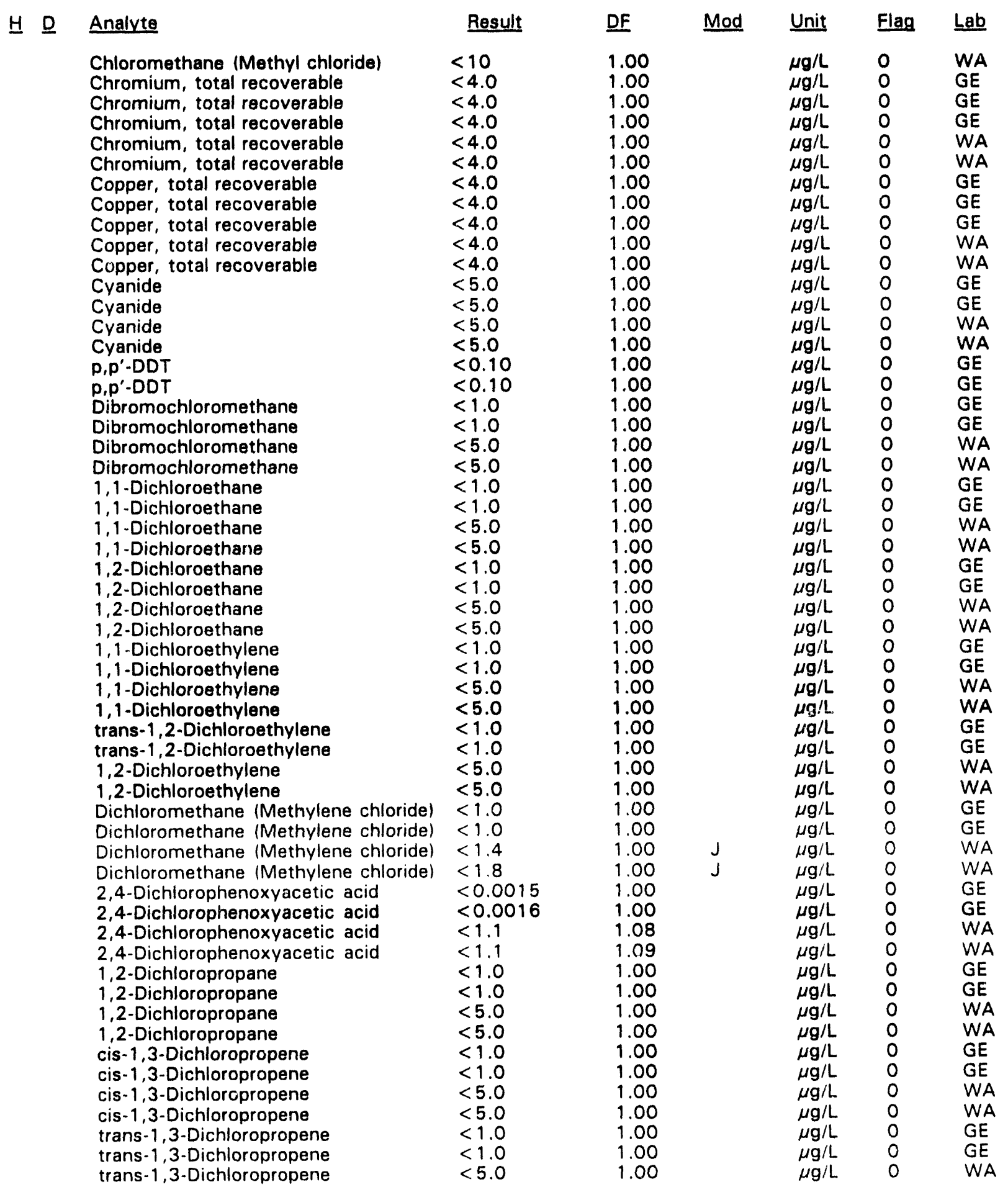

\footnotetext{
- exceeded holding time. $=$ exceeded screening level or final primary drinking water standard.
} 
WELL HMD 2D collected on 02/04/94, laboratory analyses (cont.)

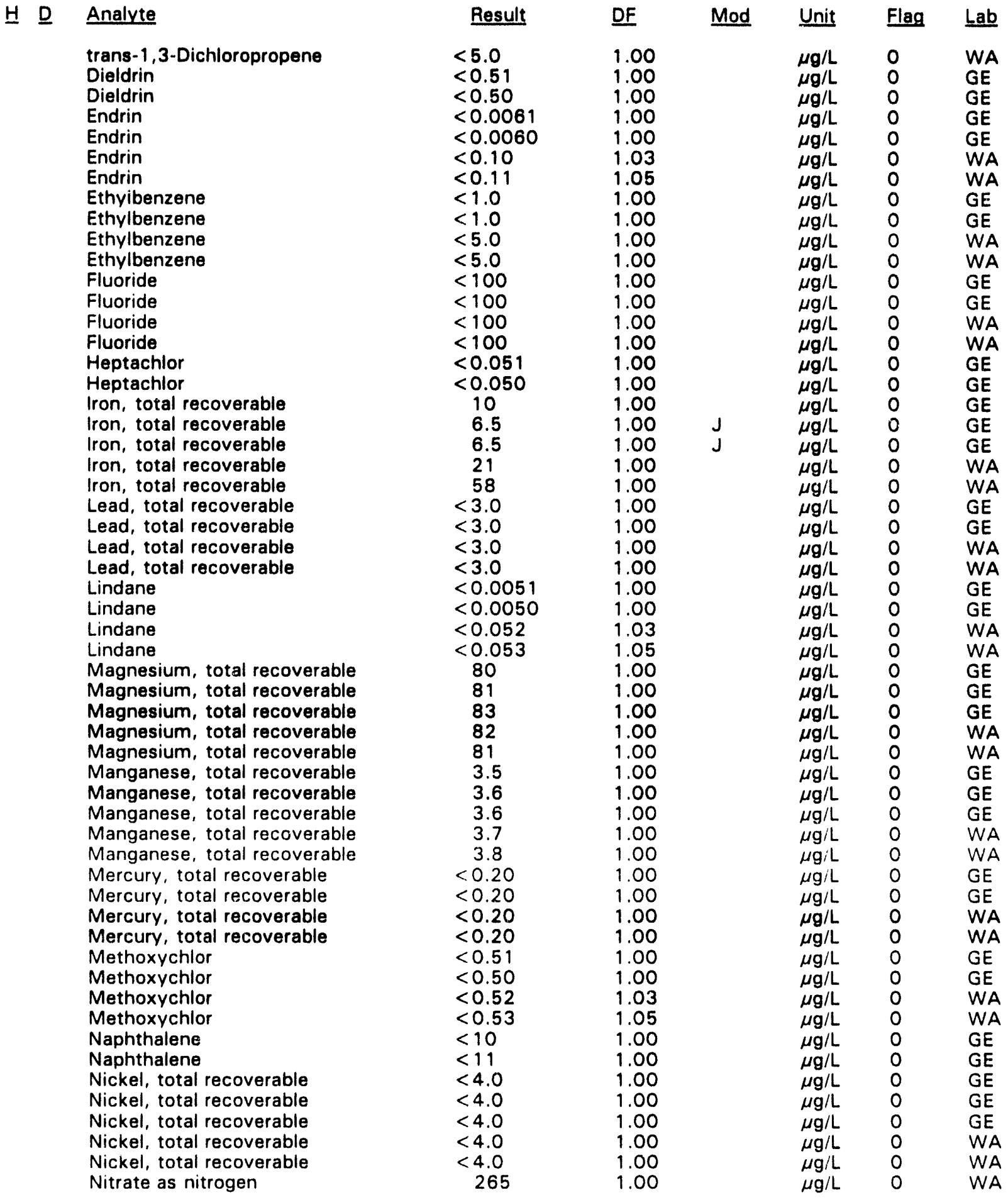

- = exceeded holding time. = exceeded screening level or final primary drinking water standard. 
WELL HMD 2D collected on 02/04/94, laboratory analyses (cont.)

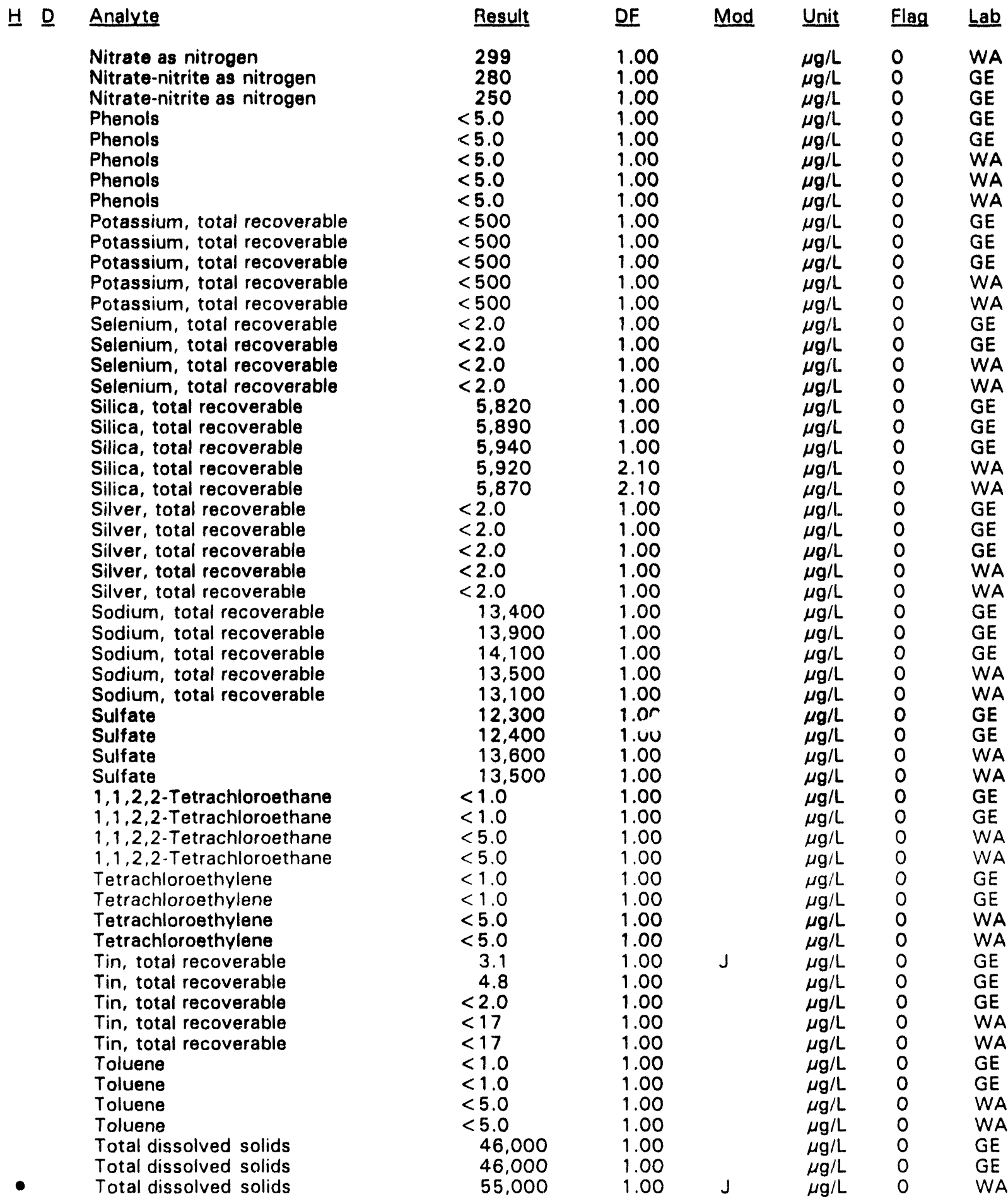

- = exceeded holding time. = = exceeded screening level or final primary drinking water standard. 
WELL HMD 2D collected on 02/04/94, laboratory analyses (cont.)

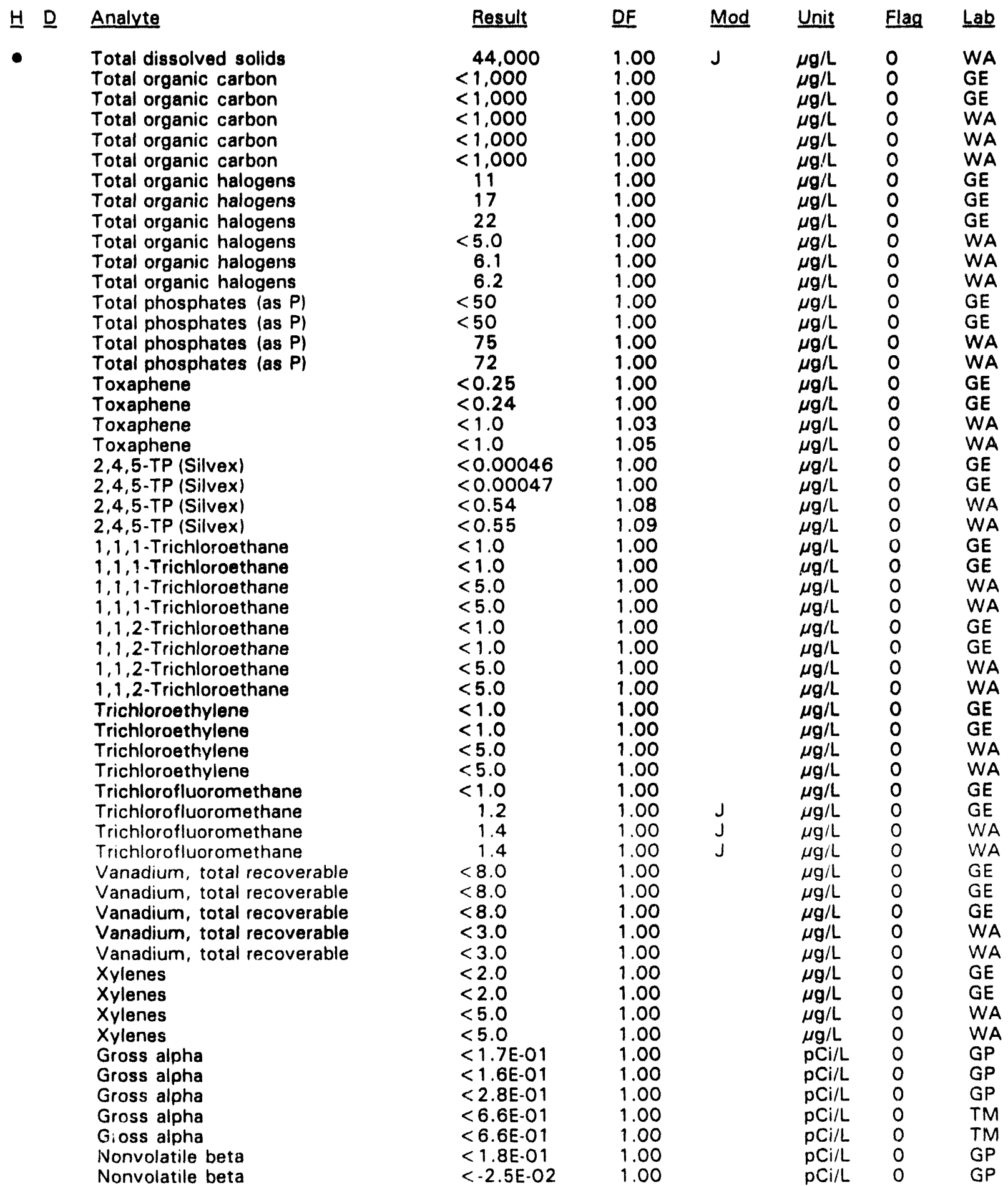

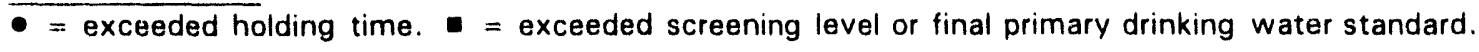


WELL HMD 20 collected on $02 / 04 / 94$, laboratory analyses (cont.)

\begin{tabular}{|c|c|c|c|c|c|c|}
\hline$\underline{H} \underline{D}$ & Analyte & Result & DF & Mod & Unit & Flag \\
\hline & $\begin{array}{l}\text { Nonvolatile beta } \\
\text { Nonvolatile beta } \\
\text { Nonvolatile beta } \\
\text { Radium-226 } \\
\text { Radium-226 } \\
\text { Radium-228 } \\
\text { Radium-228 } \\
\text { Radium, total alpha-emitting } \\
\text { Radium, total alpha-emitting } \\
\text { Tritium } \\
\text { Tritium } \\
\text { Tritium } \\
\text { Tritium }\end{array}$ & $\begin{array}{c}<2.4 \mathrm{E}-01 \\
1.2 \mathrm{E}+00 \\
1.2 \mathrm{E}+00 \\
3.5 \mathrm{E}-01 \\
8.4 \mathrm{E}-01 \\
5.0 \mathrm{E}-01 \\
7.0 \mathrm{E}-01 \\
<4.0 \mathrm{E}-01 \\
1.1 \mathrm{E}+00 \\
1.1 \mathrm{E}+01 \\
1.2 \mathrm{E}+01 \\
1.3 \mathrm{E}+01 \\
1.4 \mathrm{E}+01\end{array}$ & $\begin{array}{l}1.00 \\
1.00 \\
1.00 \\
1.00 \\
1.00 \\
1.00 \\
1.00 \\
1.00 \\
1.00 \\
1.00 \\
1.00 \\
1.00 \\
1.00\end{array}$ & $J$ & $\begin{array}{l}\mathrm{pCi} / \mathrm{L} \\
\mathrm{pCi} / \mathrm{L} \\
\mathrm{pCi} / \mathrm{L} \\
\mathrm{pCi} / \mathrm{L} \\
\mathrm{pCi} / \mathrm{L} \\
\mathrm{pCi} / \mathrm{L} \\
\mathrm{pCi} / \mathrm{L} \\
\mathrm{pCi} / \mathrm{L} \\
\mathrm{pCi} / \mathrm{L} \\
\mathrm{pCi} / \mathrm{mL} \\
\mathrm{pCi} / \mathrm{mL} \\
\mathrm{pCi} / \mathrm{mL} \\
\mathrm{pCi} / \mathrm{mL}\end{array}$ & $\begin{array}{l}0 \\
0 \\
0 \\
0 \\
0 \\
0 \\
0 \\
0 \\
0 \\
1 \\
1 \\
1 \\
1\end{array}$ \\
\hline
\end{tabular}

WELL HMD 3D

\begin{tabular}{|c|c|c|c|c|c|c|}
\hline SRS Coord. & Lat/Longitude & Screen Zone Elevation & Top of Casing & Casing & Pump & Formation \\
\hline $\begin{array}{l}N 79578.7 \\
E 57745.2\end{array}$ & $\begin{array}{l}33.295996^{\circ} \mathrm{N} \\
81.669327^{\circ} \mathrm{W}\end{array}$ & $207.7-187.7 \mathrm{ft} \mathrm{msl}$ & $259.5 \mathrm{ft} \mathrm{msl}$ & VC & $S$ & 1 \\
\hline
\end{tabular}

\section{FIELD MEASUREMENTS}

Sample date: $02 / 04 / 94$

Depth to water: $60.40 \mathrm{ft}(18.41 \mathrm{~m})$ below TOC

Water elevation: $199.10 \mathrm{ft}(60.69 \mathrm{~m}) \mathrm{ms}$

Sp. conductance: $61 \mu \mathrm{S} / \mathrm{cm}$

Turbidity: 2.5 NTU

Water evacuated before sampling: $95 \mathrm{gal}$

\section{LABORATORY ANALYSES}

\section{H D Analyte}

- $\quad \mathrm{pH}$

Specific conductance
- Turbidity

Acetophenone

Aldrin

Aluminum, total recoverable

Antimony, total recoverable

Arsenic, total recoverable

Barium, total recoverable

Benzene

Bromodichloromethane

Bromoform

Bromomethane (Methyl bromide)

Cadmium, total recoverable

Calcium, total recoverable

Carbon tetrachioride

Chloride

Chlorobenzene

Chloroethane

Chloroethene (Vinyl chloride)

2-Chloroethyl vinyl ether
Time: 12: 44

pH: 5.1

Alkalinity: $0 \mathrm{mg} / \mathrm{L}$

Water temperature: $18.8^{\circ} \mathrm{C}$

Volumes purged: 12.7 well volumes

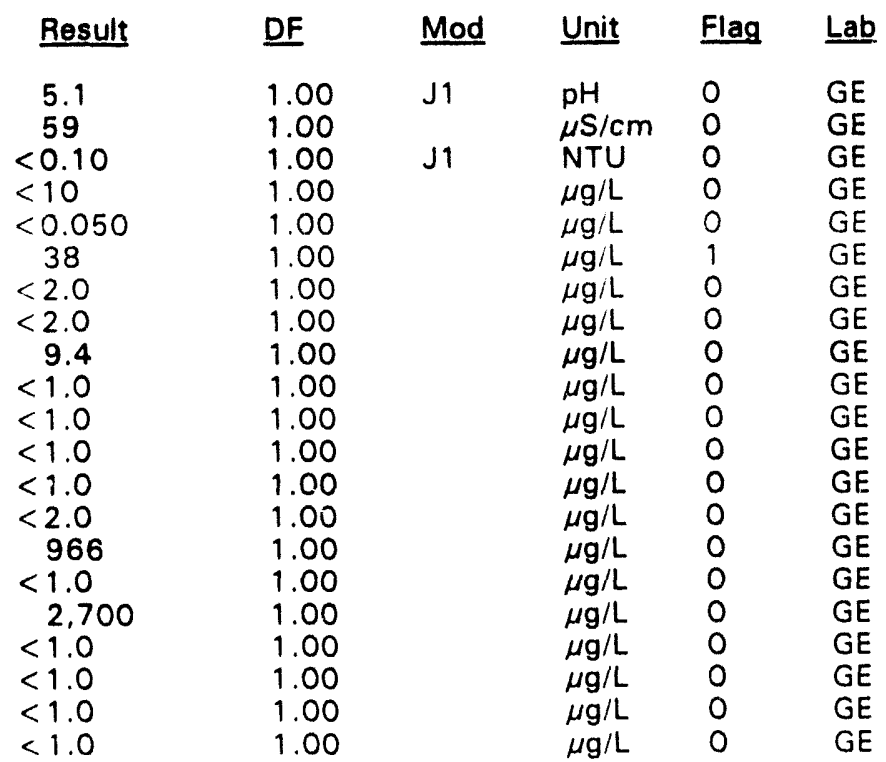

- = exceeded holding time. $\quad=$ exceeded screening level or final primary drinking water standard. 
WELL HMD 3D collected on 02/04/94, laboratory analyses (cont.)

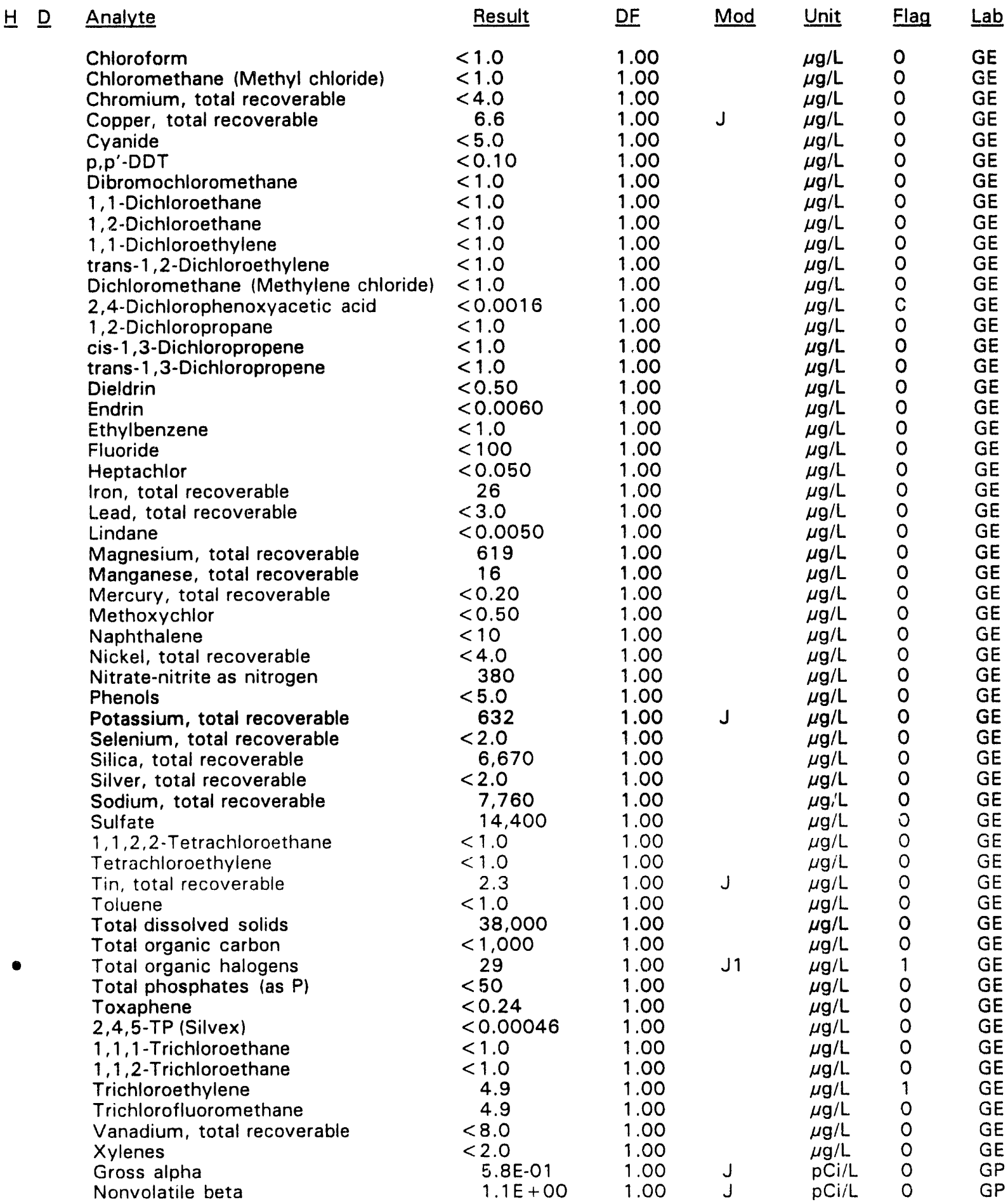

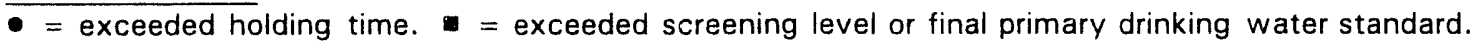


WELL HMD 3D collected on 02/04/94, laboratory analyses (cont.)

\begin{tabular}{|c|c|c|c|c|c|}
\hline Analyte & Result & DF & Mod & Unit & Flag \\
\hline $\begin{array}{l}\text { Radium, total alpha-emitting } \\
\text { Tritium } \\
\text { Tritium }\end{array}$ & $\begin{array}{l}1.5 E+00 \\
8.6 E+00 \\
8.3 E+00\end{array}$ & $\begin{array}{l}1.00 \\
1.00 \\
1.00\end{array}$ & $J$ & $\begin{array}{l}\mathrm{pCi} / \mathrm{L} \\
\mathrm{pCi} / \mathrm{mL} \\
\mathrm{pCi} / \mathrm{mL}\end{array}$ & $\begin{array}{l}0 \\
0 \\
0\end{array}$ \\
\hline
\end{tabular}

WELL HMD 4D

\begin{tabular}{|c|c|c|c|c|c|c|}
\hline SRS Coord. & Lat/Longitude & Screen Zone Elevation & Top of Casing & Casing & Pump & Formation \\
\hline $\begin{array}{l}N 79160.4 \\
E 58188.5\end{array}$ & $\begin{array}{l}33.295794^{\circ} \mathrm{N} \\
81.667346^{\circ} \mathrm{W}\end{array}$ & $208.9-188.9 \mathrm{ft} \mathrm{msl}$ & $250.9 \mathrm{ft} \mathrm{msl}$ & 4" PVC & S & ell $\left(\| B_{1}\right)$ \\
\hline
\end{tabular}

\section{FIELD MEASUREMENTS}

Sample date: 02/04/94

Depth to water: $58.38 \mathrm{ft}(17.79 \mathrm{~m})$ below TOC

Water elevation: $192.52 \mathrm{ft}(58.68 \mathrm{~m}) \mathrm{msl}$

Sp. conductance: $22 \mu \mathrm{S} / \mathrm{cm}$

Turbidity: 24.5 NTU

Water evacuated before sampling: $6 \mathrm{gal}$

The well went dry during purging.

\section{LABORATORY ANALYSES}

H $\underline{\text { Analyte }}$

- $\quad \mathrm{pH}$

Specific conductance

-

Acetophenone

Aldrin

Aluminum, total recoverable

Antimony, total recoverable

Arsenic, total recoverable

Barium, total recoverable

Benzene

Bromodichloromethane

Bromoform

Bromomethane (Methyl bromide)

Cadmium, total recoverable

Calcium, total recoverable

Carbon tetrachloride

Chloride

Chlorobenzene

Chloroethane

Chloroethene (Vinyl chloride)

2-Chloroethyl vinyl ether

Chloroform

Chloromethane (Methyl chloride)

Chromium, total recoverable

Copper, total recoverable

Cyanide

$p, p^{\prime}-D D T$

Dibromochloromethane

1,1-Dichloroethane

1,2-Dichloroethane

1,1-Dichloroethylene

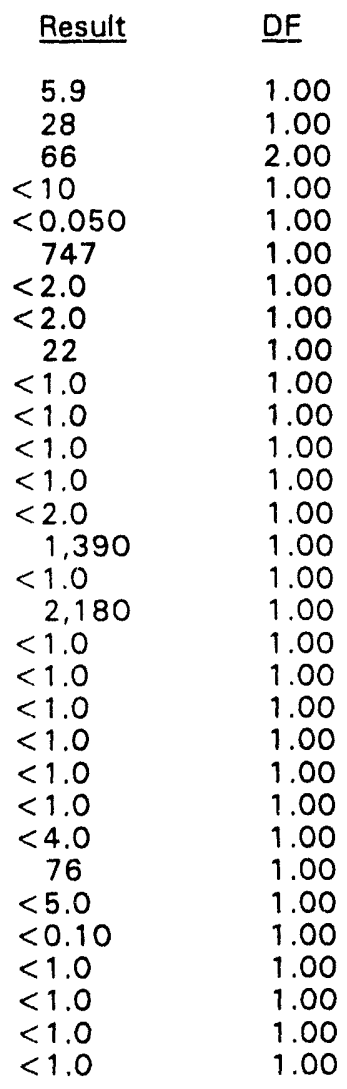

Time: $11: 15$

pH: 5.4

Alkalinity: $3 \mathrm{mg} / \mathrm{L}$

Water temperature: $17.6^{\circ} \mathrm{C}$

Volumes purged: 2.5 well volumes 
WELL HMD 4D collected on 02/04/94, laboratory analyses (cont.)

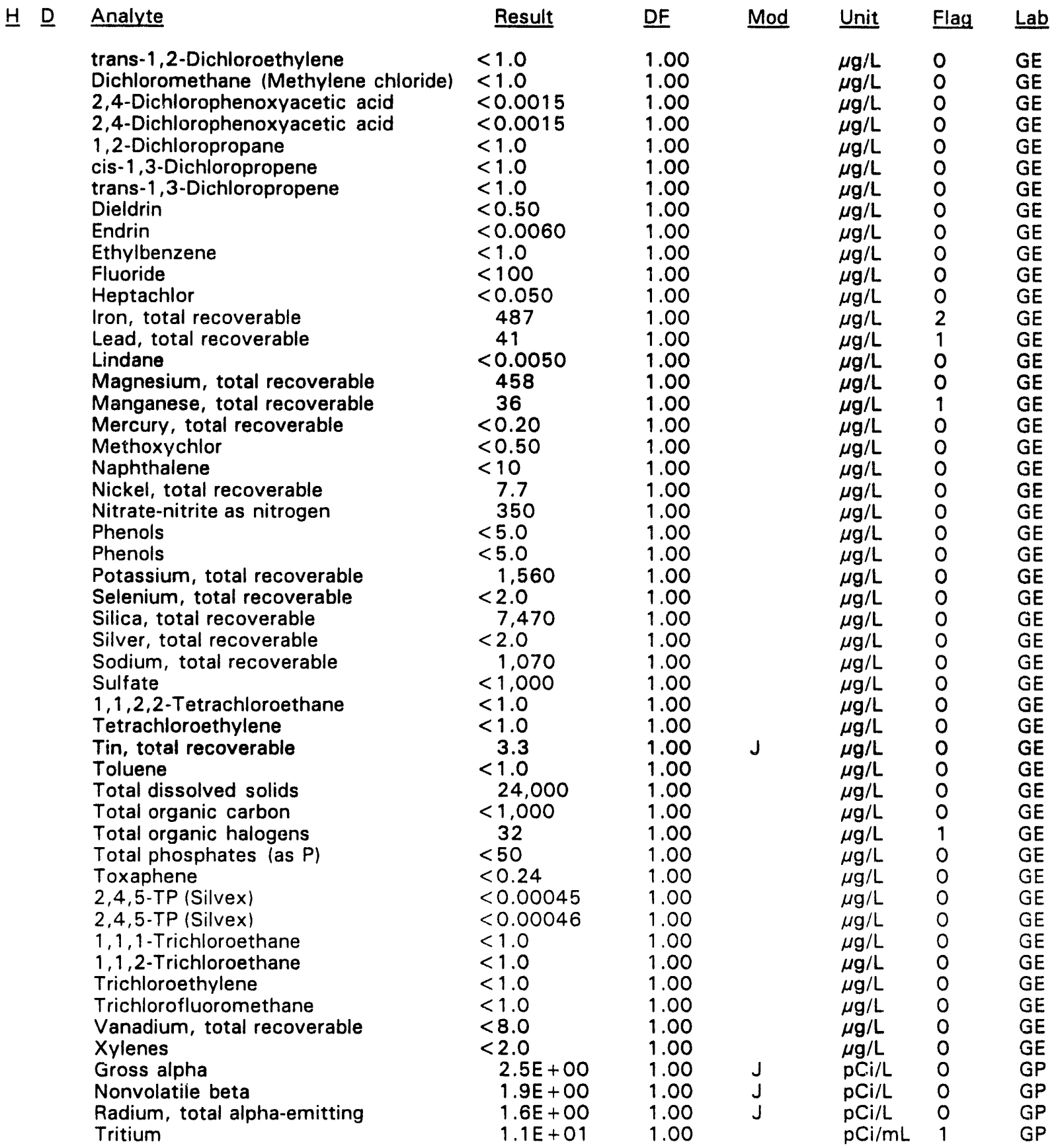

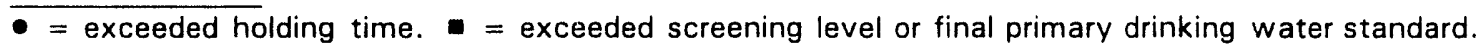


WELL HSB 85A

\begin{tabular}{|c|c|c|c|c|c|c|}
\hline SRS Coord. & Lat/Longitude & Screen Zone Elevation & Top of Casing & Casing & Pump & Formation \\
\hline $\begin{array}{l}\text { N73791.9 } \\
\text { E58943.4 }\end{array}$ & $\begin{array}{l}33.285152^{\circ} \mathrm{N} \\
81.654930^{\circ} \mathrm{W}\end{array}$ & $71.1-61.1 \mathrm{ft} \mathrm{msl}$ & $294.4 \mathrm{ft} \mathrm{msl}$ & 4" PVC & S & $U$. Congaree (IIA) \\
\hline
\end{tabular}

FIELD MEASUREMENTS

Sample date: $01 / 14 / 94$

Depth to water: $125.84 \mathrm{ft}(38.36 \mathrm{~m})$ below TOC

Water elevation: $168.56 \mathrm{ft}(51.38 \mathrm{~m}) \mathrm{msl}$

Sp. conductance: $181 \mu \mathrm{S} / \mathrm{cm}$

Turbidity: 0.1 NTU

Water evacuated before sampling: $233 \mathrm{gal}$

\section{LABORATORY ANALYSES}

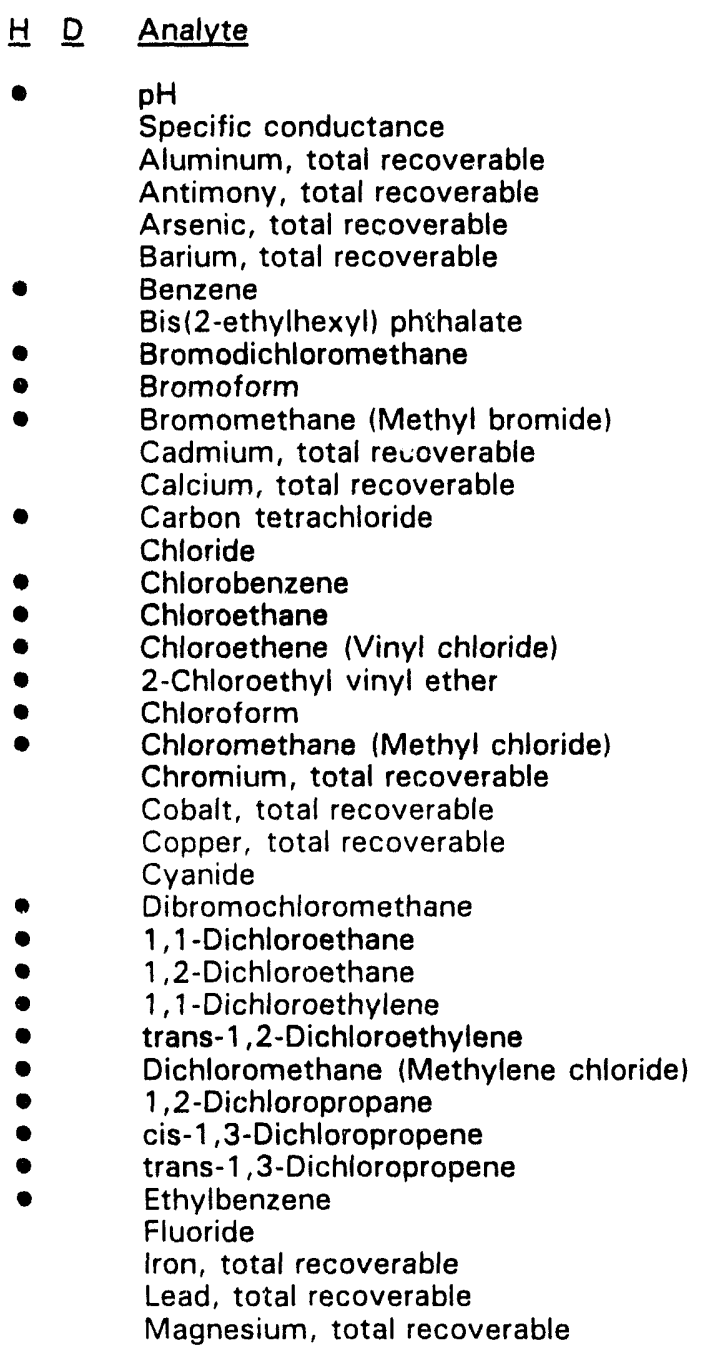

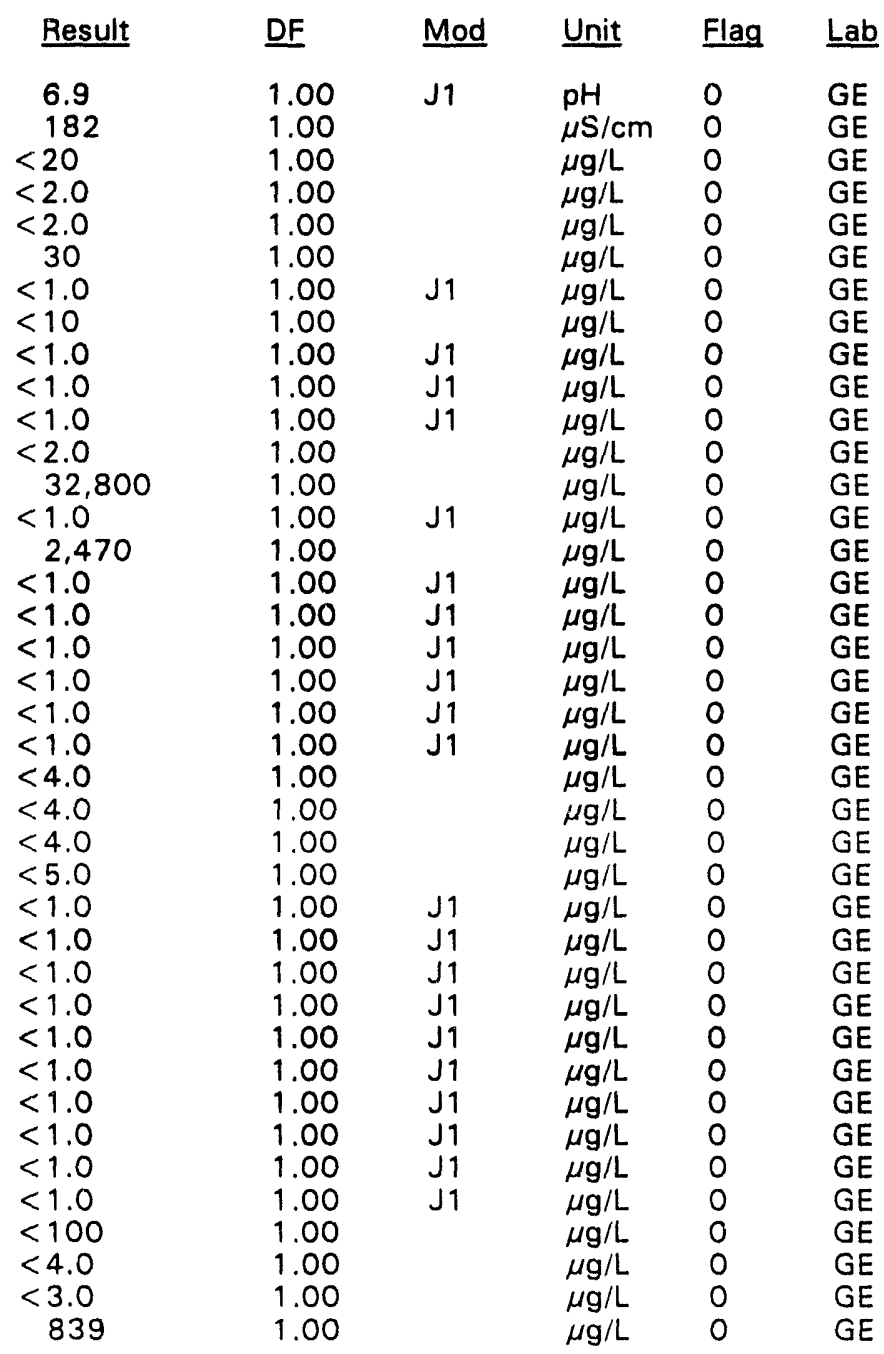

Time: 10: 02

$\mathrm{pH}: 7.0$

Alkalinity: $74 \mathrm{mg} / \mathrm{L}$

Water temperature: $19.1^{\circ} \mathrm{C}$

Volumes purged: 3.3 well volumes

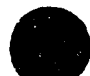

Bromomethane (Methyl bromide)

Dibromochloromethane

1,1-Dichloroethane

-

Dichloromethane (Methylene chloride)

1,2-Dichloropropane

trans-1,3-Dichloropropene

enzen

Magnesium, total recoverable

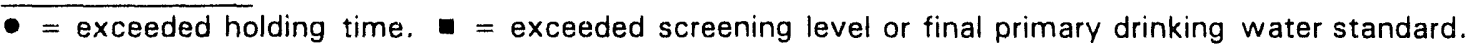


WELL HSB 85A collected on 01/14/94, laboratory analyses (cont.)

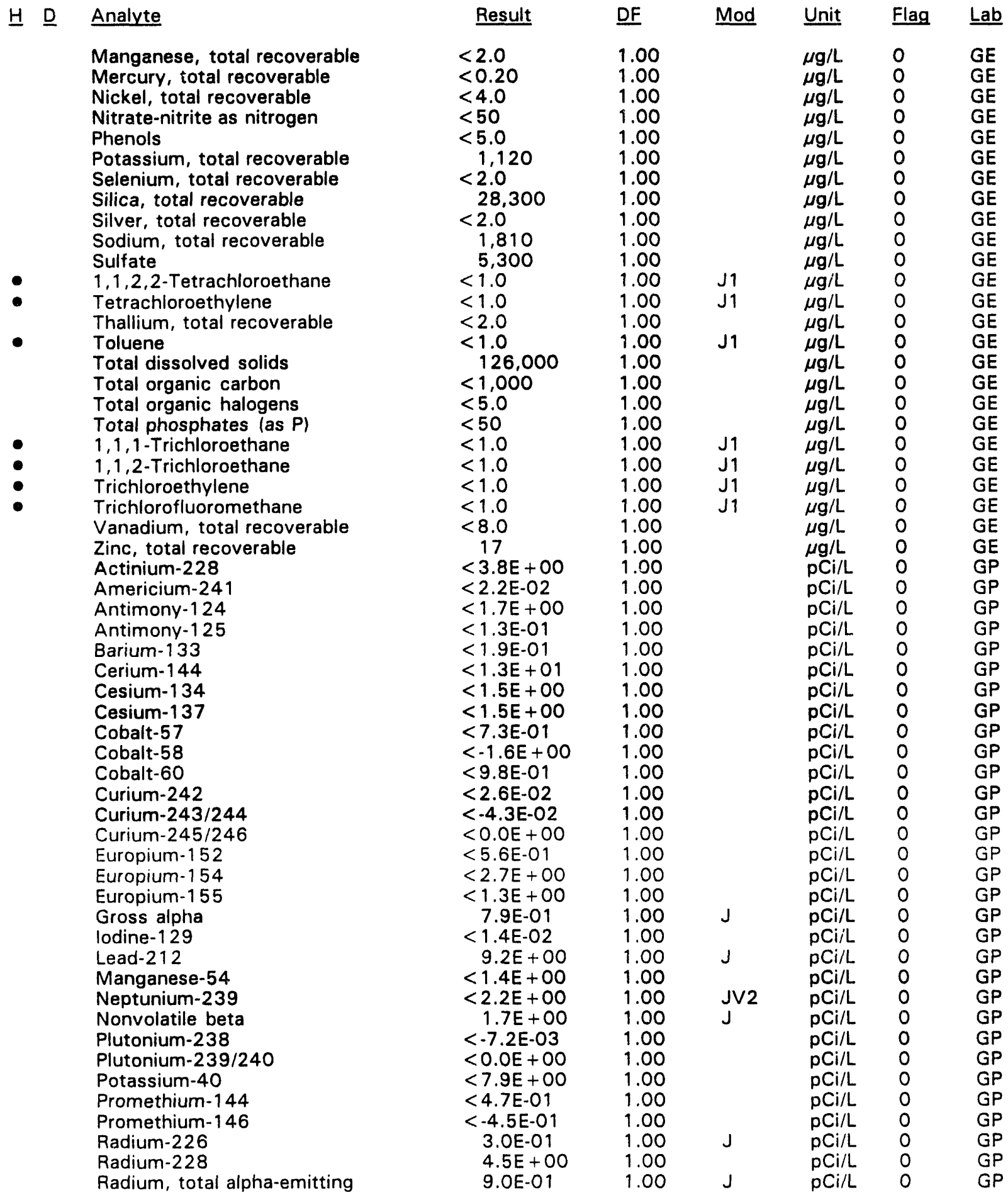

$\overline{-}=$ exceeded holding time. $=$ exceeded screening level or final primary drinking water standard. 
WELL HSB 85A collected on 01/14/94, laboratory analyses (cont.)

\begin{tabular}{|c|c|c|c|c|c|}
\hline Analyte & Result & DF & Mod & Unit & Flag \\
\hline $\begin{array}{l}\text { Ruthenium-106 } \\
\text { Sodium-22 } \\
\text { Strontium-89 } \\
\text { Strontium-90 } \\
\text { Technetium-99 } \\
\text { Thorium-228 } \\
\text { Thorium-230 } \\
\text { Thorium-232 } \\
\text { Thorium-234 } \\
\text { Tin-113 } \\
\text { Tritium } \\
\text { Uranium-233/234 } \\
\text { Uranium-235 } \\
\text { Uranium-238 } \\
\text { Yttrium-88 } \\
\text { Zinc-65 } \\
\text { Zirconium-95 }\end{array}$ & $\begin{aligned} &<-4.4 E+00 \\
& 3.1 E+00 \\
&<-1.1 E+00<-5.5 E-01 \\
&<-2.6 E+00 \\
&<-2.6 E-02 \\
&<8.4 E-02 \\
& 3.4 E-01 \\
&<7.9 E-03 \\
&<3.9 E+01 \\
&<3.9 E+00 \\
&<4.5 E-02 \\
&<-1.6 E-02 \\
&<-7.9 E-03 \\
&<-1.6 E-02 \\
&<-1.4 E+00 \\
&<1.4 E+00 \\
&<2.4 E+00\end{aligned}$ & $\begin{array}{l}1.00 \\
1.00 \\
1.00 \\
1.00 \\
1.00 \\
1.00 \\
1.00 \\
1.00 \\
1.00 \\
1.00 \\
1.00 \\
1.00 \\
1.00 \\
1.00 \\
1.00 \\
1.00 \\
1.00\end{array}$ & J & $\begin{array}{l}\mathrm{pCi} / \mathrm{L} \\
\mathrm{pCi} / \mathrm{L} \\
\mathrm{pCi} / \mathrm{L} \\
\mathrm{pCi} / \mathrm{L} \\
\mathrm{pCi} / \mathrm{L} \\
\mathrm{pCi} / \mathrm{L} \\
\mathrm{pCi} / \mathrm{L} \\
\mathrm{pCi} / \mathrm{L} \\
\mathrm{pCi} / \mathrm{L} \\
\mathrm{pCi} / \mathrm{L} \\
\mathrm{pCi} / \mathrm{mL} \\
\mathrm{pCi} / \mathrm{L} \\
\mathrm{pCi} / \mathrm{L} \\
\mathrm{pCi} / \mathrm{L} \\
\mathrm{pCi} / \mathrm{L} \\
\mathrm{pCi} / \mathrm{L} \\
\mathrm{pCi} / \mathrm{L}\end{array}$ & $\begin{array}{l}0 \\
0 \\
0 \\
0 \\
0 \\
0 \\
0 \\
0 \\
0 \\
0 \\
0 \\
0 \\
0 \\
0 \\
0 \\
0 \\
0\end{array}$ \\
\hline
\end{tabular}

\section{WELL HSB 85A}

\begin{tabular}{|c|c|c|c|c|c|c|}
\hline SRS Coord. & Lat/Longitude & Screen Zone Elevation & Top of Casing & Casing & Pump & Formation \\
\hline $\begin{array}{l}N 73791.9 \\
E 58943.4\end{array}$ & $\begin{array}{l}33.285152{ }^{\circ} \mathrm{N} \\
81.654930^{\circ} \mathrm{W}\end{array}$ & $71.1-61.1 \mathrm{ft} \mathrm{msl}$ & $294.4 \mathrm{ft} \mathrm{mst}$ & 4" PVC & $s$ & aree (IIA) \\
\hline
\end{tabular}

\section{FIELD MEASUREMENTS}

Sample date: $02 / 08 / 94$

Depth to water: $125.77 \mathrm{ft}(38.34 \mathrm{~m})$ below TOC

Water elevation: $168.63 \mathrm{ft}(51.40 \mathrm{~m}) \mathrm{msl}$

Sp. conductance: $187 \mu \mathrm{S} / \mathrm{cm}$

Turbidity: 0.1 NTU

Water evacuated before sampling: $207 \mathrm{gal}$

\section{LABORATORY ANALYSES}

\section{H $\underline{\text { Analyte }}$}

$\mathrm{pH}$

Specific conductance

Aluminum, total recoverable

Antimony, total recoverable

Arsenic, total recoverable

Barium, total recoverable

Benzene

Bis (2-ethylhexyl) phthalate

Bromodichloromethane

Bromoform

Bromomethane (Methyl bromide)

Cadmium, total recoverable

Calcium, total recoverable

Carbon tetrachloride

Chloride

Chlorobenzene
Time: 15:06

$\mathrm{pH}: 6.8$

Alkalinity: $72 \mathrm{mg} / \mathrm{L}$

Water temperature: $19.8^{\circ} \mathrm{C}$

Volumes purged: 2.9 well volumes 
WELL HSB 85A collected on $02 / 08 / 94$, laboratory analyses (cont.)

H D Analyte

Chloroethane

Chloroethene (Vinyl chloride)

2-Chloroethyl vinyl ether

Chloroform

Chloromethane (Methyl chloride)

Chromium, total recoverable

Cobalt, total recoverable

Copper, total recoverable

Cyanide

Dibromochloromethane

1,1-Dichloroethane

1,2-Dichloroethane

1,1-Dichloroethylene

trans-1,2-Dichloroethylene

Dichloromethane (Methylene chloride)

1,2-Dichloropropane

cis-1,3-Dichloropropene

trans-1,3-Dichloropropene

Ethylbenzene

Fluoride

Iron, total recoverable

Lead, total recoverable

Magnesium, total recoverable

Manganese, total recoverable

Mercury, total recoverable

Nickel, total recoverable

Nitrate-nitrite as nitrogen

Phenols

Potassium, total recoverable

Selenium, total recoverable

Silica, total recoverable

Silver, total recoverable

Sodium, total recoverable

Sulfate

1,1,2,2-Tetrachloroethane

Tetrachloroethylene

Thallium, total recoverabie

Toluene

Total dissolved solids

Total organic carbon

Total organic halogens

Total phosphates (as P)

1,1,1-Trichloroethane

1,1,2-Trichloroethane

Trichloroethylene

Trichlorofluoromethane

Vanadium, total recoverable

Zinc, total recoverable

Actinium-228

Americium-241

Antimony-124

Antimony-125

Barium-133

Cerium-144

Cesium-134

Cesium-137
$<1.0$

$<1.0$

$<1.0$

$<1.0$

$<1.0$

$<4.0$

$<4.0$

$<4.0$

$<5.0$

$<1.0$

$<1.0$

$<1.0$

$<1.0$

$<1.0$

$<1.0$

$<1.0$

$<1.0$

$<1.0$

$<1.0$

$<100$

4.4

$<3.0$

807

$<2.0$

$<0.20$

$<4.0$

$<50$

$<5.0$

1,160

$<2.0$

27,300

$<2.0$

1,730

5,680

$<1.0$

$<1.0$

$<2.0$

$<1.0$

117,000

1,200

9.5

$<50$

$<1.0$

$<1.0$

$<1.0$

$<1.0$

$<8.0$

$<2.0$

$<2.8 \mathrm{E}+00$

$<5.1 \mathrm{E}-02$

$3.2 \mathrm{E}+00$

$2.1 E+01$

4. $6 \mathrm{E}+0 \mathrm{O}$

$<1.4 E+01$

$2.9 E+00$

$<-1.6 \mathrm{E}+00$
DF

1.00

1.00

1.00

1.00

1.00

1.00

1.00

1.00

1.00

1.00

1.00

1.00

1.00

1.00

1.00

1.00

1.00

1.00

1.00

1.00

1.00

1.00

1.00

1.00

1.00

1.00

1.00

1.00

1.00

1.00

1.00

1.00

1.00

1.00

1.00

1.00

1.00

1.00

1.00

1.00

1.00

1.00

1.00

1.00

1.00

1.00

1.00

1.00

1.00

1.00

1.00

1.00

1.00

1.00

1.00

1.00
Mod Unit Flag Lab

$\mu \mathrm{g} / \mathrm{L} \quad 0 \quad \mathrm{GE}$

$\mu g / L \quad 0 \quad G E$

$\mu \mathrm{g} / \mathrm{L} \quad 0 \quad \mathrm{GE}$

$\mu \mathrm{g} / \mathrm{L} \quad 0 \quad \mathrm{GE}$

$\mu \mathrm{g} / \mathrm{L} \quad \mathrm{O} \quad \mathrm{GE}$

$\mu g / L \quad 0 \quad G E$

$\mu \mathrm{g} / \mathrm{L} \quad \mathrm{O} \quad \mathrm{GE}$

$\mu \mathrm{g} / \mathrm{L} \quad 0 \quad \mathrm{GE}$

$\mu \mathrm{g} / \mathrm{L} \quad 0 \quad \mathrm{GE}$

$\mu \mathrm{g} / \mathrm{L} \quad 0 \quad \mathrm{GE}$

$\mu \mathrm{g} / \mathrm{L} \quad 0 \quad \mathrm{GE}$

$\mu \mathrm{g} / \mathrm{L} \quad \mathrm{O} \quad \mathrm{GE}$

$\mu \mathrm{g} / \mathrm{L} \quad \mathrm{O} \quad \mathrm{GE}$

$\mu \mathrm{g} / \mathrm{L} \quad \mathrm{O} \quad \mathrm{GE}$

$\mu \mathrm{g} / \mathrm{L} \quad 0 \quad \mathrm{GE}$

$\mu \mathrm{g} / \mathrm{L} \quad \mathrm{O} \quad \mathrm{GE}$

$\mu \mathrm{g} / \mathrm{L} \quad 0 \quad \mathrm{GE}$

$\mu \mathrm{g} / \mathrm{L} \quad 0 \quad \mathrm{GE}$

$\mu \mathrm{g} / \mathrm{L} \quad \mathrm{O} \quad \mathrm{GE}$

$\mu \mathrm{g} / \mathrm{L} \quad 0 \quad \mathrm{GE}$

$\mu \mathrm{g} / \mathrm{L} \quad \mathrm{O} \quad \mathrm{GE}$

$\mu \mathrm{g} / \mathrm{L} \quad 0 \quad \mathrm{GE}$

$\mu \mathrm{g} / \mathrm{L} \quad 0 \quad \mathrm{GE}$

$\mu \mathrm{g} / \mathrm{L} \quad 0 \quad \mathrm{GE}$

$\mu \mathrm{g} / \mathrm{L} \quad \mathrm{O} \quad \mathrm{GE}$

$\mu \mathrm{g} / \mathrm{L} \quad \mathrm{O} \quad \mathrm{GE}$

$\mu \mathrm{g} / \mathrm{L} \quad \mathrm{O} \quad \mathrm{GE}$

$\mu \mathrm{g} / \mathrm{L} \quad \mathrm{O} \quad \mathrm{GE}$

$\mu \mathrm{g} / \mathrm{L} \quad \mathrm{O} \quad \mathrm{GE}$

$\mu \mathrm{g} / \mathrm{L} \quad 0 \quad \mathrm{GE}$

$\mu \mathrm{g} / \mathrm{L} \quad 0 \quad \mathrm{GE}$

$\mu \mathrm{g} / \mathrm{L} \quad 0 \quad \mathrm{GE}$

$\mu \mathrm{g} / \mathrm{L} \quad 0 \quad \mathrm{GE}$

$\mu \mathrm{g} / \mathrm{L} \quad 0 \quad \mathrm{GE}$

$\mu g / L \quad 0 \quad G E$

$\mu \mathrm{g} / \mathrm{L} \quad 0 \quad \mathrm{GE}$

$\mu \mathrm{g} / \mathrm{L} \quad 0 \quad \mathrm{GE}$

$\mu \mathrm{g} / \mathrm{L} \quad 0 \quad \mathrm{GE}$

$\mu \mathrm{g} / \mathrm{L} \quad 0 \quad \mathrm{GE}$

$\mu \mathrm{g} / \mathrm{L} \quad 0 \quad \mathrm{GE}$

$\mu \mathrm{g} / \mathrm{L} \quad \mathrm{O} \quad \mathrm{GE}$

$\mu \mathrm{g} / \mathrm{L}$

$\mu \mathrm{g} / \mathrm{L}$

$\mu \mathrm{g} / \mathrm{L}$

$\mu \mathrm{g} / \mathrm{L}$

$\mu \mathrm{g} / \mathrm{L}$

$\mu \mathrm{g} / \mathrm{L}$

$\mu \mathrm{g} / \mathrm{L}$

$\mathrm{pCi} / \mathrm{L}$

$\mathrm{pCi} / \mathrm{L}$

$\mathrm{pCi} / \mathrm{L}$

pCi/L

$\mathrm{pCi} / \mathrm{L}$

$\mathrm{pCi} / \mathrm{L}$

$\mathrm{pCi} i L$

$\mathrm{pCi} / \mathrm{L}$

- = exceeded holding time. $\mathbf{a}=$ exceeded screening level or final primary drinking water standard. 
WELL HSB 85A collected on 02/08/94, laboratory analyses (cont.)

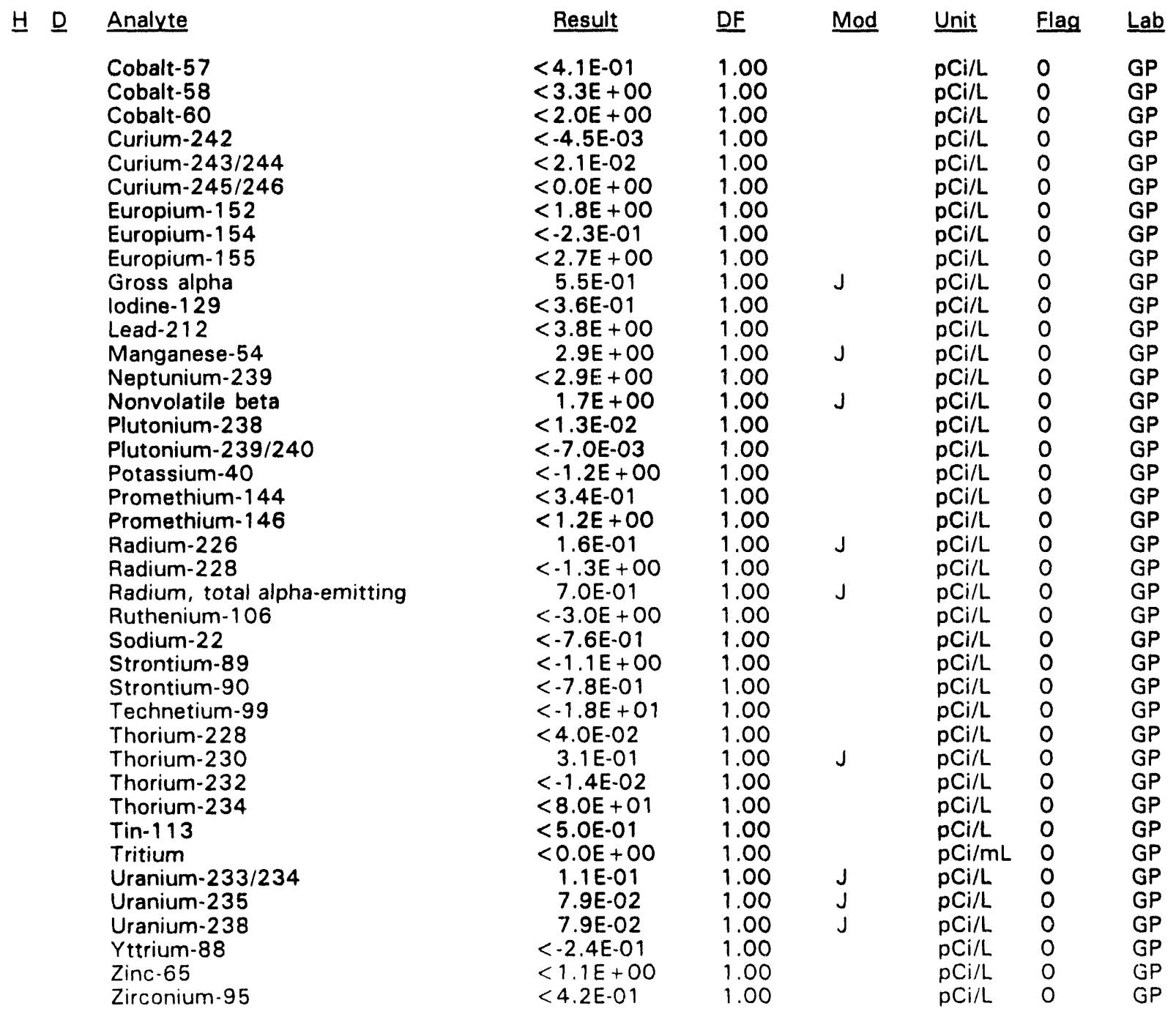

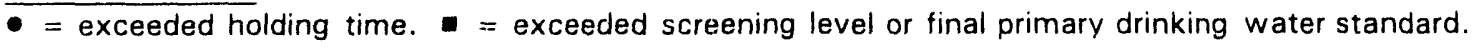




\section{WELL HSB 85A}

\begin{tabular}{|c|c|c|c|c|c|c|}
\hline SRS Coord. & Lat/Longitude & Screen Zone Elevation & Top of Casing & Casing & Pump & Formation \\
\hline $\begin{array}{l}N 73791.9 \\
E 58943.4\end{array}$ & $\begin{array}{l}33.285152^{\circ} \mathrm{N} \\
81.654930^{\circ} \mathrm{W}\end{array}$ & $71.1-61.1 \mathrm{ft} \mathrm{msl}$ & $294.4 \mathrm{ft} \mathrm{msl}$ & 4" PVC & $\mathbf{S}$ & U. Congaree (IIA) \\
\hline
\end{tabular}

\section{FIELD MEASUREMENTS}

Sample date: 03/15/94

Depth to water: $125.59 \mathrm{ft}(38.28 \mathrm{~m})$ below TOC

Water elevation: $168.81 \mathrm{ft}(51.45 \mathrm{~m}) \mathrm{msl}$

Sp. conductance: $201 \mu \mathrm{S} / \mathrm{cm}$

Turbidity: 0.2 NTU

Water evacuated before sampling: $183 \mathrm{gal}$

Time: 15: 42

pH: 6.9

Alkalinity: $75 \mathrm{mg} / \mathrm{L}$

Water temperature: $19.8^{\circ} \mathrm{C}$

Volumes purged: 2.6 well volumes

\section{LABORATORY ANALYSES}

\section{H D Analyte}

$\mathrm{pH}$

Specific conductance

Aluminum, total recoverable

Antimony, total recoverable

Antimony, total recoverable

Arsenic, total recoverable

Arsenic, total recoverable

Barium, total recoverable

Benzene

Benzene

Bis(2-ethylhexyl) phthalate

Bromodichloromethane

Bromodichloromethane

Bromoform

Bromoform

Bromomethane (Methyl bromide)

Bromomethane (Methyl bromide)

Cadmium, total recoverable

Calcium, total recoverable

Carbon tetrachloride

Carbon tetrachloride

Chloride

Chlorobenzene

Chlorobenzene

Chloroethane

Chloroethane

Chloroethene (Vinyl chloride)

Chloroethene (Vinyl chloride)

2-Chloroethyl vinyl ether

2-Chloroethyl vinyl ether

Chlo: oform

Chloroform

Chloromethane (Methyl chloride)

Chloromethane (Methyl chloride)

Chromium, total recoverable

Cobalt, total recoverable

Copper, total recoverable

Cyanide

\begin{tabular}{|c|c|c|c|c|c|}
\hline Result & DF & Mod & Unit & Flag & $\underline{L a b}$ \\
\hline 7.1 & 1.00 & & $\mathrm{pH}$ & 0 & GE \\
\hline 7.0 & 1.00 & J1 & $\mathrm{pH}$ & 0 & GE \\
\hline 181 & 1.00 & & $\mu \mathrm{S} / \mathrm{cm}$ & 0 & GE \\
\hline$<20$ & 1.00 & & $\mu \mathrm{g} / \mathrm{L}$ & 0 & $\mathrm{GE}$ \\
\hline$<2.0$ & 1.00 & & $\mu \mathrm{g} / \mathrm{L}$ & 0 & $\mathrm{GE}$ \\
\hline$<2.0$ & 1.00 & & $\mu \mathrm{g}^{\prime} \mathrm{L}$ & 0 & $\mathrm{GE}$ \\
\hline$<2.0$ & 1.00 & & $\mu \mathrm{g} / \mathrm{L}$ & 0 & GE \\
\hline$<2.0$ & 1.00 & & $\mu \mathrm{g} / \mathrm{L}$ & 0 & GE \\
\hline 29 & 1.00 & & $\mu \mathrm{g} / \mathrm{L}$ & 0 & GE \\
\hline$<1.0$ & 1.00 & & $\mu \mathrm{g} / \mathrm{L}$ & 0 & GE \\
\hline$<1.0$ & 1.00 & & $\mu \mathrm{g} / \mathrm{L}$ & 0 & $G E$ \\
\hline$<10$ & 1.00 & & $\mu \mathrm{g} / \mathrm{L}$ & 0 & GF. \\
\hline$<1.0$ & 1.00 & & $\mu \mathrm{g} / \mathrm{L}$ & 0 & GE: \\
\hline$<1.0$ & 1.00 & & $\mu \mathrm{g} / \mathrm{L}$ & 0 & GE \\
\hline$<1.0$ & 1.00 & & $\mu g / L$ & 0 & GE \\
\hline$<1.0$ & 1.00 & & $\mu \mathrm{g} / \mathrm{L}$ & 0 & $G E$ \\
\hline$<1.0$ & 1.00 & & $\mu \mathrm{g} / \mathrm{L}$ & 0 & GE \\
\hline $\begin{array}{l}<1.0 \\
<2.0\end{array}$ & $\begin{array}{l}1.00 \\
1.00\end{array}$ & & $\mu \mathrm{g} / \mathrm{L}$ & $\begin{array}{l}0 \\
0\end{array}$ & $\mathrm{GE}$ \\
\hline $\begin{array}{l}<2.0 \\
33,100\end{array}$ & 1.00 & & $\begin{array}{l}\mu g / L \\
\mu g / L\end{array}$ & 0 & GE \\
\hline$<1.0$ & 1.00 & & $\mu \mathrm{g} / \mathrm{L}$ & 0 & $\mathrm{GE}$ \\
\hline$<1.0$ & 1.00 & & $\mu \mathrm{g} / \mathrm{L}$ & 0 & $G E$ \\
\hline 2,260 & 1.00 & & $\mu \mathrm{g} / \mathrm{L}$ & 0 & GE \\
\hline$<1.0$ & 1.00 & & $\mu \mathrm{g} / \mathrm{L}$ & 0 & $E$ \\
\hline$<1.0$ & 1.00 & & $\mu \mathrm{g} / \mathrm{L}$ & 0 & E \\
\hline$<1.0$ & 1.00 & & $\mu \mathrm{g} / \mathrm{L}$ & 0 & G \\
\hline$<1.0$ & 1.00 & & $\mu \mathrm{g} / \mathrm{L}$ & 0 & GE \\
\hline$<1.0$ & 1.00 & & $\mu \mathrm{g} / \mathrm{L}$ & 0 & GE \\
\hline$<1.0$ & 1.00 & & $\mu \mathrm{g} / \mathrm{L}$ & 0 & GE \\
\hline$<1.0$ & 1.00 & & $\mu \mathrm{g} / \mathrm{L}$ & 0 & GE \\
\hline$<1.0$ & 1.00 & & $\mu \mathrm{g} / \mathrm{L}$ & 0 & GE \\
\hline$<1.0$ & 1.00 & & $\mu \mathrm{g} / \mathrm{L}$ & 0 & GE \\
\hline$<1.0$ & 1.00 & & $\mu \mathrm{g} / \mathrm{L}$ & 0 & GE \\
\hline$<1.0$ & 1.00 & & $\mu \mathrm{g} / \mathrm{L}$ & 0 & GE \\
\hline$<1.0$ & 1.00 & & $\mu \mathrm{g} / \mathrm{L}$ & 0 & GE \\
\hline$<4.0$ & 1.00 & & $\mu \mathrm{g} / \mathrm{L}$ & 0 & GE \\
\hline$<4.0$ & 1.00 & & $\mu \mathrm{g} / \mathrm{L}$ & 0 & $E$ \\
\hline$<4.0$ & 1.00 & & $\mu \mathrm{g} / \mathrm{L}$ & 0 & \\
\hline$<5.0$ & 1.00 & & $\mu \mathrm{g} / \mathrm{L}$ & 0 & \\
\hline
\end{tabular}

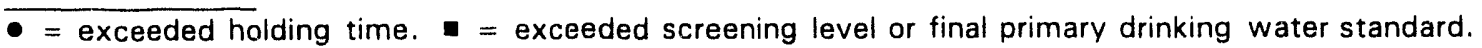


WELL HSB $85 \mathrm{~A}$ collected on $03 / 15 / 94$, laboratory analyses (cont.)

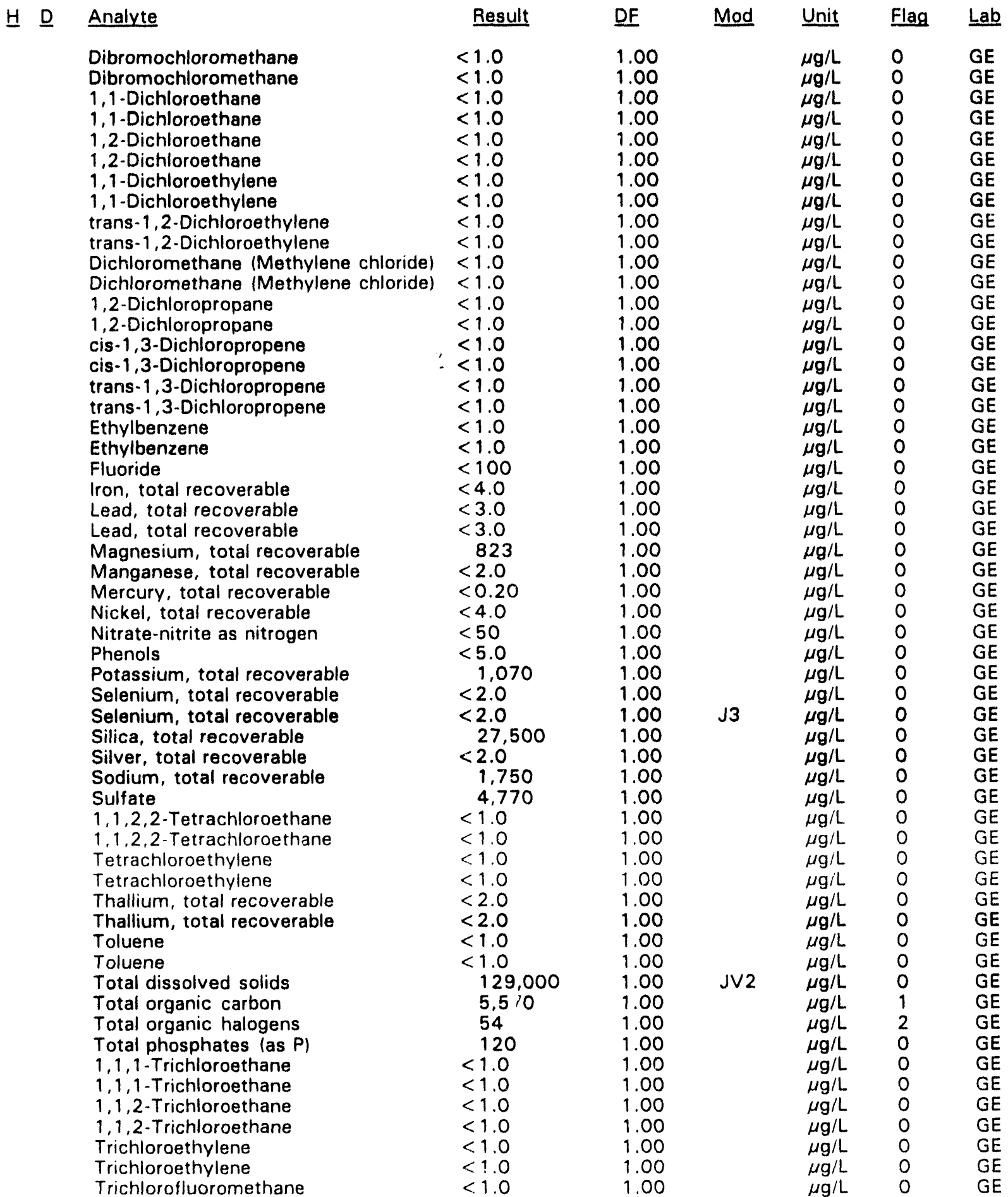

\footnotetext{
- = exceeded holding time. $=$ exceeded screening level or final primary drinking water standard.
} 
WELL HSB 85A collected on 03/15/94, laboratory analyses (cont.)

H $\underline{D}$

Analyte
Trichlorofluoromethane
Vanadium, total recoverable
Zinc, total recoverable
Actinium-228
Actinium-228
Americium-241
Antimony-124
Antimony-124
Antimony-125
Antimony-125
Barium-133
Barium-133
Cerium-144
Cerium-144
Cesium-134
Cesium-134
Cesium-137
Cesium-137
Cobalt-57
Cobalt-57
Cobalt-58
Cobalt-58
Cobalt-60
Cobalt-60
Curium-242
Curium-243/244
Curium-245/246
Europium-152
Europium-152
Europium-154
Europium-154
Europium-155
Europium-155
Gross alpha
lodine-129
Lead-212
Lead-212
Manganese-54
Manganese-54
Neptunium-239
Neptunium-239
Nonvolatile beta
Plutonium-238
Plutonium-239/240
Potassium-40
Potassium-40
Promethium-144
Promethium-144
Promethium-146
Promethium-146
Radium-226
Radium-228
Radium, total alpha-emitting
Ruthenium-106
Ruthenium-106
Sodium-22

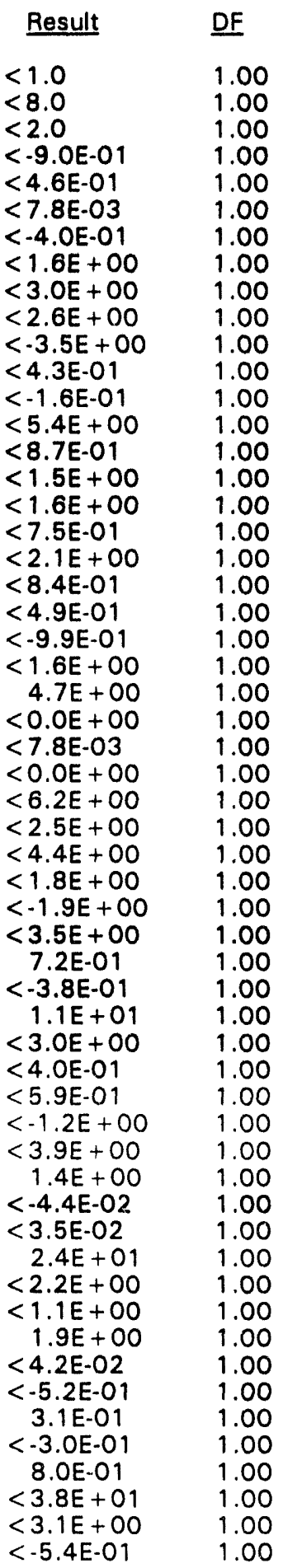

Mod Unit Flag Lab

$\mu g / L \quad 0 \quad G E$

$\mu \mathrm{g} / \mathrm{L} \quad 0 \quad \mathrm{GE}$

$\mu g / L \quad O \quad G E$

pCi/L $0 \quad$ GP

$\mathrm{pCi} / \mathrm{L} \quad 0 \quad \mathrm{GP}$

$\mathrm{pCi} / \mathrm{L} \quad 0 \quad \mathrm{GP}$

$\mathrm{pCi} / \mathrm{L} \quad 0 \quad \mathrm{GP}$

PCi/L $\quad 0 \quad$ GP

$\mathrm{pCi} / \mathrm{L} \quad 0 \quad \mathrm{GP}$

$\mathrm{pCi} / \mathrm{L} \quad 0 \quad \mathrm{GP}$

pCi/L $\quad 0 \quad$ GP

$\mathrm{pCi} / \mathrm{L} \quad 0 \quad \mathrm{GP}$

$\mathrm{pCi} / \mathrm{L} \quad 0 \quad \mathrm{GP}$

$p C i / L \quad 0 \quad$ GP

pCi/L $\quad 0 \quad$ GP

$\mathrm{pCi} / \mathrm{L} \quad 0 \quad \mathrm{GP}$

pCi/L 0 GP

pCi/L $0 \quad$ GP

pCiiL $\quad 0 \quad$ GP

$\mathrm{pCi} / \mathrm{L} \quad 0 \quad \mathrm{GP}$

$\mathrm{pCi} / \mathrm{L} \quad 0 \quad \mathrm{GP}$

pCi/L $\quad 0 \quad$ GP

$\mathrm{pCi} / \mathrm{L} \quad 0 \quad \mathrm{GP}$

$\mathrm{pCi} / \mathrm{L} \quad 0 \quad \mathrm{GP}$

pCi/L $\quad 0 \quad$ GP

$\mathrm{pCi} / \mathrm{L}$

$\mathrm{pCi} / \mathrm{L}$

$\mathrm{pCi} / \mathrm{L}$

$\mathrm{pCi} / \mathrm{L}$

$\mathrm{pCi} / \mathrm{L}$

$\mathrm{pCi} / \mathrm{L}$

$\mathrm{pCi} / \mathrm{L}$

$\mathrm{pCi} / \mathrm{L}$

$\mathrm{pCi} / \mathrm{L}$

$\mathrm{pCi} / \mathrm{L}$

$\mathrm{pCi} / \mathrm{L}$

pCi,L

$\mathrm{pCi} / \mathrm{L}$

pCi/L

$\mathrm{pCi} / \mathrm{L}$

$\mathrm{pCi} / \mathrm{L}$

$\mathrm{pCi} / \mathrm{L}$

$\mathrm{pCi} / \mathrm{L}$

pCi/L

$\mathrm{pCi} / \mathrm{L}$

pCi/L

$\mathrm{pCi} / \mathrm{L}$

pCi/L

pCi/L

pCi/L

pCi/L

pCi/L

pCi/L

$\mathrm{pCi} / \mathrm{L}$

pCi/L

$\mathrm{pCi} / \mathrm{L}$

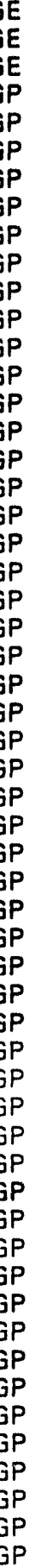


WELL HSB $85 \mathrm{~A}$ collected on $03 / 15 / 94$, laboratory analyses (cont.)

H

Analyte
Sodium-22
Strontium-89
Strontium-90
Technetium-99
Thorium-228
Thorium-230
Thorium-232
Thorium-234
Thorium-234
Tin-113
Tin-113
Tritium
Uranium-233/234
Uranium-235
Uranium-238
Yttrium-88
Yttrium-88
Zinc-65
Zinc-65
Zirconium-95
Zirconium-95

$\begin{aligned} & \text { Result } \\ &<-9.9 E-01 \\ &<-4.7 E-01 \\ &<-3.1 E-01 \\ &<-5.6 E+00 \\ &<8.9 E-02 \\ &<2.2 E-02 \\ &<5.6 E-02 \\ & 1.5 E+02 \\ &<1.5 E+01 \\ &<1.1 E+00 \\ &<2.6 E+00 \\ &<6.8 E-02 \\ &<3.4 E-02 \\ &<9.6 E-03 \\ &<-1.1 E-02 \\ &<1.3 E+00 \\ &<5.4 E-02 \\ &<-1.8 E-01 \\ &<1.5 E+00 \\ & 2.6 E+00 \\ &<6.9 E-03\end{aligned}$

DF

1.00

1.00

1.00

1.00

1.00

1.00

1.00

1.00

1.00

1.00

1.00

1.00

1.00

1.00

1.00

1.00

1.00

1.00

1.00

1.00

1.00

Mod

Unit Flag Lab

$\mathrm{pCi} / \mathrm{L} \quad 0 \quad \mathrm{GP}$

$\mathrm{pCi} / \mathrm{L} \quad 0 \quad \mathrm{GP}$

$\mathrm{pCi} / \mathrm{L} \quad 0 \quad \mathrm{GP}$

$\mathrm{pCi} / \mathrm{L} \quad 0 \quad \mathrm{GP}$

$\mathrm{pCi} / \mathrm{L} \quad 0 \quad \mathrm{GP}$

$\mathrm{pCi} / \mathrm{L} \quad 0 \quad \mathrm{GP}$

$\mathrm{pCi} / \mathrm{L} \quad 0 \quad \mathrm{GP}$

$\mathrm{pCi} / \mathrm{L} \quad 0 \quad \mathrm{GP}$

$\mathrm{pCi} / \mathrm{L} \quad 0 \quad \mathrm{GP}$

$\mathrm{pCi} / \mathrm{L} \quad 0 \quad \mathrm{GP}$

$\mathrm{pCi} / \mathrm{L} \quad 0 \quad \mathrm{GP}$

$\mathrm{pCi} / \mathrm{mL} \quad 0 \quad \mathrm{GP}$

$\mathrm{pCi} / \mathrm{L} \quad 0 \quad \mathrm{GP}$

$\mathrm{pCi} / \mathrm{L} \quad 0 \quad \mathrm{GP}$

$\mathrm{pCi} / \mathrm{L} \quad 0 \quad \mathrm{GP}$

$\mathrm{pCi} / \mathrm{L} \quad 0 \quad \mathrm{GP}$

$\mathrm{pCi} / \mathrm{L} \quad 0 \quad \mathrm{GP}$

$\mathrm{PCi} / \mathrm{L} \quad 0 \quad \mathrm{GP}$

$\mathrm{pCi} / \mathrm{L} \quad 0 \quad \mathrm{GP}$

$\begin{array}{lll}p \mathrm{Ci} / \mathrm{L} & 0 & \mathrm{GP} \\ \mathrm{pCi} / \mathrm{L} & 0 & \mathrm{GP}\end{array}$

\section{WELL HSB 85B}

\begin{tabular}{|c|c|c|c|c|c|c|}
\hline SRS Coord. & Lat/Longitude & Screen Zone Elevation & Top of Casing & Casing & Pump & Formation \\
\hline $\begin{array}{l}N 73789.3 \\
E 58953.3\end{array}$ & $\begin{array}{l}33.285162^{\circ} \mathrm{N} \\
81.654898^{\circ} \mathrm{W}\end{array}$ & $143.2-133.2 \mathrm{ft} \mathrm{msl}$ & $294.5 \mathrm{ft} \mathrm{msl}$ & 4" PVC & S & McBean (IIB, \\
\hline
\end{tabular}

\section{FIELD MEASUREMENTS}

Sample date: $01 / 14 / 94$

Depth to water: $61.71 \mathrm{ft}(18.81 \mathrm{~m})$ below TOC

Water elevation: $232.79 \mathrm{ft}(70.96 \mathrm{~m}) \mathrm{ms} /$

Sp. conductance: $137 \mu \mathrm{S} / \mathrm{cm}$

Turbidity: 0.9 NTU

Water evacuated before sampling: $50 \mathrm{gal}$

The well went dry during purging.

\section{LABORATORY ANALYSES}

H D Analyte

- $\mathrm{pH}$

Specific conductance

Aldrin

Aluminum, total recoverable

Antimony, total recoverable

Arsenic, total recoverable

- Barium, to

Bis (2 thylhexyl) phthalate

- Bromodichloromethane

- Bromoform

- Bromomethane (Methyl bromide)

Cadmium, total recoverable
Time: 9: 21

pH: 10.7

Alkalinity: $45 \mathrm{mg} / \mathrm{L}$

Water temperature: $17.5^{\circ} \mathrm{C}$

Volumes purged: 0.8 well volumes

\begin{tabular}{llllll} 
Result & DF & Mod & Unit & Flag & Lab \\
\hline 8.5 & 1.00 & $\mathrm{~J} 1$ & $\mathrm{pH}$ & 1 & $\mathrm{GE}$ \\
188 & 1.00 & & $\mu \mathrm{S} / \mathrm{cm}$ & 0 & $\mathrm{GE}$ \\
$<0.050$ & 1.00 & & $\mu \mathrm{g} / \mathrm{L}$ & 0 & $\mathrm{GE}$ \\
975 & 1.00 & & $\mu \mathrm{g} / \mathrm{L}$ & 2 & $\mathrm{GE}$ \\
$<2.0$ & 1.00 & & $\mu \mathrm{g} / \mathrm{L}$ & 0 & $\mathrm{GE}$ \\
$<2.0$ & 1.00 & & $\mu \mathrm{g} / \mathrm{L}$ & 0 & $\mathrm{GE}$ \\
26 & 1.00 & & $\mu \mathrm{g} / \mathrm{L}$ & 0 & $\mathrm{GE}$ \\
$<1.0$ & 1.00 & $\mathrm{~J} 1$ & $\mu \mathrm{g} / \mathrm{L}$ & 0 & $\mathrm{GE}$ \\
$<10$ & 1.00 & & $\mu \mathrm{g} / \mathrm{L}$ & 0 & $\mathrm{GE}$ \\
$<1.0$ & 1.00 & $\mathrm{~J} 1$ & $\mu \mathrm{g} / \mathrm{L}$ & 0 & $\mathrm{GE}$ \\
$<1.0$ & 1.00 & $\mathrm{~J} 1$ & $\mu \mathrm{g} / \mathrm{L}$ & 0 & $\mathrm{GE}$ \\
$<1.0$ & 1.00 & $\mathrm{~J} 1$ & $\mu \mathrm{g} / \mathrm{L}$ & 0 & $\mathrm{GE}$ \\
$<2.0$ & 1.00 & & $\mu \mathrm{g} / \mathrm{L}$ & 0 & $\mathrm{GE}$
\end{tabular}

- = exceeded holding time. = exceeded screening level or final primary drinking water standard. 
WELL HSB 85B collected on $01 / 14 / 94$, laboratory analyses (cont.)

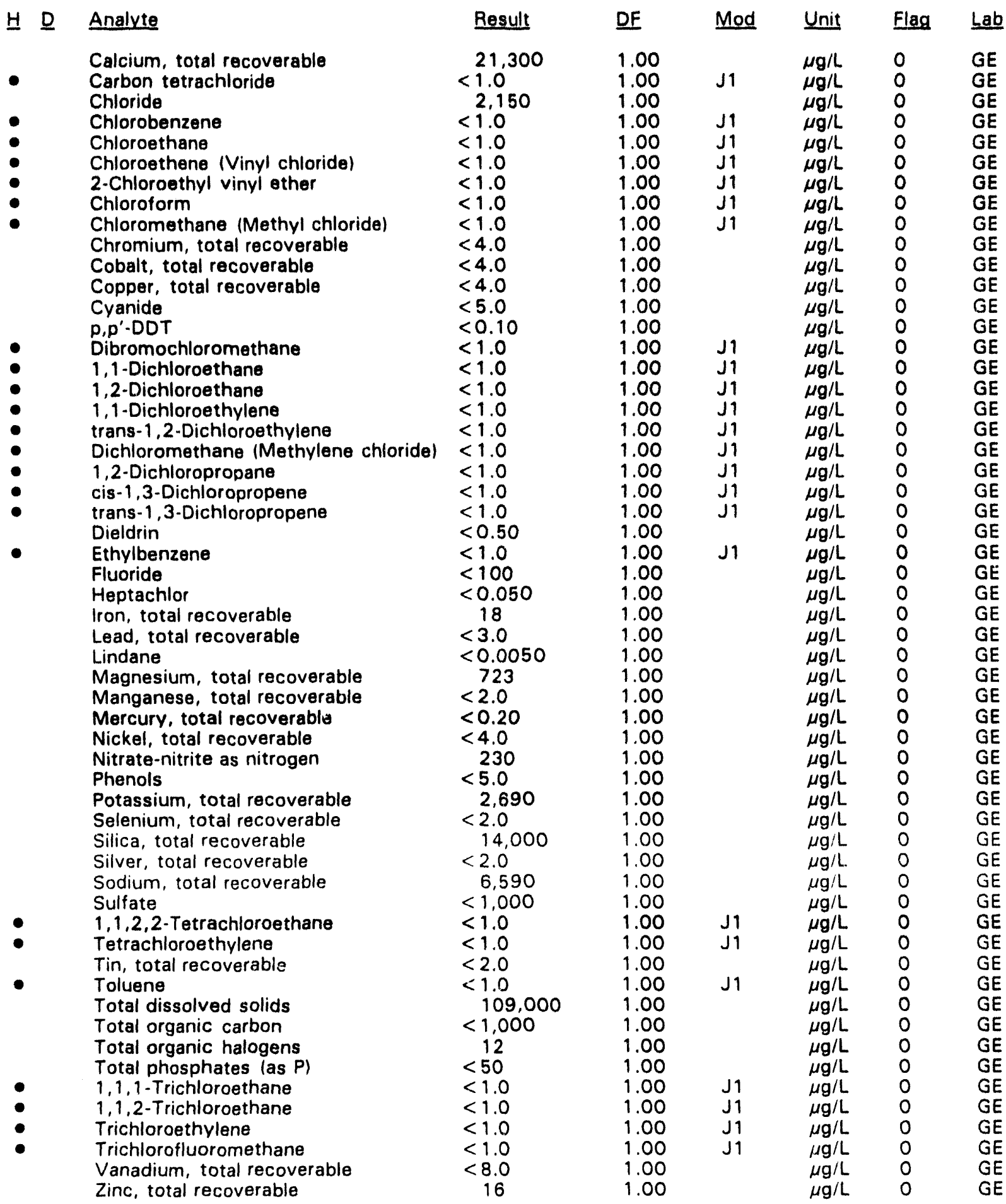

\footnotetext{
- = exceeded holding time. = exceeded screening level or final primary drinking water standard.
} 
WELL HSB 85B collected on $01 / 14 / 94$, laboratory analyses (cont.)

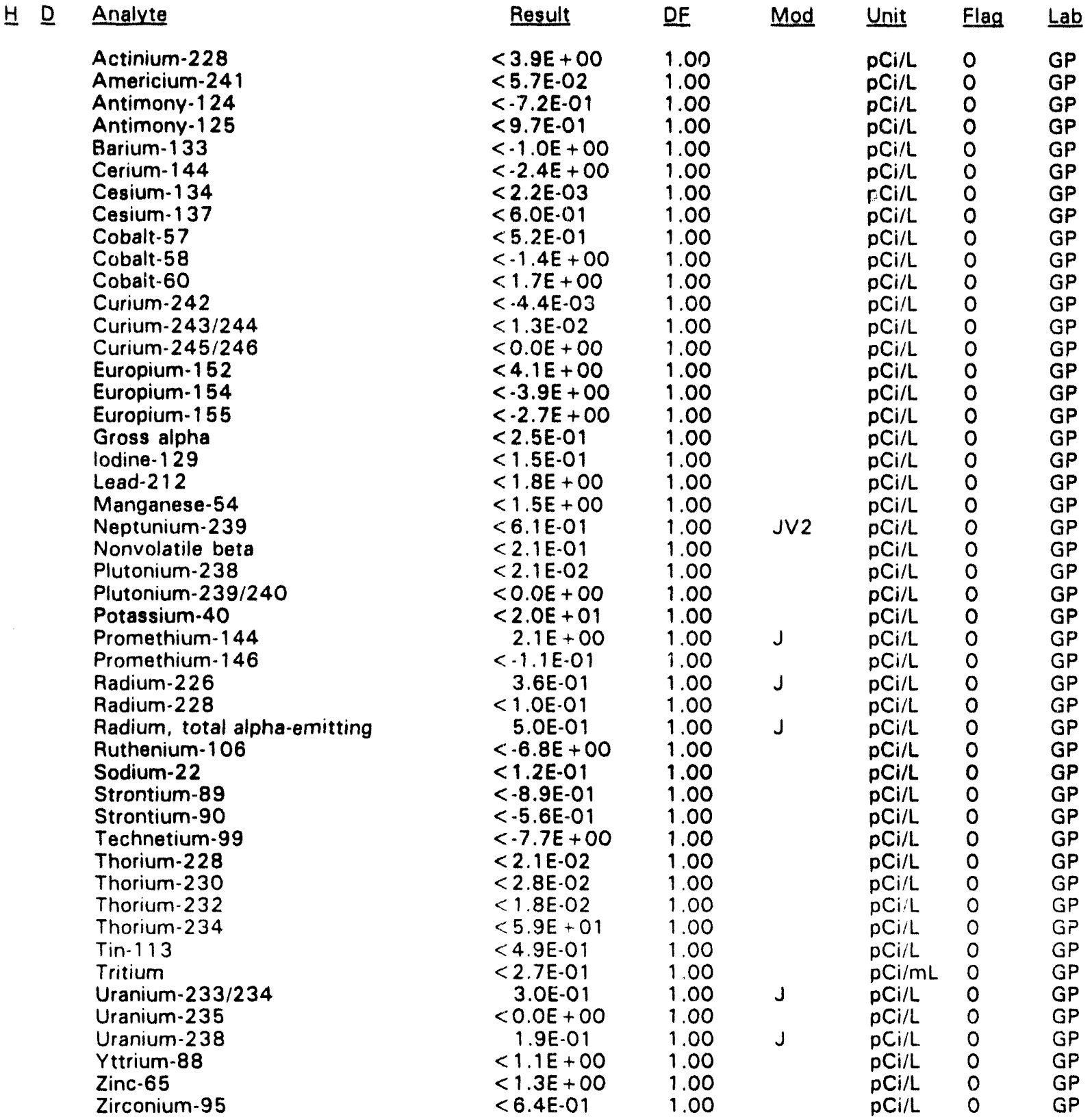

\footnotetext{
- = exceeded holding time. - = exceeded screening level or final primary drinking water standard.
} 
WELL HSB 85B

\begin{tabular}{|c|c|c|c|c|c|c|}
\hline is Coord. & Lat/Longitude & Screen Zone Elevation & Top of Casing & Casing & Pump & Formation \\
\hline 3 & $\begin{array}{l}35162^{\circ} \mathrm{N} \\
44898^{\circ} \mathrm{W}\end{array}$ & 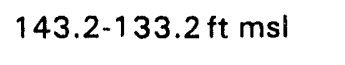 & & VC & $\mathbf{S}$ & \\
\hline
\end{tabular}

\section{FIELD MEASUREMENTS}

Sample date: $02 / 08 / 94$

Depth to water: $61.93 \mathrm{ft}(18.88 \mathrm{~m})$ below TOC

Water elevation: $232.57 \mathrm{ft}(70.89 \mathrm{~m}) \mathrm{msl}$

Sp. conductance: $140 \mu \mathrm{S} / \mathrm{cm}$

Turbidity: 1.7 NTU

Water evacuated before sampling: 50 gal

The well went dry during purging.

\section{LABORATORY ANALYSES}

\section{H D Analyte}

$\mathrm{pH}$

Specific conductance

Specific conductance

Aldrin

Aluminum, total recoverable

Antimony, total recoverable

Antimcny, total recoverable

Arsenic, total recoverable

Arsenic, total recoverable

Barium, total recoverable

Benzene

Bis (2-ethylhexyl) phthalate

Bromodichloromethane

Bromoform

Bromomethane (Methyl bromide)

Cadmium, total recoverable

Calcium, total recoverable

Carbon tetrachloride

Chloride

Chlorobenzene

Chloroethane

Chloroethene (Vinvl chloride)

2-Chloroethyl vinyl ether

Chloroform

Chloromethane (Methyl chloride)

Chromium, total recoverable

Cobalt, total recoverable

Copper, total recoverable

Cyanide

$p, p^{\prime}-D D T$

Dibromochloromethane

1,1-Dichloroethane

1,2-Dichloroethane

1,1-Dichloroethylene

trans-1,2-Dichloroethylene

Dichloromethane (Methylene chloride)

1,2-Dichloropropane

cis-1,3-Dichloropropene

trans-1,3-Dichloropropene

\begin{tabular}{|c|c|c|c|c|c|}
\hline Result & $\underline{D F}$ & Mod & Unit & Flag & Lak \\
\hline 8.1 & 1.00 & J1 & $\mathrm{pH}$ & 1 & GE \\
\hline 198 & 1.00 & & $\mu \mathrm{S} / \mathrm{cm}$ & 0 & \\
\hline 198 & 1.00 & & $\mu \mathrm{S} / \mathrm{cm}$ & 0 & \\
\hline$<0.051$ & 1.00 & & $\mu \mathrm{g} / \mathrm{L}$ & 0 & \\
\hline 523 & 1.00 & & $\mu \mathrm{g} / \mathrm{L}$ & 2 & \\
\hline$<2.0$ & 1.00 & & $\mu \mathrm{g} / \mathrm{L}$ & 0 & \\
\hline$<2.0$ & 1.00 & & $\mu \mathrm{g} / \mathrm{L}$ & 0 & \\
\hline$<2.0$ & 1.00 & & $\mu \mathrm{g} / \mathrm{L}$ & 0 & \\
\hline$<2.0$ & 1.00 & & $\mu \mathrm{g} / \mathrm{L}$ & 0 & \\
\hline 26 & 1.00 & & $\mu \mathrm{g} / \mathrm{L}$ & 0 & \\
\hline$<1.0$ & 1.00 & & $\mu \mathrm{g} / \mathrm{L}$ & 0 & \\
\hline$<9.7$ & 1.00 & & $\mu \mathrm{g} / \mathrm{L}$ & 0 & \\
\hline$<1.0$ & 1.00 & & $\mu \mathrm{g} / \mathrm{L}$ & 0 & \\
\hline$<1.0$ & 1.00 & & $\mu \mathrm{g} / \mathrm{L}$ & 0 & \\
\hline$<1.0$ & 1.00 & & $\mu \mathrm{g} / \mathrm{L}$ & 0 & \\
\hline$<2.0$ & 1.00 & & $\mu \mathrm{g} / \mathrm{L}$ & 0 & \\
\hline 28,100 & 1.00 & & $\mu \mathrm{g} / \mathrm{L}$ & 0 & \\
\hline$<1.0$ & 1.00 & & $\mu \mathrm{g} / \mathrm{L}$ & 0 & \\
\hline 2,330 & 1.00 & & $\mu \mathrm{g} / \mathrm{L}$ & 0 & \\
\hline$<1.0$ & 1.00 & & $\mu \mathrm{g} / \mathrm{L}$ & 0 & \\
\hline$<1.0$ & 1.00 & & $\mu \mathrm{g} / \mathrm{L}$ & 0 & \\
\hline$<1.0$ & 1.00 & & $\mu \mathrm{g} / \mathrm{L}$ & 0 & \\
\hline$<1.0$ & 1.00 & & $\mu \mathrm{g} / \mathrm{L}$ & 0 & \\
\hline$<1.0$ & 1.00 & & $\mu \mathrm{g} / \mathrm{L}$ & 0 & \\
\hline$<1.0$ & 1.00 & & $\mu \mathrm{g} / \mathrm{L}$ & 0 & \\
\hline$<4.0$ & 1.00 & & $\mu \mathrm{g} / \mathrm{L}$ & 0 & \\
\hline$<4.0$ & 1.00 & & $\mu \mathrm{g} / \mathrm{L}$ & 0 & \\
\hline 7.8 & 1.00 & & $\mu \mathrm{g} / \mathrm{L}$ & 0 & \\
\hline$<5.0$ & 1.00 & & $\mu \mathrm{g} / \mathrm{L}$ & 0 & \\
\hline$<0.10$ & 1.00 & & $\mu \mathrm{g} / \mathrm{L}$ & 0 & \\
\hline$<1.0$ & 1.00 & & $\mu \mathrm{g} / \mathrm{L}$ & 0 & \\
\hline$<1.0$ & 1.00 & & $\mu \mathrm{g} / \mathrm{L}$ & 0 & \\
\hline$<1.0$ & 1.00 & & $\mu \mathrm{g} / \mathrm{L}$ & 0 & \\
\hline$<1.0$ & 1.00 & & $\mu \mathrm{g} / \mathrm{L}$ & 0 & \\
\hline$<1.0$ & 1.00 & & $\mu \mathrm{g} / \mathrm{L}$ & 0 & \\
\hline$<1.0$ & 1.00 & & $\mu \mathrm{g} / \mathrm{L}$ & 0 & \\
\hline$<1.0$ & 1.00 & & $\mu \mathrm{g} / \mathrm{L}$ & 0 & \\
\hline$<1.0$ & 1.00 & & $\mu \mathrm{g} / \mathrm{L}$ & 0 & \\
\hline$<1.0$ & 1.00 & & $\mu \mathrm{g} / \mathrm{L}$ & 0 & \\
\hline
\end{tabular}

Time: $14: 33$

$\mathrm{pH}: 10.5$

Alkalinity: $41 \mathrm{mg} / \mathrm{L}$

Water temperature: $19.0^{\circ} \mathrm{C}$

Volumes purged: 0.8 well volumes 
WELL HSB $85 B$ collected on $02 / 08 / 94$, laboratory analyses (cont.)

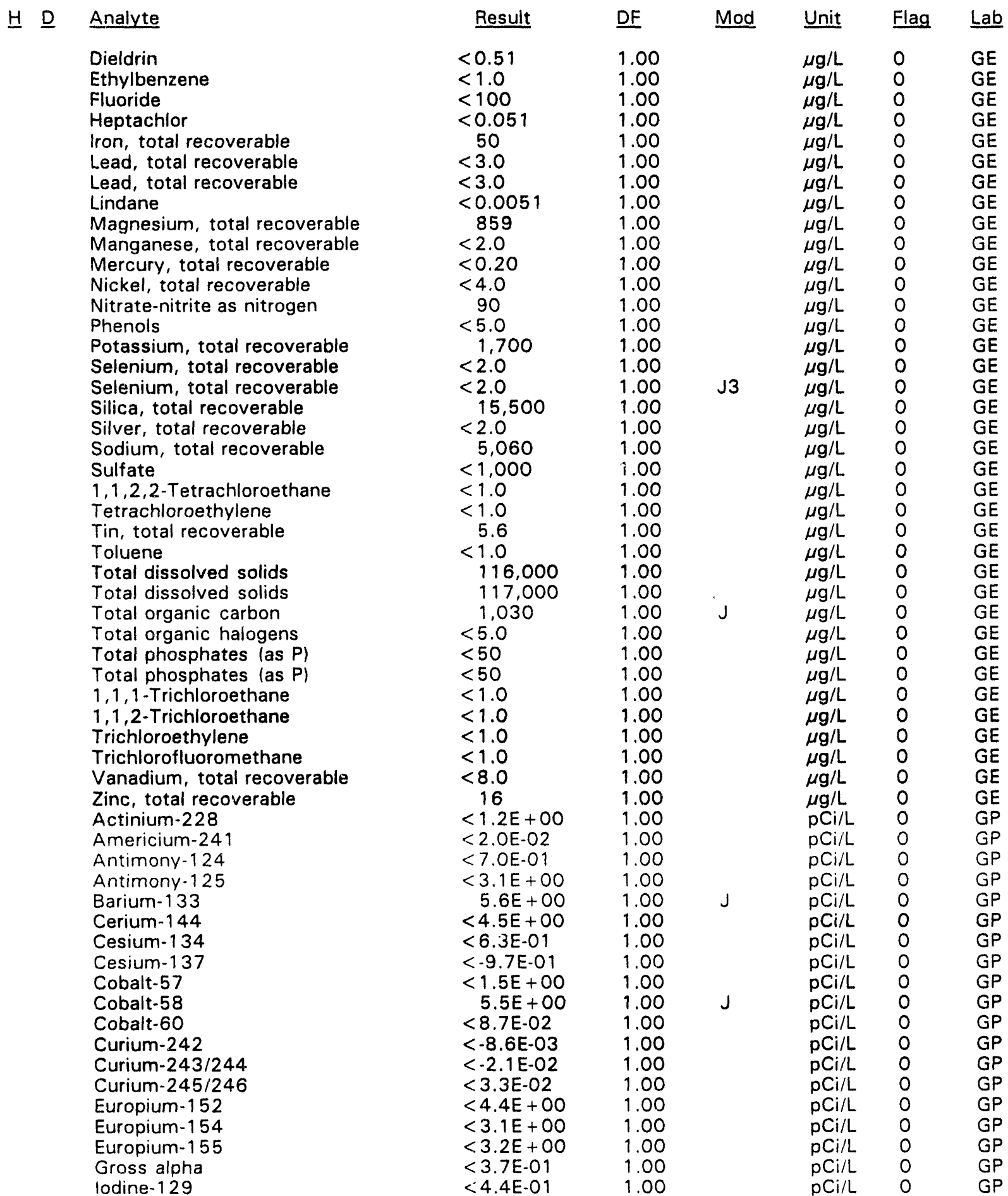

- = exceeded holding time. - exceeded screening levei or final primary drinking water standard. 
WELL HSB 85B collected on 02/08/94, laboratory analyses (cont.)

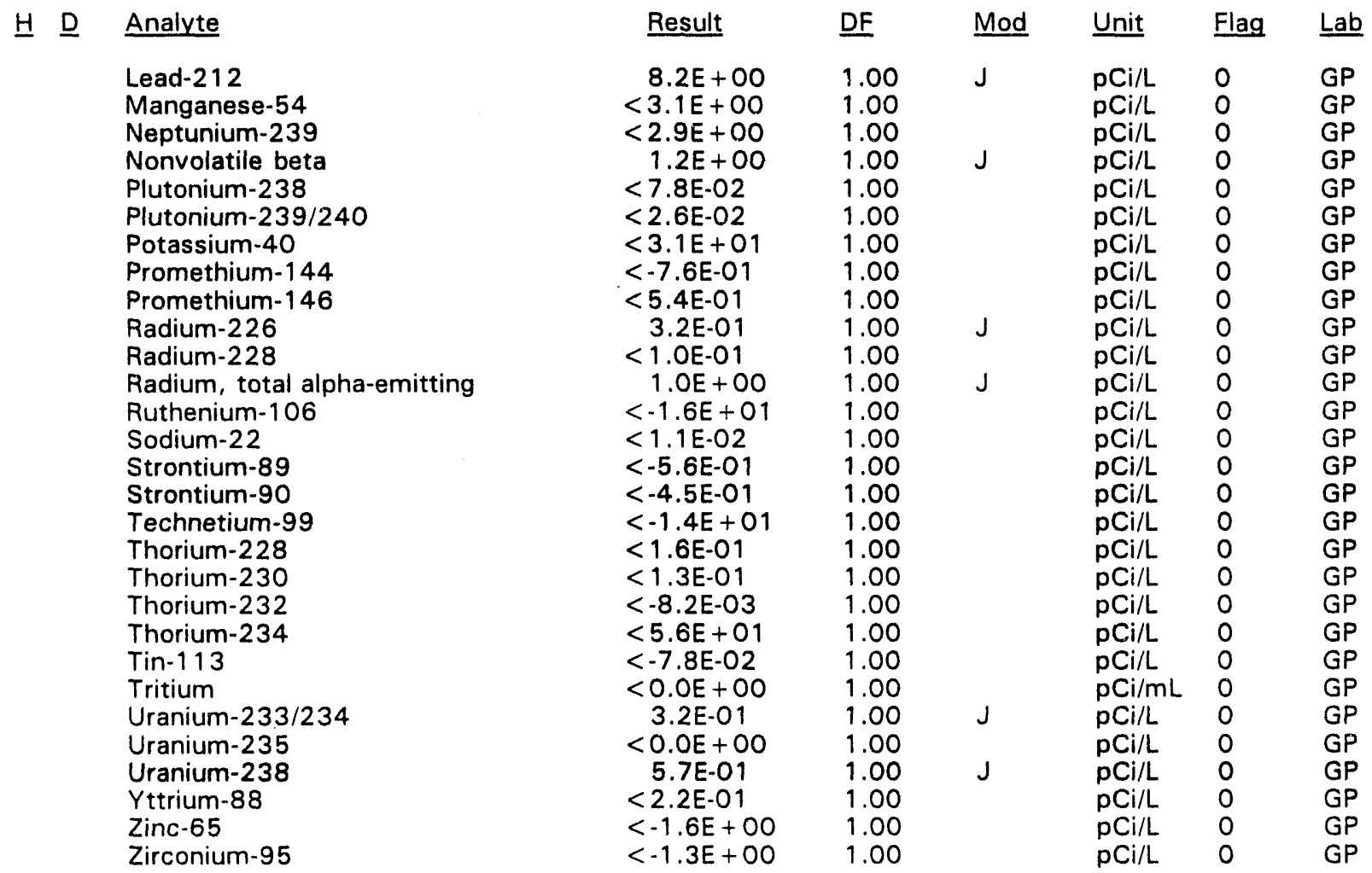

\section{WELL HSB 85B}

$\begin{array}{lllllll}\text { SRS Coord. } & \text { Lat/Longitude } & \text { Screen Zone Elevation } & \text { Top of Casing } & \text { Casing } & \text { Pump } & \text { Formation } \\ \text { N73789.3 } & 33.285162^{\circ} \mathrm{N} & 143.2-133.2 \mathrm{ft} \mathrm{msl} & 294.5 \mathrm{ft} \mathrm{msl} & 4^{\prime \prime} \text { PVC } & \text { S } & \text { McBean (IIB, } \\ \text { E58953.3 } & 81.654898^{\circ} \mathrm{W} & & & \end{array}$

\section{FIELD MEASUREMENTS}

Sample date: 03/16/94

Depth to water: $61.47 \mathrm{ft}(18.74 \mathrm{~m})$ below TOC

Water elevation: $233.03 \mathrm{ft}(71.03 \mathrm{~m}) \mathrm{msl}$

Sp. conductance: $209 \mu \mathrm{S} / \mathrm{cm}$

Turbidity: 2.8 NTU

Water evacuated before sampling: $50 \mathrm{gal}$

The well went dry during purging.

\section{LABORATORY ANALYSES}

H $\underline{\text { Analyte }}$

$\mathrm{pH}$

Specific conductance

Aldrin

Aldrin

Aluminum, total recoverable
Time: 11:05

$\mathrm{pH}: 10.2$

Alkalinity: $46 \mathrm{mg} / \mathrm{L}$

Water ternperature: $18.9^{\circ} \mathrm{C}$

Volumes purged: 0.8 well volumes

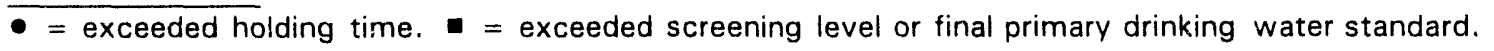


WELL HSB 85B collected on 03/16/94, laboratory analyses (cont.)

H $\underline{\text { Analyte }}$

Aluminum, total recoverable

Antimony, total recoverable

Antimony, total recoverable

Arsenic, total recoverable

Arsenic, total recoverable

Barium, total recoverable

Barium, total recoverable

Benzene

Bis(2-ethylhexyl) phthalate

Bromodichloromethane

Bromoform

Bromomethane (Methyl bromide)

Cadmium, total recoverable

Cadmium, total recoverable

Calcium, totai recoverable

Calcium, total recoverable

Carbon tetrachloride

Chloride

Chlorobenzene

Chloroethane

Chloroethene (Vinyl chloride)

2-Chloroethyl vinyl ether

Chloroform

Chloromethane (Methyl chloride)

Chromium, total recoverable

Chromium, total recoverable

Cobalt, total recoverable

Cobalt, tota! recoverable

Copper, total recoverable

Copper, total recoverable

Cyanide

$p, p^{\prime}-D D T$

p,p'-DDT

Dibromochloromethane

1,1-Dichloroethane

1,2-Dichloroethane

1,1-Dichloroethylene

trans-1,2-Dichloroethylene

Dichloromethane (Methylene chloride)

1,2-Dichloropropane

cis-1,3-Dichloropropene

trans-1,3-Dichloropropene

Dieldrin

Dieldrin

Ethylbenzene

Fluoride

Fluoride

Heptachlor

Heptachlor

Iron, total recoverable

Iron, total recoverable

Lead, total recoverable

Lead, total recoverable

Lindane

Lindane

Magnesium, total recoverable

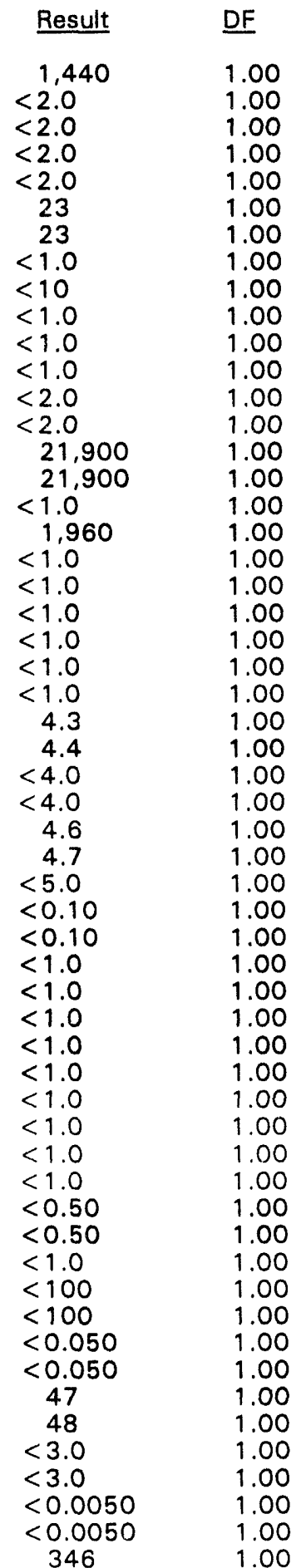

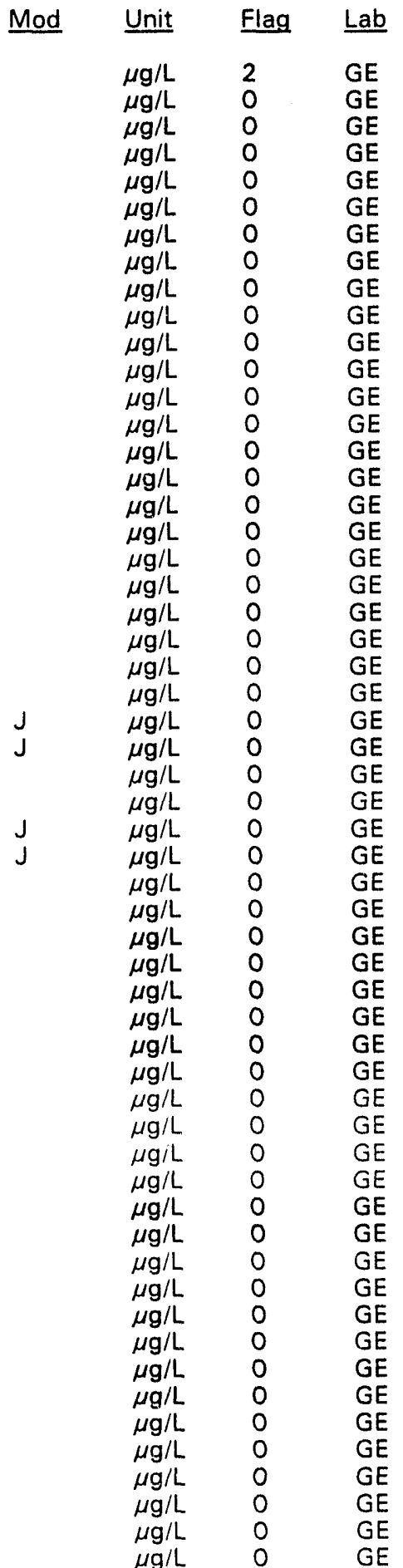

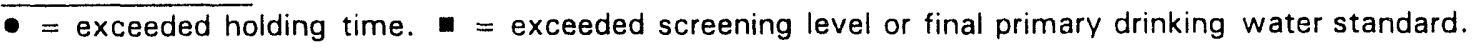


WELL HSB 85B collected on $03 / 16 / 94$, laboratory analyses (cont.)

H $\underline{\text { Analyte }}$

Magnesium, total recoverable

Manganese, total recoverable

Manganese, total recoverable

Mercury, total recoverable

Nickel, total recoverable

Nickel, total recoverable

Nitrate-nitrite as nitrogen

Phenols

Potassium, total recoverable

Potassium, total recoverable

Selenium, total recoverable

Selenium, total recoverable

Silica, total recoverable

Silica, total recoverable

Silver, total recoverable

Silver, total recoverable

Sodium, total recoverable

Sodium, total recoverable

Sulfate

1,1,2,2-Tetrachloroethane

Tetrachioroethylene

Tin, total recoverable

Tin, total recoverable

Toluene

Total dissolved solids

Total organic carbon

Total organic halogens

Total phosphates (as P)

1,1,1-Trichloroethane

1,1,2-Trichloroethane

Trichloroethylene

Trichlorofluoromethane

Vanadium, total recoverable

Vanadium, total recoverable

Zinc, total recoverable

Zinc, total recoverable

Actinium-228

Americium-241

Antimony-124

Antimony-125

Barium-133

Cerium-144

Cesium-134

Cesium-137

Cobalt-57

Cobalt-58

Cobalt-60

Curium-242

Curium-243/244

Curium-245/246

Europium-152

Europium-154

Europium-155

Gross alpha

lodine-129

Lead-212
Result D

$347 \quad 1.00$

$<2.0$

$<2.0$

$<0.20$

$<4.0$

$<4.0$

430

$<5.0$

3,120

3,130

$<2.0$

$<2.0$

13,700

13,800

$<2.0$

$<2.0$

7,010

7,010

$<1,000$

$<1.0$

$<1.0$

6.8

7.5

$<1.0$

128,000

$<1,000$

$<5.0$

$<50$

$<1.0$

$<1.0$

$<1.0$

$<1.0$

8.8

9.0

10

11

$1.3 E+01$

$<-2.7 \mathrm{E}-04$

$<-1.5 E+00$

$<-4.7 E+00$

$<2.4 \mathrm{E}+00$

$<7.9 E+00$

$<-4.0 E-01$

$<-9.8 \mathrm{E}-01$

$<7.4 \mathrm{E}-01$

$<-1.4 \mathrm{E}+00$

$<3.6 \mathrm{E}-01$

$<-1.3 \mathrm{E}-02$

$<-4.0 \mathrm{E}-02$

$<-4.4 \mathrm{E}-03$

$<2.1 \mathrm{E}+00$

$<-4.5 \mathrm{E}-01$

$<3.0 E+00$

8.8E-01

$<3.5 \mathrm{E}-01$

$<7.6 \mathrm{E}-01$
DF

1.00

1.00

1.00

1.00

1.00

1.00

1.00

1.00

1.00

1.00

1.00

1.00

1.00

1.00

1.00

1.00

1.00

1.00

1.00

1.00

1.00

1.00

1.00

1.00

1.00

1.00

1.00

1.00

1.00

1.00

1.00

1.00

1.00

1.00

1.00

1.00

1.00

1.00

1.00

1.00

1.00

1.00

1.00

1.00

1.00

1.00

1.00

1.00

1.00

1.00

1.00

1.00

1.00

1.00

1.00
Mod Unit Flag Lab

$\mu g / L \quad 0 \quad G E$

$\mu g / L$

$\mu g / L \quad 0 \quad$ GE

$\mu \mathrm{g} / \mathrm{L} \quad 0 \quad \mathrm{GE}$

$\mu \mathrm{g} / \mathrm{L} \quad 0 \quad \mathrm{GE}$

$\mu \mathrm{g} / \mathrm{L} \quad \mathrm{O} \quad \mathrm{GE}$

$\mu \mathrm{g} / \mathrm{L} \quad 0 \quad \mathrm{GE}$

$\mu \mathrm{g} / \mathrm{L} \quad 0 \quad \mathrm{GE}$

$\mu \mathrm{g} / \mathrm{L}$

$\mu \mathrm{g} / \mathrm{L} \quad \mathrm{O} \quad \mathrm{GE}$

$\mu \mathrm{g} / \mathrm{L} \quad 0 \quad \mathrm{GE}$

$\mu \mathrm{g} / \mathrm{L} \quad 0 \quad \mathrm{GE}$

$\mu \mathrm{g} / \mathrm{L} \quad 0 \quad \mathrm{GE}$

$\mu \mathrm{g} / \mathrm{L} \quad 0 \quad \mathrm{GE}$

$\mu g / L \quad 0 \quad G E$

$0 \quad G E$

$\mu g / L \quad 0 \quad$ GE

$\mu \mathrm{g} / \mathrm{L} \quad \mathrm{O} \quad \mathrm{GE}$

$\mu \mathrm{g} / \mathrm{L} \quad 0 \quad \mathrm{GE}$

$\mu \mathrm{g} / \mathrm{L} \quad 0 \quad \mathrm{GE}$

$\mu \mathrm{g} / \mathrm{L} \quad 0 \quad \mathrm{GE}$

$\mu \mathrm{g} / \mathrm{L} \quad 0 \quad \mathrm{GE}$

$0 \quad G E$

$\mu g / L \quad 0 \quad$ GE

JV2

$\mu g / L \quad 0 \quad \mathrm{GE}$

$\mu \mathrm{g} / \mathrm{L} \quad 0 \quad \mathrm{GE}$

$\mu \mathrm{g} / \mathrm{L} \quad 0 \quad \mathrm{GE}$

$\mu \mathrm{g} / \mathrm{L} \quad 0 \quad \mathrm{GE}$

$\mu \mathrm{g} / \mathrm{L} \quad 0 \quad \mathrm{GE}$

$\mathrm{GE}$

$\mu g / L \quad 0 \quad$ GE

$\mu g / L \quad 0 \quad G E$

$\mu g / L \quad 0 \quad$ GE

$\mu g / L \quad O \quad$ GE

$\mu \mathrm{g} / \mathrm{L} \quad 0 \quad \mathrm{GE}$

$\mu g / L \quad 0 \quad G E$

$\mathrm{pCi} / \mathrm{L} \quad 0 \quad \mathrm{GP}$

$p C i / L \quad 0 \quad G P$

$\mathrm{pCi} / \mathrm{L} \quad 0 \quad \mathrm{GP}$

$\mathrm{pCi} / \mathrm{L} \quad 0 \quad \mathrm{GP}$

$\mathrm{pCi} / L \quad 0 \quad \mathrm{GP}$

$\mathrm{pCi} / \mathrm{L} \quad 0 \quad \mathrm{GP}$

pCill $0 \quad$ GP

$\mathrm{pCi} / \mathrm{L} \quad 0 \quad \mathrm{GP}$

$\mathrm{pCi} / \mathrm{L} \quad 0 \quad \mathrm{GP}$

$\mathrm{pCi} / \mathrm{L} \quad 0 \quad \mathrm{GP}$

$p C i / L \quad 0 \quad G P$

$\mathrm{pCi} / \mathrm{L} \quad 0 \quad \mathrm{GP}$

$\mathrm{pCi} / \mathrm{L} \quad 0 \quad \mathrm{GP}$

$\mathrm{pCi} / \mathrm{L} \quad 0 \quad \mathrm{GP}$

$\mathrm{pCi} / \mathrm{L} \quad 0 \quad \mathrm{GP}$

$\mathrm{pCi} / \mathrm{L} \quad 0 \quad \mathrm{GP}$

$\mathrm{pCi} / \mathrm{L} \quad 0 \quad \mathrm{GP}$

$\mathrm{pCi} / \mathrm{L} \quad 0 \quad \mathrm{GP}$

$\mathrm{pCi} / \mathrm{L} \quad 0 \quad \mathrm{GP}$

$\mathrm{pCi} / \mathrm{L} \quad 0 \quad \mathrm{GP}$

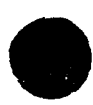

- = exceeded holding time. = exceeded screening level or final primary drinking water standard. 
WELL HSB 85B collected on 03/16/94, laboratory analyses (cont.)

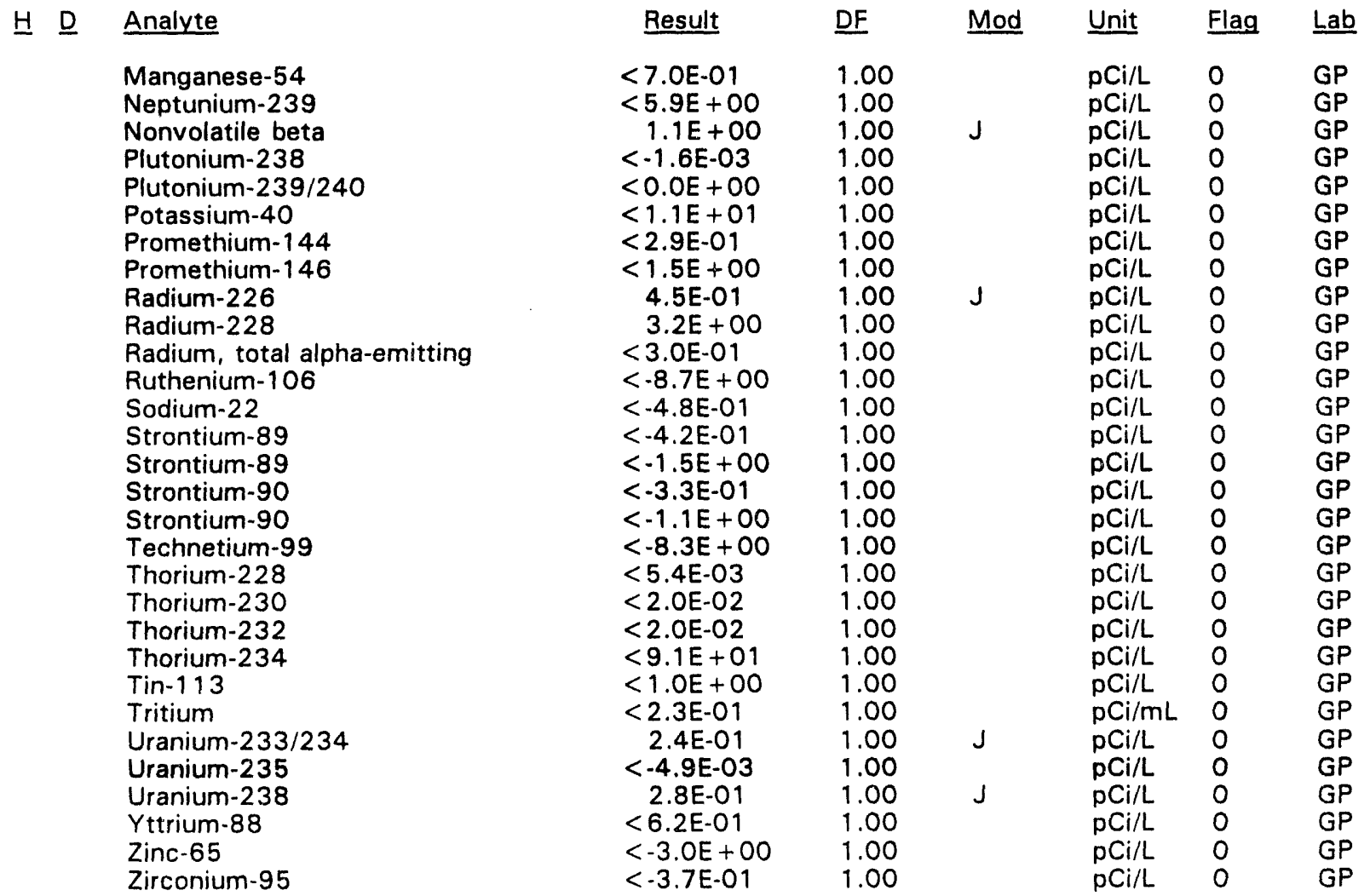

\section{WELL HSB 85C}

\begin{tabular}{|c|c|c|c|c|c|c|}
\hline SRS Coord. & Lat/Longitude & Screen Zone Elevation & Top of Casing & Casing & Pump & Formation \\
\hline$?$ & $85182^{\circ} \mathrm{N}$ & $224.2-214$ & $\mathrm{ft} \mathrm{msl}$ & 4" PVC & $S$ & $V$ \\
\hline
\end{tabular}

\section{FIELD MEASUREMENTS}

Sample date: 01/14/94

Depth to water: $55.62 \mathrm{ft}(16.95 \mathrm{~m})$ below TOC

Water elevation: $238.48 \mathrm{ft}(72.69 \mathrm{~m}) \mathrm{msl}$

Sp. conductance: $33 \mu \mathrm{S} / \mathrm{cm}$

Turbidity: 0.2 NTU

Water evacuated before sampling: $79 \mathrm{gal}$

\section{LABORATORY ANALYSES}

H D Analyte

- $\mathrm{pH}$

Specific conductance Specific conductance Aldrin
Time: 9: 51

pH: 4.6

Alkalinity: $0 \mathrm{mg} / \mathrm{L}$

Water temperature: $19.4^{\circ} \mathrm{C}$

Volumes purged: 5.0 well volumes 
WELL HSB 85C collected on $01 / 14 / 94$, laboratory analyses (cont.)

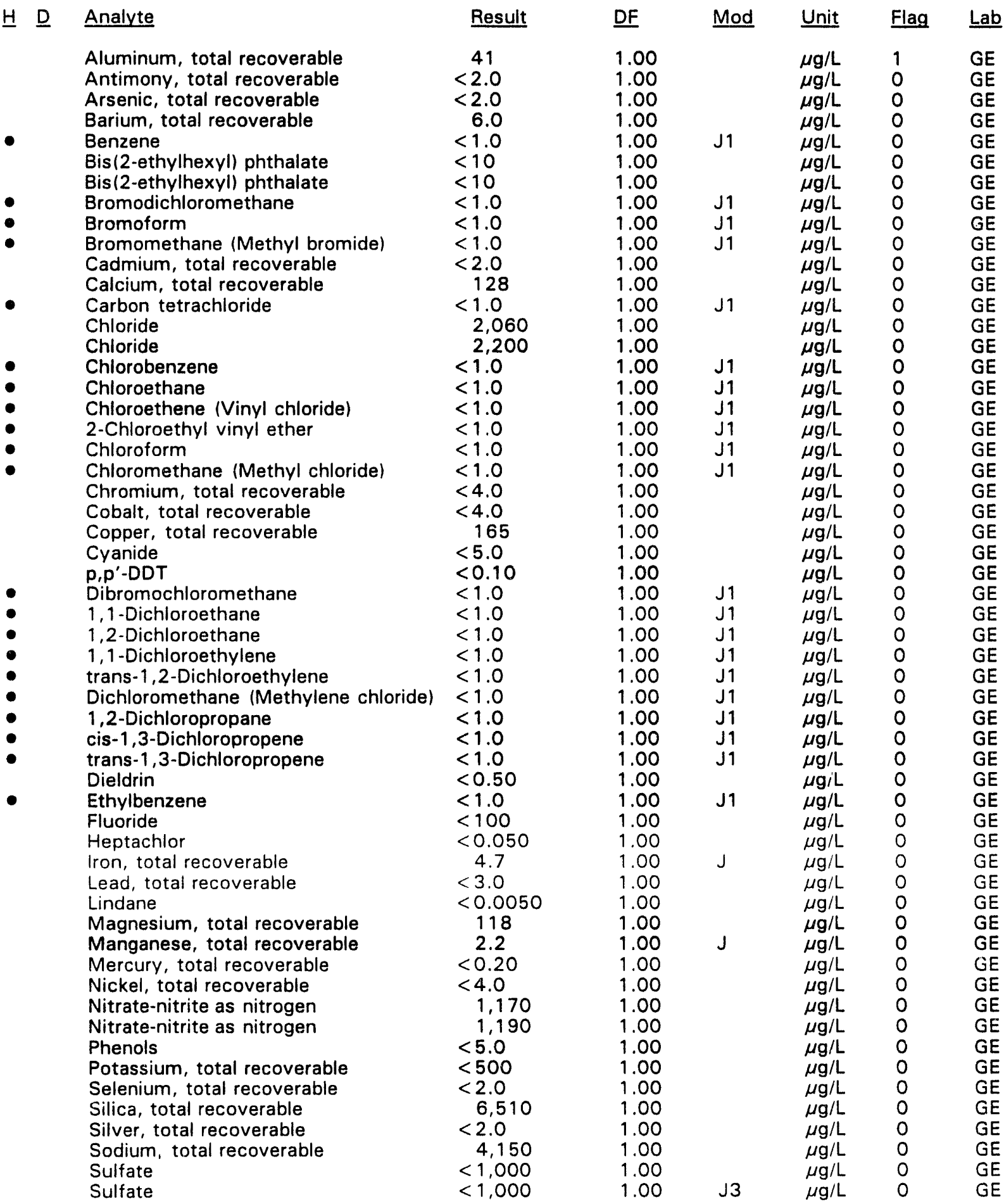

\footnotetext{
- = exceeded holding time. $\square=$ exceeded screening level or final primary drinking water standard.
} 
WELL HSB 85C collected on 01/14/94, laboratory analyses (cont.)

\begin{tabular}{|c|c|c|c|c|c|c|}
\hline Analyte & Result & $\underline{D F}$ & Mod & Unit & Flag & $\underline{L a b}$ \\
\hline 1,1,2,2-Tetrachioroethane & $<1.0$ & 1.00 & J1 & $\mu \mathrm{g} / \mathrm{L}$ & 0 & GE \\
\hline Tetrachioroethylene & & & J1 & $\mu \mathrm{g} / \mathrm{L}$ & 0 & - \\
\hline $\begin{array}{l}\text { Tin, total recoverable } \\
\text { Toluene }\end{array}$ & $\begin{array}{l}<2.0 \\
<1.0\end{array}$ & 1.00 & 11 & $\mu \mathrm{g} / \mathrm{L}$ & 0 & SE \\
\hline Total dissolved solids & 26,000 & 1.00 & J & $\begin{array}{l}\mu \mathrm{g} / \mathrm{L} \\
\mu \mathrm{g} / \mathrm{L}\end{array}$ & 0 & $\begin{array}{l}\text { GE } \\
G E\end{array}$ \\
\hline Total organic carbon & 20,400 & 1.00 & & $\mu \mathrm{g} / \mathrm{L}$ & 2 & GE \\
\hline Total organic halogens & $<5.0$ & 1.00 & & $\mu \mathrm{g} / \mathrm{L}$ & 0 & BE \\
\hline Total phosphates (as P) & $<50$ & 1.00 & & $\mu \mathrm{g} / \mathrm{L}$ & 0 & E \\
\hline 1,1,1-Trichloroethane & $<1.0$ & 1.00 & $j 1$ & $\mu \mathrm{g} / \mathrm{L}$ & 0 & $\Gamma$ \\
\hline 1,1,2-Trichloroethane & $<1.0$ & 1.00 & J1 & $\mu \mathrm{g} / \mathrm{L}$ & 0 & IC \\
\hline Trichloroethylene & $<1.0$ & 1.00 & J1 & $\mu \mathrm{g} / \mathrm{L}$ & 0 & SE \\
\hline Trichlorofluoromethane & $<1.0$ & 1.00 & J1 & $\mu \mathrm{g} / \mathrm{L}$ & 0 & JE \\
\hline Vanadium, total recoverable & $<8.0$ & 1.00 & & $\mu \mathrm{g} / \mathrm{L}$ & 0 & GE \\
\hline $\begin{array}{l}\text { Zinc, total recoverable } \\
\text { Actinium-228 }\end{array}$ & $\begin{array}{l}20 \\
<4.1 E+00\end{array}$ & $\begin{array}{l}1.00 \\
1.00\end{array}$ & & $\begin{array}{l}\mu \mathrm{g} / \mathrm{L} \\
\mathrm{pCi} / \mathrm{L}\end{array}$ & $\begin{array}{l}0 \\
0\end{array}$ & $\begin{array}{l}\text { GE } \\
\text { GP }\end{array}$ \\
\hline Americium-241 & $<-1.4 \mathrm{E}-02$ & 1.00 & & $\mathrm{pCi} / \mathrm{L}$ & 0 & GP \\
\hline Antimony-124 & $<-1.6 E+00$ & $1.0 v$ & & $\mathrm{pCi} / \mathrm{L}$ & 0 & $G P$ \\
\hline Antimony-125 & $<2.3 E+00$ & 1.00 & & $\mathrm{pCi} / \mathrm{L}$ & 0 & GP \\
\hline Barium-133 & $<2.6 \mathrm{E}-01$ & 1.00 & & $\mathrm{pCi} / \mathrm{L}$ & 0 & $G P$ \\
\hline Cerium-144 & $<-1.9 E+00$ & 1.00 & & $\mathrm{pCi} / \mathrm{L}$ & 0 & $G P$ \\
\hline Cesium-134 & $<1.7 E+00$ & 1.00 & & $\mathrm{pCi} / \mathrm{L}$ & 0 & GP \\
\hline Cesium-137 & $<-3.1 \mathrm{E}-01$ & 1.00 & & $\mathrm{pCi} / \mathrm{L}$ & 0 & GP \\
\hline Cobalt -57 & $<5.3 \mathrm{E}-01$ & 1.00 & & $\mathrm{pCi} / \mathrm{L}$ & 0 & GP \\
\hline Cobalt-58 & $<1.4 E+00$ & 1.00 & & $\mathrm{pCi} / \mathrm{L}$ & 0 & GP \\
\hline Cobalt -60 & $<-2.1 E-01$ & 1.00 & & $\mathrm{pCi} / \mathrm{L}$ & 0 & GP \\
\hline Curium-242 & $<-1.4 \mathrm{E}-02$ & 1.00 & & $\mathrm{pCi} / \mathrm{L}$ & 0 & GP \\
\hline Curium-243/244 & $<3.2 \mathrm{E}-02$ & 1.00 & & $\mathrm{pCi} / \mathrm{L}$ & 0 & GP \\
\hline Curium-245/246 & $<0.0 E+00$ & 1.00 & & $\mathrm{pCi} / \mathrm{L}$ & 0 & GP \\
\hline Europium-152 & $<2.9 \mathrm{E}+00$ & 1.00 & & $\mathrm{pCi} / \mathrm{L}$ & 0 & GP \\
\hline Europium-154 & $<-1.5 E+00$ & 1.00 & & $\mathrm{pCi} / \mathrm{L}$ & 0 & $\mathrm{GP}$ \\
\hline Europium-155 & $<3.2 \mathrm{E}+00$ & 1.00 & & $\mathrm{pCi} / \mathrm{L}$ & 0 & GP \\
\hline Gross alpha & $1.3 E+00$ & 1.00 & J & $\mathrm{pCi} / \mathrm{L}$ & 0 & GP \\
\hline lodine-129 & $<-1.5 \mathrm{E}-01$ & 1.00 & & $\mathrm{pCi} / \mathrm{L}$ & 0 & GP \\
\hline Lead-212 & $7.3 E+00$ & 1.00 & $J$ & $\mathrm{pCi} / \mathrm{L}$ & 0 & P \\
\hline Manganese-54 & $<8.5 \mathrm{E}-01$ & 1.00 & & $\mathrm{pCi} / \mathrm{L}$ & 0 & iP \\
\hline Neptunium-239 & $<1.4 E+00$ & 1.00 & JV2 & $\mathrm{pCi} / \mathrm{L}$ & 0 & GP \\
\hline Nonvolatile beta & $1.5 E+00$ & 1.00 & $J$ & $\mathrm{pCi} / \mathrm{L}$ & 0 & GP \\
\hline Plutonium-238 & $<-1.6 \mathrm{E}-02$ & 1.00 & & $\mathrm{pCi} / \mathrm{L}$ & 0 & GP \\
\hline Plutonium-239/240 & $<-1.4 \mathrm{E}-02$ & 1.00 & & $\mathrm{pCi} / \mathrm{L}$ & 0 & $\mathrm{GP}$ \\
\hline Potassium-40 & $3.0 E+01$ & 1.00 & $J$ & $\mathrm{pCi} / \mathrm{L}$ & 0 & GP \\
\hline Promethium-144 & $<9.0 E-01$ & 1.00 & & $\mathrm{pCi} / \mathrm{L}$ & 0 & $G P$ \\
\hline Promethium-146 & $<-1.9 E+00$ & 1.00 & & $\mathrm{pCi} / \mathrm{L}$ & 0 & $G P$ \\
\hline Radium-226 & $1.6 E+00$ & 1.00 & J & $\mathrm{pCi} / \mathrm{L}$ & 0 & $G P$ \\
\hline Radium-226 & $1.5 E+00$ & 1.00 & J & $\mathrm{pCi} / \mathrm{L}$ & 0 & GP \\
\hline Radium-228 & $1.5 E+00$ & 1.00 & $\mathrm{~J}$ & $\mathrm{pCi} / \mathrm{L}$ & 0 & GP \\
\hline Radium, total alpha-emitting & $1.5 E+00$ & 1.00 & $\mathrm{~J}$ & $\mathrm{pCi} / \mathrm{L}$ & 0 & GP \\
\hline Ruthenium-106 & $<5.3 E+00$ & 1.00 & & $\mathrm{pCi} / \mathrm{L}$ & 0 & GP \\
\hline Sodium-22 & $<-1.3 E+00$ & 1.00 & & $\mathrm{pCi} / \mathrm{L}$ & 0 & GP \\
\hline Strontium-89 & $<-1.2 E+00$ & 1.00 & & $\mathrm{pCi} / \mathrm{L}$ & 0 & GP \\
\hline Strontium-90 & $<-8.5 \mathrm{E}-01$ & 1.00 & & $\mathrm{pCi} / \mathrm{L}$ & 0 & GP \\
\hline Technetium-99 & $<-1.2 E+01$ & 1.00 & & $\mathrm{pCi} / \mathrm{L}$ & 0 & GP \\
\hline Thorium-228 & $<2.7 E-02$ & 1.00 & & $\mathrm{pCi} / \mathrm{L}$ & 0 & GP \\
\hline Thorium-230 & $<1.9 \mathrm{E}-02$ & 1.00 & & $\mathrm{pCi} / \mathrm{L}$ & 0 & GP \\
\hline Thorium-232 & $<0.0 E+00$ & 1.00 & & $\mathrm{pCi} / \mathrm{L}$ & 0 & GP \\
\hline Thorium-234 & $<1.3 E+02$ & 1.00 & & $\mathrm{pCi} / \mathrm{L}$ & 0 & GP \\
\hline $\operatorname{Tin}-113$ & $<6.3 \mathrm{E}-01$ & 1.00 & & $\mathrm{pCi} / \mathrm{L}$ & 0 & GP \\
\hline
\end{tabular}

- = exceeded holding time. - = exceeded screening level or final primary drinking water standard. 
WELL HSB 85C collected on 01/14/94, laboratory analyses (cont.)

\begin{tabular}{|c|c|c|c|c|c|c|}
\hline$\underline{H} \quad \underline{D}$ & Analyte & Result & DF & Mod & Unit & Flag \\
\hline & $\begin{array}{l}\text { Tritium } \\
\text { Uranium-233/234 } \\
\text { Uranium-235 } \\
\text { Uranium-238 } \\
\text { Yttrium-88 } \\
\text { Zinc-65 } \\
\text { Zirconium-95 }\end{array}$ & $\begin{aligned} & 4.5 E+00 \\
< & 0.0 E+00 \\
< & -6.6 E-03 \\
< & -6.6 E-03 \\
< & 1.0 E-01 \\
< & 1.2 E+00 \\
& 4.6 E+00\end{aligned}$ & $\begin{array}{l}1.00 \\
1.00 \\
1.00 \\
1.00 \\
1.00 \\
1.00 \\
1.00\end{array}$ & $\mathbf{j}$ & $\begin{array}{l}\mathrm{pCi} / \mathrm{mL} \\
\mathrm{pCi} / \mathrm{L} \\
\mathrm{pCi} / \mathrm{L} \\
\mathrm{pCi} / \mathrm{L} \\
\mathrm{pCi} / \mathrm{L} \\
\mathrm{pCi} / \mathrm{L} \\
\mathrm{pCi} / \mathrm{L}\end{array}$ & $\begin{array}{l}0 \\
0 \\
0 \\
0 \\
0 \\
0 \\
0\end{array}$ \\
\hline
\end{tabular}

$\overline{-}=$ exceeded holding time. = exceeded screening level or final primary drinking water standard. 
WSRC-TR-94-0240

Unclassified

\section{Appendix E}

\section{Data Quality/Useability Assessment}


THIS PAGE LEFT BLANK INTENTIONALLY 


\section{Data Quality/Useability Assessment}

Quality assurance/quality control (QAVC) procedures relating to accuracy and precision of analyses performed on groundwater samples are followed in the field and laboratory and are reviewed prior to publication of results. The review by the Environmental Protection Department Environmental Monitoring Section (EPD/EMS) of the volume of analytical data acquired each quarter and presented in various reports is an ongoing process; its review of the QAVC data cannot be completed in time to meet the deadlines for the reports required by the Resource Conservation and Recovery Act and associated regulations. Other site and regulatory personnel can obtain further information on the data quality and useability in a variety of ways, including those described below.

\section{Data Qualification}

The contract laboratories continually assess their own accuracy and precision according to U.S. Environmental Protection Agency (EPA) guidelines. They submit sample- or batch-specific QAVQC information either at the same time as analytical results or in quarterly summaries. Properly defined and used result modifiers (also referred to as qualifiers) can be a key component in assessing data useability. Result modifiers designed by EPD/EMS and used by the primary laboratories are presented in Appendix D.

\section{Assessment of Accuracy of the Data}

Accuracy, or the nearness of the reported result to the true concentration of a constituent in a sample, can be assessed in several ways.

A laboratory's general accuracy can be judged by analysis of results obtained from known samples. The non-radionuclide contract laboratories analyze commercial reference samples every quarter at EPD/EMS' request. The results of these analyses are presented in the EPD/ EMS groundwater monitoring quarterly reports. The primary laboratories also seek or maintain state certification by participating periodically in performance studies; reference samples and analysis of results are provided by EPA. Results of these studies also are published in the EPD/EMS quarterly reports.

Analysis of blanks provides a tool for assessing the accuracy of both sampling and laboratory analysis. Results for all field blanks for the quarter can be found in the EPD/EMS quarterly reports. Any field or laboratory blanks that exceed established minimums are identified in the same reports, in tables associating them with groundwater samples analyzed in the same batches.

Surrogates, organic compounds similar in chemical behavior to the compounds of interest but not normally found in environmental samples, are used to monitor the effect of the matrix on the accuracy of analyses for organic parameters. For example, for analyses of volatile organics by EPA Method 8240, three surrogate compounds are added to all samples and blanks in each analytical batch. In analyses of semivolatile organics, three acid compounds and three base/neutral compounds are used. Two surrogates are used in organochlorine pesticides analyses. Percent recoveries for surrogate analyses are calculated by laboratory personnel, reported to EPD/EMS, reviewed, and entered into the database, but they are not published. If recoveries are not within specified limits, the laboratory is expected to reanalyze the samples or attach qualifiers to the data identifying the anomalous results. 
Sample-specific accuracy for both organic and inorganic parameters can be assessed by examination of matrix spike/matrix spike duplicate results. A sarnple is analyzed unspiked to determine a baseline set of values. A second portion of sample is spiked with known concentrations of compounds appropriate to the analyses being performed, typically five volatile organic compounds for volatile organics analyses, eleven semivolatile compounds for semivolatiles, six pesticide compounds for pesticides, all metals for metals analyses by SW-846 methods (EPA 1986), and a known quantity of cyanide for cyanide analysis. The percentage of the spike compound that is recovered (i.e., measured in excess of ihe value obtained for the unspiked sample) is a direct measure of analytical accuracy. EPA requires matrix spike/matrix spike duplicates to be run at least once per 20 samples of similar matrix.

Matrix spike/matrix spike duplicate results are reported to EPD/EMS but are not published. For organic compounds, according to EPA guidelines, no action is taken on the basis of matrix spike/ matrix spike duplicate data alone (i.e., no result modifiers are assigned solely on the basis of matrix spike results); however, the results can indicate if a laboratory is having a systematic problem in the analysis of one or more analytes.

In the case of inorganic compounds, such as metals, the matrix spike sample analysis provides information about the effect of each sample matrix on the digestion and measurement methodology. Data qualifiers assigned by the laboratories on the basis of the percentage of spike recovery are reported in the published results tables.

\section{Assessment of Precision}

Precision of the analyses, or agreement of a set of replicate results among themselves, is assessed through the use of duplicates (laboratory-initiated) and blind replicates (provided by EPD/EMS). The results of duplicate and replicate analyses are presented in the results tables of these reports for the first, second, and third quarters of each year. Duplicate and replicate results are not presented in fourth-quarter reports; the results tables present instead only the highest result for each analyte for each quarter of the year.

The laboratories assess precision by calculating the relative percent difference, or RPD, for each pair of laboratory-initiated duplicate results. One of the contract laboratories uses a data qualifier (J3) to modify metals analyses when the RPD for laboratory duplicates is greater than $20 \%$.

Additional statistical comparisons of laboratory duplicate and blind replicate results, both intraand interlaboratory, are presented in the EPD/EMS quarterly reports. The calculation used for these reports is the MRD, or mean relative difference, which is similar to EPA's RPD except that the MRD provides a single value for all of the analyses of a particular compound, either intra- or interlaboratory, during one quarter. Because detection limits may vary among samples, the MRD requires calculation of a reference detection limit, which is the detection limit at the 90th percentile of the array of limits in the population of all duplicate and replicate analyses for a given analyte during a particular quarter. The MRD is not method-specific.

\section{Method-Specific Accuracy and Precision}

The contract laboratories' EPA-approved laboratory procedures include QA/QC requirements as an integral part of the methods. Thus, knowledge of the method used in obtaining data is an important component of determining data useability. EPA has conducted extensive research and development on the methods approved for the analysis of water and waste water; information on the accuracy and precision of the method is available from EPA publications, as is full information on required $\mathrm{QA} / \mathrm{QC}$ procedures. A listing of the methods used by the primary laboratories 
during fourth quarter 1993 is given below along with the source for the method description. Many, if not all, of these sources include presentations of representative accuracy and precision results.

\section{Methods Used by the Contract Laboratories}

\begin{tabular}{|c|c|c|}
\hline Method & Used to Analyze & Source \\
\hline EPA120.1 & Specific conductance & EPA EMSL 1983 \\
\hline EPA150.1 & $\mathrm{pH}$ & EPA EMSL 1983 \\
\hline EPA160.1 & Total dissolved solids & EPA EMSL 1983 \\
\hline EPA160.2 & Total dissolved solids, total suspended solids & EPA EMSL 1983 \\
\hline EPA180.1 & Turbidity & EPA EMSL 1983 \\
\hline EPA200.7 & Metals & EPA EMSL 1983 \\
\hline EPA204.2 & Antimony & EPA EMSL 1983 \\
\hline EPA206.2 & Arsenic & EPA EMSL 1983 \\
\hline EPA239.2 & Lead & EP, $\backslash$ EMSL 1983 \\
\hline EPA245.1 & Mercury & EFA EMSL 1983 \\
\hline EPA270.2 & Selenium & EPA EMSL 1983 \\
\hline EPA279.2 & Thallium & EPA EMSL 1983 \\
\hline EPA300.0 & Chloride, nitrite, sulfate & EPA EMSL 1991 \\
\hline EPA310.1 & Alkalinity & EPA EMSL 1983 \\
\hline EPA325.2 & Chloride & EPA EMSL 1983 \\
\hline EPA335.3 & Cyanide & EPA EMSL 1983 \\
\hline EPA340.2 & Fluoride & EPA EMSL 1983 \\
\hline EPA353.1 & Nitrogen, nitrate-nitrite & EPA EMSL 1983 \\
\hline EPA353.2 & Nitrogen, nitrate, nitrite, or combined & EPA EMSL 1983 \\
\hline EPA365.1 & Phosphorus, all forms (reported as total phosphates) & EPA EMSL 1983 \\
\hline EPA365.2 & Phosphorus, all forms (reported as total phosphates) & EPA EMSL 1983 \\
\hline EPA376.2 & Sulfide & EPA EMSL 1983 \\
\hline EPA413.1 & Oil \& grease & EPA EMSL 1983 \\
\hline EPA415.1 & $\begin{array}{l}\text { Dissolved organic carbon, total inorganic carbon, total } \\
\text { organic carbon }\end{array}$ & EPA EMSL 1983 \\
\hline EPA418.1 & Total petroleum hydrocarbons & EPA EMSL 1983 \\
\hline EPA420.2 & Phenols & EPA EMSL 1983 \\
\hline EPA900.0 & Gross alpha, nonvolatile beta & EPA EMSL 1980 \\
\hline EPA900.1 & Total alpha-emitting radium & EPA EMSL 1980 \\
\hline EPA906.0 & Tritium & EPA EMSL 1980 \\
\hline EPA6010 & Metals & EPA 1986 \\
\hline EPA7041 & Antimony & EPA 1986 \\
\hline EPA7060 & Arsenic & EPA 1986 \\
\hline EPA7421 & Lead & EPA 1986 \\
\hline EPA7470 & Mercury & EPA 1986 \\
\hline EPA7740 & Selenium & EPA 1986 \\
\hline EPA7841 & Thallium & EPA 1986 \\
\hline EPA8010 & Chlorinated volatile organics & EPA 1986 \\
\hline EPA8080 & Organochlorine pesticides and PCBs & EPA 1986 \\
\hline EPA8150 & Chlorinated herbicides & EPA 1986 \\
\hline EPA8240 & GCMS volatiles & EPA 1986 \\
\hline EPA8270 & GCMS semivolatiles & EPA 1986 \\
\hline EPA8280 & Dioxins and furans & EPA 1986 \\
\hline EPA9012 & Cyanide & EPA 1986 \\
\hline EPA9020 & Total organic halogens & EPA 1986 \\
\hline EPA9020A & Total organic halogens & EPA 1986 \\
\hline EPA9030 & Sulfide & EPA 1986 \\
\hline EPA9060 & $\begin{array}{l}\text { Dissolved organic carbon, total inorganic carbon, total } \\
\text { organic carbon }\end{array}$ & EPA 1986 \\
\hline
\end{tabular}



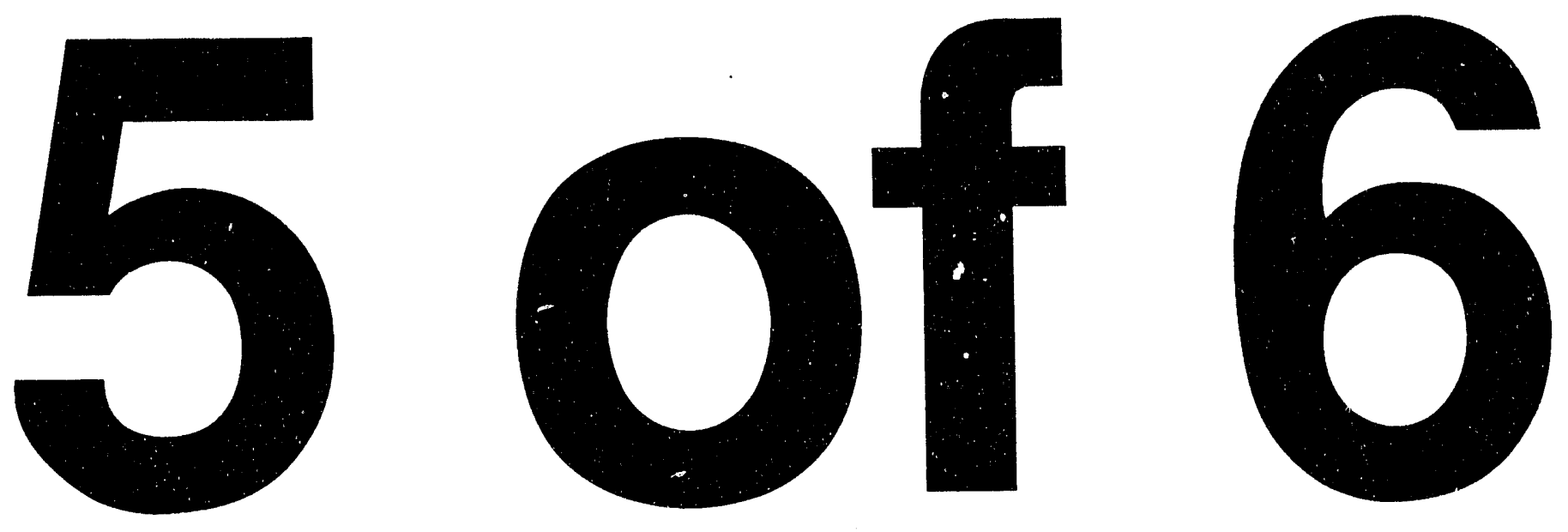
An example of available method-specific QA/QC information is that for the analysis of metals by EPA Method 6010/200.7 (EPA, 1986/EPA EMSL, 1983). The primary laboratories, General Engineering Laboratories (GE) and Roy F. Weston, Inc. (Weston), use this inductively coupled plasma (ICP) atomic emission spectrometric method.

The following precision and accuracy data are based on the experience of seven laboratories that applied the ICP technique to acid-distilled water matrices that had been spiked with various metal concentrates. (Note: Not all seven laboratories analyzed all 14 elements.) The references give results for samples having three concentration ranges; the results here are for samples having the lowest values, similar to actual groundwater results for SRS.

ICP Precision and Accuracy Data

\begin{tabular}{llll} 
Element & True value $(\mu \mathrm{g} / \mathrm{L})$ & $\begin{array}{l}\text { Mean reported } \\
\text { value }(\mu \mathrm{g} / \mathrm{L})\end{array}$ & Mear \\
\cline { 2 - 4 } & & & 33 \\
Aluminum & 60 & 62 & 23 \\
Arsenic & 22 & 19 & 9.8 \\
Beryllium & 20 & 20 & 16 \\
Cadmium & 2.5 & 2.9 & 18 \\
Chromium & 10 & 10 & 4.1 \\
Cobalt & 20 & 20 & 40 \\
Copper & 11 & 11 & 15 \\
Iron & 20 & 19 & 32 \\
Lead & 24 & 30 & 6.7 \\
Manganese & 15 & 15 & 11 \\
Nickel & 30 & 28 & 42 \\
Selenium & 6 & 8.5 & 2.9 \\
Vanadium & 70 & 69 & 45 \\
Zinc & 16 & 19 &
\end{tabular}

a Relative standard deviation. In EPA (1986), the column heading is Mean Standard Deviation (\%).

As another example, EPA Method 601/8010 (EPA, 1991/EPA, 1986) is used by both GE and Weston for analyses of halogenated volatile organics. In the presentation of the method in both references, the following table gives method-specific accuracy and precision as functions of concentration. Contract laboratories are expected to achieve or at least approach these limits.

Accuracy and Precision as Functions of Concentration for EPA. Method 601/8010

\section{Parameter}

Bromodichloromethane

Bromoform

Bromomethane

Carbon tetrachloride

Chlorobenzene

Chloroethane

2-Chloroethyl vinyl ether ${ }^{f}$

Chloroform

Chloromethane

Dibromochioromethane

1,2-Dichlorobenzene
Accuracy as recovery, $X^{\prime a}(\mu g / L)$

$1.12 C-1.02^{\mathrm{d}}$

$0.96 C-2.05$

$0.76 C-1.27$

$0.98 C-1.04$

$1.00 C-1.23$

$0.99 C-1.53$

$1.00 \mathrm{C}$

$0.93 C-0.39$

$0.77 \mathrm{C}+0.18$

$0.94 C+2.72$

$0.93 C+1.70$
Single analyst precision $(\mu \mathrm{g} / \mathrm{L})^{b}$

$0.11 \bar{X}+0.04^{e}$

$0.12 \bar{X}+0.58$

$0.28 \bar{X}+0.27$

$0.15 \bar{X}+0.38$

$0.15 \bar{X}-0.02$

$0.14 \bar{X}-0.13$

$0.20 \bar{X}$

$0.13 \bar{X}+0.15$

$0.28 \bar{X}-0.31$

$0.11 \bar{X}+1.10$

$0.20 \bar{X}+0.97$
Overall precision $(\mu \mathrm{g} / \mathrm{L})^{c}$

$0.20 \bar{X}+1.00$

$0.21 \bar{X}+2.41$

$0.36 \bar{X}+0.94$

$0.20 \bar{X}+0.39$

$0.18 \bar{X}+1.21$

$0.17 \bar{X}+0.63$

$0.35 \bar{X}$

$0.19 \bar{X}-0.02$

$0.52 \bar{X}+1.31$

$0.24 \bar{X}+1.68$

$0.13 \bar{X}+6.13$ 
Parameter

1,3-Dichlorobenzene

1,4-Dichlorobenzene

1,1-Dichloroethane

1,2-Dichloroethane

1,1-Dichlornethene trans-1,2-Dichloroethene

Dichloromethane

(Methylene chloride)

1,2-Dichloropropane $f$

cis-1,3-Dichloropropene $f$

trans-1,3-Dichloropropene ${ }^{f}$

1,1,2,2-Tetrachlorethane

Tetrachloroethylene

1,1,1-Trichloroethane

1,1,2-Trichloroethane

Trichloroethylene

Trichlorofluoromethane

Vinyl chloride
Accuracy as
recovery, $X^{\prime a}(\mu g / L)$

$0.95 C+0.43$

$0.93 C-0.09$

$0.95 C-1.08$

1.04C-1.06

$0.98 C-0.87$

$0.97 C-0.16$

$0.91 C-0.93$

$1.00 \mathrm{C}$

$1.00 \mathrm{C}$

$1.00 \mathrm{C}$

$0.95 C+0.19$

$0.94 C+0.06$

$0.90 C-0.16$

$0.86 C+0.30$

$0.87 C+0.48$

$0.89 C-0.07$

$0.97 C-0.36$
Single analyst precision $(\mu \mathrm{g} / \mathrm{L})^{b}$

$0.14 \bar{X}+2.33$

$0.15 \bar{X}+0.29$

$0.09 \bar{X}+0.17$

$0.11 \bar{X}+0.70$

$0.21 \bar{X}-0.23$

$0.11 \bar{X}+1.46$

$0.11 \bar{X}+0.33$

$0.13 \bar{X}$

$0.18 \bar{X}$

$0.18 \bar{X}$

$0.14 \bar{X}+2.41$

$0.14 \bar{X}+0.38$

$0.15 \bar{X}+0.04$

$0.13 \bar{X}-0.14$

$0.13 \bar{X}-0.03$

$0.15 \bar{X}+0.67$

$0.13 \bar{X}+0.65$
Overall precision $(\mu \mathrm{g} / \mathrm{L})^{c}$

$0.26 \bar{X}+2.34$

$0.20 \bar{X}+0.41$

$0.14 \bar{X}+0.94$

$0.15 \bar{X}+0.94$

$0.29 \bar{X}-0.40$

$0.17 \bar{X}+1.46$

$0.21 \bar{X}+1.43$

$0.23 \bar{X}$

$0.32 \bar{X}$

$0.32 \bar{X}$

$0.23 \bar{X}+2.79$

$0.18 \bar{X}+2.21$

$0.20 \bar{X}+0.37$

$0.19 \bar{X}+0.67$

$0.23 \bar{X}+0.30$

$0.26 \bar{X}+0.91$

$0.27 \bar{X}+0.40$

a $X^{\prime}=$ expected recovery for one or more measurements of a sample containing a concentration of $C$, in $\mu \mathrm{g} / \mathrm{L}$.

b Expected single analyst standard deviation of measurements.

c Expected interlaboratory standard deviation of measurements.

d $C=$ true value for the concentration, in $\mu \mathrm{g} / \mathrm{L}$.

e $\bar{X}=$ average recovery found for measurements of samples containing a concentration of $C_{1}$ in $\mu g / L$.

Estimates based on performance in a single laboratory.

\section{References}

EPA (U.S. Environmental Protection Agency), 1986. Test Methods for Evaluating Solid Waste (SW-846), Volumes IA-IC. Washington, DC.

EPA (U.S. Environmental Protection Agency), 1991. Guidelines Establishing Test Procedures for the Analysis of Pollutants, Code of Federal Regulations, Title 40, Part 136, Appendix A. Washington, DC.

EPA EMSL (U.S. Environmental Protection Agency, Environmental Monitoring and Systems Laboratory), 1980. Prescribed Procedures for Measurement of Radioactivity in Drinking Water, EPA-600/4-80-032. Cincinnati, OH.

EPA EMSL (U.S. Environmental Protection Agency, Environmental Monitoring and Systems Laboratory), 1983. Methods for Chemical Analysis of Water and Wastes. Cincinrati, $\mathrm{OH}$

EPA EMSL (U.S. Environmental Protection Agency, Environmental Monitoring and Systems Laboratory), 1991. Test Method, The Determination of Inorganic Anions in Water by lon Chromatography-Method 300.0. Cincinnati, $\mathrm{OH}$. 
WSRC-TR-94-0240

Unclassified

THIS PAGE LEFT BLANK INTENTIONALLY. 
WSRC-TR-94-0240

Unclassified

\section{Appendix F}

\section{Time Series Plots}


WSRC-TR-94-0240

Unclassified

THIS PAGE LEFT BLANK INTENTIONALLY. 


\section{pH \\ Well Cluster BGO 6}

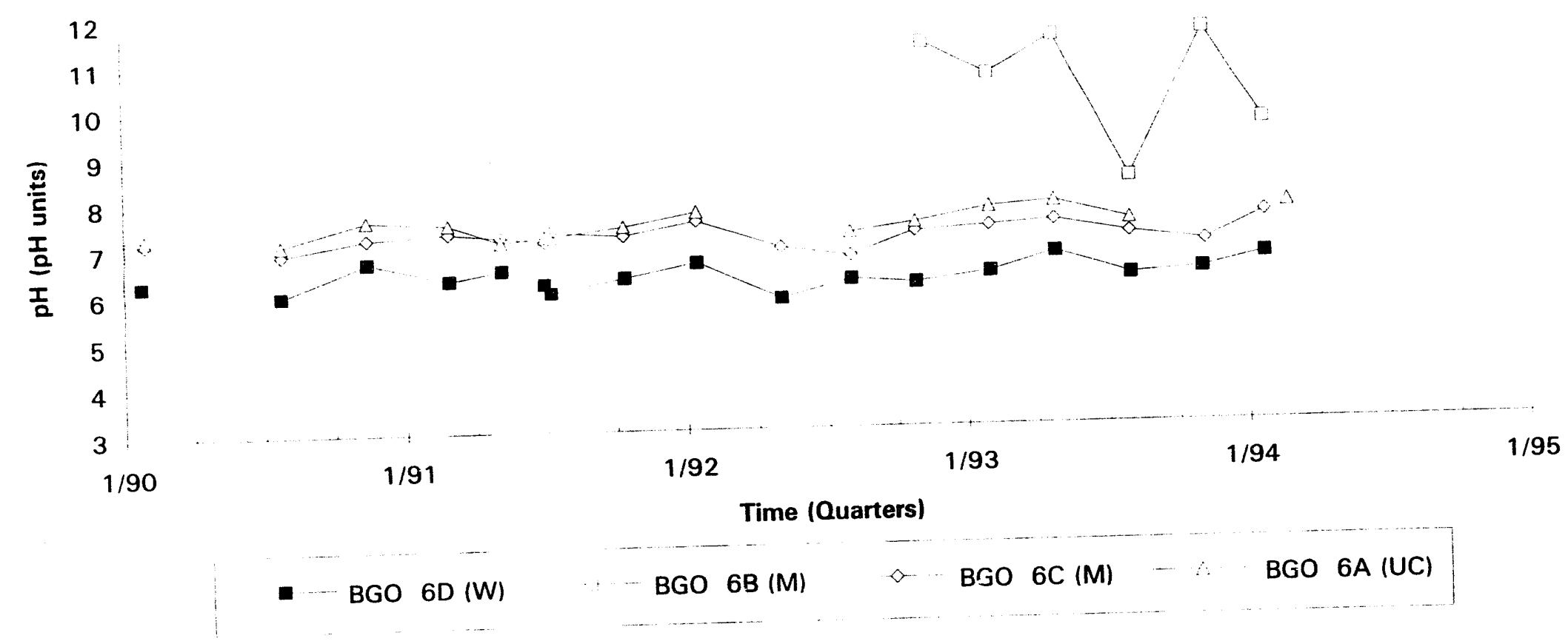

Note: $\mathrm{W}=$ Water Table (IIB2); $\mathrm{M}=$ McBean (IIB1); $\mathrm{B}=$ Barnwell (IIB1); UC = Upper Congaree (IIA); $M C=$ Middle Congaree (IIA); $L C=$ Lower Congaree (IIA) 


\section{$\mathrm{pH}$ \\ Well Cluster BGO 8}

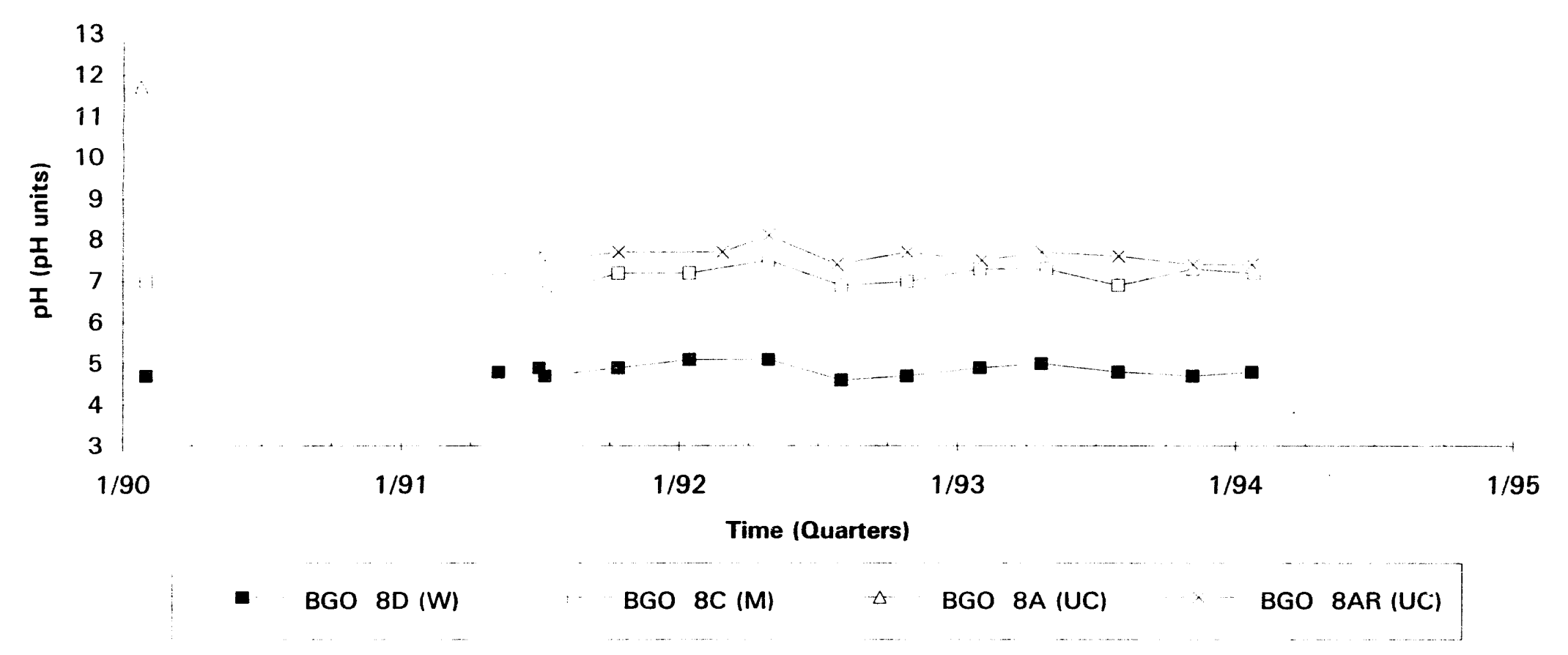

Note: $W=$ Water Table (IIB2); $M=M c B e a n$ (IIB1); $B=$ Barnwell (IIB1); UC = Upper Congaree (IIA); MC = Middle Congaree (IIA); LC = Lower Congaree (IIA) 


\section{$\mathrm{pH}$ \\ Well Cluster BGO 14}

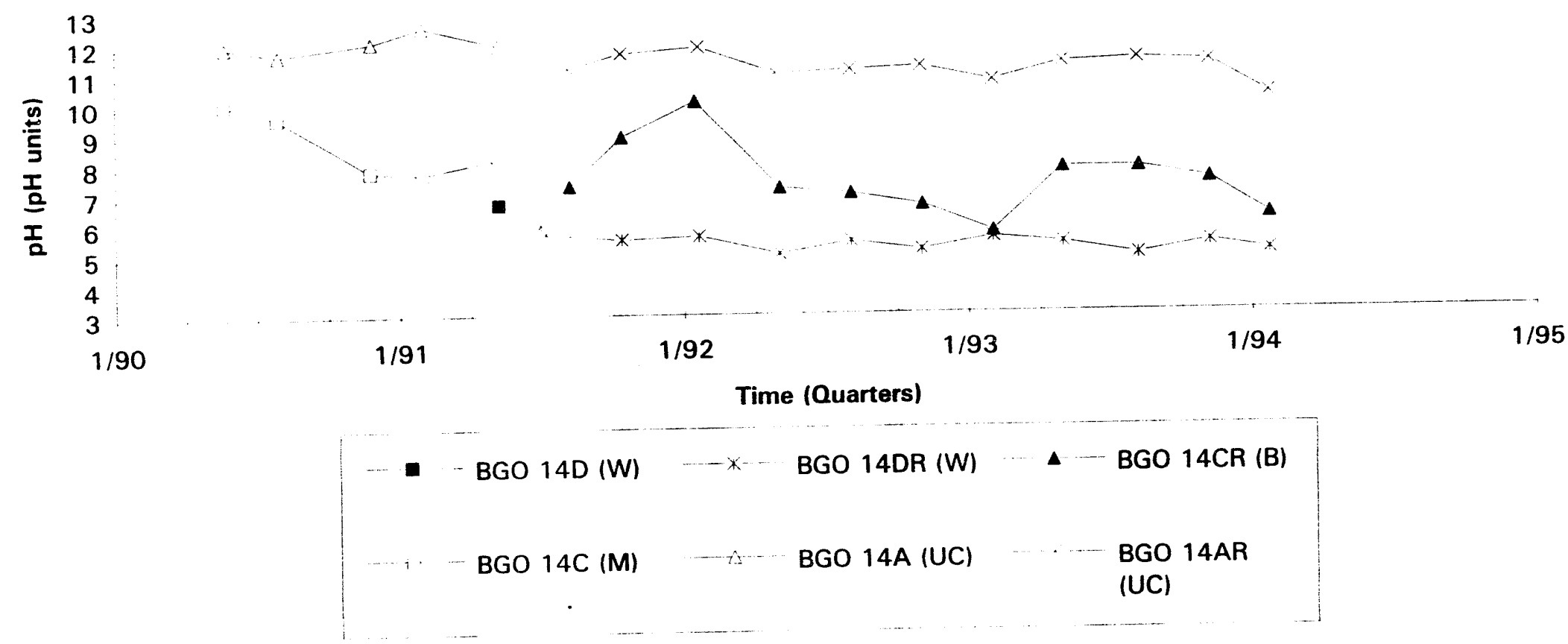

Note: $W=$ Water Table (IIB2); $M=$ McBean (IIB1); $B=$ Barnwell (IIB1); UC = Upper Congaree (IIA); MC = Middle Congaree (IIA); LC = Lower Congaree (IIA) 


\section{$\mathrm{pH}$ \\ Well Cluster BGO 16}

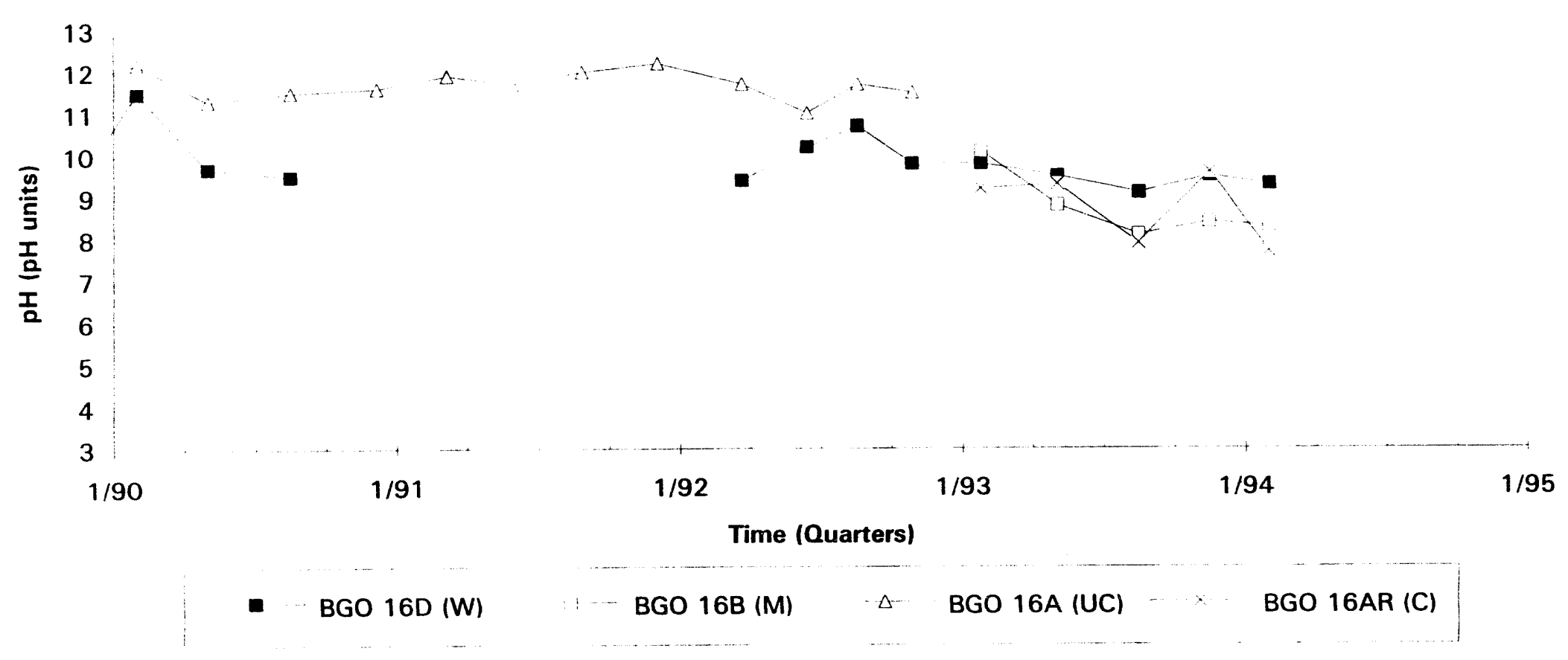

Note: $\mathrm{W}=$ Water Table (IIB2); $\mathrm{M}=$ =MCBean (IIB1); $\mathrm{B}=$ Barnwell (IIB1); UC = Upper Congaree (IIA); $M C=$ Middle Congaree (IIA); $L C=$ Lower Congaree (IIA) 


\section{pH \\ Well Cluster BGO 26}

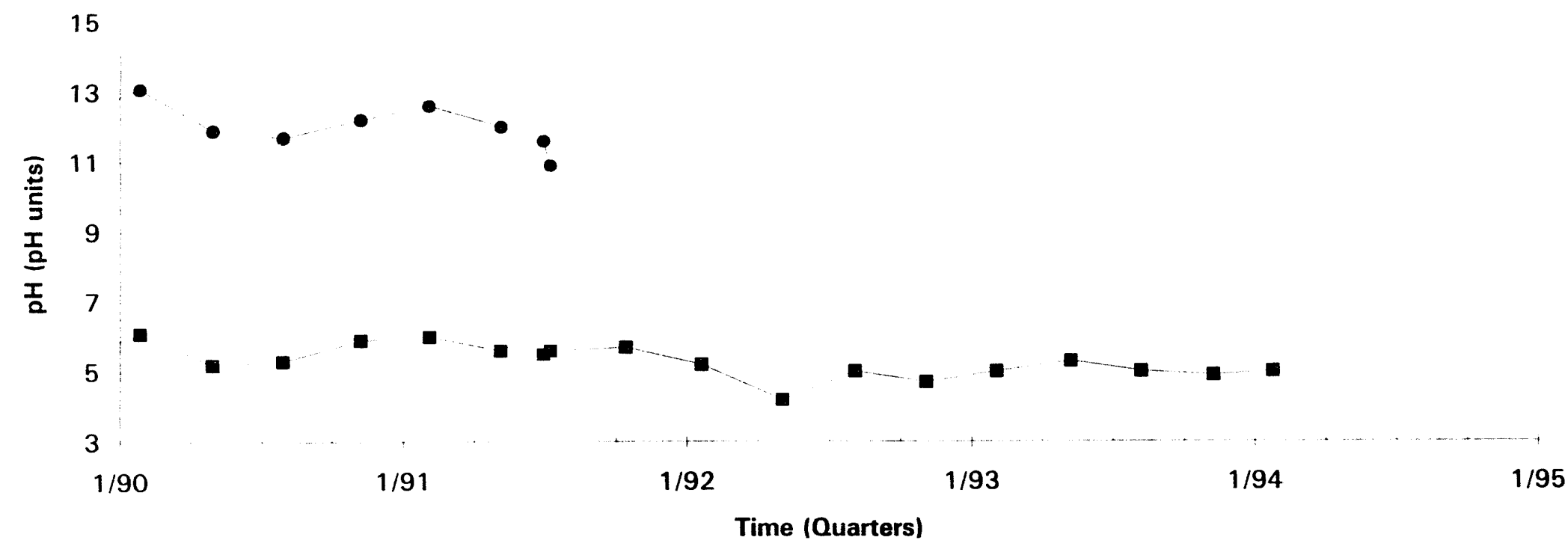

- BGO 26D (W) $\quad$ B B $\quad$ B $26 \mathrm{~A}(\mathrm{MC})$ 


\section{pH \\ Well BGO 28D}

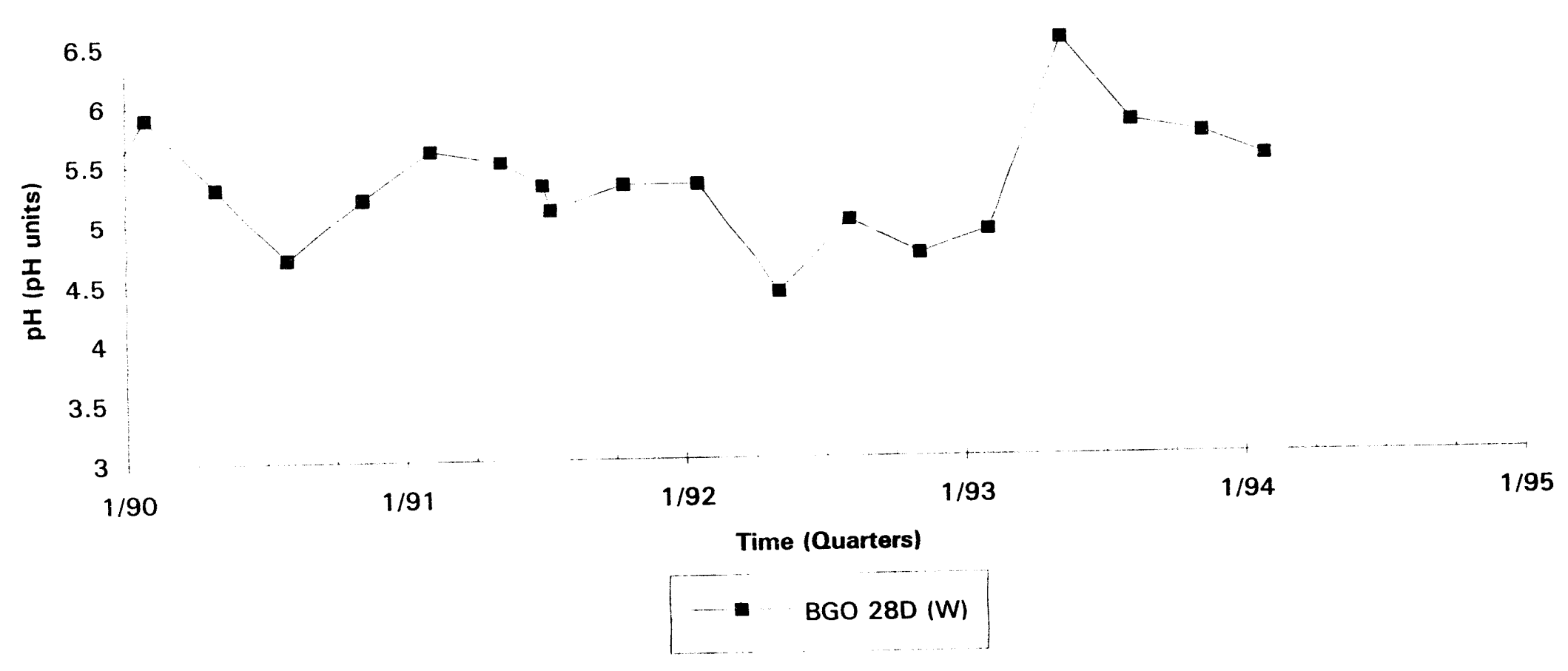

Note: $W=$ Water Table (IIB2); $M=$ McBean (IIB1); $B=$ Barnwell (IIB1); UC = Upper Congaree (IIA); MC= Middle Congaree (IIA); LC=Lower Congaree (IIA) 


\section{$\mathrm{pH}$ \\ Well Cluster BGO 30}

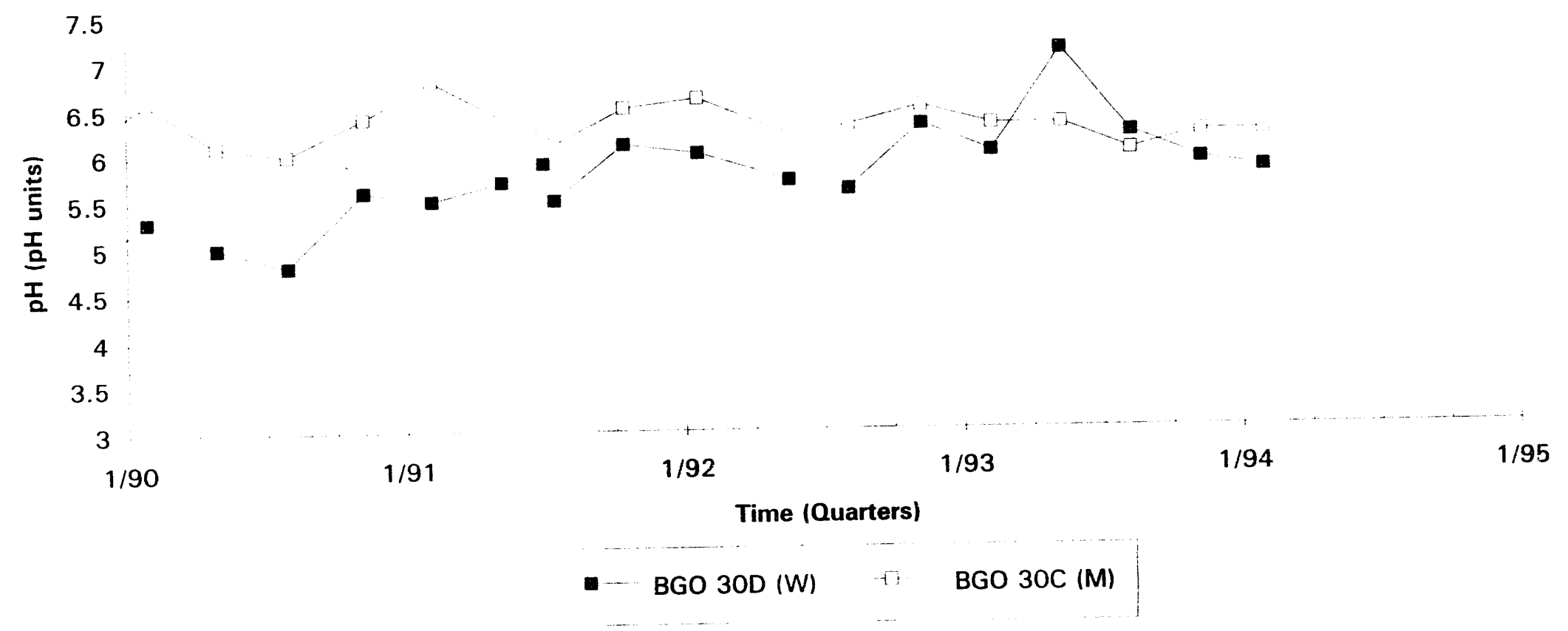

Note: $W=$ Water Table (IIB2); $M=M c B e a n(I I B 1) ; B=$ Barnwell (IIB1); UC=Upper Congaree (IIA); MC= Middle Congaree (IIA); LC=Lower Congaree (IIA) 


\section{Trichloroethylene Concentrations \\ Well Cluster BGO 6}

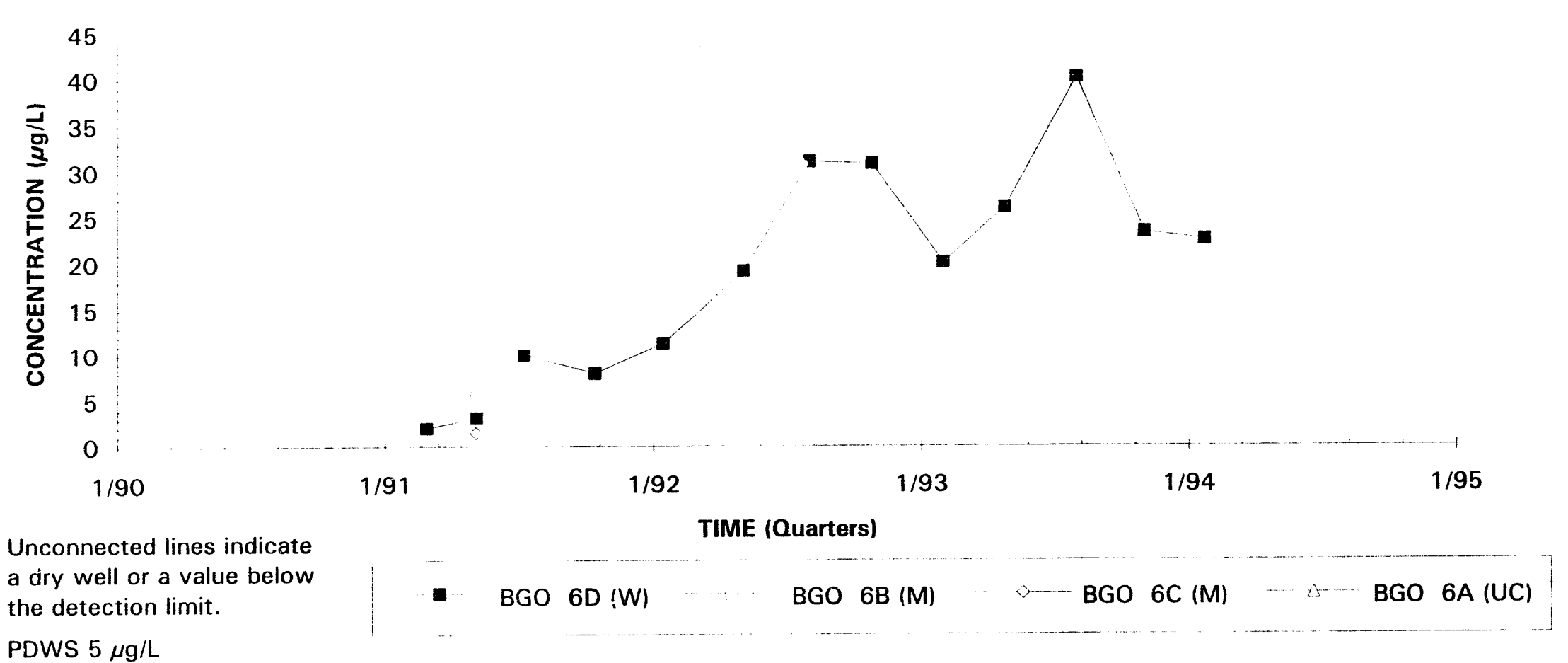




\section{Trichloroethylene Concentrations \\ Well BGO 7D}

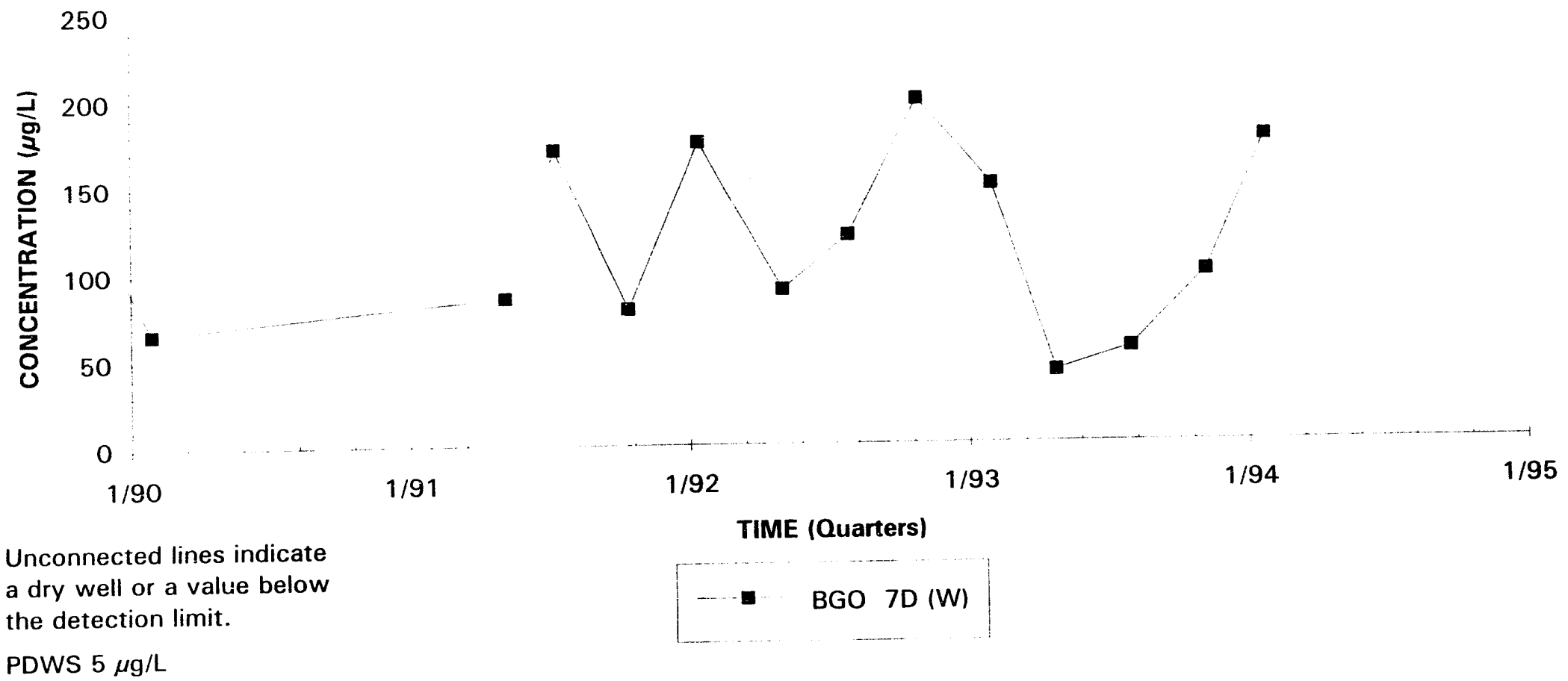




\section{Trichloroethylene Concentrations \\ Well Cluster BGO 8}
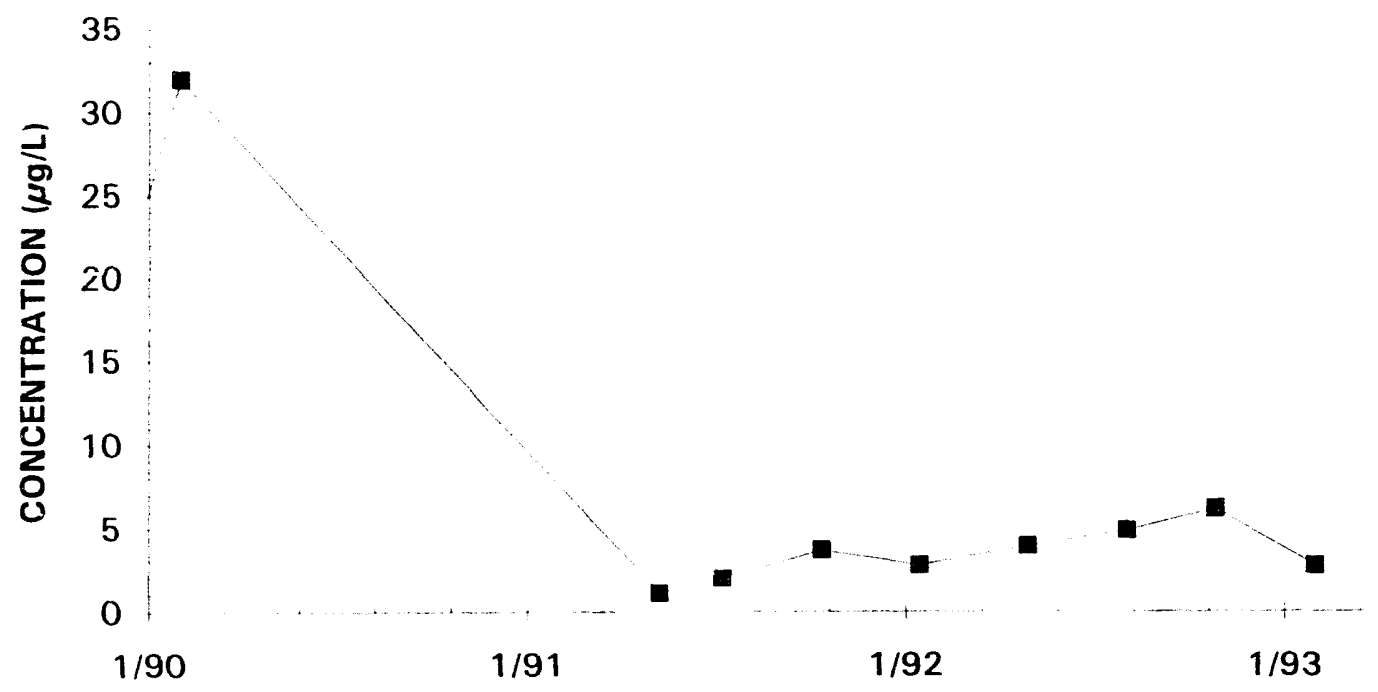

Unconnected lines indicate a dry well or a value below the detection limit. - BGO 3D (W) TIME (Quarters) PDWS $5 \mu \mathrm{g} / \mathrm{L}$ 


\section{Trichloroethylene Concentrations \\ Well Cluster BGO 12}
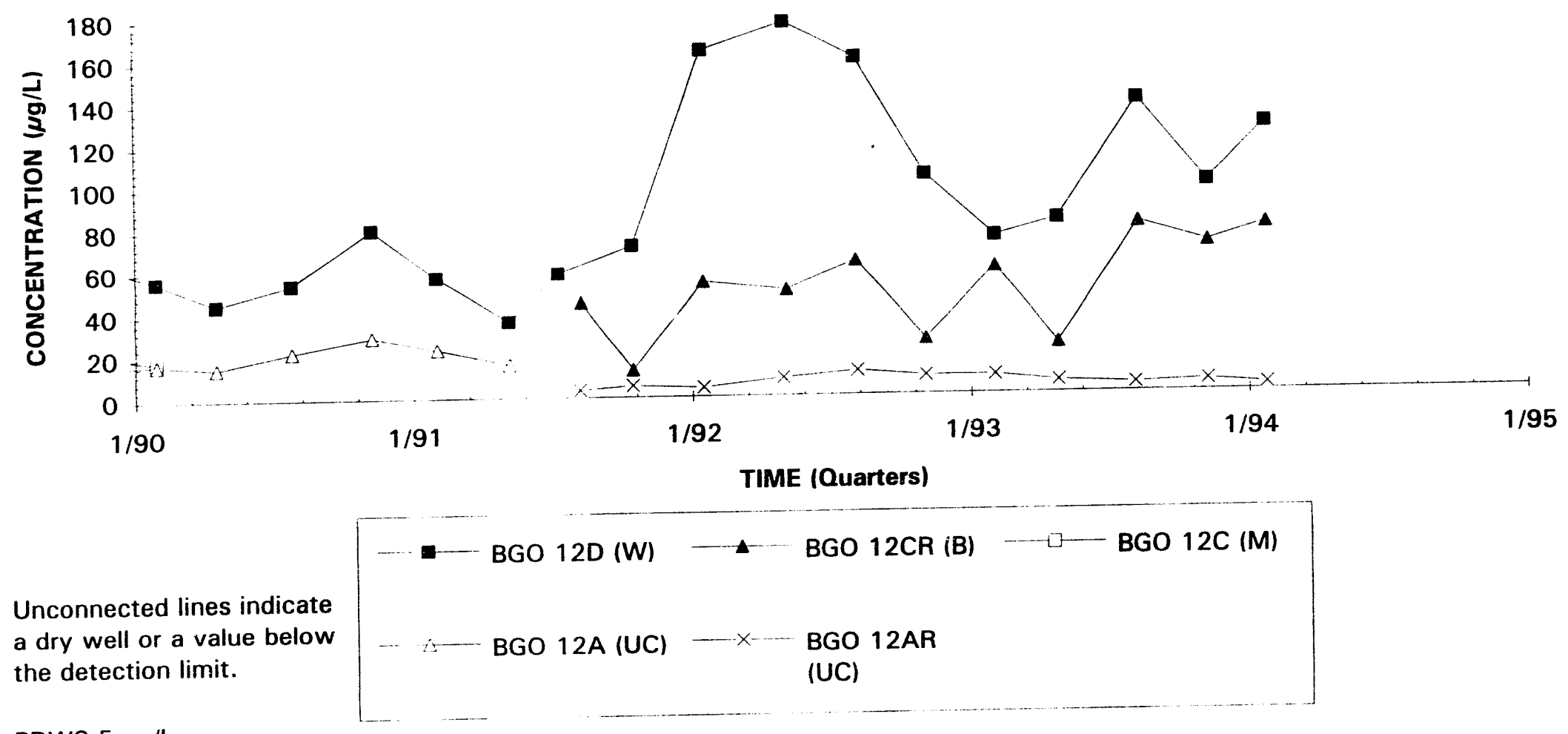

PDWS $5 \mu \mathrm{g} / \mathrm{L}$ 


\section{Trichloroethylene Concentrations Well Cluster BGO 13}

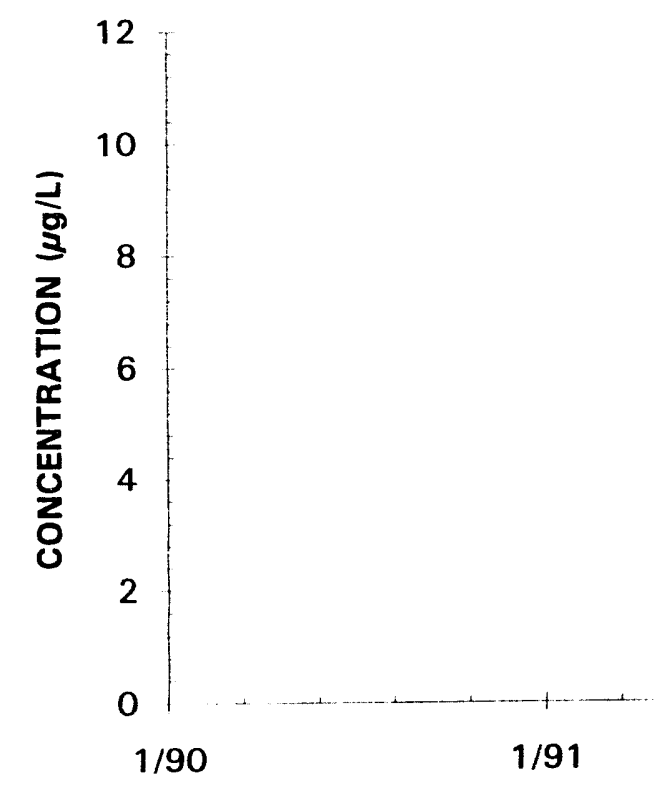

Unconnected lines indicate a dry well c: a value below the detection limit.

PDWS $5 \mu \mathrm{g} / \mathrm{L}$

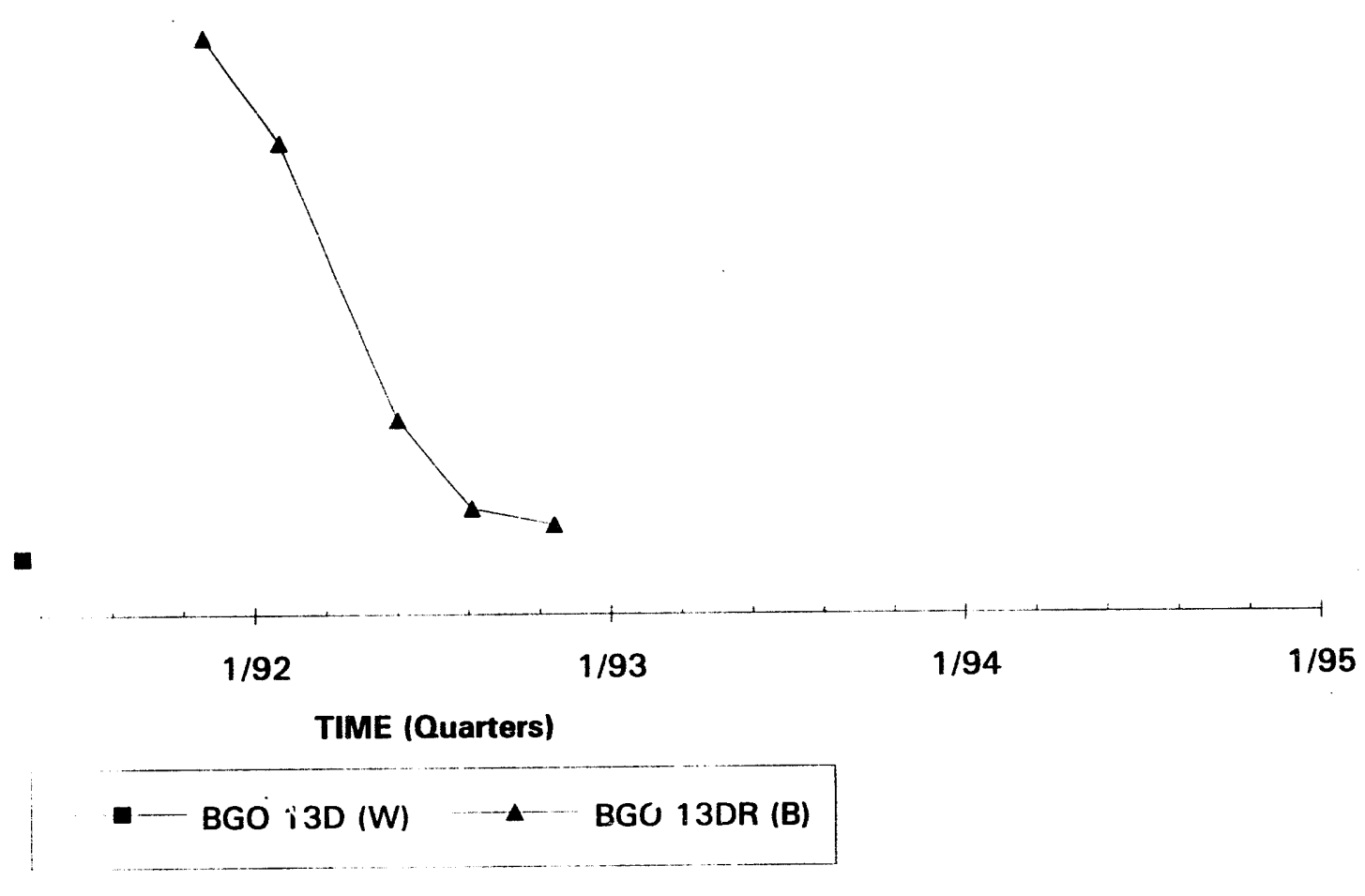

Note: $W=$ Water Table (IIB2); $B=$ Barnwell (IIB1); $M=$ McBean (IIB1); UC = Upper Congaree (IIA); $M C=$ Middle Congaree (IIA); LC=Lower Congaree (IIA) 


\section{Trichloroethylene Concentrations \\ Well Cluster BGO 14}

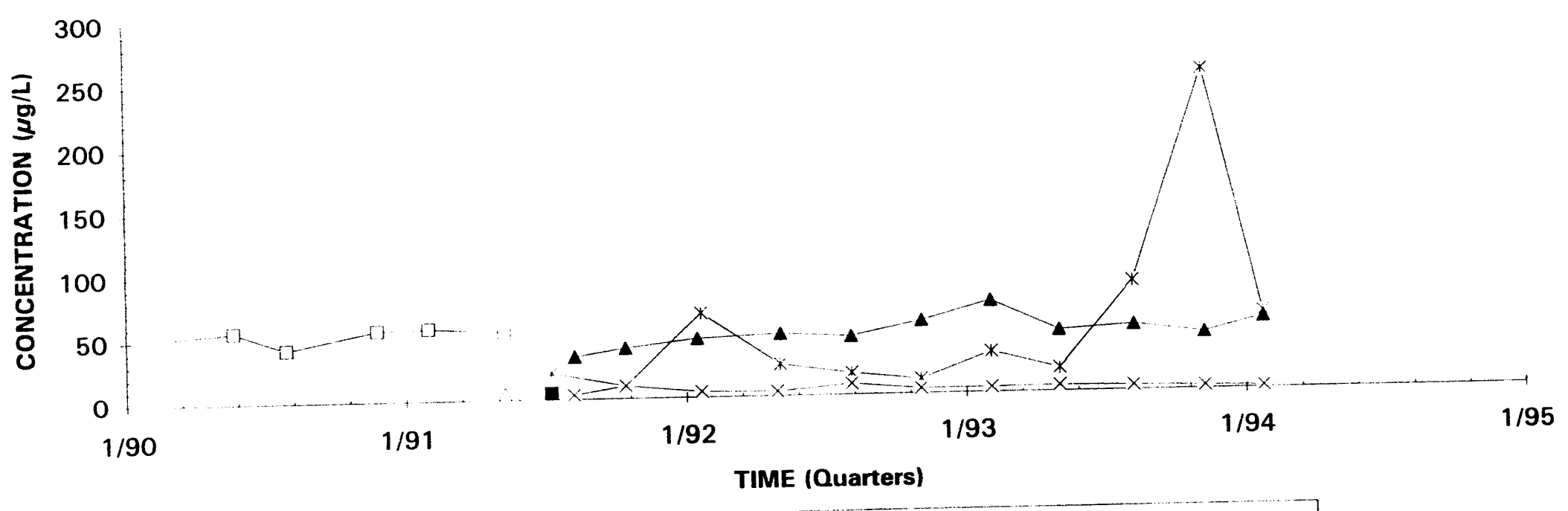
a dry well or a value below the detection limit.

- BGO 14D (W)

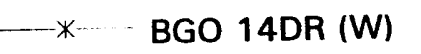

BGO 14CR (B)

PDWS $5 \mu \mathrm{g} / \mathrm{L}$ 


\section{Trichloroethylene Concentrations \\ Well BGO 15D}

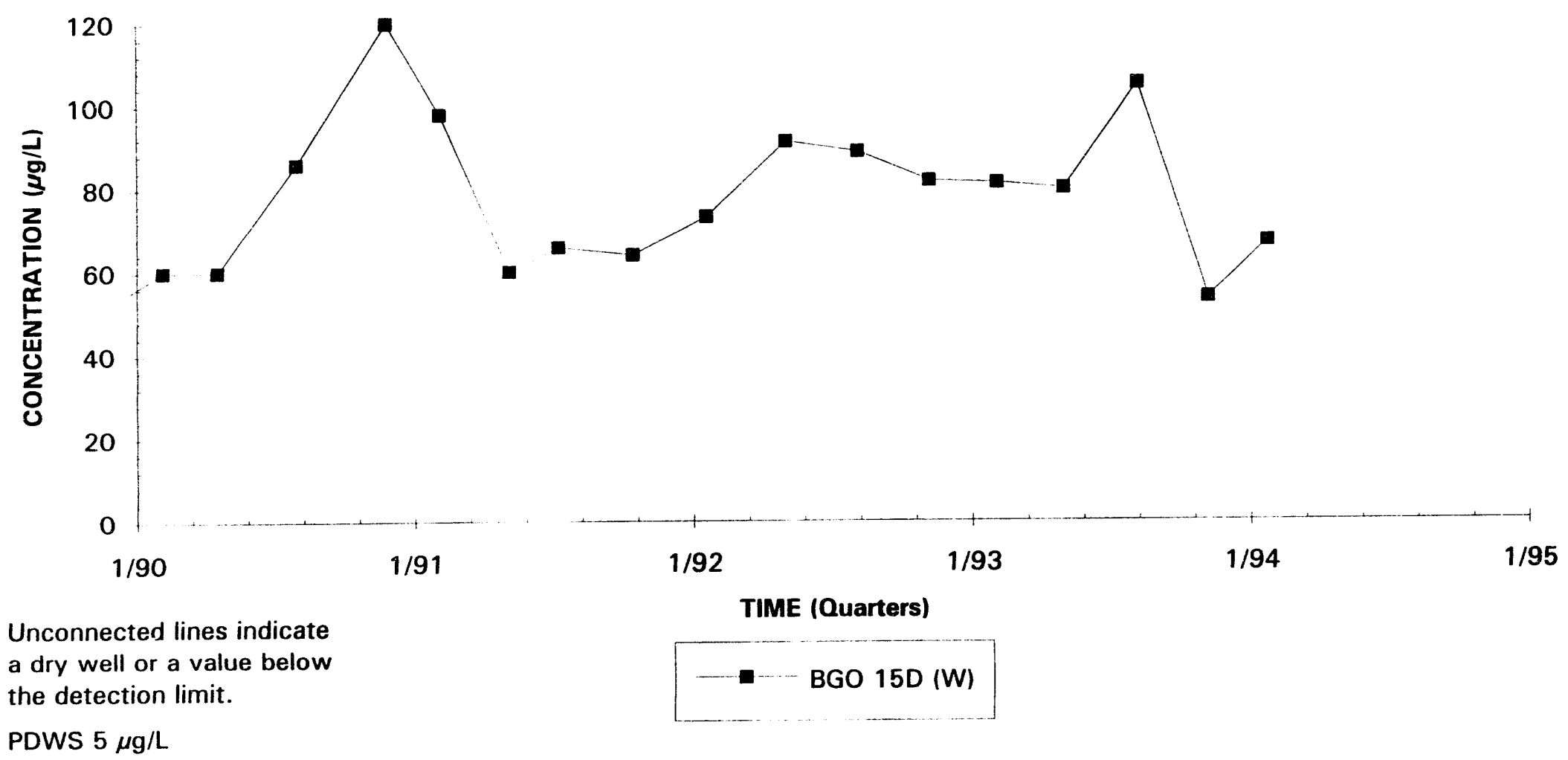

Note: $W=$ Water Table (IIB2); $B=$ Barnwell (IIB1); $M=$ MCBean (IIB1); UC = Upper Congaree (IIA); $M C=$ Middle Congaree (IIA); LC =Lower Congaree (IIA) 


\section{Trichloroethylene Concentrations \\ Well Cluster BGO 16}

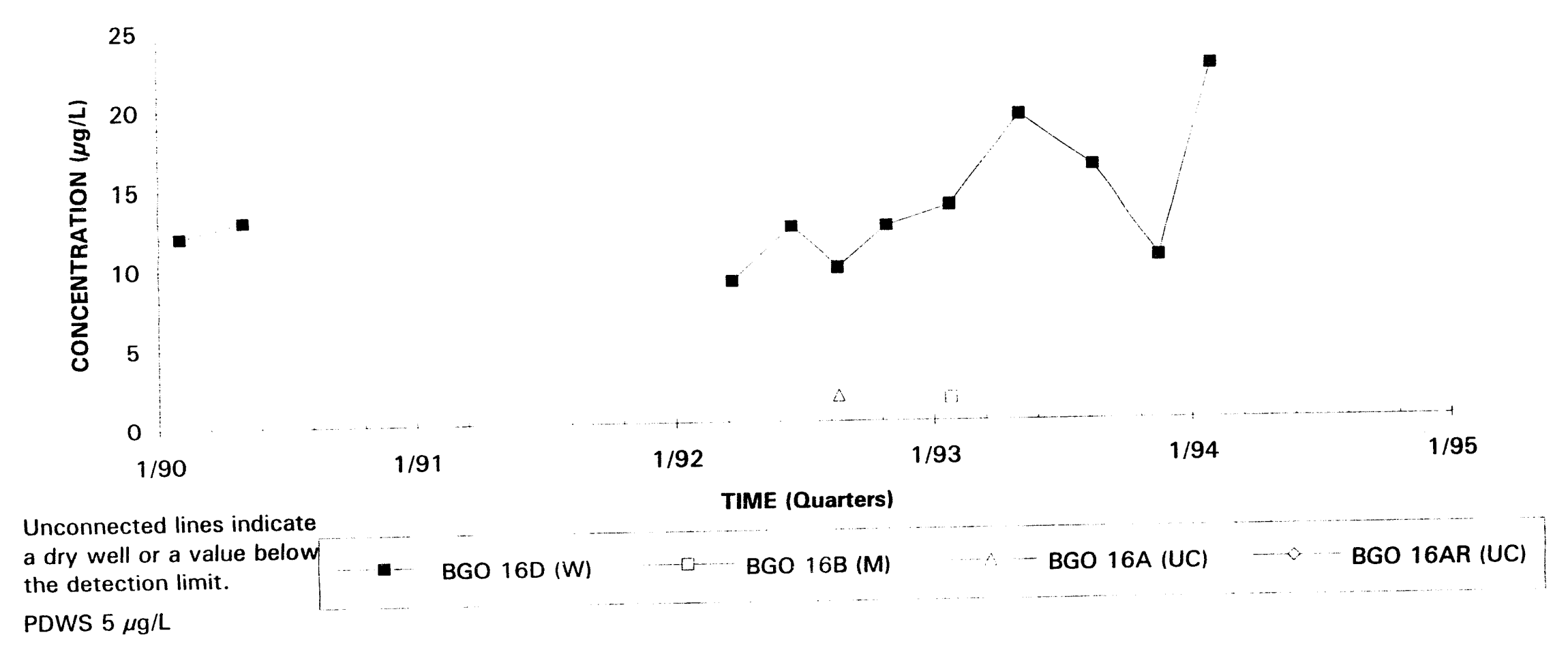




\section{Trichloroethylene Concentrations \\ Well Cluster BGO 27}

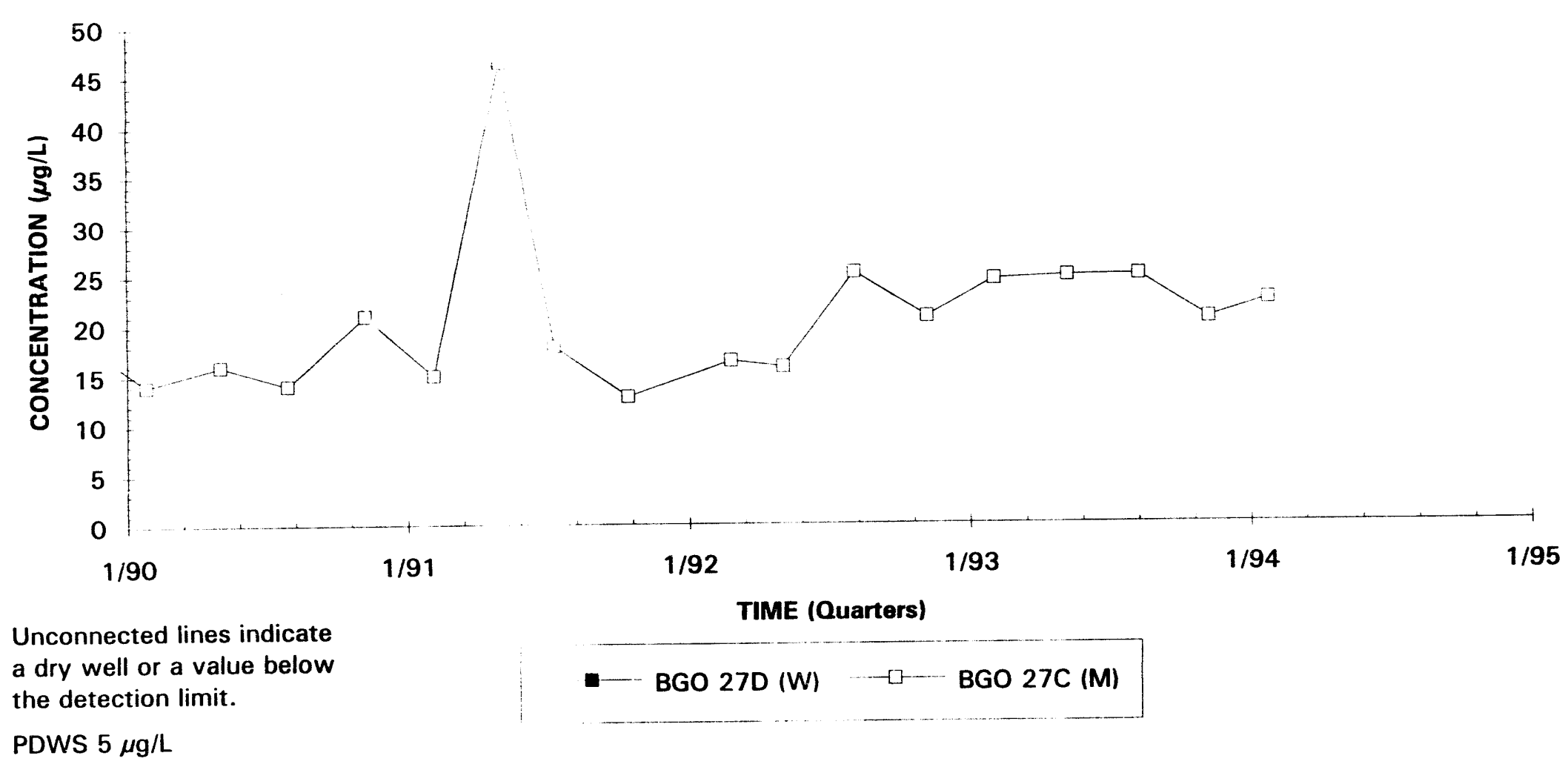

Note: $\mathrm{W}=$ Water Table (IIB2); $\mathrm{B}=$ Barnwell (IIB1); $\mathrm{M}=$ McBean (IIB1); UC=Upper Congaree (IIA); $\mathrm{MC}=$ Middle Congaree (IIA); $\mathrm{LC}=\mathrm{Lower}$ Congaree (IIA) 


\section{Trichloroethylene Concentrations}

Well BGO 28D

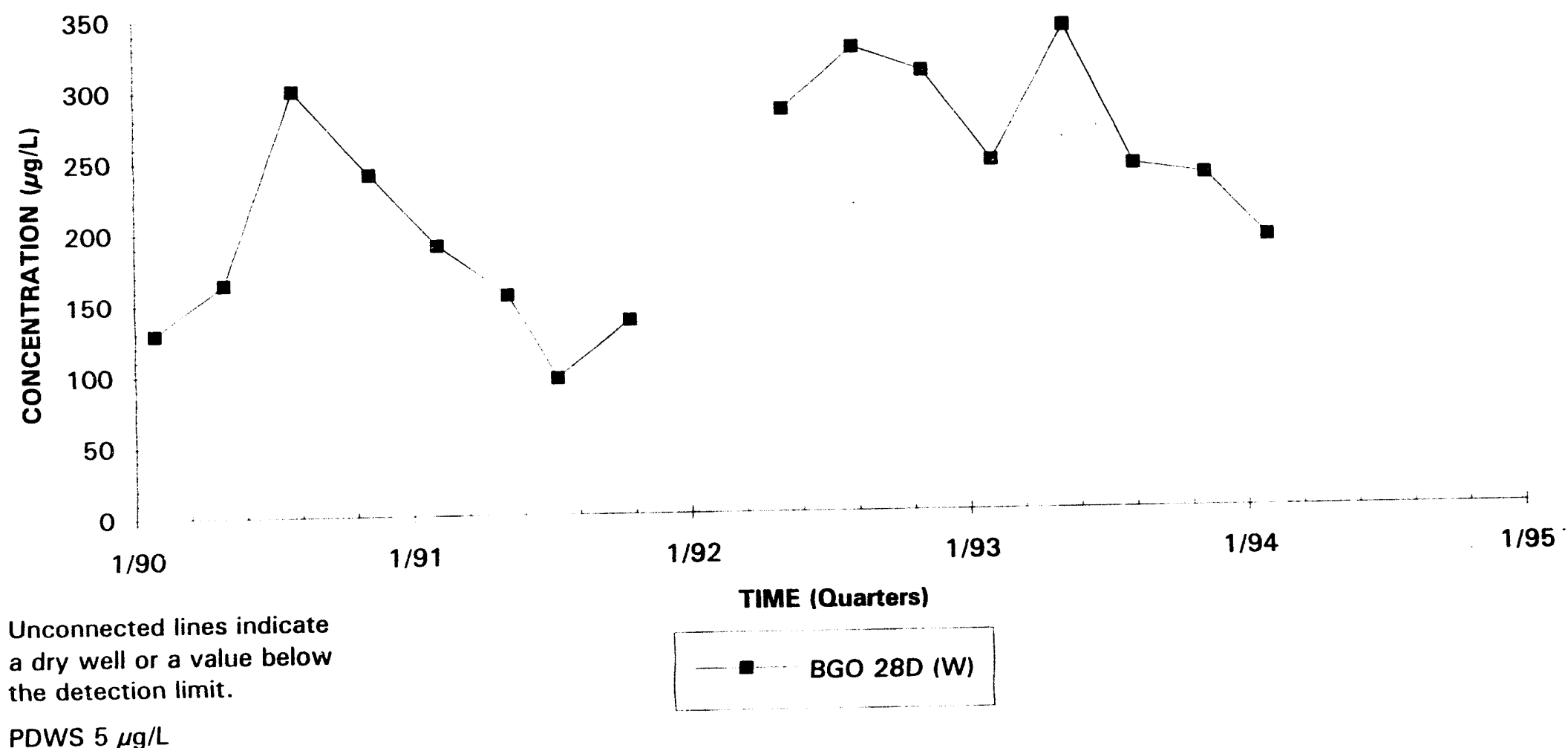

PDWS $5 \mu \mathrm{g} / \mathrm{L}$ 


\section{Trichloroethylene Concentrations}

Well Cluster BGO 29

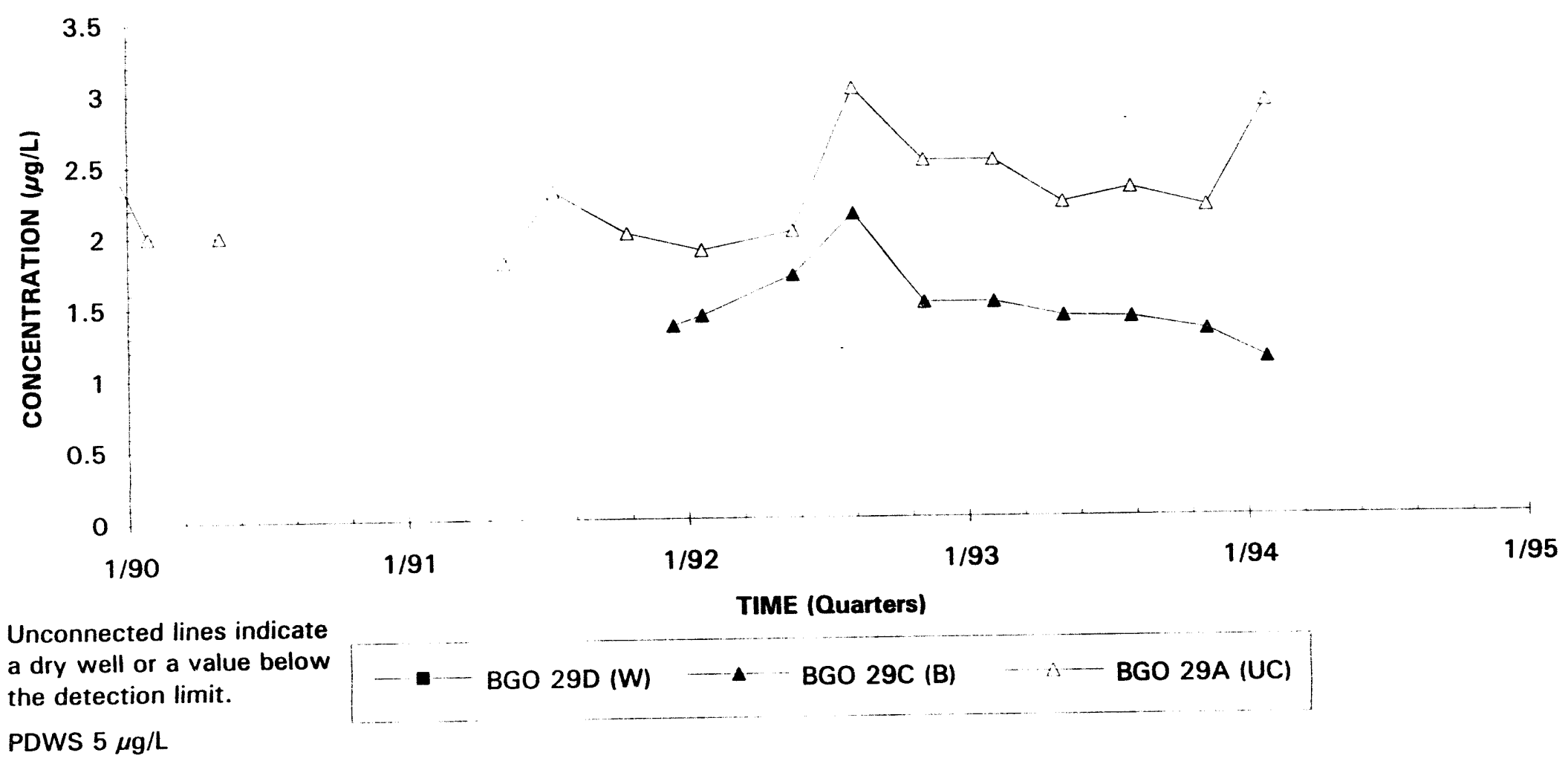

Note: $W=$ Water Table (IIB2); $B=$ Barnwell (IIB1); $M=$ MCBean (IIB1); UC=Upper Congaree (IIA); $M C=$ Middle Congaree (IIA); LC = Lower Congaree (IIA) 


\section{Trichloroethylene Concentrations \\ Well Cluster BGO 30}

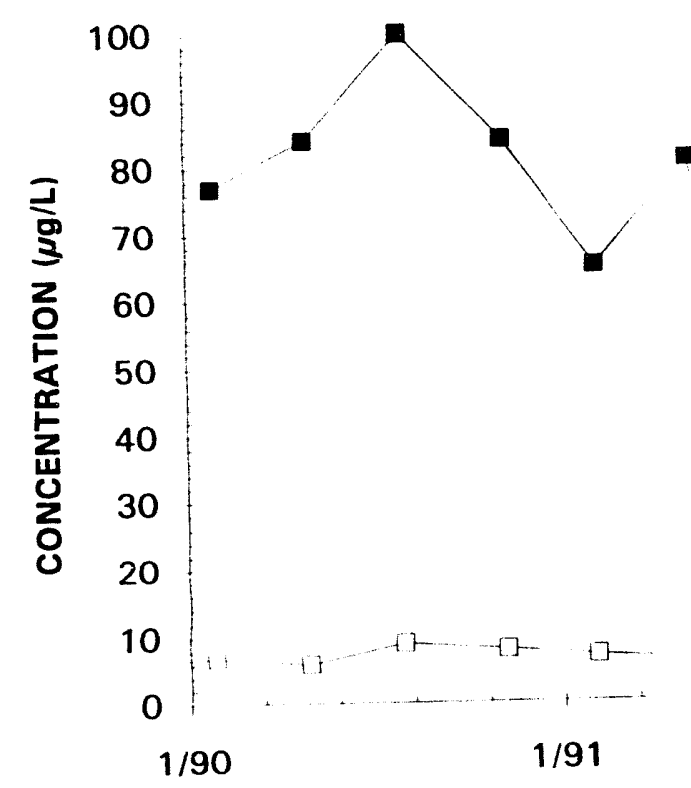

Unconnected lines indicate a dry well or a value below the detection limit.

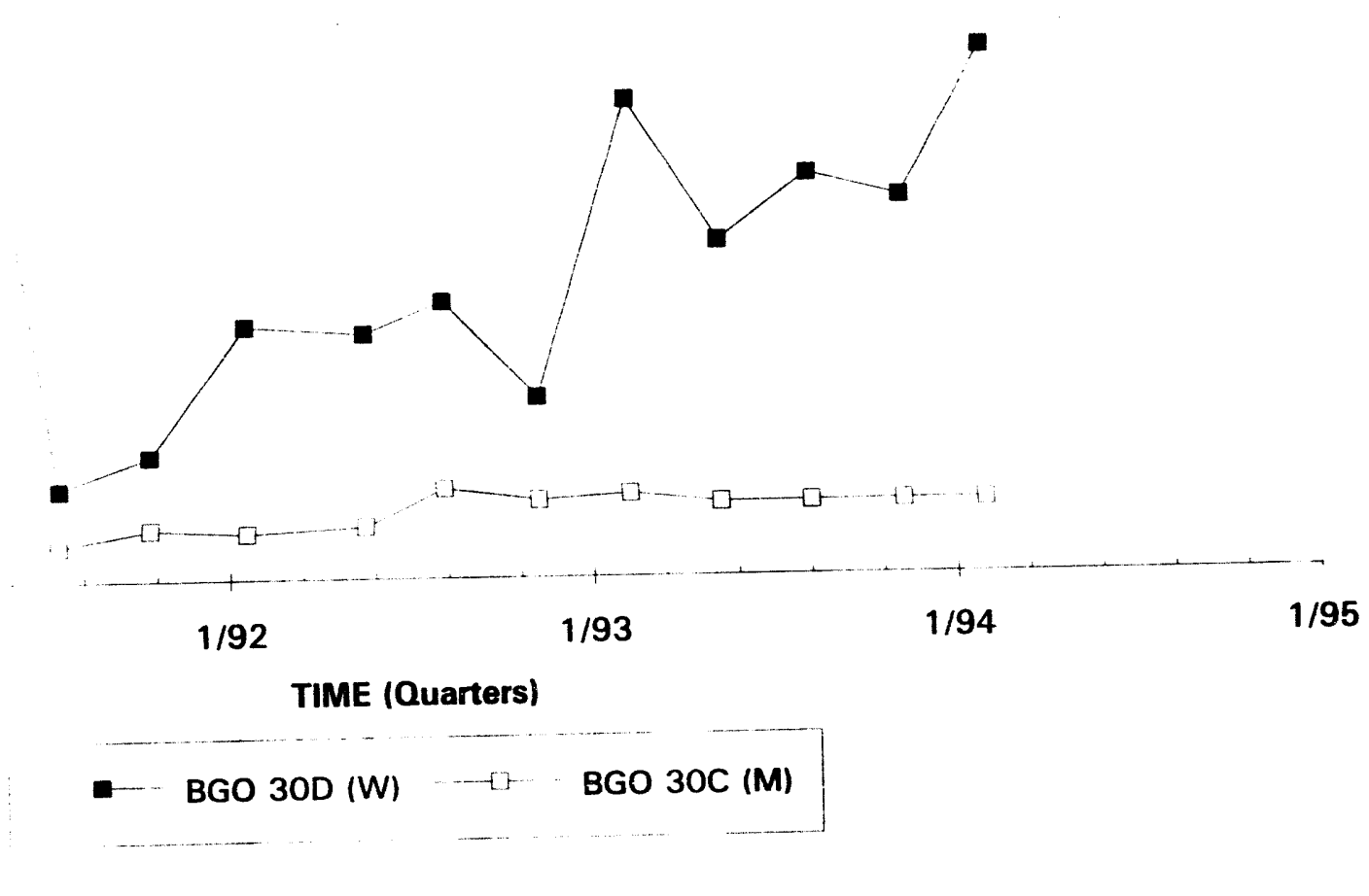

PDWS $5 \mu \mathrm{g} / \mathrm{L}$ 


\section{Trichloroethylene Concentrations Well Cluster BGO 31}

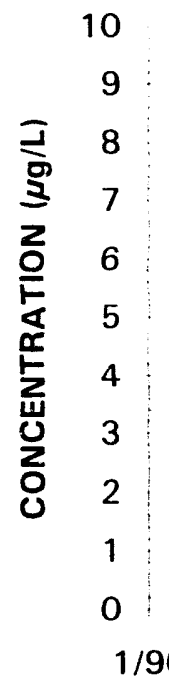

Unconnected lines indicate a dry well or a value below the detection limit.
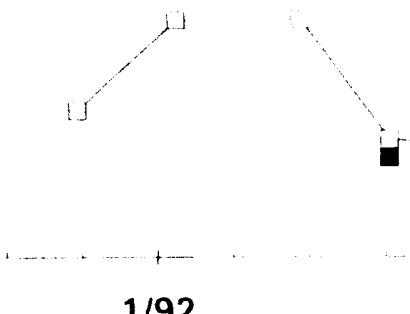

$1 / 91$

$$
1 / 92
$$

$1 / 93$

$1 / 94$

$1 / 95$

PDWS $5 \mu \mathrm{g} / \mathrm{L}$ 


\section{Trichloroethylene Concentrations \\ Well BGO 32D}

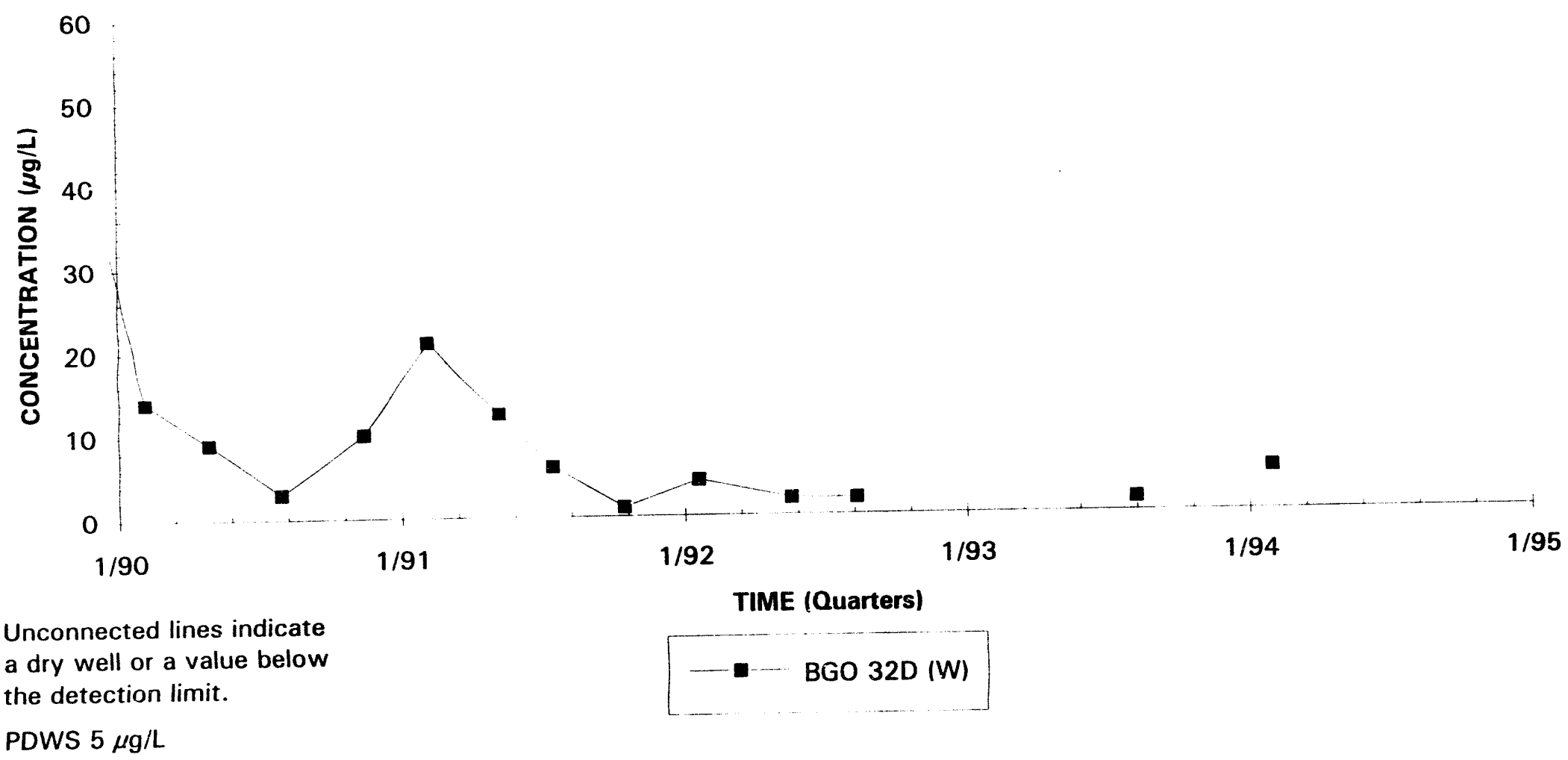

Note: $W=$ Water Table (IIB2); $B=$ Barnwell (IIB1); $M=$ McBean (IIB1); UC = Upper Congaree (IIA); $M C=$ Middle Congaree (IIA); LC = Lower Congaree (IIA) 


\section{Trichloroethylene Concentrations}

Well Cluster BGO 33

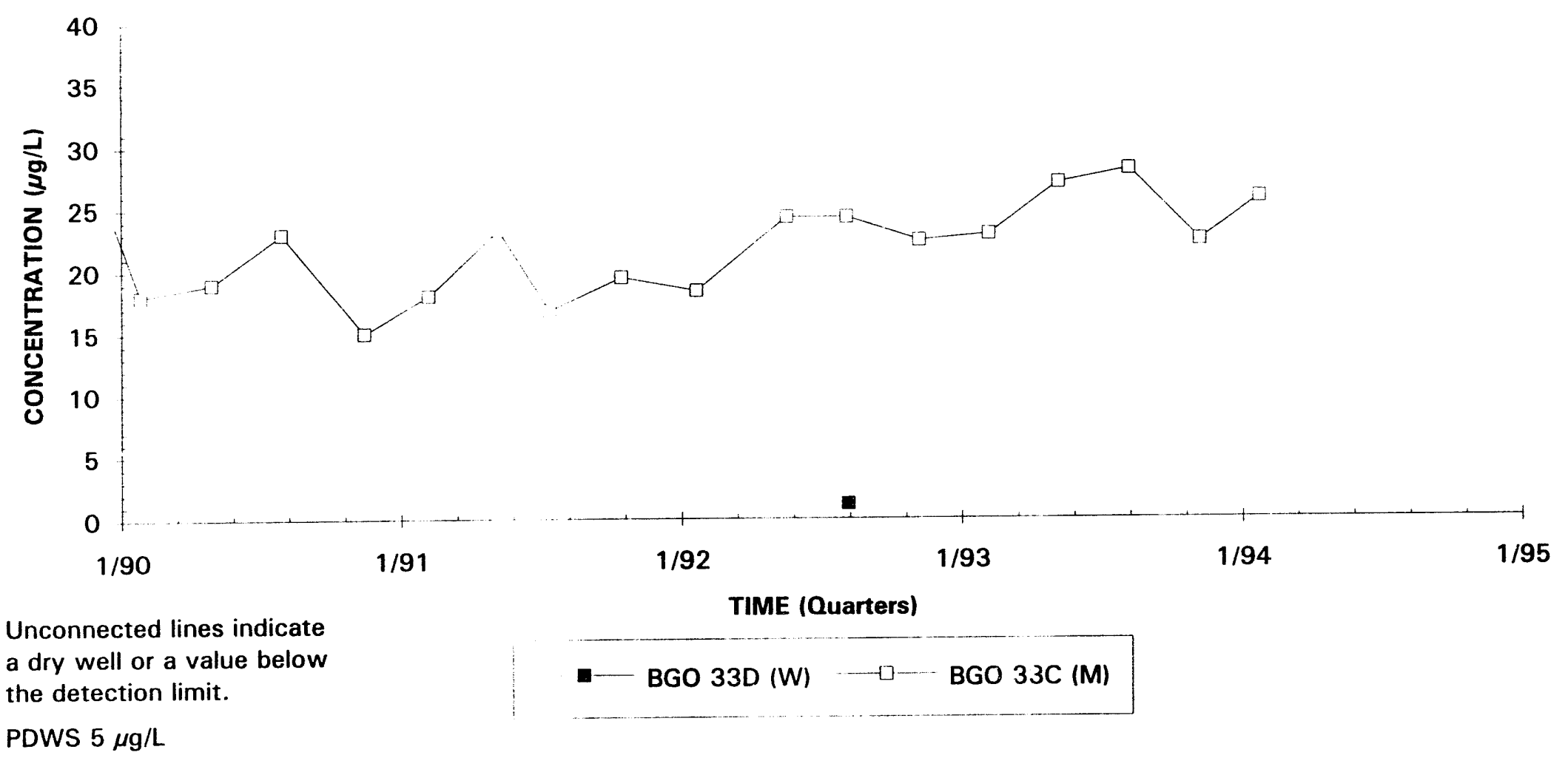

Note: $W=$ Water Table (IIB2); $B=$ Barnwell (IIB1); $M=M c B e a n$ (IIB1); UC=Upper Congaree (IIA); $M C=$ Middle Congaree (IIA); LC=Lower Congaree (IIA) 


\section{Trichloroethylene Concentrations \\ Well BGO 40D}

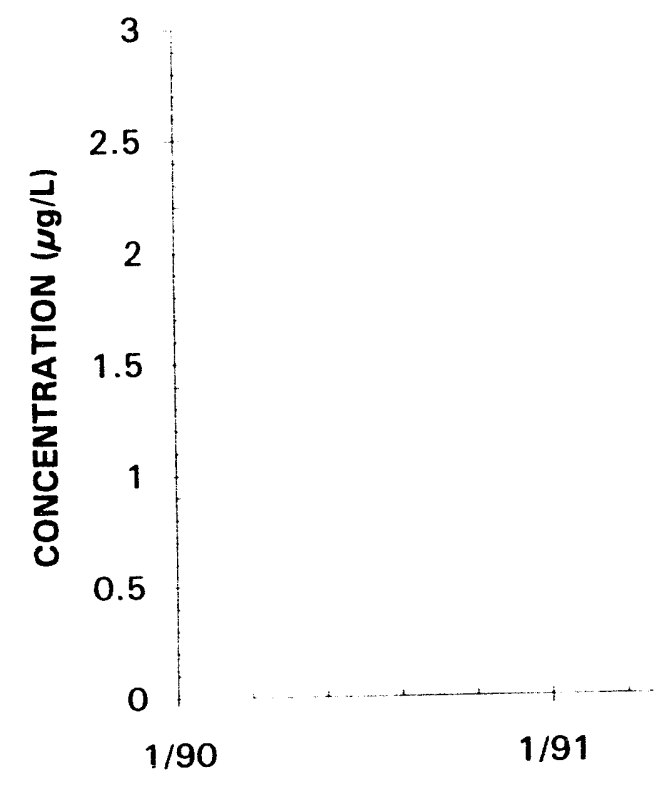

Unconnected lines indicate a dry well or a value below the detection limit.

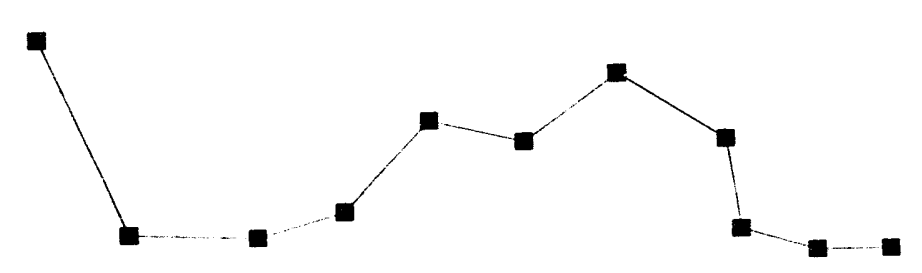

PDWS $5 \mu \mathrm{g} / \mathrm{L}$

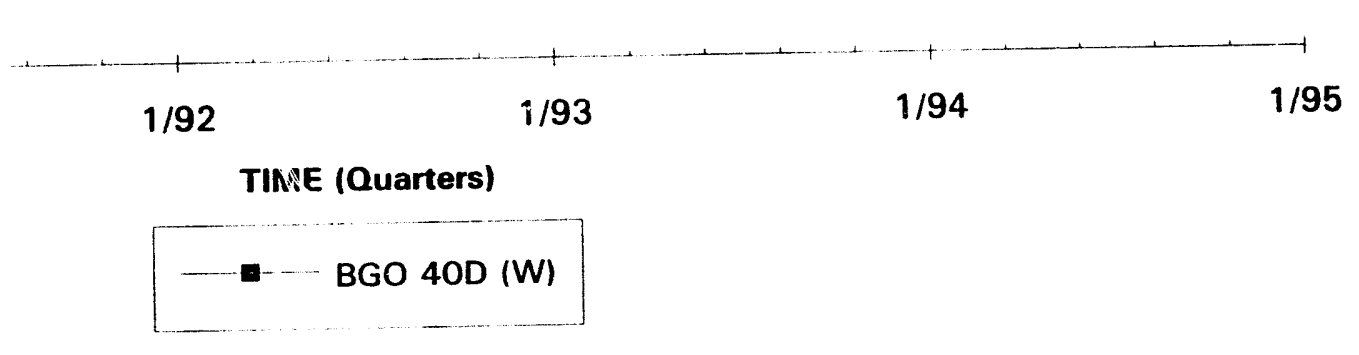




\section{Trichloroethylene Concentrations \\ Well BGO 41A}
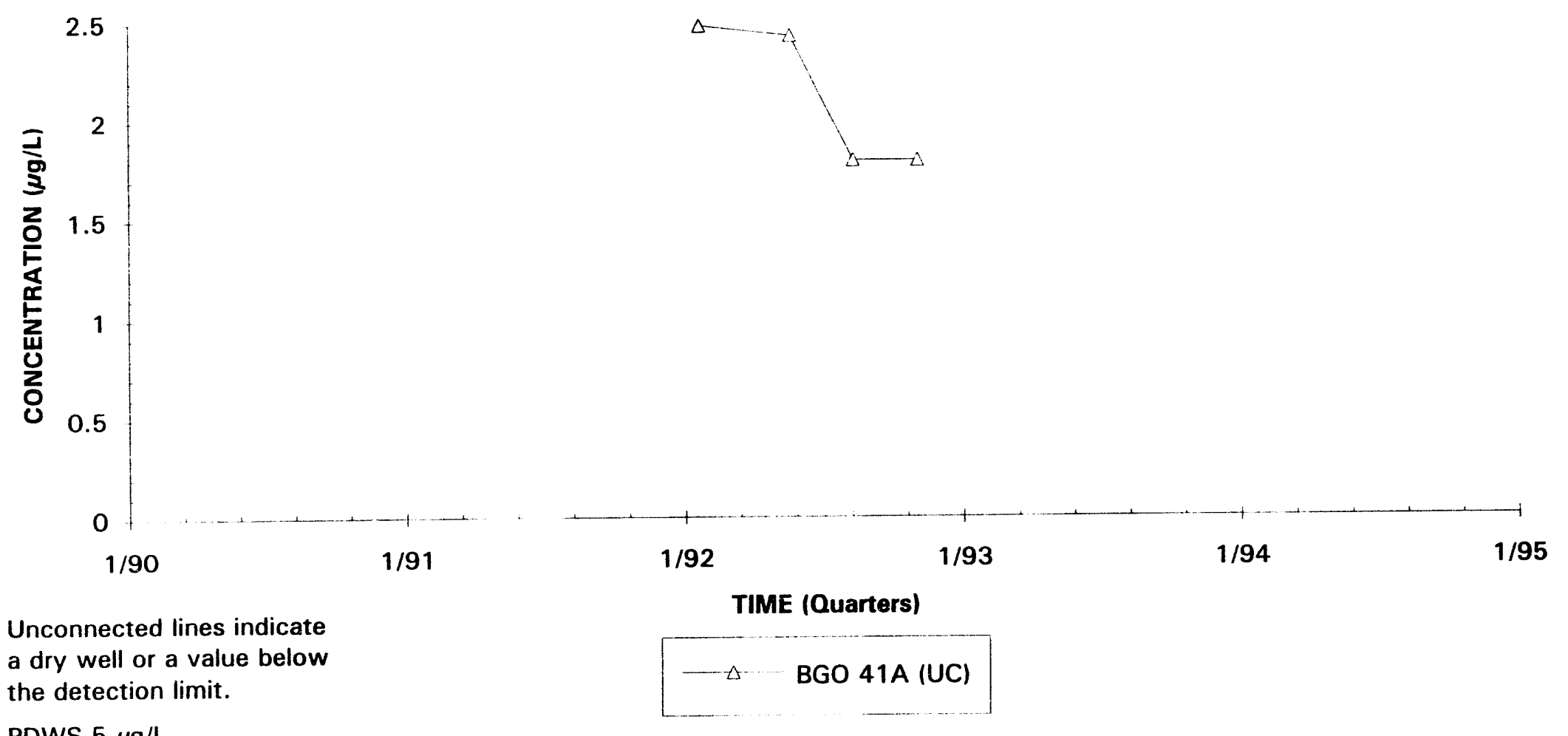

Unconnected lines indicate a dry well or a value below the detection limit.

PDWS $5 \mu \mathrm{g} / \mathrm{L}$ 


\section{Trichloroethylene Concentrations}

Well BGO 42C

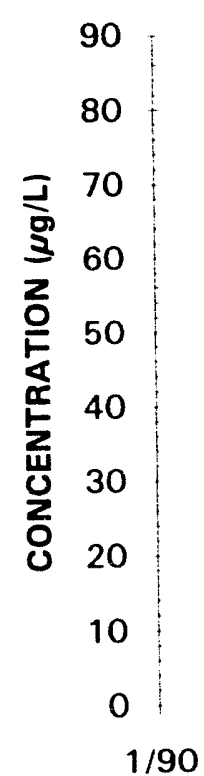

$1 / 91$

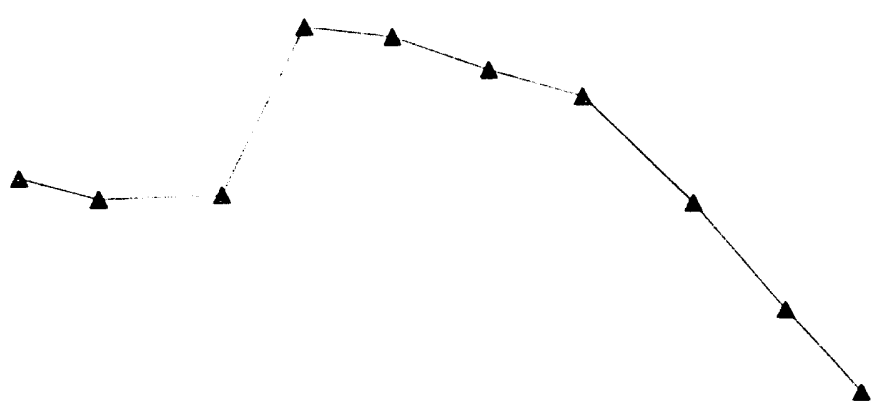

Unconnected lines indicate a dry well or a value below the detection limit.

PDWS $5 \mu \mathrm{g} / \mathrm{L}$ 


\section{Trichloroethylene Concentrations \\ Well Cluster BGO 44}
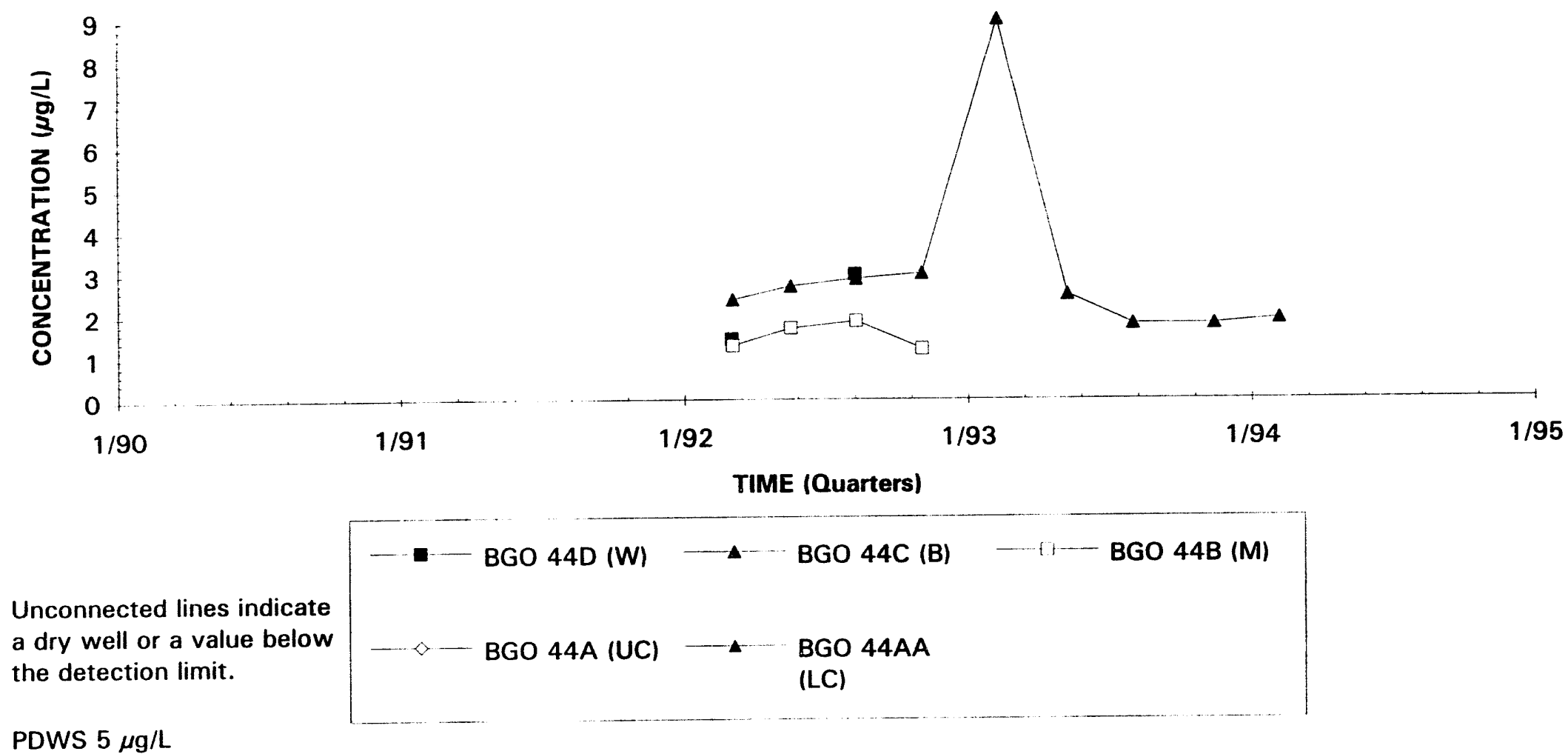

PDWS $5 \mu \mathrm{g} / \mathrm{L}$ 


\section{Trichloroethylene Concentrations Well Cluster BGO 46}

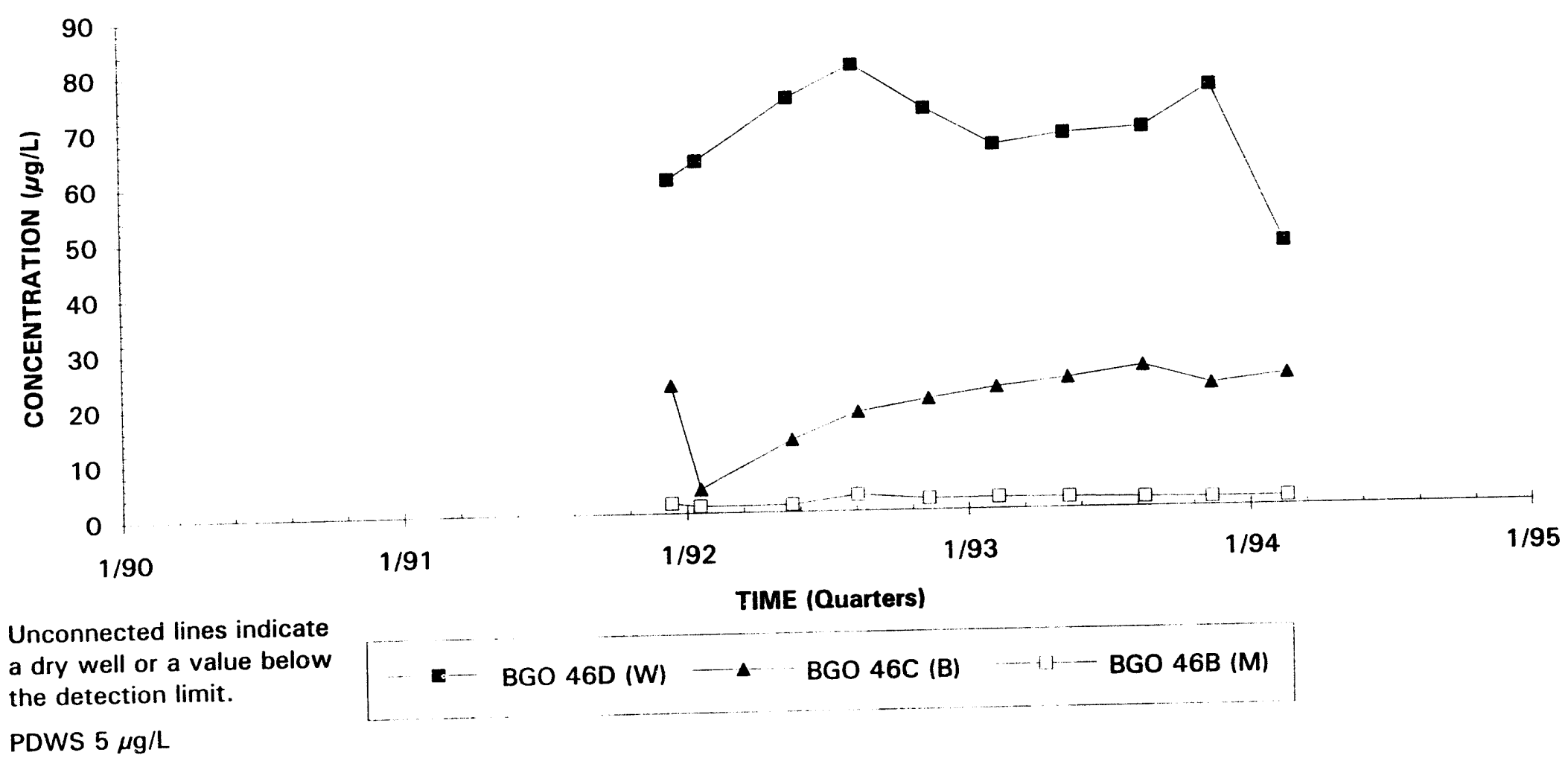




\section{Trichloroethylene Concentrations} Well Cluster BGO 47

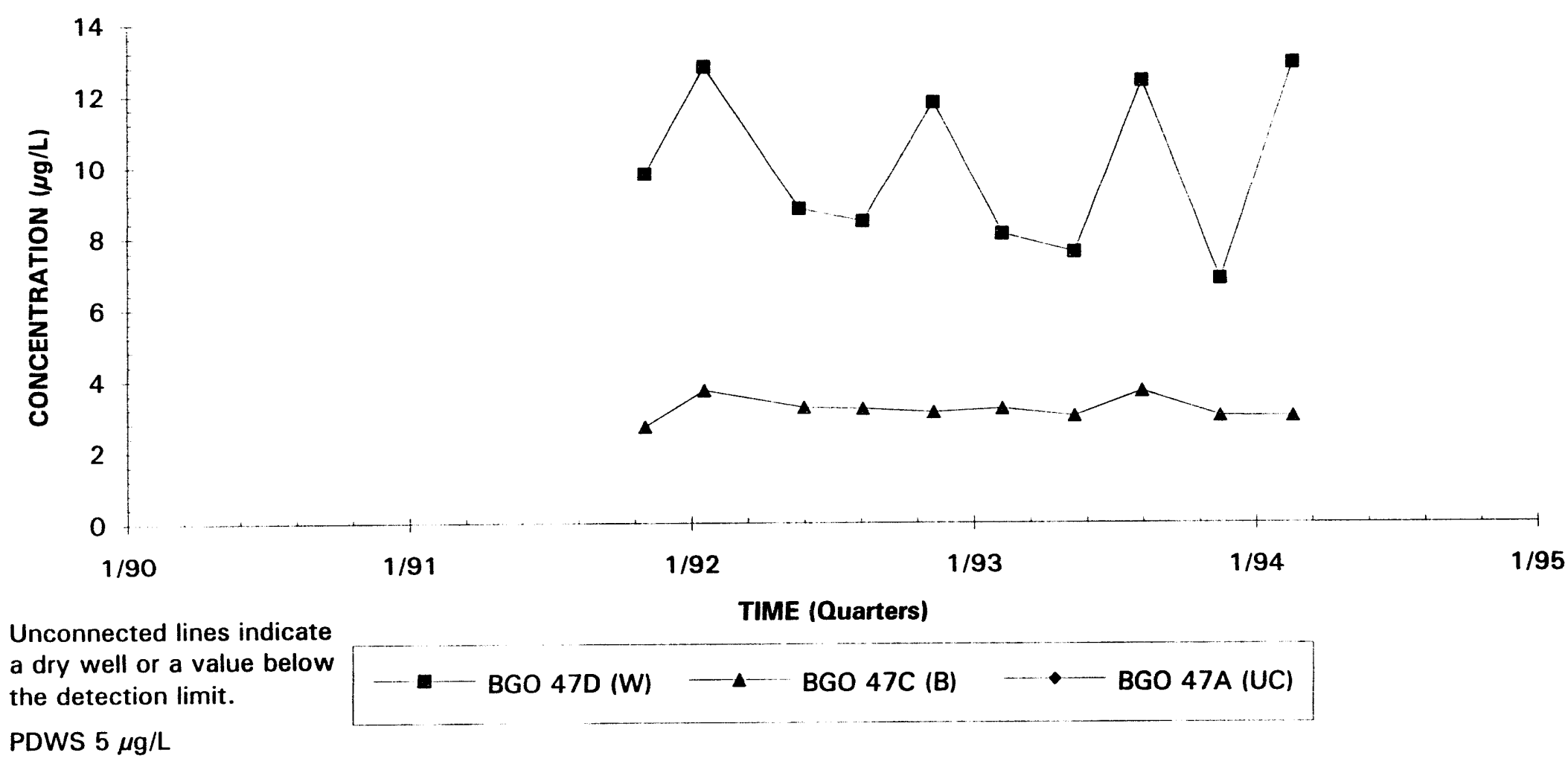

Note: $W=$ Water Table (IIB2); $B=$ Barnwell (IIB1); $M=$ McBean (IIB1); UC=Upper Congaree (IIA); $M C=$ Middle Congaree (IIA); LC=Lower Congaree (IIA) 


\section{Trichloroethylene Concentrations \\ Well Cluster BGO 48}

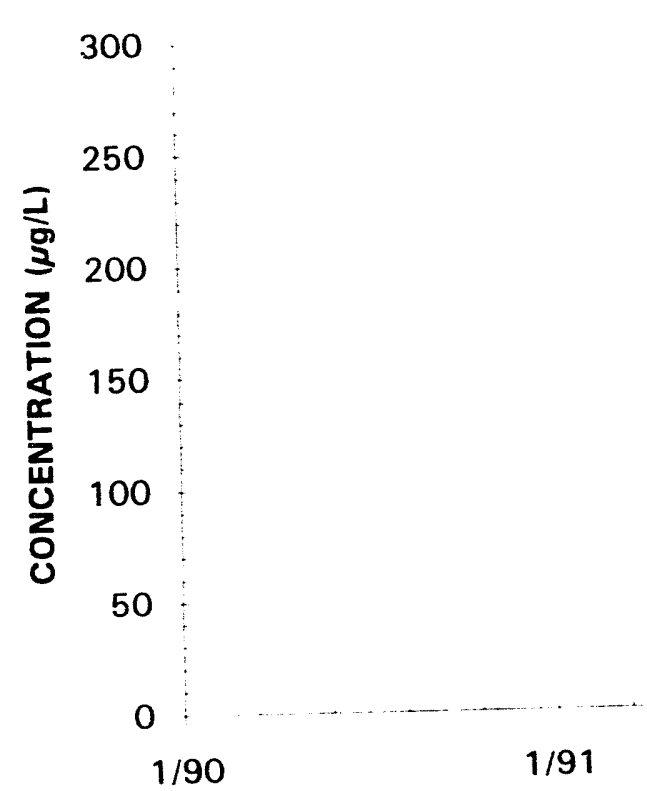

Unconnected lines indicate a dry well or a value below the detection limit.

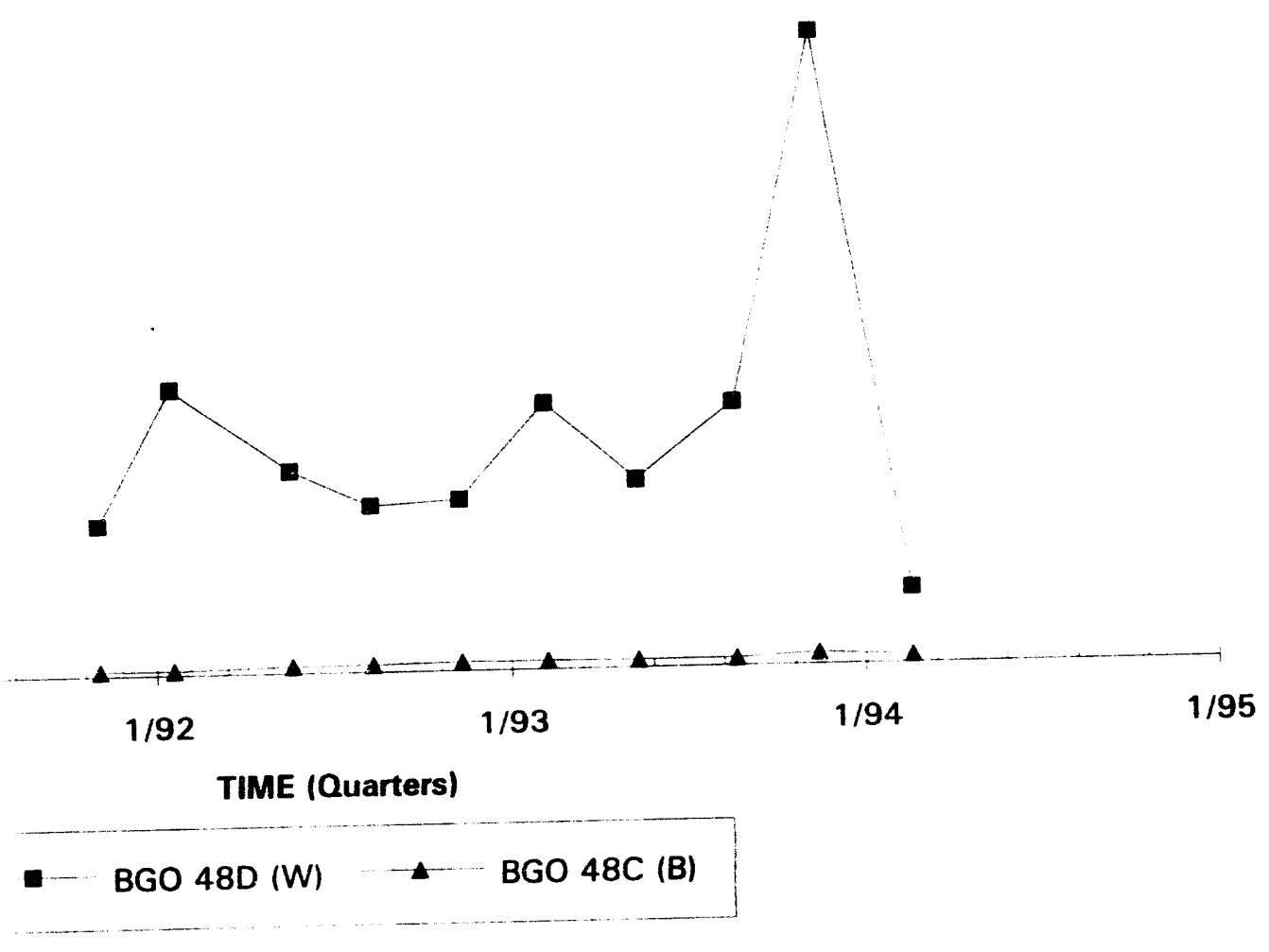

PDWS $5 \mu \mathrm{g} / \mathrm{L}$ 


\section{Trichloroethylene Concentrations \\ Well Cluster BGO 50}
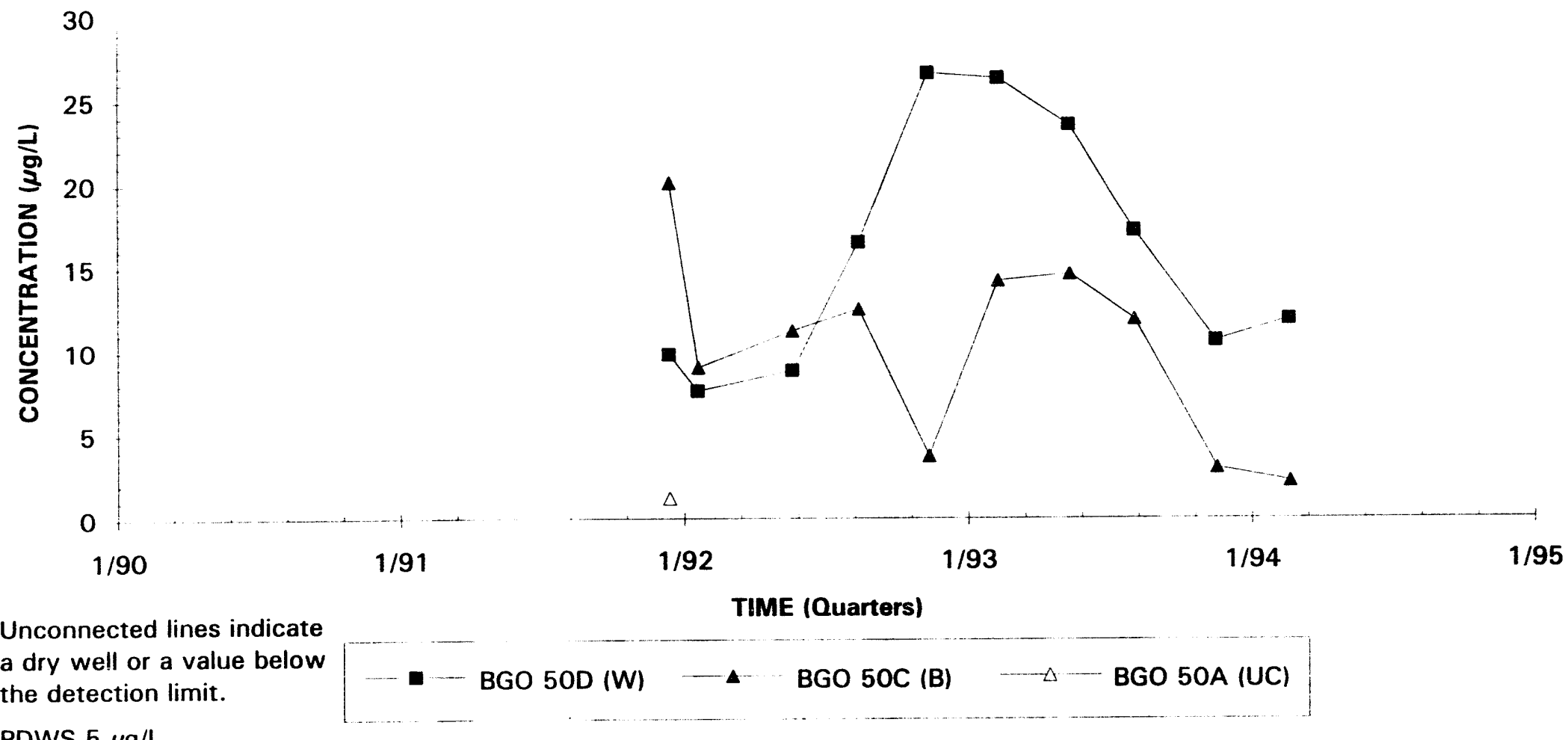

Unconnected lines indicate a dry well or a value below the detection limit.

PDWS $5 \mu \mathrm{g} / \mathrm{L}$ 


\section{Trichloroethylene Concentrations \\ Well Cluster BGX 2}

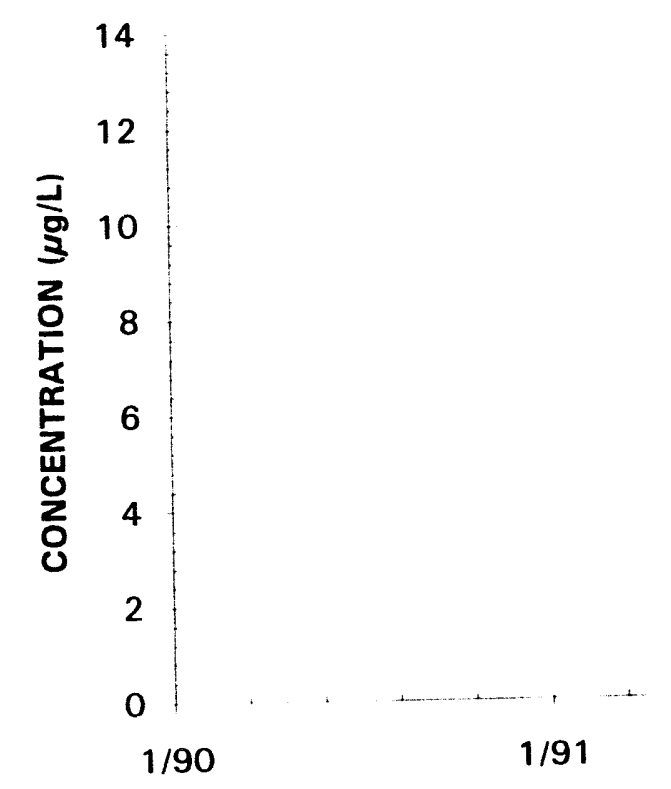

Unconnected lines indicate a dry well or a value below the detection limit.
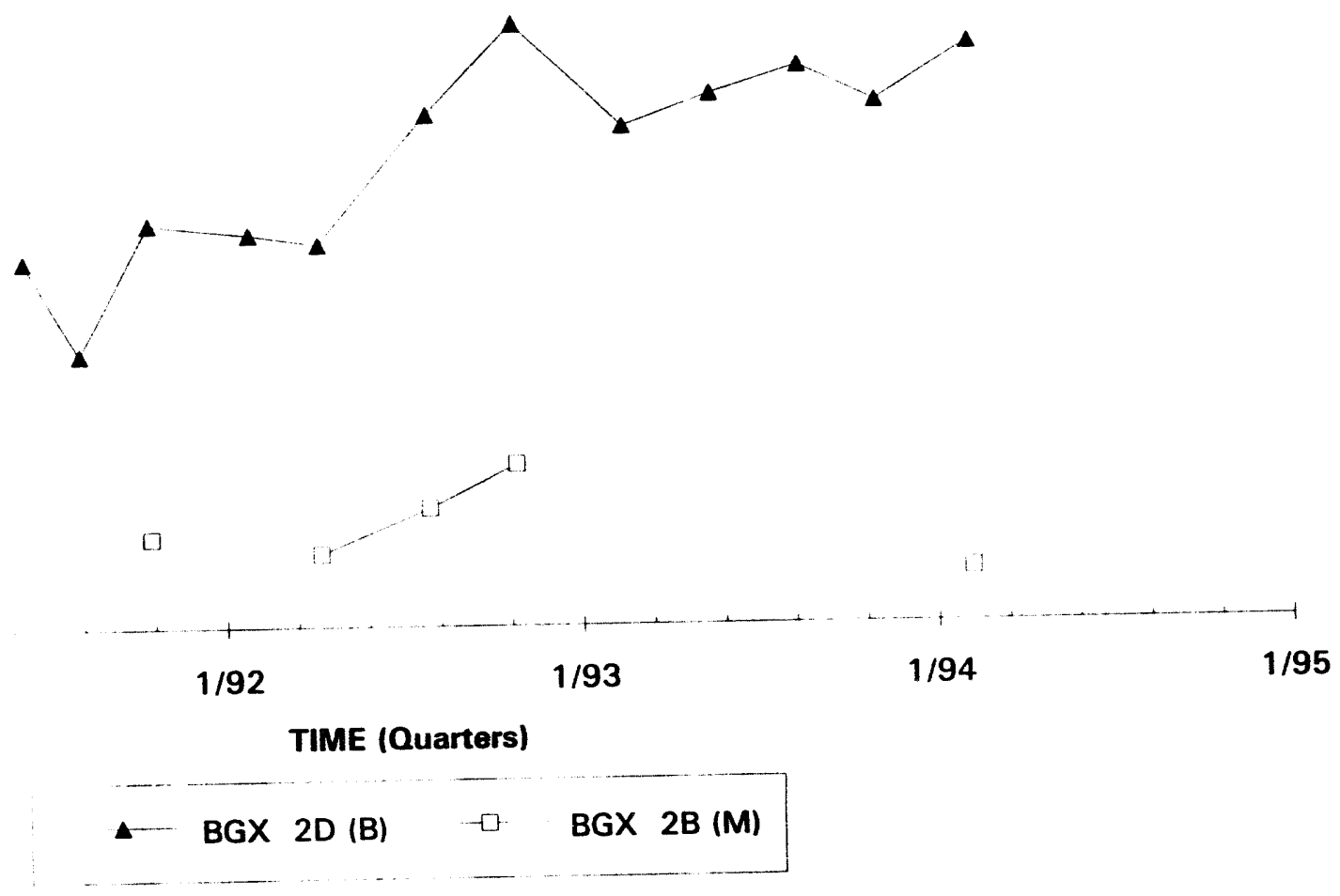

PDWS $5 \mu \mathrm{g} / \mathrm{L}$ 


\section{Trichloroethylene Concentrations}

Well BGX 3D

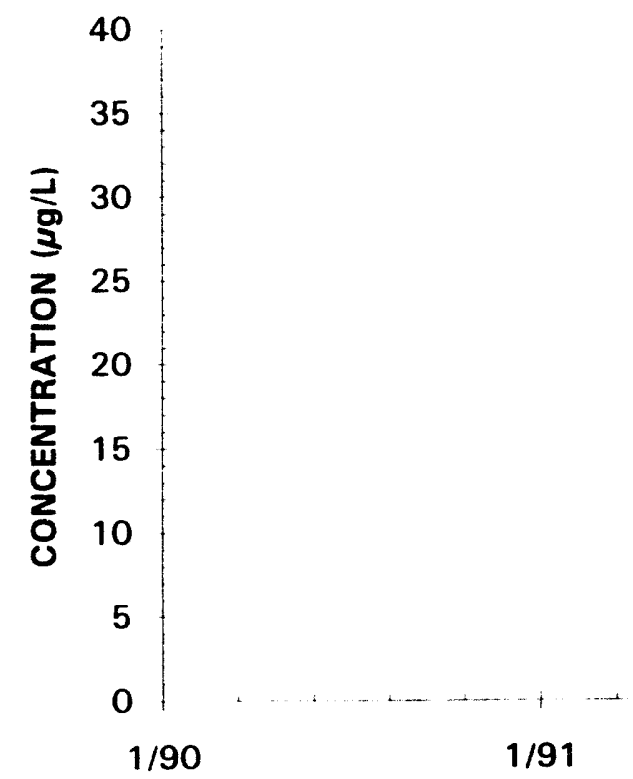

Unconnected lines indicate a dry well or a value below the detection limit.

PDWS $5 \mu \mathrm{g} / \mathrm{L}$

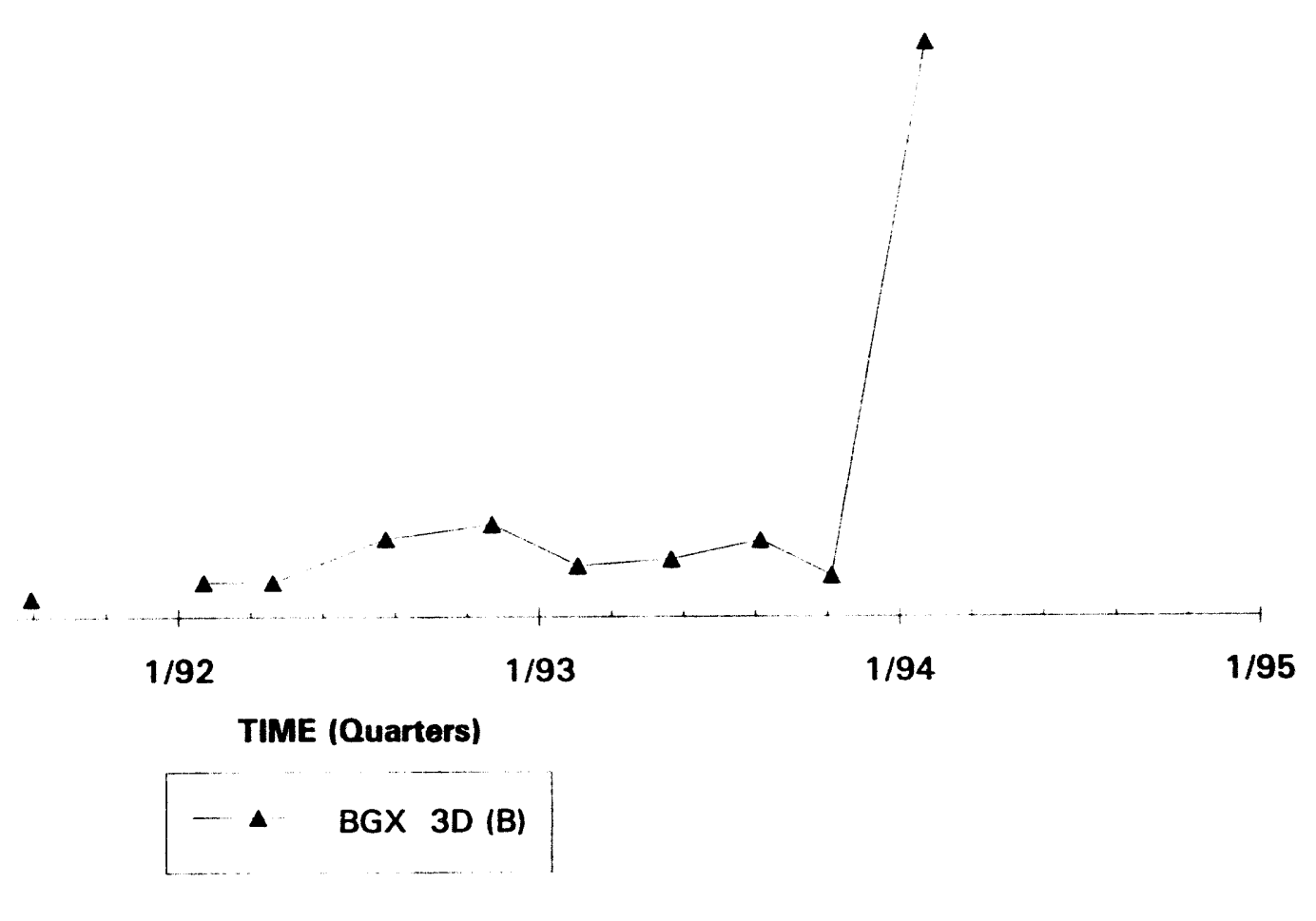

Note: $W=$ Water Table (IIB2); $B=$ Barnwell (IIB1); $M=$ MCBean (IIB1); UC = Upper Congaree (IIA); $M C=$ Middle Congaree (IIA); LC =Lower Congaree (IIA) 


\section{Tritium Activities}

Well BGO 1D

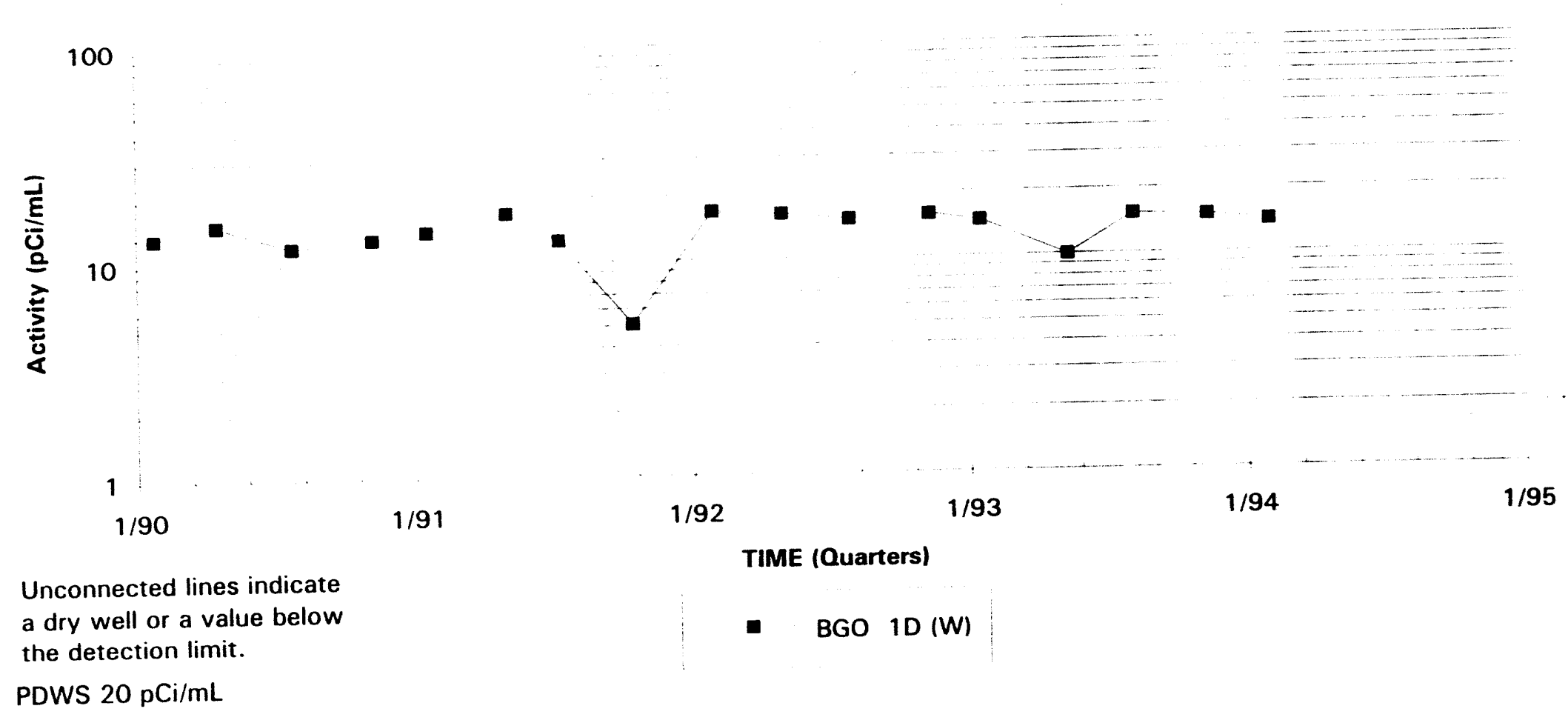




\section{Tritium Activities \\ Well BGO 2D}

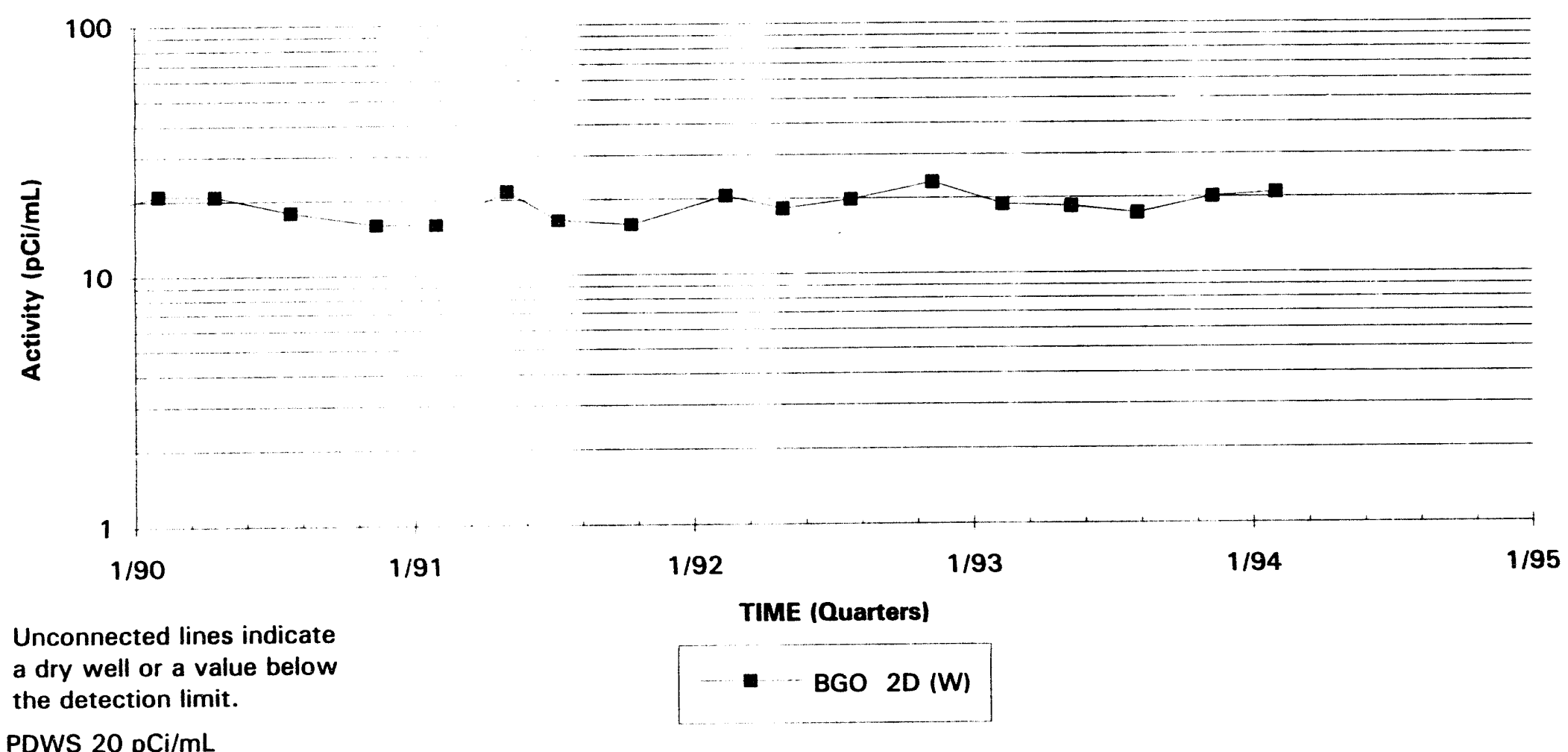

Note: $W=$ Water Table (IIB2); $B=$ Barnwell (IIB1); $M=$ McBean (IIB1); UC=Upper Congaree (IIA); $M C=$ Middle Congaree (IIA); LC=Lower Congaree (IIA 
Tritium Activities

Well BGO 3D
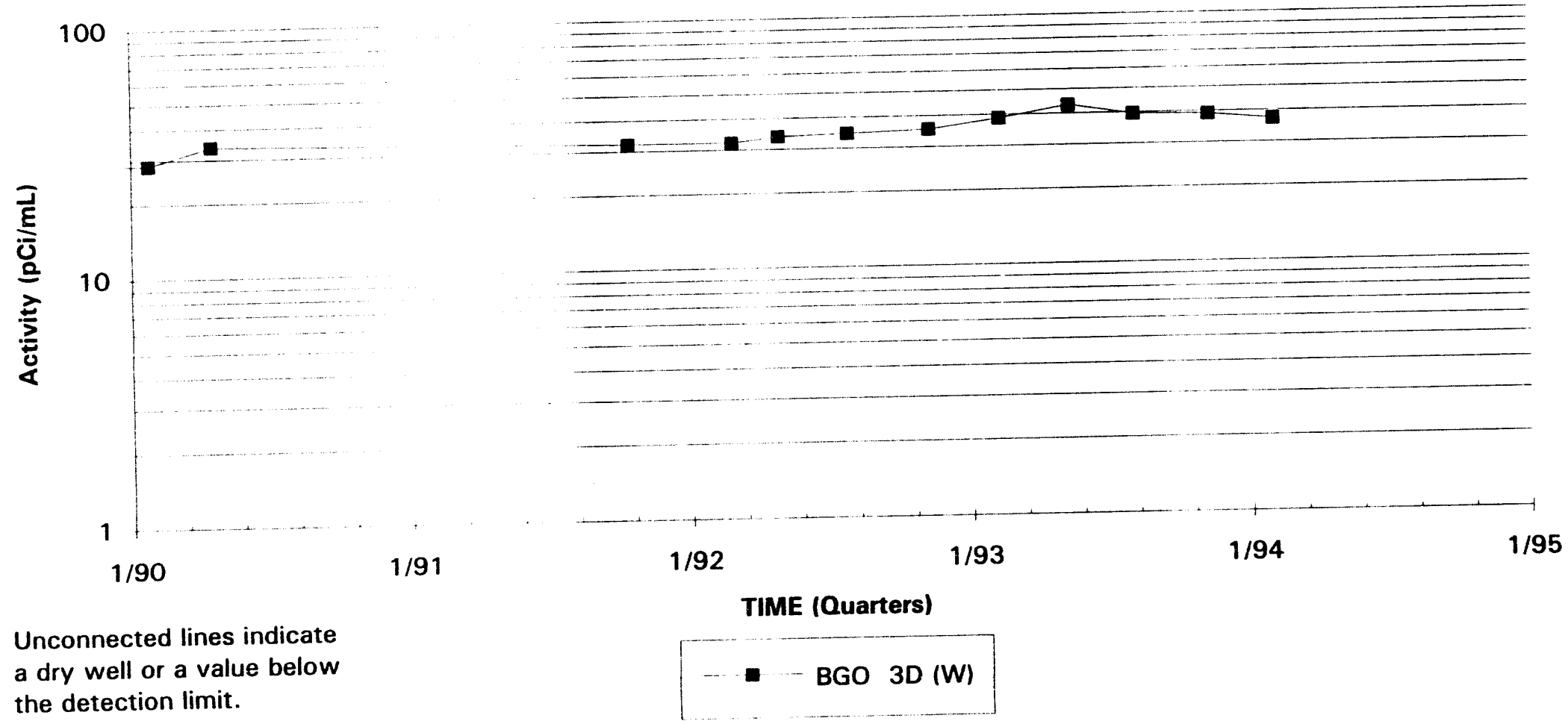

Unconnected lines indicate a dry well or a value below the detection limit.

PDWS $20 \mathrm{pCi} / \mathrm{mL}$ 


\section{Tritium Activities}

Well BGO 4D

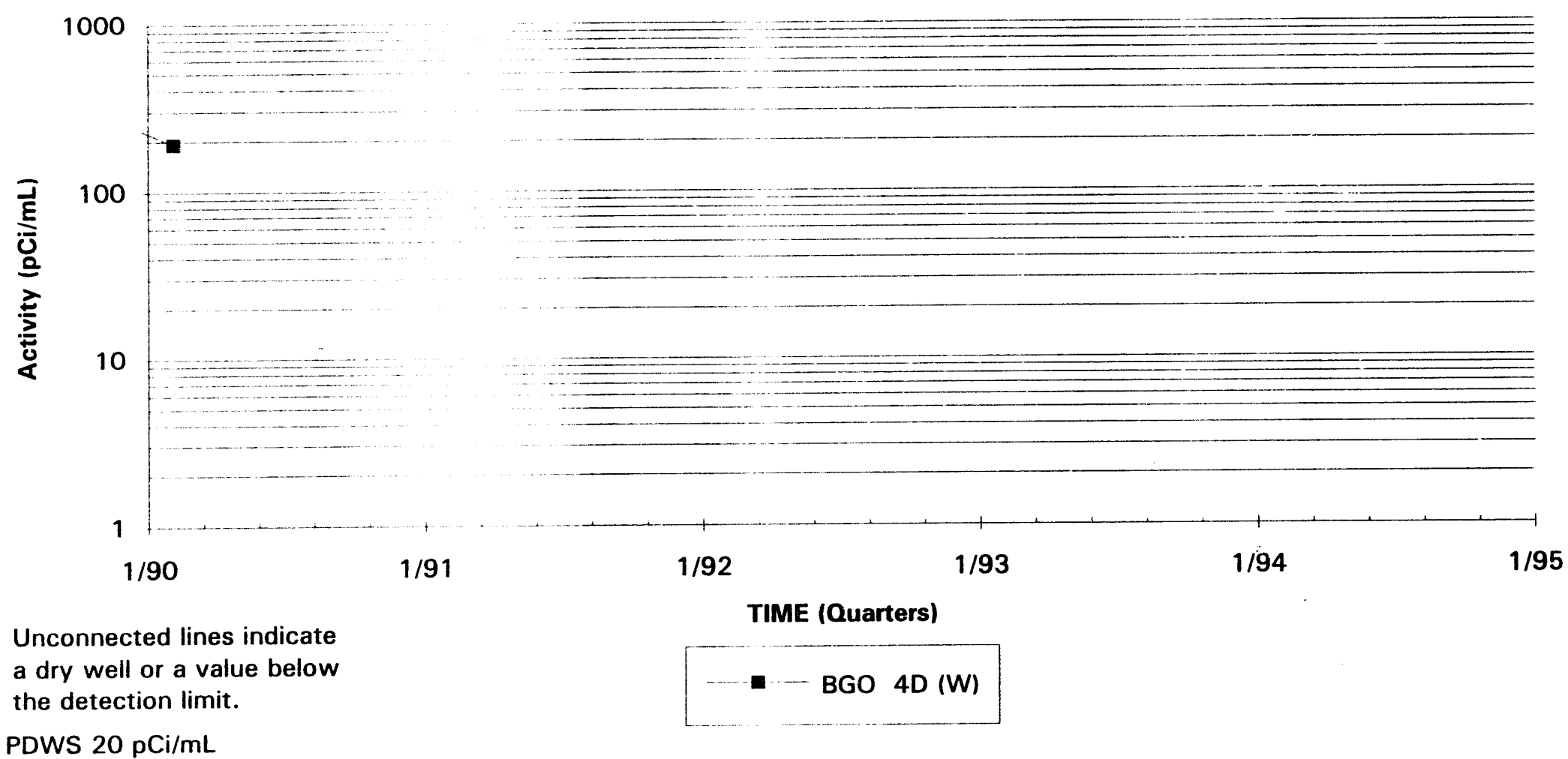

Note: $W=$ Water Table (IIB2); $B=$ Barnwell (IB1); $M=$ McBean (IIB1); UC=Upper Congaree (IIA); $M C=$ Middle Congaree (IIA); LC=Lower Congaree (IIA) 


\section{Tritium Activities \\ Well Cluster BGO 5}
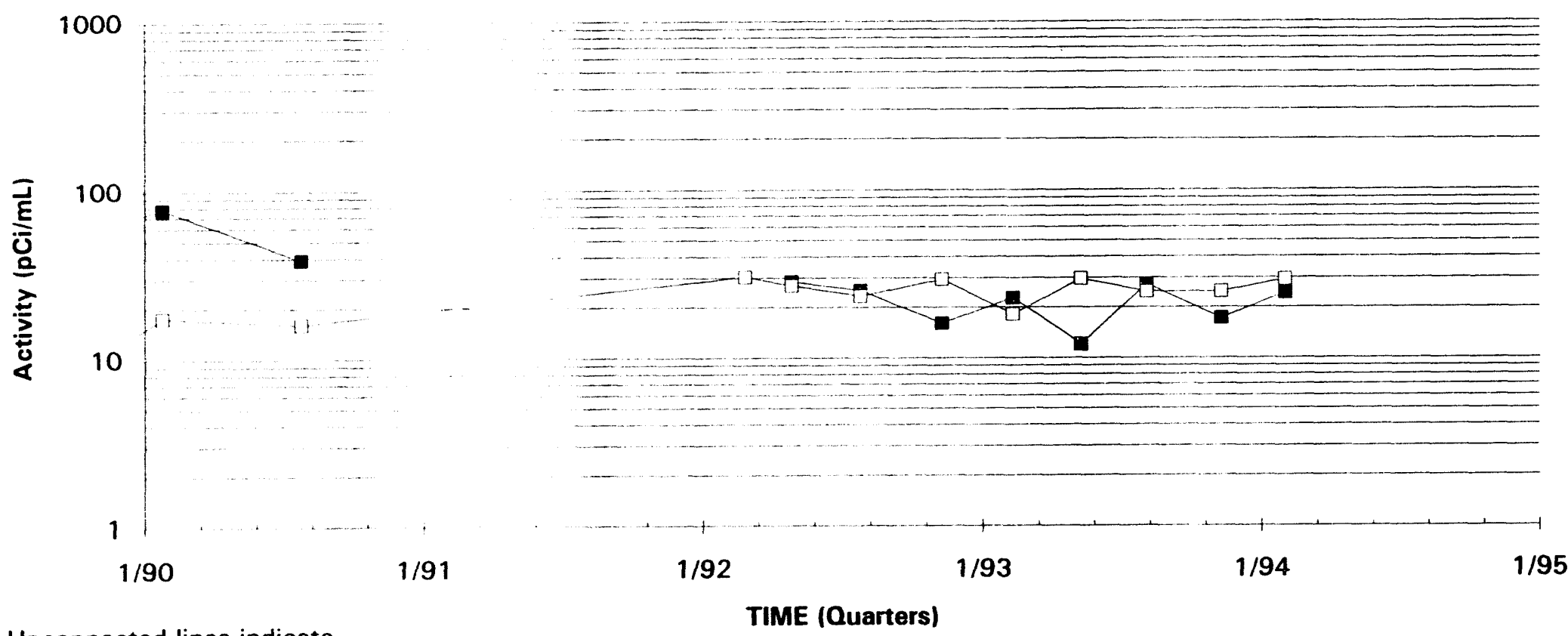

Unconnected lines indicate a dry well or a value below the detection limit.

$=B G O 5 D(W) \quad$ BGO 5C (M)

PDWS $20 \mathrm{pCi} / \mathrm{mL}$ 


\section{Tritium Activities}

Well Cluster BGO 6

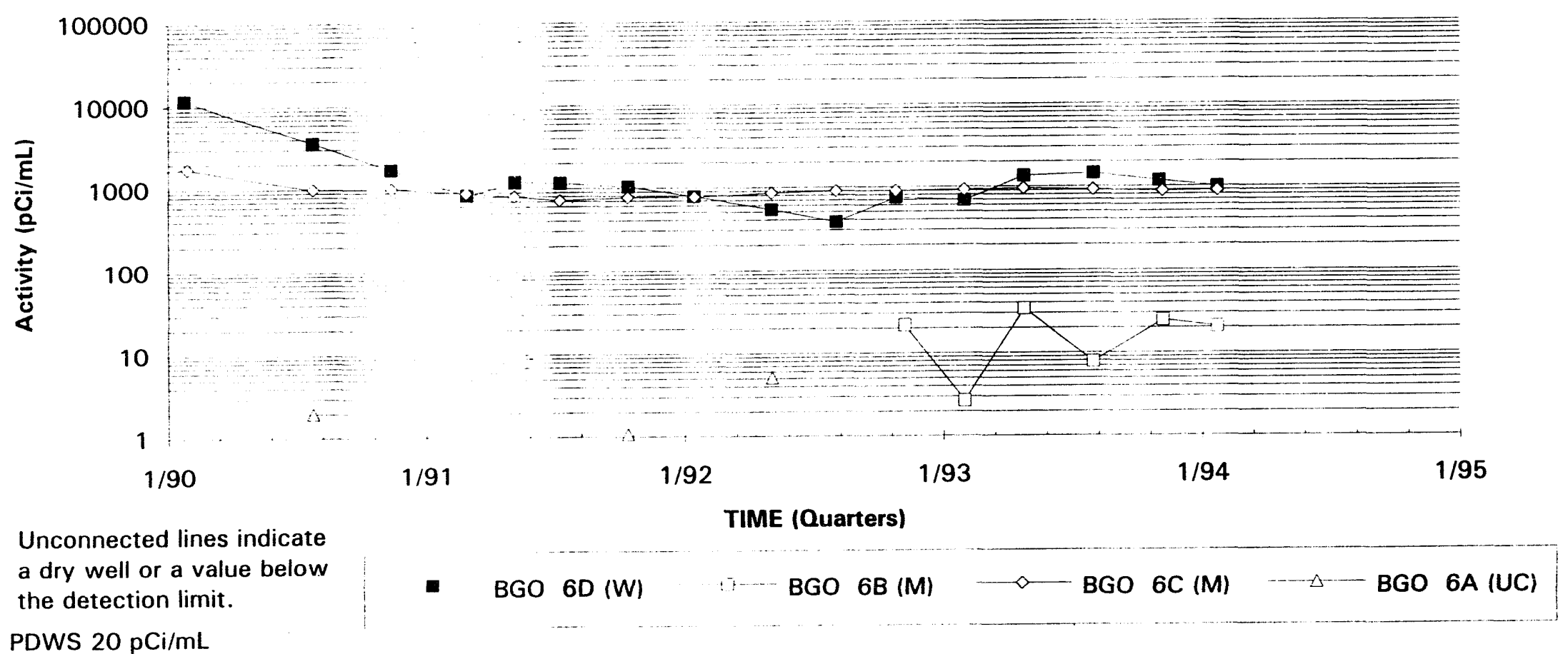

Note: $W=$ Water Table (IIB2); $B=$ Barnwell (IIB1); $M=$ McBean (IIB1); UC=Upper Congaree (IIA); $M C=$ Middle Congaree (IIA); LC $=$ Lower Congaree (IIA 


\section{Tritium Activities}

Well BGO 7D

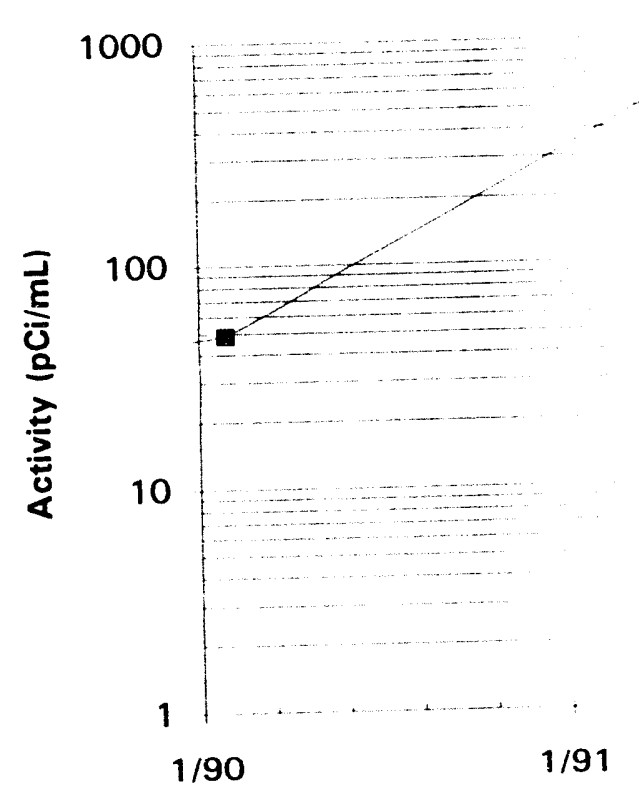

Unconnected lines indicate a dry well or a value below the detection limit.

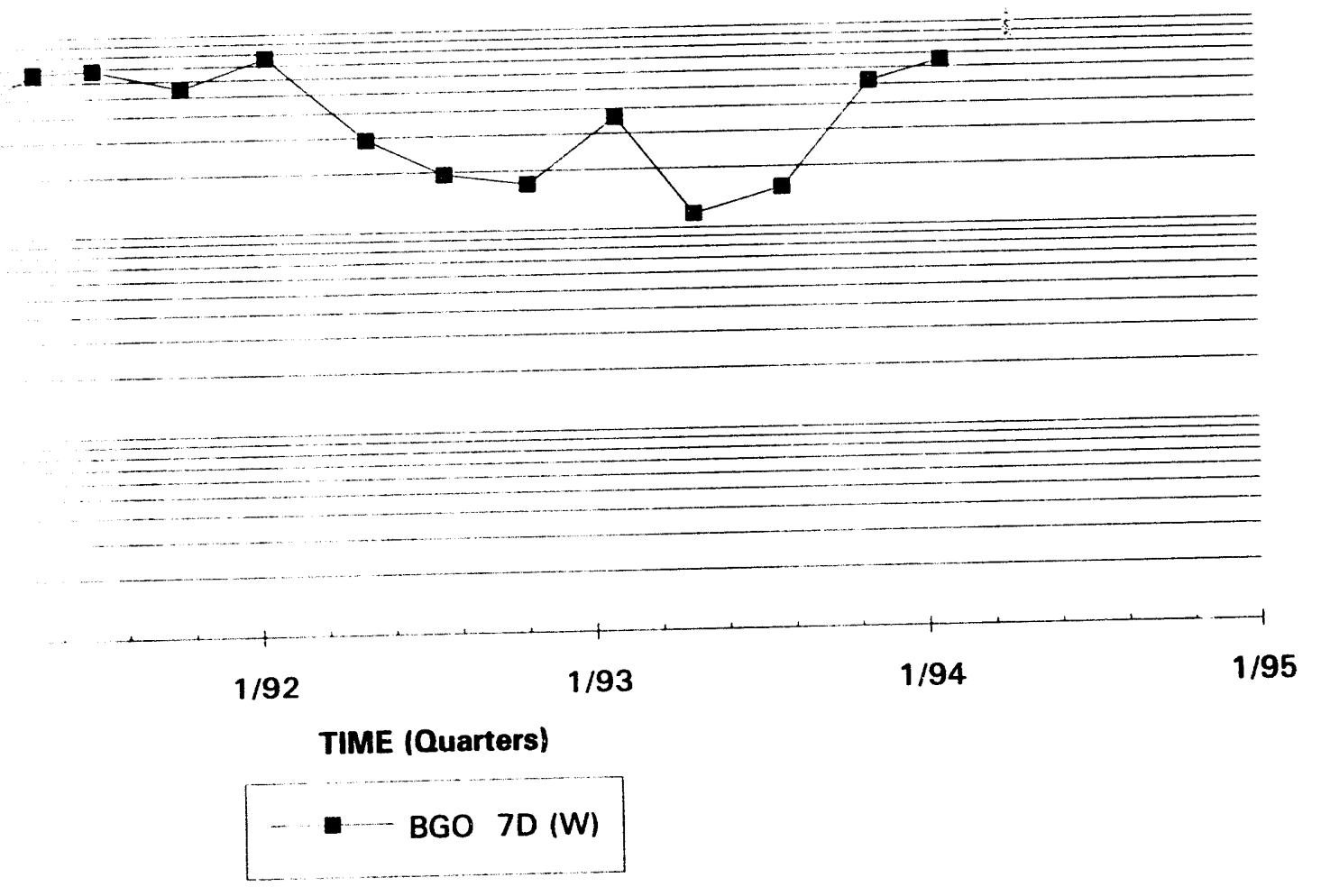

PDWS $20 \mathrm{pCi} / \mathrm{mL}$ 


\section{Tritium Activities Well Cluster BGO 8}
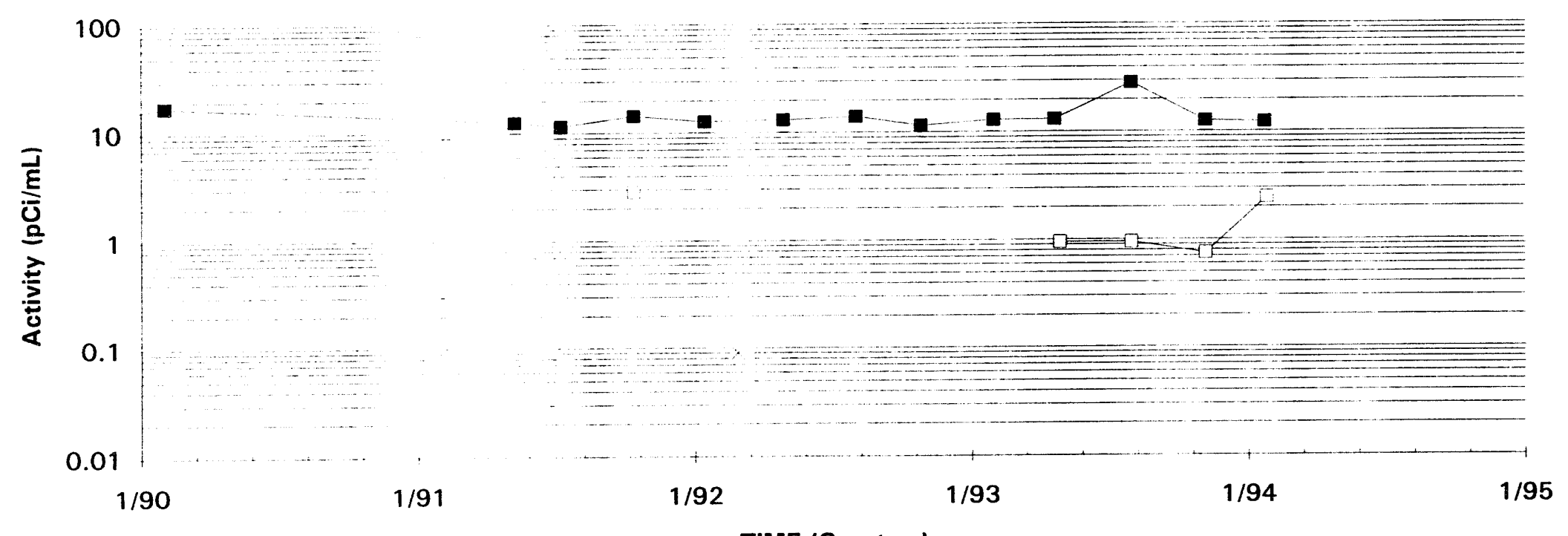

Unconnected lines indicate a dry well or a value below the detection limit.

- $\quad$ BGO $8 D(W)$

TIME (Quarters)

PDWS $20 \mathrm{pCi} / \mathrm{mL}$ 


\section{Tritium Activities \\ Well Cluster BGO 9}

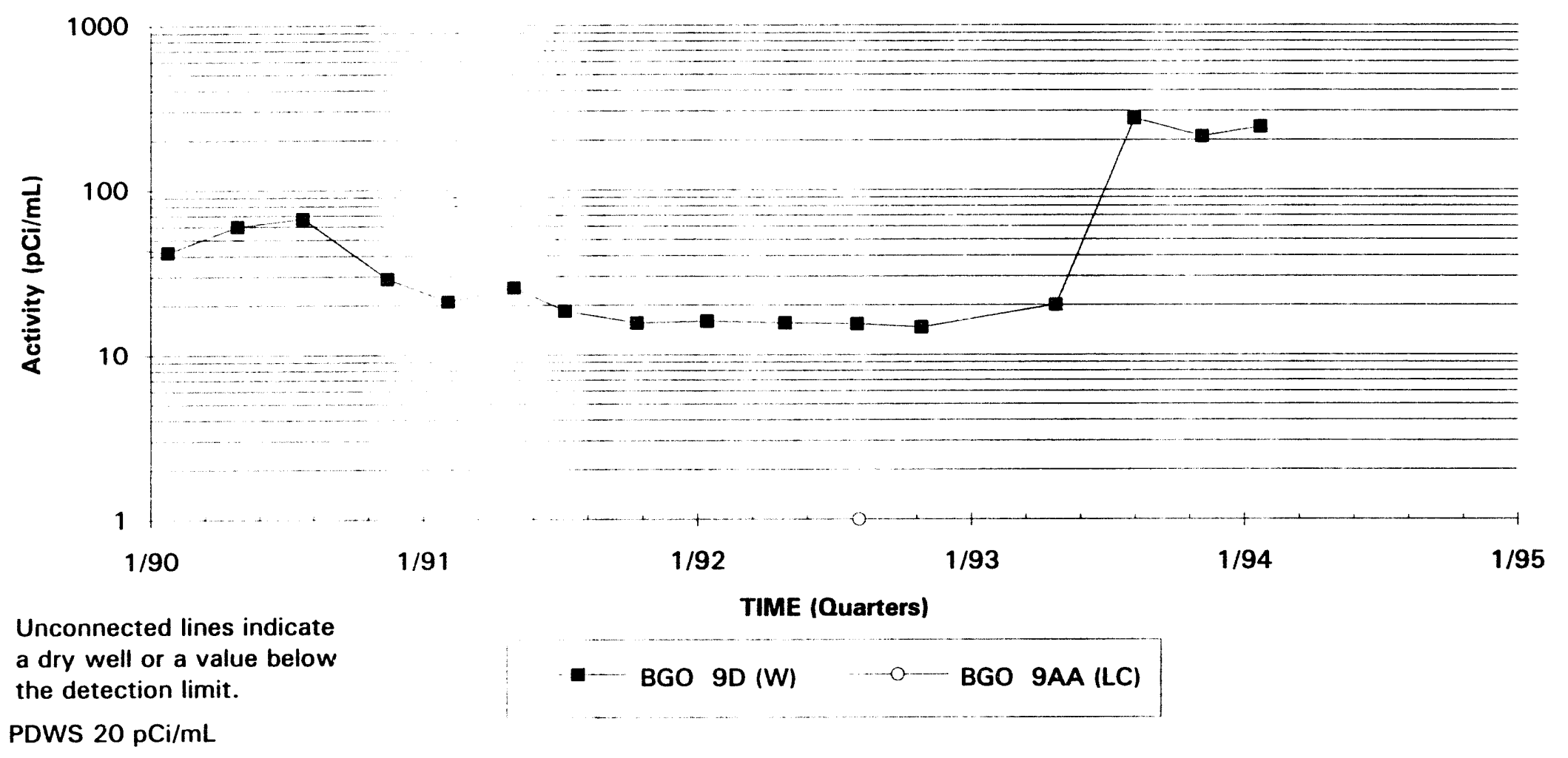




\section{Tritium Activities Well Cluster BGO 10}

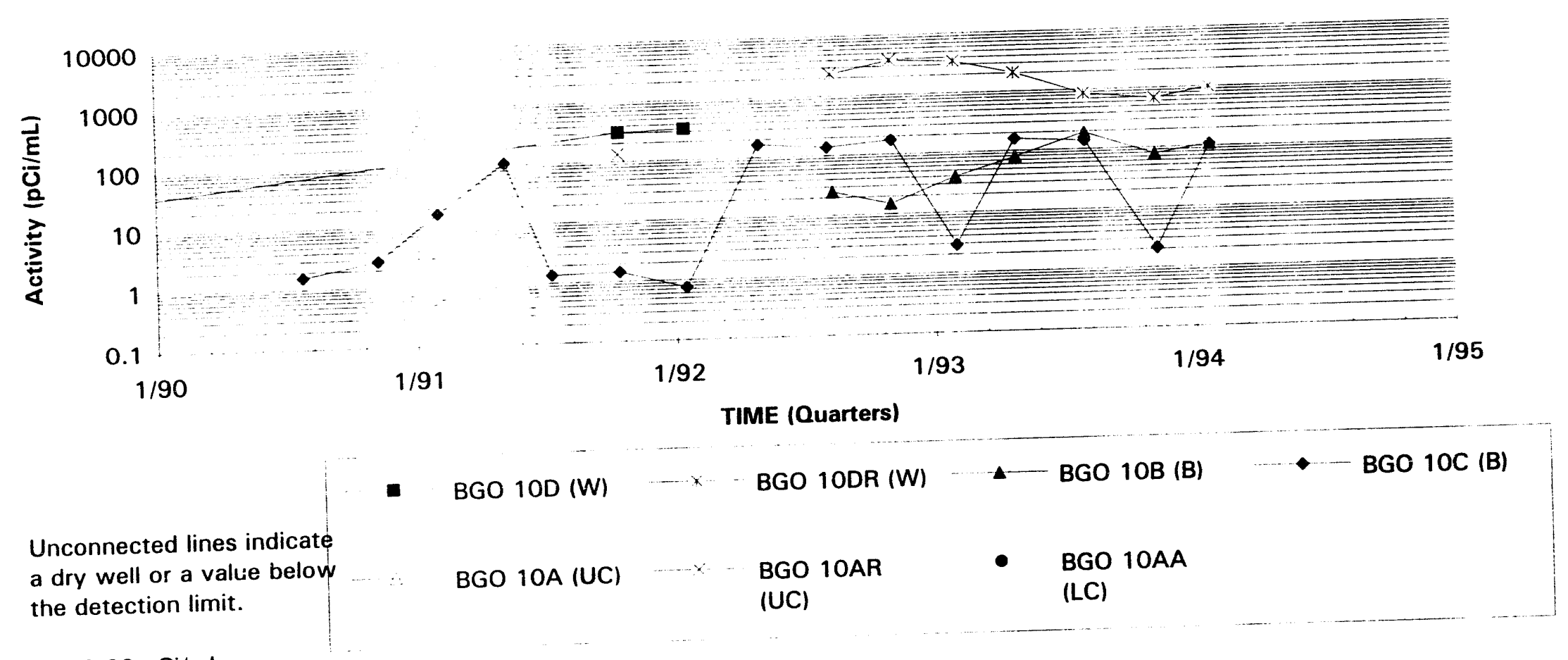

PDWS $20 \mathrm{pCi} / \mathrm{mL}$ 


\section{Tritium Activities}

Well BGO 11D

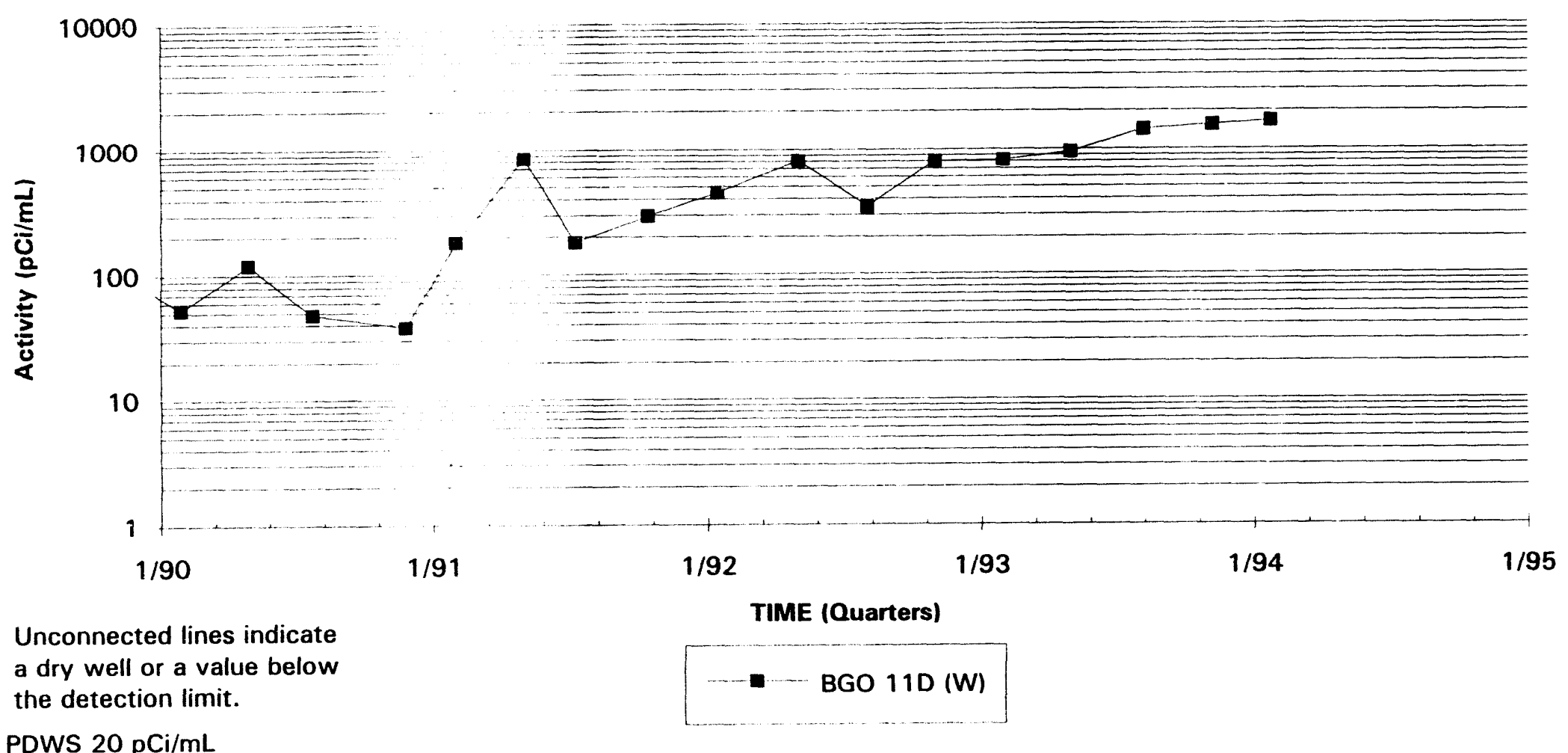




\section{Tritium Activities}

\section{Well Cluster BGO 12}

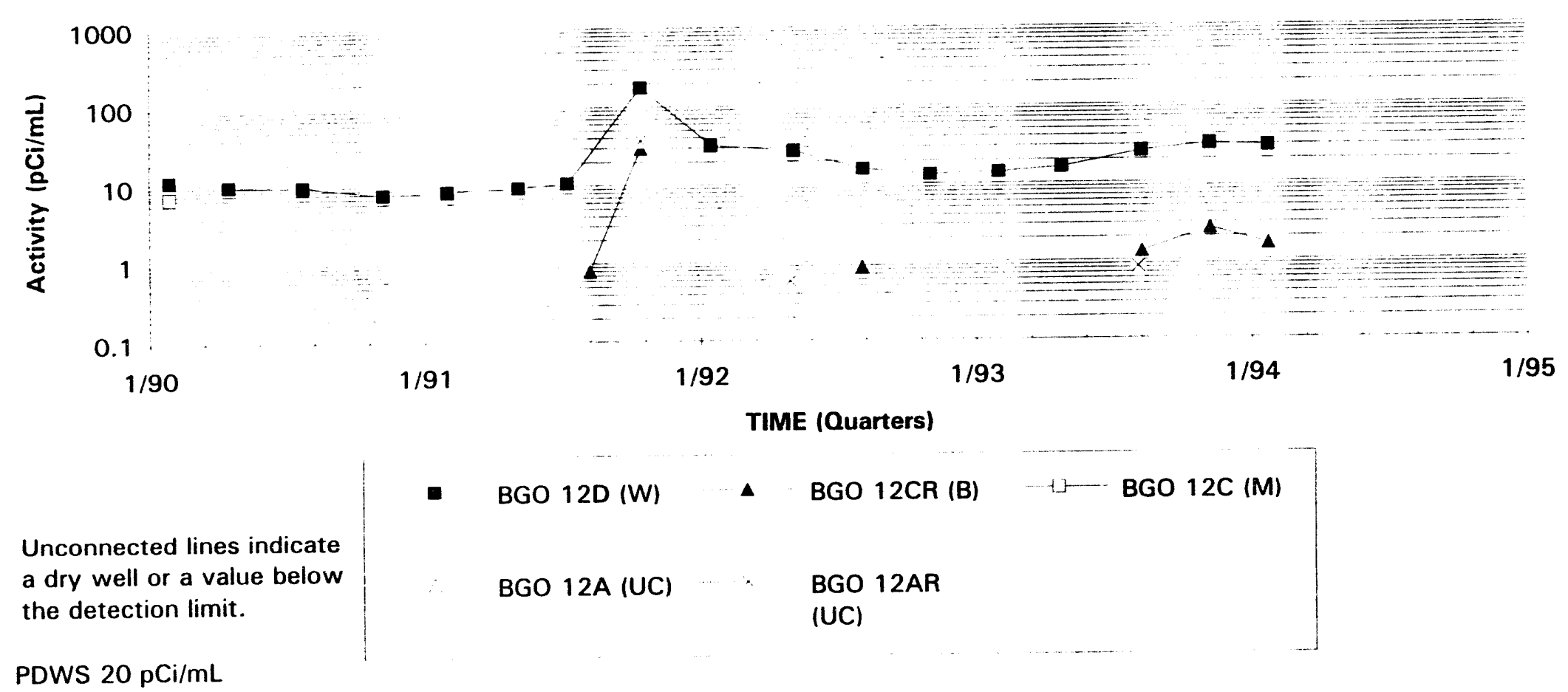

Note: $W=$ Water Table (IIB2); $B=$ Barnwell (IIB1); $M=M c B e a n$ (IIB1); UC = Upper Congaree (IIA); $M C=$ Middle Congaree (IIA); LC = Lower Congaree (IIA) 


\section{Tritium Activities}

Well Cluster BGO 13
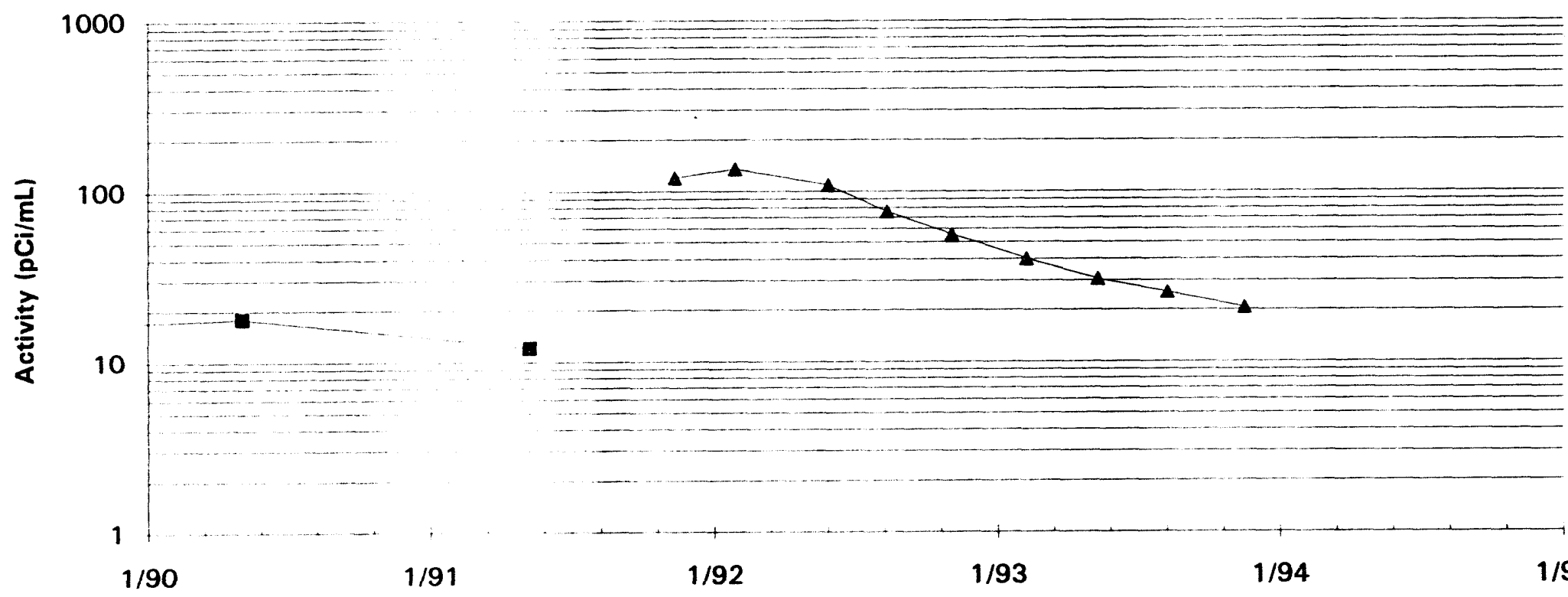

-

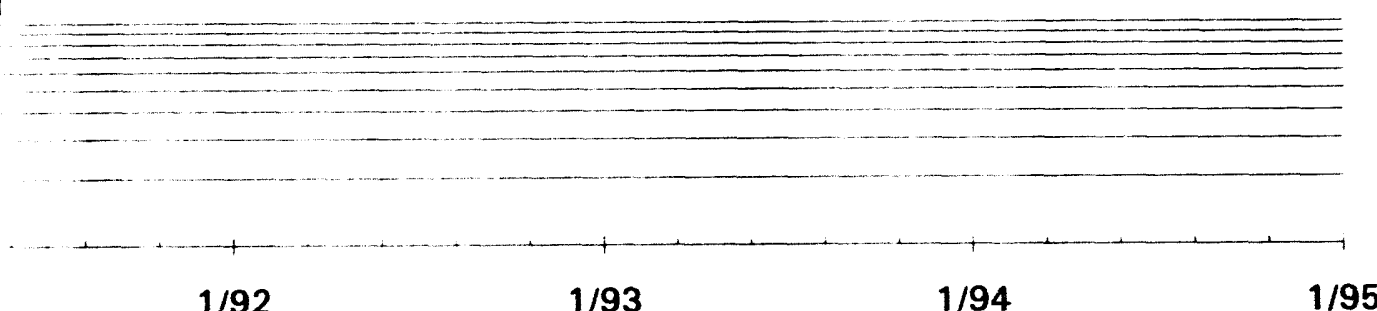

Unconnected lines indicate a dry well or a value below

the detection limit.

TIME (Quarters)

PDWS $20 \mathrm{pCi} / \mathrm{mL}$

\section{BGO 13D (W) BGO 13DR (B)}




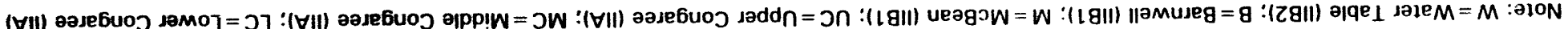

ךw/IJd oz SMOd
(כ)

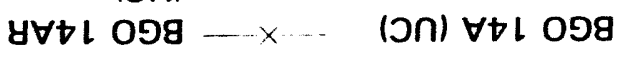

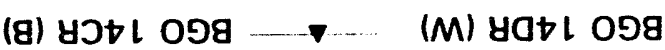

(W) כเレ 098

(M) OtL 058

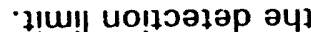
әleכıрu! sau! kaloauuojur

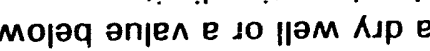

(sม⿰นеก) $\exists W I 1$

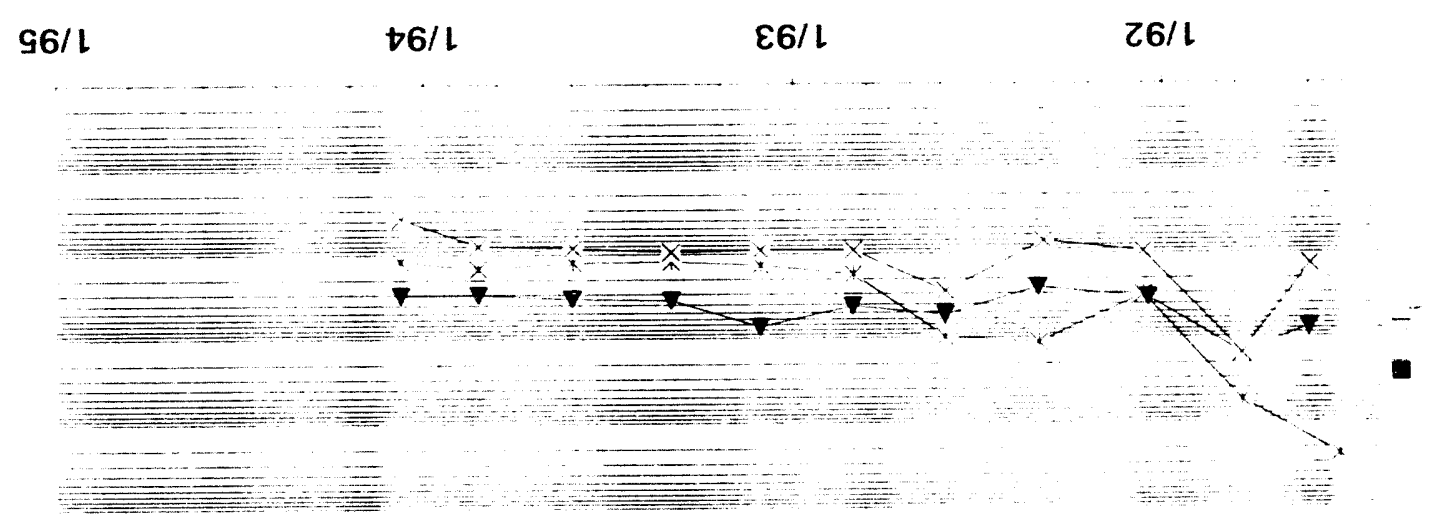

$\mathfrak{l 6 / \mathfrak { l }}$

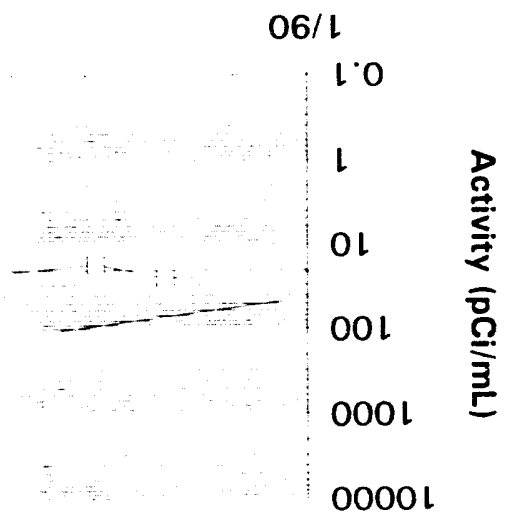


Tritium Activities

Well BGO 15D

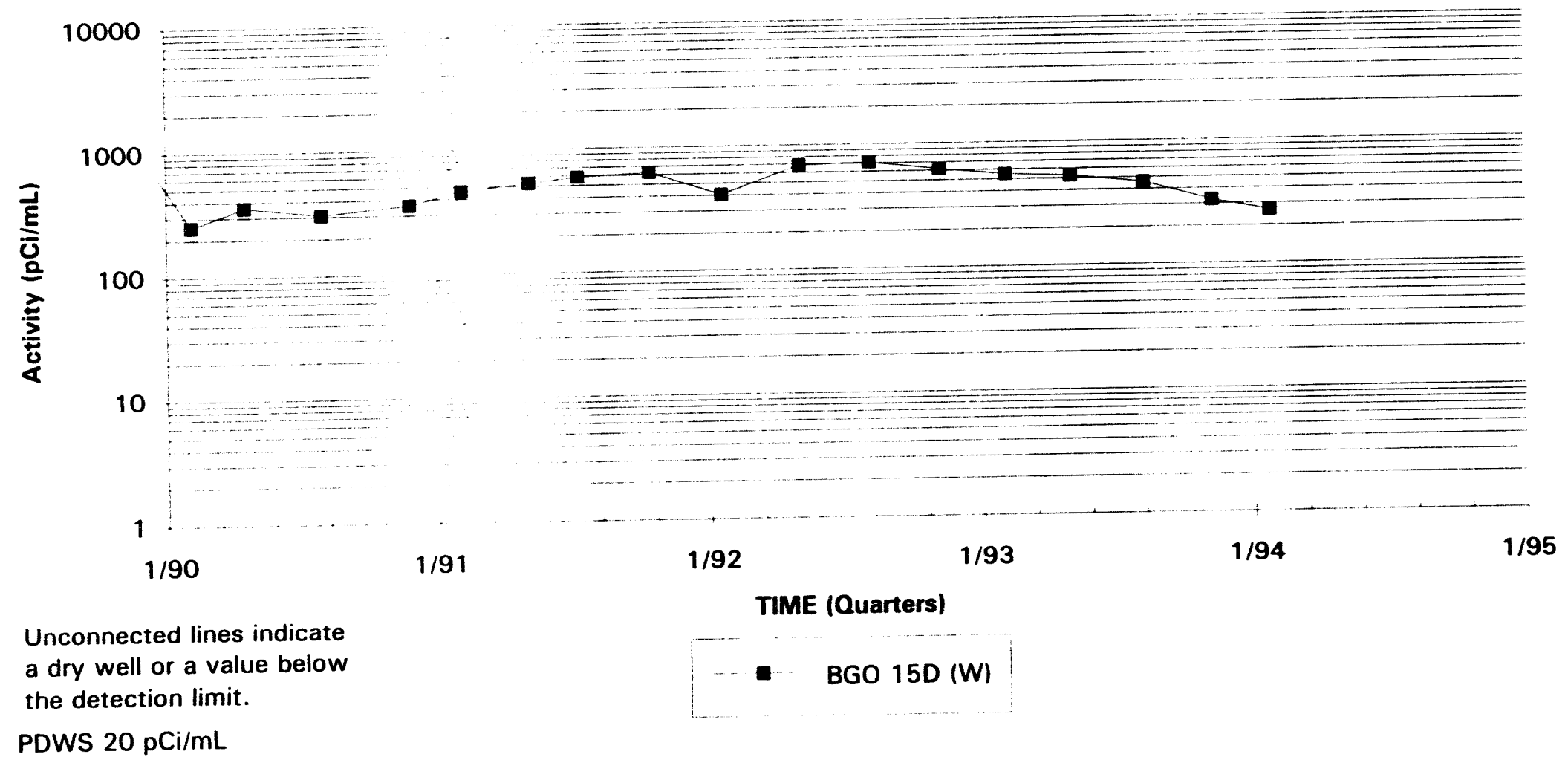




\section{Tritium Activities}

Well Cluster BGO 16

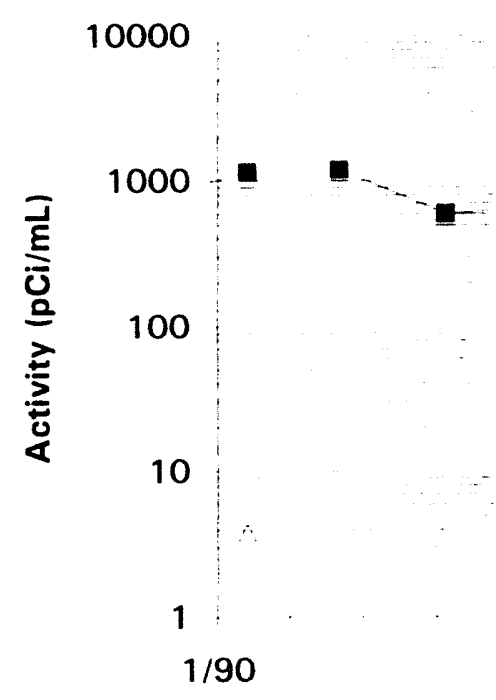

Unconnected lines indicate a dry well or a value below the detection limit.

- BGO 16D (W)

PDWS $20 \mathrm{pCi} / \mathrm{mL}$
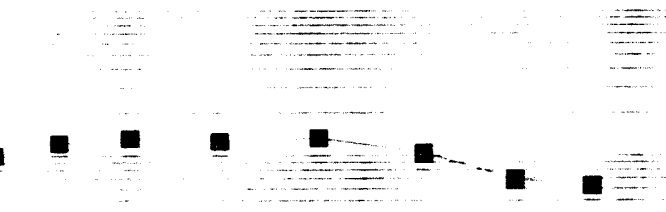

TIME (Quarters)
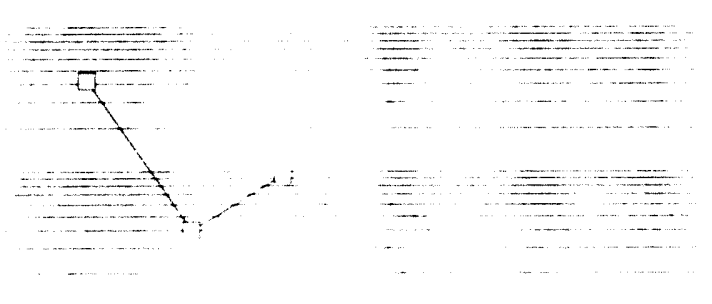

$1 / 93$

$1 / 94$

$1 / 95$

BGO 16B (M)

BGO 16A (UC)

BGO 16AR (UC)

Note: $W=$ Water Table (IIB2); $B=$ Barnwell (IIB1); $M=$ McBean (IIB1); UC = Upper Congaree (IIA); $M C=$ Middle Congaree (IIA); $L C=L o w e r$ Congaree (IIA) 


\section{Tritium Activities}

\section{Well Cluster BGO 17}

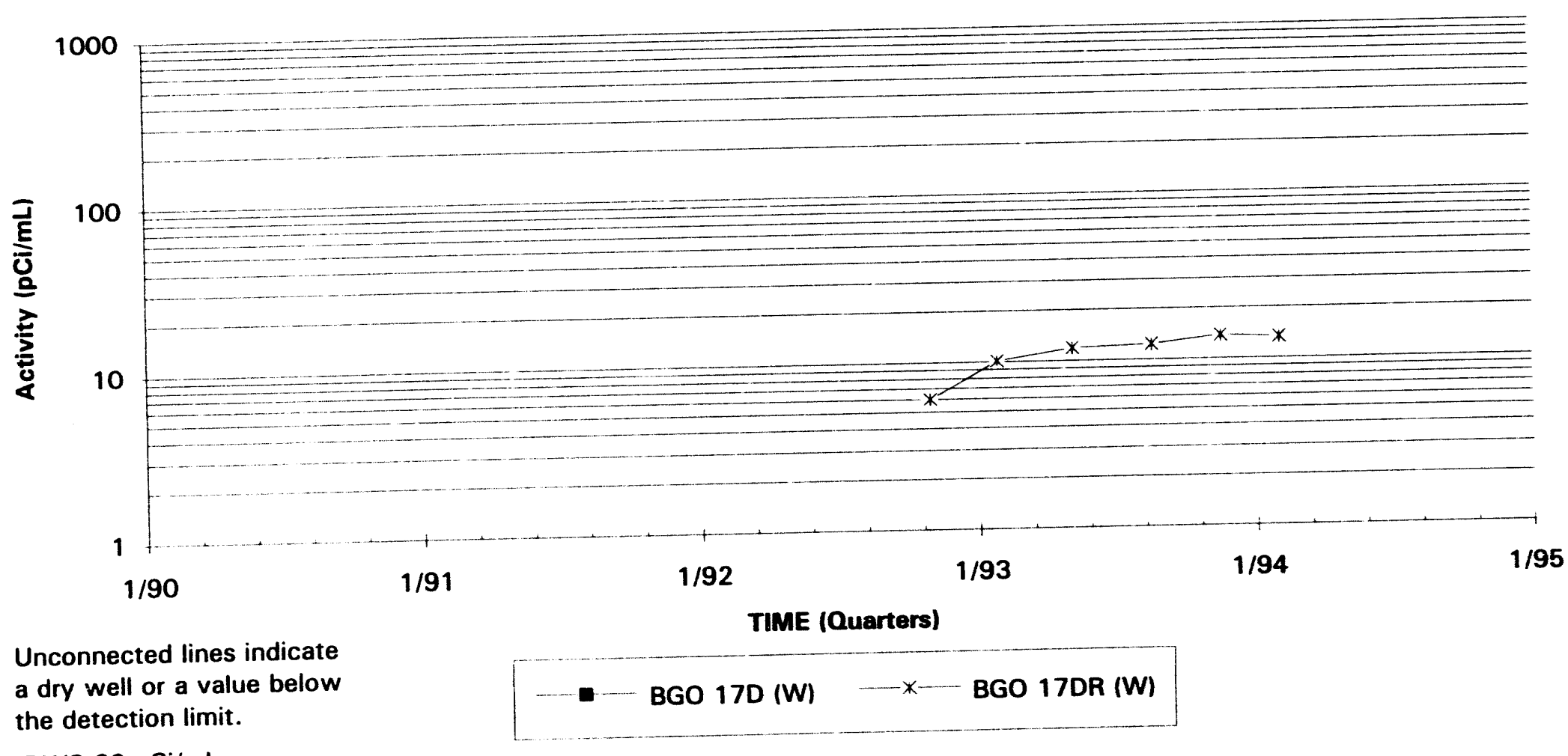

PDWS $20 \mathrm{pCi} / \mathrm{mL}$

No 


\section{Tritium Activities \\ Well Cluster BGO 18}

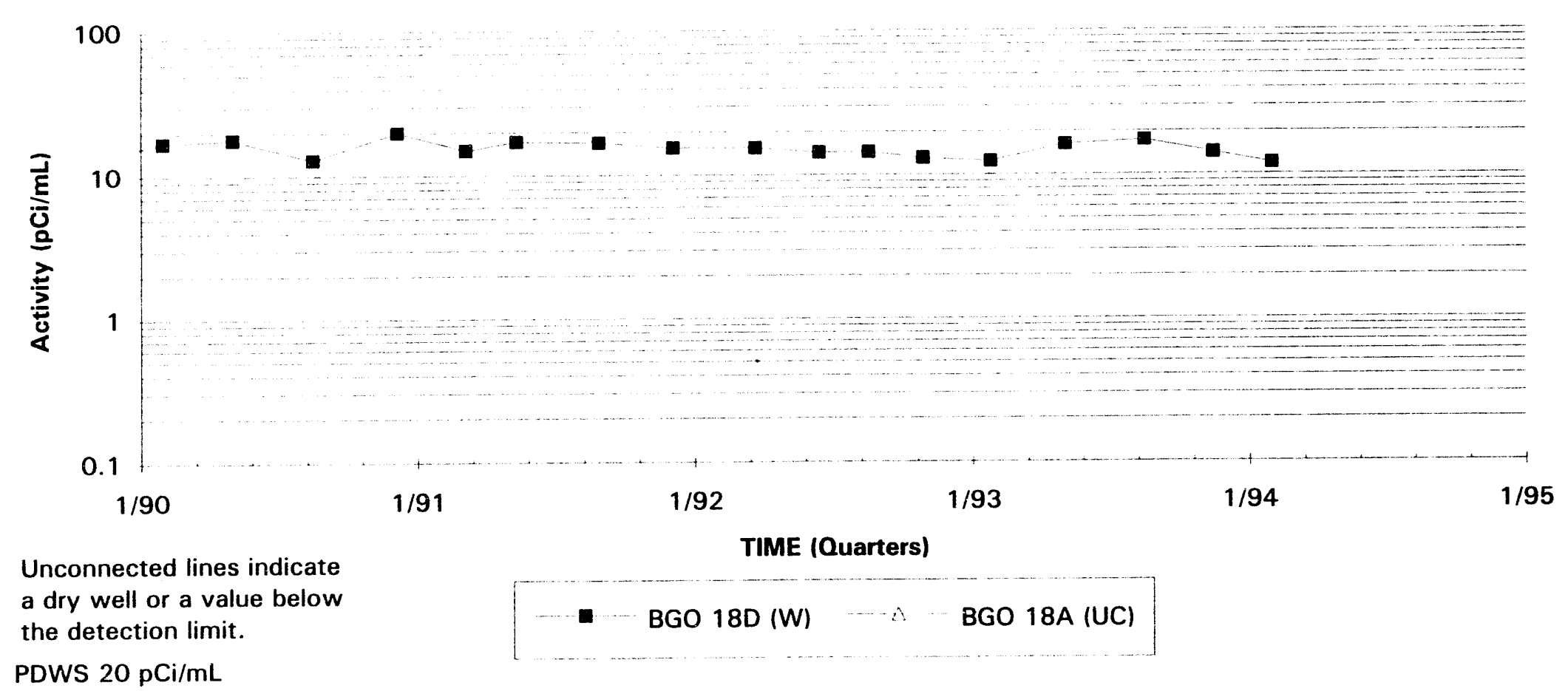

Note: $W=$ Water Table (IIB2); $B=$ Barnwell (IIB1); $M=M c B e a n$ (IIB1); UC = Upper Congaree (IIA); $M C=$ Middle Congaree (IIA); LC=Lower Congaree (IIA) 


\section{Tritium Activities}

Well BGO 19D

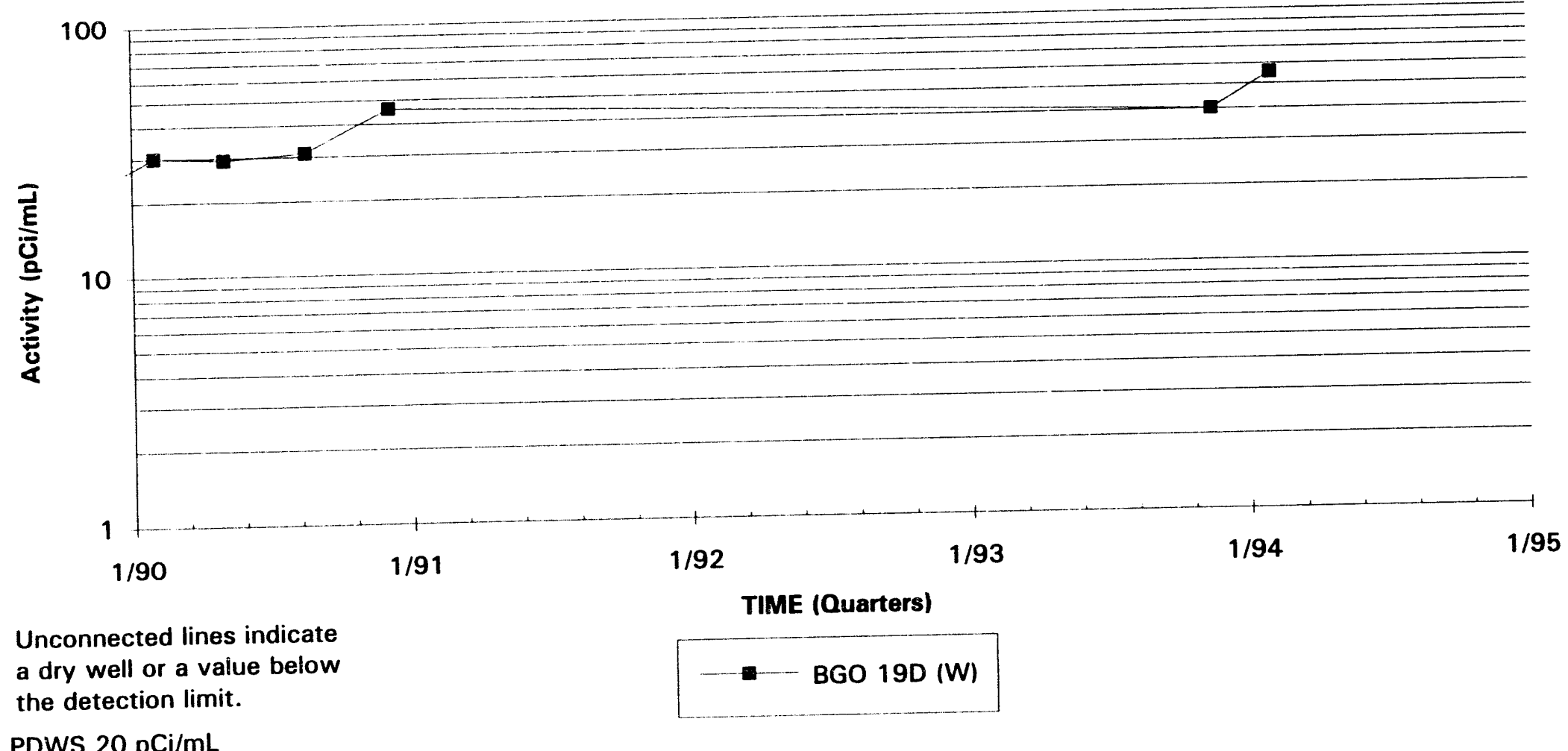

PDWS $20 \mathrm{pCi} / \mathrm{mL}$ 


\section{Tritium Activities}

Well BGO 20D

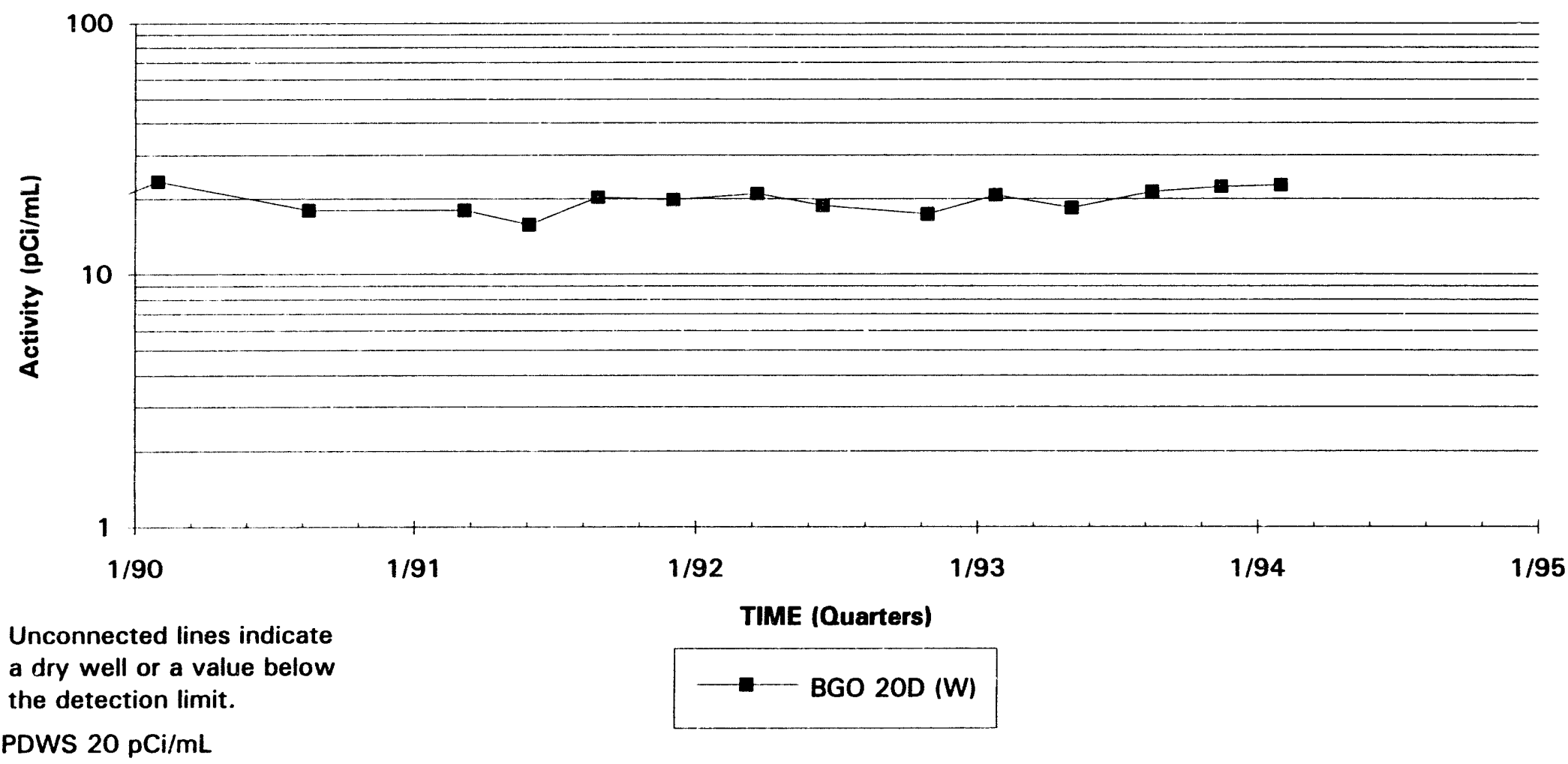

Note: $W=$ Water Table (IIB2); $B=$ Barnwell (IIB1); $M=$ McBean (IIB1); UC = Upper Congaree (IIA); $M C=$ Middle Congaree (IIA); LC=Lower Congaree (IIA) 


\section{Tritium Activities \\ Well BGO 21D}

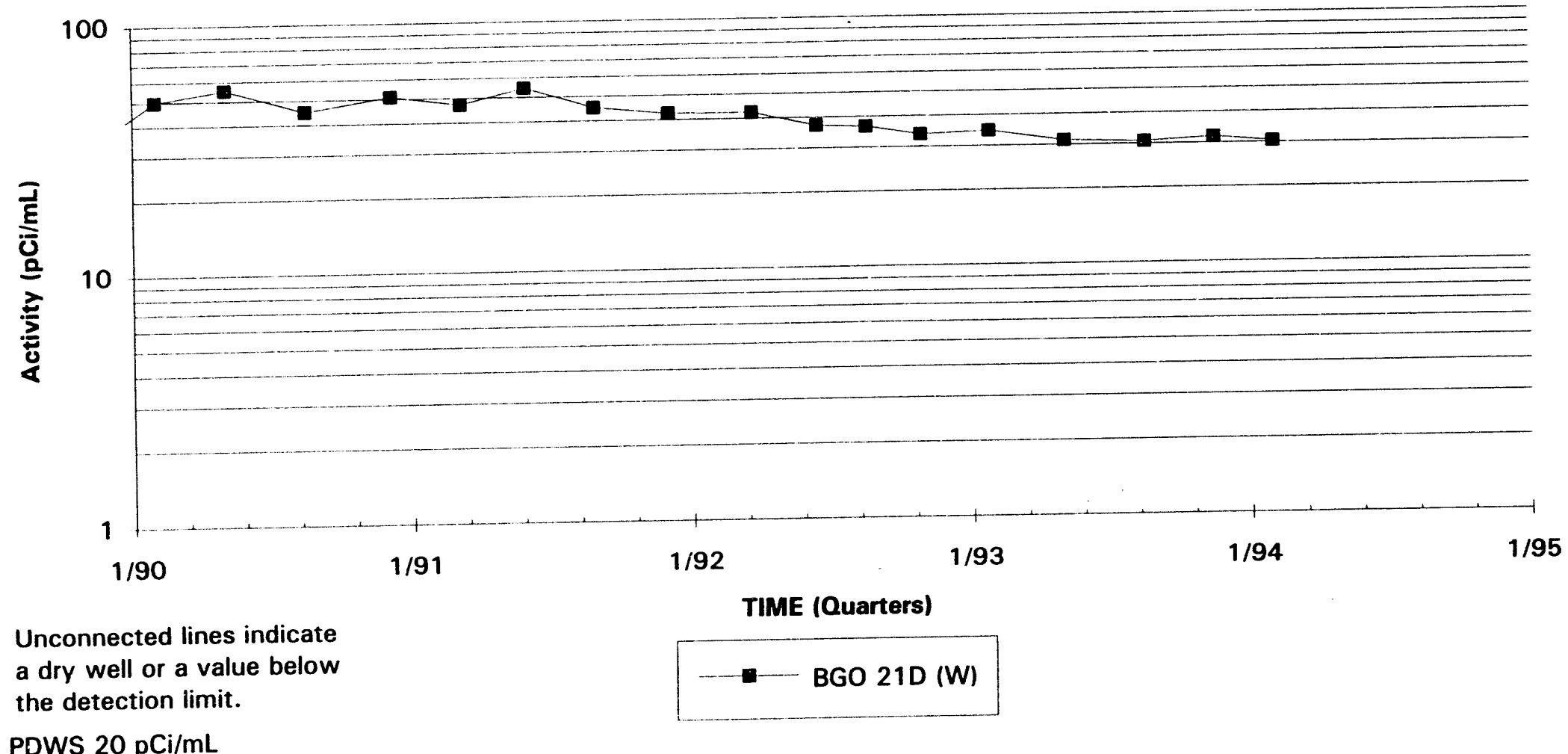

PDWS $20 \mathrm{pCi} / \mathrm{mL}$ 


\section{Tritium Activities}

\section{Well Cluster BGO 22}

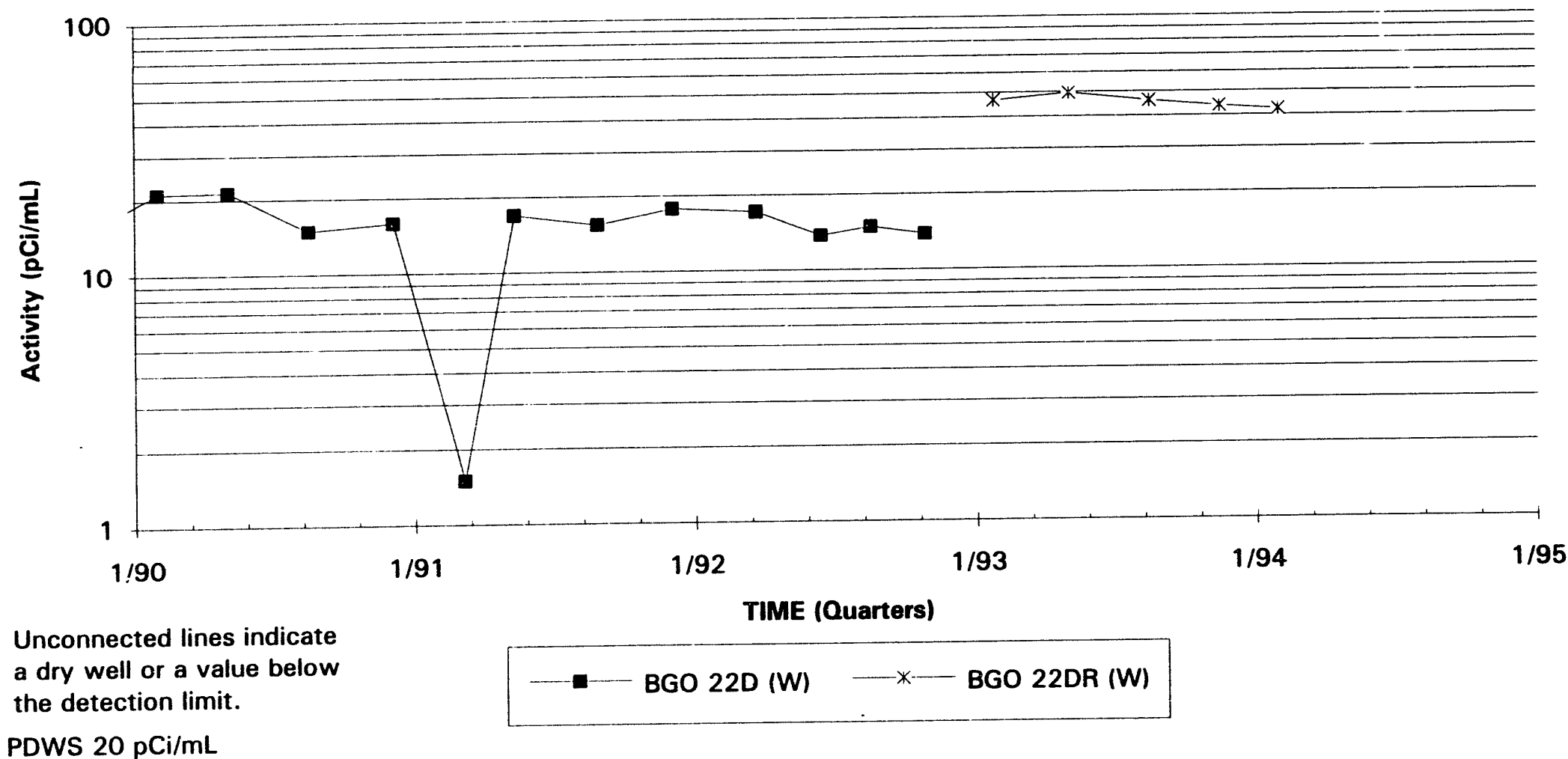

Note: $W=$ Water Table (IIB2); $B=$ Barnwell (IIB1); $M=$ McBean (IIB1); UC = Upper Congaree (IIA); $M C=$ Middle Congaree (IIA); LC = Lower Congaree (IIA) 


\section{Tritium Activities \\ Well BGO 23D}

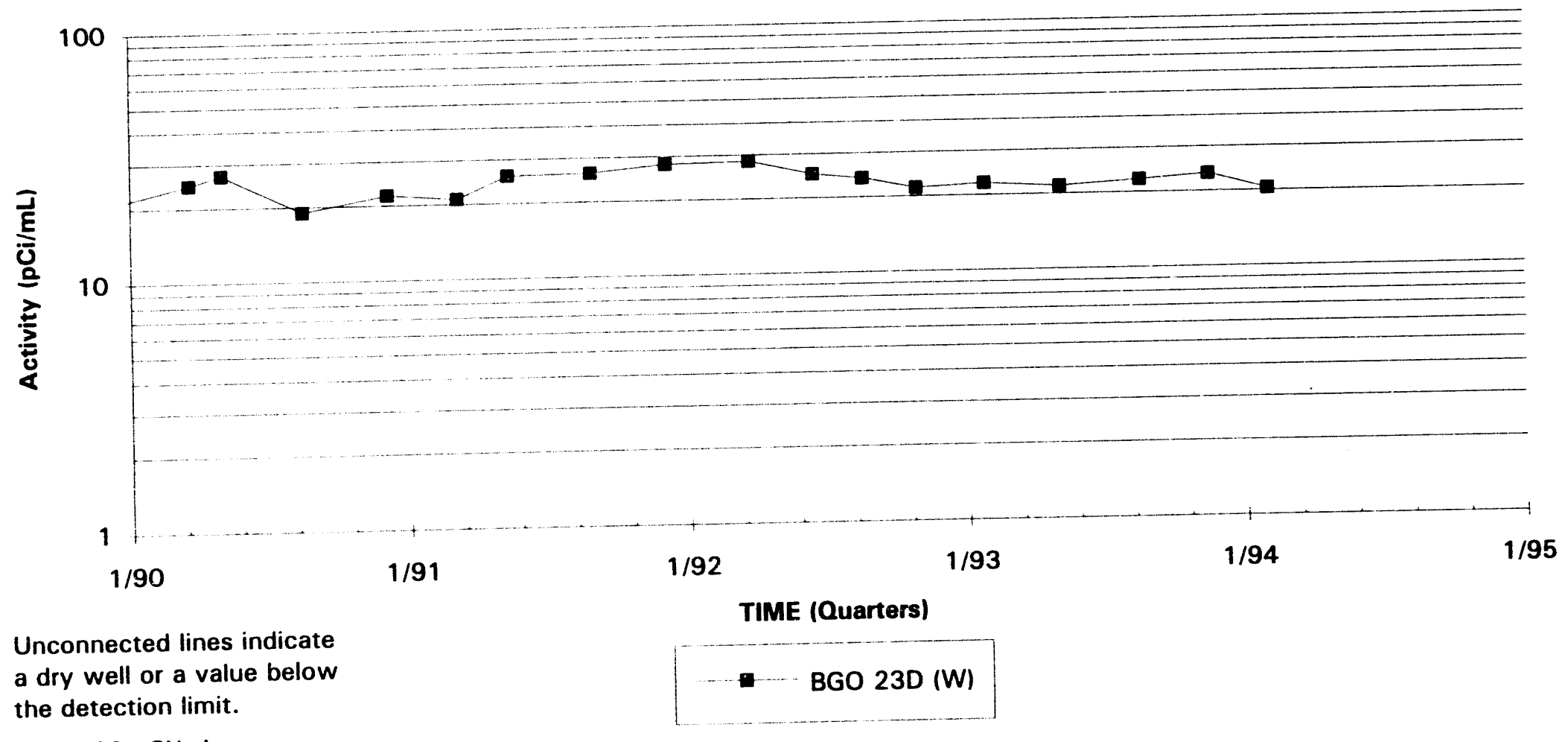

PDWS $20 \mathrm{pCi} / \mathrm{mL}$ 


\section{Tritium Activities}

Well BGO 24D

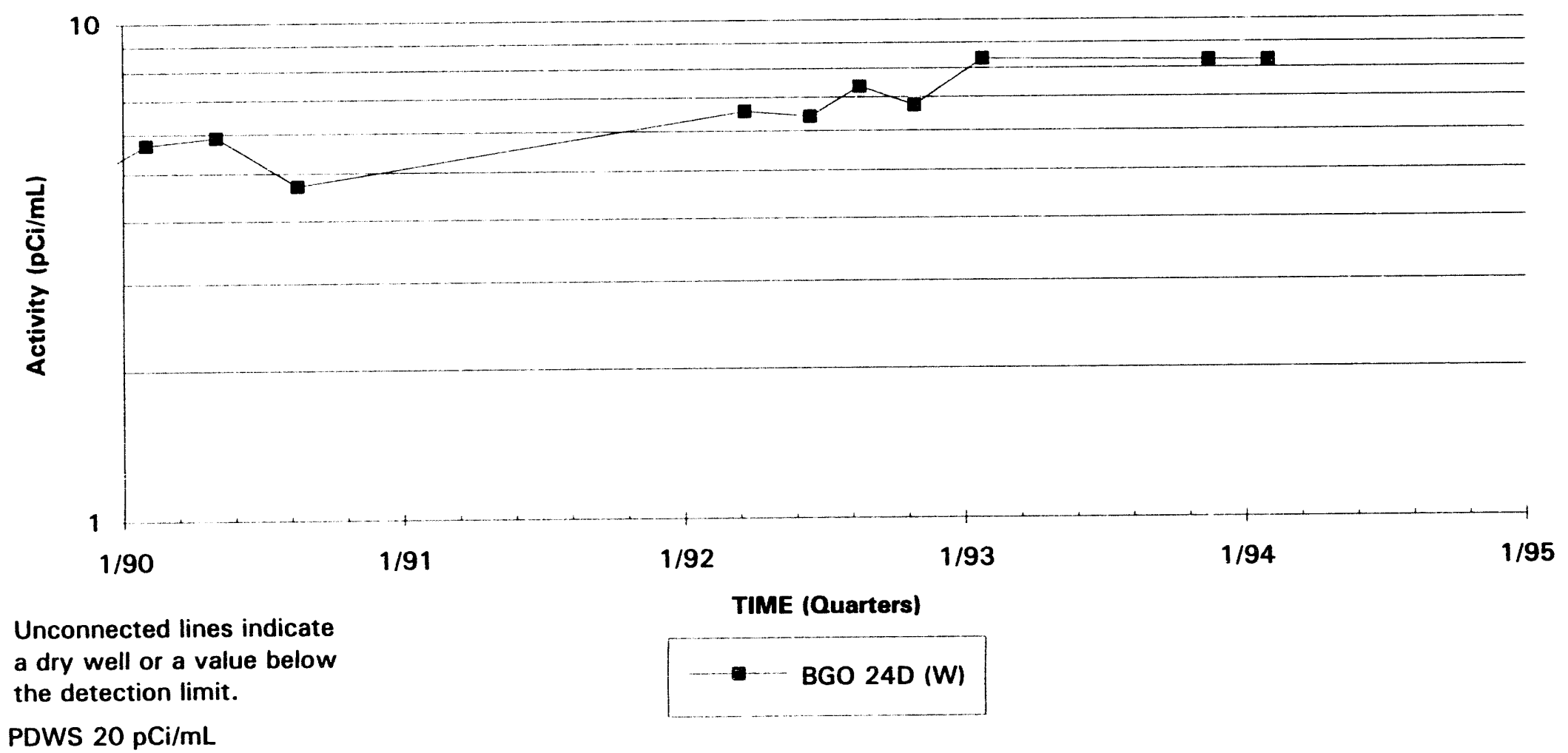

Note: $W=$ Water Table (IIB2); $B=$ Barnwell (IIB1); $M=$ McBean (IIB1); UC = Upper Congaree (IIA); $M C=$ Middle Congaree (IIA); LC=Lower Congaree (IIA) 


\section{Tritium Activities}

Well BGO 25A

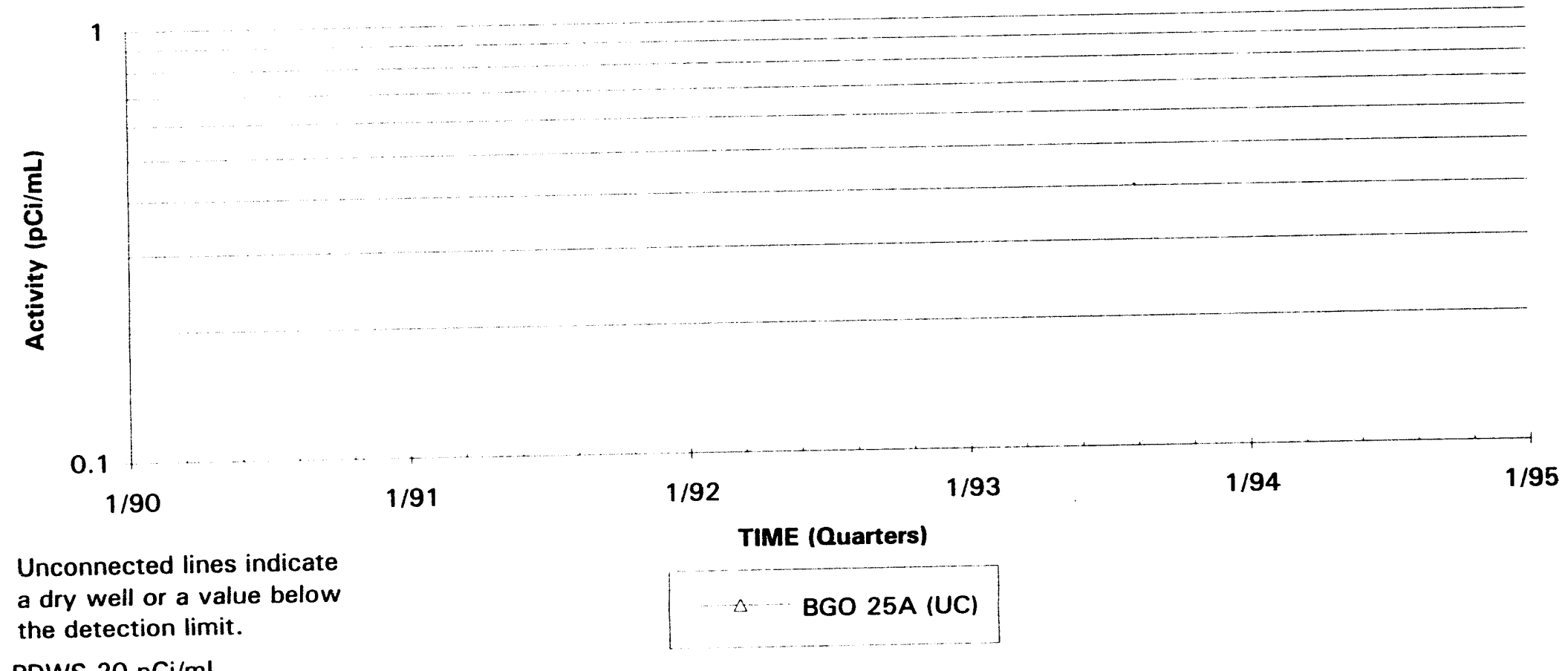

PDWS $20 \mathrm{pCi} / \mathrm{mL}$ 
Tritium Activities

\section{Well Cluster BGO 26}

Note: $W=$ Water Table (IIB2); $B=$ Barnwell (IIB1); $M=$ McBean (IIB1); UC = Upper Congaree (IIA); $M C=$ Middle Congaree (IIA); $L C=L$ Lwer Congaree (IIA) 


\section{Tritium Activities}

Well Cluster BGO 27

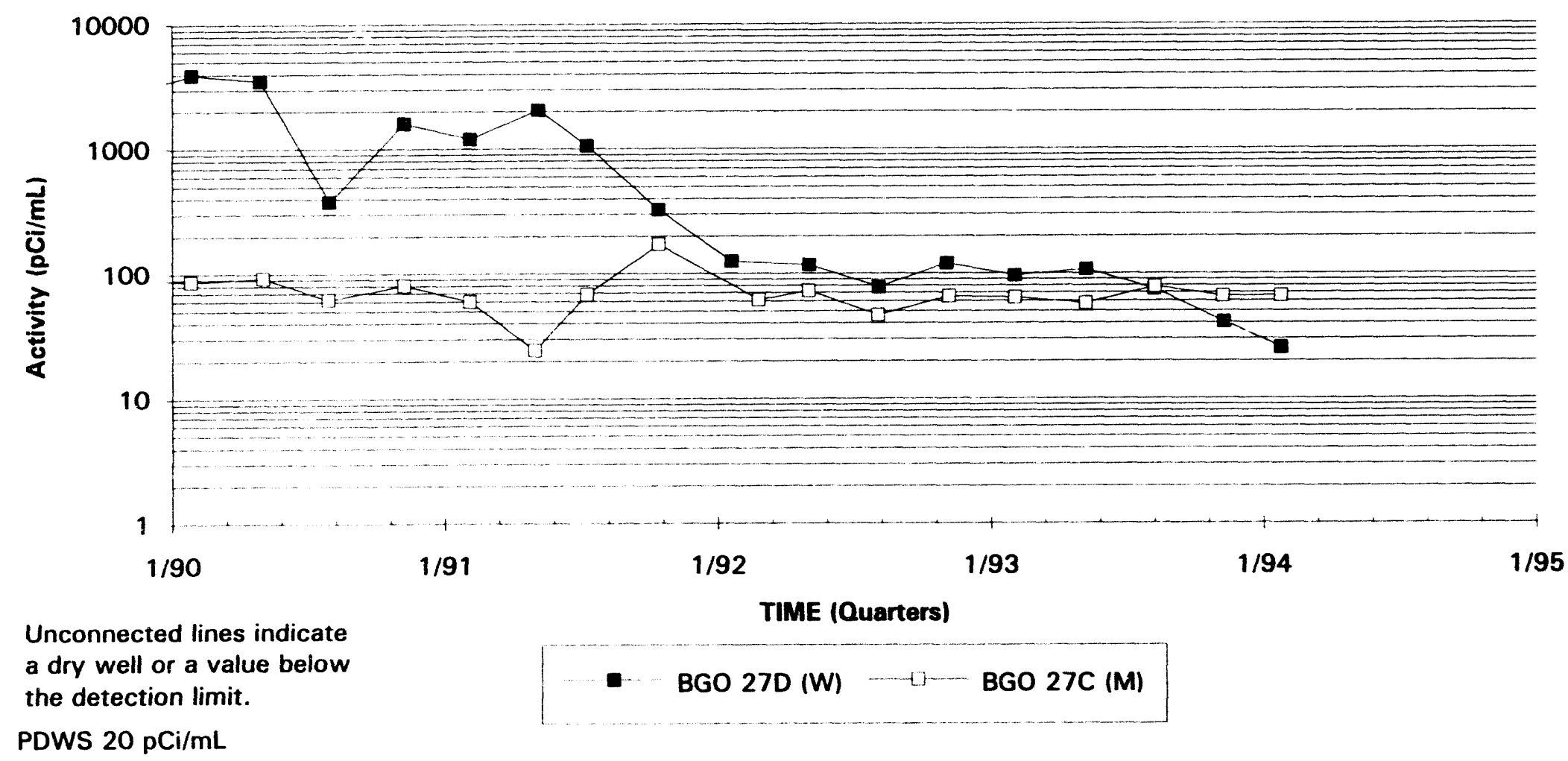




\section{Tritium Activities \\ Well BGO 28D}

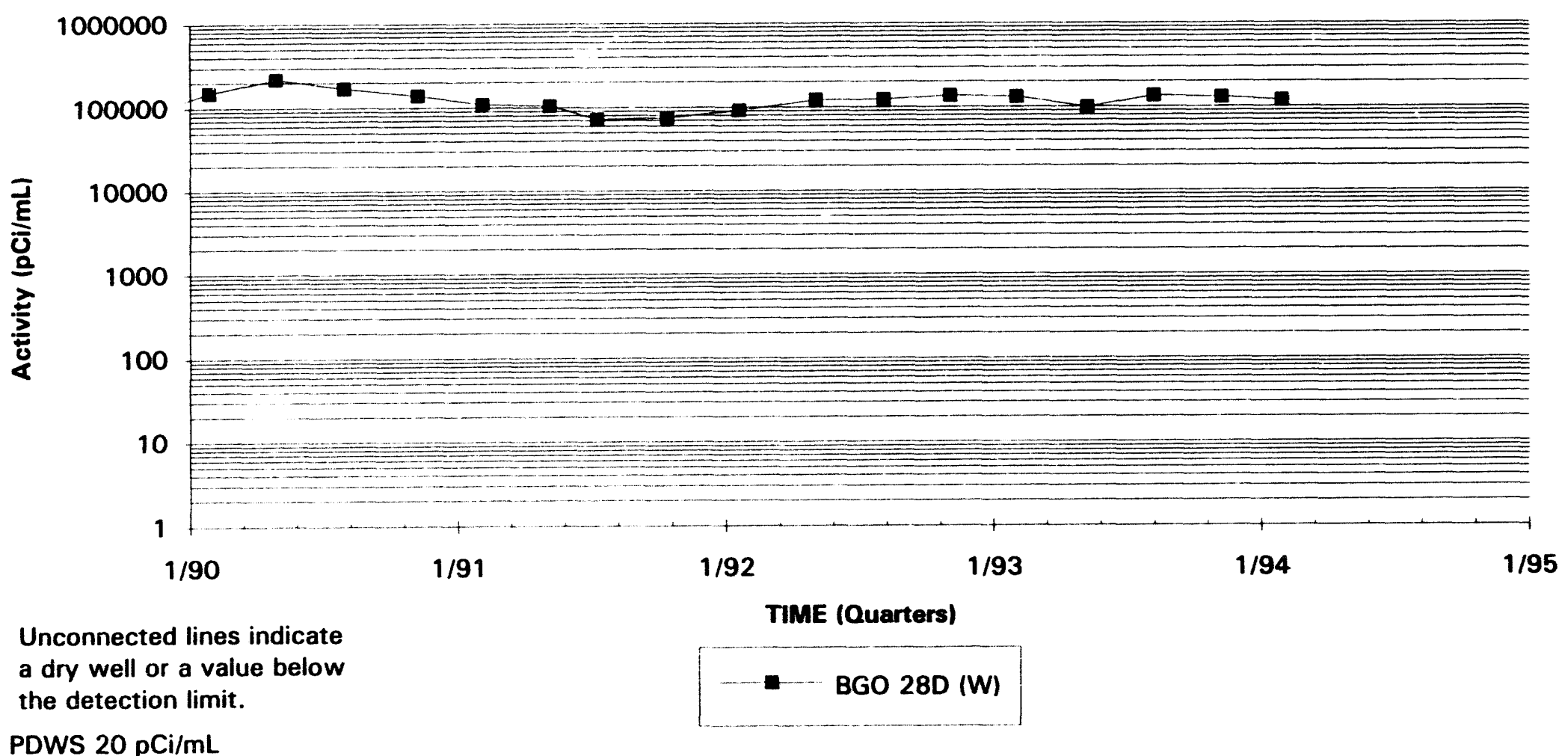

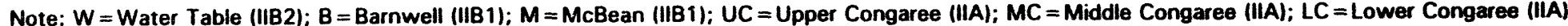




\section{Tritium Activities Well Cluster BGO 29}

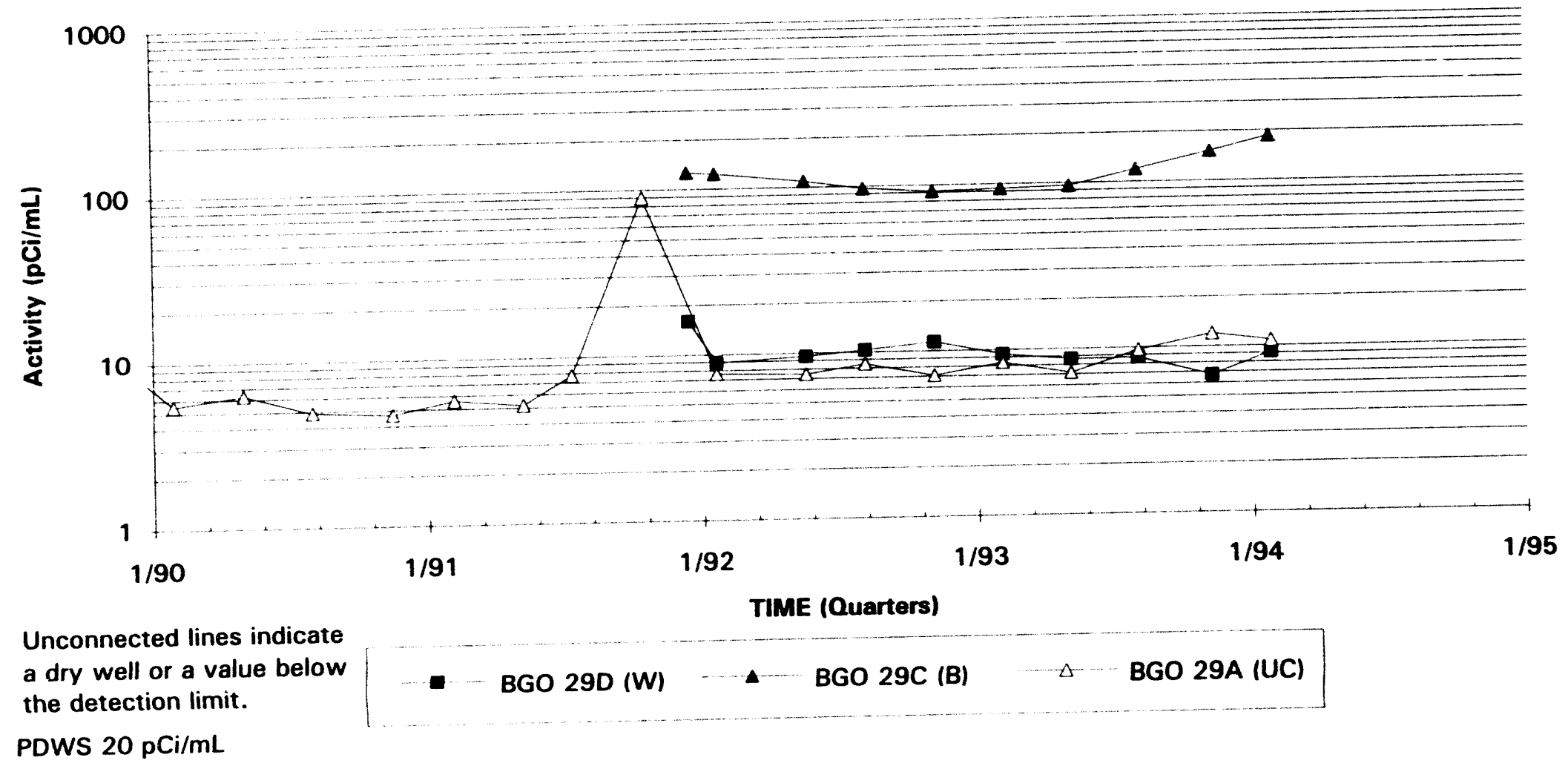

Note $W=$ Wate 


\section{Tritium Activities}

\section{Well Cluster BGO 30}

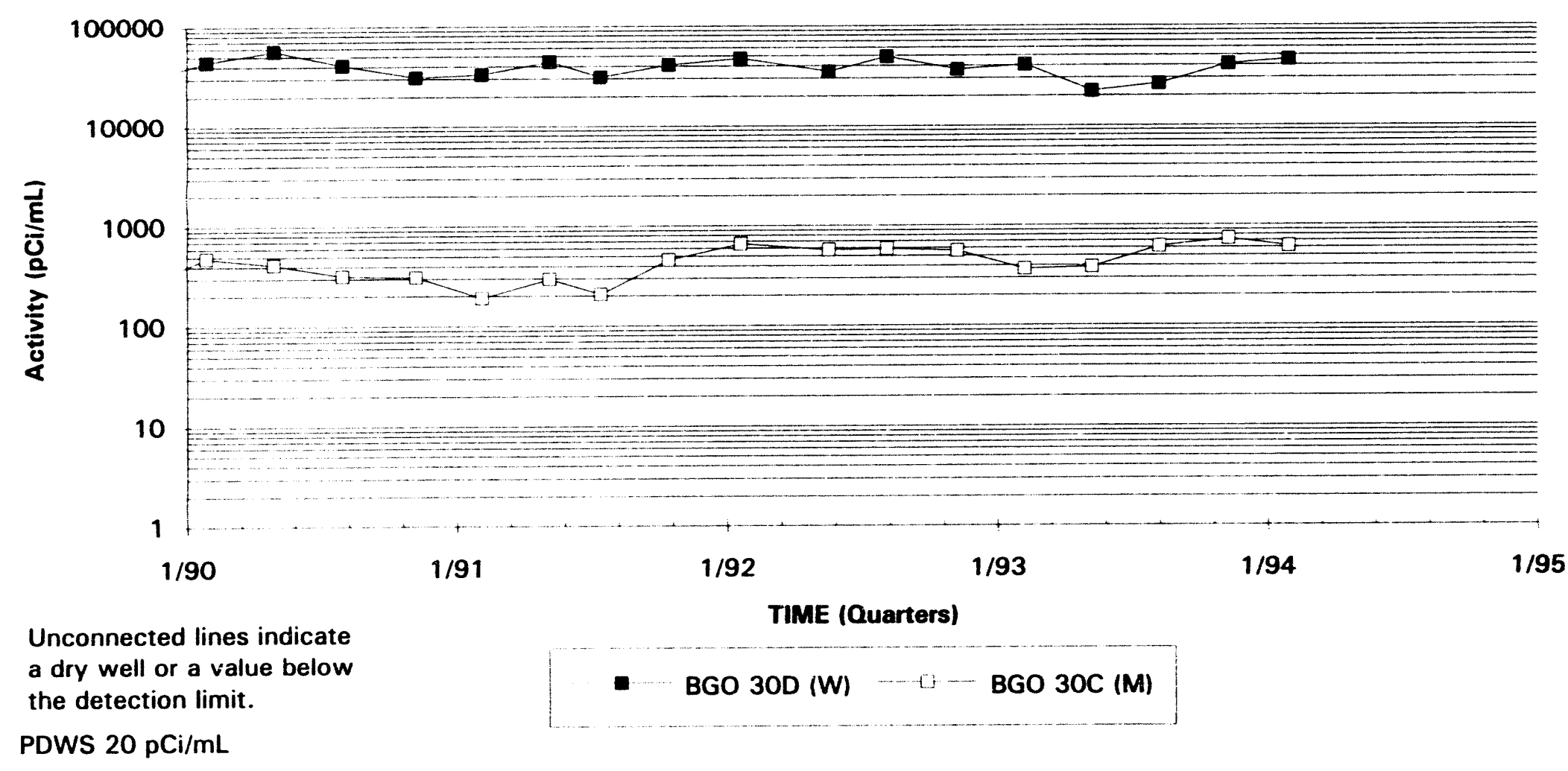

Note: $W=$ Water Table (IIB2); $B=$ Barnwell (IIB1); $M=$ McBean (IIB1); UC=Upper Congaree (IIA); $M C=$ Middle Congaree (IIA); LC = Lower Congaree (IIA) 


\section{Tritium Activities Well Cluster BGO 31}

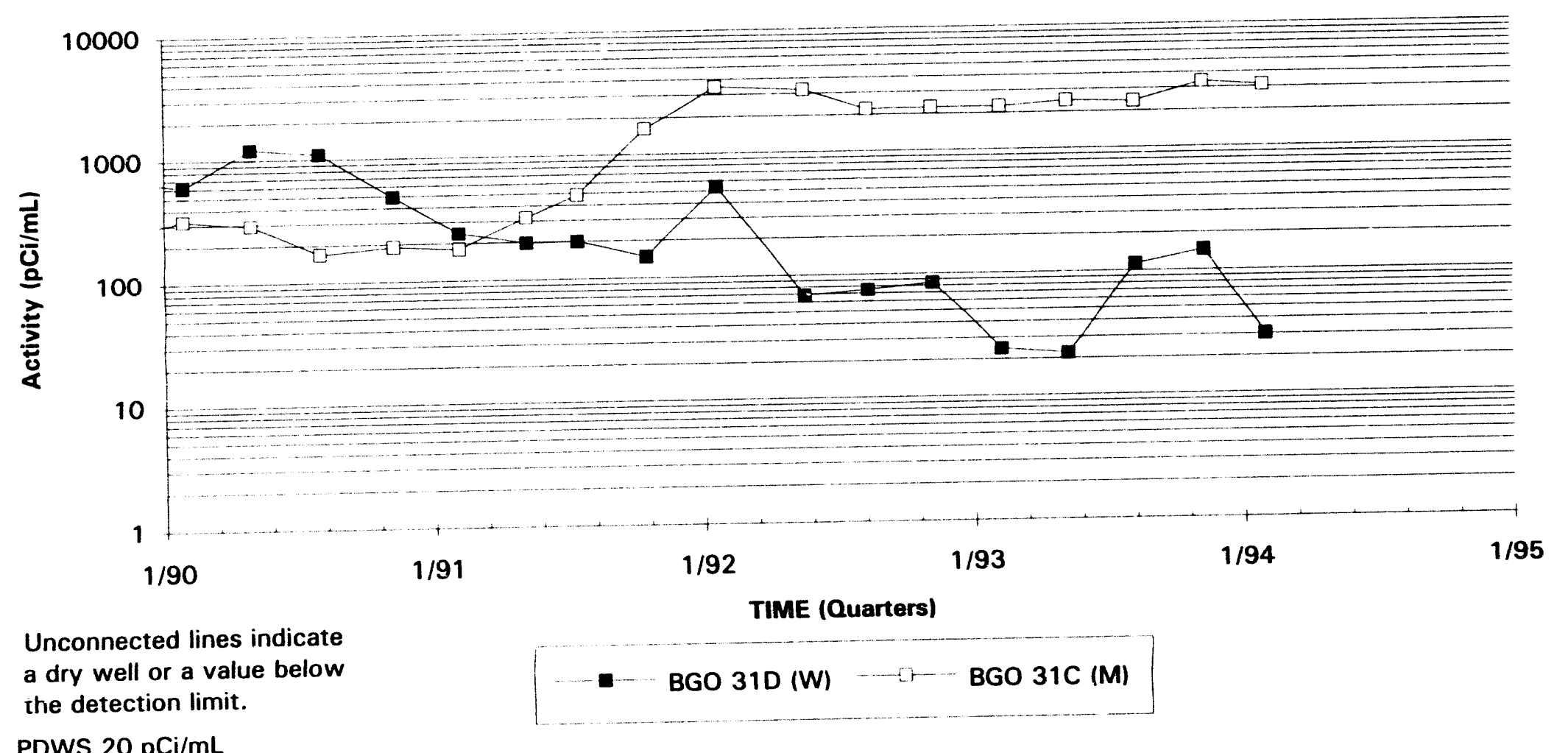

PDWS $20 \mathrm{pCi} / \mathrm{mL}$ 


\section{Tritium Activities \\ Well BGO 32D}

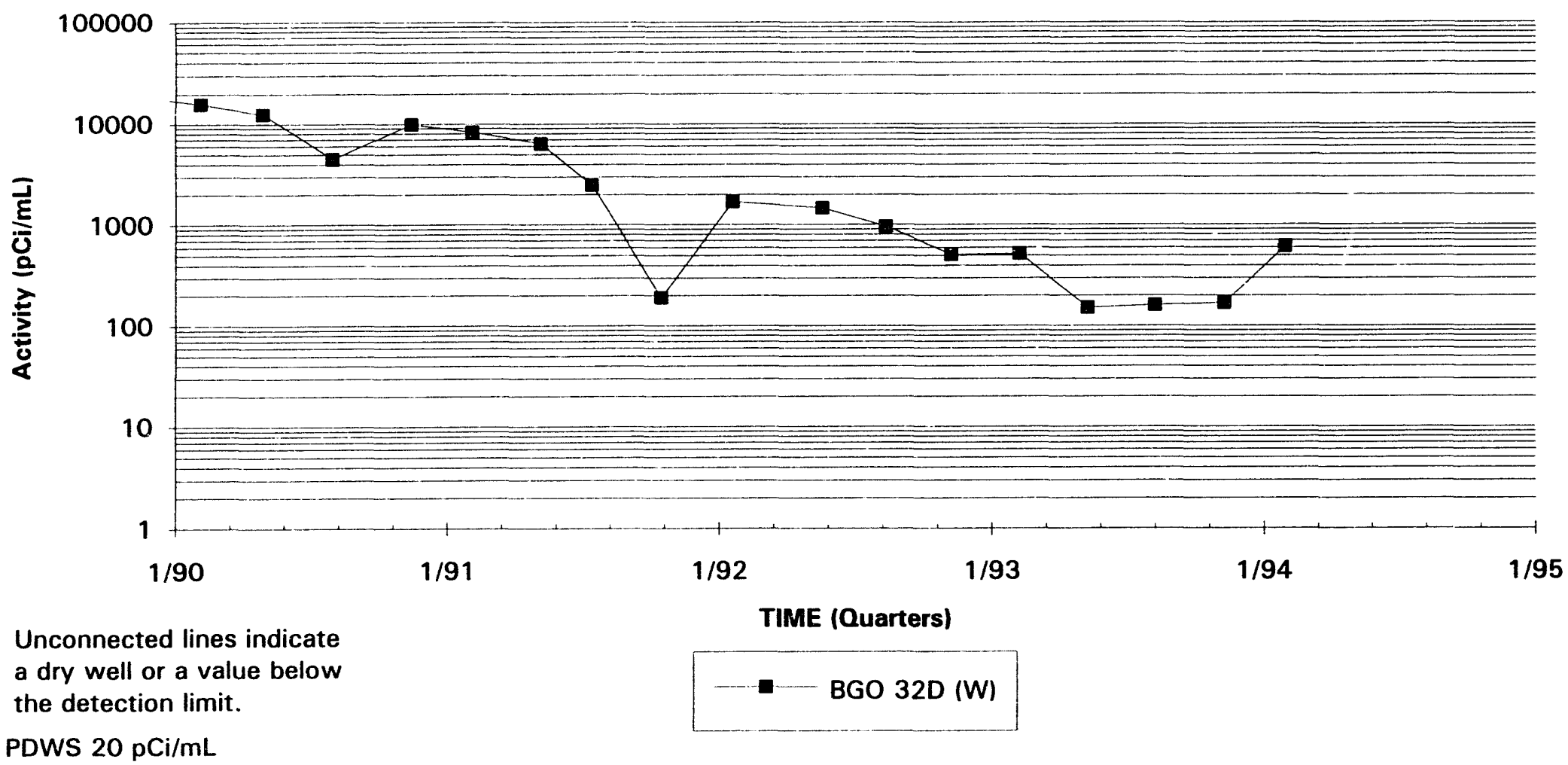

Note: $W=$ Water Table (IIB2); $B=$ Barnwell (IIB1); $M=M c B e a n$ (IIB1); UC=Upper Congaree (IIA); $M C=$ Middle Congaree (IIA); LC=Lower Congaree (IIA) 


\section{Tritium Activities Well Cluster BGO 33}

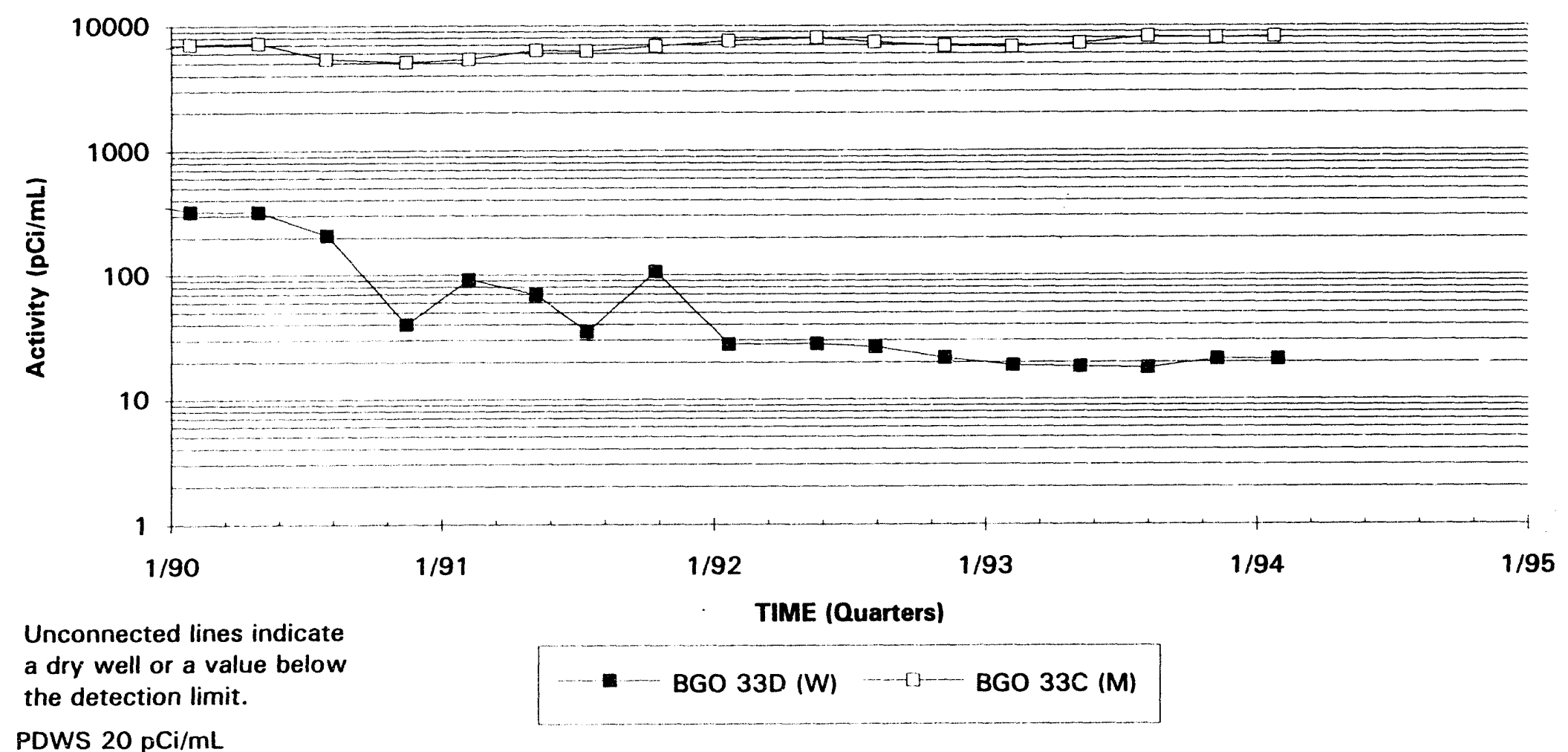

Note: $\mathrm{W}=$ Water Table (IIB2); $\mathrm{B}=$ Barnwell (IIB1); $\mathrm{M}=\mathrm{McBean}$ (IIB1); UC=Upper Congaree (IIA); $\mathrm{MC}=$ Middle Congaree (IIA); LC=Lower Congaree (IIA) 


\section{Tritium Activities}

Well BGO 34D

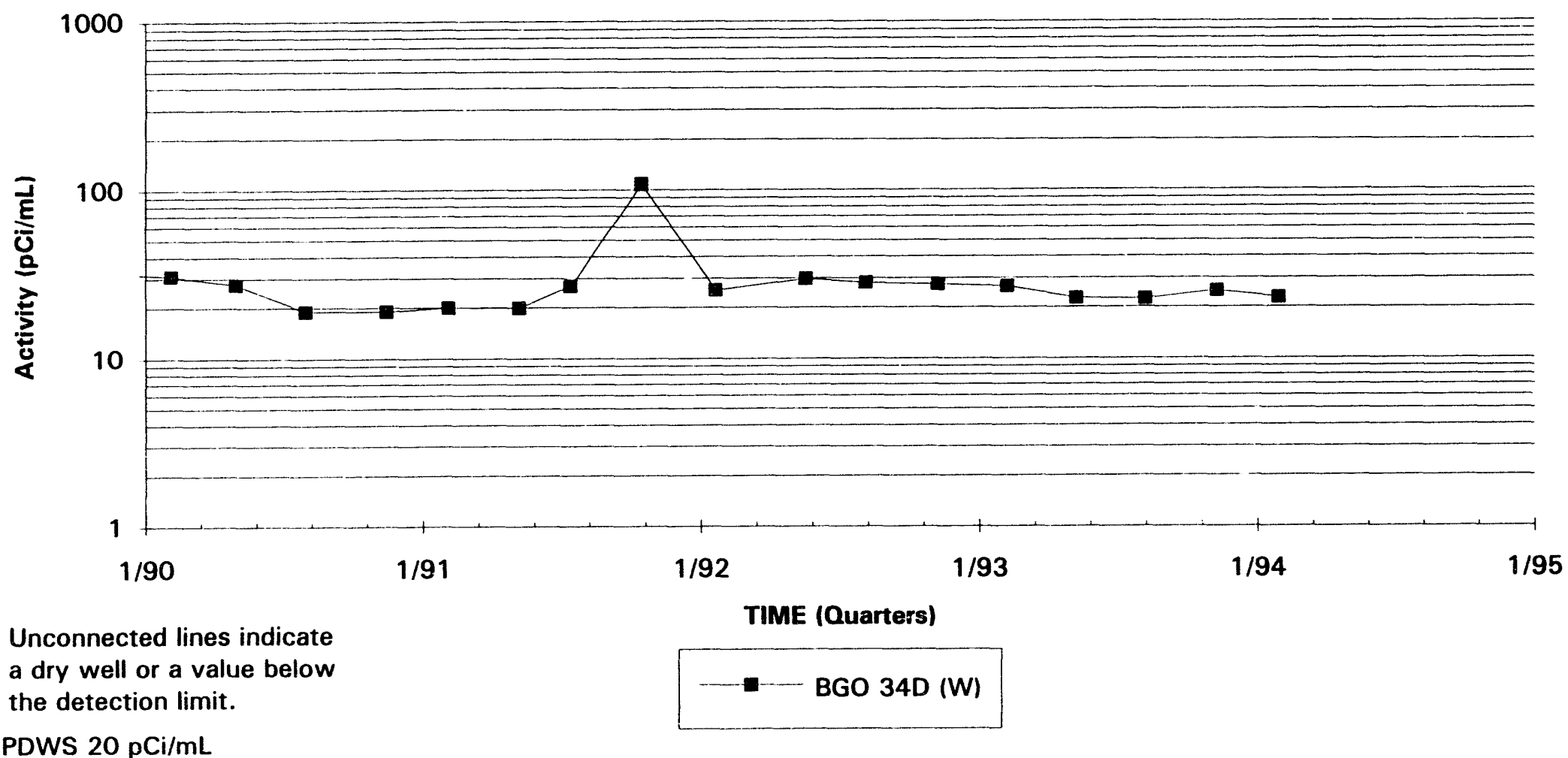

Note: $\mathrm{W}=$ Water Table (IIB2); $\mathrm{B}=$ Barnwell (IIB1); $\mathrm{M}=\mathrm{McBean}$ (IIB1); UC=Upper Congaree (IIA); $\mathrm{MC}=$ Middle Congaree (IIA); LC =Lower Congaree (IIA) 


\section{Tritium Activities \\ Well Cluster BGO 35}

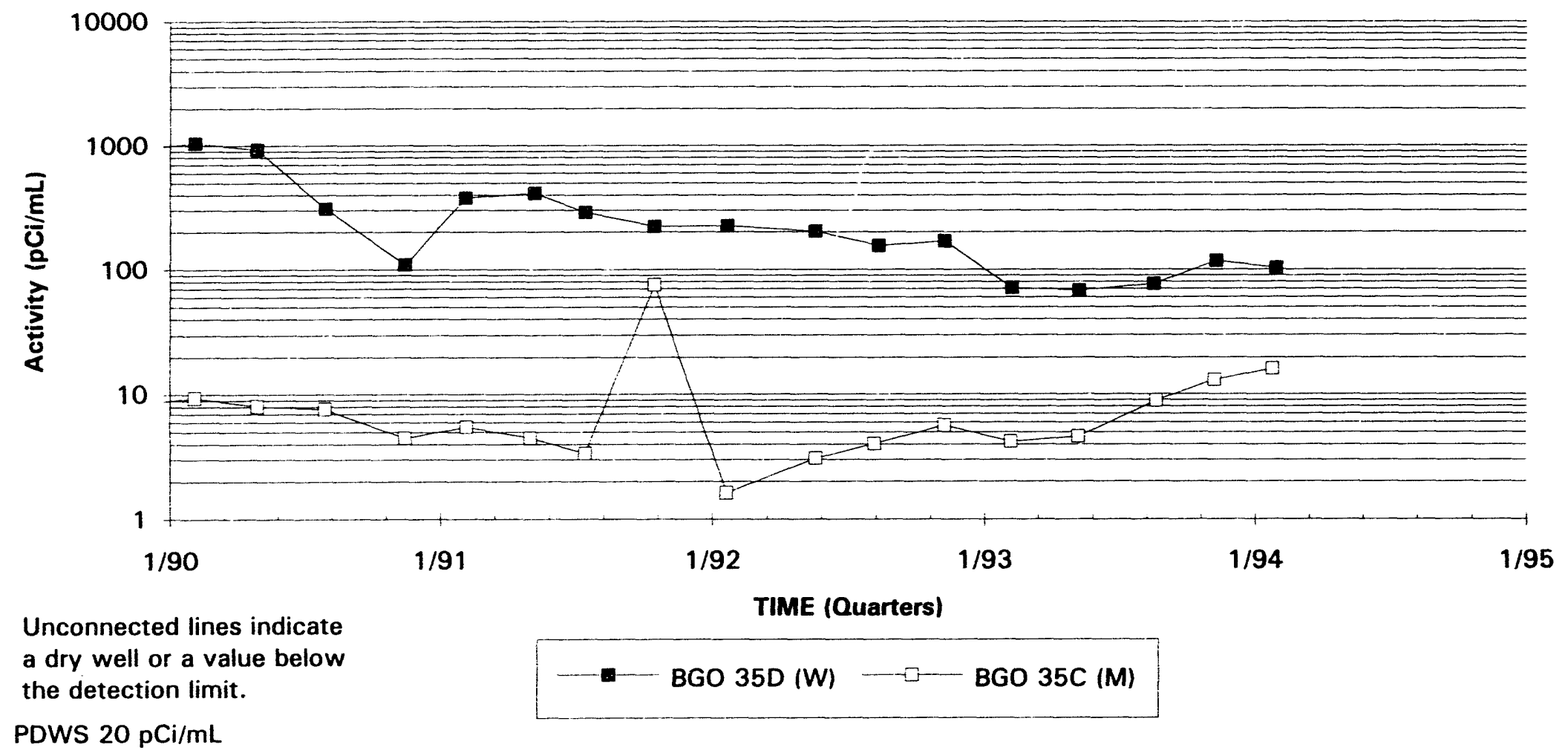




\section{Tritium Activities \\ Well BGO 36D}

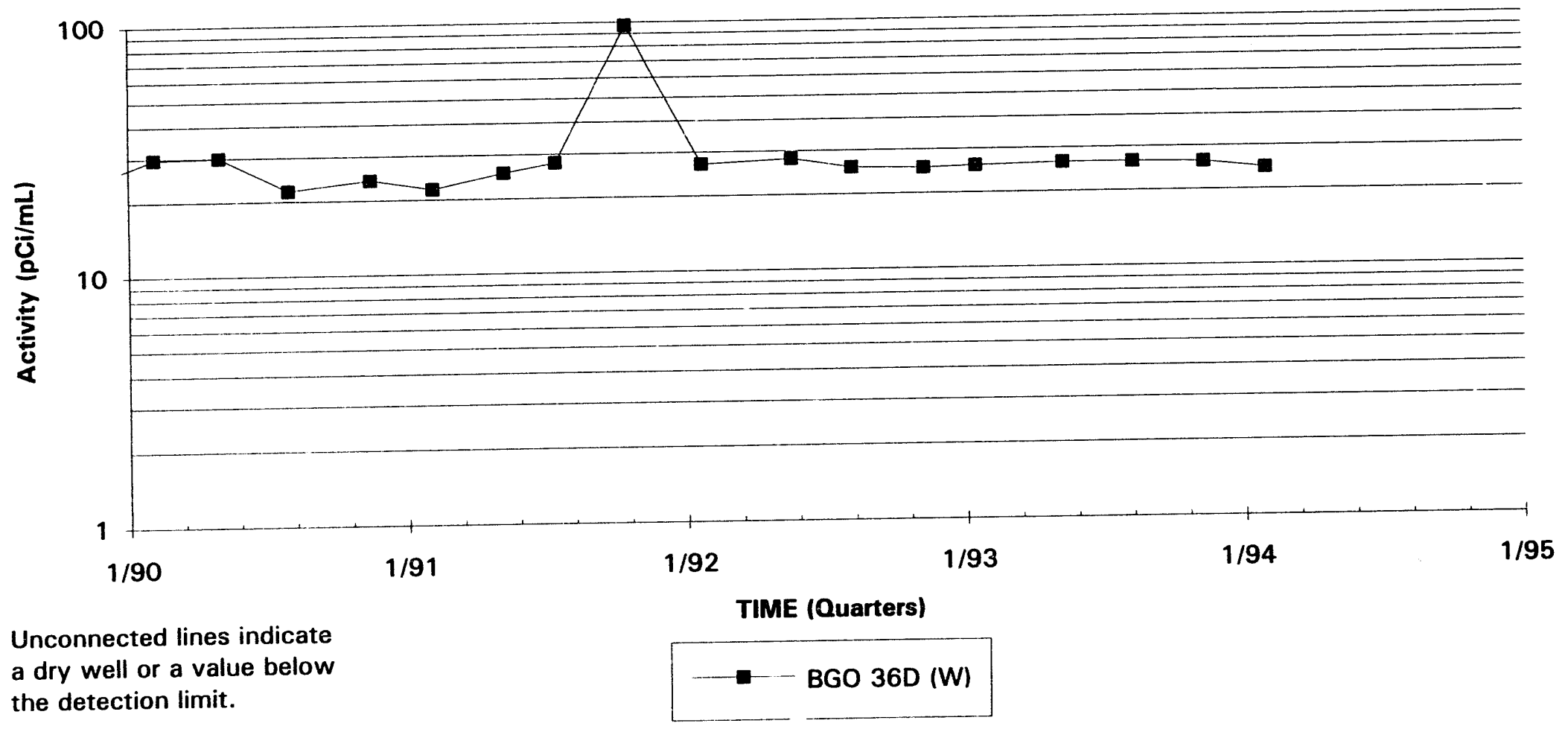

PDWS $20 \mathrm{pCi} / \mathrm{mL}$ 


\section{Tritium Activities \\ Well Cluster BGO 37}

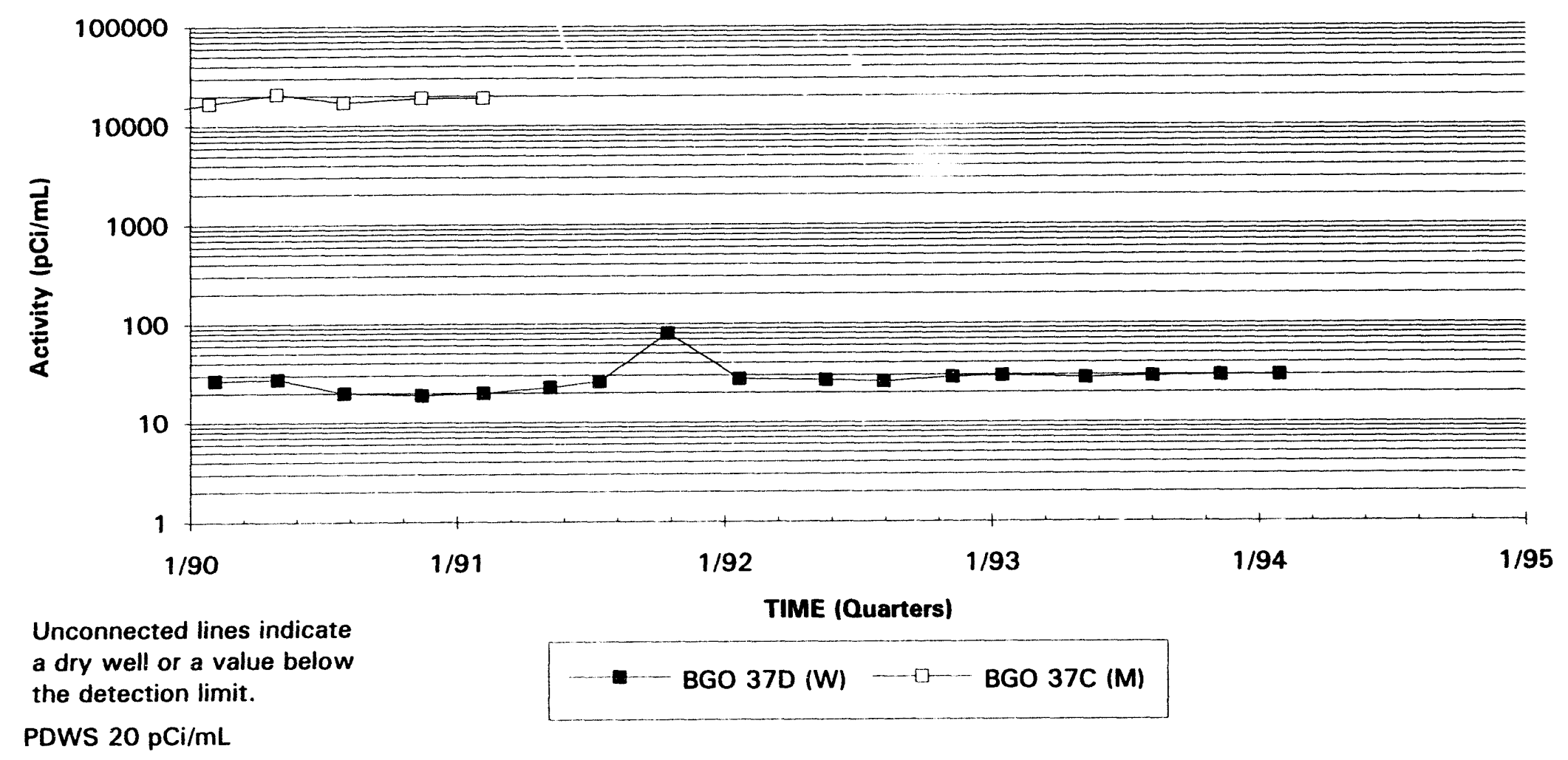

Note: $W=$ Water Table (IIB2); $B=$ Barnwell (IIB1); $M=$ McBean (IIB1); UC=Upper Congaree (IIA); $M C=$ Middle Congaree (IIA); LC=Lower Congaree (IIA) 


\section{Tritium Activities \\ Well BGO 38D}

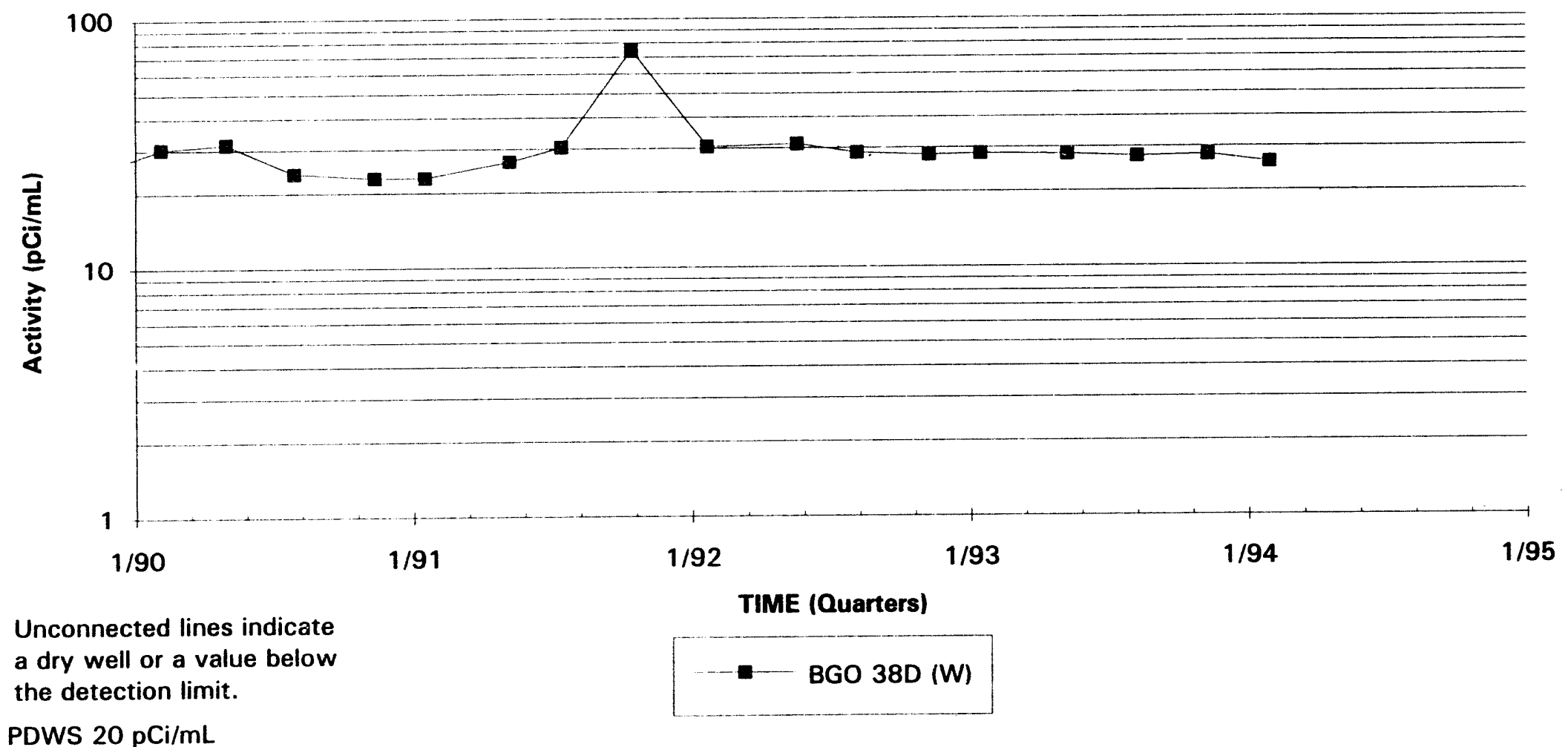

Note: $W=$ Water Table (IIB2); $B=$ Barnwell (IIB1); $M=M C B e a n ~(I I B 1) ; U C=$ Upper Congaree (IIA); $M C=$ Middle Congaree (IIA); LC = Lower Congaree (IIA) 


\section{Tritium Activities}

Well BGO 39D

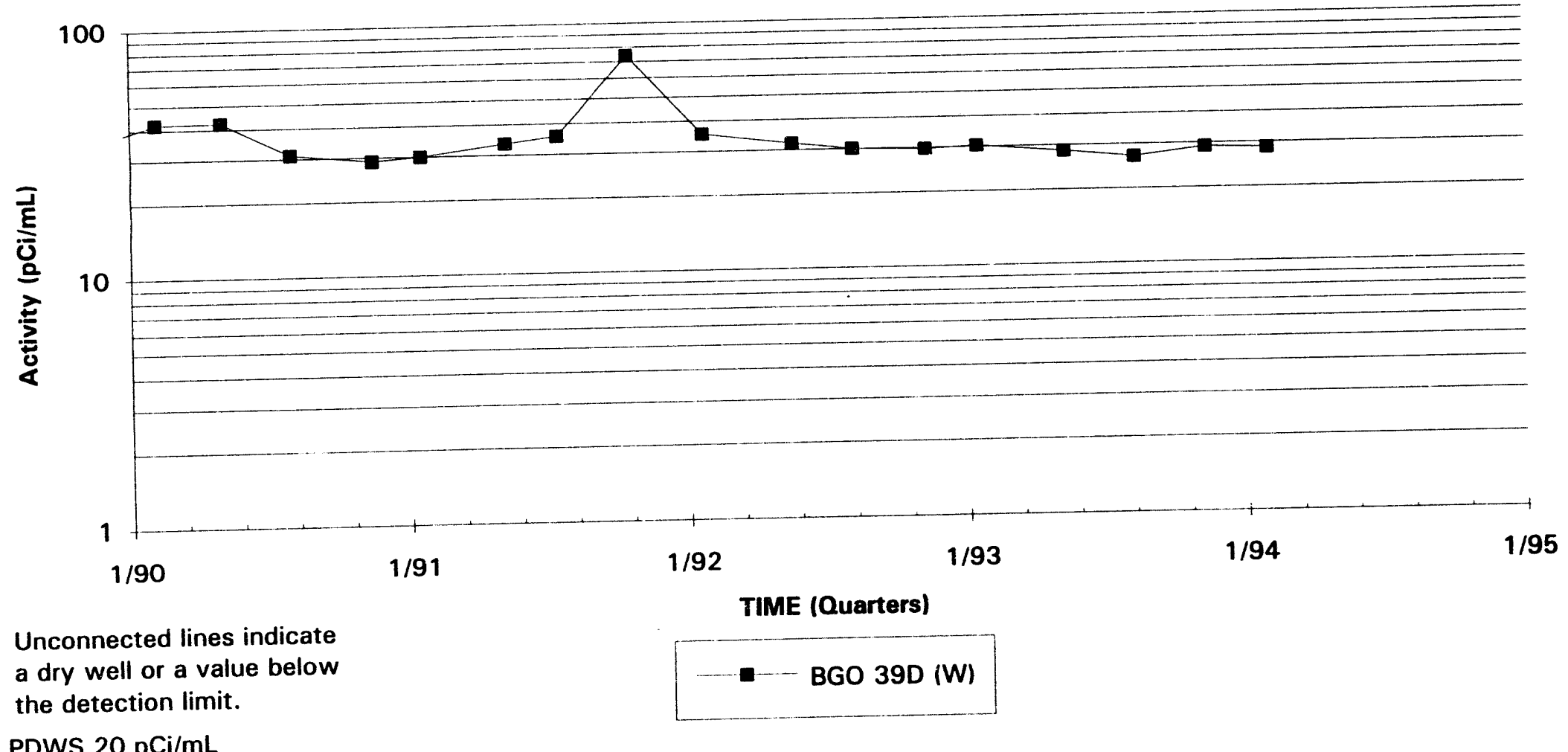

PDWS $20 \mathrm{pCi} / \mathrm{mL}$ 


\section{Tritium Activities}

\section{Well BGO 40D}

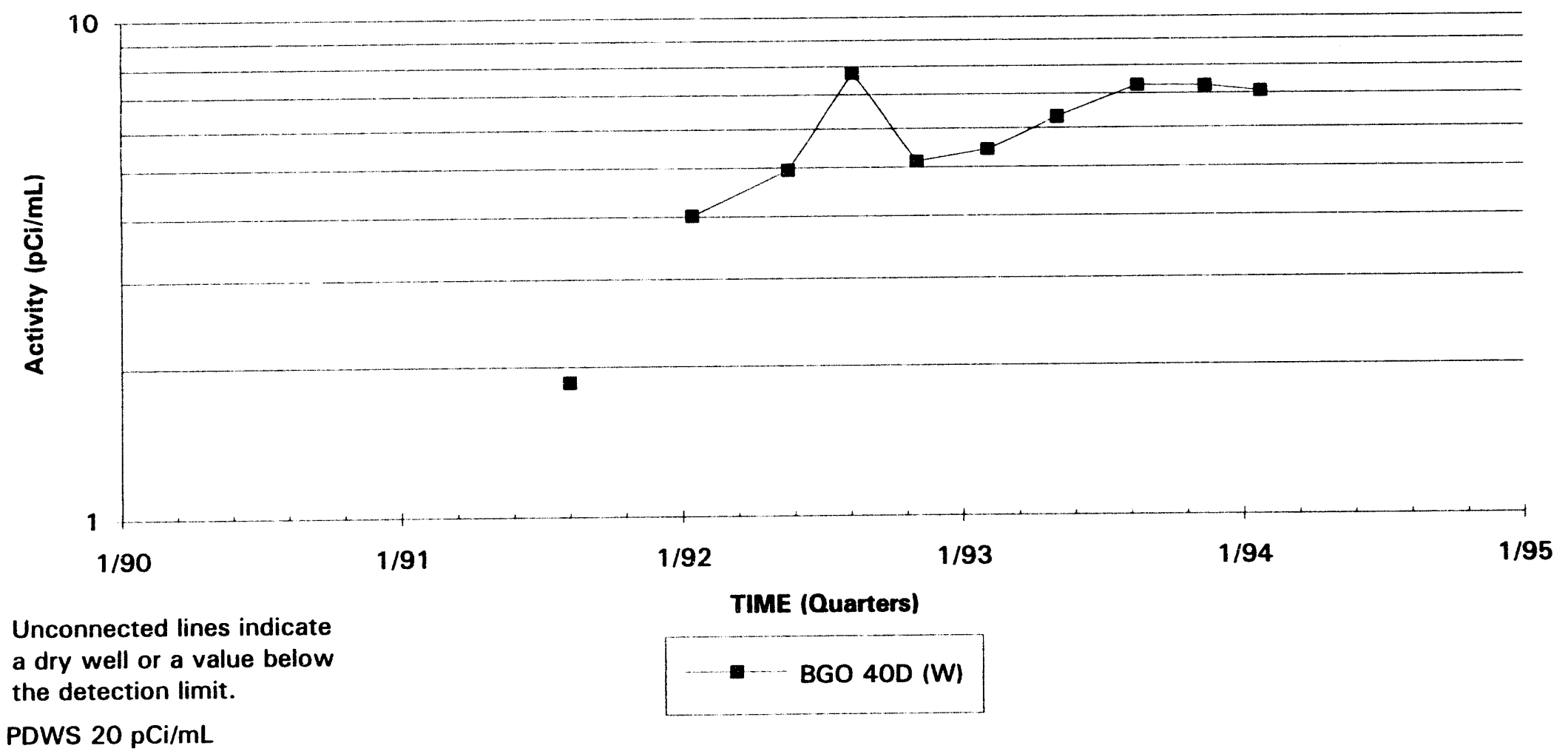

Note: $W=$ Water Table (IIB2); $B=$ Barnwell (IIB1); $M=$ McBean (IIB1); UC = Upper Congaree (IIA); $M C=$ Middle Congaree (IIA); LC = Lower Congaree (IIA) 


\section{Tritium Activities}

Well BGO 41A

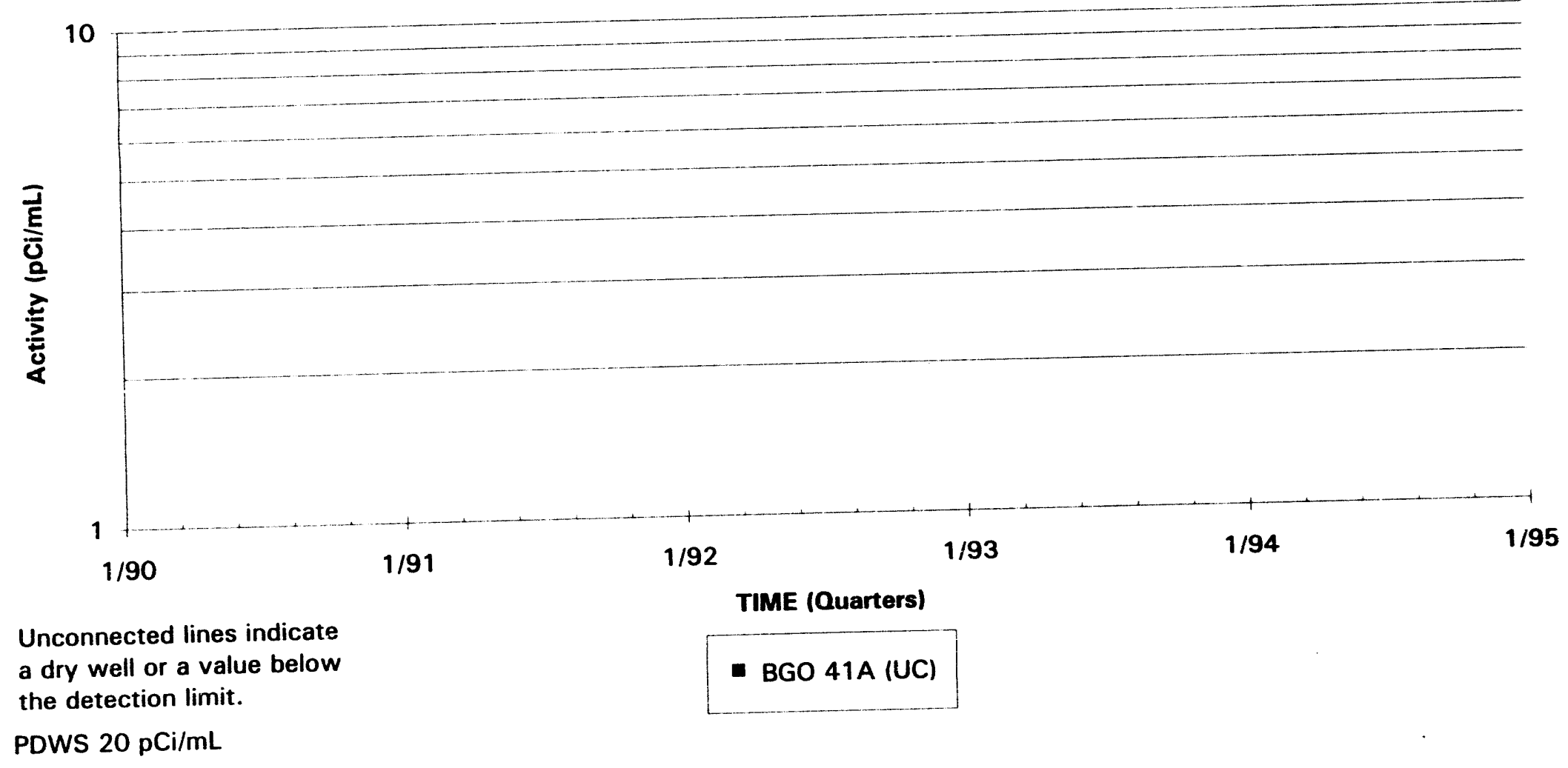

Note: $W=$ Water Table (IIB2); $B=$ Barnwell (IIB1); $M=$ McBean (IIB1); UC=Upper Congaree (IIA); $M C=$ Middle Congaree (IIA); LC =Lower Congaree (IIA) 


\section{Tritium Activities \\ Well BGO 42C}

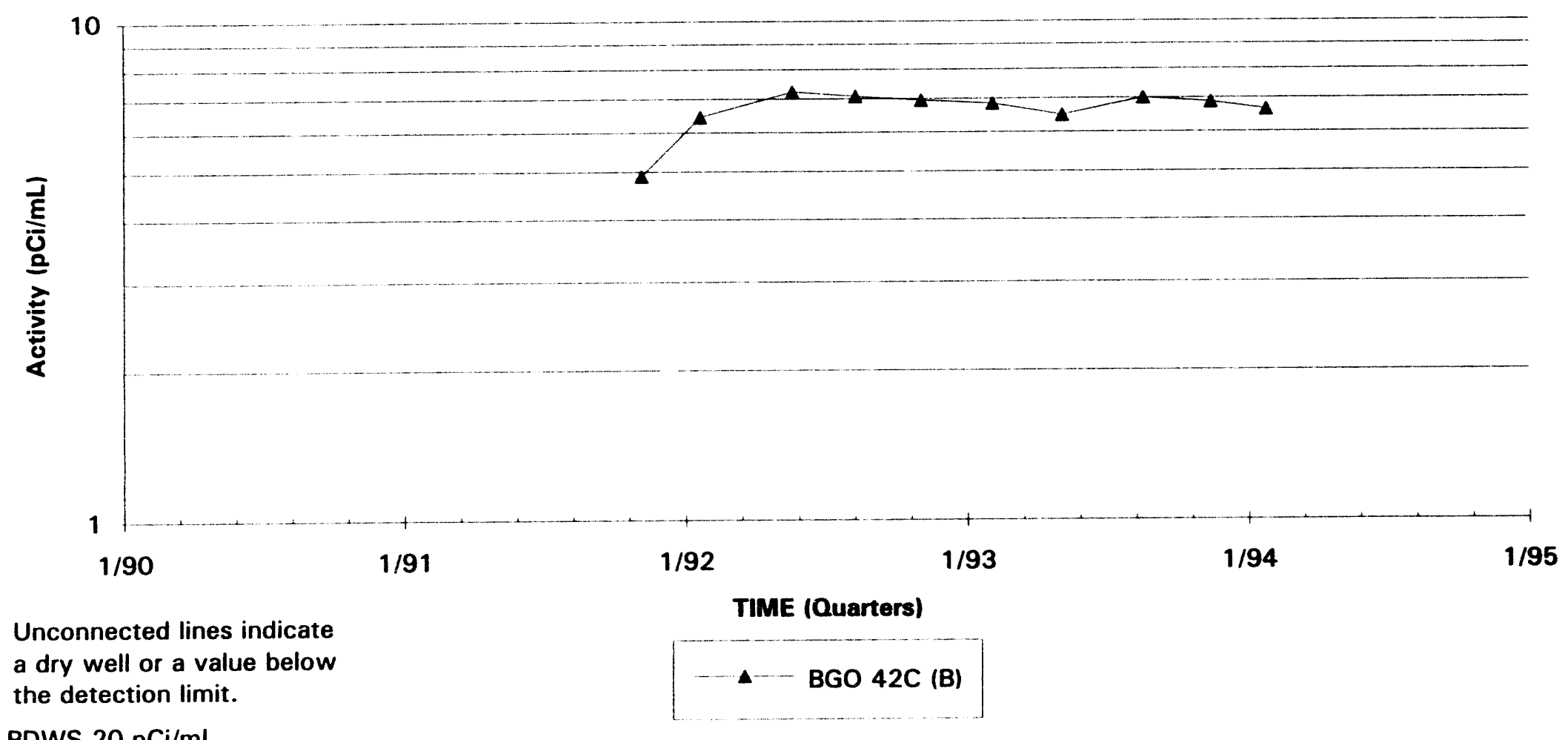

PDWS $20 \mathrm{pCi} / \mathrm{mL}$

Note: $W=$ Water Table (IIB2); $B=$ Barnwell (IIB1); $M=$ McBean (IIB1); UC = Upper Congaree (IIA); $M C=$ Middle Congaree (IIA); LC = Lower Congaree (IIA) 


\section{Tritium Activities \\ Well Cluster BGO 43}

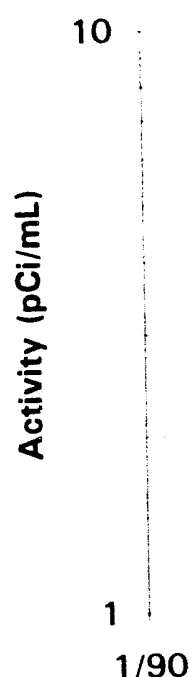

$1 / 91$

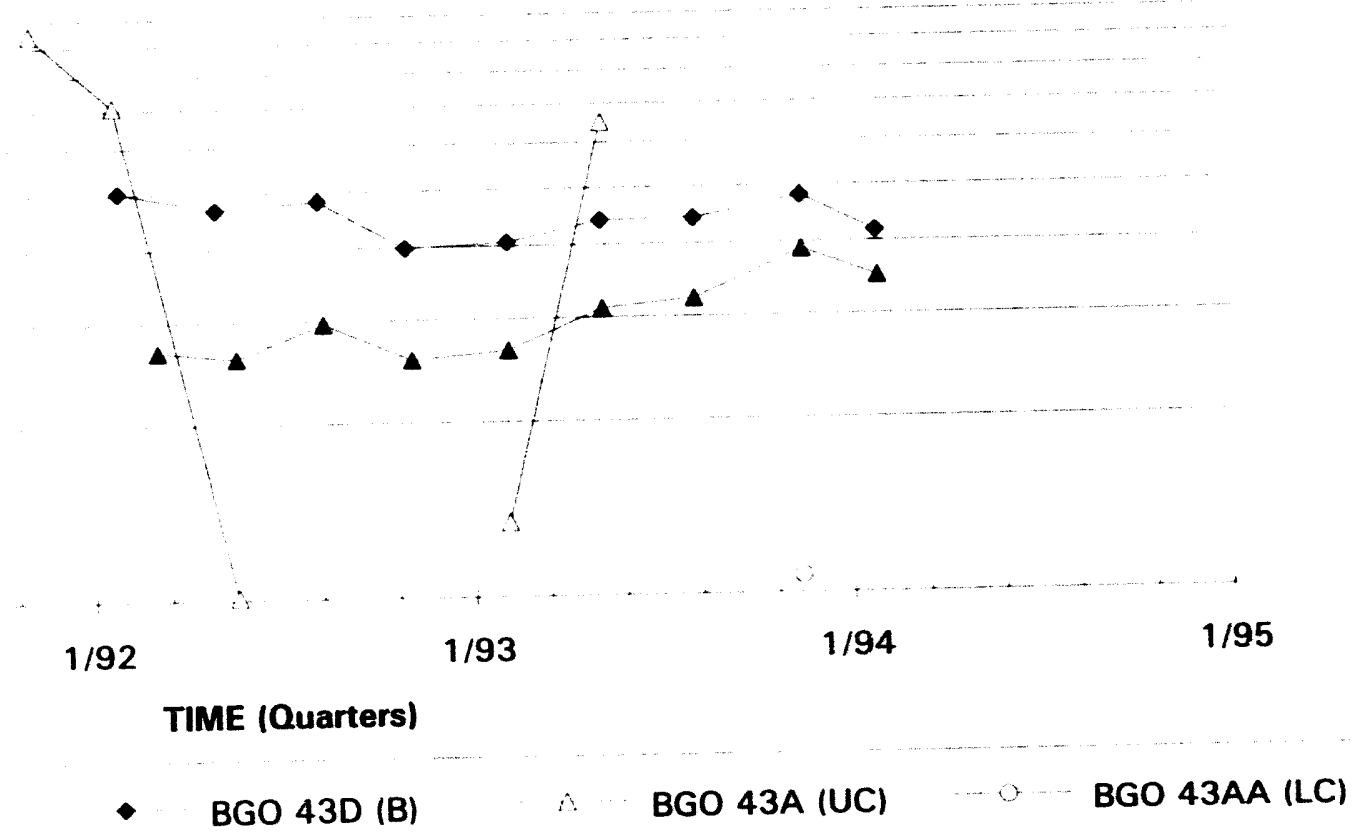

Unconnected lines indicate a dry well or a value below the detection limit.

- BGO 43CR (B)

- $\quad$ BGO 43D (B)

BGO 43A (UC)

BGO 43AA (LC) 


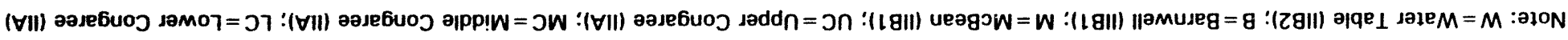

ךu/! od oz SMad

ग!

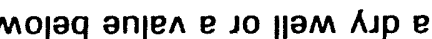
әleכ!pu! səu!! pələəuuojun (w) 9 tb 098
(วา)

\section{$\forall \forall t \nabla 098$}

(घ) כเל 098

(sseนseno) उWII

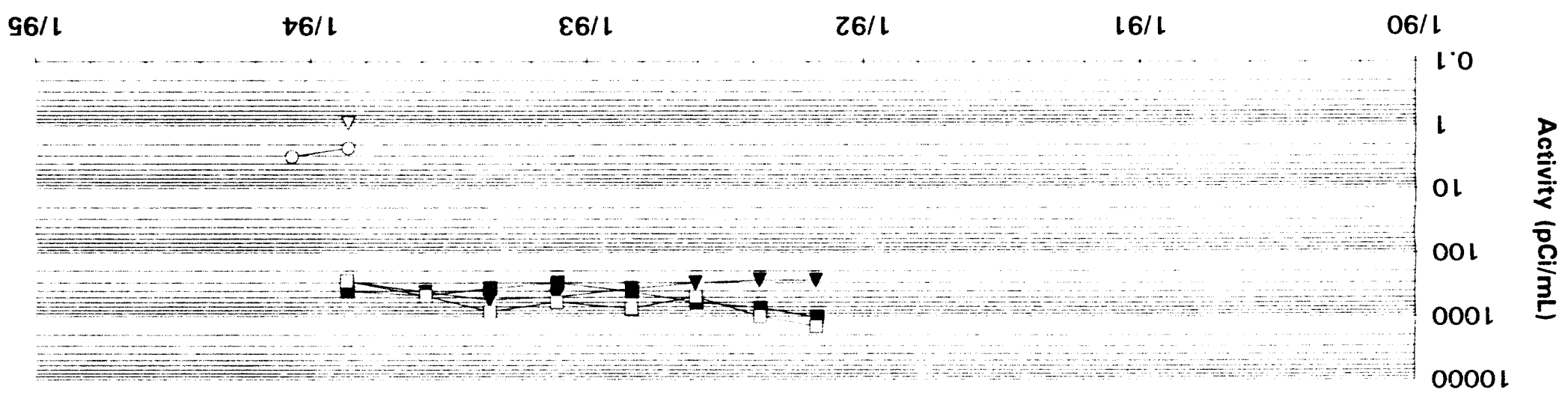

\section{†t 058 גәเsn|כ ॥әM

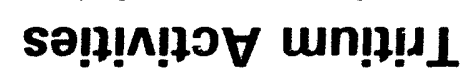




\section{Tritium Activities Well Cluster BGO 45}

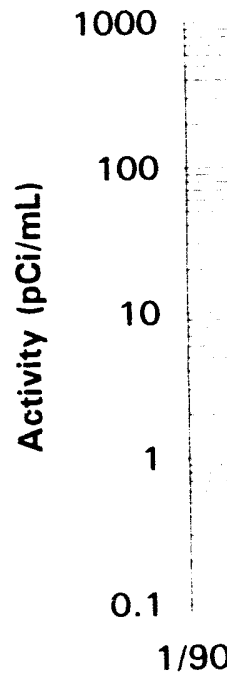

Unconnected lines indicate a dry well or a value below the detection limit. PDWS $20 \mathrm{pCi} / \mathrm{mL}$
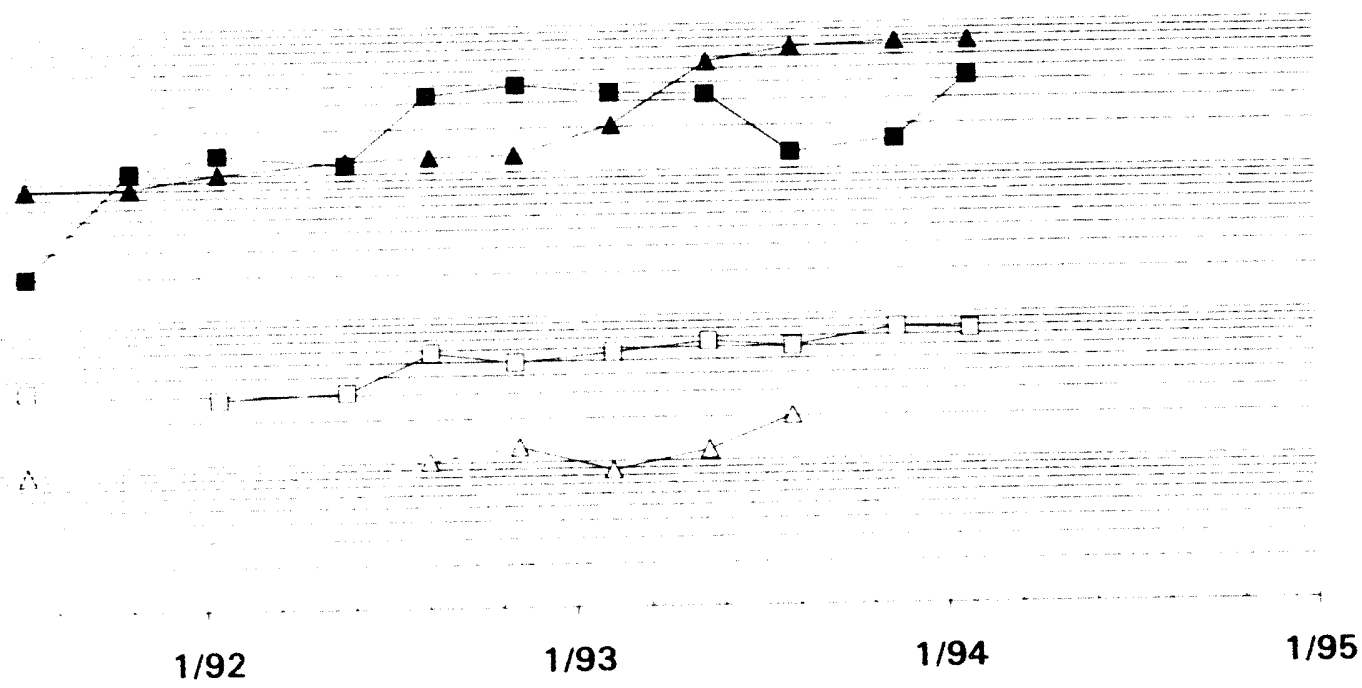

TIME (Quarters)

- BGO 45C (B) 


\section{Tritium Activities \\ Well Cluster BGO 46}

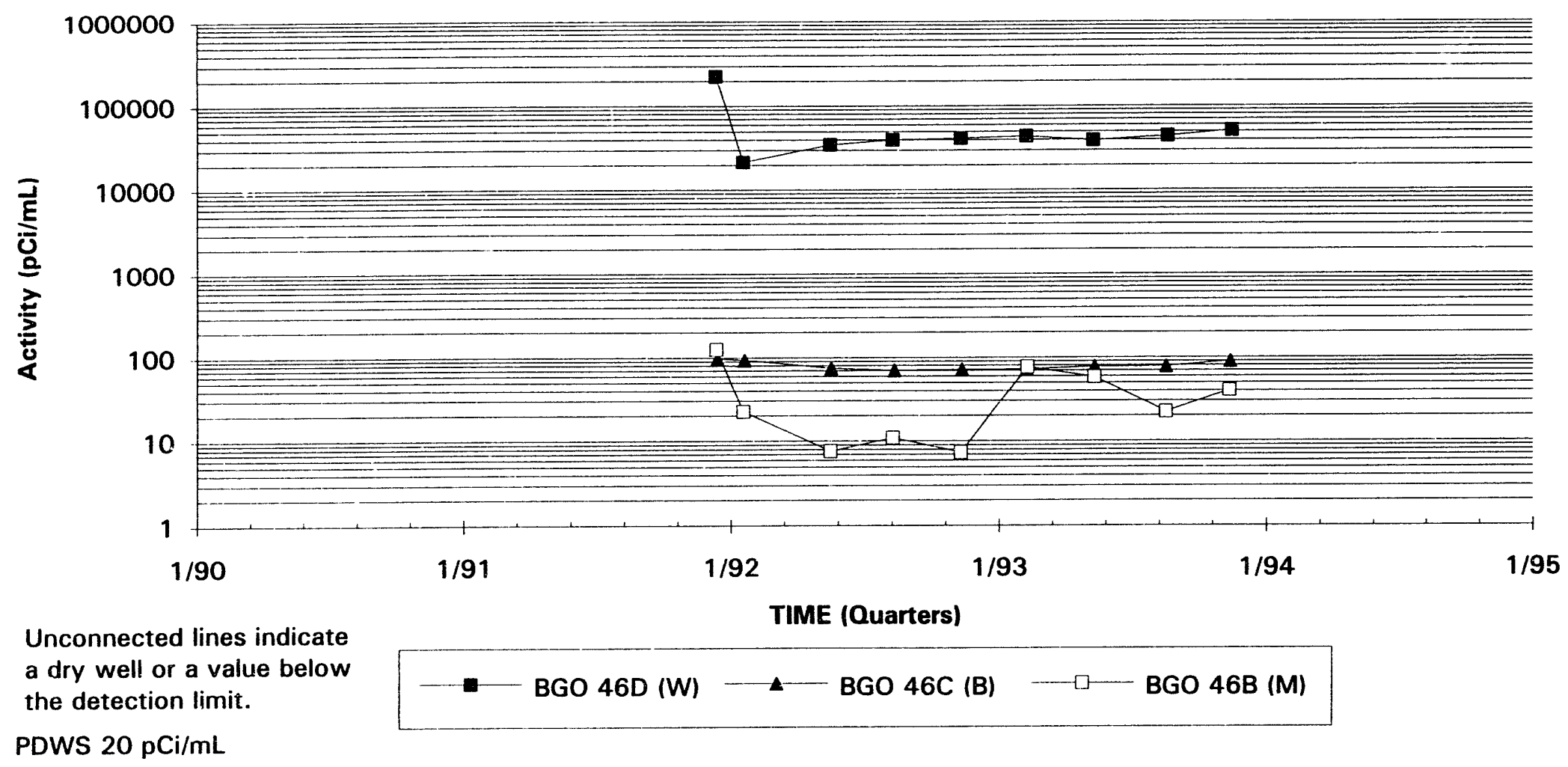

Note: $\mathrm{W}=$ Water Table (IIB2); $\mathrm{B}=$ Barnwell (IIB1); $\mathrm{M}=$ McBean (IIB1); UC = Upper Congaree (IIA); $\mathrm{MC}=$ Middle Congaree (IIA); LC $=$ Lower Congaree (IIA) 


\section{Tritium Activities}

\section{Well Cluster BGO 47}

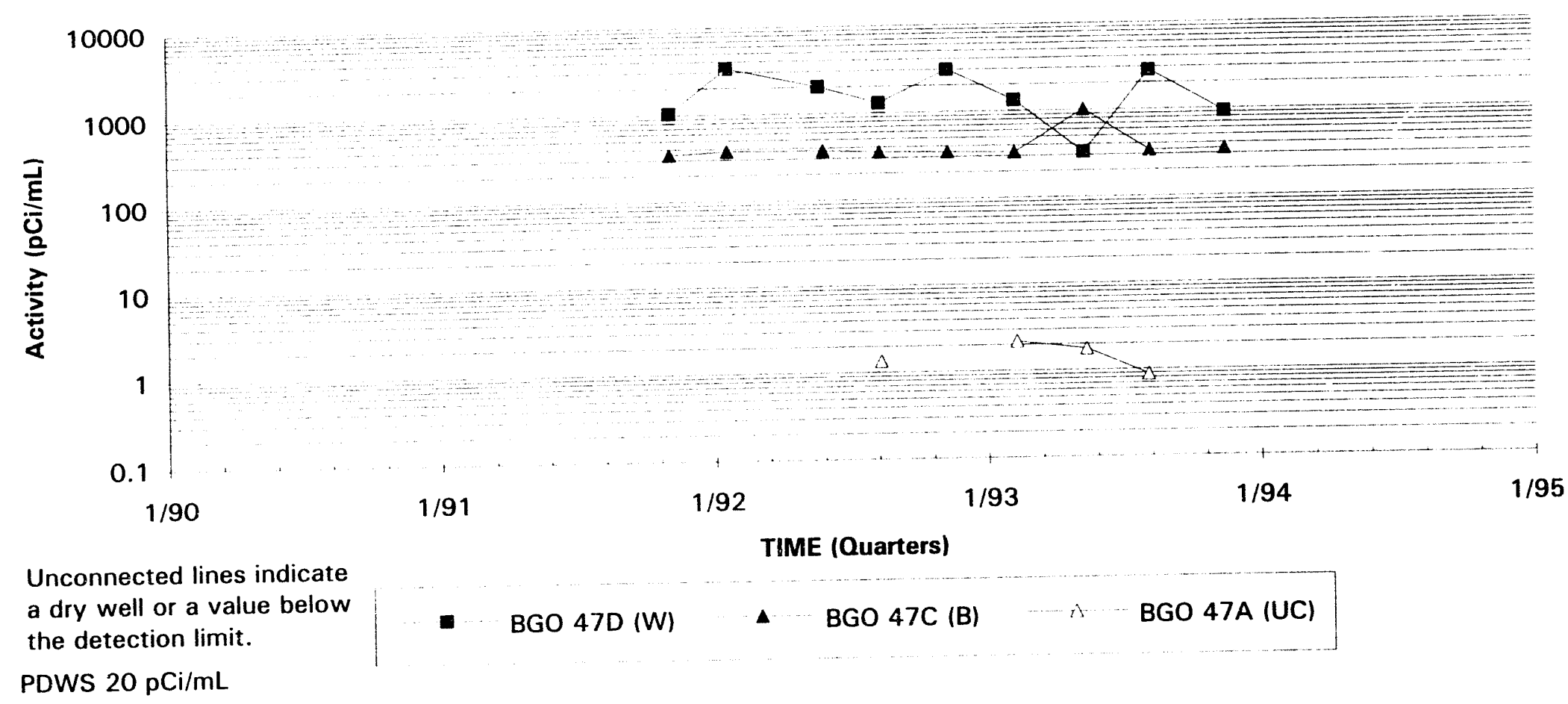

Note: $W=$ Water Table (IIB2); $B=$ Barnwell (IIB1); $M=M c B e a n$ (IIB1); UC = Upper Congaree (IIA); $M C=$ Middle Congaree (IIA); LC = Lower Congaree (IIA) 


\section{Tritium Activities}

\section{Well Cluster BGO 48}

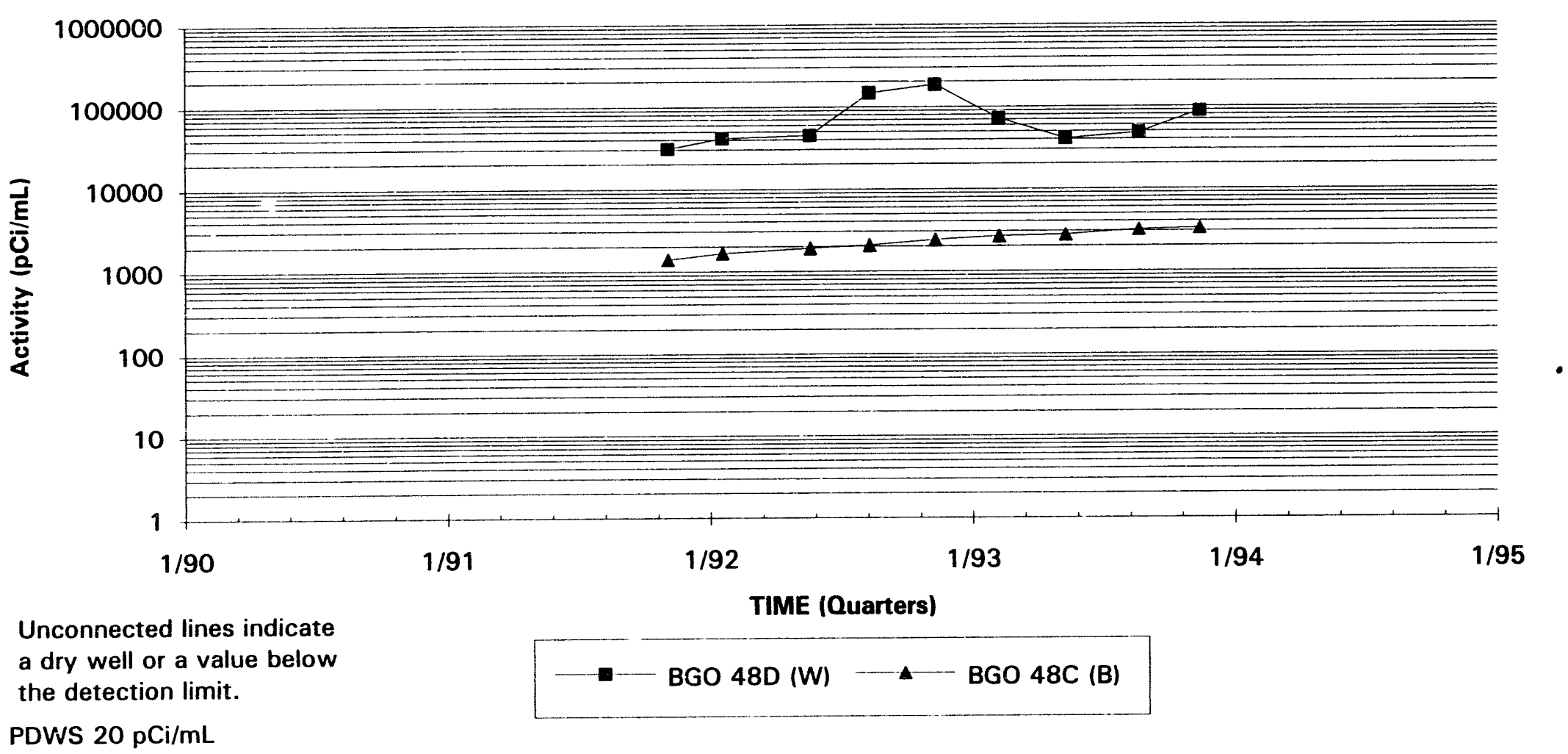

Note: $W=$ Water Table (IIB2); $B=$ Barnwell (IIB1); $M=$ McBean (IIB1); UC = Upper Congaree (IIA); $M C=$ Middle Congaree (IIA); LC = Lower Congaree (IIA) 


\section{Tritium Activities Well Cluster BGO 49}

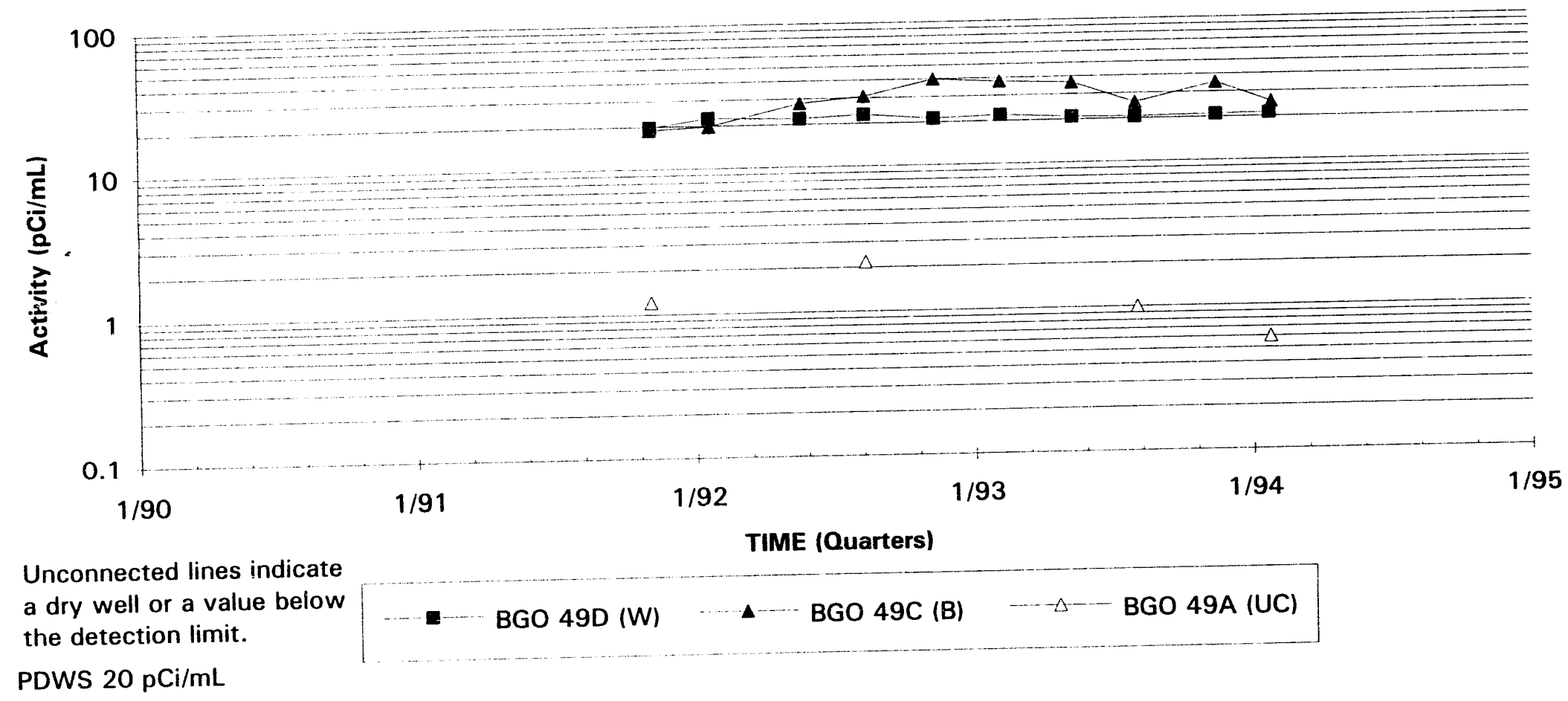

Note: $W=$ Water Table (IIB2); $B=$ Barnwell (IIB1); $M=$ McBean (IIB1); UC=Upper Congaree (IIA); $M C=$ Middle Congaree (IIA); $L C=$ Lower Congaree (IIA) 


\section{Tritium Ấctivities Well Cluster BGO 50}

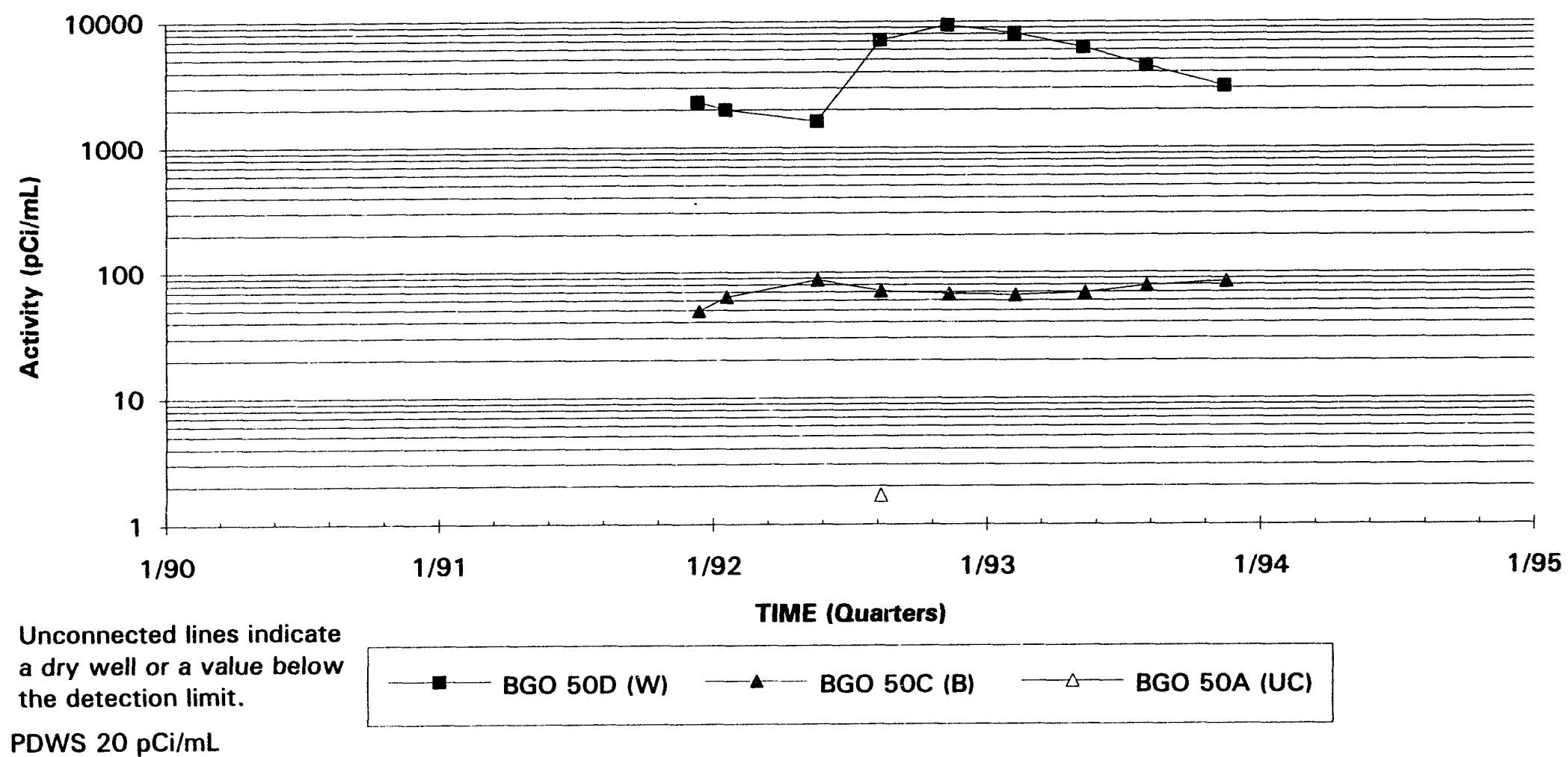

PDWS $20 \mathrm{pCi} / \mathrm{mL}$ 


\section{Tritium Activities \\ Well Cluster BGX 1}

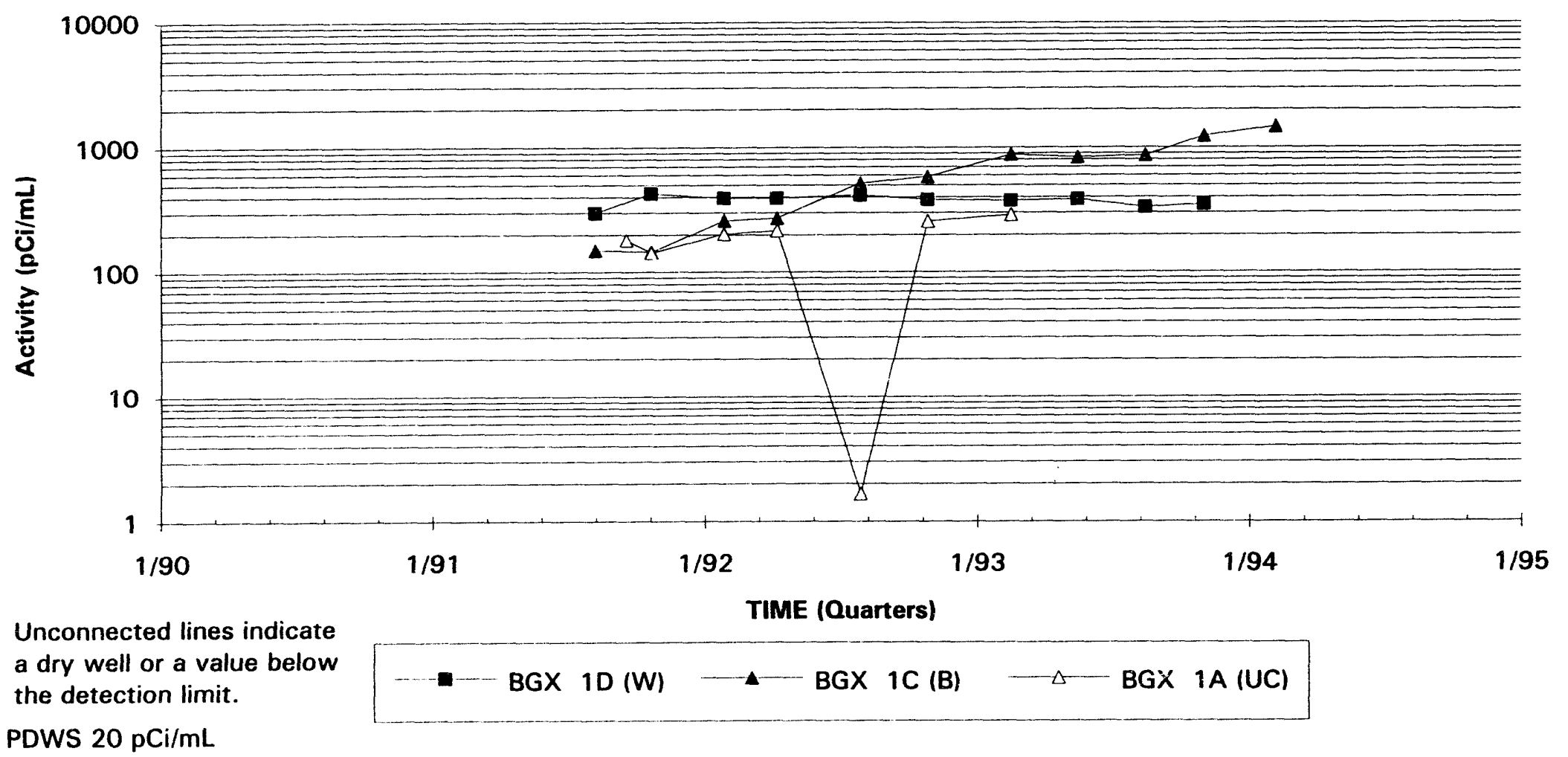

PDWS $20 \mathrm{pCi} / \mathrm{mL}$ 


\section{Tritium Activities}

\section{Well Cluster BGX 2}

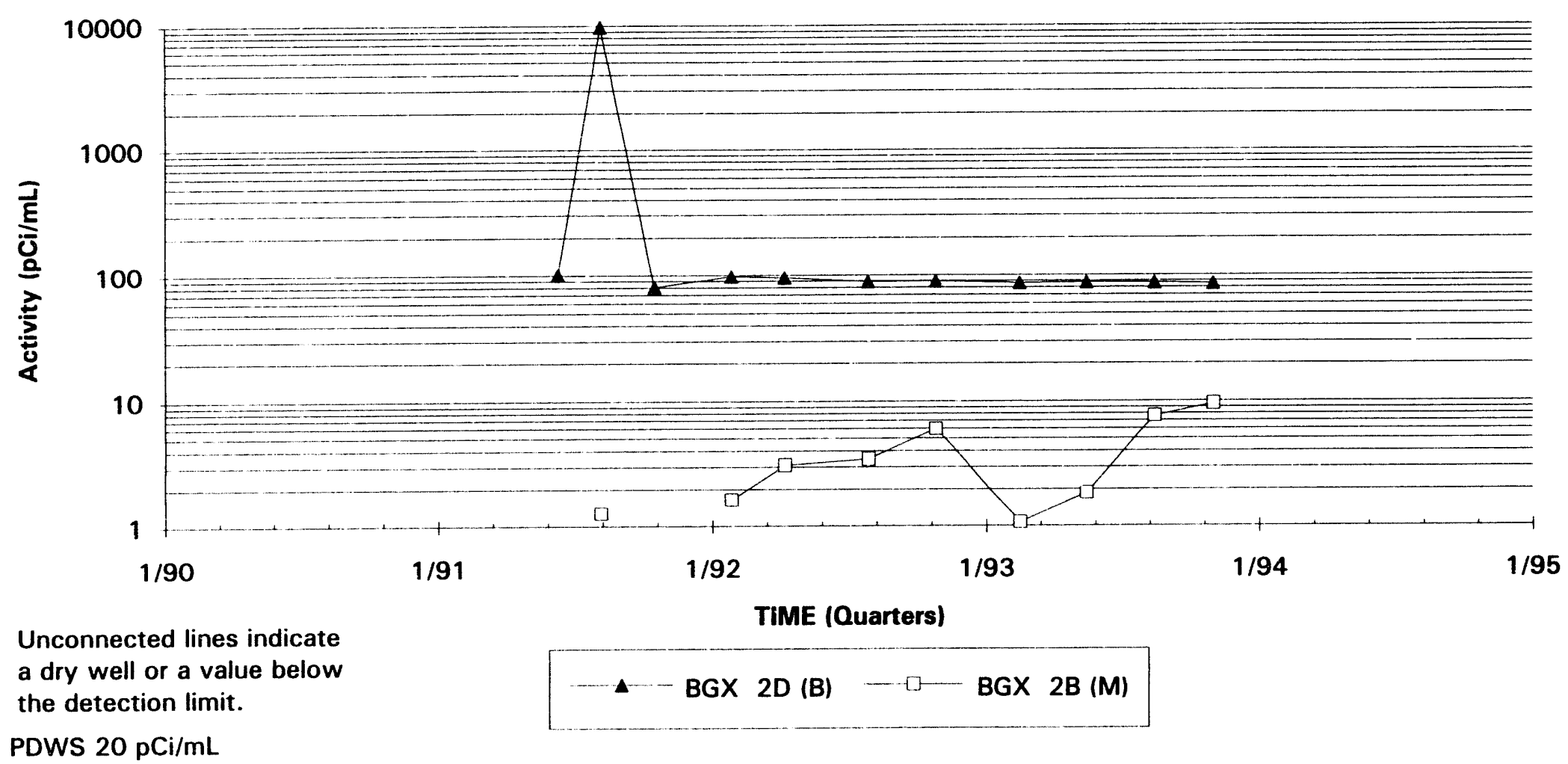

Note: $W=$ Water Table (IIB2); $B=$ Barnwell (IIB1); $M=$ McBean (IIB1); UC=Upper Congaree (IIA); $M C=$ Middle Congaree (IIA); LC = Lower Congaree (IIA) 


\section{Tritium Activities}

\section{Well BGX 30}

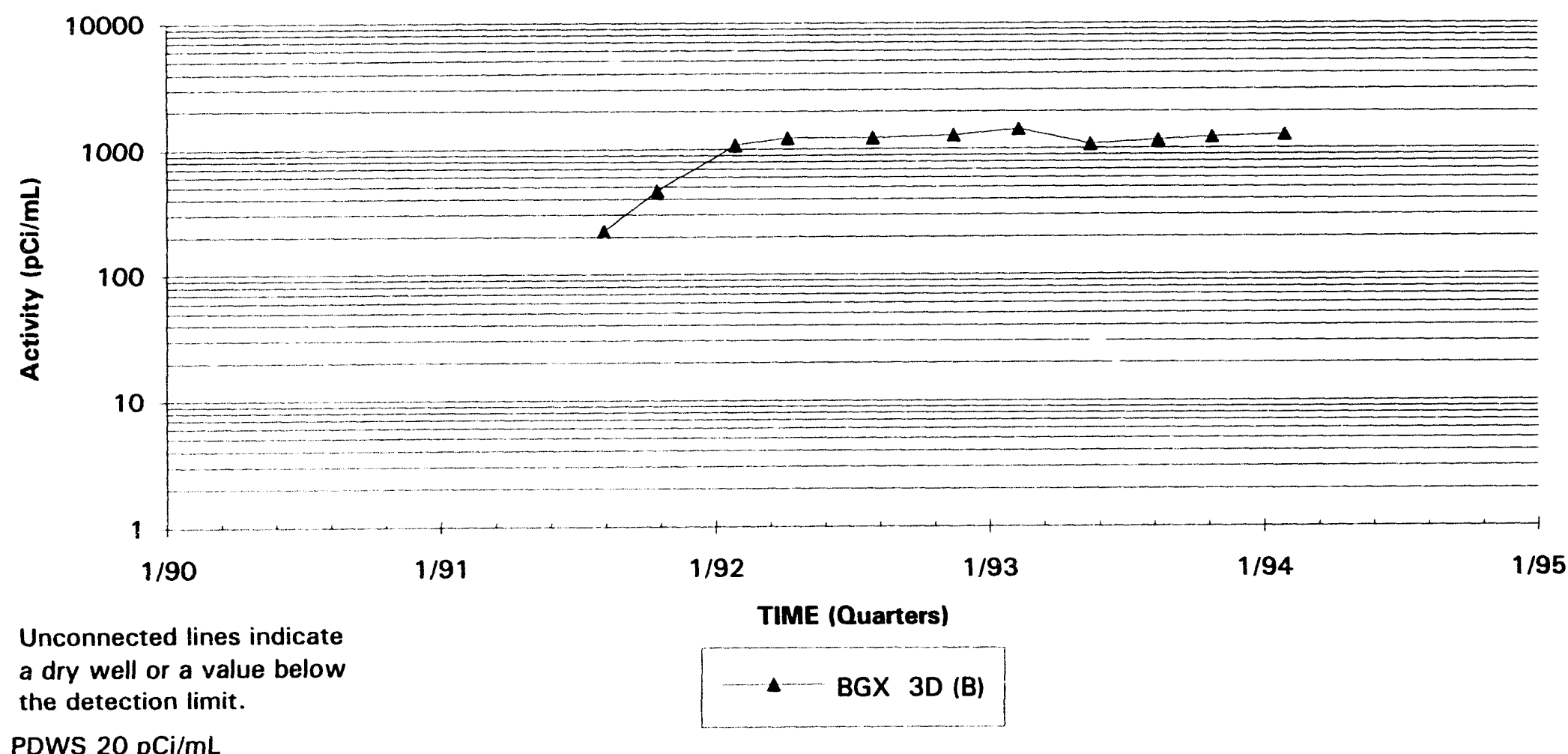




\section{Tritium Activities Well Cluster BGX 4}

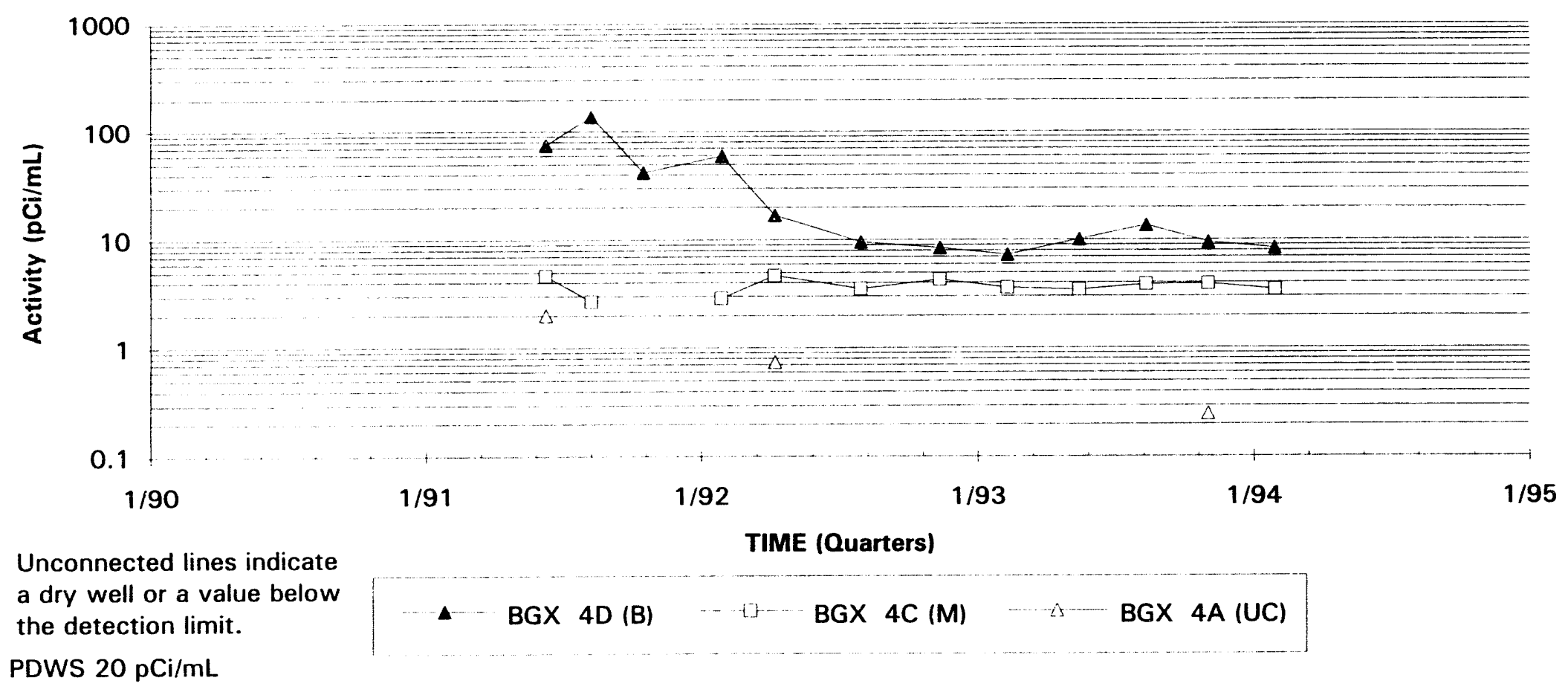

Note: $\mathrm{W}=$ Water Table (IIB2); $\mathrm{B}=$ Barnwell (IIB1); $\mathrm{M}=\mathrm{McBean}$ (IIB1); UC=Upper Congaree (IIA); $\mathrm{MC}=$ Middle Congaree (IIA); LC = Lower Congaree (IIA) 


\section{Tritium Activities}

Well BGX 5D

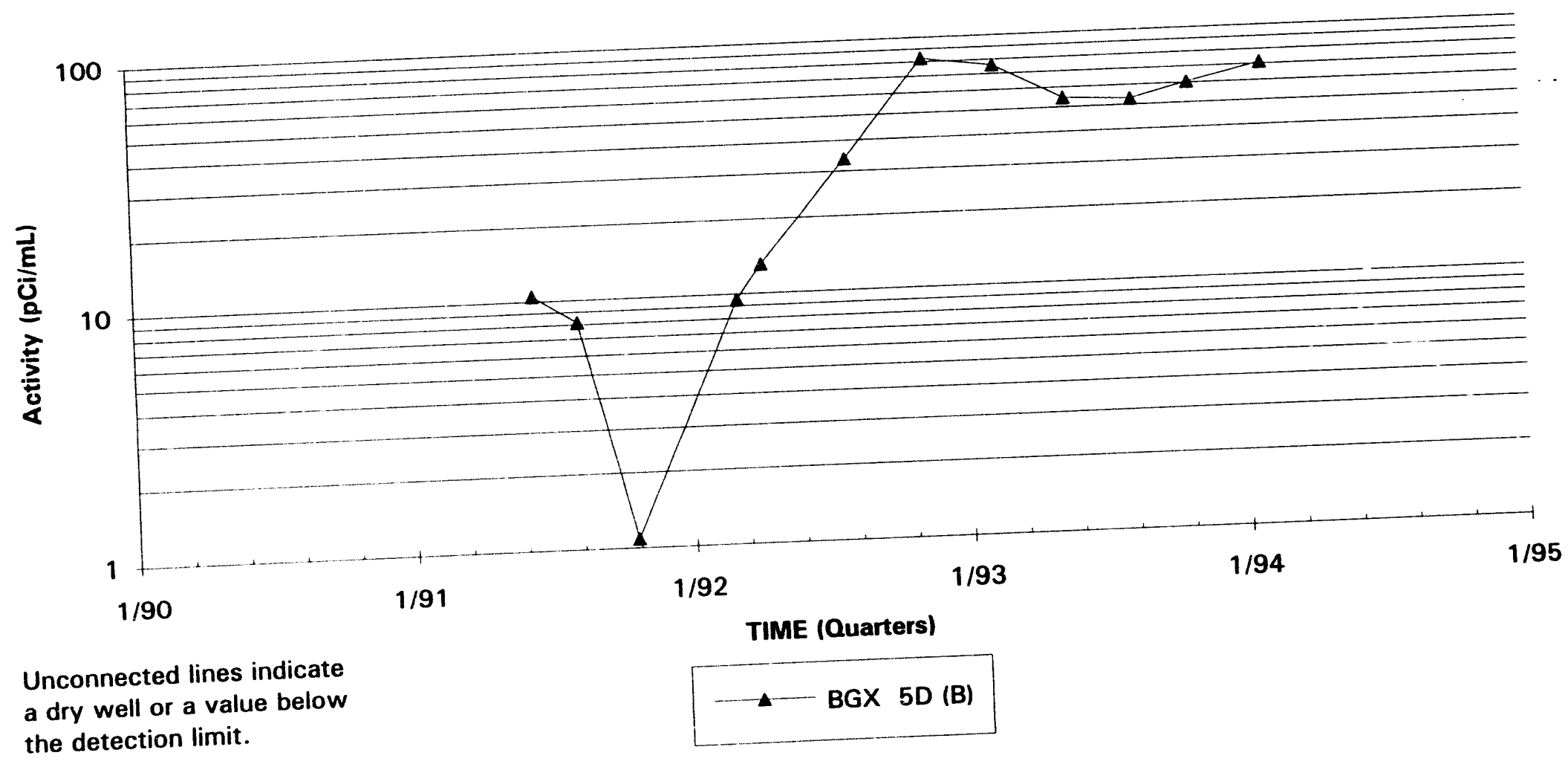

PDWS $20 \mathrm{pCi} / \mathrm{mL}$ 


\section{Tritium Activities \\ Well BGX 6D}

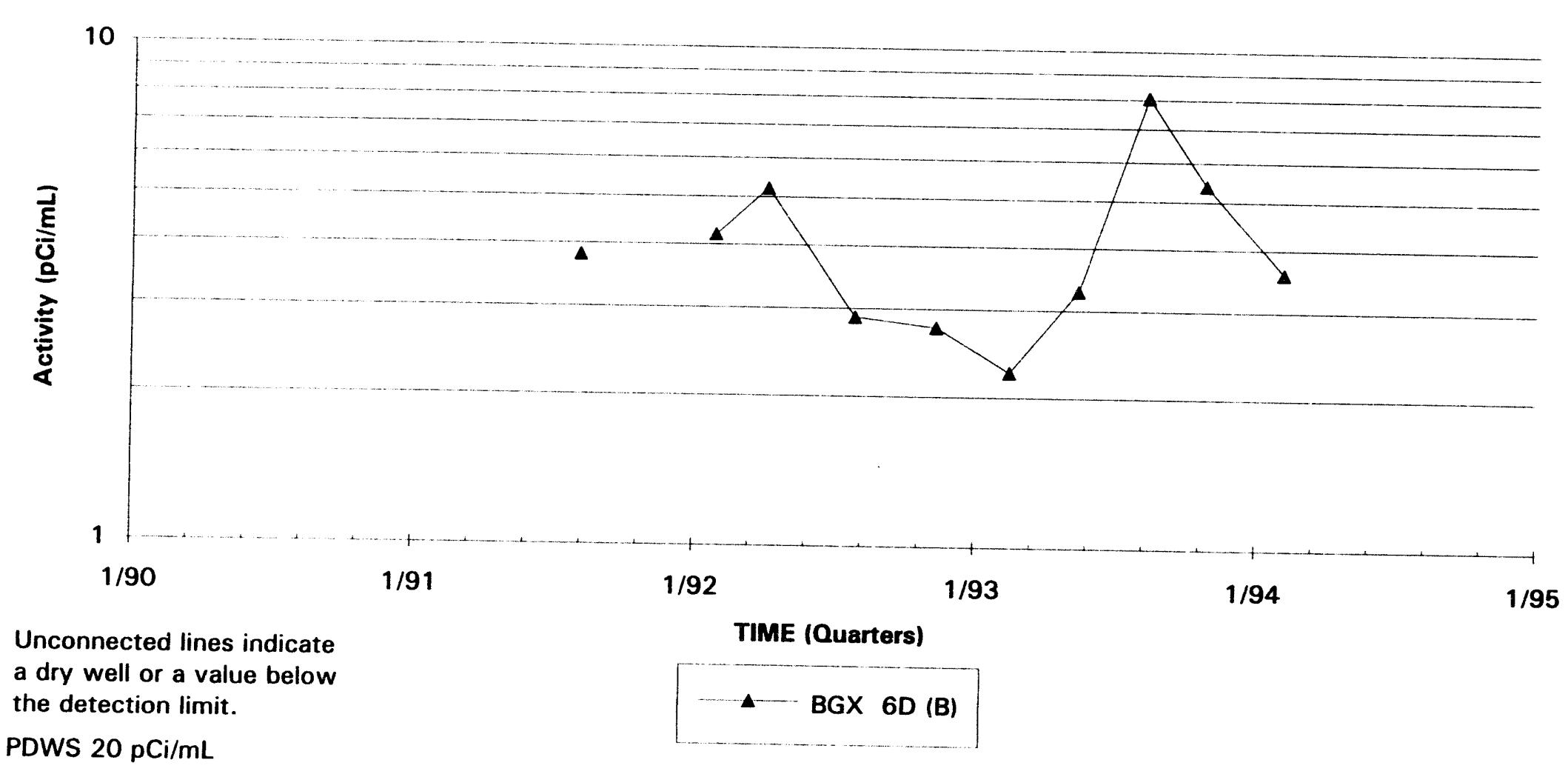

Note: $W=$ Water Table (IIB2); $B=$ Barnwell (IIB1); $M=$ McBean (IIB1); UC = Upper Congaree (IIA); $M C=$ Middle Congaree (IIA); LC =Lower Congaree (IIA) 


\section{Tritium Activities \\ Well BGX 7D}

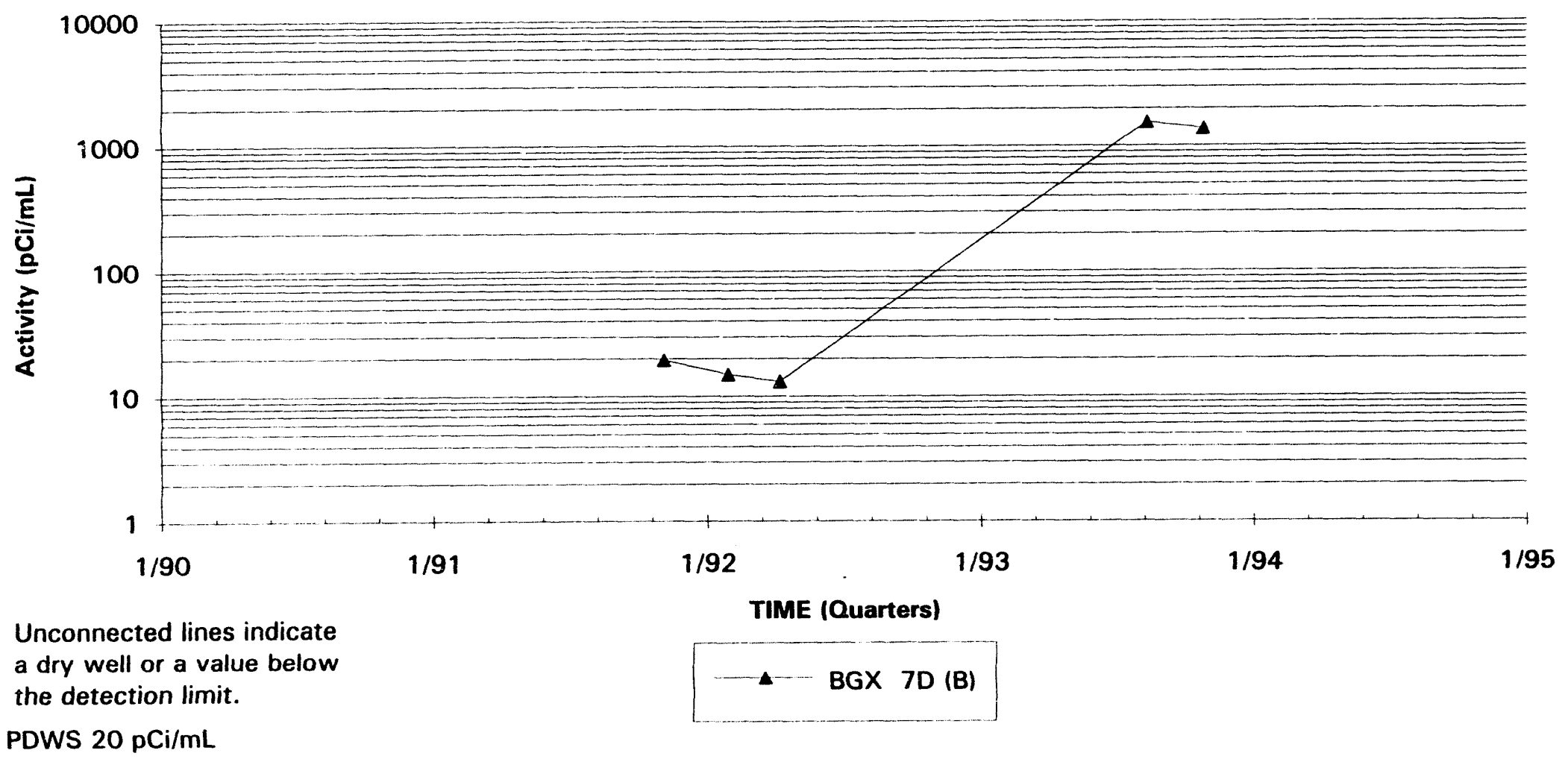

Note: $W=$ Water Table (IIB2); $B=$ Barnwell (IIB1); $M=$ McBean (IIB1); UC = Upper Congaree (IIA); $M C=$ Middle Congaree (IIA); LC = Lower Congaree (IIA) 


\section{Tritium Activities} Well Cluster BGX 8

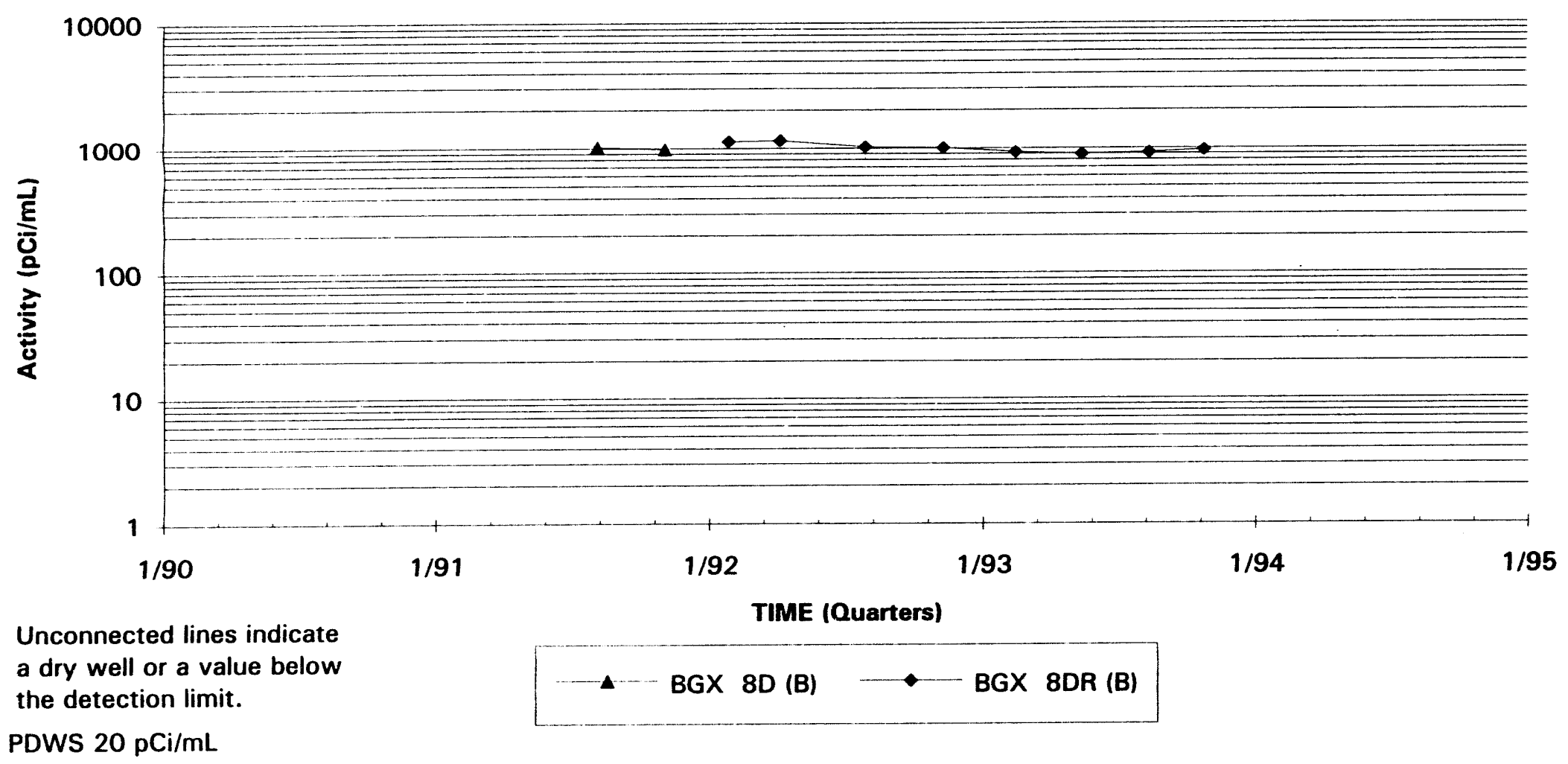

Note: $W=$ Water Table (IIB2); B = Barnwell (IIB1); $M=$ McBean (IIB1); UC=Upper Congaree (IIA); MC = Middle Congaree (IIA); LC=Lower Congaree (IIA) 


\section{Tritium Activities}

Well BGX 9D

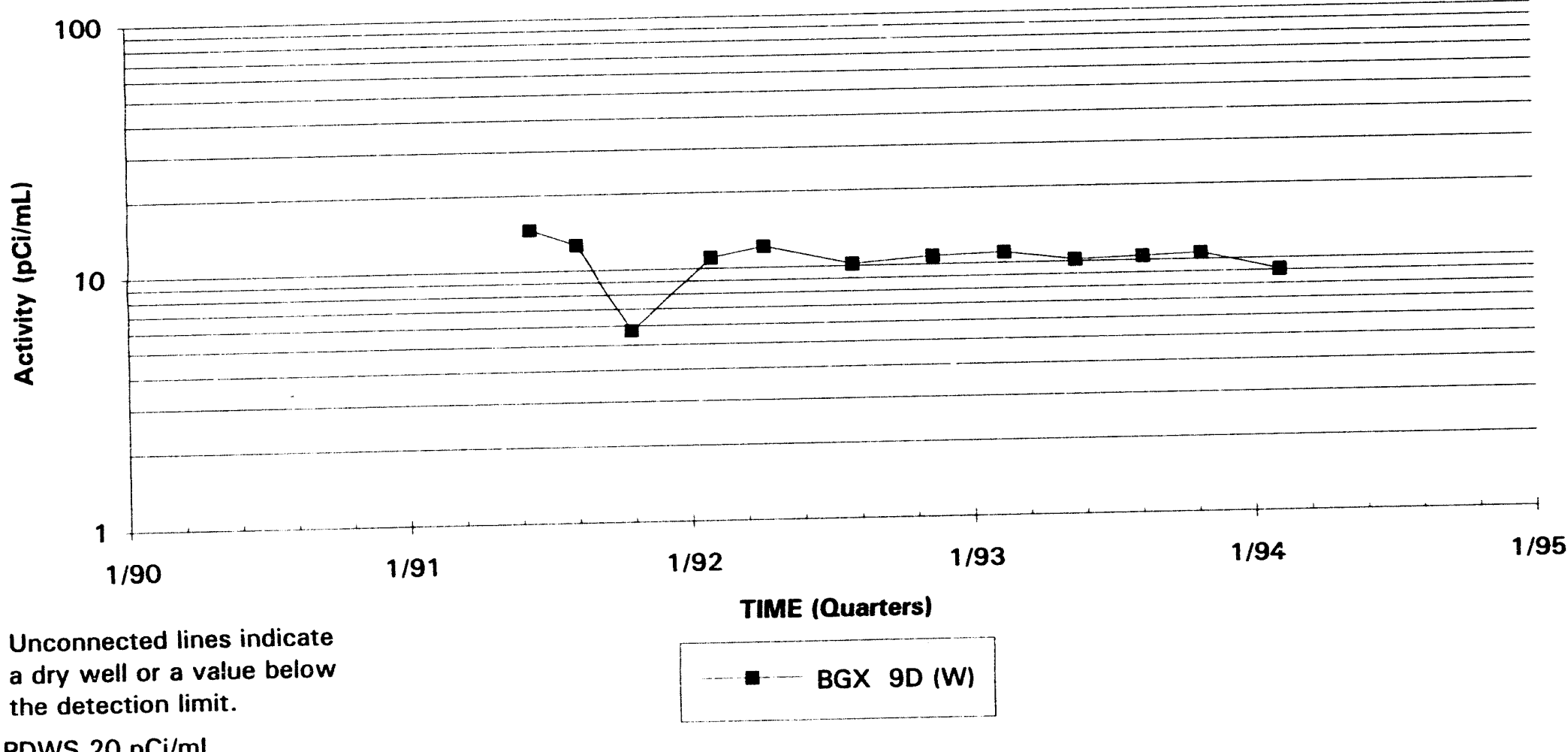

PDWS $20 \mathrm{pCi} / \mathrm{mL}$

Note: $W=$ Water Table (IIB2); $B=$ Barnwell (IIB1); $M=$ McBean (IIB1); UC=Upper Congaree (IIA); $M C=$ Middle Congaree (IIA); $L C=L o w e r$ Congaree (IIA) 

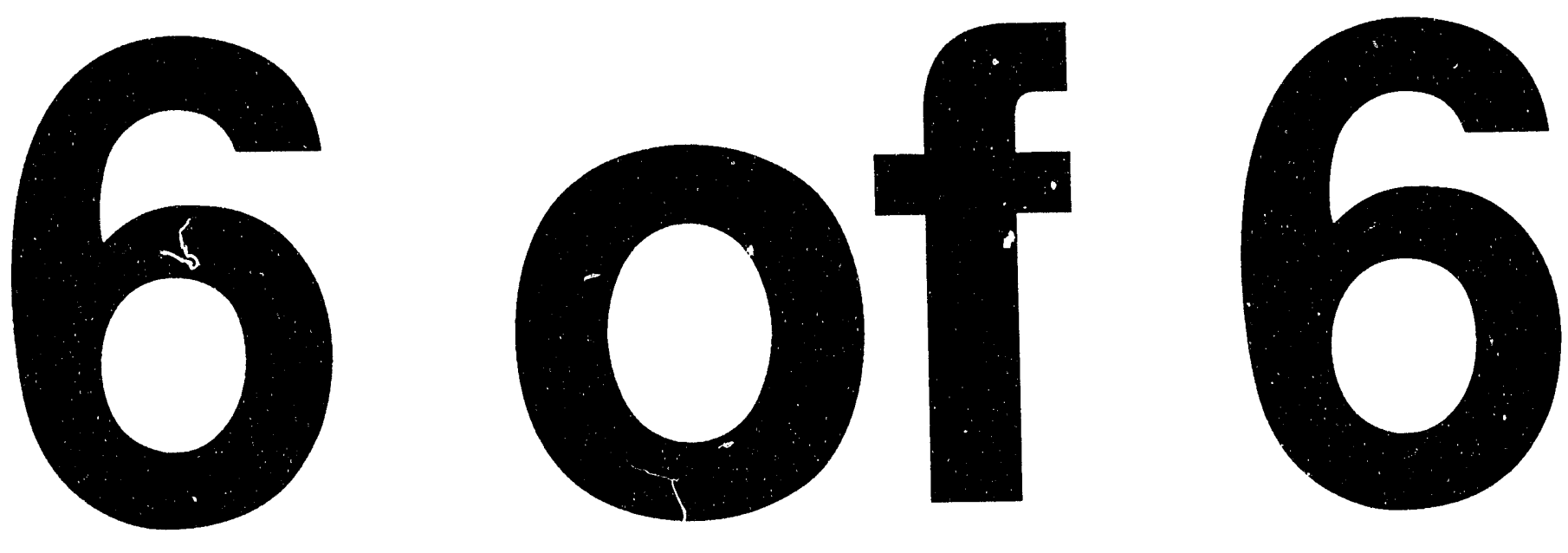


\section{Tritium Activities \\ Well BGX 10D}

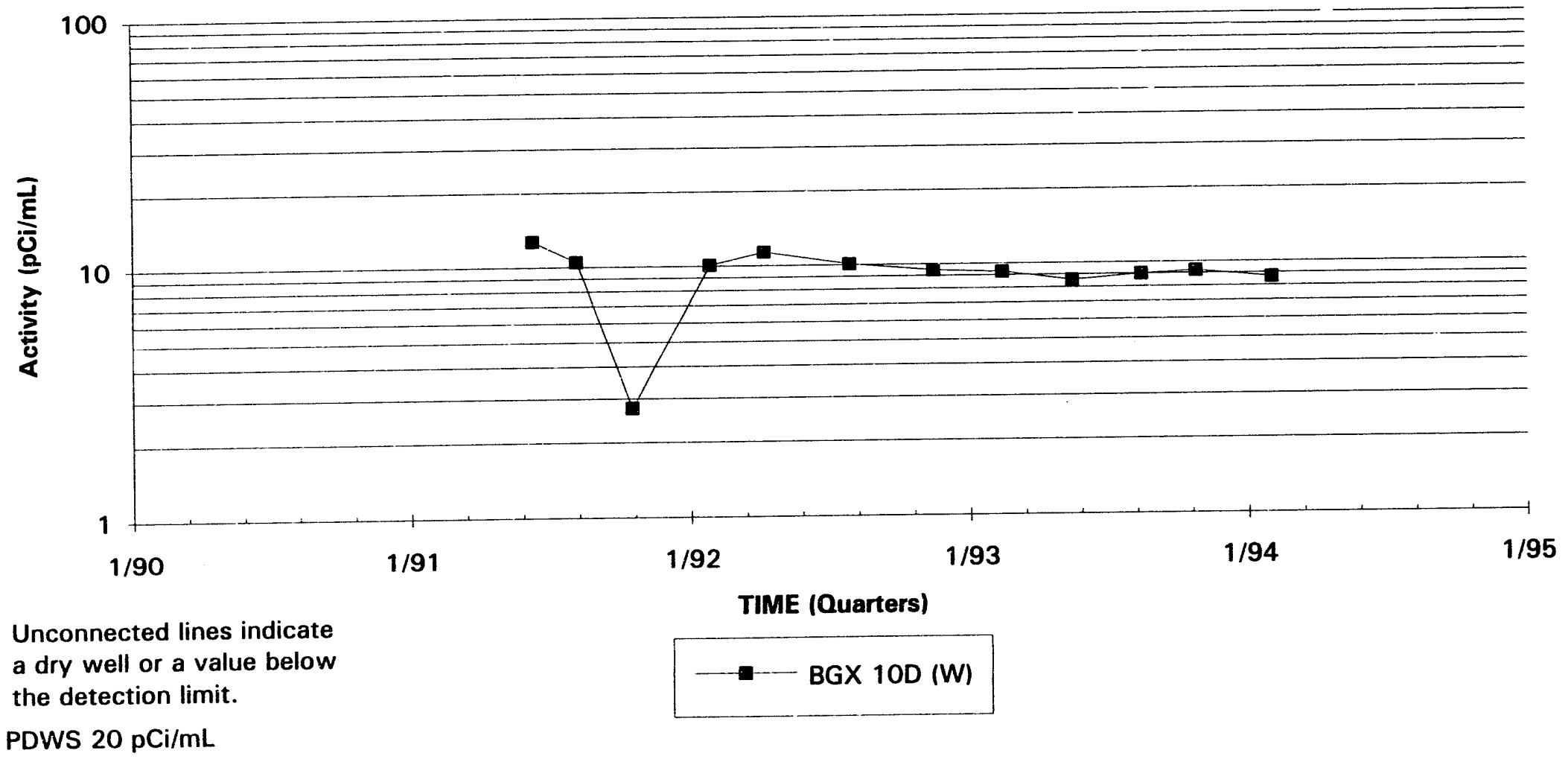

Note: $W=$ Water Table (IIB2); $B=$ Barnwell (IIB1); $M=$ McBean (IIB1); UC = Upper Congaree (IIA); $M C=$ Mic'sle Congaree (IIA); LC=Lower Congaree (IIA: 


\section{Tritium Activities \\ Well BGX 11D}

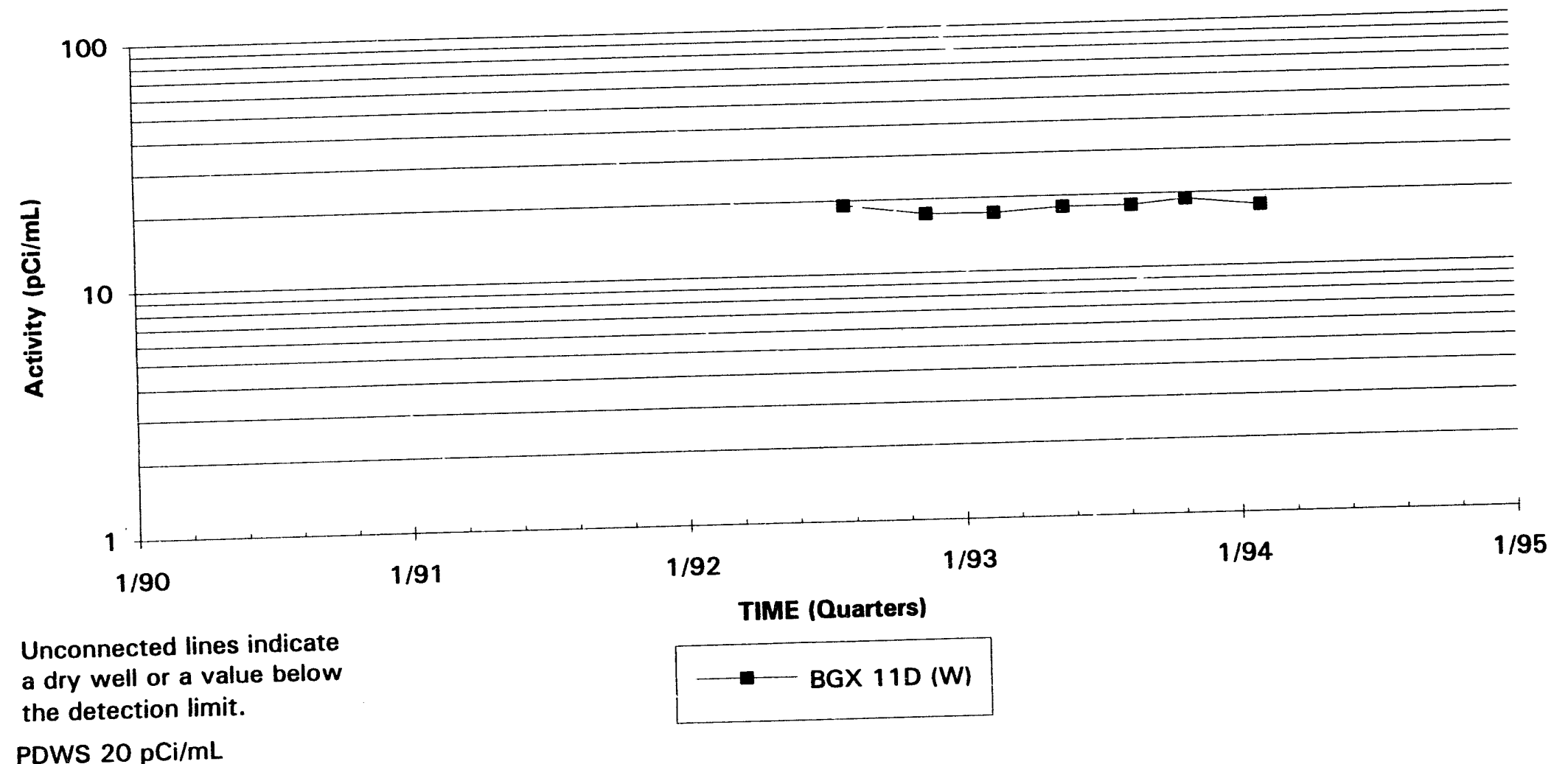

PDWS $20 \mathrm{pCi} / \mathrm{mL}$ 


\section{Tritium Activities Well Cluster BGX 12}

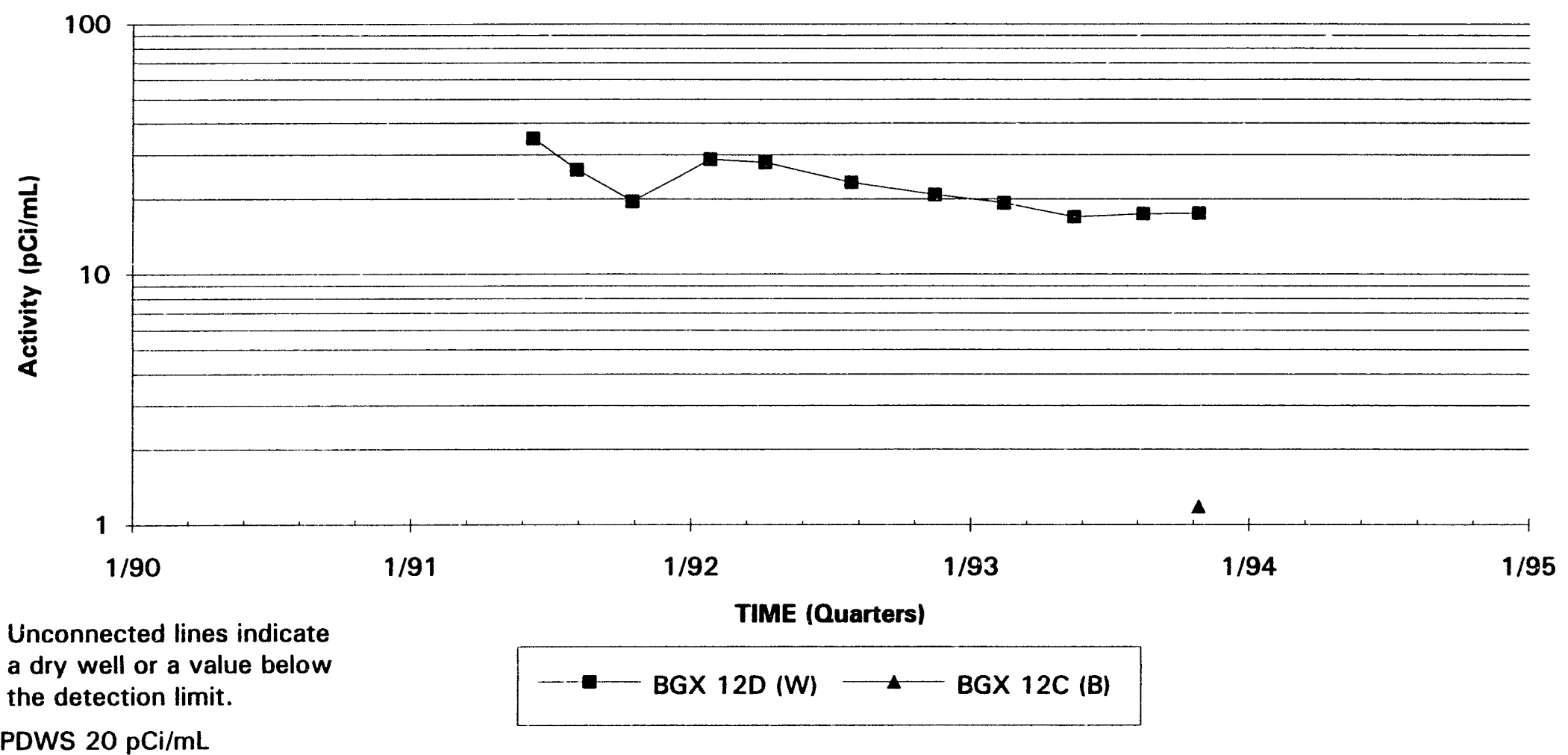

PDWS $20 \mathrm{pCi} / \mathrm{mL}$ 


\section{Tritium Activities}

Well FSS 1D

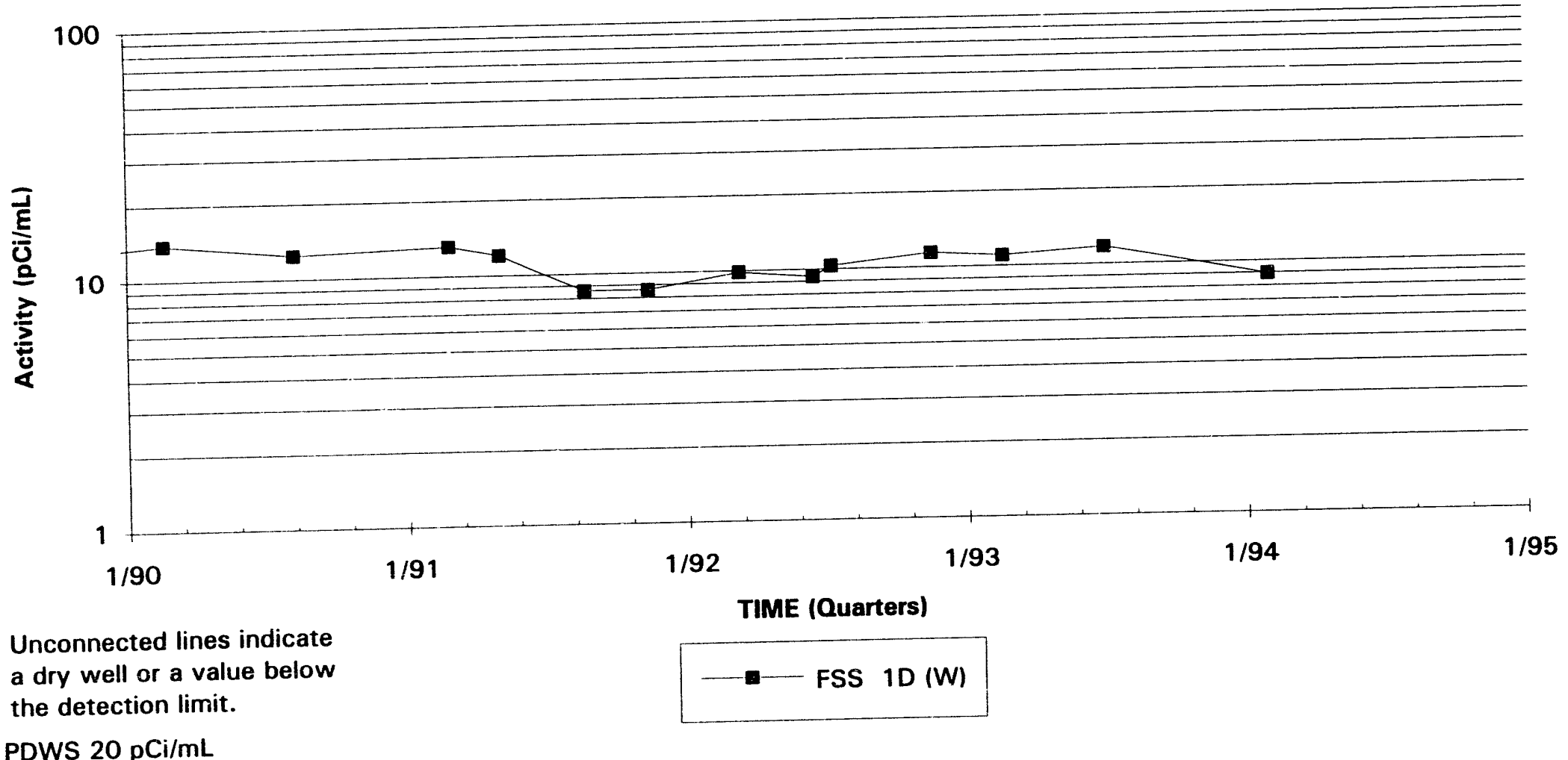

PDWS $20 \mathrm{pCi} / \mathrm{mL}$ 


\section{Tritium Activities}

Well FSS 2D

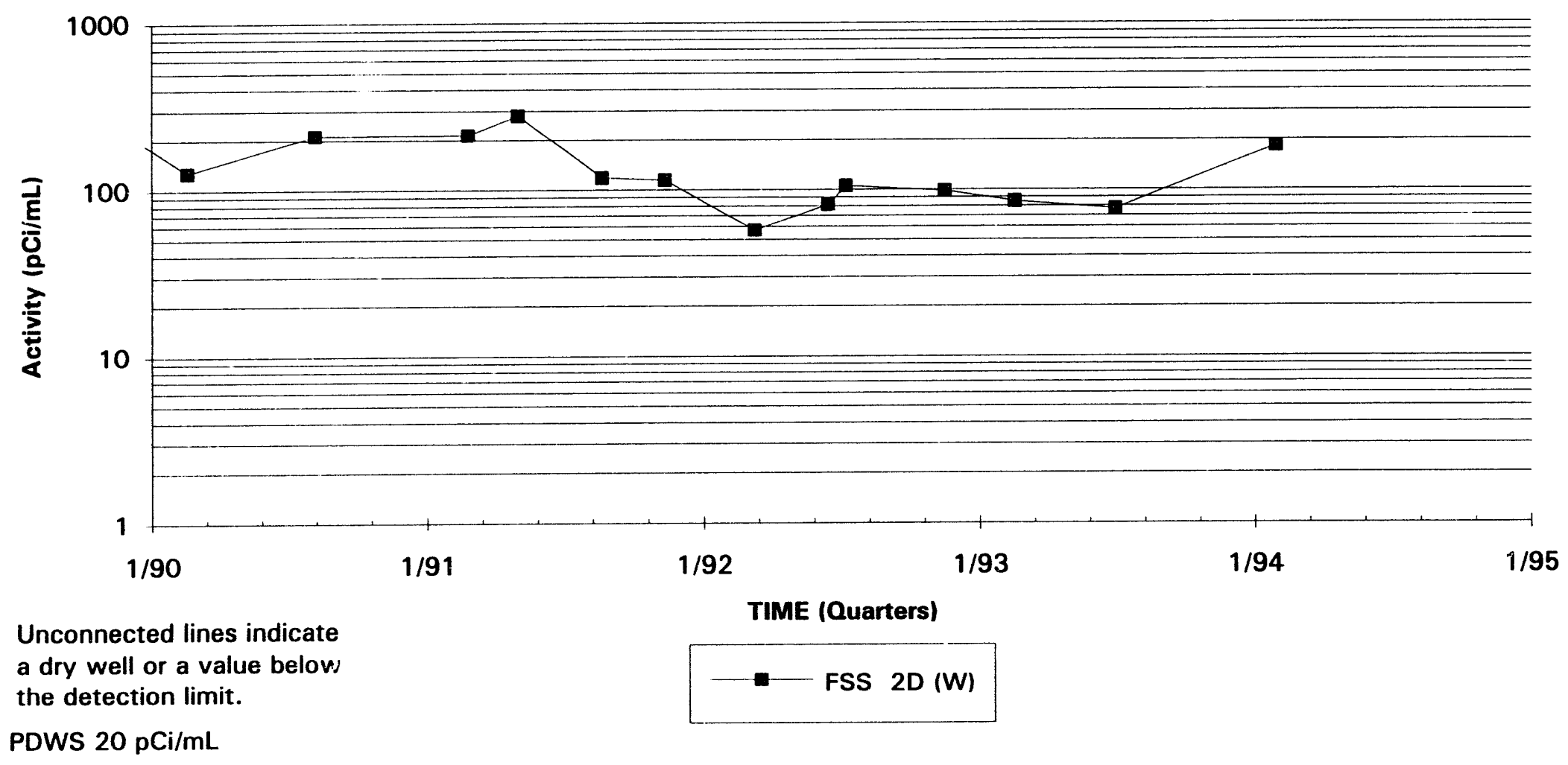

Note: $W=$ Water Table (IIB2); $B=$ Barnwell (IIB1); $M=M c B e a n$ (IIB1); UC = Upper Congaree (IIA); $M C=$ Middle Congaree (IIA); LC=Lower Congaree (IIA) 


\section{Tritium Activities}

Well FSS 3D

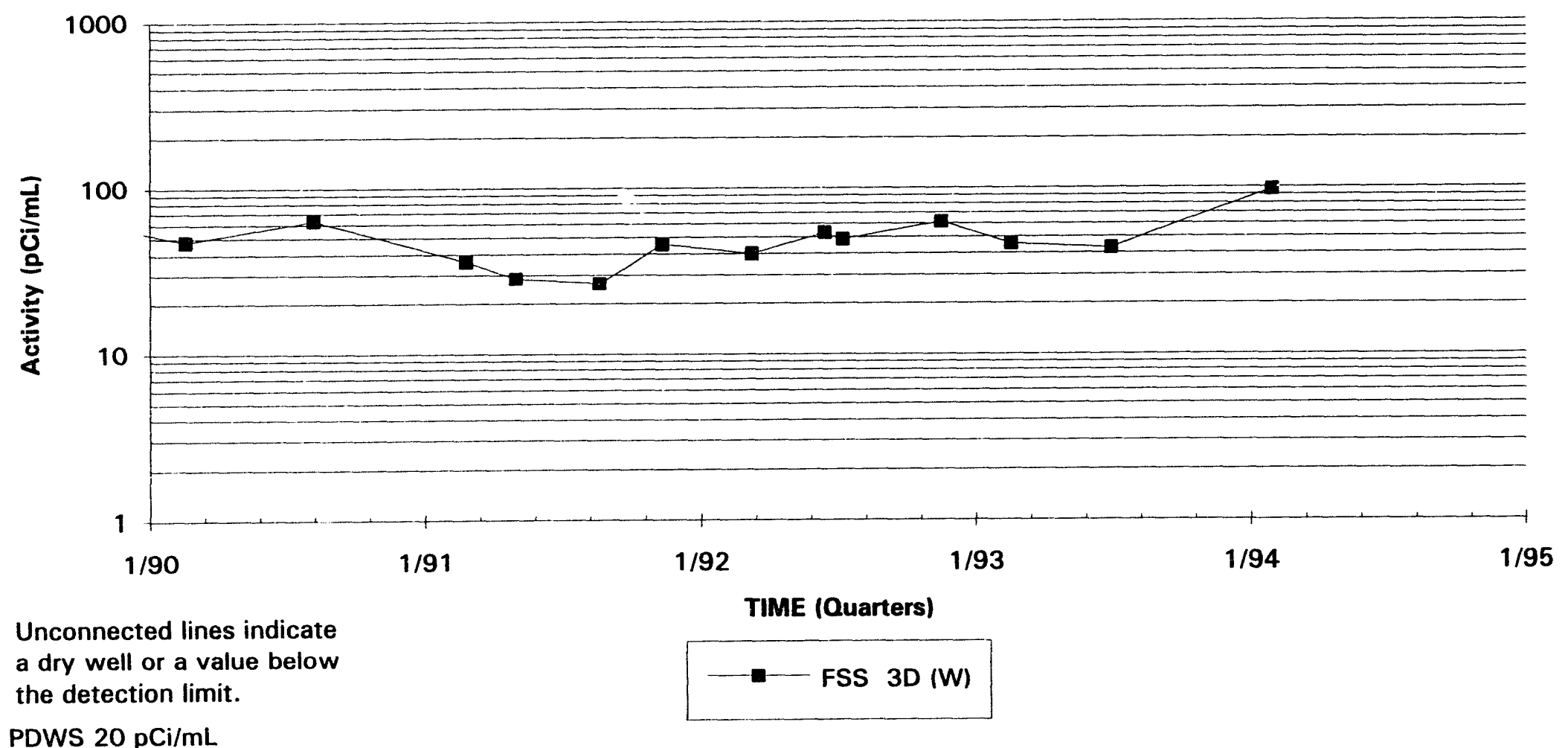




\section{Tritium Activities}

Well FSS 4D

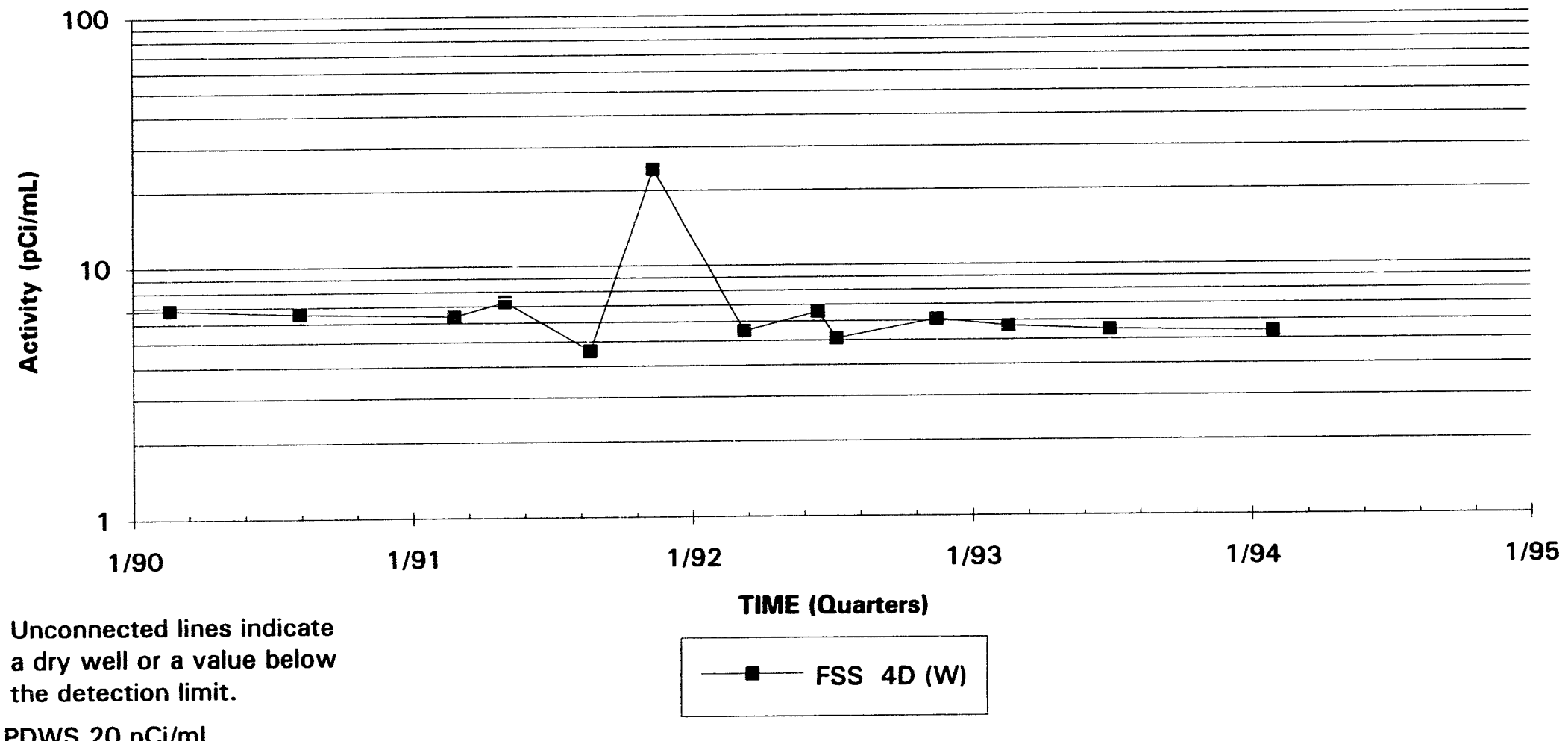

PDWS $20 \mathrm{pCi} / \mathrm{mL}$ 


\section{Tritium Activities}

Well HMD 1D

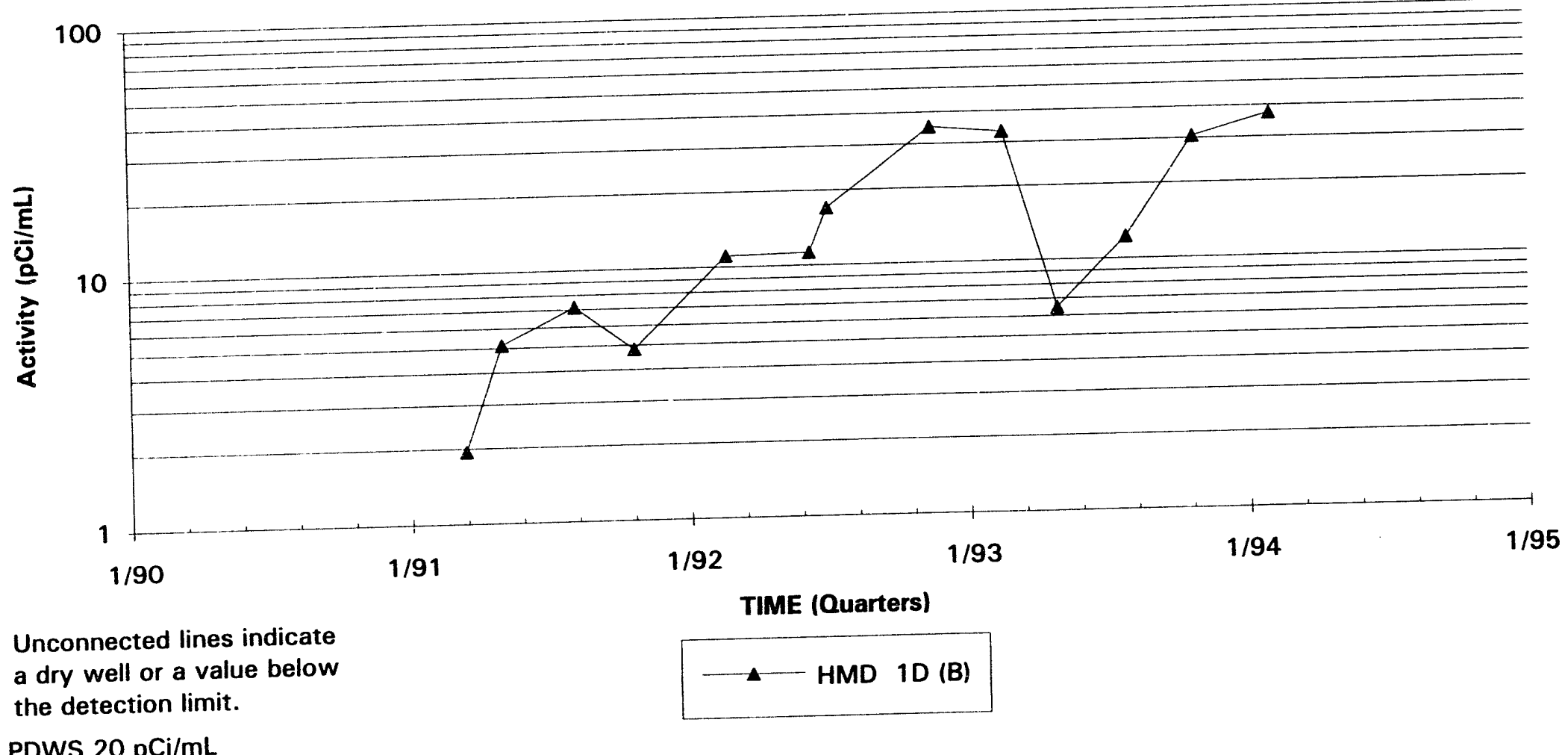

PDWS $20 \mathrm{pCi} / \mathrm{mL}$ 


\section{Tritium Activities}

Well HMD 2D

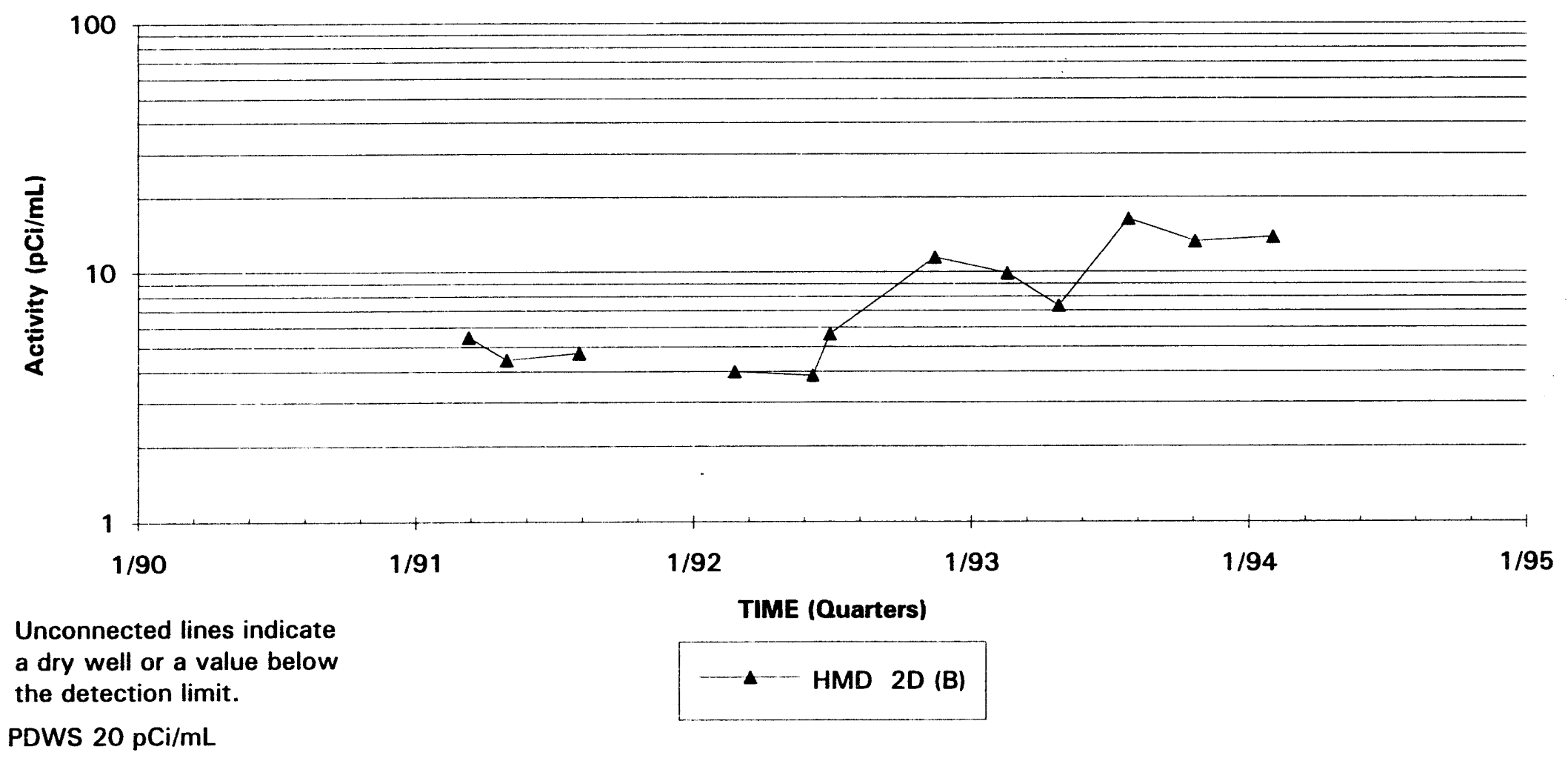

Note: $W=$ Water Table (IIB2); $B=B a r n w e l l$ (IIB1); $M=$ McBean (IIB1); UC=Upper Congaree (IIA); $M C=$ Middle Congaree (IIA); LC=Lower Congaree (IIA) 


\section{Tritium Activities}

\section{Well HMD 3D}

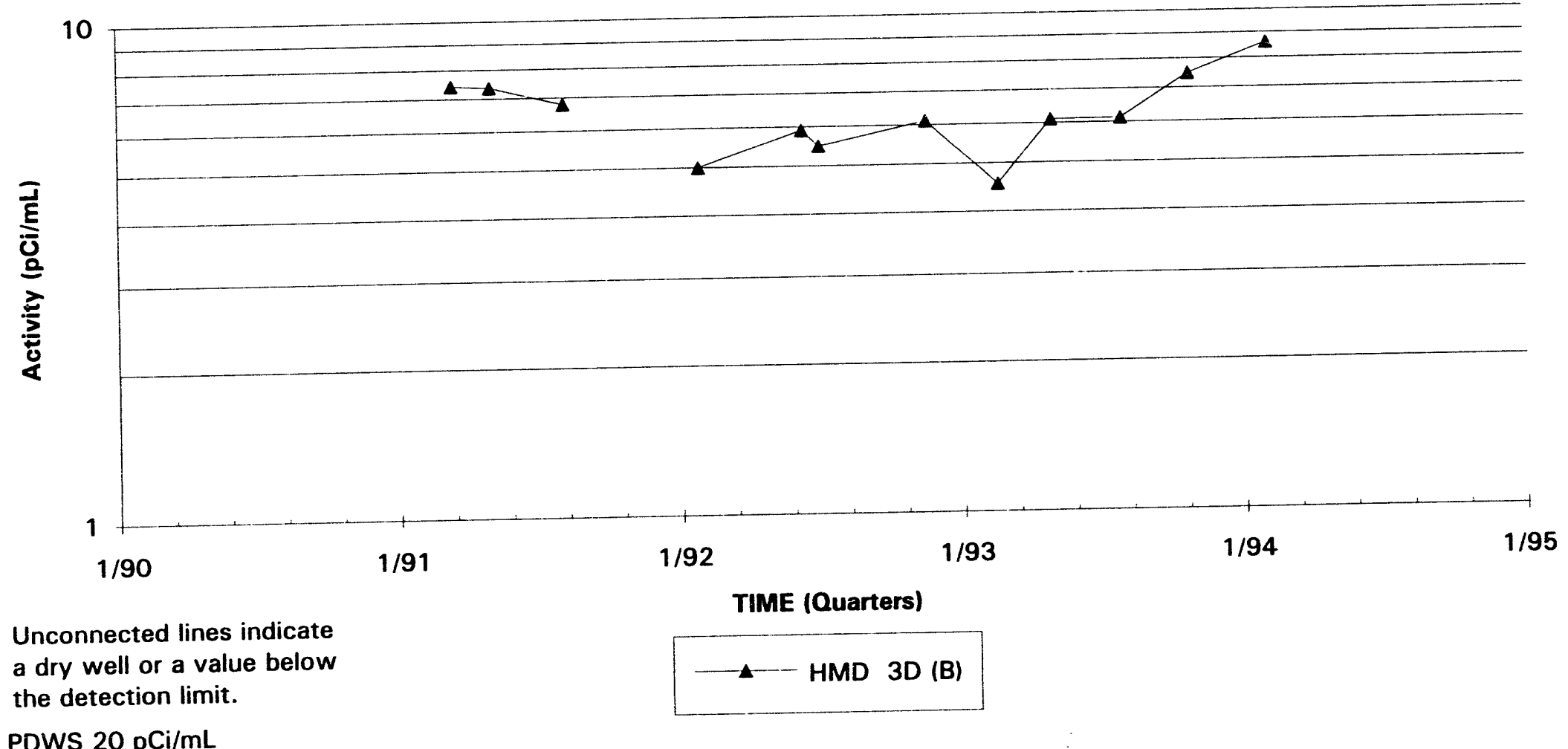

PDWS $20 \mathrm{pCi} / \mathrm{mL}$ 


\section{Tritium Activities}

Well HMD 4D

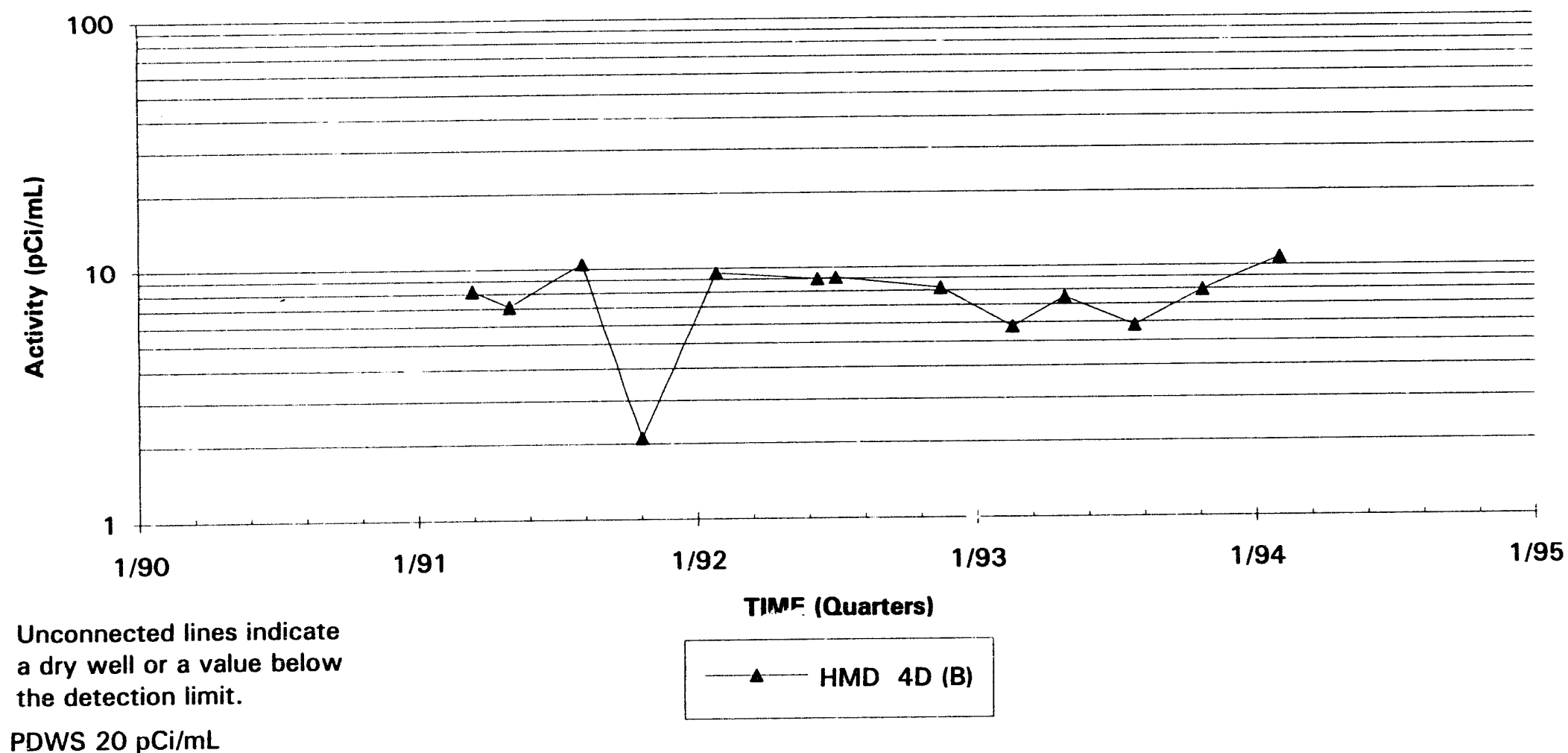

Note: $W=$ Water Table (IIB2); $B=$ Barnwell (IIB1); $M=$ McBean (IIB1); UC=Upper Congaree (IIA); $M C=$ Middle Congaree (IIA); LC=Lower Congaree (IIA) 


\section{Tritium Activities}

\section{Well Cluster HSB 85}

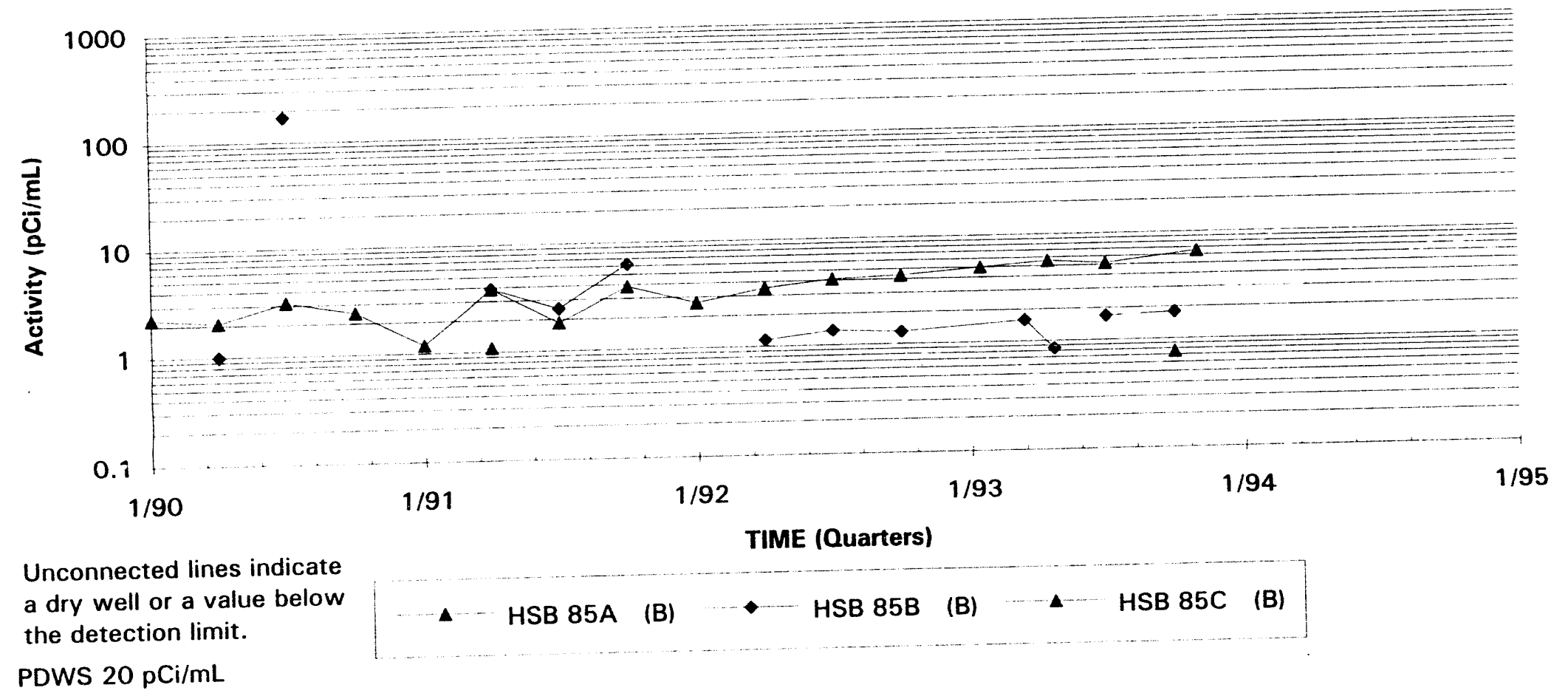

PDWS $20 \mathrm{pCi} / \mathrm{mL}$ 
○

○

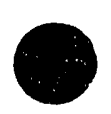




\section{Appendix G}

\section{Hydrographs}


WSRC-TR-94-0240

Unclassified

THIS PAGE LEFT BLANK INTENTIONALLY. 


\section{Hydrograph}

Well BGO 1D

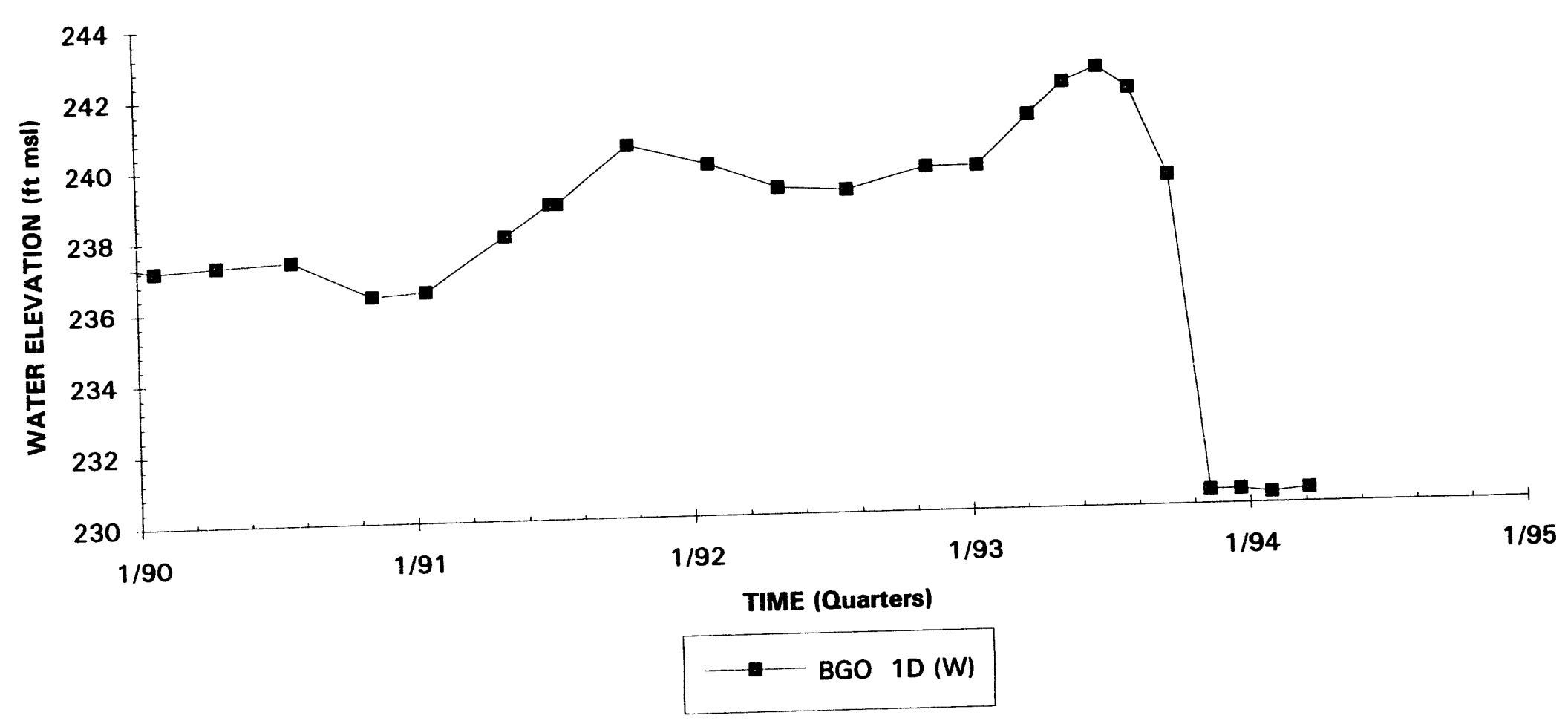




\section{Hydrograph}

Well BGO 2D

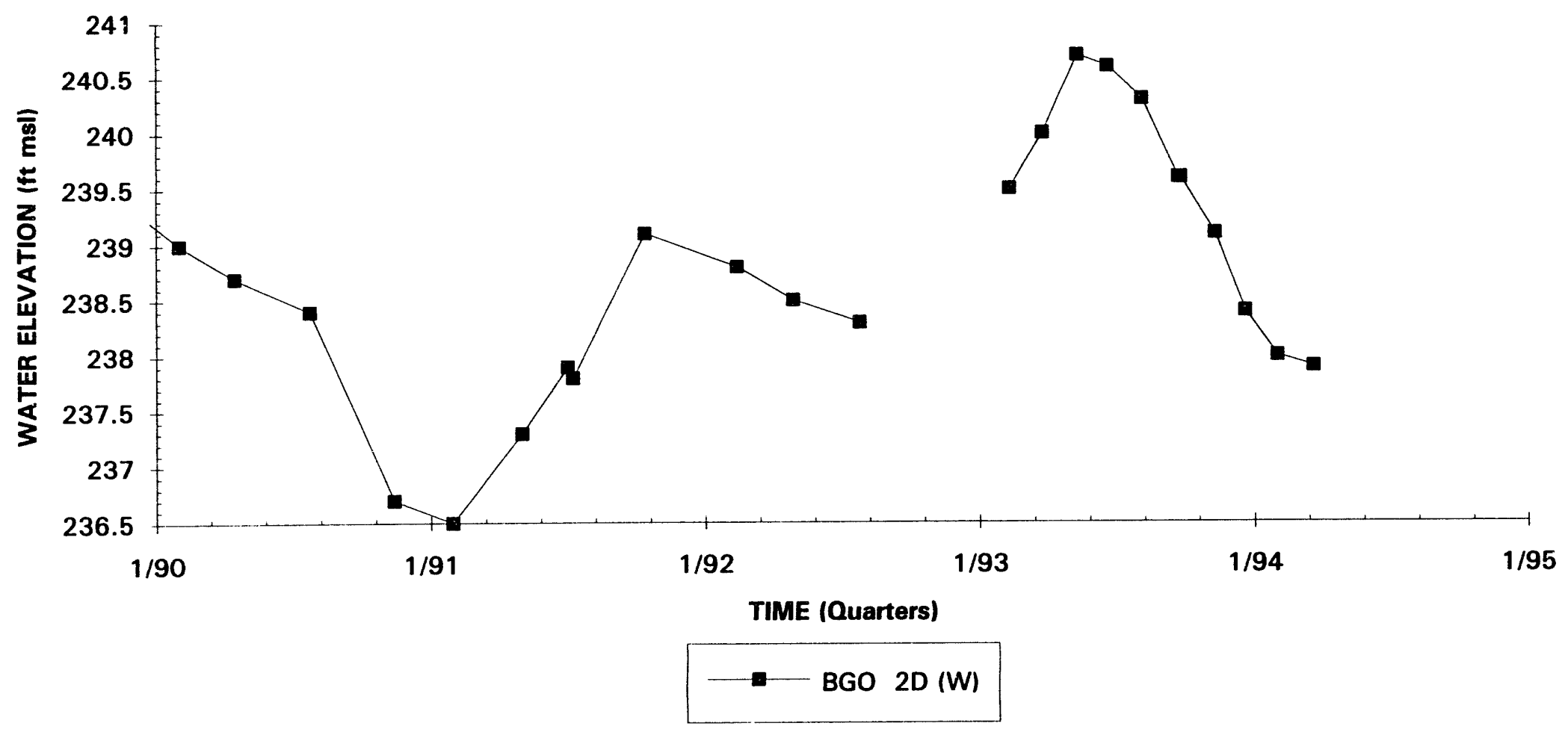

Note: $W=$ Water Table (IIB2); $B=$ Barnwell (IIB1); $M=M c B e a n$ (IIB1); UC=Upper Congaree (IIA); $M C=$ Middle Congaree (IIA); LC=Lower Congaree (IIA) 


\section{Hydrograph \\ Well BGO 3D}

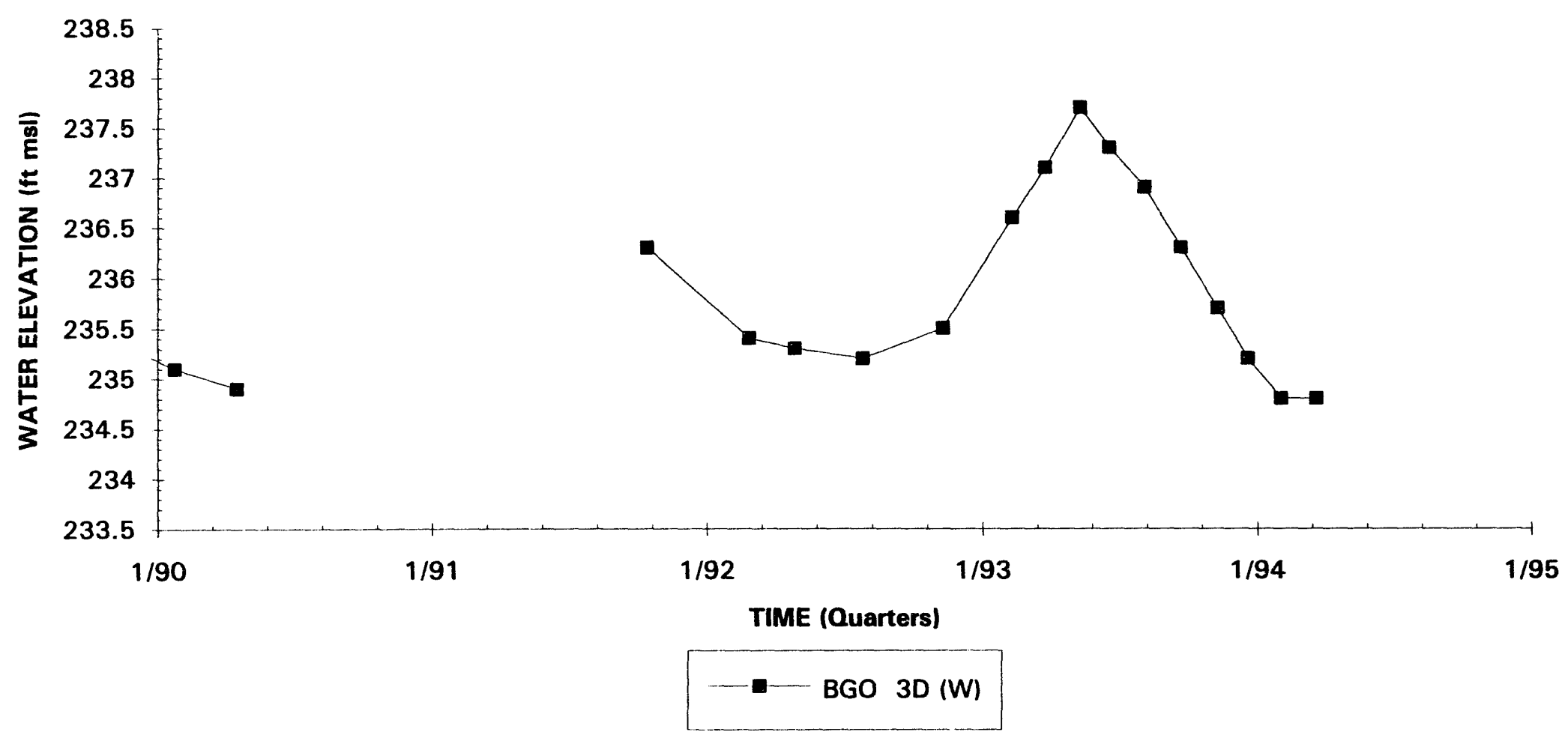

Note: $W=$ Water Table (IIB2); $B=$ Barnwell (IIB1); $M=$ McBean (IIB1); UC=Upper Congaree (IIA); $M C=$ Middle Congaree (IIA); LC = Lower Congaree (IIA) 


\section{Hydrograph \\ Well BGO 4D}

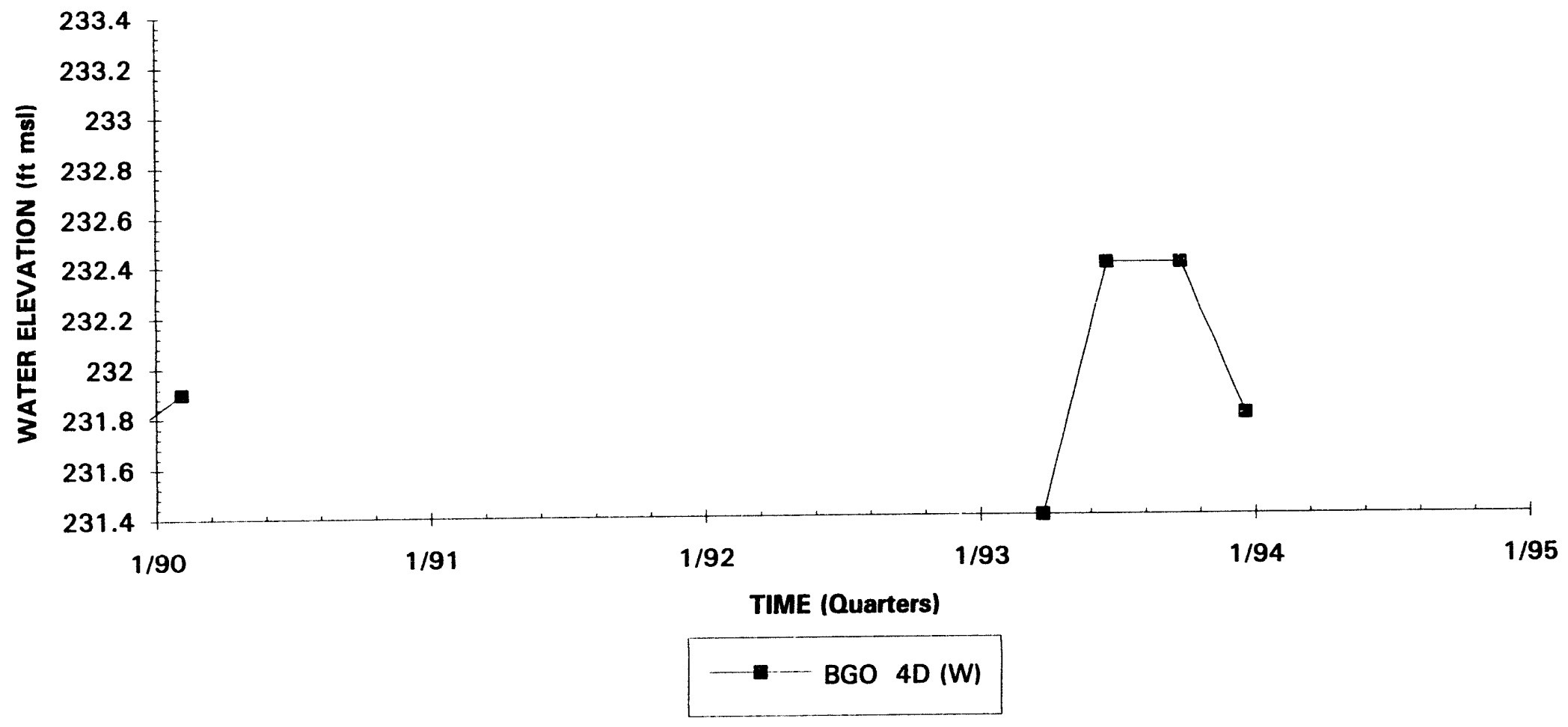

Note: $W=$ Water Table (IIB2); $B=$ Barnwell (IIB1); $M=$ MCBean (IIB1); UC = Upper Congaree (IIA); $M C=$ Middle Congaree (IIA); LC = Lower Congaree (IIA) 


\section{Hydrograph Well Cluster BGO 5}

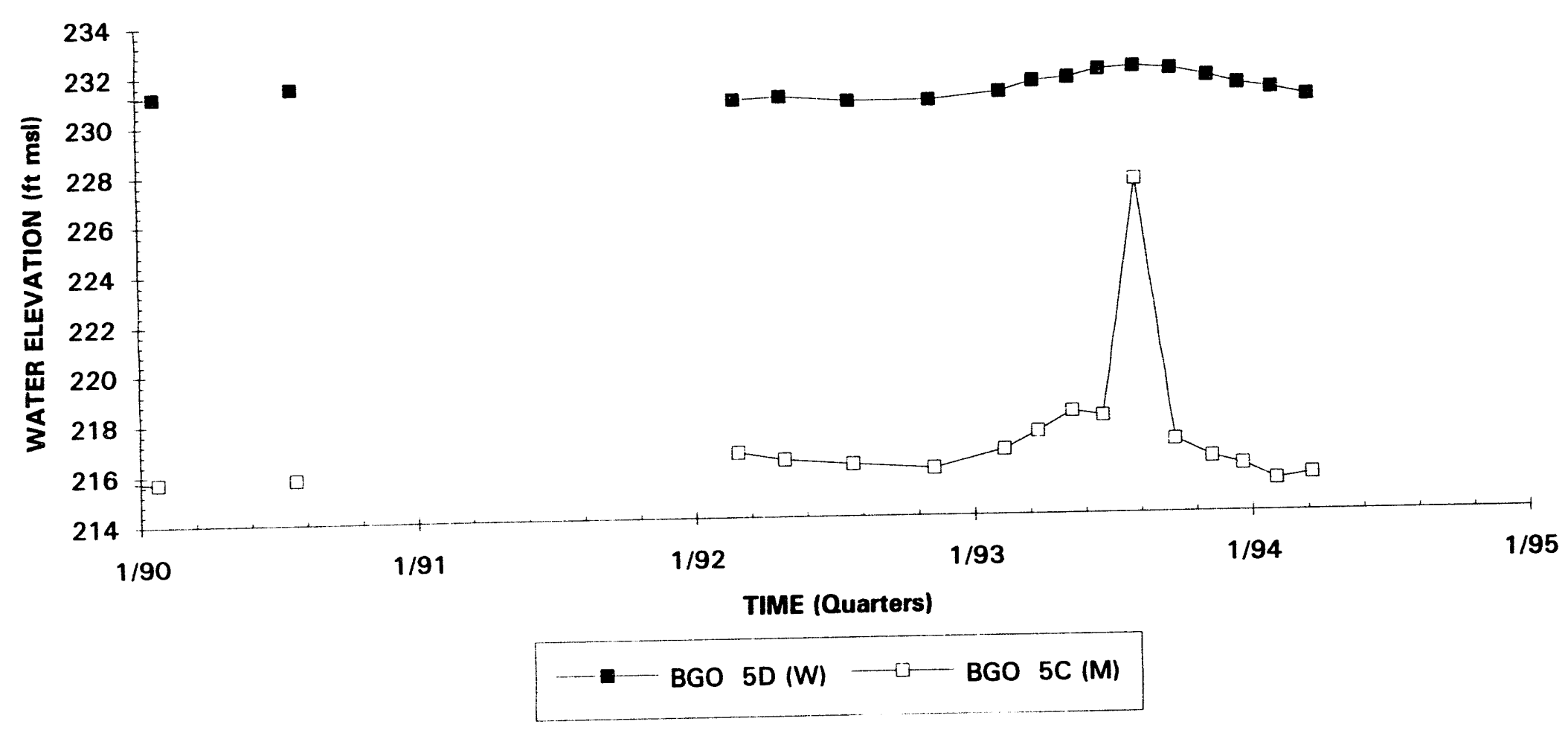




\section{Hydrograph}

Well Cluster BGO 6

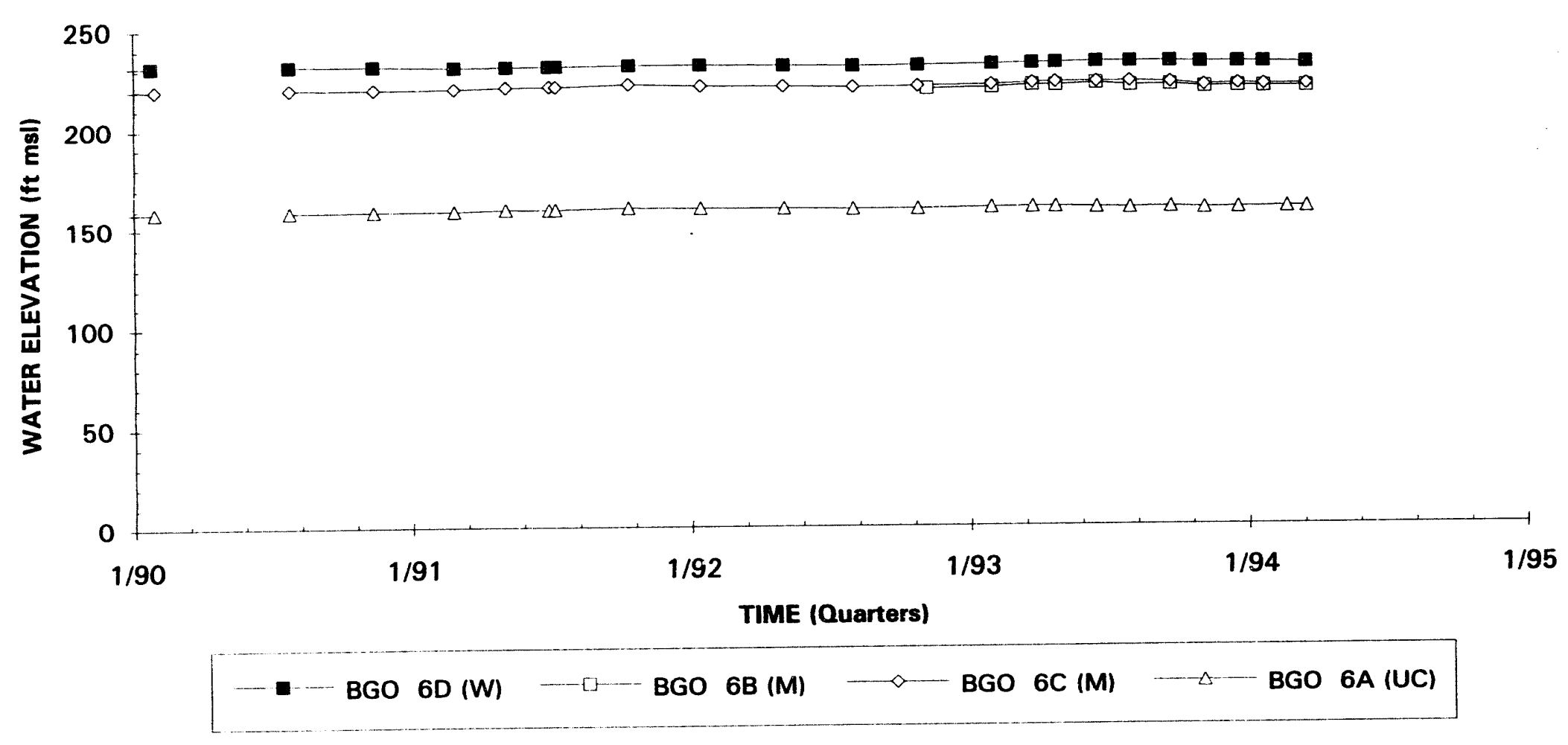

Note: $W=$ Water Table (IIB2); $B=$ Barnwell (IIB1); $M=$ McBean (IIB1); UC = Upper Congaree (IIA); $M C=$ Middle Congaree (IIA); LC=Lower Congaree (IIA) 


\section{Hydrograph}

Well BGO 7D

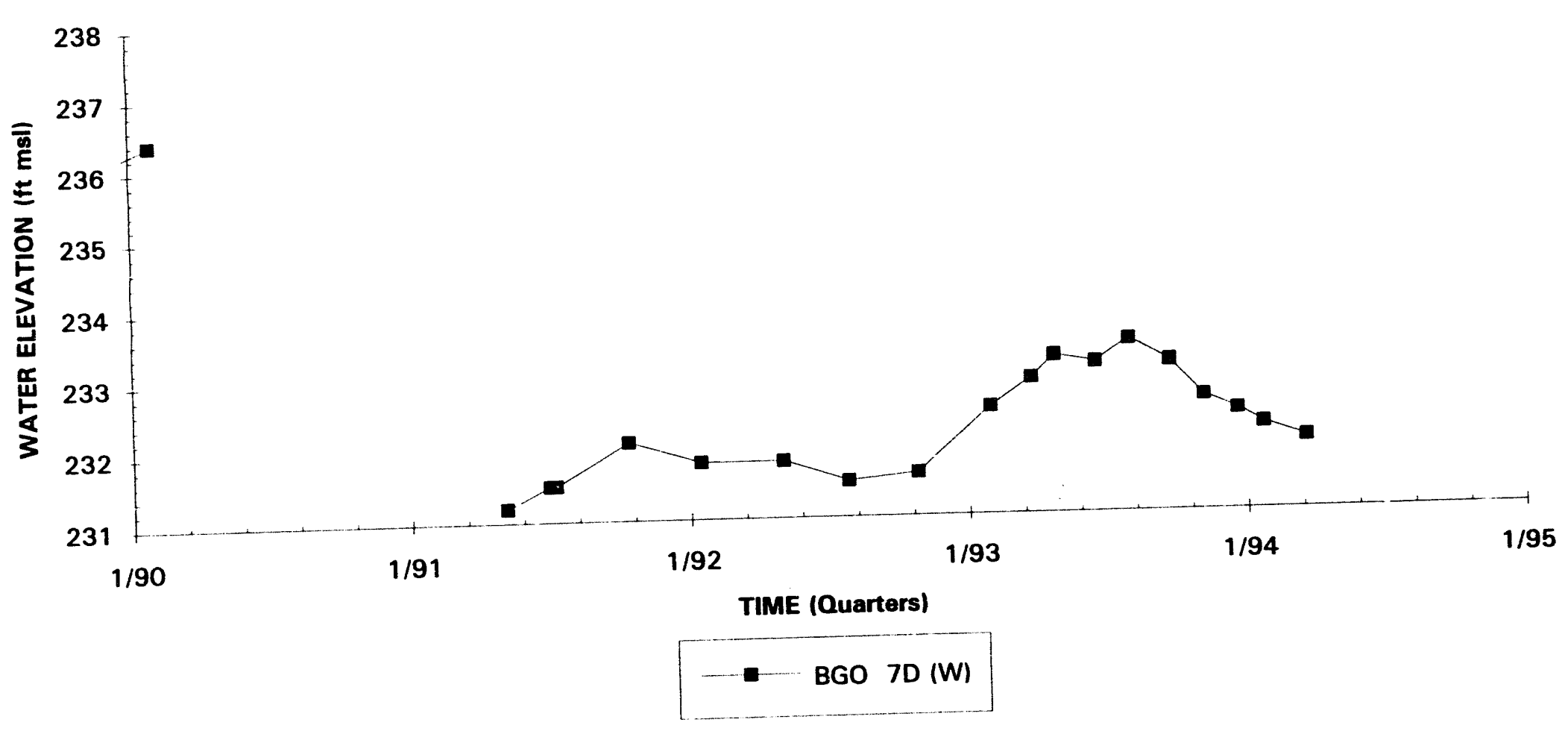

Note: $W=$ Water Table (IIB2); $B=$ Barnwell (IIB1); $M=M c B e a n$ (IIB1); UC=Upper Congaree (IIA); $M C=$ Middle Congaree (IIA); LC=Lower Congaree (IIA) 


\section{Hydrograph \\ Well Cluster BGO 8}

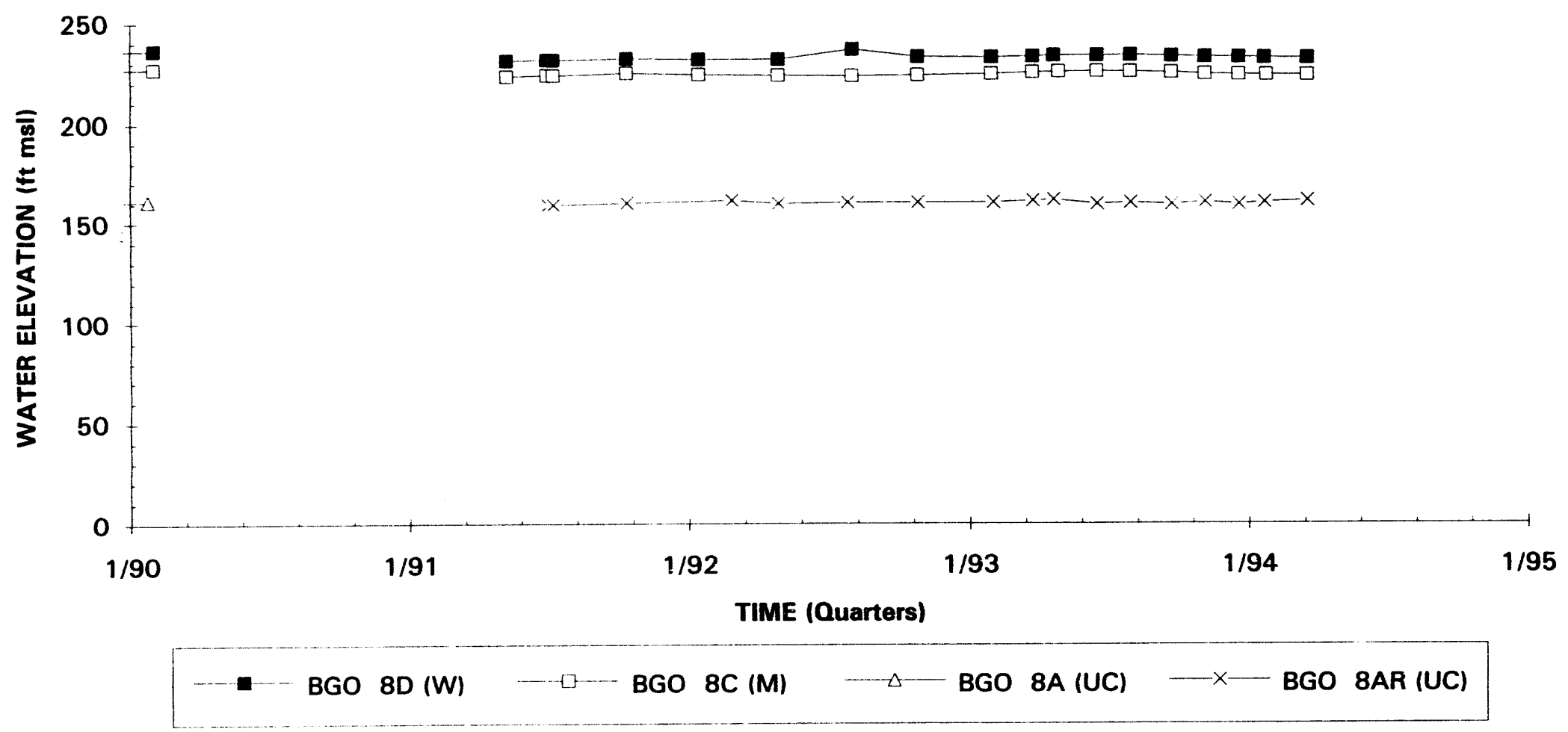

Note: $W=$ Water Table (IIB2); $B=$ Rarnwell (IIB1); $M=$ McBean (IIB1); UC = Upper Congaree (IIA); $M C=$ Middle Congaree (IIA); LC =Lower Congaree (IIA) 


\section{Hydrograph \\ Well Cluster BGO 9}

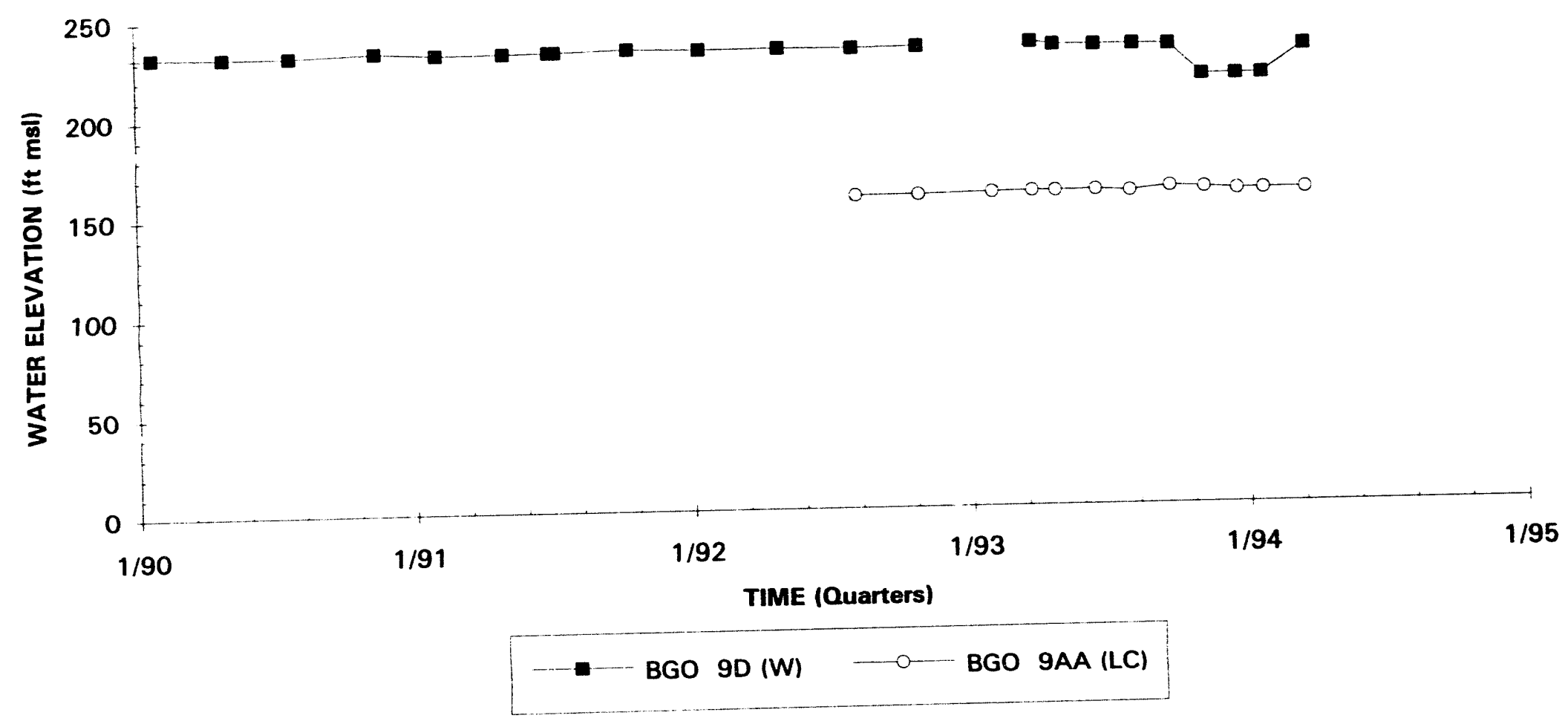




\section{Hydrograph \\ Well Cluster BGO 10}

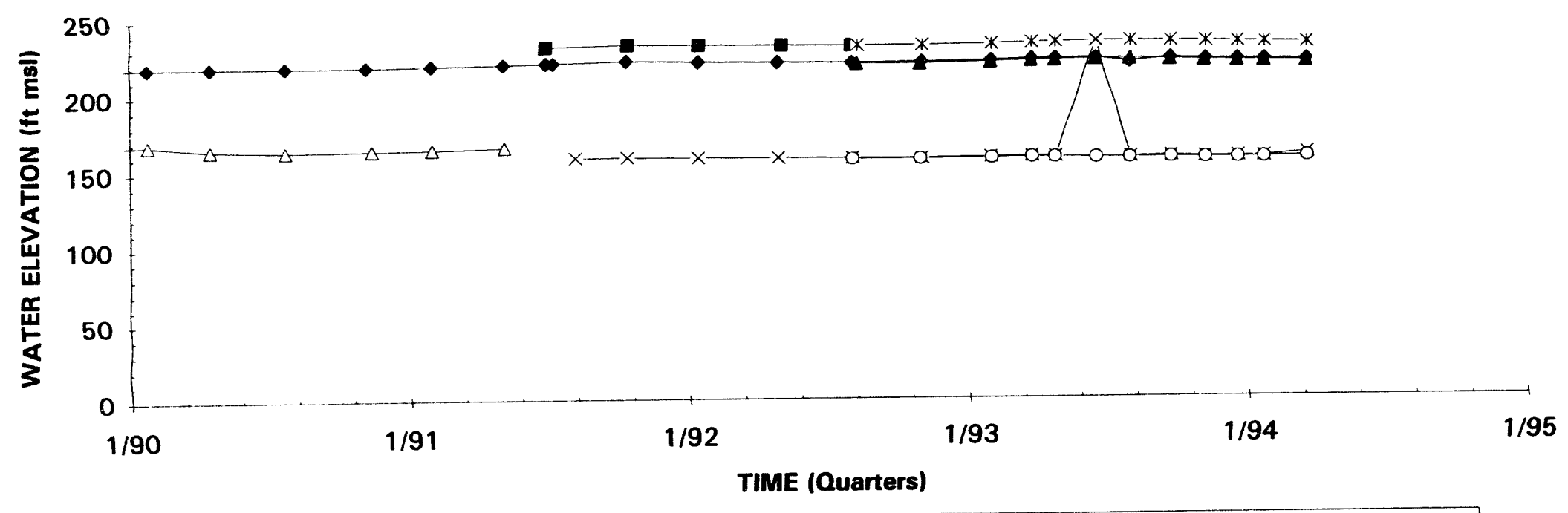

\begin{tabular}{|c|c|c|c|}
\hline$\ldots$ BGO 10D (W) & $-*-$ BGO 10DR (W) & $\ldots$ BGO $10 \mathrm{~B}(\mathrm{~B})$ & $\ldots$ BGO $10 \mathrm{C}(\mathrm{B})$ \\
\hline$\triangle \quad$ BGO 10A (UC) & $\begin{array}{c}-x-\text { BGO 10AR } \\
\text { (UC) }\end{array}$ & $\begin{array}{l}\text { BGO 10AA } \\
\text { (LC) }\end{array}$ & \\
\hline
\end{tabular}

Note: $W=$ Water Table (IIB2); $B=$ Barnwell (IIB1); $M=$ McBean (IIB1); UC = Upper Congaree (IIA); MC = Middle Congaree (IIA); LC=Lower Congaree (IIA) 


\section{Hydrograph}

Well BGO 11D

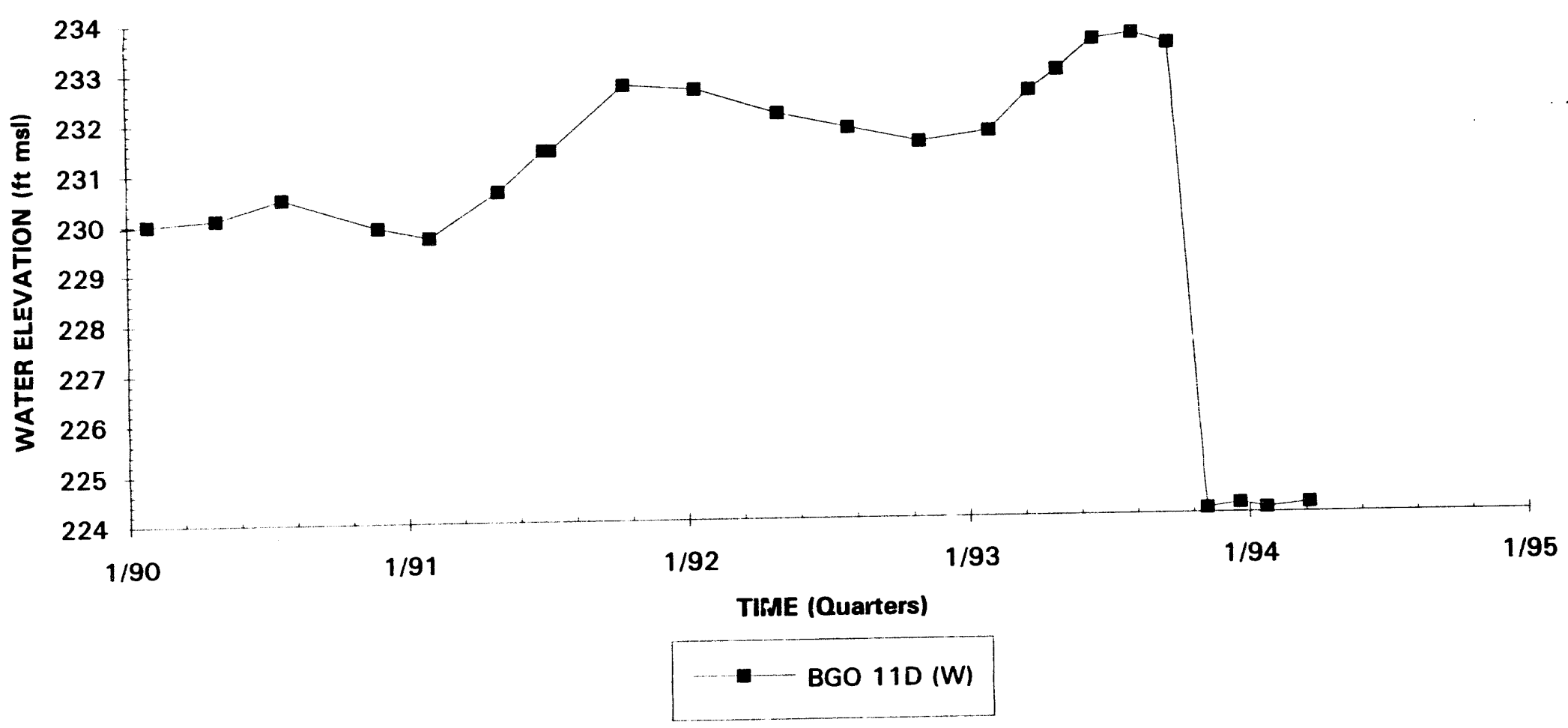




\section{Hydrograph \\ Well Cluster BGO 12}

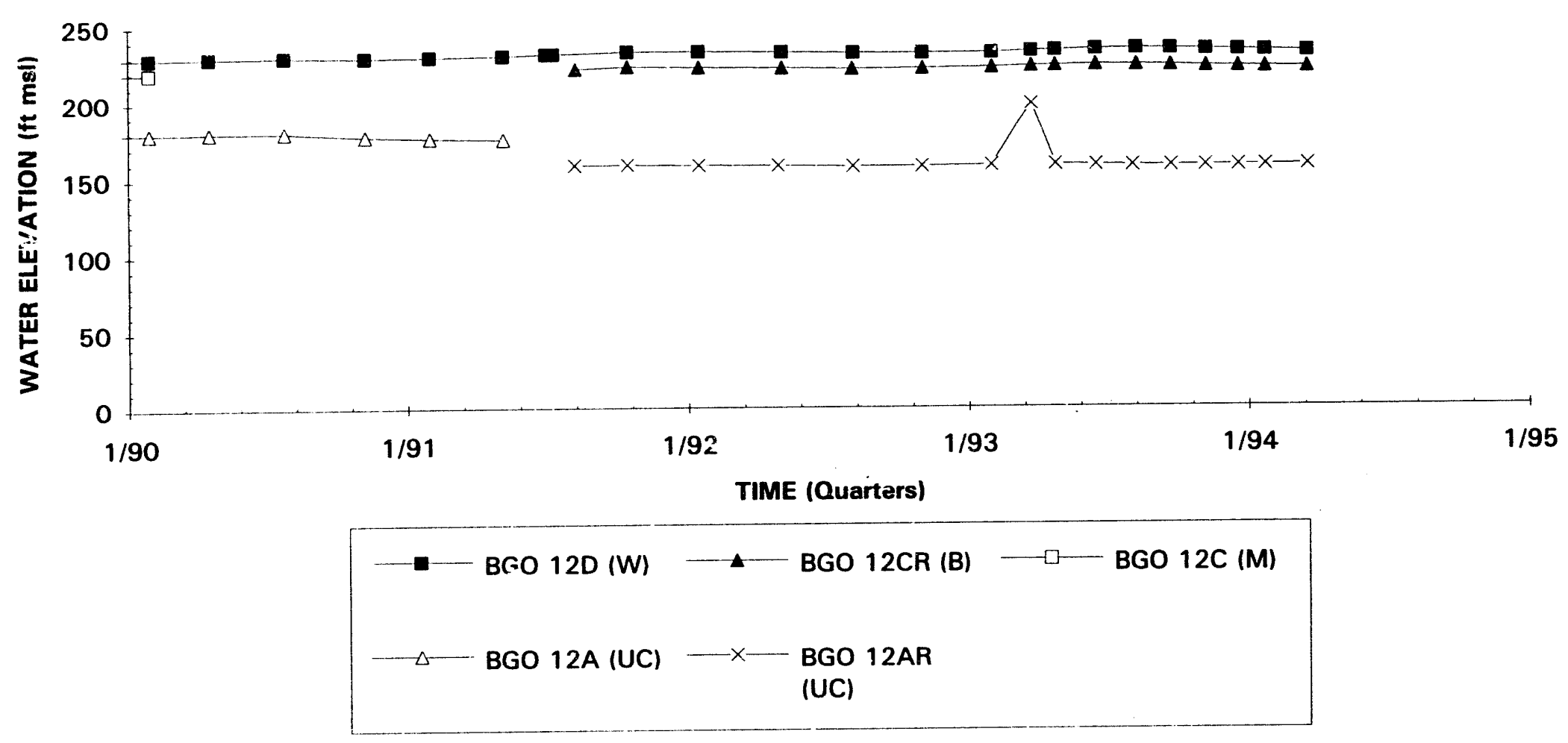

Note: $W=$ Water Table (IIB2); $B=$ Barnwell (IIB1); $M=M c B e a n$ (IIB1); UC=Upper Congaree (IIA); $M C=$ Middle Congaree (IIA); LC=Lower Congaree (IIA) 


\section{Hydrograph \\ Well Cluster BGO 13}

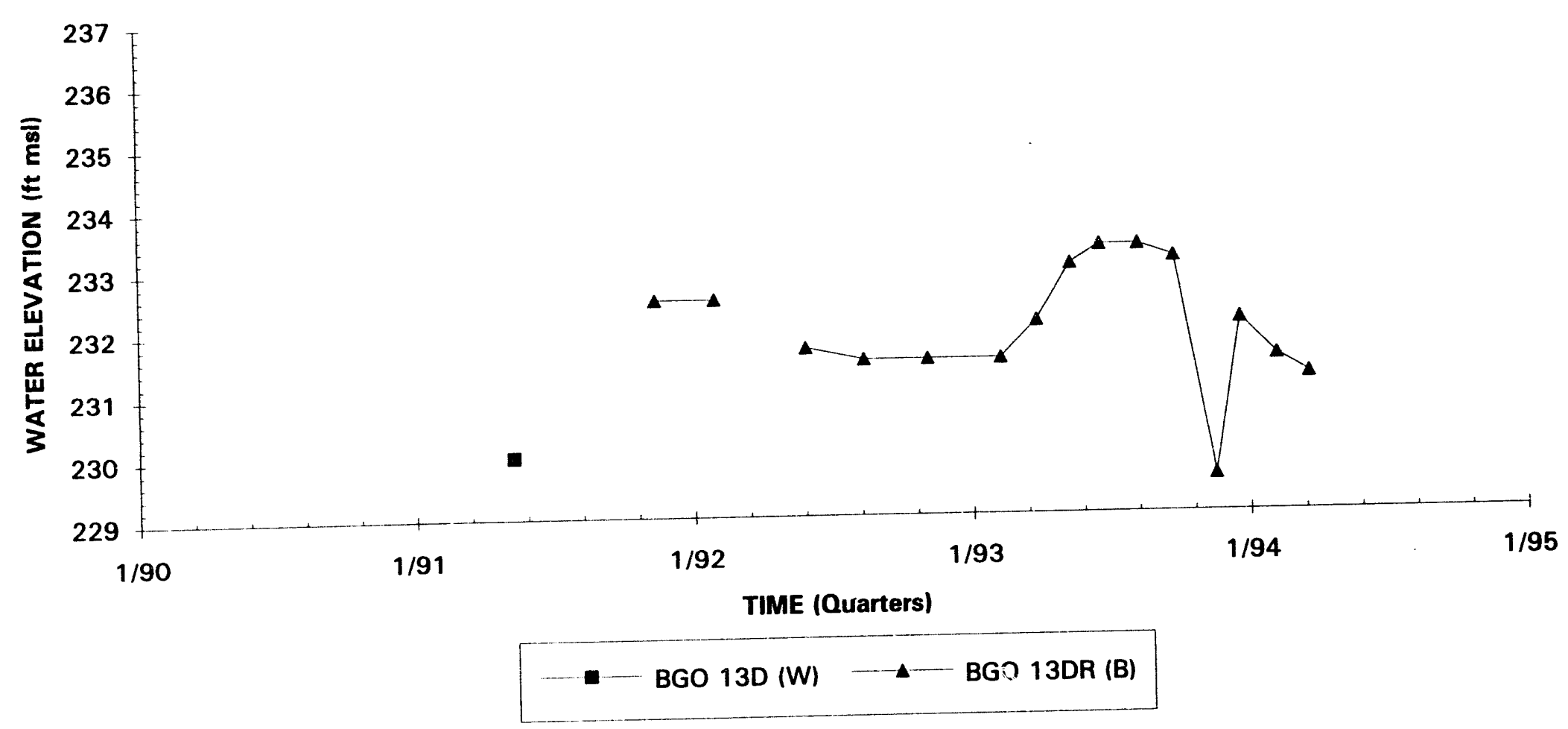

Tanell (IIB1); $M=M c B e a n$ (IIB1); UC=Upper Congaree (IIA); $M C=$ Middle Congaree (IIA); LC=Lower Congaree (IIA) 


\section{Hydrograph Well Cluster BGO 14}

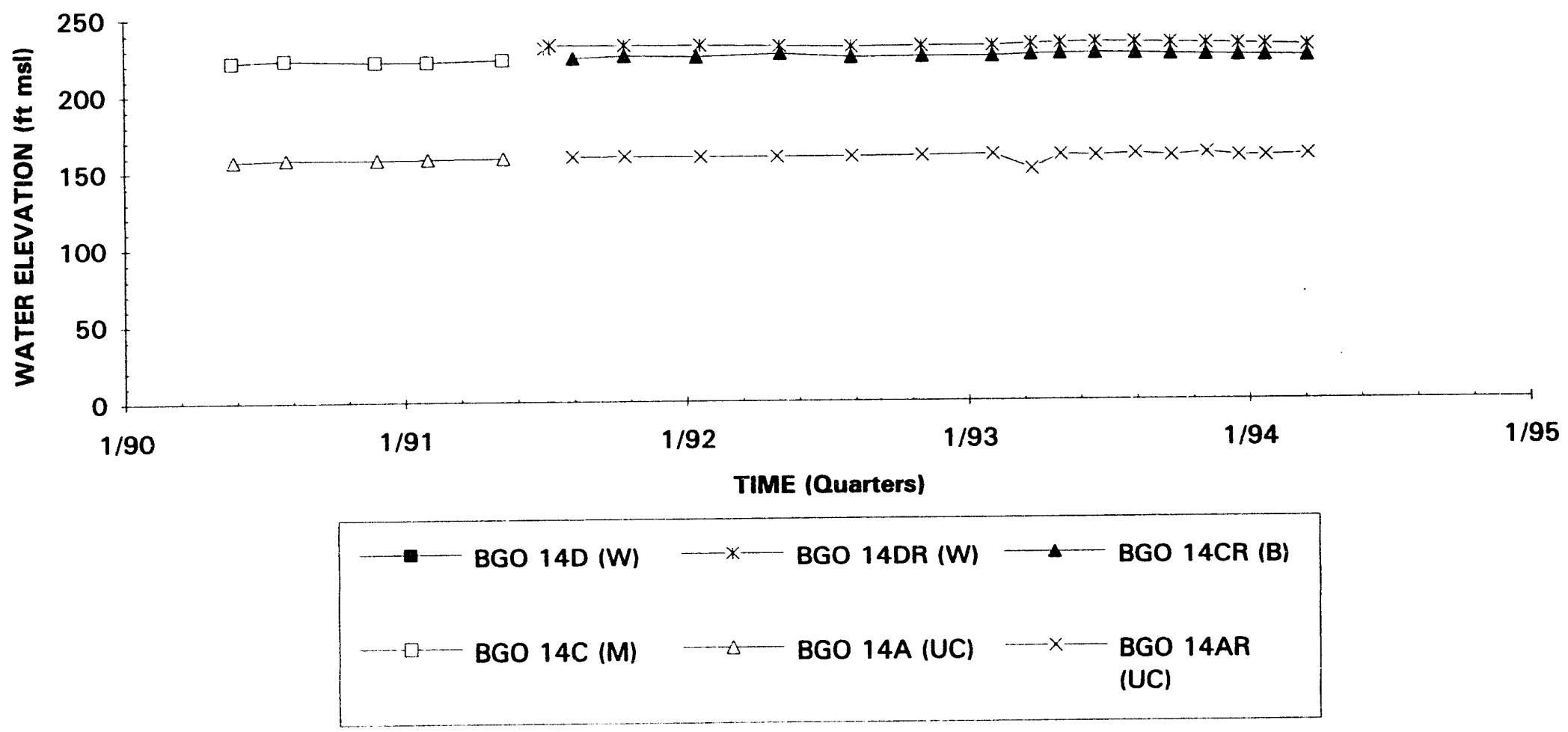

Note: $W=$ Water Table (IIB2); $B=$ Barnwell (IIB1); $M=$ McBean (IIB1); UC=Upper Congaree (IIA); $M C=$ Middle Congaree (IIA); LC=Lower Congaree (IIA) 


\section{Hydrograph}

\section{Well BGO 15D}

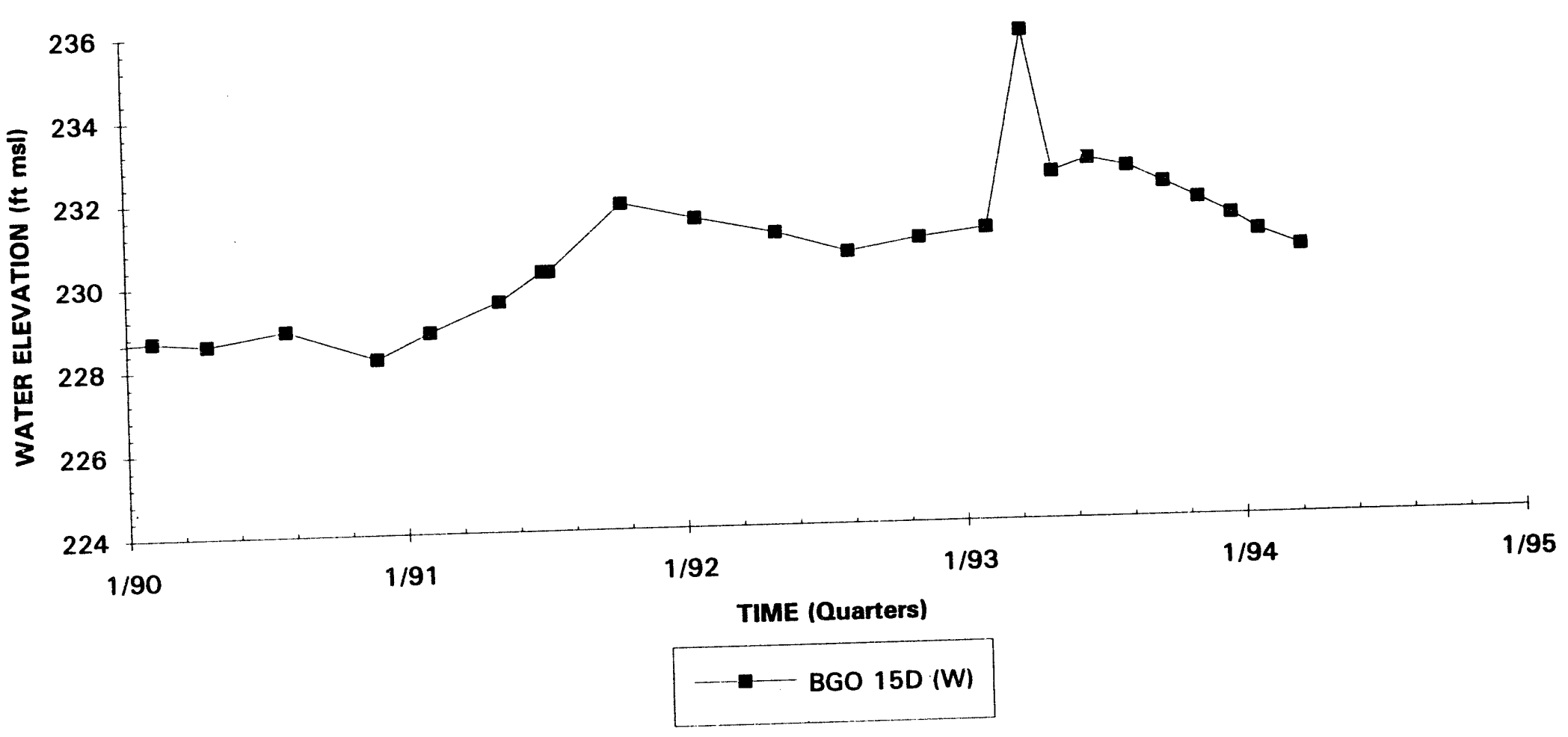

Note: $W=$ Water Table (IIB2); $B=$ Barnwell (IIB1); $M=M c B e a n$ (IIB1); UC=Upper Congaree (IIA); $M C=$ Middle Congaree (IIA); LC=Lower Congaree (IIA) 


\section{Hydrograph \\ Well Cluster BGO 16}

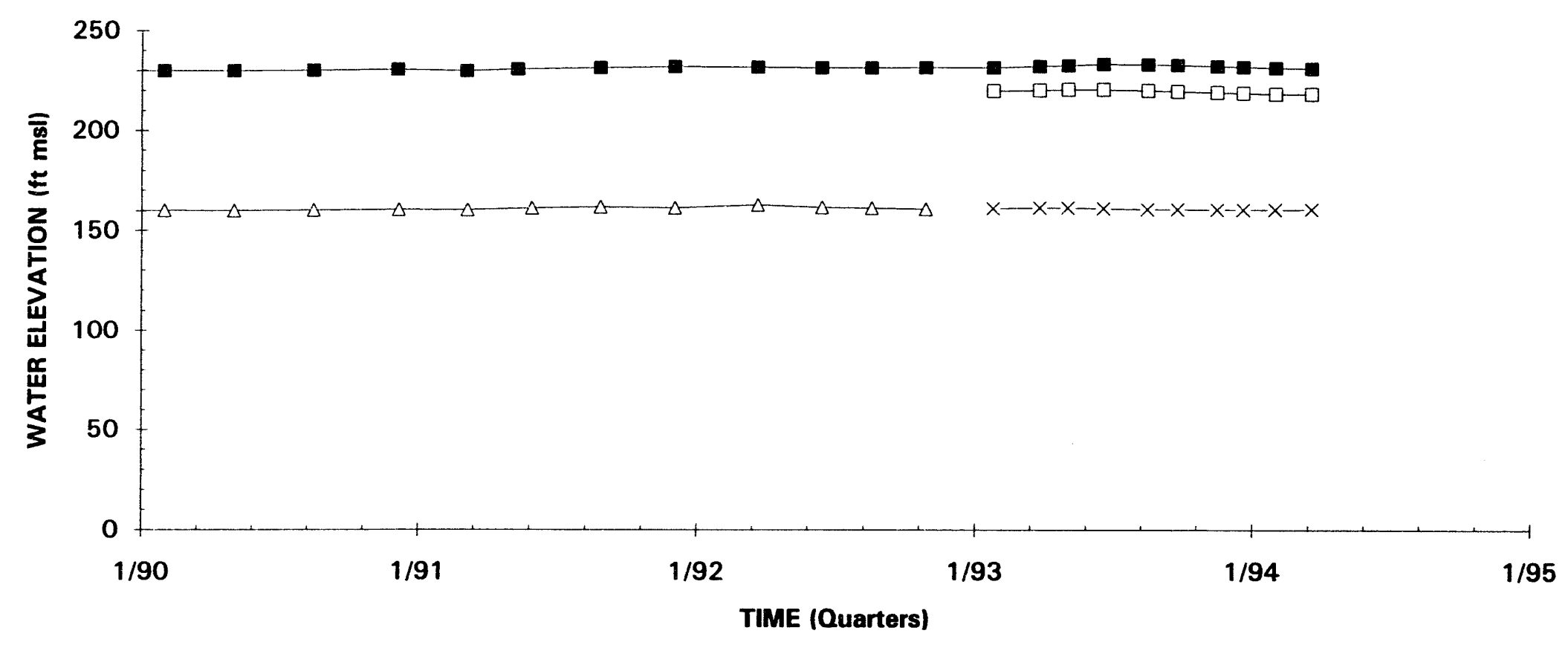

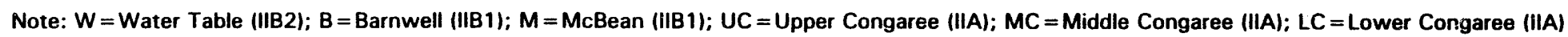




\section{Hydrograph \\ Well Cluster BGO 17}

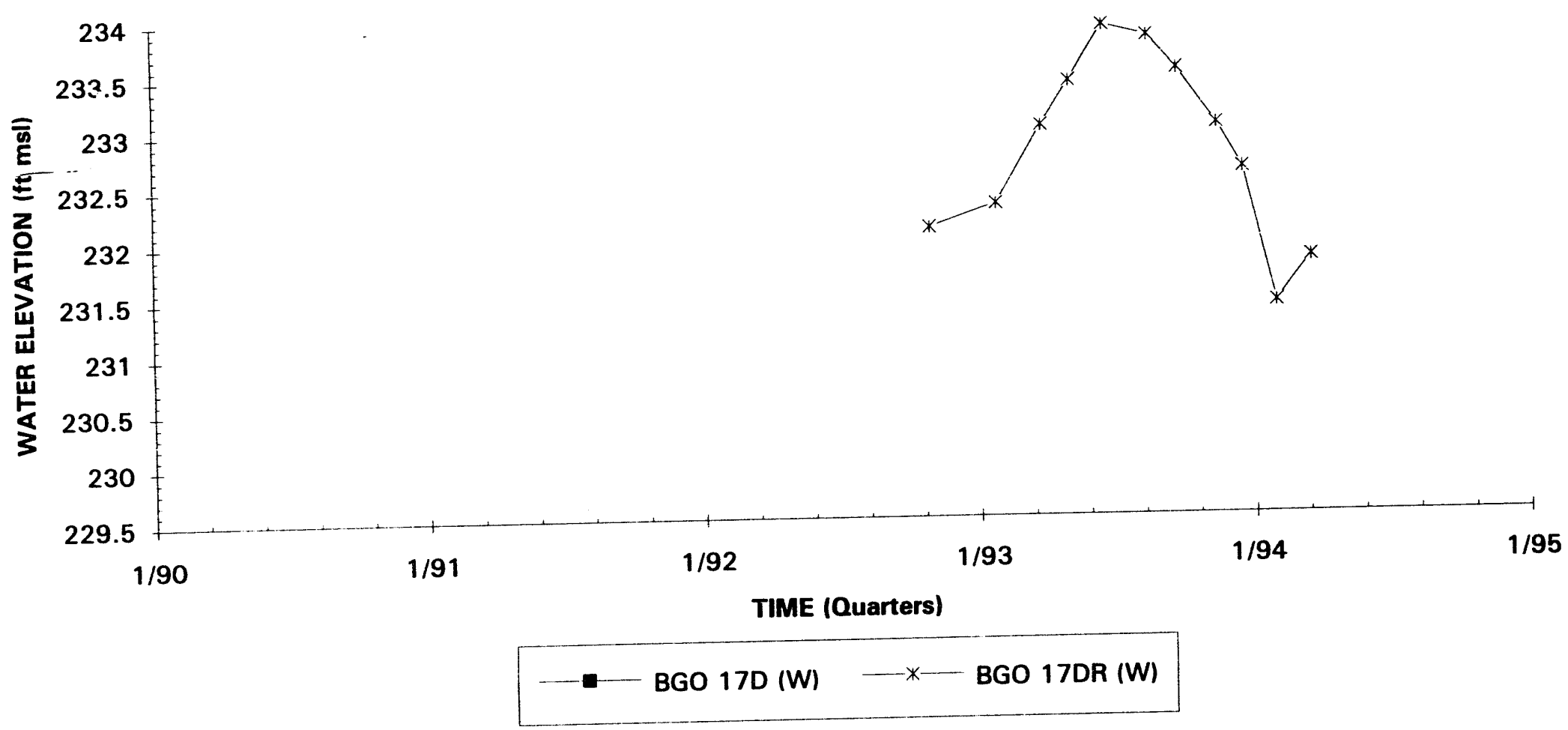

Not 


\section{Hydrograph \\ Well Cluster BGO 18}

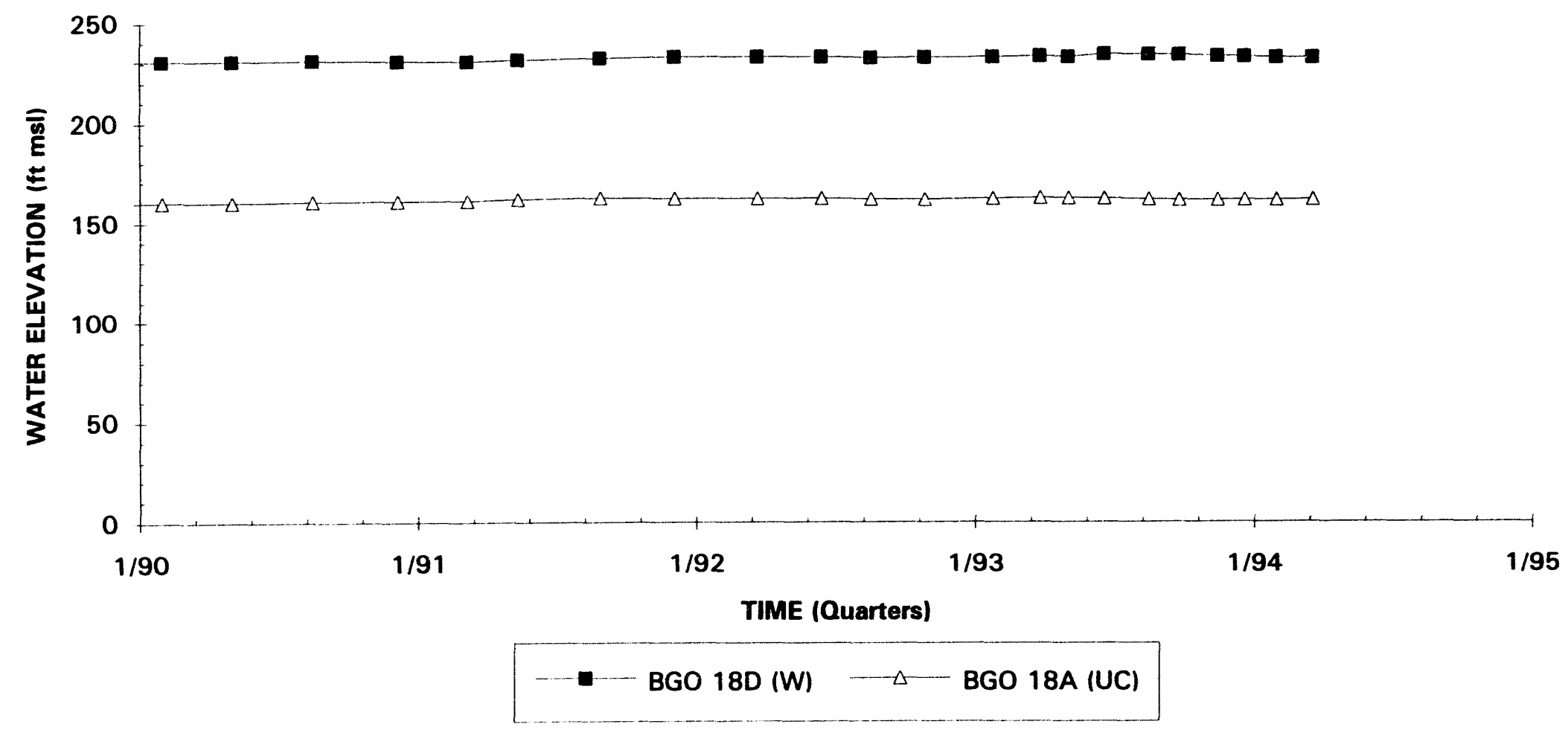

Note: $W=$ Water Table (IIB2); $B=$ Barnwell (IIB1); $M=$ McBean (IIB1); UC = Upper Congaree (IIA); $M C=$ Middle Congaree (IIA); LC = Lower Congaree (IIA) 


\section{Hydrograph}

Well BGO 19D

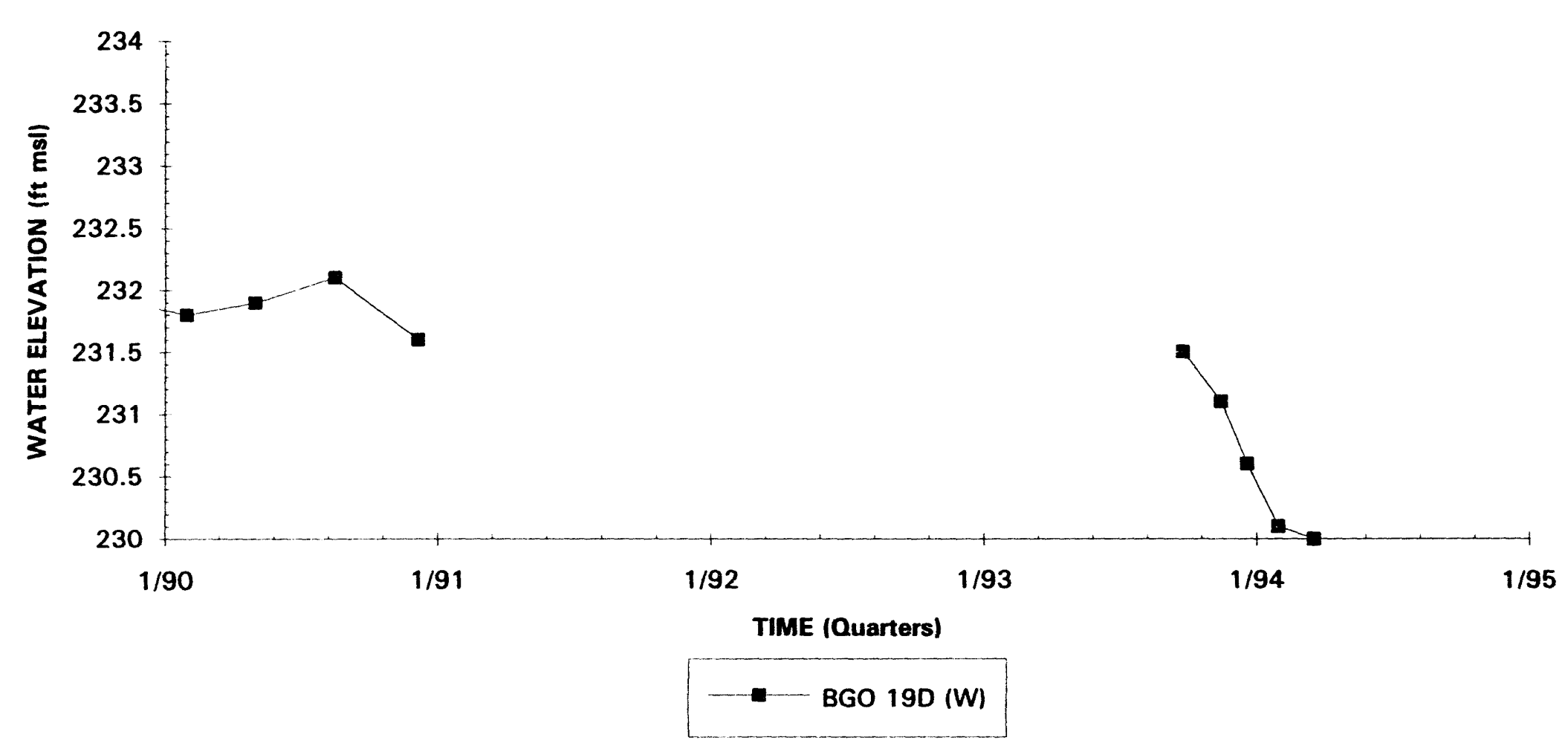

Note: $W=$ Water Table (IIB2); $B=$ Barnwell (IIB1); $M=$ McBean (IIB1); UC = Upper Congaree (IIA); $M C=$ Middle Congaree (IIA); $L C=L o w e r$ Congaree (IIA) 


\section{Hydrograph}

\section{Well BGO 20D}

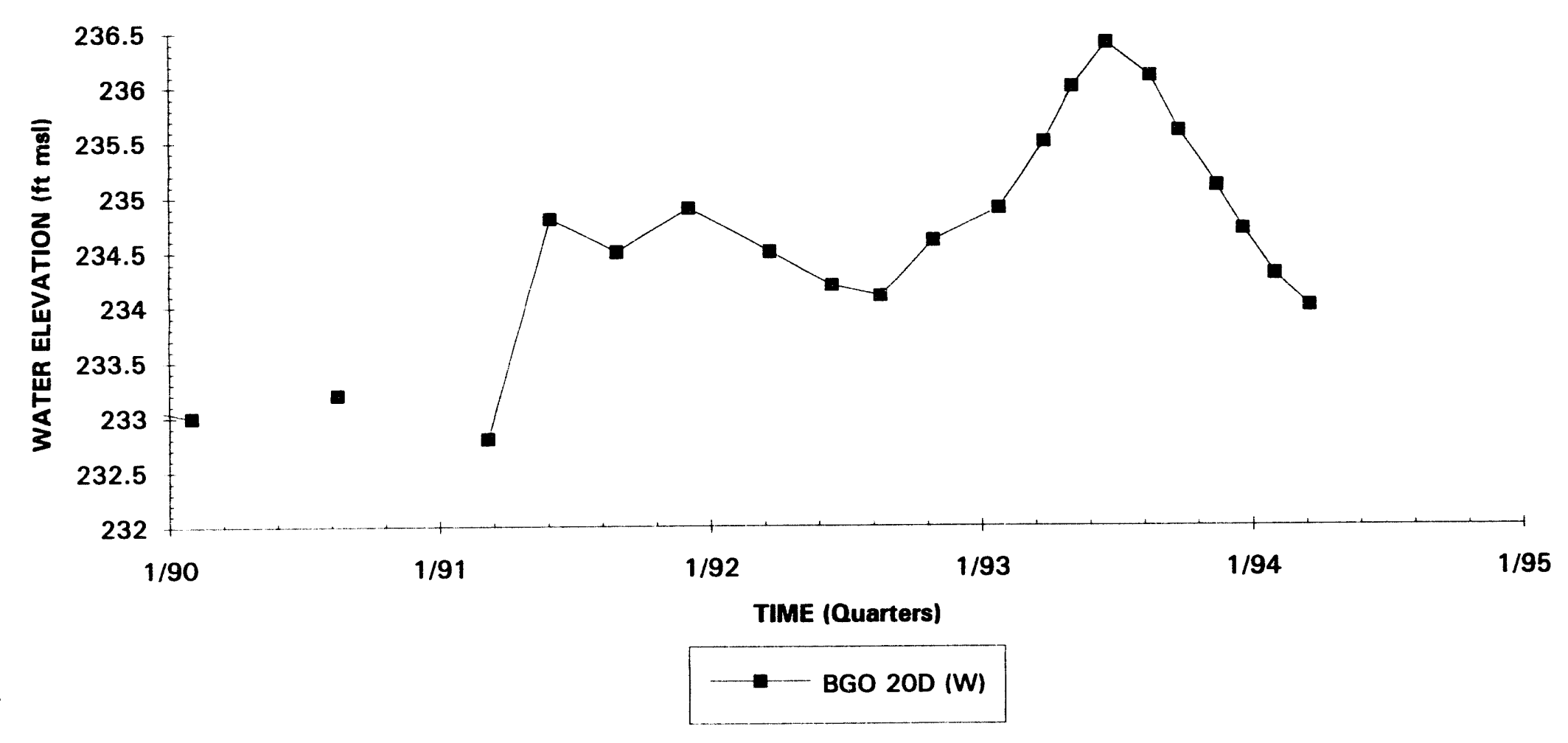

Note: $W=$ Water Table (IIB2); $B=$ Barnwell (IIB1); $M=$ McBean (IIB1); UC = Upper Congaree (IIA); $M C=$ Middle Congaree (IIA); LC = Lower Congaree (IIA) 


\section{Hydrograph}

Well BGO 21D

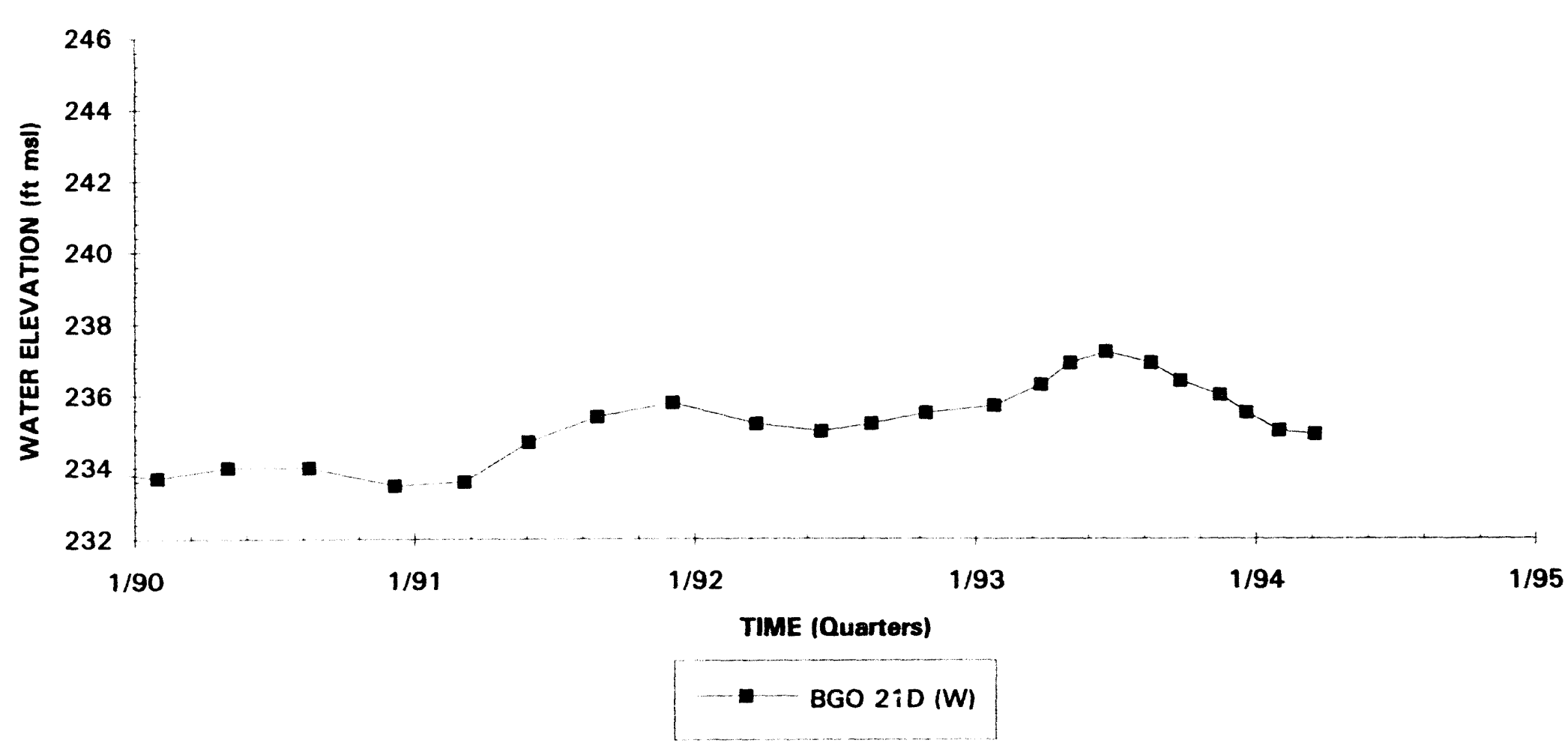

Note: $W=$ Water Table (IIB2); $B=$ Barnwell (IIB1); $M=$ McBean (IIB1); UC=Upper Congaree (IIA); MC = Middle Congaree (IIA); LC=Lower Congaree (IIA) 


\section{Hydrograph \\ Well Cluster BGO 22}

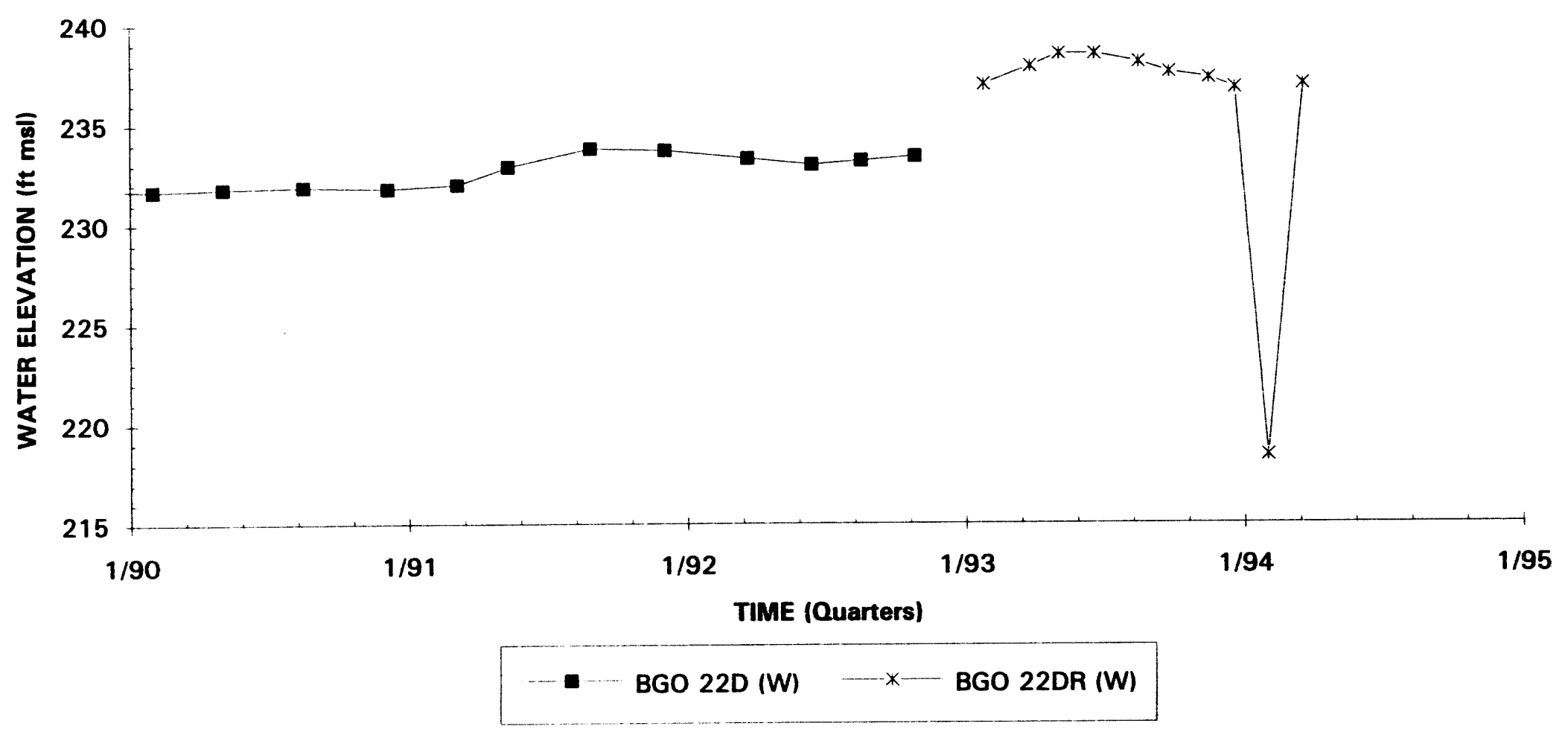

Note: $W=$ Water Table (IIB2); $B=$ Barnwell (IIB1); $M=$ MCBean (IIB1); UC=Upper Congaree (IIA); $M C=$ Middle Congaree (IIA); LC=Lower Congaree (IIA) 


\section{Hydrograph}

\section{Well BGO 23D}

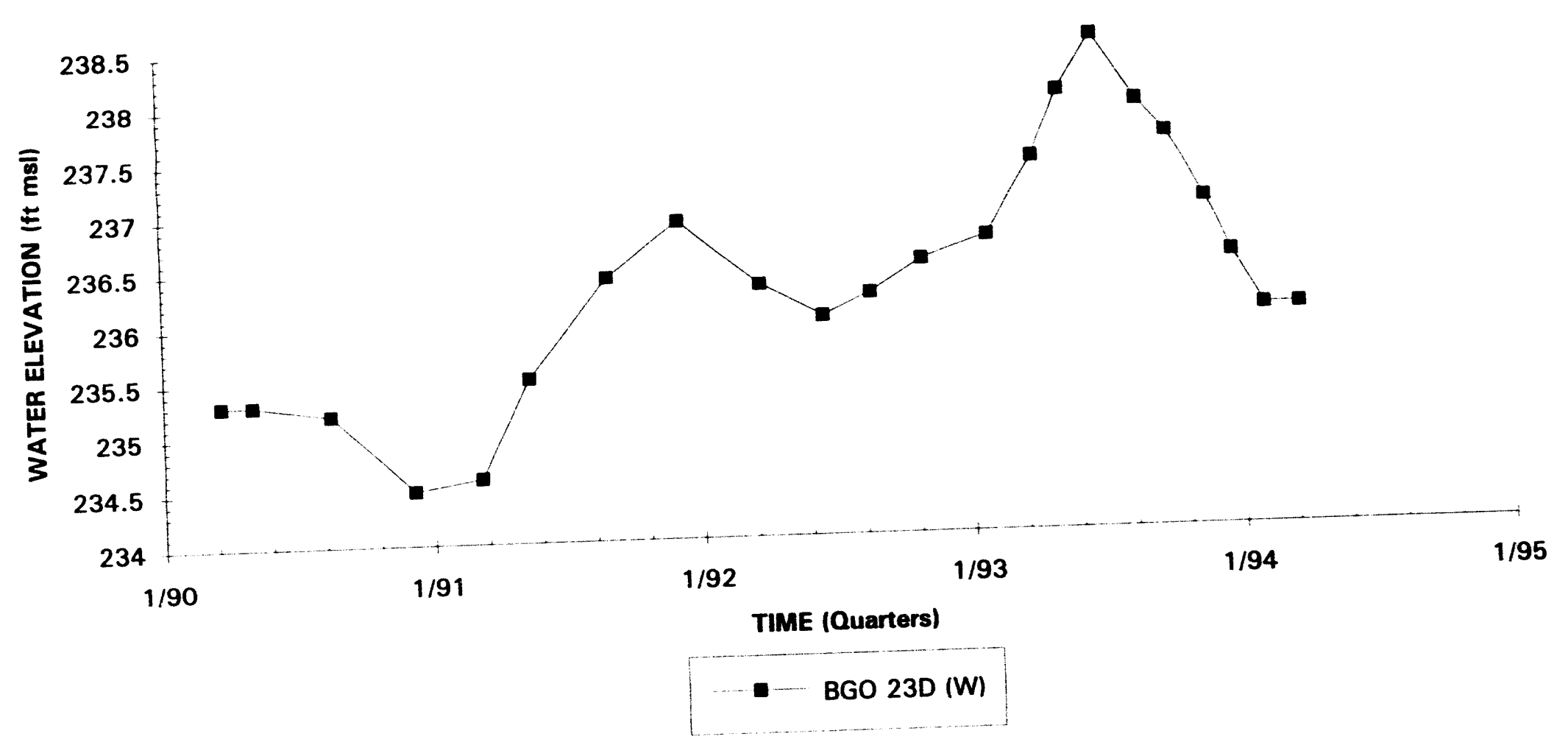

Note: $W=$ Water Table (IIB2); $B=$ Barnwell (IIB1); $M=$ McBean (IIB1); UC=Upper Congaree (IIA); MC=Middle Congaree (IIA); LC=Lower Congaree (IIA) 


\section{Hydrograph \\ Well BGO 24D}

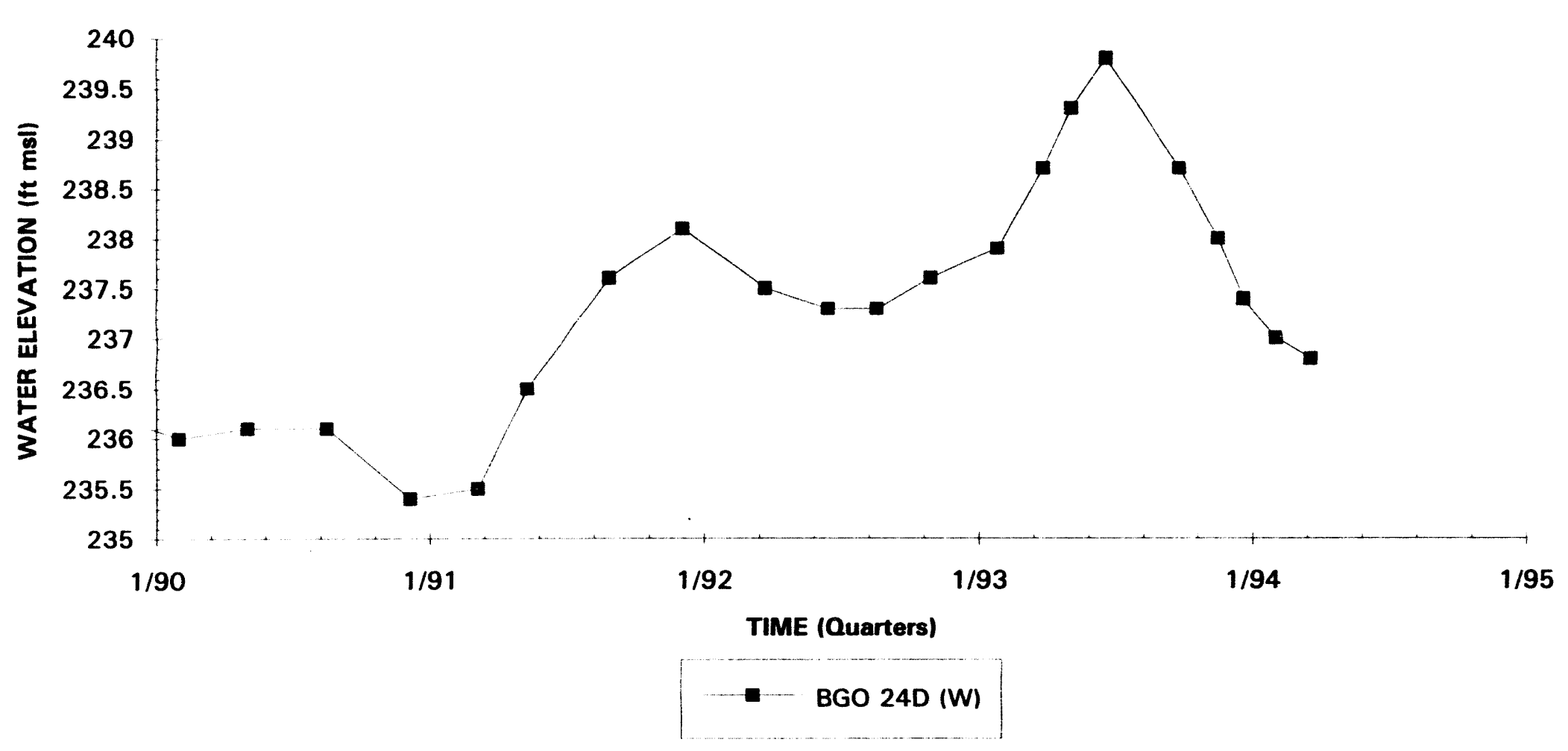

Note: $W=$ Water Table (IIB2); $B=$ Barnwell (IIB1); $M=$ McBean (IIB1); UC = Upper Congaree (IIA); $M C=$ Middle Congaree (IIA); LC =Lower Congaree (IIA) 


\section{Hydrograph \\ Well BGO 25A}

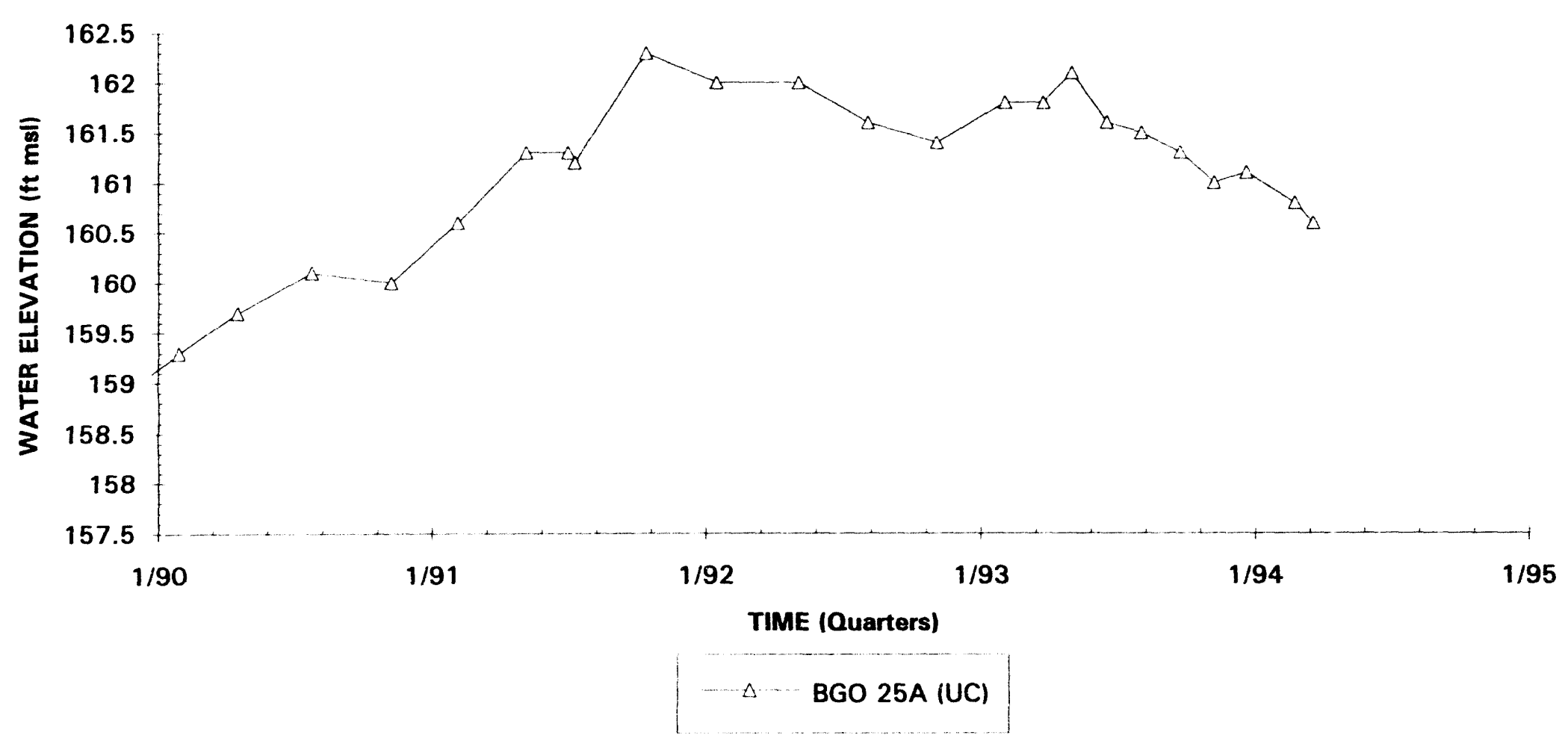

Note: $W=$ Water Table (IIB2); $B=$ Barnwell (IIB1); $M=$ McBean (IIB1); UC=Upper Congaree (IIA); $M C=$ Middle Congaree (IIA); LC=Lower Congaree (IIA) 


\section{Hydrograph \\ Well Cluster BGO 26}

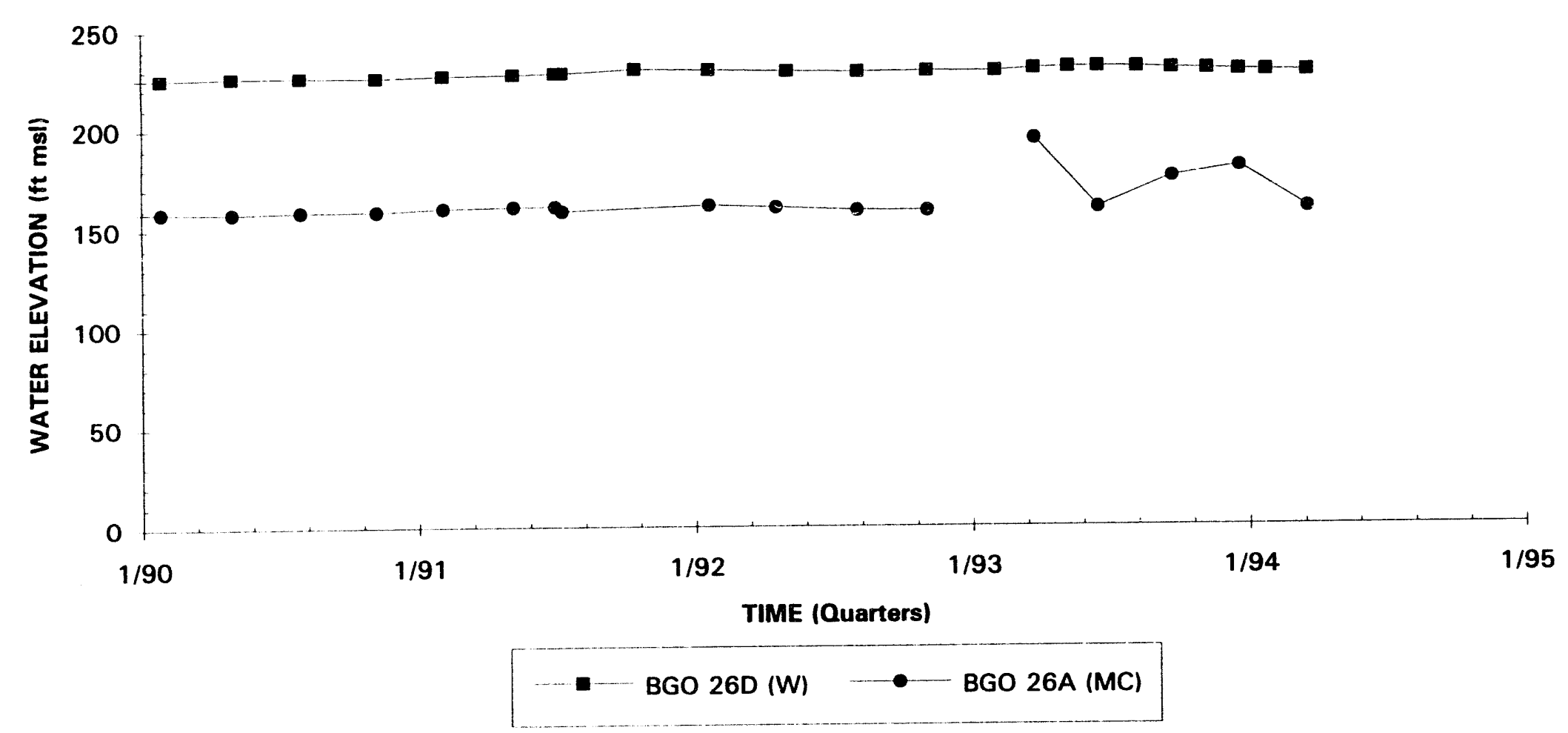

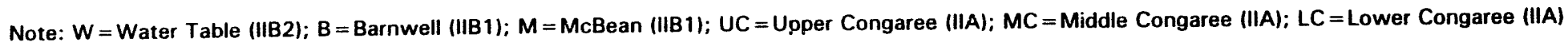




\section{Hydrograph \\ Well Cluster BGO 27}

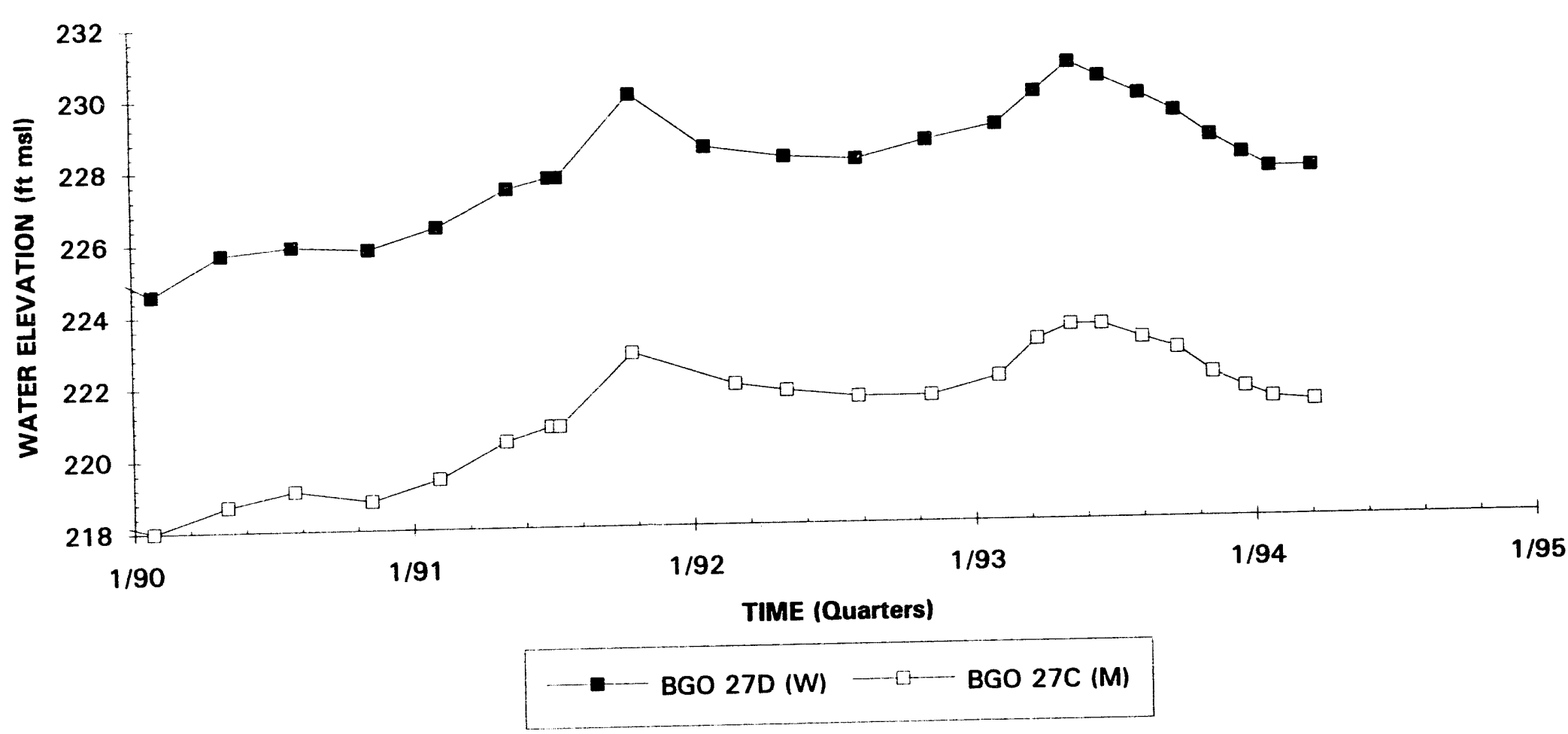

Noter $W=$ Water Table (IIB2): $B=$ Barnwell (IIB1); $M=$ McBean (IIB 1); UC=Upper Congaree (IIA); $M C=$ Middle Congaree (IIA); LC = Lower Congaree (IIA) 


\section{Hydrograph}

Well BGO 28D

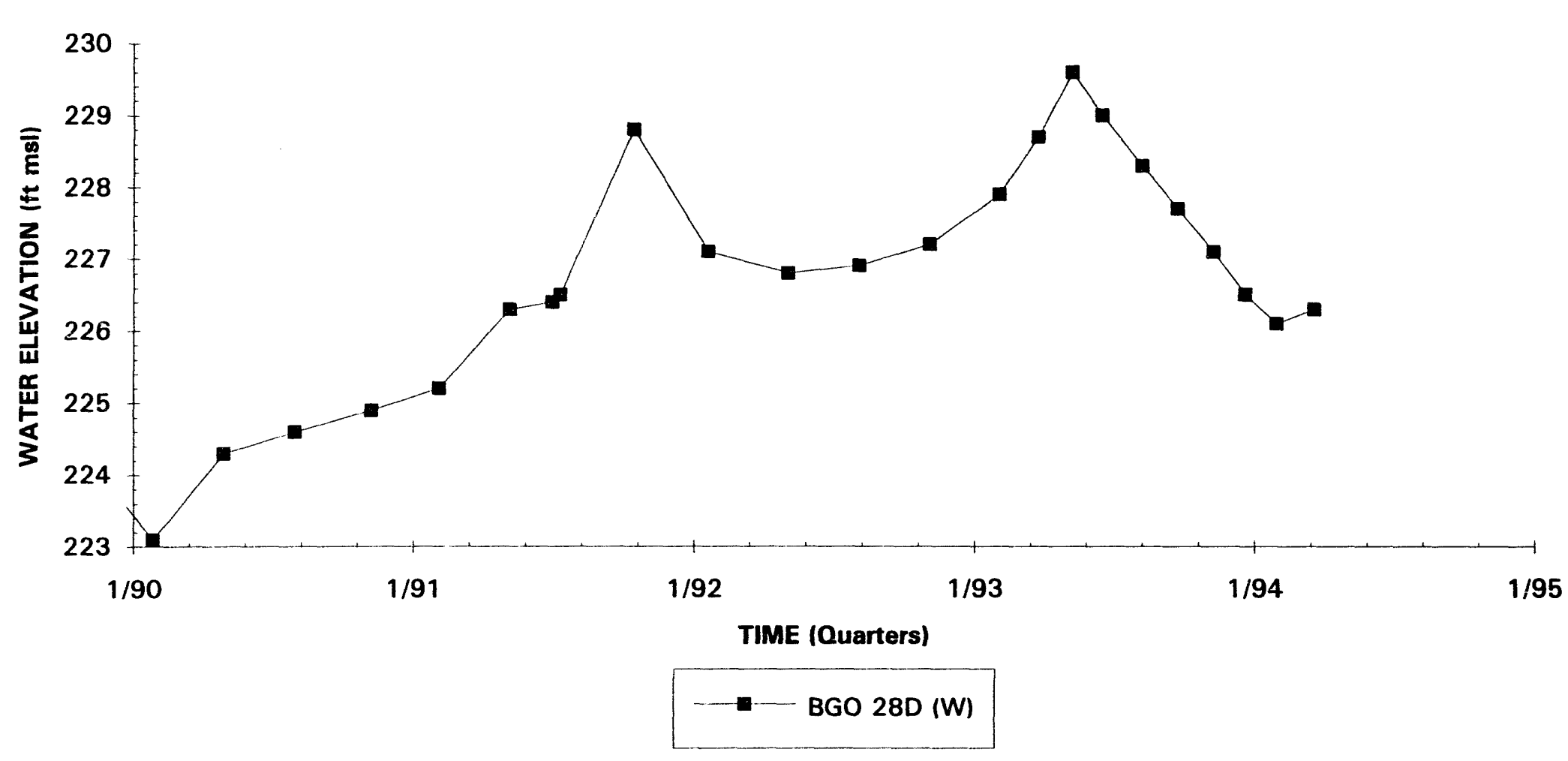

Note: $W=$ Water Table (IIB2); $B=$ Barnwell (IIB1); $M=$ McBean (IIB1); UC=Upper Congaree (IIA); $M C=$ Middle Congaree (IIA); LC=Lower Congaree (IIA) 


\section{Hydrograph \\ Well Cluster BGO 29}

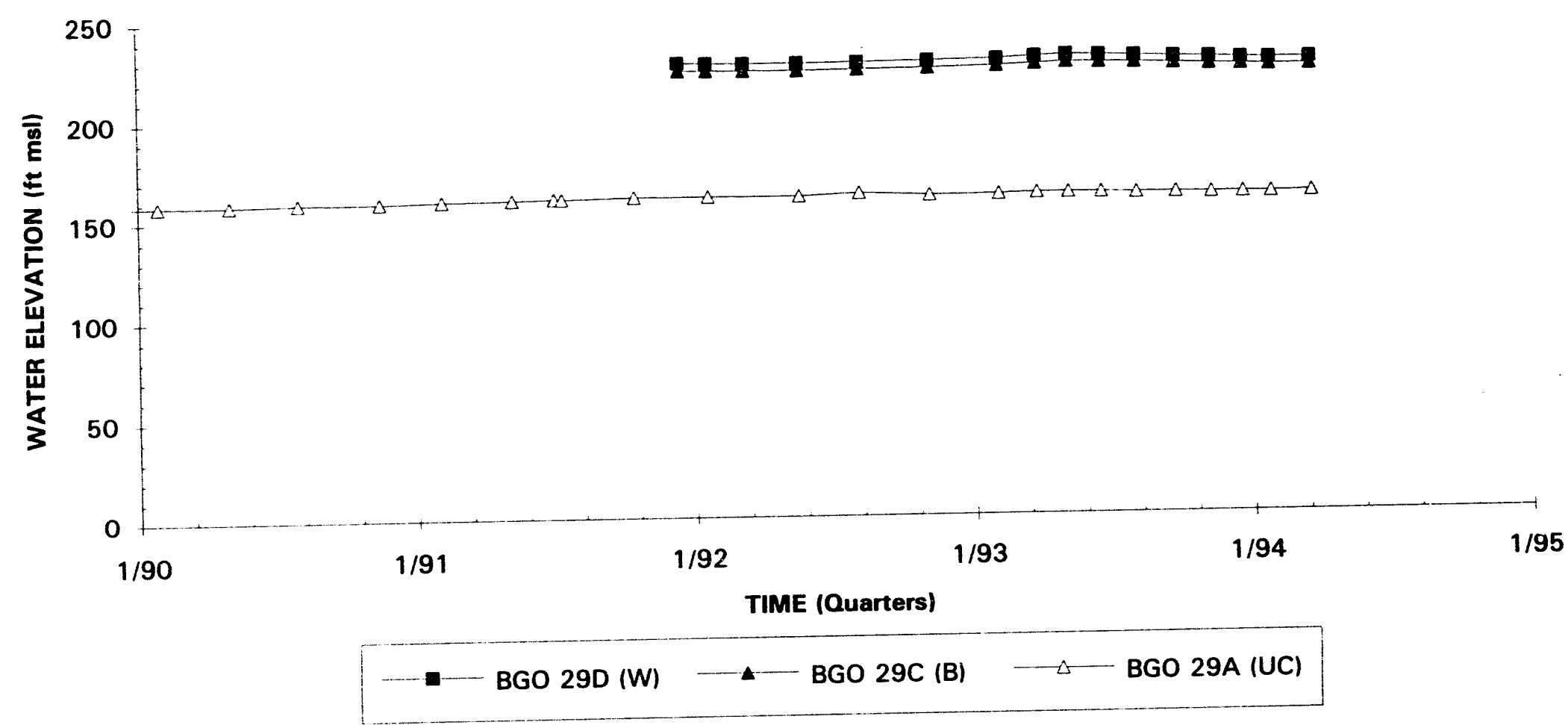

(III 


\section{Hydrograph \\ Well Cluster BGO 30}

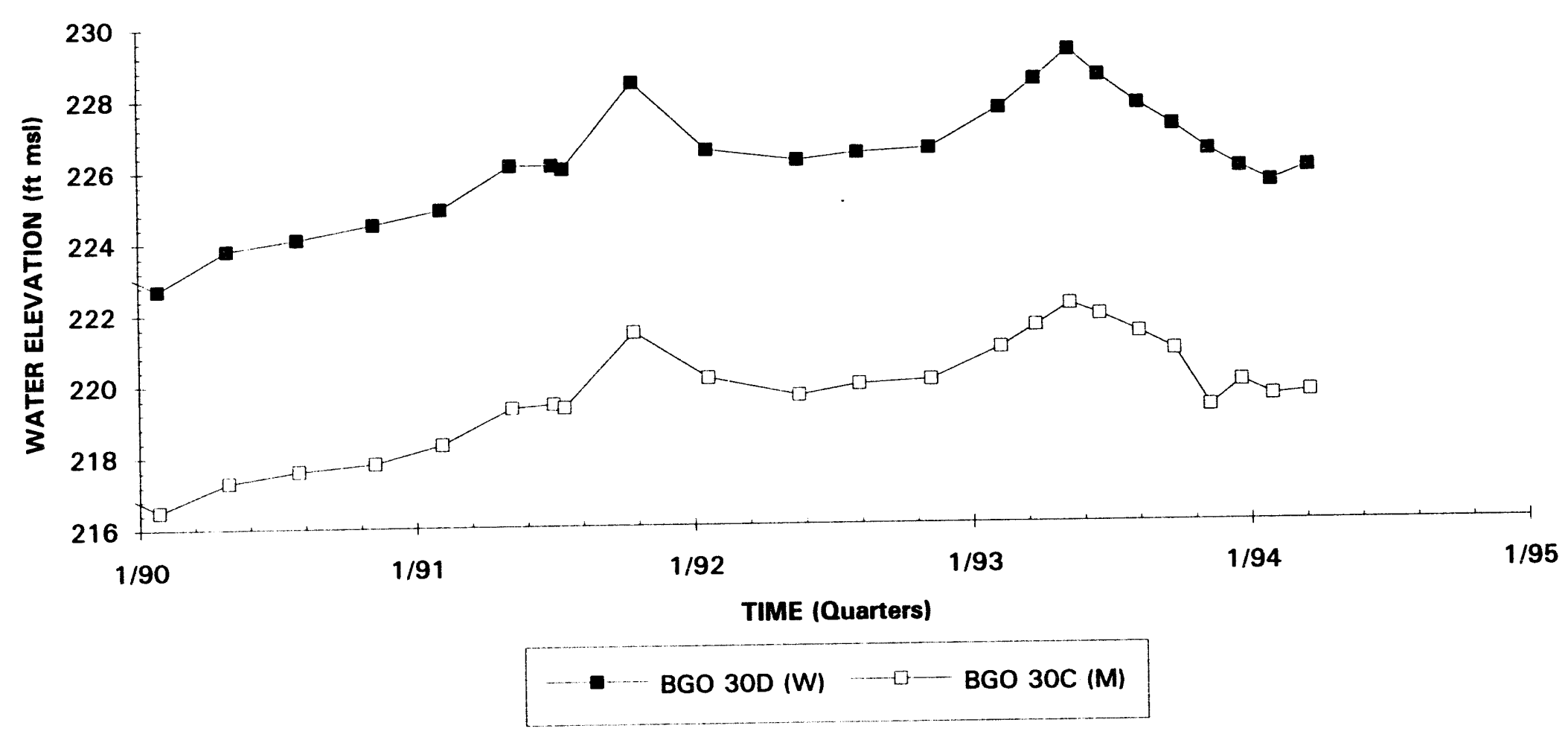

Note: $W=$ Water Table (IIB2); $B=$ Barnwell (IIB1); $M=M c B e a n$ (IIB1); $U C=$ Upper Congaree (IIA); $M C=$ Middle Congaree (IIA); $L C=L o w e r$ Congaree (IIA) 


\section{Hydrograph \\ Well Cluster BGO 31}

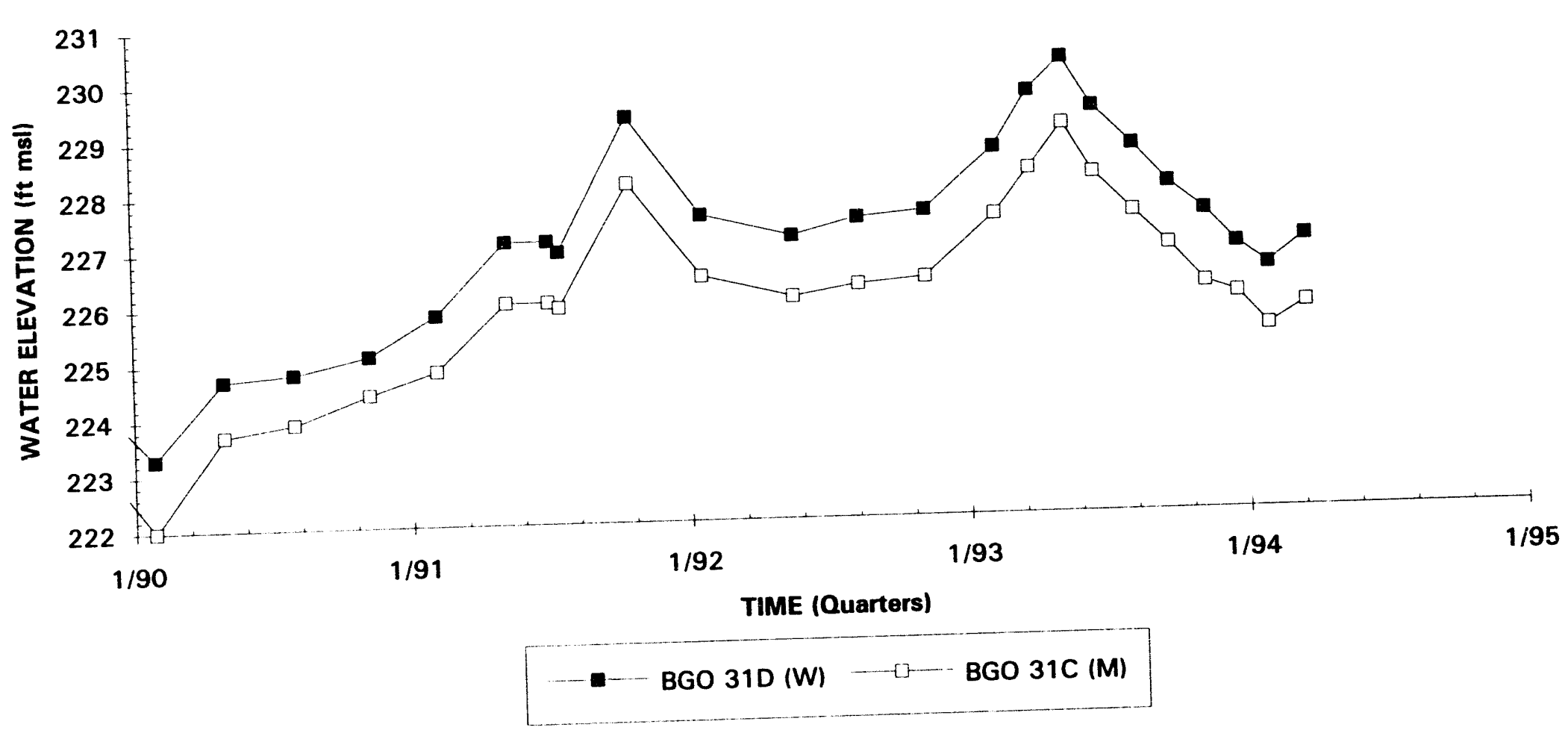

Table (IIB2); B=Barnwell (IIB1); $M=$ McBean (IIB1); UC=Upper Congaree (IIA); MC= Middle Congaree (IIA); LC=Lower Congaree (IIA) 


\section{Hydrograph \\ Well BGO 32D}

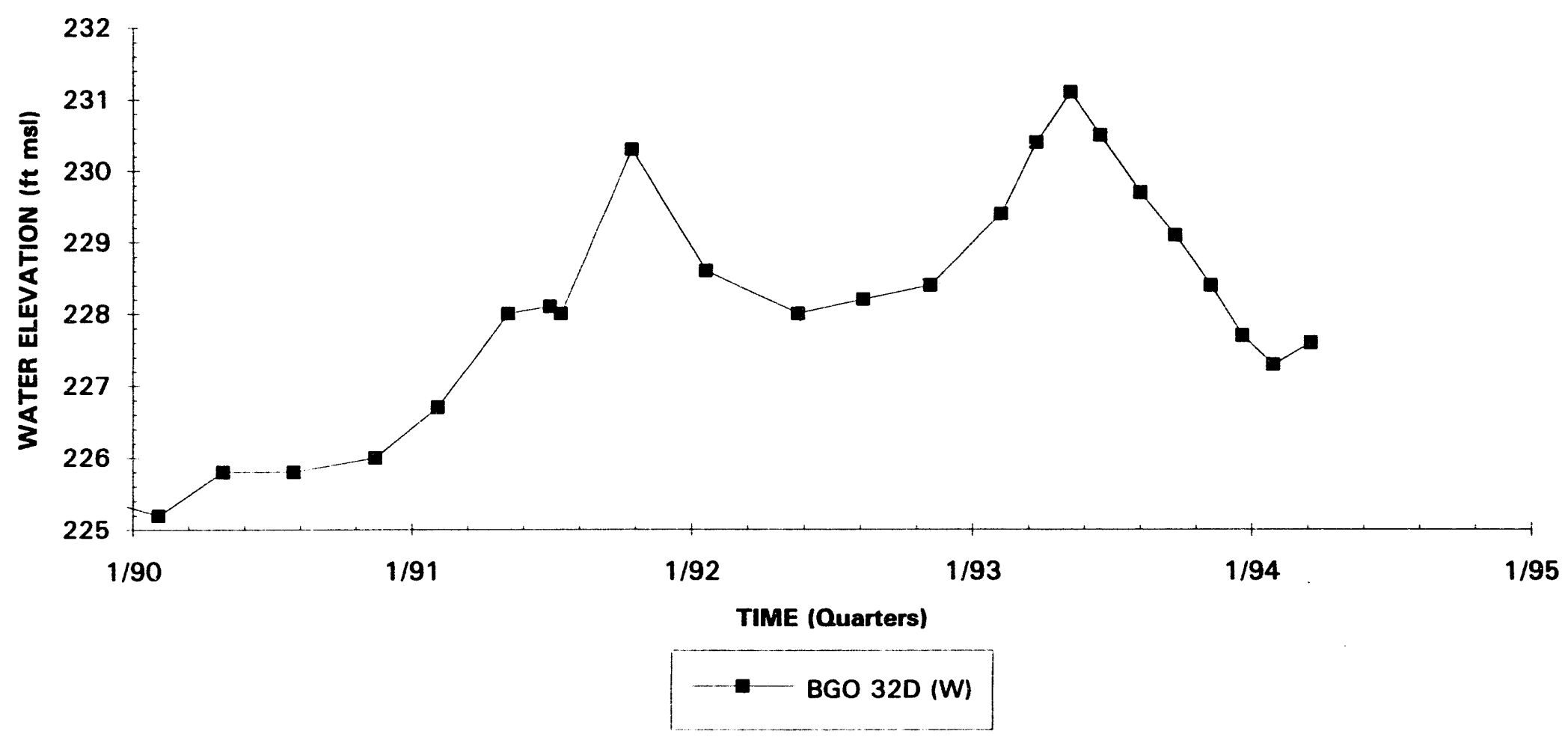

Note: $W=$ Water Table (IIB2); $B=$ Barnwell (IIB1); $M=$ McBean (IIB1); UC=Upper Congaree (IIA); $M C=$ Middle Congaree (IIA); LC=Lower Congaree (IIA) 


\section{Hydrograph \\ Well Cluster BGO 33}

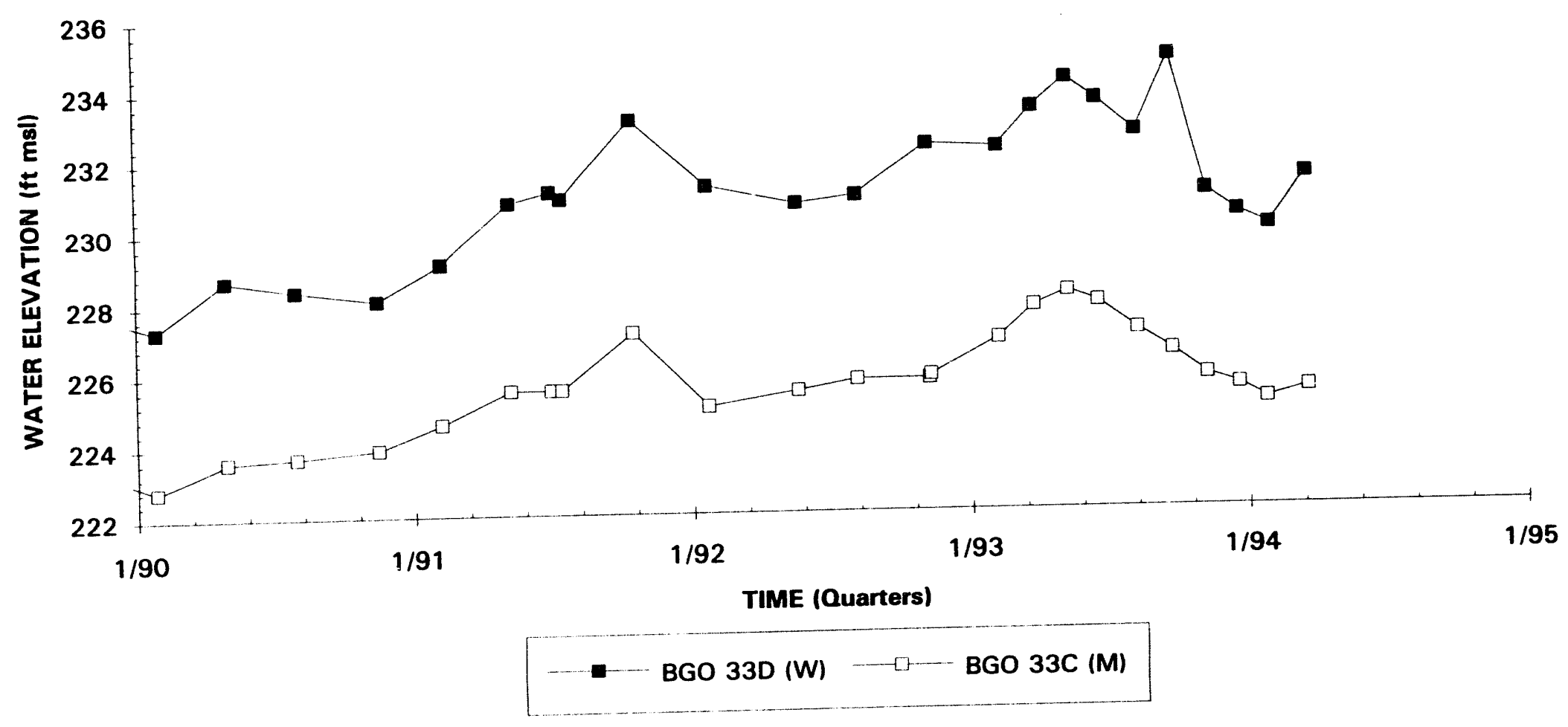

Note: $W=$ Water Table (IIB2); $B=$ Barnwell (IIB1); $M=$ McBean (IIB1); UC=Upper Congaree (IIA); MC= Middle Congaree (IIA); LC =-Lower Congaree (IIA) 


\section{Hydrograph}

\section{Well BGO 34D}

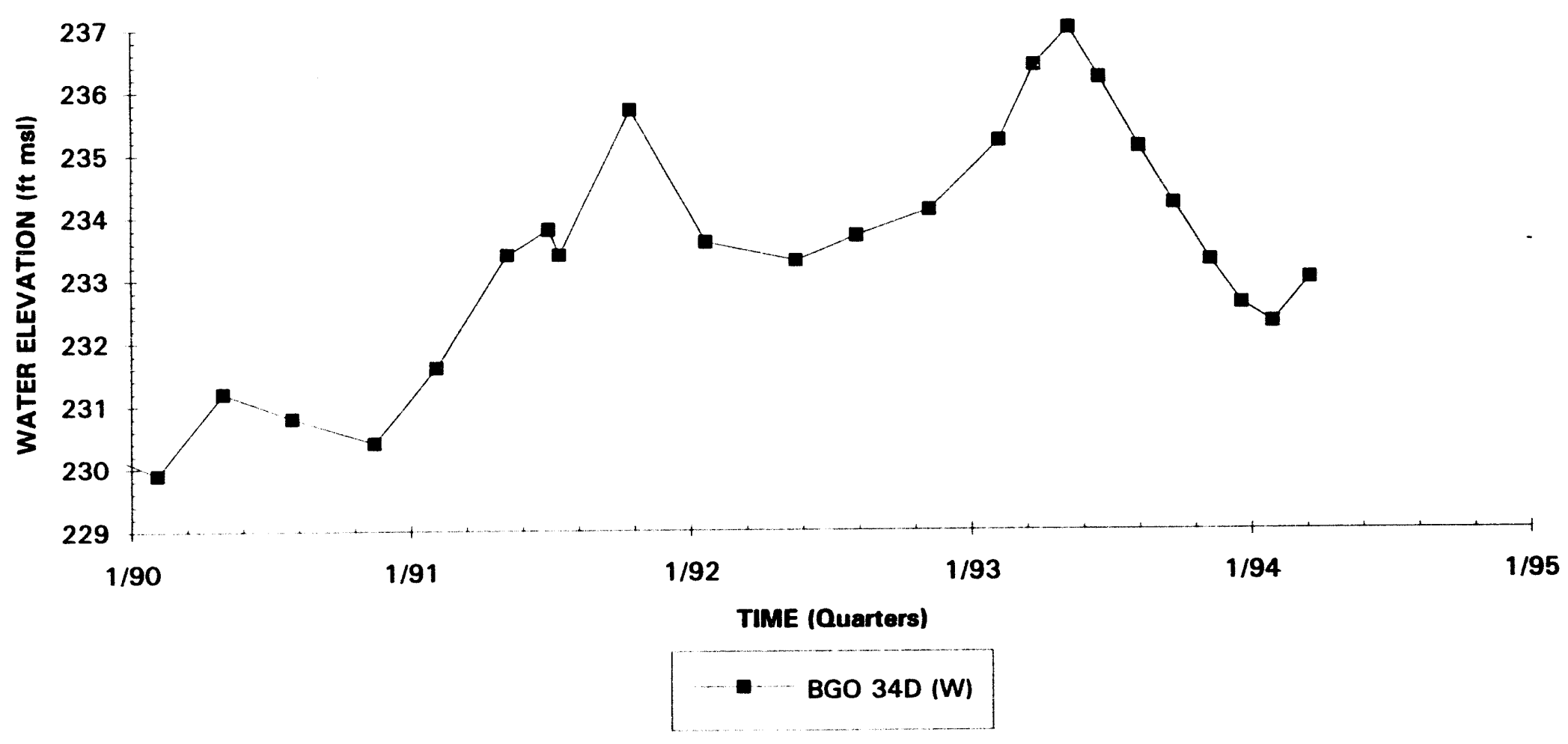

Note: $W=$ Water Table (IIB2); $B=$ Barnwell (IIB1); $M=$ McBean (IIB1); UC = Upper Congaree (IIA); $M C=$ Middle Congaree (IIA); LC = Lower Congaree (IIA) 


\section{Well Cluster BGO 35}

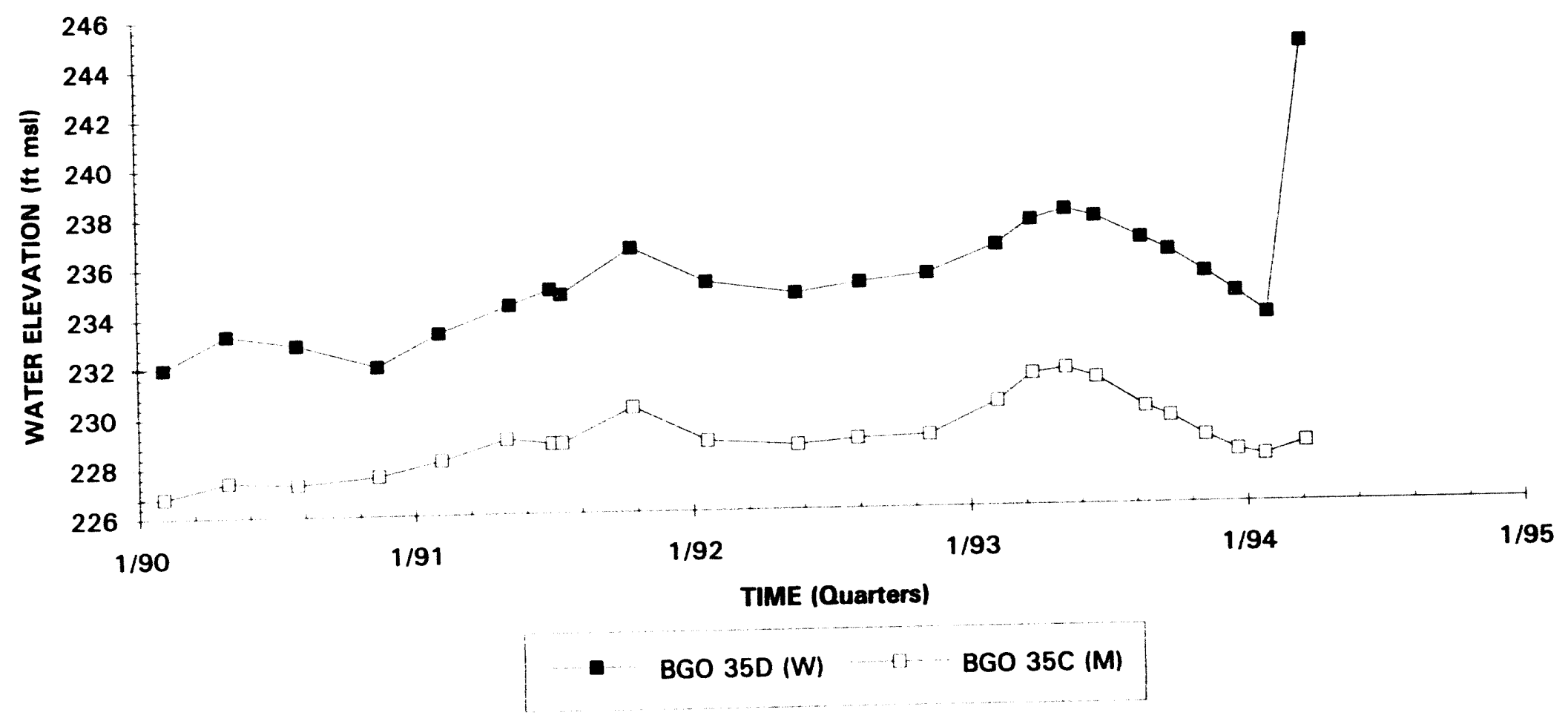




\section{Hydrograph \\ Well BGO 36D}

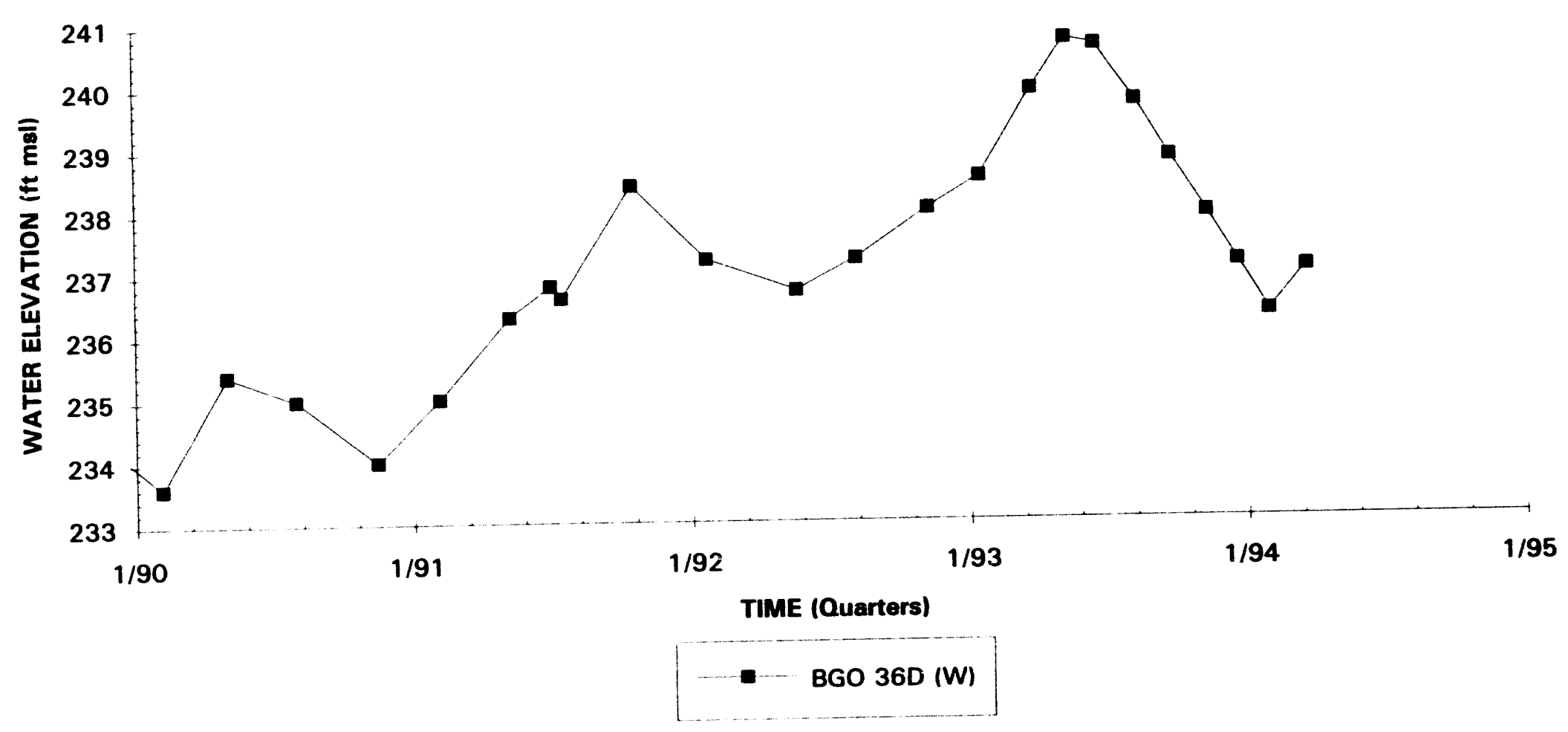

Note: $W=$ Water Table (IIB2); $B=$ Barnwell (IIB1); $M=$ McBean (IIB1); UC = Upper Congaree (IIA); MC = Middle Congaree (IIA); LC = Lower Congaree (IIA) 


\section{Hydrograph \\ Well Cluster BGO 37}

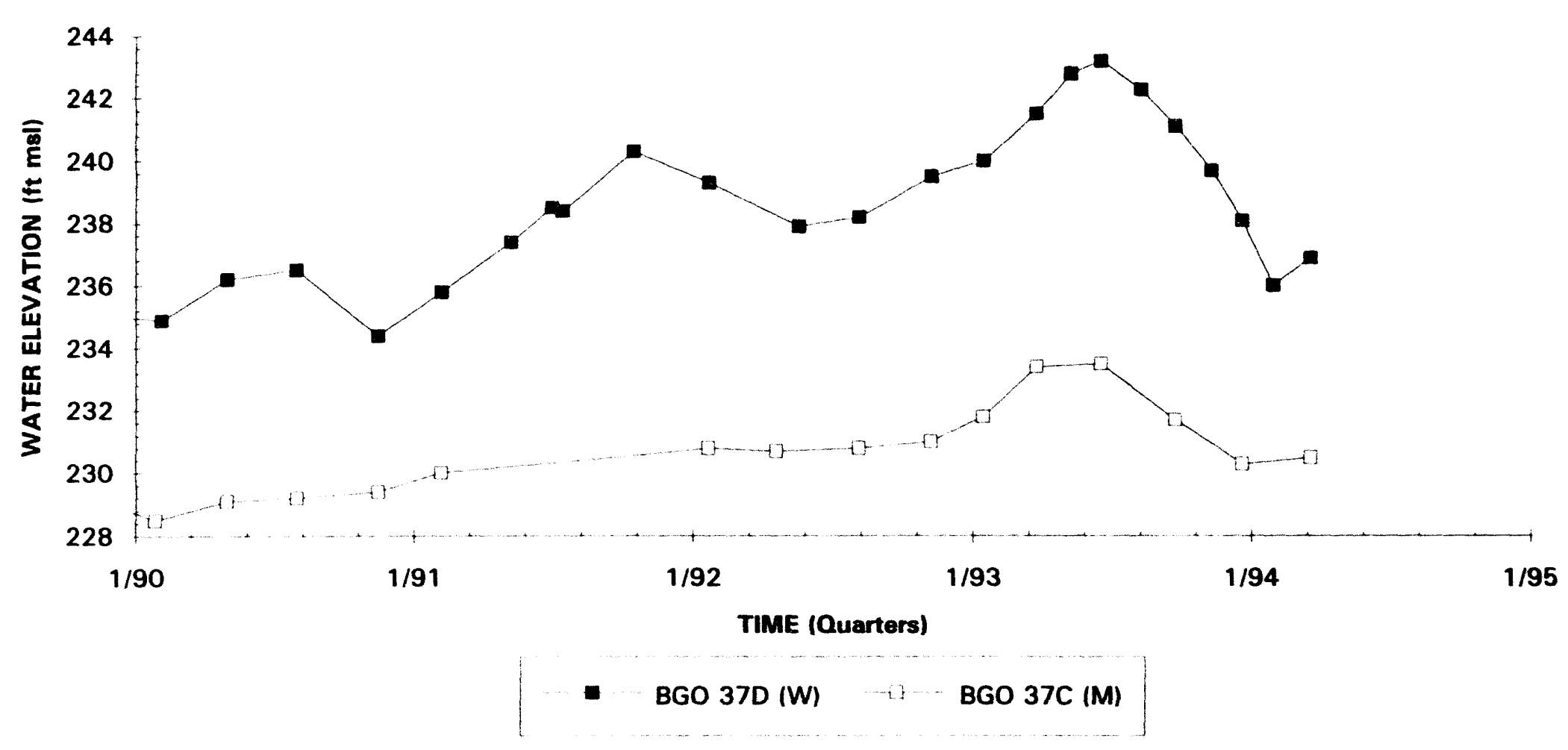

Note: $W=$ Water Table (IIB2); $B=$ Barnwell (IIB1); $M=$ McBean (IIB1); UC = Upper Congaree (IIA); MC = Middle Congaree (IIA); LC=Lower Congaree (IIA) 


\section{Hydrograph}

Well BGO 38D

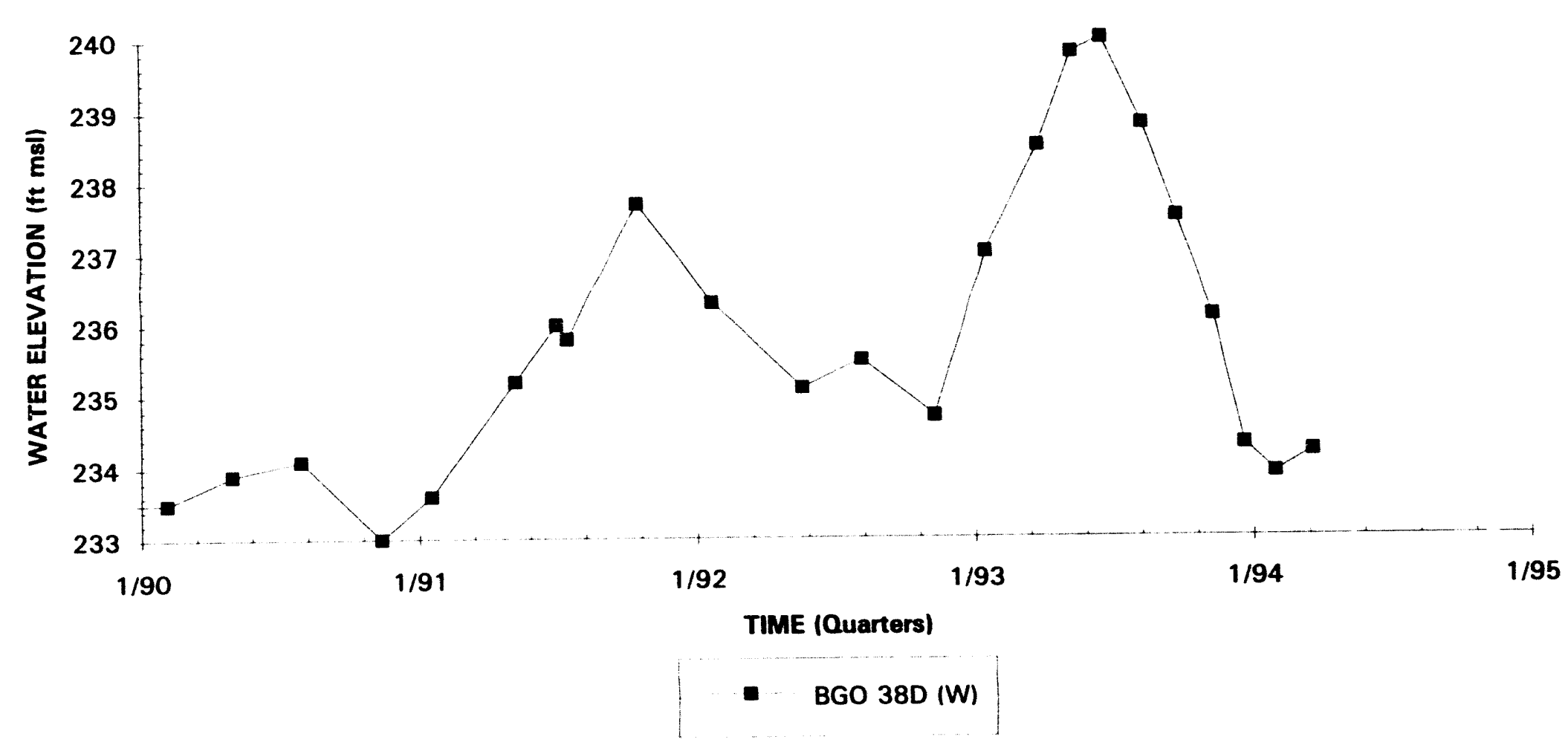

Note: $W=$ Water Table (IIB2); $B=$ Barnwell (IIB1); $M=$ McBean (IIB1); UC = Upper Congaree (IIA); $M C=$ Middle Congaree (IIA); LC = Lower Congaree (IIA) 


\section{Hydrograph \\ Well BGO 39D}

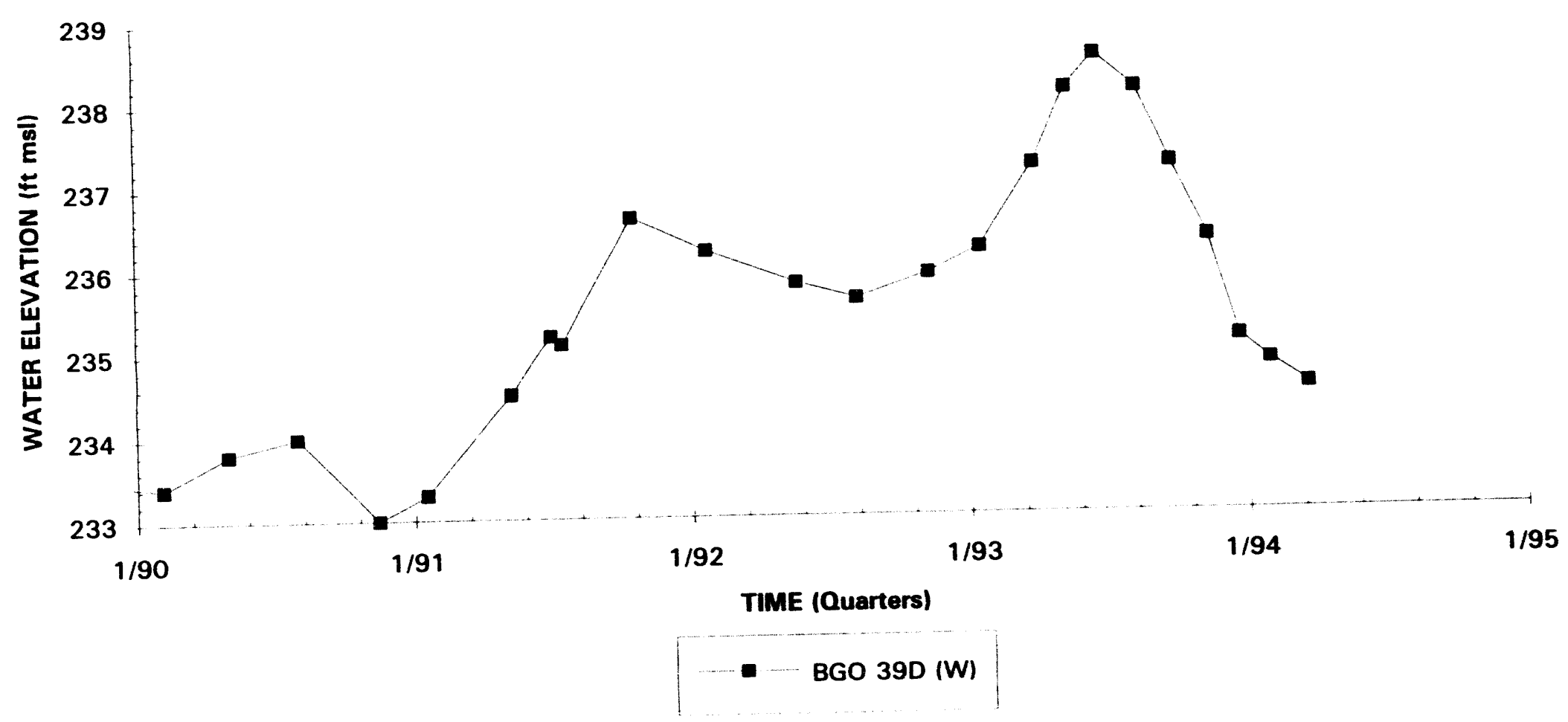

Note: $W=$ Water Table (IIB2); $B=$ Barnwell (IIB1); $M=$ McBean (IIB1); UC = Upper Congaree (IIA): $M C=$ Middle Congaree (IIA); LC=Lower Congaree (IIA) 


\section{Hydrograph}

\section{Well BGO 40D}

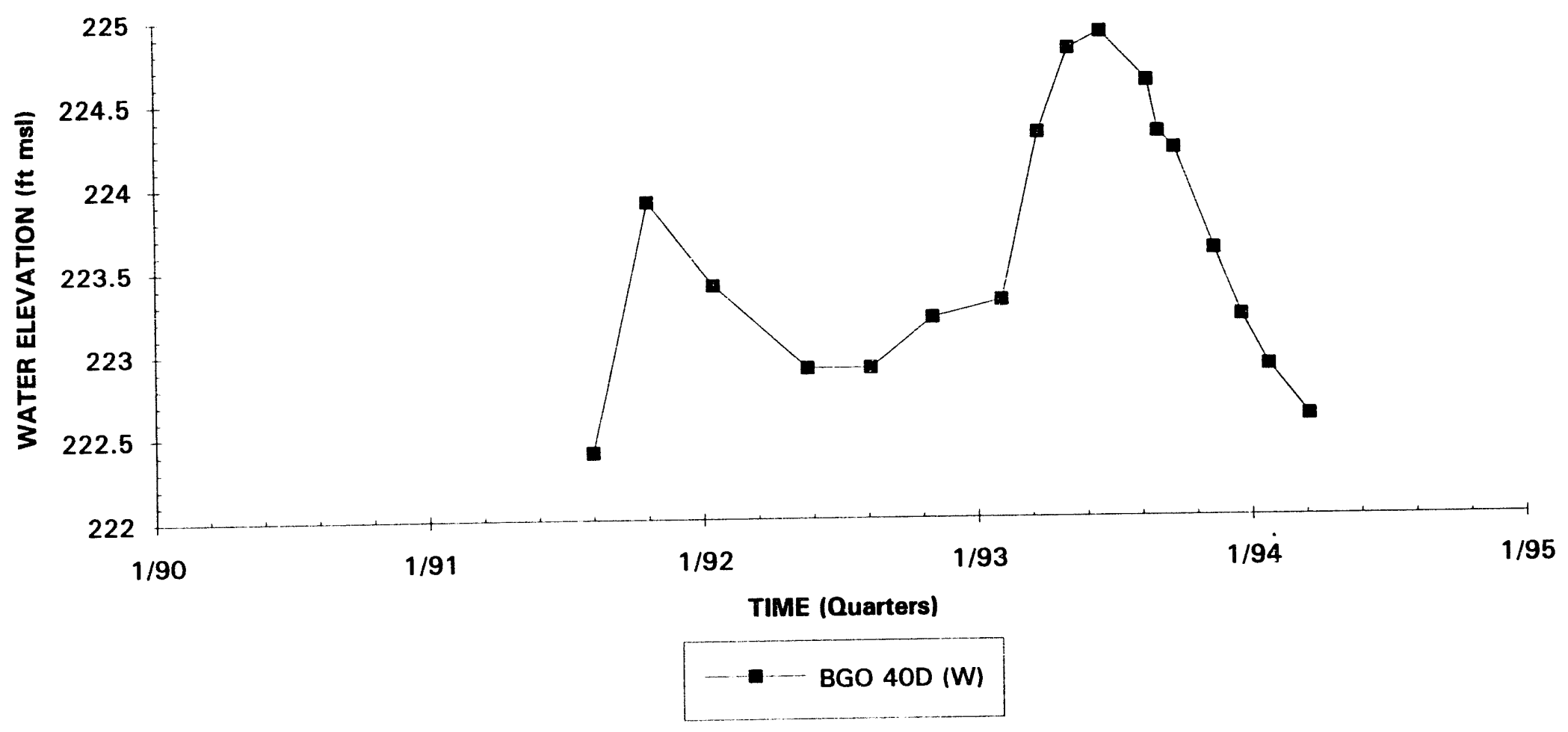

Note: $\mathrm{W}=$ Water Table (IIB2); $\mathrm{B}=$ Barnwell (IIB1); $\mathrm{M}=$ McBean (IIB1); UC=Upper Congaree (IIA); $M C=$ Middle Congaree (IIA); LC=Lower Congaree (IIA) 


\section{Hydrograph}

Well BGO 41A

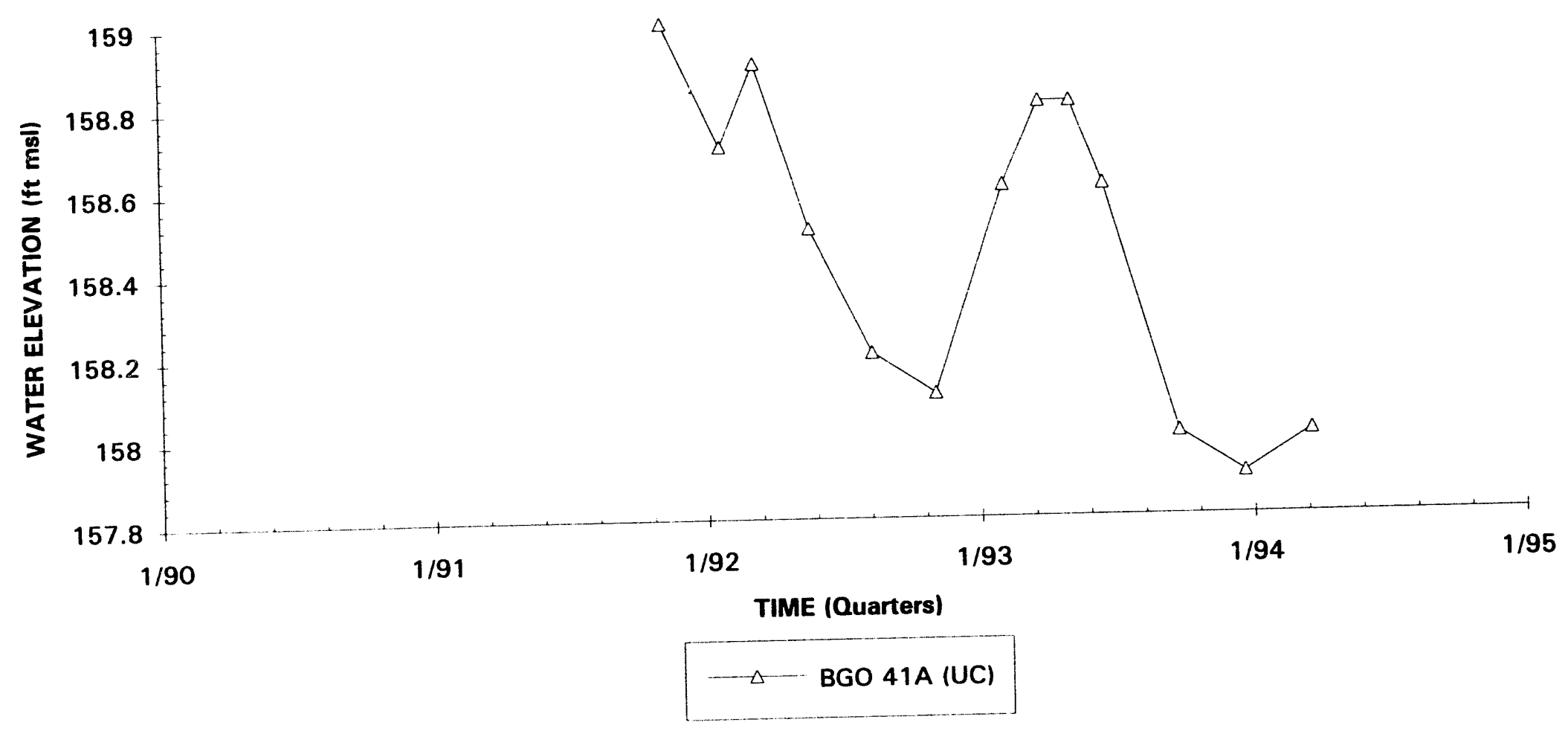

(IIB2): $\mathrm{B}=$ Barnwell (IIB1); $M=$ McBean (IIB1); UC = Upper Congaree (IIA); $M C=$ Middle Congaree (IIA); $L C=$ Lower Congaree (IIA) 


\section{Hydrograph \\ Well BGO 42C}

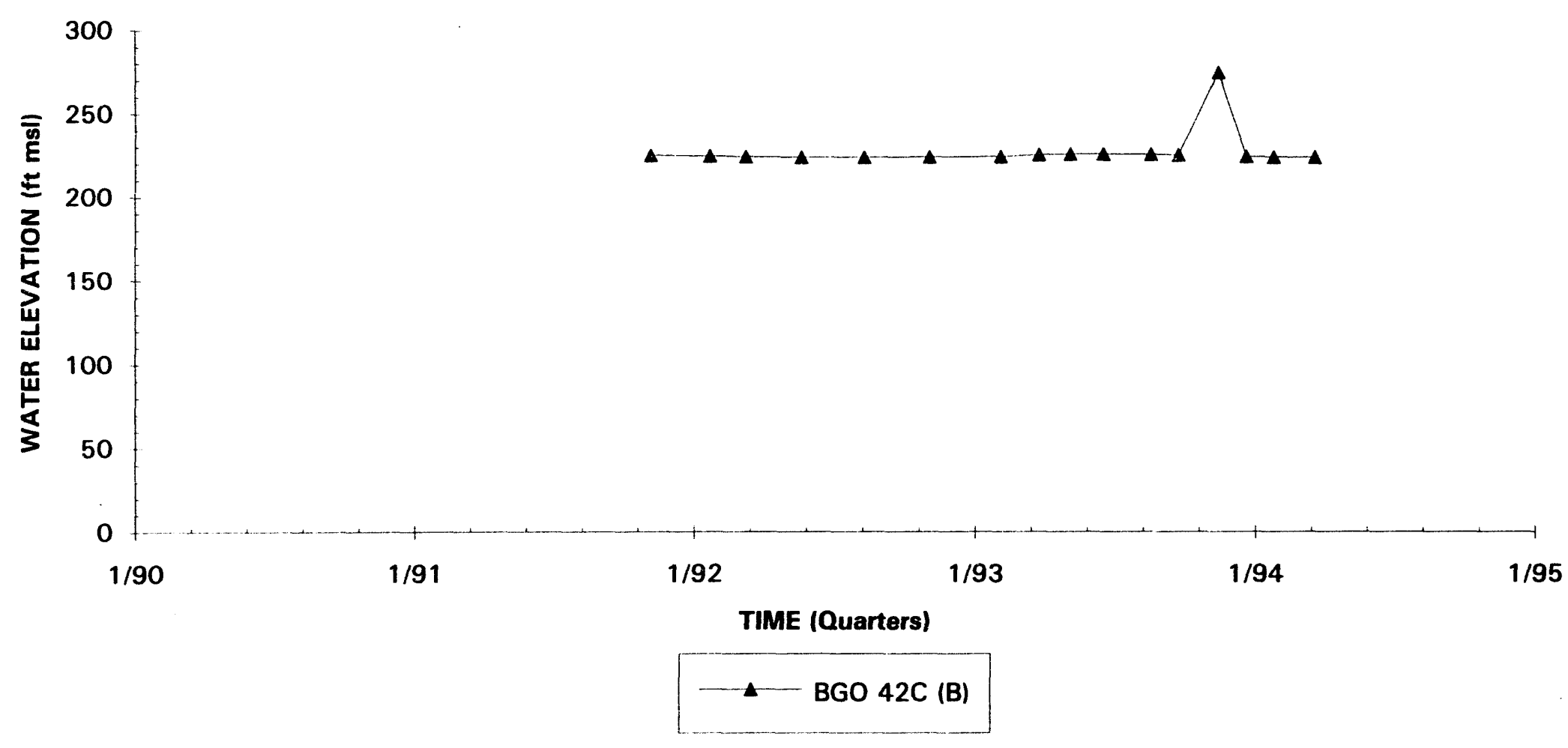

Note: $W=$ Water Table (IIB2); $B=$ Barnwell (IIB1); $M=$ McBean (IIB1); UC = Upper Congaree (IIA); $M C=$ Middle Congaree (IIA); LC = Lower Congaree (IIA) 


\section{Hydrograph \\ Well Cluster BGO 43}

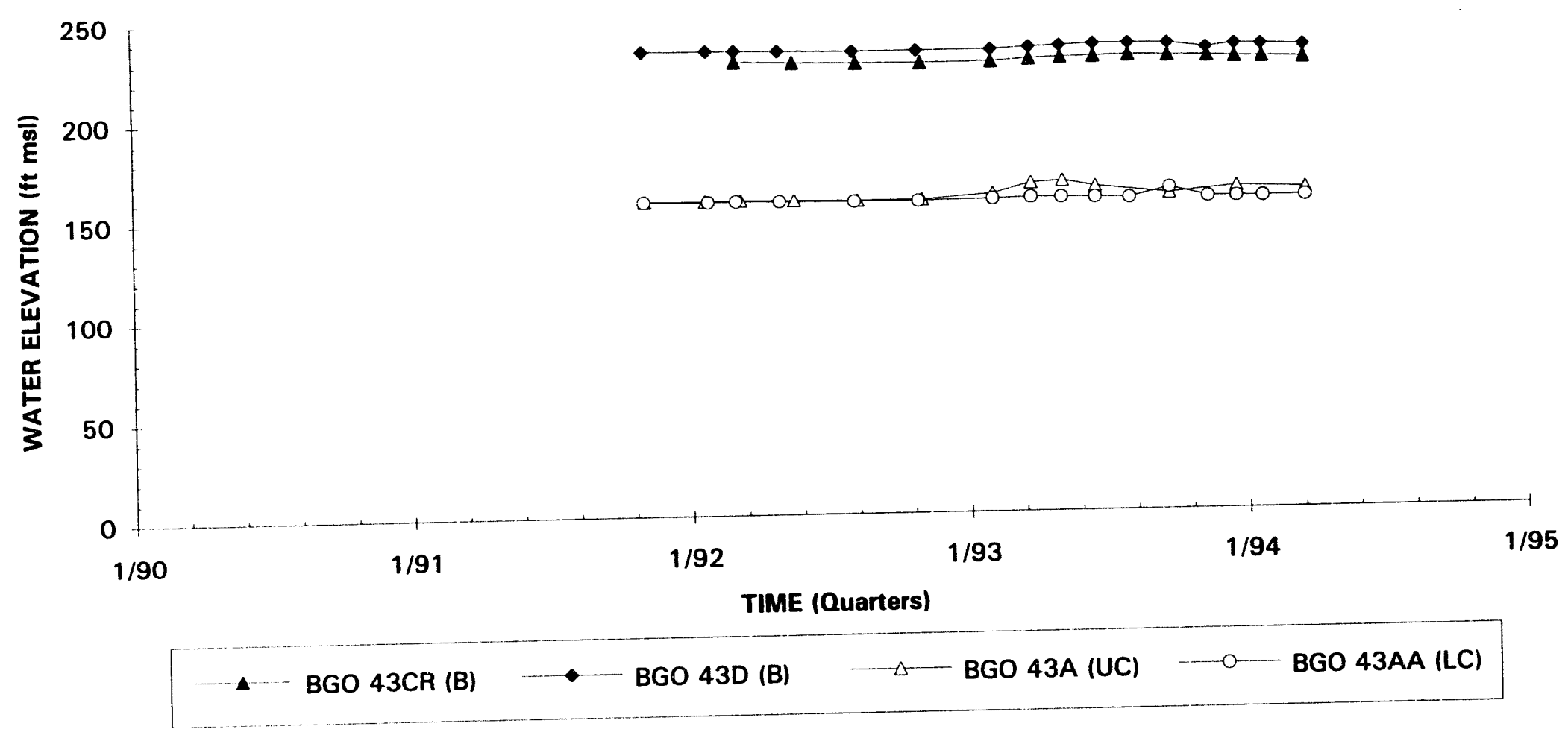




\section{Hydrograph}

\section{Well Cluster BGO 44}

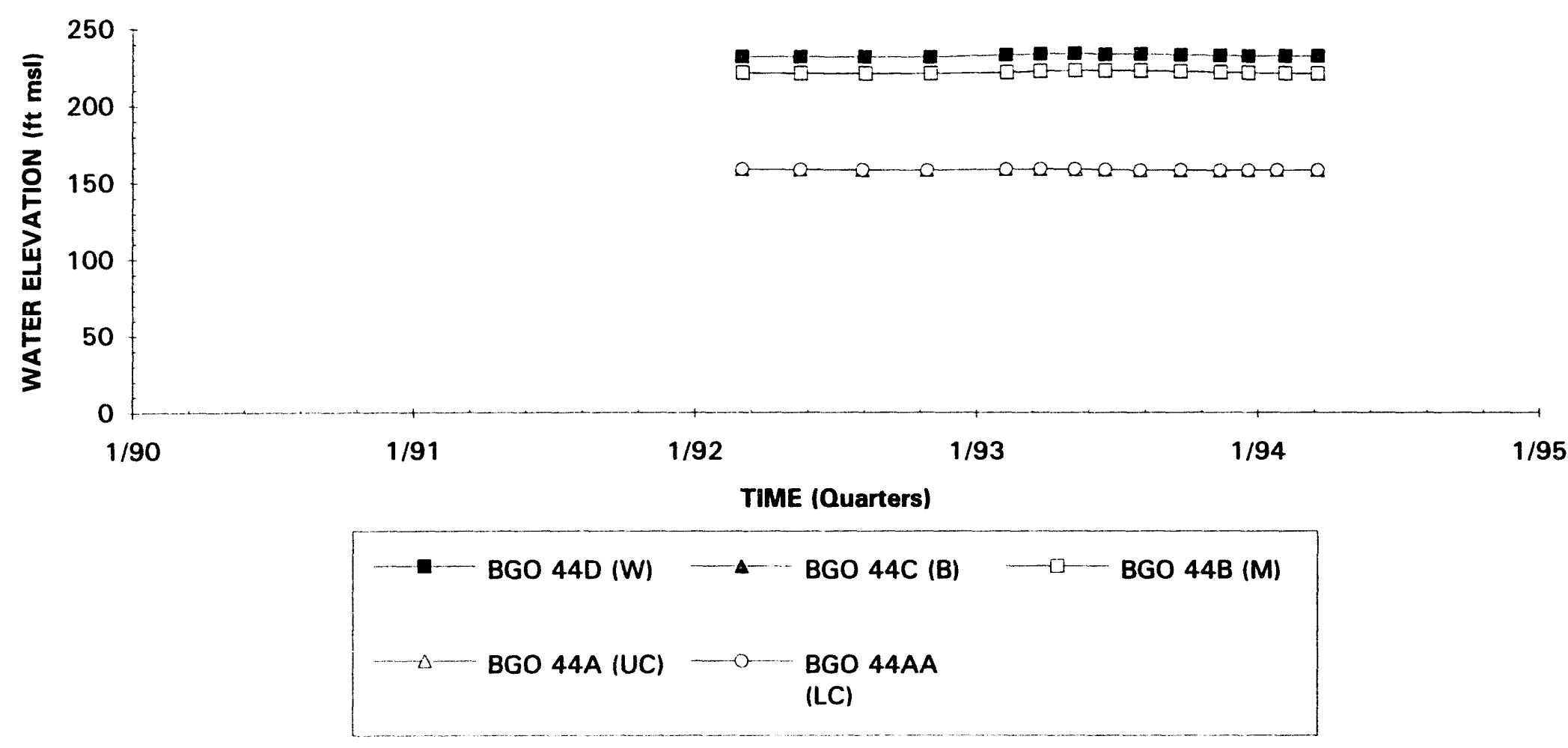

Note: $W=$ Water Table (IIB2); $B=$ Barnwell (IIB1); $M=$ McBean (IIB1); UC = Upper Congaree (IIA); $M C=$ Middle Congaree (IIA); LC =Lower Congaree (IIA) 


\section{Hydrograph \\ Well Cluster BGO 45}

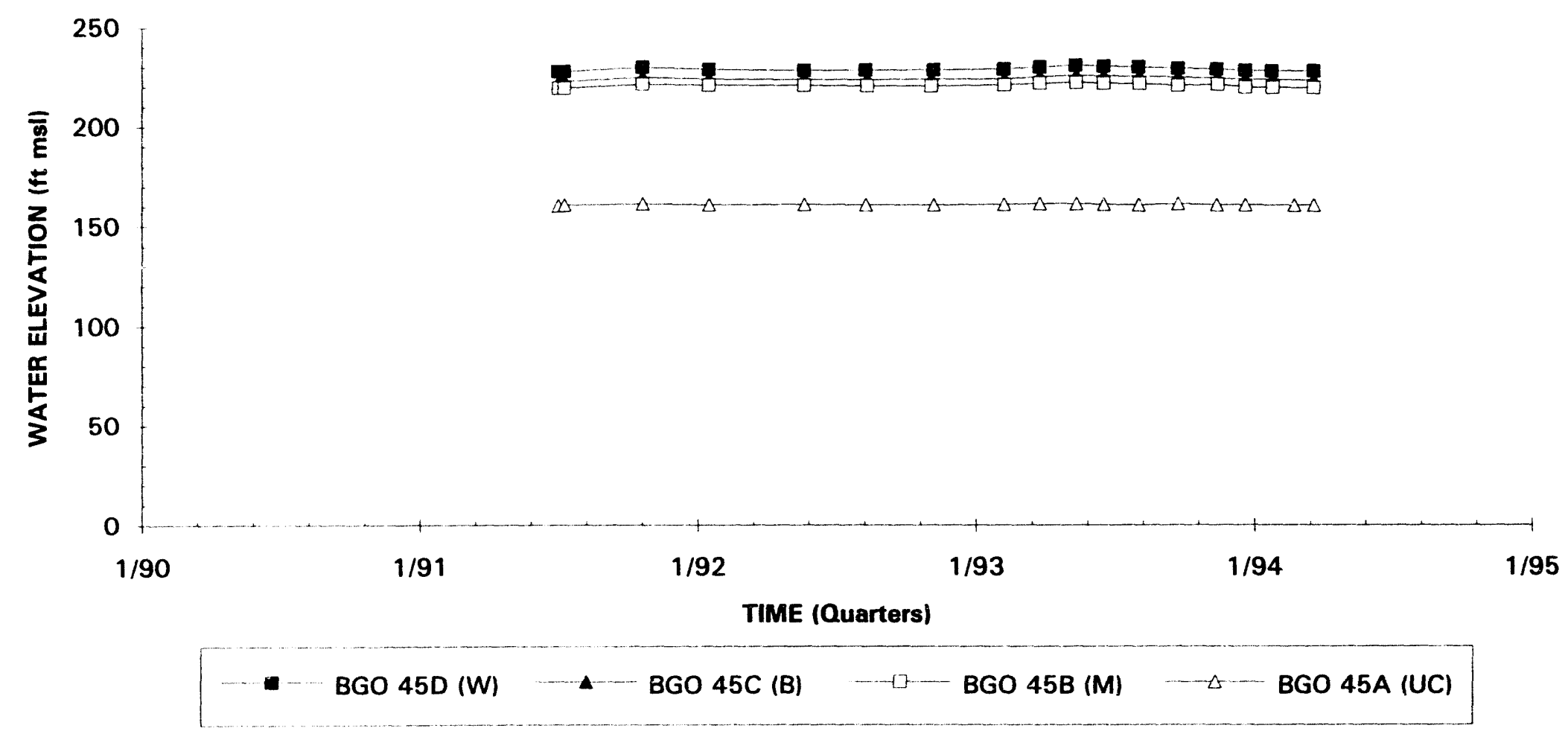

Note: $W=$ Water Table (IIB2); $B=$ Barnwell (IIB1); $M=M c B e a n$ (IIB1); UC = Upper Congaree (IIA); $M C=$ Middle Congaree (IIA); LC=Lower Congaree (IIA) 
Hydrograph

\section{Well Cluster BGO 46}

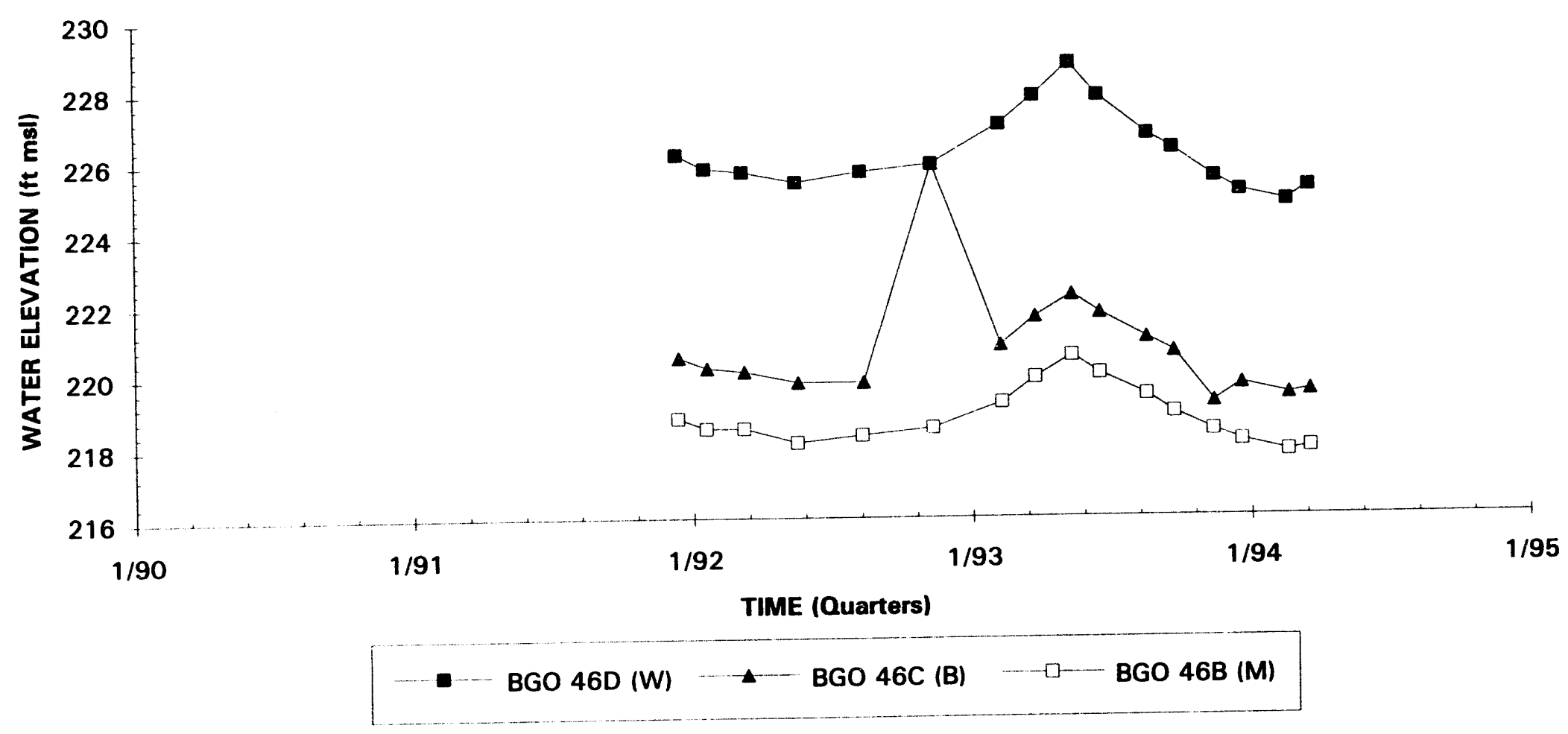

Note: $W=$ Water Table (IIB2); $B=$ Barnwell (IIB1); $M=$ McBean (IIB1); UC = Upper Congaree (IIA); $M C=$ Middle Congaree (IIA); LC=Lower Congaree (IIA) 


\section{Hydrograph \\ Well Cluster BGO 47}

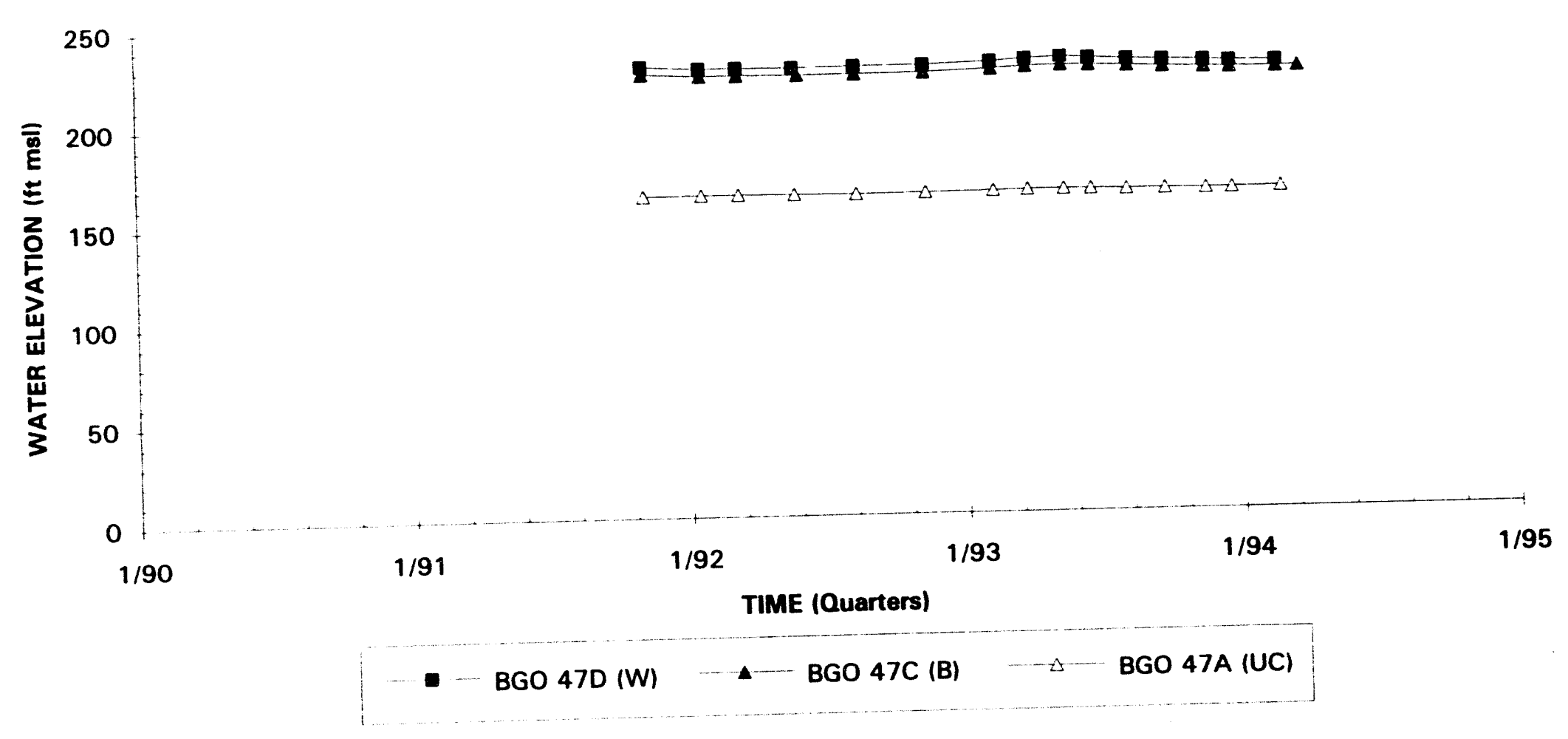

Note: $W=$ Water Table (IIB2); $B=$ Barnwell (IIB1); $M=$ McBean (IIB1); UC=Upper Congaree (IIA); $M C=$ Middle Congaree (IIA); LC=Lower Congaree (IIA) 


\section{Hydrograph \\ Well Cluster BGO 48}

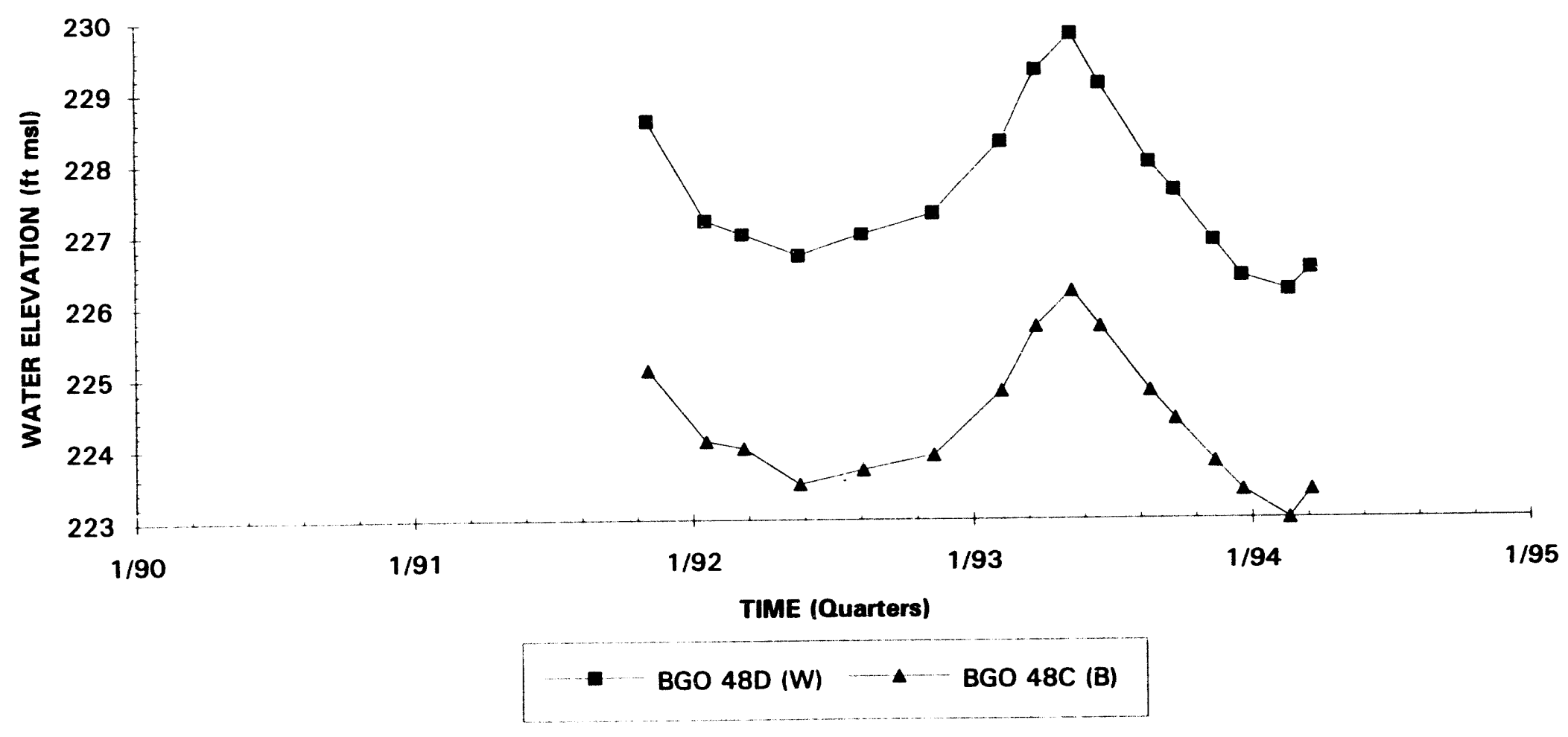

Note: $W=$ Water Table (IIB2); $B=$ Barnwell (IIB1); $M=$ McBean (IIB1); UC =Upper Congaree (IIA); $M C=$ Middle Congaree (IIA); LC=Lower Congaree (IIA) 


\section{Hydrograph \\ Well Cluster BGO 49}

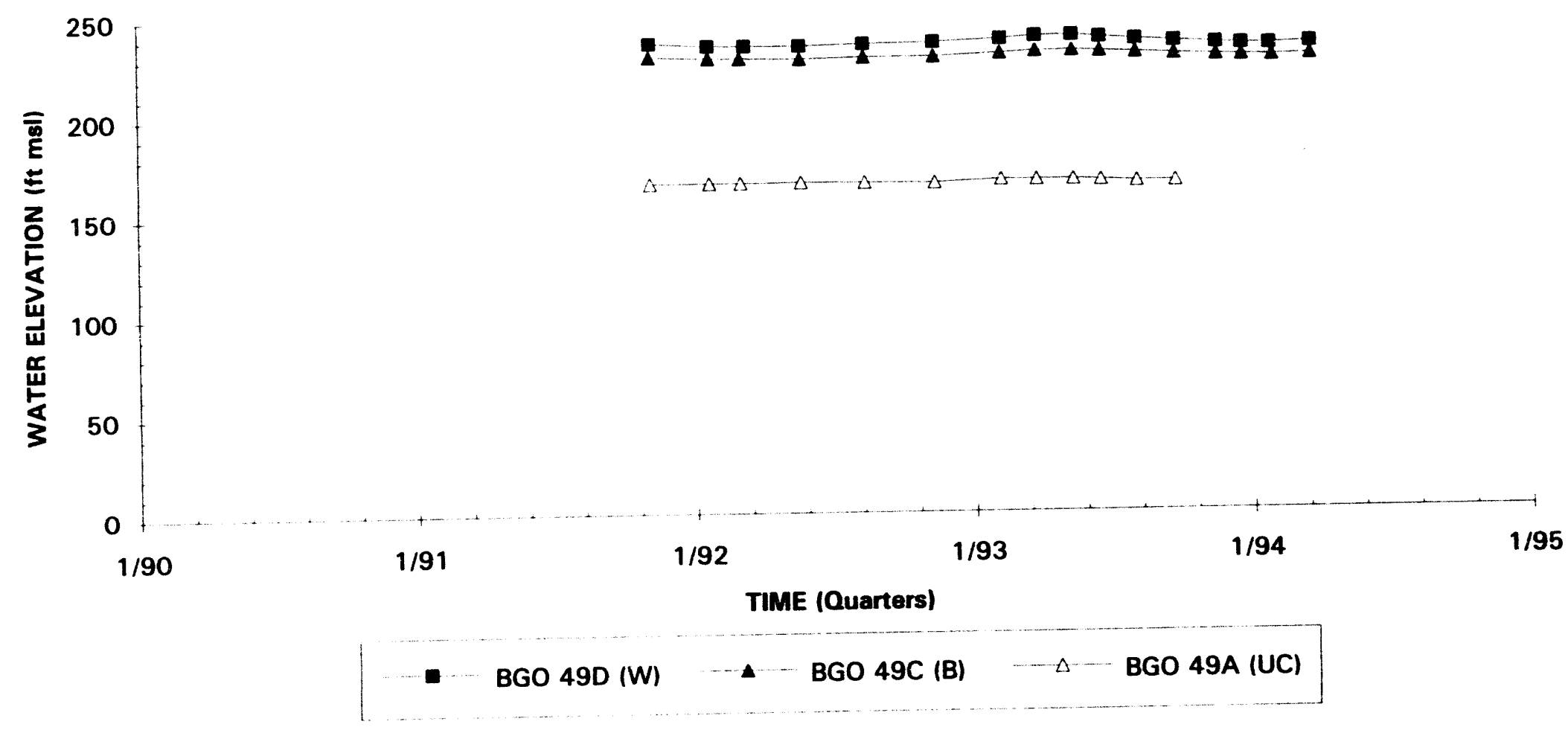




\section{Hydrograph \\ Well Cluster BGO 50}

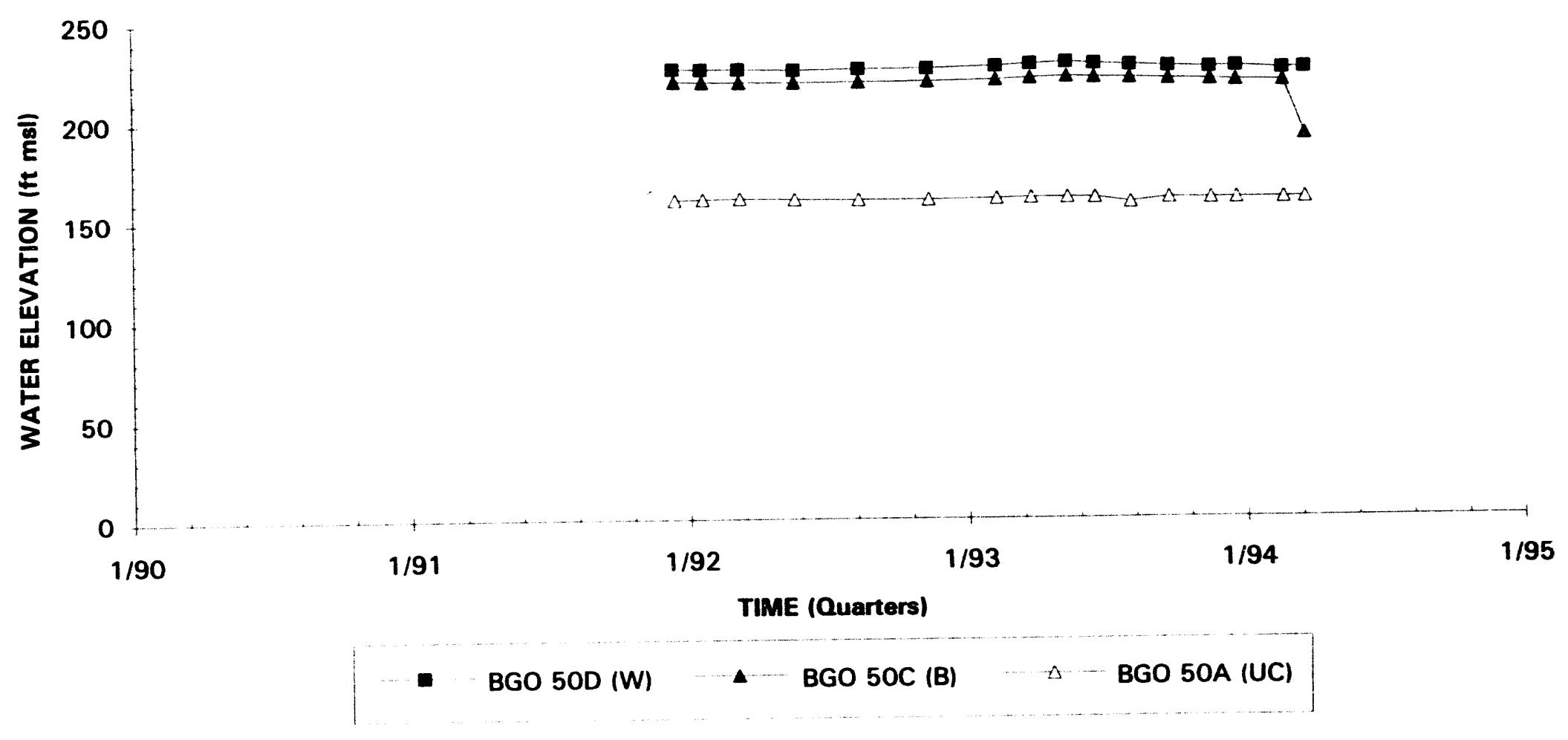

Note: $W=$ Water Table (IIB2); $B=B a r n w e l l$ (IIB1); $M=M c B e a n$ (IIB1); UC = Upper Congaree (IIA); $M C=$ Middle Congaree (IIA); LC=Lower Congaree (IIA) 


\section{Hydrograph Well Cluster BGX 1}
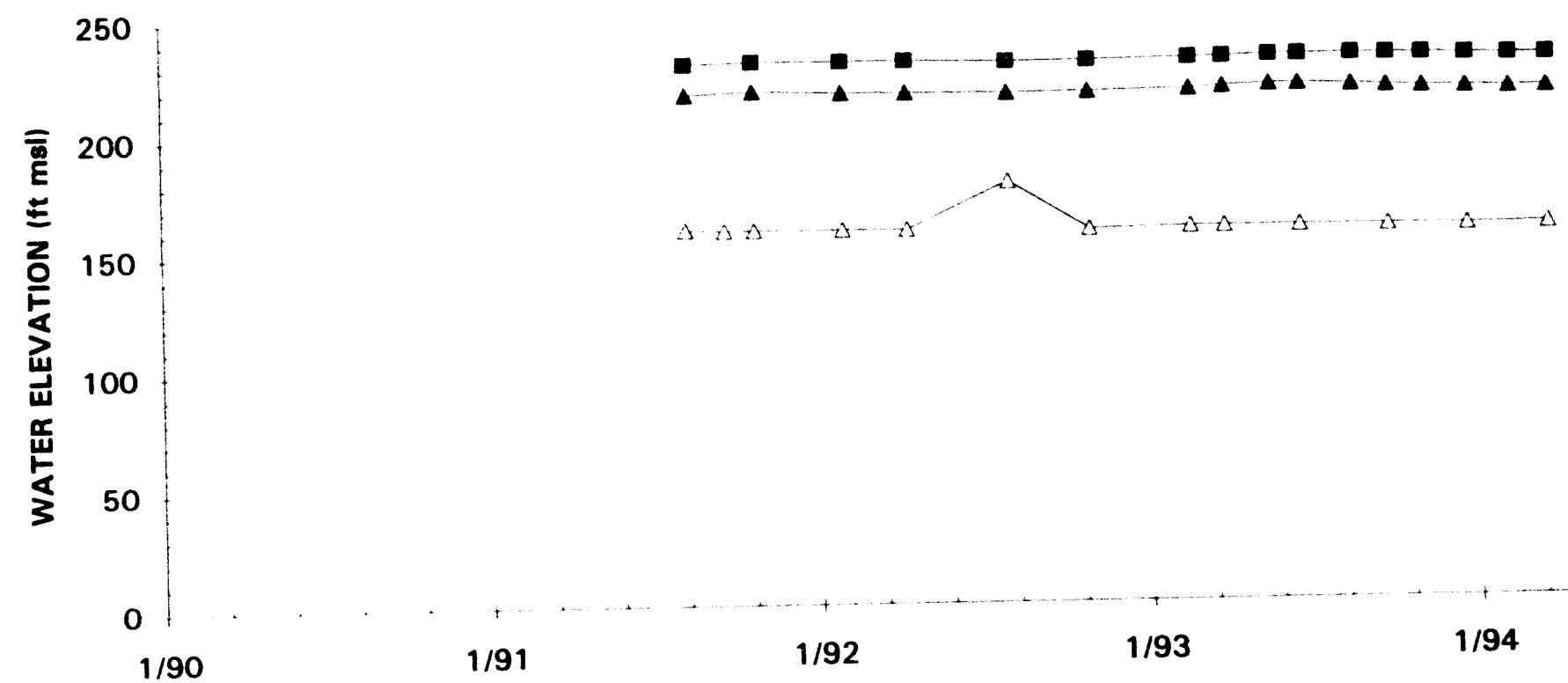

190

$1 / 91$

$$
1 / 92
$$

$1 / 93$

$1 / 94$

$1 / 95$

- BGX 1D (W) $\quad B G X 1 C(B) \cdots B G \quad 1 A(U C)$

TIME (Quarters) 


\section{Hydrograph \\ Well Cluster BGX 2}

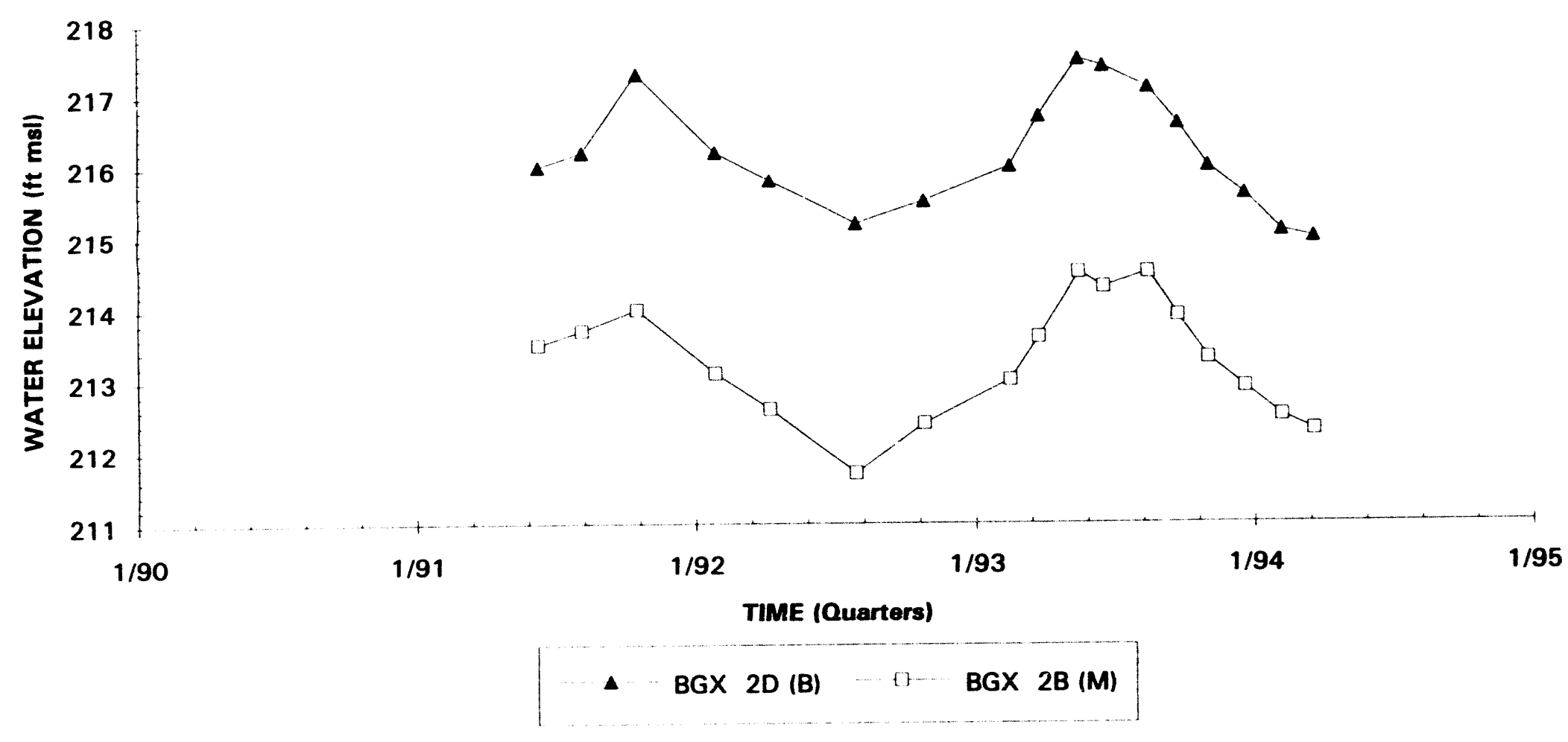




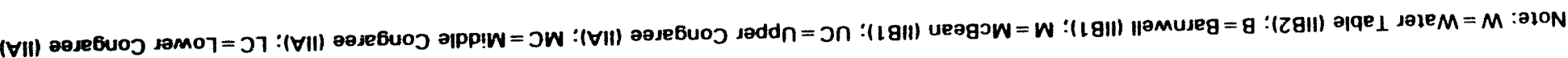

(8) $0 \varepsilon \times 98$

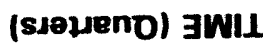

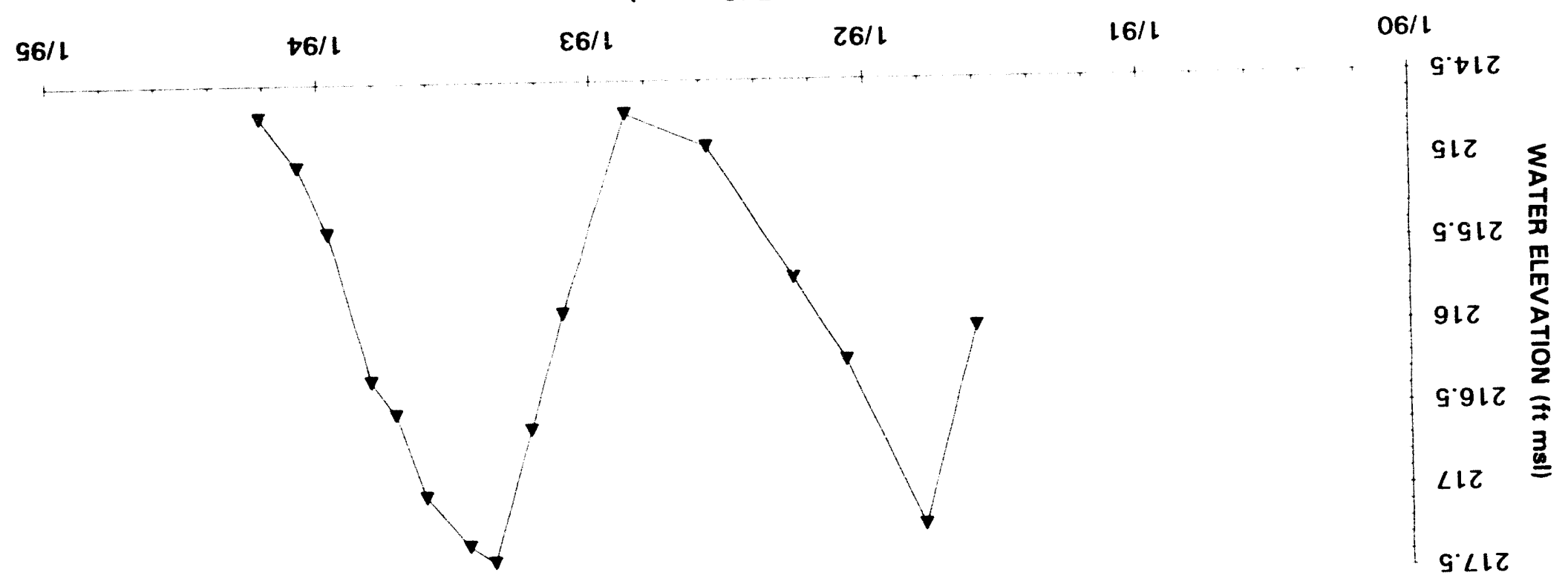

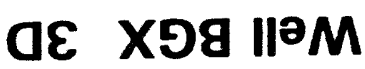 \\ पdes6osp $\hat{H}_{\mathrm{H}}$}




\section{Hydrograph \\ Well Cluster BGX 4}

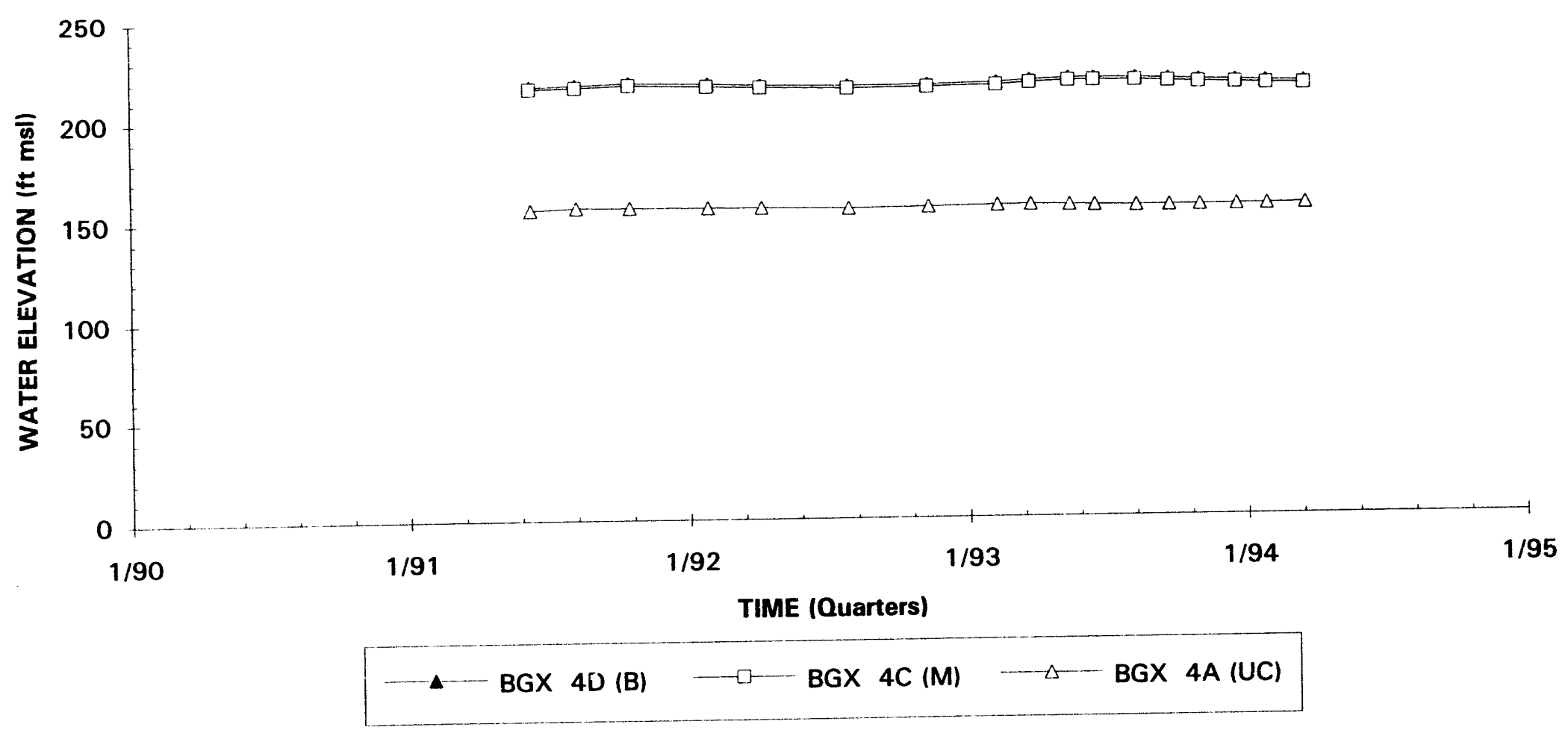

Note: $W=$ Water Table (IIB2); $B=$ Barnwell (IIB1); $M=$ McBean (IIB1); UC =Upper Congaree (IIA); $M C=$ Middle Congaree (IIA); LC=Lower Congaree (IIA) 


\section{Hydrograph Well BGX 5D}

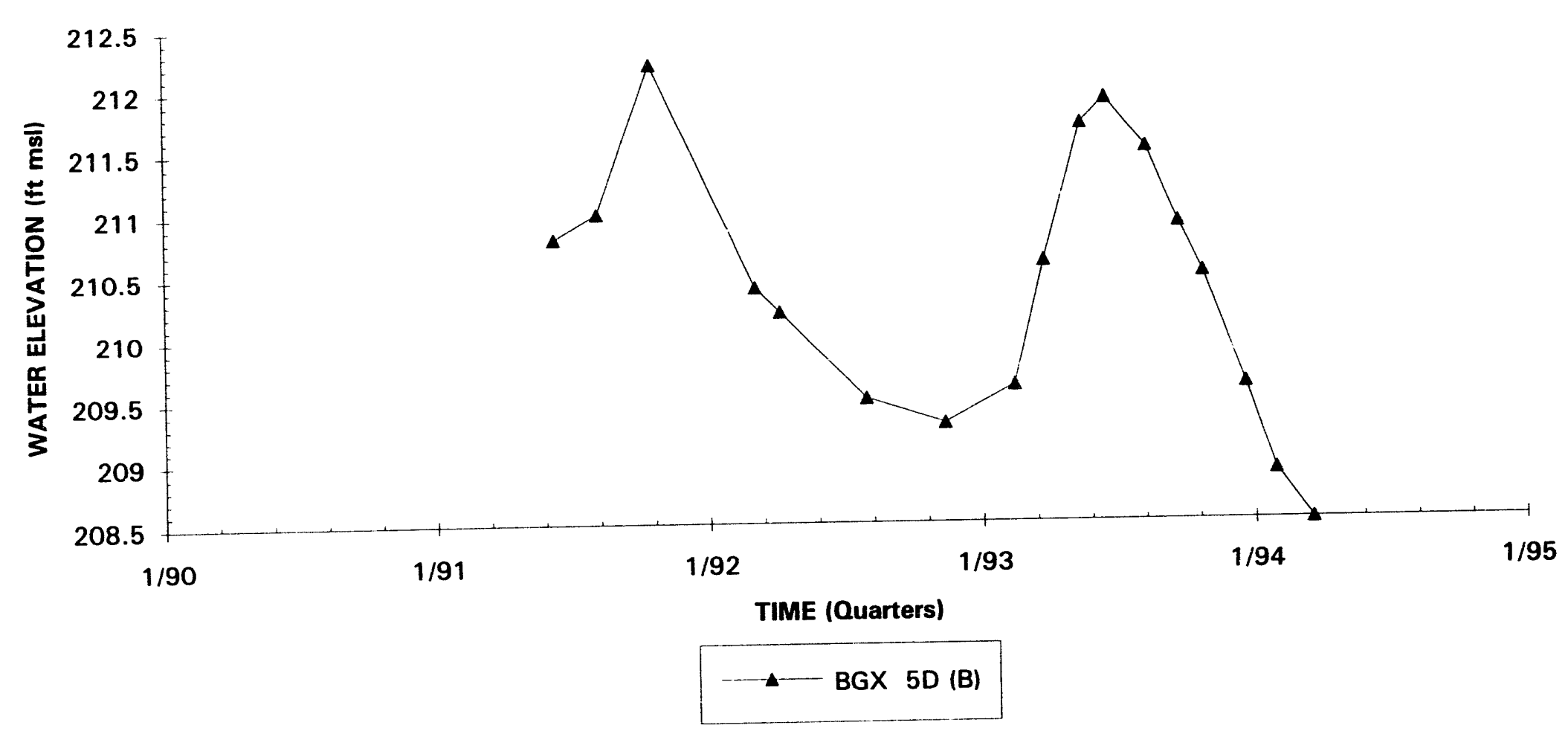

Note: $W=$ Water Table (IIB2); $B=$ Barnwell (IIB1); $M=$ McBean (IIB1); UC=Upper Congaree (IIA); MC = Middle Congaree (IIA); LC=Lower Congaree (IIA) 


\section{Hydrograph}

Well BGX 6D

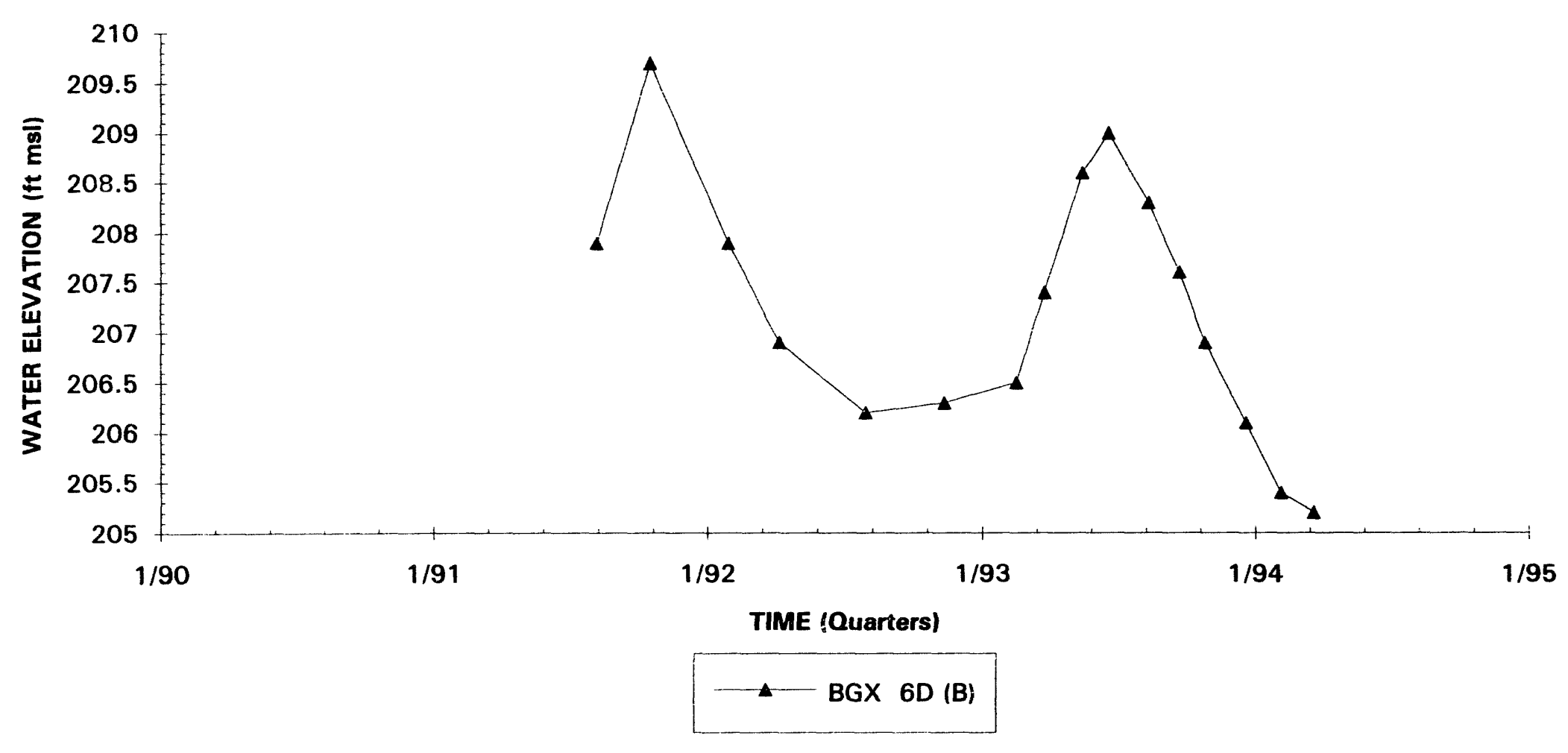

Note: $W=$ Water Table (IIB2); $B=$ Barnwell (IIB1); $M=$ McBean (IIB1); UC=Upper Congaree (IIA); $M C=$ Middle Congaree (IIA); LC =Lower Congaree (IIA) 


\section{Hydrograph}

Well BGX 7D

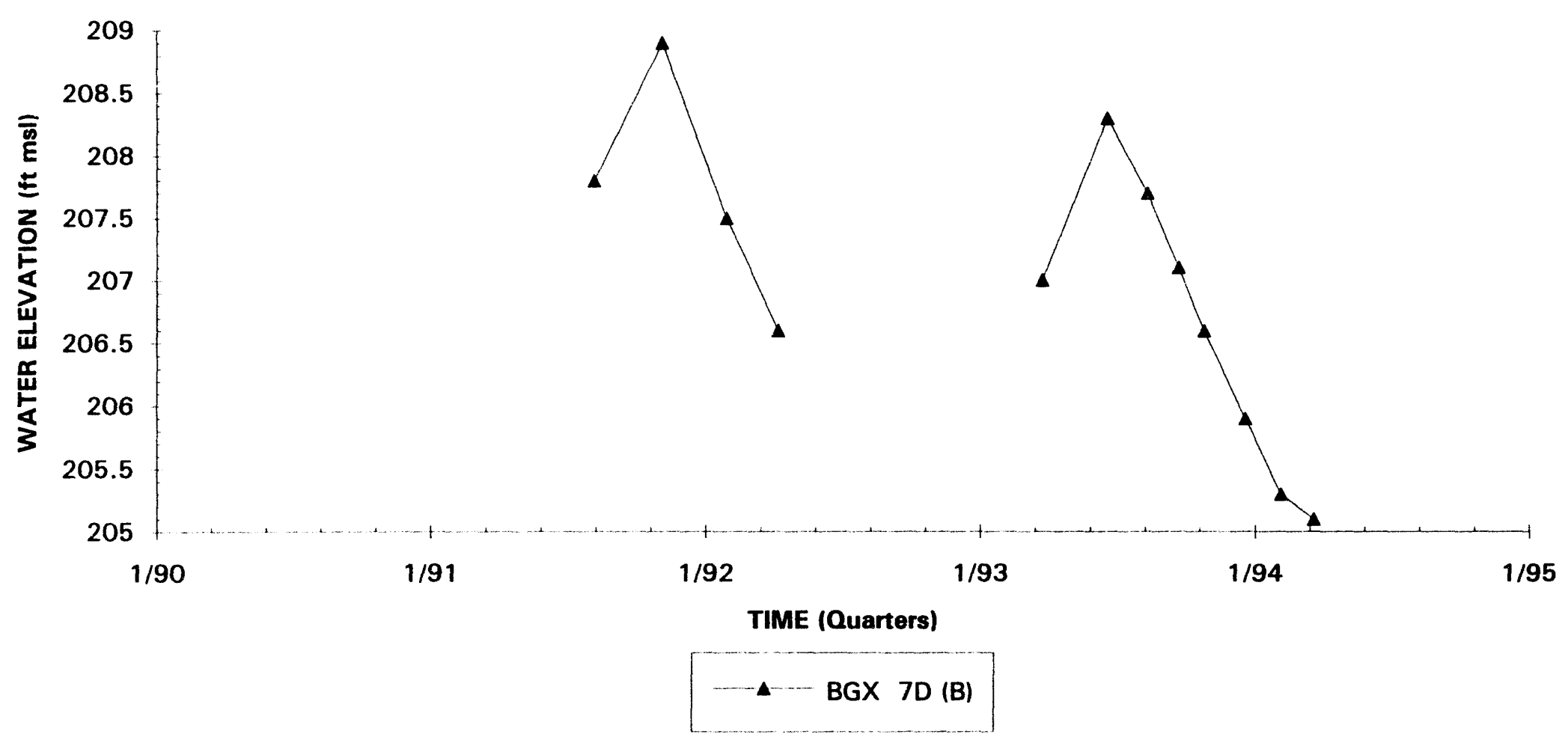

Note: $W=$ Water Table (IIB2); $B=$ Barnwell (IIB1); $M=$ McBean (IIB1); UC = Upper Congaree (IIA); $M C=$ Middle Congaree (IIA); LC=Lower Congaree (IIA) 


\section{Hydrograph \\ Well Cluster BGX 8}

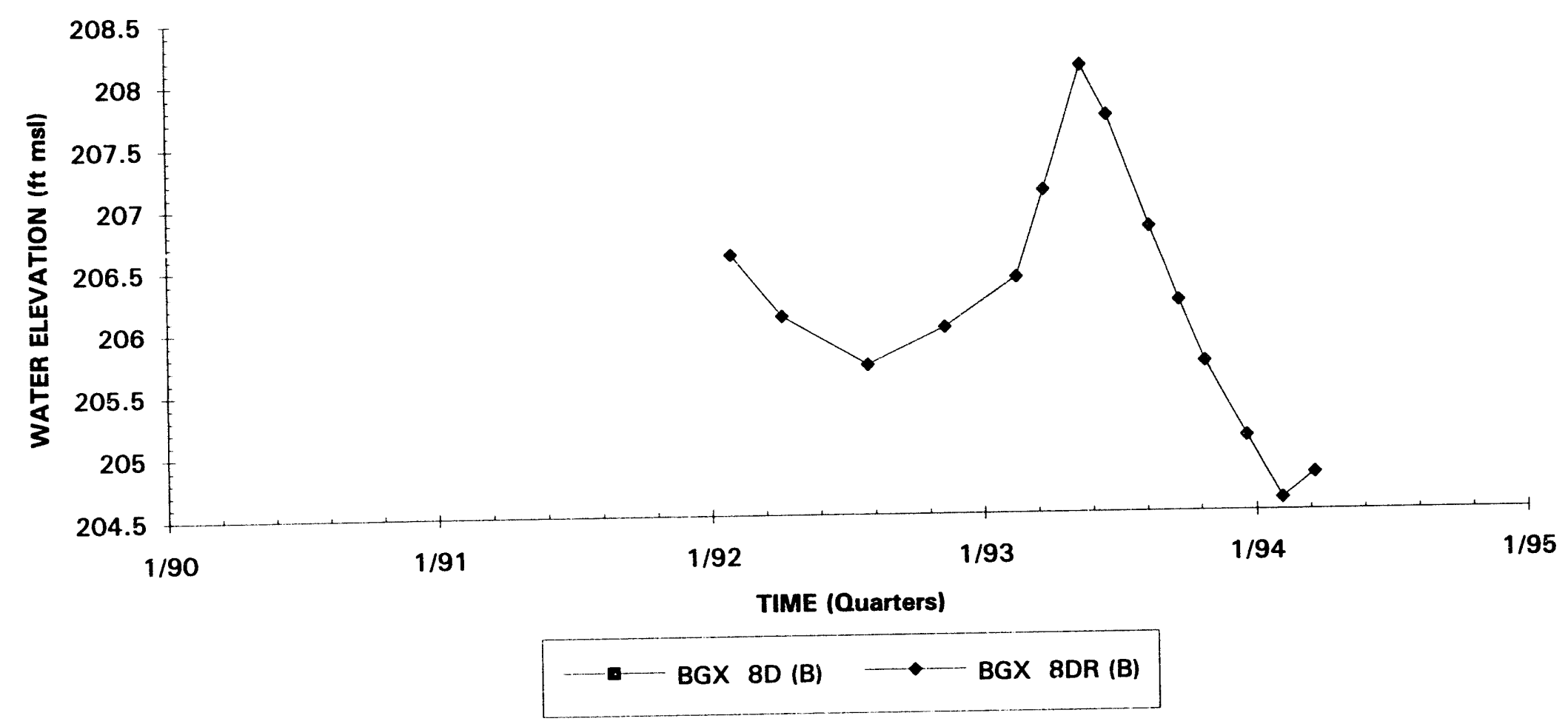

Note: $W=$ Water Table (IIB2); $B=$ Barnwell (IIB1); $M=$ McBean (IIB1); UC=Upper Congaree (IIA); $M C=$ Middle Congaree (IIA); LC=Lower Congaree (IIA) 


\section{Hydrograph}

Well BGX 9D

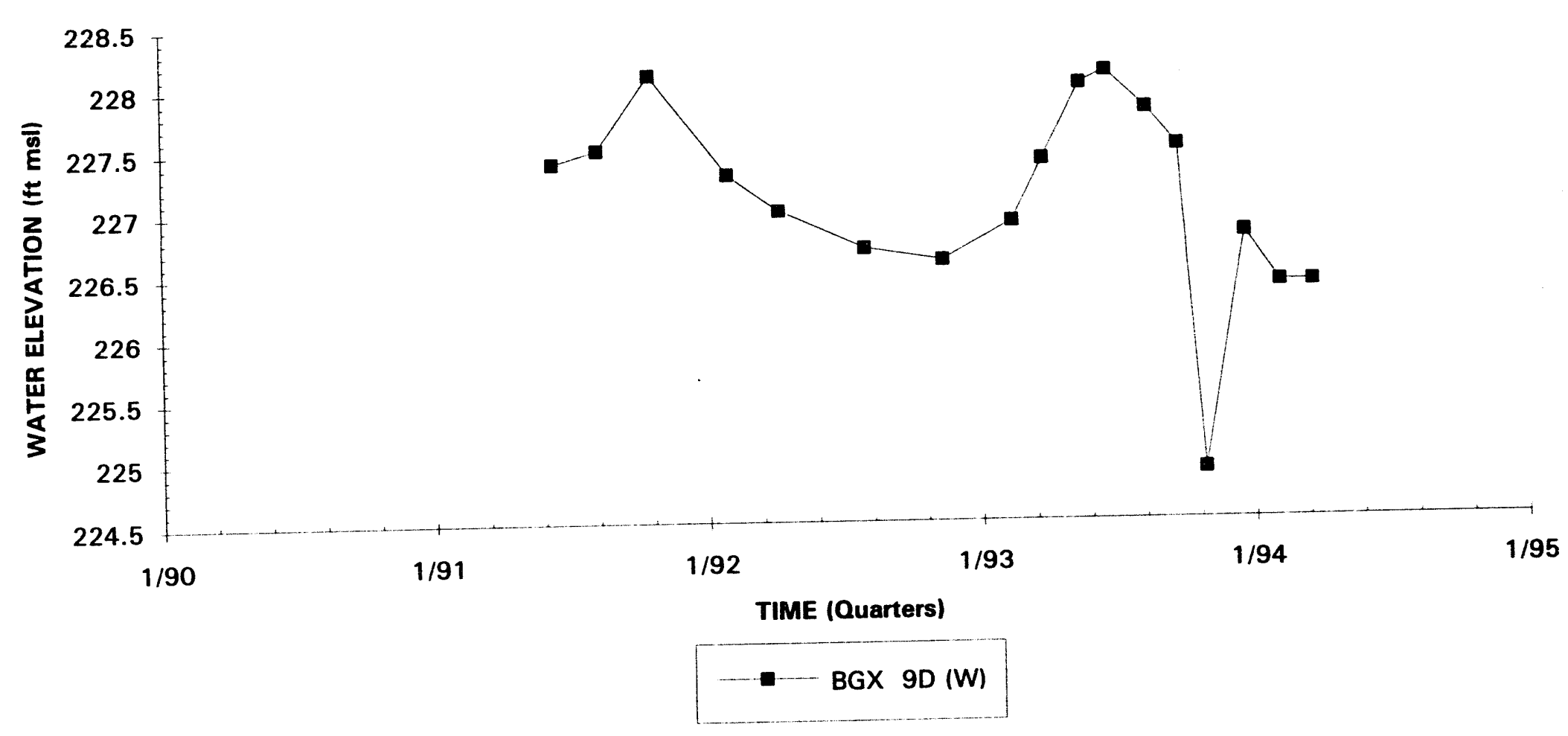

Note: $W=$ Water Table (IIB2); $B=$ Barnwell (IIB1); $M=M C B e a n ~(I I B 1) ; U C=$ Upper Congaree (IIA); $M C=$ Middle Congaree (IIA); $L C=$ Lower Congaree (IIA) 


\section{Hydrograph}

\section{Well BGX 10D}

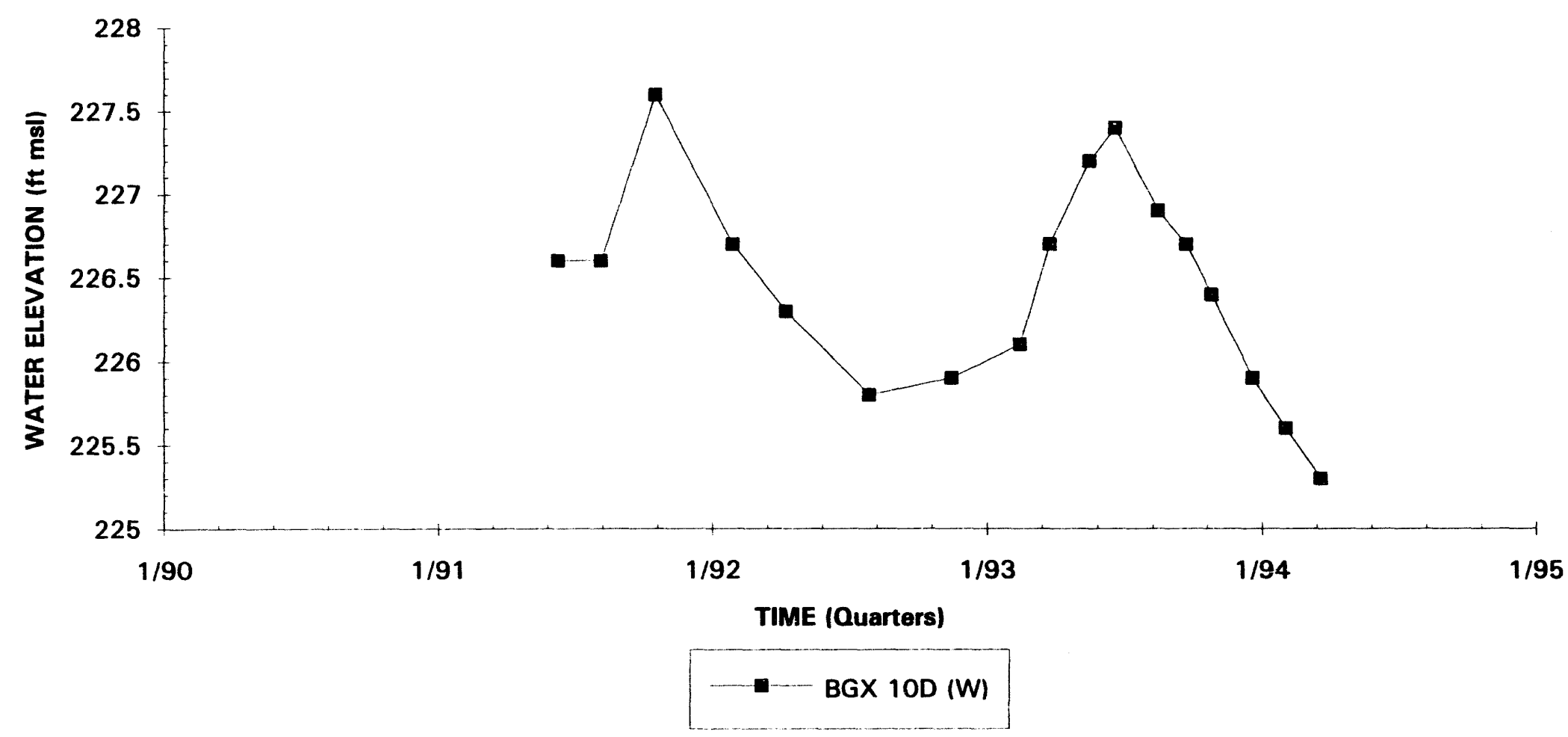

Note: $W=$ Water Table (IIB2); $B=$ Barnwell (IIB1); $M=$ McBean (IIB1); UC = Upper Congaree (IIA); $M C=$ Middle Congaree (IIA); LC =Lower Congaree (IIA) 


\section{Hydrograph}

\section{Well BGX 11D}

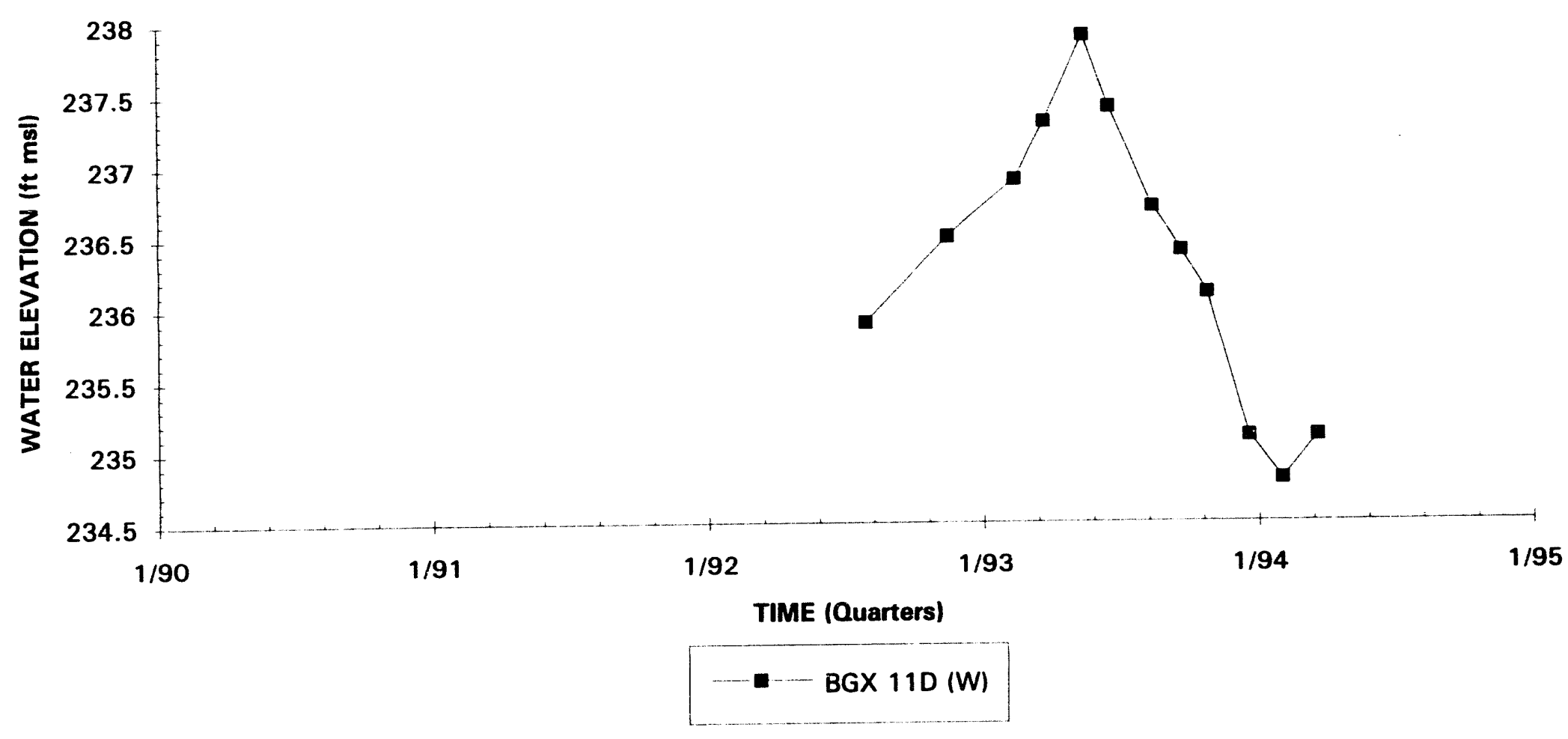

Note: $W=$ Water Table (IIB2); B = Barnwell (IIB1); $M=$ McBean (IIB1); UC = Upper Congaree (IIA); $M C=$ Middle Congaree (IIA); LC=Lower Congaree (IIA) 


\section{Hydrograph \\ Well Cluster BGX 12}

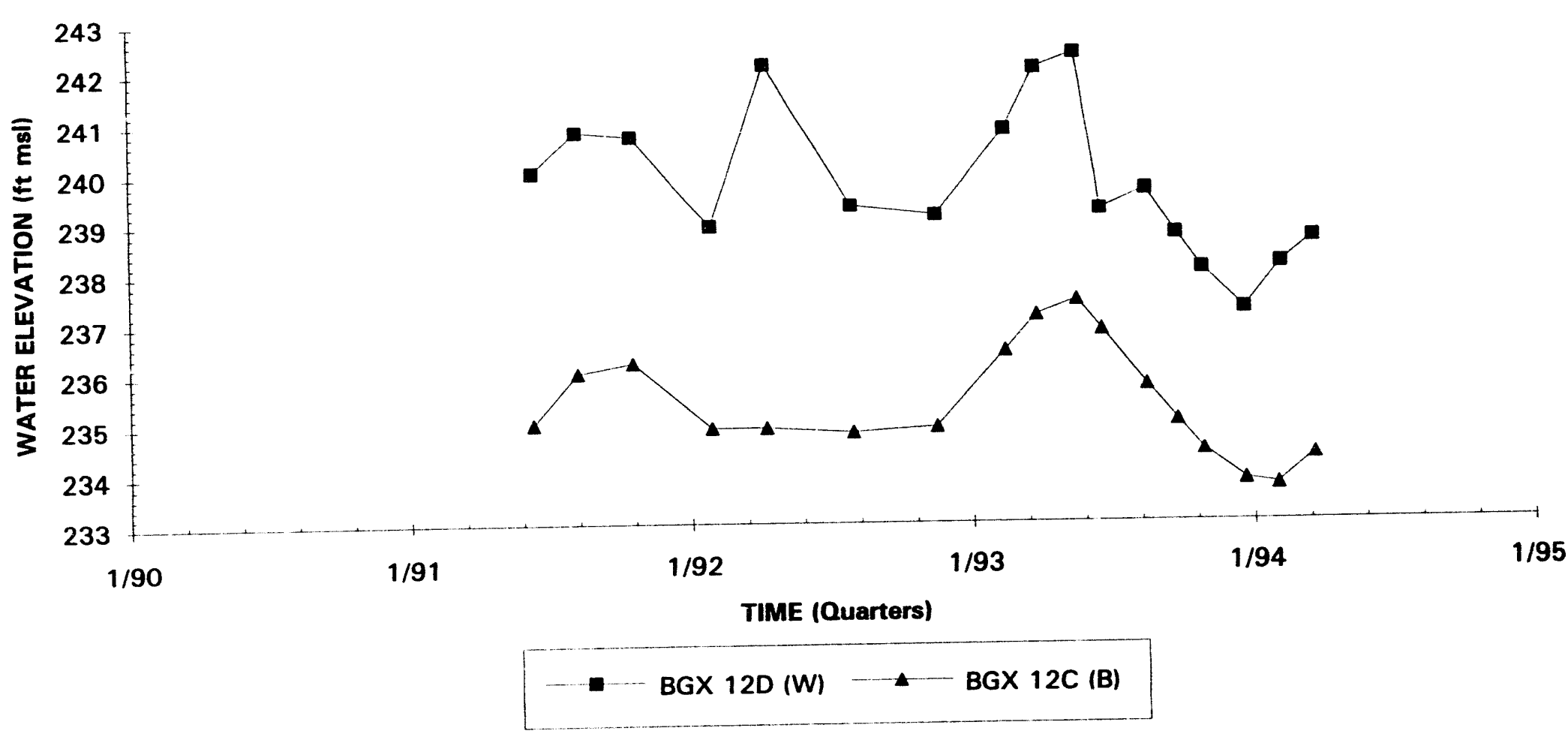

Note: $W=$ Water Table (IIB2); $B=$ Barnwell (IIB 1); $M=$ McBean (IIB1); UC=Upper Congaree (IIA); $M C=$ Middle Congaree (IIA); $L C=$ Lower Congaree (IIA) 


\section{Hydrograph \\ Well FSS 1D}

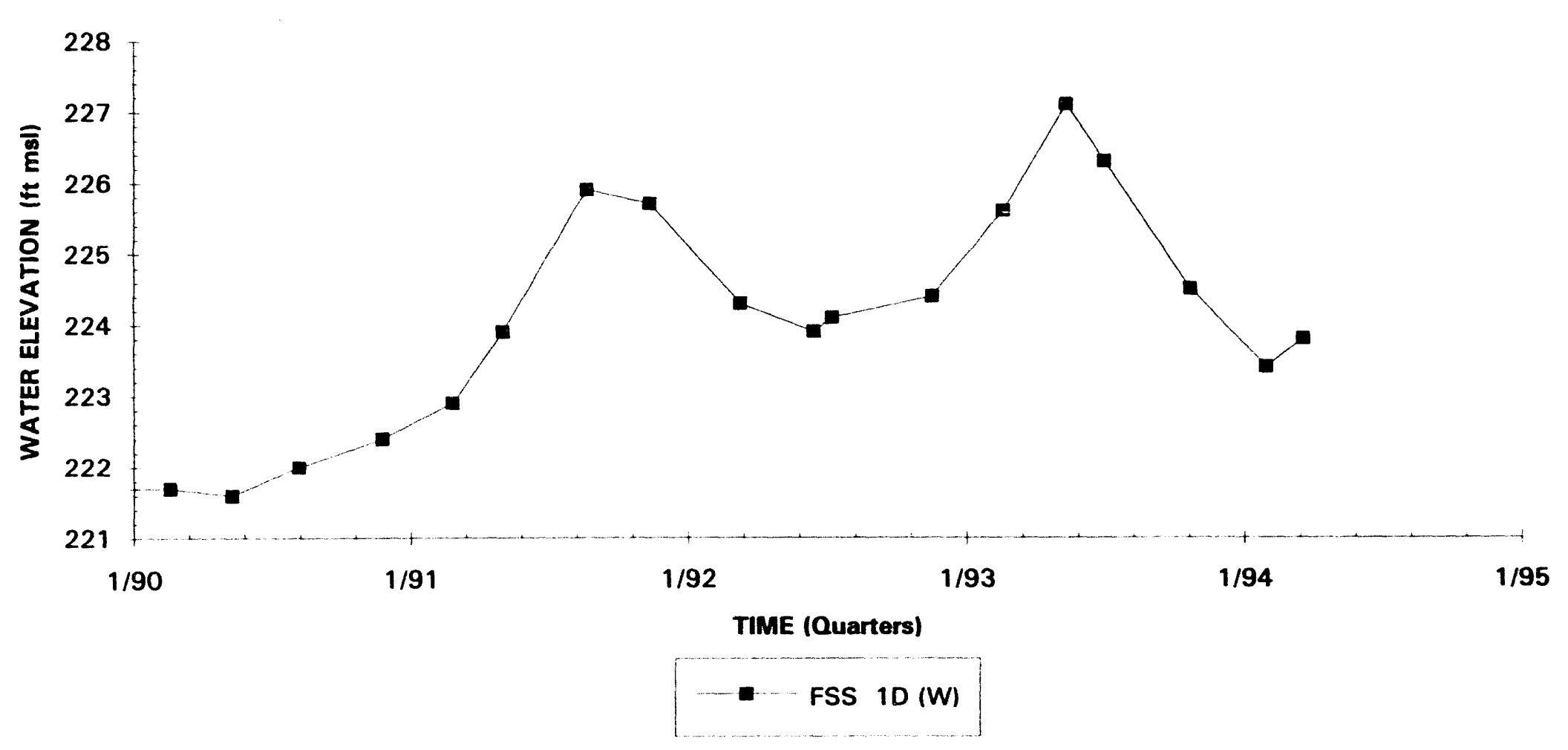

Note: $W=$ Water Table (IIB2); $B=$ Barnwell (IIB1); $M=$ McBean (IIB1); UC = Upper Congaree (IIA); $M C=$ Middle Congaree (IIA); LC = Lower Congaree (IIA) 


\section{Hydrograph}

Well FSS 2D

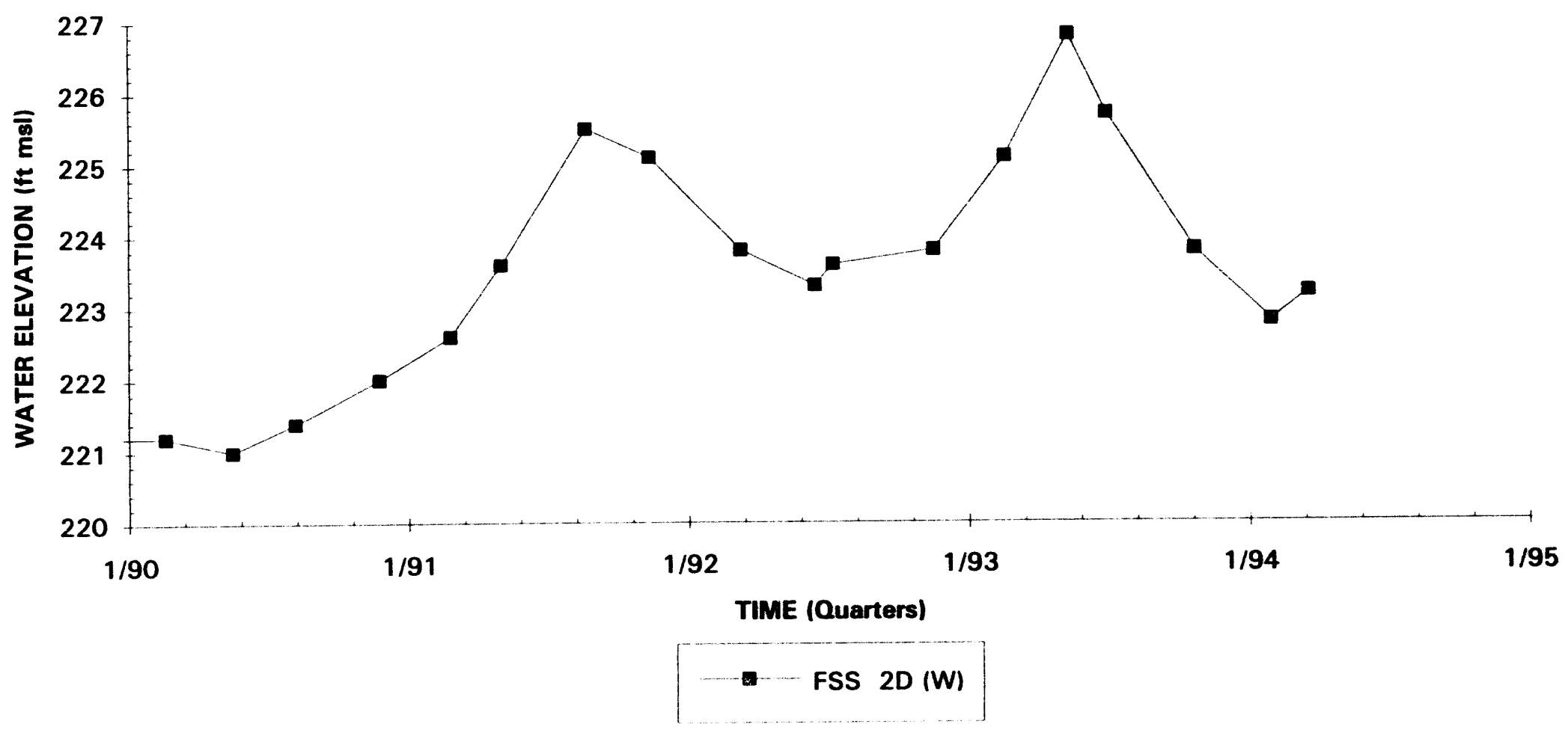

Nate: $W=$ Water Table (IIB2); $B=$ Barnwell (IIB1); $M=$ McBean (IIB1); UC = Upper Congaree (IIA); $M C=$ Middle Congaree (IIA); LC =Lower Congaree (IIA) 


\section{Hydrograph}

Well FSS 3D

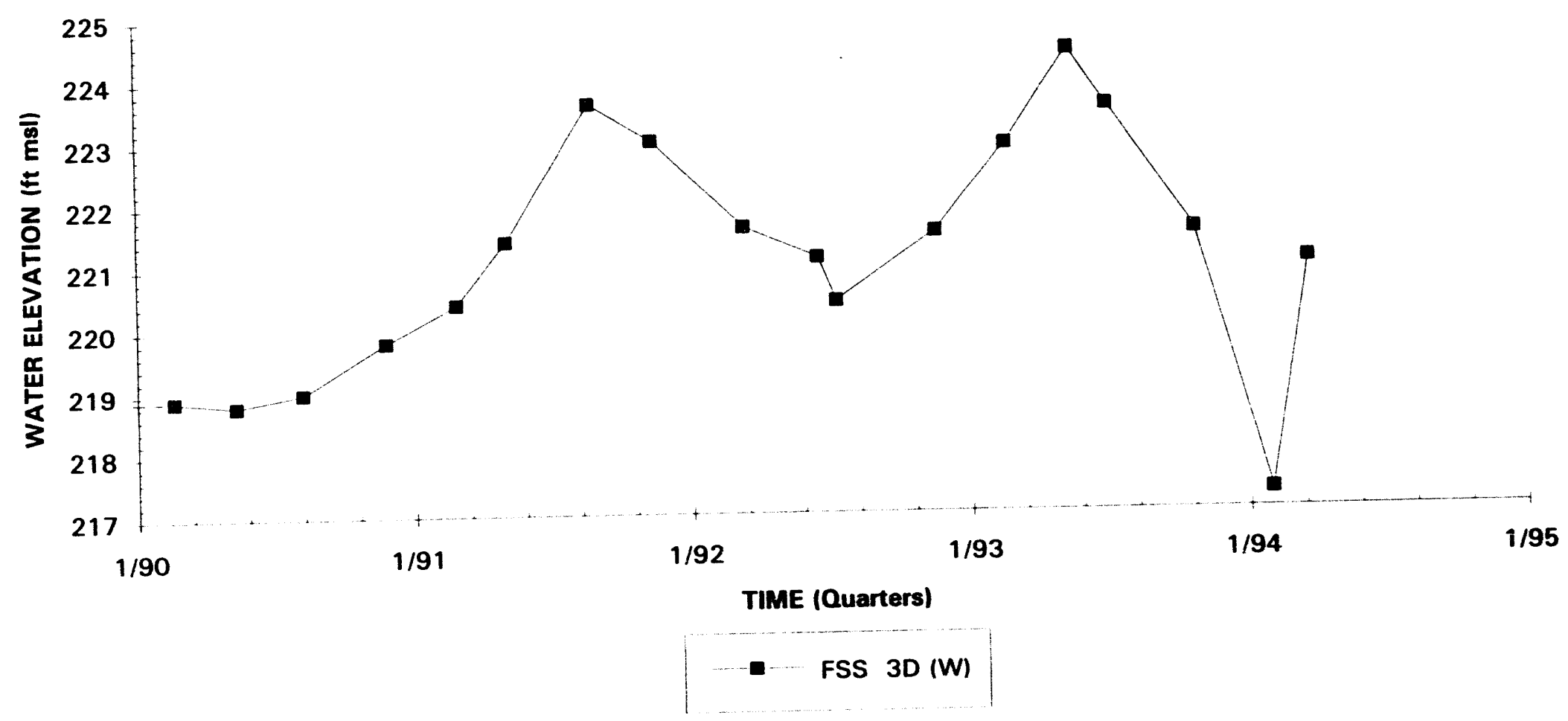

Note: $W=$ Water Table (IIB2); B = Barnwell (IIB1); $M=$ McBean (IIB1); UC, = Upper Congaree (IIA); $M C=$ Middle Congaree (IIA); $L C=$ Lower Congaree (IIA) 


\section{Hydrograph}

\section{Well FSS 4D}

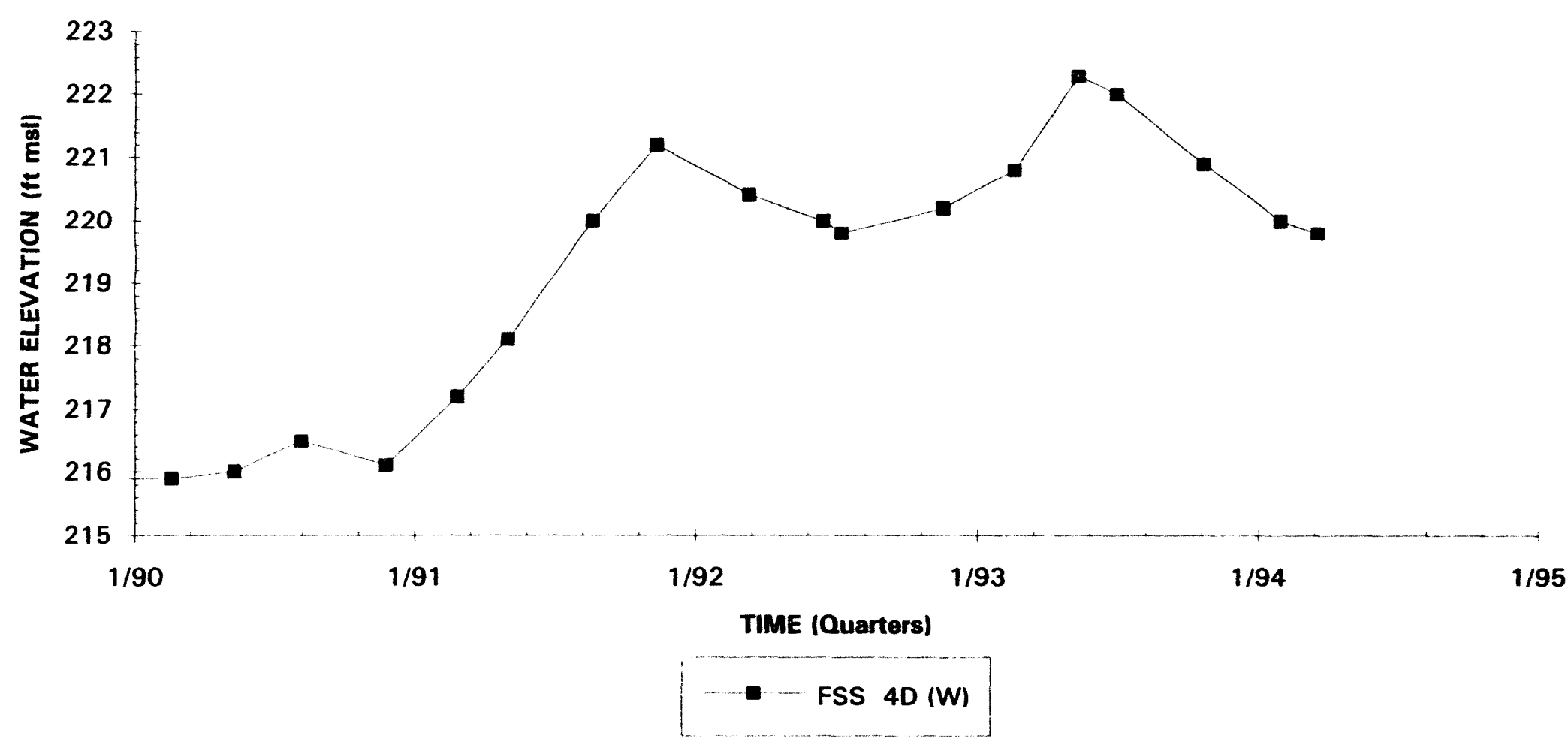

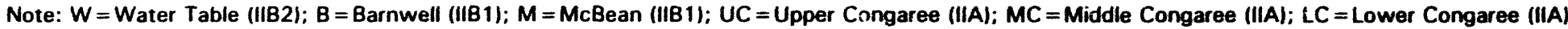




\section{Hydrograph}

\section{Well HMD 1D}

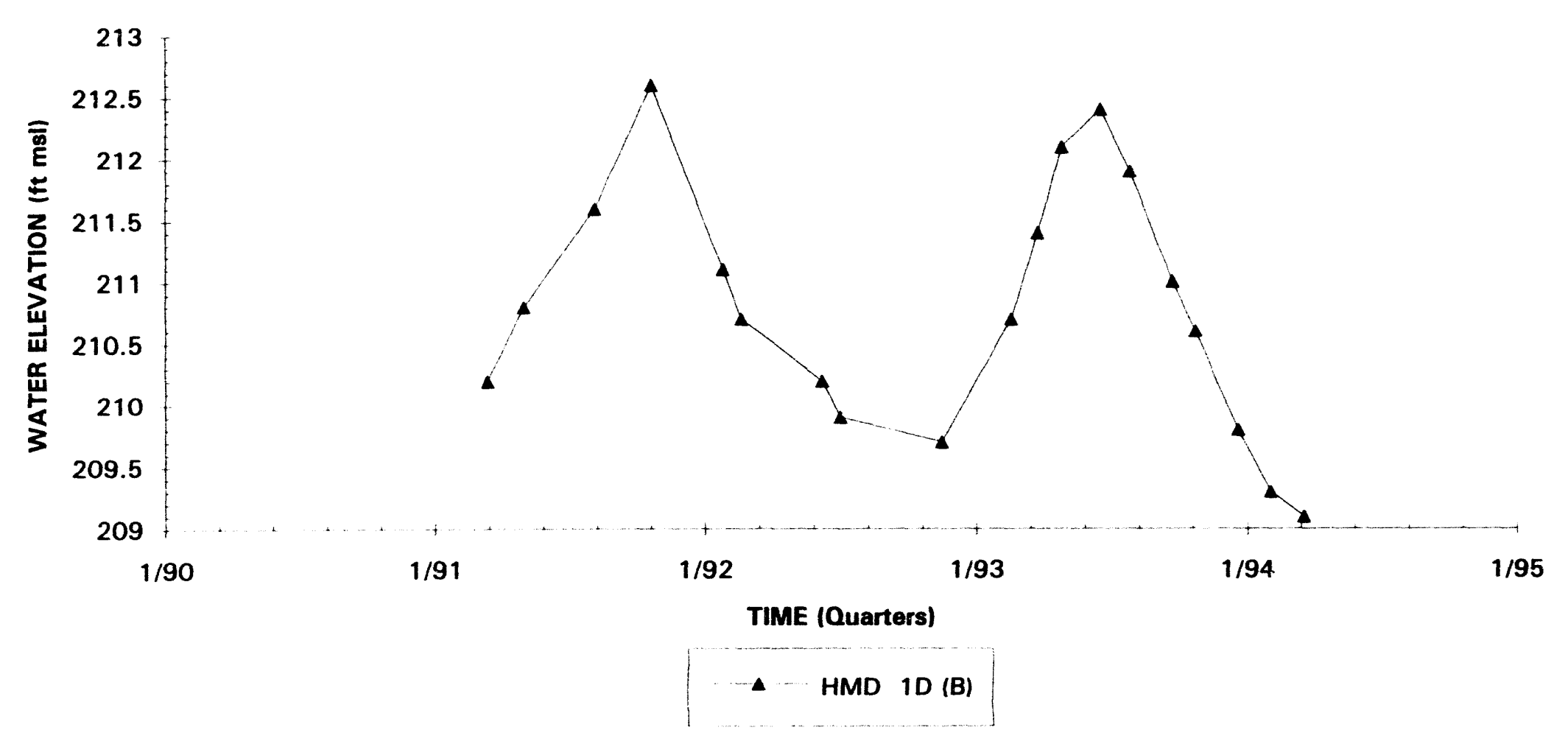




\section{Hydrograph \\ Well HMD 2D}

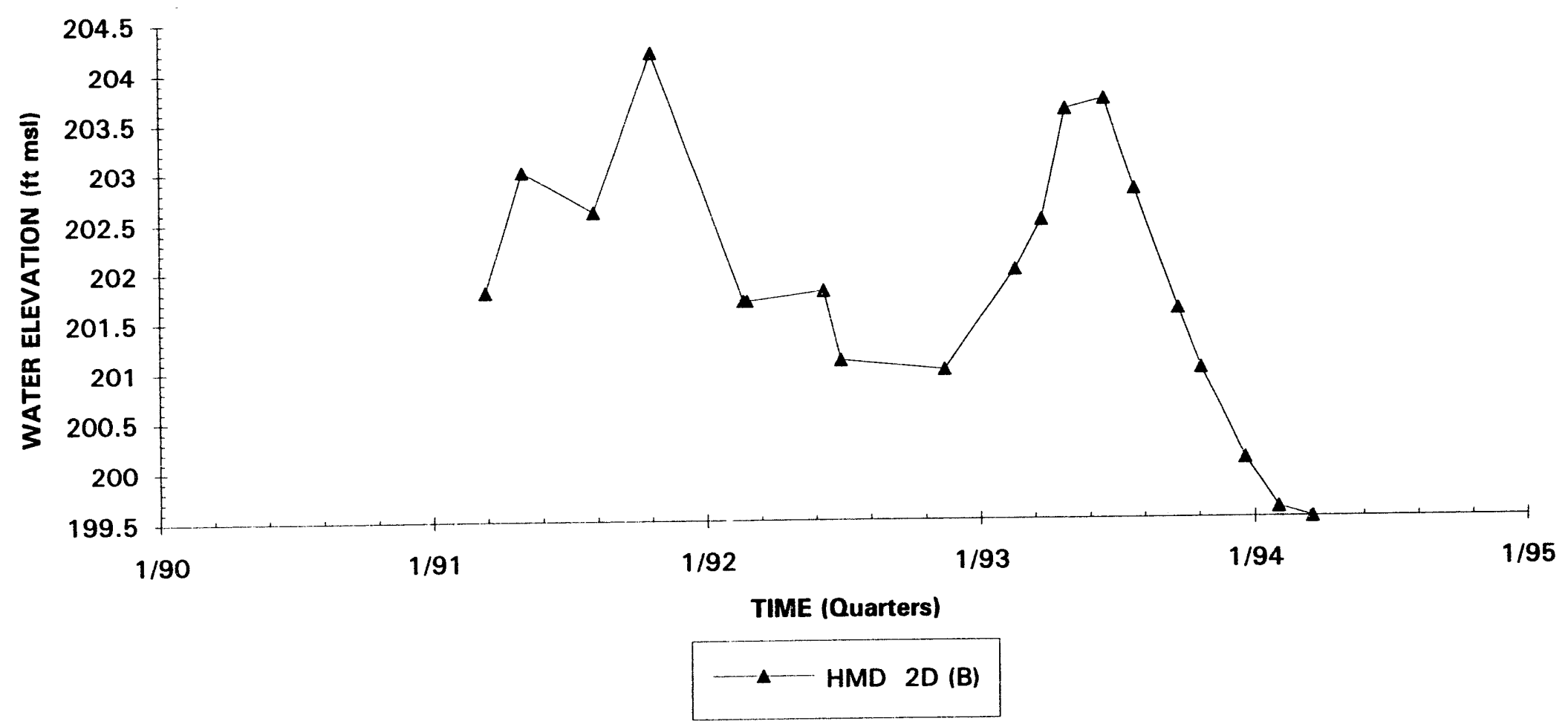

Note: $W=$ Water Table (IIB2); $B=$ Barnwell (IIB1); $M=M c B e a n$ (IIB1); UC=Upper Congaree (IIA); $M C=$ Middle Congaree (IIA); LC =Lower Congaree (IIA) 


\section{Hydrograph}

\section{Well HMD 3D}

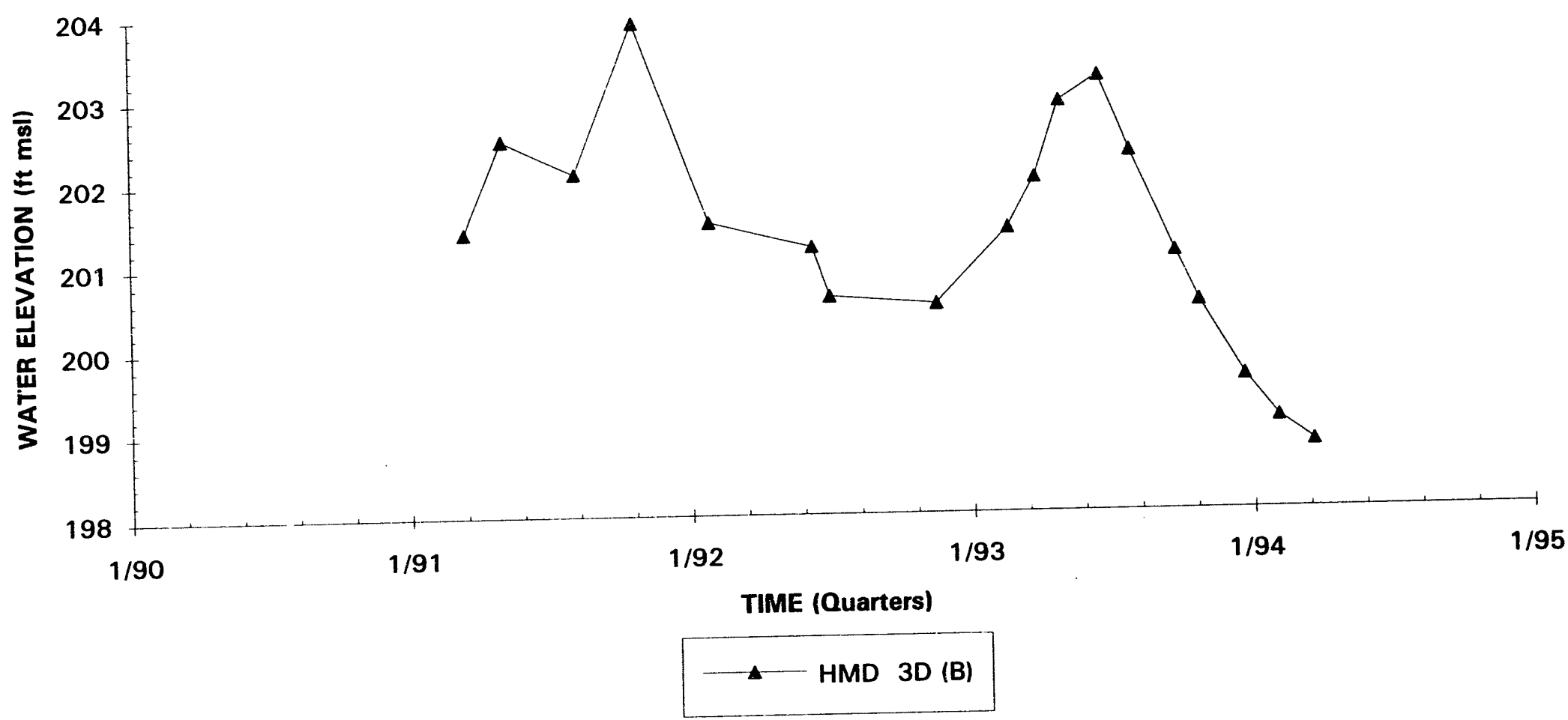

Note: $W=$ Water Table (IIB2); $B=$ Barnwell (IIB1); $M=$ McBean (IIB1); UC=Upper Congaree (IIA); $M C=$ Middle Congaree (IIA); $L C=$ Lower Congaree (IIA) 


\section{Hydrograph}

\section{Well HMD 4D}

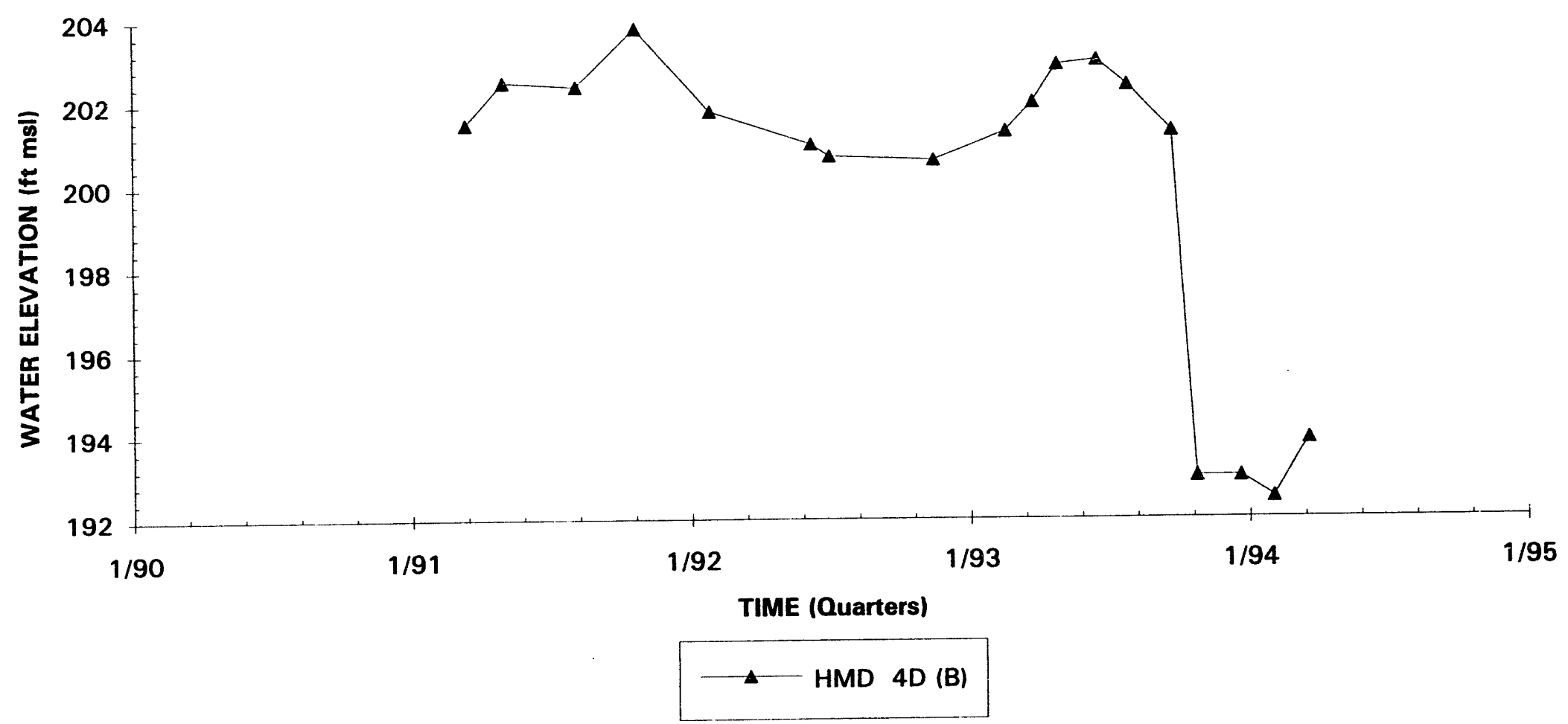

Note: $\mathrm{W}=$ Water Table (IIB2); $\mathrm{B}=$ Barnwell (IIB1); $\mathrm{M}=$ McBean (IIB1); UC=Upper Congaree (IIA); $M C=$ Middle Congaree (IIA); LC=Lower Congaree (IIA) 


\section{Hydrograph \\ Well Cluster HSB 85}

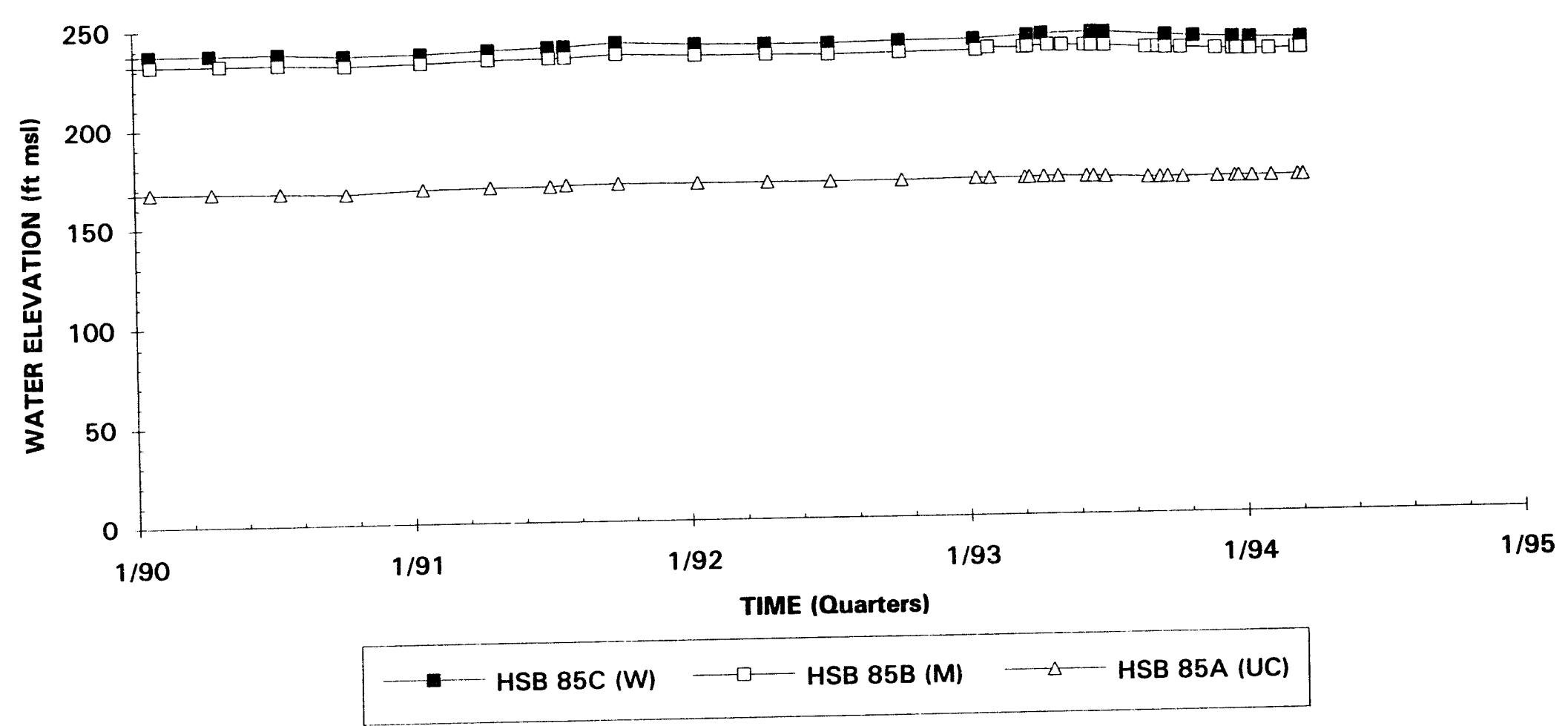

Note: $W=$ Water Table (IIB2); $B=$ Barnwell (IIB1); $M=$ McBean (IIB1); UC=Upper Congaree (IIA); $M C=$ Middle Congaree (IIA); LC=Lower Congaree (IIA) 

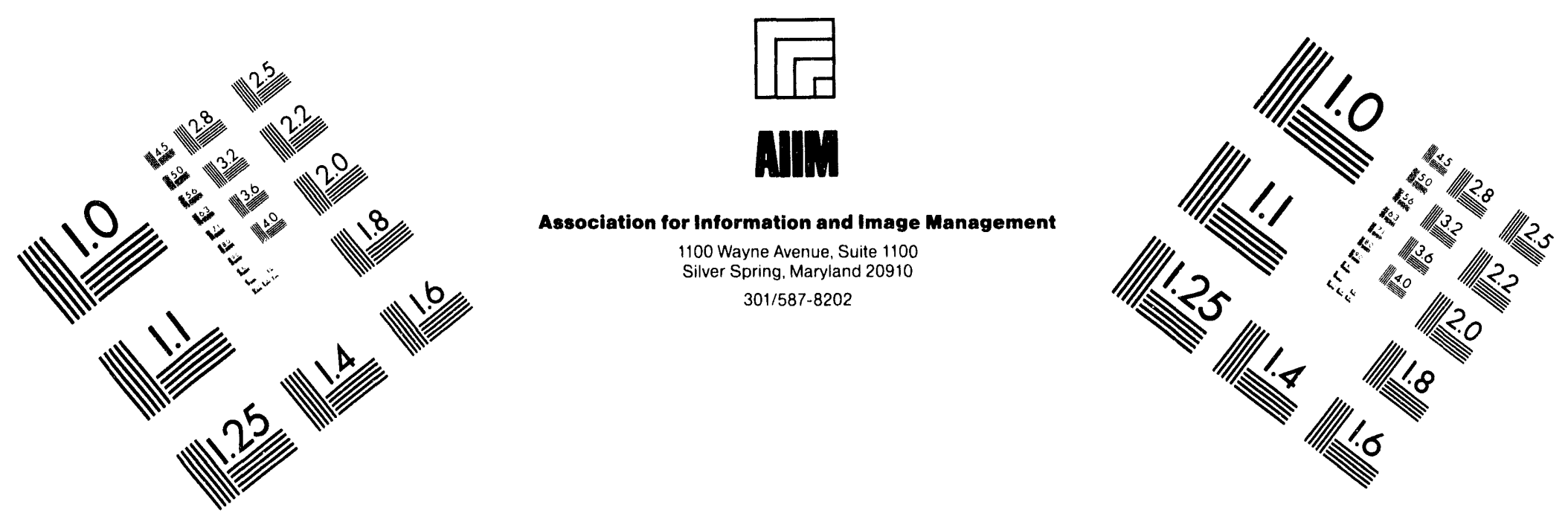

\section{Centimeter}

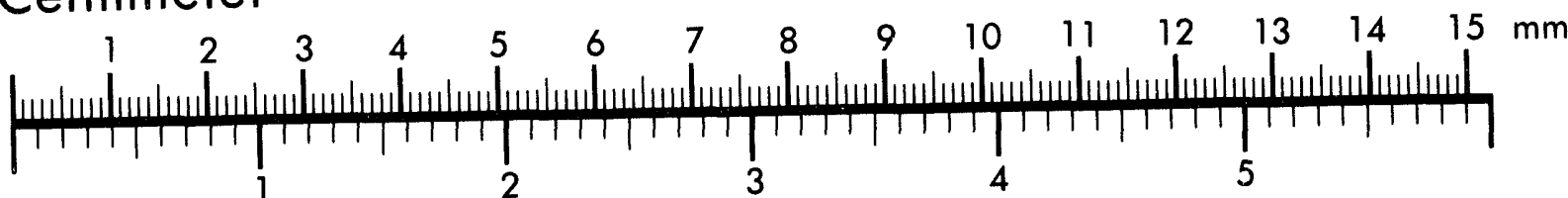
Inches
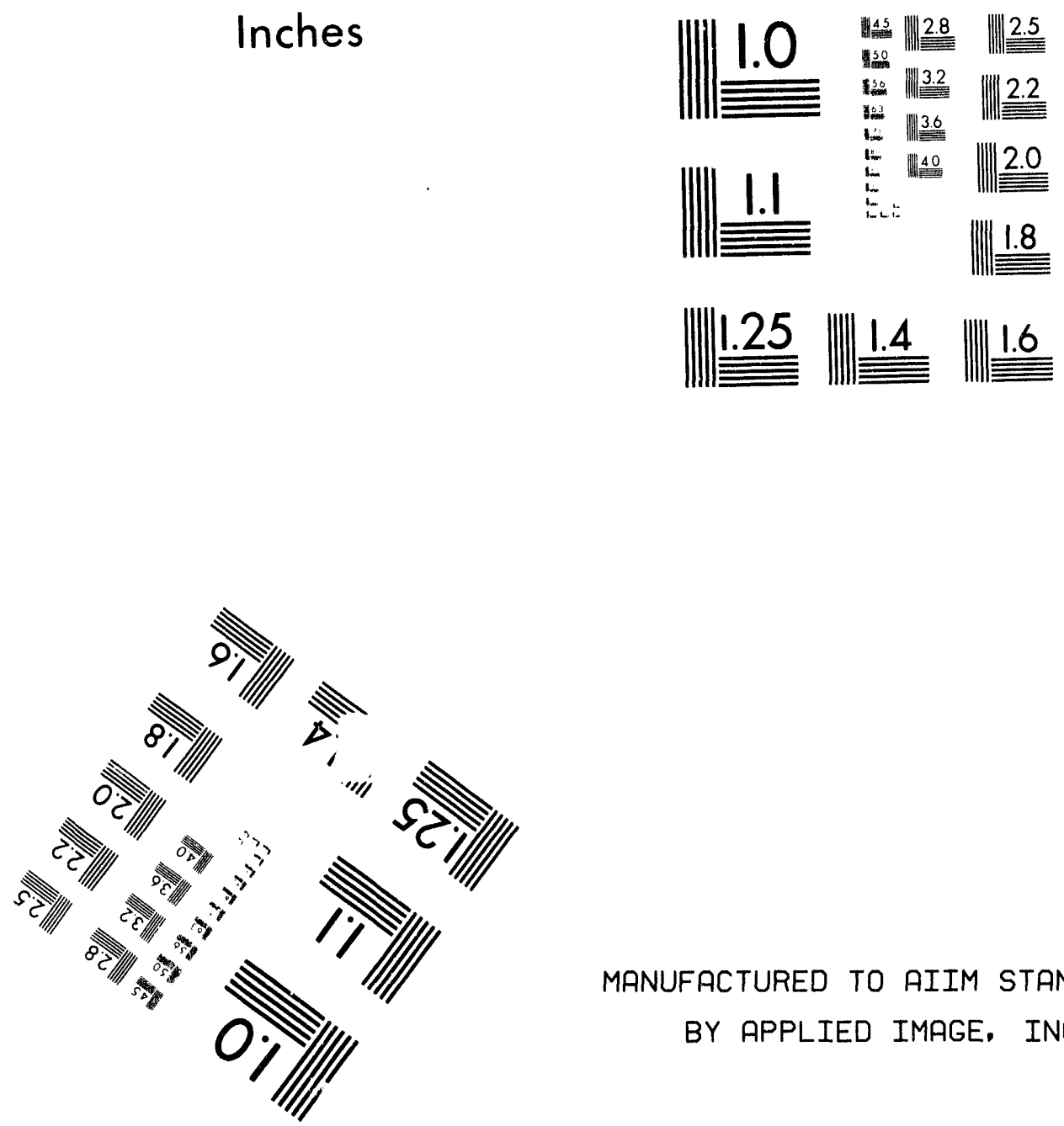

MANUFACTURED TO AIIM STANDARDS

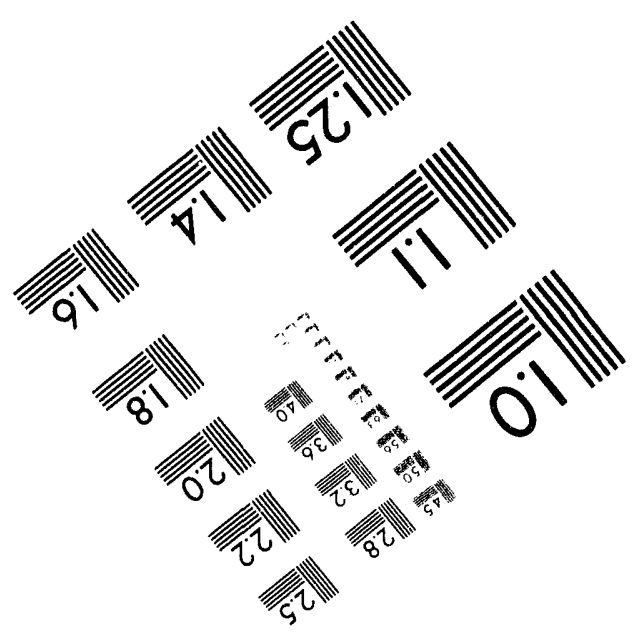




\section{(1)}



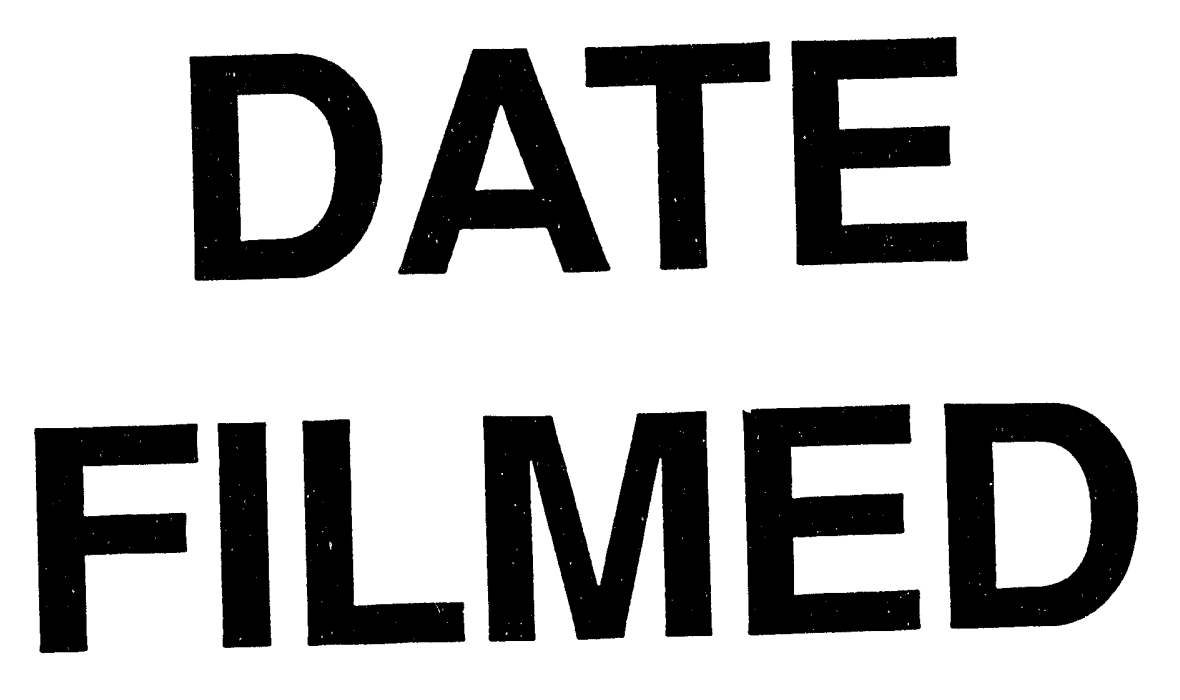

$12 / 14 / 94$
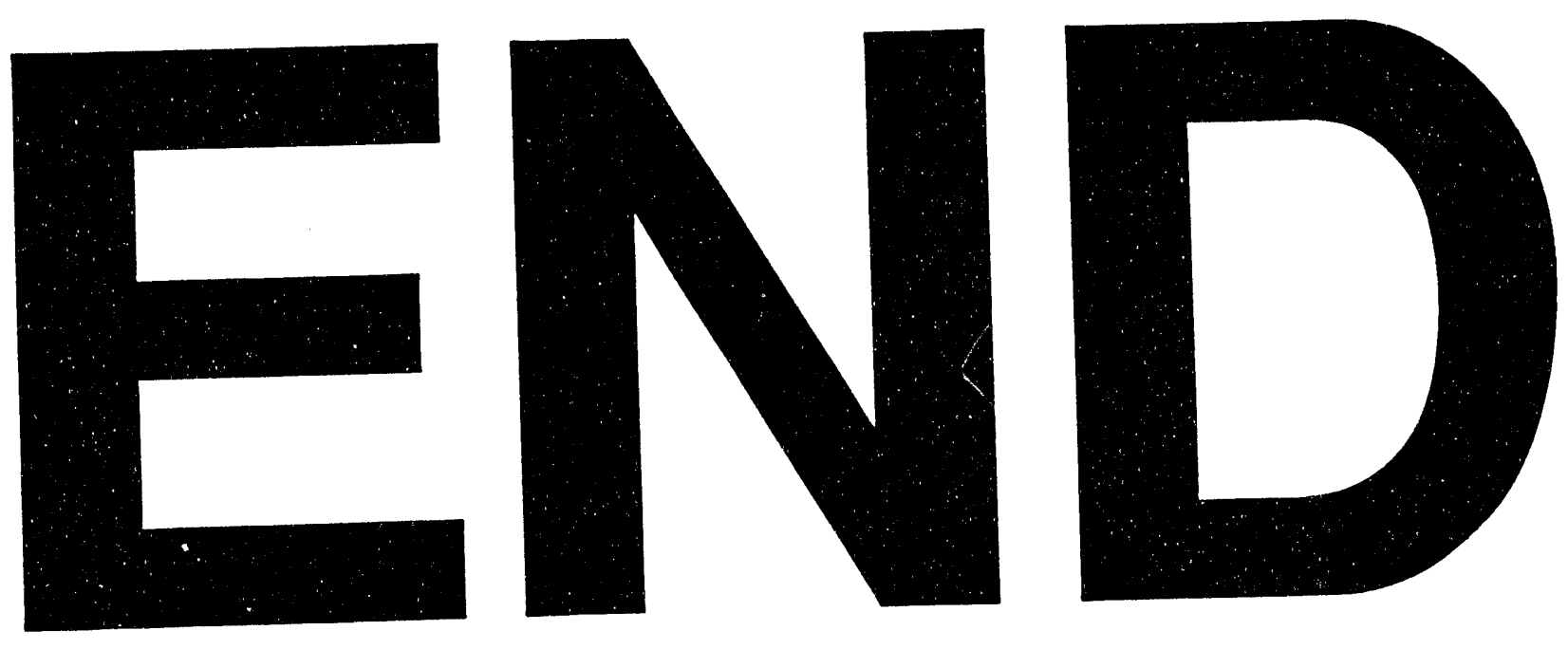